






\section{HISTOIRE NATURELLE}

DES

\section{ANIMAUX ARTICULÉS,}

ANNelides, CRUStacés, ARAGHNides,

MYRIAPODES ET INSECTES. 
Paris. - Imprimente de terzuolo, rue Madame, 30. 


\section{HISTOIRE NATURELLE}

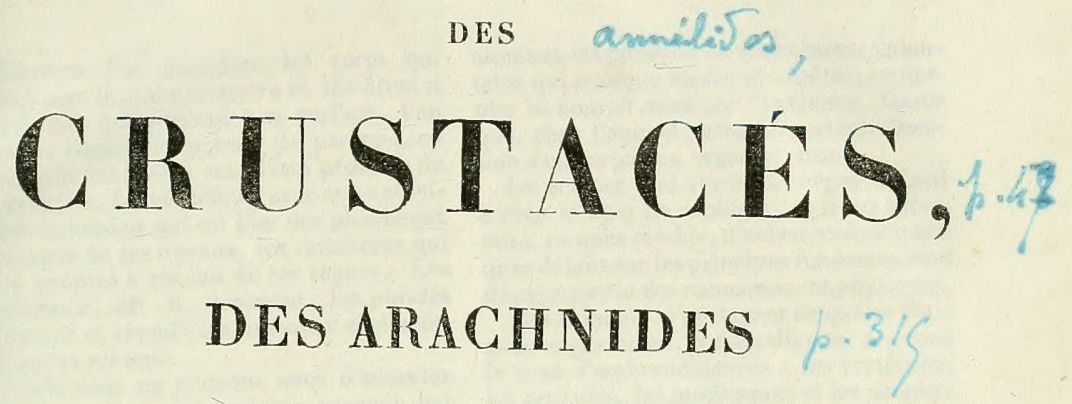

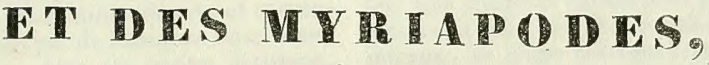

$$
\text { PAR M. LUCAS, }\left\{\begin{array}{l}
\text { L.ceds. Ond. } \\
8 \cdot 26 \cdot 63
\end{array}\right.
$$

ATTACHÉ AU MUSÉUM D'HISTOME NATURELLE DE PATIS, MEMBTE

BE LA COMMISSION SCIENTIFIQUE D'algétie ET DE PLUSIEURS SOCIÉtés SAVANTES, AUteUr de Divers oUvRages SUR L'ENTOMOLOGIE;

OUVRAGE A CCOMPAGNE

DE 46 PLANCHES GRAVÉES SUR ACIER REPRÉSENTANT PLUS DE 300 SUJETS.

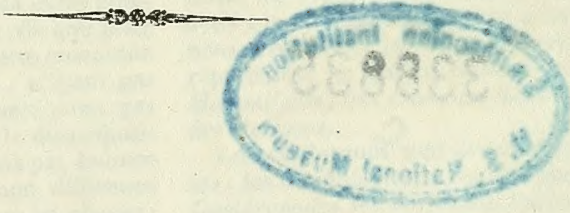

\section{PARIS,}

P. DUMÉNIL, ÉDITEUR, RUE DES BEAUX - ARTS, 10. m.m.

II DCCC XL. 


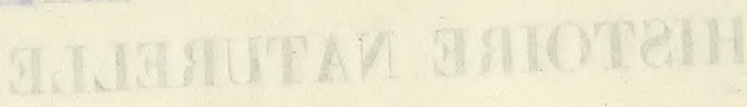




\section{ANIMAUX ARTICULES.}

Lorsque l'on considère les corps qui composent le globe terrestre et les êtres si nombreux qui cxistent à sa surface, l'on concoit bientôt la pensée de partager en trois grandes classes ces divers produits de la création. Linné définit, avec cette admirable concision qui est l'un des plus beaux apanages de ses travaux, les caracteres qui sont propres à chacun de ces régnes : Les minéraux, dit - il, croissent; les plantes croissent et vivent; les animaux croissent, vivent et sentent.

Mais nous ne pouvons nous dissimuler que la nature, qui toujours procède par une voie de graduations douces et successives, et jamais par de brusques transitions, n'a pas voulu, dans ces hautes divisions, déroger à sa marche habituelle, et qu'ici aussi nous trouvons des corps qui font le passage entre deux règnes; en sorte qu'il est souvent impossible de statuer avec certitude si certains objets doivent appartenir plutôt à l'un qu'à l'autre. Ces passages sont surtout si remarquables et si fréquens entre les animaux et les plantes, qu'il est peut-être plus philosophique de nechercher dans la création que deux branches principales : les corps organisés et les corps inorganiques. Les premiers, doués de facultés plus ou moins développées, sont, en compensation, destinés à terminer, dans un temps rapproché, leur existence éphémère. Les autres, brutes et sans vie, nous sembleroient doués del'immortalité, sicette sublime propriété n'était l'apanage de celui qui créa toutes choses et ne dủt à rien le principe de son existence. C'est donc la mort qui forme le caractère de ces divisions primordiales : les animaux et les plantes n'ayant recu le prêt de la vie que pour payer bientôt à la nature la dette commune à tous, et les minéraux, qui, n'ayant pas été animés, ne sont par conséquent pas soumis à la loi immuable de la décomposition. 11 ne faudroit cependant pas induire de ce qui précède qu'aucune différence n'existe entre les animaux et les plantes; nous voulons seulement prémunir l'esprit contre ces divisions si positives et si sèches que l'on nous enseigne dès notre enfance. C'est ainsi que la presque universalité des AnNelides. animaux est pourvue du mouvement volontaire qui manque au règne végétal; ce der. nier se nourrit aussi par l'exterieur, tandis que, chez l'animal, celte importante fonction s'opère par un organe central.

La science qui traite du rẻgne animal a reçu le nom de zoologie, et il est nécessaire, ce nous semble, d'entrer ici dans quelques détails sur les principes fondamentaux de cette partie des connaissances physiques.

Les animaux se partagent en quatre divisions supérieures, auxquelles on a donné le nom d'embranchemens : les vertébrés, les articulés, les mollusques et les zoophytes. Les premiers offrent pour principal caractère la présence d'un squelette articulé interne, et d'une colonne vertébrale percéc dans toute sa longueur pour livrer passage à la moelle épinière.

Les seconds n'ont pas de squelette interne, et leur enveloppe, plus ou moins coriace, est constamment partagée en segmens transversaux.

Les mollusques, également dépourvus de squelette, n'ont pas la disposition segmentaire que nous venons de signaler.

Les' zoophytes, enfin, animaux dont le nom dénote la simplicité d'organisation, sont une réunion d'êtres disparates, dont le caractére le plus important est de présenter une tendance de toutes leurs parties à se disposer en rayons, autour d'un centre commun. Il faut, du reste, avouer que l'on a réuni sous ce nom beaucoup d'animaux ayant fort peu de rapports les uns avec les autres, et que l'on a rangés ici, ne sachant où les placer ailleurs.

Tels sunt les quatre grands embranche. mens du rêgne animal. Si actuellement nous examinons les divisions inférieures, nous verrons que les animaux vertébrés se répartissent en quatre classes : celles des Mammiféres, des Oiseaux, des Reptiles et des Poissons.

Les mollusques sont divisés en six classes: les Céphalopodes, les Ptéropodes, les Gastéropodes, les Acéphales, les Branchiopodes et les Cirrhopodes.

Les zoophytes présentent cinq classes, dont plusieurs diffèrent autant les unes des autres que le font les autres embranche- 
mens eux-mêmes. Ce sont les Echinodermes ou Oursins, les Vers intestinaux, les Acaléphes ou Orlies de mer, les Polypes, et enfin, les Infusoires, dont l'extrême petitesse et l'innombrable multiplicité semblent animaliser la nature entière.

Nous avons onis à dessein de parler des articulés : ces animaux, étant le sujet spécial de notre travail, devoient être traités d'une manière plus étendue.

Les animaux articulés forment, ainsi que nous venons de le voir, un des grands embranchemens du règne animal. M. Cuvier les rejette après les mollusques; mais plusieurs naturalistes les placent entre ceux-ci et les vertébrés. Cette dernière disposition nous semble préférable, puisqu'elle assigne à ces êtres la position qu'ils mérilent sous le point de vue du développement de leur intelligence et de leurs facultés, et que, d'un autre côté, elle interrompt beaucoup moins la série naturelle, puisque, en commencant par les Annelides apodes, ou les Sangsues, l'on obtient un passage tellement insensible aux poissons Cyclostomes, que les auteurs de l'antiquité ont souvent réuni ces animaux. Ne voulant pas, dans cet ouvrage, multiplier les classes plus qu'il n'étoit indispensablemerit nécessaire, nous avons adopté les six suivantes: Annelides, Crustacés, Arachnides, Myriapodes, Mononiorphes, Insectes. L'avant-dernière de ces classes est formée des Thysanoures de M. Latreille, auxquels nous avons réuni des animaux que ce savant laisse parmi les insectes; mais qui en diffèrent essentiellement par l'absence des métamorphoses; mais il nous semble que l'on pourroit facilement rendre cette série plus naturelle, si 'on vouloit séparer des Annelides les Apo: des, dont on formeroit une classe particulière. Cette division seroit appuyée par des diflérences importantes, notamment dans les organes de la respiration, l'absence d'appendices extérieurs, etc.; elle a déjà, du reste, été indiquée, quoique d'une manière différente, par M. de Blainville (Dict. des Sciences naturelles).

Ainsi envisagés, les animaux articulés forment une série plus naturelle qu'ils ne l'avoient fait jusqu'à ce jour, et l'on obtient la division suivante : les Apodes, les Crustacés, les Arachnides, les Insectes, les Monomorphes, les Myriapodes, les An. nelides.

Nous avons dejà vu que les premiers de ces animaux se lioient intimement avec les vertébrés, dontils ont même la couleur du sang. Les derniers ne se rapprochent pas moins des Mollusques, et les Serpules font un passage presque insensibJe aux Dentales: tandis que les Néréides, qui commenceroient cette classe, font très-bien le passage aux Mille-pieds, qui forment la précédente. Ainsi les Annelides, qui, jusqu'ici, avoient été si difficiles à intercaler dans la chaine des articulés, se trouvent y entrer sans effort. Nous ne pouvons cependant pas nous dissimuler qu'ici, comme dans presque toutes les classes de la zoologie, il se trouve des chaînons latéraux qui réunissent les Annelides aux vers intestinaux de l'embranchement des Zoophytes, et malgré l'importance des caractères anatomiques sur lesquels' s'est appuyé notre illustre Cuvier, pour opérer la division de l'ancienne classe des Vers, c'est encore une question que de saroir si elle est bien conforme aux vues de la nature; quoi qu'il en soit, les animaux articulés se reconnaissent à leur corps divisé par segments ; leur enveloppe extérieure est, le plus souvent, d'une nature coriace et dure, et souvent même calcaire. Leurs organes de la locomotion varient à l'infini. L'immense majorité est munie de pattes et d'ailes. Ils vo. lent, marchent, sautent, nagent, etc. Leurs organes de l'ouie, de la circulation, de la génération et de la respiration, éprouvent ae nomoreuses modifications; mais leur système nerveux offre de grands rapports, même entre les classes les plus éloignées. Il se compose d'un cerveau généralement petit et placé dans la tête, et donnant nais. sance a deux forts cordons qui, après avoir embrassé l'œsophage, se réunissent un certain nombre de fois, pour former des nouds ou ganglions. Leurs organes de la manducation sont très-variables; mais il est à remarquer que, lorsqu'ils sont représentés par des pièces paires, ces dernières sont toujours placées de côté, et, par conséquent, ont un mouvement latéral, tandis que, chez les vertébrés, ce mouvement est de haut en bas.

Tels sont les principaux caractères que nous offre l'ensemble de la partie de la zoologic que nous traitons ici; nous allons actuellement présenter succinctement les caractères propres à chacune des classes dont elle se compose.

Les Annelides diffèrent des autres articulés par leur corps privé de pattes articulées, et, le plus souvent, destiné à ramper, et par leur sang de coulcur rouge.

Tous les autres ont des pattes articulées 
et le sang blanc; ils forment les Condytopes de Latreille.

Les Grustacís ont pour caractères d'être des animaux munis de branchies, sans ouvertures stigmatiques; leurs pieds sont au moins au nombre de dix; leurs yeux sont à facettes. La plupart habitent dans l'eau.

Les Arachnides respirent tantôt par des trachées, tantôt par des organes qui tiennent des poumons et des branchies; leurs pieds ambulatoires sont au nombre de huit; leurs yeux sont lisses. La plupart sont terrestres.

Les Myriapodes prẻsentent une respiration trachéenne, des ouvertures stigmatiques; pieds très-nombreux; yeux lisses, ordinairement disposés en dleux groupes: lls ne subissent pas de metamorphoses, mais le corps acquiert, avec l'âge, un plus grand nombre de segmens. Ce sont des animaux terrestres.

Les Monomorphes : Respiration trachéenne, des ouvertures stigmatiques; pieds au nombre de six; yeux composé ou lisses; pas de métamorphoses; corps semblable dans tous les temps de la vie. Animaux terrestres.

Les INSECTES diffèrent des précédents par les métamorphoses auxquelles ils sont soumis. Les uns sont terrestres, les autres aquatiques; la plupart ont des ailes, organes qui ne se trouvent dans aucune des classes précédentes. 
Ce nom vient, ainsl qu'on le verra facilement, de la forme annulaire des êtres qui composent cette classe d'animaux articulés, que l'on peut définir de la manière suivante :

Animal articulé, à sang rouge, formé de segmens réunis de manière a ce que la tête elle-même soit au plus distincte; n'éprouvant pas de métamorphoses ; n'étant pas muni de pieds articulés.

Le corps de ces animaux est généralement mou; les segmens transversaux qui le partagent deoroient peut-être être considérés comme de simples replis de la peau; la tête est peu distincte, et souvent même entièrement réunie avec les anneaux du corps; elle porte souvent des mâchoires et des antennes; ces dernières varient pour le nombre, qui ne dépasse que rarement cinq; on donne aux plus écartées le nom d'extérieures; l'autre paire est formẻe des moyennes; et celle du milieu se nomme P'impaire.

La bouche est, le plus souvent, terminale ; mais lorsque la tềte n'est pas distincte, l'ouverture buccale est située sous la face inférieure; elle laisse ordinairement sortir une trompe charnue qui est, à l'état du repos, rentrée dans l'intérieur du corps. Les mâchoires warient pour le nombre; Latreille (Dict clas.) les regarde comme Jes analogues des dents internes du gésier des crustacés.

Les yeux varient pour le nombre; ce sont de petits points oculiformes, lisses et circulaires.

La partie antérieure du corps est quelquefois élargie en forme de ventouse; les sangsues sont dans ce cas.

Les pieds ne sont jamais que rudimentaires lorsqu'ils existent; Lamarck leur donne le nom de fausses pattes; ils ne soutiennent pas le corps, dont le mouvement est ondulatoire ou de reptation. Ils sont formés de deux rames, l'une dorsale et l'autre ventrale; chacune d'elles porte le cirrhe et les soies; le premier est un filet ordinairement rétractile; les autres sont des poils rudes dont Savigny a distingué quatre sortes': les soies subulées (festuca), réunies en faisceau, sortent d'une gaîne commune et traversent les fibres de la peau pour parvenir aux muscles destinés à leur locomotion; les acicules (aciculi) sont plus grosses, en forme d'aiguillon, et iso.lées dans un fourreau spécial; les soies $a$ crochets (uncinuti) sont de petites lames courbes, comprimées, dentelées; celles $\boldsymbol{a}$ palettes (spatellulex) dont le nom indique la forme.

MM. Audouin et Milne-Edwards, dans leur excellent onvrage sur les Annelides de France, dont nous regrettons de ne posséder encore qu'un seul volume, ont fait une étude approfondie des diverses parties que nous venons d'énumérer, et se sont étendus sur les usages de chacune, sujet qui n'avoit pas encore été traité et qui jette un vif intérêt sur leur savant travail.

Les organes respiratoires de la plupart des Annelides sont des branchies extérieures qui varient beaucoup pour la forme : ce sont tantôt des houppes, des panaches, des arbuscules; tantôt des filamens simples ou pectinés; chez les sangsues, ces organes sont internes et ont la forme de petites vessies; chez d'autres, tels que les Lombrics, cette fonction s'opère par toute la surface de la peau.

L'on a donné le nom d'élytres à des écailles dorsales de consistance membraneuse et assez molle; le plus souvent elles sont placées sur des pieds dépourvus de cirrhes, et alternent avec d'autres qui en sont munis.

Le corps de quelques espèces, et des sangsues particulièrement, est terminé à son extrémité postérieure par un disque qui remplit la fonction de ventouse.

L'anus est quelquefois terminal, quelquefois situé un peu sur la face dorsale.

Le canal intestinal est tantôt droit,tantôt contourné; il aboutit, par une de ses extrémités, à la bouche, et par l'autre à l'anus; le nombre des estomacs est très-variable.

Nous avons déjà vu que le sang des $A n$ nelides est rouge; elles n'ont pas de cœur proprement dit, et leur circulation s'opère au moyen de deux artères Iongitudinales et de veines.

Leur système nerveux est formé d'un cerveau donnant naissance à des cordons 

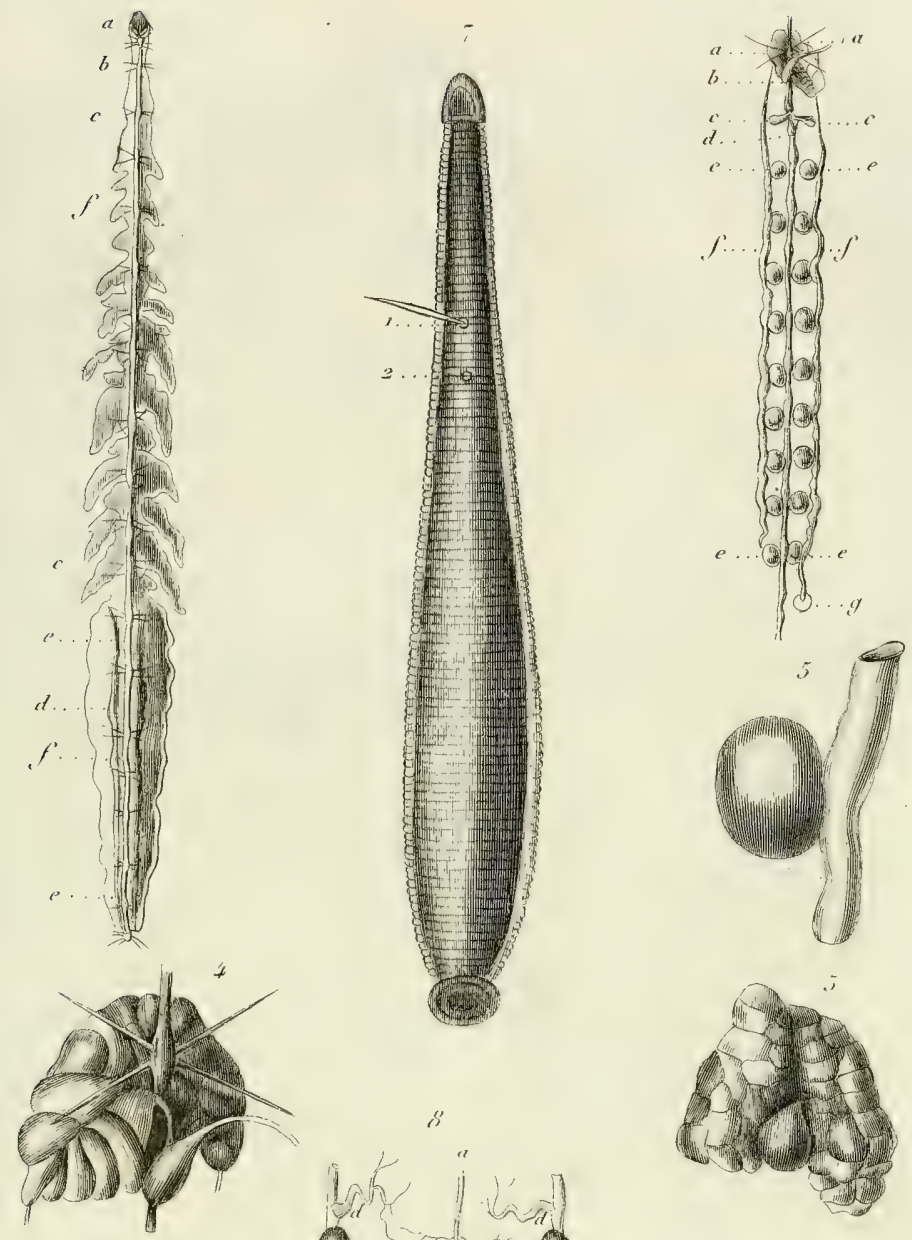

it
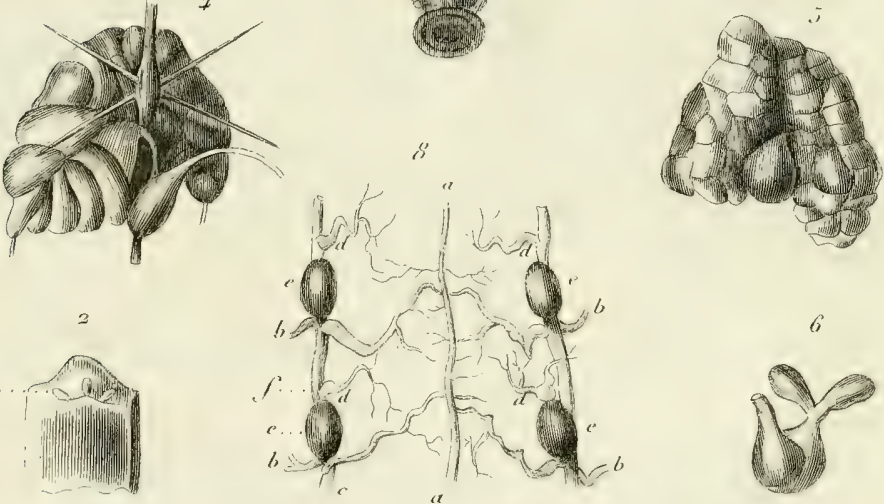

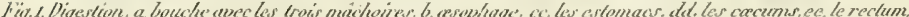

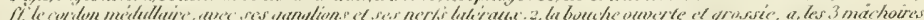

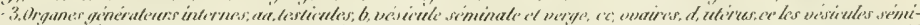

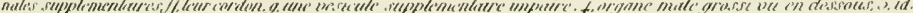

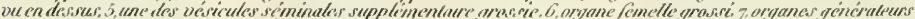

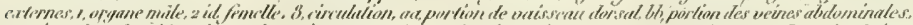

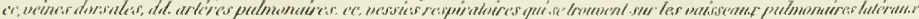



nerveux qui se réunissent en ganglions. Un système supéricur aussi été, dans ces dernières années, découvert chez plusieurs animaux de cette classe.

Elles sont hermaphrodites et munies cha cune des organes propres aux deux sexes, mais n'en ont pas moins besoin, pour la plupart du moins, de l'accouplement de deux individus semblables, pour perpétuer leur espèce. 1ls sont ovipares et pondent généralement au printemps. Un fait très-remarquable qu'ils nous présentent, c'est que le tronc mutilé et divisé en un grand nombre de morceaux se complète et continue à vivre.

Si nous jetons un coup d'œil sur l'habitation des articulés, nous verrons que le plus grand nombre habite la mer, que d'autres se trouvent dans les eaux douces, tandis que d'autres encore sont terrestres, ct se creusent des demeures souterraines. Parmi les marines, beaucoup se construisent des fourreaux tubulaires, qui sont tantôt formés de petits corps agglutinés, tantôt d'une matière calcaire sécrétée par l'animal lui-même.

Les couleurs sont très-variables. Les espéces terrestres et aquatiques sont; le plus souvent, ternes; celles qui se trouvent dans la mer, au contraire, répandent le plus vif éclat; mais ces nuances brillantes disparaissent aussitôt après la mort de l'animal.

Presque toutes les Annelides sont carnassières.

Quelques espèces marines sont douées de la faculté de répandre une lumière phosphorique,

Nous avons déjà vu que c'est à M. Cuvier qu'est dû l'établissement de la classe des Annelides; avant lui, ces animaux étoient confondus arec les vers par tous les auteurs quì tes avoient étudiés, tels que Linné, Muller, Pallas, Bosc et Othon Fabricius,; mais notre illustre naturaliste s'étoit contenté de leur conserver lo nom de vers à sang rouge, et c'est Lamarck qui, le premier, les désigna sous le nom qu'ils portent aujourd'huj. Depuis lors, ils ont été l'objet d'un grand nombre de travaux, parmi lesquels nous citerons les beaux $M i \dot{c}$ moires de Savigny, présentés à l'Académie royale des Sciences, et sa classification de ces animaux, qui fait partie du grand ouvrage de la commission d'Egypte ; l'excellente Monographie de la famille des Hirrudinées de M. Moquin Tendon, les travaux de Leach, d'Ocken, Risso, Johnston, Delle-Chiaye, Montagu, Viviani, Brullé, consignés dans des travaux particuliers, ou répandus dans les mémoires des Sociétés savantes. M. de Blainville a traité avec sa supériorité habituelle cette partie, dans le Dictionnaive des Sciences naturelles; enfin, MM. Audouin et Edwards ont publié, dans leur grand ouvrage sur le littoral de la France, un travail aussi remarquable qu'étendu sur ceux de ces animaux qui habitent nos côtes.

Nous suivrons, à peu de chose pris ici, l'ènsemble de la méthode présentée dans ce dernier ouvrage, et nous diviserons les Annelides en quatre ordres. Les Apodes ou Suceuses, se distinguent aisément par une cavité en forme de ventouse, à chaque extrémité du corps. Les Terricules n'ont pąs d'appendices mous, que l'on retrouve toujours chez les Annelides errantes, et chez les Tubicoles; mais les premières ont ces organes distribués sur toute la longueur du corps, et İeur tête est généralement bien visible; tandis que chez les derniers les appendices sont réunis vers l'extrémité céphalique, et la tête n'est point distincte.

\title{
ANNELIDES ERRANTES，
}

\author{
AUD. ET EDW.
}

\section{DORSIBRANCHES, Cuv.; NEREIDÉES, SAv.; HOMOCRICIENS ET PARAMOCRICIENS, BLAINY.}

Les Annelides qui rentrent dans cet ordre ont les facultés de nager et de ramper avec la plus grande facilité ; les unes se trou- vent sur le bord de la mer, etlesautres sont entierement pélagiennes. Presque toutes sont libres, et ne se construisent pas d'habi. 
tation; mais le pelit nombre, qui se loge dans des fourreaux, peuvent les quitter avec facilité, et ne semblent $y$ chercher qu'une habitation passagère. Leur: tête est distincte, munie d'antennes, d'yeux, souvent de mâchoires, et d'une trompe rétractile; leur corps est souvent allongé et lineaire, garni d'appendices disséminés dans toute sa longueur, excepté chez le seul genre Paripatus, les pieds sont très-saillans et d'une seule sorte, sans soies à crochets, le plus souvent armés de soies proprement dites, et presque toujours munis de cirrhes.

Cet ordre se partage en sept groupes: les Aphrodites, les Amphinomites, les Eunicites, Jes Neréidites, les Aricites, les Péripatiles et les Chétopterites.

\section{APHRODITES.}

Caractères. Des cirrhes distincts aux pieds; segmens du corps dissemblables, et présentant le plus souvent des èlytres disposées alternativement; branchies rudimentaires; tête distincte.

Genres: Aphrodita, Polynoe, Iphionea, Polyodontes, Sigalion, Palmyra.

\section{APHRODITA, LinN.;}

Inalithea, Sav., Lam.; Physalus, Swair.; Aphrodita et Hermione, Buarv.

Trompe entourée à son orifice d'un cercle de petits tentacules subdivisés en forme de houppes. - Mâchoires très-petites et cartilagineuses.- Antennes au nombre de trois, les extérieures grandes, l'impaire petite et subulée. - Yeux au nombre de deux et presque pédonculés. - Branchies dentelées, placées alternativement sur chaque segment après la vingt-cinquieme paire de pieds.-- Pieds divisés en deux rames séparées, et garnis le plus souvent de deux faisceaux de soies à la rame dorsale, et de deux à la ventrale.- Les cirrhes subulés, les supérieurs longs et filiformes, les inférieurs petits et coniques. - Elytres au nombre de treize pour le corps, et quelques autres supplémentaires sur les anneaux suivants. - Tète en grande partie cachée sous les élytres, convexe en dessus. - Corps ovalaire, formé de peu d'anneaux.

L'anatomie de l'Aphrodite hérissée a occupé plusieurs naturalistes et particulic่rement Redi, Swammerdam, Gesner, Pallas, Home, etc.; mais c'est surlout à M. Treviranus (Zeitschrift für Physiologie, t. 3 , cah. 2 , p. 157) que nous devons les observations les plus complètes. Nous allons extraire, du Bulletin de Ferussac, le passage suivant, qui est l'analyse de ce travail.

Sous le tissu, en forme d'étoupe, qui, comme on sait, recouvre le dos de l'animal, se trouvent deux membranes transparentes, dont l'une est externe et l'antre interne; la membrane externe, qui est parsemée de petits grains cartilagineux, n'est unie ni avec l'étoupe, ni avec la membrane interne; d'où il résulte qu'il y a deux cavités, l'une entre la membrane externe et l'étoupe, et l'autre entre les deux membranes. La première cavité communique avec Ie dehors par une fente transversale, dont est percée l'étoupe, tout près de l'extrémité antérieure de l'animal; cette fente a déjá été observée par. Redi. La cavité interne communique également avec le dehors, par des conduits qui s'ouvrent alternativement dans les interstices des pieds.

La membrane externe se continue avec la tunique qui recouvre extérieurement la face ventrale. L'étoupe ne s'étend pas audelà des pieds. La membrane interne du dos est continue avec la tunique interne du ventre, qui est formée de fibres musculaires entre-croisées en tous sens, et qui est entièrement distincte de la tunique ventrale externe, en sorte qu'il existe pareillement une cavité libre entre les deux tuniques du ventre. Cette cavité communique avec celle qui est comprise entre les deux membranes dorsales; d'où il résulte que l'eau a un accès libre dans l'interstice de la double enveloppe de l'animal.

Mais la cavité qui se trouve entre les deux enveloppes communique elle-même, avec la cavité de l'abdomen, par des fentes qui sont vis-à-vis des ouvertures placées entre les pieds, et dont nous avons parlé plus haut. Ainsi l'eau peut pénétrer du dehors dans la cavité in testinale, et l'on peut expliquer (ce que n'avoit pu faire Pallas) comment les œufs sont transmis dans l'interstice de la double enveloppe de l'animal, et audehors.

Jusqu'à présent on n'avoit pas trouvé d'organe spécialement consacré à la génération chez les Aphrodiles. Mais M. Treviranus croit avoir découvert des ovaires : ce sont deux séries de corpuscules qui se trouvent dans la cavité de l'abdomen, et qui sont pla. cés le long du bord externe de chaque muscle longitudinal du ventre. Cés corpuscules ont une extrémité obtuse, arrondie, 



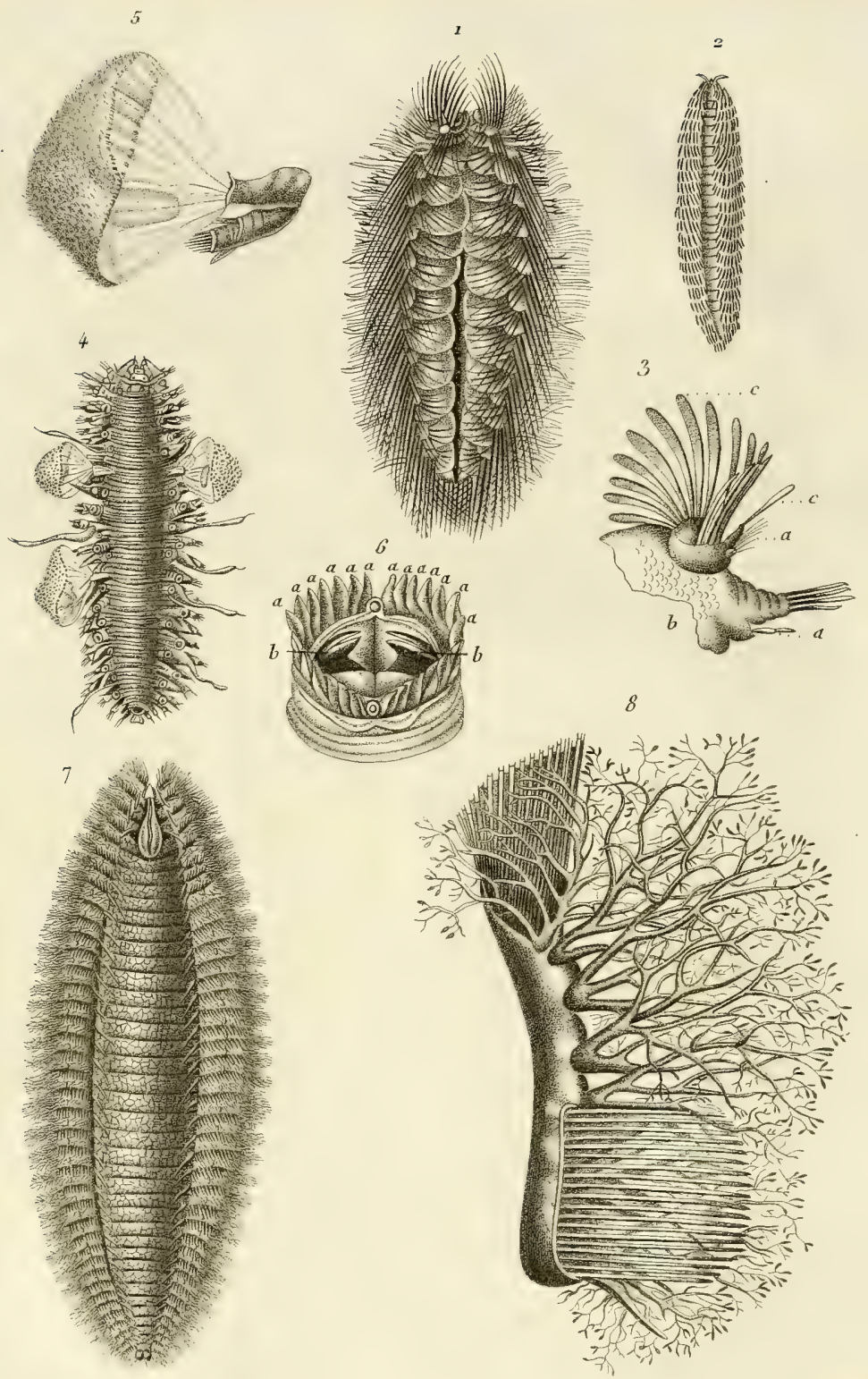

x. Aplurodita hispida. 2. Palmyra aurifer, 3, pred du méme, a, rame dorsale, b, rame ventrale, c, d, cirnhes, c, faiscenuv de soies de la rame ventrale disposés en éventuil , 4 Polinoe lmpatiens 5, élytre du même, remplaçant les cirrhes tentaculairas, $\mathcal{B}$, bouche du mème, a, tentacules, $b$, machoires . 7 . Euphrosvne Laureata, 8, branchie du méme. 
qui est appliquée contre lo muscle, et uneextrémité pointue qui est libre. Tout près de l'extrémité obtuse, on voit naître un petit canal qui se perd dans la cavité abdominale. Chaque corpuscule contient une matière jaunâtre, fibreuse.

Quant à la respiration des Aphrodites, M. Treviranus prétend qu'elle se fait par l'intermède de vaisseaux capillaires, dont sont garnis les appendices coecaux du canal digestif: Et cela se concoit facilement, puisque, comme nous l'avons dit, l'eau peut pénétrer dans le ventre, et baigner les capillaires dont il est question. Ce qui rend cette manière de voir encore plus probable, c'est que les Amphinomes, qui sont yoisins des Aphrodites, n'ont pas les cocums garnis de ces paquets de vaisseaux capillaires; mais ils ont en place des branchies extérieures conformées absolument comme les paquets de capillaires qui garnissent les cœcums des Aphrodites. Ainsi la seule chose qui distingue ces deux genres; sous le rapport de la respiration, c'est que chez l'un cette forction se fait au-dehors, tandis que chez l'autre elle se fait dans la cavité de labdomen.

Les houppes membraneuses qu'on avoit regardẻes jusqu'à présent comme faisant office de branchies ne peuvent pas servir à la respiration', selon M. Treviranus, puisqu'elles ne contiennent point de vaisseaux. sanguins; ce sont tout au plus des rudimens de branchies.

\section{PHEMIIRE DIVISION:}

Elytres recouvertes par une voûte épaisse formée de soies flexibles. - Rame supérieure garnie-de trois rangs de soies roides.

\section{(Cyanippa, mihi.)}

1. APIRODITA NCULEATA.

Baster, Opusc. Subs., p. 2, part. 2, pl. 6 , fig. 1-4.-Trevinanus, Zeitschrift. t. III, cah. 2, p. 157. - Histrix Marina, Revi, Opusc., t. III, p. 35.-Long. 4 pouc. $\frac{I}{2}$. - Elytres molles, glabres; la voûte grise glacce de vert brillant ; corps blanchâtre; écailles arrangées, marquées de brun; le corps entouré d'une frange verte et irisée, formée des soies longues et fines des rames dorsales. - Côtes de la France.

\section{APHTODITA SERICEA.}

Sav. - Long. 1 pouc. $\frac{1}{2} \cdot-$ Corps plus ovale que dans la précédente espèce; écailles blanches et sans taches; les longues soies des rames dorsales 'd'un vert éclatant sur le dos; la frange flottante de couleur blanche.

On ignore la patrie de cette espèce.

\section{APHRODITA AURATA:}

Rrsso, Eur.mérid., t. IV, p.413.-Corps ovale, oblong, assez large, varié de gris, forme de trentedeux segmens pourvus de lames orbiculaires, cachées par une peau mince ; rames dorsales formant, autour du corps, une large bande de soies très-longues et d'un beau jaune doré; une autre rangée de rames ventrales forme de chaque côté trente-deux longs pédoncules.

Cette espèce se trouve dans la Méditerranée. MM. Edwards et Audouin pensent que ce n'est peut-être qu'un jeune individu de l'Aphrodite hérissée.

\section{DEUXIEME DIVISION.}

Elytres non recouvertes par une voûte. - Rame supérieure garnie de deux sortes de soies sur. les pieds munis d'élytres, et d'une seule sur ceux qui en sont dépourvus.

\section{(Amphitus, mihi.)}

4. ApIRODITA HISTRIX (Pl. $1, \mathrm{f}, 1$. )

Sav., Annel., p. $10, n^{\circ} 3 .-$ Aud. et Eow., Litt. de la.France, t. II, Amnel., pl. 1, f. $1-9 .-$ Long. 2 pouc. $\frac{3}{2},-$ Corps formée de trente-trois segmens et recouvert par quinze paires d'élytres lisses, minces, souples et de couleur cendrèe lavée de brun ferrugineux; ventre d'un brun clair à reflets.- Méditerranée.

\section{APHRODITA AUDOUIN.}

Ressemble beaucoup à l'Aphrodita IIis. trix, mais beaucoup plus allongée etoffrant un rétrécissement plus prononcè a son extrémité postéricure; les pieds postérieurs tres-longs.

Gelte Aphrodite, qui vient de Naples, n'est, suivant MM. Audouin et Milne Edwards, qu'une variété de la précédente.

$$
\begin{gathered}
\text { POLYNOE, Sav.; } \\
\text { Aphrodita, Oliv., Fabr., Pallas, Cuv॰; } \\
\text { Eumolpe, Ocken, Blainv.; } \\
\text { Lepidonota, Leach. ; }
\end{gathered}
$$

Mâchoires cornées, grandes. - Antennes au nombre de cinq. - Yeux distincts au nombre de quatre. - Elytres fixées sur des pieds ne portant pas de branchies ni de cirrhes supérieurs ; alternant jusqu'au vingt-troisieme segment ayec d'autres pieds 
POLYNOE.

pourvus de branchies et d'un cirrhe supérieur, mais dénués d'élytres. - Quelquefois des élytres supplèmentaires placées alternativement dans un ordre différent.

Tête un peu déprimée en-dessus, carénée en-dessous entre les antennes; corps ovalaire ou linéaire.

Quelques especes de ce genre sont phosphorescentes; d'autres se construisent des fourreaux avec des fragmens de coquilles.

L'on trouve les Polynoe sur les bancs d'huitres.

\section{PREMIERE DIVISION.}

Elytres grandes, se recouvrant les unes les autres, et cachant le plus souvent le dos dans son entier.

\section{(Polinoe inflata, mihi.)}

\section{Polynoe souamata.}

Baster, Opus. Subs., t. II, part. 2, p. 62 , pl. 6. - Sav., Annel., p. 22. Aud. et Evw., Aunel., p. 80, pl. 1, f. 1016. - Scutellata, Risso, Eur. mérid., t. IV, p. 414. - Long. 12 lig. - Corps oblongo-linéaire, formé de vingt-sept segmens, recouvert entièrement par douze paires d'élytres, d'un gris vineux pointillé de brun, relevé d'une tache rousse; dessous du corps d'un gris nacré.

Cette espèce est assez commune dans toutes les mers de l'Europe, et c'est auss à cette espèce, suivant MM. Edwards et Audouin, que l'on doit rapporter l'Aphrodita Clavigera, Freminville (Nouv. Bullet. des Sciences, t. 3), qui vient du Sénégal.

\section{2. polynoe punctata.}

Mulner, Naturgeschichte Einiger, p. 170 , pl. 13. - Sav., Annel., p. 26. -Ne diffère du précédent qu'en ce que les èlytres ne se recouvrent pas et laissent à découvert une partie du dos, - Habite les mers du Nord.

\section{POIYYNoE LeVIS.}

Aud. et Edw., Litt. Annel., 1, p. 85 , pl. 11, fig. 11-19. - Long. 12 lig. Corps allongé, recouvert par quatorze paires d'ély tres membraneuses et lisses. Iles Chaussey.

Suivant MM. Edwards et Audouin, c'est peut-être à cette espèce que l'on doit rapporter l'Aphrodita Clava, Montagu, Trans., Soc. linn., t. IX, p. 108, pl. 7, f. 3.

\section{POLYNoE GirRata.}

Othox. Fabs, , Faun. Groënl., p. 308, n० 290, - Aưd. et Edw., Litt. Annel., t. I, p. 86, 3. - Long. 12 lig. - Trentehuit segmens; quinze paires d'élytres; dixhuit tentacules à la trompe. - Mer du Nord et côtes de la Manche.

\section{5. polynoe floccosa.}

Sav., Annel. , p. 23. - Long. 10 lig.Corps oblong, linéaire, de quarante segmens, muni de seize paires d'élytres caduques; d'un gris un peu violet. - Océan.

\section{6. polynoe imbricata.}

Garlin, Linn., Syst. nat., t. I, p. 3108. - Foliosa, $\mathbf{S}_{\mathrm{AV}}$, , Anuel., p. 23. - Edw. et. Aud., Annel. , 1, p. 89, n' 5. - Long. 15 lig. - Corps formé de quarante-deux segmens; trompe entourée de trente tentacules; élytres au nombre de dix-huit paires minces, caduques, lisses et d'un gris violacé. - Océan.

\section{POLYNOE SETOSISSLia.}

SAv., Annel., p. 25.- - Aud. et Edw., Annel., 1, p. 90, 6. - Long. 18 lig. Corps oblong, déprimé, formé de quarante segmens, et muni de quinze paires d'élytres; soies de la rame dorsale beaucoup plus nombreuses et plus fortes que celles de la rame ventrale. - Côtes de la Manche.

Nota. Il faut aussi placer ici la $P$. impatiens, que nous figurons $\mathrm{pl} .1, \mathrm{f} .2$.

\section{UEUXIÈME DIVISION.}

Elytres ne couvrant pas tout le dos.

\section{(Polynoe vermiformis, mihi.)}

\section{POLYNOE SCOLOPENDRINA.}

Sav., Annel., p. 23. - Edw. et Acd., Aunel., p. 92, no 8. - Long. 15 lig. Corps linéaire formé de quatre-vingt-deux segmens, et portant quinze paires d'ély tres lisses et orbiculaires; la couleur est brunâtre; une bande jaune sur le dos; élytres d'un blanc sale; parties postérieures du corps dépourvues d'élytres. - Océan.

\section{9. polynoe blainvilli.}

EDw et Aud., Annel., 1, p. 94. Scolopendrine, Blainv., Dict. Sc. nat., art. Vers, p. 45, pl. 10, t. II.-Differe de la précédente par lesélytres qui s'étendent jusqu'à l'extrémité du corps; élytres au nombre de soixante. - Habite.....

\section{POLYNOE IONGISSIMA.}

Buainv., Dict. Sc. nat., Vers, p. 459 , pl. 10 , f. 3. - Corps allongé et filiforme, muni de dix-huit paires de petites élytres 
rudimentaires, qui s'étendent jusqu'au quarante-unième segment. - Côtes de Gênes.

\section{POLYNoE LONGA.}

Otrox. Fabr., Faun. Groenl., n०293.Soixante-six segmens, cinquante-six paires d'élytres. - Côtes du Groenland.

\section{POLYNoE MiNuta.}

Othon. Fabr., Faun. Groenl., n०294. - Quarante-huit segmens ; trente-huit paires d'élytres. - Cốtes du Groenland.

\section{IPHIONEA ; \\ Polynoe Iphionea, Sav.}

Ce genre diffère essentiellement des $P_{0}$. lynoe par les antennes, qui ne sont qu'au nombre de quatre. - Le corps est subelliptique. - Les élytres sont imbriquées et écailleuses. - II n'y a point de filets postérieurs.

\section{IPHIONEA MURIGATA.}

Sar., Annel., p. 21, no 1, pl.3, t. I.Long. 12 lig. - Corps de vingt-neuf segmens, et recouvert par treize paires d'élytres; élytres brunes, avec un trait noir et longitudinal; ventre blanc à reflets brillans. - Mer-Rouge et côtes de l'Ile-de-France.

\section{POLYODONTES, ReNierI; Phyllodoce, Ranzani; Eumolpe, Ockev.}

Trompe grosse, couronnée de tentacules. - Mâchoires grandes, cornées. Antennes au nombre de deux, et assez lon. gues.-Branchies non visibles. -Des pieds munis d'élytres, mais sans cirrhe supérieur, placés sur toute la longueur du corps, mais alternativement avec d'autres munis de cyrrhes supérieurs, mais non d'élytres.

La seule espèce connue est le Poliodontes maxillosa, Ranz., Mém., pl. 1, f. 2-9. - De la Mer Adriatique.

\section{SIGALION, Aud. et Edw.}

Bouche comme celle des Polynoe. Branchies remplacées par des franges garnissant le bord extérieur des élytres. Les pieds pourvus d'un cirrhe supérieur et d'élytres, et d'autres sans élytres placés alternativement jusqu'au vingt-septième segment; les premiers continuant ensuite sans interruption jusqu'à l'extrémité. - Antenues externes très-grandes, les mitoyennes rudimentaires, l'impaire n'existant pas toujours. - Corps très-allongé, déprimé, presque linéaire, composé de beaucoup de segmens. - Tête dépassée en avant par les pieds de la première paire.

\section{SIGALION MATIILD a. $^{2}$}

Aud. et Edw., Litt. Annel., 2, p. 105, pl. 2, f. 1-10.-Long. 5 pouc. Larg. 4 lig. - Corps formé de cent quatre vingts segmens; antennes mitoyennes à peine perceptibles, pas d'antenne impaire; les externes très-longues; cent soixante-quatre paires d'élytres se croisant sur le dos. Côtes de la Manche.

\section{SIGALION HERMTONa.}

ARD. et Enw. Litt. Annel., 2, p. 107, pl.1, f.1-6. - Long. 6 pouc. Larg. 4 lig. $\frac{1}{2}$. Antennes impaires longues, les mitoyennes non visibles, les externes longues; èlytres au nombre de cent soixante paires, de forme étroite et laissant à découvert une grande partie du dos. - Côtes de La Rochelle.

M. Guérin a décrít une troisième espèce de ce genre, dans son Magasin de Zoolo. gie, sous le nom de Sigalion Herminice.

Nota. Suivant MM. Audouin et Edwards, c'est peut-être au genre Sigation que doit se rapporter la Nereis stellifera de Muller, Zool. Dan., t. II, pl. 62, f. 1-3. Dans ce cas, ce groupe devrait porter le nom de Lepidia, que Savigny lui applique sans avoir vu en nature l'espèce précitée.

\section{PALMYRA, SAv.}

Bouche ayant une trompe dépourvue, à son orifice, de tentacules. - Mâchoires demicartilagineuses. - Antennes complètes, les mitoyennes coniques et très-petites, l'impaire un peu plus longue que les mitoyennes, et du reste semblables; les extérieures grandes. - Yeux au nombre de deux. Branchies peu visibles, placées alternativement sur chaque segment après la vingtcinquième paire de pieds. - Pieds ayant deux rames séparées, la première paire garnie de quelques soies, la rame dorsale avec deux faisceaux inégaux de soies inclinées en arrière; la rame ventrale a un seul faisceau de soies fourchues. - Girrhes, tant les supérieurs que les inférieurs, grêJes, cylindriques, terminés par un petit filet également cylindrique et renflé au bout; les cirrhes supérieurs insérés derrière la base du faisceau inférieur des rames dorsales. - Corps oblong, déprimé, composé d'anneaux peu nombreux. - Tête 
déprimée, nu peu saillante au-dessous des antennes. - Elytres nulles.

Nous venons de donner les caractères de ce genre tels que les présente M. Savigny; mais MM. Audouin et Milne Edwards n'ont pas: pu apercevoir d'antennes mitoyennes, bien qu'ils aient examiné le même individu que leur devancier. (Litt. de la France, t. II, p. 110).

1. Palmira aurifera. (Pl. 1, f. 3.) Liar., Ann., t. V, p. $306, \mathbf{n}^{0}$ 1.SAY., Annel., p. 17.-Aud, et Edw., Litt. fr. 2, p. 110 , pl. 2, f. 1-7.-Long. 12 lig. - Corps obtus aux deux bouts, formé de trente segmens et pourvu par conséquent de trente paires de pieds; rames dorsales à deux faisceaux de soies inégaux; l'inférieur formé d'un petit bouquet de poils fins et courts, le supérieur composé de soies grandes, plates, pouvant se recouvrir mutuellement, et disposées en palmes voûtées; ces palmes offrent les reflets de l'or et se détachent sur un fond d'un brun nacré. - Cette espèce, remarquable par la beautë de ses couleurs, vient de l'Ile-deFrance.

\section{EUMOLPHE, Risso.}

Ce genre est très-douteux, nous en donnons les caractères d'apres son créateur. Corps ovale, aplati. - Tête arrondie en pointe. - Antennes incomplètes, inégales, les extérieures bifides. -- Quatre yeux. Mâchoires córnèes. - Des écailles sur les côtés du dos.

\section{EUMOLPHE FRAGILIS:}

Rrsso, Eur. mérid., t. IV, p. $415 .-$ Corps ovale, allongé, d'un rose clair; une bande azurée sur le milieu du dos. - Méditerranée.

\section{AMPHENONHTES.}

Caractéres. Des cirrhes distincts anx pieds. - Corps non muni d'élytres, et tous les scgmens généralement semblables. Branchies très - developpées, - Tête distincte.

Genres -: Chloeia, Amphinoma, Euphrosyna, Hipponoa, Aristenia, Zothea.

$$
\begin{aligned}
& \text { Chloeia, Sav.; } \\
& \text { Amphinome, Brug.; } \\
& \text { Chloe, Blainv., Cuv. }
\end{aligned}
$$

Antennes au nombre de cinq. - Bran- chies insérées sur lc dos, en forme de panaches ayant sur leurs bords de nombieux filamens rameux, remplacés sur les premiers anneaux par: de petits cirrhes surnuméraires.-Pieds formés de deux ranies portant chacune un faisceau de longues soies et un cirrhe filiforme.-Corps large, aplati, formé d'une quarantaine de seg. mens. - Téte petite, surmontée d'une caroncule.

\section{CHLOEH CAPILLATA.}

Brug., Encycl. méth., art. Vers, t. I, p. 45. - Flava, Paluas, Miscel, pì. 8, f. 7-11. - Long. $4 \frac{1}{4}$ pouc. Larg. 12 lig. - D'un gris fauve, une moucheture noire sur le milieu de chaque segment et une bande transversale sur les côtés. - Mer des Indes.

\section{CHLOEIA RUPESTRIS.}

Risso, Eur mérid, t, IV, p. 425.-SeIon cet auteur, cette espèce serait pourvue de mâchoires, ce qui la différencierait suffsamment de la précédente; la: couleur est hyaline, avec dés' reflets azurés et verts; le dessoú ést bleuâtre; les tentacules blancs, et les faisceaux de soies très-brillans. Méditerranée:!

Nóta: Sỉ la présence des mâchoires étoit démontrèe dalis celte espèce, nous la proposerions comme type d'un nouveau genre que nous nommerions V eleda.

$$
\begin{gathered}
\text { AMPHINoNA. Brug.; } \\
\text { Pleione, \$av., Cuv.; } \\
\text { Trebella et Nereis, Linn.; } \\
\text { Aphrodita, PaLras. }
\end{gathered}
$$

Antennes au nombre de cinq, tres-conrtes et à peu près égales. - Branchies en forme de rameaux touffus, occupant la base de rames supérieures et manquant quelquefois sur les deux premiers segmens. Pieds biramés, portant deux cirrhes. Corps épais, presque linéaire.-Tête portant une caroncule. - Yeux au nombre de quatre.

Les espèces de ce genre sont nombreuses, mais fort.peu se trouvent sur nos côtes; Ia plupart habitent les mers situées entre les Tropiques.

\section{AMPHINoma VAgavs.}

SAv., Annel., p. 60.-Long. 15 lig. Larg. 2 lig. $\frac{1}{2}$ :- -D'un gris brun à nuances violettes, dessous sans taches et plus clair; caroncule petite, très-déprimée, lisse, ne se prolongeant pas sur le second segment. - Côtes d'Angleterre? 


\section{AMPIINOMA TETRAEDRA.}

Brug., Encyc. méth., art. Vers, 1, p.48, $n^{\circ}$ h, pl. 61 , f. 1-5. - Rostrata, Pallas, Misc. Zool., p. 106, pl. 8, f. 14-18. Long. 10 pouc. Larg. 10 lig. - D'un gris rouge a reflets olivâtres, sans taches; peau épaisse, ridée régulièrement et longitudina lement en arrière, et d'une manière irrégulière en avant; caroncule comprimée en crête verticale simple, petite, et ne s'étendant pas au-delà du premier segment. Mer des Indes.

\section{AMPHINOMA CARUNGULATA.}

Pallas, Misc. Zool., p. 102, pl. 8, f. 12. 13. - N. Gigantea, LiNn., Syst. nat., et 12, t. I, part. 2, p. $1080, \mathrm{n}^{\circ} 2$ - - Long. 12 pouc. - Corps formé de nombreux segmens, d'un gris fauve tirant sur le violet; caroncule ovale, divisée de chaque côté en sept ou huit feuillets obliques et pinnatifides: - Amérique du Nord.

Nota. L'on doit peut-être rapporter à cetle espece, comme variété, l'Amphinoma Savigny. Brullé, Expéd. sc. Morée, Zols, p. 398, pl. 1 , f. 1 , qui se trouve sur les côtes de la Morée. Nous avons reproduit cette figure dans notre article Amphinomites de l'Encyclopédie du dix-neuvieme siécle.

\section{AMPIINOMA AOLIDES.}

Sav., Annel., p. 62. - Long. 9 pouc.Corps déprimé, d'un gris violet, à reflets irisés ; caronculc orale, oblongue et lisse. - Amérique du Nord?

\section{AMPIINOMA ALCYONIA.}

Sav., Annel., p. 62, pl. 2, t. III. Dict.Sc. nat., art. Vers, Atlas, pl. 7, t. II. -Long. 2 pouc. - Corps étroit, d'un bleu violet; caroncule ovale, lisse, avec un rebord ondulé; antenne impaire beaucoup plus petite que les autres. - Mer-Rouge.

\section{AMPHINOMA COMPLANATA.}

Pallas, Misc. Zool., p. 109, pl. 8, f. 19. 26. - Long. 5 pouc. - Corps linéaire, déprimé, formé de cent trente segmens, d'un gris à reflets éclatans; les trois premiers segmens portant une caroncule obtuse. - Océan américain.

Nota. MM. Audouin et Edwards citent aussi une espèce inédite de ce genre, qui a été rapportée d'Amboine par MM. Quoy el Gaymard.

\section{EUPHROSYNA, SAV.}

Bouche ayant une trompe grosse et courte. - Une antenne unique et subulée. - Branchies très-touffues, foliacées, placées derrière les pieds, s'étendant de la base de la rame dorsale à celle des rames ventrales. - Pieds biramés portant un cirrhe surnuméraire au milieu de la rame supé- rieure.-Corps ovalaire, formé de segmens peu nombreux. - Tête étroite, surmontée d'une caroncule grande, et s'étendant jusque sur le quatrième ou le cinquième segment. - Yeux au nombre de deux.

L'on connaît trois espèces de ce genre.

1. euphrosyia laureata. (P1. 1, f. 4.) Sav., Annel., p. 63 , pl. 2, f. 1.-Dict. Sc. nat. Atlas; art. Vers, pl. 8, f. 1. Icon. Reg. anim., Annel., pl. 4 bis, f. 1. Long. 2 pouc. Larg. 10 lig. - Corps formé de quarante-un segmens, d'un gris rougeâtre; caroncule ovale, lisse, avec une petite crête longitudinale sur son milieu. MerRouge.

\section{EUPHIOSYNA MTYTOSA:}

Sav., Annel., p. 64, pl. 2, f. 2.-Ann. Sc. nat., t. XX, pl. 3, f. 6, 7 et $8 .-$ Icon. Reg. anim., Annel., pl. 4 bis, f. 2.Long. 12 lig. _- Corps formé de trente-six segmens, d'un violet foncé; caroncule elliptique, carénée, bisillonnée. - MerRouge.

\section{EUPHROSYNA FOLIOSA.}

Aud, et Evw., Litt. Annel., t. I, p. 126, pl. 11, f. 1-4. - Long. 12 lig. - Très-voisine de la précédente; d'un rouge vif, nuancé sur le dos de vert et de jaune; caroncule etroile et presque linéaire; branchies à huit rameaux pour chaque pied. Côtes de la Manche.

\section{HIPPONOA, AUd, et EDW.}

Antennes au nombre de cinq, dont la médiane grande et conique. - Branchies insérées derrière les pieds, formées de houppes quadriramées. - Pieds composés d'une seule rame peu saillante, comprimée, verticale, garnie de soies fines et nombreuses, et pourvue d'un seul cirrhe ventral. - Corps presque fusiforme, composé de peu d'anneaux. - Tête petite, dépourvue de caroncule.

\section{Hipponoa gaUdiciaddi.}

Aun. et EDw., Ann., Sc. nat., t. XX, p. 156, pl. 3, f. 1-5. - Icon. Reg. anim., Anuel, pl. 4 bis, f. 3. - L'on ne 
connoît qu'une espèce de ce genre; clle a été rapportée des côtes de la Nouvelle-Hollande par le savant naturaliste auquel elle est dédiée.

\section{ARISTENIA, SAV.}

Le savant crẻateur de cé genre n'a fait que l'indiquer et le tigurer sans le décrire. - Le corps est allongé et presque cylindrique. - Les pieds sont formés de deux rames armées de soies, rudes et portant sept cirrhes. - Les branchies sont petites et pectinées.

La seule espèce de ce genre est l'Aristenia conspurcata, qui vient de la Mer-Rouge (Sav., Annel., pl. 2, f. 4).

\section{ZOTHEA, RisSo.}

Corps très-long, graduellement aminci en arrière. - Tête armée de deux mandibules cornées, aiguës, bidenlées.-Quatre yeux égaux. - Huit tentacules filiformes, inėgaux. - Dos couvert de lamelles branchiales, feuilliformes, le long des bords latéraux. - V entre à segmens munis chacun d'une pointe ciliée.

\section{ZOTHEA MERIDIONALIS.}

Risso, Hist. nat., Eur. mérid., t. 4, p. 424:- - Le corps de ce néréide est fort long, délié, flexible, d'un rouge mêlẻ de jaunâtre; les yeux sont noirs; les tentacules jaunâtres; le ventre d'un blanc sale, et les lamelles rougeâtres. - Côtes de la Méditerranée.

Nota. Nousavons reproduit ici la description de ce genre telle que M. Risso l'a donnée, ne l'ayant pas vu en nature.

\section{EUNIGITES.}

Caractères. Pieds avec des cirrhes distincts. - Corps non muni d'élytres. Tous les segmens généralement semblables. -Branchies tantôt nulles, tantôt développées. - Tête distincte.

Genres : Eunice, Onuphis, Diopatra, Lysidice, Lumbrineris, Aglaura, OEnone.

$$
\begin{gathered}
\text { EUMICE, Cuv.; } \\
\text { Nereis, Linn., Palias; } \\
\text { Branchionereida, Blajnv.; } \\
\text { Néreidonta, Blainv.; } \\
\text { Leodice, Sav., Delle Chiaye. }
\end{gathered}
$$

Antennes au nombre de cinq, assez grandes et subulées. - Branchies insérées au. dessus du cirrhe dorsal des pieds, pectinées d'un seul côté. - Pieds comprimés à une seule rame terminée par un tubercule portant deux cirrhes. - Trompe peu saillante. - Mâchoires au nombre de sept, dont. quatre à gauche.-Tête distincte, ordinairement lobée en avant. - Yeux au nombre de deux. - Gorps presque cylindrique, linéaire, un peu déprimé, à anneaux trèsnombreux.

\section{PREMIÉRE DIVISION.}

Deux cirrhes tentaculaires insérés derrière la nuque.

\section{(Leodica simplicis, SAV.)}

\section{EUNICE HaRASSII.}

Aud, et Edw., Litt. Aninel., t. I, p. 141, pl. 3, f. 5-11. - Sanguinea, LavRILl. Icon. Regn. anim., Annel., pl. 5, f. 2. Long. 6 pouc. - Tête bilobèe en avant; corps d'un rose vineux; antennes et cirrhes. blanchâtres; les antennes sont comme articulées dans toute leur longueur; les branchies s'étendent depuis les troisième ou quatrième paires de pieds jusqu'au cent trentieme segment. - Commune dans la rade de Saint-Malo.

\section{EUNiCE GALLICA.}

Sar.. Syst., p. 50. - Aud. et Epw., Litt. Annel., 1, p. 144, no 2. - Antennes non articulées; branchies commençant à paraitre sur les pieds de la sixième paire. - Côtes de France.

\section{EUNICE AVTENNATA.}

Sav., Annel., n. 50, fig. 1.-Dict.clas., pl. 74. - Dict. Sc. nat., art. Vérs, pl. 15, t. I. - Icon. Annel., pl. 5, f. 1. Long. 2 pouc. $\frac{1}{2}$. - D'un cendré rougeâtre, avec des reflets cuivreux et éclatans ; tête bilobée; antennes grêles, composées de douze, dix-huit et vingt-deux articles; l'impaire trois à quatre fois plus longue que la tête. - Mer-Rouge.

\section{EUNice mispanica.}

$\mathrm{S}_{\mathrm{AV}}$, Annel., p. 51. - Long. 20 lig. Corps grêle, d'un gris rougeả tre à reflets; tête bilobée; antennes non articulées; branchies très-menues, simples, bifides ou trifides, nulles aux deux premières paires de pieds, et disparaissant après la quinzième ou seizième. - Côtes d'Espagne.

\section{EUXICE APHrOditais.}

Pallas, Nov. Act. Petrop., t. II, p. 229, 
pl. 5, f. 1-7. - Long. 18 pouc. - D'un gris cendré; tête bilobée; antennes inarticulées; branchies nulles aux huit premières paires de pieds, simples aux trois paires suivantes, pectinées dans toutes les autres, dépassant de peu les cirrhes, quise raccourcissent à mesure que les branchies grandissent. - Mer des Indes.

\section{EUNice Gigantea:}

Cơv., Reg. anim., 2e édit., t. 3, p. 199. -Buarvv., Faun. franc., Atlas, Chétopodes, Néréides, pl. 14. - Long. 4 à 6 pieds. - D'un gris cendré, à reflets irisés; tête quadrilobée; antennes non articulées; branchies nulles aux quatre premières paires de pieds, pectinées à toutes les autres. Mer des Antilles, et peut-être la mer des Indes.

Nota. Cette espèce et la précédente sont souvent confondues; elles me semblent cependant bien distinctes, ainsi qu'à M. de Blainville. La dernière est la plus grande annelide connue.

\section{EUNICE NORWEGICA.}

Lrnv., Syst. nat., édit. 12, t. I, part. 2, p. 1086, no 11. - Pinnata, Muller, Zool. Dan., part.-1, pl. 29, f. 1-3. - Corps convexe, jaunâtre ; antennes inarticulées; branchies pectinées; cirrhes supérieurs beaucoup plus longs que les branchies. - Mers du Nord.

\section{RUNiCE PINNATA.}

Muluer, Zool. Dan., t. I, p. 31, pl. 29, f. 4-7. Corps court, roux; antennes articulées; branchies pectinées, courtes; cirrhes supérieurs encore plus longs que dans l'espèce précédente. - Mers du Nord.

\section{EUNICE PARETT.}

Blainv., Dict. Sc.nat., art. Vers, t. LVII, p. 476. - Cette espèce n'est qu'indiquée par le savant auteur que nous venons de citer; elle est remarquable, dit-il, par la brièveté et le grand nombre de ses anneaux, ainsi que par la petitesse de ses appendices. -Còtes de Gênes.

Nota. MM. Edwards et Audouin pensent que cette espèce est peut-être la même que l'Eunice hispanica.

Nota. Il faut ajouter à cette division les espèces suivantes :

10. Fasciata, Risso, Eur. mérid., t. IV, p. 421.

11. Punctata, id. id.

12. Triantennata, id., p. 422.-Toutes les trois de Gênes.
13. Bertoloni, Drlle-Chiaye, Mem. Sulla storia e notomia anim. Senza vert. del regno di Napoli, t. III, p. 474, pl. 44, f. 12-15. - De Naples.

\section{DEUXIÈME DIVISION.}

Point de cirrhes tentaculaires sur le second segment du corps.

\section{(Leodica marphysa, SAv.)}

14. EUNiCE SANGUINEA.

Montagu, Trans. Linn. Soc., t. XI, p. 26, pl. 3, f. 1.-Opalina, SAv., Annel., p. 51.-Dict. Sc. nat., art. Vers, t. LVII, p. 477 , pl. 15, f. 2 . - Long. $\frac{1}{2}$ pied à 2 pieds. - D'un vert foncé; branchies rouges; tête bilobée; branchies ne paraissant qu'après le segment; corps notablement renflé vers la vingtième tête. - Côtes de l'Océan et de la Méditerranée.

\section{EUNICE BELLII.}

Aod. et Edw., Annel., t. I, p. 149 , n。 4, pl. 3, f. 1-4, et 8-9. - Cuv., Règ. anim., $2^{\mathrm{e}}$ édit., t. III, p. 200. - Long. 2 pouc. - Corps non notablement renflé en avant; tête non bilobée, rebordée en avant; branchies commençant au quinzieme segment du corps, et s'étendant sur les dir-sept suivans et quelquefois sur les quatre-vingt-troisième et quatre-vingt-quatrième; mais ces deux dernières sont toujours beaucoup plus petites que les autres. - Côtes des Iles Chaussey (Manche).

IDeux autres espèces de cette division sont encore connues: 16 Grumwialdi, et 17 Erictrocephala; toutes les deux sont de Nice et décrites par M. Risso, Eur. Mérid., t. IV, p. 423.

\section{ONUPHIS, Aud. et EDw.;}

Spio? Delle-Ghiaye; Leodice, Sav. : Nereidonta, Blarnv.; Nereis, Muller.

Antennes au nombre de quatre, sans compter trois appendices annelés qui s'insèrent sur la nuque et recouvrent la tête. - Branchies pectinées d'un seul côté, insérées au-dessus du cirrhe dorsal des pieds. - Yeux au nombre de deux et très-petits.

Ce genre a de grands rapports avec celui d'Eunice; il habite dans des tuyaux étroits, circulaires, et demi-transparens.

\section{ONUPHIS EREMITA.}

Aud. et Evw., Litt. Annel., t. I, p. 152, pl. 3, fig. 1.5. - Long. 3 pouc. $\frac{1}{2}$.-Corps 
cylindlique, non renflé vers la tête, formé d'environ deux cents segmens; antennes externes épaisses; couleur opaline, avec deux rangées de taches rougeâtres sur le dos; tube mince et cylindrique formé de grains agglomérés. - Côtes de l'Océan.

\section{2. oxupHIS TUBicola.}

Mulere, Zool. Dait., t. I, p. 18, pl. 18.-Filicomis? Delle-Ghiaye, Mem., t. III, p. 76 , pl. $\{5$, f. $6 .-$ Antennes mitoyennes très-courtes; branchies ayant au plus une ou deux divisions ; tube solide et corné. - Mers du Nord et peut-être la Sicile.

\section{DIOPATRA, AUd. et Edw.;}

Nereis, Bosc, Delle-Chiate.

Antennes au nombre de neuf; les mitoyennes subulées et renflées à la base; cing des autres sont remarquables par leur grand développement. - Branchies en forme de frange contournée en spirale; elles manquent sur les premiers segmens du corps, et deviennent rudimentaires vers le soixantième, pour disparaître bientôt totalement. - Pieds uniramés, terminés par deux mamelons, entre lesquels l'on voit un faisceau de soies.

\section{DIOPATRA AMBOINENSIS.}

Aud, et EDW., Litt. Annel., p. 156 , pl. 3, f. 6-8. - Long. 4 pouc. - Têle courte; corps grêle; pas de branchies sur les cinq premiers segmens du corps, Amboine.

\section{Diopatra cuprea.}

Bosc, Hist. nat. des Vers . t. I, p. 164, pl. 5, f. 1-4. - Corps formé d'environ deux cents segmens, d'un bleu doré éclatant. - Ámérique du Nord.

\section{DiOPATRA ITALICA.}

Cuprea, Dzlle-Chiviye, Mém. silla storia digli anim. di Napoli, p. 393, pl. 27, f. 9-16.-Long. 1 pied $\frac{3}{2}$. - Diffère des précédens par une taille beaucoup plus grande; pas de branchies sur les six premières paires de pieds; tube cylindrique formé de sable et de coquilles. - Naples.

\section{LYSIDICE, SAV.; \\ Nereidice, Buainv.}

Mâchoires au nombre de sept, dont quatre à gauche. - Trompe dépassant le front a sa base, ayant au-dessous de son ouverture deux pièces cornées, - Bran. chies nulles. - Antennes courtes, au nombre de trois. - Pieds ambulatoires trèscourts, à deux faisceaux inégaux de soies, et terminés par un appendice mobile. Cirrhes supérieurs subulés, les inférieurs très-courts; la dernière paire de pieds convertie en deux filets. - Corps linéaire cylindrique formé de segmens nombreux. - Tête plus large que longue, décou. verte.

\section{IYYSIDICE NISCETTA.}

Aud. et Edw., Litt. Annel., t. I, p. 161, pl. 3, 6, f. 1-8. - Long. 5. pouc. Larg. 1 lig. $\frac{1}{2} .-D$ 'un brun irisé; tête bilobée en arant; pieds ne paraissant que sur le troisieme segment. - Hes Chaussey.

\section{LYSIDICE VALENTINA.}

Sav., Annel., p. 53. - Blainv., Dict. Sc. nat, t. LVIII, p. 475 . - Long. 2 pouc. - Couleur de nacre; le premier anneau à peine plus long que le second ; tête arrondie en avant. - Méditerranée.

\section{LYSTDICE OLIMPIA.}

Sav., Annel., p. 53. - Blanvv., Dict., p. 475. - Long. 14 lig. - Corps formé d'environ soixante-sept anneaux, dont les douze derniers forment une sorte de petite queue conique, ciliée de deux rangs de pieds très-petits, d'un gris blanc nacré. Océan.

\section{LYSIDIGE GALATHITA.}

Sav. Annel, p. 54. - D'un blanc laiteux, avec les trois premiers segmens d'un brun doré ; corps plus épais que dans l'espèce précédente; antennes très-courtes; un mamelon derrière l'impaire. - Océan.

Nota. Il faut encore rapporter à ce genre le Lysidice Parthenopeia, DelleGliaye, Mem. sulla Storia, etc., t. III, p. 175, pl. 44, f. 2-11.-Elle est de Naples.

\section{LUMBRINER IS, Blatwv.;}

Nereis, Pallas; Lumbricus, Mulder; Scoletoma, Buainv.

Antennes nulles, ou quelquefois représentées par deux petits tubercules arrondis. - Bouche armée de huit mâchoires. Deux pièces cornées formant une lèvre sternale. - Pieds petits et uniramës. - Tête découverte, obtuse, unilobée.-Yeux nuls. - Corps cylindrique formé de segmens nombreux. 


\section{IUMBRINERIS ORBIGNYI.}

A ud. et Evw., Litt. Annel., t. I, p. 166 , p]. 36, f. 9-12. - Long. 5 pouc. $\frac{1}{2}$. Larg. 1 lig. $\frac{1}{2}$ - Corps cylindrique jaunâtre, à reflets irisés; têle petite et globuleuse. La Rochelle.

\section{IUMBRINERIS IATRERIIEI.}

Aud. et Eow., Annel. , p. 168, n०2, pl. 3,6 , f. $13-15$. - Long. 7 pouc. Larg. 2 lig. $\frac{1}{2} \cdot-$ Corps cylindrique; tête conique sans aucune trace de tubercule antenniforme. - Côtes de l'Océan et de la Méditerranée.

Il faut aussi rapporter à ce genre les espéces suivantes:

3. Scolopendra, Blarnv., Dict., $\mathbf{t}$ XXXIV, p. 454.

4. Splendida, Businv., Dict., t. LVII, p. 486 .

5. Nereis Ebranchiata, Pallas (L. Pallasii, Brannv.).

6. L. Coccinea, Delle.Curaye, Mém., t. 111, p. 178.

7. Nesidensis, Delle-Chraye, Mem., t. II I, p. 178 .

8. Rolandi, Delle-Chiaye, Mém., t. III, p. 178.

F't 9. S.-Hilairii, Dele-Chraye, Mém., t. 111, p. 178.

Enfin; il faut aussi probablement ráp porter àce genre, suivant MM. Edwards et Audouin, le Lumbricus Fragilis de Muller, qui sert de type au genre Scoletoma de M. de Blainville.

\section{AGLAURA, SAvig.}

Antennes incomplètes, moins longues que la tête; les mitoyennes très-courtes, coniques, point sensiblement articulées; l'impaire semblable aux mitoyennes, plus longues; les extérieures nulles._Bouche : trompe dépassant le front. - Mâchoires au nombre de neuf, quatre à droite, cinq à gauche; les extérieures ne s'appliquant point sur les intérieures dans le repos. Ces mâchoires, la plus extérieure de chaque côté exceptée, larges, aplaties, profondément dentées en scie, à crochet terminal très-fort et très-courbé; les deux premières, à commencer par les intérieures ou les postérieures, exactement opposées, articulées à une tige commune beaucoup plus longue qu'elles, dilatées à leur basce, dissembla- bles; celle du côté droit plus grande, profondément échancrée par-derriere, au-dessus de sa base externe, et terminée par un double crochet; les suivantes ne se-correspondent point par paires; les deux dernières seules exactement opposées, trèspctites, divisées en deux branches à leur base, grêles, non dentées, courbées, aiguës. - Lèvre inférieure pas plus large que la première paire de mâchoires. - Yeux peu distincts.-Pieds : cirrhes tentaculaires nuls. - Pieds ambulatoires à deux faisceaux inégaux, composés, l'un de soies simples, l'autre de soies terminées par une barbe; cirrhes supérieurs allongés, obtus ; les inférieurs de mème; derničre paire de pieds ä peu près semblable aux autres. Branchiés nulles. - Têle globuleuse, inclinéc et complètement cachée, ainsi que les antennes, sous le segment qui suit. Corps linéaire, cylindrique, composé de segmens nombreux et courts : le premier, vu en dessus, très-grand, rétréci par-devant, prolongé et subdivisé, au-dessus de la tête, en deux lobes saillans et divergens; le second plus court que le troisième.

\section{A. AgLAURA FULGIDA.}

Sav., Annel., t. LV,pl. 5, f, 2.-BLaINV., Dict. Sc. nat., t. LVII, p. 480 . - Long. 10 pouc. - Corps grêle, formé de deux cent cinquante-trois segmens, le premier un peu plus grand que les trois suivans réunis; pieds courts, à rame renflée et saillante au-dessus des soies du faisceau supéricur, qui est le moins épais des deux; soies jaunâtres; les supérieures plus Iongues, plus déliées, fléchies à leur extrémité, et prolongées en pointes très-fines; les inférieures terminćes par une barbule; couleur d'un cendré bleuâtic, imitant celle de l'opale, avec les reflets lés plus éclatants. - Habite les côtes de la Mer-Rouge.

$$
\text { OENONI, SAV. }
$$

Antennes point saillantes et comme nulles.-Bouche : trompe dépassant lefront. Yeux peu distincts. - Pieds : cirrhes tentaculaires nuls. - Pieds ambulatoires à deux faisceaux inégaux de soies simples, ou terminés par une barbe.-Cirrhes supérieurs et cirrhes inférieurs presque également allongés, obtus.-Dernière paire de pieds à peu près semblable aux autres. - Branchis nulles. - Tête à deux lobes, inclinée et cachée sous le segment qui suit. - Corps linéaire, cylindrique, composé de segmens 
courts et nombreux, - Le premier segrnent, vu en-dessus, tres-grand, arroudi par-devant en demi-cercle, débordant la tête.-Le second plus long que le troisième.

\section{OENONE INUCIDA.}

SAv., Annel., p. 56. - Long. 12 lig.Corps d'un cendré bleuâtre à beaux reflets, formé de cent-quarante-deux segmens. Habite les côtes de la Mer-Rouge.

\section{NERÉIDITES.}

Caracteres. Pieds avec des cirrhes distincts.-Corps non muni d'élytres, et les segmens généralement semblables entre eux. - Branchies nulles ou remplacées par de simples languettes. - Tête distincte et portant généralement des antennes et des yeux.

Genres : Nereis, Lycastis, Syllis, Hesione, Alciopa, Myriana, Phyllodoce, Nephtys, Goniada, Glycera.

NEREIS, LINN. ;

Lycoris, Sav., Lam., Johnston;

Spio et Phyllodoce, Delle-Cuiaye.

Trompe grosse, divisee en deux anneaux cylindriques, et garnis de tubercules. Mâchoires arquées, cornées et pointues. Antennes au nombre de quatre, dont les externes grosses et biarticulées, et les mitoyennes petites et subulées. - Branchies représentées par trois languettes charnues pour chaque pied ambulatoire: la première insérée sous le cirrhe supérieur; la seconde sous la rame dos sale et disparoît avec elle; enfin, la troisième est située sous la rame ventrale : c'est l'inférieure. — Pieds formés de deux rames distinctes. - Tête libre, comprimée en dessus. - Yeux au nombre de quatre.-Corps long et presque linéaire.

Genre très-nombreux en espèces, dont beaucoup se trouvent sur nos côtes.

\section{NEREIS FUCATA.}

Sav., Annel., p. 31.-Blairv., Dict., t. XXXIV, p. $43 .-$ Long. 3 pouc. Corps d'un gris cuivreux, formé de cent dix-neuf segmens; le cirrhe supérieur beaucoup plus long que la branchie correspondante; parlie supérieure de la rame dorsale des pieds simplement comprimée.-Côtes de la Manche.

\section{NEREIS MARIONII.}

AvD. et EDw., Litt. Annel., t. I, p. 188, pl. 4 , f: $1,6$. - Long. 6 ponc. Corps fauve, formé de cent quarante segmens; partic de la base des pieds comprise entre le cirrhe dorsal et le dos, élevée en crête arrondie. - Côtes de la V endẻe.

\section{NEREIS PODOPHYILA.}

Sav., Annel., n. 30, n०2.-Long. 6 pouces.-Corps fauve, à reflets cuivreux, formé de cent huit segmens; branchies dont la languette supérieure dépasse les autres, la portion du pied qui supporte a la fois cette languette et le cirrhe supéricur, haute et comprimée en feuille. - Océan.

Nota. Les nombreuses espèces de ce genre étant encore assez mal distinguées, et les auteurs n'étant pas mème d'accord sur les caractères qui peuvent être employés pour les distinguer les unes des autres, nous n'en décrirons pas ici un plus grand nombre, et nous nous contenterons d'énumérer celles que nous avons trouvées dans les divers auteurs.

4. Lobulata, SAv., Annel., p. 30, Aud. et Enw., p. 198, pl. 4, t. V II, VIII.

5. Nereis Folliculata, $\mathrm{S}_{\mathrm{AV}}$, , p. 30, 52.

6. Nereis Heteropoda, Cнаиisso et ExSenhardt, Nov. Act. Bonna, t. X, pl. 24 , f. 2 .

7. Fimbriata, Mullen-W vrM., pl. 8 .

8. Caudata, Delle-Chraye, Mém., t. II, p. 403 ; pl. 28, f. 10,15 .

9. Beaucondrayi, Aod, et Edw., Annel. p. 192, pl. 4, f. 1, 7.

10. Rubida. SAv., p. 32.

11. Agyptia, Sav., p. 31. pl. 4, t. I, pl. 2, f. 1.

12. Nubila, $\mathrm{S}_{\mathrm{Av}}$, p. 32.

13. Pulsatoria, Sav., p. 33.

14. Fulva, Sav., p. 32.

15. Margaritacea, SAv., p. 33.

16. Dumerilii, Aud. et Evw., Annel., p. 196, pl. 4, f. 10,12 .

17. Nuntia, SAv., p. 33, pl. 4, f. 2, reproduite dans l'Icon. et dans le Dict. des Sc. nat.

18. Ventilabrum, Delle - Chraye, Mém., t. II, p. 404 , pl. 28, t. XII et XVII.

19. Coccinea, Delle-Gunay, Mém., t. II, p. 404, pl. 28, t. XI et XVI. 



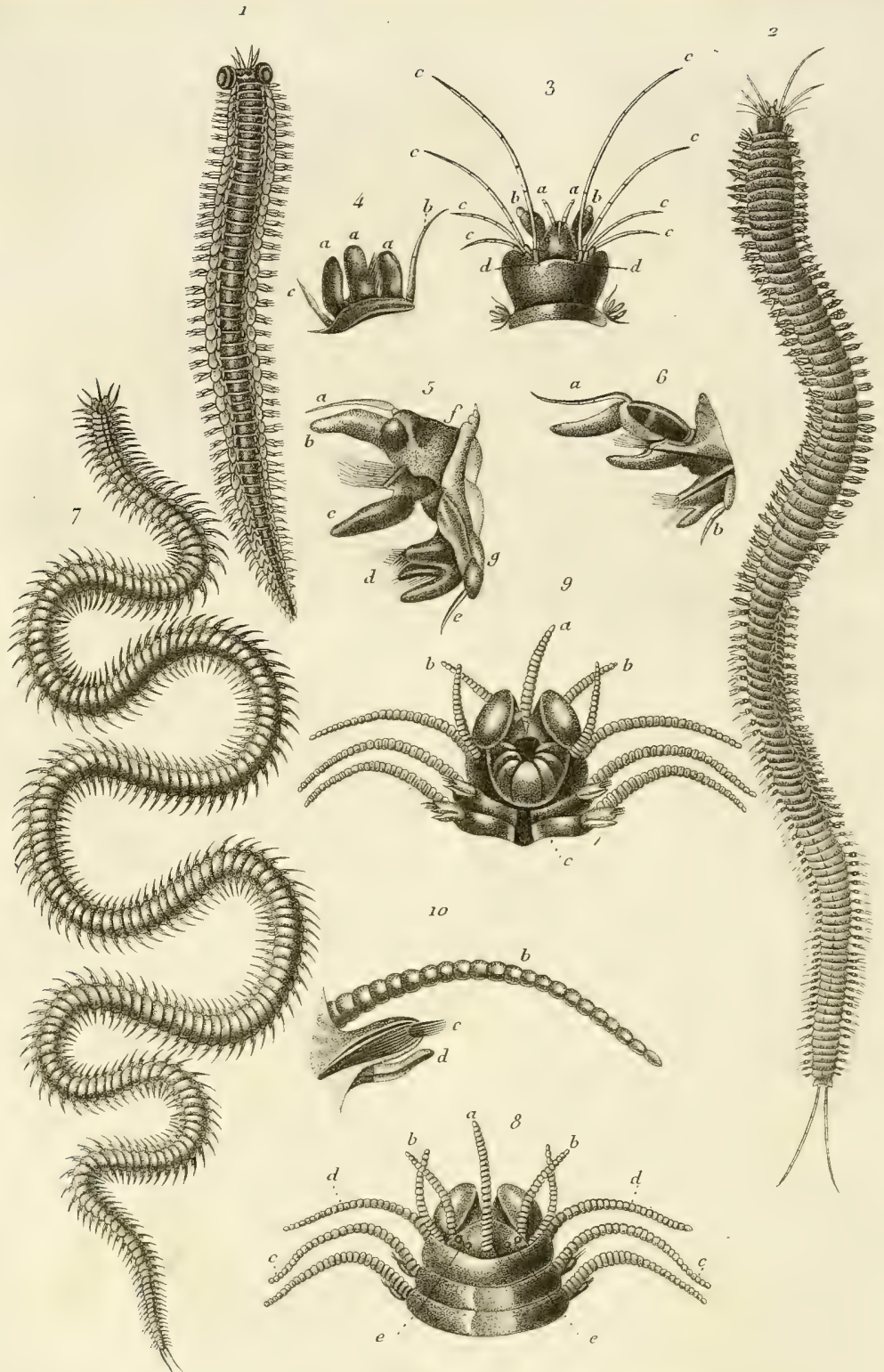

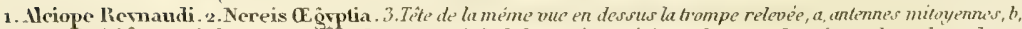
antenne intérieture, $c$, currhes tentaculaures, d, yeux. 4 , pieds de la partie supérieure du corps duméme, abranchues, $b-$ cirrhe superieure, $c$, cirrhe inferieure. 5. pied de la partie moyenne ducorps du méme, a cirrhe superteur, $b, 1$ ene

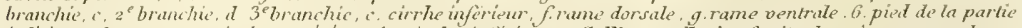

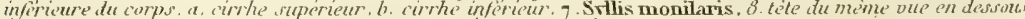

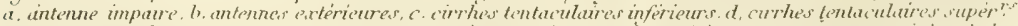

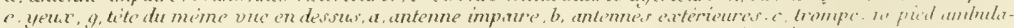

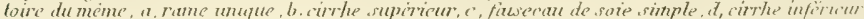


20. Pelagic Lrev., Faun. Suec., més et pointus, - Côtes de Noirmoutior. p. 2996.

Nota. Il faut aussi ajouter à ce genre,

21. Ranzani, Delle-Cuine, Mlém.,

t. III, p. 467, pl. 45, f. 8 et 9 .

22. Quadricornis, Delle-Chiaye,

Mém., t. II, p. 403, pl. 28, f. 9, 14.

23. Edwardsii, Delie - Chinay, Micm.,

t. III, p. 168, pl. 43, f. 12, 20.

24. Aphroditoides, Отнол. Faвr., Faun., p. 296, n² 272.

25. Frontalis, Bosc, art. Vers, t. I, p. 143, pl. 5 , t. V.

26. Viridis, Jonssten, Zool. Journ., t. IV, p. 419.

27. Niccensis, Risso, Eur. mérid., t. IV, p. 416.

28. Gutlata, 5, p. 417.

29. Cirrhosa, t. V, p. 417.

30? Versicolor, Mullen W UnM., p. 104, pl. 6, f. 1-6. Cette espèce aurait, suivant les auteurs, cinq antennes, et devrait alors constituer un nouveau genre ( $P$ haetusa, Minr).

\section{LYCASTIS, Sav.;}

\section{Nereis, Oliv., Fabr., Muller, Delle-} Chiaye.

Trompe forte, armée de deux mâchoires cornées et robustes. - Antennes au nombre de quatre, dont les externes plus fortes que les internes et coniques.-Cirrhes tentaculaires semblables à ceux des Néréides. - Pieds ayant les deux rames presque réunies en une seule, dépourvues de langues branchiales, munis de deux cirrhes subulés et filiformes. - Corps grêle, cylindrique, atténué en arrière.-Tête rebordée en avant et munie de quatre yeux.

\section{LYCASTIS ARMILLARIS.}

Muller W. uris, p.150, pl. 9, f. 1-5, Sav., Annel., p. 45. - Les deux antennes extèrieures grosses et inarticulées; huit cirrhes tentaculaires moniliformes; les cirrhes supérieurs et les deux styles également moniliformes; une seule rame à chaque pied ; les cirrhes inférieurs très-courts. - Mers du Nord.

\section{LYCASTIS BREVICORNIS.}

Aub. et Edw., Litt. Annel., p. 201, 1, pl. 4,6 , f. $6-12$. - Long. 7 pouc. Larg. 3 lig. $\frac{1}{2}$. - Corps grisâtre, de cent-quarante segments; cirrhes supérieurs gron, compriAnv. suivant MM. Edwards et Audouin, les $\mathrm{Ne}$ reis Otto, Ockenii et Blainvillii, de M. Delle-Chiaye, et la N. Incisa, Othon. Fabr.. Faun, y. 295.

\section{SYLLIS, SAV.;}

Nereisyllis, Blainv.; Nereis, Vivian.

Bouche à trompe de grosseur moyenne, partagée en deux anneaux, dont le second, plus petit que l'autre, est plissé à son ori. fice, dont le bord supérieur porte une petite corne dirigée en avant et solide.-Mâchoires nulles. - Antennes au nombre de trois, longues, grêles et moniliformes. Branchies nulles. - Pieds de trois sortes: les premiers, sans soies, formés, de chaque côté, d'une paire de cirrhes tentaculaires; les autres ambulatoires; les derniers formant deux filets terminaux et moniliformes. - Corps linéaire, formé de nombreux segmens. - Tête arrondie et libre en avant, renflée sur les côtés en deux lobes, que l'on peut considérer comme les rudiInens des antennes extérieures.

1. SYLLIS MONILLARIS. (Pl. 2, f. 7-10.) SAv., Annel., p. 44, pl. 4, f. 3.-Dict. Sc. nat., Atlas, art. Vers, pl. 17, f. 2. -Long. 3 pouc. $\frac{\vdots}{2}$. Corps grêle, d'un gris rougeâtre, avec un sillon sous le ventre; yeux en ligne. - Mer-Rouge et peut-être les côtes de France? (Océan):

\section{SYLLIS FULGURANS.}

Edw. et Aud., Annel., p. 207. - Long. 4 pouc. Larg. 1 lig. $\frac{1}{2}$. - Yeux en carré, le premier segment du corps très-petit, taadis que dans l'espèce précédente il est de la grandeur du suivant. - Méditerranée.

Nota. L'on trouve, dans les auteurs, quelques autres espèces qui paraissent devoir être rapportées à ce genre.

3. N. Ornata, BlaInv., Dict., t. LVII, p. 473.

4. N. Cirrhigera, Viviani, Phos. Maris., pl. 3, f. 1, 2.

5. N. Prolifera, Muller, Zool. Dan., t. II, pl. 52, f. 5-9.

6. N. Rosea, Othon Fabr., Faun., p. 301, $\mathrm{n}^{\circ} 284$.

7. Punctata, Mulner, Zool. Dan., t. II, pl. 62.

8. Noctiluca, Lrnv., Faun. Suec., n०2098. 
9. Ruidolphi, Delle-Chiaye, Mém., t. III, p. 476 , pl. 43 , f. 14-19.

10. Tiedmanni, Delle-Guiaye, id., pl. XLII, f. 13-14.

\section{HESIONE, Sav.}

Bouche à mâchoires nulles, la trompe grosse, profonde, de deux anneaux dont le dernier court, à orifice circulaire et sans plis. - Antennes petites et au nombre de quatre, les mitoyennes écartées et les extéricures rapprochées entre elles.- Pieds de différentes sortes; les quatre premières paires. non ambulatoires, sans soies et converties en huit paires de cirrhes tentaculaires très-rapprochés de chaque côté et atlachés à un segment commun, formé par la réunion des quatre premiers segmens du corps; les autres pieds ambulatoires et uniramés. - Branchies nulles. - Cirrhes filiformes. - Corps oblong, formé de peu de segmens. - Tête bilobée. - Yeux au nombre de quatre.

1. HESIONE SPLENDIDA. (Pl. 3, f. 1-5.) Siv., Annel., p. 40, pl. 3, f. 3.-Long. 2 pouc. - Corps gris, à reflets éclatans, formé de dix-huit segmens; pieds au nombre de dix-sept paires, - Mer-Rouge.

\section{HESIONE FESTIVA.}

SAy., Annel, p. 40. - Plus petite que la précédente; corps presque sans refleis; même nombre de segmens et de pieds; deux acicules; soies sans lames mobiles.Méditerranéc.

\section{HeSione PANTHERINA.}

Risso, Eur. mérid., t. IV, p. 418. AND. et Edw. , Litt. Annel., t. I; p. 219 , pl. 5, f. 4.-Long. 2 pouc. Larg. 4 lig.D'un brun rouge, annelée de petiles raies transversales et jaunes; dessous du corps blanc; dix-huit paires de pieds. - Méditerranée.

\section{ALGIOPA, Aud, et Edw.}

Antennes filiformes, subulées, au nombre de quatre; les mitoyennes les plus longues. - Mâchoires nulles. - Cirrhes tentaculairesau nombre de huit, dont la moilié de chaque côté. - Pieds uniramés, d'une seule sorte, portant deux lobes branchiaux et deux cirrhes foliacés. - Corps linéaire, un peu aplati. - Tête très-grosse, dépassant en Jargeur celle du corps.-Yeux très. gros et latéraux.
1. ALGIOPA REYNAUDI.

Aud. et EDw., Litt. Annel., t. I, p. 216, pl. 5, f. 6-11. - Long. 1 pouc. $\frac{1}{2}$ - - Corps formé d'environ cinquante segmens.

Espèce trouvée dans la Mer Atlantique par M. Reynaud.

\section{MYRIANA， SAv.; \\ Nereimyra, BLaINv.}

Bouche formée d'une trompe grosse, de deux anneaux, dont le premier très-allongé et couvert de tentacules fins et courts; le second plissé. -- Mâchoỉres nulles. - Antennes petites, au nombre de quatre, biarticulées.-Branchiesnon distinctes._-Pieds de diffèrentes sortes; des premiers aux quatriènes non ambulatoires, sans soies et convertis en huit cirrhes tentaculaires; les autres ambulatoires et uniramés. - Corps très-étroit et linéaire, composé de segmens très-nombreux. - Tête rétrécie en arrière, élevée en cône sur le front. Yeux au nombre de quatre, peu distincts.

\section{1. myriana LONGISSima.}

Sav., Arinel., 41. - Long. 27 pouc. Larg. 1 lig. $\frac{1}{2}$ - - Corps d'un blanc bleuâtre, formé de plus de trois cents segmens. Côtes de l'Océan.

Nota. Il faut aussi, suivant MM. Audouin et Edwards, rapporter à ce genre la Nereis Pennigera de Montagu, Trans. Linn. Soc., t. IX, p. 3, pl. 6, f. 3.

\section{PHYLLODOCE, Sav.; Eulalia et Etiona, SAV.; Nereiphylla, Blainv.}

Antennes ordinairement au nombre de quatre, courtes, divergentes, écartées, coniques, de deux articles. - Bouche sans mâchoires, à trompe grosse formée d'un seul anneau claviforme, dont l'orifice est entouré d'une rangée de petits tentacules. - Branchies nulles. - Pieds de deux sortes - les quatre premières paires converties en huit cirrhes tentaculaires groupés sur les côtés de deux segmens courts formés par la réunion des quatre premiers segmens du corps, les autres ambulatoires et uniramés. - Cirrhes tentaculaires charnus, souvent allongés et subulés. - Corps linéaire, peu déprimé, à segmens très-nombreux. Tête libre, élevée en un cône sur lequel sont insérées les antenues. - Yeux latéraux. 

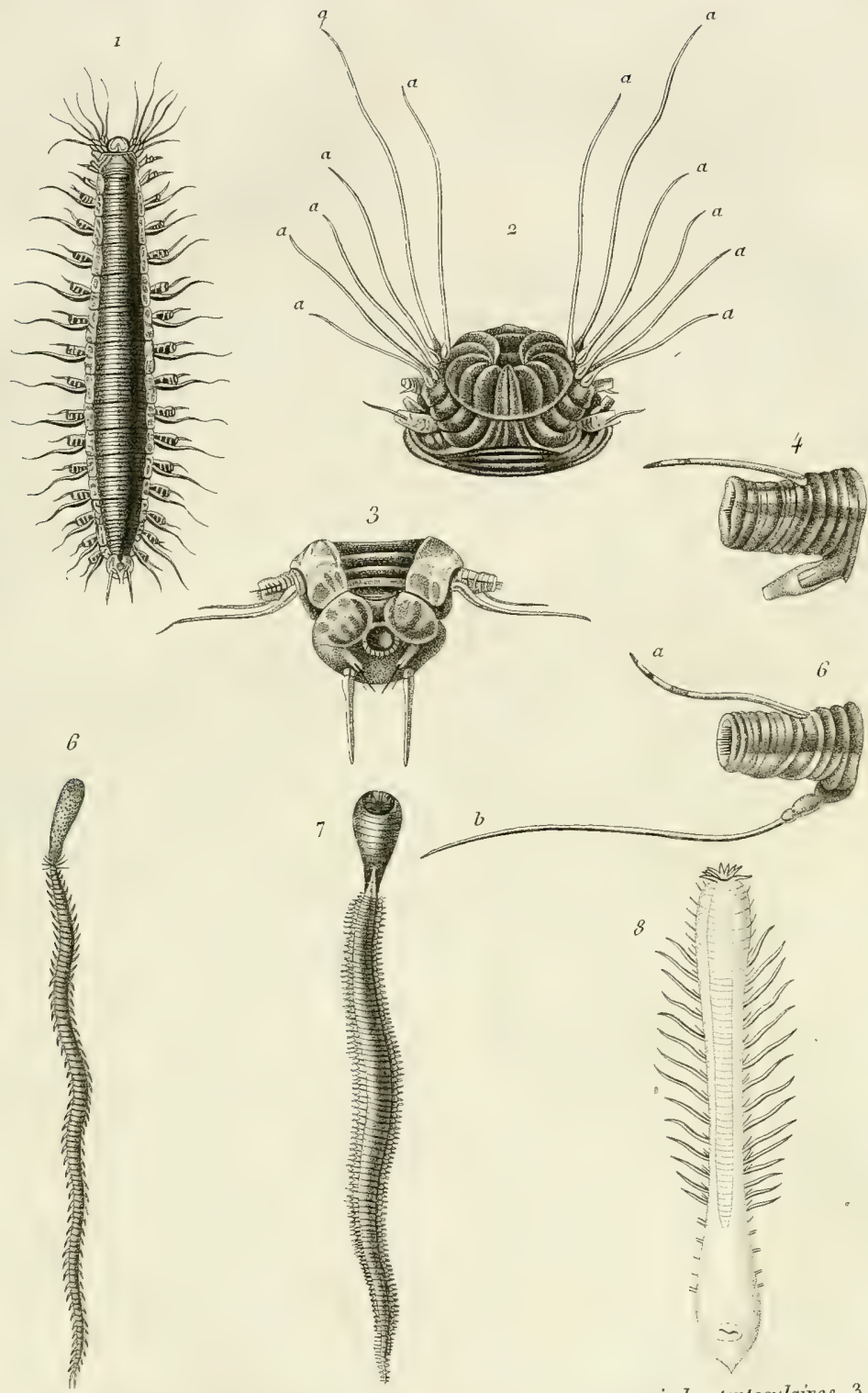

8 dernier anneau et anus avec dernicre paire de pieds, 4, $1^{\text {ere }}$ paire de pieds, 5, pied moyen, a, cirrthe inféricur, 6, cirrhe supérieur 6, Phyllodoce Claviger, 7 - Glycera Meckelii, 8, ophelia Bicomis. 



\section{PHYLIODOCE LAMINOSA.}

Annel., p. 43. - Aud. et Evw., Annel., t. I, p. 222, pl. 5, f. 1-8.-Long. 18 pouc. Larg. 3 lig. - D'un brun verdâtre irisé ; les cirrhes foliacés, d'un vert éclatant; qua. tre antennes; cirrhes tentaculaires très-développés pour la plupart. - Côtes de l'O. céan el de la Méditerranée.

2. Phyllodoce clavigera. (Pl. 3, f. 6.) Aud, et Enw., Litt. Annel., t. I, p. 226, $\mathrm{n}^{\circ}$ 2, pl. 5, f. 9-13.-Long. 4 pouc $\frac{1}{2}$. Larg. $\frac{1}{2}$ lig. - Trompe renflée en massue, dont la partie antérieure couverte de papilles nombreuses et serrées; corps d'un vertbrillant; cing antennes. - Côtes de la Manche et de l'Océan.

\section{PHYLLODOCE GERVILLT.}

A vo. et Evw., Annel., t. I, p. 228, n$^{\circ} 3$. - Quatre antennes; cirrhes tentaculaires très-courts, - Ressemble du reste à la précédente. - Manche.

\section{PHYLLODOCE GEOFFROY.}

Aud. et Enw., Litt, Annel., t. I, p. 228, n० 4. - Long. 4 pouc. - Jaune, avec des lignes transversales interrompues et noirâtres; quatre antennes; deux cirrhes tentaculaires très-courıs de chaque côté de la tête; filets stylaires très-courts. - Océan. Côtes de La Rochelle.

\section{PHYLLODOCE? VIRIDIS.}

Muller, Wurm., p. 156, pl.11.-Eulalia viridis, Sav., Annel., p. 45. - La trompe longue et tentaculée; quatre antennes; corps déprimé ; lamelles des pieds lanceolées. - Cốtes du Groenland.

\section{PHYLODOGE? MACULATA.}

Mullen, Wurm., p. 456, pl. 10.-Eulatia maculata, SAv., Annel., p. 45.Trompe longue et tentaculée; quatre antennes; corps convexe; lamelles des pieds presque en cour; vert, avec des taches noires. - Côtes du Groenland.

\section{PHYLLODOCE? FLAVA.}

Othon Fabr., Faun. Groen., p. 299, no 282. - Etiona Flava, SAv., p. 45.Trompe avancée; quatre antennes; corps déprimé; lamelles des pieds oblongues; ovales corps jaune. — Groenland.

\section{PHYLLODOCE? IONGA.}

Othon Fabr., Faun., p. 300. - Corps très-allongé; couleur très-variable; bouche avancée en massue; rames bifides; cirrhes tentaculaires coniques et terminés en mamelons. - Côtes du Groenland.

Nota. Enfin il faut peut-être aussi rapporter à ce genre la Nereis crassa de Muller et de Linné.

\section{NEPHTYS, Cuv.}

Antennes au nombre de quatre, à peu près égales, biarticulèes. - Trompe formée de deux anneaux; le premier très-long, claviforme; le second très-court, à orifice longitudiual.- Mâchoires petites; courbes et cornées, renfermées dans la trompe. Branchies nulles sur les trois premiers segmens, consistant pour. les autres en une languette charnıe attachée par sa base au sommet de la rame dorsale. - Pieds ambulatoires à deux rames, les stylaires réunis en un seul filet terminal.-Cirrhes supérieurs point saillans; les inférieurs en mamelons obtus. - Corps linéaire, formé de segmens nombreux.-Tête libre et peu convexe. - Yeux peu distincts.

\section{NEPITHYS HOMBERGH.}

Long. 2 pouc. $\frac{1}{2}$. - Corps tetraèdre, formé de cent à cent trente-un segmens; couleur d'un blanc argenté et irisé; une ligne rougeâtre sur la ligne médiane; branchies rouges. - Côtes de l'Océan.

Nota. Il faut ajouter à ce genre :

2. Nereis splendida, BlaIvv., Dict., t. XLIII, p. 439 ,

Et 3. N. Scolopen droides, Delle-Cerraye, Mém. , t. II, p. 401, pl. 28, f. 8-13.

GONIADA, Aud. et Edw.

Antennes très-courtes, au nombre de quatre. - Trompe très-longue, portant à sa face inférieure deux rangées de petites pièces cornées disposées en chevrons: Mấchoires tantôt très-petites et au nombre de deux, el tantôt nulles. - Pieds formés de deux rames écartées. - Corps allongé, presque cylindrique, grêle, formé de segmens nombreux qui paraissent chacun être divisé en deux anneaux. - Tête conique.

\section{GONIADA EMERTTA.}

Aud. et Edw., Annel., t. I, p. 247, pl. 6, f. 1-4. - Long. 9 pouc. - Pas de mâchoires; trompe hérissée de tubercules; onze chevrons à chaque série. - Méditerranée.

Nota. Les mêmes naturalistes décrivent, sous le nom de Goniade à chevrons, une seconde espèce de la Nouvelle-Hollande, 
qui diffère de la précédente par l'existence des mâchoires, et les chevrons qui sont au nombre de treize à seize.

\section{GLYCERA, SAV.;}

\section{Lumbricas, Delle-Ghiye.}

Antennes au nombre de quatre, biarticulées.-Trompe longue, cylindrique, d'un seul anneau claviforme, sans plis ni tentacules. - Branchies ayant ordinairement la forme de deux languettes charnues, oblongues, attachéesà la face antérieure des deux rames, quelquefois nulles. - Pieds ambulatoires. - Cirrhes supérieurs en forme de mamelons coniques, les inférieurs très-peu saillans. - Corps linéaire, convexe, formé de segmens très-nombreux. - Tête èlevée en cône. - Yeux peu distincts.

\section{GLYGERA UNICORNIS.}

SAv., Annel., p. 37, 1.-N. Alba? MulLER, Zool. nat., t. II, pl. 62, f. 6-7.Long. 2 pouc. - Corps d'un jaune bronzé, formé de cent six segmens; pas de mâchoires; pieds roussâtres. - Palrie inconnue.

\section{2. gLycera MECKelit. (Pl. 3, f. 7.)}

Aud. et Evw., Lilt. Annel., t. I, p. 241. -Long. 4 pouc. - Jaune à reflets métalliques; corps formé de deux cent cinquante segmens; branchies très-développées. Océan.

\section{GLYCERA ROUXII.}

Aud, et Edw., Annel., t. I, p. 242. -Ressemble à la précédente, mais pas de branchies; couleur d'un brun cuivreux. Méditerranée.

Nota. Il faut aussi rapporter à ce genre:

4. Glycera Dubia, Buarnv., Dict, t. XLIII , p. 484.

5. Polygona, Risso, Eur. mérid., t. IX, p. 417.

Et 6. Syphonostoma, Delle-Guhaye, MIém., t. II , p. 413, pl. 28, f. 21.

\section{ARICITES.}

Caractères. Pieds avec des cirrhes distincts. - Corps non muni d'élytres et formé de segmens généralement semblables entre eux. - Branchies nulles ou représentées par de simples languettes, - Tête rudimentaire, très-peu distincte.

Genres: Artcia, Aonis, Ophelia, Cir. rhatulus.
ARICIA, SAV.;

Lombricus? Muller; Scolopus, Buarwy.

Antennes quelquefois nulles, quelquefois au nombre de quatre, très-petites, biarticulées et subulées à l'extrémité.-Trompe inarticulée, courte, charnue, sans aucun appendice. - Mâchoires nulles. - Branchies consistant, au plus, en une languette charnue sur les pieds, qui s'étendent de la dix-septième à la vingt-deuxième paire, et en deux languettes sur ceux qui s'étendent après la vingt-deuxième. - Pieds de deux sortes, relevés sur le dos; ceux des vingt à trente premières paires formés de deux rames de formes différentes, et ceux des au tres, de deux rames de formes presque sem. blables.-Corps linéaire, plat en dessus, en demi-cylindre en dessous, formé de segmens courts et nombreux. - Tête petite, conique et libre. - Yeux peu distincts.

\section{PREMIÈRE DIVISION.}

Quatre antennes.

\section{(Aricia proprement dits.)}

1. aricia sertulata.

Sav., Annel.p. 36, no 1.-Long. 10 pouc. - Gris, corps frangé sur les côtés, du vingtun au vingt-septième segment. - Côtes de l'Océan.

\section{DEUXIVME DIVISION.}

Pas d'antenues.

\section{(Venadis.)}

\section{ARICIA CUVIERI.}

Aud. et Edw., Litt. Annel., t. 1, p. 258, pl. 7, f. 5-13. - Long. 10 pouc. - Fauve; pieds à rame ventrale en forme de crête, jusqu'au vingt-deuxiẻme segment.-Côtes occidentales de la France.

\section{ARICIA LATREILLEI.}

Aud. et Edw., Litt. Amel., t. I, p. 259. - Long. 5 pouc. - Pieds à rame ventrale grande et comprimée, au nombre de vingthuit paires. - Océan.

Nota. Suivant MM. Edwards et Audouin, l'on doit aussi placer dans ce genre une Annelide rapportee par Muller à celui de Lumbricus, sous le nom spécifique d'Armiger', et sur lequel M. de Blainville a on genre Scolopus (Dict. Sc. nat.). 


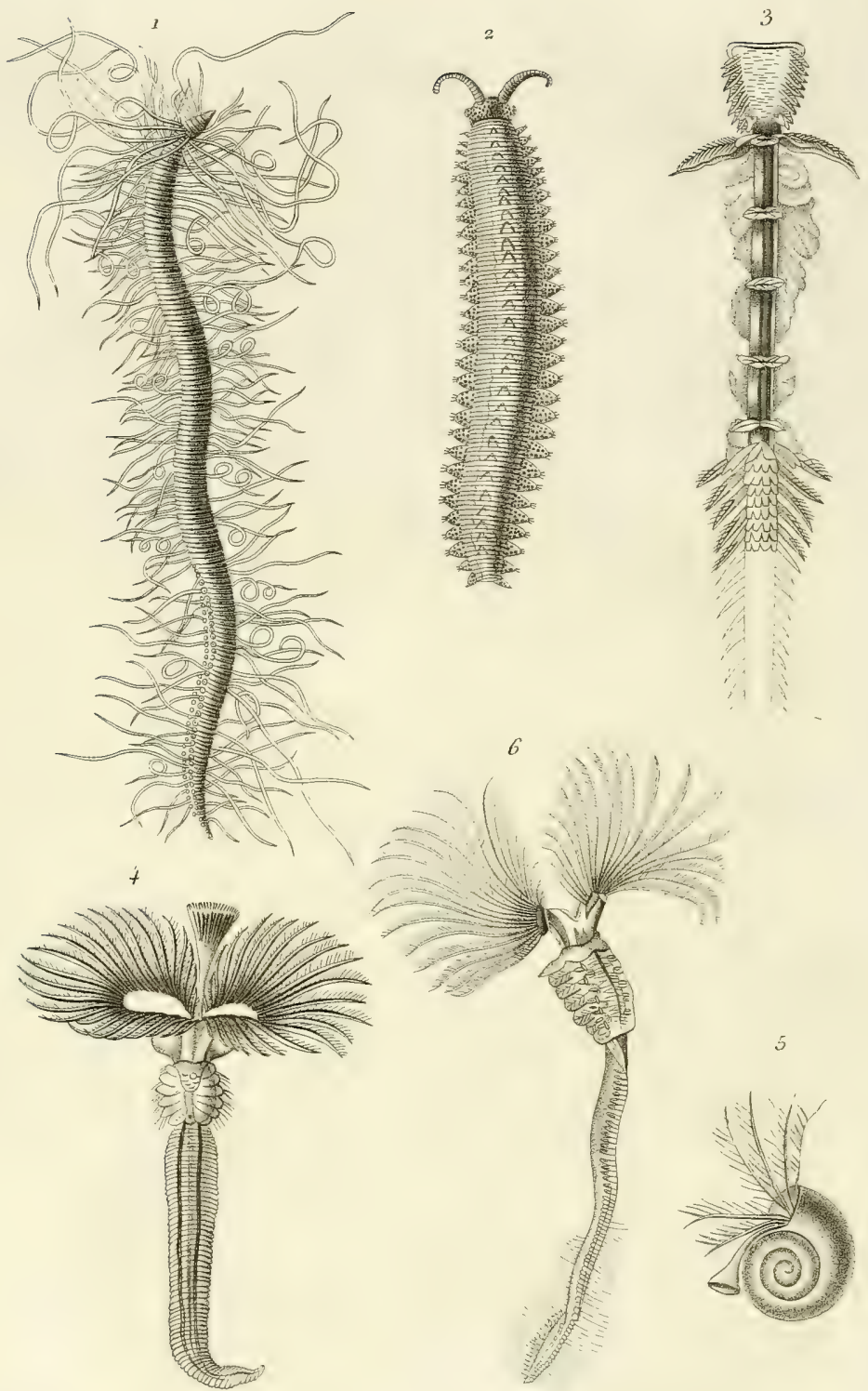

1. Cimphatula Lamarcliii .

4. Serpula Coutortuplicata.

2. Peripata Juliformis .

5. Serpula Spirorbis.

3. Chetopteus Pergamentaceus.

6. Sabella Protulata. 
AONIS, SAV.;

Scolelepis, Blainv.; Nereis? Othon FanR.; Lumbricus, Muller.

Trompe forte, courte, hérissée de petites papilles. - Antenne unique et rudimentaire. - Branchies nulles. - Pieds similaires pourvus d'un seul cirrhe, et parta. gés en deux. - Rames munies d'un lobe lamelleux. - Première paire de pieds rudimentaires et tuberculeux. - Pas de cirrhes tentaculaires. - Corps linéaire, allongé, un peu déprimé. - Tête distincte, très-petite.

\section{AONIS FOLIOSA.}

Avo. et Edw., Litt. Annel., t. I, p. $263, n^{\circ} 1$. - Soies de la rame supérieure des pieds très-fines et acérées; celles de la rame ventrale plus grosses et obtuses. Environs de La Rochelle.

Nola. Il faut rapporter à ce genre:

1. La Nereis cœca, OтноN Fab., Faun. Groent, p. 304, n० 287.

2. Lumb. Squammatus, Muller, Zool. Dan., t. IV, pl. 155, fig. 1-5.

\section{OPHELIA, Sav.}

Trompe courte, entourèe de tentacules plissés, pourvue supérieurement d'un palais charnu et prolongé en forme de côte dans l'intérieur de la trompe, et dentelée à son orifice. - Mâchoires nulles. - Antennes au nombre de quatre, très-petitcs, biarticulées et subulées à l'extrémité. - Branchies nulles. - Pieds divisés en deux rames peu saillantes, et ne présentant pas à l'extrémité de lobe terminal membraneux. Un cirrbe ventral, filiforme, sur les quinze segmens intermédiaires. - Corps cylindrique, composé de peu d'anneaux. - Tête réunie aux deux premiers segmens, bilobée en avant.

1. ophelia biconts. (Pl. 3 , f. 8.)

Long. 2 pouc. - Corps gris, formé de trente segmens; trompe garnie de qualorze ıentacules; soies dorées. - Côtes de l'Océan.

Notr. Il faut peut-être aussi rapporter à ce genre le Nais IIoratii, Delle-Cuiaye, Mém., etc.

\section{CIRrhatuluS, Lam. ;}

Lumbricus, Stroes., Othon Fabr.;

Cirrhatulus et Cirrhinereis, BuAnv.

Bouche inférieure portant une trompe petite, membraneuse, dont l'orifice est longitudinal, mais dépourvue de mâchoires et de tentacules. - Antennes nulles. - Pieds ambulatoires, nuls sur les deux premiers segmens du corps, comprimés et formés de deux rames sur tous les autres. - Rame dorsale portant au-dessus du tubercule sétifère un appendice filiforme très-long, grêle, cylindrique et charnu. - Des branchies semblables aux cirrhes. - Corps cylindrique, grêle, formé d'anneaux nombreux. - Tête peu distincte, représentée par un petit tubercule conique.

\section{PREMIÉRE DIVISION.}

\section{(Cirrhatulus proprement dits.)}

Branchies filiformes, insérées sur la partie dorsale de l'un des segmens de la partie antérieure.

1. cirriatulus cirratus. (Pl. $4, \mathrm{f} .1$. ) Oтhon Fab., Faun. Groenl., p. 281, f. 5. - Borealis, Laır., An. sans vert., t. V, p. 302 .

a Cet animal, dit Lamarck, long de deux à trois pouces, et de la grosseur d'un lombric terrestre mćdiocre, est remarquable par ses cirrhes latéraux très-longs, et par les deux paquets antérieurs d'autres cirrhes aussi très-longs, qui s'avancent comme deux faisceaux de tertacules. Au-dessus des cirrhes latéraux, deux rangées d'épines courtes (quatre sur chaque anneau) les distinguent aussi éminemment. Les segmens des extrémités sont sans cirrhes et sans épines.; celui qui est postérieur est teminé par un anus. " La rame ventrale des pieds n'a qu'une soie unique. - Mers du Nord.

\section{CirRhatules hamarckiI.}

Aud, et Edw., Litt. Annel., p. 271, pl. 7, f. 1-4. - Long. 3 pouc. - Corps formé d'environ deux cent trente segmens; filamens branchiaux correspondant aux pieds de la septième paire.-Iles Chausay, côtes de France.

Il faut aussi rapporter à cette division :

3. C. Fuscescens, Johnston, Edimb. Phil. Journ., t. XIII, p. 318.

4. C. Flavescens, id.

5. Tentaculata, Montagu, Trans.: Linn. Soc., t. IX, pl. 6, f. 2.

\section{DEUXILNE DIVISION.}

(Cirrhinereis, Buarvy.)

Branchies filiformes, insércies sur le dos. 
Il faut rapporter à cette division deux espèces encore très-peu connues : l'une est des côtes de France, l'autre de l'Ámérique du Nord.

6. C. Bellavistie, Blainv., Dict. Sc. nat., t. LVII, p. 481.

7. C. Faligera, id.

\section{PFRIPATTTES.}

Caractéres. Pieds seulement munis de soies proprement dites. - Corps non muni d'ẻlytres, formé de segmens semblables les uns aux autres.-Branchies nulles.-Tête bien distincte.

Genre : Peripatus.

\section{PERIPATUS, GuILING.}

Antennes très-grosses et longues.-Bouche inférieure munie d'une petite trompe et de mâchoires très - développées. Pieds saillans, sans cirrhes, et garnis seulement de soies. - Corps presque cylindrique, divisé en segmens peu nombreux partagés chacun en plusieurs anneaux. - Tête bien distincte. - Yeux représentés par un gros tubercule de chaque côté de la tête.

1. peripatus iulforms. ( $\mathrm{Pl} .4, \mathrm{f}, 2$. )

Guilding, Zool. Journ., t. II, pl. 14, f. 1.-Isis, t. XXI, pl. 11. Aud. et Edw., Annel., t. I, p. 276, pl. 8, f. 5-7.-Long. 2 pouc. $\frac{1}{2}$. - Corps granuleux. - Cette espèce a été trouvée par M. Lacordaire dans la rivière d'Approuague, près de Cayenne; elle habite dans la vase, sur le bord des eaux jaunâtres. M. Lansdown Guilding l'a observée le premier à la Jamaïque.

Nota. M. Mac-Leay considère ce genre (Zool. Journ., t. IV, p. 278) comme formant le passage entre les Iules de la classe des Myriapodes et celle des Annelides.

Nota. Suivant M. Gervais (Ann. Soc.
Ent., t. V, XV), M. le professeur de Blainville connaîtrait une autre espèce de ce genre venant du cap de Bonne-Espérance. D'après le même, ce savant formerait de ce genre une classe intermédiaire entre les Myriapodes et les Chétopodes (Annelides à soies), et la nommerait Malacopodes.

\section{GHETOPTERITES.}

Caractères. Pas de cirrhes distincts. Corps sans tête. - Pieds saillans, munis d'appendices très-développés et membraneux.

Genre : Chetopterus.

\section{CHETOPTERUS, Guv.}

Antennes nulles ou représentées par deux petits tubercules. - Bouche insérée sous un voile marginal, n'offrant ni trompe ni mâchoires. - Pieds saillans, de quatre sortes; les premiers composés d'une seule rame en forme de cornet; tous les autres de deux; la seconde paire de la seconde espèce est développée, et leur rame dorsale présente l'aspect d'une aile.-Corps long, un peu aplati. - Tête non distincte, indiquée seulement par un renflement large et aplati.

Ces Annelides habitent des tubes longs et épais, ayant l'aspect de parchemin et recouverts à l'extérieur de sable fin. L'on n'en connoît qu'une seule espèce.

1. Che ropterus pargahentaceUs. (PI. 4 , fig. 3.)

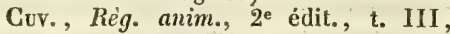
p. 208. - Aud. et EDw., Annel., t. I, p. 281 , pl. 8 , f. $1-4$. - Long. 7 pouc. Corps étroit., élargi en avant, où il a environ dix lignes; pieds de la première paire au nombre de huit; ceux de la seconde de deux, quatre à la troisième, et une cinquantaine de la dernière sorte. Mer des Antilles. 


\title{
ANNLIDES TUPTCOLES,
}

CUV.

\author{
PARTIE DES SERPULÉES, SAV.; \\ HÉTÉROCRISIENS ET SIPHOSTOMES, BLAINV.
}

Les Tubicoles ont de grands rapports avec l'ordre précédent; leur manière de vivre est cependant différente; ici, vie sédentaire ; là, mouvement continuel et changement perpétuel de lieu. Les Annelides de cet ordre habitent, les uns dans des tubes calcaires et homogènes, résultant de leur transsudation; les autres dans des fourreaux formés de grains de sable et de débris de coquille. Ces animaux sont trèsvoisins des mollusques; et quelques genres, que plusieurs auteurs y avaient placés, tels que les Dentales, les Arrosoirs, etc., sont aujourd'hui rejetés parmi ces derniers; mais si leur mode d'habitation aide à ce rapprochement, il présente cependant aussi un caractère différentiel très-important : c'est qu'aucun d'entre eux n'adhère a son tube par des muscles, tandis que la coquille des mollusques est attachée, par ce moyen, au corps de l'animal. - La tête n'est pas sensiblement distincte du reste du corps, et l'on ne retrouve ici ni mâchoires, ni yeux, ni trompe rétractile; les appen. dices, mous, sont rassemblés près de l'endroit où l'analogie fait placer la tête. - Les pieds de deux sortes et armés de soies à crochets, chez les Siphostomes. Ils sont nuls et remplacés par des soies simples; les ILermelles ont seules des cirrhes aux pieds, et encore il n'y en a qu'un sur chacun.

Nous partagerons cet ordre en cinq groupes : les Serpulites, les Hermellites, les Terebellites, les Clyménites, les Arénicolites.

\section{SERPULITES.}

Caraetères. Branchies visibles, au nombre de deux; rames ventrales de deux sortes; celles de la première paire de pieds portant des soies à crochets; celles des sui- vantes ayant des soies subulées; pas de ten: tacules.

Genres: Serpula, Sabella.

SERPULA, LINNÉ;

Penicillum marinum, SEBA;

Terebella Serpula, Amildg., Gmed. ;

Galeolaria et Vermilaria, LAM.

Bouche antérieure, saillante, transversale, sans tentacules, à lèvres plissées et égales. - Branchies au nombre de deux, portées par le premier segment; grandes, ascendantes, opposées face à face, profondément divisées, à divisions filiformes ou sétacées, comprimées; disposées, sur lebord supérieur de leur pédicule commun, en peigne unilatéral ou en éventail; obscurément articulées, et garnies sur leur côté interne $d^{2} u n$ double rang de barbes mobiles qui répondent aux articulations, et sont ellesmêmes faiblement annelées. La première division de chaque branchie, consistant en un filet imberbe séparé plus profondément que les autres; les deux filets souvent inégaux, le plus long se terminant alors par un disque propre à servir d'opercule. Pieds nuls au premier segment, ceux des autres de trois sortes: les premiers a rame dorsale petite, munie d'un faisceau de soies subulées, sans rame ventrale, ni soies. à crochets; seconds pieds et suivans, jusques et compris les septièmes, à rame dorsale pourvue d'un faisceau de soies subulées, et à rame ventrale garnie d'un rang de soies à crochets; huitièmes pieds et tous les suivans, compris la dernière paire, à rame ventrale pourvue d'un faiscean de soies subulées, et à rame dorsale garnie d'un rang de soies à crochets. Soies subulées tournées toutes en dehors, 
fines et légèrement arquées à la pointe, trèsaiguës; soies à crochets très-courtes et trèsminces, dentées en manière de scie.-Corps allongé, rétréci d'avant en arrière, formé de segmens nombreux moins distincts en dessus qu'en dessous, et serrés de plus en plus jusqu'à l'anus, qui est petit et peu saillant ; le premier segment tronqué obliquement pour l'insertion des branchies, mince et dilaté à son bord antérieur, compose, avec les sept anneaux suivans, une sorte de thorax revêtu en dessous d'un écusson membraneux, dont les bords ondulés se replient librement vers le dos, et dont la face présente les sept premières paires de pieds, qui ont aussi leurs soies subulées repliées vers le dos; les pieds de la première plus écartés. - Animal contenu dans un tube naturel, fixé, ouvert à un seul bout, de substance calcaire.

Les serpules ont l'estomac membraneux, peu dilaté et peu distinct; l'intestin est presque droit et dépourvu de cæcums.

\section{PREMIERE DIVISION.}

\section{(Serpula Simplices, SAV.) (Serpula, Buainv.)}

Branchies conformées en éventails, susceptibles de se rouler en entonnoir ou en demi-cornet; les deux divisions imberbes, inégales, dissemblables; la plus courte filiforme ou peu renflée ; la plus longue insensiblement épaissie de la bosse au sommet, et terminée par un disque operculaire. Thorax à écusson membraneux, obtusément triangulaire; les deux premiers pieds situés aux deux angles supérieurs de l'écusson, très-écartés; ceux des six paires suivantes rapprochés graduellement de la ligne moyenne du corps.

1. SERPULA CONTORTUPLICATA. (Pl. 4, f. 4.) Linv., Syst. nat., 1, part. 2, p. 1269,

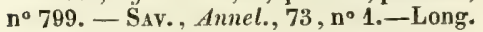
$15 \mathrm{lig}$. - Corps formé d'environ quatrevingt-quinze segmens d'un blanc rougeâtre ; branchies d'un rouge vif, ayant trente-deux digitations comprimées, garnies de barbes très-serrées, et pourvues en outre d'un petit filet terminal; le disque operculaire en entonnoir, strié en rayons et crénelé sur les bords; tube demi-cylindrique, strié transversalement, contourné d'une manière irrégulière. - On trouve souvent celte espèce dans l'Océan, attachée aux coquilles.

\section{SERPULA VERMICULARIS.}

LinN., Syst. nat., t. I, part. 2, p. 1267. n. 805. - Branchies ayant chacune huit ou neuf digitations; opercule en massue avec deux pelites cornes; tube grêle et presque lisse.

\section{SERPUlA PORRECTA.}

Othon Fabr., Faun., p. 378, n³73. Espèce de petite taille; branchies courtes, offrant trois digitations; opercule orbiculaire; tube spiral à la base, uni, ascendant, couleur d'un rouge sanguin. - Mer du Nord.

4. SERPULA SPIroris. (P1. 4, f. 5.)

Muller, Zool. Dan., part. 3, pl. 86, f. 1-6. - Nautiloides, Lan., An. sans vert., t. V, p. 359, n० 1.-Petite espèce; branchies à trois digitations pinnées, à barbes grandes et écartées; un disque en forme d'ellipse à l'extrémité du filet operculaire; tube remarquable, ayant la forme d'un planorbe, c'est-à-dire formant un spiral régulier. Cette coquille sert de type au genre $S$ pirorbis de Lamarck.

Nota. C'est encore dans cette division qu'il faut placer la $S$. Granulata d'Othon Fabricius.

\section{DEUXIÈME DIVISION.}

\section{(Serpulce Cymospira, SAY.) \\ (Cymospira, Blatnv.)}

Branchies en forme de peigne, à un seuI côté, et en spirale; divisions sans barbe; au nombre de deux; l'une courle et pointue; l'autre épaisse à la base, et terminée par un disque operculaire. - Segmens formant l'espèce de thorax portant un écusson en triangle obtus. - Les deux premiers pieds très-écartés; les six suivans se rapprochant graduellement.

\section{SERPULA GIGAVTEA.}

Pallas, Misc. Zool., p. 139, pl. 10. f. 2 10.-Animal, Flower, Hore, Lect. comp. anat., t. II, pl.1.-Long. 5 pouc.-Corps formé d'environ cent quarante segmens; branchies à divisions très-nombreuses, terminées chacune par un filet crochu; elles sont contournées six ou sept fois sur ellesmêmes ; division operculaire grosse; disque elliptique, offrant au bord postérieur un tubercule à deux cornes rameuses; talu mince et irrégulier.-Mers des Antilles.

Nota. A celle division se rapportent les $S$. Bicornis, Abildg., Schr, der Berl. Naturf, 
t. IX, p. 138, pl. 3, f. 4, et Stellata id., f. 5. Toutes les deux sont des Antilles c'est peut.être aussi ici qu'il faut placer le genre Magilus, de Denys Montfort. M. Sowerby a décrit une belle espèce fossile de ce genre; sous le nom d'Ellipticus, dans son Genera of recent and fossil shells, n'21.

\section{TROISIENNE DIVISION.}

$$
\begin{gathered}
\text { (Serpula Spiramella, Sav.) } \\
\text { (Spimella, Buarnv.) }
\end{gathered}
$$

Branchies contournées en spirale, en peigne d'un côté. La division imberbe de chacune pointue, et également courte.Segmens dits thoraciques, à écusson membraneux et peu rétréci à la partie postérieure. - Les sept premières paires de pieds.

\section{SERPUIA BISPIPAIIS.}

$\mathrm{S}_{\Delta \mathrm{v}}$, , Annel., p. 75. - Urtica marina singularis, SEв., Thes., t. I, p. 45, pl. 29, f. 1, 2.-Long. 3 pouc. $\frac{x}{2}$. - Corps formé de cent trente-quatre segmens; branchies formant neuf tours de spirale, à divisions extrêmement nombreuses, et garnies de barbes fines et serrées, et terminées par un fil crochu. - Cette espèce a été rapportée par Péron et Lesueur, et vient probablement des côtes de la Nouvelle-Hollande. Elle a servi de type a M. de Blainville pour son genre Spiramella.

\section{QUATRIEME DIVISION.}

Pédoncule des branchies contourné en spirale. - Bouche entièrement dénuée de tentacules.

\section{(Helena, Mrnr.)}

\section{SERPULA GRECA.}

Brullé, Expéd. sc. de Morée, an. art., p. $399, \mathrm{n}^{\circ} 2$, pl. 53, f. $2 .-$ Long. 2 pouc. - Corps brun, rétréci en arrière, formé de segmens très-nombreux, garni sur les côtés de faisceaux de poils; écusson presque carré; branchies disposées sur un seul rang; tube presque comme dans la Serpula Contortuplicata; il est grisàtre, enroulé irrégulièrement contre les rochers et sur les autres corps marins ; il est cylindrique, très-faiblement et inégalement strié en arrière. - Cette espèce se trouve en Morée, sur la presqu'île de Métana.

Nota. L'on connoit encore les tubes d'un grand nombre d'espèces de ce genre; mais leur habitat étant inconnue nous n'en parleróns pas ici; nous dirons seulement que M. de Lamarck a formé sur quelquesunes d'entre elles les genres Galaolaria et Vermilaria.

SABELLA, LiNn., SAV.;

Tubularia., Shaw., Othon Fabr., Muller; Pinicillus, Rondelet; Spirographis, Viviani; Amphitrita, Montagu, Lam., Leach.

Bouche exactemént antérieure, peu saillante, transverse, située entre les branchies, qui lui fournissent inférieurement une lèvre auxiliaire membraneuse, avancée, plissée et bifide en-dessous. - Point de tentacules. - Branchies au nombre de deux portées par le premier segment, grandes, ascendantes, opposées face à face, profondément divisées, à divisions nombreuses, minces, linéaires ou sétacées, disposées sur le bord supérieur du pédicule commun, en éventail ou en peigne unilatéral, obscurément articulées et garnies sur leur Iranche interne d'un double rang de barbes cylindriques et mobiles, qui répondent aux articulations et sont elles-mêmes faiblement annelées. - La division postérieure de chaque branchie consistant en un filet imberbe séparé plus profondẻment que les autres et situé plus intérieurement : les deux filets à peu près égaux, courts et pointus.Premier segment sans pieds, les autres en ayant de trois sortes. - Les premiers pieds à rame dorsale, petits, munis d'un faisceau de soies subulées, sans rame ventrale ni soies à crochets. - Seconds pieds et suivans, jusques et y compris les huitièmes ou neuvièmes, a rame dorsale pourvue d'un faisceau de soies subulées, et à rame ventrale garnie d'un rang de soies à crochets. -Neuviemes ou dixièmes pieds et tous les suivans, compris la dernière paire, à rame ventrale pourvue d'un faisceau de soies subulées, et à rame dorsale garnie d'un rang de soies à crochets.-Soies subulées, tournées en dehors, un peu dilatées et coudées vers la pointe, qui est finement aiguë.Soies à crochets, très-courtes, minces, à courbure élevée, très-arquée, terminée inférieurement par une longue dent. - Corps linéaire, droit, rétréci seulement vers l'anus, qui est petit et peu saillant, composé de segmens courts et nombreux, qui con- 
stituent sous le veutre autant de plaques transverses, divisées, à l'exception des huit ou neuf premières, par un sillon longitudinal; le premier segment tronqué obliquement d'avant en arrière, pour l'insertion des branchies, saillant et fendu à son bord antérieur, ne forme avec les huit ou neuf anneaux suivans qu'un thorax étroit, court, sans aucun écusson membraneux, et que distingue seulement, la grandeur ou mieux encore, la forme particulière des huit ou neuf paires de pieds qu'il porte; les pieds de la première paire très-écartés. - Animal contenu dans un tube fixé verticalement, coriace ou gélatineux, ouvert à un seul bout, et généralement enduit à l'extérieur d'une couche factice de limon.

M. Ruppel a publié un inféressant mémoire, sur les organes respiratoires de ces animaux; il est reproduit par extrait dans le vingt-deuxième volume du Bulletin de Ferussac.

\section{PREMIĖRE DIVISION.}

Branchies égales, flabelliformes, portant chacune un double rang de digitations et se roulant en entonnoir.

(Sabella Astarta, Sav.)

\section{SABELLA JUDica.}

Sav., Egypte, Annel., p. 77.- Long. 4 pouc. $\frac{1}{2}$. Larg. 5 lig. - Corps formé de deux cent vingt-sept segmens très-étroits; branchies très-épaisses, très-grandes, veloutées, de couleur fauve, annelées de brun ; tube épais, calcaire, d'un brun presque noir.-Grande espèce rapportée de la Mer des Indes par Péron et Lesueur.

\section{SABELLA MAGMFICA.}

Snaw., Trans. Soc. Linn., t. V, p. 228, pl. 9. - Jolie espèce de la Jamaïque, à branchies annelées de blanc et de rouge.

\section{DEUXIEME DIVISION.}

Branchies en éventail, formées par un seul rang de digitations.

\section{(Sabellce-Simplices, SAv.)}

\section{3. sabella pennicillus.}

SAV., Annel., p. 78. - Ventilabrum, Gmez. - Pinus Marinus, Rondel., Hist. des Pois., part. 2, p, 76. - Long. 3 pouc. - Corps formé de cent vingt-deux segmens; branchies égalant en longueur la moitié de celle du corps, à digitations très. grêles, à barbes très-fines, d'un fauve clair; tube très-long, épais, gélatineux et couvert de limon. - Côtes de la Manche.

\section{SABELLA FLABELLATA.}

Sav., T. Pinicillus, Otwon Fabr., Faun. Groenl., no 449. - Long. 15 lig.-Corps formé de quatre-vingt-douze anneaux; branchies ayant environ vingt-deux digitations barbues, d'un gris brun et clair marbré de taches obscures, régulières, formant des zones circulaires sur le panache.-Côtes de l'Océan.

Nota. Rapportez encore à cette divi. sion :

\section{SABELLA RENIFORMIS.}

Gmer. - Penicillus, Lam. - T. Pennicellus, Moller, Zool. dan., $3^{\mathrm{e}}$ part., p. $13, \mathrm{pl} .89$, f. 1 et 2.-Côtes de l'Océan.

\section{SABEIMA INFUNDIBULA.}

Montagu, Trans. Soc. Limn., t. 9, pl. 8. -Cótes de l'Angleterre.

\section{SABELLA VESICULOSA.}

Montagu, id., loc. cit. - Du même pays.

\section{SABELLA FABRICIA.}

Othon Fabr., Faun., n 450.-Côtes du Groenland.

\section{TROISIENE DIVISION.}

Branchies en peigne, à un scul côté et à un seul rang, se contournant en spirale.

(Sabelloc Spirographce, SAv.)

\section{SABELLA SPALLANZANII.}

Viviani, Phosph. Mar., p. 141, pl. 4 et 5.-S.Unispira, SAv., Annel., p. 80.Long. 4 pouc. - Corps formé d'environ cent cinquante segmens, muni de branchies très-longues et très-grêles; le nombre des digitations et la forme sont variables, d'un gris rougeâtre. avec des anneaux réguliers et obscurs; tube long, d'un brun verdâtre, recouvert d'un enduit sablonneux.-Côtes de France.

\section{Ajoutez à ce genre :}

10. Sabella Voluticornis, Montagu. Trans. Soc. Linn.

11. Sabella Protula. Belle espèce nommée par M. Cuvier et figurée daus l'Iconog:aphie de M. Guérin. Nous l'avons représentée pl. 4, fig. 5. - Toutes les deux des côtes d'Angleterre. 
Nota. La Tubularia Stellaris, d'Othon Fabricius n'est pas connue des zoologistes modernes. MI. Savigny la rapporte aux $S \boldsymbol{a}$ bella Simplices, et M. de Blainville, en forme, d'après la description de l'auteur que nous avons cité, le genre Fabricia.

\section{HERM ELEITES.}

Caractéres. Des branchies visibles, au nombre de deux. - Rames ventrales d'une seule sorte et portant toutes des soies subulées.-Pas de tentacules.

Genre: Hermella.

$$
\begin{gathered}
\text { HeRmella, Sav.; } \\
\text { Tubularia, Ellis; Amphitrite, Cuv., } \\
\text { Blainv.; } \\
\text { Sabellaria, Lam. : Blainv.; Tubipora, } \\
\text { Linn.; } \\
\text { Nereis, Pallas; Terebella, Guel. }
\end{gathered}
$$

Bouche inférieure placée entre les supports des branchies, munie d'une lèvre supérieure et de deux demi-lèvres inférieures longitudinales, minces et saillantes; sans tentacules. - Branchies au nombre de deux, situées sous le premier segment, occupant l'intervalle qui sépare sa couronne operculaire de ses deux cirrhes inférieurs; consistant chacune en une touffe de filets sessiles, aplatis, sétacés, alignés fort régulièrement sur plusieurs rangs transverses. Pieds du premier segment anomaux, constituant ensemble deux cirrhes inférieurs portés par deux lobules situés sous la hanche, et deux triples rangs supérieurs arqués et contigus de soies plates qui composent une couronne elliptique, destinée à servir d'opercule; les deux rangs extérieurs de cette couronne très-ouverts, à soies entières; courbées en dedans le plus extérieur des trois rangs mobile, entouré lui-même d'un cercle de dentelures charnu. - Pieds du second segment et des suivans munis, à leur'base supérieure, d'un cirrhe plat, allongé, acuminé, tourné en devant; d'ailleurs de trois sortes : les premiers sans soies visibles, mais pourvus $d^{3} u n$ petit cirrhe inférieur tourné en devant; les seconds, troisièmes et quatrièmes, à rame ventrale munie d'un faisceau de soies subulées, et à rame dorsale garnie de soies à palette lisse; enfin, les cinquièmes pieds et tous les suivans, à rame ventrale munie d'un faisceau de soies subulées, et a rame dorsale garnie d'un rang de soies à crochets; la paire des cinquièmes pieds distinguée, en outre, par deux petits cirrhes inférieurs et connivens. - Soies subulées dirigées toutes en dedans, celles des deuxièmes, troisièmes et quatrièmes pieds, comprimées et lancẻolées à leur pointe; les autres simplement infléchies.-Soies à crochets excessivement minces et courtes, découpées dans leur bout en trois ou quatre dents.- Corps cylindrique, un peu renflé au milieu, rétréci en arriẻre, formé de peu de segmens dont le premier très-grand, les derniers allongés, membraneux, dépourvus de pieds, formant une queue grêle et cylindrique repliée en dessous. - Tube fixé, sablonneux, ouvert par un seul bout, et réuni avec d'autres tubes en une masse alvéolaire, globuleux, lisse au-dedans, et à l'estomac est très-musculeux ; l'extérieur correspondant à la séptième paire de pieds ambulatoires; l'intestin presque droit.

\section{HERMELLA ARENOSA.}

Ellis, Corall., p. 104, pl. 36. - Linn., Syst. nat., éd. 10, t. I part. 2, p. 1268, no 812. - Psamatotus, Quettaho, Mém., t. III, p. 68, pl. 69, f. 2.-Areolata, LInN., Syst. nat., èd. 12, t. I, part. 2, p. 1268. -Sav., Annel., p. 82, no 1.-Astrearia, Cuv., Dict. Sc. nat., t. I, p. $79, \mathrm{n}^{\circ} 3$ ? Long. 15 lig. - D'un rougeâtre à reflets violets; corps formé de trente-trois segmens sans y comprendre la queue; couronne operculaire formée d'environ cent soixante soies, la moitié de chaque côté, et ayant l'éclat de l'or.-Côtes de l'Océan et de la Méditerranée.

Nota. Les individus décrits par M. Savigny étant du double plus grands que ceux d'Ellis, le premier de ces savans pense qu'ils constituent peut-être une espèce distincte.

\section{HERMELLA CHRYSOCEPHALA.}

Pallas, Nov. Act. Petrop, t. II, p. 235, pl. 5, f. 20.-GMez., Syst. nat., t. I, part. 6, p. $3114, \mathrm{n}^{\circ}$ 6.-SAv., Annel., p. $83, \mathbf{n}^{\circ} 2 .-$ Long. 4 pouc. $\frac{1}{2}$ - - Remarquable par sa grande taille, et par la forme de sa couronne, dont le rang le plus intérieur est moins séparé à sa base que le rang mitoyen. - Les côtes de la Mer des Indes.

\section{TEREBELLITES.}

Caractéres. Branchies visibles, au nombre de deux à six.-Rames ventrales d'une 
seule sorte, portant toutes des soies à crochets. - De longs tentacules.

Genres : Terebella, Pectinaria.

\section{TEREBELLA， Guv. ;}

Nereis, Pallas ; Amphitrite, Brug. ;

Othon Fabr., Muller, Bosc.

Bouche, antérieure, formée de deux lèvres transverses, la supéricure large, avancée, voûtée, surmontée de tentacules nombreux; l'inférieure étroite et plissée transversalement. - Branchies au nombre de deux à six, supérieures, placées sur les pre. miers segmens, ayait la forme d'arbuscules délicats. - Tentacules placés autour de la lèvre supérieure, longs, inégaux, filiformes, unisillonnés en dessous, extensibles et couverts d'aspérités très-fines. - Pieds nuls aux premiers segmens, ou représentés sur le premier et le deuxième par deux feuillets inférieurs; ceux des segmens suivans, à partir du quatrième, formés de trois sortes : premiers pieds à rame dorsale pourvue de soies subulées, sans rame ventrale ni soies à crochets; les seconds et les suivans, jusques et compris les dix-septièmes et même les dix-neuvièmes, à rame dorsale pourvue d'un faisceau de soies subulées, et à rame ventrale en forme de mamelon transverse, armée d'un double rang de soies à crochets; dix-huitièmes ou vingtièmes pieds et les suivans, compris la dernière paire, sans rame dorsale, à rame ventrale garnie, comme les précédens, d'un double rang de soies à crochets; les pieds des trois derniers segmens presque imperceptibles. - Soies subulèes, tournées toutes en dehors, terminées simplement en pointe; soies a crochets courtes et minces, étranglées vers leur sommet, qui est relevé, arrondi en dessus, et découpé par dessous en quatre dents. - Corps allongé, un peu renflé, se prolongeant en arrière en forme de queue; le fourreau est fixé, membraneux, peu solide, presque fermé en arrière, couvert de graisse, de sable et de fragmens de coquilles.

\section{PREMİRE DIVISION.}

Levre supérieure non dilatée, en deux 10 . bes.-Appendice des premier et troisieme segmens formant ensemble quatre lobes latéraux dirigés en avant. - Branchies au nombre de trois paires, ramifiées dès leur base, insérécs aux second, troisième el quatrième segmens.

\section{(Terebella simplices, Savig.)}

\section{TEREBELLA CONCHILEG.}

Pallas, Misc. Zool., p. 131, pl. 8, f. 1722. - Savig., Annel., p. 85. - Prudens, Cuv., Dict. Sc. nat., t. II, p. 80?- Long. 9 pouc. - Corps de cent trente-quatre anneaux, fauve, nuancé d'incarnat; une bande pectorale rougeâtre; tentacules blanes; soies jaunes; branchies d'un rouge vif; la queue fait plus des trois quarts de la longueur; grêle ; tube délicat, formé de fragmens de coquilles.-Cette espèce se trouve sur les côtes de l'Océan.

2. terebella medusa. (Pl. 5, f. 1.)

Sav., Annel., p. 85, 2, pl. 1, f. 3. Long. 6 pouc.-Corps d'un cendré un peı rougeâtre; bande pectorale d'un rouge clair à la base et obscur au sommet; rames ventrales du thorax avec un trait noir; deux autres semblables sur le bord postérieur de chacun des segmens, et ces mêmes parties offrant en dessous deux mouchetures de même couleur; marge postérieure des anneaux de la queue bordée de points saillans noirs ou blancs; tentacules blancs; branchies d'un rouge vif; la queue ne fait que les deux tiers du corps; l'animal est formé de quatre-vingt-dix segmens courts et serrés; le tube est rampant, tortueux, et formé à l'extérieur de cailloux et de gros fragmens de coquilles disposés confusément. - Cette espèce a été trouvée par M. Savigny sur les côtes de la Mer-Rouge.

\section{TEREBELLA CIRRATA.}

Muller-W erm, p. 188, pl. 15, f. 1-2. Cirrosa, Linn., Syst. nat., édit. in-12, t. I, part. 2, p. 1085, no 3. - Ver. Mléduse, Dicorjem., Journ. de Phys., 1777, p. 215, pl. 1, f. 10-11. - Long. 3 pouc. $\frac{\pi}{2}$. - D'un brun rouge, avee les plis du ventre plus pâles; corps formé de soixante à soixantedix segmens; tentacules d'un blanc rougeâtre; branchies divisées dìs leur base en cinq ou six ramcaux simples subarticulés; tube assez compacte, formé d'argile et de grains de sable. - Mers du Nord.

II faut aussi rapporter à ce genre les espèces suivantes, qui se trouvent en Augleterre.

4. TEREBLLLA GIGANTEA.

Montage, Trans. Soc. Limu, t. XI1.

5. TEREDELA GIRAATA.

Montagu , Trans. Soc. Lin!., t. XII. 

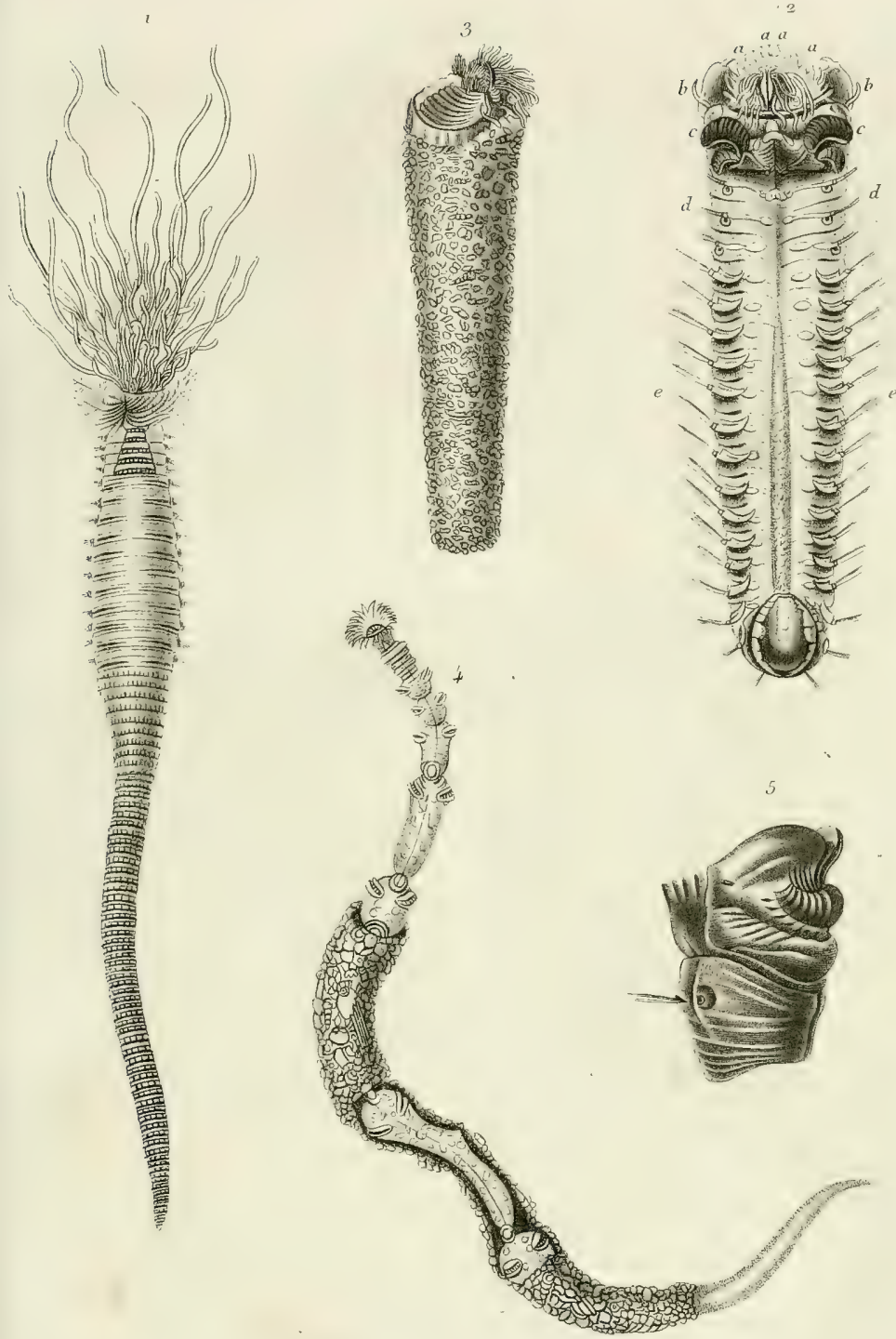

1. Terebella Medusa. 2. Pectimaria Gigyptia. a tenfacules. b. premiers segments anomaux disscmblables avec des appendices anomarux, ci. branchess. d. trois preniers pieds sans rames ventrales. - c. pieds suivants i rame ventials saillante et Lumulée. 3. Pectinaria Uigyptia de profil et dans son foureau 4. Clymene amphistoma. 5 id. profilde la partie artérieure. 

6. TEREBELLA NEBULOSA.

Montagu, Trans. Soc. Linn., t. XII.

7. TEREBELIA CONSTRICTA.

Montagu, Trans. Soc. Limn., t. XII.

8. TEREBELLA VENUSTATA.

Montagu, Trans. Soc.Linn., t. XII.

\section{DEUXIEME DIVISION,}

Lèvre supérieure dilatée à sa base, en deux lobes latéraux tentatulaires. - Appendices du premier et du troisième segmens nuls. - Branchies au nombre de deux paires, ramifiées dès leur base, insérées aux second et troisieme segmens.

\section{(Terebella Physalia.)}

\section{TEREBELLA SCYLLA.}

Sav., Annel. , p. 87, 4. - Couleur de la Conchilega; tentacules assez longs; dixneuf paires de pieds thoraciques à rames ventrales en forme de mamelons transverses; les pieds caudaux ressemblent aux pieds thoraciques, aux soies subulées près. - Cette espèce se trouve sur les côtes de La Rochelle et sur celles de la Mer-Rouge.

\section{TEREBELLA CINCINNATA.}

Othon FABR., Faun. Groenl., n 270. -Long. 9 pouc.-Gros comme une plume de cygne, formé d'environ cent segmens canuliculés sous la queue; tous les pieds garnis de faisceaux de soies subulées; tentacules assez courts, rougeâtres; soies blanclies; branchies de dix rameaux, rouges, munies à leur base d'un filet subulé et obscur. - Habite les mers du Nord.

\section{TROISIEME DIVISION.}

Appendices aux premier et troisième segmens; une seule paire de branchies ramifiées à l'extrémité, insérée au troisième segurent?

\section{(Terebella Idalia.)}

11. TEREBEILA CRISTATA.

Muller, Zool. Dan., part. 2, p. 40, pl. 70.-GMes., Syst. nat., t. II, part. 6, p. 311 , no 5. - Savig., Annel., p. 87 , n' 6. - Environ soixante-dix segmens; tentacules cinq a six fois plus courts que le corps; dix-sept paires de pieds thoraciques. - Habite les mers du Nord.

12. TEREBELLA VENTRICOSA.

Bosc, Hist. des Vers, t. I, p. 196 , pl. 6 , f. 4-5. - LAM., t. V, p. 354, n०3. - Bouche en forme d'onglet concave en dessus, rétractile, entourée inférieurement d'une trentaine de tentacules blancs, inégaux, derrière lesquels se trouvent deux branchies rougeâtres rétractiles, qui, au milieu de leur longueur, se divisent en trois ou quatre branches très-flexueuses, subdivisées en un grand nombre de petits rameaux également flexueux; point d'yeux; corps aplati en dessus, très-ventru en dessous dans la partie antérieure; composé d'environ cinquante anneaux accompagnés, de chaque côté, d'un tubercule en forme d'épine simple. - Cette espèce est trèsvoisine de la précédente; elle se trouve en abondance dans la rade de Charlestown, sur les vieilles coquilles à surface inégale, où elle se fait un fourreau peu solide avec des débris de végétaux marins ou autres.

PECTINARIA, LAM.;

Cistena, Lеacr; Amphictene, Savig.; Nereis, Palias; Solen, Klein ; Sabella, LinN., GMeL. ;

Amphitrite, Muller, Оthon Fabr., Bruc. Chrysodon, OcKeN.

Bouche transversale, bilobée, placée inférieurement; la lèvre supérieure saillante, relevée, pliée longitudinalement, surmontée d'un voile demi-circulaire et den. telé, et entourée, sous ce voile, de nombreux tentacules. - Lèvre inférieure très. courte. - Branchies au nombre de quatre, placées presque en dessous, courbées en faux, transversales, attachées à la base extérieure des appendices du troisième et du quatrième segmens, consistant chacune en une rangée de plusieurs feuillets oblongs ou demi-circulaires, portés sur un pédicule flottant à son extrémité. - Tentacules insérés autour de la bouche et sur les côtés de la lèvre supérieure, beaucoup moins grands que ceux des Tercbelles, inégaux, filiformes, striés circulairement, très-contractiles, creusés d'un sillon eu dessous, et rendus visqueux et préhensiles par de fines aspérités. - Pieds dissemblables dans les quatre premiers segmens anomaux : ceux du premier formant ensemble deux cirrhes latéraux écartés et deux rangs supérieurs, transverses et rapprochés, de soies plates étagées, légèrement recourbées, représentant les dents d'un peigne sur la face aplatie et operculaire du segment qu'elles oc- 
cupent; ceux du second réduits à deux cirches latéraux semblables aux deux précédens, et situés derrière; ceux du troisième représentés par deux petites callosités inférieures et très-rapprochées; enfin, ceux du quatrième consistant en deux callosités cartilagineuses plus grandes que les précédentes, plus saillantes, plus écartées, ne possédant de même aucune soie. Pieds du cinquième segment et de ceux qui suivent, de trois sortes : $1^{\circ}$ les premiers, seconds et troisièmes pieds, à rame dorsale munie d'un faisceau de soies subulées, sans rame ventrale ni soies à crochets; quatrièmes pieds et suivans, jusques et compris les seizièmes, à rame dorsale également munie d'un'faisceau de soies subulées et à rame ventrale saillante, lunulée, pourvue d'un rang de soies à crochets. - Dix-septièmes pieds et suivans, compris la dernière paire, sans rame dorsale et sans soies visibles, à l'exception de la dix-huitième paire, qui offre généralement deux rangs supérieurs et transverses de soies plates, disposées comme celles du peigne du premier segment.-Coies subulées tournées toutes en dehors, fines et simplement pointues; soies à crochets très-courtes, très-minces, relevées à leur bout; qui est découpé en dessous en plusicurs dents. - Corps épais, conique, la partie intérieure étant la plus large, formé de segmens peu nombreux, dont le premier tronqué obliquement pour recevoir le peigne et former l'opercule; les derniers segmens formant une sorte de queue après le peigne postéricur; elle est courte, épaisse, se replie immédiatement en dessous, et s'ouvre en un anus placé sous une lame operculaire. L'animal est contenu dans un fourreau libre, mobile, conique, presque fermé au bout inférieur, régulier et presque droit.

\section{PREMIÉRE DIVISION.}

Espèces à voile oral non distingué du segment operculaire par un étranglement.

\section{(Amphictence Cistence, SAvig.)}

\section{1. pectiraria granulata.}

Linv., Syst. nat., édit. in-12, t. I, part. 2, p. 1268, no 819. - Nereis cylindraria Belgica, Pallas, Misc. Zool., p. 117, pl. 9, f. 375. - Ann. Belgica, Brug., Encycl. méth., art. Vers, 1, p. 56, n $^{\circ} 6$, pl. 58 , f. 1 9, et pl. 58, fig. 10-15. - P. Fragilis, KLEIN, Lchin., p. 62, pl. 33, f. A et B.
- Auricoma, Mullen, Zool. Dan., p. 1, p. 26, pl. 26.-Savig., Annel., p. 89, n' 1. - Pallasii, Leacr, Encycl. Brit. suppl., t. I, p. 452, pl. 26, f. 6. - Long. 18 lig. Larg. 3 lig. $\frac{1}{2}$. - D'un blanc rougeâtre, à reflets violets; le dessous du corps pâle, avec une ligne longitudinale d'un beau rouge; branchies d'un rouge obscur; peignes et soies d'une belle couleur d'or; corps formé de vingt-six segmens. Cette espèce vient de l'Océan.

\section{DEUXIEME DIVISION.}

Espèces à voile oral, distingué du segment operculaire par un profond étranglement et par deux papilles.

\section{(Amphictenæ simplices, $\mathbf{S}_{\text {Avig. }}$ )}

2. pectinaria egyptia. (Pl. 5, f. 2 et 3. ) Sayig., Annel., p. 90, n 2. - Long. 3 pouc. $\frac{\mathrm{T}}{2}$ lig. - Ressemble beaucoup à l'espèce précédente pour les couleurs; corps plus épais; voile de la bouche découpé en dents moins nombreuses, environ vingt-quatre; des tentacules épais et d'un rouge clair ; tube membraneux, plus épais et plus solide que dans la Granulata. Côtes de la Mer-Rouge.

\section{PECTIAARIA GIRYSODON.}

Berg., Act. Stock. (1765), p. 228, pl. 9, f. 1-3.-Linv., Syst. nat., èd. in-12, t. I, p. 2, p. $1269, \mathrm{n}^{\circ} 813 .-N$. Capensis, Pallas, Misc, Zool. (1766), p. 118, pl. 9, f. 1-2,-Cuv., Dict. Sc. nat., t. II, p. 78 . - LaMr., Ann. sc., art. Vers, t. V, p. 350, n' 2. - Savig., Annel., p. 91, $\mathrm{n}^{\circ} 3$. Long. 4 pouc. - Couleurs des précédens; corps formé de vingt-six segmens bordés sur les côtés, ridés circulairement et allongés, surtout depuis le dix-huitième qui présente une quinzaine de rides annulaires; le tube es ́ papyracé, fragile, sans trait d'incrustations, et d'un cendré clair. - Cap de Bonne-Espérance.

Nota. M. Risso a décrit quelques espèces sous le nom de ce genre; mais on ne peut les y rapporter qu'avec doute.

Nous donnons ici le passage suivant, de Savigny, sur une annelide, encore bien peu connue.

"L'Amphitrite Plumosa de Muller constitue un genre particulier dont la place dans le systeme est encore incertaine. En examinant la figure publiée par Mulier je trouve la bouche surmontée d'une toulle de tentacules, et près de cette bouche, sur 
les côtés, deux filets contractiles légèrement annelés, très-gros et très-longs. Je trouve de plus des pieds disposés sur tous les segmens du corps (je parle des segmens apparens) et constitués de chaque côté par deux rames distinctes, courtes, sans cirrhe supérieur ni cirrhe inférieur. La nature des soies que portent ces rames ne paraît pas douteuse ; on croit voir des soies subulées, plus ou moins épanouies en éventail ; celle des rames dorsales les plus voisines de la bouche sont fort longues, dirigées en avant et en haut, et voûtées. Voila tout ce que peut apprendre la figure de Muller; mais quelle est l'insertion des deux gros filets antérieurs, qui ressemblent, par leur forme, aux antennes cxtérieures des Aphrodites? Tiennentils au premier ou au second segment? Ces filets sont-ils des cirrhes? sont-ils, malgré leur couleur blanchâtre, des branchies divisées? Les rames se composent-elles uniquement de soies subulées? ou les unes portent-elles des soies subulées, les auires des soies à crochets? Ce sont des difficultés que la courte notice jointe à la figure ne donne assurément aucun moyen de lever. "

Othon Fabricius donne aussi une description détaillée du même animal.

M. Ocken a établi son genre Pherusa sur cette espèce.

\section{CLYMENITES.}

Caractères. Point de branchies.

Genre : Clymene.

\section{CLYMENE, SAvig.; \\ Sabella, Отнол Fabr.}

Bouche inférieure formée de deux lèvres saillantes, cannelées et transversales: la supérieure précédée d'une sorte de voile court, échancré, marqué en arrière d'un sinus longitudinal; la lèvre inférieure renflée et avancée. - Pieds du premier segment ne consistant qu'en une rangée supérieure de crénelures charnues placées en demi-cercle; ceux des suivants, jusqu'à l'anté-pénultième, ambulatoires et de trois sortes; les premiers, seconds et troisièmes pieds, à rame dorsale pourvue d'un faisceau de soies subulées, sans rame ventrale ni soies à crochets; quatrièmes pieds et tous les suivans, ceux des trois dernières paires exceptés, à rame dorsale portant de même un faisceau de soies subulées, et à rame ventrale en forme de mamelon transver. sal, armée d'un rang de soies à crochets; pieds des trois dernières paires sans rame dorsale, à rame ventrale semblable aux précédentes, avec des soies peu visibles. Soies subulées tournées extérieurement, se terminant en pointe très-aiguë. - Soies ayant les crochets allongés, grêles, terminées par trois dents inègales, dont la plus courte est la supérieure. - Corps cylindrique, grêle, un peu renflé au milieu, formé de peu de segmens, dont le premier dilaté et tronqué obliquement; le dernier formant un opercule infundibuliforme, rayonné et denticulé. - Anus au milieu de papilles charnues formant un cercle.-Animal contenu dans un tube fixé, membraneux, cylindrique, ouvert également aux deux bouts.

1. CLYMene amphistoma. (Pl.5, f. 4 et 5. ) Savig., Annel., p. 93 , pl. 1, f. 1.-Long. 5 pouc. - Gorps rougeâtre, formé de vingt segmens; soies d'un jaune doré ; le tube est grêle, onduleux, fragile, formé extérieurement de grains de sable et de petits fragmens de coquilles. - Gette espece se trouve dans le golfe de Suez, fixée dans les interstices des rochers, ou dans ceux des madrépores et autres productions marines.

\section{CLYMENE URANTHUS.}

Savig., Annel., p. 93, n० 2. - Long. 5 pouc. - Brun; corps du double plus gros que dans le précédent, formé de vingt-sept segmens; les soies d'un jaune brun. Cồtes de l'Océan.

\section{GLYMENE LUMBRICALIS.}

Othon Fabr., Faun. Groenl., p. 374 , $\mathrm{n}^{\circ}$ 369. - S Av., Annel., p. $94, \mathbf{n}^{\circ} 3$. Roux, avec des anneaux blancs. - Côtes du Groenland.

Nota. Suivant M. Savigny, c'est peutêtre à ce genre que l'on doit rapporter les espèces suivantes:

1. Le Lumbricus tubicola, Mulder, Zool. Dan., pl. 75. - Tubifex marinus, LAM.

2. Lumbricus sabellaris, Mullen, Zool. Dan., pl. 104, f. 5.

3. Lumbricus capitatus, OTHon Fas., Faun. Groenl., no 263, sur lequel M. de Blainville a formé le genre Capitella.

\section{ARENICORTTES.}

Caractères. Branchies nombreuses, Pieds d'une seule sorte.

Genre: Arenicola. 
ARENICOLA, LAr.;

Lumbrieus, Linn., Othon Fabr., Gael., Barbut., Muller;

Nereis, Pallas.

Bouche terminale saillante, rétractile, entourée d'une lèvre très-épaisse, circulaire et hérissée de plusieurs rangées de tentacules de forme obtuse. -- Branchies nombreuses, placées par moitie de chaque côté, et finement ramifiées. - Pas de pieds au premier segment ; ceux des autres, jusqu'au vingtième, à rame dorsale munie d'un faisceau de soies subulées, et à rame ventrale en forme de mamelon transverse, et garnie d'une rangée de soies à crochets; les segmens, à partir du vingt-unième, non munis de pieds. - Soies subulées, presque cylindriques et dirigées en dehors. - Soies ayant des crochets allongés, et armées d'une seule dent à leur sommet. - Pas de pieds. - Corps cylindrique, allongé, formé de peu de segmens, mais offrant des sillons circulaires beaucoup plus nombreux. Une petite caroncule trilobée, offrant un mamelon de chaque côté, et rétractile dans une fente transversale, se voit sur le premier segment. - La partie antérieure est renflée; la partie postérieure formée des anneaux, à partir du vingtième, courte et formant une sorte de queue grêle.

Le canal intestinal est droil; l'œsophage présente deux parties musculeuses à sa jonction avec l'estomac : l'on ignore leur usage; l'estomac est plus épais que le reste de l'intestin; il est oblong, dilaté d'une manière transversale, en laissant voir sur la surface de sa membrane un réseau vasculaire; les organes de la génération consistent en cinq testicules situés à la partie antérieure du corps; les œufs ont la forme de petits grains arrondis et jaunâtres et sont répandus dans l'intérieur du corps.

\section{ARENICOLA MLARTA.}

Linv., Iter WV. Goth., p. 189, lib. 3, f. 6. - Lumbricoìdes, Pallas, Nov. Act. Petrop., t. II, p. 233, -pl. 5, f. 19.-Papillosa, Отном Fabr., Faun. Groenl., no 267. - Piscatorum, Laš., Syst. des anim. sans vert., p. 234. - Tinctoria,
LEAGH, Encycl. Brit., t. 1, p. 452, 2.Long. 8 à 10 pouc. - D'un cendré jaunåtre ou rougeâtre; papilles d'un bleu obscur, et souvent verdâtre ou ferrugineux; soies d'un brun doré; branchies au nombre de treize paires; elles s'épanouissent beaucoup lorsqu'elles sont remplies de sang, et sont alors d'un beau rouge. - Pieds au nombre de dix-neuf paires. - Les pêcheurs se servent de cette espèce comme d'appât. Elle se trouve abondamment sur les côtes sablonneuses de l'Océan; elle s'enfonce à un ou deux pieds de profondeur; lorsqu'on la touche, elle fait sortir de son corps une liqucur jaunâtre.

\section{ARENICOIA ABISDGAARDTI.}

Lumbricus marinus, Anildgaand, $\mathrm{S}_{A \mathrm{~V}}$, Muller, Zool. Dan., part. 4, pl. 155, f. 1 bis.-Long. 10 pouc. - Celte espèce, que Savigny croit devoir réunir au Marinus de Linné, m'en semble bien distincte. L'on ne peut croire, en effet, que ce soit par erreur, ainsi que le pense ce savant, qu' $A$ bildgaardt, observateur aussi judicieux que Muller lui-même, ait pu donner à cette espèce quatorze paires de branchies et vingtquatre pieds. - Elle se trouve sur les côtes du Danemarck.

\section{3. arenicola carbonaria.}

Leach, Encycl. Brit., Suppl., t. I, p. $452, n^{\circ} 1$, pl. 26, f. 4. - S $\mathrm{AV}$., Annel., p. 97, 2. - Cette espéce, que MM. Audouin et Milne Edwards (Littoral, t. II, p. 286) ne regardent que comme une variété de la Marina, est entièrement noire; la figure de Leach ne lui donne que douze paires de branchies; mais la description n'en fait pas mention, ainsi c'est sans doute par erreur. - Côtes d'Angleterre.

\section{4. arenicola clavata.}

Ranzani, Mem. di Storia nat. deca. prima, pl. 1, f. 1. - Des côtes de l'Italie.

\section{AREVICOLA BRANCHIALIS.}

Aud. et EDw., Littoral, t. II, p. 287, 2, pl. 8, f. 13. - Long. 10 pouc. - Branchies au nombre de dix - neuf paires. Des environs de Saint-Malo. 


\title{
ANNELIDES TERRICOLES，
}

\author{
LOMBRICINES et PARTIE DES SERPULÉES, SAv.; \\ ABRANCHES SÉTIGERES, Cuv.; \\ PARAMOCRICIENS ET HOMOCRICIENS, BLANV.
}

Les Annelides Terricoles diffèrent essentiellement des ordres précédens par l'absence d'organes respiratoires extérieurs: il semble que c'est la surface entière de la peau qui accomplit cette importante fonction, leur corps est presque toujours dépourvu d'appendices mous; quelques espèces de Nais semblent seules faire exception à celte règle; les pieds sont ordinairement remplacés par des soies proprement dites. La têle n'est pas distincte, et l'on ne voit que dans le genre précité et les Siphunculites une trompe protractile et des points oculaires, et encore seulement dans quelques espèces. Nous les partageons en trois groupes : les Lumbricites, les Naites et les Siphunculites.

\section{LUNBEICITES.}

Caractères. Corps long, cylindrique, partagé en segmens nombreux. - Ils vivent généralement dans la terre.

Genres : Lumbricus, Hypogeon.

\section{LUMBRICUS, LINN. ; Enterion, Sav.}

Bouche petite, un peu renflée, à deux lèvres; la supérieure avancée en trompe et lancéolée d'une manière obtuse, fendue en dessous; la lèvre inférieure très-courte. - Soies courtes, âpres, comme onguiculées, au nombre de huit à chacun des segmens réunis par paires, quatre de chaque côté; formant par leur distribution sur le corps huit rangs longitudinaux, dont quatre latéraux et quatre inférieurs. -- Corps cylindrique, obtusà son bout postérieur, allongé, composé de segmens courts et nombreux, plus distincts vers la bouche qu'à l'extrémité opposée; la plupart des segmens compris entre le vingt-sixième et le trente septieme Anv. renflés, formant à la partie antérieure et supérieure du corps une sorte de ceinture; le dernier segment pourvu d'un anus longitudinal.

L'on s'est beaucoup occupé de l'anatomie des Lombrics, et parmi les travaux qui ont le plus avancé nos connaissances à cet égárd, nous citerons ceux de Willis, Kedi, Montègre, Morren, Dugès, Dufour, elc. - Leur intestin est dépourvu de cœcum et va droit à l'anus, après avoir, durant son trajet, reçu plusieurs des fibres musculaires destinées au mouvement des segmens du corps, ce qui constitue autant de petits diaphragmes. La circulation s'opere au moyen d'une infinite de petites veines qui s'entrecroisent avec un grand nombre d'artérioles; ils naissent à la surface interne dans l'enveloppe extérieure et au canal intestinal; elles se réunissent sous le ventre en un tronc com. mun et longitudinal, qui émet en avant cinq petils canaux qui aboutissent à un vaisseau dorsal qui remplit peut-être les fonctions du cœur. Ce vaisseau donne naissance à de petitesartères qui forment un réseau avecles autres veines. La respiration paraît s'effectuer par la surface de la peau. Les organes de la génération sont près du plus gros anneau; ils présentent extérieurement deux mamelons percés chacun d'une très-petite ouverture; le cerveai est petit et arrondi. Le cordon nerveux est une suite très-nom. breuse de ganglions très-petits et serrés les uns contre les autres. Les Lombrics sont hermaphrodites et portent chacun les organes des deux sexes; l'accouplement a lieu hors de terre et pendant la nuit; ils se tiennent alors si fortement unis qu'on peut les écraser sans les séparer; ils pondent des cocons qui ont beaucoup de rapports avec ceux des Sangsues, et que M. Léon Du. four a étudiés avec soin (Ann.Sc.nat., t.V). C'est pendant les nuits chaudes et humides 
que ces animaur sortent de terre pour se chercher et s'accoupler. La terre est souvent criblée de leurs trous; ils préfèrent les terrains gras et se nourrissent de la terre elle-même dont ils retirent l'humus, et qu'ils rendent ensuite plusieurs fois par jour sous forne vermiculaire. Pendant les grands froids et les fortes chaleurs qu'ils redoutent également, ils se tiennent enfoncés à d'assez grandes profondeurs dans la terre,et n'eu sortent guère que par un temps humide. L'on assure qu'ils répandent quelquefois une lueur phosphorique; lorsqu'on coupe en morceaux l'un de ces animaux, chaque tronçon conservelong-temps un mouvement vital, et l'on prétend que chacun peut redevenir un animal parfait. Bounet a fait de nombreases expériences à cet égard. Quoiqu'ils bouleversent quelquefois la terre par leur grande inultiplication, ils ne nuisent cependant pas sensiblement à l'agriculture.

La médecine les employait autrefois comme sudorifiques et diurétiques. Dans quelques parties de l'Asie, l'on assure qu'ils servent á la nourriture des habitans; dans nos contrées on les emploie à la nourriture de la jeune volaille et comme appât pour la pêche.

\section{LUMBRICUS TERRESTRIS.}

LuNN., Syst. nat., t. I, part. 2, p. 1076 , no 1. - Muller, Hist. verm., 1, part. 2, p. $24, n^{\circ}$ 157. - Long. 5 à 6 pouc. Rougeâtre; il paraît que le nombre de segmens varie, suivant l'âge, de cent à deux cents; M. Savigny en a compté deux cent quarante-huit à un très-grand individu; il y aroit deux pores sous le quinzième el douze autres moins profonds. Sui. vant le même naturaliste, le nombre des anneaux de la partie antérieure, jusques et compris la ceinture, ne parait pas beaucoup varier.

L'on assure que cette espèce se trouve sur les deux continens, ce qui paroît au moins fort douteux. Il est beaucoup plus probable que les espèces sont très-nombreuses, mais très-voisines les unes des autres, car M. Savigny en a caraclérisé vingt, uivant M. Cuvier (Analyse des trav. de l'Acad. des sciences, 1821), et M. Dugès en distingue six; l'on en trouve quelques autres dans les ouvrages modernes, tels sont les suivantes.

\section{HUMRICUS GORDIOTDES.}

Hartaran, Neue Alpina, t. 1. - Long. 12 pouc. Larg. $\frac{1}{4}$ lig.-Confondue jusqu'ici avec les Gordius, cette espèce vit avec eux dans les eaux de source. Les segmens sont visibles seulement à la loupe; elle ne porte pas de ceinture ; sa queue est aplatie; les soies de la face inférieure de son corps sont visibles à la loupe; sa couleur est rougeâtre; elle nes'enfonce pas dans la vase, et périt quand on la tient à deux pieds de profondeur dans l'eau. Elle se trouve en Suisse.

\section{LUMIBRICUS HAGENBACHII.}

Décrite par M. Hagenbach, naturwiss anzieg der alls, schw., 1823, $n^{\circ} 11$, p. 84. - Elle n'a pas de ceinture. Son corps est moins renflé antérieurement que dans le Lumbricus Terrestris. - Sa queue n'est pas comprimée, mais terminée en pointe, ce qui la rend peu distincte de la tête; les segments sont plus courts que dans cette espèce. - Habite la Suisse. Ces deux Lombrics n'ayant pas de ceinture, se rapprochent da $L$. Vermicularis de Fabricius, dónt nous parlerons ci-après.

Nota. M. Savigny propose le nom de Clitellio, pour des Lombrics d'Othon Fabricius, qui diffèrent des précédens par la présence de deux rangées de soies, tels sont :

1. L. Arenarius, Fabr., Faun. Groen., n०264.

2. Minutus, id., n*265, f. 4 .

Quant au L. Vermicularis, du même auteur, $n^{\circ} 259$, il devrait probablement former encore une coupe nouvelle, à cause de son manque de ceinture; on pourrait lui donner le nom de Astenor. Suirant M. Cuvier (Règ. anim., $2^{\mathrm{e}}$ édit. t. III, p. 211), MM. Audouin et Milne Edwards ont aussi séparé des Lombrics, sous le nom de Trophonia, des especes qui portent, sur chaque anneau, quatre faisceaux de soies longues et brillantes qui entourent la bouche. L'espèce est nommée Barbata, et sera figurée dans leur ouvrage sur le littoral de la. France, pl.10, f. 13-15.

\section{HYPOGEON, SAvig.}

Bouche petite, à deux lèrres, la supérieure avancée en trompe, un peu lancéolée, fendue en dessous; l'inférieure trèscourte. - Soies lougues, épineuses, très-aiguës, au nombre de neuf à tous les segmens, une impaire et quatre de chaque côté; réuuies par paires; formant toutes ensemble, par leur distribution sur le corps, 
Ineuf rangs longitudinaux, savoir : un supérieur ou dorsal, quatre exactement latéraux, et quatre inférieurs. - Corps presque cylindrique, allongé, terminé d'une maniere obtuse. - Les segmens courts et nombreux, plus serrés et moins saillans dans la partie postérieure que vers la bouche; ceux compris entre le vingt-sixième et le trente-neuvième renflés, et s'unissant pour former un collier à la partie antérieure du corps.-Anus longitudinal.

\section{HYPOGEON HIRTUM.}

Savig., Annel., p. 114. - Kougeâtre; corps formé de cent six segmens; les quatorze pores tous visibles; les soies brunes et fragiles; la ceinture est recouverte de soies inégrales disposées irrégulièrement; elle est bordée en dessus de brun.-Cette espèce habite l'Amérique du Nord, et a été trouvée autour de Philadelphie.

\section{NAITES.}

Caractères. Corps allongé, partagé en anneaux peu marqués. - Ils vivent dans les eaux douces.

Genre : Nais.

\section{NAIS, Muller;}

\section{Nais et Stylaria, Lam:; Proto, ОкеN;} Xantho, Dutrocher.

Nous ne pouvons nous dissimuler que ce genre, tel que nous l'adoptons ici, ne renferme un mélange d'espèces très-différentes les unes des autres, par des caractères d'une importance réelle; mais la plupart d'entre elles échappent, par l'exiguité de leur taille, à l'œil de l'observateur, et il nous semble qu'elles ont besoin de subir une étude plus approfondie, avant qu'il soit possible d'établir leurs divisions sur des bases solides; quoi qu'il en soit, ces animaux ont le corps allongé, linéaire, comprimé, formé d'anneaux peu marqués, dépourvu, le plus souvent, de tentacules, et offrant sur les côtés des soies roides.

Ces petits animaux vivent en abondance dans les eaux douces. Trembley et Roësel en ont fait une étude spéciale, ainsi que M. Gruithuisen (Nov. Act. Acad. Cas. Leop cur. nat., t. II, part. 1). Nous allons extraire du Bulletin de Ferussac (1824) le passage suivant, qui est l'analyse de ce dernier travail. L'espèce qui a servi aux observations est la Proboscidea.

Le canal alimentaire est droit et renflé de distance en distance. - Le système vasculaire sanguin est composé d'une artère principale, appliquée en dessus, sur toute sa longueur, au canal alimentaire, ef communiquant, prés de la tête, avec plusieurs gros vaisseaux courts, qui entourent l'œesophage, et qui remplissent les fonctions de cœur. Ceur-ci poussent le sang dans une veine qui règne tout le long du ventre, et d'où le sang est distribué aux divers organes, par des vaisseaux capillaires, et revient ensuite dans l'artère supérieure.- Le cœur n'est autre chose qu'un assemblage de ces vaisseaux capillaires plus développés, où la circulation se fait en sens opposé; et cela explique comment la multiplication artificielle de ces animaux est possible.- Les sécrétions se font aux dépens du chyle qui est contenu dans la cavité générale du corps, et le sang vasculaire est plus particulièrement destiné à la respiration; celle-ci a lieu par l'absorption de l'eau par l'anus, d'où elle est bientốt rejetée. - Le canal alimen. taire peut d'ailleurs remplir les fonctions d'organe respiratoire, en recevant l'air par la bouche. Dans la partie latérale de chaque segment, on remarqne un peloton de vaisseaux, et il serait possible, suivant MI. Gruithuisen, qu'ils servissent à la respiration en versant dans le sang un liquide saturë d'oxigène.

Ces animaux se multiplient de trois ma. nières par des divisions naturelles, par des divisions accidentelles, et, enfin, par des œufs. A certaines époques, la partie postérieure du corps s'étrangle, il s'y développe peu à peu une tête, semblable à celle de la mère, et elle finit par se séparer. Les germes des œufs commencent à paraître près de la tête, et se portent peu à peu en arrière, contenu, dans la cavité générale du corps; arrivé près de l'anus, le dernier segment de. la mère, qui s'est moulé sur un ou plusieurs de ces œufs, tombe avec eux et se trouve, après quelque temps, absorbé par ces derniers.-L'on ne sait si ces animaux sont hermaphrodites.

Nous avons déjà vu que ce genre étoit susceptible d'être divisé. On a effectivement proposé de le répartir dans les coupes suivantes.

\section{PREMIİRE DIVISION.}

$$
\text { (Nais proprement dits.) }
$$

Bouche sans trompe.-Corps non dilaté en arrière.-Pas d'yeux. 


\section{NAIS VERMICULARIS.}

GMel., Syst. nat., éd. 13, t. I, p. 7120. -Roesve, Ins. , 3, pl. 93, f. 1-7.-Long. 7 lig. - Corps un peu épais, rose; pas de coies latérales, mais de longs poils au-dessus de la bouche. - Cette espèce se trouve parmi les Lenticules.

\section{NAIS SERPENTINA.}

Grel., Syst. nat., 13, p. 3121.-RoesEL, pl. 92.- Ressemble à une couleuvre microscopique; une bande longitudinale d'un noir pourpre, en spirale longitudinale, formant trois bandes sur le cou. - Dans les marais.

Les autres espèces de cette division sont le Littoralis et le Caca, Muller, Filiformis, Blainville.

\section{DEUXIÈME DIVISION.}

$$
\text { (Stylaria, Lam.) }
$$

Une trompe. - Deux points oculaires. - Corps non élargi en arrière.

\section{NAIS PROBOSCIDEA.}

GMel., Syst.nat., èd. 13, t. I, p. 3121. -Roesel, Ins., 3, pl. 78, f. 16-17, pl. 79. f. 1. - Les soies latérales solitaires; une longue trompe. - Eaux stagnantes.

\section{TROISIEME DIVISION.}

$$
\text { (Proto, Oken.) }
$$

Pas d'yeux, pas de trompe. - Corps élargi en arrière et y offrant plusieurs tentacules.

\section{NAIS Digitata.}

GmeL. , éd. 13, t. I, p. 3121.

Nota. Il faut aussi rapporter à cette division les espèces nommées Barbata, $\mathrm{Qua}$ dricuspidata, etc. Celle que Muller désigne sous le nom d'Elenquis semble constituer une quatrième coupe, cár elle est munie d'yeux et n'a pas de trompe; nous proposerons de l'appeler Adona.

C'est aussi ici la place du genre Tubifex, de Lamarck; mais, ainsi que l'observe M. Cuvier, Régne anim., 2e édit., t. III, p. 212, il est nécessaire d'en faire un nouvel examen.

Le genre Chatogaster de M. Baer, Nov. Act. Cur., t. XIII, p. 2, n'est, suivant M. de Blainville, qu'une Nais tronquée.

\section{SIPUNCULITES.}

Cette famille a été établie dans ces derniers temps par M. Delle-Chiaye, dans ses beaux Mémoires sur l'Histoire naturelle du royaume de Naples, et sous le nom de Siphunculacées. Les animaux dont elle se compose avoient été rangés, par M. Cuvier, parmi les Ehinadormes sans pieds; mais la couleur rouge de leur sang circulant dans un double système vasculaire, et les organes de la déglutition ayant la forme tubulaire, les ont fait ranger, par le savant $\mathrm{Na}$ politain, parmi les Annelides.

Caracteres. Corps allongé, offrant souvent un renflement terminal; ayant, en avant, un rétrécissement ou col étroit et cylindrique. - Bouche contenue dans une trompe ou tentacule.

Genre: Sipunculus Thalassema.

Tels sont les seuls genres que les travaux modernes ont démontré devoir rentrer dans la classe des Annelides; mais nous ne doutons pas que des observations futures n'y placent aussi les Molpadia, les Minyas, les Priapulıs, les Lithodermes, les Bonellia, les Echiuris et les Sternaspis.

\section{SIPUNCULUS, LINN.}

Corps nu, allongé, cylindrique, formant en avant un col étroit, court et tronquẻ, et se rétrécissant en arrière pour se terminer par un renflement. - Bouche or. biculaire, terminant le col, et placèe à l'extrémité d'une pompe rétractile, cylindrique, faiblement garnie de papilles; anus placé à l'extrémité du corps.

a L'intestin, dit Cuvier (Rég. anim., t. 3 , p. 243 ), part de la bouche, va jusque vers l'extrémité opposée, et revient, en se roulant en spirale, autour de sa première partie. On n'y trouve que du sable ou des fragmens de coquilles. Les nombreux vaisseaux paraissent s'unir à l'enveloppe extérieure, et il y a, de plus, le long d'un des côtés, un filet qui pourrait être nerveux. Deux longues bourses situées en avant ont leurs orifices extérieurs un peu au-dessous de l'anus, et l'on voit quelquefois intérieurement, près de ce dernier orifice, un paquet de vaisseaux branchus qui pourrait appartenir à la respiration. D

L'on trouve ces Annelides sur les bords de la mer; ils se tiennent dans le sable, à peu de distonçe des côtes. lls servent d'ap- 


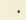


I

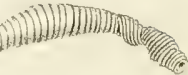
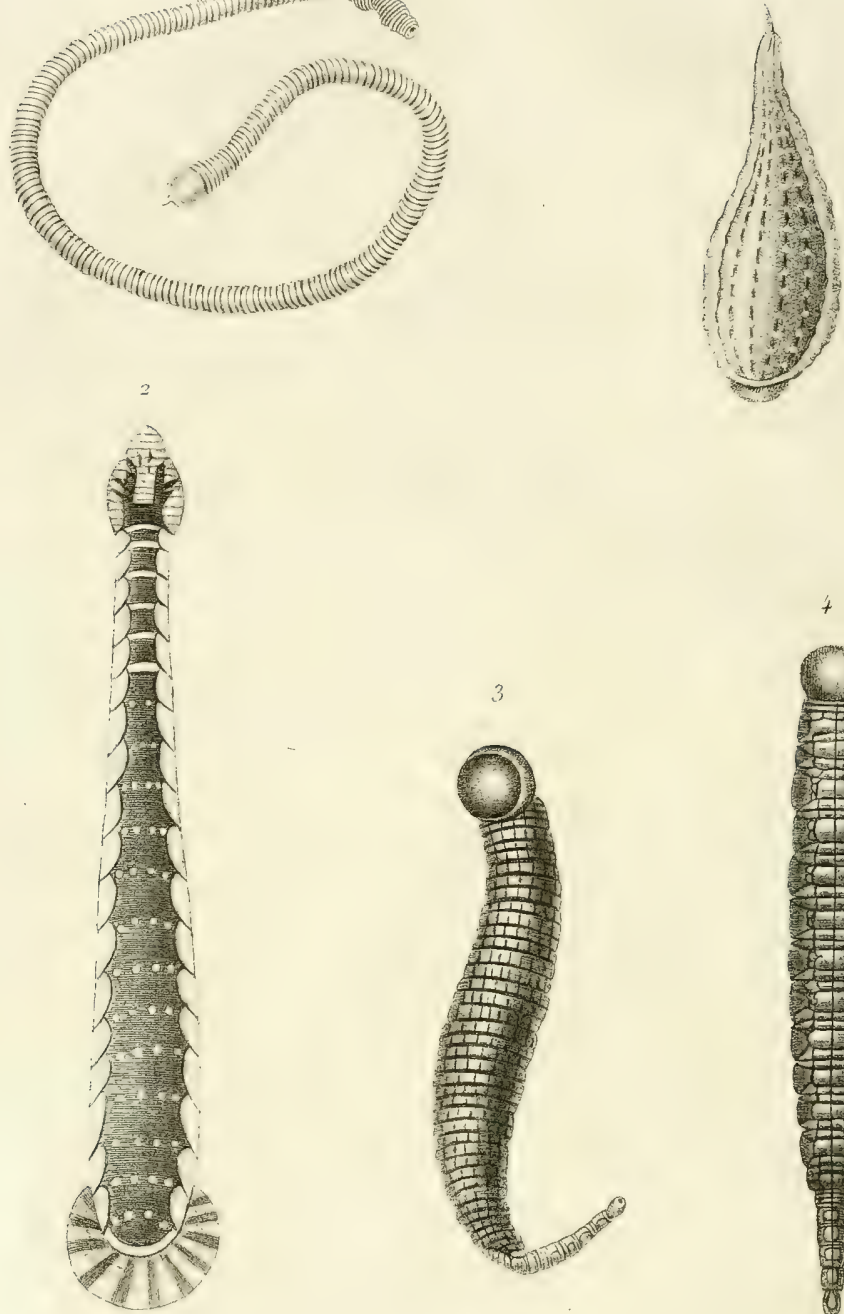

3
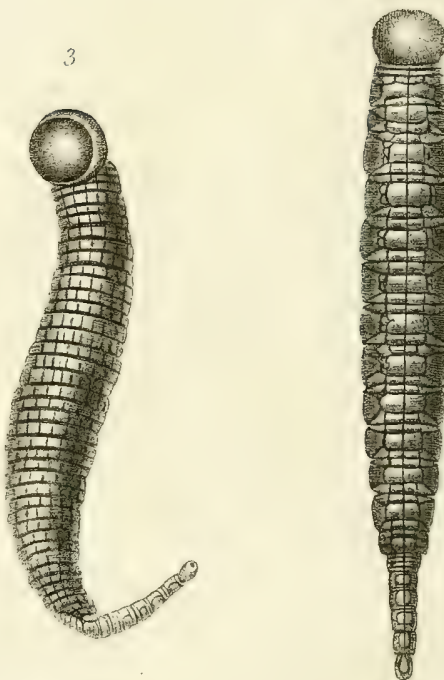

1. Sipunculus Balazophorus .

2. Piscicola Tessellata

3. Albione squalorum, vrue en dessous. 4 . id .... id ... vue en dessus 5. Glossiphonia Complanata. 
pât. L'espèce européenne de ce genre est connue depuis long-temps, et c'est sans doute elle qui a été trouvée dans les étangs salés du Languedoc, par le célèbre Rondelet; les anciens auteurs en citent deux espèces fictives, mais qui se rapportenl à une scule, ainsi que le pensoit Guvier, et que l'a prouvé, dans ces dẹmières annèes, M. Delle-Chiaye.

1. Sipunculus balaxaphorus. (Pl. 6, fig: 1.)

Delle-Chiaye, Mem. - S. Nudus et Saccat"s, LINN., Vermes Macrorhynchoteros, Rond. - Long. 4 à 5 pouc.

Le $S$. Nudus a la peau nue et tendue ; le Saccatus est un individu dont la peau s'est détachée par accident. - Méditerranée.

Nota. Suivant M. Cuvier (Reg. anim., 2 édit.), c'est aussi à cette espèce qu'il faut rapporter le Lumbricus Edulis de Gmel., Pallas, Spec. Zool., 10, 1, 7, qui sert à la nourriture des Chinois, et que les Malais vont chercher au milieu de leurs archipels, et qui forme une des principales branches de commerce de ces régions éloignées.

L'on voit combien peu ces espèces sont encore connues; M. Cuvier en cite encore plusieurs autres; chez l'une, l'épiderme est velu; chez l'autre, la peau est toute coriace; d'autres, de petite taille, percent les pierres sous-marines, pour se loger dans leurs cavités; une autre, enfin, de la mer des Indes, atteint deux pieds de long. Plurieurs sont figurées dans l'Atlas du Dict. des $S c$. nat.

THALASSEMA, Cuv. ;

Lumbricus, Pallas, Gael., Brug.

Bouche très-petite, contenue dans la base d'un tentacule large, courbé et ouvert inférieurement. - Soies lisses, droites, aplaties, formant, à la partie postérieure du corps, deux rangèes circulaires; deux soies plus fortes et crochues, rapprochées l'une de l'autre et placées sous son extrémité antérieure. - Corps très-mou, de forme presque cylindrique, obtus en arrière, atténué en avant, formé d'un grand nombre d'anneaux serrés, peu distincts, et entourés chacun d'un cercle de papilles glanduleuses, saillantes, surtout à la partie postérieure du corps. - Anus petit et en cercle.

\section{THALASSEMA ECHIURUS.}

Pallas, Misc. Zool., p. 146, pl. 2, f. 1-6. - Spicil., Zool. Fasc., 10, p. 3, pl. 1. f. 1-5. - Rupiım, L.4x., Syst. An. sans vertebres, p. 339. - Aquatica, LEACH, Encycl. Brit., suppl., t. I, p. $45 t_{0}$ Vulgaris, Savig., Annel., p. 102, 1. Long. 3 pouc. - D'un cendré clair; tentacule finement ridé en travers, soies d'un jaune d'or très-brillant. - Commun sur les. côtes sablonneuses de l'Océan.

\title{
QUATRIËME ORDRE.
}

\section{ANNELDDES SUCEUSES ET HIRUDHNES,}

SAV.

\author{
ABRANCHES SANS SOIES, Cuv.; \\ hirddinées, Lam., Latr., MIoq. Tand.
}

Le caractère le plus apparent de cet ordre est la forme du corps, qui, à ses deux extrémités, se termine en ventouse. Les organes de la respiration sont ordinairement extérieurs ; les Branchellionites font seules exception. - Le corps est complètement dépourvu de soies de toute espéce. - La tête n'est pas distincte; mais on voit ordinairement des points aculiformes et des mâchoires. - Nous les partageons en trois groupes: les Albionites, les Sanguisugites et Ies Branchillionites. Nous croyons que les Dragonueaux que M. Guvier place à la fin de cet ordre doivent être renvoyés aus vers intestinaux.

\section{ALBIONITES.}

SATgSues albioniennes, Savig. hirudinées albioniennes, MoQ. Tand.

Caractères. Point de branchies, ventouse orale d'une seule pièce, séparée du corps 
par un étranglemeni très-petil; l'ouverlure unilabiée et longitudinale; pas de branchies externes.

Genres: Piscicola, Albione.

PISCICOLA, Lam., Mog. Tand.;

Ihl., Ocken.; Homocharis, Savig.;

Gnatho, Goldf. et Schinz;

Iirudo, LlnN., Muller, Brug. ;

Ichtyobdella, Bцarnv.

Bouche très-petite, placée au fond de la ventouse orale, et vers le bord inférieur. - Ventouse orale d'un seul segment, peu concave, en forme de coupe. - Mâchoires repiésentées seulement par trois points saillans. - Yeux au nombre de huit, réunis par paires. - Ventouse anale double de la ventouse orale, concave, elliptique, non bordée, et terminant le corps d'une maniere oblique. - Corps cylindrique, aminci en avant, formé de segmens nombreux, peu distincts. - Organes générateurs placés sur les $17^{\circ}$ et $20^{\circ}$.

\section{PISCICOHA GEORETRA.}

Linn., Faun. Suec., no 283. - MoQ. Tand., Monogr., p. 131, pl. 7, f. 1. Hir. Piscium, Roeser. Ins.; t. 3. p. 199, pl. 32.-Long. 12 lig.-Corps lisse, grêle, d'un blanc jaunâtre, finement pointillé de brun, avec trois chaînes dorsales, chacune de dix-huit à vingt taches elliptiques plus claires que le fond et non pointillées; la chaîne intermédiaire mieux marquée sur les latérales; deux lignes de gros points bruns-snr les côtés du ventre, alternant avec les taches claires du clos; la ventouse anale rayonnée de brun; cette espece est ovipare; les œufs sont d'un roux jaunâtre, et se trouvent, au rapport de Bergmann, attachés aux poissons. - Elle se trouve dans les eaux douces de l'Europe. Muller l'a trouvée dans le gosier d'un brochet, et, suivant M. Moquin Tandon, elle s'attache de préférence aux cyprins.

\section{PISCICOLA MARGINATA.}

Muluer, Hist. ver'm., t. I, p. 2, p. 46, 374. - Moe. Tand., p. 132, pl. 7, f. 2. Hir. Cephalota, CAR., Monogr. hirud., p. 298,8, pl. 12, f. 9. - Long. 9 lig. Corps varié de brun et de verdâtre; le milieu du dos est garni de lignes transversales et blanches, qui, lorsque l'animal est étendu, se changent en une double séric de taches presque carrées; l'on voit, de cha- que côté, une double série longitudinale de points de même couleur; le ventre est jaunâtre, sans taches. - Cette espece habite les ruisseaux du Piémont; elle est vivipare; et, suivant M. Carena, l'on peut apercevoir les œufs et les petits dans le ventre de la mère.

3. piscicola tessellata. (Pl. 6, fig. 2.) Muller, Hist.Verm., t. I, p. 2, p. 45, n 173. - Tessellata, Bosc, Hist. des Ver's, t. I, p. 247. - MoQ. TAND., Monogr., p. 134, pl. 7, f. 3.-Hir. oscillatoria, Saint-Aн., Ann. Soc. Linn., t. 11 I, p. 153, pl. 8. - Long. 8 lig. - Corps oblong, violacé, offrant sur le dos sept rangées longitudinales de points jaunes, dont les trois inlermédiaires plus petites que les autres; Ies côtés marqués de lignes brunes et de taches jaunes ; ventre d'un cendré bleuâtre, marqué de deux rangées de taches rouges; ventouse anale d'un vert bleuâtre.

L'on ne sait si cette espéce est vivipare ou ovipare. Suivant M. Itier, un individu, renfermé dans un bocal, produisit, en huit jours, plus de soixante petits de la grosseur d'un fil. - Cette Hirudinée se trouve dans les eaux douces; elle s'attache aux poissons. M. Moquin Tandon l'a prise dans les environs d'Agen.

ALBIONE, SAvig., Mog. TAND.; Pontobdella, Luach ; Gol, Ocken, Blaryv.; Phormio, Goldruss et Scurvz;

Hirudo, Linn., Audrov., Rondel., Baster, Barb., Bose, Chamisso.

Bouche très-petite, placée au fond de la ventouse orale, et vers le bord inférieur. Ventouse orale d'un seul segment, très-concave, en forme de godet. - Mâchoires représentées par trois points saillans peu visibles. - Yeux au nombre de six, placés transversalement derrière le bord supérieur de la ventouse. - Ventouse anale terminale, très-concave et bordée. - Corps cylindrique, un peu conique, aminci en avant, formé d'anneaux nombreux (une soixantaine) généralement hérissés de tubercules, de pointes ou de verrues. - Les huit segmens compris entre le quinzième et le vingt-quatrieme, courts, serrés, présentant les organes de la génération dans la jonction du dix-septieme au dix-neuvieme, et dans celle du vingtième au vingt-unième.

Les espèces de ce genre sout généralement remarquables par leur couleur cen- 
drée, terne, leur penu très-épaisse, coriace, couverte de tubercules. - Elles habitent dans la mer, et s'attachent aux poissons, et particulièrement aux grandes espèces carnassières, telles que les requins, les raies, et meurent aussitôt qu'on les place dans l'eau douce, mais y vivent long-temps, suivant Battaro, si on y fait dissoudre du sel.

M. Moquin Tandon nous a fait connaître l'anatomie de ce genre. L'œsophage est long et très-étroit. - Les estomacs médiocrement larges, peu distincts, et réduits à un tube longitudinal sinueux sur ses bords, et plus large postérieurement. - Il n'y a qu'un seul cœecum assez large et de la longueur du rectum. - Celui-ci est étroit, sinueux et dilaté en arrière de manière à former un cloaque près de l'ouverture de l'anus. - La vésicule séminale est très-petite, à peu près de la forme de celle des Nephelis. - Les canaux déférens sont courts et dirigés antérieurement. - Les testicules sont à demi déployés.-Les vésicules séminales supplémentaires sont très - petites, ovales, presque pyriformes; on n'en observe que cinq paires.

J'ai vérifié tous ces faits anatomiques sur une espèce nouvelle de ce genre, dont on trouvera ici la description. L'œsophage m'a paru plus élargi et assez grand, et j'ai compté six paires de vésicules séminales supplémentaires.

\section{ALBIONE MURICATA.}

Linn., Faun. Suec., p. 2084. - Moe. TAND., Monogr., p. 136, pl. 714. - Hir. marina, Rond, Pisc., lib. de Ins. et Zooph., p. 111, cap. 7. - Spinulosa, Leach, Misc. Zool., t. II, p. 12,3 , pl. 65 , f. 12 . Long. 45 lig. - Corps d'un cendrè roussâtre, quelquefois un peu verdâtre; tous les segmens partant des rangées circulaires de tubercules épineux, d'une couleur plus claire; ils sont séparés de trois en trois par un segment plus petit, ainsi que les tubercules qu'il porte. Cette espèce est quelquefois tachetee de brun. - Elle est commune dans l'Océan et dans la Méditerranée; quel. ques individus ont des taches brunâtres en dessus.

Cette espèce est aussi figurée dans le Dict, des Sc. nat.

\section{ALMHORE PISGIUM.}

Bast., Opusc. subsec., t. I, f. 2, p. 8295, pl.10, f. 2.-Verrucosa, Flemi., Mem. Wern., 2, p. 245. Verrucata, Leach, Misc. Zool., t. II, p. 11; 2, pl. 64, f. 1-2.
- Long. 45 lig. - Corps d'un gris roussâtre, couvert de vcrrues non épineuses, rousses; segmens séparés de trois en trois par un plus grand portant des verrues plus grosses et rousses; le dos est quelquefois marqué de taches brunes. - Commune dans la Méditerranée et l'Océan.

\section{ALBIONE AREOLATA.}

LEACH, Misc: Zool., t. $11 \mathrm{I}$, p. 10.1, f. $63 .-\mathrm{L}$ 'on ignore la patrie de cette espèce, qui ne doit probablement pas rentrer dans ce genre et que l'on ne connaît que par la très-courte description de Leach. Le corps serait uni, subaréolé, à segmens dépourvus d'épines et de tubercules.

4. Albione sQualondr. (Pl. 6, fig. 3 et 4.)

Long. 36 lig. - Intièrement d'un brun marron obscur; uniforme; corps déprimé, très-étroit vers la ventouse orale, allant toujours en s'élargissant jusqu'à l'extrémité opposée, qui est très-large et forme un large disque, comme dans le genre $P_{i s c i-}$ cole; cette partie formant de beaucoup la portion la plus épaisse du corps, il est entièrement couvert de verrues non épineuses et formant des sillons transversaux, et séparés de trois en trois par un rétrécissement notable.

Cette espèce ne pourrait, par la présence des tubercules, être confondue qu'avec les deux que nous venons d'énumérer; mais son corps très-élargi en arrière et la disposition de ses segmens l'en distinguent suffisamment. - Elle se trouve en grande abondance sur les branchies d'une très-grande espèce de squale qui habite les côtes du Mexique, et qui atteint vingt-cinq pieds de long; elle se réunit en familles nombreuses, et adhère aux ouvertures des branchies; elle varie pour la couleur. Des indi. vidus plus petits étaient rougeâtres, et d'autres noirs. Cette Annelide a été rapportée par M. Edouard de Chaniac, chirurgien de la marine royale, et embarqué, à cette époque, sur le brick l'Adonis.

\section{ALBIONE VITTATA.}

Chamisso et Eisenhagdt, Cur. Act. Nat., t. II, part. 2, pl. 24, f. 4.-C CAREN, t. X, pl. 24, f. 4 .

\section{ALBIONE INDICA.}

LrNo, Syst. nat., édit. 12, p. 2, 1079. 1.-Bose, Hist.nat. art.Vers, t. I, p. 245 . - Corps très-déprimé, roux, formé de cent segmens élevés et muriqués; bouche très-dilatée.-Celte espèce, qui se trouve 
dans les mers des Indes-Orientales, est peu connue et n'a pas été observée depuis Linné.

\section{ALBIONE LAEVIS.}

Buarvy., Dict. Sc. nat., t. LVII, p. 557, Sungsues, pl, 64 .

\section{SANGUISUGITES.}

Savgsues bdeli.ienNes, Savig. hirudines bdelliennes, Moq. Tand.

Caractéres. Ventouse orale composée de plusieurs pièces, unie avec le corps sans étranglement. - Ouverture sensiblement transversale, comme bilabiée. - La lèvre inférieure rétuse. - Pas de branchies externes.

Genres : Glossiphonia, Homopis, Hirudo, Limnatı, Aulastoma, Nephelis, Trochetia.

GLOSSIPHONIA, JoHnson;

Erpobdella, Lam., Buarnv.; Helluo, Okex; Clepsine, Sav., Moq. Tand., Cuv. ;

Glossopora, Johnson (OLIM);

Hirudo, Linn., Berg., Kirby.

Bouche grande, munie à l'intérieur d'une sorte de trompe simple, cylindrique, en forme de tube et exsertile. - V entouse crale peu concave, à lèvre supérieure avancée en demi-ellipse, et formée des trois premiers segmens, le dernier plus grand et oblus. - Mâchoires représentées par trois plis peu visibles. - Yeux au nombre de deux, de quatre ou de six, placés sur deux lignes longitudinales. - Ventouse anale inférieure, moyenne, débordée des deux côtés par les derniers segmens. - Corps un peu crustacé, pellucide, déprimé, légèrement concave en dessus, très-plat en dessous, acuminé en avant, formé de soixante-seize segments. - Organes générateurs placés sous le vingt-cinquième et vingt-sixième et le vingt-septieme et vingthuitième. - L'œsophage est raccourci. Les estomacs nombreux et offrant plusieurs lobes. - Les deux cœcum très-grêles, écartés, et ne reposant pas sur l'intestin rectum. - Le rectum étroit et sinueux.

Les Glossiphonia se trouvent dans les eaux limpides des lacs et des ruisseaux; ils montent souvent à la surface et se renversent pour se laisser emporter par le courant. Ils meurent dès qu'on les sort de l'eau. Ils se contractent en boule. Ils marchent à la manière des chenilles arpen- teuses, et se promènent, suivant M. Moquin Tandon, sur la surface de l'eau, à l'aide de leurs ventouses.

\section{1. glossmonoxia complanata. (Pl. 6,} fig. 5.)

Lins., Faun. Suec. 2082. - Sexoculuta, Berg., Act. Stock., 1757, p. 313, pl. 6, f. $12-13 \cdot 14 .-$ Crenata, Kirdy, Trans. Soc. Linn., t. 2, p. 316, pl. 29. - Tuberculata, Jons., Treat. Med. Leech, p. 25. - Long. 1 pouc. Larg. $\frac{1}{3}$ lig. - Corps large, d'un cendré verdâtre, quelquefois roux avec des points bruns - Dos marqué de raies brunes et de mâchetures blanches. - Ventre pâle. - Cette espece a six yeux. Elle se trouve dans les eaux douces de l'Europe, et attaque les Limnés et les Planorbes.

\section{Giossiphonia mioculata.}

Berg., Act. Stock., 4, t. VI, f. 9 -11:Stagnalis, Linn., Faun. Suec., 2081. Crenale, Joнn., Treat. Med., Leech. p. 28. Punctata, John. Phil. Trans., 1819, p. 346, pl. 17, f. 11-13. - Stagnarum, Derнm., Hist. nat. des Sangsues, p. 10-20. - Pulligera? Daub., Recueil de mémoires, p. 19, pl. 1, f. 1 - 3. - Long. 10 lig. Larg. 1 lig. $\frac{1}{2}$. - Corps étroit, transparent, presque gélatineux, d'un gris livide parsemé d'atomes bruns et roux, qui, se rapprochant lorsque l'animal est contracté, le font paraittre de couleur plus obscure; le dessous du corps est concave et plus clair que le dessus. - L'on trouve cette espèce dans les eaux douces de presque toute l'Europe; les petits sont blancs; ils adhèrent par le disque postérieur a la partie moyenne du corps de leur mère, qui est dilatée et courbée en voûte. M. Savigny en a compté une quinzaine.

\section{3. grossiphonia paludosa.}

Cakena, Suppl. Monogr. Gen. Hirud., p. 231. - MoQ. TAND., Mon., p. 103, pl. 4 -3. - Leng. 15 lig. Larg. 2 lig. $\frac{1}{2}$. D'un jaune verdâtre, avec des petits points verts, qui, lors de la contraction, font paraître l'animal presque entièrement de cette couleur.

Suivant M. Carena, qui le premier a fait connaître cette espece, le canal intestinal se voit à travers le corps; les estomacs sont comme pinnés et bifides. - L'on trouve cette espèce dans les mares, près de Carmagnale (environs de Turin).

\section{GLOSSIPHONia trioculata.}

Carena, Mlonogr., p. 303,10, pl. 12 , f. 22. - Suppl., 334. - Carena, MoQ. 
Tand., Monogr., p. 105, 4, pl. 4, f. 4. Long. 3 lig. $\frac{1}{2}$. Larg. 1 lig. - D'un cendré blanchâtre, pellucide. - Corps couvert en dessus, à l'exception dela tête et des bords, de petits points verdâtres. - Cette rare espéce se trouve en Italie, dans le lac d'Avigliana; elle est ovipare; on aperçoit les mufs dans le ventre de la mére; ils sont d'un vert pâle, très-ronds et disposés régulièrement ; ils deviennent ensuite blanchâtres-transparens, prennent la forme d'un croissant; chacun ne contient qu'un seul fuetus; les petits sont roussâtres et pellucides. Cette especce a six yeux. - Se trouve en Italie.

\section{GLOSSIPHONIA HETEROCLYTA.}

Linn., Faun. Suec.-Hyalina. Mulden, Hist. Verm., t. I, p. 2, p. 49, 176. Ledenuulh, Amus. Micros., p. 165, pl. 84, f. $k-q$. - Trembl., Hist. des Polyp., Mém. 3, p. 147, pl 7, f. 7. - Long. 7 lig. Larg. 1 lig. $\frac{1}{2}$ - Corps jaune, pellucide, large en arrière, aminci en avant. Sur le dos, des lignes longitudinales de points obscurs; des lignes transverses de point roux écartés, et de taches noires et jaunes encore plus éloignées. Les yeux sont au nombre de quatre, et, suivant d'autres, de six. - Cette espèce se trouve en Europe, sur les plantes aquatiques; elle se nourrit de planorbes et de physes.

\section{GLOSSIPIONIA CIRCULANS.}

Sowerby, Brit. Miscell., t. VII, p. 6. - Johnson, Treat. Med., LEaCH, p. 27. - Moq. TAND., Monog., p. 107, 6. Long. 1 pouc. - Corps oblong, pointu vers la ventouse orale, convexe en dessus èt légèrement aplati en dessous, couleur d'un rouge mat; dessous du corps plus pâle. - L'on trouve cette espèce dans la Tamise. M. Moquin Tandon l'a placée parmi celles qui sont mal connues.

\section{7. gLOSSIPHONIA TRICOLOR.}

GraY, Zool. Miscell., 1, p. 5. - Corps ovale; châtain bordé de jaune clair. - Dos offrant deux bandes longitudinales larges ct blanches, et trois autres étroites et noires. - Points oculaires au nombre de cinq paires. - Disque antérieur sous-marginal Jancéolé; le postérieur orbiculaire. Cette espéce se trouve dans les fossés, au Bengale; elle a été rapportée par M. ie général Hardwicke.

HEMOPIS, SAVIG.

Hivudo, Lam. - Hypobdella, Buarnv.

Bouche grande. - Ventouse orale peu concave, à lèvre supérieure très-avancée, presque lancéolée, formée par les trois premiers segmens; le terminal plus grand et plus obtus. - Mâchoires grandes, dures, ovales, non comprimées, offrant deux rangées de denticules émoussées et peu nombreuses. - Yeux au nombre de dix, placés sur une ligne arquée, dont six sur les premiers segments, les quatre autres plus petits, deux sur le troisième, et autant sur le sixieme.-Ventouse orale, oblique, simple et à peine rayonnée.-Corps allongé, un peu déprimé, très-mou, formé de quatre-vingtdix-huit segmens égaux et courts; organes générateurs placés entre le vingt-septieme et le vingt-huitième, et entre le trente-deuxième et le trente-troisième. - L'œsophage est court. - Les estomacs sont au nombre de onze, très-distincts, très-sinueux, et comme formés de cinq lobes, dont les deux postérieurs plus allongés que les autres. Les deux cœcums sont larges, sinueux, et de la lougueur du rectum, qui est très-grêle. - La vésicule séminale est pyriforme; la grosse extrémité dirigée en arrière. Les canaux déférens sont très-courts et sinueux. - Les testicules sont fort gros, irréguliers, ovales, et rapprochés entre eux. - Les vésicules séminales supplémentaires sont assez grosses, globuleuses et comme sessiles; on peut en compter huit (Moq. Tand.). - Ces hirudinés se trouvent dans l'eau douce des mares et des fossés. Ils se contractent en olive. L'on a cru à tort que leur morsure était fâcheuse. Ils n'ont pas la possibilité d'entamer la peau des animaux vertébrés; c'est donc par erreur que Linné dit que neuf suffisent pour tuer un cheval. Ils se nourrissent de lombrics.

\section{HAMOPIS SANGUISUGA.}

Berg., Act. Stock., t. VI, pl. 3 - 4. Linn. Faun. Suec., 2078. - H. Vorax, Rax, Jons. Treat. Med. Leech, p. 82. Moq. Tand., Monog., p. 108, 1. - Long. 2 à 3 pouc. Larg. 4 à 5 lig. - Corps déprimé, très-lisse, d'un brun verdâtre plus ou moins couleur d'olive, marqué en dessus de six raugées de taches obscures; les bords sont jaunes; dessous du corps d'un noir verdâtre plus foncé que le dessus, mais sans taches. - Cette espèce varie beaucoup pour les couleurs; elle présente quelquefois en dessus une large bande d'un roux vif; d'autres fois elle est sans tache et de couleur presque noire. --On donne vulgairement à cette Annclide le nom de Sang - 
sue decheval ou de Sangsuc noive. - Elle se trouve communément dans les eaux douces et les marais de presque toute l'Europe.

\section{HJMOPIS NIGRA.}

Savig., Aninel., p. 116, 2. - MoQ. TAND., Monog. p. 110, n ${ }^{\circ}$ 2. - Long. 1 lig. $\frac{1}{2}$ à 2 pouc. - Corps allongè, presque cylindrique lorsqu'il est étendi, noir en dessus, d'un cendré obscur en dessous, sans taches; mâchoires non comprimées ayant daus quelques individus, outre les denticules, un pelit crochet mobile. - On trouve cette espece aux environs de Paris, dans l'étang de Gentilly.

\section{HOENOPIS LUGTUOSA.}

Sav., Annel., p. 116, 3.-Moq. Taxd., Monog.; p. 110, 3. - Long. 1 pouc. à 1 pouc. $\frac{1}{*}$ - Corps cylindrique, noir en dessus, avec quatre rangées de points plus obscurs; dessous du corps noirâtre. - Environs de Paris.

\section{HOEMOPIS LACERTINA.}

Sav., Annel., p. 117, 4.-Moq. Tand., Monog., p. 111 , 4. - Long. 1 pouc. Corps légèrement déprimé; brun en dessus, avec deux rangées flexueuses de points noirs inégaux, deux plus gros et plus intérieurs, alternant régulièrement avec trois plus petits et plus extérieurs; deux autres rangées latérales de points peu visibles; dessous du corps d'un brun clair ; ventouse anale lisse. - Environs de Paris.

\section{HIRUDO, LINN.; \\ Sanguisuga, Sav., MoQ. Tand., Cuv.; Jatrobdella, BLanNy.}

Bouche grande. - Ventouse orale peu concave; la lèvre supérieure très-avancée, presque lancéolée, formée par les trois premiers segmens; le terminal plus grand et obtus. - Mâchoires dures, très-comprimées, à deux rangs de denticules nombreux, très-pointus et très-serrés, d'autant plus gros et plus aigus qu'ils sont plus rapprochés du bord extérieur. -- Yeux au nombre de dix, peu saillans, six sur le premier segment, deux sur le troisième, et deux sur le sixième; ces quatre derniers plus petits que les autres. - Ventouse anale moyenne, terminée obliquement, légèrement sillonnée dans sa cavité. - Corps obtus en arrière, rétréci graduellement en avant, allongé, sensiblement déprimé, composé de segmens nombreux, courts, égaux, saillans sur les côtés, très-distincts ; le vinglseptième ou vingt-huitième et le trentedeuxième ou trente-troisième, portant les orifices de la génération. - L'œsophage esi très-court. - Les estomacs sont au nombre de dix; ils sont sinueux et comme bilobés. - Les deux cœecums sont larges, sinueux, et de la longueur du rectum, qui est extrêmement grêle. - La vésicule séminale est pyriforme; la partie la plus renflée étant dirigée antérieurement. - Les canaux défẻrens sont courts, étroits et sinueux. Les testicules sont ovoïdes et plus ou moins écartés l'un de l'autre. - Les vésicules séminales supplémentaires sont petites, pyriformes et portées par un pédicule assez long; on peut en compter neuf paires (Moq. Tand.):- Les Hirudo se trouvent dans les eaux douces des mares, des fossés, etc. Elles vivent assez long-temps hors de l'eau, et se contractent souvent en forme d'olive. Elles ont beaucoup d'ennemis, tels que les poissons, les oiseaux, beaucoup de larves aquatiques d'insectes. Elles se détruisent souvent aussi entre elles et saignent celles qui sont gorgées de sang. Le sel fait mourir les Sangsues, et on l'emploie souvent pour faire lâcher prise à celles qui sucent avec trop d'avidité. L'on sait le parti que la médecine tire de ces animaux; celle dont on se sert de préférence est la sangsue Officinale. L'on a remarqué qu'elles avaient l'habitude de monter á la surface de l'eau avant la pluie, et dans quelques parties de l'Europe on s'en sert comme de baromètre; mais l'on s'est assuré que l'on ne peut se procurer ainsi que des renseignemens bien douteux.

\section{Hirudo officivalis. (Pl, 7.$)$}

Savign., Annel., p. 114, 2.-MIoo. T'AND., Monogr., p. 112, n० 1, pl. 5, f. 1 . -Provincialis, Canena, Monogr., p. 282, pl. 11, f. 9-อ̃. - Long. 4 pouc. - Corps d'un vert noirâtre, clair; six bandes longitudinales ferrugineuses, tachetées de points noirs, sur leur milieu et leurs bords; dessous du corps d'un vert jaunâtre, sans taches, et avec un large bord noir; segmens très-lisses.

Cette espèce atteint souvent une grande taille; elle varie pour les couleurs; les bandes dorsales sont quelquefois interrompues d'espace en espace ; d'autres fois elles sont réduites à des points noirs plus ou moins nombreux; d'autres fois, encore, elles se réunissent au moyen de mouchelures transversales. 


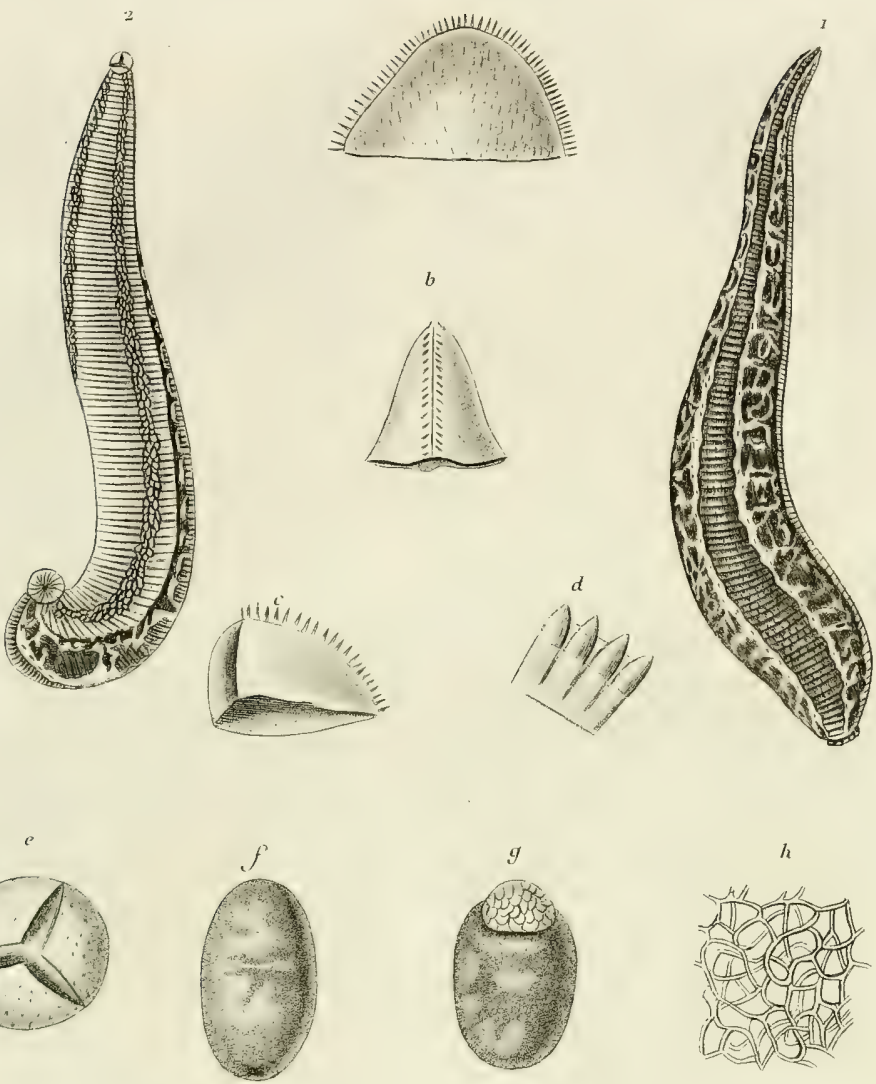

$k$

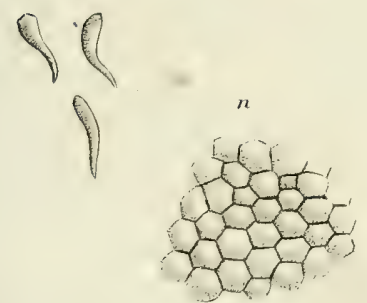

$m$
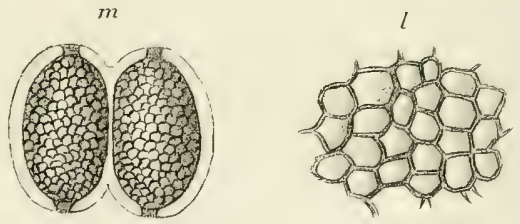

1. Ilivudo officinalis (S angsue ordinaire) pue on desisus id. pue en dessous. a, b. c. machoires grossies: d. Denticules grossies. e. blessure produite par la machoire :f' Cocon. q. id.priné dune pqrie du réscau spongieux. h. substance spongieuse vue au microscope, lijeunes sangsypes sortant du cocon. L surfuce exterieure de la capsule vue au microscope m. cocon owert. $n$. surface interieure de la capsule. 

Cetle espèce est assez commune en France; elle est ovipare; les germes sont renfermés, au nombre de six à dix-huit, dans de petits cocons, de forme ovoïde, formés, à l'extérieur, d'une enveloppe spongieuse, et, à l'intérieur, de deux enveloppes membraneuses; à chaque extrémite du grand diamètre, l'on voit deux petits opercules qui, en se détachant, laissent à découvert deux petites ouvertures par où sortent les petites sangsues.

\section{IIIUUNO MEDICINALIS.}

Ray. Ins., 3.-Linn., Faun. Suec., 2079. - H. Officinalis, Derн., Hist. nat. des Sangs., p. 11.- Long. 4 pouc. - D'un vert foncé, marque de six bandes longitudinales d'un ferrugineux clair, marquees chacune de taches noires ordinairement Iriangulaires, quelquefois carrées, se confondant rarement; dessous du corps verdâtre, bordé et taché de noir ; segmeus hérissés de mamelons grenus. - Cette espèce se trouve dans les eaux douces des parties tempérèes de l'Europe.

\section{IITRUDO OESCURA.}

Moq. Tand., Monogr., p. 116; pl. 5, f. 3. - Long. $18 \mathrm{lig}$. - Dessus du corps d'un brun obscur, rarement roussâtre, ofirant six bandes longitudinales rousses, à peine plus claires que le fond ; dessous du corps verdâtre, parsemé d'une infinité de petits points noirs, surtout à la partie postérieure. - L'on trouve cette espèce aux environs de Montpellier.

\section{IIRUDO VER BANA.}

Carten, Monogr. p. 285, 3. pl. 11, f. 6, - Moq. Tand., Monogr., p. $117, \mathbf{n}^{\circ} 4$, pl. 6, f. $1 .-$ Long. 2 pouc. $\frac{1}{2} \cdot-$ D'un vert sombre, ayant sur le dos des bandes brunes, transversales, parallèles, se changeant; lorsque l'animal est étendu, en deux lignes longitudinales interrompues; dessous du corps d'un vert jaunâtre, tantôt sans taches, ayant quelquefois de très-petits points noirs. - Cette espèce se trouve dans le LacMajeur.

\section{HIRUdO INTERRUPTA.}

Moq. TAND., Monogr., p. 118, 5, pl. 6 , f. 2 . - Long. 3 pouc. $\frac{1}{2}$ - $-D^{\prime}$ un vert obscur, assez brillant, ayant quelquefois une teinte roussâtre; marqué en-dessus de bandes dorsales interrompues et représentant des taches carrées et isolées, écartées de cind anneaux; dessous du corps jaunâtre, quelquefois largement tacheté de noir, ayant sur les côtés deux bandes de même couleur et en zig-zag; segmens tuberculeux; les taches sont quelquefois unies longitudinalement par de petits traits orangés ou noirs. - On trouve cette espèce aux environs de Montpellier.

\section{MIRUDO GRANULOSA.}

Savig., Annel., p. 115, 3.- MoQ. Tand., Monogr., p. 119,6 . - D'un vert brunâtre, avec trois bandes plus obscures sur le dos; segmens munis sur leur contour d'un rang de grains ou de tubercules. Cette espèce se trouve dans l'Inde, suivant M. Leschenault; elle est employée par les médecins de Pondichéry. C'est probablement elle qui est connue dans l'Indoustan sous le nom de Jonc.

M. Moquin Tandon, dans son excellente Monographie des Hirudinées, place à la suite de ces espèces les suivantes, qu'il considère comme mal connues.

\section{HIRUDO TROCTINA.}

Ray., JoHn., Treat. med. Leech, p. 31, 32. - Long. 3 pouc. - Corps brun, ayant sur le dos des anneaux dorés, entourant des taches noires; ventre d'un vert jaunâtre taché de noir.

Suivant M. Johnston, cette sangsue se trouve dans les rivières d'Angleterre, et s'attache fortement aux poissons; elle est einployée, dans ce pays, au défaut des $H$. Medicinalis et Officinalis. On. lui donne en Angleterre le nom de Trout-Leech (sangsue-truite), à cause du rapport que présentent ses taches avec celles de ce poissor.

M. Moquin Tandon pense que c'est peut-être l'Hirudo Interrupta.

\section{HIRUdo EGYPTIACA.}

LaRkey, Hist. chir. de l'armée d'Orient, p. 54.-Bosc., Dict. d'hist. nat., t. XXX, p. 130.-Cette espèce n'est pas plus grosse qu'un crin de cheval; mais lorsqu'elle est saturée de sang, elle acquiert la taille d'une sangsue ordinaire ; elle habite en grand nombre dans les eaux douces et bourbeuses de l'Egypte. Ėlle a causé des maladies très-graves à beaucoup de soldats de l'armée d'Egypte, qui l'avaloient en buvant; elle s'attache avec force à l'entrée de la gorge, et l'on ne pouvoit s'en débarrasser qu'en avatanl beaucoup d'eau saturée de sel.

\section{HIRUDO ZEYLANICA.}

VAlmoNt de Bomare, Dict. d'hist. nat., t. VIII, p. 69.-Bosc, Dict. d'hist. nat. (Déterville), t. XXX, p. 140,- Long. 
à 3 pouc.-Corps très-grêle, pas plus gros qu'un crin de cheval, mais pouvant acquérir la grosseur d'une plume d'oie.-Cette espèce se trouve sous l'herbe, à Ceylan; dans la saison des pluies, elle monte aux jambes des voyageurs, et suce leur sang avec avidité.

\section{HIRUdO SIVAMPINA.}

Bosc, Hist. nat. des Vers, t. I, p. 247 , pl. 8-5.-Dict: d'hist. nat. (DéTEhville), t. XXX, p. 140 , pl. 10. - Corps dilaté, rugueux en-dessus, vert varié de brun, bords et extrémités tachetés de blanc; dessous du corps $d^{4} u n$ gris brillant ou plombé. - Cette espèce se troure dans les marais de la Caroline du Sud, et s'attache aux tortues et aux grenouilles; c'est par erreur que M. Moquin Tandon l'a fait venir de l'Amérique Méridionale.

\section{Hinudo JAPONICA.}

Bosc, Dict. d'hist. nat. (DÉTerville), t. XXX, p. 140.-Suivant M. Bose, l'on trouve dans le Voyage du capitaine russe Krusenstern, pl. 65, la description d'une sangsue du Japon, à corps jaune, pointillé de rouge; elle atteint, lorsqu'elle est contractée, la grosseur d'un ouf de poule.

Nota. Quelques autres Sangsues, venant d'Alger, sont décrites par M. Gervais dans le Bulletin de la Société des Sciences naturelles.

\section{LIMNATIS, Mog. TAND. Bdella, Savig. \\ Palceobdella, Blainv.}

Bouche moyenne. - Ventouse orale assez concave, et en forme de godet; la lèvre supérieure peu avancée, profondément canaliculée en dessous, formée de trois à quatre derniers segmens; le terminal plus grand, très-obtus. - Mâchoires grandes, dures, ovales, légèrement carénées, dépourvues de denticules. - Yeux peu distincts, au nombre de huit, dont six placés en demi-cercle sur le premier segment, et les deux autres sur le deuxième, et plus écartés.-Ventouse anale grande, se terminant obliquement. - Corps allongé, cylindrique, conique, déprimé, à segmens nombreux, courts, trés-égaux et fort distincts les uns des autres. - Les orifices de la génération placés sur le vingl-septième ou vingt-huitième, et sur le trente-deuxième et le trente-troisième.

\section{Linvatis NILOTICA.}

Sav., Annel., p. 113, 1, pl.5, f. 4.-
MoQ. TAND., Monogr., p. 122, 4.- Long. 5 pouc. - D'un brun marron, avec le dessous d'un roux vif; corps formé cle quatrevingt-dix-huit segmens égaux, carénés sur leurs contours; ventouse orale de dix segmens, en y comprenant les quatre demi-an. neaux de la lèrre supéricure, sous laquelle elle est divisée en deux lobes, par un canal triangulaire, bordé, très-profond, dont la base correspond a la mâchoire impaire ; ventouse anale quatre à cinq fois plus grande que l'orale, dirigée obliquement en arrière, mince à la circonférence, à disque lisse et très-simple. - Cette espèce se trouve dans les eaux douces de l'Egypte, et surtout dans le Nil.

\section{AULASTOMA, Mog. Tand.}

Bouche très-grande. - Ventouse orale peu concave, à lèvre supérieure presque lancéolée, avancée en demi-ellipse.-Mâchoires représentées par une multitude de petits plis saillans. - Yeux au nombre de dix, placés sur une ligne courbe, les quatre postérieurs plus petils et plus isolés. - Ventouse anale assez petile, oblique; l'anus très-large.-Corps allongé, un peu déprimé, rétréci en avant, composé de quairevingt-quinze segmens assez distincts, portant les organes de la génération entre le vingt-septième et le vingt-huitieme et entre le trente-unième et le trente-deuxieme.

Suivant M. Moquin Tandon, ces Hirudinées meurent aussitôt qu'on les sort de l'ean. Lorsqu'ils nagent leur corps paraît cylindrique, et ne s'aplatit que lorsqu'on les retire de leur élément.

Nous devons au même naturaliste les dé. tails suivans sur leur anatomie :

L'œsophage est assez long, formé d'une multitude de plis longitudinaux. - Les estomacs, au nombre de sept, sont peu distincts les uns des autres, et réduits à un tube assez étroit, droit. allongé et marqué, d'espace en espace, par des étranglemens correspondant à des espèces de sphincters intérieurs. - Les deux cœcums sont trèsgrêles, sinueux, et plus étroits que le rectum.-Celui-ci est très-long, sinueux, rétréci et presque contourné en spirale, dans ses trois quarts postérieurs; il est renflé dans sa partie la plus proche de l'anus, et forme une espèce de cloaque. - La vésicule sẻminale est très grosse, pyriforme ; l'extrémité obtuse est dirigée antérieurement, son canal est très-allongé et replié plusieuı's fọis sur lui-même.- Les canaux déférens 
sont trés-développés. - Les testicules sont à peu près ovales; on peut en compter douze paires.

\section{AULASTOMA NIGRESCENS.}

MoQ. TAND., Monogr., p. 124, 1, pl. 6, f. 3. - Long. 2 à 3 pouc. Larg. 3 à 4 lig. -D'un cendrè noirâtre, assez foncé, immaculé; dessous du corps noirâtre, mais un peu plus clair que le dessus.-Cette espèce se trouve aux environs de Lyon; elle n'est pas employée en médecine.

\section{NEPHELIS, SAVig.;}

Erpobdella, Lamark., Blainv.; Helluo, OKEN ;

Hirudo, LinN.

Bouche très-grande. - Ventouse orale peu concave, à lèvre supérieure avancée en forme de demi-ellipse, formée des trois premiers segmens, le terminal plus grand que les autres et plus obtus. - Mâchoires représentées par trois plis saillans. - Yeux au nombre de huit, dont quatre placés en lunule sur le premier segment, et les autres rangés en ligne transverse sur les côtés du troisième. - Ventouse orale moyenne et oblique.-Corps très-déprimé, rétréci en avant, formé d'une centaine de segmens egaux et distincts, le irente-cinquième et le trente-huitième portant ordinairement les orifices des organes générateurs.

L'œsophage, dit M. Moquin Tendon, est très-long; il est formé de trois gros plis longitudinaux. - Les estomacs, iu nombre de sept, sont peu distincts et réduits à un tube étroit, allongé, marqué d'espace en espace par des étranglemens correspondant intérieurement à autant de sphincters. - Les cœcums sont nuls. - Le rectum est à peu près de la largeur des estomacs. Il se rétrécit graduellement en se rapprochant de I'ouverture de l'anus, et il est marqué de divers étranglemens correspondant à des sphincters qui remplacent les cœcums; sa membrane interne est marquée, à sa partie antérieure et à sa partie moyenne, d'une multitude de plis sinueux, vermiculaires, d'une couleur jaunâtre très-brillante. La vésicule séminale est très-petite. Les canaux déférens sont dirigés antérieurement. Les testicules sont déroulés; ce sont deux cordons, d'abord étroits et à peine appréciables, qui se dirigent antérieurement, se recourbent, et descendent sur les deux côtés de l'animal, formant deux conduits as- sez gros, allongés et repliés plusieurs fois sur eux-mêmes. Les vésicules séminales supplémentaires sont très-nombreuses et agglomérées sur les côtes de l'animal.

Ces animaux habitent les eaux douces; ils meurent aussitôt qu'on les en retire; ils roulent leur corps et ne se mettent pas en spirale. Ils ne peuvent pas sucer le sang de l'homme ou des animaux vertébrés.

\section{NEPHELIS Vulgaris.}

Mullen, Hist. Verm., t. I, p. 2, p. 40, 170. - Hir. octoculata, Berg., Act. Stock., 1756 , p. 199 et 4757 , pl. 6, f. 5-8. Tessellata, SAv., Annel., p. 147, 1.Long. 20 a 24 lig. Larg. 3 à 4 lig. - Cellc espèce est très-déprimèe, tantôt d'un brun rougeâtre, tantôt couleur de chair ; quelques individus présentent au-dessus des points très-petits et bruns. Suivant M. Carena, l'on en trouve dans le lac de Viverone une variété plus petite et d'une belle couleur de cornaline orientale; d'autres sont obscures. - On la trouve dans les eaux douces de l'Europe. Muller l'a vue dévorer des monocles et des infusoires. Elle est ovipare; l'enveloppe de ses œufs est ovalaire, et a de deux a trois lignes dans son grand diamètre; elle est aplatie et d'un vert jaunâtre. Linné l'a connue et en avait fait un insecte hémiptére (Coccus Aquaticus, Fauna Suec., 1. 727). Bergmann, le premier, reconnut la véritable nature de ces corps, et, d'après ses observations, Linné supprima cette prétendue espèce dans ses travaux postérieurs.

\section{NEPIELIS GIGAS.}

Moq. Tand., Monog., p. 127, pl. 6 , f. 5. - Long. 4 pouc. Larg. 1 poac. Cette espèce ne se reconnaît d'avec la précédente que par sa très-grande taille, qui est constante. - On la trouve dans le Midi de la France, et je l'ai reçue de Saxe.

\section{NEPHELIS ATOMARIA.}

Carena, Monog., p. 295, pl. 12 , f. 16. - Moq. TAND., Monog., p. 128, 3, pl. 6, f. 6. - Long. 24 lig. Larg. 2 lig. $\frac{1}{3} .-$ D'un brun pâle, moucheté en dessus de points et de lignes transversales plus claires que le fond; les bords sont couleur de chair. - Italie et Midi de la France.

\section{NePmLlis nutila.}

Savig., Annel., p. 117, 2. - Moe. Tand., Monog., p. 128, n 4. - Long. 12 à 15 lig. - Corps très-déprimé, roux, offrant en-dessus quatre rangées dorsales 
de points bruns. - Ruisseaux des environs de Paris et ceux de la Suisse.

\section{NEPHELIS TESTACEA.}

Savig., Annel., p. $117,3 .-$ Moo. TAnd., Monog., p. $129, \mathrm{n}^{\circ} 3 .-\mathrm{Corps}$ presque cylindrique, de couleur testacée, sans taches. - Environs de Paris.

\section{NEPHELIS GINEREA.}

Sav., Annel., p. 117, 4.-Mon. Tand., Monog., p. $129, \mathrm{n}^{\circ}$ 5, pl. 6, f. 7.-Corps un peu déprimé, d'un cendré clair. Cetle espèce a été trouvée dans les sources de la forêt de Fontainebleau, en Suisse et dans les Cévennes.

TROGheTA, Dutrochet ;

Geobdella, Buanv.; Nephelis, Mog. Tand.

Ce genre ne diffère essentiellement de celui des Nephetis que par un renflement remarquable que présente le corps à l'endroit des organes de la génération. L'on devrait peut-être n'en faire qu'une division de ce genre.

\section{TROCHETA SUBIRIDIS.}

Dutr., Bullet. de la Soc. philomat., 1817 , p. 130 et 131 . - Neph. Trochetia, Moq. Tand. , Monog., p. $129, \mathrm{n}^{\circ} .7 .-$ Gcob. Trochetii, Blaivv., Dict. Sc. nat. Hir., pl. 4, f. 6.-Long. 3 pouc.-Corps d'un verdâtre clair, marqué sur le dos de deux lignes longitudinales brunes, fort peu visibles. - Cette espèce se trouve dans les lieux humides et les canaux souterrains, près de Château-Renard ; elle se nourrit de Lombrics et les poursuit à terre.

\section{BRA CHELLIONITES.}

Caractères. Les branchies externes; ventouse orale d'une seule pièce, séparée du corps par un fort étranglement; ouverture circulaire.

Genre : Branchellion.

\section{BRANGHELLION, SAvIG.;}

Polydora, OKen ;

Branchiobdellion, RudoLPH ;

Branchiobdella, Blanvv. ; Hirudo, Menz.

Bouche très-petite, placée près du bord inférieur de la ventouse orale.-Ventouse orale d'un seul segment, séparée du corps par un fort étranglement, très-concave; l'ouverture inclinée, circulaire, garnie extérieurement d'un rebord. - Mâchoires réduites à trois points saillans. - Yeux au nombre de huit, disposés sur une ligne transversale, derrière le bord supérieur de lã ventouse. - Branchies nombreuses, très-comprimées, très-minces à leur bord, formant autant de feuillets demi-circulaires insérés sur les côtés des segmens intermédiaires et postérieurs $d u$ corps ; deux à chaque segment. - Ventouse anale grande, très-concave et exactement terminale.-Corps allongé, déprimé, formé de segimens assez nombreux; les treize premiers, après la ventouse orale, nus, trèsserrés, constituant une partie rétrécie et cylindrique distinguée du reste du corps par un étranglement; le quatorzième et les suivans portant des branchies; le dernier égalant au moins trois des précédens en longueur ; le vingt-unième et le vingt-quairième offrant les orifices de la génération.

\section{BPANCHELLYN TORPEDIYIS.}

Savig., Annel., p. 109, 1. - Long. 12 à 15 lig. - D'un brun noir ; corps formé de quarante-neuf anneaux, la ventouse orale comprise, garni sur les trente-cinq dont se composent ses quatre cinquièmes postérieurs, de trente-cinq paires de branchies légèrement ondulées, d'ailleurs toutes entières. - Se trouve sur la Torpille, dans la Mèditerranée.

\section{BRANChellion pUMatum.}

Sav., Annel., p. 109. - Hir. Branchiata, depressa, attenuata, etc., Menz., Trans. Soc. Linn., t. I, p. 188, pl. 17, f. 3. - Corps déprimé, atténué, blanc; les branchies brunes, au nombre de sent de chaque côté, ayant chacune trois divisions linéaires. subdivisées en deux. - L'on trouve cette espèce dans l'Océan Atlantique. Elle s'attache aux tortues; on pourroit, à raison du nombre et de la forme de ses branchies, en former un genre sous le nom de Savignia.

M. Cuvier dit, en parlant de la première de ces espèces (Rég. anim., t. III, p. 216): a Les bords latéraux de ses plis, comprimés et saillans, ont été regardés comme des branchies; mais je n'y vois pas de vaisseaux; son épiderme est ample, et l'enveloppe comme un sac très-lâche. 


\section{CRUSTACÉS.}

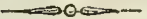

Les Crustacéssont des animaux dépourvus de squelette interieur, et d'un système nerveux cérébro-spinal; leur enveloppe extérieure est composée de segmens ou anneaux analoguesà ceux des insectes; mais elle est d'une consistance plus solide, et d'une composition chimique différente. Leur tête paraît soudée avec le trone, et présente généralement une honche pourvue, dans le plus grand nombre, d'organes de mastication, et composée d'un labre, d'une languctte, a'une paire de mandibules, d'une ou deux paires de mâchoires, ontre lesquelles trois paires de pieds mâchoires, qui servent tantôt à la locomotion, tantôt a la mastication; la première ou la troisième paire forme l'appareil buccal et remplace la lèvre inférieure, qui manque chez ces animaux. Presque tous ont des yeux composés, situés le plus souvent sur un pédoncule ordinairement mobile. Ceux des ordres supérieurs ont quatre antennes; ils sont les seuls des articulés qui présentent des organes de l'ouìe, distincts. Aucun des animaux de cette classe n'est pourvu d'organes de locomotion aérienne; le nombre de leurs pattes ambulatoires, ou natatoires, varie beaucoup; elles sont plus nombreuses que celles des insectes, et sont terminées par un seul ongle pointu, ou un appareil propre a la natation. Les sexes sont toujours séparés; et ont les parties sexuelles doubles, au moins les mâles, et situées sous la poitrine, à la naissance de l'abdomen, jamais à l'extrémité. Le système nerveux des Crustacés, ainsi que celui des autres articulés, cst libre, et composé de ganglions ou lames médullaires unies par des cordons de même nature, qui sont les centres auxquels viennent aboutir les nerfs des parties du corps. Ils respirent par des branchies analogues à celles des poissons, à moins qu'ils n'aient pas d'appareil spécial destiné à agir sur l'oxigène, et que la surface du corps n'en tienne lieu. Ces branchies varient, pour les divers genres de Crustacés, par leur nombre, leur forme et leur position. Swammerdam et Willis sont les premiers qui aient démontré, dans les Crustacés, l'existence de vaisseaux sanguins contenant un sang très. peu coloré, mis en mouvement par un vé- ritable cœur aortique. Ce système de circulation ne paraît manquer que dans un petit nombre des animaux que l'on a rangés dans cette classe. Les Crustacés sont ovipares, et leurs cufs éclosent apiès la ponte; les petits qui en naissent ne subissent point de niétamorphose ; ils changent seulement de peau à différentes époques de leur vie, ce qui leur fait éprouver plusieurs modifications; mais ils conservent toujours la forme générale qu'ils avoient en naissant. Ce n'est qu'après un certain nombre de mues, qu'ils deviennent propres à repro. duire leur espèce. La plupart sont carnassiers et aquatiques, vivent plusieurs années et donnent naissance à plusieurs générations.

Nous allons examiner successivement, et d'une manière rapide, les divers systèmes organiques de ces animaux en commençant par les tégumens.

Les anneaux qui composent le corps des Crustacés, toujours au nombre de vingt-etun, suivant M. Milne-Edwards, sont ou articulés bout à bout, saus union intime, ou soudés entre eux, de manière à paraître réunis en un seul troncon; ordinairement dans ce dernier cas deux lignes indiquent leur point de soudure.

L'ensemble de ces segmens forme en général une tête, un thorax et un abdomen.

La tête porte les yeux, les antennes, et les parties constituantes de la bouche.

Le thorax, appelé aussi abdomen parce qu'il contient les principaux viscères, donne naissance aux pattes ambulatoires; il est ter. miné, chez les mâles, par le segment qui porte les organes de la génération.

L'abdomen, que l'on appelait queue, post-abdomen, urogastre (queue-ventre), est aussi souvent pourvu d'appendices; l'anus est placé à son dernier anneau.

Cette division du corps des Crustacés en tête, thorax et abdomen, n'a pas toujours de limites bien distinctes; le nombre des anneaux qui composent chacune de ces parties n'est pas constant; il est même souvent difficile de les compter, à cause de leur fusion en un seul ironçon. Dans un grand nombre de Crustacés, et particuliè- 
rement dans les crabes, la tête paroît ne former qu'un seul tout avec le thorax, sous une carapace qui enveloppe l'un et l'autre. Cependant on peut remarquer à la partie inférieure du corps, des lignes indiquant les divers anneaux thoraciques et céphaliques. M. Milne-Edwards attribue cette sorte de bouclier céphalo-thoracique au prolongement de la partie supérieure des anneaux de la tête sur le thorax; dans ces mêmes Crustacés, un plastron, formé par la réunion de la partie inférieure des anneaux thoraciques, protége la région ventrale du corps; une échancrure pratiquée sur ce plastron fait place à l'abdomen.

M. Desmarest a divisé la surface exlèrieure de la carapace en différentesparties correspondant aux organes extérieurs, dans un traité élémentaire. Nous ne pouvons donner la nomenclature ingènieuse qu'il a établie sur ces différentes divisions.

Les élémens dont sont composẻs les anneaux qui forment le corps des Crustacés sont au nombre de quatre paires, que l'on concevra facilement, en supposant ces anneaux divisés en deux moitiés, l'une supérieure et l'autre inférieure, et chacune de ces moitiés en deux parties latérales. On a ainsi formé quatre arceaux, qui, divisés en deux, offrent deux pièces moyennes, supérieures, appelées tergum; chaque partie tergale est suivie des flancs ou epiméres; les deux pièces médianes inférieures forment le sternum; enfin, les deux dernières pièces latérales sont les épisternums. Des ouvertures sont pratiquées entre cellesci et les épimères, pour faire place à l'articulation du membre correspondant.

Ces distinctions ne peuvent pas toujours être reconnues dans un même individu. Quelques-unes de ces pièces sont souvent réduites à un état rudimentaire; quelquefois elles peuvent manquer totalement, et laisser un vide; mais leur connaissance est ut le dans l'étude du squelette extérieur des Crustacés.

A la soudure des anneaux entre eux, et des parties constituantes de ces anneaux, on remarque souvent, intérieurement, des prolongemens composés de deux lames adossées et soudées ensemble, auxquelles on a donné le nom d'Apodemes.

Le nombre des membres n'est pas le même chez tous les Grustacés ; communément ils en ont vingt paires; mais on peut en compter, chez quelques-uns, jusqu'a soixante.
La première paire de membres n'existe que dans les ordres supérieurs; ce sont les pédicules oculaives; ils ont la forme de tiges articulées, sont ordinairement mobiles, et s'insèrent à la partie antérieure de la tête, dans des cavités proportionnelles à leur grandeur et à leur forme.

Les antennes composent la seconde et la troisième paire de membres. Dans quelques Crustacés des ordres inférieurs, elles sont réduites à une seule paire; dans d'autres, tels que les parasites, elles manquent totalement, ou n'existent qu'à l'état de vestige. La première paire fait suite aux pédicules oculaires. La seconde est placée derière celle-ci, ou sur les côtés de la mème ligne. Les antennes sont formées d'une partie plus grosse, d'un à trois articles appelés pédoncules, et d'une partie composée d'un plus grand nombre de segmens, qui se divise, dans les intermédiaires en filets, plus ou moins allongés et pointus.

Les membres qui servent à la manducation se modifient suivant que les Crustacés sont masticateurs ou suceurs.

Dans les premiers on distingue des mandibules, qui portent souvent un appendice articulé, qu'on a nommé palpe mandibulaire.

Les mandibules sont suivies de mâchoires, en forme de lames cornées, dont le bord est découpé et garni de prolongemens filiformes.

Outre ces mâchoires, il y a des Crustacés qui ont encore jusqu'à trois paires de mâchoires auxiliaires, ou pieds-máchoires, appelés ainsi, parce que ces membres peuvent servir à la locomotion et à la mastication.

La dernière paire est élargie vers la base, et sert à former extérieurement la bouche.

Dans les Crustacés, qui vivent en parasite sur d'autres animaux, les parties de la bouche se modifient en un tube, dans lequel s'insèrent les mandibules, transformées en doubles filets terminés par deux lames acérées; les mâchoires sont à un ètat rudimentaire, et les pieds-mâchoires servent à fixer l'animal/sur sa proie.

Les paires de membres appartenant au thorax constituent les pattes ambulatoires, dont le nombre de paires est égala celui des anneaux du thorax.

L'abdomen donne aussi naissance à des appendices appelés fausses pattes, parce qu'ils servent aussi à la locomotion; les femelles les emploient pour retenir leurs œufs. 
La forme de ces différents membres se modifie, non-seulement dans les diffërentes espèces de Crustacés, mais encore dans ces mèmes individus. Cependant on peut reconnaître trois parties dans ceux qui ont acquis tout le développement dont ils sont susceptibles. On distingue d'abord la tige, formée presque toujours de plusieurs articles; à l'un de ses trois premiers articles basilaires, elle porte extérieurement un appendice appelé palpé, dont la forme ressemble quelquefois à une antenne, composée d'un long pédoncule inarticulé et terminé par un filet de plusieurs articles; il ressemble alors à un fouet avec son manche, ce qui lui fait donner, par Fabricius, le nom de palpe flagelliforme; d'autres fois le palpe est une longue lame de nature cornée. Du côtẻ exterieur de cet appendice, toujours à l'origine de la tige, en vient un second que l'on appelle fouet; à son commencement il représente une lame allongée de nature cornée, ou constitue une vésicule molle, membraneuse et aplatie. La tige des pattes thoraciques entierement développée, est composée de six articles; le premier a été appelé hanche, le second trochanter, le troisieme cuisse ou bras, le quatrieme jambe, carpe ou poignet, le cinquième métatarse et le sixième tarse, lequel est terminé par un ongle pointu, appelé griffe. Dans les premières paires de pattes, le cinquième article fait une saillie en forme de dent, sur le sixiẻme, et constitue avec lui une especce de pince ou main, dont le doigt mobile a reçu le nom de pollex et le doigt fixe, celui d'index.

Nous ne parlons pas ici des branchies des Crustacés, nous réservons ce sujet quand nous traiterons de la respiration chez ces animaux.

Au sortir de l'œuf, les parties extérieures des jeunes Crustacés n'ont pas toujours la forme qu'elles doivent avoir dans la suite ; ll y a quelques-unes de ces parties qui ne se montrent pas d'abord, ou n'ont pas pris tout le développement dont elles sont susceptibles. Un habile naturaliste allemand, M. Rathke, à qui l'on doit des recherches remplies d'intérèt sur le développement de l'œuf de l'écrevisse, a observé que, dans ces Crustacés, les diflérens membres naissent sous forme de lames, toutes de formes semblables; d'abord les deux paires d'anteunes, ensuite les mandibules; le labre se montre à cette même époque. Dans une seconde période, les membres prennent de l'accroissement; on aperçoit les rudimens

ANN. des yeux, on peut distinguer l'ouverture de la bouche; le prolongement abdominal commence à se former; on peut remarquer un petit enfoncement qui représente l'anus; puis on voit les mâchoires et les pattes. mâchoires commencer à naitre, d'abord, au nombre de trois paires, ensuite au nombre de quatre et de cinq paires. L'abdomen se distingue davantage; les membres déjà apparus prennent des caractères plus prononcés; les pattes ambulatoires se montrent les unes après les autres, les antérieures les premières, où, pendant une troisième période, l'abdomen grossit et présente les vestiges des fausses pattes qui y sont attachés; les branchies se développent peu à peu; la carapace est mieux formée ; enfin, dans une quâtrième période, la carapace et toutes les parties extérieures continuent de se rapprocher davantage de la forme qu'elles doivent avoir dans la suite, jusqu'à ce que la jeune écrevisse, dont les organes intérieurs se sont formés pendant les différentes périodes, rompe les membranes qui l'enveloppent. La croissance des Crustacés est lente; quelquesuns atteignent une grandeur extraordinaire. Le corps de certaines langoustes et de quelques homards a quelquefois près de trois pieds de long.

La solidité destégumens des Crustacés oblige ces animaux à rompre leur enveloppe, pour prendre leur accroissement; ils abandonnent leur ancien squelette, qu'ils laissent entier tant intérieurement qu'extérieurement, et apparaissent avec une peau nouvelle. Les uns le fontà des époques très. rapprochées, les grosses espèces ne pondent de mếme qu'une fois par an. Réaumur a observé et décrit, la manière adroite avec laquelle les écrevissesse dépouillent de leurs tégumens. Avant cette operration, ces animaux sont agités et inquiets; ils s'abstiennent de nourriture, et lorsqu'ils ont changè de peau, ils craignent l'approche de leurs ennemis, et vont se cacher dans quclques réduits jusqu'à ce que leurs nouveaus tégımens aient pris la consistance de leur ancienne enveloppe, ce qui s'opère chez les écrevisses en deux ou trois jours; mais il y a d'autres Crustacés dont la peau reste bien plus long-temps dans un état de mollesse.

Quelquefois, pendant l'opération de la mue, ou dans d'autres circonstances, les Crustacés brisent quelques-uns de leur membre ; la nature y remédie en en faisant renaitre de nouveaux ; mais il est nécessaire que la fracture ait lieu à la jonction des articles de ces membres; lorsque cela n'a 
pas lieu, l'animal y supplée lui-même en faisant une nouvelle cassure convenable.

Si l'on recherche la disposition anatomiques des tégumens, on verra qu'ils sout composés d'une pellicule mince, servant d'enveloppe commune aux viscères et de gaîne a chacun d'eux; d'une seconde couche plus épaisse, spongieuse et vasculaire, d'où suinte une liqueur retente supérieurement par une membrane trẻs-mince et diaphane; cette seconde couche peut être comparée au derme; enfin, d'une couche plus externe, qui est le test; ou, lorsque celui-ci est près de tomber, c'est une membrane mince qui paraît arrêtée par le derme pour remplacer le test après la mue. Cette dernière couche enveloppe le corps de toutes parts, et pénètre par des replis intérieurement entre les organes, comme nous l'avons vu en parlant des apodêmes. Après la mue, elle acquiert plus de consistance; elle reste a un état semi-corné chez les Crustacés qui ne sont point pourvus d'organes respiratoires spéciaux, et chez lesquels la respiration s'exécule sur tous les points de la surface du corps; car la peau doit avoir chez ces animaux assez peu de dureté et d'épaisseur pour remplir les fonctions d'organe de respiration et du tact, et assez de consistance pour protéger les parties intérieures, et fournir aux muscles de locomotion des leviers et des points d'appui. Chez les Crustacés qui ont un appareil branchial développé, la peau s'encroûte de matière calcaire, prend une consistance d'une solidité qui peut être comparée à celle des os des animaux supérieurs, à l'exception de certaines parties qui restent flexibles pour faciliter les mouvemens. On remarque quelquefois, sur le test, des prolongemens filiformes, mais qui different entièrement, par leur structure, des poils des Mammiféres.

Dans les premiers de ces Crustacés, les tégumens paraissent composés d'albumine et de chitine, substance qui entre dans la composition des parties dures des insectes. Dans les autres on trouve, outre l'albumine et la chitine, du carbonate et du phosphate de chaux.

La surface interne du test est ordinairement blanchâtre; sa face externe est quelquefois rouge, et le plus ordinaircinent brune ou verdâtre; mais la cuisson, dans la plupart des espèces des Crustacés, ainsi que l'action des acides ou de l'alcool, font prendre à ces tégumens la coulcur rouge.

Nous avons vu que, parmi les animaux rangés dans la classe des Crustacés, ies uns se nourrissent en broyant leurs alimens; les autres sucent le sang des animaux sur lesquels ils vivent en parasites. Dans les premiers, l'ouverture antérieure du canal alimentaire, ou la bouche, est formée d'un labre, ou lèvre inférieure, et d'une languette ordinairement bifide; chacune de ces deux pièces, de nature calcaire ou cornée, suivant l'espèce de Crustacés. A leur suite sont groupés les membres servant à la mastication, qui se meuvent latéralement. Dans les Crustacés parasites, le labre et la languette se modifient en un fourreau dans lequel s'insèrent les mandibules changées en deux sortes de lancettes.

Dans les différens Crustacés, le tube digestif est de la longueur du corps, et composé de deux tuniques, dont l'une antérieure et l'autre extérieure, entre lesquelles sont des fibres musculaires. On y distingue trois parties : l'œsophage, l'estomac et l'intestin.

L'œsophage sert à introduire la nourriture dans l'estomac, et à l'empêcher de revenir par la bouche.

L'estomac, plus volumineux que l'œsophage, remplit toute la capacité antérieure de la têle; il est composé de deux parties dans lesquelles on remarque des prolonge. mens plus ou moins osseux, et servant à broyer les alimens.

L'intestin est égal dans toute sa longueur; dans les ordres inférieurs et dans les Décapodes on peut y reconnaître deux divisions, dont l'une est le duodénum et l'autre le rectum, qui aboutit à l'anus, formé par une fente horizontale, à la partie antérieure du dernier anneau de l'abdomen.

Le foie, formé d'une agglomération de masses glandulaires composées d'un parenchyme granuleux, entouré par des vaisseaux sans ouvertures extérieures et recouverts par une membrane mince, s'ouvre dans l'intérieur de l'estomac, où il maintient les humeurs biliaires de couleur jaune destinées à faciliter les fonctions digestives; il s'ètend aussi sous l'intestin dans toute sa longueur.

Nous avons déja vu que, chez quelques Crustacés, la surface générale du corps tient lieu d'organe respiratoire; l'appareil branchial des antres est quelquefois représenté par la fouet et le palpe des organes locomoteurs, auxquels on a donné, dans certains cas, le nom de pattes branohiales; d'antres fois, ce sont les fausses pattes de l'abdomen qui sont chargées de cette fonc- 
tion; on les appelle alors de fausses pattes branchiales. Dans les Décapodes les branchies forment des organes particuliers qui sont situés à la naissance des deux dernières paires de pieds-mâchoires et des pattes ambulatoires du thorax, et sont recouverts par les côtes inférieures de la carapacé, qui s'ouvre en devant pour laisser passage à l'eau; une soupape, formée par la dilatation de la base des secondes pattes-mâchoires, ferme à volonté cette ouverture. La forme des branchies varie autant que leur nombre et leur mode d'insertion; chez quelques Crustacés elles sont constituées par.de simples lames ou quelques vésicules; chez d'autres, ce sont des panaches composés de lames empilées ou hérissées de barbe.

Lés Crustacés n'ont pas de système chylifère; les sucs nutritifs fournis par les alimens parviennent par imbibition dans les yaisseaux sanguins. Suivant les observations de MM. Audouin et Milne-Edwards, le liquide nutritif se distribue, au moyen des artères, dans toutes les parties du corps, pour servir à la nutrition des diffërens organes; il passe ensuite dans des canaux, et de là dans des cavités quile conduisent aux branchies; puis il retourne dans le cœur par le canal afférent des branchies, et recommence à parcourir de nouveau, au moyen des vaisseaux afférens, le même cercle.

Dans les Décapodes, où le système artériel est le plus compliqué, le cœur est situé vers la partie moyenne de la carapace, et repose sur l'intestin; le foie et les organes de la génération. Ses artères sont au nombre de six trones principaux, dont les trois premiers, situćs à la partie antérieure, ont reçu le nom d'ophthalmiques et d'antennulaires, et se rendent, en se prolongeant, dans chacun des pédoncules oculaires et dans chaque antenne. Deux autres troncs, nommés artères hépatiques, partent encore de la partie antérieure et inférieure du cour, pour se rendre au foie. Ces deux vaisseaux ne se réunissent pas; le foie n'est pas divisé en deux lobes. Enfin, le sixième tronc, appelé arbre sternal, se dirige de la partie postéricure et antérieure du cœur, au moyen de divisions, vers les appendices de la bouche, les pattes et l'abdomen.

Nous avons déja dit que, chez la plupart des Crustacés, les appareils sexuels sont duubles et situés à l'un des dernicrs anneaux du thorax, de chaque côte de la ligne médiane; mais les organes mâles et femelles n'existent pas à la fois dans un même individu. Dans les femelles, l'appareil de la génération se compose, pour chaque côté du corps, d'un ovaire, d'un oviducte, d'une vulve et d'organes accessoires servant à retenir les œufs après la ponte. L'appareil gẻnérateur du mâle est composé également, pour chaque moitié du corps, d'un testicule, d'un canal afférent terminé par une verge, et de quelques appendices accessoires.

La nature de cet ouvrage ne nous permet pas d'entrer ici dans de plus grands dètails sur l'anatomie des Crustacés. Nous renvoyons, pour plus de détails, à l'excellent ouvrage de M. Milne-Edwards, qui est, sous tous les rapports, le travail le plus complet que nous possédions sur cetle prartie de la Zoologie.

La classe des Crustacés a été ainsi divisée par M. Latreille, dans son Cours d'Entomologie, ouvrage que nous adoptons pour base :

Ier ordre. Les Décapodes. Cet ordre renferme deux familles : les Brachyures et les Macroures, dont la première comprend deux sections : les Homochéles et les Hétérochéles.

$1^{\circ}$ ordre. Les Stomapodes. Cet ordre a été divisé en trois familles : les Caridioides, les Unicuirassés et les Bicuirissés.

III ordre. Les LoEMODIPODES.

IVe ordre. Les Auphipodes. Cet ordre a été partagé en trois familles : les Crevettines, les Podocérides et les Hypérines.

Ve ordre. Les Isopodes. Cet ordre a été divisé en deux sections : les Anomaux et les Normaux. La première section, ou celle des Anomaux, renferme trois familles : les Hétéropodes, les Décempédes et les Epicarides. La seconde section, ou celle des Normaux, comprend cinq familles: les Cymothoadés, les Sphéromides, les Idotéides, les Asellotes et les Cloportides.

Vle ordre. Les Diclapodes.

T II e ordre. Les Lopuynopes. Cet ordre renferme deux familles : les Séticères et les Cladocères.

VIIIE ordre. Les Ostiapodes.

$\mathrm{IX}^{\bullet}$ ordre. Les Pnyllopodes. Cet ordre comprend trois familles: Ies Mytiloüdes, les Aspidiphores et les Cératophthalmes.

$\mathrm{X}^{\circ}$ ordre. Les Xyphosures.

$\mathrm{XIe}$ ordre. Les Siphonostomes. Cet ordre a été partagé en deux familles : les Caligides et les Lernaiformes.

XII ordre. Les Triiobitrs. 


\section{DE E C P O D E S ,}

LATR.

C'est à M. Latreille qứèst dû l'établissement de cet ordre de Crustacés, qui est connu sous le nom de Décapodes. Cet ordre, qui est le premier de la classe des Crustacés, et qui en est un des plus distincts, comprend la plus grande partie du genre Cancer, de Linné, et des autres auteurs. Comme toutes les espèces qu'il renferme ont une organisation plus compliquée que dans les espèces composant les autres ordres de la inême classe, et que leurs facultés paraissent être plus développées, nous le placerons, à l'exemple de la plupart des naturalistes, à la tête de cette classe.

Tous les Crustacés de l'ordre des Décapodes ont généralement la tête intimement liée avec le thorax, c'est-à-dire que les anneaux de la tête et ceux du thorax sont intimement soudés entre eux et toujours recouverts par un test, ou carapace, entièrement continu, mais offrant le plus souvent des lignes enfoncées, se divisant en diverses régions qui indiquent les places occupées par les principaux organes intérieurs. Par cette disposition, il est facile de voir que la tête des Crustacés décapodes n'est pas distincte du thorax, et qu'en dessus, tout le corps, a l'exception de l'abdomen, parait être formé d'une seule pièce; mais si on examine le dessous, on distinguera toujours un certain nombre de divisions annulaires; quant à l'abdomen sa forme est très-variable. Celte tête, qui, à cause de sa conformation, a reçu le nom de céphalothorax, sert de support à quatre antennes, aux pédicules oculaires toujours mobiles, dont les yeux sont recouverts par une cornée réticulée, et aux diverses parties de la bouche renfermées dans une cavité propre. Ces parties, assez compliquées, sont composées d'un labre, de deux mandibules palpigères, d'une languette, de deux paires de mâchoires multifides, de trois paires de pieds-mâchoires, accompagnés extérieurement d'un appendice en forme de palpes; les deux dernières paires munies de deux $b$ ranchies.
- Les antennes sont au nombre de quatre, composées d'un pédoncule épais, et quelquefois de trois tiges toujours multi-articulées, en forme de filets plus ou moins allongés et allant en pointe; les latérales ou les extérieures n'en ont jamais qu'une; mais il y en a au moins deux aux intermédiaires; et lorsque celles-ci sont raccourcies, repliẻes et logées dans les cavités sousfrontales, ces deux tiges sont plus courtes, coniques, de grosseur inégale, et semblent imiter deux doigts, forme qui a déterminé à les distinguer sous le nom de Chélicères, antennes en pince.

Les quatre antennes des Décapodes s'allongent, en gènéral, lorsqu'on est arrivéaux Macroures; les intermédiaires ne sont souvent plus coudées, et se terminent dans plusieurs par trois filets; souvent aussi le pédoncule des latérales est accompagné d'une écaille, et inséré plus bas que celui des intermédiaires. Suivant M. RobineauDesvoidy, ces antennes extérieures seraient les organes de l'ouie, et les intermédiaires, qu'il nomme antennes ou petites antennes, celui de l'olfaction; les premières seraient des antennes auditives, et les secondes des antennes olfactives; par leur position et leur organisation, elles correspondraient aux antennes des insectes Hexapodes; mais ce qui semble indiquer qu'elles disparaissent , c'est que dans les Cloportes et quelques autres genres analogues, Crustacés qui se rapprochent le plus des insectes, ces antennes sont presque rudimentaires. Dans les Ocypodes et les Tourlourous, Crustacés très-carnassiers, et qui doivent avoir un odorat très-fin, ces mêmes organes sont beaucoup moins développés que dans les autres Décapodes. Jusqu'à présent, rien ne nous ayant démontré que ces organes soient le siége de l'olfaction, il n'y a que des expériences directes qui puissent nous éclairer sur la destination de ces organes. - Le labre ressemble à une petite languette membraneuse, renflée et carénée; mais, généralement, cette pièce se confond avec la partie 
voisine du test. Les mandibules sont osseuses et ont la figure d'une forte dent tranchante à son sommet; elles ont chạcune, sur le dos, un palpe bi-articulé. La languette, située immédiatement au. dessous des mandibules, est lamelleuse, profondément échancrée, et comme formée de deux lobes arrondis au sommet, et réunis inférieurement. - Les mâchoires, comme nous l'avons dit plus haut, sont au nombre de deux paires; celles de la première se composent de plusieurs petites lames cornées, dont le bord interne est épineux et garni de poils; celles de la seconde paire présentent toujours, au côté externe, un grand appendice lamelleux qui se loge dans le canal afférent de la cavité branchiale, et qui est destiné à chasser l'eau qui a servi à la respiration. Ici, nous ferons remarquer que cetle disposition, se trouve à la seconde paire de mâchoire, chez tous les Crustacés décapodes, et qu'elle n'a encore été rencontrée dans aucun autre ordre. - Les pieds-mâchoires, qui sont au nombre de trois paires, différent entre eux par des, caracteres assez tranchés; ceux de la première paire sont presque toujours lamelleux; mais, au lieu de présenter au dehors une grande valvule, ils portent un palpe et souvent un appendice flabelliforme; ceux de la seconde paire ne sont, au contraire, presque jamais lamelleux, et se composent ordinairement d'une tige formée de plusieurs articles, d'un palpe et d'un fouet; enfin, les pieds-mâchoipattes de la troisième ou dernière paire recouvrent toute la bouche; leur portion interne, ou tige, présente une série d'articles dont le nombre est ordinairement de six, et dont le second et le troisième sont souvent très-èlargis.-Le palpe est presque toujours assez développé ; enfin, il exisfe généralement un fouet à la base de ces membres, qui, dans un très-petit nombre de cas, n'appartiennent plus à l'appareil buccal, mais ont la forme de pattes ambulatoires. $\boldsymbol{A}$ la suite des organes masticateurs, viennent les cinq paires de pieds, qui sont beaucoup plus développés, et qui constituent les pattes proprement dites ; ces pieds ou ces pattes sont composés de six articles : les deux antérieurs, quelquefois même les deux ou quatre suivans, sont ordinairement en forme de serres, ou terminés par un grand article ayant au bout deux doigts, dont l'un mobile et l'autre fixe : c'est ce qu'on nomme main ou pince. L'article radical de ces pieds est la hanche; le suivant, le tro- chanter; le troisième, le bras ou la cuisse; le quatrième, le carpe ou la jambe; le cinquième, le métatarse ou le métacarpe; et, enfin, le sixième porte le nom de tarse ou de doigt. Les proportions respectives et la direction des organes locomotiles sont telles, que ces animaux peuvent marcher de côté et à reculons. Le post-abdomen ou la queue est divisé en sept segmens, mais dont le nombre, dans plusieurs Brachyures, parait moindre, parce que quelques-uns des intermédiaires se soudent, et que les soudures s'oblitèrent. Le dessous de cette queue est garni de quatre à cinq paires d'appendices formés de deux tiges portées sur un article commun et radical, et plus développées dans les Macroures que dans les Brachyures. A ceux des femelles sont attachés les nufs; ils contribuent même à la natation; on peut les considérer comme des pieds raccourcis, et de là, la dénomination de fausses pattes qu'on leur a donnée.

L'organisation intérieure des Crustacés décapodes présente des caractères aussi tranchés que la structure de leurs parties extérieures. Le tube digestif offre toujours, à sa partie antérieure, un estomac très-développé dont les parois sont contenues par une sorte de charpente cartilagineuse ou osseuse, et armée de dents. Les organes hépatiques forment, de chaque côté de l'intestin, une masse volumineuse composée d'une infinité de petits cœcums qui s'insèrent sur les rameaux du conduit biliaire. - Le cœur, presque quadrilatère, occupe la partie moyenne du thorax, et donne naissance à six artères principales d'où sortent tous les vaisseaux qui portent le sang dans les diverses parties du corps. La respiration s'effectue au moyen d'un certain nombre de branchies, dont les lamelles ou les filamens sont toujours simples, et ces organes s'insèrent à la paroi interne d'une cavité spéciale située de chaque côté d" thorax, et formée par le prolongement de la carapace au-dessus des flancs. Les organes de la génération communiquent toujours au-dehors par deux ouvertures : chez la femelle, les vulves occupent toujours l'antépénultième anneau thoracique, et sont situées, tantôt sur le sternum, tantôt sur le premier article des pattes correspondantes, tandis que, chez le mâle, les organes de la génération sont situés de la même manière sur le dernier anneau du thorax. Enfin, avant de terminer ces généralités, nous dirons que, chez presque tous les Décapodes, il existe, dans l'intérieur du thoras, 
un nombre considérable de lames apodémiennes qui forment de chaque côtè une double rangée de cellules; disposition qui est particulière à ces Crustacés.

Les Crustacés décapodes se tiennent, pour la plupart, dans l'eau, mais ne meurent pas sur-le-champ lorsqu'ils en sont dehors; on les conserve même plus longtemps en vie dans cette situation, que si on les mettait dans ce fluide sans avoir soin de le renouveler. Quelques espèces ont une organisation particulière, et ont la faculté de vivre habituellement hors de cet ëlément; elles ne vont à l'eau qu'a l'époque de leurs amours, ot pour y déposer leurs œufs. Selon M. Thomson, les Cancers ct genres voisins sont toujours aqualiques dans leur premier âge, ou ce qu'ii appelle état de larve. Il parait, au reste, que les espèces même vivant a terre s'établissent dans les lieux frais et humides; sans cela, leurs branchies pourraient se dessécher. et se désorganiser, ce qui entraîneroit la destruction de ces animaux. Quelques-úns fréquentent les eaux douces. Tous sont, en général, voraces et carnassiers; il en est qui ront jusque dans les cimetières, pour y dévorer les cadavres. Leur croissance est lente, et quelques-uns atteignent une grandeur extraordinaire. Le corps de certaines Langoustes et de quelques Homards a quelquefois près de trois pieds de long.

La chair de ces Crustacés, quoique d'une digestion äifficile, est cependant généralement recherchée. Mais pour éviter la cor- ruption et les désagrémens qui en résulte. raient, il faut avoir la précaution de faire cuire vivans ces animaux, Quelques especes, et particulièrement le crabe fluviatile d'Italie et du Levant, avaient autrefois une grande réputation en médecine; mais elle s'est évanouie, ou du moins singulièrement affạblie avec le temps, puisque ces animaux ne sont presque plus emiployés dans la matière médicale.

Cet ordre, qui se compose d'un trèsgrand nombre de Crustacés, a été partagé par M. Latreille en deux grandes familles, dont voici les principaux caractères distinctifs; dans les uns la queue est courte, appliquée sur la poitrine, sans nageoires aux appendices analogues à son extrémité; les branchies sont solitaires, et l'issue extérieure des organes sexuels féminins est située entre les pieds de la troisième paire. Ils constituent la famille des Décapodes à courte queue, ou celle des Brachyures.

Dans les autres, cette queue est généralement aussi longue ou plus longue que le test, simplement courbée; munie latéralement, à son extrémité, de deux petites nageoires, en formant une générale et en éventail avec le dernier segment; les branchies sont rapprochées à leur base, par fais. ceaux, et les vulves sont situées au premier article de ces mêmes pieds, ou de la troisième paire. Ils composeront la famille des Décapodes à longue queue ou celle des $\mathrm{Ma}$ croures.

PREMILERE FAMILLE.

\section{B R A C H Y U E S}

LATREILLE.

\section{CANCERES BRACHYUHI, LiNNÉ; KLEISTAGINATHES, FABRicius,}

Tous les Crustacés qui rentrent dans cette famille ont le tronc, tantôt en segment de cercle ou presque carré, tantôt arrondi, ovoide ou triangulaire, - Les antennes sont petites, surtout les intermédiaires, qui sont ordinairement logées dans une fossette sous le bord antérieur de la carapace; celles-ci se terminent chacune par deux filets trèscourts. - Les antennes extérieures, insérées au côté interne des yeux, ont plus de longueur, et sont pourvies d'un seul filet. -
Les yeux sont, dans plusieurs, portés sur de longs pédicules: - Le tube auriculaire est presque toujours pierreux. - La première paire de pieds se termine раг une serre.Dans le plus grand nombre, la dernière paire de pieds-mâchoires, à l'état de repos, forme une sorte de lèvre qui recouvre toute la bouche.-L'abdomen, plus court que le tronc, est triangulaire dans les mâles, et garni, seulement à sa base, de quatre ou deux appendices, dont les supérieurs, plus 
grands , en forme de cornes; il s'arrondit, s'élargit, ei devient bombé dans les femelles; le dessous supporte quatre paires de doubles filets, destinés à porter les œufs, et analogues aux pieds-natatoires et sous-caudeaux des Crustacés Macroures, et autres. Les mâles sont dépourvus de ces parties, et offrent, cependant, deux ou quatre appendices, qui sont des organes de copulation. Les vulves sont doubles, placées sous la poitrine, entre les pieds de la troisième paire. Tels sont les principaux caractéres à l'aide desquels nous pensons qu'il sera fa- cile de distinguer, au premier abord, un Crustacé brachyure d'avec un Crustacé macroure.

De toutes les classifications faites par M. Latreille, nous adoptons sa derniere, c'est-à-dire celle de son cours d'entomolo. gie, laquelle nous a paru moins compliquée et plus naturelle. Dans le dernier ouvrage de ce célèbre entomologiste, la famille des Décapodes brachyures est divisée en deux sections, partagées en quatre divisions, lesquelles se divisent ensuite en neuf tribus

\section{Remiére section. - HOMOCHÈles, Latreille.}

Serres de grandeur identique (excepté les Gélasimes) ou peu différentes dans les deux scxes.-Carapace tantôt trapézoïcle, tantôt en segment de cercle, tronquće à sa pointe, vers la réunion du test avec le post-abdomen, généralement plus large en devant, à l'exception de quelques espèces, où elle est dilatée vers les angles postérieurs, pour former une voûte recevant et cachant les pieds.

\section{PREMIERE DIVISION.}

Tous les pieds insérés sur la même ligne, ou de niveau, à leur naissance.

A. Tous les pieds, les serres exceptées, toujours à découvert. - Test rétréci postérieurement, ou point dilaté, vers les angles postérieurs, pour former une voûte au.dessus de ces organes.

Cette première subdivision comprend les tribus suivantes:

Les Quadrilatéres, les Arqués, les $\mathrm{Na}$ geurs et les Christimanes.

B. Test dilalé vers les angles postérieurs, et formant une voûte sous laquelle les pieds, dans la contraction, se retirent et sont cachés, l'animal étant vu sur le dos.

Cette seconde subdivision renferme la uribu des Cryptopodes.

\section{PREMIERE TRIBU.}

\section{QUADRILATERES, LATFEILLE.}

Caracteres. Les pieds sont toujours découverts, terminés par un tarse com- primé , lamelliforme ou en nageoire La queue est presque toujours composée de sept tablettes, à sections distinctes dans toute leur étendue. - Le test est carré ou trapézoïde, cordiforme, avec le front souvent prolongé ou incliné en manière de chaperon. - Les yeux sont souvent portés par de longs pédoncules. - Le quatrième article des pieds-mâchoires est inséré au-dehors del'extrémité interne du précédent, ou uni avec lui par toute la longueur de sa base. Les genres que renferme cette tribu sont très-nombreux, et les espéces qui les composent ont des mceurs différentes. Les Ocypodes, Gélasimes, Myctires, Macrophthalmes, Gécarcins, Cardisomes et Uca sont terrestres, et la plupart des espèces qui composent ces genres se rendent à la mer pour l'accouplement et déposer leurs oufs. Les Pinnothères habitent dans les Pinnes, et étoient regardés, par les anciens, les sentinelles de ces Mollusques; les Plagusies et les Grapses se plaisent dans les fentes des rochers des bords de la mer; les Gonoplax ne sortent jamais de l'eau et n'habitent que les grandes profondeurs de trente à quarante mètres; les Telphuses se trouvent dans les rivières, et particulièrement dans les lacs; enfin, les Pilummes et les Eriphies habitent la mier et à d'assez grandes distances.

La plupart des espèces qui composent la tribu des Quadrilatères, passent une grande partie de leur vie hors de l'eau, et se creusent, près des bords des eaux, ou sur les rivages, des terriers leur servant d'habitation pendant le jour. De ce nombre sont plus particuliercment les Crabes cavaliers des anciens, et ceux qu'on nomme Tourlourous, aux Antilles ct dans I'Amérique mé- 
r Jionale. Tous ces Quadrilatères terrestres peuvent être compris dans une première section ou sous-tribu que nous signalerons ainsi :

Pieds - mâchoires extèrieurs toujours composés de six articles, dont le quatrième inséré en-dehors de l'extrémité supérieure et interne du précédent.-Pédicules oculaires (le plus souvent allongés) insérés près du milieu du bord extérieur du test ou du front. - Le test êst carré ou trapézoĩde, ou en forme de cœur.

Nous partagerons de même cette section en deux groupes, comme l'a fait M. Latreille dans son Cours d'entomologie, et, pour les distinguer entre eux, nous emprunterons à cet auteur les caractères suivans :

Les uns dont le test est toujours trapézoìde ou presque carré, épais, ayant les angles antérieurs aigus ou prolongés en pointe, et dont les pédicules oculaires naissent près du milieu du front, ou sur les còtés du chaperon, peu spacieux, et se prolongeant ordinairement jusqu'aux angles latéraux antérieurs.

Ils forment le premier groupe ou celui des Ocypodites.

Les autres ont les antennes intermédiaires très-petites, très-brièvement bifides au bout. - Les deux divisions ou tiges presque coniques, - L'interne offrant seule des articulations, qui ne sont qu'au nombie de deux.

Ils composent sept groupes : ceux de Gécarcinites, Pinnothèrites, Grapsoites, Gonoplacites, Trapézoïtes, Thelpheusites et Pilumnites.

\section{OGYPODITES.}

Ce premier groupe se compose de quatre genres : ceux d'Ocypoda, de Gelasimus, de Myctiris, de Doto, de Macrophihalmus et de Cleistoma.

\section{OCYPODA, FABR., LATR.}

La carapace est presque carrée, un peu plus large que longue, terminée en devant et de chaque côté par un angle aigu; son bord antérieur présentant, dans son milieu, un chaperon déclive, étroit et arrondi, et sur chacun de ses côtés, un sinus ou une cavitẻ transversale, profonde et ovale, destinée à loger les yeux, qui sont insérés sur les côtés du chaperon, placés sur des pédoncules assez longs et dirigés, dans le repos, vers les angles du test, en reposant dans les fossettes dont nous venons de parler. - Les antennes sont insérées immédiatement audessous de l'origine du pédicule oculaire, sur l'arête transverse qui ferme supérieure. ment la cavité buccale; les extérieures sont très-petites, un peu arquées en dehors, composées d'abord d'un pédicule court, in. sensiblement plus mince; de trois articles, dont le basilaire est allongé et aplati, et dont les deux supérieurs presque cylindriques. A la suite de ces trois articles, consiđérés, par M. Latreille, comme le pédon. cule de l'antenne, on en voit d'autres plus petits et allant en diminuant jusqu'à l'ex: trémité ; ce filet est composé d'à peu près dix ou onze articles cylindriques; les antennes intermédiaires sont très-petites, contiguës aux extérieures et composées de trois gros articles courts, dont le dernier est tronqué obliquement, et ne porte pas de filet articulé. On voit, à la partie intérieure, et à l'extrémité du second, un très-court filet, conique, composé de deux articles apparens; les antennes sont toujours repliées et cachées dans la cavité destinée à les rece. voir.-Toutes les parties de la bouche sont recouvertes par les pieds-mâchoires extérieurs, lesquels sont contigus dans toute leurlongueur.-Les premiers articles de ces pieds-mâchoires sont très-petits, et comme at tachés à un palpe flabelliforme, très-court, d'une seule pièce, et aigu à son extrémité ; le second article est très-grand; le troisième beaucoup plus petit et en forme de trapèze ; les trois suivans, à peu près de la mème Jongueur et cylindriques, au lieu que les trois premiers sont toujours aplatis. - Les pinces sont inégales, grandes, courbées, en forme de cœur, en ovales et comprimées; les autres pattes sont longues, comprimees; celles des troisième et quatrieme paires sont plus grandes.- Les ongles ou le dernier article des tarses sont très-comprimés, marqués de quelques lignes élevées, yelus et ciliés, et terminès en pointe.

Ces Crustacés ont pour habitude de se tenir le plus souvent à terre, surtout après le coucher du soleil; on les rencontre sur les plages sablonneuses des bords de la mer ou des fleuves, surtout vers leur embouchure; ils se creusent des terriers où ils se retirent pendant la nuit. Ces Crustacés sont doués d'une si grande vitesse, qu'Olivier assure avoir vainement tenté d'atteindre, à la course, une espèce qu'il a trouvẻe sur les côtes de la Syrie, et qu'il a nommée Ocypode chevalier. M. Latreille pense que c'est cette espece dont Pline fait mention, 


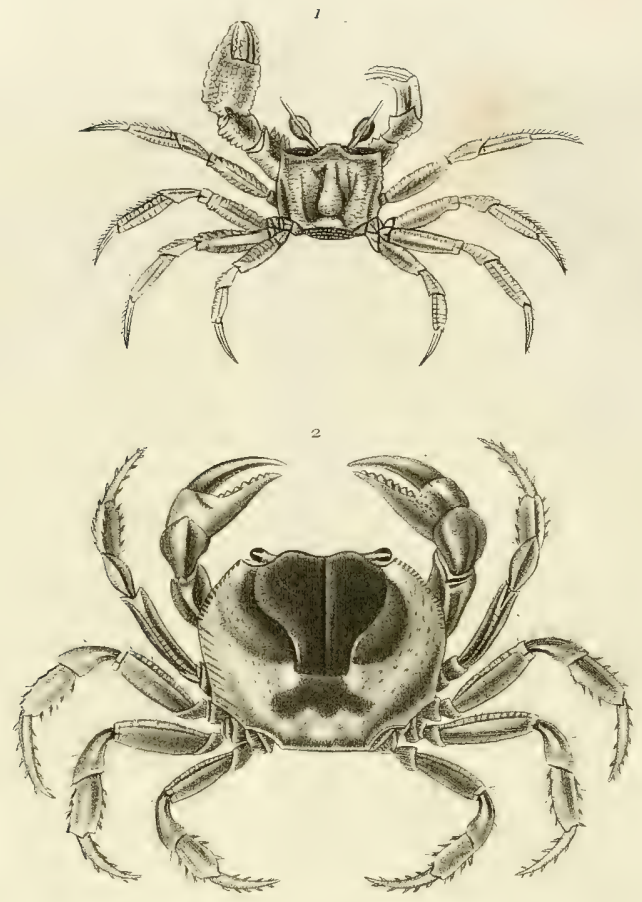

3

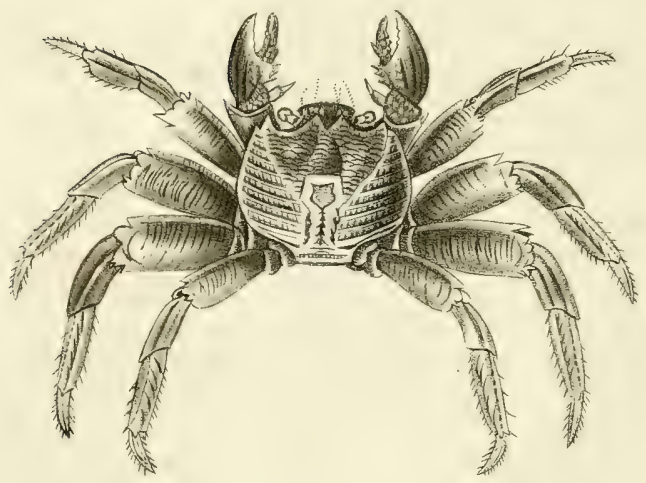

1. Ocypoda Ceratophthalma

2. Gecarcimus Lateralis

3. Grapsus pietus. 
et que les Grecs désignoient sous le nom d'Hippeus. Bosc a observé, à la Caroline, une autre espece d'Ocypode (Ocypode albicans), qu'il dit courir avec une telle vélocité, qu'il avoit de la peine à la devancer à cheval, et à la tuer à coups de fusil. M. Latreille pense que la nourriture de ces Crustacés consiste dans les cadavres d'animaux.

Ce genre renferme très-peu d'espèces; toutes sont propres aux pays chauds de l'Europe, de l'Asie, de l'Afrique et de l'Amérique. Ces espèces présentent entre elles des caractères assez tranchés. Nous les diviserons en deux petites sections, ainsi caractérisées :

\section{PREMIÉRE SECTION.}

Les pédicules des yeux sont prolongés au-delà de leur extrémité supérieure, en forme de pointe ou de corne.

\section{OCXPODA CERATOPhTHALMa. (Pl. 1 ,} fig. 1.)

FABR., Ent.Syst. Ins., Suppl., p. 347, no 1. - Latr., Hist. nat des Crust. et des Ins. , t. VI, p. 47, tab. 45, fig. 1-2. - Desu., Consid. gén. sur les Crust., pl. 12, fig. 1. - EDw., Nouv. Icon. du Règn. anim. de Cuv., Crust., livr. 2, pl. 17, fig. 1.- Cancer Cursor, OuIv., Encycl. méth., t. VIII. - Larg. 20 lig. - La carapace est dentelée à ses extrémités antérieures, et non terminée en pointe aiguë; en dessus elle est fortement granulée, avec ses régions branchiales plus saillantes que les cordiales et les hépatiques, lesquelles sont peu ou presque point granulées; les lignes de séparation des régions branchiale et liépatique sont profondément marquées; les pédoncules des yeux -sont prolongés d'un tiers au plus, de leur longueur totale, au-delà des yeux, en une pointe conique et simple; les pinces sont grosses, cordiformes, très-granuleuses, dentelées sur leurs tranches; la gauche étant plus grande que la droite; les pattes sont très-allongées, legèrement granuleuses et épineuses sur leurs tranches supérieures; le dernier article, ou le tarse, est lisse, plane à sa partie supérieure et sillonné longitudinalement. - Se trouve aux Indes Orientales.

\section{OCYPODA IPPEUS.}

Ourv., Encycl. méth., t. VIII.-SAV., Egypt. Crust., pl. 1, fig. 1. - Cancer Eques, Belon, De la nat. des Poiss., liv. 2, p. 367. - Cancer Cursor, Liss.
- Larg. 20 lig. - La carapace est presque carrée, convexe, entierement chagrinée; le chaperon est étroit, crénelé; le bord des orbites et la ligne saillante qui les sépare sont crénelès; les yeux sont oblongs; le pédicule qui les porte, les em. brasse à moitié supérieurement, les dépasse et se termine par un faisceau de poils gris, doux au toucher, soyeux, assez longs; les pattes antérieures sont plus courtes que les autres, anguleuses, fortement chagrinées; les autres sont assez longues, presque égales, raboteuses; les tarses sont minces et présentent plusieurs lignes saillantes.-Des côtes africaines de la Méditerranée et de l'Océan, depuis la Syrie jusqu'au CapVert.

\section{OCYPODA FABRICII.}

Epw., op. cit., t. II, p. 47. - Long. 20 lig. - L'appendice terminal des yeux est non sétifère, très-court et obtus; l'angle orbilaire est plus saillant; la portion post-foraminaire de l'orbite est à peu près droite et dirigée directement en avant; les mains sont épineuses, très-larges, comprimées, et terminées supérieurement par un bord mince; les pattes suivantes sont arrondies en dessus; les tarses sont aplatis, lancéolés, et garnis en dessus de deux lignes lisses, élevées, et séparées par un espace rempli de duvet. - Habite l'Océanie.

\section{OCYPODA URVILLEI.}

Guér., Voy. de Duperrey. Zool., t. II,

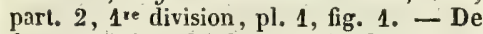
forme carrée, plus longue que large; son chaperon est étroit; le bord antérieur est sinué et terminé en pointe aux angles; le dessus de la carapace est un peu bombé, finement granulé; les régions ne sont pas saillantes, mais elles sont assez bien marquées par des lignes enfoncées; les yeux sont très-grands, avec leurs fossettes trèslarges, surtout en-dessous, et bordées d'une petite carène crénelée; ils sont terminés par une petite pointe conique, arrondie au bout; les pinces sont inégales, la droite étant la plus grande; les pattes sont longues, comprimées, garnies en dessus de petites stries courbes; leur ongle ou dernier article est cannelé dans sa longeur, garni de poils noirs, en dehors, et légèrement aplati. Cette espèce a été trouvée à Taîti.

\section{OCYPODA MAGROCERA.}

Edw. , op. cit., t. II , p. 49. - Long. 1 pouc. $\frac{1}{2}$. - Les orbites sont très-évasées et dirigées très-obliquement en dehors, la 
portion externe de leur bord supérieur se dirigeant directement en dehors et en arrière, de manière à former avec le bord latéral de la carapace un angle obtus; le dessous de l'angle orbitaire externe ne présente pas d'échancrure; les bords latéraux de la carapace sont finement granulés ; la grosse main est très-courte, très-élevée, et un peu épineuse en dessus; sa portion palmaire est beaucoup plus élevée que longue; les pinces de la main sont lamelleuses et très-élevées jusqu'à leur extrémité ; les pattes des quatre dernieres paires sont tresrugueuses en dessus; les tarses sont peu élargis; la couleur est jaunâtre.--Se trouve aux Indes-Orientales et au Brésil.

\section{SECONDE SECTION.}

Espèces dont le pédoncule des yeux se termine avec eux; telles sont :

\section{OCYPODA CORDIMANA.}

Latr., Nouv. Dict.d'Hist. nat, , deuxième édit., t. III, p. 198.-Desu., Cons. gén. sur les Crust., p. 121. - Les extrémités antérieures de la carapace sont terminées en pointes très-aiguës; sur les côtés latéraux elle est très-légèrement dentelée et sa partie supérieure tres finement granulée; les yeux sont très-allongés, et s'étendent dans toute la longueur de leurpédoncule; les serres sont très-comprimées, cordiformes, graveleuses, avec leuirs tranches dentelées; les pattes sont allongẻes, raboteuses, avec la tranche supérieure de leurs derniers articles hérissée de poils noirâtres très serrẻs.-Se trouve aux Indes-Orientales.

\section{OCYPODA RHOMBEA.}

Orrv, Encyil. méth., t. VIII.-Latr., Hist. nat. des Crist. et des Ins., t. VI, p. $52, \mathrm{n}^{*} 21$. - Bosc, Hist. nat. des Crist., t. I, p. 194. - La carapace est petite, lisse, de forme rhomboïde, avec l'angle extérieur aigu; les yeux sont grands, simples, el s'étendent dans toute la longueur de leur pédoncule; le chaperon est courbé, entier; les pinces sont ovoïdes, comprimées, finement chagrinées, avec les doigts striés, la gauche étant la plus grande; la couleur générale de cette espèce est blonde. - Habite l'Ile-de-France.

\section{OCYPODA ARENARIA.}

EDw., op. cit., t. II, p. 4', pl. 19, fig. 13, 14. - Cancer Arenarius; Catesby, Hist. of south Carolina, vol, II, pl, 35.-Ocy. poda quadrata, Bose, t. I, p. 194, pl. 4 , fig. 91 ? - FABR., Suppl., p. 347. Ocypoda Arenaria, $\mathbf{S}_{\Delta \mathbf{Y}}$, op. cit., p. 69. - Cette espèce diffère des précédentes, par ses yeux, qui sont ovales, commençant à peu de distance de la base du pédi. cule, s'étendant mème en dessus, et formant, avec lui, une espèce de massue; par son test et ses pinces, qui sont plus finement chagrinées ; par ses dojgts qui sont plus allongés, et par les poils nombreux dont les pattes sont garnies. - Habite Cayenne.

\section{OCYPODA ALBICANS.}

Bosc, Crust., t. I, p. 196, tab. 4, fig. 1. - Latr., Hist, nat. des Crust. et des Ins., t. VI , p. $48, \mathrm{n}^{\circ} 4$. - Larg. 18 lig. - Les yeux ont leur pédicule qui les embrasse, les dépasse, et se termine en pointe obtuse ou arrondie ; la carapace est blanchâtre, carrée, presque cubique, chagrinée, surtout vers ses bords et en-dessous, à sa partie antérieure; les orbites sont sinuées, et créne. lées supérieurement, et terminées en angle aigu; la queue est unie; les pattes sont blan. ches, aplaties, garnies de poils serrés, assez longs sur leurs bords ; les pinces sont hérissées de tubercules épineux, dirigés en avant; le premier article est triangulaire et épineux sur deux de ses arêtes; le second est arrondi et armé de deux épines antérieurement, dont une plus courte; la main est ovale et fortement dentelée latérale. ment; les doigts sont courts et tuberculeux en dedans. - Se trouve sur les côtes de la Caroline.

Consultez, pour les autres espèces, Olivier, Encyclopédie méthodique, t. VIII; Savigny, Description de l'Egypte, Crust., pl. 1 , fig. 2 , et le t. II de l'Histoire nat tirelle des Crustacés, par. M. Milne- Ed. wards.

\section{GELASIMUS, LATr. ; \\ Ocypoda, Bosc; Cancer, Lins.}

Chez ce genre, la carapace est en forme de trapèze, transversale et plus large au bord antẻrieur, dont le milieu est rabattu en manière de chaperon. - Les antennes sont toutes découvertes et distinctes; les latérales sont sétacées.-Les yeux sont situés chacun à l'extrémité d'un pédoncule grêle, cylindrique, prolongé jusqu'à l'angle antérieur et latéral de la carapace, et recus dans une fossette longue, linéaire. - Les pieds-mâchoires extéricurs sont rapprochés l'un de l'autre ; leur quatrième article étant 
inséré à l'extrémité latérale et supérieure du précédent. Les pinces sont comprimées, et l'une d'elles est beaucoup plus grande que l'autre. - Les pattes, proprement dites, diminuent graduellement a partir de la seconde paire.

Les Gélasimes, propres aux pays chauds, sont connus sous le nom de crabes appelants, parce qu'ils ont l'habitude singulière de tenir toujours élevée leur grosse pince en avant de leur corps, comme s'ils faisoient le geste d'usage pour faire approcher quelqu'un. Ils se tiennent non loin de la mer, dans les terrains humides, et plusieurs d'entre cux se creusent des terriers cylindriques, obliques et très-profonds, tellement rapprochés les uns des autres; qu'ils se touchent; et ces terriers ne sont habités ordinairement que par un seul individu.

Parmi les espèces remarquables que renferme ce genre, nous citerons :

\section{GELASIMUS MARACOANI.}

Latr., Hist. nat. des Crust. et des Ins., ใ.VI, p. 46, n'9--Ocypode Heterochelos, Bosc, t. I, p. 197.-Gonoplax Maracoani, LAx., op. cit., t. V, p. 251.-Sa carapace est légèrement chagrinée, avec deux lignes enfoncées, longitudinales, dans son milieu; l'une des deux serres, tantôt la droite, tantôt la gauche, est très-grande; à doigts comprimés; ces deux serres ont leur face extérieure couverte de tubercules arrondis en forme de grains, et la face intéricure lisse; la couleur générale de cette espèce est jau. nâtre lavé de rougeâtre.-Cette espèce se irouve au Brésil et à Cayenne.

M. Eydoux a fait connoitre une espèce trés-remarquable de Gélasime, qu'il a trouvée à Tanger, et qu'il a nommée :

\section{GELASIMUS TANGERII.}

Eydoux, Mag. de Zool., class. VII, pl. 17. - La carapace est de forme trapézoïde, un peu plus étroite en arrière, assez. plate en dessus, épaisse, àvec les côtés coupés carrément, ce qui la rend cubique ; elle est d'un brun verdâtre assez foncé, lavée de bleu, avec quelques teintes jaunâtres en avant; sa surface supérieure est fortement chagrinée dans toute son étendue; mais les petits tubercules qui la hérissent sont surtout abondants sur les régions branchiales, lesquelles sont séparées des régions moyennes par des lignes enfoncées, longitudinales; le bord antéricur de ses angles sont peu saillans; le chaperon est de largeur moyenne, et placé entre deux pe- tites échancrures qui correspondent au point où les pédicules oculaires prennent naissance; ceux-ci n'atteignent pas les angles de la carapace, et ne sont point terminés par une épine; les parties latérales inférieures du céphalathorax, celles qui sont en rapport avec les pieds-mâchoires, sont fortement granulées; l'abdomen est étroit, il se compose de sept tablettes, dont les deux premières sont moitié plus ètroites que les autres; les pieds sont de la couleur de la carapace, mais plus pâles à l'extrémité ; ils présentent quelques points granuleux, disposés en ligne à la face inférieure de la jambe, et leurs tarses sont comprimés et garnis à leurs bords de poils assez longs et assez serrés; la grande pince, qui seule en est dépourvue, est placée, tantôt à droite, tantôt à gauche ; les doigts sont très-longs, courbés, étroits, ne présentant de tubercules qu'à leurs bords correspondans; le doigt fixe dépasse le mobile, et est un peu plus large que lui; il n'a sur son poignet que quelques points en saillie assez rares. La femelle diffère du mâle par ses pinces; qui sont moins grosses et moins allongées, par son test qui est moins large, et par les granulations moins prononcées sur les régions branchiales; les serres sont très-courtes et grêles; les pattes sont courtes et bien plus robustes que chez le mâle; la tache rouge, qu'on aperçoit à l'extrémité des cuisses chez ce dernier est bien peu prononcée chez la femelle, et il en est de même pour les poils qui, sur les tranches supérieures et inférieures, sont très-touffus et très-serrés, et tandis que chez la femelle ils sont rares et à peine apparens; la queue est très-large et non terminée en pointe à son extrémité.

Nos Gélasimes, dit M. Eydoux; ont été pris à marée basse, vers le fond de la rade de Tanger, à l'embouchure d'une petite rivière; ils se trouvaient en très-grand nombre dans la vase que la mer, en se retirant, laissait à découvert; ils sont bons à manger, et tellement abondans que, dans : l'espace d'une heure, les matelots de la frégate la Yictoire, sur laquelle nous étions alors embarqué, en avaient rempli deux grands paniers.

\section{GeIasmus PUgiraton.}

Bosc, Hist. nat. des Crust., t. I, p. 198. - Ocypode Pugilator, Desx., Cons. gćn. sur les Crust., p. 123.- Cette espèce. qui se trouve dans les deux Amériques, a étê observée par Bosc dans la Caroline 
nous reproduirons, d'après cet auteur, la description de ses habitudes après que nous en auróns donné les caractères spécifiques.

La carapace est lisse, entière dans ses bords, sinueuse antérieurement; la pince droite est ordinairement plus grande que la gauche; toutes les deux sont légèrement chagrinées ; les doigts sont très-longs, courbes et unis; les pattes sont grises, aplaties, un peu ciliées.

Suivant Bosc, les Gélasimes combattans sont terrestres; ils vivent par milliers et même par millions sur le bord de la mer ou des rivières; dans lesquelles remonte la marée. Dès qu'un homme ou un animal paraît au milieu d'eux, ils redressent leur grosse pince, la présentent en avant, semblent le défier au combat, et se sauvent en courant de côté, mais conservant toujours la même position. Leurs trous sont si nom. breux dans certains endroits, qu'ils se touchent; ils sont cylindriques, ordinairement obliques et trés-profonds. Rarement plusieurs individus entrent dans le même trou, excepté quand ils sentent le danger trop pressant. On ne les mange point. Ils ont un grand nombre d'ennemis parmi les loutres, les ours, les oiseaux, les tortues, les alligators, etc.; mais leur multiplication est si considérable, que la dévastation que ces animaux font parmi eux n'est pas sensible. Ils ne craignent pas l'eau qui les courre quelquefois; mais ils ne cherchent pas à y entrer, et jamais ils n'y restent long-temps, si ce n'est peut-être pour faire leurs petits. Bose a vu des femelles garnies d'œufs dès le mois de mars; mais il n'a jamais trouvé de petits du premier áge ; il faut qu'ils restent dans l'eau ou dans la terre pendant l'année de leur naissance. Les mâles se distinguent des femelles parce qu'ils sont plus petits, plus colorés, et que leur queue est triangulaire.

\section{GELASIMUS VOCANS.}

LAtr., Règ. anim. de Cuv., $2^{*}$ éd., t. IV, Desh., Cons. gén. sur les Crust., p. 123. - Cancer vocans, DEgeER, t. VII, pl. 20 , fig. 12. - La carapace est unie avec le bord antérieur sinueux; Ia serre droite est ordinairement plus grande que la gauche; toutes les deux sont finement chagrinées en dehors, avec une ligne enfoncée, courle, près de leur extrémité, et ayant leurs doigts longs, étroits, très-écartés entre eux, mais comprimés; les pédoncules oculaires sont pourvus à Jeur extrémitérd'une pointe niguè. - Se trouve aux Antilles.

\section{GEIASIMUS MARIONIS.}

Desu., Cons.gén. sur les Crust., p. 123, pl. 13, fig. 1. - La carapace est entièrement lisse, terminée de chaque côté par un angle assez vif et dirigé en avant, ayant une impression en forme d'H sur le dos; les pédoncules oculaires vont en grossissant insensiblement par le bout, et sont sans pointe terminale; le bord inférieur du sillon des yeux est crénelé; la pince droite est beaucoup plus grande que la gauche, très-comprimée, granuleuse à l'extérieur et près de sa base; le pouce droit est lisse sur ses deux faces, granuleux sur sa tranche interne; le doigt immobile est arqué en dessous dans toute sa longueur, avec son bord externe largement échancré dans son milieu, et partout garni de dentelures mousses disposées sur sa tranche.-Celte espéco a été trouvẻe à Manille.

\section{Gelasimus TETRAgONON.}

Ruppel, Besch. und Abbildung, p. 25, pl. 5, fig. 5.-GuḱriN, Voy. de DuperreY, Zool., t. II, part. 2, $1^{\text {re }}$ division, pl. 1, fig. 2 et 5. - Cancer tetragonus, FABR., Suppl. Ent. Syst., p. 341, n²6.-La carapace est carrée, munie antérieurement de poils noirs; disposés en faisceaux, et armée de chaque côté de deux dents fortes, aiguës; le front est coupé, inégal; les pinces sont courtes, grosses, avec les bras crénelés de chaque côté; les carpes sont raboteux et les mains presque lisses; les pattes ont leurs jambes comprimées, munies d'une dent vers leur extrémité. - Habite les Indes-Orientales; elle se trouve aussi dans les mers d'Afrique.

Voy., pour les autres espèces, Guérin, Icon. duRèg. anim. de Cuvier, Crust., pl. 4, fig. 5, l'Encycl. meth., t. VIII, et l'ouvrage de M. Edwards, t. II, p. 49.

\section{MICTYRIS, LATR.}

Ce genre, qui a été établi par M. Latreille, est, sans contredit, par sa forme ramassée, un des plus curieux de la tribu des quadrilatères. - La carapace est presque ovoïde, molle, membraneuse, un peu plus large, et tronquée postérieurement ; elle est renflée, avec les séparations des régions, bien marquées par des lignes profondément enfoncées. - Les antennes intermédiaires sont à peine bifides au bout, avec leur pre. mier article plutôt longitudinal que transversal. - Les yeux sont saillans, gros, peu écartés, placés en avant, portés sur un pé 


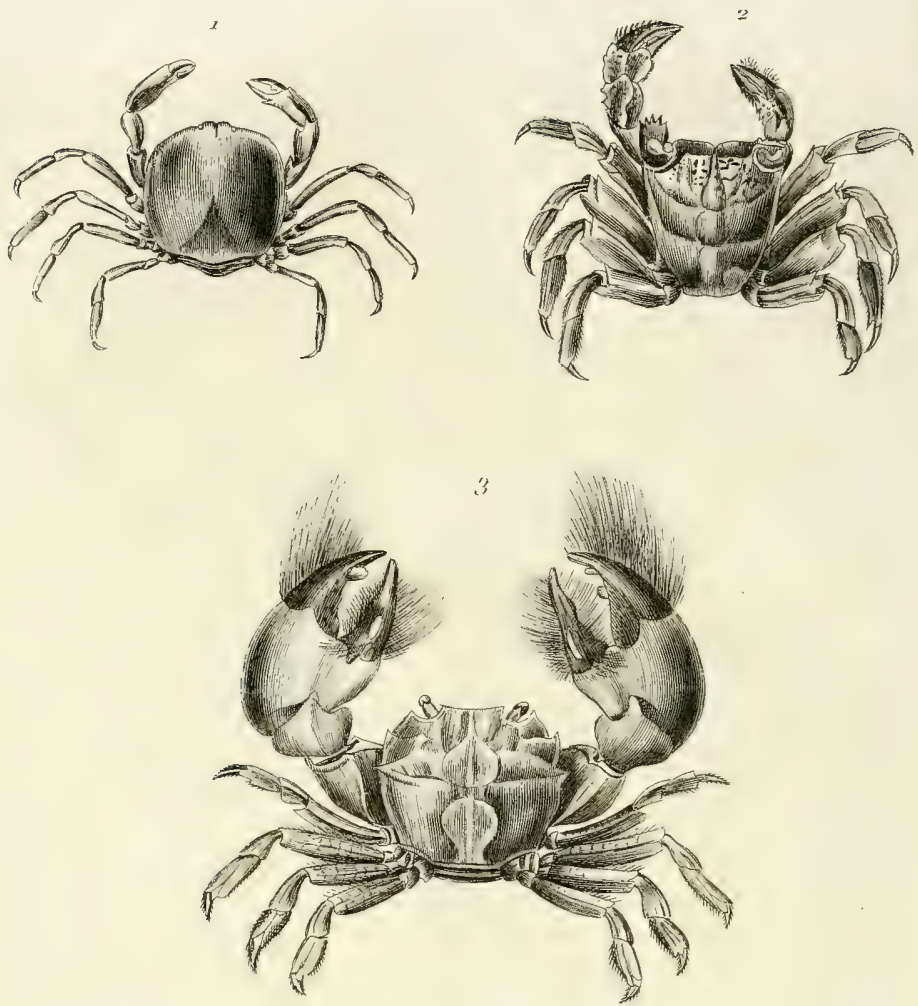

$+$

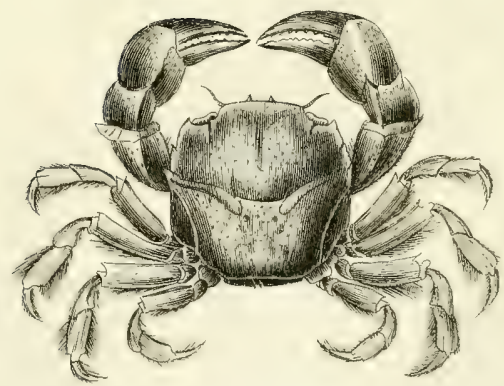
1. Pinnotheres veterum,
2. Sesarma Pisonit .

5. Pscudograpsus penicilliger...

4. Varuna litterata. 
doncule court, globuleux, et logés dans des fossettes. Les articles inférieurs des pieds-mâchoires extérieurs sont fort larges, foliacés, très-velus au bord interne, avec le second article ford graud, et le suivant presgue demi-circulaire. - Les serres sont grandes, avancées, et forment près de leur milieu, en se dirigeant brusquement en bas, un coude très-prononcé; leur carpe est très-allongé. - Les pattes sont longues, et vont en diminuant progressivement de grandeur, à partîr de la seconde paire; leurs derniers articles sont pointus, comprimés et sillonnés. Chez les femelles, l'abdomen est formé de sept pièces.

\section{MICTYRIS LONGICARPUS.}

Latr., Gen. Crus, et Ins., t. I, p. 40.Guérin, Icon.du Règ. anim. de Cuv.Crust., pl. 4, fig. 4. - Desm., Consid. gén. sur les Crust.,p. 115, pl. 11, fig. 2. - Cette espèce est de petite taille et entièrement d'un jaune grisâtre; toutes les parties saillantes de la carapace, comme les régions branchiales, cordiales, etc., sont granuleuses; les serres sont de même couleur, sillonnées longitudinalement, avec le doigt mobile élargi à sa naissance, et légèrement granulé à sa tranche supérieure; à sa tranche inférieure ce doigt presente une dent large, mousse; les pattes sont assez allongèes, comprimées, et légèrement granuleuses. Ciette espèce se trouve dans l'Océan Australasien.

DOTO, Dehane, Fauna Japonica, $1^{\text {re liv.; }}$ Cancer, Fonsk.; Mictyris, Aud., Egypt.: Forskalia, Edw., op. cit., t. 1I, p. 38.

Ce genre a beaucoup d'analogie avec ceux d'Ocypode et de Mictyre; cependant il en diffère par la conformation des piedsmâchoires externes et la forme du cadre buccal; celui-ci, très-large en arrière, est étroit en avant. - Le troisième article des pieds-mâchoires externes est beaucoup plus grand que le second, et cache presque en. tièrement les articles suivans, dont le premier s'insère à son angle antérieur et externe. - Le palpe, placé au côté extérieur de ces organes, a beaucoup d'analogie avec celui des Ocypodes, car il ne porte pas à son extrémité, comme la plupart des Brachyures, un filet multiarticulé.

Doto sulcatus. (Pl. 2, fig.1.)

Edw., op. cit., t. 1I, p. 38. - Cancer ulcatus, Forskal, Descript. anim. qua in itiner. Orient. observ. , p. 92. - Sav., Egypt. Crust., pl. 1, fig. 3. -- Mictyris Sulcatus, Aud., Explicat. des Pl. de l'Egypt. - Guér., Iconogr. du Regn. anim. de Cuv., Crust., pl. 4, fig. 5. - Long. 6 lig. - La carapace est presque carrée et sillonnée en dessus; le bord fronto-orbitaire occupe presque toute sa largeur; les régions ptérygostomiennes et les pieds-mâ. choires externes sont également sillonnés; les pattes sont assez longues et un peu comprimées. - Se trouve dans la Mer-Rouge.

\section{MACROPHTHALMUS, LATR.}

Ce genre, dont la création est due a M. Latreille, est remarquable par la carapace, qui est en forme de quadrilatère, plus large que longue, légèrement bombée; en dessus, elle présente des granulations as. sez saillantes, surtout sur ses régions branchiales qui sont assez prononcées; ses bords latéraux antérieurs sont épineux. - Les pédoncules oculaires, couronnés par de petits yeux, sont très-allongés, légèrement courbés et logés dans une fissure assez profonde, pareillement courbée, laquelle présente son bord supérieur très-dentelé. - Les antennes externes sont peu allon. gées, filiformes. - Les pieds-mâchoires sont très-larges et recouvrent entière. ment la cavité buccale. La première paire de pattes est peu allongée, terminée par une pince qui s'élargit à sa partie antérieure, laquelle est terminée, chez les máles, par des doigts robustes, allongés, courbés à leur côté interne; chez la femelle, ces doigts sont bien allongés, mais iis sont plus grêles; les seconde et cinquième paires de pattes sont peu allongées, tandis que les troisième et quatrième sont très-allongées, robustes, avec leur premier article trèslarge, épineux sur ses tranches supérieures et inférieures; le second article est trèscourt, très-élargi à sa base; le troisiéme article est plus allongé et hérissé d'épines à ses parties supérieures et inférieures; enfin, le dernier article est très-court, un peu élargi, et terminé en pointe à sa base. L'abdomen, chez les deux sexes, est composé de sept tablettes; chez la femelle, cet abdomen est très-élargi, avec le dernier article arrondi a sa base, tandis que chez le mâle il est très-étroit.

L'espèce type de ce genre est le :

1. macrophthalmus parvimanus.

Latr., Règn. anim. de Cuv, nouv, édit., 
t.1V, p. 44. - Guér., Icon. du Règ. anim. de Cuv., Crust., pl.4, fig. 1. - La carapace est trapézoïde, plane et lisse en dessus, avec deux impressions qui indiquent assez bien la région cordiale; les angles latéroantérieurs sont unidentés; le chaperon est bilobé; le bord des fossettes oculaires est très-finement dentelé ; les pédicules oculaires qui se logent dans ces fossettes, sont très-allongés, grêles et légèrement courbés; les pinces sont grêles, peu allongées; leurs doigts sont lisses, assez allongès, surtout les supérieurs; les inférieurs en dessous sont hérissés de poils peu serrés; les pattes sont robustes, surtout les seconde et troisième paires, qui sont allongées; les première et quatrieme sont petites et peu allongées; généralement dans ces pattes les tranches supérieures sont hérissées de poils assez allongés, mais peu serrés entre eux.

M. Guérin a fait connaître dans un mémoire publié en extrait, dans le Bulletin de la Société des Sciences naturelles, et qui sera inséré dans le Magasin de Zoologie, deux autres espèces qui sont:

\section{MACROPHTHALMUS ROUXI.}

Guérin, Mag. de Zool., cl. VII. - La carapace, chez cette espèce, est trapézoïde, à angles latero-antérieurs bidentés, ayant quelques petits tubercules sur les côtés. Le chaperon est bilobé; les bords des fossettes oculaires sont dentés; les doigts des pinces sont denticulés en dedans et à l'extrémité ; le doigt mobile est armé vers sa base d'une forte dent tronquée; les pattes sont lisses, velues, simples, non épineuses. Habite Bombay.

\section{MaCROPHThaLMUS DENTIPES.}

Guérin, loc. cit. - Diffère de l'espèce précédente par la carapace, qui est trapézoïde; par les angles latéro-antérieurs, qui sont bidentés, et en ce qu'elle est entièrement couverte de petits tubercules; le chaperon est bilobé; les bords des fossettes oculaires sont fortement dentés; les doigts des pinces sont infléchis en dedans, sans dents à l'extrémité ; le doigt mobile présente une forte dent tronquée à sa base; les pattes sont granuleuses, armées de rangs de fortes dents sur plusieurs de leurs tranches. - Se trouve dans la même localité que l'espèce précédente.

Voyez, pour les autres espèces, M. Edwards, t. II, p. 63 ; et les Crustacés de la Mer-Rouge, de M. Ruppel, ouvrage dans lequel est figuré Je Macrophthalmus Depressus, Rupp., pl. 4, fig. 5, p. 19.

\section{CLEISTOMA, DE HAAN, EDw. ; Macrophthatmus, Aud.}

Ce genre, établi par M. de Haan, est très-voisin de celui de Macrophthalmus; il en diffère par le front qui est beaucoup plus large, occupant environ le tiers du bord de la carapace, et peu incliné. - Les orbites sont de forme ordinaire. - Le cadre buccal est au moins aussi large en avant qu'en arrière. - Le troisieme article des pieds-mâchoires extérieurs est a peu près de même grandeur que le second, et presque carré. - Entin les pattes antérieures sont courtes dans les deux sexes.

Cleistoma leachil. (Pl. 2, fig. 2.)

EDw., op.cit., t. 2, p. 68.-Macrophihal. mus, Leachii. Aud., Sav., Egypte, Crust., pl. 2, fig. 1. - Long. 4 lig. - La carapace est fine et dépourvue de poils en dessus; ses bords latéraux sont entiers, granuleux et divergents postérieurement; les mains sont courtes, très-larges chez le mâle; les pattes de la troisième paire sont les plus longues; les cuisses sont granuleuses en dessus, - Ilabite la MerRouge.

Nousrapportons ce genre, le Macrophthatmus Boscii, Aud., Sav., ouvrage d'Egypte, Crust. Pl. 2, fig. 2.

\section{GÉCARCINTES.}

Ce groupe renferme des Crustacés d'une taille assez grande, et leur carapace est généralement cordiforme.

Genres : Gecarcinus, Cardisoma, Lca, Gecarcoïdea.

Les espèces qui composent ces genres sont toutes terrestres.

$$
\begin{aligned}
& \text { GECA RCINUS, Leach; } \\
& \text { Cancer, Linn., Fabr. ; } \\
& \text { Ocypoda, Latr., Bosc. }
\end{aligned}
$$

Toutes les espèces que renferme ce genre ont généralement le corpš épais et presque quadrilatère ; les côtes ou les régions branchiales de la carapace sont arrondies, et tellement bombées en avanit, qu'elles envahissent la place des régions hépatiques. Cette carapace, qui est largement tronquée postérieurement, se termine antérieurement, et dans le milieu, par une sorte de chaperon carré ou arrondi, et ra- 
battu ả la partie inférieure. De ehaque côté on apercoit, dans une fossette transversale, le pédicule de l'œil, qui ne se prolonge pas jusqu'à l'extrémité latérale du test. - Les antennes sont très-courtes et apparentes; les extérieures étant insérées près du canthus interne des yeux, portées sur un article radical fort large, et terminées par une petite tige conique; les intermédiaires sont repliées transversalement très-près du bord inférieur du chaperon. - Les pieds-mâchoires extẻrieurs sont très-écartés l'un de l'autre, et sont très-remarquables, en cc que les second et troisieme articles sont comprimés et comme foliacés. - La première paire de pattes a la forme de deux grandes pinces souvent inégales entre elles; la seconde est moins étendue que les suivantes, et munie, ainsi qu'elles toutes, de tarses très-épineux. - L'abdomen' est com. posé de sept anneaux; celui du mâle est triangulaire; chez la femelle, cet abdomen est large, presque demi-circulaire, et arrondi au bout.

Ces Crustacés, qu'on a nommés Tourlou. rous, Crabes peints, Crabes violets, Cancres de rivière, et plusieurs de ceux qu' on a aussi appelés Crabes de terre, forment la secoude subdivision de cette première section. Propres aux contrées inter-tropicales, ces Crustacés, au dire des observateurs, pratique. raient, comme les Gélasimes et les Ocypodes, des terriers dans lesquels ils vivraient, et n'en sortiraient que la nuit, pour aller faire leur ponte dans la mer. On dit même aussi qu'ils se rassemblent en grand nombre, qu'ils suivent la route la plus di. recte, sans s'embarrasser des obstacles, et qu'après avoir rempli leur destination, ils reviennent tres-affaiblis; ils bouchent, diton, leurs terriers, lorsqu'ils veulent changer de peau; ils y restent cachés pendant six semaines, et lorsqu'ils en sortent, ils sont encore mous; on les nomme alors Crabes boursiers, et leur chair, qu'on mange a toutes les époques, est alors plus estimée dans cet état. Elle empoisonne cependant quelquefois, et on attribue cette qualité délétère à la nourriture de l'animal, et particulièrement au fruit du mancenillier, qu'ils sont censés avoir mangé. MM. Quoy et Gaimard, bien autrement dignes de confiance, nous ont dit quelques mots touchant les habitudes de ces Crustacés. C'est, disent ces habiles observateurs, dans les vastes marais hourbeux dela baie de Rio-Janeiro, au Brésil, que nous avons vu les Telpheu. ses et des miriades de Gèlasimes faire leur domicile. Ces Crustacés ne fuient vers leurs retraites que lorsqu'ils sont sur le point d'être pris; mais les Tourlourous se tiennent à l'entrée de leurs terriers; ils y rentrentau moindre danger. Il est curieux de leur voir creuser leur profonde et dégoûtante demeure; ils en sortent tout couverts d'une boue noire qu'ils portent à l'aide de leurs pinces, et qu'ils vont entasser à quelque distance. Si la terre qu'habitent ces animaux ne contient pas de substance nutritive, nous ne savons, disent-ils, ce qui peut fournir un aliment à un aussi grand nombre d'individus qui ne paroissent jamais abandonner leur stérile contrée. Mais, comme nous l'avons remarqué, le temps de leurs excursions et de la recherche de leurs alimens est la nuit. Jusqu'à présent on n'avoit pu encore expliquer comment des animaux respirant, tels que ceux-ci, par des branchies, pouvaient vivre long-temps hors de l'eau, sans que ces organes perdissent leurs propriétés. C'est à MM. Audouin et Edwards que la science est redevable de celte découverte; ces auteurs ont vu, dans les Tourlourous ou Gécarcins, une sorte d'auge ou de rigole formée par des replis, qui tapisse et constitue les pourtours de la cavité branchiale, et destinée à conserver une certaine quantité d'eau propre à bumecter les branchies. Ce genre, jusqu'a présent, se compose d'un très-petit nombre d'espèces, parmi lesquelles nous citerons , comme étant les plus remarquables, le

\section{1. gecarcinus Ruricola.}

Latn., Régn. anim. de Cuv., nouv. édit., t. IV, p. 50. - Desm., Consid. gén. sur les Crust., pl. 12, fig. 2. - Cancer ruricola, Fanr., Suppl. Ent. syst., p. 339. - Herest. Cancer, pl. 5, fig. 36, et tab. 20, fig. 116.- La couleur générale de celle espèce est d'un sang rouge foncé, sa carapace est très-bombée sur les côtés eq en dessus, où elle est marquée, sur son centre, d'une impression en forme d'H, dont les deux branches latérales se portent en avant, jusque près des yeux; le chaperon et en forme de carré transvcrsal; les yeux et les pédoncules oculaires sont a peu près, en longueur, le tiers de la largeur antèrieure du test; les serres sont unies, avec le carpe denté, au côté interne; les tarses des autres pattes sont marqués de six arêtes plus ou moins dentées ou épineuses. Celte espèce, qui est très-commune aur Antilles, est le véritable Tourlourou des voyageurs français. 
M. Guérin, dans son Iconographie du Régn. anim. de Cuvier, Crustacés, pl. 5, fig. 1 , a représenté une espéce de ce genre sous le nom de Gacarcinus lateralis, Fréminv., et que nous avons figurée pl. 1, fig. 2.

M. Latreille a formé, aux dépens des Gecarcinus, deux sous-genres; le premier est désigné sous le nom de Cardisoma, Latr. Les antennes sont découvertes; les piedsInâchoires extérieurs sont rapprochés parallèlement au bord interne, avec tous leurs articles découveris, et dont le troisième, plus court que les précédens, est échancré à son sommet. L'espèce qui nous parait servir de type à ce sous-genre, est le

\section{CaRdisoma Carnifex.}

LATr., Encycl., t. X, p. 685.-Gecarcinus carnifex, DesM.-Consid. gén. sur les Crust., p.113._Cancer Carnifex, Herist, pl. 41, fig. 1.-Gecarcimus Hirtipes, LaM., Hist. des arim. sans vert., t. 5 , p. $251 .-$ Gecarcinus Carnifex, Latr., Nouv. Dict. d'Hist. nat., $2^{\mathrm{e}}$ édit. - Long. 2 pouc. - Chez cette espèce, la couleur est d'un jaune rougeâtre dans les individus secs; mais cette couleur parait être entrecoupée de pelites lignes purpurines dans les individus vivans; la carapace est plus haute et moins large que celle de l'espèce précédente; son sommet est presque plat et marqué d'une impression en I1 peu prolongée; le chaperon est en carré transversal, très-rebordé, et déprimé au-dessus du front; leurs yeux et leurs pédoncules ont chacun, en longueur, plus du tiers de la largeur du test; les serres sont un peu graveleuses, arec l'arête inférieure tuberculeuse; les doigts sont longs, arqués et dentelés inégalement au bord interne; les tarses des quatre dernières paires de pattes ne présentent que quatre arêtes dentées ou épineuses; la longueur du corps s'étend jusqu'à trois pouces et derni. - Cette espèce a été recueillie à l'Ile-Saint-Thomas, dans les cimetières, où elle y est trèscommune.

Le second a été désigné par cet auteur sous le nom de $U_{c a}$, Latr. Il differe des deux genres précédens par la diminution progressive de la longueur des patles, et par leurs tarses simplement sillonnés, sans dentelures ni épines très-saillantes. Outre ces caractères, le test est plus dilaté et plus bombé latéralement que chez les deux genres précédens ; les cavités oculaires sont plus allongées, et n'ont point d'élévations, ni de tubercules au canthus interne; le chaperon est demi-circulaire; le sommet de la cavité buccale est plus étroit et plus cintré, et divisé en deux par une cloison.-Ce genre ne se compose encore que d'une seule espèce, qui est :

1. UCa UNA. (Pl. 2, fig. 3.)

Latr., Reg. anim. de Cuv., nouv, édit., t. IV, p. 49.-GuÉkIN, Icon. du Rég.anim. de Cuv., Crust., pl. 6, fig. 3. Cancer una. -Linv., Syst. nat., édit., 13, t. I, p. 1041. $n^{\circ}$ 13. - De grandeur moyenne, et présente beaucoup d'analogie avec l'espèce précédente; les yeux sont assez allongés; le corps est en cœur, lisse, obtus, entier, marquè au milieu de la partie supérieure, d'une impression représentant la lettre $\mathbf{H}$, assez prononcée ; les pattes antérieures sont muriquées en dessous, et les autres sont velues. - Cette espèce se trouve dans les marais de la Guyane et du Brésil.

\section{GEGARGOIDEA，EDW.}

La carapace est plus ovalaire et moins élevée que dans les genres précédens. ue front est de longueur mediocre, droit, at très-incliné. - Les fosselles antennaires sont arrondies et séparées par un petit prolongement triangulaire du front. - Les orbites sont petites, et leur bord inférieur est beaucoup plus saillans que dans les genres précédens, et laisse entre son angle interne et l'antenne externe une échancrure large et profonde. - Le cadre buccal n'est pas aussi nettement circonscrit quel'ordinaire, et est plutôt circurlaire que carré. - Les pieds-mâchoires externes laissent entre eux un grand espace vide. - Leur troisième arlicle beaucoup, moins grand que le second, est à peu près quadrilatère, peu ou point rétréci en arrière et profondément échancré à son bord antérieur, au milieu duquel s'insère l'article suivant, qui est à décourert. - La scule espéce connue est le :

\section{Gecarcoidea laLANDII.}

EDw., op. cit., t. II, p. 25. - Long. 3 pouc. - La carapace est ovalaire et sans crête sur les bords latéraux; les pattes sont fortes; les pinces sont grosses, cylindriques, uberculeuses, et se joignent dans toute leur longueur; le bord antérieur des bras est noduleux; les pattes suivantes sont dentelées sur les bords; celles de la troisième paire sont les plus longues; il y a six rangées de dents sur les tarses; la cou 
leur est d'un rouge brunâtre.-Se trouve au Brésil.

Tous les Quadrilatères qui composent la seconde section vivent habituellement dans l'eau, et sont dépourvus de ces moyens auxiliaires que la nature a donnés aux premiers pour rafraichir leurs branchies, et les conserver dans un état propre à remplir leurs fonctions. Nous les caractériserons ainsi, d'après M. Latreille:

Pieds-mâchoires extérieurs n'offrant, dans quelques.uns, que trois articles; le quatrième, dans ceux qui en ont six, inséré soit au-dehors de l'extremité interne et supérieure du précédent, mais les pédi. cules oculaires occupant alors les angles latéraux et antérieurs du test, soit à l'ex trémité interne du même article, qui est tronqué obliquement.

Nous avons divisé cette section en plusieurs groupes : le premier se composera de petits Crustacés parasites, où le thorax est presque globuleux ou rond et solide, dans les mâles, et mou ou membraneux et presque carré, dans les femelles. Les pieds-mâchoires extérieurs n'ont, distinctement, que trois articles, dont l'intérieur est très-grand et arqué.

\section{PINNothérites.}

Ce groupe ne renferme qu'un seul genre, celui de $P$ innotheres.

Ces Crustacés sont tous d'une taille trèspetite et habitent dans les Pinnes, les Modioles et les Tridacnes.

PINNOTheres, Latr. , Bosc, Leach, LAMCK., EDW. ;

Cancer, Lins.

Ce sont les plus petits Crustacés que l'on connaisse parmi les Décapodes; généralement leur corps est lisse, et diffère un peu selon les sexes. Celui des mâles est ordinairement plus petit, plus bombé, de consistance un peu plus ferme, et un peu plusrétréci à sa partie antérieure, qui forme une sorte de chaperon très-court, arrondi ou tronqué. Le corps, chez les femelles, est presque carré, avec les angles arrondis; la carapace est très-mince, flexible, un peu déprimée, de forme orbiculaire, ou presque carrée, avec les angles mousses, sans aucune dentelure ou rugosité. - Les yeux, situés de chaque côté du chaperon, sont un peu écartés, et terminés, chacun, par un pédicule court, assez gros, presque globuARN.
leux.-Les antennes extérieures sont triscourtes, leurs trois premiers articles soni plus grands que les autres, insérés dans le canthus interne des yeux; les intérieures sont plus grandes, contiguës aux premières, et placées avec elles sur une même ligne transversale. - Les pieds-mâchoires extérieurs sont courbés sur la première pièce sternale, avec leur troisième article grand et arqué extérieurement. - Les pinces sont égales, plus grosses que les autres pieds, mais plus courtes que ceux de la troisième et de la quatrième paire, les plus longs de tous. - Les mains sont ovoïdes, plus courtes, légèrement renflées dans les mâ. les, et terminées, dans les deux sexes, par des doigts coniques et pointus; ceux des mâles sont un peu plus arqués et moins droits, et paraissent avoir des dentelures plus apparentes. - Les tarses sont courts, coniques, comprimés, et finissent brusquement en une pointe fine et très-acérée. L'abdomen des mâles, qui est en forme de triangle étroit et allongé, présente, en-dessous, à sa base, deux pièces comprimées, presque foliacées. Chez les femelles, cet abdomen est vaste, long, orbiculaire, et s'étend presque jusqu'à la bouche.

Ces Crustacés, observés par les Grees, avoient été désignés, par eux, sous les noms de Pinnother et Pinnophilax. Ils les regardoient comme les gardiens et les sentinelles des mollusques du genre Pinne ou Jambonneau, et ils leur attribuoient des qualités fabuleuses; ainsi, ils disoient que les Pinnothères avertissoient l'animal des Pinnes du danger qui le menacoit, ou qu'ils lui donnoient avis que sa proie étoit entrée dans sa coquille, et qu'elle pouvoit fermer ses valves pour la saisir, etc. Quoi qu'il en soit, les Pinnothères ayant une carapace très-molle, elle ne pourroit les défendre que foiblement des attaques de leurs ennemis ; comme certains Crustacés de la famille des Brachyures (les Pagures), ils trouvent une retraite assurée dans les coquilles de la mer; mais au lieu de choisir, comme ces derniers, des tests univalves vides, ils se logent dans des coquilles bivalves virantes. Ce sont particulièrement celles des Moules et des Jambonneaur où on les rencontre. Ils ne font aucuu mal à ces mollusques, ei tout le tort qu'ils peuvent leur causer, c'est de les gêner un peu dans leur habitation. Leur nourriture parait consister dans les pelits Crustacés ou Vers que l'eau introduit dans les coquilles où ils sont placés.

Ces Crustacés se trouvent très-rarement.

5 
libres et isolés, dans la mer, ou dans les bivalves vides; aussitôt qu'ils sont nés, leur première démarche est de chercher une coquille où ils peuvent s'établir. Il est probable, néanmoins, qu'à une certaine époque de l'année, ils quittent ces coquilles pour s'accoupler. Quelquefois dans les coquilles des moules on rencontre d'autres Crustacés outre les Pinnothères; mais ce n'est que trèsrarement, ou par accident; c'est au reste ce que Cuvier nous a appris, en nous disant que quelquefois on y rencontroit le Carcinus monas, le Portunus puber, la Galathea strigosa, etc. Le peuple de cer. tains pays maritimes attribue aux Pinnothères les qualités malfaisantes que les Moules ont, pour certaines personnes, pendant l'hiver; cette idée est sans fondement, car très-souvent nous avons mangé plu* sieurs Pinnothères dans des Moules, sans en avoir ressenti aucun malaise.

Parmi les espèces que l'on trouve le plus communément dans les moules est le

\section{PINNotheres PISUH.}

Desw., Consid. gén. sur les Crust.,pl.11, fig. 3. - Pinnotheres mytilorum, Latr., Gin. Crust. et Ins. 1. I, p. 35.-Pinnotheres, pisum, Leach, Malac. Brit., tab. 14, fig. 1-2.3, la femelle. - Pinnotheres varians, LEAGi, tab. 14, fig. 9,10 et 11, le mâle. - Pinnotheres Latreillei, ejusd., op. cit., tab. 14, fig. 7-8.-Long. femelle, 4 lig.; mâle, 2 lig. - La carapace, chez la femelle, est orbiculaire, presque carrée, molle, lisse, à front un peu arqué, entier; chez le mâle, cette carapace est rétrécie en avant; les mains sont allongées, avec une ligne de cils en dessous; les cuisses présentent une semblable ligne ciliée en dessus et en dessous; les pouces sont un peu arqués; l'abdomen de la femelle est très-large, avec les côtés de ses segmens arqués en festons, et son extrémité largement mais peu profondément échancrée. - On trouve cette espèce très-fréquemment dans les coquilles des Moules et des Modioles, sur les côtes de France et d'Angleterre.

2. PINNotheres veteruM. (Pl. 3, fig. 1.) Bosc, Hist. nat. des Crust., t. I, p. 243. - Lstr. , Encycl. mélh., t. X, p. 135. Desx., Cunsid.gén. sur les Crust. , p. 119. - Lesce, Malac. Brit., tab. 15, fig. 1-5. - EDw., op. cit., t. IJ, p. 32, pl. 19 , fig. 7-8. - Long. 2 lig.-Cette espèce est plus grande que le Pinnothère-pois; son front est presque échancré ; ses mains, en dessous, sont arquées et sinueuses. Dans le mâle, la carapace est presque carrée, transverse, assez solide, ponctuée ; son abdomen est étroit, avec ses bords latéraux entiers et droits. Dans la femelle, la carapace est bien de même forme, mais son chaperon est un peu saillant, et de plus, elle est molle et très-finement ponctuée; l'abdomen est très-large, ovalaire, avec son milieu un peu élevé en carène et comme noduleux ; les trois derniers articles, a leur partie postérieure, sont échancrés. Celte espèce, qui estassez commune dans la Méditerranée, et plus rare sur les côtes océaniques de France et d'Angleterre, se trouve dans les Pinnes marines, et rarement dans les Huitres.

\section{PINTOTHERES MONTAGUI.}

Lesch, Malac. Brit., tab. 15, fig. 6, 7, et 8.- Desu., Consid. gén. sur les Crust., p. 119. - Long. 6 lig. - La carapace est presque carrée, transverse, assez solide, ponctuée; le front est echancré ; les mains sont ovales; les doigts arqués, et les côtés de l'abdomen largement échancrés entre le troisième et le septième article; celuici étant arrondi, entier et plus large que le précédent.

\section{PINvotheres villosules.}

Guér., Voy. de Duperrey, Zool., t. 11. - Id., Iconogr. du Régne anim. de Cuv., Crust., pl. 6, fig. 6. - La carapace est de forme carrée, à angles très-arrondis; son chaperon est peu avancé, un peu échancré au milieu; il est globuleux, mou, couvert d'un duvet court, serré, et brun sur toute sa surface. Les pinces sont de la longueur du corps, égales, peu robustes; les paties sont assez fortes, courtes; les premieres $\mathrm{ct}$ les secondes sont presque égales, moins longues que la carapace; les suivantes diminuent un peu de longueur; ces pattes, ainsi que les pinces, bont couvertes d'un duvet brun. Habite les cótes de l'ile de Timor.

\section{GRAPSOITES.}

Caractéres. Les genres qui composent ce groupe ont tous un test solide, tantôt carré ou trapézoïde, tantôt en forme de cœur; les pieds-mâchoires extérieurs sont composés de six articles.

Genres : Plagusia, Giapsus, Sesarma, Cyclograpsus, Pseudograpsus, Nautilo. grapsus; V́runa. 

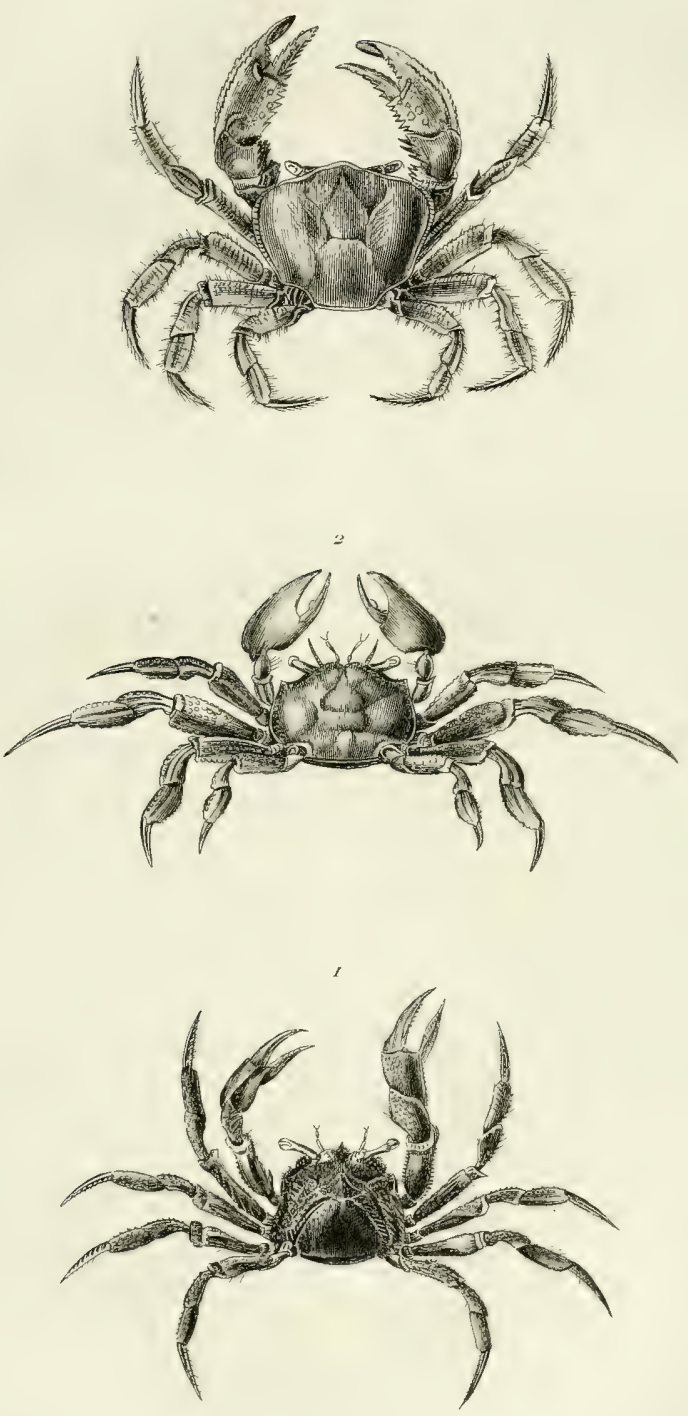

I. Dotoesulatus.

2. Cleistotoma Leachii.

3. Uca una. 

plagúsia, Latr. Edw. ; Cancer, Fabr., Herbst.

La carapace est entièrement déprimée, presque carrée, et un peu rétrécie aux deux extrémités. - Les yeux sont placés près de ses angles antérieurs, ct portés sur des pédoncules courts et assez gros. - Les antennes extérieures sont très-petites, insérées près de l'origine des pédoncules ocuIaires; les intermédiaires sont logées chacune dans une profonde entaille du dessus du front. - Les pieds-mâchoires extérieurs sont écartés entre eux inférieurement; leur troisième article est presque carré, de largeur égale, avec le côté supérieur dilaté extérieurement en manière d'angle obtus. - Les serres sont petites, égales; les autres pieds sont très-forts, comprimés, dirigés latéralement, terminés par un tarse épineux; les troisième et quatrième paires sont les plus longues de toutes. - Le postabdomen présente, dans l'un des sexes, au moins quatre segments bien distincts.

\section{1. plagusia souanosa.}

Lanck., Hist. des Anim. sans vert., t. V, p. 247. - LaTt. Encycl. méth., t. X, p. 145. - Grapsus squamosus, Bose, t. I, p. 203.-Latr., Hist. nat. des Crust. et des Ins., t. VI, p. 73. - Cancer squamosus, Herest, t. I, p. 260 , pl. 20 , fig. 113.- EDw., op. cit., t. II, p. 94.Long. 2 pouc. - La carapace est hérissée de chaque côté par quatre épines; son dessus est d'un rougeâtre clair, ponctué de rouge sanguin, et parsemé de tubercules bordés de cils noirâtres, avec l'extrémité grise; l'arête transverse et arquée, formée par la partie supérieure de la cavité buccale, est tridentée de chaque còté au-dessous des yeux, avec trois lobes intermédiaires tronqués, et dont les latéraux sont plus larges et tridentés. Les pattes sont parsemées de taches d'un rouge sanguin, et sur la tranche supérieure de leurs derniers articles elles présentent des poils grisâtres, très-serrés; les serres sont courtes, sillonnées par des poils grisâtres. - Se trouve dans la Mer-Rouge et l'Océan Indien.

\section{Plagusia depresssa.}

Latr., Encycl., mélh., t. X, p. 147.DESM., Consid. gén. sur les Crust., p. 126. -Plagusia immaculata, Laмcк., Hist. des Anim. sans vert., t. V., p. 247.-Grapsus depressus, Latr., Hist. nat. des Crust. et des Ins., t. VI, p. 66. - EDw. op. cit., t. II, p. 93.- Cancer depressus, HenBst, pl. 3, fig. 35. - F $\triangle \mathrm{BBR}$., Suppl., 343.Long. 2 pouc. - La carapace, qui est tuberculeuse et graveleuse, avec quatre dents de chaque côté, présente quelques taches d'un rouge sanguin; les lobes frontaux sont peu avancés; les serres sont sillonnées en dessus, noires sur le reste de leur surface, terminées par une main cylindrique, dont les doigts sont en cuiller. Les pattes sont aussi d'un rouge sanguin, et à la tranche supérieure de leur derniers articles elles sont hérissées, de même que dans l'espéce précédente, de poils grisâtres trèsserrés.- Se trouve dans les mers de Chine et dans l'Océan Indien.

\section{3. plagusia clatimana.}

SEBA, 1. III, pl. 29 , fig. 21. - Cancer planisșimus, Henbst, pl. 59, fig. 3.Desur., Considérat. génér. sur les Crust., pl. 14, fig. 2. - EDw., op. cit., t. II, p. 92. - Long. 1 pouc. - La carapace, en dessus, présente divers enfoncemens gar. nis d'un duvet obscur, et des espaces intermédiaires lisses, d'un jaunâtre pâle, ainsi que le corps, en forme de traits ou de petites lignes inégales; les trois divisions frontales sont avancées et dentelées; les serres, qui sont sensiblement plus longues dans les mâles, sont brusquement terminées par une main renflée, grosse, courte et ovoîde; la tranche supérieure des cuisses et des autres jambes est garnie d'une série de dentclures. - On trouve cette espèce à la Nourelle-Hollande.

\section{4. plagusia tomentosa.}

EDw., op. cit., t. I I, p. 92. - Long. 2 pouc. - Le front est large, au moins aussi large que long, terminé antérieurement par un bord granuleux, courbè et surmonté de deux épines acérées; la carapace est beaucoup plus convexe que dans l'espèce précédente; les mains sont garnies, en dessous, de plusieurs rangées de granules; les pattes sont très-aplaties, pubescentes en dessous aussi bien qu'en dessus; celle de la quatrieme paire est la plus longue; l'abdomen est composé de sept articles chez la femelle. - Habite le cap de Bonne-Espérance.

GRAPSUS, Lamck., Latr., Leach, Edw. ; Cancer, Linn., Fabr.

La carapace est plane, déprimée, lisse, carrée, à bord antéricur incliné et trans. 
verse ; la partic antérieure latérale du test présentant souvent trois dents ou crénelures dirigées en avant; la surface étant, dans quelques espèces, marquée de nombreuses rides transrerses sur les parties antérieures, et obliques sur les régions branchiales. - Les yeux sont reçus aux angles externes dans une cavité transverse, ct les antennes sont situées sur le bord inférieur du front; les latérales ou externes prennent naissance à la base des yeux, et les intermédiaires sont distantes à leur origine, et logées chacune dans une fossette du chaperon. - Les pieds-mâchoires extérieurs sont écartés à leur base, arec leur troisième arlicle à bord interne oblique, à bord externe arrondi et fortement échan. cré à son extrémité. - Les pinces sont égales, assez grosses, renflées et lisses. Les bras sont comprimés en dessus, et terminès de ce côté par une crête. - Les pattes sont comprimèes, lisses, striẻes en travers, terminées par un ongle un peu crochu, aigu à sa pointe et épineux sur ses faces; celles de la troisième et de la quatrième paire sont plus longues que les autres. - L'abdomen est de sept articles dans les deux sexes.

Les Grapses, connus dans les Antilles sous les noms de Crabes peints et Crabes des palétuviers, sont des Crustacés très-carnassiers, très-agiles, marchant dans tous les sens, mais de préférence de côté ; se soutenant momentanèment sur l'eau sans nager, sans doute à raison de la largeur de leur corps et de leurs pattes, et se tenant souvent hors de la mer. Ils sont timides, fuient à l'aspect du danger, et se sauvent en sautant à l'eau ; mais ils se défendent courageusement quand on les attaque dans le fond de leur gîte; c'est ordinairement dans les fissures des rochers que ces Crustacés se tiennent abrités; quelques-uns y fixent leur demeure. Diverses espéces propres à l'Anérique Méridionale sont abondantes dans les marais salés, et s'introduisent dans les interstices des arbres morts sur leurs bords; d'autres fréquentent l'embouchure des rivières, et il en est qui sembleraient, dit $\mathbf{M}$. P. Roux, vivre en parasite sur les tortues. Les corps morts rejetés sur le rivage composent leur nouriture ordinaire, qu'ils cherchent en rôdant la nuit et lc jour.

1. GRAPSUS CRUEHTATUS.

Latr., Hist. nat. des Crust., t. VI, p. 70. - Encycl. méth., t. X, p. 148, art. Plagusia. - Lamck, Hist. des anim. sanis vert., t. V, p. 248. - Desh., Consid. génér. sur les Crisst., p. 132. Edw., op. cit., t. II, p. 85. - Loug. 2 pouc.-Les bords latéraux de la caritpace sont armés de deux dents (y compris celle qui forme l'angle orbitaire externe): le front est très-large, presque vertical, et occupe la moitié de la largeur de la carapace; la portion postérieure de la carapace est bombée; le bord inférieur des bras est fortement denté; les pinces sont creusées au bout en cuillère ; le bord supérieur du troisième article des quatre dernières paires de pattes présente une dent arquée à son ex trémitẻ ; la couleur est rouge piquetée de jaune, arec des taches jaunes circulaires sur les régions branchiales; les pattes sont jaunes, avec des taches rouges. - Se trouve au Brésil et aux Antilles.

2. Grapsus pictus. (Pl. 1, fig. 3.)

Latr., Hist. nat. des Crust., t. VI, p. 69. —Encycl. méth., t. X, p. 147 , pl. 305, fig. 3. - LArcK., Hist. des Anim. sans vert., t. V, p. 248.-Desu., Consid. génér. sur les Crust., p. 130 , pl. 16, fig. 1.EDw., op. cit., t. II, p. 86 ; ejusd., Nouv. Iconogr. du Régne anim. de Cuvier, Crust., pl. 22.-Cancer. Tenuicristatus, Henbst, pl. 3, fig. 33, 34.- Cancer Grapsus, Fabr., Suppl., p. 349.-Long. 2 pouc.Le front est presque vertical, et sa partie médiane ne présente pas, à beaucoup près, la moitié de la longueur de la carapace; les bords latéraux sont armés de deux dents minces, courbes; la carapace est très-aplatie et moins large que dans l'espèce précédente; les régions branchiales sont marquées de lignes transversales obliques; la région stomacale est légèrement squammeuse; l'épistome est trés-grand, lisse et sans crête transversale; les pattes sont trèslongues et très-aplaties; l'extrémité du bord inférieur de leur troisième article est armée de fortes dents; les pinces sont en cuillère; la couleur est rouge, avec des taches jaunes irrégulières. - Se trouve aux Antilles, et ordinairement dans les palétuviers.

\section{3. grapsUs strigosus.}

LAtr., Hist. nat. des Crust., t. VI, p. 70.-EDw., op. cit., t. 2, p. 87.-Cancer Strigosus, Herbst, pl. 47, fig. 7.Long. 2 pouc. $\frac{1}{8}$ - La forme générale est entièrement semblable à celle du $G$. Pictus; le front est un peu moins incliné; les 
fosseltes antennaires sont beaucoup plus larges; l'épistome est très-court et présente de chaque côté une petite crête transrersale; la coulcur est rouge el jaune mélangés irrégulièrement. - Se t:oure dans la Mer-Rouge et l'Océan Indien.

\section{4. ghapges yamies.}

EATr., Hist. nat. des Crust., t. VI, 1. $67 ;$ Encycl. méth., t. X, p. 147.Desr., Consid. génér, sur les Crust, p. 131.- Enw., op. cit., t. 11 , p. 88. Cancer marmoratus, FABR. - Syst. ent., t. II, p. 450.-Heksst, t. I, p. 261 , pl. 20 , fig. 114. - Long. 16 lig. Larg. 18 lig._La carapace est presque carrée, avec le chaperon droit, non inclimé, ct quatre lobes peu élevés sur le front, desquels les deux mitoyens sont plus reculés que les latéraux; on aperçoit trois dents a chaque angle du test, sur son bord latéral; les pinces sont grosses, lisses, avec les doigts écartés à leur origine, en cuiller au bout, et pourvus de petites dents obtuses sur leur tranche interne; le carpe est dilaté en crête intérieurement; les extrémités des cuisses de toutes les pattes présentent, en arrière, une petite crête dentelée ; le corps est varié et comme finement marbré en dessus, d'une couleur brune-rougeâtre sur un fond jaunâtre; on aperçoit aussi quelques lignes de la prenière couleur obliques et parallèles entre elles, faiblement indiquées sur les ré. gions branchiales; les pinces sont d'un brunnoirâtre en dessus; les autres pattes sont variées des couleurs du corps, mais moins finement. - Cetle espèce se trouve dans la Méditerranée et sur les côtes de France baignées par l'Océan.

\section{GRAPSUS MESSOR.}

Enw., op. cit., t. II, p. 88.-G. Gaimardii, Aud., Explicat. des $p l$. de l'Egypte, Crust., pl. 2, fig. 3, par $\mathrm{SAv}_{\text {, }}$ Long. 1 pouc. - La carapace est lisse et quadrilatère, mais beaucoup plus large que dans l'espèce précédente; le front est très. incliné, peu avancé, et occupe beaucoup plus que la moitié de la largeur de la carapace; les bords latéraux sont entiers, et ne présentent, tout au plus, qu'une seule petite dent en arrière de l'angle orbitaire externe; le troisième article des pieds-mâchoires externes est moins large que dans le $G$. Varius, et donne insertion à l'article survant vers le tiers externe de son bord an. térieur; les pattes sont de longueurmédiocre.- Se trouve dans la Mer-Rouge et l'O. cézn Indien.
Ponr les \&utres esṕéces, voy. Sar. Des cription de l'Egypie, Crust., pl. 5. Guér. Iconogr. duliégne anim. de Cuvier, Cirust., pl. 6. fig. 1, et le t, II, de l'Hist. nat. des Crust, par M. Milne-Edwards.

$$
\begin{gathered}
\text { SESARMA, SAY, EDw.; } \\
\text { Grapsus. FABR. ; Cancer, LịN. }
\end{gathered}
$$

La carapace est presque équilatérale et très-élevée en avant;-le bord fronto-orbitaire en occupe toute la largeur; Ies bords latéraux sont droits et le bord postérieur très-long. - Le front est presque toujours brusquement reployé en bas, et sa longueur est très-considérable, il dépasse la moitié du diamèlre transversal de la carapace.-Les yeux sont gros et de longueur médiocre; les orbites sont ovalaires, et il existe a leur angle externe un hiatus très-grand, qui se continue avec une gouttière horizontale située immédiatement audessous du bord latéral de la carapace; le bord inférieur de l'orbite est horizontal et dirigé en avant; enfin, il s'élève de la partie interne du piancher orbitaire une dent très-forte qui se airige vers le front. - Les fossettes antennaires sont oralaires transversalement, et l'espace qui les sépare est très-large. - L'article basilaire des antennes exlernes est plus ou moins cordiforme, et donne insertion à l'article suivant dans une échancrure située au milieu de son hord interne; sa largeur est considérable, cependant le front le dépasse latéralement. - L'épistome est très-court et très-saillant, il se continue avec le bord orbitaire inférieur, et au-dessous de ce bord on voit une gouttière horizontale, qui vient aboutir à l'angle du cadre buccal ; il existe aussi 'd'autres sillons sur les régions ptérygostomiennes, dont la surface est granuleuse et réticulée; de plus, elle est divisée en petits carrés d'une régularité $\mathbf{c x}$ trềne.-- Les pieds-mâchoires externes laissent toujours entre eux un grand espace vide ayant la forme d'un losange, et leur troisième article, plus long que large, et plus long que le second, est ovalaire et peu ou point tronqué antérieurement; il existe aussi, sur la surface de cette portion lamelleuse des pieds-mâchoires externes, une ligne saillante, qui se porte obliquement de son angle externe et postérieur à son angle intérieur et interne; de plus, cette ligne ou crête est garnie de poils, et on remarque un sillon profond près de son bord externe. Le plastion sternal est convexo d'arrière eu 
avant, et, chez le mále, la portion antérieure de la cavité qui reçoit l'abdomen est arrondie et entourée d'un petit rebord. - Les pattes antérieures du mâle sont presque toujours beaucoup plus longues que celles de la seconde paire et terminées par une main forte et renflée; quelquefois il en est de même chez la femelle; les pattes de la seconde paire, sont moins longues que celles de la troisième paire, et se terminent, comme toutes les suivantes, par un article styliforme, gros, arrondi, plus ou moins distinctement cannelé . ordinairement garni de duvet, et presque toujours complétement dépourvu d'épines. - Le second anneau de l'abdomen dn mâle est presque linéaire, et le dernier est beaucoup plus étroit à sa base que le pénultième, de manière que l'abdomen présente dans ce point un rétrécissement brusque; chez la femelle, le dernier article de l'abdomen est très-petit, et en général logé presque en entier dans une échancrure de l'anneau précédent.

Ces Crustacés se trouvent sur les côles de l'Amérique, de l'Afrique et de l'Asie.

\section{SESARMA AFRIGARA.}

Evw., op. cit., t. II, p. 73. - Long。 1 pouc. - Leś bords latéraux de la carapace sont droits et armés de trois dents, dont la dernière est très-petite ; la carapace est très-élevée antérieurement, et présente dans sa moitié postérieure des lignes courbes transversales qui, chez le mâle, sont garnies de duvet; le troisième article des pieds-mâchoires externes est presque aussi large que long, et sans échancrure au milieu; les mains sont à peine granuleuses en dehors. - Se trouve au Sénégal.

\section{SESARMA IMPRESSA.}

EDW. , op. cit., t. II, p. 74. - Long. 18 lig. - Les bords lateraux de la carapace sont armés de trois dents, dont la postérieure est à peine distincte; de plus, ils sont droits, un peu divergens postérieurement, et se terminent en dessus des pattes de la quatrième paire; le front est peu élargi, et ne dépasse pas notablement le troisième ar. ticle des antennes externes : de plus il est presque vertical, et profondément quadrilobé en dessus; le deuxième article des pieds-mâchoires externes est marqué d'une dépression semi-lunaire longitudinale; les pinces sont fortes, surtout la gauche.

3. SESARMa OUADRATA.

EDw., op. cit., t. II, p. 75. - Cancer quadratus, FABR., Suppl., p. 345.-Ocy. poda plicata, Bose, op. cit., t. I, p. 198. - Oliv., Encycl. méth., t. VIII, p. 419. - Latr., Hist. nat. des Crust., t. VI, p. 47.-Long. 8 lig. - L'épistome est entièrement lisse; le front est presque vertical et à bord droit ; les orbites sont grandes et obliques; la carapace s'élargit peu à peu en arrière, et est légèrement granuleuse; les pattes antérieures sont petites, les suivantes sont tres-aplaties, - Se trouve aux environs de Pondichéry.

4. Sesarma pisonit. (Pl. 3, fig. 2.)

EDw., op. cit., t. 1, p. 76, pl. 19, fig. 4, 5. - Long. 8 lig. - La carapace est déprimée et un peu convexe transversalement; le front est très-large et presque vertical; les bords latéraux sont entiers; le troisième article des pieds-mâchoires externes, plus long que le second et ovalaire; les pattes sont longues et très-comprimées; le tarse est très-court. - Se trouve aux Antilles.

CYCLOGRAPSUS, EDw.; Grapsus, LATR.

Dans ce genre, le corps est beaucoup moins aplati que chez les Grapses, et il est plus large. - Le front est incliné. - Les bords latéraux du test sont élevés, minces et très-courts, et ses parois latérales forment d'ordinaire, avec sa face supérieure, un angle presque droit. - Les orbites sont dirigées en avant, et présentent presque toujours, au-dessous de leur angle interne, une échancrure large et profonde qui se continue en arrière, avec une gouttière transversale creusée dans les régions ptérygostomiennes de la carapace, au-dessous de son bord latéral. - Les fossettes anlennaires sont bien moins étroites que chez le genre Grapsus, et l'article basilaire des antennes externes est beaucoup moins large. - Les pieds-mâchoires externes ont beaucoup d'analogie avec ceux des Grapses; leur troisieme article est moins long que le deuxième, aussi large que long, élargi antérieurement et fortement tronqué à son bord antérieur; une petite crête saillante et pilifère se porte obliquement de l'angle antérieur et intérieur de cet article à l'angle postérieur et extérieur de l'article précédent, de manière à former avec elle, du côté opposé, un triangle dont la base est en arrière ; enfin l'appendice externe de ces pieds-mâchoires atteint presque le bord antérieur du troisième article 
de leur tige, et se termine par un appendice multi-articulé. - Les pattes diffèrent de celles des Grapses, en ce qu'elles ont le tarse moins gros et ne portent point d'épines.

Les Crustacés qui composent ce genre sont propres aux mers d'Asie.

\section{Cychograpsus punctatus.}

EDw., op. cit., t. II, p. 78.-Long. 15 lig. - Le pénultième article de l'abdomen du mâle est pentagonal; les régions cordiale et intestinale sont bien distinctes et lisses ; les régions hépatiques sont piquetées; les bords latéraux de la carapace sont garnis d'un petit bourrelet très-mince; les orbites sont très-incomplètes en dessous; les pattes sont couvertes de petits points brunrouges; les tarses sont gros et courts. - Se trouve dans l'Océan Indien.

\section{CYCLOGRAPSUS INTEGER.}

Edw., op. cit., t. II, p. 79. - Long. 4 lig. - La carapace est rétrécie antérieurement; la paroi inférieure de İorbite est bien formée, et séparée de l'angle externe par une échancrure seulement; les tarses sont légérement épineux. - Se trouve au Brésil.

\section{CYCLOGRAPSUS SEXDENTATUS.}

Eow., op. cit., t. II, p. 79.-- Long. $15 \mathrm{lig}$. - Les bords latéraux de la carapace sont granulés et divisés de chaque côté en trois dents, dont les deux premières trèslarges; la région stomacale est bosselée; le front est droit; les pattes sont minces; les tarses sont gros et courts. - Se trouve à la Nouvelle-Zélande.

\section{CYCLOGRAPSES OETODENTATUS.}

EDw., op. cit., t. II, p. 80.-Les bords latéraux de la carapace sont armés de quatre dents, dont les deux dernières sont lrèspetites; il existe entre les régions hépatiques et branchiales un sillon linéaire; les orbites sont assez largement ouvertes en dessous, mais ne se continuent pas avec une gouttière latérale; le troisième article des pieds-mâchoires externes ne présente pas de crête; les tarses sont légérement épineux.- $\mathrm{Ha}$ bite l'île de King.

\section{CYCLOGRAPSUS LATREILLEI.}

Eow., op. cit., t. II, p. 80.-Long. 4 lig. - La carapace est presque quadrilatère, très-élevée et armée de trois dents de chaque côté; les tarses sont grêles; la bouche est très-saillante. - Habile l'Ile-deFrance.

\author{
PSEUDOGRAPSUS, , EDW. ; \\ Grapsus, Latr., Desm.
}

Le corps est épais et la carapace, convexe en dessus, est assez regulièrement arrondie sur les côtés. - L'article basilaire des antennes externes est presque carré, et se joint au front; son bord externe est en contact avec une dent verticale qui s'élève sur le plancher de l'orbite; le bord interne du second et du troisième article des piedsmâchoires externes est droit, et ce dernier article, notablement plus large que long, présente au milieu de son bord antérieur une échancrure d'ou naît la tigelle terminale.-Le plastron sternal est presque circulaire et légèrement courbé d'avant en arrière. - Les pattes antérieures du mâle sont très-grosses et beaucoup plus longues que toutes les suivantes, qui sont arrondies et terminées pár un tarse velı et complétement dépourvu d'épines. - L'abdomen du mâle ne s'étend pas tout-à-fait jusqu'à la base des pattes postérieures, et son second article est linéaire.

\section{PSEUDOGRAPSUS PENICILLIGER.} (Pl. 3, fig. 3.)

EDw., op. cit., t. I, p. 82.-Grapsus Penicilliger, Latr., Régne anim. de Cuvier,

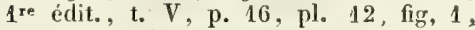
et $2^{\text {e }}$ édit., pl. 16, fig. 1; Encycl. méth.,

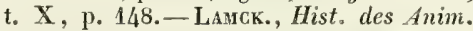
sans vert., t. V, p. 249. - Dess., Consid. génér. sur les Crust., p]. 15, fig. 1.Long. 1 pouc. - Les mains sont renflées, sans carènes ou lignes élevées, et garnies de poils qui, sur la face extérieure des doigts, sont très-longs et raides; le front est large et fortement recourbé en bas; les bords latéraux de la carapace sont très-obtus, et armés de trois dents courtes et arrondies; les pattes sont arrondies et garnies d'un duvet serré. - Se trouve dans les. mers $d^{2} A$ sie.

\section{NAUTILOGRAPSUS, EDw.; Cancer, Herbst, Fabr.; Grapsus, Latr., Roux.}

La carapace est presque plane, plus longue que large, et bombée en dessus, Les régions ne sont pas distincles. - Le front est avancé, lamelleux et simplement incliné. - Les bords latéraux sont courbes et longs. - Le bord interne du deuxieme article des pieds-mâchoires est presque uroit, et le troisieme article est plus large 
gue chez le Grapsus varius, mais à peu près de même forme.- Les pattes sont beaucoup plus courtes que chez les Grapses, et les organes générateurs mâles traversent une simple échancrure du bord du plastron sternal.

L'espèce type de cette nouvelle coupe générique est le

\section{NAUTH OGRAPSUS MIVUTUS.}

EDw., op. cit., t. II, p. 90.-Cancer Minutus, FABr., Ent. Syst., t. XI,p. 443; et Suppl., p. 343. - Livn., Mus, ad Fred. 1-8, 91; Itin. W. Goth., tab. 3, fig. 1-2. -Heriss, t. I, pl. 2, fig. 32.-Grapsus Minutus, Latr., Hist. nat. des Crust., t. VI, p, 68.-Grapsus cinereus, $\mathrm{S}_{\mathbf{A Y}}$, op. cit., p. 99.-Grapsus Testudinum, Rovx, Crust. de la Méditerr., pl. 6, fig. 1, 6.Long. 8 lig. - La carapace est glabre; on aperçoit une petite dent plusou moins arquée en arrière de l'angle orbitaire externe; les pattes antérieures sont fortes, les suivantes sont très-comprimées $€ t$ garnies en dessus d'une bordure épaisse de longs poils; les tarses sont très-courts et épineux en dessus. - Se trouve dans presque tous les parages, et souvent flottant sur le fucus natans, ou sur de grands animaux marins.

\section{VARUNA, EDw.; Grapsus, Herbst.}

Ce genre a beaucoup d'analogie avec celui de Grapsus, mais il s'en distingue par l'existence de pattes natatoires. - La carapace est très-déprimée et presque quadrilatère.-Le front est large, droit et tranchant.-Les orbites sont à peu près ovalaires; leur bord supérieur présente une fissure, leur angle externe est très-saillant, et leur bord inféxieur presque nul.-Les antennes internes se reploient un peu obliquement en dehors, et leurs fossettes sont complétement séparées des orbites par l'article basilaire des antennes externes, qui se joint au front.-L'épistome est très. grand, et les pieds-mâchoires externes se joignent presque; leur bord interne est à peu près droit, et Jeur troisième article, très-dilaté en dehors, porte l'article suivant vers le milieu de son bord antérieur, qui est fort large et échancré - Les pieds-mâchoires antéricurs sont grands, et les suivants, au lieu de se terminer par un tarse gros et cylindrique, ou styliforme, ont leur dernier article large, aplati, cilié sur les bords et de forme lancéolée. - L'abdomen, chez le mâle, est composé de sept articles distincts. La seule espèce connue est la

VARUNA LITTERATA. (Pl. 3, fig. 4.)

EDw., op. cit., t. II, p. 95.-Cancer Litteratus, FABR., Suppl., p. 342. Henist, t. III, p. 58 , pl. 48 , fig. 4. Grapsus Litteratus, Bosc, op. cit., t. I, p. 203. - La carapace est un peu piquetée en dessous, et marquée au milieu d'un $H$, formé par les sillons qui séparent les régions branchiales, cordiales, etc.; les bords latéraux sont minces et armés de trois dents très-larges, y compris l'angle orbitaire externe; on aperçoit une ligne granuleuse sur chaque région branchiale qui s'étend de la base de la dernière dent à l'origine de la dernière patte, à quelque distance du bord latéral, qui est également mince et granuleux; le bord antérieur des bras est armé de fortes dents arrondies; les mains sont un peu comprimées; les pinces sont courbees en bas, et un peu en dedans; les pattes des quatre dernières paires sont grandes, aplaties et ciliées sur les bords. Se trouve dans l'Océan Indien.

\section{GONOPLAGITES.}

Caractéres. Carapace quadrilatère ou rhomboĩdale, beaucoup plus large que longue. - Front très-large, occupant presque toujours le tiers de la longueur da bord fronto-orbitaire. - Antennes externes horizontales et lorées sur le front.-Quatrième article des pieds-mâchoires externes s'insérant, en général, dans une échancrure de l'angle antérieur et interne du troisième article.

Genres: Pseudorhombila, Gonoplax.

$$
\begin{aligned}
& \text { PSEUdORHOMbila, Edw.; } \\
& \text { Telphusa, Latr., Melia, Latr. }
\end{aligned}
$$

La carapace est légèrement arquée en avant, et entre les orbites et les bords latéraux il existe une partie assez considérable de son contour, qui se recourbe en arrière; mais sa forme générale est celle d'un rhombe, et son bord postérieur oceupe plus du tiers de son diamètre. - Le corps est trẻs-épais et très-élevé antẻrieurement.Le front est presque horizontal et divisê en deux lobes tronqués, très-larges. - Les autres organes, tels que les yeux, les antennes, l'épistome et les pieds-mâchoires externes, offrent la même disposition que chez les Crabes. -Le plastron sternal est beaucoup 


plus large que long, et assez fortement courbé d'avant en arrière ; à sa partie postérieure, qui est très-large, on remarque de chaque côté, chez le mâle, un canal d'un ralibre assez grand, qui loge les organes de la génération, dont l'origine se voit à la base des pattes postérieures. - Les pattes antérieures sont très-fortes et très-longues chez le mâle.

L'espèce type de ce noureau genre est la

PSEUDORHOUBILA QUADRIDENTATA.

EDw., op. cit., t. II, p. 59.-Melia Quadridentata, Latr., Encycl., t. X, p. 706. - Long. 2 pouc. - La carapace est presque une fois et demie aussi large que longue, et finement granulée en dessus; les orbites sont marquẻes de deux fissures à leur bord supérieur et d'une à leur bord inférieur; la portion post-orbitaire du bord antérieur de la carapace est armée de deux fortes dents, dont l'une située vers le milieu, et l'autre dans son point de réunion avec le bord latéral, qui se dirige un peu obliquement en arrière et en dedans; les pattes antérieures sont trẻs-fortes; le bord supérieur du bras présente une grosse épine, et un tubercule arrondi et très-saillant au bord interne du carpe; les pinces sont pointues, très-longues et un peu ręcourbées en bas; les pattes suivantes sont grêles et cylindriques; la couleur est rosée.

GONOPlaX, Latr., Leach, Edw.; Ocypode, Latr., Bosc;

Rhombille et Gonoplax, LaMcK.; Cancer, Fabr.

La carapace est déprimẻe, en forme de quadrilatère transversal, un peu plus large en avant qu'en arrière, ayant, dans le milieu de son bord antérieur, une avance trèsmarquée ou une sorte de chaperon.--Les yeux sont situés au bout de longs pédoncules qui s'étendent jusqu'aux angles extérieurs du test; ces pédoncules sont insérés près du milieu de son bord antérieur; ils se placent dans une gouttière.--Les antennes sont découvertes; les extérieures sétacées, très-visibles, arec leurs trois premiers articles beaucoup plus gros que les autres; les intermédiaires, bifides à leur extrémité, se logent, repliées dans l'état de repos, dans une fossette au-dessous du chaperon. - Les pieds-mâchoires extéricurs sont rapprochés, ayant leur quatrième article insérẻ à l'angle intérieur et supérieur du troisième, qui est pentagone et transversal. - Les pinces sont allongées chez le mâle ; la droite est un peu plus grande que la gauche, portée sur des bras très-longs, ayant la main comprimée et non carénée. -Les autres pattes sont généralement grêles, à articulations anguleuses, la première étant plus courte que la suivante, et la quatrième la plus longue de toutes.-Ces Crustacés, dit M. Roux, ne sortent jamais de l'eau; ils n'habitent que les grandes profondeurs de trente à quarante mètres.

- Parmi les espèces de ce genre que la Méditerranée nourrit dans son sein, nous citerons les suivantes :

1. gonoplax RHOMbomalis. (Pl. 4, fig. 1.) Latr., Nouv. Dict. d'Hist. nat., $2^{\mathrm{e}}$ éd., t. XIII, p. 205.-Desu., Consid. gén. sur les Crust., pl. 13, fig. 2, - Roux. Crust. de la Méditerr., pl. 9, fig. 1 à 9._Ocy. poderhomboïes, LATr., Hist. nat. des Crust. et des Ins. (Buffon de Sonnini), t. VI, p. 44. pl. 45, fig. 5.-Ocypode longimana. - Risso, Crust. des env. de Nice, p. 29.-Cancer rhomboides, Fabr., Syst. Ent., p. $404, \mathrm{n}^{\circ} 19$, et Mantiss. Ins., t. 1 , p. $318, n^{\circ} 20$. - La carapace, chez cette espece, est très-lisse, luisante, légérement sinuée au milieu, d'un jaune doré nuancé de rose; les angles antérieurs sont prolongés en forme d'épine; le front est entier, nu, évasé; les yeux sont d'un gris obscur; les pinces sont très-longues, à troisième article muni d'une forte épine; deux autres sur le quatrième, qui est arrondi; le doigt supérieur est mobile, noir au milieu ; l'inférieur, de cette couleur seulement vers l'extrémité; les pattes sont aussi armées d'un aiguillon sur leur troisième articulation. La femelle differe du mâle en ce qu'elle est moins colorée, ot en ce que ses pinces sont plus courtes ; cette femelle porte ses œufs en juillet. Le jeune mâle n'a que des teintes livides; il ressemble à la femelle.

Selon M. Roux, les rochers submergés depuis vingt jusqu'à quarante mètres sont les localilés où se tient constamment ce Crustacé. Sa démarche est aisée; il nage avec assez de facilité; il s'approche de la surface de l'eau, sans jamais en sortir ; il est très-difficile de se le procurer, à cause des grandes profondeurs dans lesquelles il habite.

2. GONOPLAX BISPINOSA.

Lвасн, Malac. Brit., tab. 13.-Ocypode 
angulata, Bosc. t. I ; p. 198. - Cancer angulatus, FaBr., Suppl., p. 341. - Les angles latéraux de la carapace sont avancés en forme de pointes; une seconde épine, plus petite, en arrière de celles-ci, sur chaque bord latéral de cette carapace; une épine sur le bras, et une autre à la face interne du corps; l'extrémité des cuisses des quatre dernières paires ayant aussi une pointe près de leur articulation tibiale.-Cette espèce se trouve sur les côtes de France et d'Angleterre.

\section{TRAPÉZOITES.}

Caractéres. Point de prolongement clypéiforme sur les côtés de la carapace; celle-ci terminée antérieurement par un bord fronto-orbitaire très-large et étroit, peu ou point tronqué sur les côtés, à peine tronqué en arrière, et pas très-large.

Genres : Trapezia, Melia.

\section{TRAPEZIA, Latr., Edw.}

La carapace est à peu près aussi longue que large, presque carrée, à peine bombée, et sans régions distinctes; son bord fronto-orbitaire occupe presque toute sa largeur; ses bords latéro-antérieurs sont courts, presque droits, et dirigés directement en arrière; les bords latéro - postérieurs sont obliques et très - longs. - La disposition des yeux et des antennes est a peu près la même que chez les Eriphies; mais, dans quelques espèces de Trapézies, les pieds-mâchoires ressemblent un peu a ceux des Grapses, car le bord interne de leurs second et troisième articles, au lieu de suivre une ligne droite, forme un angle rentrant, de manière que ces organes ne ferment pas entièrement la bouche, et laissent entre eux uu espace vide ayant la forme d'un losange ; d'autres fois, les piedsmâchoires ne présentent rien de particulier, et l'insertion du quatrième article a lieu toujours, comme dans la plupart des genres précédens, par l'angle du troisième article.-Les pattes antérieures sont trèslongues et fortes. - Le bras dépasse de beaucoup la carapace, et son bord antérieur est comprimé et dentelé. - La main est plus longue qu'elle, et les pinces sont pointues. - Les pattes strivanies sont de longueur médiocre et arrondies.-L'abdomen, chez le mâle, est composé de cinq articles. Ces Crustacés habitent les poys chauds.
4. TRAPEZIA DENTIFRONS.

Latr., Encycl., t. X, p. 695. - EDw., Hist. des Crust., t. I, p. 428.-Long. 5 lig. -La carapace est aussi longue que large; le front est armé de quatre dents séparées par des fissures; les deux médianes courtes et pointues; les externes larges et tronquées; les orbites sont dirigées très-obliquement en arrière; les pinces sont garnies de grosses dents, et se joignent dans toute leur longueur; la couleur est d'un jaune rougeâtre uni; les pinces sont noires. - Se troure dans l'Australasie.

\section{TRAPEZIA FERRUGINEA.}

LATr., Encycl., t. X, p. 695.-EDw., op. cit., t. I, p. 249. - T. Cymodoce, Aud., Sav., Descript. de l'Egypt., pl. 5, fig. 2.Long.10 lig. - Cette espèce diffère de la précédente par son front, qui est inégalement denté ; on y distingue en général six petites dents arrondies; le bordantérieur des bras est fortement dilaté et dentelé; les pincés sont faiblement dentelées, et ne se joignent pas dans toute leur longueur; on aperçoit quelques poils sur le bord supérieur des pattes; la couleur est d'un jaune ferrugineux. - Se trouve dans la Mer-Rouge.

$$
\text { MELIA, LAtr., EDw. }
$$

La carapace est légèrement bombée et presque carrée.-Le bord fronto-orbitaire en occupe presque toute la largeur, et les bords latéraux sont peu courbés. - Le front est large et légèrement incliné.-Les orbites sont dirigées obliquement en dehors, et ne présentent à leur bord supérieur qu'une petite fissure à peine visible. - Les antennes internes se reploient presque transversalement, et l'article basilaire des antennes externes vient se terminer dans l'hiatus qui existe entre le front et le bord orbitaire inférieur; le deuxième article de ces appendices est complétement libre et dépasse un peu le front. - Les pattes antérieures, chez la femelle, sont plus grêles et plus courtes que les suivantes, qui, à leur tour, sont beaucoup moins longues que celles de la troisième paire; les pattes de la quatrième paire sont les plus longues de toutes, et ont plus de deux fois la longueur de la carapace; toutes sont cylindriques. - L'espéce type de ce genre est la

\section{MELIA TRESSELATA.}

Edw. Op. cit., t. I, p. 431, et Lybia tresselata, pl. 18, fig. 8-9.-Grapsis tresselatus, LaTr., Encycl. , pl. 305, fig. 2. -Long. 
5 lig. - La carapace est unie et lisse en dessus; son front est divisé en deux lobes tronqués; l'angle externe de l'orbite est occupé par une petite dent, et on en aperçoit une seconde située sur le bord latéral, vers le niveau du bord postérieur de la région stomacale ; couleur blanchâtre, avec des lignes rouges; les pattes présentent quelques poils. - Se trouve à l'Ile-de-France.

\section{THELPHEUSITES.}

Caractères. Carapace plus ou moins ovalaire. - Pédoncules oculaires courts, n'atteignant pas, à beaucoup près, l'extrémité latérale de la carapace. - Quatrième article des pieds-mâchoires externes ne s'in. sẻrant jamais à l'augle externe du précédent, ni se cachant sous sa face interne. tylus.

THELPHEUSA, Latr., Edw.;

Potamophilus, Latr.; Cancer, Belon ; Gecarcinus, Lamek.

La carapace est déprimée, lisse, ayant la figure d'un cœur tronqué postérieurement, avec une impression en $\mathbf{H}$ dans son milieu, indiquant la séparation des régions de cette partie. - Les yeux sont écartés. - Les latéraux sont portés sur des pédoncules courts, gros, et logés dans une fossette ovale, transverse. - Les antennes extérieures sont très-courtes et insérées près des pédoncules oculaires, sous lesquels elles sont couchées. Les pieds - mâchoires extérieurs sont très-rapprochés, et recouvrent exactement toute la bouche. Les pinces sont fortes, de grandeur inégale, et terminées par des doigts allongés finissant en pointe, et dentelés au côté interne. - Les pattes de la troisième paire sont les plus longues de toutes, et celles des deux dernières décroissent successivement. - Le post-abdomen ou la queue est divisé, dans les deux sexes, en sept segmens ou tablettes; celui des mâles forme un triangle étroit et allongé; il est ovale, beaucoup plus grand, et recouvre le plastron dans les femelles.

Ces Crustacés, auxquels MII. Leach et Savigny avoient donné les noms génériques de Patamobie et de Potamophile, indiquent qu'ils font lcur séjour habituel dans les rivières; et c'est effectivement le crabe fluvial de Belon, de Rondelet et de Gesner, qui est le type de ce genre. L'espèce propre à l'Europe méridionale et à quelques autres contrées situées sur la Méditerranée, a joui chez les anciens, et particulièrement chez les Grecs, d'une grande célébrité, à raison des vertus médicinales qu'ils lui attribuoient; il paraît même qu'elle a été l'emblème de la constellation zodiacale dite le Cancer. Pline, Dioscoride, Avicenne, et plusieurs autres auteurs anciens, en ont fait mention. Elle est représentée sur plusieurs médailles antiques, celles d'Agrigente en Sicile notamment. Au rapport d'Elien, le crabe de rivière prévoit, ainsi que les tortues et les crocodiles, les débordemens du Nil, et gagne environ un mois auparavant les hauteurs voisines. Il est très-commun dans les rivières, et particulièrement dans divers lacs ou cratères d'anciens volcans. A Rome, on le mange dans tous les temps de l'année, et surtout les jours d'abstinence ; mais, ainsi que pour d'autres Crustacés, on préfère ceux qui viennent de muer, ou qui sont près de cette crise; on les sert alors sur les tables du pape et des cardinaux. Quelques personnes, pour adoucir leur chair, les font pẻrir dans du lait. On les porte au marché altachés avec une corde, mais placés à une certaine distance les uns des autres, afin qu'ils ne puissent pas se ronger ou se dévorer mutuellement. Suivant Belon, les caloyers du mont Athos, dans les ruisseaux duquel cette espèce est commune, la mangent crue, sa chair leur paraissant plus savoureuse dans cet état que lorsqu'elle est cuite. Les Arabes nomment ce Crustacé Saraha; mais, comme ils désignent aussi de la même manière des Ocypodes du pays, il paroîtroit que cette dénomination est synonyme de celle de Tour. lourou, donnée par divers voyageurs aux crabes de terre et de rivière. La même espèce s'ćtend jusqu'en Perse.

1. Thelpieusa flutiatilis. (PI. 4, fig. 2.) Latr., Encycl. méth., t. X, p. 563.Savig., Descript. de l'Egypte, pl. 2, fig. 5. - Cancer fluviatilis. - Crabe de riviere, Orrv., Voy. en Egypte, p. 30, fig. 2.Long. 2 pouc. $\frac{1}{2}$. - Chez cette espece, qui est très-commune dans le midi de l'Italie, la carapace est large d'environ deux pouces, lisse, avec les côtés antérieurs parsemés d'aspérités et de petites rides incisées; le chaperon est incliné, transversal, rebordé, un pcu concave; les pattes antérieures sont parsemées d'aspérités; les mains sont fortes, ovales, avec les doigts presque 
égaux, assez longs, coniques, inégalement dentés le long de leur bord intérieur, et ayant une tache roussâtre à leur extrémité ; le test est de couleur grisâtre, blanchâtre ou livide, dans les individus vivans, et d'un jaune pâle sur ceux qui sont desséchés.

\section{THELPHEUSA INDICA.}

EDw., op. cit. , t. II, p. 13.-LATR., Encycl. méth. , t. X, p. 563.-Gú́ris, Iconogr. du régn. anim. de Cuvier, Crust., pl. 3. fig. 3.-Ocypoda Aurantia, Bosc, op. cit., t. I, p. 195. - Long. 2 pouc.Le bord latéral de la carapace est armé d'une dent post-orbitaire assez forte, et ne présente ensuite que des vestiges de dentelures; de plus, on apercoit une crête élevée et droite, qui s'étend d'une dent postorbitaire à celle du côté opposé; les régions ptérygostomiennes sont lisses; la couleur est brunâtre. - Se trouve sur la côte de Coromandel.

\section{THELPHEUSA BERARDII.}

Aud., Explic. des $p l$. de l'Egypte, Crust., pl. 2, fig. 6.-Long. 1 pouc.-Les bords latéraux de la carapace sont entièrement obtus, lisses, et ne présentent aucune dent en arrière de l'angle orbitaire externe; de plus; ils sont très-courbes; la face supérieure de la carapace est bombée, lisse, et sans crête transversale. - Se trouve en Egypte.

\section{bOSCIA, Edw. ; Cancer, Herbst; \\ Thelphusa, Latr.; Potamia, ibid.}

La forme de ces Crustacés a quelque analogie avec celle de certaines Thelpheuses. Le troisième article des pieds-mâchoires externes est rélréci en avantet porte l'article suivant au milieu de son bord antérieur. Les cavités quirenferment les organes de la respiration s'élèvent beaucoup au-dessus de la surface supérieure des branchies, et présentent un grand espace vide, dont les parois sont tapissées d'une membrane tomenteuse et couverte de végétations.

Ces Crustacés sont terrestres, et habitent, comme les Thelpheuses, les bords des Ileuves.

Boscia dentata. (Pl. 5, fig. 1.)

Enw., op. cit., t. II, p. 15, pl. 18, fig. 14-16.-Cancer Fluviatilis, Hensst, t. I, p. 183 , pl. 10 , fig. 61 . - Bosc, op. cit., t. I, p. 177.-Thelphusa Dentata, Latr., Encycl. méth., t. X, p. 564.-
Desu., Consid. gènér. sur les Crust., p. 428 . - Long. 2 pouc. - La carapace, horizontale et lisse en dessus, est large; le front est granuleux sur les bords; les orbites sont entières; les bords latéraux sont tranchans, très-arqués et finement dentelés; la portion des régions ptẻrygostomiennes roisine de la bouche, est couverte d'un duvet large et serré; les pattes sont comme chez les Thelpheuses. - Se troure aux Antilles et dans l'Amérique du Sud.

\section{TRICHODACTYLUS, Latr., EdW.}

La carapace, presque horizontale en dessus, est beaucoup moins large que chez les Thelpheuses. - Le front est large, lamelleux, et simplement incliné. - Les orbites sont presque circulaires. - Les bords latéraux de la carapace sont courbes. - Les antennes ont à peu près la même disposition que chez les Thelpheuses. - La forme des pieds-mâchoires externes diffère en ce que leur troisieme article est presque triangulaire, avec son sommet dirigé en dedans, et il s'articule avec le suivant par son angle antérieur et externe.- Les pattes ont à peu près la même forme que chez les genres précédens.

Ia seule espèce connue est le :

TRICHOdACTYU. QVidARATA. (Pl. 5, fig. 2:)

Edw., op. cit., t. II, p. 16.-Long. 3 pouc. - La carapace est lisse; ses bords latéraux sont un peu relevès; les pattes sont médiocres; les tarses sont cylindriques, allongés et couverts d'un duvet couri et serré. - Se trouve dans les eaux douces du Brésil.

\section{PIeUninites.}

Ce groupe renferme trois genres : $\boldsymbol{P}_{\boldsymbol{i}}$ tumnus, Ruppellia et Eriphia.

Les Crustacés qui composent ces genres sont d'une taille médiocre et sont répandus presque dans toutes les mers.

\section{PIlUMNUS, Leach, Latr., Edw.; Cancer, Linn., Farr.}

La carapace, chez ces Crustacés, est toujours assez élevée, légèrement bombée, et sans bosselures notables entre ses diverses régions; son diamètre antéro-posiérieur 

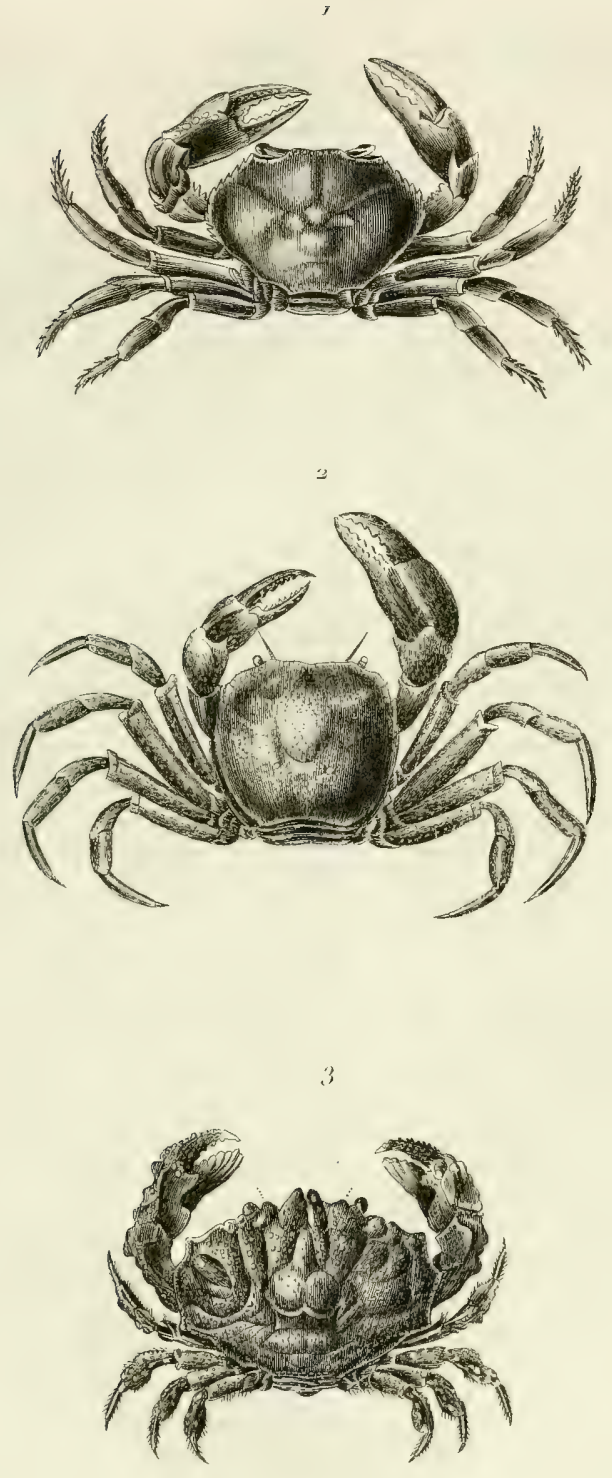

I. Boscia dentata. 2. Trichodactylus quadrata.

3. Cancer sculpetus. 

égale en longueur les trois quarts de son diametre transversal; le contour de sa moitié antérieure est assez régulièrement arqué, et se joint aux bords latéro - postérieurs, vers le niveau du bord postéricur de la région stomacale.-Les régions branchiales sont assez développées, et on remarque entre elles et les régions hépatiques une petite rainure courbe, dont la convexité est dirigée en avant. - Le front est lamelleux, assez avancé et un peu incliné. - Les orbites sont généralement plus ou moins dentelées, et les bords latéro-antérieurs de la carapace sont courts et armés d'épines aiguës. - L'article basilaire des antennes externes n'atteint pas tout-à-fait le front, et n'est guère plus large à son extrẻmitè que le second article, qui est presque aussi long que le premier, dépasse le front, et n'est pas encaissé dans l'hiatus interne, mais complètement mobile; le troisième article est également assez long, et la tige terminale est très-allongée ; elle atteint, en général, le milieu du bord antérieur de la carapace. - L'espace prélabial est pres. que toujours légèrement canaliculé. - Les pieds - mâchoires externes ne présentent rien de remarquable. - Les pattes antérieures sont fortes, renflées, assez longues et un peu inégales; celles des paires suivantes sont médiocres et arrondies; les secondes sont généralement un peu moins longues que les troisièmes, et celles-ci n'ont guère plus d'une fois et demie la longueur de la carapace; quelquefois ce sont les pattes de la quatrième paire qui sont les plus longues. - L'abdomen, dans les deux sexes, est composé de sept articles distincts. Dans toutes les espèces jusqu'ici connues, les quatre dernières paires de pattes et la partie antérieure de la carapace, sinon toute sa surface, sont poilues.

Ce genre est répandu dans presque toutes les mers.

\section{PILUMNUS mintellus.}

Leacr, Malac. Brit., pl. 12. - Desm., Consid. gén. sur les Crust., pl.11, fig. 1. - Latr., Encycl. méth., t. X, p. 125. - Evw., op. cit., t. I, p. 417.-Cancer hirtellus, Penn., t.IV, pl. 6, fig. 15.-Long. 10 lig. - Sur chacun de ses bords latéro-antérieurs la carapace présente quatre ou cinq petites dents; les mains et les carpes sont granuleux en dessus et en dehors; le corps est jaunàtre, palle, mélangé de brun ou de rouge, par des petites taches irrégulieres, cette dernière coulcur formant quelquefois des bandes sur les pattes; le corps et les membres sont hérissés de poils bruns et roides. - Se trouve sur les côtes de France et d'Angleterre.

\section{PILUMnus Vespertifio.}

Leach, Trans. Linn. Soc., t. XI. Latr., Encycl., t. X p. 175.-Desm., Consid. génér. sur les Crust., p. 112.-EDw., op. cit., t. I, p. 448. - Cancer vespertilio, Fasr., S uppl., p. 338. - Les bords latéro-antérieurs de la carapace sont armés de trois grosses épines, placées sur la même ligne, et présentant au-devant d'elles une quatrième épine, plus petite, qui est située plus bas, et qui appartient à la région ptérygostomienne; le bord inférieur des mains est lisse; le troisième article des pieds-mâchoires externes est profondément échancré à son angle antérieur et interne; le corps est entièrement couvert de longs poils bruns et d'un aspect laineux. Se trouve dans les Indes-Orientales.

\section{Pilumus tomentosus.}

Latr., Encycl., t. X, p. 125.- Edw., Hist. nat. des Crust., t. 1, p. 418.-Cette espèce diffère du Vespertilio par l'existence des granulations sur toute la partie inférieure de la main, et par la nature des poils qui constituent une sorte de duvet très. court; le corps est d'une couleur brun-noirâtre, et les pinces sont noirâtres.-Habite la Nouvelle-Hollande.

\section{Pilumies ouoli.}

EDw., Hist. nat. des Crust., t. I,p. 418. - Long. 1 pouc. - Les épines latérales de la carnpace et le front sont comme dans l'espèce précédente; le troisième article des pieds-mâchoires externes est simplement tronqué a son angle antérieur et interne, et non échancré comme dans les espèces précédentes; les pattes antérieures sont très-fortes; le carpe et la main sont armés d'épines assez grosses; toute la face supérieure de l'animal est couverte de poils roux, courts, très-roides et espacés. - Se trouve à Rio-Janeiro.

\section{5. pilunives peroni.}

EDw., Hist. nat. des Crust., t. I, p. 419. - Long. 4 lig. - 11 n'existe point d'épine située au-dessous et en avant des trois épines du bord latéro-antérieur de la carapace; qui sont-très-petites; la carapuce est assez bombée, presque lisse, et présente 
très-peu de duret. — Habite les mers de l'Asie.

\section{PILUMNUS FORSKALII.}

Epw. , Hist. nat. des Crust., t. I , p. 419. - Cancer incanus, Forsk., p. 92 . - Long. 4 lig. - La carapace est couverte de poils très-longs, gros, durs et insérés loin les uns des autres; de plus, elle est assez bombée et un peu granuleuse en dessus.

\section{Pilumus aculeatus.}

EDw., op. cit., t. I, p. 429. - GuÉr., Iconogr. durèg. anim. de Cuvier, Crust., pl. 3, fig. 2.-Cancer aculeatus, $\mathbf{S} \mathrm{AT}$, loc. cit., p. 449.-La carapace est armée en des. sus de deux petites épines très-acérées sur chaque région hépatique, près du bord latéro-antérieur, qui est lui-même armé de trois épines placées sur la même ligne, et d'une quatrième placée plus bas sur la région ptérygostomienne, près de l'angle orbitaire externe. - Habite l'Amérique Septentrionale.

8. PILUMNUS SPINIFER.(PI. 4, fig. 3.) EDW., op. cit., t. I, p. 420.-S S AVIG. , Egypte, pl. 5, fig. 4.-Cancer velu, RovDEL., t. II , p. 408. - Long. 1 pouc. - Il n'existe point d'épines sur la face supérieure de la carapace; celles des bords latéro-antérieurs sont fortes et très-aiguës; les pattes antérieures sont très-épineuses; les suivantes beaucoup plus longues et plus grêles que dans toutes les espèces précédentes; les poils sont longs, fins et rares. - Habite la Méditerranée.

\section{RUPPELLIA, EDw.; Cancer, Rupp.}

Ce genre, établi par M. Edwards, est remarquable par le bouclier dorsal, qui est un peu courbé, et environ une fois et demie aussi large que long. - Le front est beaucoup plus large que le cadre buccal, mais il n'occupe pas, avec les orbites, la moitié du diametre transversal de la carapace.-Les bords latéro-antérieurs de la carapace sont moins longs que les bords latéro-postérieurs, et se terminent avec le niveau de l'angle génital, et sont armés de dents larges et peu saillantes. - Les orbites sont presque circulaires, et dirigées en haut et en avant. - Les antennes externes sont exclues des orbites, et leur article basilaire, grand et placé obliquement, arrive cependant à très-peu de distance du canthus in. terne des yeux; il se soude au front, par un bord supérieur qui est très-large, et qui portes vers son milieu, la tige mobile de cet appendice, qui est d'une petitesse extrême.- Les antennes internes se reploient exactement en-dehors. - L'espace prélabial est canaliculé, et le troisième article des pieds-mâchoires laisse entre le bord antérieur qui est très-oblique, et le bout du cadre buccal, un espace qui correspond à l'exirémité du canal afférent de l'appareil respiratoire. Parmi les trois especes que renferme ce genre, nous citerons :

\section{RUPPELLIA TENAX.}

Evw., op. cit., t. I, p. 421. - Cancer Tenax, Rupr., Crust. de la Mer-Rouge, pl. 3 fig. 1. - Long. 2 pouc. - Le bord supérieur de l'orbite est marqué de deux fissures séparées par une petite dent, et on aperçoit une fissure à son angle externe, et deux dents à son bord inférieur; la cara. pace est bombée et légèrement granuleuse en avant, lisse et légérement bombée en ar. rière; le front est armé de six dents arrondies et à peu près équidistantes, dont les externes moins saillantes que les autres oc. cupent l'angle du bord orbitaire supérieur; les bords latéro-antérieurs de la carapace sont armés de quatre ou cinq dents aplaties, très-larges et à peine saillantes; le bord an. térieur du troisième article des pieds-mâchoires extérieurs externes est échancré au milieu; les pattes antérieures sont grosses, arrondies, et très-inégales dans les deux sexes; les mains sont granuleuses. - Se trouve dans la Mer-Rouge.

\section{RUPPELLIA ANVULIPES.}

EDw., op. cit. , t. I, p. 422. - Long. 10 lig. - On n'aperçoit pas de fissures, ni de dents, aux bords orbitaires supérieur et inférieur; le front est très-incliné, assez profondément dentelé, et creusé d'un petit sillon transversal; les bords latéro-antérieurs de la carapace présentent une petite crête horizontale; les pattes antérieures sont lisses. La couleur de cette espèce est blanchâtre, avec des bandes rosées sur les pattes.-Patrie inconnue.

\section{ERIPHIA, Litr., Edw.; Cancer, FAbr, Herbst.}

La carapace est en forme de cœur, tronquée postérieurement, avec ses côtés et son bord antérieur épineux; sa longueur dépasse de beaucoup les deux tiers de sa 


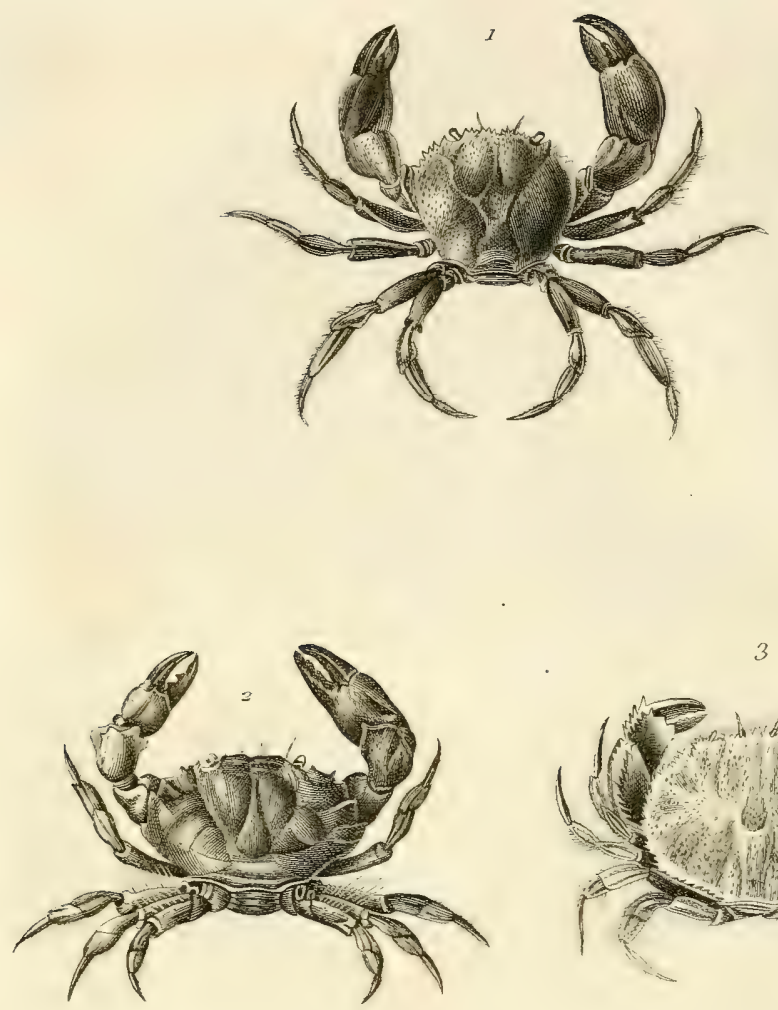

3
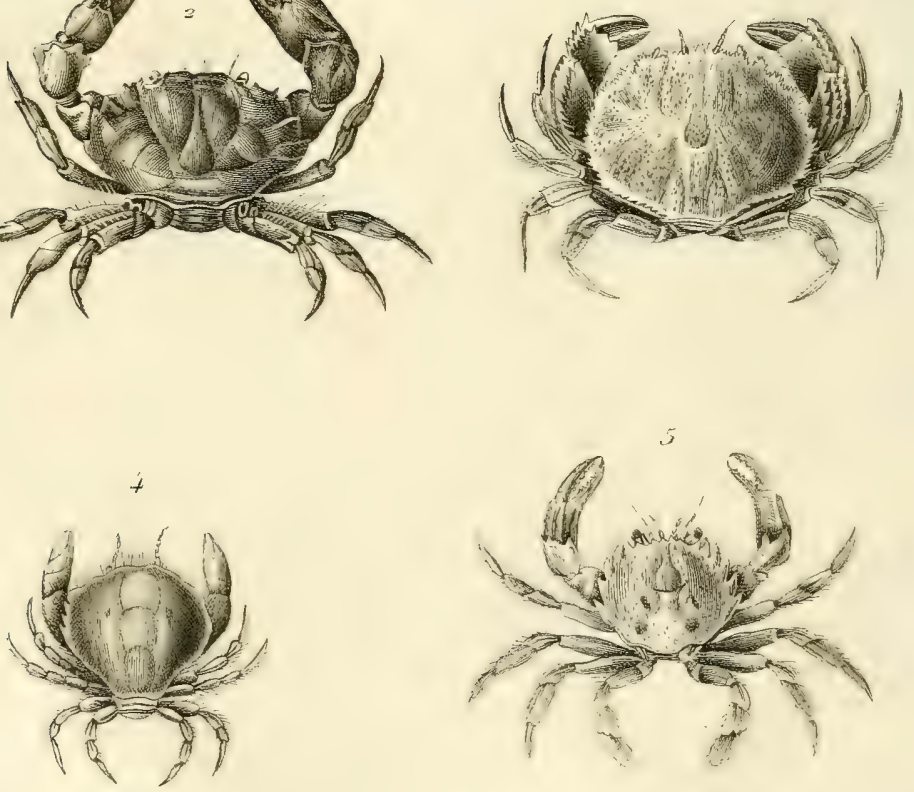

1. Eriphia loevimana .

5. Atelecvelus cruentatus .

2. Jantho rivulosus,

4. Thia polita.

5. Platronichus bipustulatus. 
largeur; son bord fronto-orbitaire occupe plus de la moitié et quelquefois même plus des trois quarts de sa largeur, et ses bords latéro-antérieurs, dirigés presque directement en arrière, ne décrivent qu'une faible courbure, et ne se prolongent que peu. - Les yeux sont écartés, portés sur des pédoncules courts, et logés dans une fossette. - Les antennes extérieures sont longues, distantes de l'origine des pédoncules oculaires, et insérées près du bord antérieur de la carapace; les inférieures sont entièrement découvertes. - Les pieds-mâchoires extérieurs sont rapprochés. - Les serres sont grosses et inégales. - Les pattes sont médiocrement fortes, un peu comprimées, parse. mées de poils roides, et terminées par des ongles presque droits, striés.

\section{ERIPIIA SPINIFRONS.}

Savig., Descript. de l'Egypte, Crust., pl. 4, fig. 7.-Desм., Cons. gén. sur les Crust., pl. 14, fig. 1.-Cancer Spinifrons, Herbst, pl. 11, fig. 5. - Fabr. , Suppl., p. 339. - Long. 2 pouc. - La carapace, chez cette espèce, est à régions peu distinctes; elle est garnie, en avant, de quelques petites lignes transversales de dentelures; le front est divisé en quatre lobes hérissés d'épines; les bords orbitaires sont épineux; les bords latéro-antérieurs de la carapace sont armés d'une série de cing ou six dents, dont les trois ou quatre antérieures sont grosses et dentelées sur le bord; les mains sont couvertes en-dessus et en dessous de gros tubercules arrondis; les pinces sont à dentelures tranchantes,-Se Irouve sur les côtes de France.

\section{ERIPIIA GONAGRA.}

EDw., op. cit., t. I, p. 426, pl. 16, fig. 16-17. - Cancer gonagra, FABR., Suppl., p. 337. - Long. 1 pouc. - La carapace est à régions bien distinctes, inégale et armée de tubercules pointus en avant; le bord fronto-orbitaire occupe plus des trois quarts de son diametre transversal; le front est divisé en quatre lobes, dont les deux médians sont avancés et tronqués; de plus, on aperçoit deux fissures sur le bord supérieur de l'orbite, et une dent aiguë à son angle externe; les bords latéro-antérieurs sont armés de cing ou six dents spiniformes; les pattes extérieures sont garnies de tubercules arrondis et déprimés; la couleur est jaunâtre mêlée de rouge et de violet; les pinces sont brunâtres. - Se trouve sur les côtes de l'Amérique du Sud.
3. Eniphia LeVrana. (Pl. 6, fig. 1.)

LAtr., Coll. du Mus.-Guér., I con. du régne anim. de Cuvier, Crust., pl.3, fig. 1. - Cette espéce a beaucoup d'analogie avec 1'E. Spinifrons; mais elle en diffère en ce que la carapace est beauconp moins élargie; en ce que Je front est plus incliné et armé d'épines moins. longues; en ce que les bords latéro-anterieurs se dirigent presque directement en avant et ne présentent qu'une série de cinq ou six tubercules pointus et isolés; et en ce qu'il n'existe à la face supérieure et externe des pattes antérieures, ni éj ines, ni tubercules. - Se trouve à l'Ile-de-France.

\section{DEUXIÈNE TRIBU.}

\section{LES A R Q UES, LatrenLLe.}

Caractéres. Cette tribu diffère de la précédente en ce que les espèces qui la composent, au lieu d'offrir un post-abdomen, composé de sept tablettes, n'en présentent ici, ou dans cette tribu, que cinq, c'est-à-dire que deux sutures de ces tablettes s'eflacent, du moins au milieu dans les mâles, de sorte que leur queue ne présente distinctement que cinq tablettes; celle des femelles en a scpt d'ordinaire.--Tous les pieds sont à nu, et aucun d'eux n'est terminé en nageoires. - La cavité buccale est carrée supérieure ment. - Le test est plus arqué en avant que celui des derniers genres du groupe précédent, et le bord antérieur est presque en ligne droite. - Ses contours dessinent un segment de cercle tronqué à sa pointe, c'est-à-dire à la jonction du test à la queue.

Nous avons partagé cette tribu en deux groupes.

\section{CANCÉRITES.}

Point de prolongement clypéiforme sur les côtés de la carapace, qui est beaucoup plus large que longue, arquée en avant, et fortement tronquée de chaque côté dans sa portion postérieure.

Genres : Cancer, Carpilius, Zoximus, Lagostoma, Xantho, Chlorodius, Panopeus, Oxius, Pseudocarcinus, Etisus, Pla tycarcinus, Atelecyclus, Pirimela.

\section{CaNCER, Linn., Fabr.; Latr., Edw. : Carpilius, Leach.}

La carapace est très-large, presque towjours au moins une fois et demie aussit 
large que longue, assez régulièrement ovalaire, et très-convexe en-dessus. - Les bords antérieurs et latéraux forment une ligne courbe, très-régulière, qui, de chaque côté, se courbe en arrière ou en dedans, de manière à décrire plus que la moitié d'une ellipse, dont le contour semble se continuer sur la partie postérieure des régions branchiales, pour aller gagner le niveau de la région intestinale.-Le front est large, très-incliné, et peu saillant ; toujours il est divisé sur la ligne médiane par une fissure ou une petite échancrure, et souvent il paraît quadrilobé, à cause de la saillie que forme sa partie moyenne ainsi que les angles externes. - Les bords latéro-antérieurs de la carapace sont très-larges et généralement tranchans; ils se dirigent presque directement en dehors, puis se recourbent en arrière, et enfin reviennent en-dedans vers leur extrémité postérieure. - Les bords latéro-postérieurs sont trèscourts, et forment avec le bord postérieur un angle très ouvert. - Les diverses régions de la carapace sont généralement peu distinctes. - Les orbites sont presque circulaires; on n'y distingue pas d'angle externe, mais la portion externe de leur contour paraît comme tracée par l'existence de trois fissures linéaires et presque parallèles, dont deux sont placées en haut, et une au-dessus du niveau du bord latéral de la carapace; enfin, au-dessous de leur angle interne, les parois de ces cavités sont interrompues par un hiatus que remplit l'antenne externe. - La région antennaire est large, mais très-courte. - Les fossettes antennaires sont transverses, et l'épistome presque linéaire. - L'article basilaire des antennes externes est presque droit, et ne touche au bord inférieur du front que par un angle antérieur et interne. - La tige mobile de ces appendices est extrêmement courte, et s'insère dans l'hiatus du bord orbitaire de manière à pouvoir se reployer dans l'orbite.-Le troisième article des pieds-mâchoires externes est plus large que long et presque carré; son angle antérieur et interne est à peine tronqué, et son bord antérieur est entier.-- Le plastron sternal est presque une fois et demie aussi long que large, et ses bords latéraux sont presque droits. - Le sillon qui loge l'abdomen du mâle est très-profond, et les sutures qui séparent les derniers anneaux thoraciques sont presque transversales. - Les pattes antèrieures sont grosses, courtes et disposées de façon à pouvoir s'appliquer exactement contre les régions ptérygostomiennes._La main présente en dessus une crête plus ou moins tranchante, et les pinces sont cannelées en-dehors et en-dessus, armées, dans touto leur longueur, de dents comprimées et tranchantes, et pointues à leur extrémité ; les suivantes sont très-courtes, comprimées, et garnies en-dessus d'une crête tranchante, et d'une rangée de fortes épines, qui s'étend jusqu'à l'insertion du tarse, lequel est court, renflé et armé d'un petit ongle corné. - Chez le mâle, les appendices de l'abdomen de la première paire sont très-longs et filiformes à leur extrémité, et on n'y distingue ordinairement que cinq articles.

\section{CANCER ROSEUS.}

Eow., Hist. nat. des Crust., t. 1, p. 374 . - Carpilius Roseus, Ruppelı, op. cit., p. 13, pl. 3, fig. 3. - Long. 18 lig. La carapace est à bords mousses, ovoīde, une fois et deux tiers aussi large que longue; elle est très-bombée et piquetée partout, et l'extrémité de ses bords latéro-antérieurs ne présente ni tubercule ni tran. che; les crêtes des pattes sont très-élevées, tranchantes et inégales; leur pénultième article présente une crête à leur bord inférieur; la couleur est rougeâtre, avec les pinces noires. - Habite la Mer-Rouge.

\section{CANCER INTEGEREIMUS.}

Lav., Hist. des Anim. sans vertèbres, t. 5, p. 273. - La carapace est entourée en avant et sur les côtés d'un rebord mince et tranchant, ovoĩde, présentant, sur les régions branchiales, un repli courbe qui se continue vers les bords latéro-antérieurs; elle est un peu piquetée antérieurement; les pattes ont des crêtes très-élevées, tranchantes et inégales; une crête sur le bord inférieur de l'avant-dernier article des postérieures. Chez cette espèce, les régions ptérygostomiennes, qui, au lieu d'être convexes, sont ici concaves d'arrière en avant, présentent ainsi une large gouttière transversale, dans laquelle vient se replier la main. - Se trouve dans l'Océan Indien.

\section{CANGER Marginatus.}

Enw., Hist, nat. des Crust., t. 1, p. 375. - Carpilius marginatus, Rupp., op. cit., p. 15, pl. 3, fig. 4.-Long. 10 lig.-La carapace est à limbe latéro-antérieur lamelleux et tranchant, ovoïde, sans repli ni tubercule à l'extrémité du bord latéro-antérieur; le bord inférieur des pattes des quatre dernières paires présente une crête ; la 
carapace est de couleur marron, avec une bordure blanchâtre ; les pattes sont de couleur chair, avec les pinces noires - Habite la Mer-Rouge.

\section{CaNGER OCXROE.}

EDw., Hist, nat, des Crust., t. I, p. 375. - Henbst, t. III, pl. 54, fig. 2.-Long. 2 pouc. - La carapace est à limbe latéro-antérieur lamelleux et tranchant, oroide, mais moins large que dans les espèces précédentes et un peu bosselée; on aperçoit une ou deux fissures au bord latéro-antérieur, qui se terminent par une petite pointe arrondie; la crête des pat'tes est élevée; il n'y a point de crête au bord inférieur de leur pénultième article; la couleur est blanchâtre, avèc une multitude dé pètites taches jaunes. - Habite les mers d'Ásie.

\section{CANCER LOBATUS.}

EDw., Hist. nat. des Crust., t. I, p. 375. - Long. 9 lig. - Les bords latéro-antérieurs de la carapace forment une crête horizontale, tranchante, et divisée seulement en quatre lobes séparés par des sillons linéaires; la carapace est ovoïde, fortement bosselée en dessus, excepté dans son tiers postérieur, qui est très-rétréci ; les mains sont presque lisses, garnies en dessus d'une crếte tranchante très-élevée, et de quelques ligues saillantes sur la face externe; les pinces sont trés-pointues et cannelées; les pattes suivantes sont courtes, comprimées, lisses, et garnies en dessus d'une crète tranchante. -.. Habite les Antilles.

\section{CaNCER MaMiLlatus.}

Evw., Hist. nat. des Crust., t. 1, p. 376. - Long. 2 pouc. - Les bords latéro-antérieurs de la carapace, découpés en six dents, sont arrondis et obtus ; la carapace est ovoide, entierement couverte de bosselures élevées, lisses, très-nombreuses; le front et les orbites sont beaucoup plus élevés que la terminaison des bords latéro-antérieurs de la carapace; les pattes sont toutes couvertes de bosselures; le bord superieur des mains est presque tranchant.Habite I'A ustralasie.

7. Gavcer sculptus. (P1. 5, fig. 3.)

Herbst, t. I, p. 265.-Sav., Descript. de l'Egyple, Crust., pl. 6, fig. 3.-Long. 2 pouc. - La carapace est ovalaire, bombée, fortement bosselée, et garnie en dessus de quelques granulations miliaires; le front est formé de quatre lobes arrondis, dont les deux médians sont inclinés et avancés ; les bords latéro-antérieurs sont très-courbes, granuleux, ne présentent ni dents, ni lobes bien distincts, et se prolongent jusqu'au niveau du milieu de la région cordiale ; les bords latéro-postérieurs sont trèsconcaves; les mains sont surmontées d'une crête triangulaire contournée sur elle-même, et d'un aspect vermoulu en dehors; les pinces sont granuleuses, sillonnèes en dehors, et legèrement creusées sur leur bord préhensible; les pattes des quatre dernières paires sont comprimées, surmontées d'une petite crête, et garnies en dehors de beaucoup de tubercules arrondis en pointes; le corps, à sa partie inférieure, est granuleux. Cette espèce, qui est de couleur blanchâtre, présente quelques poils sur les pattes. - Elle se trouve dans la Mer-Rouge.

\section{8. cancer limbatus.}

Eow., Hist. nat. des Crust., t. I, p. 377, pl. 16, fig. 14. - Xantho granulosus, Rupp., Ciust., pl. 5, fig. 3. - La carapace est ovoìde, bosselée, et couverte de petites granulations miliaires; le front est peu saillant et à peine sinueux; le bord latéro-antérieur de la carapace est garni d'une crête horizontale, très-saillante, mince, tranchante, divisée par deux ou trois fissures, et se continue jusqu'au niveau du milieu de la région cordiale; les bords latéro-postérieur's sont courts et concaves; les pattes antérjeures sont granuleuses en dehors; les doigts sont courts et pointus, le supérieur garni de trois crêtes tranchantes; les pattes des quatre dernières paires sont lisses et surmontées d'une crête tranchante qui s'étend jusqu'à l'origine du tarse. - Cette espèce, qui est de couleur janne, se trouve dans l'Océan-Indien et dans la Mer-Rouge.

\section{GANCER SAVIGNYI.}

EDw.; op. cit., t. I, p. 378.-Cancer, Sav., Descript. de l'Egyp., Hist. nat., t. II, Crust., pl. 6, fig. 2. Cancer granulatus, Avp., Explicat. des Pl. de l'Egypte. - Long. 10 lig. - La carapace est très-bombée, d'un aspect comme framboisé, et bien moins élargie que dans les espèces précédentes. Les granulations dont elle est couverte sont entassées les unes sur les autres, et subdivisées en une foule de points arrondis; ses bords latéro-antérieurs sont granuleux, et ne sont pas distinctement divisés en lobes ou dents, et ses bords latéro-postérieurs sont très-concaves; les pattes sont courtes et toutes couvertes de granulations; la couleur est rougeátre, avec des taches 
brunes et blanches: les pinces sont brunes. - Habite la Mer-Rouge et l'Océan-Indien.

\section{CaNcer catculosus.}

Edw., Hist. nat. des Crust., t. I, p. 378. - Long. $6 \mathrm{lig}$. - La carapace est peu bombée et garnie de granulalions assez grosses, peu saillantes, et non réunies en groupe, peu bosselée; les bords latéro-antérieurs sont confusément divisés en quatre lobes un peu arrondis; les pattes sont courtes; les antéricures sont granuleuses et sans crête; les autres sontcomprimées et surmontées d'une crête dentelée. - Habite la Nouvelle-Hollande.

\section{Gaxcer spinimanes.}

EDw., Hist. nat. des Crust., t. I, p. 378. -Long. 1 pouc. $\frac{5}{2}$. - La carapace est peu bombèe, médiocrement granuleuse, presque circulaire, tronquée en arrière et bosse. lée; les bords latéro-antérieurs sont armés de quatre dents triangulaires, entre lesquel!es on remarque desséries de petites espèces; les mains sont surmontées d'une crête élevée formée par cinq grosses dents; les pattes suivantes sont épineuses; la couleur est blanchâtre, avec des épines brunes. - Patrie inconnue.

\section{CANCER ACANTHUS.}

Evw., op. cit., t. I, p. 379. - Long. 4 pouc. - La carapace est ovalaire, trèsélargie, fortement bosselée et couverte d'èpines; le front est peu incliné et divisé en quatre dents; les bords latéro-antérieurs, fortement courbés, se prolongent jusqu'au niveau du milieu de la région cordiale, et sont armés de cinq à six dents hérissées d'épines; les bords latéro-postérieurs sont trèsconcaves; les pattes sont couvertes d'èpines; celles de la première paire ne présentent pas en dessus de crête élevée; le corps est finement granulé en dessous, et couvert en dessus de poils raides, - La patrie de celle espèce est inconnue.

Parmi les Crustacés fossiles qui ont étć décrits par M. Desmarest, et qui afpartiennent a ce genre, nous citerons : le Crabe de Bose, Desm., Crust foss., p. 94, pl. 8, fig. 3 et $4 .-$ Le Crabe de Leach, p. 95, pl: 8 , fig. 5 et 6 . - Le Crabe Pointillé, Desm., Knorr et Walch, Monum. du Délug., t. I, pl. 16 A, fig. 2 et 3 ; Desm., pl: 7, fig. 34. - Le Crabe Quadiilobe , pl, 8, fig. 1 et 2. - Le Crabe aux grosses pinces, Desm, (Rumpr., pl. 60 , fig. 3); Desm., pl. 7, fig. 1 et 2.
CarpiliUS, Leach, Edw. ;

$$
\text { Cancer, Linn., Fadr., Desm. }
$$

Ce genre a été établi par M. Leach, aux dépens du genre Cancer de Linné. La carapace est ovoïde, très-bombée; ses bords latéro-antérieurs sont obłus et terminés en arrière par une espèce de tubercule arrondi. - Les pattes sont plus longues que chez la plupart des autres Crabes, et ne sont ni comprimées, ni garnies en dessous d'une crête ; leur dernier article est grêle, très-allongé et styliforme. - Les mains sont plus renflées et d'inégale grosseur, et les doigts, plus gros, plus arrondis, sans cannelures, et obtus au bout, sont armés (au moins d'un côté de deux ou trois gros tubercules arrondis seulement. - L'article basilaire des antennes externes est plus long, plus oblique, et en contact avec le front dans le tiers de sa longueur; le bord antérieur du troisième article des pieds-mâchoires externes est très-oblique.

\section{CaRpilius CORAILINUS.}

EDw. , Hist. nat. des c'rust., t. I, p. 381.-Cancer corallinus, FABR., Ent. Syst., t. III, p. 446. - Cancer Floridus, Iйuph., pl. 8, fig. 5. - Cancer Flosculosus, Seba, t. III, pl. 19, fig. 3-5.-Cancer Adspersus, Herbst, pl. 5, fig. 40. - Cuncer Maculatus, Latr., Hist. nat. des Crust., t. VI. - Long. 4 a 5 pouc - Le front est étroit (sa largeur n'excède pas la longueur de l'espace compris entre le plastron sternal et le bord antérieur des fossettes antennaires) et divisé en quatre lobes, dont les deux latéraux sont arrondis et séparés des médians par une échancrure profonde, et dont les deux médians sont à peine distincts l'un de l'autre et très-avancés; à l'angle externe de l'orbite on apercoit un petit tubercule saillant ; les bords latéro-antérieurs sont arrondis, obtus, non carénés, et terminés par un gros tubercule arrondi situé au niveau de l'angle rentrant du bord latéral de la région cordiale. $\mathrm{La}$ cloison inter-antennaire est très-large; l'article basilaire des antenmes externes est trèșoblique; l'épistome est lisse; le bord antérieur du cadre buccal est à peine saillant et sans tubercule à ses extrémités; le bord antérieur du troisième article des pieds-mâchoires externes est très-oblique, et son bord postérieur est presque droit; les pattes sont très-grosses, renflées, et n'ont pas deux fois la longueur de la carapace; les pattes de la 
seconde paire, un peu plus courtes que celles de la troisiéme paire, sont lisses et arrondies; leur troisième article dépasse de beaucoup le bord latéral de la carapace; les tarses sont cylindriques et plus longs que l'article qui les précède; la couleur de cette espèce est d'un rouge-jaunâtre, avec des vergetures jaunes; les pinces et les ongles sont de couleur brune. - Se trouve aux Antilles.

\section{CarpiliUs maculatus.}

Eow., op. cit., t. 1, p. 382. - Cancer Ruber, RumpH., pl. 10, fig. 1. - Cancer Sexatilis, Seba, p. 3, pl. 19, fig. 8.--Long. 2 pouc.-Le front est très-large (sa largeur excédant notablement la longueur de l'espace compris entre le bord antérieur du front et du plastron sternal), formé de quatre lobes, dont les deux latéraux sont arron. dis et séparés des médians par une échancrure profonde. L'épistome est divisé transversalement par un sillon très-profond. La couleur est d'un jaune pâle, avec quelques taches circulaires' d'un rouge intense sur la carapace.- Habite l'Océan Indien.

\section{CARPILIUS CONVEXUS.}

EDw., Hist. nat. des Crist. , t. I, p. 382, pl. 16, fig. 9, 10. - Rupp., Crust. d'Egypte, pl. 3, fig. 3. - Cancer Convexus, Forskal, Descript. des Anim., p. 88. Long. 3 pouc. -- Le front est assez large et formé de quatre lobes, dont les deux latéraux sont presque droits et les deux médians presque confondus et peu saillans; la carapace est beaucoup plus convexe que dans le $C$. Corallin; la région hépatique et la portion antérieure de la région stomacale sont piquetées; la couleur est jaune, avec un grand nombre de taches irrégulières de couleur orange.-Habite la MerRouge.

\section{GARPILIUS VENOSUS}

EDw., op. cit., t. I, p. 383. - Long. 6 lig. - Chez cette espèce les bords latéro-antérieurs de la-carapace sont divisés par des replis en quatre lobes larges, arrondis et peu saillans; la région stomacale est divisée en cinq bandes longitudinales par des sillons, et les bépatiques en trois portions principales, par deux sillons obliques qui partent des deux dernières échancrures du bord latéro-antérieur; la carapace est lisse dans sa moitié postérieure; les pattes sont légèrement comprimées. La patrie de cette esperce est inconnue.
ZOZYMUS, Leach, DES., Edw.; Cancer, Linn., Fabr., Latr.

M. Leach a établi, sous le nom Zozymus, un genre de Crustacés qui est extrêmement voisin des deux précédens, et qui ne s'en distingue guères que par la forme des pinces, dont l'extrémité est élargie et profondément creusée en cuillère; la forme générale des espèces qui composent ce genre est un peu moins ovalaire que chez les Crabes proprement dits, et les bords latéropostérieurs de la carapace sont présque aussi longs que les bords latéro-antérieurs, qui, eux-mêmes, deviennent fortement dentelés. Cette nouvelle coupe générique renferme cinq ou six espèces, parmi lesquelles nous citerons :

\section{ZOZYMUS LATISSIMUS.}

Eow., op. cit., t. I, p. 384. - Long. 3 pouc. - La carapace est ovoïde, extrêmement large, assez bombée; son bord latéro-antérieur est très-long, et bordé d'une crête lamelleuse et entière qui ne se termine point par un tubercule', mais se recourbe brusquement sur la région branchiale; les lobes médians du front sont courbes et très-avancés; les pattes antérieures sont fortes ; les pinces sont sans crêtes ni crénelures sur leur face externe; on aperçoit une crête élevée tant sur le bord supérieur que sur le bord inférieur des huit dernières pattes. Elle est de couleur rougeâtre - Se trouve à la Nouvelle-Hollande.

\section{ZOZYMUS PUBESCENS.}

EDw., op. cit., t. I, p. 384. - Long. $10 \mathrm{lig}$. - La carapace est régulièrement ovoïde, bombée, très-large, et couverte de petites granulations pointues; le front est trés-étroit, incliné ; les bords latéro-antérieurs sont tiès-courbes, épais, granuleux, sans crête ni dentelures, et se prolongent jusqu'au niveau de la région cordiale; les pattes des quatre dernieres paires sont arrondies dans leur moitié externe, avec le troisième article comprimé et tranchant; le corps, qui est de couleur blanchâtre, est garni d'un duvet très-fin. - Se trouve à l'lle-de-France.

\section{ZOZYNUS TOMENTOSUS.}

EDw., Hist. nat. des Crust., t. I, p. 385 . - Long. 8 lig. - La carapace est ovoīde, très - large, très-bombée, fortement bosselée en dessus, et divisée par un 
grand nombre de sillons linéaires; la région génitale est divisée en trois portions par des sillons nombreux; les bords latéro-antérieurs sont granuleux, et divisés par quatre fissures qui se prolongent en forme de sillons sur la région ptérygostomienne. laquelle n'est point granuleuse; les bords latéro-antérieurs sont concaves et très-courts ; les pattes sont courtes et couvertes de granulations; le corps est couvert d'un duvet noirằtre. - Habite l'Océan Indien.

\section{ZOZYMUS RUGATUS.}

EDw., Hist. nat. des Crust., t. I, p. 385. - Latr., Collect. du Muséum. Long. 4 lig. - Cette espèce, observée par M. Edwards, était en très-mauvais ètat; elle ressemble beaucoup à la précédente; mais les granulations de la carapace sont plus fines et plus serrées, et la région génitale n'est pas divisée; les bords latéroantérieurs de la carapace sont divisés en quatre lobes arrondis et bien distincts; il y a très-peu de duvet; les pinces sont lisses.

\section{ZOZYMUS ENEUS.}

Edw., Hist. nal. des Crust., t. I, p. 385. - Cancer Floridus, Herbst, t. I, p. 132, pl. 3, fig. 39 , pl. 21, fig. $120 .-$ Cancer Eneus, Fabr., S LATr., Hist. nat. des Crust., t. V, p. 375. -LaMck.. Hist. des Anim. sans vert., t. V, p. 271. - Long. 2 a 3 pouc. - La carapace est médiocrement large, convexe, très-inégale, fortement bosselée, et presque tuberculeuse à sa partie postérieure; le front est peu avancé et distinctement divisé en quatre lobes; les bords latéro-antérieurs de la carapace ne se prolongent pas au delà du niveau de la région cordiale; ils sont armés de quatre dents très-larges, comprimées et réunies en manière de crête ; les pattes antérieures sont tuberculeuses en dehors; les suivantes, sur leur face, sont creusées par des sillons; la couleur de cette espèce est jaune, avec des taches rougeâtres. - Habite l'Océan Indien.

\section{LACOSTOMA, EDW. ; Cancer, FABR.}

Ce nouveau genre a beaucoup d'analogie, par les espèces qu'il renferne, avec Jes Zozymes; mais ce qui les en distingue, ainsi que de tous les autres Crustacés de la mème tribu, c'est l'existence d'une échancrure large et profonde vers le milieu du bord antérieur du troisième article des pieds-mâchoires externes. - Leur carapace est un peu oroïde et bombée dans tous les sens. - Le front est incliné et les bords latéro-antérieurs très-recourbés en arrière. - L'article basilaire des antennes internes est remarquablement saillant, et l'article basilaire des antennes externes n'arrive pas tout-à-fait jusqu'au front.- Les pattes antérieures sont comprimées, inégales, et leurs pinces sont creusées en cuillère ; les pattes suivantes sont courtes, comprimées et épineuses en dessus.

\section{LAGOSTOMA PERLATA}

EDw., Hist.nat. des Crust., t. I, p. 387. -Cancer Perlatus, Hen bst, t. I, pl. 21 , fig. 122. ibid., Cancer Daira, t. III, pl. 35 , fig. 2. - Cancer Variolosus, FarR., Suppl., p. 338. - Long. 15 lig. - Chez cette espèce, la carapace est ovalaire, trèsbombee, et couverte de gros tubercules pisiformes; les lobes médians du front sont petits, saillans et arrondis ; les bords latéro. antérieurs de la carapace sont garnis d'une douzaine de tubercules dentiformes, et ils se prolongent jusqu'au niveau de la partie postérieure de la région cordiale; les pattes antérieures sont tuberculeuses; les suivantes sont garnies en dessus de poils assez longs et hérissées d'épines, excepté sur le tarse, qui ne présente pas de dentelures notables; la face inférieure du corps est lisse. - Cette espèce. qui est de couleur brunátre, habite l'Océan Atlantique, et paraît se rencontrer quelquefois sur les côtes de la Bretagne.

\section{XANTIIO, Leach, Desm., Edwi; Cancer, Lrns., Fabr.}

Chez les espèces qui composent cette coupe générique, la carapace est très-large, jamais régulièrement ovoïde, et presque pas bombée; sa surface est entierement horizontale transrersalement, et n'est courbéc dans le sens de sa longueur que dans sa nortion antérieure. - Le front est avancé, lamelleux, et presque horizontal ; une fissure étroite le divise en deux lobes, dont le bord est plus ou moins échancré au milieı. - Les orbites sont semblables à celles des Crabes. - Les bords latéro-antérieurs de la carapace se prolongent, en général, bien moins en crrière que dans les genres précédens, et n'arrivent ordinairement qu'au niveau du milieu de la région génitale, de manière que la portion antérieurs 
de la carapace n'est guère plus étendue que la portion postérieure. - Les bords latéro-postérieurs sont presque toujours longs, droits, et dirigés beaucoup moins obliquement en dedans que dans les genres prècédens. - Les fossettes antennaires sont étroites, transversales et séparées par une cloison mince. - L'article basilaire des antennes externes est placé comme chez le genre Zozyme, mais il est généralement plus court. - Le plastron sternal est ovalaire.-Les pattes antérieures sont fortes, inégales, chez les mâles, - Les pinces sont tantôt pointues, tantôt arrondies, mais jamais creusées en cuillère; elles sont noires ou d'un brun foncé; les pattes suivantes sont médiocres, plus ou moins comprimées, et terminées par un tarse très-court et armé d'un petit onglet corné. - L'abdomen chez la femelle présente sept segmens, tandis que chez le mâle il n'est. consposé que de cinq.

Les espèces qui composent ce genre sont repandues dans toutes les mers.

\section{Xavtho hirtissimus.}

EDw., op. cit., t. I, p. 386. - Rupp., op, cit., pl. 4, fig. 8. - Long. 7 lig. Larg. 7 lig. - La carapace est granuleuse, et très-fortement bosselèe dans toule son étendue; la région cordiale et la portion postérieure des régions branchiales sont bosselèes et sillonnées comme les parties antérieures de la carapace; la forme est presque ovoîde; les bords latéro-antérieurs de la carapace sont très-courbes et divisés en quatre lobes obtus; les bords latéro-postérieurs sont très-concaves; les régions ptérygostomiennes sont granuleuses et creusées de petits sillons qui se continuent avec les échancrures des bords latéro-antérieurs; les pattes sont médiocres et comprimées; le corps est entièrement couvert de poils roides. Cette espèce habite la Mer-Rouge.

\section{XANTHO RUFOPUNCTATUS.}

Eow., op. cit., t. 1, p. 389. - Long. 1 pouc. - La carapace est granuleuse et entièrement bosselée, comme dars l'espéce précédente, mais beaucoup moins ovóilde; les sillons de la carapace sont très-profonds, très-larges et lisses; les bords latéroantérieurs sont divisés en cinq grosses dents et arrondis; les bords latéro-postérieurs sont presque droits; les régions pterygostomiennes sont granuleuses, mais sans silJons notables; les pattes sont très-noduleuses et granulcuses, de couleur blanche, avec des taches rouges. - Se troure à l'llede-France.

\section{XANTHO ASPER.}

Edw., op. cit., t. I, p. $390 .-$ Rupp., op. cit., pl. 5, fig. 6. - Long. 5 lig. - La carapace, comme dans les espèces précédentes, est granuleuse et bosselée partout, mais beaucoup moins large; les bords latéro-antérieurs sont très-courts et divisés en quatre dents, hérissées à leur extrémité d'une série d'épines carrées; les pattes antérieures sont comprimées, et garnies de plusieurs rangées de tubercules granuleux ; les suivantes sont lisses. - Habite la MerRouge.

\section{XANThO SETIGER.}

EDw., op. cit., t. 1, p. 390.-Long. 5 lig. - La carapace est entièrement granuleuse, et fortement bosselée en avant, mais sans bosselures ni sillons notables sur la région cordiale et la portion correspondante des régions branchiales; les bords latéro - antérieurs sont très - courbes et divisés en quatre lobes à peine distincts; les bords latéro postérieurs sont concaves; les pattes antérieures sont assez grosses et très-granuleuses; les pinces sont pointues, tranchantes et cannelées en dehors; le corps est couvert de poils. - Habite les Antilles.

\section{XANTHO SCABER.}

Edw. , op. cit., t. I, p. 390. - FABR., Suppl., p. 336 . - Eong.10 lig. - La carapace est comme dans les espèces précédentes, mais moins large, et ses bords latéro-posterieurs sont droits; les. mains sont plus grosses, et les pinces sans cannelures distinctes. - Habite les iles de la Sonde.

\section{XaNtho LaMarckil.}

EDw., Hist.nat. des Crust., t. 1 , p. 391. - Long. 4 lig. - La carapace est presque lisse dans sa moitie postérieure, et un peu plus large que dans l'espèce précédente; les dents latéro-antérieures sont plus pointues; les mains sont très-granuleuses, et creusées en dehors de deux sillons longitu. dinaux très-profonds. - Habite l'lle-deFrance.

\section{Xavtho Vermiculatus.}

Evw., op. cit., t. I , p. 391. -- Cancer Vermiculatus, Laмcк., Hist.nat. des Anim. sans vert., t. V, p. 271.- Long. 2 pouc.-La carapace est à peine bombée, fortement bosselèe, et présentant sur chaque bosselure un grand nombre de tuberules réll? 
nis entre eux, de manière a former des lignes élevées et découpées de chaque côté, qui s'unissent à leur tour et donnent à la carapace l'aspect d'une substance vermoulue; les bords latéro-antérieurs sont divisés en quatre lobes à dents triangulaires dont les bords sont dentelés; les bords latéro-postérieurs sont concaves; le front est trés-incliné, et on apercoit, vers le milieu du bord antérieur du troisieme article des pieds-mâchoires, une échancrure étroite et profonde; les pattes sont vermoulues en dessus et en dehors; celles de la première paire sont médiocres et arrondies en dessus; les pinces sont sillonnees; les pattes des quatre dernières paires ont leur bord supérieur tranchant et poilu, de couleur blanchâtre. - La patrie est inconnue.

\section{XANTHO REYNAUDIL.}

Edw. , op. cit., t. I, p. 392.- Long. 1. pouc. $\frac{1}{2}$. - La carapace offre des régions très-distinctes et bosselees, de plus elleest tuberculeuse dans toute son étendue, peu convexe, fortement tronquée en arrière, et couverte de tubercules peu saillans; le front est divisé en deux lobes sinueux et tronquẻs; les bords latéro-postérieurs ne dépassent que de peu le niveau de la région stomacale ; ils sont armés de quatre grosses dents triangulaires et tuberculeuses; les bords latéro-postérieurs sont: un peu concares et très-longs; les pattes antérieures sont renflées et couvertes, en dedans comme en dehors, de gros: tubercules arrondis; les pinces sont pointues; les pattes suivantes sont grêles, assez longues, et portent sur le bord supérieur de leur troisième article une série de six à sept grosses dents; la face inférieure du corps est granuleuse; la couleur est rouge mélangé de jaune et de blanc. - Se trouve dans l'Océan Indien.

\section{XANTHO PERONI.}

EDw., op. cit., t. I, p. 392. - Long. 4 lig. - La carapace est à régions peu distinctes, et peu ou point tuberculeuse dans sa moitié postérieure; les paltes antérieures sont grosses, et couvertes en dehors de tubercules pointus; celles des quatre dernières paires sont hérissées d'épines. - Habite la Nouvelle-Hollande.

\section{XANTHO InPRESSUS.}

Edw., op. cit., t. I, p. 393. - Cancer Impressus, Lam., op. cit., t. V, p. 272. Long. 3 pouc. - La carapace n'est presque pas bombée, et est couverte de bosselures dont la surface est inégale et piquetée; le front est peu incliné et divisé en quatre lobes arrondis, dont les deux médians sont grands et saillans, et les deux latéraux Irès petits; les bords latéro-antérieursprennent naissance beaucoup au-dessous du niveau de l'orbite; ils ne se prolongent pas au delà du niveau du milieu de la région génitale, et ils sont divisés en quatre gros lobes arrondis; les pattes antérieures sont courtes, grosses et piquetées; sur le bord interne du carpe est un gros tubercule bilobè ; les mains ne présentent ni tubercules ni cpines; les pinces sont pointues et arrondies au bout; les pattes des quatre dernières paires sont arrondies en dessus; de couleur jaune lavée de rouge.-Se trouve à l'Ile-de-France.

\section{Xantho Lividus.}

EDw., op. cit., t. I. p. 393.-LAM., op. cit., t. V; p. 272. - Long. 3 pouc. - La face supérieure de la carapace est notablement bombée; le bord inférieur du hiatus de l'angle interne de l'orbite s'avance jusqu'au niveau du quatrième article de l'angle externe; les bords latèro-antérieurs de la carapace sont divisés en quatre dents; les pattes antérieures sont médiocres; la main est arrondie en dessus; le bord supérieur des paites des quatre dernières paires est arrondi, garni d'un grand nombre de petits tubercules, et très-poilu; la couleur est rougeâtre.-Habite l'Ile-de-France.

\section{XANTO FLORIDUS.}

EDw., op. cit., t. I, p. 394. - Xantho Florida, LeAcI, Malac., pl. 11. - Xantho Poressa, Leach. - Long. 2 pouc. La face supérieure de la carapace est horizcntale transversalement et à peine courbée d'avant en arrière;- les bords latèroantérieurs sont armés de quatre gros tubercules dentiformes et presque triangulaires; les pinces sont arrondies et ne présentent aucune trace de cannelures. La carapace est large et assez fortement bosselée dans toute sa moitié antérieure; le front est légèrement incliné, peu saillant et presque droit; les bords latéro-antérieurs sont courbes, et atteigent presque le niveau du bord antérieur de la région cordiale; les pattes antérieures sont renflées et très-grosses; les suivantes sont courtes, arrondies, et garnies de poils sur le bord supérieur de leur troisième article; de couleur brun rougeâtre, avec les 
pinces noires. - Se trouve très-communément sưr nos côtes.

13. Xantho Rivulosus: (Pl. 6, fig. 2.) Risso, Crust. de Nice, t. I, p. 14.-Roux, Crust. de la Méditer., pl. 35, fig. 1 et suiv. - EDw., Hist. nat. des Crust., p. 394.Long. 1 à 2 pouc. - ta carapace est ordinairement d'un vert pâle ou jaunâtre, tachetee de pourpre, de brun ou de violet; elle est régulièrement traversée, dans plusieurs sens, par des impressions longitudinales peu profondes; ses bords latéraux sont pourvus de quatre dents obtuses dont les trois dernières sont les plus fortes; le front est coupé en ligne droite; les pinces sont grosses, épaisses, glabres, munies d'un ou quelquefois de deux tubercules chez les vieux individus: la droite ordinairement plus grande que la gauche; les doigts sont noirs. La femelle offre plıs fréquem. ment que le mâle des variétés de couleur, et il est à remarquer, dit M. Roux, que ces variétés ne s'observent que chez les individus au-dessus de luit lignes de longueur; au-dessous de cette dimension, les couleurs sont assez constantes; Ies jeunes ont les dentelures latérales de la carapace peu marquées, de même que les impressions viscêrales ; leurs doigits sont quelquefois bruns. M. Roux, dans la planche 35 de l'hist. des Crust. de la:Méditerr., a figuré plusieurs variétés de cette espèce. Les Xanthes rivuleux, selon le même auteur, s'accouplent de bonne heure, et si l'âge auquel les femelles portent déjà des oufs doit déterminer celui auquel le Crustacé a obtenu un accroissement complet et parfait, on peut considérer comme extraordinaire la dimension à laquelle il parvient. J'ai sous les yeux, dit l'auteur ci-dessus cité, des femelles de trois lignes de long, chargées de leurs œufs. La remarque que j'ai faite relativement à la forme peu développée que montre quelquefois l'abdomen chéz la plupart des femelles des jeunes Décapodes Brachyures, présente une exception chez le Xanthe rivuleux, car cette difformité, qui me fait considérer comme stériles les femelles, dans ce cas, s'offre ici à mon observation sur un individu de six lignes de longueur, dimension par conséquent supérieure à d'autres individus portant moins d'œufs. - C'est sous les galeis du rivage, dans les creux où l'eau de la mer demeure tranquille, que se tient le Xanthe rivuleux; il marche lentement, et, lorsqu'on le surpprend, il cherche plutôt à se blottir qu'à fuir. Il est commun sur nos côtes; on le rencontre durant toute la belle saison, portant des œufs verdâtres ou bruns, seìn qu'il $\mathrm{y}$ a plus de temps, qu'ils ont été pondus.

\section{4. xamtho parvelus.}

EDw., op. cit., t. I, p. 395.-Cancer parvulus, FABr., Ent. syst., t. II, p. 451. Long. 4 lig. - Les bords latéro-antérieurs de la carapace sont minces, tranchans et divisés en quatre lohes tronqués et detitiformes, et dont la face supérieure de la carapace est simplement ridée et non bosselèc en devant; la main du côtẻ droit est beaucoup plus large que l'autre, et on remarque a la base de son doigt mobile une dent tuberculeuse extrêmement forte; la couleur est brunâtre. - Habite les Antilles et le Brésil.

\section{XANTHO HIRTER.}

Edw. , op. cit. , t. I, p. 395,-LATR., Coll. du Mus., Savig., Egypte, pl. 6, fig. 1 ? - Long. 5 lig. - La carapace est. un peu plus bombée que dans le X. vivulosus; le front est marqué d'un lèger sillon transversal, et la face externe des mains est. garnie de plusieurs rangées de petits tubercules perlés. - Habite la Mer-Rouge.

\section{6. хаNTHo CReNatus.}

EDw., op. cit., t. I, p. 396. - Long. 10. lig. - La carapace est très-élargie et lisse; le front est divisé en deux lobes lamelleux très-larges, tronqués, et à bords presque droits; les bords latéro-antérieurs sont divisés en trois lobes minces et presque carrés, suivis d'une quatrième dent triangulaire; les pattes antérieures sont très-inégales et médiocres; les pinces sont un peu comprimées et courbées en dedans. et au bas; les pattes suivantes sont grêles. - Se trouve sui les côtes du Pérou.

\section{XaNtho GaUdichaUdi.}

Edw., Hist. nat. des Crust., t. I, p. 396. - Long. 2 pouc. - Le front est peu avancé, très-étroit, et profondément divisé en quatre lobes arrondis et tres-saillans; la forme générale est semblable à celle du X. Floridus. - Habite le Chili.

\section{Xantro punctatus.}

EDw., op. cit., t. I, 396: - Long. 1 pouc. - Le front est peu avancé, large, sinueux, divisé obscurément en quatre lobes arroudis et peu saillans; la carapace est ovoüde, peu large, divisée, sur la région 
hépatique, par deux sillons qui se continuent avec deux échancrures des bords latéro-antérieurs; les mains sont amples et lisses. Habite l'Ile-de-France.

\section{9. xavtho planus.}

EDw., op. cit., t. I, p. 397. - Long. 1 pouc. $\frac{1}{2}$. - Le front est très-avancé , droit, horizontal, et divisé en deux lobes par une petite fissure médiane; la carapace est plane en dessus, sans ré. gions distinctes; les bords latéro-antérieurs sont épais, obtus, très-courbes, se prolongeant jusqu'au niveau du milieu de la région génitale, et présentant en arrière deux tubercules arrondis dont l'antérieur est a peine distinct; les pattes sont presque semblable à celles du $\boldsymbol{X}$. Floridus, elles en diffèrent seulement en ce qu'il existe une dent à l'extrémité du bord supérieur du troisième article; la couleur est jaunâtre. - Habite les côles du Chìli.

\section{XANTHO ROTUNDIFRONS.}

EDw., op. cit., t. I, p. 397. - Long. 10 lig. - Le front est extrêmement avancé, demi-circulaire, sans fissure médiane, et incliné ; la carapace est ovoïde, presque plane; les bords latéro-antérieurs sont épais, obtus, entiers, très-courbes, et se prolongeant jusqu'au niveau de la région cordiale.

\section{Xavtho INcisus.}

EDw., op. cit., t. I, p. 397. - Long. 1 pouc. - La face externe des mains est garnie de plusieurs rangées horizontales de petits tubercules; la carapace est trèslarge, peu bombée, fortement bosselée, et présentant, sur les régions stomacale et hépatique, plusieurs petites crêtes transversales; le front est à peine incliné, et divisé en quatre lobes arrondis dont les deux externes très-petits; les bords latéroantérieurs de la carapace sont divisés en quatre dents, dont les deux premières arrondies et comprimées, et les deux dernières triangulaires et carénées en dessus; les pattes antérieures sont granuleuses; la carapace, ainsi que les pattes, présentent quelques poils. - Habite l'A ustralasie.

\section{XANTHO OCTODENTATUS.}

Eow., op. cit., t. I, p. 398.-Cancer Rumphii, - Gux́r., Icon. du Régn. anim. de Cuvier, Crust., pl, 2, fig. 1. -- Long. 2 pouc. - La face externe des mains ne présente pas de petits tubercules disposés par rangées horizontales; les bords latéro-antérieurs de la carapace sont armés de dents Irès-fortes, et séparées entre elles. par des échancrures très-profondes; la carapace est légèrement bombée, assez forte= ment bosselée près du bord antérieur, et lisse dans sa partie postérieure; le front est à peine saillant et divisé en deux lobes; les pattes antérieures sont médiocres; le carpe est garni en dedans de deux gros tubercules; les pinces sont généralement cannelées; les pattes suivantes sont très-comprimées et berdées de poils. - Patrie inconnue.

\section{Xantho Raditus.}

EDw., op. cit., t. I, p. 398. - Cancer Dodone? Herast, t. III, p. 37 , pl. 52, fig. 5. - Long. 4 lig. - La face externe de la main est granuleuse, mais ne présente pas de rangées de tubercules; les bords latéro-antérieurs de la carapace sont comme festonnés, armés de trois ou quatre petites dents pointues, réunies entre elles par une crête mince; la face supérieure de la carapace est presque plane, lisse, légèrement bosselée en avant, et offrant des régions assez distinctes; ses bords latéro-postérieurs sont droits; le front est presque droit, et divisé par une fissure médiane à peine visible ; les pattes antérieures sont assez grosses; le carpe est armé en dedans de deux tubercules pointus; la main est bordée en dessous comme en dessus d'une crête tranchante; les pattes suivantes sont très-com: primées.-Se trouve à l'Ile-de-France.

\section{Chlorodius, Leace, Edw.; Cancer, Fonskal, Herbst.}

Les Crustacés qui composent cette coupe générique ont beaucoup d'analogie avec le genre précédent; cependant ils s'en distinguent par leur carapace, qui est généralement moins large, et surtout par la disposi. tion de leurs pinces, dont l'extrémité est élargie et profondément creusée en cuillẹre.

\section{CHLORODIUS UNGULATUS.}

Evw., op. cit., t. I. p. 400 , pl. 16. Long. 10 lig. - La carapace est à peine bombée, fortement bosselée dans toute son étendue, et peu élargie; le front est divisé en quatre lobes, mais cependant presque droit et assez large; Jes bords latéro-antérieurs sont armés de cinq dents triangulaires et très-épaisses; les pattes antérieures sont très-longues, leur troisième article dépassant le bord de la carapace dans plus 
de la moitié de leur étendue ; les mains sont très-fortes, inégales, et couvertes de tubercules arrondis; les pattes suivantes sont épineuses et poilues; de couleur brun-rouge, avec les pinces noires et bordées de blanc. - Habite l'Australasie.

\section{CHLORODIUS AREOIATUS.}

Edw., op. cit., t. I, p. 400. - Long. $4 \mathrm{lig}$. - La carapace est fortement bosselée et perlée; le front est large et divisé en quatre lobes bien distincts; les bords latèroantérieurs sont courts, presque droits, et divisés en quatre dents triangulaires; l'hiatus de l'angle orbitaire inte Ine est étroit, et peut à peine loger la tige mobile de l'an. tenne externe; les pattes antérieures sont granuleuses; les suivantes, ainsi que la face inférieure du corps, presque lisses. - Habite la Nouvelle-Hollande.

\section{CHLORODIUS LONGIMANUS.}

EDw., op. cit., t. I, p. 401. - Long. 6 lig. - Le troisième article des pattes des quatre dernières paires est armé d'épines sur le bord supérieur; la carapace est aplatie, un peu bosselée en avan t, unie à la partie postérieure, avec ses régions peu marquées; les bords latéro-antérieurs sont à peine courbés: ils ne dépassent pas le niveau $d u$ milieu de la région génitale, et ils sont divisés en cinq dents pointues, dont la première constitue l'angle orbitaire externe; on aperçoit une échancrure arrondie au milieu du bord antérieur du troisieme article des pieds-mâchoires externes; les pattes antérieures, chez le mâle, sont grêles et extrèmement longues; leur troisième article est plus long que la carapace, et il est armé, sur le bord antérieur, de quatre épines mousses; le carpe présente une épine; les mains sont très-longues et s'élargissent vers le bout; les pattes suivantes sont courtes, arrondies, et couvertes de poils dans leur moitié externe.-Se trouve sur les côtes de Porto-Rico.

\section{CIILORODIUS NIGER.}

Rupp., op. cit., p. 20, pl 4 , fig. 7 . - Long. 4 lig. - Le troisieme article des pattes des quatre dernières paires non épineux; les pattes antérieures sont trèslongues, leur troisième arlicle dépassant de beaucoup les bords de la carapace; celle-ci est presque plane en dessus, età régions peu distinctes; le front est trés-large et presque droit; les bords latéro-antérieurs, armés de quatre dents, sont à peine courbés, et se dirigent presque directement en arrière, le grand diamètre latéral de la carapace n'étant guère plus long que le bord fronto-orbitaire; les pattes sont lisses; la couleur de la carapace est noirâtre; les pinces sont noires, avec une bordure blanche a leur extrémité. - Se trouve dans la Mer-Rouge.

\section{Chlorodius exaratus.}

EDw. , op. cit., t. 1, p. 402. - Long. 6 lig. - Le troisième article des pattes est non épineux; celles de la première paire sont courtes, leur troisième article dépassaut à peine les bords de la carapace ; la carapace est à peine bombée, et très-inégale dans sa moitié antérieure ; les bords latéro-antérieurs sont armés de quatre dents triangulaires et courbes; le front est étroit, et formé de deux lobes minces el tronqués; le bord fronto-orbitaire n'occupe qu'envi. ron la moitié du diamètre transversal de la carapace; les pattes sont courtes; celles de la première paire sont grosses, renflées et lisses. - La couleur est d'un jaune rougeâtre, avec les pinces noires. - Se trouve sur les côtes de l'Inde.

\section{CHIORODIUS SANGUINEUS.}

EDw., op. cit., t. I, p. 402. - Long. 4 lig. - Cette espèce présente les mêmes caractères que la précédente, si ce n'est que les bords latéro-antérieurs de la carapace sont armés de six ou sept dents; la couleur est blanchâtre, mêlée de rouge. Se trouve dans les mers de l'Ile-de-France.

\section{CHLORODIUS EUDORUS.}

EDw., op. cit., t. I, p. 402. - Cancer Eudora, Неrist, t. III, pl. 51, fig. 3. Ne diffère de la précédente que par les bosselures, qui sont plus élevées et plus nombreuses; et par la forme du front; dont les lobes moyens sont étroits et profondément échancrés, de façon à présenter chacun deux petites dents arrondies. - Se tiouve à la Nouvelle-Zélande.

\section{PANOPEUS, EDw.;} Cancer, Herbst, Say.

Ce nouveau genre diffère de celui de Xanthe et de Chlorode, par la carapace, qui est bien moins ovalaire. - Les bords latéro - antérieurs sont minces, dentelés, peu courbés, et ne se prolongent que peu en arrière. - Les bords latéro-postérieurs sont, au contraire, très-longs, et forment avec le bord postérieur un angle presque droit. Ils se distinguent aussi de tous les 
genres précéderis par l'existence d'un hiatus au bord inférieur de l'orbite, au dessous de l'angle externe de cette cavité. Ces Crustacés sont propres à l'Amérique.

\section{PANOPEUS HERBSTI.}

Enw., op. cit., t. I, p. 403.-Cancer Panope, Henbst, pl. 54, fig. 5.-Say, loc. cit. , pl. 4, fig. 3.-Long. 2 pouc. - La carapace est à peine bombée et légèrement bosselée en avant; on aperçoit une petite dent à l'angle orbitaire externe, au-dessus de l'hiatus; les bords latéro-antérieurs sont armés, en outre, de quatre dents triangulaires, comprimées et saillantes, avec un petit tubercule au-dessous de la base de la première; les pattes antérieures sont grosses et renflées; le bord interne du carpe présente un petit tubercule pointu; les pinces sont courtes, fortes et arrondies; les pattes suivantes sont assez minces, lisses, et de longueur médiocre; enfin, le second segment de l'abdomen du mâle est à peu prés de même.longueur que les deux segmens quil'avoisinent; la couleur est jaunâtre, mélangée de vert, avec les pinces noires. - Se trouve sur les côtes de l'Amérique septentrionale.

\section{Panopeus Limosus.}

Enw., op. cit., t. I, p. 404.-Cancer Limosa, $\mathrm{S}_{\mathrm{AY}}$, loc. cit., p. 446. - Long. 2 pouc. - Cette espèce diffère de la précédente par sa carapace, qui est beaucoup plus large, et par ses bords latéro-antérieurs, qui sont dirigés moins obliquement en arrière; par l'épine placée sur la région ptérygostomienne, qui est rudimentaire, et parce que, chez le mâle, le deuxième segment de l'abdomen est beaucoup moins long que les deux segmens qui l'avoisinent, et par ses bords latéraux qui sont droits.Se trouve sur les côtes de l'Amérique septentrionale.

\section{OZIUS, Edw.}

Ce genre a les plus grands rapports avec les Xanthes; cependant la carapace est généralement moins large, et les bords latéro. antérieurs moins courbes, ils ne se prolongent pas aussi loin en arrière, et n'atteignent que le niveau du milieu de la région génitale. La carapace n'est bosselée qu'à sa partie axtérieure, et ses bords latéro-postérieurs sont ordinairement un peu convexes. - De plus, il existe de chaque côté de l'espace prélabial, et du canal de la cavité branchiale, une gouttière profonće qui fait suite a ce canal, dont le bord interne est très-saillant, et vient se réunir au bord antérieur du cadre buccal. - La disposition des antennes, des orbites, des pieds-mâchoires et des pattes, est à peu près la même que chez les Xanthes. - L'abdomen, dáns le mâle, ainsi que dans la femelle, est composé de sept anneaux parfaitement distincts, et qui ne se soudent pas entre eux.

\section{OzIUS TUBERCuLOSUS.}

EDw., op. cit., t. I, p. 405. - Long. 2 pouc. - La carapace est peu convexe, bosselée et granuleuse à sa partie antérieure; le front est armé de quatre dents arrondies; les orbites sont dirigées très-obliquement en haut; les bords latéro-antérieurs de la carapace ne dépasșent pas le niveau du milieu de la région cordiale; les bords latéro. postérieurs sont convexes; l'article basilaire des antennes externes est très-oblique; leur tige mobile est rudimentaire, et l'hiatus qui la renferme est très-étroit; les régions ptérygostomiennes sont granuleuses ; le troisieme article des pieds-mâchoires externes est échancré à son bord antérieur; les pattes antérieures sont très-fortes, renflées et granuleuses; les suivantes sont cour. tes, cylindriques, et légèrement granulées; la couleur est brunâtre. - Se trouve dans l'Océan Indien.

\section{OzIUS TRUNGaTUS.}

Enw., op. cit., t. I, p. 406.- Long. 1 pouc. $\frac{1}{2}$. - La carapace est peu élar. gie, presque plane en dessus, et légèrement bosselée en avant; le front est très-large; les orbites sont sans fissures distinctes; les bords latéro-antérieurs sont courts ; les régions ptérygostomiennes, 'les antennes externes, et les pieds-mâchoires externes, sont à peu près comme dans l'espèce précédente; les pattes sont moins fortes; la couleur est brunâtre. - Se troure dans l'Australasie.

\section{3. ozIUS GUTTATUS.}

EDW, op. cit., t. I, p. 406. - Longa 2 pouc. - La carapace est ovalaire, à peine bombée, lisse en dessus; le firont est presque droit; les orbites avec une fissure en dessus et une petite dent à l'angle externe ; les bords latéro-antérieurs sont à peine découpés; du reste, à peu près comme dans les espèces précédentes; la couleuír est jaunâtre, piquetéc de rouge. - Se trouve à Ia Nouvelle-Hollande. 


\section{4. ozíus Frontalis.}

EDw., op. cit., t. I, p. 106. - La carapace est ovalaire, très-élärgie, presque entièrement plane en dessus, un peu rugueuse à sa partie antérieure; le front est cannelé et obscurément divisé en quatre dents; les orbités sont sans dents à l'añgle externe; les bords latéro-antérieurs sont longs, trèscourbes, et divisés en quatre lobes fort larges, tronqués, et à peine saillans; l'article basilaire des antennes externes est droit et trés-petit; il n'existe pas d'échancrure au bord antérieur du troisième article des pieds. mâchoires externes; les pattes antérieures sont trës-inëgales, fortes èt lisses; les suivantes sont petites et arrondies; d'un brun-jaunâtre, avec les pinces d'un brun noirâtre. - Se trouve sur la côte de Tranquebar.

\section{PSEUDOCARCINUS, EDw.; \\ Cancer, Fabk., Herbst, Lam.}

Les Crustacés qui composent ce genre ont la forme générale des Xanthes. - Leur carapace est légèrement boimbée et un peu bosselée près du front, quí est presqúe horizontal. - Les bords latéro-antërieurs sont médiocrement courbes, et armés de dents plus ou moins saillantes.-Enfin, la portion postérieure de la carapace est a peu près de même étendue que l'antérieure, et ses bords latéraux sont droits èt dirigés trèsobliquement en arriere. - Ils diffèrent aussi des genres précédens par la disposition des antennes externes, dont l'article basilaire est tres-petit, dont le second article atteint a peine le front, et dont le troisième, qui est logé dans l'hiatus ordinaire, ne le remplit pas, de sorte que la fossette antennaire n'est pas complètement séparée de l'orbite ; enfin, la tige terminale de ces appendices, au lieu d'être très-courte, est plus de deux fois aussi longue que son pédoncule. L'espace prélabial n'est pas canaliculé comme chez les Ozies, et les pieds-mâchoires externes ne présentent rien de particulier.-Les pattes de la première paire sont remarquables par leur grosseur, chez le mâle surtout; elles ont à peu près la même forme que chez'les Carpilius, mais sont en core plus fortes. - Les pinces sont également arrondies et obtuses au bout, inégales, et armées de gros tubercules arrondis, lesquels, d'un côté (en général le droit), ne sont qu'en très-petit nombre et d'un volume remarquable.-Les pattes suivantes sont assez longues, avec leur dernier arti- cle allongè. - L'abdomen, chez le mále, est divisé en sept tablettes bien distinctes. -Les espèces que renferme ce genrè appartiennênt à l'Ócéan Indien.

\section{PSEUDOGARCINUS RUMPHII.}

Edw., op. cit., t. 1, p. 408. - Cancer Rumphii, FABR., Suppl., p. 356. - Long. 3 pouc. - Les bords latéro-antérieurs de la carapace sont armés de quatre dents triangulairesprofondement découpées (l'angle orbitaire externe non compris); la face supérieure de la carapace est légèrement bosselée, presque entièrement lisse, à régions peu distinctes, et présentant près du front quatre tubercules mamillaires; le front est profondèment divisé en deux dents arrondies et saillantes, en dehors desquelles on remarque, de chaque côté, deux petits tubercules; les orbites sont marquées d'une fissure au bord supérieur, et présentent deux tubercules arrondis à leur angle externe; les pattes antérieures sont extrêmement grosses, renflées et lisses; le bras est court, avec le carpe très-développé et presque globuleux; enfin, Ja main a à peu près la longueur du diamètre transversal de la carapace; les pattes suivantes sont de longueur médiocre, arrondies et poilues vers le bout.-Se trouve dans la mer des Indes.

\section{PSEUdocarcinus BELLANGERI.}

EDw., op. cit., t. I, p. 409, pl. 44 bis, fig. 10. - Long. 2 pouc. - Les bords latéro-antérieurs de la carapace sont armés de quatre dents à peine découpées, et ayant la forme de lobes tronqués; les tubercules de l'angle orbitaire externe sont moins gros. et moins saillans que dans l'espèce précẻdente, et la tige terminale des antennes externes est plus longue; couleur de la carapace, brunâtre mêlée de jaune; les pattes sont jaunes, et les pinces noires. - Se trouve dans la mer des Indes.

\section{PSEUdOGARCINUS OCELLATUS.}

Eow., op. cit., t. I, p. 409. - Long. 3 pouc. - Differe du $P$. Rumphii par le front, qui est plus saillant et divisé en deux lobes tronqués assez larges; la disposition de la carapace est la même que dans le $P$. Bellangerii; la couleur de la carapace est jaunâtre, avec une multitude de taches circulaires rouges; les pinces sont noires; les pattes des quatre dernieres paires sont ornées de bandes rouges et jaunes. - $\mathbf{P a}$ trie inconnue.

\section{PSEUDOCARCINUS GIGAS.}

EDw., op. cit., t. I, p. 409. - Cancer 
Gigas, Larr., Hist. des Anim. sans vert., t. V, p. 272. - Long. 7 pouc. - La carapace est légèrement bombée et renflée sur les côtés; le frontest armé de quatre grosses dents pointues, près de la base desquelles on distingue, sur la région stomacale, autant de tubercules arrondis; les bords latéroantérieurs sont obscurément divisés en quatre lobes, armés chacun de deux ou trois dents spiniformes; les orbites sont divisées par quatre fissures; les pattes anlérieures sont très-grosses; le bord postérieur du bras est épineux; le carpe est armé en dedans de deux dents; les pattes des quatre dernières paires sont arrondies, armées d'épines sur le bord supérieur du troisième article, et recouvertes d'un duvet épais sur les articles suivans; de couleur jaunâtre mar. brée de rouge; les pinces sont noires.-Se trouve dans les mers de la Nouvelle-Hol. lande.

\section{ETISUS , Edw.; Cancer, Herbst.}

Ce genre, qui a été établi par M. Edwards, diffère des précédens par la carapace. qui est moins ovalaire et moins large.-Le front est large, et divisé sur la ligne médiane par une fissure; les deux lobes larges et tronqués qui en forment la partie principale. sont séparés par une échancrure profonde de l'angle antérieur et supérieur de l'orbite, qui est arrondi et saillant.-Les bords latéro-antérieurs de la carapace sont fortement dentés. - Les antennes internes se reploient presque longitudinalement, et l'article basilaire des antennes externes, qui est très-grand, se réunit au front, et présente du côté externe un prolongement qui remplit l'hiatus de l'angle orbitaire interne; enfin, la tige mobile de ces antennes, qui est trés-courte, s'insère complètement hors de ce hiatus, au-dessous du front, et plus près de la fossette antennaire que de l'orbite. - Les pattes de la première paire sont assez grosses, et les pinces, très-èlargies au bout et arrondies, sont profondément creusées en cuillère.

\section{ETISUS DENTATUS.}

EDw., op. cit. t. I, p. 414. - Cancer Dentatus, Herist, t. I, p. 186 ; pl. 11 , fig. 66. - Long. 4 pouc. - La carapace est bombée et à régions distinctes; le front est avancé et formé de deux grands lobes aplatis et tronqués, en dehors desquels est un gros tubercule arrondi, qui occupe l'angle orbitaire interne; les orbites sont armées de quatre dents, savoir : une en dessus, une à. l'angle externe, et deux en dessous; les bords latéro-antérieurs sont fortement cour. bés; ils atteignent le niveau de la région cordiale, et sont obscurèment divisés en quatre lobes, garnis chacun d'une forte dent arrondie et recourbée en avant; les deux lobes moyens présentent, en outre, deux ou trois dents plus petites, de manière que leur nomire total est au moins de huit de chaque côté; les fossettes antennaircs. sont plus larges que longues; les pattes antérieures sont médiocres; les mains sont un peu comprimées; les pattes des quatre dernières pạires sont hérissées en dessus d'épines; la couleur est rougeâtre. - Se trouve dans l'Archipel Indien.

\section{ETISUS ANAGLYPTUS.}

EDw., op: cit., t. I, p. 411. - Long. 1 pouc. $\frac{1}{2}$. - La carapace est à peine bombée, et n'est pas une fois ét demie aussi large que longue; le front et les orbites. sont à peu près comme dans l'espèce précédente; les bords latéro - antérieurs, peu courbes, sont à peu près de même longueur que les latéro-postérieurs, et armés de quatre grosses dents triangulaires et saillantes. (l'angle orbitaire externe non compris); les pattes antérieures sont fortes et garnies. de tubercules; la couleur est blanchâtre. - Se trouve dans l'Australasie.

Platycareinus, Latr., Edw.;

Cancer, Linn;, Fabr.

C'est un genre de Crustacés qui a étẻ établi par M. Latreille, et qui diffère de tous les autres genres, quoiqu'il ait avec eux une grande analogie par la carapaee, qui est légèrement bosselée et très-élargie; par le front, qui est étroit, presque horizontal, et divisé en plusieurs dents dont une occupe la ligne médiane, - Les bords latéroantérieurs de la carapace sont divisés par des fissures en un grand nombre de lobes dentiformes; leur extrémité postérieure atteint le niveąu du bord antérieur de la région cordiale, et se continue avec une ligne élevée qui surmonte le bord latéro. postérieur. - Les antennes internes, au lieu de se reployer obliquement en dehors, sc dirigent presque directement en avant ; les antennes externes ont à peu près la même disposition que dans le genre précédent; 


\section{ATELECYCLUS.}

leur article basilaire est très-dévèloppé, et se loge en partic dans l'espace qui existe entre l'angle interne du bord orbitaire inférieur et le front; mais le second article de ces appendices, au lieu de naître près du bord externe du premier, dans le canthus orbitaire interne, s'insère à peu de distance de la fossette antennaire, complétement hors de l'orbite.-La disposition de la bouche, des pattes et de l'abdomen est à peu près la même que dans les Xanthes.

\section{Platycarcinus pagurus.}

EDw., op. cit., t. I, p. \13. - Cancev Manas, Rondel., t. II, p. 400.-Cancer Pagurus, Lins., Mus. Adolp. Fréd., t. I, p. $85 .-$ Herbst, t. I, pl. 9, fig. 59 . -Lench, Malac., pl. 10.- Desm., p. 103 , pl. 8, fig. 1. - Bell, Trans. Zool. Soc, t. I, pl. 43, p. 342. - La carapace est plus d'une fois et demie aussi large que longue, à régions peu distinctes, légèrement bombée et très-finement granulće en dessus ; le front est très-étroit, peu saillant, et garni de cinq dents arrondies, óont les externes contiennent l'angle orbitaire supérieur et interne; l'orbite présente deux fissures à son bord supérieur, et ni dent ni tubercule à son angle cxterne ; les bords latéro-antérieurs se dirigent d'abord en dehors et en avant, puis se recourbent en irrière, et se continuent presque sans interruption avec les bords latéro postérieurs, qui sont minces et divisés en neuf lobes légèrement dentiformes; les stries sont larges, à peine saillantes, et séparées par des plis; on aperçoit un lobule semblable, mais arrondi, a la partie antérieure du bord latéro-postérieur ; les fossettes antennaires sont beaucoup plus longues que larges; on aperçit un tubercule très-saillant à l'extrémité de l'article basilaire des antennes externes, en dehors du point d'insertion de l'article suivant; les pattes antérieures sont fortes, arrondies, et ne présentent ni épines ni dents ; les pinces sont pointues, garnies de dents arrondies; Jes pattes suivantes sont un peu comprimées et irrégulièrement anguleuses ; de chaque côté du tarse on aperçoit un sillon profond. Cette espèce, dont la couleur est d'un rouge-brun en dessus, blanchâtre en dessous, avec des pinces noires, des faisceaux de poils bruns, raides et courts, sur les pattes des quatre dernières paires, sc trouve sur nos côtes Océaniques; elle acquiert près d'un pied de longueur, et pèse alors jusqu'à cinq livres ; sa chair est assez estimée.

\section{PLATYCARCINOS IRRORATUS.}

EDw., op. cit., t. 1, p. 414. - Belx. Trans. Zool. Soc., t. I, pl. 46, p. 342. Cancer Irroratus, $\mathrm{S}_{\mathbf{A x}}$, op. cit., p. 59 , pl. 4, fig. 2.-Cancer Amœneus, Herbst, t. III, pl. 9, fig. 3 ?-Long. 5 pouc. - La carapace, légèrement convexe, est finement chagrinéc en dessus, et presque une fois et demie aussi longue que large ; le front est plus large et armé de dents moins saillantes que dans l'espèce précédente; le bord latéro. antérieur se porte de suite au dehors et en arrière, décrit une courbe assez forte, et estarmé de neuf dents plus ou moins distinctes, tronquées, peu saillantes et granulées; on aperçoit une dixieme dent plus petite au commencement du bord latéro-postérieur les pattes antérieures sont comprimées et de grandeur médiocre; le carpe est armé en dedans d'une forte dent; les mains sont élevées et garnies au dehors de quatre ou cinq lignes longitudinales et élevées; les pattes suivantes sont comprimées et dépourvues de dents ou épines; la couleur est rougeâtre; les bords des pattes présentent des poils assez longs. - Se trouve sur les côtes de l'Amérique du Nord.

Voyez, pour les autres espèces, le travail de M. Bell, inseré dans le t. I des Trans. Zool. Soc.

\section{ATELECYCLUS, Leach, Latr., Desm., Eow.; \\ Cancer, Montagu.}

La carapace est presque circulaire, tron. quée en arrière, avec ses bords latéraux prolóngés postérieurement en cercle et dentelés. - Les yeux, moins gros que le pédoncule qui les supporte, sont logés dans les orbites, dont le bord postérieur a deux fissures, et l'inférieur une troisième. - Les antennes extérieures ont au plus la moitié de la longueur du corps; elles sont ciliées, avec leur troisieme article cylindrique et allongé. - Les pieds-mâ. choires extérieurs ont le troisième article de leur Iranche interne étroit, terminé en pointe, et échancré en dedans pour l'insertion des articles suivans. - Les pieds de la premiere paire dans les mâles sont plus longs que le corps, robustes, avec les mains très-comprimées; ceux des femelles sont de la longueur du corps, seulement moins forts, avec les mains également comprimées. - Les pieds des autres paires ont les tarses et les jambes à peu près 
de longueur égale, et terminés par des ongles droits, allongés, anguleux, sillonnés Iongitudinalement, aigus aubout, avec la pointe nue, dont les postérieurs sont légèrement comprimés. - L'abdomen, chez la femelle, est étroit et allongé.

Ce genre se compose d'un très-pelit nombre d'espèces; toutes habitent les mers, et ne se trouvent qu'a de très-grandes profondeurs.

\section{ATELECYCLUS HETERODON.}

Leach, Malac., Brit. - Latr., Encycl., pl. 303, fig. 1-2.--EDw., op. cit., t. II, p. 143. - Atelecyclus Septem-Dentatus, Desm., Consid. génér. sur les Crust., p. 8, pl. 4, fig. 1. -Cancer Hippa, SeptemDentatus, Montag., Trans. of the Linn. Soc., t. II, p. 1. - La carapace est de forme orbiculaire, peu bombée, avec trois dents obtuses au front, et sept dents principales de chaque côté, dont le bord se prolonge en arrière et est garni de petites denteIures el de granulations. - Se trouve sur les côtes d'Angleterre.

\section{2. atelecyolus cruentatus. ( Pl. 6 , fig. 3.)}

Desu., Consid. génér. sur les Crust., p. 89.-Guérin, Iconogr. du Rég. anim. de Cuvier, Crust., pl. 2, fig. 2.-Long. 2 pouc. - La carapace est arrondie, bombée, et garnie sur son pourtour d'un petit rebord; desteintes rougeâtres et d'un jaune pâle la colo. rent; ses bords latéraux sont poilus en des sus, et munis de neuf aiguillons courbés de chaque côté; le front est divisé en trois pointes aplaties, dentelées, dont l'intermédiaire est la plus longue; les deux premiers articles des antennes extérieures sont assez allongés; les pinces sont comprimées , épaisses, poilues, garnies en dehors de cinq rangées de petits points relevés, disposés en chaînons; les pattes sont. variẻes de jaune et de rougeâtre. Suivant M. Risso, la femelle pond des oufs d'un rouge clair en avril et en juillet. Cette espèce a été découverte sur les côtes de l'íle de Noirmoutiers, par M. d'Orbigny.

Pour les espèces fossiles, voy. Desm., Crust. foss., p. 3, pl. 9, fig. 9.

\section{PIrimela, Leach., Deșm., Latr., Enw.;} Cancer, Montagu.

La carapace est subtransverse, avec son bord antérieur arqué en forme de cercle. - Les orbites ont une fissure à leur bord supérieur et postérieur, et une autre à leur bord inférieur. - Les ycux sont portés sur des pédoncules assez épais. Les antennes extérieures sont longues, insérées dans le canthus interne des yeux. -Les intermédiaires sont placées dans les fossetles allongées du chaperon. - Le troisième article des pieds-mâchoires extérieurs est carré, tronqué et presque échancré à son extrémité el du côté interne. Les pinces sont égales - Les autres paires de pieds sont légèrement comprimées et terminées par des ongles aigus, ambulatoires. - L'abdomen des femelles est allonge et assez élroit.

Ce genre se' compose d'une seule espèce.

\section{PIRIMELA DENTICULATA.}

Leach., Malac, Brit., tab. 3.- Desm., Consid. génér. sur les Crust., pl. 9, fig. 1. - EDw. op. cit., t. I. p. 424.-Long. 6 lig. - La carapace est lisse, mais fortement bombéc sur les régions stomacale; génitale et branchiale, et cuncave sur les régions hépatiques; les bords latéro-antérieurs sont minces, et ne dépassent pas le niveau du milieu de la région génitale; les mains sont garnies d'une petite crête en dessus, et d'une ou deux lignes carénées sur leur face externe; la couleur est verdâtre. - Se trouve dans la Méditerranée, sous les pierres, sur les côtes de Sicile; elle a été aussi trouvée sur les côtes d'Angleterre et d'Ecosse.

\section{CARGINITES.}

Ce groupe renferme trois genres: Thia, Carcinus et Polydectus.

\section{THIA, Leach, Desm., Latr., Edw. ; Cancer, Herbst.}

La carapace est de forme orbiculaire, tronquée postérieurement, avec le front avancé. - Les yeux sont très-petits, à peine saillaus, contenus dans les orbites, dont le bord postérieur est sans aucune fiśsure. - Les anteines extérieures sónt ciliées des deux côtés, assez longues, avec le troisième article de leur pédoncule allongé et cylindrique. - Le troisième article des pieds-mâchoires extếrieurs est beaucoup plus court que le second, tronqué el presque échancré du côté interne et près de son extrémité. - Les pieds de la premiere paire sont un peu plus longs que le corps dans les mâles, avec Jes mains comprimées; ceux des autres paires ayant les tarses deux fois plus courts que les jam- 
bes, et terminés par un article aigu, sillonné et flexueux. - Le premier article de l'abdomen chez le mâle est transversal, arqué et-linéaire; le second est un peu plus long, avec sa partie antérieure un peu avancée; le troisieme est beaucuup plus grand; le quatrième est presque carré échancré au bout; et enfin le cinquième est triangulaire.

THIA polita. (Pl. 6, fig. 4.)

Leach, Misc. Zool., t. II, pl. 103.Gú́rin, Iconogr. du Rég. anim., de Cuvien, Crust., pl. 2, fig. 3.-EDw., op. cit., t. II, p. 144.-Long. 6 lig.-Entièrement convexe; la carapace est lisse, pointillée dans quelques endroits, avec sa partie antérieure ou le front, entiére et arquée, et quatre plis peu marqués de chaque côté ; les bords latéraux et antérieurs de la carapace sont couverts de poils assez allongés et serrés, ainsi que les tranches supérieures et inférieures des pattes.

Cette espèce se Irouve sur nos côtes océaniques; elle a étè aussi observée près de Naples, par M. Milne Edw̧ards.

\section{CARCINUS, Leach, Edw.; Cancer, Linné, Fabr., Latr.}

C'est sur le Crabe commun de nos côtes océaniques et méditerranéennes que M. Leach a établi ce genre, el dont nous donuons les principaux caractères génériques.

La carapace présente son diamètre trans. versal plus grand que le longitudinal, avec son bord antérieur demi-circulaire et dentelé, et le postérieur tronqué et rebordé. - Les orbites n'ont qu'une seule fissure à chacun des bords supérieurs et inférieurs. - Les antennes externes sont relevées, courtes, avec leurs deux premiers articles plus grands que les autres; le troisieme article de la division intérieure des piedsmâchoires exterieurs est presque carré. - Les pieds de la première paire sont inégaux, avec la face externe des mains glabre; le dernier article des ongles des huit pattes postérieures et surtout de celles de la dernière paire, est comprimé et présente la forme d'une nageoire qui serait très-ètroite et allongée. - L'abdomen de la femelle est large et de forme ovale.

La seule espèce connue est le :

CARGINUS MANAS.

Lrach, Malac. Brit., tab. 5, fig. 1, 2. -Sav:, Descript. de l'Egypt., Crust., pl. 4, lig. 6.- Cancer Mcenas, LinN., Mus. Lud.
$U l r$. - Hensst, pl. 6, fig. 4-6. - Long. 2 pouc. - La carapace est plane, légèrement granuleuse, verdâtre, avec cinq dents ou épines, anguleuses de chaque côté, et troís lobes au front, dont l'intermédiaire est le plus long ; au côté interne de l'article qui précède la pince des serres, on aperçoit une saillie forte et pointue; les doigts sont relevés, noirs au bout, avec des dents obtuses à leur bord interne. Dans leur jeưne âge, ces Crustacés sont très-variés dans leur coloration, ils ont la carapace parsemée de taches blanches, rouges ou noires, de formes les plus bizarres; ils sont très-communs sur nos côtes, et, suivant M. Savigny, ils paraîtraient s'étendre jusqu'aux rivages de I'Egypte. _- On les trouve sous les pierres; quoique leur chair ne soit pas très-delicate, on en expédie cependant beaucoup pour les villes de l'intérieur, dans les mois de juin et juillet; ils servent d'appât pour la pêche lorsqu'ils sont à l'état mou. La femelle, suivant M. Bouchar 1-Chantereaux, porte des œufs, de cent quatre-vingt-quatre mille à cent quatre-vingt-cinq mille, de couleur jaune ou aurore, qui deviennent bruns quelque temps avant l'éclosiorı ; c'est à ce Crustacé, selon M. de Brébisson, que le peuple, dans le département du Calvados, a donné le nom de Crabe enragé.

\section{POLYDECTUS, EDW.}

La carapace est presque hexagonale, et très-bombéc; elle se rétrécit pìus en avant qu'en arrière, mais est notablement plus large que longue; les bords sont très-obtus; le front est avancé, lamelleux, droit. Les orbites, dirigées très-obliquementen dehors, sont incomplètes antérieurement. Les antennes internes se déploient transversalement en dehors. - L'article basilaire des antenues externes est cylindrique, et placé entre la fossette antennaire et l'orbite; il arrive jusqu'au front, maisnes'y soude pas ; leur deuxième article s'insère dans le canthus interne des yeux. - Le cadre buccal est rétréci antérieurement, mais sans être triangulaire, et son bord antérieur est trèssaillant et en forme de W. - Les piedsmâchoires externes sont allongés. - Les pattes de la première paire sont grêles e très-courtes chez la femelle. - La main est très-petite et les pinces cylindriques. Las patles suivantes sont a peu près cylindriques, et terminées par un article cour et pointu; lcur longueur augmente jusqu'à 
la quatrième paire; celles de la cinquième paire sont plus longues que les secondes.

\section{POLYDECTUS CUPULIFERA.}

Edw., op. cit., t. II, p. 146. - Pilumnus Cupulifera, Latr., Encycolp. méth., t. X. - Chaque orbite est entourée par trois gros tubercules cupuliformes : une de ces éminences, élargie et concave au bout, occupe l'angle externe; et les deux autres le bord inférieur de l'orbite; la carapace est très-bombée; le front est horizontal, avancé, divisé par une fissure mé diane, et terminé par un bord droit; les bords latéro-antérieurs sont à peine distincls et présentent d'abord une légère eoncavitè.

\section{TROISIÈME TRIBU.}

\section{N A G E U R S,}

\section{Latr.}

Caractères. La forme générale des Crus. facés qui composent cette tribu est ordinairement peu différente de celle de la plupart des arqués; mais la carapace est toujours très-peu élevée, et elle a quelquefois la forme d'un losange. - Les orbites sont dirigèes en haut et en avant. Les antennes internes se reploient transversalement, et l'article basilaire des antennes externes est logé en partie dans un hiatus de l'angle orbitaire interne ; le troisième article des pieds-mâchoires externes est toujours plus large que long, et fortement tronqué ou échancré à son angle antéricur et externe pour l'insertion du quatrieme article. - Le plastron sternal est toujours très-large, et le dernier segment thoracique est beaucoup plus déve. loppé que tous les autres, même que celui portant les pattes antérieures; la suture qui sépare ce segment du précédent se dirige très-obliquement en avant et en de: dans. - La voûte des flancs est généralement presque horizontale. - Les pattes antérieures sont en général trés-allongées ; les suivantes sont quelquefois natatoires, comme cela a lieu dans les Orithyes et les Matutes; et les postérieures le sont toujours, leur tarse étant lamelleux.

Cette tribu renferme des Crustacés qui sont essentiellement nageurs, et qui vivent souvent en pleine mer; ils composent deux groupes: ceux de Portunites et d'Orithytes.

\section{PORTUNITES.}

Garapace peu élevẻe, aýant la forme d'un losange, et présentant le plus souvent à chaque bord latéral, cinq dents, dont la postérieure est.de la grandeur des autres ou peu différente:- Pattes antérielures très-allongées; les suivantes quelquefois natatoires, et les postérieures toujours, avec leur tarse lamelleux; celles de la seconde paire ayant ordinairement plus d'une fois et demie la longueur de la carapace.

Genres: Platyonichus, Polybius, Portunus, Lupa, Thalamita.

\section{PLATYONICHUS, LATr., Edw.; \\ Cancer, Linv., Fabr. ; \\ Porlunus, Leach, Desir.}

La carapace est étroite et régulièrement convexe; souvent elle est beaucoup plus longue que large, et d'autres fois elle est circulaire. - Le front est très-étroit et dentẻ ; les bords latéro-antérieurs sont peu courbés et se dirigent presque directement en arrière ; de mème que chez les $\mathrm{Car}$ cinus, les Polybius, et la plupart des Portunus, ils sont divisés en cinq dents. Les orbites sont peu profondes et dirigées en avant. - Les antennes internes se reploient obliquement en avant, et leurs fossettes ne sont que très-imparfaitement séparées des orbites. - Les antennes externes diffèrent de celles des Carcins, des Portunes, des Thalamites et des $L u$ pées, en ce que leur premier article, qui est très-petit, ne se soude pas au front, mais reste mobile comme les suivants, et s'in. sère entre le bord orbitaire inférieur de la fossette antennaire. - Les pieds-mâchoires externes ont le troisième article plus étroit que chez la plupart des Portunus : il s'avance obliquement jusqu'au noyau des fossettes antennaires. - Le plastron sternal est ovalaire, étroit et très-rétréci postérieurement; la suture médiane n'occupant que ses deux derniers segmens. Les pattes antérieures sont médiocres et peu inégales : elles s'appliquent exactetement contre la région buccale; celles de la seconde paire sont assez longues, et ont le tarse aplati, un peu élargi et de formé presque lancéolée. - Le tarse des pattes suivantes est également un peu aplati , mais plutôt styliforme que lamelleux; les dernières, ou les pattes de la cinquième paire, sont entièrement natatoires. 


\section{A. Platyoniciús itipes.}

Enw., op. cit., t. I, p. 436. - Cancer Latipes, Peñ., Brit. Zool., t. VI, pl. 2, fig. 3. - Poriunus Variegatıs; Leach, Malac., pl. 4.-Platyonichus Depurator, LATr., Encyclop., t. X, p. 151. - Long. 1 pouc. - La carapace est cordiforme, presque aussi longue que large et fortement rétrécie postérieurement; les dents frontales sont très-pelites; les bords latéro-antérieurs sont dirigés presque directement en arrière, et armẻs de dents très-pelites; lés pattes antérieures son: courtes; le bras dépasse à peine la carapace; le carpe présente une seule épine; les mains sont sans dents ni carène marquées; les tarses des pattes de la deuxième paire sont un peu élargis; les suivans presque styliformes; l'abdomen du mâle est composé de cinq segmens. - Cette espèce se trouve sur nns côtés.

\section{PLATYONICHUS OCELLATUS.}

LАTณ., Encycl., t. XVI, p. 152.-EDv., op. cit., t. 1, \%. 437.-Portunus pictus, S.y, Acad. Philad., t. I, pl. 1, fig. 4.Cancer Ocellatus, Henest, pl. 49, fig. 4 . -Long. 2 pouc. - La carapace est presque circulaire, beancoup plus large que jongue; les dents frontales et latéro-antéricures sont grandes; les pattes antérieuressont grandes; le bras dépasse de beaucoup la carapace; le carpe est bidenté.

3. platyoxiches mipestentas. (Pl. 6, fig. 5.)

EDw., op. cit., 1. 1, p. 437, pl. 17, fig. 7 à 10. - Long. 5 pouc. - La carapace est presque circulaire, bombée et très-finement granulée; le front est très-reculé et armé de quatre pelites dents; les dents des bords latéro-antérieurs sont arquées et trés-grandes; le bord orbitaire superieur ofire une dent plus ou moins saillante vers son milieu; les pattes antérieures sont mé. diocres et à peu près de même forme que chez l'espèce précédente; le larse de la seconde paire est lamelleux, lancéolé et un peu falciforme chez le mâle ; ceux des deux paires suivantes sont lamelleux, mais se rétrécissant de plus en plus; les tarses des paltes postérieures sont ovalaires; l'abdo. men, chez le mâle, est composé de sept segmens distincts. - Se trouve dans l'Océan Indien.

\section{PLatyoniches nasutus.}

Latr., Encyclop., t. X, p. 151.- Portusius Biguttatus, Risso, Crust. de Nice, pl. 3, fig. 1. - EDw, op. cit., t. I, p. 438.-La carapace, qui est d'un blanc-jaunâtre, ornée de deux grandes taches d'un rouge corail, est bombée au milieu et inégale; le bord supérieur orbitaire présente the fissure; les serres sont petiles; les troisième et quatrième articles sont unidentés; le dernier est marqué par des rainures en dessus; les pattes sont courtes, larges, aplaties; les postérieures sont ovaies, lancéolées et aiguës; la femelle a des taches rouges plus grandes que celles du mâle ; selon M. Risso, elle pond des œufs d'un jaune doré, en mai et en aviril. - Se trouve sur nos còtes de l'Océan et de la Méditerranée, dans la région des coraux.

POLYBIUS, Leach, Desu., EDW. ; Platyonichus, Larti.

La carapace est plane, orbiculairc, à bord antérieur arqué et demi-circulaire, sans angles latéraux bien marqués, ayant un diametre transversal un peu plus grand que le longitudinal, et ses còtés présentant chacun cinq dents. - Les yeux sont portés sur de courts pédoncules, et plus gros que ceux-ci; et au bord supérieur et postérieur des orbites on aperçoit deux fissures. Les altennes extérieures sont courtes, sétacées, avec leurs deux premiers articles plus grands que les autres; le troisième article de la division interne des pieds-máchoires extérieurs est échancré en dedans. - Les pieds de la première paine sont égaux, très-forts. - Les mains sont marquées de lignes élevées sur leur face extévieure. - La dernière pièce de tous les autres pieds est comprimée, aplatie eten forme de nageoire; celle de la dernière paire est beaucoup plus arge, plus ovale et moins pointue au bout que les précédentes. L'abdomen de la femclle est large, ovalaire; et celui du mâle légèrement élroit et pointu.

La seule espèce connue est le:

\section{POLYBIUS HENSUOUII.}

Leach, Malac. Brit., tab. 9; Desur., Consid. génér. sur les Crust., pl. 7, fig. 1. -Enw., op. cit., t. 1, p. 439.-Long. 2 pouces. - Le corps est Ires-comprine; la carapace est orbiculaire, entièrement lisse et plane en dessus; le frout est armo de cinq dents triangulaires peu saillantes, surtout les externes, qui occupent les angles orbitaires internes; le bord supérieur présente deux fissures: les dents des borí 
latéro-antérieurs sont très-larges, mais à peine saillantes; la couleur est entièrement brune. - Se trouve dans la Manche; il paraît se tenir toıjours à une distance assez considérable de la côte.

\section{portunus, Fabr., Latr., Edw.; Cancer, Linn.}

La carapace est plane, son diamètre transversal est un peu plus grand que le longitudinal, et ses régions viscérales sont assez bien marquées. - Les bords latéroantérieurs de la carapace sont en demi-cercle et découpés en dentelures plus ou moins nombreuses (cinq à sept). - Le bord postérieur est tronqué transversalement, avec une échancrure de chaque côté pour l'articulation de la patte postérieure. - Les yeux sont plus gros que leur pédoncule, qui est court, et on apercoit aux bords supérieur et postérieur de chaque orbite deux fissures. - Les antennes extérieures sont courtes, terminées par un filet sétacé, beaucoup plus long que leur pédoncule. - Le troisieme article de la division interne des pieds-machoires extérieurs est presque carré, avec des angles arrondis; cet article est échancré près de l'extrémité de son bord interne. - Les pieds de la première paire sont un peu inégaux, avec le côté externe de la main margué de lignes longitudinales élevées. - Les bras sont souvent inermes. - Les derniers articles de la seconde, troisième et quatrième paire de pattes sont allongés, étroits, pointus, souvent striés, et plus ou moins ciliés; ceux de la cinquieme paire sont élargis et aplatis en forme de lame plus ou moins ovale, et ciliee sur le deux bords. - L'abdomen de la femelle est large et de forme ovalaire, composé de sept articles: celui du mâle plus ou moins étroit, et composé de cinq.

Ce genre, dans la méthode de $\mathbf{M}$. Latreille, comprenait naguère un grand nombre d'espèces; mais M. Leach en a retiré, sous le nom de Lupa, celles dont les bords latéro-antérieurs sont munis de neuf dents. Ce même auteur a aussi créé, aux dépens de ce même genre, celui de Portumnis, auquel-M. Latreille a substitué le nom de $P$ liatyonichus. Voyez ses caractères ci-dessus énoncés.

La conformation de ces Crustacés leur donne les moyens de nager avec la plus grande facilitè dans tous les sens, en avant, en arrière et de côté; ils peuvent aussi se soulever à la surface de l'eau sans bouger; et, lorsqu'ils sont à terre, ils marchent avec autant de vitesse que les Carcins. La plupart virent en société; il en est qui se tiennent lans les fonds vaseux; d'autres font leur séjour parmi les rochers couverts d'algues; quelques-uns habitent la haute mer: ils n'ont pour se reposer que les bancs flottans de l'espèce de fucus connu sous le nom de raisin des Tropiques, où pullulent beaucoup de petits Crustacés dontil est probable qu'ils se nourrissent. Ils font, dit M. Risso', plusieurs pontes par an, ou peut-être est-ce la même espéce et non les mêmes individus, qui pondent à diverses époques de la belle saison. Selon M. Roux, ces Crustacés sont quelquefois attaqués par de pelits Caligides qui vivent en parasites sur leurs branchics. On trouve des Portunes dans toutes les mers; ils y sont abondamment répandus; on ne fait pas grand cas de la chair de ceux de la Méditerranée.

Parmi les espèces qui vivent sur nos côtes océauiques et méditerranéennes, nous citerons :

\section{PORTUNUS PUBER.}

Fabr., Suppl., p. 355.-Leach, Malac. Brit., pl.6.-DesM., Consid. génér. sur les Crust., pl. 5, fig. 1.-Bualny., Faun. franc., Cancer puber, Lins., Syst. Nat., t. V, p. 2978. - Loug. 2 pouces $\frac{1}{2}$. - La couleur générale de ceite espèce est brune; les antennes sont de moitie moins longues que le corps; la carapace est velue; le front est multidentẻ, chaque côtẻ du bord antérieur du test présente cinq dents en avant; les serres sont graveleuses; les carpes sont bidentés; la dernière pièce des pattes postérieures est ovale, avec une ligne élevée dans son milieu. - Se trouve sur les côtes océaniques de France et d'Angleterre.

\section{2. portunus picatus.}

Risso, Crust, de Nice. - Roux, Crust. de la Médit., pl. 32, fig. 6.-EDw., op. cit., t. I, p. 442. - Long $18 \mathrm{lig}$ - - Chez. cette espece le front est tridenté, la partic latérale et antérieure du test est armée de cinq dentelures égales entre elles; les pattes ont des côtes ou des saillies longitudinales fortement prononcées; elles sont lisses et comprimées; les doigts sont cannelés sur leur surface extérieure, dentés intérieurc. ment; les maius sont armées d'une forle pointe, et portent sur le dos trois nervures granuleuses; on voit une autre dent ou aiguillon sur l'angle intérieur du carpe; le 
dessous du corns est glabre et luisant; l'abdomen est lavé de bleuâtre; le reste du test est de couleur de chair, quelquefois roussâtre; les yeux sont gris de perle; les pattes postérieures ont la lame ovale aplatie, de couleur violette, et bordèe de cils jaunâtres; la carène médiane est à peine distincte; la pince droite est presque toujours plus forte que la gauche. Les jeunes ont quelquefois le corps fascié de rouge; la femelle diffère du mâle en ce qu'elle est moins colorée : elle porte et dépose, en mars et en décembre, des ceufs d'un jaune-grisâtre. Ce Crustacé ne s'approche pas du rivage : c'est dans les profondeurs rocailleuses, à vingt ou trente mètres, qu'il fait sa résidence annuelle; il n'est nullement abondant. Les plus grands individus atteignent un pouce dix lignes de diamètre transversal. - On le trouve sur toutes les côtes de la Miediterranée, et sur celles de France et d'Angle\{erre baignées par l'Océan.

\section{3. portunus marnoreus.}

Leach, Malac. Brit., pl. 8. - Edw., op. cit., t. I, p. 442 . - Long. 18 lig. Chez cette espèce, le dernier article des pattes postérieures se termine en pointe; la carapace est légèrement granuleuse et moins rétrécie postérieurement que dans l'espèce précédente; le front est étroit et armé de trois petites dents obtuses. - Se trouve sur nos côtes.

\section{Portunus holsatus.}

FABR., Suppl., p. 326.-Portunus Lividus, Leach, Malac., pl. 9 , fig. 3 et 4.EDw., op. cit., t. I, p, 443.- Le dernier article des pattes postérieures est arrondi au bout; la carapace est plus rétrécie postérieurement et plus déprimée que dans l'espèce précédente, avec laquelle elle a beaucoup d'analogie.-Cette espece, quí se trouve sur nos côtes, habite les laisses de basse mer de nos plages sablonneu. ses.

\section{PoRtunus cornugatus.}

Buativ., Faun. franc. Crust., pl. fig. 1. - Evw., op. cit., 1. I, p. $443 .-$ LEACH, Mal. Brit., tab. 7, fig. 1, 2.-Long. 2 pouc. - Sa couleur est d'un rouge clair; la carapace est marquée de nombreuses lignes transverses, dentelees el granuleuses, lesquelles supportent autant de rangées de ćls dirigés en avant; le front est bilobé; les bords latéro-antéricurs du test présentent cinq dents, dont les pointes se portent en avant, et dont les postérieures sont les plus aiguês;- les mains et le carpe sont très-dentés en dessus; la dernière pièce de la cinquième paire de pieds est ovale, allongée, pointue au bout, et est marquée dans son unilieu d'une ligne élevée, longitudinale. - Cette espèce se trouve dans la Méditerranée.

\section{6. portunus pusilius.}

Leach, Malac., pl. 9, fig. 5 à 8 . Latr., Encycl., t. X, p. 192.-EDw, op. cit., t. I, p. 444. - Long. 4 lig. - La carapace est très-bombée et bosselée, et entièrement dépourvue de poils; le front est très-avancé; le dernier article des pattes postérieures el lancéolè. - Se trouve dans la Manche.

\section{PORTUNUS RONDELETI.}

Latr., Encycl., t. X, p. 192. - Risso, Hist. des Crust. de Nice, pl. 1, fig. 3. - Roux, Crust. de la Médit., pl. 4, fig. 3. - Edw., op. cit., t. I, p. 444, Portunus arenatus. - LEACH, Malac. Brit., pl. 7, fig. 5 à 6 , et $P$. Marginat us, ejusd., fig. 3 à 4. - Long. 1 pouc. - Cette espèce a le test un peu bombé, d'un brun-rougeâtre, marqué de sinuosités régulières et couvert d'un duvet rubigineux; le front est droit, entier, tronqué, poilu; les bords latéraux de la carapace sont munis de cinq dents dont les deux postérieures et surtout la pénultième plus petites; les pinces sont inégales, glabres, à troisième article tacheté en dedans de rougeâtre; le quatrième armé en dessus d'une pointe; le dernier sillonné, avec des dents obtuses, noirâtres vers leur extrémité; les pattes sont inégales, déprimées, parsemées de poils courts. Il est des individus dont le corps est tacheté de blanc, de gris ou d'autres teintes. C'est dans le mois d'avril, de juin et de septembre, que la femelle porte de petits oufs d'un rouge brun. - Ce crustacé habite toute l'année dans les dépôts vaseux et peu profonds qui avoisinent l'embouchure des ports; il est très-commun dans la Méditerranée, et rare dans l’Océan.

\section{PORTUXUS LONGIPES.}

Risso, op. cit., pl. 1, fig. 5. - Latr., Encycl., t. X, p. 192. - Roux, Crust. de la Médit., pl. 4, fig. 1.-EDw., op. cit., t. I. p. $444 .-$ Long. 1 pouc. Chez cette espèce, les pattes sont proportiontellement plus longues que celles des autres espéces du même genre; elles sont grêles et armées d'une arête longitudinale; la lame natatoire de la dernière 
paire est ètroite, bordée de cils jaunátres, ainsi que les articles qui la précèdent; le test est entièrement glabre sur la moitié postérieure, finement chagriné sur la partie antẻrieure de la carapace, qui est légèrement bombée; celle-ci est transversalement divisée par une forte impression; son front est partagé en quatre lobes obtus; chaque bord latéral est muni de cinq dents inégales dont les trois postéricures plus aiguës: la pénultième est un peu plus courte que les autres; la forme des serres diffère: celle de droite est la plus grosse; le troisième article est triangulaire, le quatrième armé de deux pointes, le cinquième d'un aiguillon; la couleur est d'un rouge laqueux légèrement tacheté de jaunâtre, particulièrement sur les pattes, qui sont d'une teinte plus pâle; Je dessous du corps est moins coloré que le dessus; le pénultième article de la queue du mâle est gris et plus long que large; le dernier est étroit, allongé et d'un rouge sanguin. Suivant M. Risso, la femelle a, dans le temps des amours, deux grandes taches d'un rouge foncé sur la partie antérieure du test; ses œufs sont de couleur aurore, et éclosent depuis juin jusqu'en septembre.

C'est dans les trous des rochers profonds, dit M. Roux, que ce Portune me parait vivre solitaire. 11 est rare d'en pècher plusieurs à la fois, et la sécurité dont il jouit dans les antres qu'il habite augmente la difficulté de se le procurer.

\section{9. portunus tunerculatus.}

Roux, Crust. de la Médit., pl. 32, fig. 1. Cette nouvelle espèce, dit M. Roux, est bien caractérisée par les nombreux tubercuJes qui sont distribués sur sa surface, etn'est non moins remarquable par la longueur des deux épines postérieures du côté du test. Ces epines augmentant beaucoup sa largeur transieisale, donnent à ce Crustacé l'aspect des $L u p a$, avec lesquelles on ne peut cependant les confondre, à cause du nombre des dentelures latérales, qui n'est que de cinq. Le front est tridenté; la région cordiale est relevée par trois tubercules poinlus et saillans disposés en triangle; la main est surmontée, à l'articulation du doigt, d'une pointe aiguë; on voit une épine encore plus Jongue sur l'angle antérieur du. carpe, et une autre plus petite à l'extérieur; les doigts sont dentés intérieurement, cannelés sur leur surface supérieure; le prolongement de ces cannelures se change en arête crénelée surle dessus de la main; tout le corps et les paites soni légèrement tomenteux; les anneaux de l'abdomen seuls sont glabres el lisses; la pince gauche est un peu plus petíte que la droite; la couleurgénérale de ce Portune est d'uin roux jaunâtré les pinces, d'une teinte plus claire, sont légérement fasciées de rouge. - Cette espécè à été Irouvée dans le golfe de Naples, parmi des Portunes plissés, dans des profondeurs de ving 1 à trente metres.

\section{0. pontunus integrifrons.}

LATH., Encycl., t. X, p. 192.-EDw., op. cit., t. I, p. 445 . - Long. 2 pouc.-La carapace est peu élevée, inégale et pubescente: le front est très-large et arqué; les dents latéro-antérieures sont larges et peu saillantes; les pattes antérieures sont inègales, assez grandes; les mains sont armées d'un grand nombre de petiles granulations spiniformes disposées en petites lignestrans. versales. - Se trouve dans l'Océan Indien.

\section{LUPA, Leach, Desm., Edw. ; Portunus, FABR.}

La carapace est aplatie, beaucoup plus large que longue, ayant son bord antérieur arqué et muni de neuf dents, dont la posterieure quelquefois plus grande que les au. tres, et dirigée latéralement. - Les yeux sont plus gros que leur pédoncule, qui est court; il y a deux fissures aux bords postérieur et supérieur de chaque orbite. - Les antennes extérieures sont courtes et médiocres, terminées par un filet sétacé beaucoup plus long que leur pédoncule : les intermédiaires, coudées, sont logées sous le chaperon. - Les pieds-mâchoires extérieurs ont le troisieme article presque carré, à angles arrondis, échancré a son extrémité interne; les pinces sont d'égale grosseur; les bras sont allongés. - Les pieds des deuxieme, troisième et quatrieme paires sont terminés par un article ou ongle aigu et pointu; ceux de la cinquième pais e déprimés et finissent par une pièce foliacée, ovale, trèslarge, ciliée, dont le milieu présente toujours une arête saillante longitudinale.

Les Lupées different aussi des Portunes par leurs mours: car elles se tiennent presque toutes à de grandes distances en mer, dans le voisinage des bancs, de Fucus natans, se jouant quelquefois à la surface des flots, nageant avec une sorte d'aisance et de grâce, pouvant se soutenir assez long-temps str l'eau sans se donner des mouvemens 
spparens : tel est, selon $\mathrm{M}$. Bosc, le Lijia Pelagica; il en est qui fréquentent l'em. bouchure des rivières. Ges Crustacés abondent dans les mers qui avoisinent les Tropiques; on les pêche facilement à la marée montante; on ne connaît encore qu'une seule espèce de la Méditerranée; parmi les espèces exotiques il en est une qui est remarquable par sa grandeur, ct même que l'on peut dire ètre la plus grande du genre. M. Edwards, dans son Ilistoire naturelle des Ciustacés, afin de rendre ce genre plus facile à l'étude, l'a partagé en trois sous-genres.

\section{PREMIER SOUS-GENRE.}

\section{(Lupées convexes, Edw.)}

Espèces ayant le corps très-épais et bombé en dessus; les pattes de la première paire grosses et un peu allongées; la main naturellement moins longue que la carapace.

Ce sous-genre ne renferme encore qu'une seule espèce.

\section{LUPA Tranouebarica.}

Edw., op. cit., t. I, p. 448. - Portunus Tranquebaricus, Fabr., Suppl., p. 336.Portunus Serratus, Ruppele, op. cit., pl. 2, fig. 1.-Long. 6 à 8 pouc. - La carapace est unic en dessus et assez régulièrement bombée; son diametre antéro-postérieur égale les deux tiers de son diamètre transversal. Le front est saillant et armé de deux dents triangulaires, larges et courtes; les bords latéro-antérieurs sont beaucoup moins droits que chez les autres $L u$ pées, et se prolongent plus loin en arrière; les neuf dents dont chacun d'eux est garni sont spiniformes, aiguës, dirigées un peu en avant et semblables entre elles; les pattes de la première paire ne sont pas trèslongues, mais elles sont très-grosses; on compte trois épines sur le bord interne du bras, deux sur son bord externe, trois sur le carpe, et trois sur la main, qui est renflée et un peu courbée en dedans; les pattes des trois paires suivantes sont aplaties, mais leur dernier article est épais et plutôt styliforme que lancéolé.-Habite les mers d'Asie.

\section{DEUXIÈME SOUS-GENRE.}

\section{(Lupées nageuses, EDw.)}

Espéces ayant le corps très-comprimé; les pattes de la première paire très-allon- gées; les mains presque toujours plus lon. gues que la carapace; tarse des pattes des deuxième, troisième et quatrième paires aplati, lamelleux, et de forme presque lancèolée.

1. LUPa pelagica. (P1. 7, fig. 2.)

Leacr, Edinb. Encycl., art. Crust., Dess. , Consid. génér. sur les Crust.,

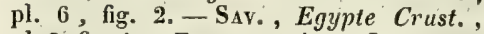
pl. 3, fig. 1.- Eow., op. cit., t. I, p. 450 . - Cancer Pelagicus, Linn., Mus. Lud., Ulr., p. 434. - Long. 3 à 4 pouc. - La dent postérieure des côtés de la carapace est très-forte; le front a six dents ou stries, en y comprenant les oculaires, dont les deux du milieu sont les plus petites; elles forment un triangle avec unc pointe qui est saillante entre les bases des deux antennes intermédiaires; les serres sont trois fois plus longues que le test, avec les bras tridentés au côté interne; le carpe a deux dents, l'une interne et l'autre extcrne; les mains sont allongées, avec des côtes longitudinales, saillantes en dehors, qui se terminent clacune par une dent; une arête finissant par une pointe sur la face interne de ces mêmes mains; les doigts sont allongés, pointus, fortement siriés, avec des dents molaires lobées sur leur bord intérieur; la çouleur est verte claire ou brune, plus ou moins marbrée ou tachetée de jaunâtre. - Se trouve aux Indes-Orientales.

\section{LUPA SANGUINOIENTA.}

EDw., op. cit., t. I, p. 451. - Cancer Sanguinolentus, Herbst, t. I, p. 161, tab. 8, fig. 56-57.-Portunus Sanguinolentus, Fabr., Suppl. Ent. Syst., p. 365. -Latr., Encycl. méth., t. X, p. 190.Long. 2 ponc. - Le bord postérieur des bras n'offre pas d'épine; la carapace est plus large et moins granuleuse que dans l'espèce précédente; le front est très-reculé et armé de six dents, dont les quatre médianes sont spiniformes, et les externes obtuses; la der nière dent est très-grande; les pattes antérieures sont plus courtes; les mains n'ont pas une fois et demie la longueur de la carapace, et ne portent que deux épines; le troisième article des pattes suivantes n'atteint pas l'exirémité de l'angle latéral de la carapace, laquelle porte en arrière trois grandes taches circulaires d'un rouge vif. - Se trouve dans l'Océan Indien.

\section{LUPA DICANTHA.}

Edw., op. cit., t. I, p. 451.-- Portunus Petagicus, Besc, Hist. nat, des Crust, t. 1, 
p. 220, tab. 5, fig. 3. - Portinus Hastatus, Fabr., Suppl. entom. Syst., p. 367. - Portunus Dicanthus, Latr., Encycl., t. X, p. 190. - Long. 4 pouc - L'extrémité du bord postérieur du bras présente une épine très-aiguë; la carapace est plus de deux fois aussi large que longue, et marquée de quelques lignes granuleuses transversales; les pattes antérieures sont grosses; l'abdomen du mâle est très-large a sa base; mais il devient tout-à-coup, à partir du quatrième anneau, presque linéaire, de manière à av oir quelque ressemblance arec la lettre $\amalg$ renversée. - Se trouve sur les côtes de l'Amérique.

\section{LUPA CRIBraria.}

EDw., op. cit., t. I, p. 452, pl. 18, fig. 1 . -Portunus Cribrarius, LaM., op. cit., t. V, p. 259. - Long. 3 pouc. - La carapace est très-aplatie, entièrement lisse, et à peu près de même forme que chez l'espéce précédente; le front est très-reculè ; l'épine inter-antennaire est courte; les fissures orbitaires sont très-profondes; les dents latérales sont légérement courbées; l'abdomen est de forme ordinaire; la couleur est fauve, avec une multitude de taches blanches. - Se trouve sur les côtes du Brésil.

\section{LUPA SPINIMANA.}

Leach, Desm., Consid. génér. sur les Crust., p. 98. - Portunus Spinimanus, Latr., Encycl., t. X, p. 188. - Long. 3 à 4 pouces. - La carapace n'est guère plus d'une fois et demie aussi large que Inngue, un peu bombée et très-inégale; le front est sailiant et armé de huit dents, dont les quatre médianes sont les plus saillantes; les dents des bords latéroantérieurs sont spiniformes et dirigées un peu en avant; les pattes antérieures sont armées à peu prẻs comme dans l'espèce précédente; les mains présentent un grand nombre de tubercules granuleux et des côtes longitidinales arrondies; les pattes suivantes sont très-comprimées. - Se trouve surur les côtes du Brésil.

\section{LUPA LOBIFROSS.}

EDw., op. cit., t. I, p. 453. - Long. 1 pouc. - La carapace est comme dans la Lupée crible, c'est-à-dire aplatie,mais bien plus carénée ; le front est avancé, divisé en quatre lobes arrondis, et armé d'une petite dent au-dessus de l'angle orbitaire interne ; les dents des bords latéro-antérieurs sont très-petites; les pattes antérieures sont très- petites; les mains sont renflees et moins' longues que la carapace. - Cette espèce se trouve dans l'Ocèan Indien.

\section{TROISIÈME SOUS-GENRE.}

$$
\text { (Lupérs marcheuses, Epw.) }
$$

Tarse des pattes des deuxième, troisième et quatrième paires aplati, lamelleux, de forme presque lancéolée.

\section{IUPA RUBRA.}

EDw., op. cit., t. I, p. 454.-Portunus Ruber, LaMr, op. cit., t. V, p. 260.Long. 2 pouc. - La carapace est une fois et demie aussi large que longue; le front est très-avancé, fort large, et divisé en huit dents, dont les quatre moyennes sont trèslongues et séparées des autres par une échancrure profonde; le bord antẻrieur et l'angle externe des orbites sont moins avancés que le front ; les bords latéro-antérieurs de la carapace sont courts et armés de cinq grosses dents spiniformes, séparées entre elles par quatre petites; les pattes antérieu: res sont de grandeur médiocre; sur le bord antérieur du bras on aperçoit quatre ou cinq grosses épines, et quatre sur la partie supérieure de la main; le troisième article des pattes postérieures porte une épine à l'extrémité de son bord inférieur; la couleur générale est rougeâtre, avec l'extrémité des pinces noire. - Se trouve sur les côtes du Brésil.

\section{MUPA GRANULATA.}

Eow., op. cit., t. I, p. 454. - Long. 2 pouc. - La carapace est inégale et granuleuse; le front est avancé et divisé en cinq dents, ou plutôt lobes; le bord postérieur des bras présente des épines aussi bien que son bord antérieur, et la main plusieurs crêtes longitudinales et granuleuses. - Se trouve à l'lle-de-France.

\section{LUPA SEBE.}

Edw., op. cit., t. 1, p. 455.-Portunus Sanguinolentus, LaTr., Encycl., pl. 272, fig. 6. - Long. 2 pouc. - La carapace est à peine bombée; le front est armé de six dents, en général toutes aiguës et trèsgrandes; les dents des bords latéro-antérieurs sont très-pointues et un peu recourbées en avant ; la dernière est environ deux fois aussi longue que les autres, mais proportionnellement plus mince ; les pattes antérieures sont longues et ćpineuses; le troisième article des pattes postérieures est 
comme dans la Lupée rouge. - Se trouve sur les côtes du Brésil.

\section{LUPA hastata.}

EDw., op. cit., t. 1, p. 455.-Portunus Hastatus, Latr, Encycl., t. X, p. 189. - Lupa Dufourii, Desm., Consid. génér. sur les Crust., p. 99. - Roux, Hist. des Crust. de la Méditerr., pl. 44, fig, 1. Long. 2 pouc. - La surface de la carapace de cette espèce est sinuée de lignes raboteuses d'un rouge brique pâle; ces lignes sont lisses sur toutes les autres parties du corps; tout le reste du test est couvert d'un duvet jaunâtre soyeux, très-serré ; les côtés sont armés de neuf dents acérées, tournées en avant, dont la postérieure très-forte : on en voit quatre au milieu du front, dont les deux intermédiaires plus petites; entre chacune des dents laterales on apercoit un petit espace d'un blanc nacré brillant, qui caractérise très-bien cette espèce; la première paire de pattes portant les serres est presque trois fois plus longue que le corps; les bras ont quatre dents aiguës sur leur bord interne; le carpe porte sur sa surface externe cinq côtes longitudinales; le bord supérieur est, en avant, armé de deux fortes pointes; les dents des doigts sont inégales et arrondies; le dessous du corps est blanchâtre; cette espèce atteint deux pouces deux lignes, de largeur près de l'extrémité des deux pointes latérales. - Suivant M. Roux, e'est toujours en haute mer qu'on rencontre cette espèce de Lupée, ordinairement dans le voisinage de quelques fonds rocailleux éloignés de la côte; elle est en troupe, et on la rencontre quelquefois aussi sur des fucus flottans; il parait qu'on la trouve dans la Méditerranée; mais elle n'est abondante nulle part, et ne s'approche jamais du littoral ; on ne connait point la couleur de ses æufs, ni l'époque à laquelle la femelle en est pourvue.

\section{LUPA FORCEPS.}

Leach, Zool. Misc., t. I, pl. 54.-Desh., Consid. génér. sur les Crust., p. 99. LATR., Règn. anim. de Cuvier, $2^{\prime}$ édit. t. IV, p. 34.-EDw, op. cit., t. 1, p. 456. - Portunus Forceps, FABR., Suppl., p. 368.-Long. 1 pouc. - La carapace chez cette espèce est très-aplatie et très-rétrécie postérieurement; le front est très-reculé ; les orbites sont dirigées très-obliquement en haut; la dert latérale est presque aussi longue que l'espace occupé par les huit uremières dents; les pattes antérieures sont très-grêles, et environ quatre fois aussi longues que la carapace; les suivantes sont longues et grêles. - Se trouve aux Antilles.

THALAMita, Latr. Edw. ; Portunus, Fabr.

Ce genre, qui a été établi par M. Latreille, diffère du précédent en co que la carapace a tantôt la forme d'ur carré allongé; son diamètre transversal est presque le double de sa longueur, et son bord fronto-orbitaire forme, avec ses bords latéroantérieurs, un angle presque droit; d'autres fois, cette carapace est presque hexagonale; ses six bords forment entre eux des angles à peu près égaux, et sa largueur n'excède que d'environ de moitié sa longueur. - Le front est toujours très-large, aaillant, et au moins aussi avancé que le bord inférieur et l'angle externe de l'orbite.-Les bords latéro-antérieurs sont plus ou moins obliques, et forment toujours avec le bord fronto-orbitaire un angle trèsprononcé; on y compte de quatre à sept dents. - Les yeux sont gros, courts. Les orbites sont ovalaires, et complétement séparées des fossettes antennaires. - Les antennes internes se reploient complétement dans leurs fossettes, et la cloison inter-antennaire est peu saillante; l'article basilaire des antennes externes est trèslarge; il est toujours soudé au front dans toute l'étendue de son bord antèrieur, et présente en dehors une saillie plus ou moins considérable qui sépare l'orbite du point d'articulation de la tige mobile et de ses appendices; celle-ci est très-longue, et s'insère quelquefois loin de la cavité orbitaire. - Le cadre buccal est très-large. Les pieds-mâchoires externes sont disposés à peu près comme chez le genre Portunus. -Le plastron sternal est très-large, et sà suture médiane s'ẻtend sur les troisderniers anneaux. - Les pattes antérieures sont grandes, et ne peuvent se cacher sous la portion antéricure du corps; leur troisième article est épincux en avant, et dépasse de beaucoup la carapace. - La main est hérissée d'un nombre considérable de dents, et sa longueur égale au moins celle de la carapace. - Les pattes des trois paires suivantes sont beaucoup moins longues et se raccourcissent successivement ; leur tarse est généralement styliforme; celles de la cinquieme paire ont leur troisieme article assez allongé; il se trouve a l'extrémité de 
son bord inférieur une épine assez forte; vers le bout, les pattes deviennent trèslarges, et leur tarse est ovalaire. Ce genre a été divisé en deux sous-genres par M. Edwards, dans son Hist. nat. des Crustacés.

\section{PREMIER SOUS-GENRE.}

\section{(Thalamites quadilatéres, Evw.)}

Bord fronto-orbitaire occupant presque toute la largeur de la carapace, et formant un angle presque droit avec les bords latéro-antérieurs, qui ne sont armés que de quatre à cinq dents.

\section{TILIAHTA ADMETE.}

LAtr., Régn. anim. de Cuvier, $2^{e}$ édit., t. $1 \mathrm{~V}$, P. 33; Portunus Admete, Latr., Nouv. Dict. d'Hist. nat., t. XXVIII, p. 44.- Enw., op. cit., t. I, p. 459. Cancer Admete, Henbst, pl. 57, fig. 1. - Portunus Admete et Portunus Poisoni, Aub., Egypt. Crust., par SAv., pl. 4, fig. 3, 4. - Long. 1 pouce. - La carapace est presque plane en dessus; le bord fronto-orbitaire occupe presque toute la largeur de la carapace, il est presque droit et divisé en quatre lobes; lo bord latéro-antérieur de la carapace est presque droit et armé de quatre dents trésaiguës, dont la pénultième est beaucoup plus petite que les autres; le bord infé. jieur de l'orbile est dentelé, mais if ne présente pas de dents spiniformes; l'article basilaire des antennes externes est gami d'une petite çête dentelée qui séparc les lobes moyens du front; Je bord antérieur du bras offre trois épines, fortes et obtuses; la main, qui est granuleuse en dehors, présente sur sa face supérieure six épines disposẻes alternativement en deux rangées; le pattes suivantes sont courtes et grises; on apercoit une série de petites dents spiniformes sur l'avant-dernier article de celles de la cinquième paire, dont le tarse est ovalaire, mais porte à son extrémité un petit angle conique et pointu. - Se trouve dans l'Océan Indien et dans la Mer-Rouge.

\section{THALAMITA CHAPTALII.}

Evw., Hist. nat. des Crust., t. I, p. 460 . - Portunus Chaptalii, Avd., Crust. de M. Savigny, Egypt., pl. 1, fig. 1.-. Long. 1 pouc. - La carapace est comme dans l'espèce précédente; le front est également large et à peine divisé; les dents du bord latéro-antérieur sont larges, obtuses, pres. que carrées et semblables entre elles; la main n'offre pas de grosses épines. - Se trouve dans la Mer-liouge.

\section{THAI,AMTA SHA.}

Evry., op. cit., tom. I, p. 460. - Long. 8 lig. - La carapace est très-bombée ; son bord fronto-orbitaire est notablement plus court que son diamètre transversal; le front est avancé au milieu, mais à peine lobé; les bords latéro-antérieurs sont assez obliques et armés de dents très-aiguës dont la derniere est plus grosse que les autres; l'avantdernier article des pattes postérieures ne présente pas d'épine. - Se trouve sur la côte de Coromandel.

\section{THAIMITA CRENATA.}

EDw., op. cit., t. I, p. 461. - Thalamïta Admete, Gúr., Icon. du Régn. anim. de Cuvier, Crust., pl. 1, fig. 4. - Long. 2 pouc. - Le bord latéro-antérieur de la carapace présente cinq dents spiniformes à peu près égales; sa forme générale la rapproche beaucoup du Thal $a$ mite Adméte; les six dents mitoyennes du front sont à peu pıès de même grandeur et beaucoup moins grosses que les externes, qui occupent l'angle interne et l'orbite; les pattes sont semblables à celles de la Thalamite Admete; on n'apercoit pas d'épines sur le bord inférieur de l'avant-dernier article de celles de la cinquième paire. Se trouve dans les mers de l'Asie.

\section{DEUXIEME SOUS-GENRE.}

\section{(Thalamites Hexagonales, Eow.)}

Bord fronto-orbitaire $n^{2}$ occupant pas plus des deux tiers de la largeur de la carapace, et formant un angle assez ouvert avec les bords latéro-antérieurs, qui sont armés de six à sept dents.

\section{THALAMITA GRUCIFERA.}

Edw., op. cit., t. I, p. 462. - Portunus Crucifer, Fabr., Suppl., p.364.-Portinus Crucifer, Latr., Hist, nat, des Crust., t.VI, p. 34. - Long. 4 pouc. - Les pattes des deuxième, troisieme et quatrième paires sont trés-aplaties et sillonnées sur les trois derniers articles; Ja carapace lisse, à peine ridée, est plus de deux fois moins longue que le bord fronto-orbitaire; le front est profondément échancré et armé de neuf grandes dents obtuses; les dents latérales de la carapace sont courtes, laiges ct comme tronquées; la première est échancrée au 
bout de manière à paraître bifide; les mains sont à peu près de la longueur de la carapace, et armées en dehors de quatre grosses épines; les pinces sont profondément cannelées et armées de grosses dents comprimées; le tarse des trois paires de pattes suivantes est étroit et lancéolé ; la ligne médiane des deux derniers articles des pattes postérieures ne présente pas d'élévation; la couleur est rougeâtre, avec des taches et des bandes jaunes, dont les médianes représentent une croix. - Se trouve dans l'Océan Indien.

\section{THALAMITE ANVCLATA.}

Eow., op. cit., t. I, p. 463.-Portunus. Annulatus, Farr., Suppl., p. 364; Latr., Hist. nat. des Crust., t. V I, p. 19.-Long, 2 pouces. - Les pieds des deuxième, tro:sième et quatrième paires sont cylindriques, marqués de quelques lignes longitudinales, et terminés par un article spiniforme; la carapace est lisse, les dents latérales sont spiniformes et toutes de même grandeur, excepté la dernière, qui est plus petite que les autres; les pinces sont armécs de dents tuberculeuses. - Se tronve dans l'Océan Indien et dans la Mer-Rouge.

\section{THALAMITA TIUNCATA.}

Ebw., op. cit., t. I, p. $463 .-$ Port $u$ nus Truncatus, Fabe., Suppl., p. 365.Latr., Hist. nal. des Crust., t. VI, p. 16. - Long. 2 pouc. - La face supérieure de la carapace est lisse, sans lignes saillantes, et légérement bombéc; son bord fronto-orbitaire égale presque son diamètre transversal; le front est arme de huit dents rudimentaires constituant les angles de quatre lobes tronqués; les dents du bord latéro antérieur de la carapace sont larges, tronquées, et si courtes qu'elles ont plutôt la forme de crénelures que de dents ordinaires. - Se trouve dans l'Océan Indien.

\section{THALAMITA CALLIANASSA.}

EDw., op. cit., t. I, p. 464. - Cancer Callianassus, Неn.вst, t. III, p. 54, fig. 7.Long. 1 pouc. - La carapace est fortement ridèe en dessus et très-large; le front est étroit. armé de huit dents, petites, aiguës, et également espacées; les bords latéroanterieurs sont courts et armés de dents étroites et pointues; les pattes antéricures sont granuleuses et hérissées d'épines courtes. - Se troure dans l'Océan Indien.
5. THALAMTA ERYTHRODACTYLA.

Edw., op. cit., t. 1, p. 364. - Portunus Erythrodactylus, Laß., op. cit., t. V, p. 259. - Long. 2 ponc. $\div$-La carapace est à peine ridée en dessus et trèsaplatie; les dents frontales sont longues et aiguës; les bords latéro-antérieurs sont armés de cinq grosses dents spiniformes et semblables entre elles, et de deux dents rudimentaires cachées dans les échancrures que les premières grosses dents laissent entre-elles; on n'aperçoit ni granulations ni tubercules entre les dents spiniformes, dont la main est armée. - Habite l'Australasie.

\section{PODOPHTHALMUS , Lam., Latr., LEach, Desm. , EDW.; Portunus, Fabr.}

Ce genre, qui a été établi par Lamarck aux depens du genre Portunus, est très remarquable par la longueur excessive des pédoncules oculaires. - La carapace a la forme d'un quadrilatère très-allongé dont les deux côtés latéraux seraient fortement tronqués; son diamètre antéro-postérieur n'égale pas la moitié de son diametre transversal; son bord antérieur, qui est presque droit, a environ quatre fois la lon. gueur du bord postérieur. - Le front est linéaire, et de chaque côté le bord antérieur de la carapace est creusé dans toute sa longueur, d'une gouttière profonde et très-large qui constitue les orbites. - Les yeux sont portés sur des pédoncules minces et d'une largeur extrême; ces pédoncules s'insèrent près de la ligne médiane du front, et póstent à leur extrémité la seconde piece oculaire. - Le bulbe oculaire n'est pas très-grand, et alteint l'extrémite latérale de la carapace. - Les antennes internes sont situees au-dessus de l'origine des yeux, et leur tige ne peut pas se dẻployer dans la cavitè qui les loge; les antennes externes se trouvent également audessus des yeux; elles sont placées entre les fossettes antérieures et les orbites, au côté externe des premières, et leur article basilaire se soude avec les bords de ces deux moitiés, de manière à compléter leurs parois ct à les séparer entre elles. - La tige mobile qui se termine aux antennes ect formée de deux petits articles pédonculaires et d'un filet multi-articulé, grêle et assez court. - Le cadre buccal est extrèmement large; il n'est séparé des fossettes antennaires que par un bord mince; 
son bord antérieur est environ deux fois aussi long que ses bords latéraux, et ceuxci se portent obliquement en arrière et en dedans. - Les pieds-mâchoires externes laissent entre eux un espace considérable, et leur troisième article est à peu près aussi large que long. - Les palles de la premiès e paire sont grandes, et se terminent par une main presque droite; les pattes suivantes sont beaucoup moins grandes que les antérieures, et celles de la troisième paire sont plus longues que les autres; l'article qui termine les seconde, troisième et quatrième, est styliforme et un peu aplati; les pattes de la cinquième paire sont trèsélargies et en forme de rames natatoires. L'abdomen, chez le mâle, est triangulaire, et se compose seulement de cinq pièces mobiles. - La seule espèce connue est le :

podophthalmus vigik. (Pl. 7 , fig. 1 .)

Leacir, Zool. Miscell., vol. II, tab. 118. - Guén., Icon. du Régne anim. de Cuvier, Crust., pl. 1, fig. 3.-EDw., op. cit., t, I. p. 467. - Portunus Figil, FaBr., Suppl. Ent. Syst., p. 363, no 1 . Podophthalmus Spinosus, LAM., Syst. des Anim. sans verteb., p, 152. - Long. 4 pouc. - La carapace, chez ce singulier Crustacé, est lisse et armée de chaque côté d'une forte épine qui est dirigée transversalement en dehors, et occupe l'angle externe de l'orbite; en arrière de cette dent, on en voit une autre beaucoup plus petite, mais dans le reste de son étendue, le bord latéral n'est que granulé ; les antennes externes sont beaucoup moins longues que les internes; les pattes de la première paire sont hérissées d'un grand nombre d'épines; on en voit trois sur le bord antérieur du bras, deux du côté externe du même article, deux sur le carpe, et deux sur la main; les pattes des trois paires suivantes ont le tarse cannelé; le cinquième article des pattes postérieures est grand et trèsélargi postérieurement; le dernier article est ovalaire et cilié sur les bords. - Se trouve dans l'Océan Indien.

M. Desmarets, dans son Histoire naturelle des Crustacés fossiles, a décrit et figuré, p. 88 , pl. 5 , fig. 6 et 8 , une espèce fossile de ce genre dont on ignore le gisement, et a laquelle il a donné le nom de Podophthalmus Francii, Dess.

\section{ORTHYTES.}

Cavité buccale ne se rétrécissant pas en pointe à sou sonmet; troisième article des pieds-mâchoires extérieurs triangulaire, allongé et pointu ; carapace presque orbiculaire, ovoïle et tronquée en devant; pinces comprimées, presque en crète à la tranche supérieure.

Genres: Matuta, Orithya.

MatuTa, Faer., Latr, Desh., Edw.

La carapace de ces Crustacés est déprimée, presque en forme de cœur tronqué en devant, avec les côtés arrondis antérieurement, dilatés, en forme d'épines fortes, saillans vers leur milieu, resserrés et convergens ensuite, vers leur extrémité postérieure.-Les yeux sont portéssur des pédoncules assez longs et logés dans des fossettes transverses. - Les antennes extérieures ou latérales sont beaucoup plus petites que les intermédaires et insérées près de leur base externe; le second article des pieds-mâchoires extérieurs est triangulaire, allongé, pointu, prolongé jusqu'aux antennes ou jusque sur le chaperon ; les derniers articles des mèmes pieds-mâchoires sont entièrement cachés par les articles précédens. La cavité buccale est terminée en pointe. - Les pinces des serres sont épaisses, tuberculées, dentelées et presque en crète; tous les autres pieds sont terminés en nageoires, mais leur forme varie; celles des deuxième, troisième et quatrième paires ont leur troisième article lamelleux et prolongé inférieurement en une crête triangulaire contre laquelle se replie le tarse. qui est large et lancéolé, tandis qu'aux pattes postérieures le prolongement lamelleux de ce pénultième article est arrondi et le tarse ovalaire; enfin l'abdomen du mâle ne se compose que de cinq articles distincts, dont le troisiẻme présente en arrière une crête transversale très-saillante.

\section{MATUTA LUVARIS.}

Leach, Zool. Misc., t. III, tab. 127, fig. 3-5. - Enw., op. cit., t. JI, p. 114 . - Matuta Planipes, Desu., Consid. génér. sur les Crust., p. 102. - Matuta Peronii, Guér., Iconog. du Rég. anim. de Cuvier, Crust., pl. 1, fig. 1.-Cancer Lunaris, Herbst, t. III, p. 43, pl. 48 , fig. 6. - Les épines latérales de la carapace sont généralement dirigées très-obliquement en avant; la ligne granuleuse du bord postérieur đe la carapace se prolonge jusqu'à la base de ces épines; les mains sont tuberculeuses plutôt que pennères; le traj. 

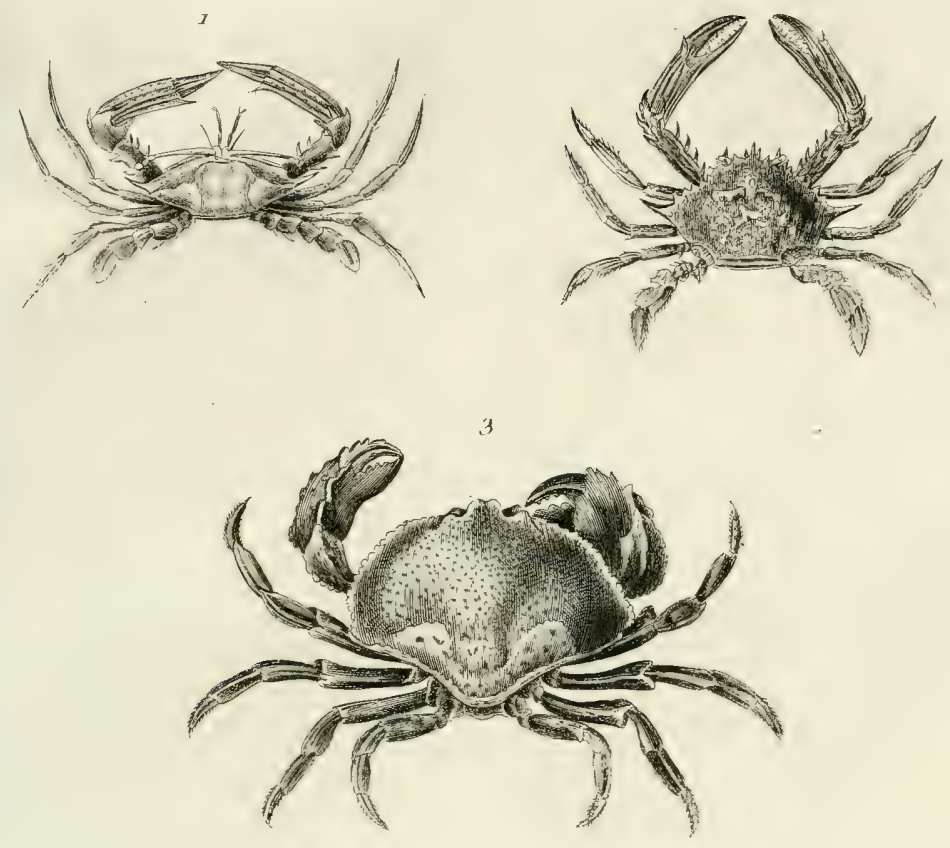

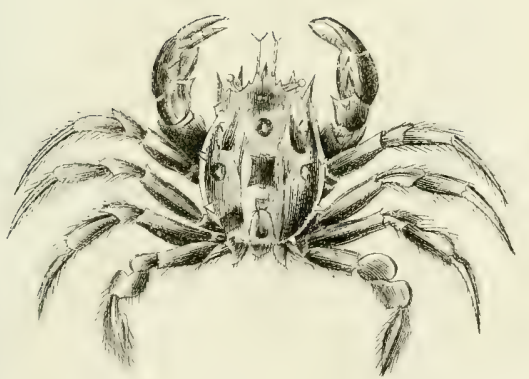

1. Podophthatmus vigil,

2. Lupa pelagica.

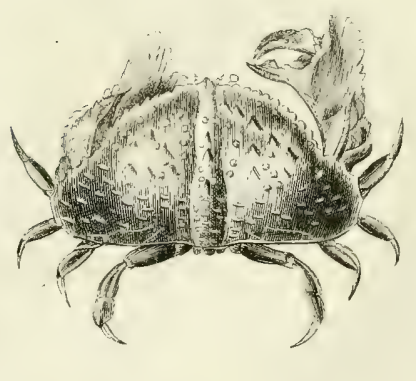

3. Hepatus fasciatus.

4.- Orithya mamillaris.

Calappa mbereulosa. 

sième article des pattes ae la quatrième paire est bicaréné ; la couleur est jaunâtre, avec une multitude de points rouges qui, sur la carapace, forment des lignes continues et décrivent des cercles plus ou moins irréguliers.

\section{MATUTA VICTOR.}

EDw.; op. cit., t. II , p. 115, pl. 20 , fig. 3, 6; ejusd., Allas die Règn. anim. de Cuvier, 3 e édit., Crust., pl. 7, fig. 1 , Matuta Victor, FABR., Suppl., p. 369. Matuta Victor, Latr., Encycl. méth., pl. 127, fig. 3, 4.-Matuta Lesueurii, LEACH, Zool. Misc., t. III, p.14.-Matuta Victor, Dessr., Consid. génér. sur les Crust., p. 101, $\mathrm{pl}_{4}$ 7, fig. 2. - Cancer Lateralis, Herbst, t. I, p. 140 , pl. 6 , fig. $44 .-$ Les épines latérales de la carapace sont tantôt droites, tantôt plus ou moins obliques; la ligne granuleuse du bord postérieur de la carapace s'arrête au tubercule situé sur la région branchiale, à quelque distance de cette épine; généralement le bord extérieur de la main présente deux grosses épines et même quelquefois trois; de plus il y a une carène sur le troisième article des pattes de la quatrième paire; la couleur est jaunâtre, avec une multitude de points rouges épars et ne formant pas de lignes continues.

ORIthya, Latr., Fabr., Desm., Edw; Cancer, Heksst.

La carapace est presque ovoïde, rétrécie et largement tronquée en devant; les orbites sont très-grandes; les yeux sont portés sur un pédoncule assez long, grêle et cylindrique. - Les antennes extérieures sont plus courtes que les intermédiaires, et sétacées; le premier article fort long, cylindrique, les autres très-nombreux et fort petits; les intérieures ou les intermédiaires une fois plus longues, repliées, de quatre articies, dont le second et le troisième plus longs: ce dernier très-court, subulé, bitide; le troisième article des pieds-mâchoires extérieurs est triangulaire, étroit, allongé et pointu au bout; les serres sont épaisses, éşales, assez courtes. - Les pieds des trois paires suivantes sont terminés par un article ou ongle droit et pointu ; ceux de la troisieme et de la quatrième les plus larges de tous; les pieds de la cinquième paire sont terminés par une lame natatoire, ovale et ciliée sur ses bords. - La queue est courte, sans feuillets natatoires au bout, et offre sept segment distincts; ce genre renferme nne seule espèce, qui est :

orithya manhllaris. (Pl. 7, fig. 4.)

Latr., Hist. nat. des Crust. et des Ins., t. VI, p. 130, pl. 50.-Génér. Crust. et Ins., t. I, p. 12. - Desr., Consid. génér. sur les Crust., p. 141, pl.19, fig. 1. - EDw., Régn, anim. de Cuvier, Atlas, pl. 8, fig. 1.-Fabr., Suppl. Ent. Syst., p. 363. - Guér., Icon. du Règn. anim. de Cuvier, Crust., pl. 1, fig. 2. - Cancer Bimaculatus, HenBst, t. I, p. 248 , pl. 18 , fig. $101 .-$ Long. 2 pouc. - La carapace est bosselée et garnie de trois rangées longitudinales d'élévations mamillaires, dont les deux latérales sont divergentes postérieurement; le front est armé de cinq dents spiniformes, dont une au milieu du bord supérieur de l'orbite, et une autre beaucoup plus forte à son angle externe; de plus, on aperçoit deux petites fossettes sur la portion antérieure du bord latéral de la carapace, et trois très-fortes sur la portion postérieure ; une petite crête terminée par une dent sur le bord supérieur du bras, et une dent spiniforme trèsforte à sa face inférieure; trois pointes, dont une grande sur le carpe et deux autres sur le bord supérieur de la main; une épine à l'extrémité du bord inférieur du deuxième article des pattes suivantes, et une seconde plus petite à l'extrémité du bord supérieur du troisième article des pattes des deuxième, troisième et quatrième paires. - Se trouve dans les mers de la Chine.

QUATRIEME TRIBU.

\section{LES CHRISTIMANES, LATREILLE.}

Caractéres: Par la forme générale de leur test, les Crustacés qui composent cette tribu ont beaucoup d'analogie avec les Crabes et les Atélécycles, de la tribu des arqués.-La queue est aussi composée de même, mais la cavité buccale va en se rétrécissant vers son extrémité supérieure, ainsi que le troisième article des pieds-mâchoires extérieurs, dont la figure est aussi plus ou moins triangulaire. - Les pinces sont fortes, élevées, comprimées, et dentées en manière de crête à la tranche supérieure, ainsi que les autres pieds; elles sont toujours à découvert. - Cette tribu comprend un seul groupe, celui des $H_{\dot{e}}$ patites. 


\section{HEPATTES.}

Ce groupe renferme trois genres: $\mathrm{He}^{\dot{ }}$ patus, Mursia et Platymera.

\author{
HEPATUS, LATr., Enw.; \\ Calappa, Fabr.
}

La carapace est plus large que longue, évasée en segment de cercle en devant, rétrécie postérieurement, avec ses bords latéro-antérieurs munis d'un grand nombre de dentelures. - Les yeux sont assez rapprochés, petits, portés sur des pédoncules courts et logés chacun dans une cavité presque oṛbiculaire. - Les antennes extérieures sont excessiv ement petites, coniques, insérées à la base des pédoncules oculaires; les intérieures logées dans deux fossettes obliques qui sont situées au-dessus du front. - Les pieds-mâchoires extérieurs sont très-semblables à ceux des Leucusies, appliqués exactement l'un contre l'autre; leur troisieme article ayant une forme triangulaire, et se terminant en pointe. Les pinces sont grandes, aplaties, ayant leur tranche supérieure comprimée, el dentée en forme de crète; les autres pieds sont rerminés par un article aigu, ambulo. toire, et diminuant progressivement Iongueur depuis la seconde paire jusqu id cinquième. - La queue, en forme de triangle étroit et allongé, est composé de sept tablettes chez les mâles; chez les femelles cette queue est trés-étroite; les tablettes qui la composent sont très-larges, surtout les quatrième, cinquième et sixième; la seplième et très-étroite et terminée en pointe à sa base.

nepatus Fasciatus. (Pl. 7, fig. 3.)

Latr., Hist. nat. des Crust. et des Ins., t. V, p. 98.-Desw., Consid.génér. sur les Crust., p. 407, pl. 9, fig. 2. - Evw., op. cit., t. II, p. 117; ibid., Atlas du Règ. anim. de Cuv., Crust., pl. 15, fig. 2.-Calappa Angustata, FABr., Suppl., p. 347. - Cancer Princeps, Hendst; t. II, p. 154, pl. 38, fig. 2..-Cancer Princeps et Calappa Angustata, Bosc, op. cit., t. I, p. 175 et 184. - Long. 2 pouc. $\frac{1}{2}$. - La carapace est peu convexe, presque unie. - Le front est droit et comme tronqué, graveleux au bord antérieur; les bords latéro-antérieurs sont assez fréquemment crénelés; les tarses et la poitrine sont couveris d'un duret noiràtre. La couleur générale est jaunâtre, avee des points rouges très-nombreux sur le dos, qui se changent en petites lignes postérieurement; les quatre dernières paires de pattes sont marquées de bandes transverses également rouges; les doigts des serres sont noirâ'res. - Se trouve sur les côtes dẹ l'Amérique du Nord et de Saint-Domingue.

mursia, Leach, Desh., Latr., Edw.

La carapace est presque circulaire, et ne se prolonge pas en forme de bouclier audessus des pattes ambulatoires; sa face supérieure est bombée' et inégale, et vers le milieu du bord latéral se trouve une longue dent spiniforme. - Le front est triangulaire, a vec les orbites presque circulaires. Le troisième arțicle des pieds-mâchoires externes est aussi long que le second, et a la forme d'un carré-long, dont l'angle antèrieur cependant est très-oblique, et donne insertion a l'article suivant vers son tiers externe. - Le plastron stemal est étroit et allongé. - Les pattes antérieures ont à peu près la même forme que chez les Calappes, et les mains, garnies en dessus d'une crête élevée, s'appliquent aussi contre la bouche, de manière à sé cacher sous la partie antérieure du corps; les pattes suivantes sont longues et de force médiocre; le tarse qui les termine est styliforme, cannelè et trèslong. - L'abdomen du mâle ne présente que cinq segmens mobiles,

\section{IURSIA CRISTATA,}

Drsar., Consid. Géner. sur les Crust., p. 108 , pl. 9, fig. 3.-Latr. Rég. anim. de Cuvier, 2 e èdit., i. IV, p. 39. - EDw. op. cit., t. II , p. 109 ; ibid., Allaș du Reg. anim. de Cuvier, Crust., pl. 13, fig. 1 et $1, a$. - Long. 2 pouc. - La carapace est inégale, et garnie en dessus de plusieurs tubercules. saillans, dont les principaux forment une rangée transversale se. mi-circulaire et trois rangées longitudinales dont une médiane, et les deux autres placées sur les régions branchiales; le front est armé de cinq petites dents ; le borci latéral de la carapace présenie une dizaine de petites dents, lesquelles sont suivies d'une dent très-forte et très-aigüe qui se dirige en dehors; il y a une ou deux épines très-fortes à l'extrémité de la face externe des bras, et dix ou douze dents de même forme, mais moins longues, sur la face externe des mains; le bord supérieur de celles-ci est très-élevé, mince et découpé en dents de scie; leur bord inférieur est également dentelé; couieur blanchâtre lavée de rouge. 

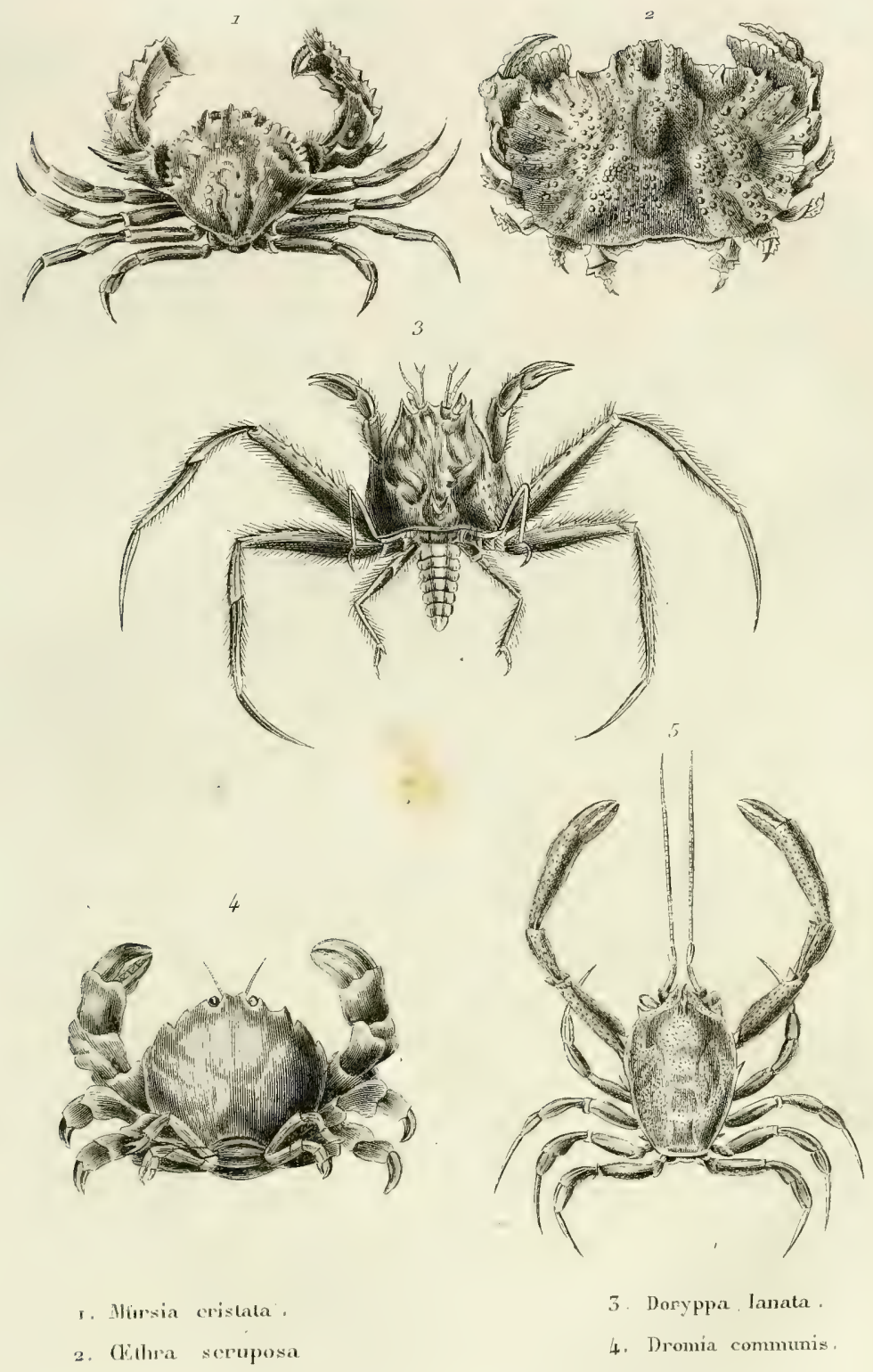

5. Corvstes dentalus. 

PLATYMERA, EDw.

La carapace est très-large, et assez régulièrement elliptique; seulement, de chaque côté elle se prolonge en une forte dent spiniforme; ses bords latéro-postérieurs ne se prolongent pas au-dessusdes pattes. - Le front est triangulaire. - Les orbites sont ovalaires, profondes et de grandeur médiocre; on remarque une fissure au milieu de leurbord inférieur. - Les antennesinternes et externes sont comme dans le genre précédent. - Le cadre buccal est beaucoup plus large antérieurement, et la petite portion de l'espace prélabial qui dépasse les piedsmâchoires externes n'est pas divisée par une cloison médiane, et n'est qu'imparfaitement recouverte par les prolongemens lamelleux des pieds-mâchoires externes. L.es pieds-mâchoires externes sont très-larges antérieurement; leur troisième article, de la Jongueur du second, se termine par un bord antérieur assez large. et présente, audessus de son angle antérieur et interne, une grande et profonde échancrure, dans laquelle s'insère le quatrième article; ce dernier est à découvert et tiès-grand; mais il n'arrive pas au niveau de l'extrémité antérieure du troisième article. - L'appen. dice basilaire de ces organes est lamelleux, très-grand et semi-lunaire. - Le plastron sternal est ovalaire. - Les pattes de la première paire sont longues et peu élevées; les suivantes sont très-longues et très-comprimées; leur troisième article est très-large et presque lamelleux. - Les tarsessont longs et styliformes. - Les pattes de la troisième paire sont un peu plus longues que les secon. deset les quatriemes; les cinquiemes sont les plus courtes de toutes.-- L'abdomen du mâle se compose de cinq arlicles distincts, dont Je troisième présente en arricire une crêtc transversale très-forte.

Píatyma gaudichaddi.

EDw., op., cit.. t. II, p. 108. - Long. 3 pouc. - La carapace est légérement convexe, inégale, finement granulée; le front est petit, tridenté; les bords latésoantéricurs de la carapace sont garnis d'une quinzaine de petites dents obtuses, qui les font paraitre comme fesionnées; les dents latérales sont très-fortes; les mains sont su:montées d'une grande crête dentelée, et garnies sur leur face externe d'une rangée de tubercules; le carpe présente quelques points; le bord supérieur des pattes suivantes est granuleux; le sternum du mâle est armé de chaque côté d'une grosse dent, près de la base des pattes antéricures; la couleur est rougeâtre. - Se trouve sur les côtes du Chili.

\section{CINQUIEME TRIBU.}

\section{LES CRYPTOPODES, LATREILLE.}

Caractéres. Tous les pieds, à l'exception des serres, peuvent se retirer sous deux voûtes formées, une de chaque còté, par les dilatations latérales et postérieures du test, de sorte que, lorsqu'on considere l'animal par le dos dans un moment de contraction, on ne voit aucun de ses organes; car il applique aussi ses serres sur la face antérieure du corps; il peut a'autant mieux les cacher, que la tranche supéricure des pinces forme, par son élévation, sa compression et les dentelures de son bord, une crète ; aussi $\mathrm{a}-\mathrm{k}$-on nommé ces crustacés Ceq de mer, Crabe honteux; lout le contour du test est le plus souvent incisé ou denté; la disposition et la forme de ses dents, ainsi que la configuration des serres, indiquent l'affinité de ce genre avec les précédents.

Cette tribu est composée de deux groupes: les Calappites et les Cryptopodites.

\section{GALAPPITES.}

Tous les Crustacés renfermés dans ce groupe sont remarquables par la forme de leur carapace, el surtout celle des pieds antéricurs; tous généralement sont d'une taille assez grande.

Geures: Calappa, Crypt osoma.

$$
\text { CALAPPA, Fabr., Edw. }
$$

La carapace est courte, convexe, plus large postérieurement qu'antérieurement, et formant en arrière une voủte sous laquelle sont cachées les pattes postérieures dans le repos..- Les yeux sont portés sur des pédoncules courts, peu éloignés l'un de l'autre. - Les antennes externes el in. ternes sont sernblables a celles des Crabes proprement dits. - Le troisième article des pieds-mâchoires extérieurs se termine en pointe. - Les pinces sont égales, tresgrandes, comprimées, ayant leur tranche supéricure très-élevée, en crête, s'adaptant parfaitement aux bords extérieurs du test. de manière à couvric toute la région de la 
bouche. - Les autres pattes sont courtes et simples.

Les Calappes, dit M. Roux, ont dansleur démarche une sorte de gravité qui, jointe à l'èclat de leurs couleurs et à la singularité de leur forme, en a fait un de nos plus beaux Crustacés. Ils montrent autant de fermeté dans le danger, que de courage dans leurs entreprises, et ne se laissent pas facilement intimider lorsqu'ils out une proie en vue ou qu'ils font une curée; mais lorsqu'on les saisit, et que le péril leur parait imminent, ils retirent leurs pattes sous leur test, et, semblables à des boules, se laissent tomber au fond des eaux, sans nager ni faire aucun mouvement. Ces Crustacés se tiennent ordinairement dans les fentes des rochers profonds qui bordent İes côtes. C'est vers le crépuscule qu'ils vont à la recherche des mollusques dont îs se nourrissent. L'époque de leur reproduction, ainsi que l'a remarqué $M$. Risso, est vers le printemps. Leurs œufs sont d'un jaune doré; leur chair est assez bonne, et n'a aucune odeur désagréable.

Ces Crustacés sont voraces; ils habitent les fentes des rochers, et ne s'approchent que des rivages qui avoisinent de grandes profondeurs. On en connait neuf espèces environ, dont huit vivent dans les mers d'Amérique et dans les Indes Orientales; une seule se trouve dans la Méditerranée.

\section{Galappa granulata.}

Roux, Crust. de la Méditer., pl. 2, fig. 1.-Fabr., Suppl., p. 346. - Latr., Hist. nal. des Crust. et des Ins., t. Y, p. 392, pl. 45, fig. 1, 2.-EDw.; op. cit., t. II, p. 104. - Le test de cette espece est large, très-bombé, traversé par quelques sillons longitudinaux; entre chacun de ces sillons sont des protubérances tuberculeuses d'un rouge carmin ; le front est terminé par deux petites élévations ; les bords sont découpés par sept dents, dont trois courtes et robustes et quatre plus fortes et aiguës vers l'angle postérieur, avec deux autres petites tout-à-fait en arrière; la région hépatique postérieure et les pinces sont forifment granulées; celles-ci dentelées en crête, poilues sur leurs bords, aplaties et épaisses; une belle couleur de chair s'éiend sur ce Crustacé; les bords latéranx et postérieurs de la carapace sont jaunes, de même que les pattes; l'extrémité des ongles est brune; le dessous du corps est d'un blanc d'émail ; la femelle est quelquefois moins colorée que le mâle.
Cetle espèce se trouve sur toutes les côles rocailleuses baignées par la Mer Méditerranée.

\section{CALLAPA GALLUS.}

EDw., op. cit., t. II, p. 105. - Cancer Gallus, Herst., t. III, p. 46 , pl. 58 , fig. 1.-Long. 2 pouc. - La carapace, beaucoup moins large que dans l'espèce précédente, est très-élevée, et couverte de gros tubercules inégaux; le front est entier et triangulaire; les dents du bord postérieur de la carapace sont à peine saillantes, avec les prolongemens clypéiformes grands. Se trouve sur les côtès de l'lle-de-France.

\section{Calappa cristata.}

Latr., Hist, nat. des Crust. et des Ins., t. V, p. 394. - Eəw., op., cit., t. II, p. 105, pl. 20, fig. 1. - FaBr., Suppl., p. 346.-Cancer Circumspectus, Herbst, t. II, p. 162 , pl. 40 , fig. 3.-Long. 2 pouc. - La carapace est mediocrement large et garnie en dessus de gros tubercules, dont les principaux forment cinq rangées longitudinales; Te front est bidenté; les bords latéro-antérieurs de la carapace sont finement dentés; de plus, il y a troís grosses dents pointues dirigées $\mathrm{e} . \mathrm{z}$ avant sur la partie postérieure du bord latéral, et trois autres dirigées en arrière de chaque côté de la dent mediane du bord postérieur.-Se trouve dans les mers d'Asie.

4. CAI appa tuberculosa. (Pl. 7, fig. 5., Fabr., Suppl., p. 345.-Herist, pl. 13, fig. 78. - Bosc, op. cit., t. I, p. 183.Latr, , Hist. nat. des Crust. et des Ins., t. 1, p. 293. - Desir., Consid. génér. sur les Crust., p, 109, fig. 1.-GuéRIN, Icon. du Reg. anim. de Cuvier, Crust., pl. 12, fig. 2.-EDw., op. cit., t. II, p. 106. La carapace est bombée et granuleuse en dessus; il y a une douzaine de dents triangulaires et bien distinctes sur son bord latéro-antérieur, et quatre dents larges, plates, et pointues sur la portion antérieure des prolongemens clypéiformes, qui sont trèsgrands; la face externe des mains est tuberculeuse, mais sans épines; la couleur est blanchâtre.--Se trouve dans l'Archipel indien.

M. Brullé a établi, sous le nom de Cryptosoma, un nouveau genre de Crustacé qui vient se placer naturellement après celui de Calappa ; il se distingue de ce dernier par la carapace, qui est presque circulaire; par la longueur plus considérable du troisième article des pieds-mâchoires externes, et sur- 
tout par les tarses, qui, aux pattes posté. rieures, sont de forme sublancèolée.

L'espèce type de cette nouvelle coupe générique est le Cryptosoma Cristata, Brullé. Cette espéce sera décrite et figurée dans le voyage de $\mathbf{M M}$. W ebb et Berthelot aux Canaries.

\section{GRYPTOPODITES.}

Les espèces comprises dans ce groupe sont remarquables par leur carapace, qui est peu bombèe, très-èlargie sur les côtés latéraux, et cachant presque entièrement les organes de la locomotion.

Genres: : Ethra, Cryptopodia.

$$
\begin{gathered}
\text { EThra, Leach., Lam, Latr., Edw॰; } \\
\text { Cancer, Linn. }
\end{gathered}
$$

La carapace est d'un tiers plus large que longue, et a la forme d'un ovale assez régulier; elle est fortement bombée en dessus, et ses bords latéraux sont dentelés et recourbés un peu en haut. - Le front est entier et un peu plus saillant au milieu que sur les côtés. - Les yeux sont très-petits, et les orbites presque circulaires; leur bord supérieur présente deux pelites fissures, et le bord inférieur est séparé du front par un hiatus très-large. - Les fossettes antennaires sont presque carrées, et l'article basilaire des antennes internes les remplit presque en entier; enfin la lige mobile de ces appendices est extrêmement petite et se replie longitudinalement en avant. - L'article basilaire des antennes externes est très-grand, et s'avance jusqu'au bord inférieur du front, de facon à remplir l'hiatus; son extrémité antérieure est très étroite, et se trouve sur le niveau du bord orbitaire inférieur; le second article des antennes externes est très-petit; il occupe le canthus interne des yeux. - Les pieds-mâchoires externes ferment complétement le cadre buccal. - Le plastron sternal est beaucoup plus long que large, et les pattes antérieures ont environ une fois et quart la longueur de laportion post-frontale de la carapace.Leur face supérieure et interne est légérement concave, de manière à pouvoir s'appliquer exactement contre les portions inferieure et antèrieure du tronc. - Les pattes de la seconde paire sont beaucoup plus courtes que la portion post-frontale de la carapace, et les suivantes diminuent successivement de longueur; toutes sont sur. montées d'une crête tranchante et inégale, et leur tarse est court et styliforme. - L'abdomen se compose de sept articles chez la femelle, et de cinq seulement chez le måle.

Les Fthres habitent l'Océan Indien et les mers d'Afrique; on ne connait encore qu'une seule espèce.

AETHRA SCRUPOSA. (Pl. 8, fig. 2.)

EDw., op. cit., t. I, p. 371. - Cancer Scruposus, Linn., Mus. Ent., Ins., p. 450. - Ethra Depressa, Lam., Guérin, Icon. du Règ. anim. de Cuv., Crust., pl. 12, fig. 6. - La région stomacale est renflée et creusée en avant d'une gouttière longitudinale qui se prolonge jusqu'au front; la carapace présente de chaque côté dix à douze dentelures en forme de plis; le bord inférieur des pattes de la première paire est armé de dents spiniformes plus distinctes que celles qu'on voit aux pattes suivantes; la couleur générale est grisâtre.-Se trouve dans les eaux de l'Ile-de-France et del'Archipel Indien.

\section{CRYPTOPODIA, EDW.}

Ce nouveau genre, qui a été établi par M. Edwards, offre beaucoup d'analogie avec le genre Athre. - La carapace est légérement bombée, et a la forme d'un triangle très-large, très-court et à base arrondie. - Le ventre est triangulaire, horizontal et assez avancé. - Les yeux sont trèspetits et complétement rétractiles.-Les antennes internes ont la même forme que chez les Ethres; leur premier article est quadrilatère et plan, et leur tige se déploie presque longitudinalement. - Le premier article des antennes est très-petit; le second est un peu plus long et atteint jusqu'au front; le troisième cst logé presque en entier dans la fente qui existe entre le front et l'angle interne du bord orbitaire inférieur; la tige terminale, qui naît aussi du canthus interne des yeux, est extrêmement courte. - L'épistome est un peu plus large que long ; le second article des pieds-mâchoires externes se termine par un bord presque droit; et le troisième, qui est carré, présente en avant une échancrure. - Le plastron sternal est beaucoup plus long que large. - Les pattes de la première paire sont très-grandes, et à peu près prismatiques; celles des quatre dernières paires: sont très - petites et presque de même longueur; elles dépassent à peine la voûte dé la caraoace, qui les recouvre. - L'abdo. 
men, chez la femelle, est composé de sept articles.

L'espèce type de ce genre est la :

\section{CRYPTOPODA FORMICATA.}

Enw., op. . cit., t. I, pag. 362. Cancer Formicalus, Fabr., Ent., Syst. , t. II, pag. 453. - La carapace est lisse en dessus et dente'ée sur les bords; le ventre est entier, aussi long que large; les pattes antérieures sont environ une fois et demie aussi longues que la carapace; leur troisième article est très-dilaté postérieurement, et armé d'épinessur le bord antérieur; Ies mains sont armées en deśsus d'une forte rangée d'épines; les pattes des quatre dernières paires sont garnies en dessus et en dessous d'une crête dentelée presque tout le long de leur troisième article. - Se trouve dans l'Océan Indien.

\section{DEUXIEME DIVIŚ́ON.}

La situation des deux ou quatre pieds postérieurs, qui, insérés sur le dos ou au-dessus des autres, sont tournès vers le ciel, distingue très bien cette division de la précédente, et même de tous les autres Cruslacés, à l'exception des Homoles. Au moyen de cette disposition des pieds et du crochet aigu de leur extrémilé, ces animaux peuvent se tenir et fixer sur leur dos divers corps marins, comme des alcyons, des éponges, et jusqu'à des valves de coquilles, et tromper ainsi leurs ennemis. - Cette division ne comprend qu'une seule tribu.

\section{SIXIEME TRIBU.}

\section{LES NOTOPODES,}

\section{Latreille. i}

Caractéres. Le test est orbiculaire, ovoïle ou globuleux. - Les dernières paltes sont siluées sur le dos.

Cette tribu renferme deux groupes: les Dromites et les Dorippites.

\section{DROMITES.}

Les Crustacés renfermés dans ce groupe sont généralement d'une taille assez grande; ils se trouvent à des profondeurs très-considérables, et souvent ils se recouvrent d'une éponge ou d'un alcyon, qu'ils fixent sur leur dos au moyen de leurs pattes postérieures.

Genres : Dromia, Dynomene.

\author{
DROMia, Fabr., Iatr., Edw.; \\ Cancer, LINN.
}

La carapace est ovale, arrondie, trèsbombée, découpée sur les bords antérieurs, velue ou hérissée, ainsi que les pieds et les serres. - Les yeux sont petits, portés sur de courts pédoncules, assez rapprochés, et logés dans des fossettes orbiculaires ou cylindriques. - - Les antennes extérieures sont petites, insèrées au-dessous des pédoncules oculaires; les intermédiaires sont placées au-dessous et un peu en dedans des yeux. - Les pieds-mâchoires extérieurs présentent leur troisième article presque carré, qui est légérement échancré à son extrémité el en dedans. - Les pinces sont grandes, fortes, et égales. - Ĺes pieds de la seconde et de la troisième paire sont terminés par un article simple et plus grand que ceux de la quatrième et de la cinquième paire, qui sont relevés sur le dos et pourvus d'une pince, parce que leur dernier article, qui est arqué et pointu, est opposé a une épine à peu près de même forme qui termine l'avant-dernier article. La réunion de ces deux épines, qui constitue une sorte de pince, parait avoir pour usage de saisir divers corps étrangers pour les fixer sur leur dos. Ces Crustacés, assez indolents dans leur demarche, vivent dans les lieux où la mer est médiocrement profonde, et ils choisissent pour leur habitation les endroits où les rochers ne sont pas cachés sous la vase. On les troure presque toujours recouverts d'une espèce d'alcyon ou de valves de coquilles, qu'ils retiennent avec leurs pieds de derrière, et dont ils semblent se servir comme d'un bouclier, qu'ils opposent aux attaques de leurs cnnemis. Lesalcyons, qui sont en général de l'esjeece appelee Alcio. nium Domoncuta, continuent même à s'é. tendre et à se développer sur leur carapace, qu'ils finissent par cacher entièrement. $\mathrm{Au}$ mois de juillel, suivant M. Risso, les femelles sortent de l'état d'engourdissement qui leur est ordinaire, et se rendent près des bas-fonds pour y déposer un très-grand nombre d'œufs. On connaît plusieurs espéces de Dromics; parmi les plus remarquables nous citerons :

1. oroma communs. (Pl. 3 tig. 4.) Ediv., op. cit., t. II, p. 173, pl. 21, fig. 5, 8.- Esusd, Atlas du Rég. Anim. de Cuv., Crust., pl. 40, fig. 1. -- Cancer Dromia, Oliv, Zool., ADR. p. 45,-Dromia Rumphii, 
Bosc., Hist. nat, des Crust., t. I, p. 229. LAM., Hist. nat. des Anim. sans vert., t. V, p. 264.- Desm., Consid.gén. sur les Crust., p. 137.-Buainvilue, Faun. Franc. Crust., pl. 7, fig. 1.-Risso, Hist. de l'Europe mérid., t. V, p. 32.-Long. 2 à 3 pouc. -La carapace est fortement bosselée en dessus; le fiont est armé de trois grosses dents obtuses, qui, par les progrès de l'âge, deviennent de simples bosses arrondies; il y a une fissure au-dessus de l'angle externe des orbites, ct une assez grosse dent trèssaillante au bord inférieur de cette cavité; res bords latéro-antérieurs de la carapace sont armés de quatre grosses dents, dont la première est située beaucoup au-dessous du niveau des orbites, dont la seconde présente à sa base un tubercule, de manière à paraître double; dont l'avant-dernière, quoique peu saillante, occupe presque autant de place que les deux précédentes réunies, et dont la dernière est assez petite; les bords latéro-postérieurs sont à peu près de même longueur que le bord latéro-antérienr; les pattes antérieures sont très-noduleuses; le bord supérieur de la main présente plusieurs petites dents coniques; les pattes suivantes sont grosses et courtes; les tarses sont conicques, crochus, et armés en dessus d'une rangée de grosses épines; l'abdomen du mâle est bombé au milieu, mais sans gouttières latérales; le dernier article est beaucoup plus large que long; et les deux articles précédents sont distincts entre eur; les poils sont courts, serrés et claviformes, surtout dans.les individus qui ne sont pas cncore parvenus à l'âge adulte; la couleur est brun-foncé, et les pinces sont légérement teintées de rose.-Se trouve dans la Méditerranée et dans l'Océan.

\section{DROMIA RUMPHIT.}

Fabr., Suppl., p. 359.-Latro, Hist. nat. des Crust. et des Ins,, t. V, p. 386. - EDw., op. cit., t. II, p. 174 . - Cancer Lanosus, Ruмpн., Mus., t. II, fig. 1. - Cancer Dromia, Lins., Aman. Acad., t. VI. - Cancer Dorminator, Hersst. , t. I, p. 250 , pl. 18, fig. 103. - Long. 2 pouc. - La carapace est tris. bombée et sans bosselures notables; le front est saillant et armé de trois dents coniques, très-pointues et également saillantes;l'angle orbitaire externe est très-échancré; la dent orbitaire inférieure est petite; les bords latéro-antérieurs sont armés de quatre grosses dents peu saillantes, de même forme et de même dimension; le bord supé-

ANN. rieur de la main présente une ou deux petites dents; les pattes des deuxième et troisième paires sont plus longues: et plus grêles que dans les espèces précédentes; leur tarse est styliforme, peu courbé, et armé en dessous d'épines trés-petites; l'abdomen du mâle est étroit et creusé de chaque côté par une goutière longitudinale bien distincte; ce dernier article est beaucoup plus long que large, et les deux précédens sont presque entièrement soudés cntre cux; les pièceslatérales sont très-petites chez le mâle, plus longues et plus fines chez la femelle; les poils sont courts, gros et serrés; la couleur générale est brune. - Se trouve dans les Indes Orientales.

\section{DROMIA HIRTISSIMA.}

LaM., Hist, nat. des Anim. sans vert., t. V, p. 264.-Desm., Consid. gén. sur les Crust., p. 137, pl. 18, fig. 1.-Eow., op. cit. , t. I1, p. 176. - Long. 2 pouc. - La carapace est très-large; le front est avancé, profondément sillonné sur la ligne médiane, et ayant les bords latéraux très-relevés; les orbites sont avancées, armées à leur angle exlerne d'une dent pointue, au côté externe de laquelle se trouve une épine; le bord latéro-antérieur de la carapace est con. cave dans sa moitié antérieure, el armé d'une forte dent triangulaire; il y a une petite dent obtuse au milicu de sa portion convexe, et une troisième plus saillante au delà du sillon qui sépare ce bord du bord latéro-postérieur; les pattes antérieures sont médiocres; la main est très-déprimée en dessus; tout l'animal est couvert (excepté l'extrémité des pinces) d'un duvet très-court, cachè sous de longs poils jaunâtres, peu serrés. - Se trouve au cap de Bonne-Espérance.

\section{DROMIA CAPUT MORTUUM.}

Latr., Coll, du MIus. - EDw., op. cit., t. 1I, p. 178. - La carapace est très-bombée et lisse; le front est peu saillant; la dent médiane est rudimentaire; il y a un lobe arrondi au-dessus de l'angle orbitaire interne ; l'angle orbitaire externe est assez saillant; la dent orbitaire inféricure est trèsobtuse; les bords latéro-antérieurs sont régulièrement convexes et armés de quatre dents arrondies, peu saillantes; les bords latéro-postérieurs sont courts et peu convexes; les pattes sont á peine noduleuses.Se trouve dans l'Océan Indien.

DYNOMENE, Latr., Desm., EDw.

Ce genre a beaucoup d'analogie avec ce. 
lui de Dromie : ses caractères sont, suivant M. Latreille, d'avoir les deux pieds postérieurs beaucoup plus petits que les autres, lesquels sont seuls dorsaux et mutiques. Le test est érasé, presque en forme de cœur, renversé et tronqué postérieurement. - Les pédicules oculaires sont un peu plus larges que ceux des Dromies. On n'en connait qu'une seule espèce, qui est :

\section{DYNOMENE HISPIDA.}

Desir., Consid. gén. surles Crust., p.133, pl. 18, fig. 2.-Latr., Règ. Anim. de Cuv., $2^{\mathrm{e}}$ édit., t. IV, p. 69. - EDw., op. cit., t. II, p. 180. - IвID., Rég. anim. de Cuv., Crust., 3 édil.,pl. 40, fig. 2.-Guér., Icon. Crust., pl.14, fig. 2.-Long. 7 lig. - La carapace est plus large que longue, arrondie et finement dentelée sur les côtés latéro-antérieurs; les pinces sont courtes, avec leurs doigts élargis à l'extrémité; les pattes sont assez robusies, surtout la troisième paire; la quatrième est peu allongée et très-grêle; le corps de cette espèce est entièrement couvert de poils roux. - Se trouve à l'lle-deFrance.

\section{DORIPIITES.}

Les Crustacés que comprend ce groupe ont la carapace trés-déprimée, tronquée en avant, un peu élargie en arrière, et presque quadrilatère; les pattes antérieures sont courtes; celles des deux paires suivantes sont terminees par un article styliforme; celles des deux dernières paires s'insèrent sur le dos, et sont toujours beaucoup plus petites que les précédentes.

Genres : Cymopolia, Caphyra, Etusa et Dorippa.

\section{CYMOPOLIA, Roux. Edw.}

Ce genre, qui a été établi par M. Roux, est ainsi caractérisé par cet auteur : la carapace est déprimée, plus large que longue, tronquée, épineuse en avant et sur les parties latérales antérieures, sinueuse et rebordée en arrière, ayant la surface marquée de bosselures, de tubercules et de nombreuses rugosités. La partic inférieuse du test est creusée pour recevoir l'abdomen. - Les yeux sont placés sur un pédoncule très-court, insérés à l'extrémité antérieure et latérale du test, qu'ils n'atteignent point. - Les antennes extérieures sont insérées sur la même ligue que lesintermédiaires, sous le chaperon, auprès des yeux, celles-ci repliées, se logeant dans les cavités propres à les recevoir; les premières ont leur premier article anguleux el lobé, le dernier sétacé; le premier article des intermédiaires est gros et renflé, le dernier estbifide.-Les pieds-mâchoires extérieurs sont ciliés, avec le deuxième article échancré intérieurement, et le troisième extérieurement. - Les pinces sont inégales, courtes, rugueuses, la droite constamment plus grosse que la gauche; le deuxième article est contourné, légérement carèné; chez les femelles elles sont un peu moins grosses. - Les pieds de la première paire sont courts; ceux de la seconde et de la troisième sont les plus longs. presque égaux; les uns et les autres sont trés-aplatis, à carène aiguë, membraneuse; la quatrième paire seulementest très-courte, grêle, arrondie, relevée sur le dos, et terminée par un ongle peu crochu. - Enfin, l'abdomen est replié et composé de six articles dans les deux sexes--La seule espèce connue est la :

\section{CYMOPOLIA CARONIT.}

Roux, Crust. de la Méditerr., pl. 21, fig. 1. - Edw., op. cit., t. 2, p. 159. - Le front est quadridenté; les côtés sont armés de quatre dentelures dont la première, formant la raie de l'œil, est la plus grande; la quatrieme est peu distincte; le dessous du corps présente un grand nombre de protubérances el de rugosités disposées d'une manière transversale; les pattes sont aplaties; les cuisses des trois premières paires ont, vers l'articulation du troisième article, une espèce de lobe épineux; les autres articles et les ongles sont fortement dèprimés, dilatés extérieurement et longitudinalement sillonnés; la quatrième paire, relevée sur le dos, est très-grêle et arrondic; les pinces sont inégales, rugueuses, la gauche plus petite que la droite; celle-ci étant étendue, ne dépasse pas la longueur de la première paire de pattes; les trois premiers anneaux de l'abdomen sont, dans les deux sexes, transversalement carénés; une teinte de couleur de chair nuancée de rougeâtre colore cette espèce; les pattes sont fasciées de rouge, et l'on voit chez le mâle deux bandesparallèles qui, sortant du dos, viennent s'étendre jusque sur les premiers anneaux de l'abdomen.

La femelle diffère du mâle par ses pinces, qui sont un peu plus petites; par sespattes, qui ne sont point fasciées; par l'abdomen seul qui est coloré chez le mâle, et par les rugosités du dos, qui sont moins saillantes; les individus jeunes sont d'une seule teinte, brune ou roussâtre. 
Les habitudes de ce Décapode. dit l'auteur de ce nouveau genre, doivent être semblables à celles de la Dorippe Laineuse; il vit dans les mêmes localités, c'est-ádire dans les grandes profondeurs vaseuses; il doit, comme elle, se cacher sous les pierres, sous les débris de végétaux, et se couvrir le corps de ces derniers avec le secours de ses deux pattes postérieures.

\section{CAPHYRA，Guérin，EDW.}

Après les Cymopolies de M. Roux, nous plaçons ce nouveau genre de Crustacés, qui a été établipar M. Guérin, dansle Voyage de la Coquille. Voici les caractères qui lui ont été assignés : La carapace est glabre, quadrilatère, un peu plus large que longue, un peu avancée, et sinuée au bord antérieur, tronquée carrément en arrière, à régions presque effacées, et très-peu convexeen dessus. - Les antennes extérieures sont assez courtes, sétacèes, insérées au dessus des intermédiaires et aux angles cxtérieurs de la cavité buccale ; leur premier article, soudé au test, est allongé et terminé en pointe aiguë à l'angle externe et supérieur; le second article, beaucoup moins long, est ovoĩde; le suivant, de même forme et de même longueur; les autres sont beaucoup plus petits, et vont en diminuant de largeur, vus en dessus; le second article dépasse le test. - Les antennes internes sont insérées sous le chaperon, dans descavités transversales: leur premier article, ou celui qui reste dans ces cavités, est grand, triangulaire; les deux autres sont de forme ordinaire. - Les yeux sont portés sur des pédoncules courts, gros, pouvant se cacher en partie dans les fossettes oculaires; ils sont insérés derrière les antennes latérales. - Les pieds - mâchoires extérieurs sont ciliés; le deuxième article est élargi, un peu avancé et arrondi à son extrémité supérieure interne; le second est presque aussi large à la base que le précédent, aussi haut que large, tronqué obliquement à l'angle supérieur interne, et tronqué carrément en haut et derrière l'insertion des trois derniers articles. - Les pinces sont courtes, égales, et de grandeur moyenne dans les femelles. - Les pieds sont semblables et diminuent un peu de longueur à partir des premiers; ils sont terminés par un crochet recourbé en dedans et velu; les deux dernières paires sont relevées sur le dos. - L'abdomen est replié, lisse, composé de sept tablettes dans les femelles. La seule espèce connue estla :
CApHYRa noUxiI.

Guér., Ann. des $S c$. nat., t. XXV, pl. 8, fig. 1. - Evw., op. cit., t. II, p. 160. - La carapace est un peu bombée en dessus, lisse, d'un vert-jaunâtre; son front est avancé, un peu échancré au milieu, sinué en avant et de chaque côté de l'échancrure; on voit au-dessus de l'insertion des yeux une pelite proéminence, en avant de laquelle sort le troisieme article des antennes latérales; derrière cette petite dent arrondie sont les fossettes oculaires, qui sont terminées en arrière par une forte dent aiguë; les côtés de la carapace sont un peu courbés, garnis de trois épines, en y comprenant celle qui termine les fossettes oculaires ; ces épines sont rapprochées, aiguës, dirigées en haut; la dernière arrive à peu près au milieu de la longueur des côtés, et il part de sa base un sillon courbe qui s'avance vers le centre du bord postérieur de la carapace ; ce bord est coupé carrément, un peu sinué au milieu, et aussi large que les côtes jusqu'aux yeux ; les antennes débordent la carapace de presque la moitié de sa longueur; les pinces sont à peu près de la longueur de tout le corps; leurs mains, en y comprenant les doigts, sont aussi longues que les deux premiers articles; elles sont épineuses; les doigts sont courbés, aigus et garnis en dedans de dentelures peu saillantes et arrondies; les pattes sont un peu grêles; les premic̀res sont de la longueur du corps, les autres un peu plus courtes; leurs articles sont cylindriques, lo dernier est cilié de chaque côté et terminé par un tarse de sa longneur, crocha et cilié en dedans. - Chez la femelle, la quene est très-large, presque orbiculaire; les trois premiers segmens sont plus élroits et paraissent en dessus; les autres, recourbés en dessous, sont à peu près le double plus large que le troisieme; le dernier est triangulaire. - Cette espèce, dont le mâle nous est inconnu, a été trouvéeà la Nouvelle-Hollande.

DORIPPA, Fabr., Latr., Desm., Edw.

La carapace est un peu déprimée, plus large postérieurement sur les côtés qu'antérieurement; tronquée et épineuse en avant ; tronquée, sinueuse et rebordée en arrière ; ayant sa surface marquée de bosselures on de tubercules qui correspondent exactement aux régions propres aux parties qui sont situées en dessous. De plus, elle présente deux grandes ouvertures obliques, ciliées sur leurs bords, communiquant arec 
les cavités branchiales, et situées en dessous du test, l'une à droite et l'autre à gauche de la bouche. - La partie inférieure et postérieure du corps est tronquée en gouttière pour recevoir l'abdomen replié, et dont les piéces sont noduleuses ou tuberculeuses. -Les yeux sont petils, latéraux, portés sur des pédoncules assez longs, placés près des angles du test, et protégés par les cornes anguleuses de celui-ci, qui composent les bords de leur orbite. - Les antenues extérieures sont assez longues, sétacées, insérées au-dessus desintermédiaires, qui sont plièes, mais non entièrement logées dans les cavités où elles prennent leur insertion. - Le troisième article des pieds-mâchoires extérieurs est étroit , allongé, et terminé en pointe. L'ouverture buccale est triangulaire.-Les pinces sont petites, courtes, égales; les autres pieds sont très-longs, comprimés; ceux de la troisième paire étant les plus grands, ceux des deux dernières paires relevés sur le dos, terminés par un petit angle crochu et replié sur l'article qui le précède. - L'ab. domen est replié, noduleux, et de sept articles dans les deux sexes.

\section{1. dorippa lanata. (Pl. 8, fig. 3.)}

Desir., Consid. génér. sur les Crust., p. 135, pl. 17, fig. 2. - Latr., Encyl. Méthod., pl. 306, fig. 2. - Rovx, Crust. de la Méditerr., pl. 17, fig. 1.-EDw., op. cit., t. II, p. 155. - Cancer Lanatus, Lis., Syst. nat. - Cette espèce a le front quadridenté ; on voit une forte pointe latérale qui fait à la fois l'angle du test et le bord externe de l'orbite; les côtés de la carapace sont, vers leur milieu, armés d'une pointe; les pinces sont courtes, crochues; leur pénultième article et les doigts sont blancs; ces derniers dentelés inféricurement; l'abdomen du mâle est blanchâtre; les pattes sont aplaties, longues, ciliées; la tranche supérieure des cuisses des première et deuxième paires garnie d'une série d'épines; la carapace, de couleur de chair, est légérement. couverte d'un duvet roussâtre. - La femelle ne diffère extérieurement du mâle que par la forme arrondie de l'abdomen. - Cette espèce a été trouvée dans la Méditerranée et dans l'Adriatique.

C'est sur les rochers éloignés de la côte, à trente ou à cinquante mètres de profondeur, et dans le voisinage des lieux vaseux, que se tient la Dorippe Laineuse. Elle vit isolée ; ses mouvemens sont faibles et lents; elle rampe plutôt qu'elle ne nage ; son test est presque mou; ses pinces, qui sont petites, la longueur et la disposition de ses jambes, dont quatre seulement semblent faites pour la locomotion, doivent s'opposer à ce qu'elle puisse avec avantage combattre ses ennemis ou fuir le péril. Ce Crustacé paraît donc être du nombre de ceux à qui la nature, en refusant des armes pour attaquer ou se défendre, a du moins compensé cette disgrâce par un instinct admirable de conservation et des moyens de ruse qui protégent leur existence. Malheureusement la difficulté d'étudier les Dorippes dans les profondeurs qu'elles habitent nous mettra long-temps dans l'impossibilité de connâitre des détails sur leurs habitudes particulières.

\section{DORIPPA QUADIIDENTATA.}

Latr., Hist. nat. des Crust., t. VI, p. 125. - Dess., Consid. génér. sur les Crust., p. 135. - EDw., op. cit., t. II, p. 156. - Dorippa Nodulosa, Guér., Iconogr. du Règn. anim. de Cuvier., Crust., pl. 13, fig. 2. - Dorippa Atropos, LaM., Hist. des Anim. sans vert. t. V, p. 245.Cancer Frascone, Henust, t. I, p. 192, pl. 11, fig. 70. - Long. 16 lig. - La carapace est très-allongée antérieurement, trés-inégale, et garnie de douze à quinze tubercules arrondis; le front est lamelleux, avancé, et forme deux dents triangulaires ; l'angle orbitaire externe est très-saillant, et la portion interne du bord orbitaire inférieur forme une grosse dent pointue et dentelée en dessous, qui s’avance beaucoup au-devant du front, et atteint presque le niveau de l'origine de la tigelle multi - articulée des antennes externes; l'extrémité du cadre buccal n'atteint pas le bord du front; les pattes antérieures sont granulées chez le mâle; les deuxième et troisième articles de l'abdomen sont armés chacun de trois tubercules dentiformes disposés par rangée transversale; le quatrieme article de l'abdomen, chez le mâle, présente une grosse dent et deux autres très-petites. - Se trouve dans $l^{\prime} \mathrm{O}$ céan Indien.

\section{DORIPPA ASTUTA.}

FABr., Suppl., p. 361.-EDw., op. cit., t. II, p. 157. - Cancer Astuta, Herist, t. III, p. 45 , pl. 55, fig. 6. - Cancer Pinnophylax, FABR., Syst., t. II, p. 444. - Long. 6 lig. - La carapace est trèsallongée, plate, presque entièrement lisse en dessus, mais présentant quelques sillons profonds et presque dépourvus de duret; 
le front est très-saillant.etlargement échancré, de maniére à présenter deux dents trjangulaires et aplaties; il n'y a ni dent ni dilatation au-dessus de l'angle orbitaire interne; la dent du bord inférieur de l'orbite est rudimentaire; le cadre buccal se termine dans l'échancrure médiane du front; les mains du mâle sont grosses, courtes et renflées; l'abđomen est dépourvu de tubercules dentiformes. - Se trouve dans les mers d'Asie.

Consultez, pour les autres espèces, l'Histoire Naturelle des Crustacés de M. Edwards, t. 2, p. 154 .

\section{ETHUSA, Roux, Edw. ;}

$$
\text { Dorippa, FABr.; Cancer, HeRBst. }
$$

La carapace est glabre, quadrilatère, plus longue que large, plus élargie postérieurement qu'antérieurement, tronquée et dentée en avant.-Les régions génitale, cordiale et branchiale sont séparées par un sillon.-La partie inférieure du test est creusée en gouttière pour recevoir l'abdomen replié. - Les yeux, portés sur des pédoncules assez longs, sont insérés sur la partie antérieure du test, qu'ils dépassent en s'étendant obliquement. - Les antennes extérieures, assez longues, sétacées, sont insérées au-dessous des intermédiaires; celles-ci, pliées, peuvent se loger dans les cavités propres à les recevoir, et sont terminées par un article kifide.-Les pieds-mâchoires extérieurs sont légérement ciliés ; le deuxième article est élargi, le troisième dilaté et en forme de cœur. Les pieds-mâchoires intermédiaires, ou la quatrième paire de piedsmâchoires, sont composés de cinq articles: le deuxième allongé, le troisième trapézoïdal ; le quatrième quadrangulaire, et le cinquieme obtus. - Les pinces sont courtes, égales, grêles dans les deux sexes; la première et la deuxième paire sont les plus longues; celles - ci étant les plus grandes de toutes. Les deux dernières paires sont courtes, relevées sur le dos ou rejetées sur les côtés; elles sont terminées par un angle crochu formant, avec l'article qui le précède, une sorte de pince. On n'aperçoit aucune ouverture branchiale. - L'abdomen, replié, noduleux, est composé de sept articles chez les, femelles, et de cinq seulement chez les mâles.

Les Ethuses habitent les régions coralligènes, et se tiennent peu dans les lieux vaseux, Leurs habitudes doivent avoir beaucoup d'analogie avec celles des Dorippes. L'espèce qui sert de type à ce nouveau genre est :

\section{ETHUSA MASCARONE.}

Roux, Crust. de la Méditerr., pl. 18, fig. 1. - EDw. , op. cit., t. II, p. 162. Cancer Mascarone, Herbst, t. $l$, p. 191 , pl. 11, fig. 69.- Long. 10 lig. - Le front de l'Ethusa Mascarone a deux dentelures de chaque côté au-dessus des antennes; qu'elles protégent; l'angle latéral antérieur est formé par une forte épine; l'ensemble des éminences de la carapace donne à ce Notopode l'aspect d'une figure humaine; le test est presque lissse, d'un rouge pâle, fascié de teintes plus foncées sur les pattes, chez le mâle seulement. - La femelle est un peu moins grosse et moins colorée ; son abdomen est ovale, allongé ; ses pattes sont grêles; celles du mâle sont plus fortes; l'un et l'autre ont des pinces petites, courtes, glabres. - Celte espèce, qui se trouve dans la Méditerranée, relève avec facilité ses deux pattes postérieures, qu'elle agite dans tous les sens avec assez de vivacité; elle habite les régions rocailleuses et profondes. De même que les Dorippes, elle doit avoir l'habitude de se servir de ses pattes de derrière pour se couvrir le dos de débris marins, et échapper ainsi aux regards de ses ennemis, et se cacher pour surprendre une proie.

\section{SEGONdE SECTION. - HETEROGHELLES, Latreille.}

C'est principalement avec les genres Leucosia, P'arthenope et Inachus de Fabricius, ou avec ceux des triangulaires et une portion de ceux des orbiculaires, que nous formons cette division de Brachyures. La dénomination d'Hétérochéles imposée par R. Latreille, ne provient pas seulement de la considération isolée des serres de l'indi- vidu, mais de leur comparaison dans les deux sexes : celles des mâles sont, en effet, sensiblement plus longues que celles des femelles. - Lethoracide va en se rétrécissant d'arrière en avant, de sorte qu'il est ovoïde ou triangulaire, et quelquefois aussi presque globuleux; il est surtout remarquable par ses inégalités, comme les tubercules, 
les épines dont il est chargé, et ses saillies ou cornes frontales; à raison de sa forme, les pédicules oculaires sont insérés sur les côtés et dans des cavités petites et circulaires. ,Dans plusieurs, ils peuvent être rejetés en arrière. - Aucun des pieds n'a de nageoire. - L'épistome est ordinairement presque symétrique, ou pluslong que large, et carré. - La teinte est uniforme, grise et cendrée, et l'on peut juger, d'après cela, que ces Crustacésquitient rarement leur séjour habituel ou la mer. - La queue du plus grand nombre est de sept ou six segmens dans les deux sexes. Nous terminerons cette section de la même manière que la première, ou par ceux dont les pieds sont sur deux rangs ou dorsaux. - Cette section a été partagée en deux divisions.

\section{PREMIÈRE DIFISION.}

Tous les pieds sont insérés sur la même ligne, et les deux postérieurs ne diffèrent pas de ceux qui les précèdent immédiatement par leur forme et leurs usages. - Les pieds-mâchoires extérieurs ne font point de saillie en avant. - Les yeux sont généralement écartés et latéraux. - Cette division renferme deux tribus : les Orbiculaires et les Triangulaires.

\section{SEPTIÈME TRIBU.}

\section{O R B I C UL A I R E S,} LATr.

Caractères. Cette tribu se distingue de la suivante par le rétrécissement supérieur de la cavité buccale; par la forme étroite, allongée et plus rétrécie vers l'extrémitè su. pèrieure du troisième article des pieds-mâchoires extérieurs; souvent encore par la petitesse des yeux et des antennes latérales, et par le nombre des segmens de la queue, qui n'est que de quatre dans les deux sexes.

Cette tribu renferme deux groupes : les Corystites, et les Leucosites.

\section{GORYSTITES.}

Le cadre buccal n'est pas très-étroit antérieurement, et les pieds-mâchoires ne le closent pas exactement. - Les antennes externes sont très grandes. - Le plastron sternal est très-étroit.

Genres : Corystes, Nautilocorystes, et Pseudocorystes.
GORYSTES, Leach, Latr. Ediv.; Albunea, FAbr. ; Cancer, Herbst, Edw.

La carapace est oblongue-ovale, presque terminée par un rostre; antérieurement elle est tronquée, et rebordée postérieurement; les régions sont légérement indiquées, si ce n'est la cordiale; les branchiales sont très-allongées. - Les yeux, assez écartés, sont portés sur des pédoncules gros, presque cylindriques et un peu courts. Les pieds-mâchoires extérieurs ont leur troisième article plus long que le second, étroit, et terminé par une pointe obtuse, avec une échancrure sur son bord interne. - Les pieds antérieurs sont grands, égaux entre eux, cylindriques, deux fois plus longs que le corps dans les mâles, seulement de la longueur du corps chez les femelles, comprimés, surtout vers la main; les autres pieds sont terminés par un ongle allongé, court, aigu, et sillonné longitudinalement. - L'abdomen, chez les mâles, est composé de cinq tablettes, et de sept chez les femelles.

conystes dentatus. (Pl. 8, fig. 5.)

Latr., Hist. nat. des Crust., t. VI, p. 122. - Lali, , op. cit., t. V, p. 234. - Corystes Cassivelanus, Leach, Malac., Pod. Brit., tab. 1, - Corystes Dentatus, Desm., Consid. génér. sur les Crust., p. 86, pl. 5, fig. 2.-Cancer Cassivelanus, Penn., Brit. Zool., tab. 7, fig. 13.-Cancer Personatus, Herist, loc. cit., fig. 13. - Albunea Dentata, FaBk., Suppl., p. 398. - Roux, Crust. de la Méditerr. pl. 12.-Corystes Personatus, Guśr., Icon. du Règn. anim. de Cuv., Crust., pl. 6 , fig. 1, 2.- EDw. , op . cit. t. II, p. 148. - La carapace de ce Crustacé est ovale; sa surface et celle des tarses antérieurs sont granuleuses, pointillées de brunrouge sur un fond couleur de chair; le front est bifide, un peu avancé ; l'échancrure qui reçoit les yeux est festonnée, armée d'une pointe sur le bord extérieur; les côtés sont tridentés ; la dent du milieu est obtuse, les deux autres aiguës; on voit une quatrième dent ou pointe sur les côtés du bord postérieur; les antennes intérieurement sont ciliées sur deux rangs; quelques parties de la carapace et des pattes sont aussi bordées de poils roussâtres; les pattes sont presque lisses; leur dernier article est étroit et allongé ; les pinces du mâle sont grandes, longues et tortueuses. - La femelle diffère du mâle par la forme de l'abdomen, qui est de 
sept pièces, tandis que celui - ci n'en a que cinq; mais on aperçoil très-distinctement sur cette partie du corps du mâle, c'est-adire sur la pièce intermédiaire ou la troisieme, qui est la plus grande de toutes, des vestiges de la séparation des deux autres. La longueur des pattes de la femelle dépasse à peine la hauteur du front. - Habite l'Océan et la Méditerranée.

Les mouvemens de ces Crustacés sont Ients; ils vivent sédentaires, à la profondeur de quelques mètres seulement. Les œufs que la femelle porte au printemps sont de couleur aurore.

\section{NAUTILOCORYSTES, EDw. ; Corystes, Latr.}

La carapace est à peu près semblable à celle du genre précédent. — Le front est large et à peine saillant. - Les antennes sont semblables à celles des Corystes. - Les pieds-mâchoires externes ont aussi à peu près la même forme; mais leur troisième article, un peu moins long que le deuxième, donne insertion par son sommet à l'article suivant. - Les pattes antérieures sont courtes et arrondies; celles des quatre paires suivantes sont trés-comprimées et terminées par un tarse lamelleux et plus ou moins lancéolé; celui des pattes postérieures est trèslarge.

\section{NAUTILOCORYSTES OCELLATUS.}

EDw., op. cit., t. II, p. I49. - Le front est lamelleux, divisé en deux lobes par une fissure médiane profonde ; les bords latéroantérieurs de la carapace sont armés de quatre dents outre l'angle orbitaire externe ; le carpe présente une forte épine sur sa partie supérieure. - Se trouve au cap de Bonne-Espérance.

\section{PSEUDOCORYSTES, EDw.}

Les Grustacés qui composent cette nouvelle coupe générique ont beaucoup d'analogie avec les Corystes, et surtout les Nautilocorystes; leur forme générale se rapproche extrêmement de celle des premiers, et ils ont les pattes natatoires comme les derniers; mais ils diffèrent des uns et des autres par leurs pieds-mâchoires externes. - La carapace est à peu près ovalaire et assez bombèe. - Le front est étroit, avancé et horizontal. - Les pédoncules oculaires sont de grandeur médiocre, et les orbites, très-peu profondes, sont tout-à-fait ouvertes extérieurement. - Les antennes internes sont petites et complétement recouvertes en dessus par le front; lear tige se reploie longitudinalement comme chez les Corystes. - Le cadre buccal est assez grand. - L'épistome ne se distingue pas de l'espace prélabial, et le cadre buccal, tout-à-fait ouvert antérieurement, se prolonge latéralement au-devant de la base des antennes externes, qui forme, avec cet appendice, la paroi inférieure de l'orbite. Les pieds-mâchoires externes sont assez larges; leur second article est très grand, tandis que le troisième est petit, triangulaire et à peu près aussi long que large. - Le plastron sternal est à peu près de même forme que chez les Corystes. - Les pattes antérieures sont grosses, comprimées, et de longueur médiocre. - Celles des quatre paires suivantes sont toutes à peu près de inême longueur et très-comprimées; leur tarse est lamelleux, large, et de forme lancéolé, surtout à celles de la deuxième et de la cinquième paire. - L'abdomen est trèsétroit; et ne présente chez le mâle que cinq segments distincts : les troisième, quatrième et cinquième anneaux étant soudés entre eux.

PSEUDOCORYSTES ARMATUS.

EDw., op. cit., t. II, p. 151. - Long. 2 pouc. - Le front est triangulaire, armé de trois dents, dont la médiane est la plus grosse; il y a une fissure au milieu du bord orbitaire supérieur, et deux grosses dents (dont la première représente l'angle orbitaire externe) sur le bord antérieur de la carapace, suivies de deux petites pointes assez éloignées; il y a aussi une dent très-saillante au-dessus de l'insertion des yeux et des antennes externes. Les pattes antérieures sont armées d'une dent très-forle et de deux petites dents sur le carpe, d'une pointe située vers le milieu du bord inférieur de la main, et d'une série de dents coniques sur le bord supérieur de la main et du doigt mobile. Les pattes suivantes sont ciliées sur les bords, - Cette espèce se trouve sur la côte de Valparaiso.

\section{LEUCOSITES.}

Les Crustacés compris dans ce groupe sont généralement de petite taille, et ils se distinguent des précédens par les antennes externes, qui sont rudimentaires.

Genres : Ilia, Leucosia, Guaia, Ebatia, Myra, Oreophorus, Philyra, Arcania, Ixa, Persephona, Nursia et Iphis. 


\section{IliA, Latr., Fabr., Edw.; Cancer, Linn., Herbst.}

La carapace est globuleuse. - Le front est profondément échancré. - Les yeux, à pédoncules courts; sont petits, rapprochés, presque immobiles dans la fossette qui les contient. - Les antennes extérieures sont très-courtes, implantées à côté des yeux; les intermédiaires sont rapprochées et logées dans une fossette; les unes et les autres sont terminées par un article bifide. Les pieds-mâchoires extérieurs sont graduellement rétrécis, à tige extérieure arrondie à son extrémité; ees extrémités se logent dans une excavation poilue de la partie antérieure et inférieure du test. Les pinces sont égales, cylindriques, de même grandeur dans les deux sexes. - Les pieds sont onguiculés et diminuent graduellement. - L'abdomen, dans les deux sexes, est composé de cinq articles.

Ces Grustacés, à test très-dur, vivent solitaires, crampounés parmi les flustres et les madrépores, ou sur les écueils, à de moyennes profondeurs; leur marche est lente; ils manquent d'agilité; la forme de leur corps et la débilité de leurs pattes s'opposent à ce qu'ils puissent nager; on ne les voit qu'à l'aspect du danger. - Parmi les espèces que la Méditerranèe nourit dans son sein nous citerons :

1. ILIA NUCleus. (Pl. 13, fig. 3.)

Leach, Zool. Misc., t. III, p. 24. Desm., Consid. génér. sur les Crust., p. 169 , pl. 27, fig. 5. - Eow., op. cit., t. II, p. 12/, ibid.; Atlas du Règn. anim., Crust., pl. 25, fig. 2. - Roux, Crust. de La Méditerr., pl. 8, fig. 1 à 8. - Cancer nucleus. - Herest, t. I, p. 87, pl. 2, fig. 14. - Long. 10 lig. - Le test de cette espèce d'Ilia est épais, très-dur, couvert de petits points arrondis qui, examinés à la loupe, présentent d'autres granulations plus grosses, isolées, régulièrement distribuées sur la surface; cette surface est sillonnée par deux impressions longitudinales que prẻcèdent ordinairement deux points jaunâtres. Le bord de la partie postérieure du test est orné de deux proéminences obtuses; plus haut, de chaque côté, sont placées deux pointes aiguës; le front est bidenté; les pinces sont filiformes, à deuxième articulation fortement granuleuse; les pattes sont grềles; le corps, en dessus, est d'un brun roussâtre; en dessous il est blanchâtre-luisant.
Cette espèce est extrêmement timide, elle habite les moyennes profondeurs coralligènes, d'où elle ne sort que lorsque le hasard lui présente quelque proie facile à saisir. Elle ne s'approche jamais des rochers du rivage On la rencontre rarement parmi les algues, si ce n'est en mars, époque à laquelle la femelle vient quelquefois y déposer des œufs nombreux, d'un noir-rougeâtre, qui éclosent en été. Sa chair a peu de saveur.

\section{ILIA RUgULOSA.}

Roux, Crust. de la Méditerr., pl. 8, fig. 9 à 12 ; Evw., op. cit., t. II, p. 125.Cette espèce a beaucoup d'analogie avec l'Ilia nucleus; mais elle en diffère par les granulations de son test, qui sont plus grosses, très-distinctes à l'œil nu, rudes au toucher, et parsemées sur un fond entièrement lisse et pâle. Les deux proéminences obtuses de la partie postérieure et inférieure de la carapace sont davantage échancrées; les deux autres pointes latérales sont fortement émoussées, et on distingue facilement les vestiges d'une cinquième protubérance placée entre les deux pointes. Le front est terminé par deux petíts prolongemens obtus; le test est coloré de brun-roux mêlé de jaunâtre.-Cette espèce se trouve dans le golfe de Naples; on la rencontre aussi dans la Mer du Nord. Elle vit retirée dans les algues et habite arec les Alphées et autres Salicoques.

\section{LEUCosia, Fabr., Latr., Desm., Edw.; Cancer, LInN., HeRBst.}

La carapace est bombée, presque globuleuse, se rétrécissant un peu en avant et présentant tout-à-coup un prolongement qui se relève un peu et porte à son extrémité le front et les yeux. - Les régions de la carapace sont presque entièrement confondues. - Le front s'avance un peu au-dessus et au-devant de la région antennaire. - Le cadre buccal est triangulaire, et la portion antérieure de ses bords latéraux se confond avec celle de la portion avancée de la carapace. Le palpe, ou tige externe des pieds. mâchoires externes, n'est pas dilaté, mais il est large, très-oblus au bout; guère plus large à sabase qu'a son extrémité, et presque aussi long que la portion interne de ces appendices. - Les pattes de la première paire sont grosses; chez le mâle elles sont environ une fois et demie de la longueur de la portion post-frontale de la carapace, et chez la fe- 


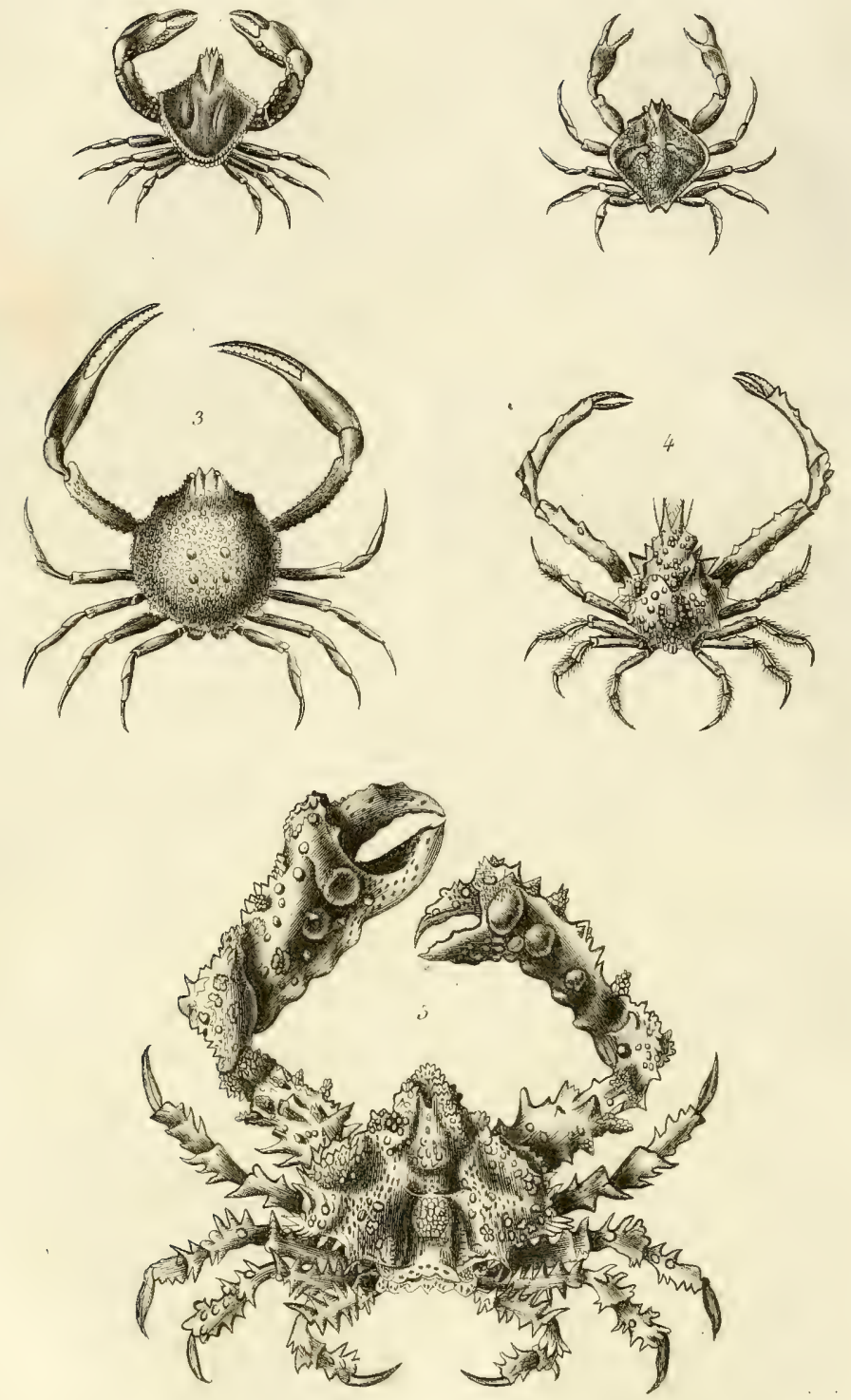

1. Lencosia craniolaris ,

3. Fia nuclens .

2. Ebahia pennantii.

4. Farynome aspera.

5. Parthenope horrida , 
mèlle une fois et un tiers cettelongueur. - La main est renfléc, et la pince courte, un peu infléchie, est garnie de petites dents obtuses. - Les pattes suivantes sont beaucoup plus courtes, et diminuent rapidement de longueur d'avant en arrière. - Chez le mâle tous les segmens de l'abdomen, à l'exception du premier et du dernier, se soudent en une seule pièce; chez la femelle les quatre segmens qui précẻdent le dernier se soudent en un grand bouclier très-bombé.

\section{I.EUCOSIA URANia.}

Licut., Berl. Magas., 1816, p. 40. LeACH, Zool. miscell., t. III, p. 21. Desir. Consid.géner. sur les Crust., p.167, - Guér, Iconogr. du Règn. anim de Cuv., Crust, , pl. 6, fig. 4.-EDw., op. cit., t. 1I, p. 122, ibid., Atlas du Règn. anim de Cuv., Crust., pl. 25, fig. 2. - Cancer Urania, Herbst, t. III, pl. 53, fig. 3. - Long. 1 pouc. -Les bords latéraux de la carapace sont régulièrement arqués, et garnis d'une ligne de granules perlées bien distinctes. Le front est droit et armé de trois petites dents, dont la médiane est très peu saillante. Les bras sont couverts de gros tubercules arrondis. - Se trouve à la Nouvelle-Guinée.

2. reucosia cramolaris. (PI. 13, fig. 1.) 。

FAER., Suppl., p. 350. - latr., Hist. nat des Crust. et des Ins., t. VI, p. 117.LeACr, Zool. misc., t. III, p. 21,-Desur, Consid. génér. sur les Crust., p. 167, pl. 27, fig. 2. - EDw., op. cit., t. II, p. 122. Long. 40 lig. - Les bords latéraux de la carapace sont peu granuleux, et coudés vers le milieu de manière à rendre ce bouclier hexagonale plutôt que circulaire. Le front est presque triangulaire. Le bras ne présente de tubercules que sur les bords et sur la surface inférieure. - Se trouve sur les côtes de l'Inde.

\section{GUAIA, Edw.}

La carapace est très-bombée, avec le front peu avancé. - Les portions latérales du bord antérieur du cadre buccal le dépassent très-sensiblement, et rendent. la direction des orbites oblique en haut et en avant. - Les fossettes antennaires sont étroites et presque transversales. - Les pattes antérieures sont fortes, longues, et la main est comprimée et terminée par une pince forte, de longueur ordinaire, et ar. mée d'un bord tranchant très-obtusément dentelé. - Les paties suivantes ont la même disposition que celles du geure Ilia.

\section{gUaia pUNctata.}

EDw., op. cit., t. II, p. 127. - Cancer Punctatus, Brown, Civil and nat. History of Jamaïca, t. I, pl. 42, fig. 3.-Cancer Mediterraneus, Henist, t. I, pl. 37, fig. 2. - Long. 2 pouc. - La carapace, régulièrement bombée, est couverte de petites granulations miliaires assez espacées entre elles; le front est bilobé; les bords latéraux de. la carapace sont garnis de petites pointes; de plus il y a une forte épine conique et horizontale sur la partie inférieure de la région intestinale, et deux autres un peu au-dessus, à l'extrémité du bord postéricur, qui est granulé; les régions ptérygostomiennes sont renflées, avec un pe. tit tubercule dirigé en dehors et se liant au bord latéral; les pattes antérieures sont fortes, à peu près de même grandeur dans les deux sexes; les bras sont granuleux; les mains sont légérement granuleuses sur le bord supérieur; les pattes suivantes sont lisses, avec le tarse styliforme et cannelé; la couleur est jaunâtre, avec de grandes taches rougeâtres. - Se trouve aux Antilles.

\section{eBAlia, Leach, Desm., Latr., Edw.; Cancer, DESM.}

La carapace est à peu près carrée, avec les angles tronquẻs et disposés sur les lignes médiane et transversale, ou plutôt hexagonale. - Les bords latéraux et postérieurs sont minces, saillans. - Le front est assez large, assez avancé, et terminé par un bord à peu prés droit. - Les fossettes antennaires' sont complétement cachées sous le front, assez grandes et dirigées trèsobliquement en dehors. - Le cadre buccal est triangulaire, et séparé des régions ptérygostomiennes par un rebord saillant. - Les pieds-mâchoires externes s'avancent jusqu'au bord de l'épistome, et leur palpe, obtus en avant, diminue graduellement de largeur depuis sa base, et se termine en dehors par un bord tout-à-fait droit. - Les pattes antérieures sont grosses et courtes. - La main est renflée et les pinces sont courtes. - Les pattes suivantes, beaucoup plus courtes, mais assez grosses, diminuent progressivement de longueur, et se terminent par un article styliforme assez gros.

1. ebalia penvanti. (Pl. 13, fig. 2.)

LEAch, Zool. Misc., t. III, p. 19. Ejusd. Malac. Brit., pl. 25, p. 1 a 6.- 
Desm., Consid. génér. sur lcs Crust., p. 165. - Cancer Tuberosus, Pennant, Enw., op. cit., t. II, p. 129. - Le bord latéro-antérieur de la carapace est divisé en deux lobes par une fissure; la carapace est assez élevée, et présente une espèce de crête obtuse et à trois branches, dont l'antérieure occupe la ligne médiane de la région stomacale, et les deux autres s'étendent sur les régions branchiales. - Se trouve sur les côtes d'Angleterre.

\section{EBaLia Granchir.}

Leach, Zoot. Misc., t. III, p. 20. Ejusd. Malac. Brit., pl. 25, fig. 7 à 11. Desm., Consid. génér. sur les Crusta, p. 166. - EDw., op. cit., t. II, p. 129. Long. $8 \mathrm{lig}$. - Le bord latéro-antérieur de la carapace est entier; le front est assez profondément échancré. - Se trouve sur les côtes d'Angleterre.

\section{EBALIA BAYERII.}

Leach, Zool. Misc., t. III, p. 20. Ejusd. Malac. Brit., pl. 25, fig. 12 à 13 . Desm., Consid. génér. sur les Crust., p. 166. - EDw., op. cit., t. II, p. 129. - Long. 3 lig. - Le bord latéro-antérieur de la carapace est entier; le front est à peine échancré; le bord postérieur de la carapace est plus large et moins profondément dilaté que dans les espèces précédentes; les pattes antérieures sont médiocres. - Se trouve sur les côtes d'Angleterre.

Consultez, pour les autres espèces, M.Edwards, op. cit., t. II, p. 130.

\section{MYRA, Leach, Desar, EDw.; \\ Cancer, LinN.; Leucosia, FABR.}

Le palpe des pieds-mâchoires externes, un peu dilaté dans sa partie inférieure, se termine en dehors par un bord légérement arqué, mais se rétrécit graduellement vers l'extrémité.-La main est grêle, et n'est pas contournée sur son axe. — La pince est courte, forte, et armée de dentelures peu aiguës et plus comprimées. - Les paties sont courtes, comprimées. - L'espèce type de ce genre est le :

\section{MYRa FUgax.}

Leacu, Zool. Misc., t. II, p. 24. Desm., Consid. génér. sur les Crust., p. 169, pl. 28, fig. 2, - EDw., op. cit., t. II, p. 126 ; ibid.-Atlas du Rég. anim. de Cuv., Crust., pl. 25, fig. 3.-Leucosia Fugax FaLR., Suppl.; 351. - Latr.,
Hist. nat. des Crust. el des Ins., i. VI, p. 149. - Long. 1 pouc. - La carapace est peu bombée, un peu élevée sur la ligne médiane, el couverte de petites granulations déprimées à peine visibles, et trèsespacées entre elles; chaque région hépatique présente une ligne élevée, mais trèsobtuse; er le bord de la carapace, une échancrure large et profonde au-dessus. de l'insertion des pattes antérieures; la région intestinale offre trois épines très-grosses près du bord postérieur de la carapace, et dirigées en arrière.

\section{OREOPHORUS, RUPp., EDW.;}

La carapace est à peu près subtriangulaire, avec les côtés latéraux arrondis, et sa substance est épaisse ct rugueuse. - Le front est étroit et saillant. - Les bords latéraux de la carapace sont très-dilatés et ondulés. - Les antennes internes se reploient très-obliquement sous le front. Les paties antérieures sont courtes et renflées, est leur tarse est styliforme et extrêmement petit.

\section{OREOPHORUS HORRIDUS.}

Rupp., op. cit., p. 19, pl. 4, fig. 5. Evw., op. cit., t. II, p. 131. - Long. 1 pouc. - La carapace est bombée, avec deux tubercules sur la région stomacale, et un petit sillon de chaque côté de la région intestinale, qui est presque verticale; le front est garni de deux tubercules obtus; les bords latéraux de la carapace sont obtus en avant, minces et tranchans dans la moitié postérieure, ou ils se prolongent audessus de ses pattes; le bord postérieur de la carapace est transversal, et séparé des bords latéraux par deux grands enfoncemens très-profonds qui 'se prolongent sur la carapace; les pattes antérieures sont bosselées et granuleuses; les pattes suivantes sont bosselées et épineuses; la couleur est rougeâtre. - Se trouve dans la Mer. Rouge.

PHylir A, Leach, Desm., Latr., Edw. ; Leucosia, Fanr. ; Cancer, Herbst.

La carapace est circulaire et déprimẻe, avec le front s'avançant beaucoup moins que l'épistome. - Les antennes externes sont à peu près transversales, et le cadre buccal est presque circulaire en avant. La portion principale des pieds-mâchoires externes est triangulaire, avec le palpe ou 
branche extérieure de ces organes fortement dilaté en dehors. - Les pattes des quatre dernieres paires ont le tarse déprimé et presque lamelleux.

\section{1. phylira scabriuscula.}

Leach, Zool. Misc., t. III. - Desm., Consid. génér sur les Crust., p. 167. Evw., op. cit. t. II, p. 132, pl. 20, fig. 9 et 10. - Leucosia Scabriuscula, FABR., Suppl. Ent. Syst., p. 349. - Latr., Hist. nat. des Crust., t. VI, p. 116. - Long. 6 lig. - La carapace est déprimée, granuleuse sur les côtés et en arrière; le front est bilobé beaucoup moins saillant que l'épistome, qui est échancré au milieu, et presque triangulaire; la surface supérieure de la carapace présente à son contour une bordure de granulations; les pattes antérieures sont grêles, et environ deux fois et demie aussi longues que la carapace ; les bras sont garnis de plusieurs rangées longitudinales de tubercules; les mains sont comprimées; les pinces sont très-comprimées, recourbées en bas, finement dentelèes, avec le doigt mobile plus long que l'inférieur et crochu au bout; la couleur est d'un gris rosé. - Se trouve aux Indes-Orientales.

\section{PHYLIRA PORCELLANa.}

EDw., op. cit., t. II, p. 133. - Leucosia Porcellana, Fadr., Suppl. Ent. Syst., p. 350. - Latr., Hist. nat. des Crust., t. VI, p. 117. - Cancer Porcellanus, Fabr., Ent. Syst., t. II, p. 441.- Herbst, t. I, p. 92, pl. 2, fig. 18. - Long. 8 lig. - La carapace est bombée et très-finement piquetée; le front est un peu droit et ne dépasse l'épistome que très-peu; le bord de la carapace est très-finement granulé; les pattes antérieures sont deux fois aussi longues que la carapace et très-fortes; les bras sont cylindriques et granuleux; les mains sont renflées et lisses; les tarses sont trèsdéprimés et assez larges.-Patrie inconnue.

arcania, Leach, Desm. , Latr., Edw.; Cancer, Herbst ; Leucosia, Fabr.

La carapace est globuleuse, et le front est relevé. - Les antennes internes se reploient presque longitudinalement sous le front. - Le cadre buccal est assez large antérieurement, ne se rétrécit pas sensiblement en avant, et la branche externe des pieds-mâchoires externes est droite et étroite. - Enfin les pattes antérieures sont grêles et allongées. - L'espèce type de ce genre est :
ARCANIA ERINAGEUS.

Leach, Zool. Misc., t. III, p. 24. Desu., Consid. génér. sur les Crust., p. 170 , pl. 28, fig. 1. - EDw., op. cit., t. II, p.134.-Ejusd. Atlas du Rég. anim. de Cuv., Crust., pl. 24, fig. 2. - Leucosia Ericaneus, Fabr., Suppl., p. 352. - Latr., Hist. nat, des Crust., t. VI, p. 119. - Cancer Erinaccus, Herbst, p1. 20, fig. 111. - Long. 10 lig.-La carapace est couverte d'épines acérées, et entourée d'une espèce de couronne ou de pointes plus longues, et garnies elles mêmes d'épines; le front est armé de deux prolongemens triangulaires; le bord orbitaire inférieur présente des épines. - Se trouve dans la mer des Indes.

IXA, Leach, Desm., Latr. . Edw. ; Leucosia, Fabr., Latr.; Cancer, Herbst.

Ce genre est remarquable par la forme de la carapace, dont la portion moyenne est à peu près sphérique, ou plutôt elliptique transversalement, et se continue de chaque côté avec une portion cylindrique qui triple sa largeur et dépasse l'extrémité des pattes. - Les prolongemens naissent du milieu de la région branchiale, se dirigent directement en dehors, et diminuent à peine de diamètre jusqu'à leur extrémité. - La face supérieure de la carapace est plus ou moins profondément sillonnée par deux gouttières ou sillons longitudinaux qui séparent les régions branchiales des régions médianes, et qui se bifurquent antérieurement poụr séparer les régions hépatiques des régions stomacales et branchiales. - - Le front est très-relevé et assez large. - Les orbites présentent en dessus deux fissures. - Les pattes sont filiformes. - L'abdomen de la femelle est très-large et orbiculaire, et présente en avant un prolongement formé par undernier article qui s'avance dans un sillon du plastron sternal jusqu'à la base de la bouche.

\section{IXA Canaliculata,}

LEAGH. , Zool. Misc., t. III, p. 26, pl. 129 , fig. 1. - DesM., Consid. génér. sur les Crust., p. 171, pl. 28, fig. 3. EDw., op. cit., t. II, p. 135. - Ejusd. Atlas du Règ. anim. de Cuv., Crust., pl. 24, fig. 1. - Leltcosia Cylindricus, Fabr., Suppl., p. 352. - Latr., Hist. nat. des Crust., t. VI,p.119.-Cancer Cylindricus, Henist, pl. 2, fig. 30 et 31. - Long. 8 lig. Larg. 2 pouc. - Les prolongemeng 
latéraux de la carapace sont grauuleux, et garnis à leur extrémité d'une petite dent styliforme; les régions médianes de la carapace et les régions latérales sont séparées par deux cannelures; les mains de la femelle sont longues, grêles, minces, arrondies, et diminuent beaucoup d'épaisseur vers leur extrémité; les pinces sont très-courtes. - Se trouve sur les côtes de l'Ile-de-France.

\section{PERSEPHONA, LEAch, DEsM., LATR., EDw.}

Les tiges externes et internes des piedsmâchoires extérieurs sont amincies insensiblement depuis leur base, l'externe étant très-obtuse à l'extrémité. — La carapace est arrondie, déprimée, dilatée de chaque côté. - Le front est peu avancé, mais pas plus long que le chaperon.-Le grand article de l'abdomen du mâle est composé de trois pièces soudées. - Les pieds de la première paire sont beaucoup plus gros que les autres, qui ont leurs deux derniers articles comprimés.

\section{PERSEPHONA LATREILLEI.}

LEACH, Zool. Misc., t. 111, p. 22. Desr., Consid. génér sur les Crust., p. 168. - Latr., Règ. anim. de Cuv., $2^{\mathrm{e}}$ édit., t. IV, p. 54. - EDw., op. cit., t. II, p. 136. - Long. 2 pouc. $\frac{1}{2}$ La partie antérieure de la carapace est graduellement et obtusément dilatée est recouverte de granulations; sa partie postérieure présente trois épines recourbées; le bras est tuberculeux.

\section{PERSEPHONA LICHTENSTENI.}

LEACH, Zool. Misc., t. III, p. 22. Desur., Consid.'génér. sur les Crust.,p. 166. - EDw., op. cit., t. II, p. 137. - Long. 1 pouc. $\frac{1}{4}$. - La carapace est aplatie, recouverte de granulations éparses, armée d'un tubercule sur chacun de sesangles latéraux, et de trois épines à peine recourbées dont la médiane est la plus longue sur son bord extérieur; de plus, cette carapace est couverte de tubercules. - La patrie de ces deux espèces nous est inconnue.

NURSia, Leach, Desm., Edw.

La carapace est un peu avancée en forme de rostre, et présente ses côtés extérieurs échancrés et dentés. - La tige externe des pieds-mâchoires extérieurs est dilatée. Les pieds de la première paire sont angu. leux, avec les doigts des pinces fortement infléchis - L'avant-dernier arlicle de l'ab- domen, chez le mâle, est pourvu d'une petite pointe à son bord postérieur.

\section{NURSIA HARDIVEGKII.}

Leach., Zool. Misc., t. III, p. 20, Desm., Consid. génér. sur les Crust., p. 166. - Evw., op. cit., t. II, p. 137. La carapace est armée de quatre dents de chaque côté, et de trois tubercules disposés en triangles sur le milieu de la face supérieure, et pourvue, près de son extrémité postérieure, d'une ligne transversale élevée portant un tubercule. - Se trouve dans l'Inde.

\section{IPHIS, Leach, Desh., Latr., Edw.; Leucosia, FABR.; Cancer, HerbSt.}

La carapace a presque la forme d'un rhom: be, dont les côtés seraient arrondis, et l'un des angles, dirigé en avant pour former le front, serait tronqué ; de chaque côté, elle se prolonge horizontalement sous la forme d'une grosse et longue épine. - La tige externe des pieds-mâchoires extérieurs est presque linéaire, mais un peu plus étroite vers son extrémité qu'à sa base. Les pattes antérieures sont filiformes et terminées par une pince pointue un peu recourbée en dedans et armée de petites épines. - Les pattes suivantes sont cylindriques et extrêmement grêles.-Le grand segment de l'abdomen est formé de deux articles soudés chez la femelle, et de trois chez le mâle.

\section{IPIIS SEPTEM-SPINOSA.}

LEACH, Zool. Misc., t. III, p. 25. Desu. , Consid. génér. sur les Crust., p. 171. - EDw., op. cit., t. II, p. 139. Ejusd, Atlas du Règ. anim. de Cuv., Crust., pl. 25, fig. 4.-Leucosia Septem-Spinosa, Faвr., Suppl. Entom. Syst., p. 351. Cancer Septem-Spinosus, FABR., Mantissa, t. I, p. 325. - La carapace un peu granuleuse, estarmée de chaque côté d'une épine très-forte et un peu recourbée en avant, d'une troisième épine semblable, mais moins longue, sur le milieu de son bord postérieur, et de deux autres épines courtes de chaque côté de la précédente; la base des bras est granuleuse. - Se trouve dans la Mer des Indes.

HUITIEME TRIBU.

\section{LES TRIANGULAIRES, Latreille.}

Caractéres, Chez les Crustacés qui com- 
posent cette Iribu, la carapace est ordinairement triangulaire, et guère plus longue que large; en général, ses bords latéropostérieurs sont presque transversaux, et les latéro-antérieurs suivent la même direction que les bords du rostre; mais quelquefois les parties latérales de la carapace sont arrondies; sa surface est presque toujours bosselée et tuberculeuse. - Le rostre est, en général, petit et entier, ou seulement échancré au bout:- Les yeux sont presque toujours parfaitement rétractiles. - L'article basilaire des antennes externes présente quelquefois la même disposition que chez les Maïtes; mais, dans la grande majorité des cas, il en est tout autrement : cet article est petit, et ne se soude pas aux parties voisines du test; son bord externe ne concourt pas à former la naroi orbitaire inférieure, et son extrémité n'atteint pas le front; enfin la tige mobile de ces antennes est courte, et prend naissance dans un hiatus de l'angle orbitaire interne. - L'épistome est beaucoup plus large que long, et la forme des pieds-mâchoires externes est à peu près la même que chez les Maïtes. Les pattes antérieures sont très-développées, et s'écartent presque à angle droit du corps; chez le mâle elles sont toujours plus de deux fois aussi longues que la portion post-frontale de la carapace, et quelquefois elles ont quatre fois cette longueur. - La main est presque toujours triangulaire, et la pince brusquement recourbée en bas, de manière que son axe forme un angle très-marqué avec celuì de la main; les pattes suivantes sont, au contraire, courtes; en général, celles de la seconde paire ont moins d'une fois et demie la longueur de la portion post-frontale de la carapace, et les autres diminuent progressivement. - L'ab. domen présente encore des différences assez grandes dans le nombre des articles distincts que l'on compte chez le mâle, tandis que chez la femelle leur nombre est loujours de sept.

Ces Crustacés hajitent des parages trèsvariés: on en rencontre dans la Manche, dans la Méditerranée et dans l'Océan Indien. Leurs mœurs nous sont entièrement inconnues. Cette tribu renferme trois groupes: les Parthénopites, les Maites, et les Macropodites.

\section{PATTILENOPITES.}

Pattes des quatre dernières paires beaucoup plus courtes que les pattes anté- rieures; celles de la deuxième paire ayant, en général, moins d'une fois et demie la longueur de la portion post-frontale de la carapace; celles de la première paire, au contraire, très-grosses, et ayant chez les mâles sinon dans les deux sexes, deux ou trois fois cette longueur.--Article basilaire des antennes externes presque toujours peu développé, point soudé au front, et ne contribuant que peu à constituer la paroi intérieure de l'orbite.

Genres: Parthenope, Lambrus, Eurynome et Eumedon.

\section{PARTHENOPE, FABR., LATR., LEAcH, EDw.; \\ Cancer, Herbst; Mä̈a, Latr.}

La carapace est rhomboïdale et excessivement irrégulière er dessus ; elle se prolonge en un rostre entier en avant, et en angles assez aigus latéralement.--Les yeux sont gros, portés sur des pédoncules courts, et logés dans des fossettes latérales. - Les antennes. extérieures sont extrêmement courtes, avec leurs deux derniers articles, surtout celui de la base, très-gros. - Le troisième article des pieds-mâchoires extérieurs est tronqué et échancré vers l'extrémité de son côté interne. - Les serres sont inégales, très-grandes, avec leurs articulations anguleuses et couvertes de tubercules, de rugosités et de pointes; elles sont terminées par des doigts courts, inclinés en dedans; les autres pattes sont également rugueuses, médiocrement lorgues, et décroissant depuis la seconde jusqu'à la cinquième paire. La seule espèce connue est le :

par thenope honidoa. (Pl. 13, fig. 5.)

Fabr., Suppl., p. 353. - GuériN, Icon. du Reg. anim. de Cuv., Crust., pl. 7, fig. 2. - EDw., op. cit., t. I p. 360 ; ejusd., Atlas du Rég. anim. de Cuvier, Crust., pl. 26, fig. 2.-Cancer Horridus, Lins., Mus.lud.ulr. p. 442. - Long. 5 pouc.-La carapace est pentagonale, beaucoup plus large que longue, horizontale, fortement bombée et tuberculeuse en dessus; le rostre est court, triangulaire, et armé en dessous d'une forte dent inter-antennaire; les orbites sont circulaires, avec une fissure sur le bord supérieur; les bords latéro-antérieurs de la carapace sont très-obliques et armés d'épines; les pattes antérieures sont très-grandes et grenues, inégales, et couvertes de gros tu. bercules spiniferes; les pinces sont moins comprimées et moins infléchies que chez le 
genre suivant; les pattes des quatre paires suivantes sont hérissées, jusqu'àl'origine du tarse, d'épines aiguës et très-grandes formant une rangée en dessus et deux en dessous ; la couleur est grisâtre. - Cette espèce se trouve dans l'Océan Indien et Atlantique.

\section{LAMBRUS, Leach, Desu., Edw.; Parthenope, Faba., Latr., Lasf.; Cancer, Linné, Herbst.}

Les régions de la carapace sont très-prononcées. - Les yeux sont portés sur un pédoncule court et gros. - Les antennes extérieures sont très-courtes, tout au plus aussi longues que les pédoncules des yeux, insérées sous eux dans une échancrure du bord inférieur de leur orbite, ayant leur pédoncule aussi long que leur tige, et leur second article le plus grand de tous. - Les pieds-mâchoires extéricurs ont leur troisieme article plus long que le second, et échancré du côté interne pour l'in. sertion du suivant. - Les pieds antérieurs surpassent plus d'une fois la longueur du test ; ils sont étendus en angles droits, terminés par des pinces trièdres dont les doigts sont comprimés, pointus et courbés angulairement au côté interne. - Les pieds suivans sont courts. - L'abdomen des mâles est composé de cinq articles dont le troisième est le plus long.-Celui des femelles est ordinairement de sept. - Les mœurs de cesCrustacés, dit M.P. Roux, dans son Hist. nat. des Crust. de la Méditerranée, son douces et tranquilles, car la grande dimension de leurs serres doit gêner leurs monvemens; ils vivent sédentaires parmi les rochers qui sont à de grandes profondeurs.

\section{HAMBRUS LONGIMANUS.}

Leace, Trans. Linn., t. II, p. 310.Edw., op. cit., t. I, p. 354 ; ejusd., Atlas du Règ. anim. de Cuvier, Crust., pl. 26, fig. 1. - Cancer Macrochelos, SEBA, t. III, pl. 19, fig. 8, 9 et 10.-Parthenope Longimana, FABR., Suppl., p. 353.-Long. 1 pouc. - Le rostre est très-petit, à peine saillant, horizontal et formé de trois dents; la carapace est presque circulaire, garnie en dessus d'épines simples et de tubercules; les bords latéraux sont armés d'épines trèslongues et légérement rameuses; les mains sont triangulaires, presque lisses sur la face supérieure, garnies d'épines rameuses sur le bord supérieur, et de grosses dents poinŁues, et à bords dentelés sur le bord externe; les bords supérieurs et inférieurs du troisième article des quatre dernières paires présentent quelques épines très-courtes.Se trouve à Pondichéry.

\section{LAMBRUS ANGULIFRONS.}

Eow., op. cit., t. I, p. 355. - Parthenope Angulifrons, Latr., Encycl. Méth., t. X, p. 15. - Lambrus Montgrandis, Roux, Crust. de la Méditerr., pl. 23, fig. 1, 6. - Long. 1 pouc. - La carapace est de la longueur d'un pouce; elle est glabre, couverte en dessus de tubercules arrondis, dentelée sur les bords latéraux; les régions stomacale, branchiale, cordiale et hépatique sont relevées en bosses; les deux dernières sont réunies; le front est avancé, terminé en pointe, longitudinalement traversé par un large sillon; les pinces sont inégales (la droite ordinairement plus grosse que la gauche), triangulaires, couvertes en dessus de tubercules ou de pointes émous: sées; le dessous du corps est lisse de même que les pattes, qui ont leur partie supérieure légérement chagrinéc; les pattes postérieures et le bord extérieur des bras, qui portent les pinces, sont ciliés; la couleur en dessus est d'un roux-jaunâtre lavé de rose, surtout sur la face inférieure des pinces; le dessous est blanchâtre ; les pattes et la carapace sont parsemées de petits points d'un rouge-pourpre. - Cette espèce, qui a été figuree par M. Roux, pl. 23, fig. 1, 6, se trouve dans les profondeurs rocailleuses des parties les plus méridionales de la Méditerranée.

\section{LAMBRUS MASSENA.}

Roux, Crust. de la Méditer., pl. 25, fig. 7, 12.-EDw., op. cit., t. I, p. 356.Long. 1 pouc. - Le front, chez cette espèce, est avancé en pointe et s'incline brusquement en partant des yeux; il est traversé par un large sillon; la carapace est triangulaire, en forme de cœur renversé; les régions stomacale, branchiale et cordiale sont fortement relevées; elles ont quelques tubercules émoussés à leur sommet; les bords de la seconde de ces régions et de l'hépatique sont dentelés; tout le reste du dos est lisse; les pinces sont inégales; l'une des deux, ordinairement la droite, est très-renflée; elles sont quadrangulaires; les doigts sont dentés intérieurement; on distingue quelques épinessur les cuisses; les autres articles des pattes sont lisses; l'abdomen, le thorax et le dessous des bras, qui portent les pinces, sont granuleux; 
une teinte roussâtre nuancée de rouge colore le test de cette espèce; les pattes, le dessous du corps, sont toujours plus pâles que le dessus; les jeunes présentent sur la carène extérieure de chacun des articles qui portent les doigts, deux fortes pointes qui s'amincissent et disparaissent avec l'âge ; l'abdomen du mâle est composé seulement de quatre articles. - Cette espèce habite les rochers volcaniques des côtes de la Sicile.

\section{LAMBRUS MEDITERRANEUS.}

Roux, Crust de la Méditerr., pl. 1. Cancer Macrochelos, Herbst, t. I; pl. 19, fig. 107. - Eurynome Aldrovandi, Risso, Hist. de l'Europ. Mérid., t. V, p. 22. - Eow., op. cit., t. I, p. 357. Long. 2 pouc. - La carapace est cariée, rugueuse; des piquants surmontés d'autres petites épines en occupent le tour, et com. posent sur le dos trois rangées longitudinales; celle du milieu se divise, sur le front, en deux parties. Les pinces, très-longues, quadrangulaires, comprimées, trièdres à leur extrèmité, sont couvertes en dessus de fortes épines dentées et rameuses, et en dessous de petits tubercules; les jambes sont lisses, excepté les cuisses, qui ont une rangée latérale de piquans; la couleur de ce Crustacé est un roux légẻrement rosé sur la carapace, plus foncé sur les pinces, et d'un brun rougeâtre sur les pieds; les angles sont couverts d'un duvet brun. - Cette espèce, figurée par M. Roux, pl. 1, fig. 1, 3, habite les environs de Toulon et de Nice, et parait se te. nir constamment parmi les rochers coralligènes. Selon M. Risso, ses œufs sont nombreux et d'un rouge vif.

EURYNOME, Leach, Edw.;

Cancer, Penn. ; Parthenope, Latr.

La carapace de ce genre, qui a été établi par M. Leach, a presque la forme d'un triangle a base arrondie ; elle est fortement bosselée et couverte d'aspérités.-Le rostre, horizontal, est divisé en deux cornes triangulaires. - Les yeux sont petits; les orbites sont profondes; leur bord supérieur est très-saillant, et séparé de l'angle externe par une fente. - Les antennes internes se reploient longitudinalement; le premier article des externes se termine à l'angle interne de l'orbite, et porte l'article suivant au bord supérieur de son extrémité, de sorte que la tige mobile de ces antennes, qui se prolonge sur le rostre, paraît naître du canthus interne desyeux. - L'épistome est à peu près carré, et le troisième article des pieds-mâchoires externes est fortement dilaté en dehors.-Le plastron sternal est à peu prẻs ovalaire , et sa suture médiane occupe les deux derniers anneaux thoraciques. - Les pattes de la première paire ne sont guère plus grosses que les suivantes. Chez le mâle, elles sont assez longues, tandis que chez la femelle elles sont très-courtes, et moins cependant que celles de la seconde paire; les pattes suivantes diminuent progressivement de longueur.-L'ab. domen, dans les deux sexes, est composé de sept articles. - La seule espèce con:uue, et qui sert de base à ce genre, est :

1. eUrynome aspera. (PI. 13, fig. 4.) Eow., op. cit., t. I, p. 351.-LEACH, Malac. Brit., pl. 17.-Desm., Consid. génér. sur les Crust., pl. 20, fig. 2. - GuÉR., Icon. du Règ. anim. de Cuv. , Crust., pl. 7, fig. 4. - Cancer Aspera, Penn., t. IV, pl. 9, fig. 20. - Long. $\frac{1}{2}$ pouc. - La carapace est à régions distinctes, rugueuse, avec une grande dent triangulaire à l'angle externe de l'orbite, et trois ou quatre plus petites le long du bord latéral, sur la région branchiale; la tige des antennes externes est mobile et très-courte, avec ses deux premiers articles très-petits; les pattes antérieures sont tuberculeuses et un peu comprimées, presque droites chez la femelle, et ont la pince recourbée en dedans chez le mâle; les pattes suivantes sont rugueuses et garnies d'une crête qui est plus marquée que sur le troisième article; la couleur est rosée, avec des teintes bleuâtres. - Se trouve sur les côtes de Noirmoutiers et de la Manche, à d'assez grandes profondeurs.

$$
\text { EUMEDON, EDw. }
$$

Ce nouveau genre diffère du précédent par sa carapace, qui est presque pentagonale; - par le corps, qui est déprimé ;par le rostre, qui est très-large et très-avancé, et n'est divisé que vers son extrémité; par les yeux, qui sont très-courts, et dont le pédoncule remplit entièrement leur orbite, qui est circulaire;-par les antennes, qui se reploient très-obliquement en dehors et dont les externes sont peu développées;par les pattes thoraciques de la première paire, qui, chez le mâle, sont grosses et beau. coup plus longues que les suivantes; - enfin par l'abdomen du mâle, qui se compose de sept articles dont les deux premiers se 
voient à la face dorsale du corps, en avant de la carapace.

La seule espèce connue est:

\section{EUMEDON NIGER.}

Evw., op. cit., t. I, p. 350, pl.15, fig. 17. - Remarquable par le prolongement qu'on lui voit de chaque côté de la carapace; ces pointes sont dirigées en dehors, et leur base occupe toute la région hépatique; la face supérieure de la carapace présente quelques dépressions et est recouverte, comme toutle reste du corps, de petites granulations milliaires; le rostre est très-large, plat, largement échancré au bout, et d'environ le liers de sa longueur et celle de la carapace en entier; les pattes antérieures sontarmées d'une forte épine qui occupe le bord inférieur du carpe, et de deux petites pointes placées sur le bord superieur de la main, qui est un peu renflée; les pinces sont garnies de quelques dents arrondies, et elles ne sont pas sensiblement recourbées en dedans; les autres pattes sont légérement poilues; la couleur est d'un noir bronzé. - Se trouve sur les côtes de la Chine.

\section{MAITES.}

Pattes de grandeur médiocre; celles de la seconde et de la troisième paire n'ayant jamais deux fois la longueur de la portion post-frontale de la carapace; celles de la première paire souvent plus longues et plus grosses que les suivantes, mais n'ayant jamais plus de deux fois la longueur de la portion post-frontale de la carapace. - Article basilaire des antennes externes trèsdéveloppé, constituant la majeure partic de la paroi inférieure de l'orbite, et allant toujours se souder avec le front au-devant du canthus interne des yeux.

Genres : Mithrax, Stenocionops, Menothius, Acanthonix, Epialtus, Leucippa, Maia, Camposcia, Pericera, Naxia, Lissa, Chorina, Micippa, Criocarcinus, Paramicippa, Hyas, Halimus, Libinia, et Horbstia.

MithraX, Lfach, Latr., Desh., Edw.;

Cancer, Herbst ; Maia, Bosc, LaM.

La carapace, chez ces Crustacés, est toujours très-peu bombée en dessus, et assez fortement rétrécie en avant. - Le rostre est bifide, court, séparé du canthus interne des yeux par un espace assez considérable. - Les orbites sont presque toujours ar- mées de deux ou troisépinesà leur bord supérieur, d'une à leur angle externe, et d'une ou deux à leur bord inférieur. - Les bords latéro-antérieurs de la carapace sont dentés. - Les antennes internes se reploient obliquement en dehors, et la portion frontale de la cloison qui les sépare est armée d'une épine recourbée en avant.-L'article basilaire des antennes externes est grand, et est presque toujours armé en avant de deux fortes épines. - Le second article de ces appendices est, au contraire, grêle et cylindrique; il s'insère sur les côtés du rostre, plus près de la fossette antennaire que de l'orbite; le troisième article est presque aussi long et aussi gros que le deuxième. - La tige terminale est articulée et généralement assez courte. - Le plastron sternal est presque circulaire. - Les pattes an térieures, chez le mâle, sont généralement plus longues et plus grosses que celles de la seconde paire, et la main qui les termine est presque toujours forte et renflée. Les pinces sont courbées à leur base, élargies au bout, profondément creusées en cuillère, et terminées par un bord tranchant semicirculaire. - Les pattes de la seconde paire se raccourcissent successivement. - Leurs tarses sontcourts, crochus, et souvent armés de quelques pointes à leur face inférieure.-L'abdomen, dans les deux sexes, est formé de sept articles distincts; mais quelquefois les femelles, dans leur jeune âge, n'en présentent que quatre; les second, troisième et quatrième segmens étant intimement soudés entre eux.

Tous les Crustacés qui composent ce genre, peu nombreux en espèces, appartiennent pour la plupart aux mers d'Amérique, et quelques-uns d'entre eux parvien. nent à une grandeur très-considérable.

M. Edwards, dans son Histoire natu. relle des Crustacés, a divise ce genre en trois sous-genres.

\section{PREMIER SOUS-GENRE.}

Bord supérieur de l'orbite armés de for. tes épines. - Pattes les quatre dernières paires non épineuses.

\section{Mithrax triangulaires.}

Mithrax digatronus. (Pl. 14; fig. 2.) Dess., Consid.gén. sur les Crust., p. 150. -Evw., Mag. d'Ent., 1831, cl. 7, pl. 1.Ejusd., op. cit., t. I, p. 519, pl. 15, fig. 1 à 4. - Long. 2 pouces. - La carapace est granuleuse avec son dessus sans épi- 
nes; les cornes du rostre sont très-divergentes, guère plus longues que larges, et Cicrminées par deux dents presque égales; le bord supéricur de l'orbite est armé de deux épines triangulaires; les bords latéraux de la carapace sont armés de sept grosses dents spiniformes, dont une formant l'angle orbitaire externe, et cinq insérées sur la région branchiale; le bord postérieur de la carapace présente deux petites pointes; les fossettes antennaires sont très-larges en avant, sans tubercule saillant sur leur pédoncule extérieur; le bord orbitaire interne est entièrement lisse; les pattes antérieures sont médiocres, hérissées de pointes sur les troisième et quatrième articles; la main, chez la femelle, est aussi grosse que le bras; les pinces sont faibles; les pittes suivantes sont crochues, et munies d'une petite dent à l'extrémitẻ du troisième article, et garnies de poils; la couleur de cette espèce est jaunâtre. - Elle se trouve sur les côtes des illes Baléares.

\section{MITHRAX DAMA.}

EDw., Mag. d'Entom., 1831, cl. 7, pl. 1; ejusd., op. cit., t. I, p. 319. - Cancer Dama, Неквsт, pl. 59, fig. 5. - Plus petite que l'espèce précédente ; la carapace est granuleuse et sans épines en dessus; les cornes du rostre sont très-divergentes, plus de trois fois aussi longues que larges, et armées de trois dents spiniformes, dont une terminale et deux externes.

\section{DEUXIÈME SOUS-GENRE.}

\section{Mithrax Transversaux.}

Pattes des quatre dernières paires hérissées d'èpines.

\section{MITHRAX SPINOSISSIMUS.}

EDw., Mag. d'Entom., cl. 7, 1831, pl. 2,5 ; ejusd., op. cit., t. I, p. 320 . - Maia Spinosissima. - LaMk., Hist. des Anim. sans vert., t. V, p. 241.-Long. 5 pouces. - Le bord supérieur de la main est armé de tubercules spiniformes; la carapace est couverte d'épines plus ou moins allongées, mais lisse dans l'espace que ces pointes laissent entre elles, et garnie, ainsi que les pattes, d'une multitude de poils roides; le rostre est formé de deux épines très-écartées entre elles, mais dirigées en avant; le bord orbitaire supérieur est armé de trois ou quatre épines dont l'antérieure est très-forte et se dirige en avant; les

ANN. bords latéra-antérieurs de la carapace sont armés chacun de cinq ou six grosses épines dont les deux premières sont bifurquées; l'article basilaire des antennes externes est terminé par deux épines, dont l'interne est très-longue; le troisième article de cet appendice est très-court; les pattes sont très-épineuses. - Cette espèce, qui atteint jusqu'à quatre ou cinq pouces de longueur, se trouve aux $\Lambda$ ntilles.

\section{Mithrax VERRUCOSUS.}

EDw., Mag. d'entom., cl. 7, 1831, pl. 2 , 3 ; ejusd., op cit., t. I. p. 321.- - Long. 2 pouc. - Le bord supérieur des mains est entièrement lisse; la carapace est couverte de granulations; le rostre dépasse à peine les épines terminales de l'article basilaire des antennes externes; les pinces sont armées de huit à dix dents marginales et d'un bouquet de poilsnoirs inséré au fond de la cuillière formée par l'excavation de leur bord préhensile; la face inférieure des tarses des autres pattes offre à peine quelques traces d'épines. - Cette espèce se trouve aux Antilles.

\section{MITHRAX MISPIDUS.}

Edw., Mag. d'Entom., cl. 7, 1831, pl. 2, 3 ; ejusd., op. cit., t. I, p. 322.-Maic Spinicincta, - LaM., Hist. des Anim. sans vert., t. V, p. 241.- Mithrax Spinicinctus, Desm., Consid. géner. sur les Crust. , p. 150 , pl. 23 , fig. 1 à 2. - Le bord supérieur des mains est lisse; la carapace est nue, verruqueuse, mais armée de quelques épines; le rostre ne dépasse pas l'article basilaire des antennes externes, qui n'est armé que de deux épines; le troisième article de ces antennes est notablement plus long que le second; il y a environ vingt dentelures sur le bord des pinces; point de bouquet de poils dans la cuillière; on aperçoit sous le tarse des quatre dernières paires une rangée de petites pointes. Se trouve aux Antilles.

\section{TROISIEME SOUS-GENRE.}

\section{Mithrax deprimé.}

Bord supéricur de l'orbite dépourvu d'épines.

\section{6. mitmrax sculptus.}

Edw., Mag. d'Entom., cl. 7, 1831, pl. 5; ejusd., op. cit., t. I, p. 322.-Maia Sculpia, Lax., Hist. des anim. sans vert., t. V; p. 242. - La surface de la carapace est cou- 
verte de petites bosselures lisses; le rostre est formé de deux petites dents arrondies, et n'occupe qu'environ le tiers de la largeur du front; le bord latéro-antérieur de la carapace est comme festonné, et, de plus, il est garni de quatre à cinq tubercules arrondis; le carpe et les mains sont parfaitement lisses; l'extrémité des pinces ne présente pas de dentelures; les pattes des quatre dernières paires sont très-épineuses en dessus et très-poilues.

\section{PARAMITHRAX, EDw.}

Ce genre, établi par M. Edwards, diffère du précédent par le rostre, qui est formé de deux grosses cornes, et notablement moins large que le front, qui a en tout presque autant d'étendue que le cadre buccal. - Les orbites sont ovalaires; leur bord supérieur est arqué et présente postérieurement trois fortes épines séparées par deux échancrures plus ou moins profondes; leur bord inférieur est largement échancré et incomplet. - Les yeux sont rétractiles, à pédoncules grêles, assez longs et un peu courbés. - L'article basi. laire des antennes externes est grand; il est armé d'épines dont une (l'externe) s'avance en général au-delà du bord du front, et sépare l'orbite de l'insertion de la tige mobile qui n'est pas recouverte par le front. - Les pattes antérieures sont de force médiocre et terminées par des pinces pointues et arrondies, qui sont unidentées, et qui ne sont point creusées en cuillère; les pattes qui suivent sont cylindriques et presque pas épineuses. Parmi les espéces qui composent ce genre, et qui se trouvent dans l'Australasie, nous citerons:

\section{1. paramiturax peroni.}

Edw., op. cit., t. I, p. 324. - La carapace est tuberculeuse et épineuse en dessus; les régions hépatiques sont assez bien marquées; le front est de largeur médiocre; l'épine formant l'angle orbitaire externe est très-saillante et suivie d'une série de cinq ou six épines plus ou moins fortes; l'article basilaire des antennes externes est peu élargi en avant, et porte à son angle externe une épine qui ne dépasse que de très-peu l'espace orbitaire; les pattes antérieures du mâle sont longues et garnies en dessus d'une crête tranchante sur l'anté-pénultième article.-Se trouve dans l'Océan Indien. Voyez, pour les autres espèces, l'Hist. nat. des Crustacés, par M. Edwards, t. I, p. 32h.
STENOCIONOPS, Latr., Edw. ; Cancer, Herest.

Ce genre de Crustacé est remarquable par sa carapace, qui est étroite, très-inégale, et garnie en arrière d'un grand prolongement triangulaire qui recouvre l'insertion de l'abdomen. - Le rostre est formé de deux cornes styliformes et divergentes. -Le bord superieur de l'orbite est armé d'une corne analogue à celle du rostre, mais dirigée plus obliquement. - Les tiges oculaires sont minces, immobiles et extrêmement- saillantes; leur longueur êgale la moitié de la plus grande largeur du corps.Le premier article des antennes externes est beaucoup plus long que large, le second est grêle et s'insère sous le rostre, un peu au-devant du niveau des yeux. - L'épistome est presque carré, et le troisième article des pieds-mâchoires externes est extrêmement dilaté vers l'angle externe et antérieur. - Les pattes sont grêles, cylindriques; chez la femelle, celles de la première paire ne sont guère plus grosses que les autres et sont beaucoup plus courtes que les secondes; les suivantes deviennent progressivement plus courtes, et l'article qui les termine est acéré et recourbé. L'abdomen, chez la femelle, est composé de cinq articles; les trois anneaux qui pré. cèdent le dernier étant soudés entre eux. - Le mâle est inconnù; la seule espèce qui compose ce genre est :

STENocionoPs CERVICORNIS. (Pl.14, fig. 3.)

Gúk., Iconogr. du Régn. anim. de Cuvier, Crust., pl. 8 bis, fig. 3. - EDw., op. cit., t. I, p. 338. - Cancer Cervicornis, Herbst, pl. 58, fig. 2.-Long. 3 ponces.La carapace est bosselée et garnie de tubercules; les cornes du rostre et du bord orbitaire supérieur sont grêles, très-longues et à peu près égales entre elles; on aperçoit sur les côtés de chaque région hépatique deux grosses élévations coniques; les antennes externes sont moins longues que le rostre; les pinces sont finement dentées et un peu recourbées en dedans; les pattes sont entièrement lisses. - Cette espèce habite l'Ile-de-France.

\section{MENOETHIUS, EDw. ;} Pis $a, \mathbf{L}_{\text {ATr. }}$

Ce petit genre, établi par M. Edwards, est remarquable par la carapace, qui es» 
environ une fois et demie aussi longue que large, extrêmement rétrécie antérieurement, et ayant la forme d'un triangle allongé et arrondi à sa base. - Le rostre est formé pay un grand stylet pointu qui ert placé sur la ligne médiane du corps, et occupe environ le tiers de la longueur totale de la carapace. - Les angles antérieurs des orbites sont surmontés d'une grande dent pointue et horizontale qui se dirige en avant; les bords de ces cavités ne présentent pas de fissures et entourent exactement la base du pédoncule oculaire, qui est court et un peu mobile. - L'abdomen du mâle se compose de sept articles distincts, tandis que chez les femelles on n'en compte que cinq, dont l'avant-dernier est formé par la soudure de trois anneaux. L'espèce qui a servi de type à ce nouveau genre est le :

\section{MENOETHUS MONOCEROS.}

Edw., op. cit., t. I, p. 339.- Pisa Monoceros, Latr., Encycl., t. X, p. 139. Inachus Arabicus, Ruppelu, Crust. de la Mer-Rouge, pl. 5, fig. 4.-Long. 10 lig. - La face supérieure de la carapace est bombée, mais presque horizontale; on apercoit sur la région stomacale trois tubercules disposés en triangle, et un sur chaque région branchiale; les bords latéroantérieurs sont divisés en trois dents irrégulières, triangulaires et peu saillantes; le troisième article de toutes les pattes est armé de quelques épines; celles de la deuxième paire étant beaucoup plus longues que les suivantes; le rostre est garni de poils de couleur brunåtre. - Cette espèce se trouve sur les côtes de l'Ile-de-France, dans la Mer-Rouge.

\section{ACANTHONYX, Latr., Edw.; Maïa, Risso; Libinia, Dess.}

La carapace, chez ce genre, est allongée, légérement bombée et épineuse.-Le rostre est horizontal et formé de deux cornes aplaties et divergentes. - Les orbites sont circulaires, et occupées en entier par la base des pédoncules oculaires, qui les dépasse d'une manière très-notable.-Les pattes sont courtes, assez grosses; celles des quatre dernières paires ètant comprimées ; leur cinquième article est élargi en dessous, - échancré près du bout et armé d'une dent pilifere, contre laquelle le doigt vient se replier en manière de pince; celles de la seconde paire présentent cette disposition particulière d'une manière encore plus marquẻe que les postérieures.

Parmi les trois espéces que renferme ce genre, nous citerons:

\section{1. aGanthonyx LUNULATUS.}

Epw., op. cit., t. I, p. 342.-Maïa Lunulata, Risso, Crust. de Nice, pl. 1, fig. 4, pl. 15, fig. 6-8.-Acanthonyx Lunulatus, LaTR, Règ. anim. de Cuvier, $2^{\mathrm{e}}$ édit. t. IV, p. 58. - Guérun, Icon. du Rég. anim. de Cuvier, Crust., pl. 8, fig. 1.-Long. 8 lig. -L'angle orbitaire externe ne présente pas d'épines; les bords latéraux de la carapace sont armés de trois dents dont l'antérieure est recourbée en avant; la carapace est légérement convexe, et presque une fois et demie aussi longue que large; le rostre est terminé par deux cornes séparées par une échancrure semi-circulaire; l'angle antérieur des orbites est surmonté d'une dent assez forte et dirigée en avant; - les deux dents postérieures du bord latéral de la carapace sont petites, arrondies et obtuses; les pattes antérieures du mâle sont beaucoup plus grosses, mais pas plus longues que les suivantes; le quatrième article de celles-ci est arrondi en dessus; leur cinquieme article est garni de poils sur la portion tronquée de son bord inférieur, et les tarses sont armés en dessous de deux rangées de pointes; l'abdomen du mâle présente six articles, le quatrième et le cinquième anneaux étant soudés entre eux; le corps est lisse, avec quelques faisceaix de poils sur le front; la couleur est d'un vert foncé. - Se trouve sur les côtes de la Provence et dans la baie de Naples, où elle se cache dans les fentes des rochers et dans les fucus du rivage; selon M. Risso, la femelle pondroit de très-petits œufs jaunâtres au printemps.

\section{AGavthony X PETIVeri.}

EDw., op. cit., t. I, p. 3/3.-Cancer Muricatus Compressum, Petrv., Petrograph. Amer., pl. 20, fig. 8.-Long. 8 lig.- Il n'y a point d'épines à l'angle externe des orbites; les bords latéraux de la carapace sont armés de trois dents dont l'antérieure, très-grande, aplatie et arrondie, n'est pas recourbée en avant, et dont les deux postérieures sont très-petites et obtuses; au reste. cette espéce a beaucoup d'analogie avec la précédente, seulement la carapace est moins convexe; les dents des angles orbitaires antérieurs sont plns fortes et plus élevées; les pattes antéricu. 
res sont un peu plus fortes et leur quatrième article est caréné en dessus. - Se troure aux Antilles.

\section{EPIALTUS, Edw.}

Ce genre diffère du précédent par la carapace, qui est hexagonale, régulièrement bombée, et lisse en dessus. - Le rostre est étroit, triangulaire.-Les bords latéro-antérieurs de la carapace sont très-courts, et forment, avec les bords latéraux, un angle très-ouvert.-Les yeux sont très-courts, ne dépassant pas notablement l'orbite, qui est circulaire et à bords entiers. - La région antennaire est très-petite. - La tige mobile des antennes externes s'insère dans le rostre, assez loin au-devant de l'orbite, et l'article basilaire de ces appendices est presque triangulaire et très-étroit ì son extrémité; le second article est un peu élargi et presque deux fois aussi long que le troisième. - L'épistome est petit, carré. - Les pieds-mâchoires externes sont grands, et leur troisième article est presque carré.-Le plastron sternal est circulaire, et sa suture médiane anticipe sur l'avant-dernier segment. - Les pattes antérieures sont assez fortes et les pinces sont légérement creu. sées en cuillière ; les suivantes sont cylindriques, et on aperçoit, au bord inférieur de leur avant-dernier article, un petit tubercule pilifère plus ou moins saillant; mais leur dernier article, qui est garni en dessous de deux rangées de petites épines, est peu flexible, de manière que ces organes ne peuvent agir qu'en manière de pince; les pattes de la seconde paire sont beaucoup plus longues que toutes les autres. - Les articles qui composent l'abdomen chez le mâle sont au nombre de six à sept.

\section{1. epialtus oculatus.}

EDw., op. cit., t. I, p. 345. - Long. 4 pouc. - Le rostre, chez cette espèce, est bifide; sur le devant de chaque orbite on aperçoit une petite dent, et trois autres spiniformes de chaque côté de la carapace sur son bord latéro-antérieur; la carapace est très-bombée; les pattes sont longues, et présentent sur le bord inférieur du métatarse un petit tubercule pilifère; le tarse en dessus est garni de deux rangées de petites épines; l'abdomen, chez le mâle, est composé de sept articles distincts. - Cette espece se trouve sur les côtes du Chili.

\section{EPialtus bi-tUbERCULATUS.}

EDw., op. cit., t. 1, p. 345, pl. 18 , fig. 11.- Long. 4 lig. - Le rostre est entier, avec deux angles saillans de chaque côté de la carapace, et deux tubercules sur la région stomacale; les pattes sont courtes; l'abdomen du mảle est composé seulement de six articles, et la couleur générale est d'un brun-rougeâtre. - Se trouve sur les côtes du Chili.

\section{LEUCIPP\&, EDW。}

M.Ed wards a créé dans les $A n n$. de ia $S o c$. Ent. de France, t. III, p. 512, fig. 1, 2 B, un genre de Crustacé qui a beaucoup d'analogie avec les Acanthonyx; il se rappro. che aussi de celui d'Eurynome, mais il s'en distingue par sa carapace, qui est entièrement lisse ; sa portion antérieure est à peu près triangulaire, et ses bords latéro-antérieurs sont avancés et tranclians. - Le rostre est horizontal, avancé, très-large, et tormé de deux cornes lamelleuses. - Les orbiles sont incomplets, et l'œil ne peut pas s'y cacher en entier. - Les yeux sont petits, et portés sur un pédoncule très-court. - Le premier article des antennes externes est étroit dans toute sa longueur; les second et. troisième sont complétement cachés sous le rostre, et ce dernier est presque deux fois aussi long que celui qui le précède. - L'épistome est peu développé, et les pieds-mấchoires externes ont leur troisième article très-dilaté en dehors, et légérement tronqué à son angle antérieur et interne.- Les pattes sont courtes, comprimées, et surmontées dans presque toute leur longucur d'une crête tranchante.-L'abdomen, chez la femelle, est composé de sept articles, et couvre entièrement le plastron sternal.

L'espèce type de ce genre, est la :

LEUGIPPA PENTAGONA.

Edw., Ann. de la Soc. Entom. de France, t. II, p. 512, pl. 18, fig. 1, 2 B; ejusd., op. cit., t. I, p. 347 , pl. 15 , fig. 9 à 10 . - Le rostre est arrondi en avant et divisé par une fissure étroite; les bords latéro-antérieurs de la carapace sont tranchans et découpés en trois grandes dents, dont l'antérieure constitue l'angle orbitaire externe; l'article basilaire des antennes externes est armé, en dehors, d'une crête longitudinale très-saillante; la region ptérygostomienne est garnie d'une série de dentelures; les pinces sont petites, dentées; les pattes des quatre dernières paires sont pubescentes en dessous; la couleur est d'un gris pâle. - Se trouve sur les côtes du Chili. 
MaIA, Lamck., Latr. , Leach, Desm., EDw.;

Cancer, Linn., Herbst ; Inachus, Fabr.

Le genre Mä̈a, établi par Lamarck, comprenoit autrefois les genres Inachus et $P$ arthénope de Fabricius; mais depuis il a été bien restreint, et il ne renferme plus aujourd'hui qu'un très-petit nombre d'espèces qui se trouvent sur nos côtes. Ce genre, tel qu'il est caractérisé maintenant par M. Edwards, a sa carapace d'environ un quart plus long que large, et assez fortement rétrécie en avant. - Sa face supérieure est hérissée d'une infinité de petits lubercules, et les régions sont peu distincles. - Le rostre est horizontal et formé de deux cornes divergentes, - Le bord latéroantérieur de la carapace est armé de fortes épines. - Les orbites sont ovalaires, assez profondes.- Les antennes internes ne présentent rien de remarquable, seulement la portion du front qui sépare leurs fossetles se prolonge en une forte épine qui se dirige en bas. - Le premier article des antennes externes est très-grand; son extrémité est armée de deux grosses épines et porte l'article suivant à son bord supérieur et externe, de sorte que la tige mobile de ces appendices naît dans le canthus interne des yeux. - L'épistome est plus large que long; il en est de même pour le cadre buccal:- Le second article des pieds-mâchoires externes se prolonge assez loin du côté interne, au-devant du niveau de son articulation avec la pièce suivante, et celle-ci, notablement plus large que longue, est dilatée en dehors et fortement tronquée à ses deux angles internes. - Le plastron sternal est presque circulaire, et sa suture médiane, quoique assez large, n'occupe que le dernier anneau thora. cique.- Les pattes de ìa première paire ne sont guẻre plus longues que les autres; elles sont assez grêles, légérement cylindriques, et terminées par une pince dont les doigts, presque styliformes, ne sont jamais creusés en cuillère, ni dilatés vers le bout, et ne présentent que peu ou point de dentelures. La longueur des pattes de la seconde paire ne dépasse guère une fois et demie la longueur de la carapace, et les pattes suivantes deviennent successivement plus courtes; l'article qui les ternine est styliforme, et ne présente ni épines ni dentelures à son bord inférieur. - L'abdomen, chéz les deux sexes, est composé de sept articles distincts.
Ces Crustacés sé plaisent dans les lieux pierreux et vaseux de la mer, et se dérobent à la recherche de leurs ennemis par l'aspect rocailleux, la dureté et la couleur de leur test; menacés de quelque danger, jls se blottissent contre un rocher et attendent qu'il soit passé ou qu'il les atteigne, dans une immobilité parfaite; dans le dernier cas, leurs pinces sont leurs moyens de défense. L'Océan et les côtes de la Méditerranée nourrissent les Maĩa. Suivant M. Risso, lorsque ces Crustacés sont prêts à changer de peau, ils se retirent dans les moyennes profondeurs, se cachent sous les ulves, les algues ou les fucus, et restent plusieurs jours dans un état de langueur; c'est ordinairement après cette espèce de métamorphose que le mâle court à la recherche de la femelle pour s'accoupler. Plusieurs espèces portent au delà de six à dix mille œufs; d'autres n'en font qu'un trèspetit nombre et ne frayent qu'une fois dans l'année. Dans le prélude de leurs amours, les grandes espèces s'approchent du rivage, et parcourent la mer en tous sens, se jettent plus facilement dans les filets que pendant les autres époques de leur vie. Aussitôt que la femelle veut se débarrasser de ses œufs, elle choisit les endroits tapissés de plantes marines, et les dépose parmi ces végétaux. La plupart de ces Crustacés vivent plusieurs années; ils ne vont à la recherche de leur nourriture que pendant la nuit. Quelques espèces acquièrent une taille assez considérable; elles sont connues dans les contrées méridionales, sous le nom d'Araignées de mer, et en provençal d'Esquinade; on mange ces grandes espèces.

\section{1. maia sournado.}

Latr. , Hist. nat. des Crust., t. VI, p. 93. - EDw., op. cit., t. I, p. 327.Cancer Squinado, Rondel., liv. 18, p. 401. - Herbst, pl. 56,-Inachus Cornutus; FaBr., Suppl., p. 356.-Long. 5 pouc.La carapace est converte d'épines aiguës; elle est assez bombée et fortement rétrécie en avant; l'angle antérieur du bord orbi. taire supérięur est très-arrondi; la moitié postérieure de ce même bord présente deux épines, dont une très-grosse et recourbée en haut, et une autre petite située derrière la précédente; les bords latéroantérieurs de la carapace sont armés de cinq ou six grosses épines très-aiguës, dont la première constitue l'angle orbitaire externe; la face inférieure du front est armée de cinq grosses épines, dont une médiane 
inter-antennaire; recourbée en avant, et deux placées de chaque côté, appartenant a l'article basilaire des antennes externes; le second article de ces antennes est cylindrique et de même longueur que le troisième; les pattes antérieures du mâle sont un peu plus fortes que celles de la seconde paire, et armées d'épines sur les troisième et quatrième articles; le corps, dont la couleur est rougeâtre, est couvert de poils crochus. Suivant NI. Risso, la femelle dépose ses œuf́, qui sont d'un rouge-brunâtre, en mars, juillet et septembre.

Ceste espèce se trouve sur nos côtes océaniques et méditérranéennes; les anciens en avoient fait un attribut de Diane d'Ephèse; elle étoit considérée, par eux, comme douée d'une grande sagesse, et comme sensible aux charmes de la musique; on la: voit aussi figurée sur quelquesunes de leurs médailles.

2. MAi verRucosa. (Pl. 14, fig. 1.)

EDw., op. cit., t. I, p. 328, pl. 3, fig. 1-4. - Cancer Squinado, Herest, t. I, pl. 15, fig. 84-85. - Maía Squinado, Bosc, t. I, pl. 7, fig. 3 ?-Long. 2 pouc.-Cette espèce, qui a été établie par M. Edwards, a été pendant long-temps confondue, par les zoologistes, avec la précédente, avec laquelle, en effet, elle présente beaucoup d'analogie; cependant elle s'en distingue par sa carapace, qui est à peine bom. bée, couverte de petits tubercules arrondis et armée de quelques épines sur la ligne médiane; par la face supérieure de cette carapace, qui ne présente pas d'épines; par sa forme, qui est plus ovalaire et beaucoup moins bombée, et enfin par la petitesse de ses pattes antérieures, qui, chez le mâle, sont plas grêles que celles de la seconde paire.- Se trouve sur nos cốtes méditerranẻennes; elle a été figurée, par M. Savigny, dans le grand ouvrage d'Egypte, sous le nom de Maïa Squinado, Aud., pl. 6 , fig. 4 .

\section{CAMPOSCIA , Latr. , Leach , Edw.}

La carapace, chez ce genre, est bombée, presque pyriforme, mais tronquée en avant. - Le rostre est rudimentaire, et dépasse à peine le canthus interne des orbites.-Les yeux sont portés sur des pédoncules assez allongés, recourbés en avant et très-gros à leur base; ils peuvent se replier en arrière et sont non rétractiles. - Les antennes internes se reploient un peu obli- quement en avant, - Les fossettes qui les logent ne présentent pas, comme d'ordinaire, une cloison longitudinale, et ne forment qú une seule cavité quadrilatère.-Le premier article des antennes externes est long et mince; il se prolonge presque aussi loin que le rostre, et porte, à son extrémité, une tige mobile qui est entièrement à découvert.-L'épistome est à peu près carré, et les pieds-mâchoịres externes sont très-allon. gés; ils se terminent par un ongle cylindrique, légérement recourbé à sa base.-Leur forme, chez le mâle, nous est inconnue; il en est de même pour la disposition de l'ab. domen de ces Crustacés.

L'espèce type de ce genre est la :

Camposcia retusa. (PI. 15, fig, 1.)

LaTk., Rég. anim., $2^{\mathrm{e}}$ édit., t. IV, p. 60.-Guér., Icon. du Règ. anim. de Cuvier, Crust., pl. 9, fig. 1.-EDw., op. cit., t. I, p. 283 , pl. 15, fig. 15-16.-Le corps est entièrement couvert de poils laineux, lesquels deviennent plus longs et bien plus touffus sur les pattes; la carapace, qui est bombée, présente des régions assez distinctes ; le rostre est très-large, tronqué, et terminé par deux petits tubercules qui dépassent à peine l'extrémité de l'article basilaire des antennes externes; on aperçoit une dent assez forte sur la partie latérale de la carapace, à quelque distance en arrière des yeux; les pattes de la première paire sont cylindriques et terminées par une pince faible, légérement recourbée en dedans, dentelée sur. les bords et point creusée en gouttière; celles de la troisième paire sont à peu près aussi longues que le corps. - Cette espèce, dont la patrie nous est inconnue, est d'une couleur jaunâtre.

$$
\begin{aligned}
& \text { Pericer A, Latr., Edw.; } \\
& \text { Cancer, Herist ; Maia, Bosc. }
\end{aligned}
$$

La carapace est très-allongée,plus ou moins triangulaire, un peu bombée et inégale en dessus. - Le rostre est horizontal, formé par deux grandes cornes coniques, acérées et ordinairement divergentes. - Le front est très-large et occupe à peu près deux fois autant d'espace que la base du rostre.Les orbites sont circulaires, très-petites et extrêmement profondes; elles sont dirigées directement en dehors; et remplies en entier par les pédoncules oculaires qui y sont renfermés comme dans une gaine, les dépassent à peine, et ne peuvent se reployer ni en avant ni arrière; leur bord 


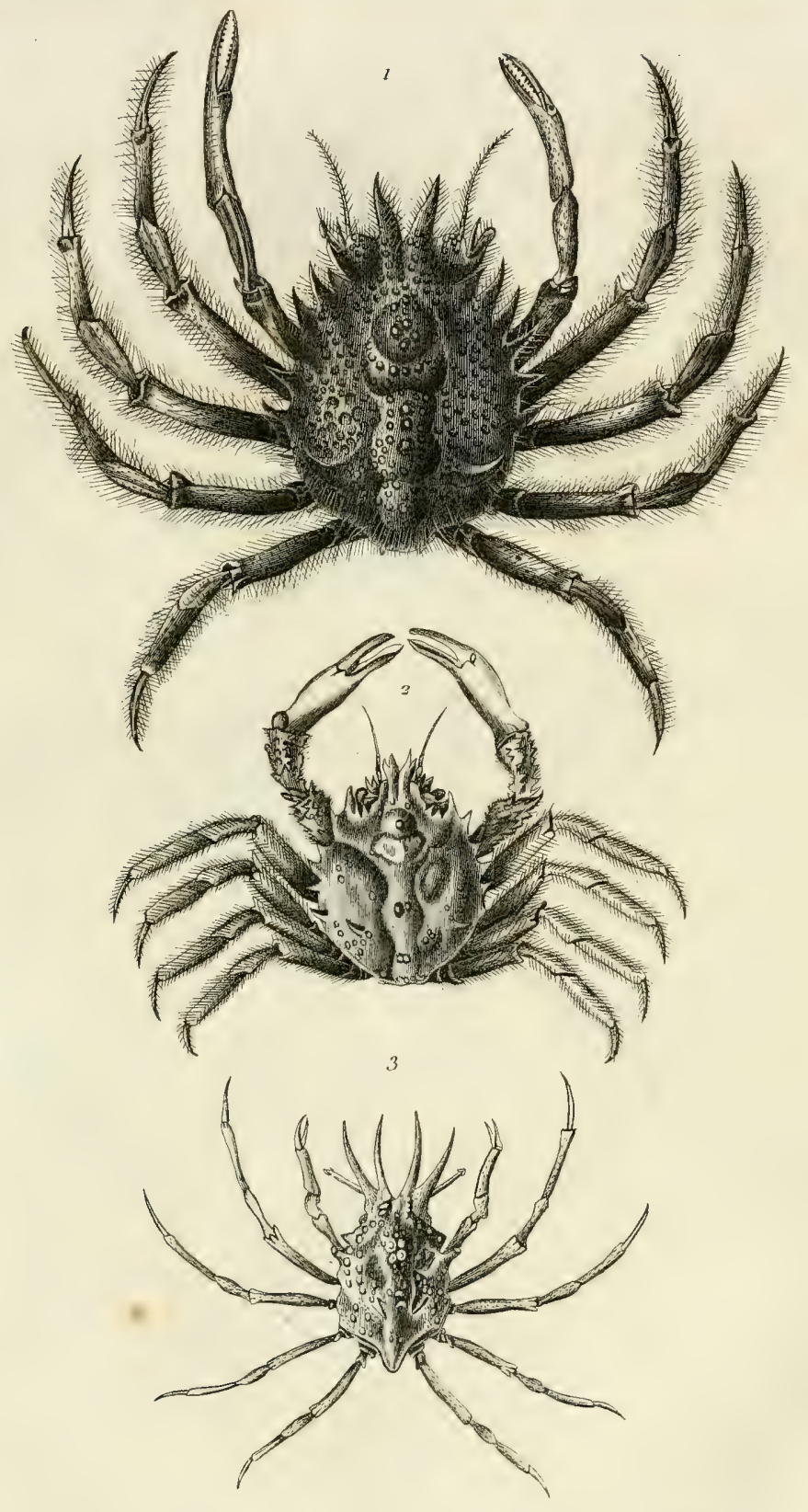

1. Maia versucosa,

2. Mithrax dicotomus.

3. Stenocionops cervicornis. 

Tome aer I ére partie.

Crustacés, Pl, 75 .

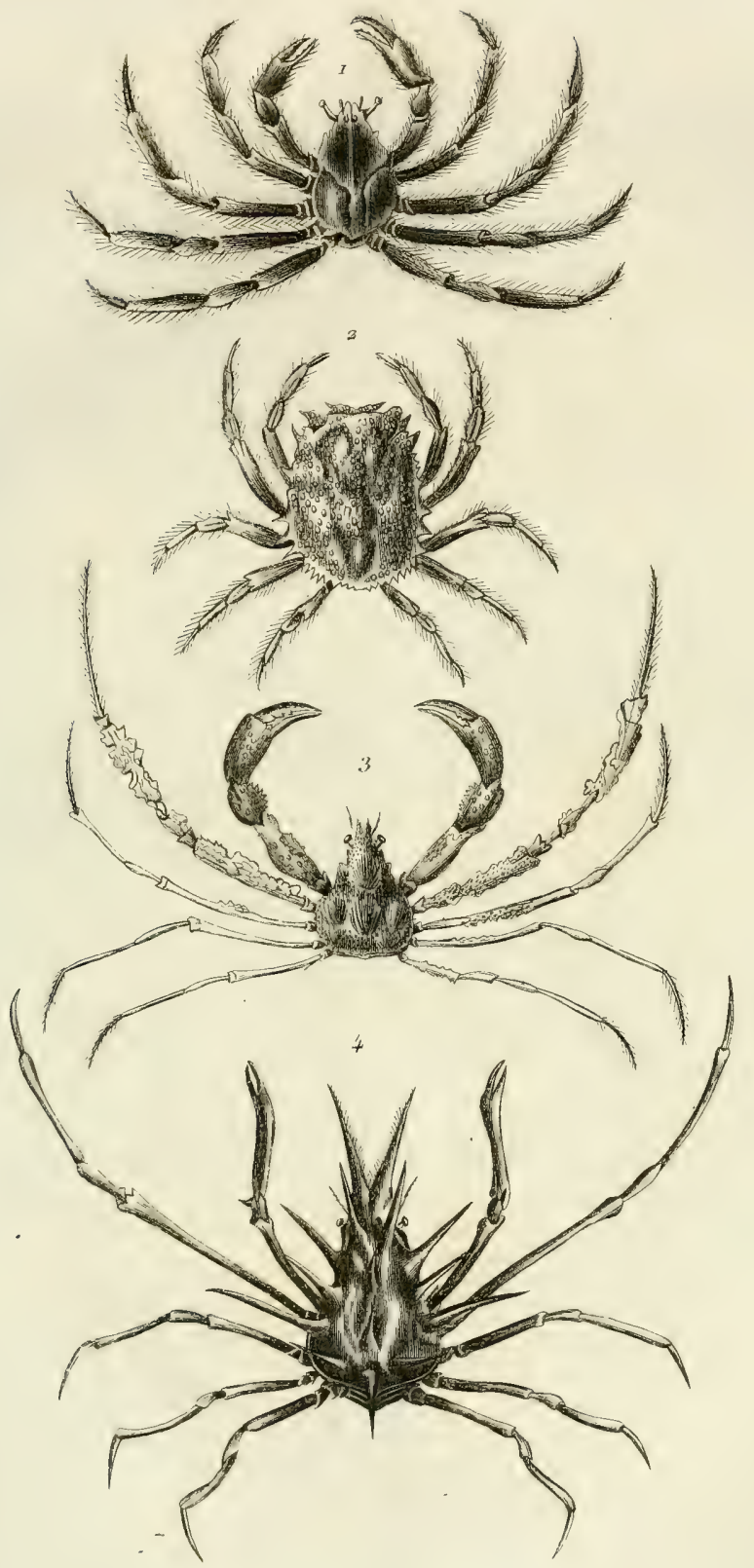

1. Camposcia retusa.

3. Thachus thoracicas.

2. Micippa plryliua.

4. Amathia Ríssoana. 

supérieur est très-avancé, et présente une fissure. - L'article basilaire des antennes externes est extrêmement grand, il est beaucoup plus large en avant qu'en arrière, et se termine par un bord transversal trèsétendu, qui se soude au front, sur les côtés du rostre. - La position de la tige mobile des antennes externes varie un peu; tantôt elle s'insère sur le rostre, tantôt un peu en dehors du bord latéral de ce prolongement, mais toujours très-près de la fossette antennaire et très-loin de l'orbite. - La disposition des pieds-mâchoires externes, ainsi que celle du plastron sternal, des pattes et de l'abdomen, est à peu près semblable à celle des $P$ ises.

\section{1. peficera connuta.}

Evw., op. cit., t. I, p. 335. - Cancer Cornudo, Herbst, pl. 59, fig. 6. - Maia Taurus, Lam., Hist. nat. des Anim. sans vert., t. V, p. 242. - Long. 4 pouc. - Les cornes du rostre sont styliformes et trèsdivergentes; la carapace est inégale, non épineuse supérieurement, mais armée sur les bords d'une ceinture d'épines grosses, très-longués et aiguës, dont une est placée sur les régions hépatiques, trois sur lesbranchiales, et une impaire sur la région intestinale. L'article basilaire des antennes externes est armé en avant d'une petite épine qui ne sépare pas le front; le deuxième article est cylindrique, grêle, allongè, et inséré sur le rostre; le troisième article est plus court que le second. Les pattes antérieures sont cylindriques, un peu plus grosses que les suivantes; les bras sont épineux; les pinces sont très-grêles; les pattes suivantes sont médiocres; celles de la seconde paire n'ayant pas une fois et demie la longueur de la portion post-frontale de la carapace; le corps est entièrement couvert d'un duvet brunâtre. - Se trouve dans la mer des Antilles.

\section{2. pericera trispinosa.}

EDw., op. cit., t. I, p. 336. - Guér., Iconog. du Rég. anim. de Cuv., Crust., pl. 8, fig. 5. - Pisa Trispinosa, Latr., Encycl., t. 10, p. 142. - Long. 1 pouc. $\frac{T}{2}$. - La portion posterieure de la carapace est triangulaire el armée de trois fortes épines, dont deux latérales et une médiocre dirigée en arrière; les bosselures de la carapace sont assez bien maiquées; le front est large, avec le rostre court; la tige mobile des antennes externes s'insère immédiatement au-dessous du bord latéral du rostre; les pattes de la seconde paire sont de la longueur de la portion post - frontale de la carapace, et leur troisième article est légérement onduleux vers le bout; le corps, chez cette espéce, est couvert d'un duvet jaunâtre très-court. - Se trouve dans les mêmes localités que l'espèce précédente.

\section{3. pericera biconti.}

Edw., op. cit., t. I, p. 337. - Pisa Bicornuta, LaTr., Encycl., t. X, p. 141. Long. 1 pouce. - La carapace est arrondie postérieurement et sans épine médiane audessus de l'insertion de l'abdomen; les cornes du rostre sont très-divergentes; de plus, la carapace est couverte de tubercules arrondis, et armée d'une épine transversale sur chaque région branchiale, mais du reste peu ou point épineuse; le bord supérieur de l'orbite est a angles peu saillans et marqué de deux fissures; la tige mobile des antennes externes est insérée entre le bord du rostre et la dent terminale de l'article basilaire de ces appendices; son premier article est élargi et presque aussi long que le second; la couleur est jaunâtre. - Se trouve aux Antilles.

\section{NAXIA, EDw.}

Ce petit genre, qui a été créé par M. Edwards, a beaucoup d'analogie avec le genre Pisa; mais il s'en distingue par la disposition des antennes et des orbites. La carapace, chez ce genre, est presque pyriforme, et le rostre, quoiqu'il ne soit pas lamelleux, ressemble beaucoup à celui dès Pisa. - Les orbites sont très-petites, presque circulaires, profondes et marquées d'une fissure en dessus, mais sans biatus a leur bord inférieur. - L'article basilaire des antennes externes est grand, étroit en avant, très-avancé, entièrement caché par le rostre et par l'angle antérieur du bord orbitaire supérieur. - La tige mobile de ces appendices s'insère sous le rostre, tout près de la fossette antennaire, et non au delà du niveau du bord externe de ce prolongement. - L'épistome est très-grand.

\section{NAXIA SERPULIFERA.}

EDw., op. cit., t. I, p. 313. - Pisa Serpulifera, Edw., Guér., Iconog. Crust., pl. 8, fig. 2.- Long. 4 pouces. - C'est la Pisa Serpulifera quia servi de type à M. Edwards pour l'établissement de cette nouvelle coupe générique. La carapace est fortement bosselée et tuberculeuse en dessus, arrondie 
postéricurement, et très-rétrécic en avant; le rostre est grand et formé de deux cornes cylindriques, tronquées au bout, et terminées par deux grosses dents spiniformes; l'angle antérieur du bord orbitaire supérieur est occupé par une grosse dent triangulaire ; les régions ptérygostomiennes et branchiales présentent une dent semblable; le deuxième article des antennes externes est grêle, cylindrique, et une fois et demie aussi long que le troisième; les pattes de la première paire du mâle sont plus grosses et aussi longues que celles de la seconde paire, qui ont elles-mêmes environ une fois et demie la longueur des suivantes; chez la femelle, la disposition des pattes est tout le contraire, c'est-à-dire que les pattes antérieures sont plus courtes que celles de le seconde paire, lesquelles ne sont guère plus longues que celles de la troisième paire; les tarses sont sans dentelures en dessous; le corps est couvert d'un duvet brunâtre, et souvent la carapace présente en dessus des incrustations de flustres, de serpules et d'éponges. - Se trouve à la Nouvelle-Hollande.

PISA, Leach, Desu., EDw. ;

Cancer, Herest; Inachus, FABR. ; Maĩa, Bosc, Risso.

Les Crustacés qui composent ce genre appartiennent tous, pour la plupart, aux mers de l'Europe; ils sont remarquables par leur forme triangulaire et par leur rostre qui est ordinairement très-allongé. La carapace, chez tous ces Crustacés, se rétrécit graduellement dans ses trois quarts antérieurs, et ses bords latéro-antérieurs se prolongent obliquement en lignes presque droiles jusqu'à une petite distance de son bord postérieur; ses bords latéro-postérieurs sont dirigès presque transversalement, et sa - surface est très-bombée. Les régions généralement sont assez distincles, et la stomacale surtout est trèsdéveloppée. - Le front est plus large que le cadre buccal, et armé de quatre cornes dirigées en avant, dont les deux externes occupent l'extrémite antérieur du bord orbitaire supérieur, et les deux moyennes forment le rostre, qui est toujours au moins une fois et demie aussi long que large. - Les yeux sont portés sur des pédoncules très-courts, et se reploient en arrière dans les orbites, qui sont ovalaires et dirigées directement en dehors et en bas; le bord supéricur de ces cavités présente deux fentes séparées entre elles par une dent triangulaire, et leur angle externe esi situé plutôt au-dessous qu'au-dessus du bord latéral de la carapace, qui vient s'y terminer; le bord orbitaire en dessous est interrompu par une large échancrure. - L'article basilaire des antennes externes est beaucoup plus long que large; il n'est que peu rétréci en avant, et dépasse le niveau du canthus interne des yeux; mais il est entièrement caché en dessus par le prolongement spiniforme du bord orbitaire supérieur. - Le second article de ces appendices est grêle et cylindrique; il s'insère à distance à peu près égale de la fossette antennaire et de l'orbite; le troisième article est petit, pareillement cylindrique; enfin le dernier ou le quatrième est assez allongé. - La région antennaire est à peu près de la grandeur du cadre buccal, et l'èpistome est grand et presque carré. Le second article des pieds-mâchoires externes se prolonge du côté interne beaucoup au-devant du niveau de son angle externe; et le troisième article, plus long que large, est fortement dilaté en dehors, et profondément échancré à son angle inférieur et interne. - Le plastron sternal est plus long que large. - Les pattes, chez les femelles, sont gẻnèralement ả peu près de même longueur que celles de la se. conde paire; mais chez le mâle, elles sont plus grosses et bien plus allongées. - La main est renflée, etles doigts sont tranchans, fincment dentelés dans leur moitié terminale; les pattes qui suivent sont cylindriques et de longueur médiocre; celles de la seconde paire ne sont pas beaucoup plus longues que la portion post-frontale de la carapace; la longueur des autres pattes diminue graduellement, et leur dernier article est garni en dessous de petites pointes cornées qui sont placées très-régulièrement sar une ou deux lignes longitudinales. - L'abdomen est composé de sept articles bien distincts, et tout le corps de ces Crustacés est ordinairement couvert de poils; souvent ces poils sont recourbés au bout, ce qui explique facilement pourquoi ces Crustacés sont couverts d'herbes marines et d'éponges,

Ces animaux habiient de préférence les eaux profondes: on en prend souvent dans les filets traînans des pêcheurs, et à mer basse, lors des marees très-fortes, on en trouve cachés sous des pierres; ils ne sont pas employés comme aliment. La Méditer- 
ranée est habitée par deux à trois espèces de ce genre; il en est qui n'abandonnent pas les vallées sous-marines; d'autres se tiennent dans les fentes de rochers, parmi les-algues, et non loin du rivage.

\section{PISA TETRAODON.}

Leach, Malac. Brit. , pl. 20. - Desm., Consid. génér. sur les Crust., pl. 22, fig. 1. - EDw., op. cit., t. I, p. 305.Cancer Tetraodon, PenN., 1. IV, pl. 8, fig. 15. - Pisa Tetraodon, Latr., Encyl., t. X, p. 142 . - Long. 3 ponc. - La carapace est d'un quart plus longue que large, légérement bombée en dessus, à régions peu distinctes; ses bords latéraux sont légérement arrondis et armés de quatre épines assez fortes, dont une placée sur la région hépatique et trois sur la région branchiale; la région intestinale présente une petite pointe, et on aperçoit sur la stomacale quelques petits tubercules; le rostre est légérement incliné et formé par des cornes assez grosses, dont la longueur égale à peu près la largeur du front, et dont l'extremité est fortement courbée en dehors ; les épines de l'angle orbilaire antérieur sont très-grandes et divergent obliquement en dehors; les troisième et quatrième articles des pattes antérieures sont tuberculeux; les mains sont renflées, avec les pinces arrondies en dessus; le tarse des pattes qui suivent est armé en dessous d'une rangéc de dents spiniformes assez grosses; le corps est presque entièrement couvert d'une espèce de duvet et de quelques poils crochus; la couleur est brunâtre. -Se trouve assez communément surnos côtes de France et sur celles d'Angleterre.

\section{PISA CORALLINA.}

EDw., op. cit., t. I, p. 306. - Maia Corallina, Rrsso, Crust. de Nice, pl. 1, fig. 6. - Long. 15 lig. - La carapace est presque deux fois aussi longue que large et à peine bombée à sa face supérieure; les régions sont peu distinctes; les bords latéraux sont armés, sur la région branchiale, de deux ou trois épines semblables entre elles; et sur la région hépatique, d'une petite pointe plus ou moins distincte; la région intesinale présente une petite épine; le rostre est horizontal, formé de deux cornes styliformes très-grêles, contiguës -jusque vers leur extrémité, presque droites, et dont la longueur a'excede pas heaucoup la largeur du front; les épines des al!gles orbitaires antéricurs sont grandes et dirigées en avant; les pattes sont presque entièrement lisses; Ies pinces sont arrondies en dessus; les tarses sont armés en dessous de petites dents pointues et de poils raides; le corps est parsemé de touffes de poils assez longs et renflés vers le bout; la couleur est d'un rouge-corail pâle. La femelle pond des œufs d'un rouge foncé, dans les mois de février, juin et septembre. - Se trouve sur les côtes de la Provence.

\section{PISA GIBSII.}

Leach, Malac. Brit., pl. 19. - Roux, Crust. de la Méditer., pl. 34, fig. 1.EDw., op. cit., t. I, p. 307.-Cancer Bimaculatus, Linn., Trans., t. II, pl. 1, fig. 2. -Long. 2 pouc. - La région intestinale, chez cette espèce, est surmontée d'un gros tubercule obtus et arrondi; la carapace est une fois et demie aussi longue que large; les régions branchiale, cordiale, stomacale et intestinale sont très-renflées et sćparées par des dépressions profondes; le rostre est ovalaire et formé de deux cornes styliformes presque droites et contiguës jusqu'auprès de leur sommet; les dents de l'angle orhitaire antérieur sont médiocres et dirigées en avant; les bords latéro-antérieurs de la carapace ne sont presque pas épineux, et ils se terminent par une grosse dent spiniforme dirigée en dehors; les bords latéro-postérieurs s'étendent du sommet de ces parties latérales au sommet de la région intestinale; le second article des antennes externes est assez gros, environ une fois et demie aussi long que le suivant, et plus court que la fossette antennaire; le plastron sternal se rétrécit brusquement entre les pattes de la premiẻre paire, qui sont légérement tuberculeuses sur les troisième el quatrième articles; les mains sont comprimées, assez fortes; les doigts sont mobiles, aplatis en dessus ct triangulaires; les pattes de la seconde paire sont beaucoup plus longues que les suivantes; leur troisième article n'étant pas noduleux et leurs tarses étant armés en dessous de quelques pointes; la couleur de cette espèce est orange, el le duvet qui la recouvre est roux. - Cette Pise vit sédentaire et solitaire parmi les rochers couverts de plantes marines, à quelques mètres de profondeur; les œufs que la femelle porte pendant la belle saison sont d'un beau rouge-orange. - Se trouve dans la Méditerranée, mais pas communément; elle se rencontre aussi sur nos côtes Océaniques et sur celles d'Angleterre. 


\section{PISA ARMATA.}

Roux, Crust. de la Méditerr., pl. 55, fig. 1. - EDw., op. cit., t. I, p. 308.Maîa Rostrata, Bosc, t. I, p. 255. Maïa Armata, Latr., Hist. nat. des Crust., t. V1, p. 98. - Long. 2 pouc. Cette espèce diffère de la précédente par sa région intestinale, qui se prolonge en une grosse épine très-aiguë; les épines latérales sont également longues et aiguës ; les cornes du rostre sont séparées jusqu'à leur base par une fente assez large, plus divergentes et plus longues que dans l'espèce précédente; le second article des antennes externes est très-grêle, environ deux fois aussi long que le suivant, et notablement plus long que la fossette antennaire. Les mouvemens de cette espèce, dit M. Roux dans son Hist. nat. des Crust. de la Méditerr., sont très-lents; elle vit solitaire parmi les rochers couverts de plantes marines ; d'un caractère timide, elle s'arrête et replie ses pattes crochues sous son test, a l'aspect du moindre danger, et demeure immobile; c'est au printemps et en été que les femelles cherchent à déposer leurs œufs de couleur orangée; et les mâles, courant après elles, parcourent la mer en tous sens, et se jettent dans les filets des pêcheurs. Se trouve sur les côtes de Provence et d'Italie.

\section{PISA STYX.}

Latr., Encycl., t. X, p. 141. - Edw., op. cit., t. I, p. 308. - Cancer Styx, Herbst, pl. 58, fig. 6.-Long. $10 \mathrm{lig}$. - Diffère de la Pisa Tetraodon par sa carapace, qui est plus allongée, plus fortement bombée; par ses bords latéro. anterieurs, qui, au lieu d'être armés de grosses épines, ne présentent que quelques pointes a peine saillantes; enfin par le bord orbitaire supérieur, qui ne présente qu'une fissure étroite; les dents sont spiniformes; les pattes de la seconde paire, armées d'épines, sont aiguës et assez membraneuses; sur les pattes suivantes elles devienvent plus courtes et plus rares; la couleur est d'un jaune-roussâtre. - Se trouve à l'Ile-de-France.

$$
\begin{gathered}
\text { LISSA, Leacr, Edw. ; } \\
\text { Cancer, Herbst ; Inachus, Fabr. ; } \\
\text { Pisa, Latr. }
\end{gathered}
$$

C'est dans son Zool. Misc., t. II, pl. 83, que M. Leach a établi ce nouveau'genre aux dépens de celui de $P$ isa, avec lequel il a la plus grande analogie, car il n'en diffère qu'en ce que les caractères du genre Lissa consistent dans la forme du rostre, qui est formé par deux cornes lamelleuses tron= quées antérieurement, et même plus larges en avant qu'avant la base, et dans l'ab. sence d'épines sur les tarses. - La seule espèce connue et sur laquelle il a établi ce genre est la :

\section{LISSA CHIPAGRA.}

Leaci, Zool. Misc., t. II, pl. 83. EDw., op. cit., t. I, p. 310.-Cancer Chiragra, HeRBst, pl. 17, fig. 96. - Inachus Chiragra, FABR., Suppl., p. 357.Long. 2 pouc. - La carapace est presque de forme hexagonale, environ un quart plus longue que large, rétrécie en avant, trèsfortement bombée et noduleuse en dessus; le rostre est très-large et armé en avant de deux dents dirigées en dehor's; l'angle antérieur du bord orbitairese prolonge en avant sous la forme d'un gros tubercule arrondi; le deuxième article des antennes est grêle, cylindrique, et deux fois aussi long que le troisième; les pattes de la première paire sont petites et tuberculeuses; celles de la seconde paire sont moins longues que la carapace, et,fortement noduleuses comme les suivantes; le front est inerme; les pattes sont garnies de quelques poils en massue; la couleur est rouge intense. - Cette espèce se trouve dans la Méditerranée.

CHORINUS, Leach, Edw. ;

Cancer, Herbst; Pisa, Latz.

M. Leach a établi ce genre de Crustacé aux dépens de celui de Pisa, avec lequel il a la plus grande analogie, mais qui est remarquable par la grande disproportion qui existe ordinairement chez le mâle entre les pattes des seconde et troisieme paires, et par la position de la tige mobile de leurs antennes externes. - La carapace, chez ce genre, est plus longue et plus étroite que celle de presque toutes les espèces qui composent le groupe des Maites; mais sa forme diffère peu de celle de quelques Pises. - Le rostre est formé de deux grosses cornes pointues et horizontales. - Les yeux sont rétractiles, et les orbites sont dirigées en dehors et en bas. - L'article basilaire des antennes externes est étroit et sans épines notables à son extrémité ; la tige mobile de ces appendices s'insère sous le rostre, et est en grande partie cachée par lui, - L'épistome, les 
pieds-mâchoires, le plastron sternal et l'abdomen sont disposés à peu près comme dans le genre Pisa. - Les pattes antérieures sont plus longues, surtout chez les mâles, et la pince qui les termine est assez fortement courbée en dedans, dentelée et pointue, mais un peu creusée en gouttière. - Les pattes qui suivent sont cylindriques; celles des trois dernières paires sont de longueur médiocre; mais les secondes sont très-longues; chez le mâle, elles sont généralement une fois et demie, ou même près de deux fois aussi longues que celles de la troisième paire.

\section{CHORINUS MEROS.}

Edw., op. cit., t. I, p. 315. - Cancer Heros, Hendst, pl. 42, fig. 1. - Maia Heros, Bosc, t. I, p. 251. - Pisa Heros, LATr., Encycl., t. X, p. 139. - Long. 3 pouc. - La carapace est presque deux fois aussi longue que large et convexe en dessus; la région stomacale est très-grande, renflée, et tuberculeuse dans sa moitié antérieure; les régions branchiales sont peu développées et presque entièrement lisses; le rostre est très-allongé; l'angle antérieur et supérieur de l'orbite est surmonté d'une grande épine horizontale; les bords latéroantérieurs sont armés en avant de deux dents arrondies; les pattes antérieures du mâle, deux fois aussi longues que la portion post-frontale de la carapace, sont cylindriques, avec les doigts fortement recourbés en dedans; celles de la seconde paire sont une fois et demie aussi longues que la portion post-frontale de la carapace, et deux fois aussi longues que celles de la troisième paire; les tarses sont armés en dessous d'une rangée de petites épines cornées; le rostre, les côtés de la carapace et les pattes des quatre dernières paires sont garnis de poils; la couleur est jaune.rougeâtre.-Se trouve aux Antilles.

\section{ChORINUS AGULEATA.}

EDw., op. cit., t. I, p. 316. - Long. 2 pouc. - La carapace est armée de cinq épines très-longues sur la ligne médiane, et de deux sur chaque région branchiale; les cornes du rostre sont fortement recourbées en dehors; le bord orbitaire supérieur est armé d'une forte épine à son angle antérieur, et présente deux fentes séparées par une dent triangulaire; le bord inférieur de l'orbite est presque nul, et son angle externe affecte la forme d'une dent aplatie; les pattes de la première paire sont armées en dessus d'une crête tranchante sur le quatrième article et dentelée sur le troisième; les pattes qui suivent sont cylindriques, et garnies d'une forte épine à l'extrémité des troisième et quatrième articles; celles de la seconde paire ne sont guère plus longues que les suivantes; les tarses sont lisses en dessous; le corps est légérement pubescent. - Se trouve dans les mers de l'Asie.

\section{CHORINUS DUMERILIY.}

EDw., op. cit., t. I, p. 317. - Long. 6 lig. - La carapace est lisse en dessus et sans épines notables; le bord orbitaire supérjeur est armé en avant d'une forte épine, et divisé en arrière par une fissure ; l'extrémité de l'article basilaire des antennes $\mathbf{e x}$ ternes présente une forte épine. - Se trouve à l'île de Vanikoro.

\section{MICIPPA, Leach, Edw.}

Ce genre, qui a été établi par Leach, a la portion post-frontale de la carapace presque en forme de quadrilatère, légérement bombée, arrondie en arrière, et à peine rétrécie antérieurement. - Son bord fronto-orbitaire est droit et très-large, et ses bords latéraux sont armés d'épines. Le rostre est lamelleux et dirigé verticalement de manière à former un angle droit avec l'axe du corps et l'épistome. - Les orbites sont placées au-dessus et sur les côtés du rostre, et on remarque à leur bord supérieur une fente profonde. - Les pédoncules oculaires sont rétractiles, assez longs, rétrécis au milieu, et se prolongent jusqu'à l'extrémité de la cornée. - La tige des antennes internes, en se déployant, demeure verticale, au lieu de devenir horizontale. - L'article basilaire des antennes externes est très-grand et plus large en avant qu'en arrière; le second article de ces appendices s'insère entre le bord du rostre, à une assez grande distance de l'orbite. - Le troisième article des pieds-mâchoires est extrêmement dilaté du côté externe, et très-profondément échancré dans le point où il s'articule avec la pièce suivante. - Le plastron sternal est presque de forme circulaire. - Les pattes sont cylindriques et de longueur médiocre; celles de la première paire ne sont guère plus grosses ni plus longues que les suivantes, même chez le mâle, et les pinces sont effilées vers le bout, tranchantes, et presque pas sensiblement creusées sur leur face. 
- Les pattes de la scconde paire ont à peu pres une fois et demie la longueur de la portion post-frontale de la carapace, et les tarses ne sont pas dentelés en dessous. - L'abdomen, chez les deux sexes, se compose de sept articles distincts. - Les deux seules especes qui composent ce genre se trouvent dans l'Ócéan Indien.

\section{MICIPPA Cristata.}

Leaci , Zool. Miscell., t. III, pl. 128. - Eow., op. cit., t. I, p. 330. - Cancer Cristatus, Live., Mus. Lud. Utr., p. 443. - Maïa Cristala, LATr., Encycl., pl. 28, fig. 1. - Long. 3 pouc. - Chez cette espèce, la carapace est hérissée en dessus d'un grand nombre d'épines longues et aiguës, dont deux placées sur le front, et deux autres occupant le milieu du bord postérieur; les bords latéraux du rostre sont armés de quatre ou cinq dents; l'angle antérieur du bord orbitaire est armé d'une forte épine; les bords supérieurs de l'orbite et les bords latéraux de la carapace sont garnis de longues épines très-aiguës; l'article basilaire des antennes externes est beaucoup plus long que large; les pattes sont couvertes de petites granulations; la couleur générale est blanchâtre. - Se irouve sur les côtes de Java.

\section{MICIPPA PIILYRA.}

LEACH, op. cit., GuÉr., Icon. du Régn. anim. de Cuv., Crust., pl. 8 bis, fig. 1.EDw., op. cit., t. II, p. 330. - Long. 2 pouc. - La carapace est entièrement couverte de tubercules granuleux, mais non ípineux, à sa surface supérieure; le rostre cst terminé par quatre dents, dont les deux externes crochues et dirigées en dehors; l'angle antérieur du bord orbitaire supérieur est arrondi, non spiniforme; les bords latéraux de la carapace sont armés de quelques épines courtes et peu acérées; l'article basilaire des antennes externes est beaucoup plus large que long; les pattes sont à peine granuleuses; la couleur est jaunâtre. - Se trouve dans l'Océan Indien et sur les côtes de l'Ile-de-France.

\section{CriogarcinUS, Guér., Edw.}

M. Guérin a désignè sous le nom de Criocarcinus un genre de Crustacé qui a beaucoup d'analogie avec les Micippes; mais il en différe par les cavités orbitaires, qui ont presque la forme d'un tube dirigé en dehors, long et déprimé à son extré. mité, mais n'engaînant pas les yeux commé chez le genre Pericera. - Leur pédoncule oculaire est long, grêle, et assez semblable à celui des Maĩa; il s'y insère de manière à être entièrement à découvert et à pouvoir se reployer en arrière, et à s'appliquer dans. toute sa longueur.entre le bord extérieur de-l'article basilaire des antennes externes; position dans laquelle il est caclé sous les épines post-orbitaires de la carapace. - La seule espèce connue, et qui est le type de ce singulier genre, est le :

\section{CRIOCARCINUS SUPERGILIOSUS.}

Guén., Collect. du Mus., Eow., op. cit., t. 1, p.332.-Cancer Superciliosus, Henвst, pl. 44 ; fig. 89.-Long. 18 lig. - La carapace est bombée, inégale, et à bords latéraux presque parallèles; le rostre est vertical et armé de deux cornes recourbées en dehors; le bord orbitaire supérieur est lamelleux, extrêmement saillant, et armé de trois fortes épines: les bords latéro-antérieurs de la carapace présentent trois ou quatre fortes épines, dont deux sur la région stomacale, et une sur la région intestinale. - La patrie de cette espèce est inconnue.

\section{PARAMICIPPA, EDW.}

Ce genre, établi par M. Edwards, et qui a beaucoup d'analogie avec celui de Iicippe, en differe par sa carapace, qui est presque aussi large que longue, par le rostre, qui est reployé en bas, et par les bords latéro-antérieurs, qui sont armés de dents. - La disposition des antemnes externes est à peu près la mềme que chez celui de Micippe; seulement leur second article, qui est placé sur le même niveau que la face supérieure du front, est aplati, élargi, très-court et cordiforme ; mais cel'e des yeux est très-différente, en ce que ces organes ne peuvent se reployer en arrière, et en ce qu'il n'existe pas de cavité orbitaire post-foraminaire. - Leur pédoncule dépasse de beaucoup les bords de l'orbite, et présente les mêmes disposions que chez les Criocarcinus, si ce n'est qu'il est immobile. - La forme des pieds-mâchoires externes est entièrement la même que celle du genre Pisa; mais l'épistome est extrêmement court. - Les pattes sont courtes; celles de la seconde paire ne sont guère plus longues que la portion post-frontale de la carapace, et les suivantes se raccourcissent progressivement. - L'abdomen 
est composé de sept articles distincts chez la femelle. - Le mâle est encore inconnu. - Ce genre renferme deux espèces, et celle qui lui a servi de type est le:

\section{PARAMICIPPA TUBERCULOSA.}

EDw., Hist. nat. des Crust., t. I, p. 333. - Les pattes des quatre dernières paires sont cylindriques et épineuses en dessus; la carapace est légérement bombée, à régions presque pas distinctes et couverte de petits tubercules arrrondis; le rostre est formé de deux cornes aplaties et reployées en bas vers la moitié de leur longueur; les bords latéro-antérieurs de la carapace sont armés de six ou sept dents à bord̉s granuleux; les pédoncules oculaires sont élargis à leur base, rétrécis vers le haut, et dépassent l'orbite dans une étendue à peu près égale à la largeur de la base du rostre; l'article basilaire des antennes externes est peu élargi en avant; le second article de ces appendices est inséré entre le bord du rostre et le canthus interne de l'œil, tout près de l'orbite; le troisième article est grêle, cylindrique et plus long que le second; le troisième article des pieds màchoires externes est très-dilaté sur l'angle antérieur externe ; Jes pattes, ainsi que la carapace, présentent quelques poils; la couleur est brunâtre.

\section{HYAS, LEACH, EDW. ; \\ Cancer, Herbst ; Inachus, Fabr.; Maia, Bosc; Pisa, Latr.}

Ce genre est extrêmement voisin de celui $P$ isa, et il habite comme lui nos côtes de France et celles d'Angleterre. Il est remarquable en ce que la carapace est assez large, surtout antérieurement, peu bombee et arrondie en arrière. - Le rostre, formé de cornes triangulaires, aplaties et convergentes, est médiocre, et laisse enlièrement à découvert l'insertion de la tige mobile des antennes externes, dont le premier article est aplati et élargi du côté externe. - Le front est large, et les orbites sont dirigées un peu en avant; leurs bords ne sont pas épineux, et leur dessus ne présente qu'une seule fissure. - Le bord externe de l'article basilaire des antennes externes est droit; il est séparé de la portion externe de l'orbite par une échancrure qui est très-large. Le troisième article des pieds - mâchoires externes est peu dilaté en dehors. - Les pattes ont la même disposition que celles du genre $P^{\prime} i s a$, si ce n'est que celles des quatre dernières paires sont plus longrues et ne présentent pas d'épines à la face inférieure du tarse. - Deux espèces composent ce genre; ce sont :

\section{HYAS ARANEA.}

LeACH, Malac., pl. 21 a. - Edw., op. cit., t. I, p. 312.-Cancer Araneus, LinN., Mus. Lud. Ulr., p. 439. - Inachus Araneus, Fabr., Suppl., p. 356. - Long. 3 pouc. - La carapace n'offre pas de rétrécissement notable derrière les orbites; elle est renversée en avant, arrondie en arrière, à régions peu distinctes, et tuberculeuses en dessus; les angles orbitaires externes sont comprimés et très-gros; mais ils ne se prolongent pas au dela du niveau de la portion voisine du bord de la carapace; les pattes de la première paire sont plus grosses; mais un peu plus courtes que les suivantes, armées de quelques tubercules; les pattes de la seconde paire sont presque deux fois aussi longues que la portion post-frontale de la carapace; elles sont cylindriques comme les suivantes; le corps est inerme; la couleur est un jaune rougeâtre. - Cette espèce se trouve sur nos côtes de France et sur celles d'Angleterre.

\section{HYAS COARCTATA.}

LÉach , Malac., pl. 21 b. - EDw., op. cit., t. I, p. 312.-DesM., Consid. génér. sur les Crust., p. 148. - Long. 3 pouc. - La carapace est fortement resserréc derrière les angles orbitaires externes, qui sont fort grands, comprimés en forme d'oreille, beaucoup plus saillans que la partic voisine du bord latéral de la carapace; laquelle est trés-large en avant, arrondie postérieurement, étverruqueuse en dessus ; les pattes antérieures sont médiocres; les suivantes sont un peu moins longues que chez l'espèce précédente; le corps est inerme ; la couleur est jaunâtre. - Sc trouve sur nos côtes océaniques,

\section{HaL IMUS, Latr. , EDw.; \\ Cancer, Herist ; Maia, Bosc.}

Chez ce genre, qui a été établi par M. Latreille, la carapace est environ une fois et demie aussi longue que large, et bombée en dessus. - Le rostre est avancé, et formé de deux grandes cornes divergentes. - Le bord orbitaire supérieur est saillant, et les bords latéro-anterieurs de la carapace sont presque toujours droits et 
portent des épines très-fortes, - Les yeux ne sont pas rétractiles et dépassent notablement les bords de l'orbite, qui se prolonge en arrière. - Le premier article des antennes externes est très-long, droit, et à peu près de même largeur à son extrémité qu'à sa base; l'insertion de la tige mobile de cet appendice n'est pas recouverte par le rostre. - L'épistome est trèsgrand et à peu près carré. - Le troisième article des pieds-mâchoires est fortement dilaté en dehors. - Les régions ptérygostomiennes sont très-petites. - Les pattes antérieures sont grêles, de longueur médiocre chez le mâle aussi bien que chez la femelle. - Les pattes suivantes sont longues, grêles et comprimées; leur avantdernier article est èlargi en dessous et tronqué en manière de pince substyliforme. -- L'abdomen, chez le mâle, est composé de sept segmens, et seulement de cinq chez la femelle. - Ce genre se compose de deux espèces, parmi lesquelles nous citerons :

\section{HALIMUS ARIES.}

LATr., Collect. du Mus, - GuÉr., Icon. du Règ. anim. de Cuvier, Crust., pl. 9, fig. 2,-EDw., op. cit., t. I, p. 344.Long. 1 pouc. - Le bord supérieur de la carapace est armé, sur la ligne médiane. d'une forte épine dirigée en arrière; d'une autre petite épine placée en arrière de l'orbite et suivie d'un prolongement lamelleux armé de deux grosses épines; de trois grosses épines dirigées en dehors sur chaque région branchiale; de cinq pointes sur la région stomacale; d'une pointe sur la génitale et d'une grosse épine sur l'intestinale immédiatement en avant de la postérieure déjà mentionnée ; les pattes sont peu élargies en dessous et portent une multitude de petites pointes sur la portion tronquée du bord inférieur de leur avant-dernier article. - Se trouve dans l'Océan Indien.

\section{LIBINIA, LEACH, EDW.}

Ce genre, qui a été créé par M. Leach, a la plus grande analogie avec le genre Doclée, et de même que lui la carapace est très-bombée en dessus, généralement presque circulaire, et sa portion orbitofrontale est placée sensiblement au-dessus du niveau de ses bords latéraux, qui se prolongent vers la bouche plutôt que vers le canthus interne des yeux. - Le rostre est petit, étroit et échancré au miliè -
Le front est étroit. - Les orbites sont presque circulaires et dirigées très-obliquement en avant et en dehors. - Leur angle externe est formé par une grosse dent comprimée qui est séparée du reste des parois de cette cavité par deux fissures, l'une su. périeure très-étroite, et une inférieure plus ou moins ouverte. - La région stomacale de la carapace est peu développée; mais les régions branchiales le sont beaucoup, et leur bord latéral, qui est armé d'épines et très-courbé, se dirige vers l'angle antérieur de la bouche. - Les yeux sont petits et très-courts. - L'article basilaire dés antennes externes est court, trèsdéveloppé, et présente toujours assez de largeur en avant. - Le second article des antennes est gros, court, cylindrique et resserré sur les côtés du rostre, à distance à peu près égale de l'orbite et de la fossette antennaire. - Le troisième article est un peu plus petit que le second, et le quatrième est très-grèle et très-court. - L'épistome est petit. - Les pieds - mâchoires externes sont semblables à ceux des Pises; il en est de même pour le plastron sternal. - Les pattes antérieures sont plus longuesque chez les Doclées, mais moins développées que chez les Pises; elles sont toujours à peu près de la grosseur de celles de la seconde paire, mais généralement elles sont moins longues, même chez les mâles. - La main est presque cylindrique et peu renflée. Les pinces sont arrondies, tranchantes et assez finement dentelées, et se joignent presque dans toute leur longueur. - Les pattes qui suivent ressemblent beaucoup à celles des Pises, seulement leur dernier article est plus long et n'est jamais armé en dessous d'épines cornées comme chez la plupart de ces dernières; leur longueur diminue progressivement, et celles de la seconde paire n'ont au plus qu'une fois et demie environ de la longueur de la portion post-frontale de la carapace, L'abdomen, chez les deux sexes, est composé de sept articles. - Les espèces qui composent ce genre sont peu nombreuses et paraissent toutes appartenir aux mers $d^{\prime} A$ mérique.

\section{Libinia ganaliculata.}

EDw., op. cit., t. I, p. $300 .-\mathbf{S}_{\Delta \mathrm{Y}}$, Journ. of Philadelph., t. I, pl. 4, fig. 1. - Long. 2 pouc. - Les pattes de la seconde paire sont une fois aussi longues que la carapace, et un peu moins que les pattes antérieures du male; la portion post- 
orbitaire de la carapace est circulaire, hérissée en dessus d'un assez grand nombre de petits tubercules spiniformes, et bordée latéralement par six ou sept épines assez fortes; la région intestinale présente une épine médiane très-courte, et le front, dans son milieu, offre une dépression en forme de losange; les pattes antérieures sont légèrement granuleuses; le corps est couvert de poils très - courts et très-serrés. - Se trouve sur les côtes des Etats-Unis.

\section{LIBINIA SPINOSA.}

EDW., op. cit., t. I, p. 301. - GứR., Iconog. du Règn. anim. de Cuv., Crust., pl. 9, fig. 5. - Long. 4 pouc. - La carapace de cette espèce est presque circulaire et hérissée d'une trentaine de grosses épines, dont cinq sur la région stomacale, trois sur la ligne médiane, et deux sur les côtés, trois sur la région cordiale, une sur la région intestinale, deux sur chaque région hépatique, et les autres sur la face postérieure de ces mèmes régions; les deux premiers segmens de l'abdomen du mâle présente deux épines; les pattes de la seconde paire ont une foiset quart la longueur de la carapace, et sont notablement plus longues que celles de la première paire, même chez le mâle; le corps est entièrement couvert d'un duvet court et brunâtre. - Se trouve sur les côtes du Brésil.

\section{HERBSTIA, EDw.}

Les Herbsties de M. Edwards sont des Crustacés qui ont la carapace plus triangu. laire que celle des Libinies. - La région stomacale est presque aussi développée que les régions branchiales. - Le rostre est petit, presque aussi long que large, et formé de deux cornes aplaties, pointues et divergentes, dont la base occupe presque toute la longueur du front. - Les orbites sont ovalaires et dirigées obliquement en avant, en dehors et en haut; leur bord supérieur présente deux petites fissures, et se termine antérieurement par une petite épine, moins saillante que celle située au-desșus, et appartenant à l'orbite basilaire des antennes externes; leur bord inférieur est complet et ne présente qu'une petite fissure. - La disposition de la rẻgion antennaire, des antennes externes, des piedsmâchoires, du plastron sternal et des pattes, est absolument la même que chez le genre $P$ is $a$, excepté seulement que les tarses des quatre dernières pattes ne présentent que quelques petites épines cornées placées ir-
régulièrement.-L'espèce type de ce nouveau genre est :

\section{HERBSTA CONDYLIATA.}

Edw.. op. cit., t. 1, pl. 18 bis, fig. 6.Cancer Condyliatus, HeRBst, pl. 18, fig. 99. Inachus Condyliatus, Fabr., Suppl., p. 356. - Maia Condyliata, Litr., Hist. nat. des Crust., t. 6, p. 95. - La carapace est environ un quart plus longue que large, arrondie en arrière, rétrécie en avant, et hérissée en dessus d'un grand nombre d'épines obtuses et peu saillantes ; son bord latéro-antérieur est armé de quatre à six épines pointues; son bord postérieur est surmonté d'une petite crête transversale formée par quatre à cinq épines; l'article basilaire des antennes externes est étroit antérieurement et armé en dehors de deux épines; le deuxième article est un peu renflè en avant, et guère plus long que le troisième arlicle; les régions ptérygostomieunes sont trèsépineuses; les pattes de la première paire du mâle atteignent quelquefois presque deux fois la longueur de la carapace; les bras et le carpe sont très-épineux; les mains sont renflées, tuberculeuses en dessus; les pinces sont dentelées et légèrement creusées en gouttière vers le bout; les pattes de la seconde paire sont une fois et demie aussi longues que la portion post-orbitaire de la carapace ; de mêmé que les suivantes, elles sont grêles, cylindriques, armèes d'une épine médiocre à l'extrémité du troisième article, et pourvues de quelques pointes cornées à la face inférieure du tarse; le corps est couvert d'un duvet rare et fin, et est couleur rouge-påle. Suivant M. Risso, la femelle est pleine de petits œufs d'un rouge cinabre en juillet. - Cette espèce se rencontre dans la Méditerranée, dans les profondeurs habitées par les Coraux.

\section{MA CROPODITES.}

Pattes grêles, très-longues; celles de la seconde ou troisième paire beaucoup plus longues que les pattes antérieures, et plus de deux fois aussi longues que la portion post-frontale de la carapace.

Genres : Doclea, Egeria, Amathia, Inachus, Stenorhynchus, Leptopodia, Latreillia et Achous.

DOCLEA, LEACH ;

Inachus, FABR., LATr.

La carapace est presque globuleuse, velue, et plus ou moins hẻrissée d'épines. Le front est relevé, et les bords latéraux. 
de la carapace se dirigent vers le bord antérieur du cadre buccal. - Le rostre est court, très-étroit. - Les orbites sont dirigées obliquement en avant, et elles logent en entier les yeux, qui sont très-petits et ne présentent aucune trace d'épine à l'angle antérieur de leur bord supérieur. - L'article basilaire des antennes externes avance beaucoup au-delà du canthus interne des yeux, et se termine presque en pointe sous le front, auquel il est intimement uni; le second article de ces antennes est court et placé près du bord du rostre; le troisième et le quatrième sont très-petits. - L'épistome est très-peu développé et beaucoup plus large que long. - Le troisième article des pieds-mâchoires externes est à peu près carré, légérement dilaté en dehors, et assez profondèment échancré à l'angle interne et antérieur.-Le plastron sternal est presque circulaire. - Les pattes antérieures sont faibles et très-petites; elles n'ont guère plus d'une fois et demie la longueur de la carapace, et la main est presque cylindrique; les pattes suivantes sont, au contraire, très-longues, grêles et cylindriques; l'article qui les termine est long et styliforme; celles de la seconde paire ont deux à trois fois la longueur de la portion post-frontale de la carapace, et les suivantes diminuent progressivement. - La disposition de l'abdomen varie : tantôt il ne présente chez la femelle que cinq articles distincts, tantôt on y compte sept segmens comme chez le mâle.

Ce genre renferme quatre à cinq espèces appartenant toutes aux mers des Indes.

\section{DOCLEA OVIS.}

EDw., op. cit., t. I, p. 294. - Cancer Ovis, Herbst, t. I, p. 210, pl. 13, fig. 82.Inachus Ovis, Faвr., Suppl., p. 355. Maĭa Ovis, Bose, t. 1, p. 256. - Long. 2 pouc. - Le bord postérieur de la carapace ne présente pas d'épines médianes; la ligne médiane de la région stomacale offre une série de petites pointes; le rostre est creusé en dessus d'un sillon longitudinal et bifurqué au bout; les bords latéro-antérieurs de la carapace sont armés de quatre dents spiniformes, médiocrement saillantes; clont la dernière n'est pas plus grosse que les autres, et occupe, ainsi que la pénultième, la région branchiale; les pattes de la première paire sont un peu plus grosses que les secondes, et celles-ci ont presque deux fois et demie la longueur de la porfion post-frontale de la carapace; l'abdo- men, chez la femelle, est composé de sept articles distincts, dont le second est surmonté d'un gros tubercule médian; tout le corps, les mains et les doigts exceptés, est recouvert d'un duvet laineux, très-long, serré, et de couleur brunâtre. - Se trouve dans la mer des Indes.

\section{DOCLEA IIYBRIDA.}

Edw., loc. cit., t. I, p. 294. - Inachus IIybridus, FABR., Suppl., p. 355. - Maia IIybrida, Bosc, t. 1, p. 256. - Long. 3 pouc. Le bord postérieur de la carapace est armé sur la ligne médiane d'une petite épine; les bords latéro-antérieurs de cetle mème carapace sont armés de quatre épines courtes, dont la postérieure n'est pas plus grande que les autres; les pattes de la seconde paire ne sont pas deux fois aussi longues que la carapace; le rostre est plus court que chez l'espèce précédente; on aperçoit quelques pointes sur la ligne médiane des régions génitale, cordiale et intestinale, aussi bien que sur la stomacale; l'abdomen de la femelle est formé seulement de cinq pièces distinctes (les quatrième, cinquième et sixième segmens étant soudés entre eux), et ne portant pas de tubercule notable au milieu du second anneau; le plastron sternal du mâle est armé de deux épines entre les pattes de la deuxième paire; le corps est couvert de poils courts très-serrés, a peu près de même couleur que l'espèce précédente, mais d'un aspect beaucoup moins laineux; les mains et les tarses sont cutièrement nus. - Cette espèce se trouve sur la côte de Coromandel.

\section{DOCLEA MURICATA.}

Ebw., loc. cil., t. 1, p. 295. - Cancer Muricatus, HerBST, t. I, p. 221, pl. 14, fig. 88. - Inachus Muricatus, Fabr., Sup., p. 355.-Cette espece ressemble beaucoup à la Doclée Hybride, mais elle en diflère par sa taille, qui est beaucoup plus petite, par le bord postérieur de la carapace, qui est armé d'une épine médiane, et par les bords latéro-antérieurs, qui sont armés de quatre épines dont la postérieure est beaucoup plus grande que les autres; on apercoit quelques points sur la ligne médiane et sur les régions branchiales. - Se trouve aux Indes-Orientales.

EgERIA, Latr., Leach, Edw.;

Inachus, FABri.; Macropus, LATR.; Leptopus, LaM.

La carapace est bosselée en dessus et se 
prolonge en un rostre court, êtroit et dirigé très-obliquement en haut et en avant. -Les pédoncules oculaires sont très-courts, et les orbites presque circulaires, - Les antennes internes sont dirigées longitudinale. ment, et l'article basilaire des antennes externes, qui est étroit, se termine presque en pointe, et s'avance beaucoup au dela du canthus interne des yeux. - L'épistome est peu développé, et le troisième article des pieds-mâchoires externes est à peu près carré et lêgérement dilaté à son angle antérieur et externe. - Le plastron sternal est presque circulaire. - Les pattes chez les mâles sont toutes fliformes, et il en est de même pour les femelles; celles de la première paire ne présentent rien de remarquable; elles n'ont pas plus d'une fois et demie la longueur de la portion post-frontale de la carapace; celles de la seconde paire, qui sont les plus longues de toutes, ont au contraire plus de six fois cette même longueur. - L'abdomen, chez la femelle, est composé de cinq articles distincts, les trois anneaux qui précèdent le dernier, étant soudés entre eux. - Les Grustacés qui composent ce genre se trouvent dans les mers de l'Asie.

\section{EGERIA ARACHNOIDES.}

Latr., Encycl., pl. 281, fig. 1.- Edw., op. cit., t. I, p. 291. - Cancer Arachnoides, Rumpu., pl. 8, fig. 4. - Inachus Longipes, FaвR., Suppl., pag. 358.-Cancer Longipes, Linn., Mus, Lud. Ulr., p. 446. - Maeropus Longipes, LATr., Hist. nat. des Crust.; t. VI, p. 3.-Leptopus Longipes, Laиск., Hist. nat. des Anim. sans vert., t. V, p. 235.-Long. 1 pouc.-Le rostre est trè-court, moins long que large; la carapace est armée en dessus de lorgues épines, dont cinq sur la région stomacale, une sur la cordiale, une sur l'intestinale, et trois sur la branchiale; le rostre est avancé el terminé par deux petites cornes ; les bords latéraux de la carapace sont armés de deux à trois épines; les orbites en dessus ont trois fissures, et une seule en dessous; les pattes antérieures sont filiformes dans les deux sexes; celies des quatre dernières paires sont également filiformes et armées d'une petite épine à l'extrémité du troisième article; le corps est couvert d'un duvet brunâtre. - Se trouve sur la côte de Coromandel.

Â.N.
iNAChUS, Fabr., Ltach, Desm., Latr., Roux, Edw.;

Cancer, Penn. ; Maïa, Lamck. ; Macrope, Latr. ; Doclea, Risso.

La carapace, de forme triangulaire, n'est guère beaucoup plus longue que large, avec sa face supéricure très-tuberculée. - Le rostre est médiocrement allongé. -Les yeux sont saillans, portés sur des pédoncules courts qui peuvent se reployer en arrière et se loger dans une cavité orbitaire.-Les antennes extérieures sont distantes, insérées entre les yeux et le rostre, dépassant une ou deux fois la longueur de ce dernier, et ayant leurs trois premiers articles plus gros que les suivans; les antennes intermédiaires sont petites et cachées dans une fossette, à premier article globuleux et assez gros. - L'épistome est plus large que long; le troisième article des pieds-mâchoires est, au contraire, beaucoup plus long que large et de forme triangulaire. - Le plastron sternal se rétrécit as. sez brusquement entre les pattes de la première paire, et sa longueurn'égale pas toutà-fait sa plus grande largeur.-Les pattes de la première paire sont très-petites chez les femelles; chez les mâles elles sont plus grosses; les serres sont toujours terminées en pointe et recourbées en dedans; les pattes suivantes sont grêles, allongées, diminuant progressivement à partir de la première paire, et se terminant toutes par un article cylindrique assez allongé, et peu ou point courbé. - L'abdomen se compose de six articles dans les deux sexes.

Ces Crustacés sont tous de petite taille; ils se tiennent sur le sable, parmi les fucus, à quelques mètres de profondeur ; leur corps est couvert de poils, auxquels s'attachent des éponges.

\section{INAGHUS SCORPIO.}

Fabr. , Suppl., p. 358. - Eow. , t. I, p. 288. - Desu., Consid. génér. sur les Crust., pl. 24, fig. 1.-Macropus Scorpio, Latr., Hist. nat. des Crust., t. VI, p. 109. - Inachus Dorsettensis, LеАсн, Malac., pl. 22, fig. 1-6.-Cancer Scorpio, FaBr., Ent. Syst. , t. II, p. 462. - Le rostre est assez large, court et profondément échancré au milieu; la carapace est armée de quatre épines ainsi disposées : une sur la région stomacale, une sur la cordiale et une sur les branchiales; un peu au-devant de ces dernières épines, est situe de chaque 
côté un tubercule; on aperçoit aussi une épine assez forte entre les fossettes antennaires, et une série de petites pointes sur l'article basilaire des antennes externes; le sternum, chez le mâle, ne présente pas de disque calcaire; les pattes antérieures de celui-ci sont renflées. - On trouve cette espèce sur nos côtes océaniques.

\section{IVACHUS DORYNCHUS.}

Leacr, Malac. Brit., pl. 22, fig. 7-8. LATr., Encycl., pl. 30, p. 7 à 8.- Desa., Consid. génér. sur les Crust., pl..24, fig. 2. - EDw., op. cit., t. 1, p. 288.Le rostre est avancé, hastiforme, divisé par une fissure, mais sans échancrure au bout et se terminant en pointe; la carapace est garnie de tubercules disposés comme les épines de l'Inachus Scorpio, si ce ne n'est qu'on n'en compte que trois sur la région stomacale, et qu'il en existe deux petites près du bord postérieur de la carapace; les pattes antérieures du mâle sont courtes, et la longueur de la main est moins grande que la longueur de la carapace. - Se trouve sur les côtes d'Angleterre.

3. inachus thonacicus. (Pl. 15, fig. 3.)

Rowx, Crust. de la Méditerr., pl. 26 et 27. - Guér., Icon. du Règ. anim., Crust., pl. 10, fig. 2.-EDw., op. cit., t. I, p. 289. - Long. 1 pouc. - Le rostre est peu allongé, échancré, bifide à son extrémité ; on voit une épine latérale derrière chaque orbite, trois petits tubercules sur la région stomacale, et un autre très-grand terminé par une forte pointe; plus bas on aperçoit cinq épines dont trois sur une même ligne; celle du milieu plus forte, placée sur la région cordiale; les deux autres ne sont bien apparentes que chez les mâles assez avancés en âge ; les pinces sont renflées, leurs doigts sont sillonnés; elles sont velues, cou. vertes d'une espèce de mousse; ce duvet revêt toutes les autres parties du corps, et surtout la première paire de pattes; les doigts seuls, le sternum et le dessus de la bouche sont nus; la pièce sternale qui embrasse la base des pinces et des trois premières pattes est avancée en pointe obtuse, fortement échancrée, et se dilatant de chaque côté en deux plaques arrondies; toutle test est d'une teinte tantôt brune, tantôt rousse ou livide; l'extrémité des pinces et des pieds-mâchoires, quelques articulations et la pièce sternale sont rouges. - Se trouve sur les côtes de la Méditerranée: elle habite les algues et les fucus; en avril elle pond des œufs rouges, qu'elle conserve durant les mois de mai, juin et juillet.

\section{INACHUS LEPTORYNCHUS.}

Leach, Malac.'Brit., pl. 22 B. -Desus., Consid. génér. sur les Crust., p. 152.EDw., op. cit. , t. I, p. 289. - Long. 1 pouc. - Le rostre est étroit et échancré ; la carapace est armée comme celle de l'Inachus Dorynchus, si ce n'est qu'il n'y a point de tubercules près de son bord postérieur; les pattes antérieures du mâle sont cylindriques et très-longues; la longueur de la main égale presque une fois et dernie la longueur de la carapace; le sternum du mâle est garni en avant d'une petite pla. que calcaire de forme ovalaire; l'abdomen du mâle est beaucoup plus long que large. - Se trouve sur les côtes d'Angleterre.

Sous le nom de Microrynchus, M. Bell désigne un nouveau genre de Grustacé, quå vient se placer naturellement après celui d'Inachus. L'espèce type de cette nouvelle coupe générique est le:

MCRORYNCHUS DEPRESSUS.

Belu, T'rans. Zool. Soc., t. II, pl. 8, э. 42, fig. 2.

\section{EURYPODIUS; GUẺR., EDW。}

Ge grenre, qui a été établi par M. Guérin, se distingue des précédens par sa carapace, qui est triangulaire, rétrécie en avant et terminée par un rostre bifide.Les serres sont égales, plus grandes dans les mâles, et à mair comprimée et allongée.-Les yeux sont pédonculés, non rétractiles. - Les antennes externes sont longues, insérées au-dessus des yeux, ayant lenr pedoncule formé de trois articles égaux; les intermédiaires sont beaucoup plus courtes, avec leur filet interne ou le plus petit de sept articles. - L'épistome est transversal. - Le troisième article des pieds-mâchoires extérieurs est plus long que large, et profondément échancré à son bord interne et supérieur. - Les pattes sont longues, décroissant de longueur depuis la première paire, et ayant le métatarse dilaté. - L'abdomen, dans les deux sexes, est de sept tablettes. Ce genre a quelque analogie avec les Inachus et les Sténorhynchus; mais il s'en distingue par des caractères bien trazchés: ainsi le troisième article des pieds-mâchoires, dans les Sténorhynques, est au moins deux fois plus long que large, rétréci à ses deux extrémités, et 
plus étroit que le second, dont le bord inférieur est dilaté et remonte en s'arrondissant jusqu'au milieu de la longueur; dans le genre Eurypode, ces pièces offrent des formes toutes différentes; le troisième article des pieds-mâchoires est aussi large que le second, et il n'est pas beaucoup plus long que large; les autres pièces de la bouche n'offrent pas de caractères bien sensibles; mais ce qui le distingue encore des Sténorhynques et des Inachus, c'est le nombre des articles du filet interne, qui est de sept, tandis qu'on n'en compte que quatre dans les genres précités; enfin, un caractère encore plus apparent, et qui le distingue à la première vue, c’est la dilatation du métatarse de ses quatre paires de pattes ambulatoires.

L'espéce type de ce genre est:

\section{EURYPODIUS LATREILLEI.}

Guér., Icon. du Rég. anim. de Cuvier, Crust., pl. 11, fig. 1.-EDw., op. cit., t. I, p. 284. - Cette espèce est longue de plus de trois pouces; sa carapace est triangulaire, tuberculée et velue, ayant deux épines de chaque côté et sous les yeux; le rostre est bifide; les serres sont allongées, un peu comprimées; les pattes sont allongées, avec le cinquième article dilaté et cilié.

Cette espèce se trouve aux îles Malouines.

M. Audouin fera connaître, dans la description qu'il a faite des Crustacés de l'Amérique Méridionale rapportés par M. d'Orbigny, dleux espèces nouvelles appartenant à ce genre; il nomme l'une Eurypode de Humboldt, et l'autre Eurypode de Cuvier.

\section{AMATHIA, Roux, Edw.}

C'est à M. Roux de Marseille qu'est dû l'établissement de ce nouveau genre, qui est remarquable par sa carapace qui présente la forme d'un triangle allongé et à base arrondie; sa face supérieure et ses bords sont armés d'épines très-allongées. Le rostre, qui se termine par deux grandes cornes divergentes, est presque aussi long que la portion post-orbitaire de la carapace. - Les yeux sont ronds, saillans, portés sur un pédoncule épais à sa base, rétréci vers le milien, placé sur chaque côtẻ du rostre dans une cavité échancrée; ils sont comme chez les genres précédens, c'est-à-dire non rétractiles. - Les antennes externes sont courtes, entièrement glabres, terminées par un filet sétacé; les premier et second articles sont d'égale longueur. L'épistome est grand et presque aussi long que large; le troisième article des piedsmâchoires externes est dilaté en dehors et tronqué à ses deux angles internes. - Les pattes de la première paire sont plus courtes que les suivantes; elles sont filiformes chez la femelle, et un peu renflées chez le mâle; les suivantes sont longues et filiformes. - L'abdomen du mâle, de même que celui de la femelle, est composé de sept anneaux.

amathia Rissoana. (Pl. 15 ; fig. 4.) Roux, Crust. de la Méditer., pl. 3 , fig. 1. - EDw., op. cit., t. I, p. 286. - La carapace esi armée de treize fortes épines distribuées ainsi : trois sur sur la région stomacale, une sur la cordiale, et les autres occupant le bord de ce bouclier, savoir : une sur la région intestinale, trois de chaque côté sur la région branchiale, une sur chaque région hépatique, une petite épine devant les yeux, et une plus forte aux angles antérieurs du cadre buccal; les pattes sont couvertes d'un duvet très-court, rougeâtre, qui ne laisse nu que l'extrémité des ongles; celui qui revêt la carapace est jaunâtre; celle-ci a deux espaces glabres longitudinaux; deux taches d'un rose vif colorent le front; cette teinte s'étend en dessous vers les parties de la bouche.

Ce Crustacé se trouve dans la rade de Toulon, et habite des profondeurs assez considérables.

\section{aChoeUS, Leach, Desm., Latr., Edw.}

Ce genre, qui a été établi par M. Leach, est caractérisé par sa carapace, qui ne s'étend pas sur le dernier segment du thorax, et par sa forme qui est triangulaire et renflée sur les régions branchiales. - Le rostre est très-peu apparent. - Les yeux, non rétractiles, sont portés sur des pédoncules assez allongés. - Le premier article des antennes externes est soudé au front, et s'avance au delà du niveau du canthus interne des yeux; l'insertion du second article se fait sur les côtés du rostre, et reste complé. tement à découvert en dessus. - L'épistome est à peu près carré. - Le troisième article des pieds-mâchoires est plus long que large et presque triangulaire. - Le plastron sternal se rétrécit brusquement entre les pattes antérieures, qui sont 
grêles et courtes; celles des quatre paires suivantes sont filiformes; les secondes sont terminées par un article styliforme et tout-â-fait droit; les suivantessont beaucoup moins longues, avec l'article terminal des quatre dernières grand, comprimé et falciforme.-L'abdomen, dans les deux sexes, est composé de six articles.

Ce genre, qui se trouve sur nos côtes océaniques, ne se compose jusqu'à présent que d'une seule espece, c'est :

\section{ACHOEUS CRANCHIT.}

Leacr, Malac. Brit., 22, C. - Edw., op. cit., t. I, p. 281.- Elle est entièrement brune; le rostre, qui est formé de deux petites dents triangulaires, ne dépasse pas le second article des antennes externes; sur la face antérieure des pẻdoncules oculaires est une épine; les régions génitale et cordiale sont élevées en forme de tubercules; les pattes sont garnies de quelques poils assez allongés, et crochues.

Cette espèce se trouve sur les côtes d'Angleterre, elle a été aussi rencontrée près de Saint-Malo; elle vit parmi les algues et les huîtres.

STENORYNCHUS, Latr., Lam., Edw.; Cancer, Linn., Penn., Herbst ; Inachus, FABr.; Maia, Bosc; Macropus, Latr.;

Miacropodia, Leach, Desm., Risso.

La carapace est triangulaire, trẻs-rétrécie en avant, et ne se prolongeant pas au-dessus du dernier anneau thoracique. - Le rostre est avancé, bifide et aigu. - Les orbites sont circulaires, et les yeux, assez saillans, ne sont nullement rétractiles. Les antennes internes se reploient longitudinalement, et les fossettes qui les logent ne sont pas complétement séparées entre elles. - Le premier article des antennes externes, confondu avec les parties voisines, est très-étroit; le second s'insère sur les cốtẻs du rostre, et le troisième est beau. coup plus long que le second.-L'épistome est plus long que large, et les régions ptérygostomiennes sont rudimentaires. - Le cadre buccal est également plus long que large.-Les pieds-mâchoires externes sont étroits ; leur troisième article est ovalaire, et le quatrième est assez long. - Le plastron sternal est étroit entre les pattes antèrieures, mais devient ensuite très-large, et présente sur la ligne médiane une suture qui occupe le dernier segment. - Les pattes de la première paire sont plus courtes, mais beaucoup plus grosses que les suivantes; la main qui les termine est renflée, et les doigts sont un peu écartẻs en dedans. - Les pattes des quatre dernières paires sont filiformes et extrêmement longues; la longueur de celles de la seconde paire égale cinq ou six fois la largeur de la carapace; les autres deviennent progres. sivement plus courtes; leur pénultième article est un peu dilaté vers le bout, et le dernier est styliforme et un peu courbé.L'abdomen, dans les deux sexes, est composé de six articles, dont le dernier est formé par la soudure du sixième et du sep. tième anneau.

Les espèces qui composent ce genre sont en petit nombre; elles sont toutes de petite taille, et habitent la Méditerranée et les autres mers de l'Europe.

\section{1, Steyorynchus Phalangium.}

Edw., op. cit., t.I , p. 279.-Macropus Phalangium; Latr., Hist. nat. des Crust., t. VI, p. 110. - Guéf., Iconog. du régn. anim. de Cuv., Crust., pl. 21, fig. 2. Inachus Phalangium, FaBr., Suppl., p. 358. - Macropodia Phalangium, LEACH, Zool. Misc., t. II, p. 18 ; et Malac., pl. 23, fig. 6. - Dess., Consid. génér. sur les Crust., pl. 23, fig. 3.-Cancer Phalangium, Pens., t. IV, pl. 9, fig. 17.-Cancer Rostratus, Lins., Faun. Suec., n० 2027. - Herbst, pl. 16, fig. 90.-Le rostre, quoique allongé, n'atteint pas l'extrémité des antennes externes ; l'épistome est armé de chaque côtẻ d'une seule petite épine située près de l'organe auditif ; la région stomacale est armée de trois pointes, dont les deux antérieures sont très-écartées entre elles; la région cordiale présente une épine, et on en aperçoit deux sur chaque région branchiale; le troisième article des pieds-mâchoires externes est sans dentelures notables sur le bord externe.

Se trouve communément sur nos côtes méditerranéennes et océaniques.

\section{STENORYNGHUS EGYPTIUS,}

Evw., op. cit., t. I, p. 280. - Slenorynchus Phalangium, Aud., Expl. des Pl. de l'Egypt., pl. 6, fig. 6. - Cette espèce diffère de la précédente en ce que l'épistome présente de chaque côté deux épines placées l'une au-devant de l'au- 
tre; elle en differe cncore en ce que la forme gnérale du corps est beaucoup plus allongée, en ce que les deux tubercules antérieurs de la région stomacale se tou. chent presque, et en ce que le bord externe du troisième article des pieds-mâchoires est armé de deux ou trois épines. -Se trouve sur les côtes de l'Egypte.

\section{STENORYNGHUS LONGIROSTRIS.}

EDw., op. cit., t. I, p. 280. - Inachus Longirostris, FABR., Supp., p. 358.-Macropus Longirostris, Latr., Hist. nat. des Crust., t. VIII, p. 110. - Macropodia Tenuirostris, Leach, Malac. Brit., pl. 23, fig. 1, 5.-Desy., Consid. génér. sur les Crust., p. 154. - Maia Longirostris, Rrsso, Hist. de l'Europe Mérid., t. VI, p. 27.- Bцаinv., Faun. Franç., pl. 8, fig. 1.- Le rostre dépasse de beaucoup le pédoncule des antennes externes.

Se trouve sur nọs côtes océaniques et méditerranéennes.

\section{LEPTOPODIA, LEACH, S SY, DESM., LATR., EDW.; \\ Inachus, FABR.; Cancer, Herbst; Maia, Bosc; Macrope, Latr. ; Stenorynchus, LAM.}

Chez ce genre, la carapace est de forme triangulaire et ne recouvre pas le deruier anneau du thorax. - Le rostre est styliforme et très-allongé. - Les yeux sont gros ct non rétractiles. - Les antennes internes, en se reployant, suivent directement la direction longitudinale du corps. - Le premier article des antennes externes est trèslong et entièrement confondu avec les parties voisines du test; le second s'insère assez loin au-devant des orbites et au-dessous du rostre. - L'épistome est beaucoup plus grand que large. - Le troisieme article des lieds-mâchoires est presque triangulaire, et porte à son angle externe l'article suivant, qui est très-développé. - Le plastron ster. nal est aussi long que large, mais très-rétréci entre les premières pattes; ces organes sont très-grêles et extrêmement longs. - L'abdomen, dans les deux sexes, se compose de six articles dont le premier, très. développé, est aussi long que large, occupe la face dorsale du corps, et dont le dernier est formé par la soudure du sixième et du septième anneau abdominal.

LEPTOPODIA SAGITTARIA.

Leach . Zool. Misc., t. II, pl. 67.-Lacr., Encyct., pl. 99, fig. 1. - Dess.,
Consid, génér. sur les Crusl., pl. 16 , fig. 2. - Gứr., Iconag. du Rẻg. anim. Crust., pl. 11, fig. 4.- EDw., op. cit., t. I, p. 275. - Inachus Sagittarius , Fabr., Supp. Ent. Syst., p. 359. - Cancer Seticornis, Herbst, p. 3, pl. 35, fig. 2. - Les épines du bord terminal du troi. siéme article des huit dernières pattes sont très-courtes; les pédoncules oculaires sont parfaitement cylindriques; le rostre, presque deux fois aussi long que la portion postfrontale de la carapace, est entier, styliforme, et armé de chaque côté d'une série de pointes, d'une épine à la face inférieure de l'article basilaire des antennes externes, près l'insertion des yeux, et une de chaque côté de la carapace, à quelque distance en arrière des orbites; les pattes sont armées d'épines, surtout le troisième article, mais finement granulées. - Cette espèce se trouve dans le golfe du Mexique et dans la mer des Antilles.

\section{LATREILlia, Roux, Edw.}

La carapace est glabre, triangulaire, tronquée en devant, portant au front deux fortes épines divergentes. - Les yeux sont portés sur des pédoncules très-longs, biarticulés. - Les antennes exterieures sont insẻrées au-dessus des intermédiaires, sétacées; les intermédiaires sont immédiatement implantées au-dessous des yeux. Les pieds-mâchoires extérieurs sont ciliés, à troisième article ovale, rétréci vers le haut; le second allongé. - Les pattes sont très-allongées, grêles, filiformes; le deuxième article est presque aussi long que les deux suivans. - Les trois premieres paires de pattes sont dilatées là oú l'angle s'articule; le dernier article de la quatrième paire de pattes est muni d'un onglet trèscourt; les autres angles sont assez allongés. - L'abdomen, chez la femelle, est divisé en cinq tablettes; on distingue cependant les sutures des autres articles, qui en porteraient le nombre à sept.

La seule espèce connue est la :

\section{hatreildia ELEGANS.}

Roux, Crust. de la Méditerr., pl. 22 , fig. 1.- - Ebw., op. cit., t. I, p. 277. - La carapace est lisse, laisante; les pattes sont très-grêles; le second article est très-long, épineux ; les pinces de la femelle sont arrondies, allongées, lisses, de la gros. seur des pattes; les deuxième et troisième anneaux de l'abdomen portent au milieu 
une épinc aiguë; le quatrième anneau en a sur le bord latéral; il en est de même de la partie de l'abdomen qui correspond à une cinquième tablette; les autres en sont privés; le dessous du corps présente une épine dirigée en avant, entre les antennes intermédiaires et le pied des pédoncules oculaires; la couleur de la carapace est jaunâtre, mélangée de rose; les pinces et les pattes sont également fasciées de rougepâle; le dessous du corps est lavé de violet. Le mâle est inconnu. - Cette jolie espèce se trouve sur les côtes de la Sicile.

\section{HYMÉNOSOMITES.}

Carapace circulaire, au moins aussi longue que large. - Second article beaucoup plus étroit que la partie correspondante du plastron sternal. - Front presque toujours très-étroit. - Pédoncules ovalaires, trèscourts. - Quatrième article des pieds-mâchoires s'insérant au sommet ou à l'angle externe.

Genres: Elamena, Hymenosoma.

$$
\begin{gathered}
\text { ELAMENA, EDw.; } \\
\text { Iymenosoma, LATr., Rupp. }
\end{gathered}
$$

La carapace est à peu près triangulairc, plane en dessus. - Le corps est lamelleux. - Le front est large, très-avancé, et a la forme d'un petit rostre lamelleux et à peu près horizontal, au-dessous duquel sont cachés les yeux; ces derniers organes sont de grandeur médiocre, et ne sont pas logés dans les cavités orbitaires; ils sont libres sous le front, et s'appuient en arrière contre une petite saillie de la région ptérygostomienne. - Les antennes internes sont séparées entre elles par une petite lame verticale de la face inférieure du front; leur article basilaire est très-petit, et leur tige mobile se reploie longitudinalement et dépasse ainsi les pédoncules oculaires. - Les antennes externes sont très-petites et cylindriques dès leur base; elles naissent audessous des pédoncules oculaires et n'atteignent pas le bord du front. - L'épistome, au lieu d'être à peine distinct comme chez le genre suivant, est très-grand et à peine carré. - Le cadre buccal est petit, quadrilatère, et rempli en entier par les piedsmâchoires externes, dont le troisieme article est presque carré et est tronqué à son angle antérieur et interne pour l'insertion de l'article suivant, lequel est complétement à découvert. - Le plastron ster- nal est beaucoup plus large que long. Les pattes sont toutes grêles, filiformes et longues; celles de la première paire se terminent par des pinces renflées ou sont creusées en cuillère; les suivantes par un article lamelleux et un peu falciforme. L'abdomen de la femelle est très-grand.L'espèce type de ce nouveau genre est:

\section{ELAMTEN A MATHAI.}

EDw., op. cit., t. II, p. 35.-Hymenosoma Mathai, Dessr., Consid. génér. sur les Crust., p. 163.- Rupp., Krab., p. 21, pl. 5, fig. 1. - Long. 4 lig. - La carapace est lisse, très-large en arrière, arrondie sur les côtés et se rétrécissant graduellement jusqu'au rostre, qui est un peu relevé; les bords sont garnis d'une espèce de crête ho. rizontale extrêmement mince et irrégulièrement découpée; les pattes de la seconde paire sont les plus longues, et ont à peu près trois fois la longueur de la carapace.Se trouve à l'Ile-de-France et dans la MerRouge.

\section{Hymenosoma, Latr., Desm., Edw.}

La carapace est très-aplatie en dessus et presque circulaire. - Le front est très. ètroit et incliné. - Les orbites sont trèspetites et presque circulaires; pour s'y loger, les yeux doivent se reployer plutôt en bas qu'en dehors. - Les fossettes antennaires sont longitudinales et se continuent sans interruption avec les orbites. - La tige dèsantennes internes est grande. - Les antennes externes s'insèrent près de l'angle externe de l'orbite et sont très-allongées. L'épistome est à peine distinct et se trouve caché par les pieds-mâchoires. - Le cadre buccal a la forme d'un carré long. Les bords latéraux sont très-saillans et viennent se terminer à l'angle extérieur des orbites. - Les pieds-mâchoires externes sont longs et étroits; leur troisième article est beaucoup plus large que le second, et porte l'article suivant à son extrémité antérieure. - Le plastron sternal est circulaire. - Les pattes antérieures sont médiocres, et celles de la troisième paire sont les plus longues. - Les tarses sont grêles et styliformes. - L'abdomen du mâle est trèspetit et n'arrive qu'au niveau des pattes de la troisième paire.

\section{HYMENOSOMA ORBICULARE.}

Desir., Consid. génér. sur les Crust., p. 163, pl. 26, fig. 1. - EDW., op. cit., 



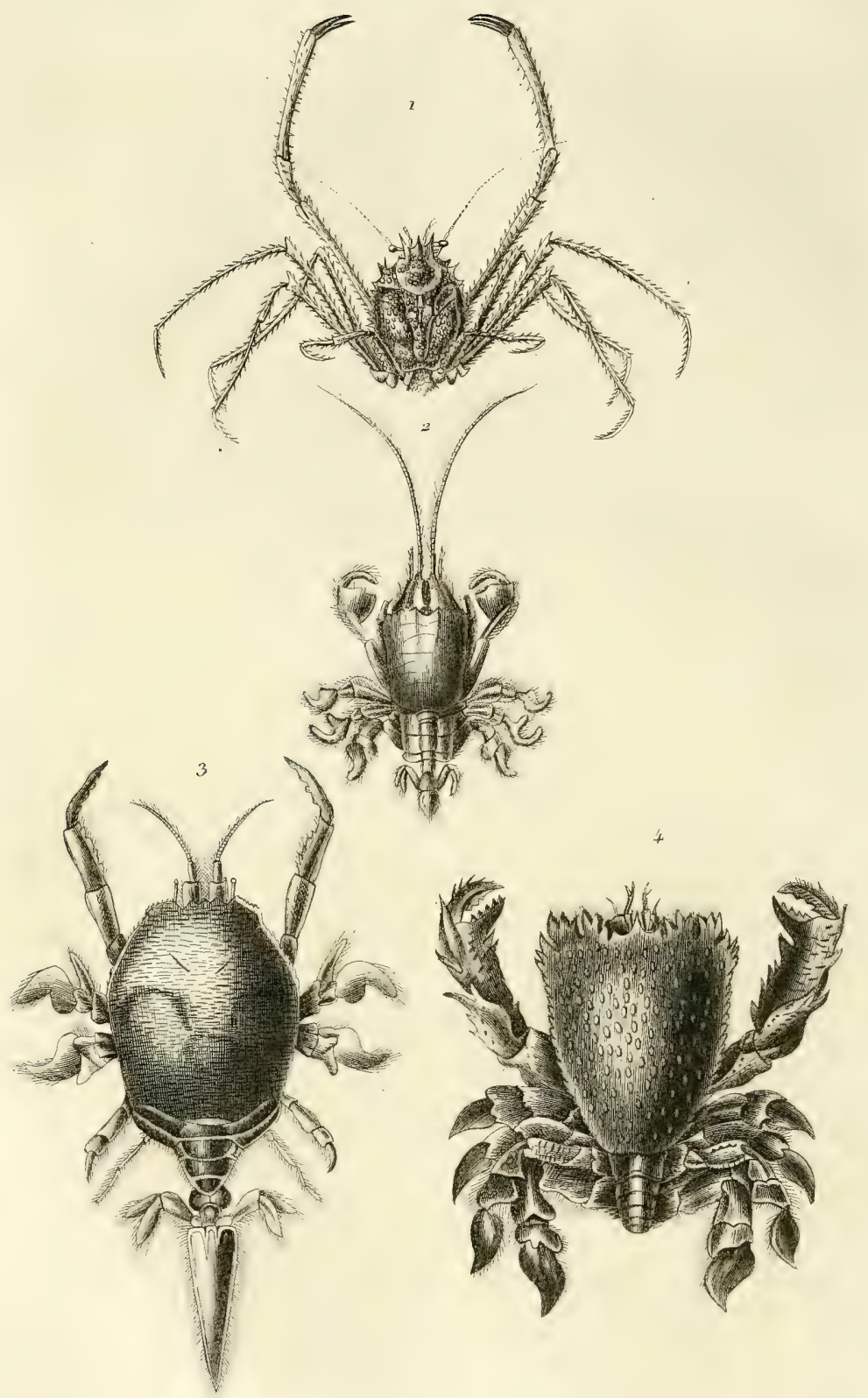

1. Ilomola Cuvieri.

3. Remipes testudinarius .

2. Hippa emerita .

t. Ramina dentala. 
t. I1, p. 36. - La carapace est orbiculaire, avec ses parois latérales solides, crustacées, granuleuses et relevées, et le sommet tronqué horizontalement, presque membraneux. lisse, et marqué d'une impression en $\mathrm{H}$ qui indique les limites des régions moyennes et latérales; le rostre est excessivement court; les yeux sont petits; les pinces sont moyennes, à peu près égales, avec des mains lisses, renflées, arquées en dedans, et des doigts minces et courbès; les autres pattes sont un peu rugueuses et poilues, assez fortes, médiocrement longues; celles de la troisième paire sont les plus courtes de toutes.-Se trouve au cap de Bonne-Espérance-

\section{DEUXIÈME DIVISIUN,}

Les deux pieds postérieurs sont subitement plus petits que les autres, tantôt ccpendant très à découvert, insérés sur le dos, terminés par un crochet et préhenseurs; tan tôt beaucoup plus petits et moins apparens, mutiques, comme mutilés ou avortés; les pieds-mâchoires extérieurs sont allongés, saillans et courbés en dehors; les yeux sont très-rapprochés à leur insertion, qui est située sous le museau; le test est épineux.

\section{NEUVIEME TRIBU.}

\section{H Y P O P T H A L M S,} Latreille.

Cette tribu se compose de deux groupes: les Homolites et les Pactolites.

\section{HOMOLYTES.}

Les Crustacés qui composent ce groupe ont la carapace épineuse et armée d'un rostre; les deuxieme, troisieme et quatrième paires de pattes sont très - longues, tandis que celles de la cinquieme paire sont très-courtes, ne servent pas à la marche, et sont plus ou moins complétement préhensiles.

Genres : Homola, Lithodes et Lomis.

homola, Leagh, Latr., Desh., Rovx, EDw. ;

Thelxiopa, RafinesQUe.

La carapace est plus longue que large, quadrangulaire, tuberculeuse ou épineuse surtout en avant, bordéc ou crénelée sur les côtés.-Le front est peu avancé. Les yeux sont gros, globuleux, bi-articulés par une espèce de ginglyme, portés sur un pédoncule mince se dirigeant latéralement vers l'angle du test. - Les antennes externes, assez longues, ont leur premier article gros et court; terminées par un filet sétacé, glabre, très-menu, le second très-long; insérées sous les pédoncnles oculaires; les intermédiaires placés au canthus interne des yeux. - Les pieds - mãchoires extérieurs sont très-velus; les quatrième et cinquième articles presque aussi longs que le premier et le deuxième; celui-ci cilié extérieurement ou épineux; le troisième très-court. - Les pinces sont longues dans les mâles, égales entre elles, d'épaisseur moyenne, terminées par des doigts assez courts. - Les pieds des seconde, troisième et quatrième paires, semblables entre eux, sont terminés par un ongle comprimé, aigu, peu arqué, et cilié sur sa tranehe postérieure; ceux de la cinquième paire, de moitié plus courts, relevés sur le dos, ayant leurs derniers articles ployés de manière à figurer une pince en crochet.

Les Homoles, dit M. Roux, habitent les plus grandes profondeurs rocailleuses, et ne s'approchent jamais de la côte. Leurs habitudes doivent être actives et diligentes; bien que leurs pattes postérieures soient á peu près conformées comme celles des Dromies, elles ne doivent pas en partager l'indolence et la paresse, qui, selon la remarque de M. Risso, peuvent permettre à des alcyons et des serpules, etc., de venir se fixer et grandir sur leur test; d'ailleurs la longueur des autres pattes ne s'opposerait pas moins à la présence de ces hôtes incommodes. Il me paraîtrait plus probable de penser que ces pieds dorsaux, terminés, en crochet, leur servent à se cramponner dans les anfractuosités et les fissures des rochers où ces Crustacés font leur résidence ordinaire.

1. homola cuvieri. (Pl. 16, fig. 1.)

Roux, Crust. de la Médit., pl. 7, fig. 1 à 8.- - GuÉr., Icon. du Rég. anim. de Cuv., Crust., pl. 13, fig. 1.- Evw., op. cit., t. II, p. 184. - Hippocarcinus Hispidus, Aldrov. de Crust., p. 179 à $181 .-\mathrm{La}$ carapace de ce grand Brachyure est relevée, inégale, chargée de tubercules coniques ou épineux; plusieurs impressions profondes la traversent; deux sillons longitudinaux s'étendent de chaque côté de sa surface su- 
périeure; les bords latéro-antérieurs offrent des protubérances fortement aiguillonnées ; le front est terminé par trois pointes qui forment un triangle, l'intermédiaire étant située plus bas que les latérales; le premier article des antennes est épineux; les pinces du mâle sont longues, épaisses, arrondies, épineuses, parsemées vers leur extrémitè de faisceaux de poils roussâtres; les pattes, un peu aplaties, sont aussi très-épineuses, particulièrement sur leur crête; les doigts des pinces sont noirs; un léger incarnat jaunâtre est répandu sur le corps de cette espèce; mais cette couleur prend une teinte rougeâtre en s'étendant sur les pattes; les pinces des femelles sont courtes, guẻre plus Jongues que le corps, et moins épaisses que les pattes.

M. Risso considère ce Crustacé comme paroissant devoir occuper le dernier degré de l'échelle géographique, comprenant depuis la surface sèche de nos bords jusque dans les vastes et profondes vallées sousmarines, où règne une température uniforme d'environ dix degrés. Jamais élle ne s'approche de la côte, et si, forcèe d'obéir au vou de la nature, la femelle abandonne un instant, pour venir pondre, les immenses profondeurs de la Méditerranée, ce n'est qu'à l'époque des plus fortes chaleurs et sur les bancs de rochers, plongés, à de grandes distances du rivage, à plus de cent mètres sous l'eau, qu'elle sc permet de déposer des œufs, qui sont d'un jaune-pâle. On la prend alors au palangre. M. Risso, qui a eu l'avantage de voir quelques individus vivans de cette espèce, dit que leur contenance est menacante, qu'ils se relèvent sur leurs Iongues pattes, marchent avec précipitation, et ne cessent de remuer vivement diverses parties de leur corps, surtout les pinces, dont ils font battre les doigts. Le même auteur ajoute que ces animaux mouraient peu de temps après leur sortie de la mer, et que leur chair est fort bonne à manger.

On trouve cette espèce dans la Méditer ranée; elle a été observée dans les environs de Nice; on la pêche quelquefois à Tou. lon, sur un banc sous-marin, à douze lieues de la côte; et elle a été aussi rencontrée à quelques lieues au large du phare de l'île de Planier, dans le golfe de Marseille.

\section{HOMOLA SPINIFRONS.}

LeACH, Zool. Misc., t. II, tab. 88. Desm., Consid. génér. sur les Crust., p. 134, pl. 17, fig. 1.-EDw., op. cit., t. II, p. 183, pl. 22 , fig. 1 à $4 .-D o$ rippe Spinifrons, Laur., Hist. nat. des Anim. sans vert., t. V, p. 245.-Cancer Barbatus, HERBst, pl. 42 , fig. 3.Cancre jaune, Rondel. , Poissons, t. II, p. 405. - Long. 18 lig. - Le rostre est bidenté; les dents orbitaires : supérieures sont plus grosses que celles situées de chaque côté de la base du rostre et placées sur la même ligne; la région stomacale est hérissée de neuf grosses épines, dont une médiane et postérieure, quatre mitoyennes disposées en carré, et deux latérales de chaque côté, situées à peu près sur la même ligne transversale; les bords latéraux de la carapace sont armés antérieurement d'une très-grosse épine, située à l'extrémité du sillon qui sépare les régions stomacales et hépatiques; il y a une seconde épine moins forte, mais un peu plus en arrière, qui est suivie d'une série de petites pointes; le reste de la carapace ne présente point d'épines; les bras sont prismatiques et armés d'une rangée d'épines sur chaque bord; les mains sont un peu comprimées, et ćpineuses sur le bord inférieur seulement; les paltes suivantes sont comprimées, armées en dessous d'une rangée de petites épines assez fortes sur le troisième article; le second anneau de l'abdomen présente une grosse dent médiane, conique; le corps est couvert de poils fauves. - Habite la même localité que l'espèce précédente.

\section{Lithodes, Latr., Leach, Desh., Edw.; Cancer, Linn., Henbst ; Inachus, Fabr.; MIaīa, Bosc.}

La carapace, de forme triangulaire, est très-épineuse, renflée postérieurement de chaque côté par le grand développement des régions branchiales, terminée en avant par. un rostre bifurqué garni de fortes pointes sur les côtes.-Les yeux sont gros, rapprochés, portés sur de courts pédoncules. - Les antennes extérieures ont à peu près la moitié de la longueur du corps, sétacées, avec leurs deux premiers articles plus longs que les autres; insérées sous les yeux et en dehors; les intermédiaires sont avancées, assez longues, divisées en deux soies comprimées, multi - articulẻes. - Le troisième article des pieds-mâchoires extérieurs est petit, court et carré, dilaté et denticulé intérieurement; les serres sont assez courtes et grosses, cylindriques, inégales, droites, épineuses, ayant leur carpe 
assez long et dans la direction de la main, dont les doigts sont courts, épais, et un peu inclinés en dedans; les pieds des trois paires suivantes sont plus longs, robustes, épineux; ceux de la troisième paire sont les plus grands; les pieds de la cinquième paire étant quatre fois plus courts et dix fois moins épais que ceux de la quatrième, non épineux, adactyles, inutiles au mouvement. - L'abdomen est membraneux, avec des plaques crustacées disposées sur ses bords, dont le nombre peut faire supposer qu'elles sont les rudimens de six articles. - L'espèce qui sert de type à ce genre est :

\section{LITHODES ARCTICA.}

LaMck. , Hist. des Anim. sans vert., t. V, p. 240. - Desur., Consid. génér. sur les Crust., p. 160 pl. 25.-Gúer., Iconog. du Rég. anim. de Cuv., Crust., pl. 12, fig. 1.-Enw., op. cit., t. II, p. 186.Lithodes Maia, LEACH, Malac.Brit., pl. 24, - Cancer Maía, Herbst, t. I, p. 919, pl. 15. - Parthenope Maia et Inachus Maia, FABr., Suppl., p. 354 à 458.-Long. 5 pouc. - La carapace, sur ses côtés latèraux, est épineuse; son rostre est grêle, bifurqué en haut et épineux à sa base; en des(sus, cette carapace est déprimée, couverte d'épines plus ou moins longues; ses régions sont assez fortement prononcées, et séparées entre elles par des fissures profondé., ment marquées; les serres sont allongées, hérissées d'épines très-acérées; les mains intérieurement sont fortement denticulées, 'et garnies extérieurement de fascicules de poils; les pattes sont très-allongées, grêles et couvertes d'épines; la couleur de ce Crustacé est d'un rouge foncé en dessus, et d'une couleur un peu plus claire en dessous. - Habite les mers du nord de l'Europe.

\section{LOMIS , EDw.}

La carapace est déprimée, rétrécie antérieurement et tronquée en arrière; elle ne dẻpasse pas le milieu dela base des pattes de la troisième paire, et le reste de la face dorsale du corps est occupé par la base de l'abdomen. - Le front est tronqué et armé d'une petite dent médiane; il n'y a point de fosses orbitaires, et les pédoncules oculaires ont la forme de deux gros articles triangulaires qui se touchent par leur bord interne et portent les yeux à leur angle externe. - Les antennes interne sont médiocres; leurs trois premiers ar- ticles sont cylindriques, et elles se terminent par deux petits filets. - Les antennes externes sont insérées en dehors des yeux et à peu près sur la mème ligne; elles sont grandes et terminées par une grosse tige mul. ti-articulée, garnie de longs poils à son bord inférieur. - Les pieds-mâchoires externes sont pédiformes; leur troisième article ne présente pas de dilatation notable, et les trois articles suivans sont très-gros. - Le sternum est large, et le dernier anneau thoracique n'est pas soudé au précédent.Les pattes de la première paire sont trèsgrandes, très-larges et extrêmement déprimées. - Ise carpe est aussi long que le bras et à peu près quadrilatère. - La pince est grosse, courte et presque horizontale. - Les pattes des trois paires suivantes sont courtes, grosses et terminées par un article presque conique; celles de la cinquième paire sont très-grêles, et reployées en dessus des autres dans la cavité branchiale. - L'abdomen est très-large, mais lamelleux, reployé en dessous contre le sternum, et ne présente aucun vestige d'appendice appartenant au pénultième anneau. - L'espèce type de ce nouveau genre est la :

\section{LOMIS HIRTA.}

EDw., op. cit., t. II, p. 188. - Porcellana hirta, LaM., Hist. des Anim. sans vert., t. V, p. 299. - DesM., Consid. génér. sur les Crust., p. 259. - Le corps est couvert en dessus de poils très-courts et très-serrés. - Les mains sont presque aussi larges que la carapace. - Se trouve dans les mers de l'Australasie.

\section{PAGTOLITES.}

Pattes antérieures adactyłes; celles des deux dernières paires terminées par une pince didactyle.

Genre: Pactolus.

\section{PaCtolus, Leach, Latr., Desh., Edw.}

Les antennes externes ont leur premier article long et cylindrique. - Les pieds sont médiocrement longs et assez épais ; les deux antérieurs sont plus courts que les autres, non terminés par une main, mais pourvus d'un simple ongle crochu; ceux de la seconde paire sont semblables. - Les pieds de la troisième paire sont inconnus; ceux de la quatrième et de la cinquiènie paire sont didactyles. - La carapace est 
triangulaire, allongée, assez renflée de chaque côté en arrière, non épincuse en dessus, et terminée en avant par un rostre fort long, aigu, mince et entier. - L'abdomen de la femelle est composé de cinq articles dont le premier étroit, les trois suivans transverses, linéaires, et la cin. quième très-grand, presque arrondi. Les yeux sont très-gros, situés derrière les antennes, toujours saillans hors de leur fossette; il y a une seule pointe à chaque orbite.

\section{pactolus Boscix.}

Leach., Zool. Miscell., t. II, pag. 68, - Desm., Consid. gén. sur les Crust., p. 182, pl.25, fig. 2.-EDw., op. cit., t. II, p. 189. - Long. 1 pouce 8 lig. - La moitié de.cette longueur appartient à peu près au rostre, qui porte des petites épines dirigées obliquement sur les côtés; la carapace est lisse, brunâtre; les pieds sónt variés de roux et de blanchâtre. - La patrie de cette espèce nous est inconnue.

DEUXIEME FAMILLE.

\section{A C R O U R S,}

LATREILLE.

\section{CANGERES MACRóURI, Linv.; EXOGNATHES, Farr.}

Tous les Crustacés qui composent cette famille, à l'exception des Ranines, distingués cependant des Brachyures par la queue étendue et par les pieds dorsaux natatoires, ont des appendices latéraux au bout de la queue et forment. le plussouvent, avec son dernier segment, une nageoire.Cette queue, aussi longue au moins que le test, est, les Porcellanes exceptés, étendue, découverte et simplement courbée en dessous vers son extrémité postérieure. Elle offre ordinairement à sa face inférieure cinq paires de fausses pattes formées de deux feuillets ou de deux filets insérés à l'extrémilé d'une petite tige ou de support commun. - Telle est aussi la composition des deux appendices latéraux mentionnés plus haut, et qui prennent naissance un de chaque côté de l'avant-dernier segment, ou le sixième, car il y en a toujours sept.Les ouvertures génitales de la femelle sont situées sur le premier article des pieds de la troisième paire- - Les branchies consistent en des pyramides vésiculaires barbues et velues, disposées dans plusieurs sur deux rangées en petit faisceau. - En général, les antennes sont plus longues, les pédoncules oculaires sont plus courts, et les pieds-mâchoires extérieurs plus allongés que dans les Brachyures. - Les pieds paroissent ĉtre plus propres à la natation, sans être cependant terminés, du moins dans la plupart, en manière de nageoire.-Le corps a aussi moins de largeur, et le test se termine en pointe par-devant.-Vers la fin de cette famille, l'épaisseur des tégmens, s'affoiblit et ils deviennent flexibles et presques membraneux.-La queue, étant plusà découvert que dans les Brachyures, est mieux protégée.
Tels sont les principaux caractères de cette famille, qui embrasse le genre Ecre visse, Astacus de Degéer, d'Ôlivier, etc.

M. Latreille partage cette famille en trois sections, lesquelles se divisent en dix tribus; la première section comprend à elle seule huit tribus.

\section{PREMIBRE SECTION.}

Celte section renferme les Crustacés dont les antennes et les pieds sont toujours à nu, et où le pédoncule des antennes latérales, de niveau arec les intermédiaires, n'est point recouvert par une grande écaille, ou en offre une, mais latérale, et le laissant à découvert.

\section{PREMIERE DIVISION.}

Caractéres. Appendices du bout de la queue, soit nuls, soit rejetés sur les côtés, et point réunis en une piece commune avec le dernier segment.-Les deux premiers pieds tantôt filiformes et très-différens des précédens, tantôt conformés de même, natatoires et dorsaux, soit seuls, soit avec les deux pénultièmes. - Cette division comprend les tribus suivantes: Notoptérygiens, Hippides et Paguriens.

PREMIERE TRIBU.

\section{NOTOPTERYGIENS, LATREille.}

Caractères. Les Crustacés composant cette tribu sont les seuls Macroures qui 


\section{RANILIA.}

n'aient point d'appendicesà l'extrémité latérale de la queue, dont tous les pieds, à l'exception des deux antérieurs, qui sont pourvus d'une pince didactyle, triangulaire et comprimée, soient à la fois terminés en nageoires, et disposés sur deux rangs, les deux des quatre postérieurs étant dorsaux. - Les antennes médianes sont coudées et ressemblent à celles des Brachyures. - Le test est allongè, et a la forme d'un triangle renversé, dont la base ou le bord antérieur est dentelé. - Les pédicules oculaires sont allongés. - Les antennes latérales sont longues et avancées. - Les pieds-mâchoires extérieurs sont droits, allongés, et, comme dans la famille précédente, appliqués sur la bouche, et repliés sur eux-mêmes au côté interne. - Les pieds sont fort rapprochés; les doigts des pinces sont brusquement fléchis. - La queue est étendue, allongée, et ressemble à celle de la plupart des Brachyures mâles. - Cette tribu renferme les genres suivans : Ranina, Ranilia, Raninoides.

RaNina, Lam., Latr., Desh., EDW.; Cancer, Rumph., Linn., Henbst ; Albunea, FABR.

La carapace est un peu déprimée et bombée d'un côté à l'autre, cunéiforme ou oblongue, tronquée et dentelée intérieurement, tronquée et rebordée extérieurement. - Les yeux sont portés sur des pédicules longs, cylindriques, naissant près du milieu du front, et divisés transversalement. - Les antennes latérales sont convergentes intérieurement, avancées ensuite, longues et sétacées; les intermédiaires repliées, mais saillantes. - Les pieds - mâchoires extérieurs sont étroits, allongés; leur troisième article est large, pointu, avec une troncature oblique précé. dée d'un angle à l'extrémité de son côté extérieur, et une échancrure au bord opposé, au-dessus de la pointe terminale ; le quatrième article est inséré dans cette échancrure; mais caché et recu, ainsi que les deux suivans et derniers, dans une rainure longitudinale de ce bord. - La cavité buccale est creusée a sa partie supérieure de deux sillons profonds recevant une portion des premiers pieds-mâchoires. - Les pinces sont comprimées, triangulaires, plus larges à leur extrémité qu'à leur base, en crête dentelée sur leur bord interne, ayant les doigts perpendiculaires à leur axe, mobiles et en faux; les autres pieds sont terminés par des ongles aplatis, ovalaires, ou en forme de lames natatoires, mais un peu arqués et pointus à leur extrémité. - Les pieds de la dernière paire sont plus courts que les autres, et insérés sur le dos. - La queue est allongée, élendue, garnie de poils, composée de sept segmens, le second et le troisième portant des appendices sexuels.

Les trois ou quatre espèces que renfermoit ce genre étoient toutes propres aux Indes-Orientales; maintenant il ne se compose que d'une seule espèce, cependant on en a trouvé une seconde, mais á l'état fossile, dans les terrains d'Italie, et elle a été décrite par l'abbé Rauzani.

\section{Raniva Dentata. (PI. 16, fig. 4.)}

Latr., Encycl., t. X, p. 268. - Edw., op. cit., t, II, p. 194, pl. 21, fig. 1 à $/$. Ranina serrata, Laur., Syst., p. 256, et Hist. des Anim. sans vert., t. V, p. 225. - Dess., Consid. génér. sur les Crust., p. 140. - Guér., Iconogr. du Régn. anim. de Cuv., Crust., pl. 14, fig. 3.-EDw.,Atlas du Rég. ánim.de Cuv., $3^{\mathrm{e}}$ édit., Crust., pl. 41. - La carapace est couverte de tubercules peu saillans, étroits et très-allongés; le bord latéro-antérieur est concave chez le mâle, arqué en sens contraire chez la femelle, et divisé en sept lobes dont le médian, ou frontal, très peu saillant, présente au milieu un rostre triangulaire, et de chaque côté une dent saillante; les lobes mitoyens internes sont gros et terminés par une seule dent; les suivans (ou mitoyens externes) sont armés de deux dents, et les lobes externes de trois qui, chez le mâle, sont aplatis, triangulaires et assez grands; immédiatement en arrière de ce lobe interne on remarque sur le bord latéral de la carapace un prolongement à peu prẻs de même forme et également tridenté; dans le reste de son étendue, le bord latéral est très-finement denté; les pattes antérieures sont chagrinées; il y a deux grosses épines sur le bord supérieur du carpe et de la main, et cinq dents sur son bord inférieur; la pince est mobile, dentelée en dessus et en dessous.

Habite les mers des Indes, et se trouve aussi à l'Ile-de-France.

RANILIA, Enw.

Le bord antérieur de la carapace est très - courbe. - Les orbites sont dirigées 
très-obliquement en bas et en avant, de manière à représenter par leur réunion un $V$ renversé. - Les antennes externes sont dirigées en avant; leur article basilaire est un peu dilaté en-dedans, mais ne présente pas en dehors de prolongement auriculiforme, et ne dépasse pas l'insertion de l'article suivant qui est gros et cylindrique. - Les pieds-mâchoires externes ont à peu près la même forme que chez le genre précédent; mais leur troisième article est plus long que le second, et donne insertion au quatrième article tout près de son extrémité. - Le plastron sternal présente aussi à sa partie antérieure la même disposition, et devient aussi linéaire entre les pattes de la seconde paire; mais entre celles de la troisième et de la quatrième paire il s'élargit de nouveau, et y forme un disque hexagonal un peu concave. - Les pattes sont conformées de la même manière que chez les Ranines, et l'abdomen ne parait présenter rien de particulier; mais, dans l'individu observé, cette partie manquoit.

\section{RANILIA MURICATA.}

Edw., op. cit., t. II, p. 196. - Long. $16 \mathrm{lig}$. - La carapace est lisse postérieurement, mais présente dans sa partie antérieure une foule de petites lignes transversales pilifères; le rostre est mince et arqué ; le bord antérieur de la carapace est armé de chaque côté de quatre dents aiguës donc les internes constituent les angles internes des orbites, et les troisièmes surmontent l'angle externe de ces cavités, qui se prolongent cependant un peu plus loin audessous; les pattes antérieures sont courtes; le carpe est grand, granuleux, et armé en dessus d'une épine terminale; la main est muriquée et armée en dessus d'une seule épine aiguë; son bord inférieur est droit et sans dentelure. - La patrie nous est inconnue.

\section{RANINOIDES, EDW.}

La carapace est près de deux fois aussi longue que large, et sa face supérieure, parfaitement lisse, est presque horizontale d'avant en arrière, mais courbe transversalement. - Le bord fronto-orbitaire est un peu moins large que la portion médiane de la carapace, et fortement denté. - Un rostre triangulaire recouvre la base des pédoncules oculaires, dont la portion terminale est large, grêle et susceptible de se reployer en dehors et en arrière dans un orbite profonde.- Les antennes sont disposées comme chez les Ranines, si ce n'est que l'oreille externe de la grosse pièce basilaire est moins grande.--Les pieds-mâchoires externes ont aussi à peu près la même forme; mais leur quatrième article. s'insère plus près de l'extrémité de l'article précédent. - La portion antérieure du plastron sternal est conformée de la même manière que chez les Ranines; mais, au. lieu de devenir linéaire entre les pattes de la deuxième paire, ce bouclier ventral s'elargit de nouveau entre les pattes de la deuxième et de la troisieme paires, qui sont très-éloignées entre elles, et ne devient linéaire qu'au devant des pattes de la quatriẻme paire. - Les pattes postérieures sont filiformes et s'insèrent en dessus des pattes de la troisième paire.

\section{RANINOIDES LEVIS.}

EDw., op. cit., t. II , p. 197. - Ranina Dorsipes, Desm., Consid. génér. sur les Crust. , p. 140, pl. 19, fig. 2. - Ranina Levis, Katr., Encycl. méth., t. X, p. 268. - Long. 26 lignes. - Le bord latéroantérieur de la carapace est divisé en cinq lobes tronqués par quatre échancrures étroites et irès-profondes; le lobe moyen frontal est armé de trois dents dont la médiane constitue un rostre triangulaire; il y a une seule dent à l'angle interne des lobes mitoyens, et deux à l'extrémité des lobes externes; il y a aussi une forte dent sur le bord latéral prẻs de l'angle orbitaire externe; les pinces sont de même forme que chez les Ranines; il y a deux épines au bord supérieur du tarse, une au bord supérieur de la main, et plusieurs sur le bord inférieur; le doigt mobile est à tranchant non dentelé; il y a des dents aiguës sur le bord du doigt immobile.Nous ne connoissons pas la patrie de cette espèce.

\section{DEUXIEME TRIBU.}

\section{H I P P I D E S, Latreille.}

Caractères. Les Crustacés qui composent cette tribu ont, de même que tous les Macroures suivans, des appendices latéraux au bout de la queue, mais, ainsi que dans la tribu suivante, repliés sur les côtés, ct point connivens avec le dernier segment, et en forme de petites nageoires courbes; les deux postérieurs sont très-grêles, filiformes et repliés. - Les quatre antennes, velues 
ou ciliées, sont avancées et saillantes; aucune d'elles n'est coudée; de plus, le test est tronqué et plus ou moins denté à son extrémité antérieure. - Les pieds-mâchoires extérieurs ont également plus de rapports avec ceux des Brachyures qu'avec ceux des Macroures; les deux pieds antérieurs se terminent soit par une pince comprimée dont le doigt mobile ou le pouce s'applique sur la main, soit par un article en forme de palette ovale ou bien conique; les tarses des suivans, à l'exception des deux derniers, forment une nageoire plus ou moins lunulée et en faucille dans la plupart. - Les appendices souscaudaux sont au nombre de quatre paires, dont la tige est très-grêle et filiforme.-Le premier segment de la queue est court et large; les suivans sont étroits; le dernier est grand et a la figure d'un triangle allongé. - Suivant MM. Quoy et Gaimard, ces Crustacés fuient constamment la lumière et vivent sous les sables humides.

Genres : Albunea, Hippa, Remipes.

ALbUNEa, Fabr., Latr., Desm., Edw. : Cancer, LinN., Henbst.

La carapace est de forme ovalaire, le. gérement convexe, un peu plus étroite postérieurement, et tronquée en devant. Les yeux sont portés sur des pédoncules en forme d'écailles contiguës au milieu du front. - Les antennes intermédiaires sont d'un seul filet, beaucoup plus longues que les latérales et insérées sous les yeux. Les pieds antérieurs finissent en une serre criangulaire, avec un doigt immobile trèscourt; ceux de la seconde paire et les deux suivans sont terminés par une lame en forme de faulx; les deux derniers pieds sont filiformes, repliés. - L'abdomen est court et présente son article terminal ovoïde.

\section{ALBUNEA SYMnista.}

Fabr., Suppl., p. 237. - Edw., op. cit., t. II , p. 203. - Ejusd., Atlas du Régne

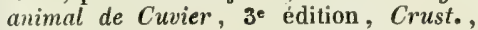
pl. 42, fig. 3. -- Guér., Iconog. du Régne anim. de Cuv., Crust., pl. 15, fig. 1. Cancer Dosipes, Herdst, t. II, p. 5, pl. 22, fig. 2. - Il y a une échancrure très - pro. fonde et semi-circulaire au bord antérieur de la carapace et au-dessus de l'insertion des pédoncules oculaires; la portion moyenne de ce bord est armée de dents très-aiguës, at de deux autres dents spiniformes à son angle externe; les pédoncules oculaires sont beaucoup plus longs que larges; le tarse des pattes de la troisième paire est plus large que celui des pattes précédentes; les bords de la carapace et ceux des pattes présentent de longs poils. - Habite la mer des Indes.

\section{HIPPA, Fabr., Latr., Desh., Edw.; Emerita, Grovov.}

La carapace est ovalaire, un peu bombée et tronquée aux deux extrémités, non rebordée. - Les yeux sont rapprochés au-devant du test, et supportés sur des pédoncules minces en forme d'écailles. - Les antennes intermédiaires sont divisées en deux filets avancés et un peu courbés. Les antennes latérales sont beaucoup plus longues et recourbées, plúmeuses au côté extérieur, avec une grande écaille dentelée qui recouvre leur base. - Les pieds antérieurs sont terminés par un article ovale, comprimés, en forme de lame, et sans doigt mobile; ceux de la seconde, de la troisième et de la quatrième paire finissent par un article aplati, falciforme ou en croissant; ceux de la cinquième paire sont très-menus, filiformes et repliés. - Le troisième article des pieds-mâchoires extérieurs est très-grand et recouvre la bouche. - L'abdomen, comme échancré de chaque côté à sa base, est terminé par un article triangulaire long et étroit, sur chaque côté duquel il existe, près de son origine, une lame natatoire, petite, ciliée sur ses bords, et coudée ou conique.

On ne sait rien sur les habitudes de ces Crustacés, et l'espèce qui sert de type au genre et qui se trouve dans l'Océan qui baigne les côtes de l'Amérique Méridionale, est :

HIPPA EMERITA. (Pl. 16, fig. 2.)

Fabr., Suppl. Ent. Syst., p. 370.Latr., Hist. nat. des Crust., t. VI, p. 176, pl. 52, fig. 1.- Lax., Hist. des Anim. sans vert., t. V, p. 222. - Desm., Considér. génér. sur les Crust., p. 174, pl. 29, fig. 2. - Eow., op. cit., t. II, p. 209. Ejusd., Atlas du Rég. anim. de Cuv., Crust., pl. 42 , fig. 2. - GUв́R. , Iconog. du Rég. anim. de Cuv., Crust., pl. 15, fig. 3. - Cancer Emeritus, Lins. - Long. 1 pouc. - La carapace est garnie de petites lignes rugueuses, transversales, qui y donnent une apparence squammeuse; il y a un sillon transversal droit devant le front, et un autre moins marqué de chaque côté, à moitié distance entre le premier et le sillon post-stomacal; l'article terminal 
des pattes antérieures est ovalaire et arrondi au bout; l'épine externe du grand article basilaire des antennes externes dépasse de beaucoup la portion globuleuse formée par le quatrième article pédonculaire de ces organes. - Se trouve au Brésil.

\section{REMIPES, Latr., LaM., Desm., Edw.}

Les antennes latérales et intermédiaires sont courtes, presque d'égale longueur, avancées et un peu recourbées. - Les piedsmâchoires extéricurs sont semblables à de petits bras, et sont terminés à l'extrémité par un fort crochet. - Les pieds de la première paire sont adactyles, terminés par des lames qui finissent en pointes; ceux des autres paires sont terminés par des lames ciliées, un peu plus larges dans leur milieu et également pointues.

REMIPES TESTUdNarius. (Pl. 16, fig. 3.)

EDw., op. cit., t. II, p. 206. - Ejusd., Allas du Rég. anim. de Cuv., $3^{\mathrm{e}}$ édit., Crust., pl. 42, fig. 1.-Guér., Iconog. du Règ. anim. de Cuv., Crust., pl. 15, fig. 3. -Hippa Adactyla, Faвr., Suppl., p. 370. Cancer Emeritus, Herbst, t. II, p. 8, pl. 12, fig. 4. - Latr., Gener. Crust., et Ins., t. 1, p. 45. - Squilla Barbadensis Ovalis, Pexiv., Potrigraph. Am., tab. 2, fig. 9. - Long. 15 lig. - La carapace est couverte de petites stries transversales crénelées, courtes et arquées; le front est échancré au milieu, et moins saillant que les angles orbitaires externes; les bords latéraux de la carapace sont minces et surmontés d'un sillon garni de petits bouquets de poils très-courts, de manière à paraitre dentelé; la longueur les pattes antérieures varie suivant les sexes. - Habite les mers de la Nouvelle-Hollande.

\section{TROISIEMB TRIBU.}

\section{P A G U I E N S, \\ Latreille.}

Cavactères. Les Macroures de cette tribu sont faiblement crustacés, et leur queue, ordinairement molle, en forme de sac et contournée, ne présente, et dans les femelles seulement, que trois appendices divisés chacun en deux branches, et situés sur l'un des côtés. - Le thoracide, rétréci cn devant, est plus ou moins triangulaire, tantôt terminé en pointe, et comme divisé en deux par une impression transrerse et arquee. - Les deux pieds antérieurs se terminent toujours on une pince didactyle, et dans le plus grand nombre-l'une est plus forte que l'autre; les quatre suivans sont en pointe, ou ont un tarse conique; l'extrémité des quatre derniers forme une petite pince plus ou moins didactyle. - Les pédicules oculaires sont cylindriques et de longueurs variées.

Ces Crustacés vivent, pour la plupart, dans des coquilles univalves et vides.

Genre : Pagurus, Cancellus, Cenobita, Birgus.

\section{PAGURUS, Fabr., Latr., Leach, DESM., EDw.; \\ Cancer, Linn., Herbst.}

La carapace, chez ces singuliers Crustacés, n'a de solide que la région stomacale, qui est plane ou légérement convexe en dessus, tronquée en avant et infléchie sur les côtés. - Les régions postérieures à celles-ci sont séparées par un sillon transversal; la génitale et la cordiale occupent un espace médian, linéaire ; les branchiales sont recouvertes d'un test mou, membraneux et ridé. - Les yeux sont rapprochés, portés sur des pédoncules mobiles, allongès, cylindriques, placés au-dessus des antennes intermédiaires, et pourvus d'un appendice à leur base. - Les antennes extérieures sont distantes, longues, sétacées, et ont l'extrémité supérieure de leur second article pourvue d'une épine mobile; les intermédiaires ou intérieures sont courtes, rapprochées; courbées, notablement moins longues que les latérales, filiformes, terminées par deux filets courts dont le supérieur est en forme de cône allongé ou subulé. - Les pieds-mâchoires extérieurs ont leur tige interne formée de six articles dont le premier court et inégal, le second court, le troisième anguleux et dentelé inférieurement, supportant les trois derniers, qui sont aplatis et ciliés. - Les pinces sont inégales, courbées tantôt à droite, tantôt à gauche, suivant les espèces; le plus souvent anguleuses, rugueuses, et couvertes de poils roides divisés en faisceaux; les quatre grands pieds des seconde et troisième paires sont inégaux en longueur, et suivent la direction des pinces; les quatre dernières pattes sont très-courtes, un peu molles, velues et didactyles; le doigt immobile est chagriné extérieurement en forme de râpe ou de pelotte. - L'abdomen est très-mou, en forme de sac vésiculeux, contourné, 
sans anneaux bien distincts, terminé par deux appendices latéraux, petits, d'inégale longueur, composés d'un article commun qui porte deux autres petits articles dont l'animal ne peut se servir que pour se fixer aux parois intérieures de la coquille qu'il habite; de plus, on aperçoit des fausses pattes ou filets portant les æufs sur un seul côté; l'autre côté en offre quelquefois; dans ce cas, ils sont oblitérés ou solitaires.

Ces Crustacés sont très-nombreux en espéces et très-difficiles à distinguer; c'est un travail dont la science est redevable à M. Milne Edwards, car cet habile observateur, dans le second volume de son Histoire naturelle des Crustacés, a très-bien distingué les espèces qui composent ce genre, et les caractères qu'il leur a assignés les rendent bien distinctes entre elles.

C'est sous les noms de Bernard l'Ermite, soldats, que sont connus ces Crustacés, ainsi dénommés à cause de l'habitude singulière qu'ils ont de s'emparer des coquilles univalves qu'ils rencontrent, pour y loger la partie postérieure de leur corps. En Provence et sur plusieurs côtes de l'Italie les pêcheurs les nomment Piados, Bieou-Arpus, Ermitos, etc.

Les mœurs curieuses des Pagures ont été observées par les Grecs. Ces Crustacés portaient le nom générique de Carcinion; les Latins les distinguoient sous celui de Can. celli, et c'est aussi cette dénomination que leur conservèrent Aldrovande, Gessner, Rondelet, Swamerdam; mais Fabricius leur substitua mal à propos, ainsi que le fait observer M. Latreille, celle de Pagurus, par laquelle les anciens désignoient une espèce de Crabe.

Quoique ces Macroures fussent bien connus depuis long-temps, Swamerdam a néanmoins prétendu, contre l'autorité d'un grand nombre d'auteurs, que les Pagures naissoient avec leur coquille et avoient la faculté de l'agrandir. Cette assertion erronée a été facilement combattue, et on sait aujourd'hui positivement que ces Crustacés sont privés de l'organe sécréteur que la nature a accordé aux Mollusques pour former des coquilles. C'est une fois par an, à l'époque de la mue, que le Pagure ayant grossi, et se trouvant trop à l'étroit dans son domicile, se voit obligé d'en chercher un autre plus spacieux; à cette fin, il entre successivement à reculons dans presque toutes les coquilles vides qu'il rencontre, se replace promptement dans son habita. tion, et se remet en route pour recommencer de nouveaux essais jusqu'à ce qu'enfin le hasard le favorise. Plusieurs auteurs ont assuré que, lorsque pressé de changer de logement, un Pagure en rencontroit un autre possesseur d'une coquille qui paroissoit lui convenir, un combat étoit engagé, et le plus foible étoit contraint de céder la place au plus fort.

Dans leur jeunesse, ces Crustacès s'enfoncent quelquefois entièrement dans leur coquille; plus avancés en âge et ayant grossi, leurs serres et leurs deux pattes suivantes se montrent presque toujours au dehors; les autres restent cramponnées au fond du gîte. Quelques espèces de Pagures choisissent de préférence pour demeure des coquilles de la même espèce; on en rencontre qui se logent constamment dans les Murex; les uns, à cause de la longueur de leur abdomen, semblent ne se plaire que dans les Cérites; d'autres habitent indifféremment les Colombelles, les Cassidaires, les Buccins, et même des Bulimes, des Hélices et des Cyclostomes entrainés dans la mer; il en est enfin qui se placent dans des algues, qui se fixent dans les cavités des éponges ou dans des fragmens de Serpules. J'en ai même vu, dit M. Roux, qui s'étoient contentés de se blottir dans des trous de vieux morceaux de bois cariés.

Suivant ce même auteur, la plupart des Pagures qui habitent nos rivages font plusieurs pontes dans l'année; les femelles portent leurs œufs sur le côté, et les retiennent avec des filets qui y sont placés. Quelques espèces s'approchent des bords où la mer accumule les détritus de petites coquilles vides, afin que leurs petits puigsent se choisir au plus tôt un berceau protecteur; mais il en est qui n'abandonnent jamais les grandes profondeurs; d'autres se tiennent à quelques mètres seulement sous l'eau, dans les lieux fangeux, ou passent leur vie à rôder le long des rochers du rivage ; où, dès qu'on veut les saisir, ils se retirent dans leur retraite et se laissent tomber dans la mer. Il en est d'autres qui vivent en société, si toutefois l'on peut considérer dans ce cas ceux qui se rassemblent et s'entassent sur des corps morts dont ils dévorent les lambeaux en se les disputant; mais, le festin terminé, chacun se retire et va chercher fortune ailleurs. Leur démarche est irrégulière; la moindre éminence devient un obstacle qui les fait se heurter, trébucher et rouler avec leur coquille. L'èpoque de leurs amours et du renouvelle. 
ment de leur habitation leur est toujours dangereuse et souvent fatale : car les poissons les guettent sans cesse pour en manger la chair, dont ils sont très-friands : aussi s'en sert-on avantageusement comme appât à la pêche. M. Risso a observé que, soit qu'ils se promènent sur les rochers, hors de l'eau, ou qu'ils se traînent dans ce fluide, leurs palpes et leurs antennes sont dans un mouvement continuel. Les Pagures sont abondamment répandus dans toutes les mers du globe; il est des plages, dans quelques îles des mers des Indes, qui en sont couvertes. Pendant l'hiver ils s'éloignent de la côte.

Les autcurs ont décrit un grand nombre d'espèces de Pagures, et parni les plus remarquables nous citerons :

\section{1. pagurus prideauxiI.}

Leach, Malac. Brit., pl. 26, fig. 5, 6. Desu., Consid. gén. sur les Crust., p. 178. -Evw., Ann. des $S c$. nat., $2^{\mathrm{e}}$ série, t. VI, p. 268; ejusd., op. cit., t. II, p. 216. Pagurus Solitarius, Risso, Hist, de l'Eu. rope Mérid., t. V, p. 40. - Roux, Crust. de la Méditerr., pl. 36. - Long. 3 pouc. - La carapace, chez cette espèce, est latéralement renflée; les ycux sont d'un gris terne, portés sur des pédoncules courts et épais; les pinces sont granuleuses, inégales, épaisses, carénées au milieu, garnies de petites pointes irréguliéres, surtout sur l'angle interne; les dents sont blanches; les deux paires de pattes antérieures sont longues, effilées, armées de petites pointes sur le bord extérieur des deuxième et troisième articles; le dernier onguiforme, très-allongé, un peu arqué, est longitudinalement traversé par une bande blanche qui s'étend sur les deux articles précédeus; la couleur générale de ce Pagure se compose de teintes rouges, jaunes-verdâtres, qui se fondent entre elles; l'abdomen est plus pâle que la carapace; ses plaques sont bleuâtres; les crochets de la queue sont blancs; le mâle est privé de filets abdominaux qui rappellent ceux ovifères de la femelle dans la plupart des autres espèces de Pagures. C'est durant la belle saison que celle-ci porte des œufs d'un rouge-aurore foncé.

Ce Pagure ne s'approche jamais du rivage; c'est toujours dans des profondeurs de vingt-cinq à trente mètres qu'il se tient. On le trouve dans la Méditerranée.

\section{Pagurus angulatus.}

Risso, Crust. de Nice, pl. 1, fig. 8. Drsm., Consid. génér. sur les Crust., p. 173. - Roux, Crust. de la Méditerr., pl. 41. - EDw., op. cit., t. II, p. 217. Ce Pagure diffère du précédent par la forme de ses pinces, dont la dernière articulation est fortement relevée par-dessus en trois carènes aiguës formant deux excavations profondes sur la pince droite; la pince gauche, qui est beaucoup plus petite, n'est munie que de deux carènes; l'articulation qui précède la main de cette dernière pince est épineuse sur l'angle intérieur seulement, tandis que cette même partie, correspondante de la pince droite, est en dessus entièrement parsemée de granulations à peu près semblables; la carapace est presque glabre, parsemée de quelques poils variés de rouge, sinuée antérieurement; les yeux sont renflés, d'un vert-bleuâtre, portés sur des pédoncules de moyenne longueur; les pattes sont aplaties et ont leur troisiene et quatrième articles légérement dentés sur l'angle intérieur ; l'abdomen est oblong, terminé par des crochets inégaux. La couleur générale de ce Pagure est d'un roux couleur de chair dont quelques parties tirent sur le rougeâtre; le dessous du corps est d'un blanc-jaunâtre.

La femelle diffère du mâle par la forme de ses pinces, qui sont raccourcies, plus dilatées, et privées de granulations qu'on remarque sur l'angle de ces dilatations chez ceux-ci. C'est pendant la belle saison qu'elle porte des œufs roussâtres. On trouve ce Pagure, pendant toute l'année, dans les grandes profondeurs coralligères. 11 vit isolé, manque de vivacité, et habite indifféremment dans les diverses espèces de coquilles commeles Murex, les Tritons, etc.

\section{PAGURUS MEDITERRANEUS.}

Roux, pl. 42, fig. 1 à 2. - Ce Pagure ressemble à l'espèce précédente; comme elle il présente trois fortes carènes sur la pince droite, mais ces carènes diffèrent essentiellement entre elles; celles du second sont aiguës, très-dilatées et lisses; elles sont, au contraire, obtuses, peu dilatées et fortement granuleuses chez le premier; le carpe est, en dessus, couvert de petites épines; la pince gauche, beaucoup plus petite que la droite, est épineuse sur les carènes qu'elle offre; on voit de forts points sur la partic supérieure du carpe ; elle est intérieurement et dans toute sa longueur bordée de poils; le dessous des pinces est entièrement granuleux; tout le corps est lisse, on apercoit seulement quelques poils roussâtres disséminés sur la cârapace et l'abdo- 
men; la tranche supérieure des troisième et quatrième articles des deux pattes antérieures est armée de petites pointes; il en est de même des ongles de ces pattes, qui sont fortement ciliés; la couleur de ce $\mathrm{Pa}$ gure est pareille à celle de l'espèce précédente, c'est un mélange de teintes nuancées de fauve et de rougeâtre sur un fond couleur de chair; les yeux sont renflés, verdâtres, portés sur des pédoncules de moyenne longueur. - Se trouve dans le golfe de Na. ples.

\section{4. pagurus striatus.}

Bosc, Hist. nat. des Crust., t. II, p. 77. - Latr., Hist., nat. des Crust., t. VI, p. 163. - Risso, Crust. de Nice, p. 54.Desa., Consid. genér. sur les Crust., p. 178. - Roux, Crust. de la Méditerr., pl. 10.-EDw., op. cit., t. II, p. 218. Cancer Arrosor, Henest, t. II, p. 170 , pl. 43 , fig. 1. - Long. 8 pouc. - G'est la plus grande espèce de la Méditerranée; elle atteint quelquefois onze pouces de longueur, et se loge dans de grands individus du Murex Tritonis, Linn.; la carapace est plane, presque quadrangulaire, allongée, un peu sinueuse, marquée à sa partie antérieure de quelques points et enfoncemens; on voit des stries irrégulières vers ses régions postérieures; le chaperon est tridenté ou plutôt sinué; les yeux sont portés sur un pédoncule assez gros; on voit à leur base supérieure une lame à dents aiguës, presque en forme de peigne; les antennes extérieures sont un peu plus longues que les pinces; le premier anneau est accompagné d'un rameau pointu, court, 'garni d'épines; les pinces sont grandes, bombèes, épineuses sur le bord extérieur, en dessus et sur les côtés; composées, ainsi que les pattes, de plaques circulaires, irrégulières, ciliées, à arêtes granuleuses; les unes et les autres sont armées sur leurs bords de faisceaux de poils roux; le dessous est presque lisse; les premier, deuxième et troisième articles n'ont que quelques impressions transversales; la pince gauche est plus grande que la droite; le corps est rouge, passant par diverses nuances au jaune pâle ; les yeux sont verts. - La femelle porte des œufs pointillés de jaune, durant le mois de juin.

Cette espèce, qui habite la Méditerranée, vit dans les profondeurs de 25 à 30 métres. Elle ne s'approche guère de la côte. Ce n'est pas seulement dans le Murex Tritonis, Linn., qu'elle habite, mais AnN. aussi dans d'autres eșpèces du même genre, souvent dans des Turbos, des Cassidaires, etc. Sur les mêmes coquilles sont ordinairement fixées des Anomies, des Actinies, particulièrement l'Actinia effota, diverses Sertulaires, Millépores et Serpules; chacun vit de son côté, et cette colonie ambulante est forcée de s'accommoder des diverses régions sous-marines qu'il plait au Pagure de leur faire parcourir dans ses courses vagabondes, - Sa chair est peu estimée; cependant quelques personnes la mangent cuite.

\section{5. pagurus callidus.}

Roux, pl. 15, fig. 1 à 3.-EDw., op. cit., t. II, p. 220. - La couleur générale du test est d'un rouge-carmin; la carapace est allongée, garnie de quelques faisceaux de poils; le front présente sur son bord antérieur trois sinuosités, dont les deux latéra. les saillantes; les yeux, olivâtres, ont à la base de leur pédoncule une lame dentée, en forme de peigne; les antennes intermédiaires sont le double plus longues que ces organes; les pinces, presque triangulaires, bombées, fortement granulées ou plutôt épineuses en dessus, sont hérissées de faisceaux de poils roux, très-rudes; les côtés branchiaux, ainsi que les pattes, sont fasciés d'un rouge foncé; celles-ci sont armées de piquans et d'une ligne de poils, qui s'étendent jusqu'aux ongles, et règnent sur le bord supérieur des premier, deuxième et troisième articles; les antennes extérieures sont un peu plus longues que les pinces.Gette espèce, qui atteint jusqu'à six pouces de longueur, habite des profondeurs de vingt-cinq à trente mètres; on ne la rencontre qu'en été. Elle est rare et s'éloigne en hiver.

\section{PAgURUS TIMIDUS.}

Roux, pl. 24, fig. 6 à 9.-EDw., op. cit., t. II, p. 221. - Long. 1 pouc. - Cette espèce est de petite taille; la carapace et les pattes sont grises; ces dernières, légérement pointillées, ont sur chacun de leurs articles une bande transversale verdâtre, et sur cette teinte un ou deux traits longitudinaux de couleur noirâtre; le dernier anneau des pattes est dentelé intérieurement et terminé par un angle aigu; les pinces, dont la couleur est d'un gris - verdâtre, ont les doigts blanchâtres; les pédoncules des y'eux sont ornés d'une bande rouge longitudinale ; les antennes intermédiaires sont violettes; l'abdomen est noirâtre, avec 
sas crochets blancs. - La femelle porte en mai et en juillet des œufs d'un brun-rougeâtre. Chez les individus desséchés, la couleur verte qui les colore se change en une teinte plus ou moins rousse.

Celte espèce n'est pas rare sur les côtes de Marseille. Elle se mêle quelquefois avec les petites familles du $P$. Misanthro$p u s$, et on les voit rôder ensemble, à fleur d'eau, autour des rochers. Elle se tient ordinairement à de moyennes profondeurs.

\section{PAgurus misanthropus.}

Roux, pl. 14, fig. 1-2. - Risso, Hist. nat. de l'Europe Mérid., t. V, p. 41; ejusd., Pagurus Tubularis, Crust. de Nice, p. 56.-Long. 18 lig. - La carapace est striée, couverte de points enfoncés; les yeux sont bleus; placés sur de longs pédoncules rougeâtres; les antennes sont de cette couleur; les extérieures, à peine plus longues que les pinces, ont leur premier article muni d'une pointe à sa base; les pinces sont égales entre elles, courtes, rudes, pointillées de bleu pâle, avec des poils roussâtres; les pattes, d'un fauve-verdâtre, ont leur dernier article élégamment décoré de bandes longitudinales bleues et rouges; l'abdomen est marbré de bleu, de vert et de noirâtre; les crochets qui les terminent sont d'un blanc-jaunâtre. La femelle a des couleurs moins vives. Les jeunes ont les pattes rougeâtres. Se trouve dans diverses espèces de Cerithium; on le rencontre aussi dans de jeunes Trocus et de jeunes Murex. Sa démarche est très-vive, et lorsqu'on l'inquiète il rentre brusquement dans sa coquille. Il vit ordinairement en socièté. Les œufs que la femelle porte sont violets. Habite la Méditerranée.

\section{8. pagurus orvatus.}

Roux, pl. 43, fig. 1.-Edw., op. cit., t. II , p. 228. - Long. 1 pouc. - Toutes les parties du corps de ce Pagure sont glabres; lisses, généralement assez épaisses; les yeux sont portés sur des pédoncules allongés, rougeîtres; les antennes inférieures sont courtes, de la longueur des pinces, annelées de rouge; les pieds-mâchoires sont bleu de ciel; la carapace est parsemée de quelques points enfoncés; sa partie antérieure est bleue; les côtés, surtout les régions branchiales, sont d'un rouge sanguin; cette couleur est celle des plaques abdominales et des bras; l'abdomen est d'un rouge-brun; les extrémités caudales sont blanches, légérement ciliées; la main est bleue; les doigts sont: blancs; l'une et les autres, parsemés de points rouges, légérement granuleux; les pattes jaunâtres ont leur premier arlicle pointillé de rouge; les second, troisieme et quatrième articles sont longitudinalement ornés de filets de cette couleur; on remarque aussi des points enfoncés; le dernier article des pattes est blanc et orné de petits points rangés en ligue transversale, d'un rouge-carmin; l'angle terminal et les articulations des troisième et quatrième articles sont noirs.-Habite la Méditerranée.

\section{9. pagurus maculatus.}

Desur., Consid. gènér. sur les Crust., p. 179. - Risso, Hist. nat. de l'Europe Mé. rid., t. V, p. 39. - Roux, Crust. de la Méditerr., pi. 24, fig. 1 à 4.-EDw., op. cit., t. II , p. 231. - Pagurus Oculatus, Henibst, t. II , p. 24, pl. 23, fig. 4.-I carapace de ce Pagure est unie, luisante, parseméee de petits points enfoncés; les yeux, d'un noir-bleuâtre, sont portés sur de longs pédoncules rouges; les antennes sont coudées, et ont à leur base une forte épine, elles atteignent dans leur longueur l'insertion du doigt despinces; lesintermédiaires sont'presque de la longueur des yeux; les pinces sont subtriangulaires, inégales, anguleuses, muriquées, un peu dentées sur la tranche supérieure de l'article qui les précède ; on remarque, sur 'la partie interne du troisième article de chacun des bras, une belle tache pourpre, entourée d'un cercle azuré ; les pattes ont quelques poils courts, qui, sur le bord supérieur du dernier article des deux paires antérieures, forment un liseré serré; les quatrième et cinquième articles de la première paire sont dentés sur leur bord supérieur; la couleur de cette espéce est d'un rouge de brique; l'abdomen est un. peu jaunâtre. - La femelle a les pinces moins grosses que celles du mâle; ses appendices ovifères sont bifides; on voit, à la troisieme articulation de son abdo. men, une grande membrane un peu concave, légérement ciliée, qui lui sert à recourrir les œufs qu'elle porte; rẹunis en grappes; ces œufs sont d'une teinte orangée. C'est en été qu'elle en est pourvue. Cette espèce habite constamment les coquilles univalves, et on la rencontre tantôt dans le Cassidaria Echinophora, et tantôt dans les Murix Brandarius, Murex Trunculus, et diverses espèces de Natica. Les plus grands individus n'atteignent pas trois pouces de long. 
Les Pagures tachetés vivent en famille, dans des profondeurs sablonneuses de vingt-cinq à trente mètres, et dans les localités où se propagent les Alcyons Demoncules. Ils choisissent ordinairement des coquilles assez grandes pour leur permettre, en se relevant brusquement au fond, de se soustraire aux regards de leurs nombreux ennemis. Ces Pagures vivent plusieurs jours après avoir été retirés de l'cau. On ne les trouve jamais rôdant sur les rochers du rivage, si ce n'est après les jours de tempête, durant lesquelles la violence des vagues les jette quelquefois sur la côte, et en jonche les plages.

10. pagurus pugrlator. (P1. 9, fig. 1.) Roux, pl. 14, fig. 3-4. - La couleur de cette espéce est généralement d'un brun livide; le test est glabre; la carapace, presque lisse, est élargie en arrière; les yeux sont portés sur de courts pédoncules; les pinces sont fortement chagrinées, inẻgales; la droite est très-petite; la gauche est très-grosse, et renflée; les pattes sont grêles et allongées et présentent une impression longitudinale; les antennes extérieures ne sont pas aussi longues que les pinces; les intermédiaires dépassent du double la longueur des pédon. cules oculaires. - Cette espéce se trouve parmi les rochers submergés du bord de la mer, placée ordinairement dans des Cerithes, et c'est surtout en été qu'on la rencontre sur la côte.

\section{CENOBITA, Latr., Edw, ; \\ Cancer, Herbst ; Pagurus, Fabr.}

La.carapace, rétrécie et comprimée en avant, présente dans sa moitié postérieure un bord saillant qui sépare sa face supérieure de la portion latérale, laquelle descend verticalement vers les pattes. - Les pédoncules oculaires sont assez courts. Les antennes internes, insérées un peu en arrière des externes, sont très-grandes; les antennes externes sont très-fortement comprimées; leur pédoncule est long, mais n'alteint pas l'extrémité du deuxième article des antennes internes, et leur palpe n'est représenté que par un petit tubercule rudimentaire. - Les pieds-mâchoires externes sont filiformes, courts, presque cylindriques, et dépourvus de dents vers leur base. - Les pattes antérieures sont grosses, inégales, et terminées par une main courte et comprimée en dedans; les pattes des deuxième et troisième paires sont grandes; celles de la quatrième pairc sont presque rudimentaires, et leur dernier article a la forme d'un pelit tubercule à peine mobile ; les pattes de la cinquieme paire sont semblables a celles des Pagures.- L'abdomen est membraneux et contourné sur lui-même; chez les femelles, il porte du côté gauche trois fausses pattes ovifères assez grandes et fixées à des plaques dorsales; plus loin en arrière, on voit une quatrième plaque cornée qui ne porte pas d'appendice. - L'extrémité de l'abdomen présente un segment corné, portant à son bord postérieur une lame médiane, et de chaque côté un appendice; celui du côté droit est de beaucoup plus petit; chez le mâle, tous les appendices abdominaux, à l'exception de la paire terminale, manquent compléte. ment; mais on retrouve encore des plaques cornées, dorsales, qui indiquent la division de l'abdomen en anneaux.

\section{CENOBITA GLYPEATA.}

NDw., op. cit., t. II, p. 239.-Pagurus Clypeatus, Fabr., Suppl., p. 415.-Cancer Clypeatus, Herbst, p. 22, pl. 23, fig. 2. - Long. 5 pouc. - La carapace est un peu convexe, tuberculée sur les côtés, en forme de cône tronqué antérieurement; les yeux sont portés sur un pédicule court; assez gros, accompagnés à leur base supérieure d'une lame peu avancée. à peine dentelcé ; les antennes extérieures sont plus courtes que les pinces, et placées à leur côté latéral inférieur; les deux premiers articles sont très-courts, comprimés; le troisième est un peu plus long et plus petit que les deux autres, et il est également comprimé; les antennes inférieures sont presque aussi longues que les autres; le premier article est le plus court, dilaté et tranchant à sa base supérieure; le troisicme article est le plus long de tous; les pin. ces sont couvertes de tubercules clairsemés, rougeâtres, dirigés en avant, qui paroissent comme implaniés; les serres sont armées de dents blanches très-fortes; les doigts sont courts, assez gros; la pince gauche est beaucoup plus grosse que l'autre, et toutes les deux, ainsi que les pattes, ont leur bord supérieur tranchant, et leur partie interne plane ou même un peu creuse. On voit sur les pattes les mêmes tubercules que sur les pinces; mais ils sont plus clairsemés, si ce n'est sur les doigts, où ils sont serrés el garnis de poils; le dernier article est gros et armé d'un ongle noir; la couleur est d'un rouge très-clair, jaunâtre ou brun. - Se srouve aux Indes-Orientales. 


\section{CENOBITA RUgOSA.}

EDw., op. cit., t. II, p. 241.-Long. 3 pouc. - La région stomacale est presque plate; le bord latéral des régions branchiales est très-saillant et légérement courbé; les pédoncules oculaires sont presque deux fois aussi longs que hauts, avec leur écaille basilaire médiocre et pointue; les pattes sont granuleuses et légérement muriquées; la grosse main est médiocre et garnie en dessus d'une rangée de petites crêtes obliques et parallèles; les tarses sont courts et triangulaires; le bord supéricur et externe des deux derniers articles de la troisième patte gauche est élevé en une crête obtuse.

\section{Se trouve dans l'Océan Indien.}

\section{CANCELLUS, EDw.}

Ce genre a beaucoup d'analogie avec ce. lui de Pagure; mais l'abdomen, au lieu d'èire contourné sur lui-même et de se terminer par une espèce de queue filiforme, est parfaitement symétrique.-Les appendices du pénultième anneau abdominal ont la même forme que chez les Pagures, mais sont semblables des deux cốtés ; et il n'existe, du reste, aucun autre appendice adhérent à l'abdomen entre ce segment et le thorax.

\section{CANCELLUS TYPUS.}

Enw., Ann. des Sc. nat., $2^{\mathrm{e}}$ série, Zool., t. VI, pl. 14, fig. 3 ; ejusd., op. cit., t. II , p. 243.- La dent rostriforme est large, triangulaire, mais peu saillante ; le front est profoudément échancré de chaque côté de sa base; la portion antérieure de la carapace est bombée et sans sillons notables; les pédoncules oculaires sont grêles; ils dépassent le pédoncule des antennes externes de près de la moitié de leur longueur, mais cependant ils sont plus courts que le bord antérieur de la carapace; la cornée transparente est très-petite et sans échancrure à son bord supérieur; les antennes externes sont extrêmement courtes, guère plus de deux fois aussi longues que les pédoncules oculaires ; les pattes antérieures sont égales et déprimées supérieurement; il y a une crête dentelée sur le bord supérieur de la main, qui se réunit à une élévation longitudinale arrondie de la face externe de la main, de manière a former, sur le carpe, une pyramide à trois faces; la face externe de la main est un peu verruqueuse; les pinces sont trèg. courtes; les pattes de la seconde paire sont beaucoup plus grosses et plus longues que celles de la troisième paire, et garnies d'une crête qui s'étend du milieu du troisième article jusqu'à leur extrémité, en décrivant une courbure régulière, dont la convexité est en dehors; l'extrémité supérieure de cette crête s'élève, comme celle des pattes antérieures, en pyramide, et correspond exactement à l'extrémité des pédoncules oculaires, lorsque les pattes sont dirigées en avant; les tarses sont très-couris et assez gros ; les pattes de la troisième paire sont très-comprimées; l'article basilaire des pattes postérieures est grand et squammiforme; l'abdomen du mâle est court, large, garni en dessus de lames transversales très-étroites qui ne portent pas d'appendices, et terminé par une paire d'appendices conformés comme chez les autres $P a$ gures, mais symétriques, et par une lame inédiane également symétrique.

\section{BIrGUS, Leach, Latr., Desm., Edw.; Pagurus, Latr., Fabr., OLrv. ; \\ Cancer, Rumpe., Linv., Hekest.}

La carapace est en forme de cœur rénversé dont la pointe est en avant; son dessus est marqué d'une impression en $\mathbf{X}$ qui indique la séparation des régions médianes. - Le second article des antennes est en forme de crête.-Les pieds de la première paire sont inégaux, terminés en pince; les pieds des seconde et troisième paires se terminent par un ongle simple paroissant servir au transport de l'animal, ainsi que ceux de la quatrieme paire, qui sont plus petits que les premiers et didactyles; les pieds de la cinquième paire sont rudimentaires. - L'abdomen est orbiculaire, crustacé en dessus et divisé en tablettes transversales qui sont des rudimens d'anneaux.

On ne connoît encore qu'une seule espèce propre à ce genre, c'est le

birgus iatro. (Pl. 9, fig. 2.)

Leace, Trans. of the Linn. Soc., vol. 11. - Desm., Consid. génér. sur les Crust., p. 180 , pl. 30 , fig. 3. - Quox et Gaim., Koy. de l'Uranie, pl. 80.- GuÉr., Icon. du Rég. anim. de Cuvier, Crust., pl.16, fig. 1.-EDw., op. cit., t. II, p. $246 .-P a$. gurus Latro, FABR., Suppl., p. 411.LATr., Hist., nat. des Crust., t. V I, p. 164. - Cancer Crementatus, RumpH., Mus., pl. 4.-SEBA, t. III, pl. 31, fig, 1, 2.- 
Tome $x^{e r}$,ére partice.

Cruslacés $P l \cdot g$.

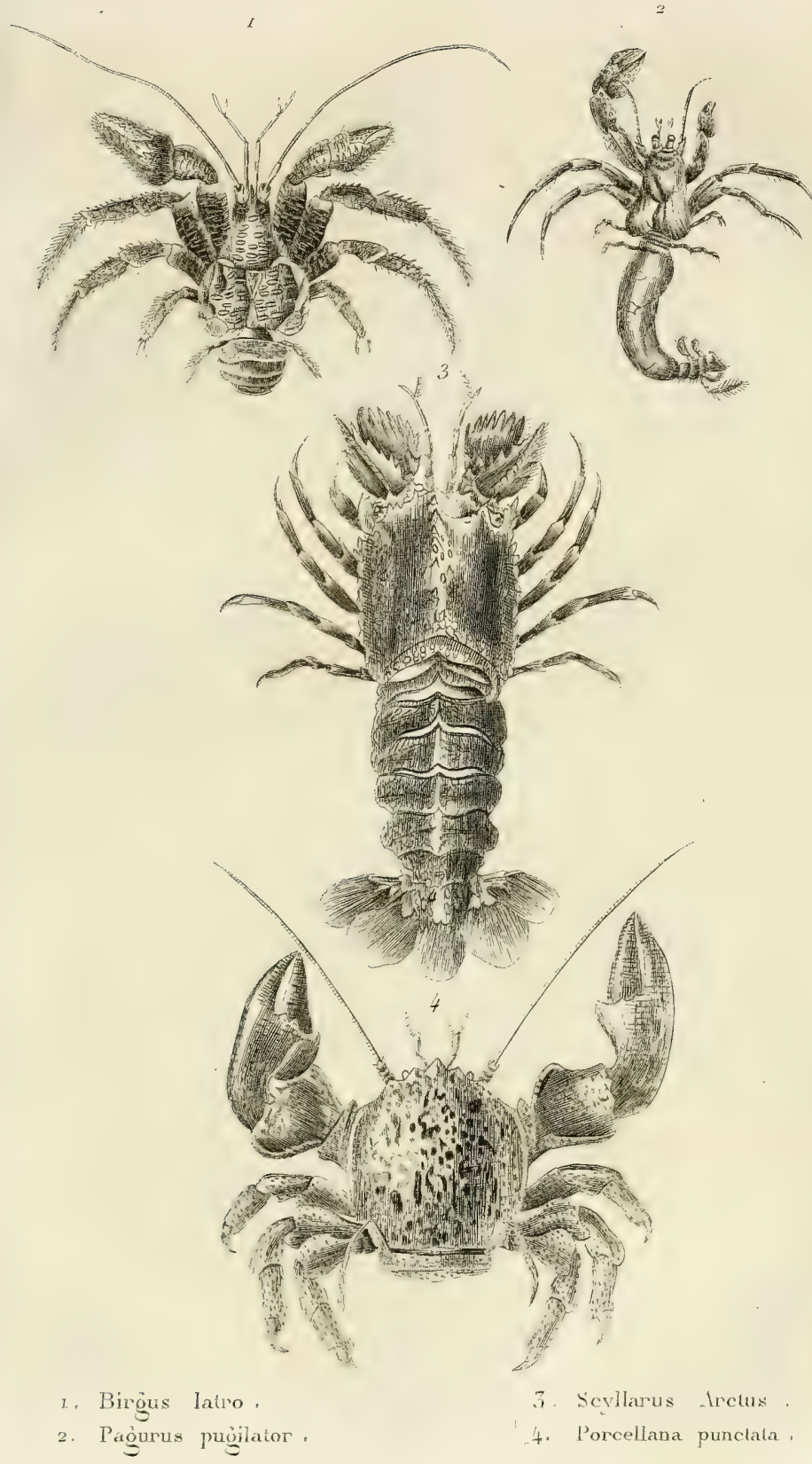



Long. 6 pouc. - Cette espèce est trèsgrande, d'un beau rouge; son rostre est terminé par une seule pointe; ses pinces sont rouges, la gauche étant plas grosse que la droite, toutes deux ayant leurs doigts garnis de fortes dents; les pattes des trois paires suivantes sont dentelées sur leurs bords et marquées de taches ondulées. Se trouve dans la mer des Indes. Flle habite à terre les fentes des rochers, d'où elle sort la nuit pour se rendre sur le rivage, où elle cherche sa nourriture. C'est cette même espèce qui feroit, suivant une tradition populaire des Indiens, sa nourriture des amandes de fruits de cocotiers, et ses excursions auroient lieu la nuit.

\section{QUATRIÈME TRIBU.}

\section{S C Y L L A R I D E S, LATREILLE.}

Caractères. Carapace plus longue que large. - Orbites situées à peu de distance de ce bouclier.

C'est du genre Scyllarus de Fabricius que se compose cette tribu, laquelle renferme trois genres: Scyllarus, Ibacus et Thenus.

\section{SCYLLARUS, Fabr., LATr., Lairck, , DESM., EDW.}

La carapace est courte, déprimée, carrée, tronquée en devant, s'insérant en arrière, angulaire autour des orbites, qui sont placées aux angles antérieurs. - Les antennes extérieures sont remplacées par leurs pédoncules, qui ont la forme d'une grande crête aplatie et horizontale; le premier étant assez court et transverse; le second très-grand et externe; le troisième petit, interne, et placé dans une échancrure du second; le quatrième, en forme de crête horizontale, très-large, triangulaire, denté et cilié sur son contour. Les antennes intermédiaires sont en forme de deux appendices pluri-articulés, portẻes sur un large pédoncule composé de cinq articles à peu près cylindriques, dont le premier est le plus grand. - Les pieds - mâchoires extérieurs sont courbés en dedans comme les pattes de la première paire et appliqués l'un contre l'autre dans toute leur étendue. Les pattes sont courtes, d'autant plus petites et plus écartées entre elles qu'clles appartiennent à des paires postérieures; les deux premières étant les plus grosses, et toutes finissant par une seule pointe chez les mâles; les deux dernières ont, chez les femelles, le pénultième article prolongé en dessous de facon à former une sorte de doigt opposable à l'angle terminal. - L'abdomen est médiocrement allongé, peu recourbé au bout, composé de six articles et terminé par cinq lames natatoires crustacées à la base, membraneuses à l'extrémité, dont les deux externes de chaque côté sont entières et articulées avec le sixième article. - Ghez les femelles chaque segment de l'abdomen est muni de deux pièces abdominales; l'une, ciliée, composée de plusieurs articles, présente, suivant les espèces, diverses configurations, et sert à retenir et à porter les œufs; l'autre est membraneuse, très-élargie.-Le mâle ne possède qu'une de ces pièces, qui répond à la membraneuse; elle est étroite et ne parait avoir d'autres usages que d'aider à la nutrition et à protéger la délicatesse de la peau de l'abdomen.

Les Scyllares ont été connus des anciens; Belon les rapporte à l'Arctos d'Aristote; Scaliger y cherche le Crangon de cet auteur; d'autres ont cru y voir le Gammarus des Latins.

Ces Décapodes, dit M. Roux, ont la natation vive et très-bruyante; c'est par bond qu'ils l'exécutent, comme les Langoustes; les uns se tiennent sur les terrains argileux, à de moyennes profondeurs; d'autres n'habitent que les profondeurs rocailleuses. Dans la saison des amours ils s'approchent des endroits où croissent les ulves et les fucus. La femelle n'abandonne ses œufs qu'après qu'ils sont développés. La chair de ces Macroures est excellente. On en trouve deux espèces dans la Méditerranée. On n'en connaît point de fossiles. Ces Crustacés sont connus sur plusieurs points de la Méditerranée, sous les noms de Chiambré, Macoto, $C_{i-}$ galo et Masquo.

1. Scyllarus arctus. (Pl. 9, fig. 3.) Fabr., Suppl., p. 399. - Latr., Hist. nat. des Crust., t. VI, p. 180. - DeSM., Consid. gén. sur les Crust., p. 182. Roux, Crust, de la Méditer., pl.11, fig. 1 à 5. -Evw., op. cit., t. II, p. 282; ejusd., Atlas du Régn. anim. de Cuv., $3^{\circ}$ édit., Crust., pl. 45, fig. 1. - Cancer Ursus Minor, IIerest, t. II, p. $83, \mathrm{pl}, 30$, fig. 2. Cancer Arclus, Roemer, Gener. insect. , pl. 32, fig. 3. - Linn., Faun. Suec., et 
Syst. nat. - Longueur 3 pouces. - Chez cette espèce, la carapace est longitudinalenent traversée par trois crêtes aiguillonnées dont les antérieures sont lesplus longues; les bords latéraux ont deux séries de granulations ; on en voit une autre sur le bord postérieur de la carapace; iln'y a point d'avance frontale; les antennes extérieures sont profondément dentées; les articles de l'abdomen sont élégamment sculptés en dessus; leursłbords latéraux ne sont point crénelés; le corps est d'un brun-lougeâtre; le premier anneau de l'abdomen, d'un rouge vermillon, est noir au milieu; le second de la même couleur, bleuà l'insertion de sa partie supérieure; on voit aussi du rouge à la naissance des suivans; les pédoncules des yeux, très-courts, sent aussi d'une teinte de cina. bre; les pattes sont annelées de violet et de jaune; les écailles natatoires sont striées. Cette espèce atteint jusqu'à cinq pouces de longueur. Les æufs que la femelle porte au printemps sont d'un jaune doré.

M. Roux regarde comme une variété de cette espèce le Scyllarus Cicada de M. Risso.

On trouve communement ce Scyllare dans la Méditerranée; on le rencontre même toute l'année. Les individus de cette espèce habitent de préférence les terrains argileux, surtout ceux que circonscrivent ou que resserrent des rochers couverts d'algues, placés à cinq ou six mètres de profondeur ; c'est là que, réunis en famille, et tranquilles au milieu de leurs remparts qui les abritent, les mâles se livrent à des combats que l'amour fait naître, ou s'exercent à des jeux que, dans les jours de calme, la sécurité dont ils jouissent leur fait goûter avec plus de plaisir. Aux époques de l'accouplement et de la ponte, qui sont celles de la belle saison, ils se rapprochent des bords de la côte et semblent, pour célébrer leurs noces, choisir de préférence les endroits tapissés de verdoyantes ulves et décorés d'élégans fucus. Ils ont l'habitude de creuser dans le sol des tanières un peu obliques, de la grandeur de leur corps, afin d'y établir leur demeure; ils s'y tiennent dans le jour ou se cachent sous les pierres. C'est pendant la nuit qu'ils vont a la recherche de leur nourriture, sans pourtant beaucoup s'éloigner de leur habitation. On les prend dans des nasses que l'on met à l'eau pour pêcher les Langoustes, les Congres, les Murénophis et autres poissons nocturnes. Les différentes espèces de Clupées, les Oursins, les pattes de Poulpes brûlées, les autres mollusques céphalopodes, divers Spares, etc., qu'on y place pour appât, sont les aliments dont les Scyllares sont très-friands et qui les attirent. Leur chair est excellente.

\section{SCYLLARUS LATUS.}

Latr., Hist, nat. des Crust., t. VI., p. 182. - DesM., Consid. gén. sur les Crust., p. 182. - Savigny, Descript. de l'Egypte, pl. 8, fig. 1.-GuÉk., Iconogr. du Règn. anim. de Cuv., Crust., pl. 17, fig. 1. - EDw., op. cit., t. II. 284. Cette espèce, qui atteint quelquefois jus. qu'à un pied de long, a le corps et la carapace couverts de gros tubercules déprimés et hérissés de poils très-courts; le milieu de la région stomacale présente une élévation conique, et un peu plus en avant deux tubercules pointus très-rapprochès l'un de l'autre; les régions branchiales sont hérissées de pointes disposées en série longitudinale; les bords supérieurs des orbites et les bords labiaux de la carapace sont armés de dents triangulaires et pointues, surtout chez le mâle; les antennes externes sont très-grandes; leur pénultième article, aussi long que large, est armé de deux grosses dents pointues sur son bord interne, et d'une dent moins forte vers le tiers interne de son bord antérieur; $d^{2} u n c$ dent recourbée en haut et.très-forte à son angle antérieur et externe, qui est trèsavancé; et de plusieurs dents inégales sur son bord externe; l'article suivant, également plus long que large, est armé en dedans de deux grosses dents pointues; le plastron sternal et la base de chaque patte présentent de très-gros tubercules pointus.

Cette espèce se trouve sur les côtes de la Méditerranée, où sa chair est très-estimée; ses œufs sont d'un rouge vif; elle a été aussi rencontrée aux îles Canaries.

\section{SCYLLARUS MQUTYOXILIS.}

Fabr, Suppl., p. 399. - Bosc, Hist. nat. des Cirust., t. II, p. 19. - LATR., Hist. nat. des Crust., t. VI, p. 182. EDw., op. cit., t. II, p. 285, pl. 24, fig. 6. - Cette espèce a beaucoup d'analogie avec la précédente; mais les tubercules dont toute la surface du corps est recouverte sont-à peine poilus; il n'y a point de dents coniques. sur la région stomacale, et les bords latéraux de la carapace ne sont garnis que de dents très-obtuses; les antennes externes sont beaucoup plus courtes; leurs pénultième et anté-pénultième articles 
sont beaucoup plus larges que longs, et ne sont ornés que de dents peu saillantes; la couleur est d'un jaunâtre mêlé de rouge. Se trouve aux Antilles.

\section{THENUS, LEACH, EDw. ; Scyllarus, Fabr., Latr.}

Ce genre, qui a été établi par M. Leach, diffère du précéd̄ent par le corps, qui est. très-déprimé et se rétrécissant beaucoup d'avant en arrière. - Les pédoncules oculaires sont très-longs; les yeux dépassent latéralement la carapace; et les orbites, dirigées en dehors, occupent l'angle externe de ce bouclier. - Le sternum est beaucoup plus large que chez les Scyllares proprement dits, et l'abdomen présente à peu près la même longueur proportionnelle que chez ces Crustacés. - L'espèce type de ce genre est le

\section{THENUS ORIENTALIS.}

Edw., op. cit., t. II , p. 286, - Scyllarus Orientalis, Fabr., Suppl., p. 399. - LATr., Hist. nat. des Crust.; t. VI, p. 181. - Desm., Consid. gén. sur les Crust., p. 182, pl. 31, fig. 1. - Long. 8 pouc. - La carapace est très-déprimée et verruqueuse; il y a une petite crête obtuse garnie de trois dents sur la ligne médiane; le rostre est armé de deux grosses cornes divergentes; on aperçoit une épine à l'angle interne de l'orbite, deux sur son bord supérieur, et une à son angle postérieur; on apercoit aussi une autre dent sur la face supérieure de la carapace, un peu en arrière de l'orbite, et une rainure profonde et large sur son bord externe; un peu plus loin en arrière, le milieu du bord postérieur de l'arceau supé: rieur du cinquième anneau de l'abdomen présente une forte épine.

Se trouve dans l'Océan Indien.

IB ACUS, Leach, Desy. , Edw. ; Scyllaruz, Fabr., Latr.

La carapace est beaucoup large que longue, et présente de chaque côté un prolongement lamelleux qui recourre la majeure portion des pattes; ces prolongemens sont plus grands en avant qu'en arrière, d'où il résulte que la carapace se rétrécit postérieurement ; on remarque aussi chez ces Crustacés une large et profonde fissure qui, de chaque côté, divise ces prolongemens clypéiformes en deux portions égales. - Les orbites, au lieu d'ệtre placées très-près de l'angle externe de la carapace, en -sont très-éloignées. - L'abdomen est très-court, et se rétrécit brusquement d'avant en arrière.

\section{IBACUS PERONII.}

LEACH, Zool. Miscel., t. II, pl. 119. - Desw., Consid. génér. sur les Crust., p. 183, pl. 31, fig. 2. - EDw., op. cit., t. II, p. 287.-Scyllarus Incisus, PÉRON, Collect. du Mus. - Latr, Encycl., pl. 320 , fig. 1. - Lavr., Hist des Anim. sans vert., t. V, p. 213. - Long. 5 pouc. - Les orbites sont situées beaucoup plus près de la ligne médiane que des angles externes de la carapace, qui sont recourbés en avant et dépassent de beancoup le niveau du front; la carapace est très-déprimée, piquetée plutôt que verruqueuse, et présente trois crêtes longitudinales dont la médiane est garnie de quel. ques tubercules mousses, et les latérales sont situées sur la même ligne longitudinale que les orbites; les bords latéraux de la carapace sont très-obliques et armés de sept dents, dont une seule, située au-devant de la grande échancrure latérale, forme l'angle antérieur; les antennes externes sont beaucoup plus larges que longues; leur premier article est très-petit et dépasse a peine le rostre; le second faible. ment denté, et le quatrième armé seulement de trois ou quatre dents très-larges; les pieds-mâchoires externes sont armés d'épines sur le bord externe du quatrième article; l'abdomen est piqueté et surmonté d'une crête médiane obtuse.

Se trouve dans les mers de l'Australasie.

\section{CINQUIÈE TRIBU.}

\section{A NGO US TIN ES, Latreille.}

Caractères. Cette tribu se compose d'un seul genre qui est celui de Langouste. Les Langoustines se distingue des Scyllarides par leur corps proportionnellement plus étroit, plus allongé et semi-cylindrique; par leurs antennes latérales, qui sont fort longues, sétacées et hérissées de petites épines, et par l'absence de pinces didactyles, Les yeux sont moins écartés et situés sous des saillies anguleuses. - Les femelles, de même que celles de la tribu précédente, ont une dent ou ergot à l'avant-dernier article des deux pieds postérieurs.

Genre: 'Palinurus. 


\section{PALINURUS, Fabr., Latr., LaMck., Leach, Desm., Edw.}

La carapace est médiocrement allongẻe, demi-cylindrique, hérissée de pointes, surtout en avant et au-dessus des orbites, qui sont latérales; elle est marquée d'un sillon transversal et arqué en arrière, qui sépare les régions stomacale et hépatique antérieures des autres régions, et de deux impressions longitudinales postérieures qui comprennent entre elles les régions génitale et cordiale, en laissant en dehors les branchiales. - Les yeux sont grands et ronds, portés sur des pédoncules étroits, transversaux, et qui semblent partir du même point au milieu du front. - Les antennes extérieures, proportions gardées, beaucoup plus grosses que les correspondantes des autres Macroures, sont portées sur un grand pẻdoncule très-hérissé de poils et d'épines et fort longues; les antennes intermédiaires ont essentiellement la figure des antennes analogues des Brachyures, et n'en diffèrent que parce qu'elles sont plus grandes; elles sont formées d'un long pédoncule mince composé de trois articles, dont le premier est trèsgrand, et de deus pelites branches multiarticulées, six fois plus courtes que ce pédoncule.-- Les pieds-mâchoires extérieurs ressemblent à une paire de pieds avancés, dont les deux premières paires sont dentelées et velues au côté interne. - La poitrine forme une espèce de plastron triangulaire, inégal ou tuberculé, sur les côtés du. quel sont insérées les pattes, qui, à raison de la figure triangulaire de cette pièce, s'écartent graduellement de devant en arrière.-Les pattes sont médiocrement longues, assez fortes, et se terminent toutes par un doigt simple, court, aigu, légérement courbé et hérissé de quelques poils rudes en dessous; elles n'ont point de pinces; les antérieures sont plus couries que les quatre suivantes et que celles surtout de la troisième paire.-Les segmens de la queue sont ordinairement traversés par un sillon dans leur longueur; ils se terminent latéralement en manière d'angle dirigé en arrière et souvent dentelé ou épineux en dessous; les anneaux sont unis les uns aux autres par une membrane.-Ce qui distingue les femelles des mầles, c'est qu'elles ont, aux quatre anneaux du milieu de la queue, deux filets membraneux ovales, auxquels les œufs s'attachent après la pontc.-
Les branchies sont composées de filamens cylindriques, courts et serrés en manière de brosses; on en compte dix-huit de chaque côté, savoir : deux au-dessus du second pied-mâchoire, trois au-dessus du pied-mâchoire externe, trois au-dessus de la patte antérieure, quatre au-dessus de chacune des trois pattes suivantes, et une au-dessus de la cinquieme patte.- Un large appendice flabelliforme s'élève entre chacun de ces faisceaux de branchies.

Les Grecs ont donné le nom de $K \alpha$ pabos à l'espèce de Langouste la plus commune de nos mers; c'est celle que les Latins nommèrent Locusta. Belon, Rondelet, Gesner, l'ont mentionnée sous ce dernier nom. De lá l'origine du mot de Langouste, par lequel on désigne dans notre langue cette espèce.

Les femelles des Langoustes que l'en trouve dans nos mers portent, depuis le mois de mai jusqu'en août, leurs œufs, que l'on nomme corail; ils sont disposés dans l'intérieur de leur corps en deux masses allongées de la grosseur d'un tuyau de plume et d'un très-beau rouge; ils se dirigent, en divergeant, vers deux ouvertures situées, une de chaque côté, vers la base des pattes intermédiaires; ces œufs sont très-petits en sortant du corps de la mer; mais íls croissent insensiblement pendant une vingtaine de jours qu'ils demeurent attachés aux fevillets du dessous de la queue; ce temps écoulé, elle les détache tous ensemble de leur enveloppe, et ont les trouve souvent fixés contre des rochers, ou errans, ou abandonnés aux courans et aux vagues. Ce n'est qu'une quinzaine de jours après que ces œufs éclosent. Après cette première ponte, elles en font une seconde en se débarrassant totalement de leurs œufs; alors elles sont maigres et peu estimées, et l'on ne recherche que les mâles.

Les Langoustes abandonnent nos côtes vers la fin de l'automne ou au commencement de l'hiver, et alors elles gagnent la haute mer et vont se cacher dans les fentes des rochers, à de très-grandes profondeurs. Elles vivent de poissons et de divers animaux marins, et parviennent, au bout de quelques années, à la longueur d'un pied. Ces Crustacès peuvent vivre très-long-temps, et s'ils parviennent à se réfugier dans quelques lieux peu favorables à la pêche, îls atteignent une grosseur très-considérable. Suivant M. Risso, les mâles vont à la recherche de leurs fe melles en arril et en août. Dans l'accouple- 

a
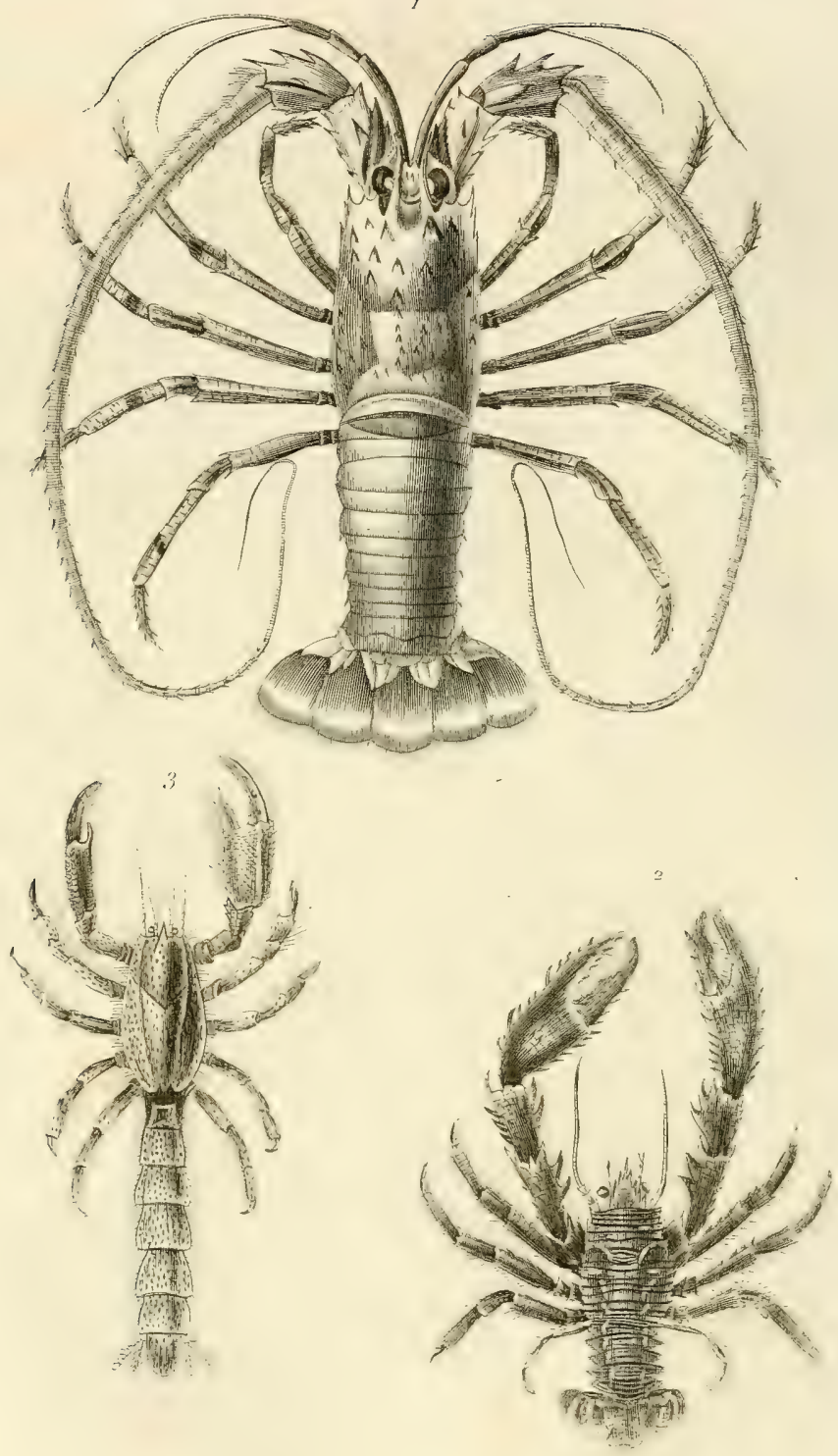

3. Palinurus Ricordi.

2. Galathoca Striōosa

3. Thalassina Scorpionoides. 
ment, les deux sexes sont face à face, ct se pressent si fortement qu'on a de la peine à les séparer, même hors de l'eau. Sur les cótes de Nice, on pêche ce Crustacé avec des nasses. On met dans le panier des pattes de Poulpes brûlées, des petits poissons, des Crabes, etc. ; on le descend pendant la nuit dans des endroits rocailleux, où les Langoustes se plaisent beaucoup, et on prend, le lendemain matin, celles qui sont dedans. On fait une très-grande consommation de ces Crustacés sur nos tables, et on les envoie dans l'intérieur de Paris, où ils sont très-recherchés. Pour les faire voyager on les fait cuire, sans quoi ils se gâteroient en route.

M. Edwards, dans son Histoire naturelle des Crustacés, divise ce genre en deux groupes, savoir : les Langoustes ordinaires et les Langoustes longicornes.

\section{Langoustes ordinaires, EDw.}

Les espèces qui composent ce groupe présentent, sur le milieu du front, une petite dent rostriforme plus ou moins saillante. - L'anneau antennaire est droit, de manière que les antennes externes se touchent jusqu'à leur base et recouvrent les antennes internes; enfin, celles-ci se terminent par deux tigelles multi-articulées, très-courtes.

\section{1. palinurus velgaris.}

Latr., Ann. du Mus., t. III, p. 391.Laмск., Iist. des Anim. sans vert., t. V, p. 220. - Desu., Consid. génér. sur les Crust., p. 185, pl. 2, fig. 1. - Risso, Hist. nat. des Crust. de Nice, p. 64.-EDw., op. cil., t. II , p. 292 ; ejusd., Atlas du lieg. anim. de Cuvier, Crust., pl. 46, fig. 1. -Cancer Homarus, Penn., Brit. Zool., t. IV, pl. 11 , fig. 2. - Astacus Homarus, Ourv., Encycl. Méth., t. VI, p. 343. Palinurus Quadricornis, Fabr., Suppl., p. 401.- Les cornes latérales du front sont lisses en dessus et armées en dessous de plu. sieurs dentelures aiguës; la carapace est extrêmement épineuse; les dents sous-orbitaires du bord de la carapace sont trèsgrandes; l'abdomen est presque entièrement lisse, et présente sur les quatre anneaux qui suivent le premier un sillon tıansversal, profond et pilifère, interrompu sur la ligne médiane; les cornes latérales formées par les angles de ces anneaux sont armées, sur leur bord postérieur, de trois ou quatre dents situées près de leur base ; les deux derniers anneaux de l'abdomen sont épineux; les antennes internes sont très-grêles et de longueur médiocre; les pattes antérieures sont courtes et armées d'une dent à l'extrémité du bord inférieur du pénultième article; il y a un vestige de doigt immobile aux pattes postérieures chez la femelle; les fausses pattes abdominales de la première paire portent, chez la femelle, deux grandes lames ovalaires; tandis que les suivantes ne présentent qu'une seule de ces lames et un appendice grèle et bi-articulé. - Cette espèce, qui atteint jusqu'à dix-huit pouces de long, se trouve communément sur les parties rocailleuses de nos côtes méridionales et occidentales.

2. Palivurus ricordi. ( $\mathrm{Pl} . \mathbf{1 0}$, fig. 1.)

GuÉR., Icon. du Rég. anim. de Cuvier, Crust., pl. 17, fig. 2.- Nous avons figuré comme type de ce genre cette espèce, qui a été représentée par $M$. Guérin dans son Iconographie du Régne animal de Cuvier, et qui sera décrite dans le même ouvrage.

\section{Langoustes Longicornes, EDw.}

Dans ce groupe il n'existe, sur le bord antérieur de la carapace, aucun vestige de rostre.-L'anneau antennaire est très-large et presque carré, de manière à écarter beaucoup plus entre elles les antennes externes et à laisser à découvert les antennes internes; enfin, ces derniers organes se terminent par deux tigelles multi-articulées, très-longues.

\section{Palinurus guttatus.}

Latr.," Ann. du Mus. , t. III , p. 393.OLIV., Encycl., t. VIII, p. 672.- Lанск., Hist. des Anim. sans vert., t. V, p. 210.Desm., Consid. génér. sur les Crust., p. 185.-EDw., op. cit., t. II, p. 297.Long. 8 pouc.-La carapace est hérissée de piquans assez grands, pointus, dont les uns sont entièrement bleus, les autres en partie bleus, partie blancs; quelquesuns sont blancs, avecl'extrémité rougeâtre; on en voit de bleus. qui ont un cercle blancà leur base ; outre ces piquans, il y a des tubercules et des poils très-courts, roussâtres ; les piquans antćricurs sont beaucoup plus grands que les postérieurs; on en voit deux simples, forts grands, an-dessus des yeux, et deux plus petits de chaque côté; il y en a deux autres au-dlessous des antennes inférieures; ces antennes sont bleuâtres, marquées de taches blanches sur le premier article; les deux filets qui les terminent sont filiformes, 
plus courts que les trois premiers articles pris ensemble; les antennes extérieures sont mélangées de bleu et de blanc; les trois premiers articles sont armés de très-grands piquans; le dernier a des épines assez fortes; les pattes sont bleues, marquées de taches rondes, blanches, surtout sur les premiers articles; les derniers ont des faisceaux de poils; la queue est bleue, toute mouchetée de blanc; chaque segment est traversé par un sillon velu, entier, et terminé de chaque côté en pointe très-aiguë, arquée; les feuillets de la queue sont terminés, à leur partie crustacée, par des piquans; le reste est chagriné et hérissé de poils raides et très-courts; - Se trouve aux Indes-Orientales.

\section{SIXIÈME TRIBU.}

\section{GALATHINES, LATreille.}

Caractères. Appendices du bout de la queue réunis aussi avec le dernier segment, en une nageoire, mais entièrement crustacés. - Les deux pieds antérieurs à peine didactyle, les deux derniers ordinairement très-petits et repliés. - Yeux trèsgros, et appendices du bout de la queue composés d'une seule lame, dans ceux dont les deux pieds postérieurs ne diffèrent pas des autres. - - Antennes mitoyennes, coudées,' et dont le pédoncule est plus long que les deux filets du bout.

Genres : Porcellana, Galathea, OEglea, Grimothea, Megalops, Monolepis.

\section{PORCELLANA, Lami, Bosc., Latr., Risso, Evw.; \\ Cancer, Linn., Fabr.}

I a carapace est presque orbiculaire, déprimée, légérement bombée en dessus, un peu rétrécie en pointe à son extrémité antérieure.--Les antennes latérales, insérées au côté extérieur des yeux, sont sétacées, Jongues; lesintermédiaires sont très-petites, et logées entre les yeux dans deux cavités longitudinales et creusées au-dessous du front. - Les pieds-mâchoires extérieurs ont leurs second, troisième, quatrième et cinquième articles comprimés et dilatés intérieurement, surtout le second; le sixiẻme est en forme de triangle allongé, garni d'une série de très-longs poils sur son bord interne. - Les pattes de la première paire ou les serres sont grandes, terminées par une main plus ou moins comprimée, didactyle; celles des seconde, troisième et quatrième paires sont assez grandes et terminées par un ongle ou article pointu; cel. Ies de la cinquième paire sont très-petites, filiformes, mutiques, repliées de chaque côté du test, cachées ou peu apparentes. -L'abdomen, entièrement recourbé et appuyé sur la poitrine, est terminé par une nageoire caudale qui est formée de la dernière pièce abdominale, divisée par des rainures en quatre parties distincies, et de deux nageoires placées de chaque côté, lesquelles se composent de deux lames portées sur un pédoncule commun.

Ces Crustacés, généralement de petite taille et dont la démarche est assez lente, se tiennent sur les bords de la mer etrestent cachés sous les pierres pendant lc jour. Les femelles déposent leurs oufs. dans le sable graveleux baigné par les. flots.

\section{1. porcellana platycheles.}

Larr., Syst. des Anim. sans vert., p. 153. -Latr., Hist.nat. des Crust., t. IV, p. 75. -Leaci, Dict. des Sc.nat., t. XVIII, p. 35. - Desur, Consid. génér. sur les Crust., p. 195, pl. 34, fig. 1. - EDw., op. cit., t. II , p. 355. - Cancer Platycheles, Penn., Brit. Zool., t. IV, pl. 6, fig. 12. - Long. 5 lig. Larg. 4 lig. $\frac{1}{2}$ - Les serres son! très-larges, triangulaires, aplaties surtout au côté externe, qui est fortement cilié, à doigts assez droits, écartés vers leur base et connivens par leur pointe: on aperçoil une avance lobiforme interne du bras dentelée, ainsi qu'un pareil lobe du carpe; le test est aplati, granuleux, terminé par trois pointes mousses dont celle dumilieu, qui est la plus avancée, est creusée d'un sillon longitudinal dans son milieu; le corps est d'une couleur rouge-testacé en dessus, blanche en dessous. - Se trouve dans les rochers du bord de l'Océan européen et de la Méditerranée, fixéc sous les pierres isolées. Suivant M. Risso, les femelles sont pleines d'œufs rougeâtres au printemps.

\section{PJRGELLANA LONGICORNIS.}

Eow., op. cit., t. II, p. 257. - Cancer Longicornis, PeNn, Brit. Zool., t. IV, pl. 1, fig. 3.-Pisidia Longicornis, LeACH, Desir., Consid. génér. sur les Crust., p. 198. - Long. 3 lig. - La carapace est bombée, presque circulaire, assez lisse, 
et présente latéralement un petit bord mince; le front est divisé en trois lobes dont le médian est armé par un sillon si profond qu'il paroît bidenté; les lobes latéraux sont triangulaires et presque aussi saillans que le médian; les pattes antérieures sont longues; le corps est arrondi, et présente en dedans un bord droit; les mains sont étroites dans le jeune âge, et présentent alors des crêtes longitudinales qui s'ef. facent peu à peu; chez l'adulte elles sont très-inégales, et l'une d'elles, devient trèsrenflée; les pinces sont grêles et recourbées en dedans; elles se touchent d'abord par toute leur longueur; mais par les progrès de l'âge elles se recourbent de manière ì laisser entre elles un vide notable; les pattes suivantes sont grêles et à peine poilues. - Celle espèce est très-commune sur nos côtes.

\section{PORCELlina pUNCTATA.}

GuÉrin, Iconogr. du Rég. anim. de Cuv., Crust., pl 18, fig. 1. - Cette espèce, que nous avons représentée à la pl. 9 , fig. 4 , sera décrite par M. Guérin dans son Iconographie. Consultez, pour les autres espèces, le tome deuxième de l'Hist. nat. des Crust., par M. Edwards.

\section{Galathea, Fabr., Latr., Edw.; \\ Cancer, Linn., Degeer, Herbst ; \\ Galathea et Munida, Leaci, Desm.}

La carapace est déprimée, divisée par des incisures nombreuses, ciliées, transversales sur le dos et l'abdomen, en forme d'écailles sur les pinces et Ies pattes; de plus elle est prolongée en avant par un rostre épineux ; sa surface présente un sillon trans versal arrondi derrière la région stomacale, et quelques autres impressions qui indiquent la position des viscères. - Les yeux sont gros, assez écartés l'un de l'autre.-Les antennes extérieures sont longues, sétacées, trèsécartées entre elles, sans écailles à la base. - Les supérieures ou intermédiaires ont leurs second et troisième articles égaux, et le premier terminé par trois épines. - Les pieds-mâchoires extérieurs sont allongés, et ont l'extrémité de leurs deux premiers articles épineuse. - Les mandibules sont dépourvues de dents. - Les pinces sont égales, aplaties, tuberculeuses, épineuses, allongées, et ont leurs doigts dentelés et creusés intérieurement. - - Les trois paires de pattes antérieures sont fortement épi- neuses sur leur branche supérieure.-Les ongles des mêmes pattes on leur dessous un peu épineux. - Les pieds de la dernière paire sont beaucoup plus petits que les autres, filiformes et repliès sur eux-mèmes. -L'abdomen, très-replié sous le corps, est formé de segmens obtusément anguleux sur les côtés.-La nageoire caudale est composée de cinq pièces dont les latérales sont arrondies, entières, et la mitoyenne trèsgrande et comme partagée en plusieurs autres.

Les Galathées sont des animaux nocturnes; les unes se tiennent dans les profondeurs rocailleuses; d'autres vivent à quelques mètres sous l'eau, sur un sol uni, parmi les algues et les fucus. On ne connaît que trois ou quatre espèces propres à ce genre ; elles vivent dans la Méditerranée et sur les.côtes de France baignées par l'Océan.

1. Galatimea strigosa. (Pl. 10, fig. 2.)

Fabr., Suppl., p. 414. - LaTr.. Hist. nat. des Crust., t. III, p. 198 ; et Encyl., pl. 294, fig. 2, et pl. 326, fig. 1. - Desm., Consid. génér. sur les Crust., p. 189. pl. 33, fig. 1. - GuÉRIN, Iconogr. du Reig. anim. de Cuv., Crust., pl. 17, fig. 3. Cancer Strigosus, Linv., Syst. nai.Heniss, t. II, p. 50, pl. 26, fig. 2.-Roux, pl. 19 , fig. 1 à 5 . - Long. 5 pouc. - Tout le corps, chez cette espece, est d'un rouge foncé, plus pâle vers les articulatious des pattes; l'abdomen et le dos surtout ont, la plupart, les enfoncemens ou les sutures de la carapace colorés en bleu-outremer; les nombreuses divisions du test de cette espèce sont toutes ciliées; lesincisures sont semi-circulaires, en forme d'ècailles sur les pattes; la carapace est garnie sur les bords de six aiguillons; le front est avancé, le rostre a sept pointes; les yeux, arrondis, sont portés sur des pédon: cules bleus; les pinces sont larges; aplaties, comprimées, hérissées d'aiguillons sur le côté et sur le dessus ; l'arête supérieure des deuxième et troisième articles des pattes est aussi fortement épineuse; les écailles natatoires sont grandes, arrondies; l'intermédiaire est bifide.

La femelle a les pinces un peu plus petites que celles du mâle; c'est en mars, en août et en décembre qu'elle porte des œufs d'un rouge noir.

Les localités les plus rocailleuses de la Méditerranée, et jamais à moins de dix mètres de profondeur, sont celles où so plaît cette espèce de Galathée; elle nage avec vivacité en agitant sa queue avec force, 
ce qui la fait ainsi aller à reculons; lorsqu'elle marche, son abdomen est replié; c'est aussi en marchant en se reculant qu'elle entre dans son gîte, d'où elle ne montre que ses antennes et les pinces qui en défendent l'entrée; elle demeure en repos dans le jour, et ne sort que ta nuit pour chercher sa nourriture. - Cette espèce est commune sur les côtes océaniques de France et d'Angleterre. C'est durant la saison du printemps qu'on se la procure le plas communément, parce que les sexes se recherchant, tombent, en rôdant, dans les filets des pêcheurs.

\section{GALATHEA SQUAMMIFERA.}

Leach, Malac. Pod. Brit., pl. 28, a, et Dict. des Sc. nat., t. XVIII, p. 51. Eow., op. cit., t. II , p. 275. - Galathea Strigosa, Latr., Hist. nat. des Crust., t. VI, pl. 53, fig. 2. - Gatathea Fabricii, Leach, Encyl. Brit., Suppl., pl. 21.-Long. 2 ponc. - Le troisième article des pieds-mâchoires extérieurs est plus long que le premier; les serres sont couvertes de tubercules aplatis, ciliés, et ne présentent d'épines remarquables que dans la partie inférieure de leur bord interne; le rostre est muni de neuf dents, et est plus court que celui de l'espèce précédente; les doigts des mains sont plus longs; la couleur est brun-verdâtre.-Cette espèce se trouve dans la Méditerranée et sur les côtes océaniques de France et d'Angleterre.

\section{3. galathea rugosa.}

Fabr., Suppl., p. 415. - Latr., Hist. nat. des Crust. et des Ins., t. VI, p. 198. -EDw., op. cit., t. II, p. 274.-Galathea Longipeda. LAM., Anim. sans

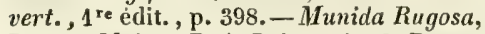
Leach, Malac. Pod. Brit.. tab.29, Desm., Consid. génér. sur les Crust., p. 191. Long. 3 pouc. - Les pinces sont très-longues, cylindriques, épineuses intérieurement; le second segment de l'abdomen présente six ẻpines et le troisième quatre; toutes sont dirigées en avant; dans les jeunes individus, les doigts des pinces sont appliqués l'un contre l'autre dans toute leur longueur, tandis que dans les adultes ils sont écartés à leur base.- - Se trouve sur les côtes de France et d'Angleterre.

$$
\begin{aligned}
& \text { EGLEA, Leach, Desw., Edw.; } \\
& \text { Galathea, Latr. }
\end{aligned}
$$

La carapace est presque unie, avec son rostre simple, épineux, son bord posté- rieur presque droit, et son dos marqué de plusieurs impressions qui en séparent les régions. Les antennes intermédiaires ou supérieures ont leur second article plus court que le dernier; les mandibules sont fortement dentées. - Les pieds-mâchoires extérieurs sont simples; les serres sont légérement inégales, avec leurs doigts entiers; les cuisses et les ongles des pattes des seconde, troisième et quatrième paires sont simples. - L'abdomen est lisse. - Les lames natatoires latérales de la queue sont séparées.

\section{EGLEA I.EVIS.}

Leacr, Dictionn. des Sc.nat., t. XVIII, p. 49.-Desm., Consid. gén. sur les Crust., pl. 33, fig. 2. - EDw., op. cit., t. II, p. 260.-Galathara Levis, Latr. Encycl. Méth., pl. 302, fig. 2.-Long. 2 pouc.La carapace est échancrée de chaque côté antérieurement', assez finement granuleuse sur sa surface, sans lignes transverses, épineuses, comme celles que l'on remarque sur le test des Galathées; les poils des pa:ties supérieures du corps sont de couleur brune.

Se trouve au Chili.

\section{GrimotheA, Leach, Desm., Edw.; Galathea, FABR.}

La carapace est échancrée sur son bord postérieur, et sa surface est marquée de nombreuses lignes transversales, écailleuses et ciliées en avant. - Les antennes supérieures intermédiairesn'ont pas leur second article plus court que le premier, et cet article est claviforme à son extrémité. Les mandibules sont dépourvues de dents. Les picds-mâchoires supérieurs sont allongés, avec leurs trois derniers articles foliacés. - Les serres sont égales; les doigts des mains sont denticulés intérieurement, aigus et très-recourbés à leur extrémité. Les cuisses des seconde, troisième et quatrième paires de pattes sont épineuses en dessous; les ongles des mêmes pattes sont simples. - L'abdomen est strié. - La nageoire caudale est formée de plusieurs plaques, dont les deux postérieures sont les plus grandes.

\section{GRIMOTHEA GREGARIA.}

Leach, Dictionn. des Sc.nat., t. XVIII, p. 50. - Desn., Consid. génér. sur les Crust., p. 188. - EDw., op. cit., t. II, p. 277; ejusd., Atlas du Régn. anim. ds 
Cuv., Crust., pl. 47, fig. 2. - Galathea Gregaria, FABr., Ent. Syst., t. II, p. 473. - Le rosire est effilé et triangulaire, avec ses angles légérement dentelés; les pinces sont comprimées, avec des épines et des tubercules écailleux garnis de poils sur leurs bords ; la couleur est rouge, mais plus foncėe sur la région cordiale qu'ailleurs. Cette espèce fut découverte sous le $37^{\circ} 30^{\prime}$ de latitude sud, par sir Joseph Banks, daus son voyage autour du monde avec le capitaine Cook; la mer en ètait tellement couverte qu'elle paraissait rouge comme du sang.

\section{MEGALOPS , Leach , Desm., Latr., EDw.}

Cancer, Montagu.

La carapace est courte, large et un peu déprimée, terminée en avant par un rostre pointu, large à sa base, quelquefois infléchi. - Les yeux sont très-gros, portés sur un pédoncule très-court. - Les antennes extérieures, sétacées, n'ont pas le quart de la longueur de la carapace, et sont formées d'articles allongés; les intermédiaires sont terminées par deux soies dont la supérieure est la plus longue. - Les piedsmâchoires extérieurs ont les deux premiers articles comprimés; le second est le plus court, et échancré au bout pour l'insertion des autres. - Les pieds antérieurs sont égaux, en forme de serres didactyles assez courtes el grosses ; ceux des quatre dernièrespaires sont un peu plus longs, moins épais, et terminés par un ongle simple et un peu courbé.-L'abdomen est étroit, étendu, linéaire, composé de sept articles dont les cinq intermédiaires sont pourvus d'appendices, savoir : les quatre premiers de fausses pattes, ayant leur division externe trèsgrande et ciliée; et le cinquième, de chaque côté, d'une lame horizontale, ovale et ciliée, composant, avec le dernier article de la queue, qui est arrondie, une sorte de nageoire un peu différente de celles des autres Macroures.

\section{MEgalops montagui.}

LEACH, Malac. Brit., tab. 16, fig. 1 à 6 . - Desm., Consid. génér. sur. les Crust., p. 204. - Evw., op. cit., t. II , p. 262. Cancer Rhomboidalis, Montag., Trans. of the Lin. Soc., t. V II, pl. 6, fig. 1. --Long. 3. lig. - Le rostre est entier, terminé par une seule épine dirigée en avant; la carapace est inerme postérieurement; les han- ches des huit premières pattes sont pour. vues en dessous d'une petite épine recour bée. - Trouvé sur la côte du Dévon. shire.

\section{MEGALOPS MUTICA. (PI. 12, fig. 2.)}

Desm., Consid. génér. sur les Crust., p. 201, pl. 34, fig. 2. - GuÉr., Iconogr. du Régn. anim. de Cuv., Crust., pl. 18, fig. 3. - EDw., op. cit., t. II, p. 262. Long. 6 lig. - Le rostre se replie perpendiculairement sur l'extrémité de la carapace, et son milieu est canaliculé ; les hanches de toutes les pattes sont privées d'épine recourbée. En arrière, le test est tronqué et ne présente pas de pointe; le dessus de la carapace est uni; les quatre paires de fausses pattes proprement dites sont très-longues et très-aplaties; les deux derniers appendices sont extrêmement transparens et entourés de très-longs cils; dans le repos, ils sont entièrement cachés par le dernicr article de la queue, qui est arrondie à son bout, et qui a la forme d'un bouclier; l'avant-dernier article et le premier sont les plus étroits de tous; les ongles sont épineux en dessous; la couleur est brunâtre. -Trouvé sur les côtes de l'Océan, près de l'embouchure de la Loire.

\section{MONOLEPIS, SAY, EdW.}

La carapace est convexe, oblongue d'avant en arrière, un peu rétrécie en avant, et lerminée par un petit rostre. - Les yeux sont très-grands et éloignés entre eux. - Les antennes internes sont épaisses et cachées sous les côtés du rostre; leur article basilaire est arrondi, et leur extrémité bifide.-Les antennes externes sont insérées entre les pédoncules oculaires et les angles du cadre buccal; elles sont coudées entre le troisième et le quatrième article.-Les pieds-mâchoires externes sont inermes et se composent d'articles subégaux dont le dernier est brusquemrnt rétréci. - Les pattes sont de Iongueur médiocre; celles de la première paire sont didactyles, et celles des trois paires suivantes monodactyles; celles de la cinquième paire sont très-petites, terminces par des soies allongées et reployées au-dessus des angles de la carapace. - L'abdomen, semi-cylindrique, est reçu dans une fossette profonde du plastron sternal, et terminé par une nageoire composée de trois lames; on y voit aussi des fausses paltes natatoires assez grandes dont la lame terminale interne est très-petite; 
la lame qui est placéedc chaque côté du dernier segment abdominal est pelite, subovale, ciliée et portẻe sur un petit pédoncule. - M. Edwards pense que ce genre ne doit pas être conservé, et qu'il n'a été établi que sur de jeunes Crustacés dont le développement n'était pas encore terminẻ; mais cet auteur ne les ayant pas observés lui-même, il ne peut former une opinion arrêtée á cet égard. M. Say en dècrit deux espèces.

\section{MONOLEPIS INERMIS.}

$\mathrm{S}_{\mathrm{AX}}$, Journ. of the Acad. of Philadelph., t. I, p. 157. - EDw., op. cit., t. II, p. 264. - Long. 3 lig. - La carapace est inégale, armée d'une dent de chaque côté des yeux; il y a un tubercule tronqué au bout, de la longueur du pédoncule oculaire, et qui est situé derriẻre chaque œil sur le bord inférieur du corps; les pattes antérieures sont assez petites, avec les mains renflées; les tarses sont simples. - Se trouve sur les côtes du Maryland.

SEPTIÈNE TRIBC.

\section{T.H A L A S S I N I D E S,}

\section{Latr.}

Caractères. Antennes extérieures n'offrant pas de lame mobile insérée à la face supérieure de leur pédoncule.-Sternum linéaire - Abdomen allongé, grêle et long.

Genres: Glaucothoe, Gebia, Thalassina, Callianassa, Axius, Callianidea, Callianisea.

\section{GLAUCOTHOE, Edw. , LATr.}

La portion céphalothoracique du corps est presque ovoïde, et son abdomen, étroit et allongé, n'est nullement contourné sur lui-même; son enveloppe tégumentaire est cornéc ou plutôt semi-membraneuse, et elle présente partout à peu près la même consistance.-La carapace est lisse etne présente pas de prolongement rostriforme; le sternum est assez large en arrière, et l'anneau qui supporte les pattes de la première paire n'est pas soudé comme chez la plupart des Décapodes. - L'abdomen est divisé en sept segmens symétriques, dont le dernier ne constitue plus qu'une lame natatoire. - Les yeux sont saillans, grands, mobiles, et à peu près piryformes. - Les antennes, au nombre de quatre, sont insérées sur deux lignes; celles de la paire su- périeure sont courtes, cylindriques et coudees.-. Le troisième article de leur pédoncule est le plus long de tous, et porte à son extrémité deux petits appendices multi-articulés, très - courts et assez gros; l'un de ces filets, plus grand que l'autre, est garni de beaucoup de longs poils. - Les antennes inférieures ou externes sont, au contraire, grêles et terminées par un seul filet sétacé; leur pédoncule est encore coudé, et son premier article donne insertion à une petite écaille qui ne recouvre nullement les articles suivans. - L'appareil buccal se compose de six paires de membres et de deux replis tégumentaires impairs. - Les mandibules sont à peine dentées surle bord, et portent un palpe grêle et court. - Le labre, la languette, les mâchoires ainsi que les pieds-mâchoires de la première paire, ne présentent rien de remarquable; celles de la seconde paire diminuent de grosseur depuis le troisième article, et portent en dehors un palpe assez grand. - Les piedsmâchoires externes sont très-allongés; leur article basilaire supporte un palpe semblable à ceux de la seconde paire; ce second article, guère plus gros que les suivans, est armé, du cốté interne, d'une série de dents, et les dernières sont garnies de cils nombreux. - Les pattes proprement dites sont au nombre de dix; celles des trois premières paires sont très-longues et dirigées en avant; mais les quatre dernières sont fort petites et relevées sur les côlés dı corps. - Les pattes de la première paire sont terminées par une grosse main didac. tylebien formée; leur volume est très différent; celle du côté droit étant beaucoup plus forte et plus longue que la gauche. Les pattes des deux paires suivantes sont toutes exactement semblables entre elles; leur longueur égale celle de la grosse pince antérieure ; mais elles sont grêles et terminées par un article pointu. - Les pattes de la quatrième paire n'ont guère plus du tiers de la longueur des précédentes; elles sont aplaties, assez larges et imparfaitement didactyles, le doigt immobile de leur main n'étant formé que par un tubercule peu saillant; celles de la quatrième paire sont encore plus petites; mais la main didactyle qui les termine, quoiquo lamelleuse, est assez bien formée. - Le premier anneau de l'abdomen est beaucoup plus étroit que les suivans et ne porte pas d'appendices; les quatre segmens suivans donnent, au contraire, attache chacun à une paire de fausses paltes natatoires assez grandes, formées, 
par un article basilaire, cylindrique, et deux lames terminales dont l'une, très-petite et obtuse, l'autre grande, terminée en pointe, et garnic sur les bords de longs poils ciliés. - Les appendices du sixième anneau, symétriques comme les précédens, constituent les pattes latérales de la nageoire caudale, dont la lame médiane, arrondie et ciliée, est formée par le septième segment de l'abdomen. - Le pédoncule de ces appendices est assez grand, et leur écaille interne est petite et arrondie, tandis que l'externe cst grande et allongée. - Tels sont les caractères du nouveau genre établi par M. Edwards, et dont l'espèce type est le

\section{GLAUCOTHOE [DERONII.}

EDw., Ann. des $S_{c}$. nat., t. XIX,pl. 8, fig. 1. - Ejusd., op. cit., t. II, p. 307.Long. 8 lig. - De forme assez svelte; la carapace est lisse; les tégumens sont peu solides. - Se trouve dans les mers d'Asie.

\section{GEBIA, Leach, Desm., Latr., Enw.; \\ Upogebia, Leach; Cancer, Montag.; Thalassina, Latr.}

La carapace est peu épaisse, membraneuse, poilue ou plutôt garnie de très-petits piquans, et terminée en avant par une pointe du rostre peu avancée; elle se prolonge en dessous jusqu'à la base des pattes, de manière à la recouvrir en partie. - Les quatre antenues sont insérées sur la même ligne, avancées; Ies latérales à pédoncule nu; les intermédiaires terminées par deux filets allongés. - Les pieds antérieurs sont en forme de serre, avec l'index notablement plus court que le pouce. - Les autrespieds sont simples, ciliés à leur extrémité, et présentent des franges de poils sur leurs bords extérieurs. - L'abdomen est allongé, avec les lames natatoires qui le terminent entières, fort larges, et surmontées de côtes longitudinales; ces feuillets sont presque triangulaires.

Trois espèces de ce genre sont connues, et toutes propres aux mers de l'Europe; ce sont des Crustacés assez rares, que l'on rencontre dans les endroits ou la mer est habituellement calme et où il y a des plages sablonneuses; ils se creusent, dans le sable ou dans la vase, de petits trous dont ils ne sortent que la nuit; c'est alors qu'ils vont chercher leur nourriture, qui consiste en Annélides et petits Mollusques, dans le sable. - Elles nagent avec leur queue, en Ia repliant et en la tendant avec force.
1. gebia sterhata. (Pl. 12. fig. 6.) Leach, Malac. Brit., tab. 31, fig. 1 à 9-Desm., Consid. génér. surles Crust., p.204, pl. 35, fig. 2.-EDw., op. cit., t. II, p. 313. - Cancer Stellatus, Montag., Trans. Linn. Soc., t. IX, tab. 3, fig. 5. - Long. 2 pouc. - L'abdomen est entièrement crustacé, terminé par des lames foliacées ; l'exlérieure arrondie, l'intérieure coupée jobliquement et ayant une forme triangulaire ; celle du milieu en forme de trapeze, plus longue que large, et très-peu arrondie à son bord postérieur. Les serres sont grosses; et le doigt, immobile, est un peu moins grand que l'autre, mais pas de moitié plus petit. - Se trouvesur les côtes de France et d'Angleterre.

\section{GEBIA LITTORALIS.}

Desm., Consid. génér. sur les Crust., p. 204.-Eow., op. cit., t. II, p. 313. Thalassina Littoralis, Risso, Crust., p. 76, pl. 3, fig. 2. - Long. 1 pouc. 10 lig. Larg. 4 lig. - Le corps est glabre, d'un vert sale; la carapace est unie, rougeâtre, sillonnée sur le bord, terminée par un rostre aplati et couvert de petits faisceaux de poils rudes; les yeux sont noirs, situés sur des pédoncules courts et renflés; les antennes intérieures sont petites, profondément bifides; les deux extérieures sont longues et poilues à leur base; les deux premières paires de pattes sont terminées par des aiguillons crochus, dont l'inféricur est fort court; les autres paires sont inejgales, comprimées et poilues; les segmens de l'abdomen sont bombés, striés; les écailles caudales sont ovales, ciliées, et présentent chacune deux nervures longitudinales; elles sont adhérentes à une large plaque solide. La femelle est pleine d'œufs verdâtres en juin.

Suivant M. Risso, elles choisissent ordinairement des terrains argileux, calcaires, où elles se creusent, avec leurs pattes, de petits trous ronds très-profonds, du diamètre de leur corps, qu'elles élargissent en augmentant de diamètre ; elles s'y tapissent et n'en sortent que pendant la nuit, pour aller chercher leur nourriture. Si le jour les surprend, elles restent tranquilles sous les pierres du rivage ou à l'abri des fucus. Aussitôt qu'on les approche, elles sortent avec dextérité et se mettent à nager en repliant leur queue, et en la jetanc avec force en arrière, de manière que leur natation ne semble s'effectuer que par gar.bades. L'espèce qui vit sur nos bords pri- 
fére les endroits où la mer est toujours calme et tranquille. Quand les vagues, agi. tées par de gros rents, viennent boucher l'ourerture de leur retraite, elles en sortent avec frayeur et sont alors rejetées sur le rivage. Ces animaux se nourrissent de Néréides et d'Arénicoles; elles ne dédaignent pas non plus les Moules et les Vénus, dont elles ouvrent les valves, au moyen de leurs pinces, avec beaucoup d'adresse. Leur chair est recherchée par les pêcheurs comme un appât des plus fins et des plus exquis pour prendre les poissons à la ligne.

\section{THALASSINA, Latr., Lrach, Desm., Edw.; Cancer, Herbst.}

La carapace est allongẻe, un peu renflée, et plus large postérieurement qu'antérieurement, terminée par un rostre, marquée d'un silion transversal arqué qui sépare la région de l'estomac des autres régions; celles des branchies ètant séparées des intermédiaires par deux lignes enfoncées, longitudinales. - Les yeux sont petits. Les antennes extérieures sont médiocre. ment longues (un cinquième de la grandeur du corps), sẻtacées, minces, a vant leur pédoncule simple et mutique; les intermédiaires sont plus courtes, surtout leur filet intérieur. - La tige interne des piedsmâchoires extérieurs est formée de six articles velus, dont le premier est le plus long et épineux, les autres étant inermes; les pieds de la première paire sont plus grands et plus épais que les suivans, et en forme de serres à deux doigts, dont l'immobile est le plus court; les pieds de la seconde, paire sont plus petits et de même forme, mais avec le doigt inférieur immobile et encore plus court; ceux des trois dernières paires sont monodactyles et décroissent successivement de grandeur ; les deux premiers de ceux-ci étant les plus longs de tous. - L'abdomen est étroit, trèslong, linéaire, formé de six segmens, dont le dernier est pourvu d'une large écaille natatoire intermédiaire et de quatre lames latérales très-étroites et linéaires. - On ne connait qu'une seule espèce, qui est :

THALASSIXA sCOMPIONOIDES. (Pl. 20, fig. 3.)

Latr., Gener. Crust. et Ins., t. I, p. 52. - Dess., Consid. génér. sur les Crust., p. 203, pl. 35, fig. 1.-EDw., op. cit., Ł. II, pl. 316. - Ejusd., Atlas du Régne anim. de Cuv., Crust., pl. 48, fig. 1.Gúr., Iconog. du Règne anim. de Cuv., Crust., pl. 18, fig. 4. - Cancer Anomalus, Heribst, t. III, pl. 62. - Long. 6 pouc. - Le rostre est rebordé, avec son bord antérieur granulé; les cuisses sont pourvues sur leur branche inférieure de deux séries de petites épines; le dessus de la main et du doigt mobile des serres présentent deux carènes longitudinales dentées en scie. Habite les côtes du Chili.

Callianassa, Leach, Desu. , Latr., EDw.;

Cancer, Montagu.

La carapace est peu allongée, lisse, terminée brusquement par un petit rostre. Le second arlicle des pieds - mâchoires extérieurs est le plus long de tons. - Les pieds de la première paire sont très-inégaux, terminés par une pince bien formée ct comprimée; les pieds de la seconde paire sont également didactyles, ceux de la première monodactyles, ceux de la quatrième simples, et les derniers presque didactyles par le prolongrment en dessous de l'arantdernier article, sur lequel le dernier peut s'appuyer comme sur un doigt mobile. L'abdomen est grand, assez large, presque membraneux, pourvu à son extrémité de lames foliacées dont les latérales sont trèslarges, arrondies, et l'intermédiaire presque triangulaire et obtuse au bout.

Ce genre n'est composé que d'une seule espèce; elle vit dans les sables de nos plages, et se creuse un trou comme les Gébies.

Calliatassa subterkayea. (Pl. 12 , fig. 1.)

LeAch, Malac. Brit., tab. 32. - Desir., Consid. génér. sur les Crust., p. 205. Guér., Iconog. du Régne anim. de Cuv., Crust., pl. 19, fig. 4.- EDw., op. cit., t. II, p. 209. - Ejusd., Allas du Régre anim. de Cuv., Crust., pl. 48, fig. 3.Long. 2 pouc. Larg. 3 lig. - Le rostre est un peu en carène en dessous et arrondi à sa pointe; les anneaux de l'abdomen sont inégaux entre eux, et les lames foliacées qui le terminent sont courertes de longs poils ả leur extrémité. - Se trouve sur les côtes océaniques de France et sur celles d'Angleterre.

AXIUS, Leach, Latr., Desm., Edw.

Les antennes sont placées sur la même 

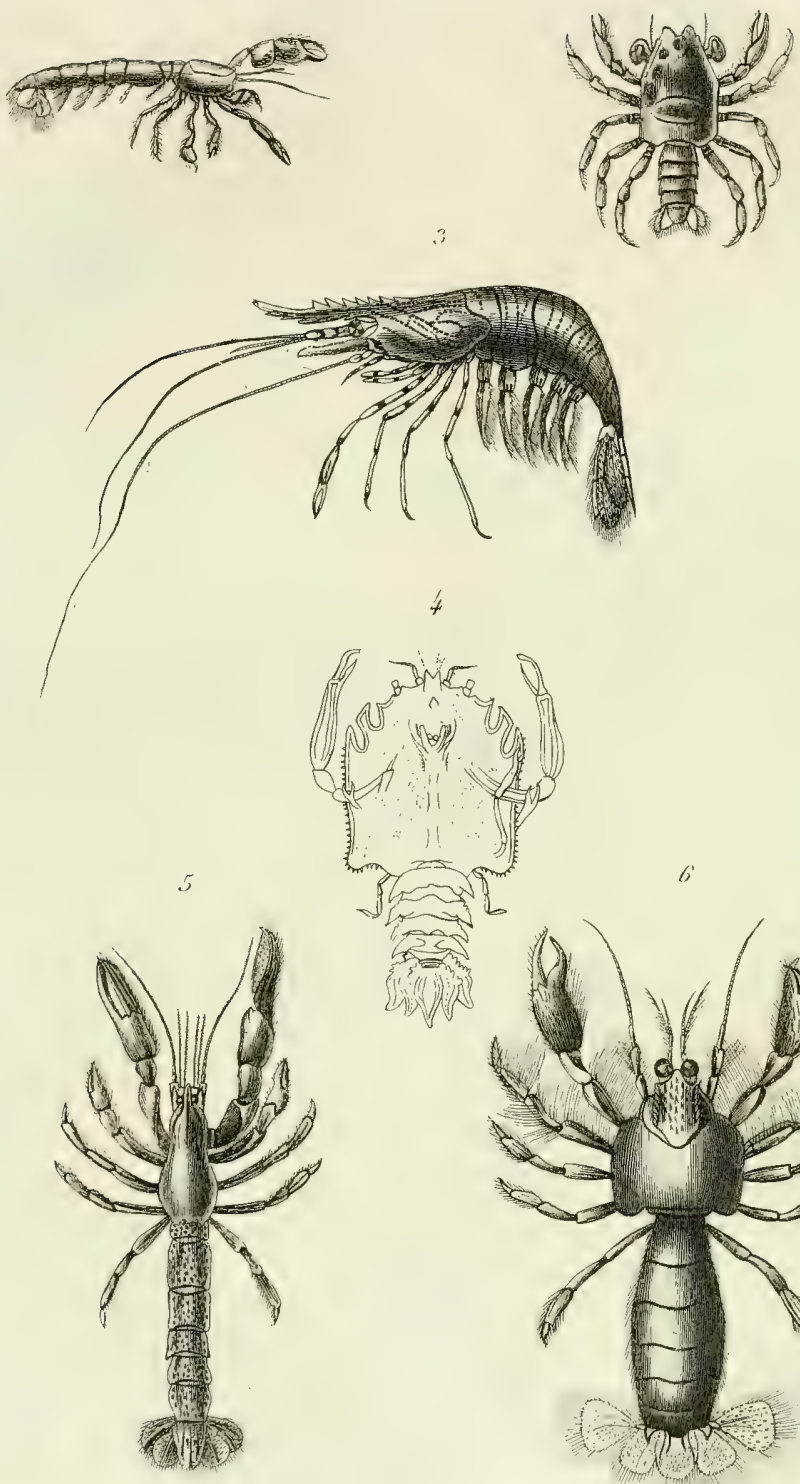

둔 17
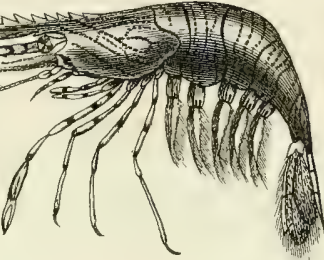

4
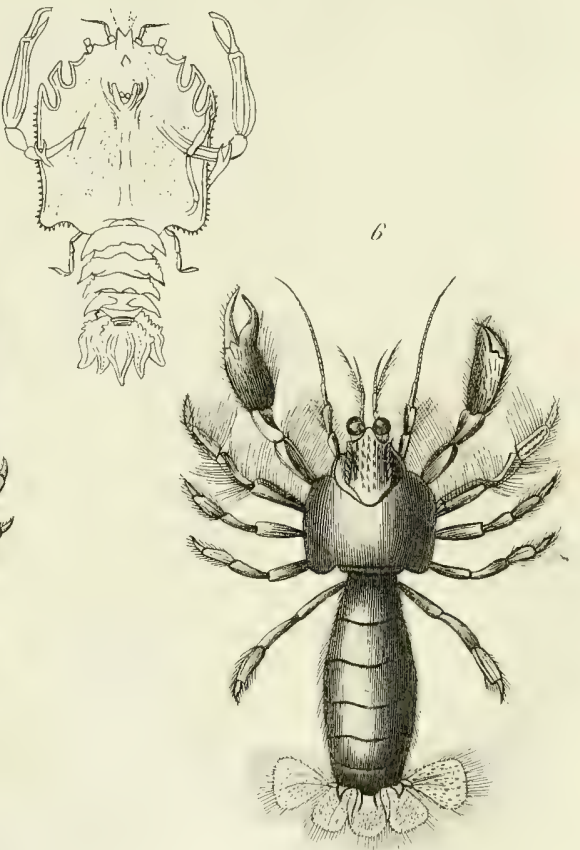

1. Callianassa Subtermenea.

4. Eryon Cuvieriu.

2. Megalopus Muticus.

3. Palomon squilla.

5. Axims Stirleyncus.

6. Ciebia stellata. 

ligne. - Le pédoncule des antennes intermédiaires est formé de trois articles dont le premier est le plus long. - Les pieds-mâchoires extérieurs ont leurs deux premiers articles assez longs et égaux. - Les pieds de la première paire sont a peine inégaux, terminés par une pince bien formée; les pieds de la seconde paire sont égaux, plus gros que les suivans, aplatis et terminés par une pince très-plate et à doigts égaux; les autres pieds sont plus minces, aplatis et pourvus d'un ongle comprimé. - On ne connaît qu'une seule espèce, c'est :

Axies Stirnyxcus. (Pl. 12, fig. 5.)

Leach, Trans. Societ. Linn., t. XI, r. 373 ; et Malac. Brit., tab. 33. - DesM., Consid. génér. sur les Crust., p. 207, pl. 36, fig. 1. - Guér., Iconog. du Régne anim. de Cuv., Crust., pl. 18, fig. 5. EDw. , op. cit., t. II, p. 311; ejusd., Atlas du Règne anim. de Cuv., Crust., pl. 48 , fig. 2. - Long. 3 pouc. $\frac{\frac{1}{2}}{2},-$ La carapace forme en avant un rostre court, caréné dans son milieu, et dont les bords sont relevés et terminés en arrière par deux lignes saillantes peu prolongées; les écailles latérales de la queue sont arrondies; l'intermédiaire est triangulaire, allongée et pointue. - Se trouve sur les côtes d'Angleterre.

\section{CALLIANIDEA, Edw.}

La carapace n'a guére plus du tiers de la longueur de l'abdomen, et ne recouvre pas le dernier anneau thoracique; elle est comprimée et assez élevée; elle ne présente pas de rostre, mais son bord antérieur est échancré de chaque côté de la ligne médiane pour recevoir la base des yeux, dont les pédoncules sont courts. - Les antennes, au nombre de quatre, sont grêles et s'insèrent à peu près sur la même ligne transversale; les 'premières se terminent par deux filets à peu près égaux en longueur, mais dont l'un est plus gros et lé. gérement renflé vers l'extrémité. - Les appendices de la bouche sont petits; les pieds - mâchoires externes sont grêles et pédiformes. - Les pattes de la première paire sont longues, et l'une d'elles est trèsgrosse; la main qui termine celle-ci est trèsgrande; les pattes des deux paires suivantes sont petites et aplaties; celles de la quatrieme paire sont cylindriques, et leur article basilaire est très-élargi; les pattes de la cinquième paire sont presque aussi granANw. des que ces dernières, et se terminent par une pince imparfaite et rudimentaire. I'abdomen est composé de sept segmens, et porte en dessous cinq paires de fausses pattes; celles de la première paire sont réduites à une simple lame étroite, légérement ciliée en haut; mais celles des quatre paires suivantes offrent un mode de conformation bien différent : on y distingue un pédoncule et trois lames terminales, dont deux très-grandes et une très-petite sur le bord de l'une des précédentes; enfin tout autour du bord de ces grandes lames se trouve une espèce de frange touffue, composée d'une rangée de cylindres dont chacun donne naissance à deux filamens plus petits, lesquels se bifurquent à leur tour. - Les cinq lames dont se compose la nageoire caudale sont larges et arrondies. La seule espèce connue est la

\section{CALLIANIDEA TYPA.}

EDw., op. cit., t. II, p. 320, pl. 25 bis, fig. 8 a 14 . - Long. 20 lig. - Les antennes externes sont médiocres, avec leur pédoncule coudé, et ayant le troisième article pius long que le second et le quatrième; ia petite patte antérieure est très-allongée et ciliée sur les bords inférieur et supérieur; la grosse main est beaucoup plus grande que le thorax, bombée en dehors, et cilice sur ses deux côtés; sa pince est garnie de dents tuberculeuses; les pattes de la seconde paire sont garnies de poils trèslongs sur leur bord inférieur; le dernier segment de l'abdomen est arrondi en haut; les lames latérales sont ovalaires. - Cette espèce a été trouvée sur les côtes de la Nouvelle-Hollande.

\section{Gallianisea, Edw.; IscKa, GUÉr.}

Le corps est de consistance demi-membraneuse, allongé et comprimé sur les côtés. - La carapace est très-petite, et couvre à peine la base des quatre premières paires de pieds; on voit, à la suite de cette carapace, un segment thoracique entièrement découvert qui donne attache à la cinquième paire de pattes, et qui ne diffère presque point des segmens suivans appartenant à la queue. - Le bord antérieur de la carapace est.échancré pour recevoir les yeur et les antennes internes; ces yeux sont portés sur des pédoncules très-courts; ils sont peu apparens et presque contigus à leur insertion. - Les antennes internes sont in- 
sérées un peu plus haut que les externes; leur pédoncule est d'une longueur égale au tiers de celle de la carapace, composé de trois articles dont le premier plus court et les deux suivans égaux; le troisième article donne insertion à deux filets égaux en longueur, multiarticulés, placés au-dessus l'un de l'autre, et dont le supérieur est renflé vers son extrémité et terminé ensuite en pointe; ces deux filets ont presque trois fois la longueur du pédoncule; ils sont garnis d'assez longs poils. - Les antennes externes présentent aussi un pédoncule de trois articles; mais il est plus long que celui des précédentes; leur premier article est plus épais que les suivans, dirigé en dedans, comme chez les Pagures; le second article est le plus long de tous : il atteint l'extrémité du pédoncule des antennes internes; le troisième est de moitié moins long que le précédent, et terminé par un long filet multiarticulé, ayant au moins la moitié de la longueur de l'animal. - Les deuxième et troisième pieds-mâchoires 1 diffèrent peu de ceux des Pagures; le premier article des pieds-mâchoires de la seconde paire est très-court, ainsi que le second; le troisième est allongé, aplati, fortement cilié en dedans; le quatrième est court, triangulaire, et forme l'angle droit avec le précédent; le cinquième est un peu plus grand, également aplati, et le dernier est conique et pius court; ils sont tous garnis de longs poils. - Le palpe flagelliforme est inséré sur le côté externe du premier article; il est court, atteint à peine la longueur des deux premiers articles des piedsmâchoires, et se termine par un flagre multiarticulé et garni de longs poils. - Les pieds-mâchoires extérieurs sont beaucoup plus grands, pédiformes; les pieds vont en diminuant insensiblement depuis les premiers jusqu'aux quatrièmes, les derniers pieds étant démesurément plus petits. L'abdomen est composé de cinq segmens égaux, plus longs que larges, comprimés sur les côtés, et d'une consistance semimembraneuse; le bord postérieur gauche du premier, dans les second et quatrième articles, présente un appendice ovifèrc composé d'une tige courte garnie d'un grand nombre de ramuscules en forme de grappe; le dernier segment, ou la lame impaire de la nageoire terminale, est ar-

'On n'a pu voir les premiers pieds-mâchoires, l'individu sur lequel ce genre a été formé étant en très-mauvais état. rondi postérieurement en forme de demiovale; il y a de chaque côté deux lames ovales, a peine plus longues, et insérées sur un article commun très-court. - L'espèce qui a servi de type à ce genre est:

\section{CALlianisea ELONGATA.}

EDw., op. cit., t. II, p. 323. - Isca Elongata, Guen., Ann. de la Soc, Ent. de France, t. I, pl. 10, fig. 1. - Cette espèce est longue d'environ trois centimètres; sa couleur nous est inconnue; mais dans l'alcool elle est brunâtre, avec quelques portions transparentes; la earapace forme un peu plus du cinquième de la longueur totale de l'animal. - Elle a été trouvée aux îles Mariannes.

\section{HUITIEME TRIBU.}

\section{H O M R D I E N , LATREILLE.}

Caractéres. Les deux pieds antérieurs très-grands, se terminant en une pince didactyle. - Antennes latérales ayant leurs pédoncules pourvus de deux saillies en forme de dents, mais ne les recouvrant pas.

Genres : Eryon, Nephrops, Astacus, Homarus.

ERYON, Desm., EDw.;

Cancer, Schlótteim; Locusta, BaÏer; Astacus, Richter.

La carapace est très-déprimée, large, presque carrée, peu avancée antéricure. ment, profondément échancrée sur ses bords latéro-antérieurs. - Les antennes extérieures sont courtes (un huitième de la longueur totale du corps, la queue comprise), sétacées, pourvues à leur base d'une écaille assez large, ovoïde et fortement échancrée du côté interne; les intermédiaires sont sétacées, bifides, beaucoup plus courtes que les extérieures, et ayant leurs filets égaux. - L'ouverture buccale est allongée et assez étroite. - Les pieds de la première paire sont à peu près aussi longs que le corps, grêles, linéaires, non épineux, terminés par des pinces très-longues et étroites, à doigts peu arqués, mais légérement infléchis en dedans; les carpes sont courts; les pieds des autres paires sont aussi grêles, et ceux de la seconde et de la troi. sième paire sont terminés par des pinces, 
comme cela a lieu chez les Ecrevisses. L'abdomen est assez court, formé de six articles, dont les quatre intermédiaires ont leurs bords latéraux prolongés en angles bien détachés, comme chez les Ecrevisses. - La nageoire caudale est formée de cinq pièces, dont les deux latérales sont entières, assez larges, un peu arrondies au côté interne échancrées au côté extérieur, et dont les trois moyennes sont triangulaires, allongées, surtout l'intermédiaire.

IEYON CUVIERI. (Pl. 12, fig. 4.)

Dess., Hist, nat. des Crust. fossiles, p. 128 , pl. 10, fig. 4; ejusd., Consid.génér. sur les Crust., p. 209, pl. r4, fig. 3. Gúk., Iconog. du Reg. anim. de Cuv., Crust., pl. 19, fig. 3. - EDw., op. cit., t. II, p. 278. - BaJer, Oryct. Noric, Suppl., p. 13, tab. 8, fig. 1, 2.-Richter, Mus. Richt., tab. $13 \mathrm{M}, \mathrm{n}^{\circ} 32$. - KNonR et W ALCH., Rec. des Mon. des catastr. du glo$b e$, t. I, pl. 141, $141 \mathrm{~A}, 141 \cdot \mathrm{B}$. - Ce fossile, long de quatre à cinq pouces, a la carapace finement granulée en dessus, marquée de deux échancrures profondes et étroites sur ses deux bords latéro-antérieurs, et finement crénelée sur ses deux bords latéro-postérieurs. - Trouvé à l'état fossile dans la pierre calcaire lithographique de Pappenheim et d'Aichtedt, dans le margraviat d'Anspach.

$$
\begin{aligned}
& \text { NePhrops, Leach, Edw.; } \\
& \text { Astacus, Penn., Fabr., Latr.; } \\
& \text { Cancer, Linn. }
\end{aligned}
$$

Les yeux sont très-gros, réniformes, portés sur de courts pédoncules beaucoup moins épais qu'eux. - Le filet supérieur des antennes intermédiaires est plus gros que l'inférieur. - Le premier article du pédoncule des antennes extérieures est pourvu d'une écaille qui s'étend jusqu'à l'extiémité de ce pédoncule. - Le second article des pieds - mâchoires extérieurs est dentẻ en dessus et crénelẻ en dessous. Les pieds de la première paire sont trèsgrands, inégaux, à mains allongées, prismatiques, et dont les angles sont épineux. - Les côtés des segmens de l'abdomen sont anguleux.

Ce genre a beaucoup d'analogie avec les Ecrevisses; cependant il en diffère par les yeux et par l'écaille des antennes extérieures. Il ne se compose jusqu'à présent que d'une seule espèce, c'est :

\section{NEPIROPS NORWEGICUS.}

Leach, Malac. Brit., tab. 36. - Desm. Consid. génér. sur les Crust., p. 213, pl. 37, fig. 1. - Guśr., Iconog. du Régne anim. de Cuv., Crust., pl. 19, fig. 1.EDw:, op. cit., t. II, p. 336. - Cancer Norvegicus, Linn., Faun. Suec., n' 2039. -Astacus Norvegicus, Penn., Brit. Zool.. t. IV. - Long. 7 pouc. - La carapace est presque cylindrique, munie antérieurement de quelques épines; le rostre est avancé, mince, aigu, muni d'une dent en dessous, vers l'extrémité, et de trois de chaque côté; les antennes supérieures sont presque de la longueur du corps; le premier article est muni d'une épine et d'un avancement comprimé, fortement cilié; les inférieures sont bifides; les pattes antérieures sont très-grandes, épineuses; la jambe est anguleuse et les angles sont dentés; les deux paires de pattes qui suivent sont terminées en pinces. - Se trouve sur les côtes de Norwége.

$$
\begin{aligned}
& \text { ASTACUS, Fabr., Latr., Lam., Desh., } \\
& \text { Edw.; } \\
& \text { Cancer, Linn., Herdst. }
\end{aligned}
$$

Le rostre est aplati, très-large à sa base, et plus ou moins triangulaire. - L'appendice, dont le pédoncule de leurs antennes externes est garni, est lamelleux et assez grand pour couvrir la majeure partie des deux derniers articles pédonculaires situés au-dessous. - Le cinquième anneau du thorax, au lieu d'être soudé aux précédens, y est simplement articulé. - Leur carpe est court, renflé, et ne forme pas d'angle vers le bras. - La lame médiane de la nageoire caudale présente de chaque côté une dent vers son tiers postérieur, et est très-arrondie au bout.

Ces Crustacés habitent les rivières et les ruisseaux, et se tiennent ordinairement sous des picrres ou dans des trous situés dans les berges; ils sont très-voraces, et se nourrissent de charogne aussi bien que de Mollusques, de petits poissons et de larves d'insectes. Notre écrevisse commune change de segmens vers la fin du printemps, et à chaque mue grandit beaucoup, quelquefois du cinquième de son volume. Quelque temps avant cette époque, on trouve dans l'estomac de ces animaux des petites masses calcaires semblables à des disques, qu'on appelle des yeux d'Ecrevisses, et qu'on employait jadis en médecine. La durée de leur vie paraít être de plus de ving 
ans, et leur croissance ne s'arrête jamais complétement. Ce genre renferme environ quatre ou cinq espèces, parmi lesquelles nous citerons.

astacus floviatilis. (Pl. 11, fig. 4.)

Fabr., Suppl., p. 406.-Desir., Consid. génér. sur les Crust., p. 211. - GuéRIN, Iconogr. du Rég. anim. de Cuv., Crust., pl. 10, fig. 2.-EDw., op.cit., t. II, p. 330. Cancer Astacus, Linn., Syst.nat., p. 1051, $n^{\circ} 63$. - Long. 4 pouc. Larg. 9 lig. - Les antennes supérieures sont plus courtes que le corps, et munies d'une très-grosse épine a leur base latérale; le rostre est avancé, pointu, muni d'une dent à sa base et d'une autre de chaque côté, un peu au delà du milieu; la carapace est lisse, légérement chagrinée sur les còtés, et marquée d'un sillon transversal arqué; les pattes antérieures ont des pinces munies de petits tubercules presque épineux; les seconde et troisième pattes sont terminées en pince; les bords latéraux des segmens de l'abdomen sont terminés en pointe ; la couleur générale est d'un brun plus ou moins verdâtre.

L'Ecrevisse de rivière se trouve dans les eaux douces de l'Europe; elle se tient sous les pierres et dans des trous, et n'en sort que pour chercher sa nourriture, qui consiste en petits Mollusques, en petits poissons et en larves d'insectes; elle se nourrit aussi de chairs corrompues, de cadavres de quadrupèdes flottants dans l'eau. Des circonstances accidentelles font varier sa couleur, qui est ordinairement d'un brun-verdâtre. II. Guérin, dans l'Iconographie du Règ. anim. de Cuv., a représenté une variété de cette espèce qui est remarquable en ce que, au lieu d'ềtre d'un brun-verdâtre, elle est d'un beau bleu cobalt.

HOMARUS, EDw.;

$$
\begin{aligned}
& \text { Astacus, Fabr., Latr., Lam., Leach, } \\
& \text { Desm. }
\end{aligned}
$$

Ce genre se distingue du précédent par le rostre, qui est grêle et armé de chaque côté de trois ou quatre épines; par la petitesse de l'appendice lamelleux des antennes externes, qui ressemble à une dent mobile et ne recouvre qu'imparfaitement le pénultieme article pédonculaire de ces organes; par la soudure interne du dernier anneau du thorax avec les précédens; par la conformation des branchies, qui ressem-blent à autant de brosses, et qui sont au nombre de vingt de chaque côté du corps. - Les yeux sont globuleux. - Les mains sont extrêmement grandes, comprimées et ovalaires, avec le carpe allongé et un peu rejeté en-dehors. - La lame médiane de la nageoire caudale est à peine arrondie au bont, et des épines latérales en occupent les angles antérieurs. - Parmi les trois espèces renfermées dans ce genre, nousciterons :

\section{HOMARUS VULGARIS.}

EDw., op. cit., t. II, p. 334. - Astacus Marinus, Fabr., Suppl., p. 406. Latr., Hist, nat. des Crust. et des Ins., t. VI, p. 233. - LaM., Hist. des Anim. sans vert., t. V, p. 216. - Bosc., Hist. nat. des Crust., t. II, p. 62, pl. 11, fig. 1. - Desm., Consid., génér. sur les Crust., pl. 41, fig. 1.-Cancer Gammarus, LinN., Syst. nat., p. 1050, $1^{\circ}$ 62. - PenN, Brit. Zool., t. IV. tab. 10, fig. 21. - Long. 1 pied $\frac{1}{2}$. Larg. 2 pouc. - La carapace est arrondie, sillonnée ciliée, terminée par un rostre pointuà cinq dents; les yeux sont gros; les antennes supérieures sont minces, presque de la longueur du corps, avec les deux premiers articles épineux; les inférieures ont les trois premiers articles courts et les deux derniers longs et sétacés; les pinces sont très-grosses, inégales; l'une ovale, avec des dents fortes et mousses; l'autre plus petite, oblongue, avec de petites dents nombreuses; les seconde et troisieme pattes sont velues à leur extrémité et terminées en pinces; les bords des segmens de l'abdomen sont obtus; le corps, dans l'animal vivant, est d'un bleu-verdâtre changeant, parsemé de taches blanchâtres.

Cette espèce, qui atteint jusqu'à un pied et demi de longueur, se trouve sur les côtes de l'Océan, de la Manche et de la Méditerranée; elle se tient dans les lieux remplis de rochers, à une profondeur peu considérable; dans le temps de la ponte, qui a lieu vers le milieu de l'été, sa chair est alors très-estimée.

\section{NEUVIÈIE TRIBU.}

\section{S A L I COQUE, Latreille.}

Caractéres. Le corps est comprimé latéralement.-L'abdomen est très-grand, et les tégumens sont simplement cornés. - La base des antennes externes est garnie en dessus d'un anpendice lamelleux, et recouvre 
presque enticrement le pédoncule qui est situé au-dessous. - Les pattes sont généralement grêles et très-longues, et les fausses pattes natatoires sont encaissées à leur base par des prolongemens lamelleux du segment dorsal des anneaux correspondans de l'abdomen, qui descendent très-bas. - La nageoire caudale est grande et bien formée. - Les branchies sont toujours composées de lamelles horizontales, et sont généralement peu nombreuses. Cette tribu a été divisée en quatre groupes : Les Crangonites, les Alphéites, les Palemonites, et les Peneites.

\section{CRANGONITES.}

Les antennes sont insérées sur la même ligne que les externes. - Les paties de la première paire sont terminées par une main subchéliforme.

Genre : Crangon.

\section{Grangon, Fabr, Eatr., Edw.}

La carapace est mince, demi-transparente, lisse, demi-cylindrique, terminée en avant par un rostre fort court, non comprimé. - Les antennes extérieures sont sétacées, de la Iongueur du corps, placées très-peu au-dessous des intermédiaires, ayant leur pédoncule pourvu d'une grande écaille allongée. - Les antennes intermédiaires sont divisẻes en deux filets dont l'interne est droit et le plus long, et l'externe un peu arqué.-Les pieds-mâchoires extérieurs sont composés de quatre articles visibles: le premier est court et gros, le second long et contourné en $\mathrm{S}$, et les deux derniers moyens, égaux entre eux et droits. - Les pieds de la première paire sont grands, comprimés, presque didactyles. - Le crochet mobile se replie sur une petite pointe de l'extrémité interne de la grande pièce qui représente la main; la seconde paire de pieds est allongée, mince et didactyle; la troisième paire est mince, mais un peu plus grosse et plus longue que la précédente, et finissant par un très-petit ongle simple; la quatrième et la cinquième plus grosses que la troisième, et terminées comme elles par un ongle simple, mais un peu comprimé. - L'abdomen est allongé, plus mince postérieurement qu'en avant, un peu arqué en dessous, et terminé par cinq lames natatoires, allongées, étroites, ne se recouvrant mutuelllement qu'à leur base.

Les Crangons ont beaucoup d'analogic avec les Alphèes, mais ils en diffèrent par le doigt inférieur ou immobile des deux premiers pieds et par ceux de la seconde paire, qui sont coudés et filiformes. Ces Crustacés ont un test incolore ou tirant un peu sur le vert, marqué souvent d'une infinité de points et de lignes noires. Ces couleurs changent singulièrement lorsqu'on les cuit ou quand on les plonge dans l'esprit de vin; alors ils se colorent en rouge. Les Crangons ont des mouvemens très-brusques; ils nagent ordinairement sur le dos et frappent l'eau avec leur abdomen, qu'ils replient contre leur thorax et qu'ils distendent ensuite avec force. On les trouve communément sur nos côtes, dans les endroits sablonneux, où nos pêcheurs en prennent une grande quantitè dans leurs filets, et s'en servent quelquefois comme d'amorce pour attirer plusieurs poissons riverains qui s'en nourrissent. On les sert aussi sur nos tables; mais leur chair n'est pas aussi délicate que celle des chevrettes proprement dites.

1. craygon vulgaris. (PI. 11 , fig. 5.)

Fabr., Suppl., p. 410. - Latr., Hist. nat. des Crust. et des Ins., t. VI, p. 267, pl. 55, fig. 1, 2. - Dess., Consid. génér. sur les Crust., p. 218, pl. 38, fig. 1. Guérin, Iconogr du Rég. anim. de Cuv. . Crust,, pl. 20, lig. 4.-EDw., op. cit., t, II, p. 341. - Cancer Crangon, Sera, t. III, pl. 21, fig. 8. - Long. 2 pouc. La carapace et l'abdomen sont presque entièrement lísses, seulement il y a une petite épine médiane sur la région stomacale, et une latérale au-dessus de chaque région branchiale; les filets terminaux des antennes internes sont plus de deux fois aussi longues que leur pédoncules; l'appendice lamelleux des antennes externes est grand et allongé; le dernier article des pieds-mâchoires externes estlong et étroit; les pattes des deux dernières paires sont delongueur médiocre ; il y a une forte épine insérée sur le sternum, entre les pattes de la deuxième paire, et dirigée en avant; l'abdomen est lisse et sans carène ; la lame médiane de la nageoire caudale est pointue et sans sillon en dessus; la couleur est d'un gris-verdâtre ponctué de brun. - Se trouve sur nos côtes méditerranéennes et océaniques.

\section{Crangon fasciatus.}

Risso, Crust. de Nice, pl. 33, fig. 1. EDw., op. cit., t. 1I, p. 342. - Long. 
1 pouc. Liarg. 3 lig. $\frac{1}{2}$ - Le corps est oblong, renflé, d'un blanc translucide, marqué d'une infinité de petits points noirs; la carapace est grande, bombée, parsemée de quelques pointes courbes, et terminée par un petit rostre arrondi et creusé au milieu; les yeux sont petits, d'un noir brillant, placés sur de courts pédicules; les pinces latérales sont oblongues et ciliées; les antennes supérieures ont leur premier article épineux; la première paire de pattes est courte, épaisse et garnie d'aiguillons; les autres sont longues et très-ciliées; l'abdomen est presque conique et fascié à sa base de bleu-noirâtre ; le dernier segment est terminé par quatre pointes; les écailles caudales sont longues, adhérentes à une pièce triangulaire solide. - La femelle dépose des cufs blancs en juillet. - Habite les bas fonds sablonneux de la mer de Nice.

\section{ALPIIÉITES.}

Les antennes sont insérées sur deux rangs; les internes étant au-dessus des externes. - Le rostre est très-petit et aplati. - Les pattes sont robustes et ne présentent jamais de vestiges d'appendices flabelliformes, ni de palpes; celles de l'une des trois premières paires sont très-fortes; celles destrois dernières paires sont toujours monodactyles.

Genres: Atya, Hymenocera, Alpheus, Pontonia, Autonomea, Caridina, Nika, Athanas.

\section{ATYA, Leach, Desh., Latr., Edw.; Atys, LEACH.}

La carapace est lisse, demi-cylindrique, terminée en avant par un petit rostre et tronquée en arrière. - Les antennes extérieures sont sétacées, presque de la lon. gueur du corps, pourvues à leur base et au côté extérieur d'une grande écaille unidentée; les intermédiaires sont formées de deux filets placés sur une même ligne horizontale. - Les pieds de la première paire sont petis, ayant leur avant-dernier article ou le carpe très-court, et le dernier divisé en deux lanières d'égale longueur, dont l'extrémité est garnie de longs cils; ceux de la seconde paire sont semblablement conformés, mais plus grands; ceux de la troisième beaucoup plus longs et plus gros que tous les autres, inégaux entre eux et pourvus d'un ongle très-court et crochu; ceux des deux dernières paires sont médiocres, et se terminent par un ongle peu robuste. - L'abdomen est allongé, formé de six articles, et pourvu d'une nageoire flabelliforme dont les deux lames latérales sont composées de deux pièces, et dont l'intermédiaire est triangulaire et tronquée droit à son extrémité.

ATYA SCABRA. (P1. 12, fig. 1.)

Leach, Zool. Misc., t. III, pl. 131; ejusd., Trans. of the Linn. Soc., t. XI, p. 345. Desu., Consid. génér. sur tes Crust., p.217, pl. 37, fig. 2.-Guér., Icon. du Riè. anim. de Cuv., Ciust., pl. 20, fig. 2.-Evw.. op. cit., t. 11 . p. 348, pl. 24. fig. 15 a 19. - Long. 4 pouc. - Le rostre est triangulaire, armé de trois petites crêtes paral. léles dont la médiane est la plus longue; la région stomacale est un peu rugueuse; lea. paltes des deux premières paires ne dépasseut pas le pédoncule des antennes exlernes, et sont terminées pardeux faisceaux de poils; celles des trois dernicres paires sont hérissées de petites pointes; la lame médiane de la nageoire caudale présente? deux petites séries d'épines. - Se trouve sur les còtes du Mexique.

\section{HYMENOCERA, LATR.}

Les antennes mitoyennes des supérieures sont bifides, et leur division superieure est foliacée. - Les pieds-mâchoires extérieurs sont foliacés el couvrent la bouche. - Les quatre pattes antérieures sont terminées par une main didactyle foliacée. - Le carpe, ou pièce qui précède la main dans ces quatre pattes, est non divisé en petites articulations; les pieds des trois paires postérieures sont terminés par des articles simples; ceux de la dernière étant plus petits que ceux des deux qui précédent.

$\mathrm{L}$ espèce qui sert de type à ce genre, et qui a été établi par M. Latreille, nous est entièrement inconnue; seulement nous savons qu'elle vient de la mer des Indes, et M. Desmarest pense qu'elle a quelques rapports avec le genre Atye, à cause de la forme de ses deux premières paires de pattes, qui sont plus courtes que les deux autres, didactyles et foliacées. Ce qui l'en distingue éminemment cesont le filet supérieur des antennes intermédiaires et les pieds-mâchoires extérieurs.

ALPHEUS, FABr., LATR., Desu., EDw.;

Astacus, FABR. - Palemon, Ourv.

Le bord antérieur de la carapace s'a- 


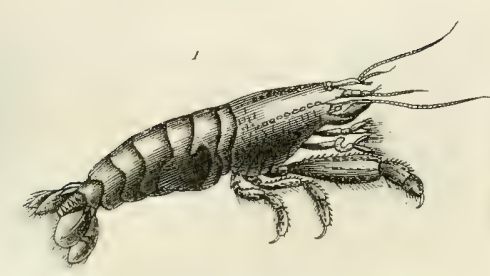

2
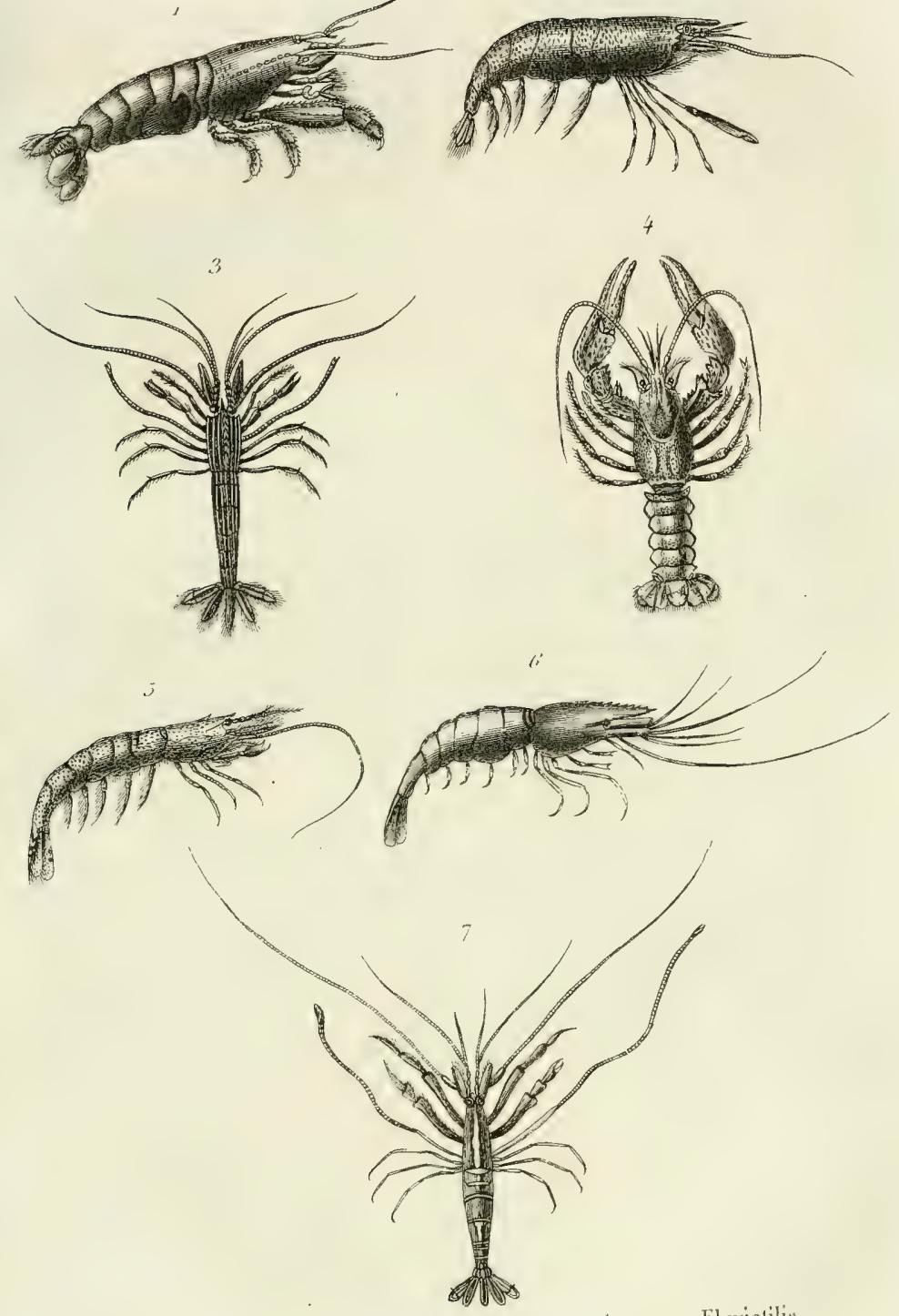

1. Nya Scabra.

2. Athanas nitescens,

3. Lismata seticanda.

4. Astacus Thuvatilis.

3. ('rangon Vulgaris.

6. Ilvppolite Desmarelii.

7. Nika jiculis. 

vance au-dessus des yeux, et forme au dessus de chacun de ces organes un petit bouclier voûté. - Le rostre est très-petit et manque quelquefois. - Les antennes supérieures sont petites, leur premier article est court el armé en dehors d'une lame ordinairement spiniforme; les deux articles suivans sont cylindriques et les filets terminaux sont au nombre de deux, dont le supérieur est plus gros et plus court que l'in. férieur, et présente des traces d'une division en deux filamens vers le bout. - Les antennes inférieures s'insèrent en dehors et en dessous des précédentes; leur palpe lamelleux est de grosseur médiocre, ou même quelquefois petit et pointu; les mandibules sont pourvues d'un appendice palpiforme, court, large et aplati.-- Les pieds-mâchoires sont tantôt grêles et aIlongés, d'autres fois de longueur médiocre, et terminés par un article élargi et presque foliacé. - Les pattes des deux premières paires sont didactyles; les antérieures sont fortes et se terminent par une grosse main renflée dont la forme et les dimensions different de beaucoup des deux côtés du crrps; celles de la seconde paire sont, au contraire, grêles et filiformes; leur main est rudimentaire et leur carpe multiarticulé. - Les pattes des trois dernières paires sont monodactyles et de longueur médiocre. -L'abdomen est grand, et ses fausses pattes sont allongées.

\section{ALPHEUS RUBER.}

EDw. , op. cit., t. II, p. 351. - Long. 15 lig.-Le corps est très-svelte; la grosse main est garnie de quatre crêtes longitudinales, obtuses et ainsi disposées : deux sur son bord supérieur et deux sur sa face externe; son bord inférieur est obtus; le doigt mobile est beaucoup plus court que le doigt immobile; le bord supérieur des deux bras présente une épine à quelque distance de sa terminaison. - Se trouve dans la Méditerranée.

\section{ALPHEUS DENTIPES.}

GuÉrIn, Lixpéd. scient. de Morée, part. zool., p. 39, pl. 27, fig. 3. - EDw., op. cit., t. II, p. 352. - Les voûtes sus-orbitaires sont prolongées en pointe; les deux pattes antérieures sont presque de la mêne grosseur, et les pinces de la moins grande sont grosses à leur base, mais extrêmement rétrécies vers l'extrémité; le troisième article des pattes des deuxième, troisième et quatrième paires est armé d'une dent pointue vers son tiers externe, - Habite Ies mèmes localités que l'espèce précédente. - Cousultez, pour les autres espèces, le tome deuxième de l'Histoire naturelle des Crustacés, par M. Milne Edwards.

$$
\begin{gathered}
\text { Pontonia, Latr., Edw。; } \\
\text { Alpheus, Risso ; Cancer, Forskael. }
\end{gathered}
$$

La carapace est courte et renflée. - Le fronl est armé d'un rostre court, mais robuste et infléchi. - Les yeux sont cylindriques, saillants et très-mobiles. - Les antennes internes sont trés-courtes. - Le premier article de leur pédoncule est trèslarge, lamelleux en dehors; les deux articles suivans sont petits et cylindriques.les filets terminaux, au nombre de deux. sont très-courts, et l'un d'entre eux est bifide à l'extrémité.- - Les antennes externes s'insèrent au-dessous et au-dehors des precedentes; leur appendice lamelleux est grand et ovalaire. - Les pieds-mâchoires externes sont petits et très-étroits dans toute leur longueur.--Les pattes des quatre premières paires sont didactyles; celleside la première sont grêles et terminées par une main bien formée, mais très-petite; les mains de la seconde paire sont au contraire trèsgrandes et de grosseur très-inégale, chez la femelle surtout; mais c'est tantôt celle de droite, tantôt celle de gauche qui l'emporte sur l'autre dans la même espèce; les pattes suivantes sont médiocres, monodactyles, et terminées par un tarse presque rudimentaire. - L'abdomen est grand, surtout chez les femelles, et la lame médiane de la nageoire caudale ne porte pas d'épines sur la face supérieure.-Les branchies, bien développées, ne sont qu'au nombre de cinq de chaque côté : celles fixées au-dessus des appendices de la bouche étant rudimentaires, et les premiers anneaux du thorax n'en portant chacun qu'une seule paire. - Ce genre est très-peu nombreux en espèces, et nous citerons comme les plus remarquables :

\section{Pontonia anmata.}

EDW., op. cit., t. II, p. 359. - Long. 2 pouc. - La carapace est armée d'une petite épine près de la base des antennes externes, et déprimée près de l'insertion des yeux; le rostre ne dépasse pas la moitié de la longueur de l'écaille des antennes externes; l'abdomen est très-gros; les pattes de la seconde paire sont médiocres, 
mais peu renflées. - Cette espèce a été trouvée sur les côtes de la Nouvelle-Irlande.

\section{PONTONIA TYRRHENA.}

Latr., Encyl., pl. 326, fig. 10.-Edw., op. cit., t. I1, p. 360 .-Callianassa Tyrrhenus, Risso, Hist. nat. de l'Europ. Mérid., t. V, p. 54.-Pontonia Custos, Guśr., Expéd. Scient. de Morée, Zoot., p. 36, pl. 27, fig. 1.-Gnatophyllum Tyrrhenus, Drsu., Consid. génér. sur les Crust., p. 229. - Long. 18 lig. - Elle est très-voisine de la précédente, mais elle s'en distingue par la grandeur des pattes de la seconde paire, qui sont plus Iongues que le thorax, et très. grosses; le rostre est court, courbé en bas, atteignant à peine le milieu du troisième article des antennes internes, et garni en dessous, près de son extrémité, d'une petite dent peu visible. - Elle habite la Méditerranée, et se trouve entre les valves de la pinne-marine.

\section{AUtonomea, Risso, Dessi, EDw.}

La carapace est un peu renflée, terminée en avant par une pointe aiguë ou rostre qui dépasse à peine les yeux. - Ceux-ci sont globuleux, portés sur dẹ pédoncules trés-courts. - Les antennes intermédiaires ou supérieures sont terminées par deux filets dont un est beaucoup plus long et plus épais que l'autre; les externes ou inférieures sont sétacées et beaucoup plus longues que le corps; les pédoncules des premières, triarticulés, ont leur pièce inférieure renflée et armée d'un aiguilion; l'intermédiaire longue et cylindrique, et la dernière courte et arquée; les pédoncules des secondes sont biarticulés, sans écailles, avec leur deuxième pièce velue à leur extrémité. - Les pieds-måchoires extérieurs sont non foliacés. - La première paire de pattes est terminée par une main didactyle; les autres sont simples. - La seule espèce de ce genre est :

\section{AU TONOHEA OLIVI.}

Risso, Crust. de Nice, p. 166. - Dess., Consid. génér. sur les Crust., p. 332. Edw., op. cit., t. II, p. 361. - Long. 1 pouc. 3 lig. Larg. 3 lig. $\frac{1}{2}$. - Le corps est allongé, glabre; la carapace est un peu renflée; les yeux sont sessiles et d'un bleu noirâtre; les antennes intérieures sont formées d'une base tri-articulée dont l'article inférieur est renflé et armé d'un aiguillon; l'intermédiaire long et cylindrique, et le dernier court et arqué; celui ci sert de point d'attache aux deux filets qui terminent les antennes, et dont l'un est plus long et plus épais que l'autre; les pièces latérales qui sont situées à côté de ces antennes sont subulées, arquées et pointues; les antennes extérieures sont blanchâtres, placées audessus des inférieurs, une fois et demie plus longues que le corps, très-déliées, composées d'une multitude d'articles dont les deux premiers sont les plus gros; le second présentant à son extrémité une touffe de poils rudes; les palpes sont petits, courts et anguleux ; les deux extérieurs ciliés et un peu plus longs que les internes; les pattes de la première paire, d'un assez beau rouge en dessus et d'un jaune-clair en dessous, sont grandes, inégales, didactyles, composées de six articles, dont le premier est presque quadrangulaire, le second court et à peu près cylindrique, le troisième anguleux, terminé par une pointe; le qua-. trième triangulaire, allongé, armé de huit épines très-effilées sur l'une de ses arêtes; le cinquième petit, en forme de cœur renversé; et le dernier fort long, aplati, rebordé de cliaque côté, avec une ligne élevée au milieu de sa surface inférieure, et des dents crochues et poilues à son extrémité; les autres pattes sont courtes, minces, et terminées par des crochets simples; l'abdomen est composé de six segmens lisses, arrondis, festonnés sur les côtés; il est garni en dessous d'appendices foliacés; la queue est terminée par cinq écailles natatoires, dont l'intermédiaire est solide, tronquée au sommet, avec une pelite pointe de chaque côté; les latérales sont arrondies et ciliées. La femelle porte ses æufs, qui sont rougeâtres, vers le milieu de l'été. - Se trouve dans la mer-Adriatique, et rarement aux environs de Nice.

$$
\text { CARIDINA, EDw. }
$$

La carapace se termine par un rostre Jamelleux dont la longueur varie. - Les yeux sont saillans. - Les antennes internes sont très-longues, et terminées par deux grands filets multiarticulés, dont l'un est renflé à sa base. - Les pieds-mâchoires externes sont longs, grêles et pédiformes. - Les pattes des deux premières paires sont didactyles; les antérieures sont très-courtes, et présentent une disposition très-remarquable. - Le carpe est à peu près triangulaire, et se termine antérieurement par un 
bord concave qui reçoit la base de la main fixée à son angle inférieur; la main est courte et terminée par deux doigts lamellcux profondément creusés en cuillère. Les pattes de la seconde paire sont plus longues et plus grêles; le carpe est de forme ordinaire, mais la main est conformée comme celle de la patte précédente. - Les pattes des trois dernières paires sont grêles et à peu près de même longueur. L'abdomen est comme chez le genre $\mathrm{Pa}$ lémon.

\section{CARIDINA LONGIRostris.}

Evw., op. cit., t. II, p. 363. - Long. 6 lig. - Le rostre est très-long, dépasse le pédoncule des antennes externes, un peu relevé vers le bout, et armé d'une douzaine de dents qui en occupent les deux tiers postérieurs, et d'une autre dent près de sa pointe; son bord inférieur présente en dessus une douzaine de dents; le carpe des pattes antérieures est peu épais. - Cette espèce a été trouvée dans la rivière de Macta, près d'Oran.

\section{NIKA, Lam., Risso, Desm., Edw.; Processa, Leach, Latr.}

La carapace est peu allongée, lisse, pourvue en avant d'un petit rostre simple, comprimé. - Les yeux sont globuleux, rapprochés. - Les antennes intermédiaires ou supérieures sont terminées par deux filets sétacés, dont l'inférieur est le plus long, portées sur un pédoncule formé de trois articles dont le premier est le plus grand. Les antennes extérieures ou inférieures sont sétacées, beaucoup plus longues que les premières, pourvues à leur base d'une écaille allongée, unidentée à l'extrémité et en dehors, ciliée sur le bord interne. - Les pieds-mâchoires extérieurs ne couvrent pas la bouche; ils sont formés de quatre articles visibles dont le second cst très-long. - Les pieds sont généralement grêles et longs; ceux de la première paire monodactyles à gauche et didactyles à droite, n'ayant pas le carpe multiarticulé; les pieds de la seconde paire sont plus grêles, très-longs, filiformes, multiarticulés sur le carpe et l'article qui le précède, de grandeur inégale, et finissant chacun par une petite main didactyle; les trois dernières paires de pieds sont simplement terminés par un angle aigu, légérement arqué et non épineux. - L'abdomen, arqué vers le troisième segment, est ter- miné par des lames foliacées allongées, dont l'extérieure de chaque côté est bipartie à l'extrémité.

Ce genre est très-remarquable par le défaut de symétrie des pieds de la première paire, et par l'allongement extrème d'un de ceux de la seconde. Les espèces qu'il renferme sont très-communes sur les côtes de Provence et sur celles de Nice.

NIKA EDULIS. (Pl. 11, fig. 7.)

Russo, Crust. de Nice, p. 85, pl. 3 , fig. 3. - Desu., Consid. génér. sur les Crust., p. 230. - EDw., op. cit., t. II , p. 364. - Roux, loc. cit., pl. 45.-Processa Edulis, Latr., Rég. anim. de Cuv., $2^{\mathrm{e}}$ édit., t. IV, p. 95.-Gúk., Icon. du Règ. anim. de Cuv. Crust., p. 20, fig. 3. - Long. 1 pouc. $\frac{1}{2}$. Larg. 5 lig.-Le corps est entierement glabre, lisse, d'un rouge incarnat, plus ou moins pointillé de jaunâtre ou de tlanc, ordinairement marqué le long du dos de quelques taches jaunes ou blanchâtres; la carapace est terminée en avant par trois pointes aiguës : celle du milieu plus longue, composant le rostre ; les deux autres trèscourtes; le dernier segment de l'abdomen est terminé par une plaque allongée, armé de quatre pointes à son extrémité et de quatre autres épines en dessus; cette plaque est canaliculée le long de sa partie supérieure; les écailles caudales sont ovales, oblongues, pointillées de rouge, ciliées sur leur bord inférieur.

La femelle est à diverses époques de l'année munie d'œufs verdâtres, qu'elle dépose, à quelques mètres sous l'eau, sur les algues ou les ulves.

Celte espèce comestible est pleine de vivacité; elle abonde sur toutes les côtes de la Méditerranée. Il est facile de la pêchr à la drague; elle vit en troupe avec les Palémons, quelques Hippolytes et divers Alphées. Durant l'hiver elle est d'un excellent appât pour la pêche à l'hameçon.

\section{aTHaNaS, Leach, Latr., Desm., Edw. ; Palemon, Leach ; Astacus, Montagu.}

La carapace est cylindrique, un peu plus étroite en avant qu'en arriere, et prolongée en forme de rostre aigu, mais court. - Les antennes supérieures ou intermédiaires sont terminées par trois filets, dont le plus gros et le plus court est situé sur la base du plus court des deux autres. - Les antennes extérieures ou inférieures sont un peu plus courtes que le corps, sétacées, ayant l'écaille c'e 
leur base grande et terminée par une seule pointe aiguë au côté externe de son extrémité. - Les pieds-mâchoires sont assez grêles, le premier article étant plus gros que les deux autres ensemble, et le dernier de ceux-ci plus long que l'avant-dernier. - Les pieds des deux paires antérieures sont terminés par une main didactyle, la première paire étant la plus grande de toutes, et la seconde, qui est la plus grêle, ayant son carpe multiarticulé. - Les pieds des troisième, quatrième et cinquième paires se terminent par un ongle simple un peu arqué. - Les lames natatoires extérieures de la queue sont formées de deux pièces.

Ce genre a la plus grande analogie avec le précédent, et il n'en est réellement bien distinct que par la différence de proportion de ses pattes de la première paire, qui sont les plus grosses, tandis que dans celui - ci ce sont les pattes de la seconde paire qui ont le plus de volume.

L'espèce type de ce genre est :

athanas nitescens. (Pl. 11, fig. 2.)

Leach, Malac. Pod. Brit., tab. 44. Desur., Consid. génér. sur les Crust., p. 240, pl. 39. fig. 5.-Guér., Icon. du Règ. anim., Crust., pl. 22, fig. 2. - EDw., op. cit., t. II , p. 366. - Palemon Nitescens, LEACH, Edinb. Encycl. - Long. 10 lig. Le rostre est aigu, moins long que le pédoncule des antennes internes; il y a une épine de chaque côté de sa base, sur le bord antérieur du carpe; les mains sont inégales, renflées et à doigts courts et obtus; le carpe des deuxièmes pattes est divisé en cinq ou six articles; la lame médiane de la nageoire caudale porte sur sa face supérieure quatre épines; le bord postérieur des quatre pièces lalérales est dentelé.

Se trouve sur les côtes de France et d'Angleterre.

\section{PALEMONRTES.}

Les antennes sont insérées sur deux rangs. -- Le rostre est grand, lamelleux, comprimé et denté. - Les pattes sont robustes, sans appendices à leur base; celles des deux premières paires sont en général didactyles, mais grêles, et celles des trois dernières paires toujours monodactyles.

Genres : Gnathophyllum, Hippolyte, Rhynchocinete, Pandalus, Lismata, Palemon.

\section{GNATOPHILLUM, LatK., Desh., EDW.; Drimo, Risso.}

La carapace est terminée par un rostre moyen. - Les antennes mitoyennes sont terminées par deux filets de forme ordinaire, et assez courtes; les extérieures ou inférieures sont sétacées, assez longues, mais un peu moins que le corps. - Les pieds-mâchoires extérieurs sont foliacés ; ils couvrent la cavité buccale, comme dans le genre précédent. - Les quatre pattes antérieures sont terminées par une main didactyle, et leur carpe est non divisé en petits articles. - Les pinces de la seconde paire sont plus minces et beaucoup plus longues que celles de la première.

C'est aux dépens des Alphées que ce genre a été formé; il se rapproche beaucoup des Hippolytes par sa forme générale et par la configuration de ses deux premières paires de pieds, qui sont terminés en pinces ; mais il s'en écarte par le défaut des petitsarticles subdivisantl'avant-dernière pièce des uns ou des autres de ces pieds; il s'en éloigne encore par ses pieds-mâchoires extérieurs foliacés, et, sous ce rapport, il ressemble, au contraire, au genre précédent; mais ce dernier, au contraire, a le filet supérieur des antennes antérieures et les pinces foliacés, ce qui les en distingue tout-à-fait. - Enfin le nombre des serres, qui n'est chez les Gnatophylles que de quatre en totalité, les distingue suffisamment des Penées et des Sténopes, où il est de six.

\section{GNATOPHYLLUM ELEGANS.}

Larr., Rég. anim. de Cuv., t. IV, p. 96. - Dessr., Consid. génér. sur les Crust., p. 228. - EDw., op. cit., t. II , p. 369. - Drimo Elegans, Risso, Hist. de l'Europ. Mérid., t. V, p. $71, \mathrm{pl} .1$, fig. 4. - Alpheus Elegans, Risso, Crust. de Nice, pl. 2, fig. 4. -Long. 1 pouc. $\frac{1}{2}$. Larg. 4 lig. $\frac{1}{2}$. - Le corps est oblong, renflé, arqué vers le troisième article de l'abdomen; la carapace est lisse, terminée en avant par un petit rostre comprimé et denté en dessus; les quatre antennes sont épineuses à leur base ; les pièces natatoires de la queue sont arrondies, ciliées et blanches; la couleur-générale est variée de nuance carmélite et de points d'un jaune doré ; les pédoncules des yeux sont jaunâtres; le rostre etles pieds des deux premières paires sont blancs; le dernier segment de l'abdomen est violet; la femelle de cette espèce, suivant M. Risso, 
pond des œufs d'un brun violet en juillet et en novembre. - Ce Crustacé habite les rivages de Nice.

hippolyte, Leach, Desm., Latre, EDw.;

Alpheus, LaM., Risso ;

Palemon, Ourv. ; Cancer, LinN.

La carapace est courte, large, terminée en avant par un rostre assez court, mais trèscomprimé en haut, non relevé en arc à sa pointe, et plus ou moins découpé en dents de scie sur ses bords. - Les antennes su. périeures ou intermédiaires sont les plus courles, bifides, supportées par un pédoncule de trois articles dont le premier et le plus grand est échancré au côté des yeux, et pourvu d'une lamelle qui se prolonge au. dessous de ceux-ci ; les antennes exterieures ou inférieures sont plus longues que le corps, sétacées, pourvus a leur base d'une écaille allongée, unidentée en dehors vers son extrémité. - Les pieds des deux premières paires sont didactyles, les autres terminés par un ongle simple, très-épineux sur son bord inférieur; ceux de la paire antérieure sont les plus courts et les plus gros de tous; ceux de la seconde paire, les plus longs et les plus grêles, avec leur carpe ou la pièce qui le précède multiarticulé; ceux des troisième, quatrieme el cinquieme paires sont intermédiaires aux deux premiers pour la longueur, et décroissent successivement d'avant en arrière. - L'avant. dernier article des pieds - mâchoires extérieurs est beaucoup plus court que le dernier, qui est épineux. - L'abdomen est arqué vers le troisième segment.-Les lames natatoires de la queue sont allongées, surtout l'intermédiaire, qui est pourvue de petites épines à son extrémité.

Les espèces qui composent ce genre sont assez nombreuses. - Elles ont été ainsi par. tagées par M. Edwards, dans son Hist. nat. des Crustacés :

Espèces dont le rostre naît du front et ne se continue pas en arrière, avec une crête élevée occupant la ligne médiane de la carapace :

\section{HIPPOLYTE VARIANS.}

Leach, Malac. Pod. Brit., pl. 38, fig. 6 à 16. - Desm., Consid. génér. sur les Crust., p. 224, pl. 39, fig. 2. - EDw., op. cit., t. II, p. 371. - Long. 5 lig. - Le rostre, qui ne dépasse pas le pédoncule des antennes internes, est droit, grêle et armé de deux dents en dessus (une située à sa base, et l'autre près de son extrémité), et de deux en dessous, situées un peu en arrière de la dernière dent supérieure; la base du rostre, au-dessus de l'insertion des yeux, présente une petite épine de chaque côté; le premier article des antennes internes est armé en dehors d'une épine de grandeur médiocre; les appendices lamelleux des antennes externes dépassent un peu plus le rostre, et sont natatoires ou plutôt tronqués obliquement de dessous en dehors, et d'avant en arrière àleur extrémité ; les pieds-mâchoires externes sont courts, ne dépassant que de peu le pédoncule des antennes, et sont terminés par un article court, aplati, tronqué et épineux en dedans; les pattes antérieures sont très-courtes et ne dépassent guère l'article basilaire des antennes externes; celles de la seconde paire sont médiocres, moins longues que celles de la troisième paire, et ont le carpe divisé en trois ou quatre segmens peu distincts; la lame médiane de la nageoire caudale porte sur sa face supérieure deux paires de petites épines, - Gette espèce se trouve sur les côtes de la Manche et de la Vendée.

\section{HIPPOLYTE PRIDEAUXIANA.}

Leach, Malac. Brit., tab. 38, fig. 1, 3 , 4, 5. - Desur., Consid. génér. sur les Crust., p. 291. - Evw., op. cit., t. II, p. 372.-Long. 6 lig. - Le rostre est droit, simple, avec une seule dent en dessous, près de son extrémité. - Cette espèce est trèsvoisine de la précédente, et n'en diffère que par les caractères que nous venons d'énoncerci-dessus. - Se trouve sur les côtes d'Angleterre et sur celles de la Manche.

\section{HIPPOLYTE VIRIDIS.}

EDw. op. cit., t. II, p. 372.- Alpheus Viridis, Otto, Mém. de l'Acad. des Cur. de la nat. de Bonn., t. XIV, pl. 20, fig. 4. Long. 20 lig. - Le corps est svelte ; le rostre est droit, dépasse l'appendice lamelleux des antennes externes, sans dents en dessus, et armé en dessous de trois dents; les piedsmâchoires externes sont très-courts, et assez larges vers l'extrémité; les pattes antérieures sont courtes et grosses; les pattes de la deuxième paire sont grêles et de longueur médiocre ; leur carpe est divisé en trois articles; la lame médiane de la nageoire caudale est garnie en dessus de deux paires d'épines. - Cette espece se trouve dans la Méditerranée et sur lescôtes de la Vendée. 
Espèce dont le rostre forme une crête éle. vée sur la partie antérieure de la région stomacale, mais ne se prolonge pas sur la partie postérieure de la carapace :

4. IIIPPOLYTE DESMARETI. (PI. 11, fig. 6.) Milet, Ann. des Sc.nat. ,t. XXV, pl. B, fig. 1 et 2, p. 461 (1832). - Evw., op. cit., t. II , p. 376. - Long. 15 lig. - Corps transparent, couvert, ainsi que les écailles des lames natatoires de la queue, de trèspetits points verts, quelquefois rougeâtres, qu'on ne distingue bien qu'à la loupe; abdomen composé de deux anneaux inégaux, arqué vers le troisième article, et terminé par cinq écailles natatoires dont les quatre extérieures sont courbées, frangées à leur extrémité, et plus larges que l'intermédiaire, qui est droite, plus courte que les autres, et terminée par plusieurs petites épines, comme réunies; quatre petites épines sur la partie antérieure du test, l'une-à droite et l'autre à gauche de chaque æil; yeux noirâtres, mais leur pédicule de la couleur du corps; antennes blanchâtres, ainsi que les pieds; la pince des pieds antéricurs petite et le dernier article des pieds-mâchoires extérieurs terminé par un faisceau de poils.

Les oufs que l'on observe en automne sont elliptiques, d'un sixième de ligne de diamètre. Une femelle que nous examinâmes était garnie de deux cents œufs au plus.

Cette espèce, dont on se procure facilement desindividus en visitant les herbes amenées par les filets des pêcheurs, habite les eaux de la Mayenne, de la Sarthe, de la Loire, du Thouet et du Layon.

Espèce dont la base du rostre s'élève en crête et se prolonge jusque vers le bord postérieur de la carapace :

\section{MipPoLYTE ACULEATUS.}

EDw., op. cit., t. II, p. 380.-Alpheus Aculeatus, sab. app. to PArrx's, voy. tab. 2, fig. 29.-Cancer Aculeatus. Fabr., Faun. Groênland., p. 239. - La carapace est très-bombée en dessus; le rostre est grêle, ne dépasse que de peu le pédoncule des antennes supérieures, se continue en arrière avec une crête qui est Irès-élevée, et se prolonge jusque vers le bord postérieur de la carapace; il y a quatre ou cinq grosses dents sur la crête basilaire du rostre, trois ou quatre dents très-petites sur le bord supérieur de sa portion antérieure, et trois sur son bord inférieur; les pieds - mâchoires sont longs, dépassent l'appendice lamelleux des antennes externes, qui sont larges et tronquées à l'extrémité ; les pattes antérieu. res sont grosses et de longueur médiocre; la lame médiane de la nageoire caudale présente cinq paires d'épines. - Cette espèce habite les mers polaires.

\section{RHYNCHOCINETES, EDW.}

Ce genre se distingue de celui d'Hippotyte par la conformation singulière du rostre, qui, au lieu d'être un simple prolongement du front, est une lame distincte de la carapace et articulée avec le front, de manière à être très - mobile et à pouvoir s'abaisser au-dessous.des antennes, ou s'élever verticalement; il est très-grand, en forme de lame de sabre placée de champ et den. telée sur les deux bords. - Les yeux sont. saillans, et lorsqu'ils se reploient en avant; ils se logent dans une excavation des pédoncules des antennes supérieures, dont l'article basilaire est grand et armé en dehors d'une lame spiniforme. - Les filets terminaux de ces appendices sont au nombre de deux, et présentent la même conformation que chez les Hippolytes. - L'appendice lamelleux des antennes externes est grand et triangulaire. - Les pieds-mâchoires externes sont pédiformes et allongés; leur dernier article est grêle, cylindrique el épinçuxau bout. Les pattes sont semblables à celles du genre Hippolyte, si ce n'est qu'on trouve, du côté externe de la base de chacune d'elles, un petit appendice palpiforme, rudimentaire, et que le tarse de celles de la seconde paire n'est pas multiarticulé. - Les branchies sont au nombre de neuf de chaque côté.L'espèce type de celte nouvelle coupe générique est :

\section{RHYNCHOCINETES TYPUS.}

EDw., Ann. des Scienc. nat., $2^{\mathrm{e}}$ série, t. VII, pl. 4; ejusd., op. cit., t. II, p. 383. - Long. 2 pouc. $\frac{1}{2}$. - Le front est armé de trois épines, dont la médiane, placée audessus de la base du rostre, est suivie d'une autre épine médiane; le rostre est trèsgrand, plus long que la lame des antennes externes, armé en dessus de deux épines situées près de la base, et de sept ou huit dentelures situées à son extrémité; son bord inférieur est garni d'une vingtaine de dents très-grandes; les pieds-mâchoires externes sont de la longueur du rostre; les pattes antérieures sont plus grosses que les autres, et dépassent un peu le pédoncule des antennes externes; les pinces sont courtes et 
creusées en cuillère ; le doigt mobile est dentelé; les pattes de la deuxième paire sont de la longueur de celles de la première paire, mais beaucoup plus courtes que celles de la troisième paire; la face supérieure de la lame médiane de la nageoire caudale présente en dessus trois petites épines. Se trouve dans l'Océan Indien.

\section{PANDalus, Leach, Latr., Desm., Edw.; Astacus, FaBr.; \\ Pontophilus, Risso.}

La carapace est allongée, cylindrique, carénée et dentelée dans son milieu, terminée en avant par un long rostre comprimé, denté en dessous et relevé à sa pointe. Les antennes supérieures ou intermédiaires sont les plus courtes, bifides, supportées par un pédoncule de trois articles, dont le pre. mier et le plus grand est échancré du côté des yeux et pourvu d'une lamelle qui se prolonge au-dessous de ceux-ci. - Les antennes extérieures ou inférieures sont plus longues que le corps, sétacées, pourvues à leur base d'une écaille allongée, unidentée en dehors vers son extrémité. - Les piedsmâchoires extérieurs sont formès de trois articles visibles, dont le premier est aussi long que les autres ensemble, échancré en dedans depuis sa base jusqu'à son milieu, et dont les deux derniers, égaux entre eux, sont couverts de petites épines sur toutes leurs faces. - Les pieds de la première paire sont assez courts, sans pinces, avec leur dernier article simple et pointu; ceux de la seconde paire sont didactyles, trèslongs et grêles, inégaux entre eux, ayant les troisième, quatrième et cinquième articles marqués de beaucoup de petits sillons transverses et comme multiarticulés; les pieds des trois dernières paires sont plus gros et moins longs que ceux de la seconde, et décroissent successivement de grandeur entre eux; tous sont terminés par un ongle simple pourvu de petites épines du côté interne; l'abdomen est arqué vers le troisième segment; les écailles de la queue sont allongées, étroites, surtout celle du milieu, qui est garnie de petites épines à sa pointe. - Les mours de ces Grustacés nous sont inconnues.

\section{Pandalus anduliconvis.}

Leach, Malac. Brit., tab. 40. - Desm., Consid. génér. sur les Crust., pl. 38, fig. 2. -Las., Hist. nat.des Anim. sans vert., $\mathrm{t} . \mathrm{V}$, p. 203. - EDW., op. cit., t. II, p. 384. -
Le rostre est de la longueur de la carapace, armé en dessus d'une dizaine de dents qui occupent la région stomacale et la moitié postérieure de sa partie libre; il y a une petite dent près de la pointe du rostre, qui est séparée des précédentes par un espace lisse assez long; le bord intérieur du rostre est armé de sept à huit dents très-grosses vers sa base, et dont les dernières demeurent vers l'extrémité ; les pattes sont assez fortes et de longueur médiocre; celles de la première paire n'atteignent pas l'extrémité de l'appendice lamelleux des antennes externes; les pattes des trois dernières paires sont armées d'épines. - Se trouve sur les côtes d'Angleterre et d'Irlande.

\section{PANDALUS NARIVAL.}

LATr., Règn. anim., t. IV , p. 97. Desn., Consid. génér. sur les Crust., p. 220. - EDw., op. cit. , t. II , p. 385. Pontophilus Pristis, Rrsso, Hist. nat. de l'Europ. Mérid., t. V, p. 62, pl. 4, fig. 14. - Palemon Pristis, ejusd., Crust. de Nice, p. 105. - Astacus Narwal, Fabr., Mantiss., t. II, p. 331. - Long. 4 pouc.Le rostre est beaucoup plus long que la carapace et fincment dentelè en dessus dans toute sa longueur; les dents de sa base ne se prolongent que fort peu sur la région stomacale; son bord inférieur est armé de dents très-fines qui disparaissent peu ả peu vers sa base. Les pattes sont très-longues et très-grêles; celles de la première paire dépassent de beaucoup l'appendice lamelleux des antennes externes; celles des deux premières paires sont plus grêles que celles de la troisième paire, et sans épines. - Se trouve dans la Méditerranée.

\section{LYSmata, Risso, Latr., Desh., Edw. ; Melicerta, Risso.}

La carapace est carénée en dessus, et terminée en avant par un rostre fort court. Les yeux sont globuleux, rapprochés. Les antennes intermédiaires ou supérieures sont formées de trois filets dont le plus court joint la base de l'extérieur, qui est le plus long. - Les antennes extérieures sont un peu plus longues que le corps et sétacées, insérées sur un pédoncule court; le deuxième article donnant attache à une écaille mem. braneuse, allongée, pourvue d'une dent à son extrémité extérieure. - Les pieds-mâchoires extérieur's sont avancés, presque filiformes, étroits, composés de quatre articles dont le second, le plus grand de tous, est 
échancré au côtẻ interne; le dernier est en forme d'onglet écailleux et légérement parsemé de poils. - Les pieds des deux premières paires de pattes sont didactyles; ceux de la seconde paire étant les plus longs, très. grêles, et ayant leur carpe divisé en plusieurs petits articles. - Les pieds des trois paires postérieures sont très-minces, terminés par un ongle simple; les quatre derniers un peu plus courts que les autres. L'abdomen est allongé, légérement arqué, terminé par une pièce étroite, arrondie, ciliée, ainsi que les nageoires caudales, qui sont ovales; l'extérieure divisée en deux parties. - Le genre Lysmate a de l'analogie avec celui de Palémon, comme il sera facile de le voir d'après les caractères ci-dessus exposés; mais il en diffère essentiellement par les sections annulaires dont les carpes des deux pattes antérieures sont pourvus, et par la longueur et la forme grêle de la seconde paire de pieds. - A ces caractères on peut ajouter que les Lysmates ont le corps plus raccourci que celui des Palémons; que leur rostre est plus court, que leurs pieds sont plus minces, et que l'extrémité de l'abdomen, au lieu d'être épineuse et arrondie, est ciliée seulement.

1. LYSMATA SETICAUdA. (Pl. 11, fig. 5.) DEsM., Consid. génér. sur les Crust., p. 129. - EDw., op. cit., t. II, p. 386 , pl. 25, fig. 10. - Roux, loc. cit., pl. 37, fig. 1 à 11. -Melicerta Seticauda, Lysmata Seticauda, Risso, Crust. des env. de Nice, p. $110, S p .1$, pl. 2, fig. 1. - Long. 1 pouc. $\frac{1}{2}$. - Chez cette espèce tout le corps est d'un rouge corail, marqué sur l'abdomen et sur la carapace de lignes longitudinales blanchâtres; celui-ci un peu déprimé, svelte, muni de chaque côté de deux pointes; le rostre, qui ne dépasse pas l'extrémité du troisième article des antennes intermédiaires, est armé de six dents en dessus et de deux en dessous; les yeux sont noirâtres, paraissent réticulés dans les individus desséchés, et sont portés sur de courts pédoncules; laplaque caudale est munie de quatre épines : son extrémité arrondie en est dépourvue et se termine par des cils roides. la a femellepond en été des œufs d'un rouge hrun.

Les habitudes de cette espèce, la seule connue, diffèrent peu de celles des Palémons; cependant il est à remarquer qu'elle s'approche moins du rivage et qu'elle vit solitaire; car, quoiqu'on la pêche en même temps que les Palémons, qui sont partout très-abondans, il ne parait jamais que quelques individus de la Lysmata Seticauda; la chair est plus délicate que celle des genres précédens; ce Décapode meurt plus vite que les Palémons lorsqu'il est hors de l'eau : ses mouvemens sont moins vifs. La nature paraît avoir accordé à ce Grustacé des mœurs plus douces qu'a ceux-ci, que la nécessité de conserver leur existence au milieu des nombreux ennemis qui les recherchent sans cesse, a rendu alertes, agiles et méfians.

Cette espèce se trouve sur tous les points de la Méditerranée, parmi les rochers couverts d'algues et peu profonds.

$$
\begin{aligned}
& \text { Palemon, Fabr., Latr., Oliv., Edw.; } \\
& \text { Cancer, Linv. ; Astacus, Penn.; } \\
& \text { Squilla, Bast.; } \\
& \text { Lysmata } \text { et Melicerta, Rrsso. }
\end{aligned}
$$

Le corps, chez ce genre de Crustacé, est recouvert d'un test ou de plaques minces beaucoup moins solides que les tégumens des autres animaux du même ordre ; il est comprimé, arqué, comme bossu, allongé et rétréci en arrière. Le test se termine de chaque côté, en devant, par deux dents aiguës; de la partie antérieure du milieu du dos, s'élève une carène qui se détache et s'avance ensuite à la manière d'un bec comprimé, en forme de lame d'épée, dont la tranche est perpendiculaire avec une arête ou côte de chaque côté, et les bords supérieur et inférieur aigus, ordinairement dentelés en scie, et ciliés. - Les yeux sont presque globuleux, portés sur un pédoncule court; ils sont assez gros, rapprochés, insérés de chaque côté, à l'origine $d u$ bec, avancés, et reçus en partie dans la concavité de la base du premier article du pédoncule des antennes intermédiaires. -- Les an. tennes latérales ou inférieurès sont plus longues que le corps; elles sont insérées sur un pédoncule court de quatre articles. dont le second donne attache à une forte écaille ovale, allongée, pourvue à son extrémité et en dehors d'une dent bien prononcée; les antennes intermédiaires sont formées de tro is filets; les deux plus longs sont sétacés, multiarticulés; et le troisième est très-court, assez gros, et denté sur la base de celui des deux premiers, qui est sétacé supérieurement ; ces antennes sont portées sur un pédoncule de trois articles dont le premier, ou le plus grand, est dilaté , comprimé extérieurement, avec une échancrure en dessous pour recevoir la partie inférieure de l'œil: - La bouche est formée par les pieds. 
mâchoires extérieurs, qui sont avancés et se prolongent jusqu'un peu au delà des pédoncules des antennes intermédiaires; ils sont presque filiformes, amincis vers leur extrémité, étroits, comprimés et velus ; leur second article, le plus grand de tous, est concave ou échancré au côté intérieur, et plus large à son extrémité; le dernier est très-petit, membraneux, sétacé, sans articu. lations bien distinctes, avec quelques soies allongées vers le bout. - Les autres parties de la bouche (excepté les mandibules) ne présentent rien de remarquable : elles sont généralement semblables à celles des autres Macroures. - Ces dernières ont leur extrémité supérieure bifide et comme fourchue. - Leur côté antérieur présente une excavation assez forte, et se dilate près de l'origine de cet enfoncement pour former une petite lame comprimée, presque carrée ou peu arquée en dessus, dentelée au bout, se dirigeant vers la bouche, et que Fabricius compare à une dent incisive.-On peut considérer avec lui, comme une dent molaire échancrée angulairement à son extrémité, l'autre branche de la mandibule ou celle qui la termine, et qui est opposée à la précédente. - Quelques légères différences se font remarquer dans ces mandibules; elles portent chacune un palpe court, grêle, presque sétacé, terminé en pointe, triarticulé, inséré au-dessus de l'origine de la dent incisive, s'appliquant contre son bord supérieur, mais n'atteignant pas tout-à-fait son extrémité. - Les pattes sont rapprochées à leur naissance, généralement longues, grêles, et coudées en arrière, à la jointure des quatrième et cinquième articles; les quatre antérieures sont terminées en une pince allongèe et didactyle; celles de la seconde paire sont les plus grandes de toutes, et contrastent souvent, sous cerapport, avec les autres; les deux premières sont pliées en deux, de sorte que leurs pinces sont cachées entre les pieds-mâchoires extérieurs, et que souvent on ne les aperçoit pas au premier coup d'œil. L'article qui précède la pince est simple. Les six pattes postérieures sont terminées par un article co. nique, comprimé, au bout duquel est un onglet écailleux; les deux dernières sont un peu plus longues; les quatre autres, ou celles de la paire antérieure, sont presque de la même longueur; aucune d'elles n'offre de divisions d'appendices a leur base. .. La queue est plus longue que le test, Irès-comprimée, courbée en dessus', avec les extrémités latérales des plaques dorsa- les de ses premiers anneaux, celle du second surtout, élargies et arrondies; les quatre feuillets de la nageoire terminale sont ovales, ciliés sur leurs bords, minces et demi-transparents. - La côte des deux feuillets extérieurs est cependant plus épaisse et plus crustacée, et se prolonge en pointe aiguë près du sommet; vue à la lumière, l'extrémité de ces mêmes feuillets présente une division linéaire et arquée qui semble les partager en deux portions. - La pièce intermédiaire de la nageoire est étroite, alIongée,et finit insensiblement en pointe tronquée, au bout de laquelle sont deux pointes mobiles. - On voit près du milieu de son dos quatre petites épines disposées par paires. - Les deux fausses pattes, ou appendices natatoires, qui garnissent sur deux rangs le dessous de la queue, consistent chacune en deux lames membraneuses, étroites, allongées, ayant de chaque côté un rebord épais strié transversalement, ciliées et portées sur un article commun, creux le long de sa face postérieure ou presque demi-tubulaire.

Les Palémons forment un genre assez nombreux en espèces, qui sont presque toutes marines, et plusieurs sont comestibles; on les désigne par les noms de Crevettes, Chevrettes, Salicoques, Squilles, et Bouquets. Leur chair, cuite et salée, est très-estimée, tant dans les pays des bords dela mer que dans ceux de l'intérieur. Dans le Levant on sale les grandes especes et on les conserve dans des paniers faits de feuilles de palmier. On les envoie dans toutes les villes de la Turquie. Leur chair est tendre et très-agréable au goût; on la regarde comme très-nourrissante et de digestion facile; on en recommande l'usage aux personnes menacées de phthisie.

Les Grecs donnaient à ces animaux le nom de Karis; sur les côtes de Provence on les dèsigne sous celui de Carambos, et sous celte dénomination sont confondus les Penées, les Nikas, les Crangons, et autres Salicoques. Dans plusieurs parties de l'Italie ils sont connus sous celle de Macoltos.

On trouve des Palémons dans toutes les mers. Les Indes Orientales et les Antilles en offrent de très-grands; ceux de nos côtes sont beaucoup plus petits. Il est des espèces qui se tiennent volontiers à l'embouchure des rivières; d'autres habitent les localités rocailleuses ou couvertes d'algues, et quelques-unes, essentiellement pélagiennes, n'abandonnant jamais le fucus natans de l'Atlantique, vivent el meurent 
sur ces plantes flottantes. Ils sont partout fort abondans. Leur natation se fait ordinairement en avant, et c'est en agitant les lames du dessous de leur abdomen; ils se servent en même de leurs pieds pour se diriger; mais lorsque, agités par la frayeur d'un danger quelconque, ils veulent promptement s'y dérober, c'est en nageant à reculons sur le côté, et par bonds répétés, qu'ils se sauvent. La vivacité avec laquelle ils portent la queue sous l'abdomen facilite à ces Salicoques l'exécution du mouvement; quelquefois il leur arrive de s'arrêter un moment après chaque élan. Leur nourriture consiste en animaux marins, ils sont très-friands des Sardines ou autres Clupées, avec lesquelles il est facile de les attirer. La manière de les pêcher la plus avantageuse est la drague, sorte de filet en forme de poche que l'on traîne au fond de l'eau. Leur chair, crue et tendre, est d'un goût agréable, ils se colorent en rouge après la cuisson, et ont un fumet particulier que quelques personnes apprécient. Ces animaux vivent hors de l'eau plus de vingt-quatre heures, pourvu qu'on ait soin de les tenir au frais. La pointe aiguë dont leur front est armé paraît leur servir à lutter avec avantage contre leurs nombreux ennemis. C'est un excellent appât pour la pêche, recherché par tous les poissons; mais ceux-ci sont forcés de les faire descendre à reculons dans leur estomac: aussi les Palémons, qui semblent connaître les moyens de défense dont la nature les a pourvus, font-ils toujours face à l'ennemi qui se présente, et ne fuient-ils jamais en tournant le dos.

Les Palémons sont souvent inquiétés par un Crustacé du genre Bopyre, qui se fixe sous un côté du test, sur les branchies, et force la carapace à se relever en forme de loupe. Quelquefois ces Salicoques sont attaquées par deux de ces parasites sans qu'il leur soit possible de s'en débarrasser.

La fécondité de ces Crustacés est prodigieuse : suivant M. Roux, des femelles pondraient deux fois dans l'année des milliers d'œufs. Cette double ponte est sans doute nécessaire pour compenser la destruction qu'en font presque tousles animaux marins.

\section{4. palemon seritatús.}

Leach, Malac. Pod. Brit., pl. 43, fig. 1 à 10.-Desy. , Consid. génér. sur les Crust., pl. 40, fig. 1.-EDw., op. cit., t· 1I, p. 389. - Astacus Serratus, Penn., Brit. Zool., t. IV, pl. 16, fig. 28. - Herrst, t. II, p. 55, pl. 27, fig. 1.-Long. 4 pouc. Larg.
() lig. - Le rostre est très-prolongé en pointe, relevé à son extrémité, pourvu, sur sa tranche supérieure et près de sabase, de six, sept ou huit dentelures, et sur l'inférieure, de quatre, cinq ou six dents pareilles; les doigts sont aussi longs que la main; Ia couleur générale est le rouge-pâle, devenant plus vif sur les antennes, le bord postérieu: des segmens de l'abdomen et les lames natatoires. - Habite les côtes de France et d'Angleterre.

\section{Palemon squilla. (Pl. 12 , fig. 3.)}

Leace, Malac. Brit., tab. 43, fig. 11 à 13. - Desm., Consid. génér. sur les Crust., p .235. - GuÉR., Iconogr. du Régn. anim. de Cuv., Crust., pl. 22, fig. 1.LaTr., Hist. nat. des Crust. et des Ins., t. VI, p. 257. - EDw., op. cit., t. II, p. 390. - Cancer Squilla, LrNo, Syst. nat.-Astacus Squilla, Fabr., Ent. Syst., t. II, p. 485 . - Long. 2 pouc. $\frac{x}{2}$ - - Cette espèce diffère de la précédente par son ros. tre, qui est plus court, plus droit, échancré au bout, pourvu sur sa tranche supérieure et dans presque toute son étendue de sept ou huit dents, et sur l'inférieure de deux ou trois seulement; les doigts sont un peu plus courts que la main.--Habite les mêmes localités que l'espèce précédente.

\section{3. palemon trilianus.}

Risso, Hist. nat. de l'Europ. Mérid. t. VIII , p. 61.- Desur. , loc. cit. , p. 235. - Roux, Crust. de la Méditerr. pl. 39, fig. 1. - EDw, op. cit., t. II, p. 392.-Melicerta Triliana, Risso, Crust. des environs de Nice, p. 111, pl. 3, fig. 6. - Long. 3 pouc. - Le corps est épais, allongé, d'un blanc de chair translucide, finement pointillé de rougeâtre, traversé sur l'abdomen de petites bandes circulaires d'un rouge violet, disposées en divers sens sur le test; le rostre est large, à huit dents en dessus, cinq en dessous, tridenté au sommet; les antennes extérieures sont d'une seule teinte, sans anneaux colorés; les pattes sont fasciées de violet, de jaune et de blanc; le dernier segment de l'abdomen, garni de quatre prolubérances épineuses, est terminé par cinq pointes; les écailles caudales sont ovales, ciliées, et pointillées de rouge et de violet; la femelle est nuancée de rougeâtre, marquetée de points obscurs; elle porte des œufs jaunâtres en été.

Cette espèce se tient de préférence dans le voisinage des petits ruisseaux qui se jettent à la mer, pourvu que le fond soit rocail. 
leux; elle s'approche heaucoup des bords, et paraît se plaire au milieu des petits espaces d'eau tranquille qui entourent les rochers du bord de la côte, où elle se cache sous leur avancement. Il est facile de faire sortir ces Crustacés de leur retraite en leur présentant un poisson mort, surtout une Sardine, sur laquelle ils s'acharnent avec tant de voracité, que c'est dans ce moment qu'on peut, en avançant, les saisir sans difficulté. Ils sont très-bons à manger, et servent d'appât à la pêche. Consultez pour les autres espèces' le t. II de l'Histoire naturelle dos Crustacés, par M. Edwards.

\section{PÉnÉITES.}

Caractères. Les antennes sont insérées sur deux rangs. - Le rostre est en général petit ou nul. - Les pattes sont grèles, et portent presque toujours à leur base un appendice lamelleux plus ou moins développé; celles de la troisième paire sont souvent didactyles. - L'abdomen est extrêmement long et comprimé.

Genres : Stenopus, Sicyonia, Penous, Euphema, Ephyra, Oplophorus, Pasiphoea, Sergestes, Acetes.

\section{Stenopus, Latr., Desm., Edw. ;}

Palomon, Oliv.; Cancer, Herist.

La carapace est terminée en avant par un rostre court, épineux, mais non denté en scie. - Le corps est mou, hispide.-Les antennes mitoyennes ou supérieures sont terminées par deux filets sétacẻs presque égaux entre eux et plus longs que le corps; les extérieures étant encore plus grandes. - Les pieds des trois premières paires se terminent par une main didactyle ; ceux de la troisième et des suivantes sont très-longs; les deux avant-derniers segmens des quatre pattes postérieures sont divisés en un grand nombre de petits articles et se replient sur cux-mêmes.

C'est sur un Crustacẻ rapporté des mers Australes par Përon et Lesueur que M. Latreille a formé ce genre, qui se rapproche des Pénées par la considẻration du nombre de ses pattes pourvues de mains; cependant il s'en éloigne par la conformation de ses pieds et l'allongement excessif des filets de ses antennes supérieures. Mais un caractẻre qui le distingue tout-à-fait et qui ne permettra pas de le confondre avec le suirant, c'est la longueur extrême ct la gros.

ANA seur des pieds de la troislème paire, les quels, au reste, sont inégaux entre eux. L'espece type de ce genre est :

STENOPUS HSPIDUS.

Iarr., Rég. anim. de Cuvier, $2^{\mathrm{e}}$ édit., t. IV, p. 93. - Dess., Consid. génér. sur les Crust., p. 227. - EDw., op. cit., t. II, p. 407; ejusd., Atlas du Règ. anim. de Cuvier, Crust., pl. 50, fig. 2. - Palomon Hispidus, OLIv., Encycl., Insect., t. VIII, p. 666, Crust., pl. 319, fig. 2. - Long. 2 pouc. - La carapace est hérissée de petits piquans un peu arqués, terminée en avant par un rostre avancé, pointu, assez court, et couvert en dessus et sur les cốtés de petits piquans semblables aux autres; une impression demi-circulaire derrière le rostre sépare la région stomacale; l'abdomen et les lames natatoires de la queue sont armés de piquans ; ces dernières présentent deux arêtes sur leur face supérieure et des cils sur leurs bords, l'intermédiaire ayant un sillon profond dans son milieu; les deux paires de pattes antérieures sont menues, courtes, surtout la première; la troisieme est très-grande, un peu renflée, anguleuse, hispide, terminée par une main à doigts allongés, clont l'inférieur a sur son bord interne deux grosses dents entre lesquelles s'enchâsse une autre dent conique du doigt supérieur.

\section{SICYONIA, Edw.}

Le thorax se termine antẻrieurement par un rostre à peu près droit, qui n'atteint pas l'extrémité des antennes supérieures, mais dépasse de beaucoup les yeux, et qui se continue en arrière avec une série de trois épines situées sur la ligne médiane de la carapace; depuis l'origine de l'abdomen jusqu'a la pointe du rostre, on compte six de ces épines; et au bord inférieur du rostre, près de l'extrémité, on en voit une qui est très-petite. - Sur les cổtẻs de la carapace on remarque aussi une épine située à peu près au niveau de l'insertion du pied-mâchoire externe; mais dans le reste de son étendue, ce bouclier céphalo-thoracique est seulement inégal et pubescent. - Les épines qui garnissent supẻrieurement le thorax se continuent avec une carène élevée qui règne dans toute la longueur de l'abdomen; près du bord postérieur de chaque anneau cette carène se bifurque pour receroir celle de l'anneau suivant, si ce n'esł pas dans le sixième, oú elle se 
termine en pointe; enfin, de chaque côté de la crête longitudinale ainsi formée, on voil plusieurs sillons irréguliers qui se dirigent en bas. - Le sternum est assez large cntrc les pattes de la cinquième paire; mais entre celles de la quatrieme il devient linéaire, et présente une forte épine dirigée en arant. Les cinq premiers anneaux de l'abdomen ont aussi en dessous une armature semblable.-Les antennes supérieures sont courtes et terminées par deux filets moins longs que leur pédoncule, et dont la base ne présente pas un appendice lamelleux qui vient se recourber sous les yeux; ces derniers organes sont saillans, mais courts. - Les antennes inférieures ont une grande écaille qui en recouvre la base; mais le bord externe de cette lame et l'épine qui la termine sont fortes; le pédoncule de la tige de ces antennes est trèscourt, et le flament qui les termine est cylindrique et glabre. - Le palpe des mandibules est grand et lamelleux. - Les mâchoires ne présentent rien de remarquable. - Les pieds-mâchoires de la première paire présentent en dehors un grand palpe flabelliforme, au-dessus duquel est fixé un appendice vésiculeux qui est l'analogue du fouet des membres suivans; ceux de seconde et troisième paires ressemblent beaucoup à ceux que l'on voit chez les Pénées; seulement ils sont dépourvus de palpes, tandis que chez ces derniers ces appendices sont très - grands et d'une forme particulière. - Les pattes des trois premières paires sont grêles et didactyles; les antérieures sont moins longues que les pieds - mâchoires externes ; mais celles de la troisième paire les dépassent de beaucoup et s'avancent au delà du rostre et des filets terminaux des antennes supérieures; les pattes des deux premières paires sont terminées par un article court et pointu; celles de la cinquième paire sont plus longues que les précédentes, et leur pénultième article n'est pas annelé. - Les cinq premiers anneaux de l'abdomen supportent chacun une paire de fausses pattenatatoires terminées par une seu'e lame, qui est grande, pointue, et ciliée sur les bords. - Les appendices du sixième segment forment, avec le septième anneau, la nageoire caudale; ce dernier segment présente sur la ligne médiane un sillon longitudinal, et se termine par une pointe aiguë, de clıaque côté de laquelle est une épine qui se contipue supérieurement avec une ligne légérement saillante, de manière que la lame médiane de la queue parait creusée de trois sillons longitudinaux; ses bords sont fortement ciliés. - Les lames latérales de la nageoire caudale sont arrondies, et ne présentent rien de remarquable à leur extrémité.

\section{Sicyonia sculpta.}

Epw. , Ann. des Sc. nat., $1^{\text {re }}$ série, t. XIX, p. 339 , pl. 9 , fig. 1 à 8 ; ejusd., op. cit., t. II, p. 409.-Cancer Carinatus? OLIv., Zool. Adriat., pl. 3, fig. 2.-Long. 2 pouc. - Le rostre est de la longueur du pédoncule des antennes supérieures; il y a six grosses dents situées tant sur le bord supérieur que sur la crête dorsale de la carapace; il y a une seule dentelure en dessous, près de la pointe du rostre; le filament terminal des antennes inférieures est grêle et cylindrique; les pieds-mâchoires externes sont médiocres. - Gette espèce se troure dans la Méditerranée.

\section{SICYONIA GARINATA.}

EDw., Ann. des $S_{c . n a t}$, t. XIX, pl. 9, fig. 2 ; ejusd. , op. cit., t. II, p. $410 .-$ Long. 2 pouc. 4 lig. Larg. 6 lig. - Ceite espece se distingue de la précédente par la briéveté du rostre, qui s'avance à peine au delà des yeux et ne présente sur le bord supérieur que deux petites denls situées près de sa pointe; par le nombre des dentelures de la carène dorsale faisant suite au rostre; depuis la base des yeux on n'en compte que deux au lieu de trois, de ma. nière que le nombre total des épines situées sur la ligne médiane de la carapace, depuis la pointe du rostre jusqu'à la base de l'abdomen, est seulement de quatre, tandis que chez l'espèce précédente il est de six; par l'existence d'une petite épine aiguë au bord antérieur de la carapace, immédiate. ment derrière l'insertion des antennes, dont l'extrémité du pédoncule n'atteint pas, à beaucoup près, l'extrémité de l'écaille des antennes inférieures; par la longueur de l'article basilaire de la tige des antennes inférieures, qui atteint presque l'extrémité de l'écaille qui le reconvre; par la forme du filament terminal de ces dernières antennes, qui, au lieu d'être circulaire, ert aplati et fortement cilié sur scs deux bords; et enfin par le développemeni des pieds-mâchoires externes, qui s'avancent presque aussi loin que les pattes de la troisième paire. - Habite Rio-Janeiro. 
Pejoed S, Fabr., Latr., Desm., Edw.; Squilla, Rond.; Astacus, Sera; Cancer, Fonskael, Linn. ; Palomon, OLrv.

La carapace est cylindrique, terminée en avant par un rostre pointu, comprimé, dentelé et cilié. - Les yeux sont gros, presque globuleux, portés sur un pédoncule court. - Les antennes supérieures ou intermédiaires sont très-courtes, bifides, portées sur un pédoncule fort grand, profondément creusé en dessus pour recevoir l'œil; les antennes exlérieures ou inférieures sont sétacées, très-allongées, pourvues à leur base d'une grande écaille de forme allongée. - Les pieds-mâchoires extérieurs ont la forme de pieds pointus et velus, composés de cinq articles visibles, dont le premier, qui est très-petit, s'avance jusque sous les écailles des antennes extérieures. - Les palpes mandibulaires sont saillans, velus et terminés par un article très-grand et foliacé. - Les pieds sont peu allongés, grêles, pourvus d'un pelit appendice à leur base; les six premiers un peu arqués en dedans, didactyles et croissant successivement depuis la première jusqu'à la troisième paire; les pieds de la quatrième paire sont plus courts que ceux de la troisième; ils finissent par un ongle simple; les pieds de la cinquième paire sont plus courts que ceux de la quatrième, et conformés de même. - Le second article de l'abdomen est peu dilalé sur les côtés; les derniers portant dans leur milieu une carène assez prononcée, et le sixième étant terminé en pointe aiguë. - Les écailles natatoires de la queue sont allongées et arrondies au bout.

Les Pénées sont des Crustacés plutôt propres aux contrées tempérées et chaudes qu'aux mers septentrionales. Une espèce très-commune de la Méditerranée, et qui est connue sous le nom de Caramote dans le midi de la France et de l'Italie, est l'objet d'un commerce considérable; non-seulement on la consomme en grande quantité sur les côtes, mais encore on la sale pour la conserver, et ainsi préparée on en fait des envois en Grèce, dans l'Asie Mineure et dans la Perse. Les Grecs et les Arméniens en font une assez grande consommation.

Ce genre, assez nombreux en espèces, a été ainsi divisé par M. Edwards :

Espéce ayant les anterines tcrminées par des filets-très - courts. - Un sillon médian s'étendant de la base du rostre au bord postérieur de la carapace .

\section{1. peyogus caramotr.}

Desm., Considér. génér. sur les Crust., p. 225. - Risso, Hist. Nat. de l'Europe Mérid., t. V, p. 57.-EDw., op. cit., t. II, p. 415 ; ejusd., Atlas du Règ. anim. de C'ıv., Crust., pl. 30, fig. 1. - Palamon Sulcalus, Ouzv., Encycl., t. VIII, p. 661. -Pencus Sulcatus, Làn., Hist, des Anim. sans vert., t. V, p. 206. - Alpheus Caramote, Risso, Crust. de Nice, p. 90. Long. totale 9 pouc. - Son corps est allongé, luisant, lisse, très-mince, d'un blanc de chair mêlé de rose; sa carapace est oblongue, arrondie, sillonnée longitudinalement, et terminée de chaque côté par des aiguillons; son rostre est assez long, comprimé, a onze dents en dessus ct une seule pointe en dessous; ses yeux sont très-gros, placés sur des pẻdicules poilus; les antennes supérieures sont courtes, poilues et bifides; les inférieures, très-longues, sont situées à cỏté d'une pièce latérale cordiforme; les trois derniers segmens de l'abdomen sont carénés, et terminés par une plaque solide, sillonnée au milieu, à trois dentelures aiguës de chaque côté, à laquelle sont adhérentes quatre longues écailles rougeâtres bordées de bleu. La femelle pond des œufs rougeâtres en été. - Habite les grandes profondeurs de la Médilerranée.

Espèce ne présentant point de sillon médian entre la base du rostre et le bord postéricur de la carapace :

\section{PENOEUS MONOCEROS.}

Fabr., Suppl. Ent. Syst., p. 409. LaTr., Hist. nat. des Crust. et des Insect., t. VI, p. 249. - EDw., op. cit., t. II, p. 415. - Long. 3 pouc. - Le rostre es? droit, un peu élevé, cilié en dessons, et armé en dessus de neuf à dix petites dents, dont la dernière se trouve sur le milieu de la région stomacale; la crête rostrale est à peine marqueje; les yeux sont courts et gros; les filets terminaux des anlennes supérieures sont extrêmement courts (moins longs que les deux derniers articles dı pé. doncule); les pattes sont courtes, arcc les bords de la lame médiane de la nageoire caudale non épincux. - Sc trouse dans l'Inde.

Fspèce ayant les anteunes supćrieures :erminées par des filets plus longs que la carapace : 


\section{PENOEUS MEMRRATACEUS.}

Fавн., Ent. Suppl., p. 409. - EDw., op. cit., t. II, p. 417. - Long. 3 pouc.La carapace est légérement carénée dans toute sa longueur; le rostre est un peu relevé, lamelleux, très-court, ne dépassant pas les yeux, armé en dessus de cing ou six dents assez grosses, et cilié en dessous; les yeux sont gros et courts; les filets terminaux des antennes supérieures sont beaucoup plus longs que la carapace; l'un est grêle et cylindrique; l'autre est gros, aplati et cilié en dedans; les antennes extèrieures sont médiocres; les pattes sont courtes; celles de la troisième paire ne dépassant qu'à peine le pédoncule des antennes supérieures; la lame médiane de la nageoire caudale est allongée et armée d'une paire d'épines latérales près de sa pointe. - Se trouve dans la Méditerranée.

\section{EUPHEMA, EDw.}

La carapace se termine antérieurement par un rostre très-long, et l'abdomen est soudé vers le milieu; son second anneau se prolongeant postérieurement en une longue épine qui se dirige horizontalement en arrière, comme le fait le rostre en avant. - Les yeux sont courts et assez gros. - La disposition des antennes ne présente rien de remarquable; celles de la première paire ont, comme de coutume, leur premier article excavé en dessus pour loger les yeux, et elles se terminent par deux filets multiarticulés. - Les antennes de la seconde paire s'insèrent au-dessous des précédentes. - Les mandibules sont courtes, grosses, peu dentelées et pourvues d'une tige palpiforme, courte, large et biarticulée. - L'appendice valvulaire des mâchoires de la seconde paire est ovalaire, et ne se prolonge que très-peu en arrière.Les pieds-mẩchoires des deux dernières paires sont médiocres, pédiformes, et pour. vus d'un palpe lamelleux presque aussi long que la tige interne; ils portent aussi à leur base un appendice qui représente le front, mais qui est membraneux et vésiculeux.-Les pattes thoraciques des trois premières paires sont terminées par une petite main imparfaitement didactyle ; et celles des deux dernières paires sont monodactyles et fortement ciliées, de manière à être plutôt natatoires qu'ambulatoires; tou. tes portent à leur base un petit fouet trèscourt, aussi bien qu'un palpe lamelleux. Les appendices des cinq premiers anneaux de l'abdomen sont composés d'un pédoncule cylindrique et de deux articles terminaux, comme chez les Salicoques ordinaires; seulement les lames ne sont pas ciliées. - Les branchies sont lamelleuses, et fixées sur plusieurs rangs de chaque côte du thorax.

\section{L'espèce type de ce genre est :}

\section{EUPHEMA ARMATA.}

Evw., op. cit., t. II , p. 421. - Long. 8 lig.- Le rostre est de la longueur de la carapace, horizontal, armé d'une dent à sa base, et légrérement denticulé le long de son bord supérieur; le bord antérieur de la carapace présente une petite épine de chaque côté; les antennes internes sont moins longues que le rostre; les pattes de la première paire sont les plus courtes; l'épine dorsale du second anneau abdominal est longue et acérée, et dépasse l'anneau suivant; le milieu du bord postérieur de chacun des quatre segmens suivans en présente une très-petite en dessus; la lame médiane de la nageoire caudale est étroite, pointue, et terminée par deux petites épines; les lames latérales sont étroites et ciliées.-Cette espèce a été trouvée dans l'O. céan Atlantique austral.

\section{EPHYRA, Roux, EDw.}

Ce genre, qui a été établi par M. Roux et adopté par M. EDwards, est remarquable par son corps, qui est comprimé latéralement. - La carapace est lisse. - L'abdomen est caréné et le rostre denté. - Les pieds-mâchoires sont très-allongés, et les pattes thoraciques portent à leur base un appendice palpiforme. - Les p?ttes des deux premières paires sont petites, plus courtes que les suivantes et didactyles.

Ce genre, jusqu'à présent, paroît propre à la Méditerranée.

\section{1. epitra pelagica.}

Roux, Mém. sur les Salicoques, p. 24. - Evw., op. cit. t. II, p. 422.-Pandalus Pelagicus, Risso, Hist. nat. de l'Europe Mérid., t. VI, p. 79 , pl. 2, fig. 5.-Le corps est arqué, comprimé, d'un rouge-corail vif; sa carapace est allongée, ornée sur les côtés d'une suture courbe, avec quatre aiguillons et un rostre cannelé, quoique denté en dessus et bidenté et cilié en dessous; l'œil est grand, bleu-noirâtre ; les antennes inférieures sont longues, placées sur un pédicule bi-articulé; les pièces latérales 
sont striées ct présentent un aiguillon; les pieds - mâchoires sont triangulaires ; les deux premières paires de pattes sont courtes, minces; les autres sont un peu plus longues; l'abdomen présente six segmens comprimés, et est terminé par des écailles caudales ovales, oblongues et ciliées; la plaque du milieu est courte, solide, bombée et aiguë. - Cette espèce habite les grandes profondeurs de la Méditerranée.

\section{EPHYRA PUNGTata.}

Roux, Mém. sur les Salicoques, p. 24. - Edw., op. cit., t. II, p. 423.-Pandalus Punctulatus, Risso, Hist. nat. de l'Europe Mérid., t. V, p. 80 , pl. 2, fig. 7.Long. 4 pouc. - Le rostre, armè de six dents en dessus et d'une en dessus, est traversé à sa base par un sillon profond; les antennes supérieures sont très-courtes; les pattes de la seconde paire sont plus courtes que celles de la première; l'abdomen est très-long; la lame médiane de la nageoire caudale est munie de sept pointes à son extrémité ; la couleur est d'un blanc livide, avec des points rouge-bruns disposés par lignes transversales. - Irabite la mème localité que l'espèce précédente.

\section{OPLOPHORUS, Enw.}

Cette nouvelle coupe générique, qui a été créée par M. Edwards, a beaucoup d'analogie avec celles des Ephyres et des $\mathrm{Pa}$ siphées, mais elle s'en distingue par des caractères assez tranchés. - Le corps n'est pas comprimé. - La carapace se termine par un rostre styliforme, très-long et dentelé sur les deux bords. - Le pédoncule des antennes supérieures est très-court, et l'un des filets terminaux est très-gros et pyriforme à sa base, mais devient bientôt grêle et cylindrique comme l'autre. - L'appendice lamelleux des antennes externes diffère beaucoup de celui de loutes les autres Salicoques; il est grand, se rétrécit graduellement depuis sa base, se termine par une pointe très-aiguë, et présente une série d'épines sur son bord externe.-Les piedsmâchoires externes sont courts, et portent en dehors un palpe lamelleux extrêmement large. - Les pattes des deux premières paires sont très-courtes, terminées par une main très-petile, et pourvues a leur base d'un appendice lamelleux très-grand et cilié; les pattes des trois paires suivantes sont médiocres et monodacty les; l'appendice fixé à leur base est petit.-Le tarse de la troisieme et de la quatrième paire est styliforme et assez grand, tandis que celui des pattes postérieures est arrondi et extrêmement étroit; il y a aussi à la base de chaque patte un petit appendice flabelliforme qui remonte entre les branchies, et le nombre de ces derniers organes est de neuf.L'abdomen, par sa conformation, ne présente rien de remarquable, et même diffère très-peu de celui du genre Hippolyte.

La seule espèce connue est :

\section{OPLOPHORUS TYPUS.}

EDw. , op. cit., t. II , p. 424, pl. 25 , fig. 6. - Long. 20 lig. - Le rostre, de la longueur de l'appendice lamelleux des antennes externes, est grêle, relevé et garni de sept ou huit petites dents sur chacun de ses bords; il y a une crête médiane qui s'ètend de la base du rostre au bord postéricur de Ia carapace, et deux petites crêtes latérales sur la région stomacale; enfin, de chaque côté sont deux épines sur le bord antérieur de la carapace et une autre à son angle postérieur ; il y a une dent acérée, très-forte, dirigée en arrière, et nais. sant de la face supérieure des trois anneaux abdominaux qui précèdent le pénultième ; la lame médiane de la nageoire caudale est pointue et beaucoup plus longue que les lames latérales. - Cette espèce a été trouvée à la Nouvelle-Guinéc.

\section{PASIPII EA, Savig., Latr., Risso, Rovx, EDw. ; \\ Alpheeus, Risso.}

Le rostre est très-court, rudimentaire, avec la carapace beaucoup plus étroite en avant qu'en arrière. - Les yeux sont médiocres et dirigés en avant. - Le pédoncule des antennes internes est grêle, el terminé par deux filets articulés dont l'un est assez long. - Les antennes externes sont in. sérées au-dessus des précédentes. - Les mandibules sont fortement dentées et dépourvues de tige palpiforme. - Les piedsmàchoires externes sont très-longs, grêles, pédiformes, avec leur base pourvue d'un palpe lamelleux. - Les paties thoraciques portent aussi, suspendu au côté interne de leur article basilaire, un appendice lamelleux assez long et de même forme, mais membraneux et peu ou point cilié ; les pattes des deux premières paires sont assez grosses, à peu près de même longueur, armées d'épines sur leur troisième article, et terminées par une main didactyle dont les pin- 
ces sont grêles et garnies d'une série d'épines acérées sur le bord préhensile; les pattes des trois paires suivantes sont très-grêles, monodactyles, et plus ou moins natatoires; généralement celles de l'avant-dernière sont de beaucoup les plus courtes. L'abdomen est très-allongé et assez comprimé.- Les fausses pattes du premier anneau se terminent par une seule lame; mais celles des quatre paires suivantes portent chacune deux lames natatoires, courtes et peu ciliées.- Le sixième anneau abdominal est très-long, et le septième court et triangulaire; enfin les lames externes de la nageoire caudale sont grandes et rétrécies vers le bout.

\section{PASIPIREA SIVADO.}

Risso, Crust. de Nice, p. 94, pl. 3, fig. 4 . - Latr., Règ. anim. de Cuv., t. IV, p. 99. - Dess. , Consid. génér. sur les Crust., p. 240. - GuÉr., I I conogr. du Règ. anim. de Cuv., Crust., pl. 22, fig. 2. - EDw., op. cit., t. II , p. 426 . - Long. 2 pouc. $\frac{1}{2}$. Larg. 4 lig. $\frac{1}{2} .-$ Le corps est très-comprimé, arqué, d'un beau blanc nacré, transparent et bordé de rouge ; la carapace est lisse, terminée sur le dcvant par un rostre aigu et courbé; les antennes inférieures sont situées à côté des pièces latérales, qui sont oblongues, ciliées et terminées par une épine; les deux premières paires de pattes sont épineuses et rougeâtres; les trois autres très-grêles et crochues; le dernier segment de l'abdomen est très-mince; les ecailles natatoires de la queue sont égales, pointillées de rouge, celle du milieu triangulaire et pointue. - La femelle dépose des cufs nacrés en juin et en juillet. Cette espèce, suivant M. Risso, est très-commune et sert de proie à une infinité de poissons. Elle habite la plage de Nice.

\section{SLRGESTES, Edw., Latr., Rovx.}

Le corps est grêle, allongé et un peu aplati. - Le bouclier céphalo-thoracique s'étend jusqu'à l'abriomen, et présente antérieurement une petite èpine qui tient lieu de rostre. - L'abdomen n'offre rien de re. marquable, si ce n'est que les parties latérales de l'arceau supérieur de ses cinq premiers anneaux ne se prolongent pas inférieurement de manière à cacher l'insertion des fausses pattes. - Les yeux sont tréssaillans, et leur pédoncule, dont la longueur varie suivant les sexes, sinsère sur un tabercule médian qui n'est pas complétement recouvert par la carapace. - Les antennes sont placées sur deux rangs; les supérieures ou internes sont extrêmement longues; leur pédoncule est composé de trois articles bien distincts, dont le dernier est au moins aussi long que les prècédens; et outre le filet multiarticulé, grêle et sétacé, qui le termine, et qui est beaucoup plus long que le corps, on distingue à son extrémité deux petits appendices filiformes, rudimentaires; les antennes inférieures sont également trèslongues, et leur base est recouverte par une lame cornée, ciliée sur son côté interne.Les mandibules sont grosses; leur bord interne est large et pas sensiblement denté; le palpe qu'elles supportent est très-long et grêle. - Les quatre mâchoires proprement dites et les pieds-mâchoires de la première paire ne présentent rien de remarquable; celles de la seconde paire sont presque pédiformes, et ne portent ni palpe ni appendice flabelliforme; elles sont grêles, trèslongues, reployées sur elles-mêmes, et appliquées sur les autres parties de l'appareil buccal.-Les appendices qui correspondent aux pieds-mâchoires externes n'offrent rien qui puisse les faire distinguer des pieds ambulatoires; ils sont minces, très-longs ciliés, et terminés par un articlestyliformı - Les autres pattes ont la même struı ture; toutes sont grêles, filiformes, mono dactyles et garnies de beaucoup de poils. elles s'insèrent près de la ligne médiane du sternum, et ne présentent a leur base ni appendice flabelliforme ni aucun vestige de palpe; celles de la seconde paire sont beaucoup moins longues que les précédentes, tandis que les deux paires qui suivent ont à peu près la même longueur; celles de l'avant-dernière paire sont très-courtes, et les dernières sont presque rudimentaires. Les cinq premiers anneaux de l'abdomen supporient chacun une paire de fausses pattes assez grandes, dont l'article basilaire est renflé inférieurement et se termine par deux lames natatoires étroites, allongées, pointues, ciliées sur les bords et d'inégale grandeur, si ce n'est la première paire, où l'on ne voit qu'un de ces appendices foliacés. - Chez les mâles, l'article basilaire de ces fausses pattes antérieures présente aussi une disposition particulière : à son côté interne il existe un prolongement corné d'une forme bizarre, qui va s'articuler sur la ligne médiane avec celui du côté opposé, et qui paraît appartenir à l'appareil de la génération.- Le septième segment del'abdomen, petit et pointu, forme la pièce mé- 
diane de la nageoire caudale, dont les pièces latérales sont étroites, à peu près ovalaires, terminées en pointe, et d'autant plus longues qu'elles sont plus externes. - L'espece type de ce nouveau genre est:

\section{SERGESTES ATLANTICUS.}

Edw., Ann. des Scienc. nat., t. XIX, pl. 10,fig. 1; ejusd., op. cit., t. II, p. 428. Long. 1 pouc. - Le troisieme article du pédoncule des antennes supérieures est au moins aussi long que leprécédent ; lespattes antẻrieures sont beaucoup moins longues que les pieds-mâchoires externes, qui sont à peu près de même longueur que les pattes des deuxième et troisieme paires. Cette espèce a été trouvée dans l'Océan Atlantique, à une grande distance des côtes.

\section{ACETES, Edw., Latr., Roux.}

Ce genre a beaucoup d'analogie avec le précédent: - La forme générale est la même. - La carapace est lisse et présente à son extrémité antérieure une série longitudinale de très-petites dents; mais il n'y a pas de rostre proprement dit. - Les yeux sont sphériques et portés sur des pédoncules assez longs. - Les antennes supérieures, placées au-dessus des externes, ont un long pédoncule; maisson dernier article est plus court que le premier, et ne porte que deux soies, dont l'une ayantà peu près la longueur đu corps; les antennes inférieures ou externes présentent un filet terminal non moins allongé, et leur base est recouverte par une grande lame cornée. - Les mandibules, les mâchoires proprement dites et les deux paires de pieds-mâchoires, ne diffèrent pas notablement de celles des Sergestes. Il en est de même des pattes ambulatoires, qui sont filiformes et terminées par un article pointu; celles des deux paires postérieures manquent complétement; cependant en arrière des dernières qui existent, on distingue encore un segment thoracique portant des branchies comme les précédens, mais sans appendices locomoteurs. - L'abdomen ne présente rien de remarquable.- Les fausses pattes natatoires se terminent toutes par deux lames étroites et pointues qui sont d'abord à peu près de même longueur, mas dont l'interne devient plus courte sur les derniers segmens. - Le pédoncule de ces appendices présente des modifications tout opposées, car sur les premiers anneaux de l'abdomen il est long et étroit, tandis que sur les derniers il devient gros et court.
- La nageoire caudale n'offre rien de remarquable. - La seule espèce connue est:

\section{ACETES INDICUS.}

Edw., Ann. des Scienc. nat., t. XIX, pl. 11, fig. 1 ; ejusd., op. cit., t. II, p. 430 . - Long. 1 pouc. - Le corps est déprimé latéralement; la crête rostrale est armée de trois ou quatre dentelures; les pattes postérieures sont plus longues que celies des deux paires précédentes, mais un peu plus courtes que les pieds-mâchoires externes; l'antenne inférieure est environ quatre fois aussi longue que le corps. - Se trouve à l'embouchure du Gange.

DIXIÈME TRIBU.

\section{O L É O P ODES, LaTr.}

Caractères. Cette tribu est distincte de toutes les autres, en ce que le Crustacé qui la compose a son test qui sert comme d'étui ou de gaine aux pattes; il est presque ovoïde, renflé, replié intérieurement sur les côtés, de manière à recouvrir une grande partie du dessous du corps, et à ne laisser entre ses bords rapprochés qu'un vide étroit ou une fente longitudinale.-Les antennes latérales sont accompagnées, ainsi que dans les Salicoques, d'une écaille. - Les yeux sont gros et écartés. - Les pattes sont en forme de lanières, allant en pointe, et ont à leur base un appendice latéral.

Genre : Cryptopus.

\section{CRYPTOPUS, LATR.}

Le test est subovoïde, renflé, replié inférieurement sur les côtés, enveloppant le corps ainsi que les antennes et les pattes, et ne laissant à découvert en dessous qu'une fente longitudinale. - Les yeux sont écartés. - Les pieds sont en forme de lanières, avec un appendice latéral. - L'espèce type de ce genre est le

\section{CRYPTOPUS DEFRANGI.}

Latr., Règ. anim. de Cuv., t. IV, pag. 100. - Cette espèce nous étant inconnue, nous ne pouvons en donner la description. - Elle habite la Méditerranée ${ }^{\text {I. }}$

1 Nous ne décrirons pas ici les genres Zoé et Mulcion, ces genres étant regardés, surtout le premier, par M. Edwards, comme des Crustacés imparfaits, c'est-à-dire n'ayant pas encore subi leurs dernières métamorphoses. 


\section{DEUXIÈME ORDRE}

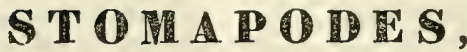

LATREILLE.

Les Crustacés que cet ordre renferme ont leurs branchies à découvert et adhérentes aux cinq paires d'appendices situés sous l'abdomen. La queue que cette partie nous a offerte dans les Décapodes, ici, comme dans la plupart des Macroures, sert à la natation ou sont des pieds-nageoires. - Leur test est divisé en deux parties, dont l'antérieure porte les yeux et les antennes intermédiaires, ou bien compose la tête sans porter les pieds-mâchoires. Ces organes, ainsi que les quatre pieds antérieurs, sont souvent rapprochés de la bouche, sur deux lignes convergentes inférieurement, et de là la dénomination de Stomapodes donnée à cet ordre. - Le cœur, à en juger par les Squilles, un des genres lesplus remarquables de cet ordre, et le seul que l'on ait encore étudié, est allongé et semblable à un gros vaisseau. Il s'étend le long du dos, repose sur le foie et le canal intestinal, et se termine postérieurement et près de la partie anale en pointe. - Ses parois sont minces, transparentes et presque membraneuses. - Son extrémité antérieure, immédiatement placée derrière l'estomac, donne naissance à trois artères principales, dont la médiane (l'ophthalmique), jetant des deux côtés plusieurs rameaux, se porte plus spécialement aux yeux et aux antennes mitoyennes, et dont les deux latérales (les antennaires) passent sur les côtés de l'estomac et vont se perdre dans les muscles de la bouche et des antennes extérieures, - La face supérieure du cœur ne produit aucune artère; mais on en voit sortir de ses deux côtés un grand nombre, et dont chaque paire, à ce qu'il nous a paru, correspond à chaque segment du corps, à commencer aux pieds-mâchoires, soit que ces segmens soient extérieurs, soit qu'ils soient cachés par le test, et même très-petits, comme le sont les antérieurs. Au niveau des cinq premiers anneaux de l'abdomen, ou de ceux portant les appendices natatoires et les branchies, cette face supérieure du cœur reçoit, près de la ligne mé- diane, cinq paires de vaisseaux (une paire par chaque segment) venant de ces derniers organes, et qui, suivant MM. Audouin et Milne Edwards, sont les analogues des canaux branchio-cardiaques des Décapodes. Un canal central, situé au-dessous du foie et de l'intestin, reçoit le sang veineux qui aflue de toutes les parties du corps. Au niveau de chaque segment portant les piedsmâchoires et les branchies, il jette de chaque côté un vaisseau latéral se soudant à la branchie située à la base du pied-nageoire correspondant. - Les parois de ces conduits ont paru aux mêmes observateurs, lisses et continues, mais formées plutôt par une couche de tissu lamellaire celluleux accolé aux unuscles voisins, que par une membrane propre; il leur a semble que ces conduils communiquaient entre eux vers le bord latéral des anneaux; mais ils n'osent l'assurer. - Les vaisseaux afférents ou internes des branchies, qui, dans les Squilles, forment de houppes ou panaches, se continuent vers les canaux branchiocardiaques, ne sont plus logẻs dans les cellules, passent entre des muscles, contournent obliquement la partie latérale de l'abdomen, gagnent le bord antérieurde l'anneau précédent, et vont se terminer à la face supérieure du cœur, près de la ligne médiane, en chevauchant légérement l'un sur l'autre. - Le cordon médullaire n'offre, outre le cerveau, que dix ganglions, dont l'antérieur fournit les nerfs des parties de la bouche, les trois suivans ceux des six pieds-natatoires, et lessix derniers ceux de la queue. Ainsi les quatre derniers pieds-nâchoires, quoique représentant les quatre pieds antérieur's des Décapodes, font néanmoins partie des organes de la mastication. L'estomac des mêmes Crustacés (Squilles) est petit, et n'offre que quelques très-petites dents vers le pylore. Il est suivi d'un intestin grêle et droit, qui règne dans toute la longueur de l'abdomen, accompagné à droite et à gauche de lobes glanduleux pa. raissant tenir lieu de foie. - Un appendice 
en forme de rameau, adhérent à la base interne de la dernière paire de pieds, parait caractériser les individus mâles. Les segmens des Stomapodes sont minces et presque membraneux, ou diaphanes dans plusieurs. - Le test, ou carapace, est tantôt formé de deux boucliers, dont l'antérieur répond à la tête et l'autre au thorax; tantôt d'une seule pièce, mais libre parderrière, laissant ordinairement à découvert les segmens thoraciques portant les trois dernières paires de pieds, et ayant en devant une articulation servant de base aux yeux et aux antennes intermédiaires; ces derniers organes sont tonjours étendus et terminés par deux ou trois filets. - Les yeux sont toujours rapprochés. - La composition de la bouche est essentiellement comme celle des Décapodes; mais les palpes des mandibules, au lieu d'être couchès sur elles, sont toujours relevés. - Les piedsmâchoires sont dépourvus d'appendices en forme de fouet ; ils ont la forme de serres ou de petits pieds; et dans plusieurs au moins (les Squilles), leur base extérieure, ainsi que celle des deux pieds antérieurs proprement dits, offre un corps vésiculeux ; ceux de la seconde paire; dans les mêmes Stomapodes, sont beaucoup plus grands que les autres et que les pieds même : aussi les a-t-on considérés comme de véritables pieds, et en a-t-on compté quatorze. Les quatre pattes antérieures ont aussi la forme de serres, mais sont terminées, ainsi que les pieds-mâchoires, en griffe ou par un crochet qui se replie, du côté de la tête, sur la tranche inférieure et antérieure de l'article précédent ou de la main; mais dans quelques autres, tels que les Phyllosomes, tous ces organes sont filiformes et sans pinces. - Les sept derniers segmens du corps renfermant une bonne partie du cœur, et servant d'attache aux organes respiratoires, ne peuvent plus, sousce rapport, être assimilés à cette portion du corps qu'on nomme queue dans les Décapodes; c'est un abdomen proprement dit. Son avantdernier segment a de chaque côté une nageoire composée de même que celle de la queue des Macroures, mais souvent armée, ainsi que le dernier segment ou la pince intermédliaire, d'épines ou de dents. Tous les Stomapodes sont marins, habitent de préférence les contrées situées entre les Tropiques, et ne remontent pas au delà des zones tempérées.

Cet ordre a été divisé en trois familles : les Caridioïdes, les Unicuirassés, et les Bicuirassés.

\section{A R I D I O I D E S,}

LATREILLE.

Caractères. Thorax épais et comprimé latéralement. - Garapace reployée en dessous contre la base des pattes, et recoucouvrant la presque totalité du thorax. Article basilaire des pattes très-court. Abdomen très-développé. - Cette famille a été partagée en deux groupes : les $M I y$ sites et les Leuciférites.

\section{MYSITES.}

Pattes thoraciques au nombre de six à huit paires, pourvues d'un palpe très-développé qui les fait paraître doubles. Bouche située près de la base des antennes.

Genres: Mysis, Cynthia, Thysanopoda.

\author{
MYSiS, Latr., Lam., Leach, Desm., \\ Tномгs., EDw.
}

Le corps, chez ces Crustacés, est étroit et allongè. - Leur carapace recouvre l'extrémité antérieure du tronc ainsi que la plus grande partie du thorax, et se reploie en bas de chaque côté, de manière à s'appliquer contre la base des pattes; elle est libre latéralement, et n'adhère pas aux derniers anneaux du thorax; antérieurement elle se rétrécit beaucoup et se termine par un petit rostre aplati, très-court; son bord postérieur est profondẻment échancré. - Les yeux sont gros, courts, et ont leur base cachée sous le bord antérieur de la carapace. - Les antennes internes 
s'insèrent au-dessus des yeux, près de la ligne médiane; leur pédoncule a la même forme que chez les Salicoques, et porte à son extrémité deux filets multiarticulés assez longs. - Les antennes de la seconde paire s'insèrent au-dessous des précédentes, et se dirigent également en avant; le premier article de leur pédoncule donne naissance à un appendice lamelleux très-allongé et cilié sur le bord interne, qui recouvre la base de ces organes comme chez les Salicoques; les deux articles suivans du pédoncule sont grêles et cylindriques, et le filet terminal est filiforme, multiarticulé, et plus long que les antennes supérieures. La bouche est très-rapprochèe de la base des antennes, et présente, comme d'ordinaire, une lèvre supérieure transversale, suivie d'une paire de mandibules, d'une lèvre inféricure, de deux paires de mâchoires et d'un certain nombre de piedsmâchoires. - Les mandibules sont dentelées sur le bord interne, et portent une tige palpiforme très-développée qui se porte en avant et assez loin. - Les mâchoires de la première paire se composent chacune de deux petites lames ou lobes aplatis, ciliés sur le bord interne; les mâchoires de la seconde paire sont plus grandes, lamelleuses, divisées du côté externe en quatre lobes par des rainures plus ou moins profondes; le dernier de ces lobes est formé par l'article terminal, et le premier appartient aussi à un article basilaire distinct; mais les deux lobes moyens sont confondus entre cux à leur base, et paraissent appartenir à un seul article dont le bord externe est dilaté, arrondi et cilié; le bord interne de ces organes est également garni de poils. - Les pieds - mâchoires sont au nombre de deux paires, et ils ne différent que très-peu des pattes proprement dites; celles de la première paire sont courtes, assez longues à leur base, et composées de trois branches; l'interne est pédiforme, divisée en cinq articles, garnie de poils, et reployée en dedans au-devant de la bouche; la branche moyenne ou palpe est plus allongée, et présente un article basilaire très - grand suivi d'une espèce de rainure ciliée de chaque côté, et composée d'un très-grand nombre de pelits articles; la branche externe ou appendice flabelliforme est représentée par une lame semi-membraneuse, qui est dirigée en haut ct logée entre la carapace et les flancs. Les pieds-mâchoires de la seconde paire ont la même forme; mais leur branche in- terne est plus allongée, et ils manquent d'appendice flabelliforme; de meme qu'aux précédentes, le dernier article de leur branche interne est lamelleux, large, court et arrondi au bout. - Les six paires de pattes thoraciques qui font suite à l'appareil buo cal, et qui se composent de membres correspondans aux pieds - mâchoires externes et aux cinq paires de pattes ambulatoires chez les Décapodes, sont toutes grêles et divisées en deux branches; leur longueur augmente progressivement d'avant en arrière, et elles sont toutes conformées pour la nage seulement; la branche interne présente à peu près ỉa même forme, mais se termine par un tarse onguiforme à peine visible, qui précède un article styliforme qui semble multiarticulé, et qui est cilié sur les deux bords; la branche externe ou le palpe est presque aussi longue que la branche interne, et a la même forme que celle des pieds-mâchoires. Les pattes des quatre premières paires ne portent pas de branche externe ou appendice flabelliforme, tandis que celles des deux dernières en sont pourvues. Chez le mâle ces appendices sont rudimentaires; mais chez les femelles ils acquièrent un développement extrême, et constituent de grandes lames demi-cornees, reployées en dedans sous le sternum de manière à former une espèce de poche destinée à loger les œuf́s et les jeunes pendant les premiers temps de la vie. - Les deux derniers anneaux du thorax sont entiers, plus ou moins complétement à découvert, et semblables à ceux de l'abdomen. - Cette dernière partie est allongée, presque cylindrique, et graduellement rétrécie d'avant en arrière; la portion dorsale de ses derniers anneaux ne se prolonge pas latéralement de manière à encaisser la base des fausses pattes, comme chez la plus grande partie des Salicoques : elle se termine par une grande nageoire caudale composée de cinq lames dispersées en éventail. - Les cinq premières paires de fausses pattes sont rudimentaires, et ne se composent chacune que d'une petite lame ciliée chez la femelle; mais chez le mâle on y distingue un pédoncule et une lame terminale; et celles de la première et de la quatrieme paire acquièrent quelquefois un développement considérable. - Il n'existe aucun vestige de branchies soit à la voûte des flancs, soit à la base des pattes, soit à la face inférieure de l'abdomen; et le seul appendice qui paraisse être modifié dans sa structure, de manière à devenir plus propre 
que le reste du corps à remplir les fonctions d'un organe de respiration, est le fouet des pieds-mâchoires de la première paire, dont la disposition est du reste la même que celle qu'on remarque chez un grand nombre de Grustacés dépourvus de branchies.

M. Thompson, qui a observé la circulatıon dans les Mysis, dit que le cœur de ces Crustacés est allongé et occupe la partie antérieure du thorax; il donne naissance antérieurement à un vaisseau grêle qui se porte au-dessus de l'estomac, et se continue en arrière avec une grosse artère abdominale ; de chaque cồté il reçoit un vaisseau qui parait être un tronc branchiocardiaque. Les pulsations du cœur sont si rapides, qu'elles ressemblent à des vibrations; et le sang est si transparent et si peu coloré, qu'on n'en distingue le mouvement qu'à raison des globules qui y flottent. Le même auteur pense que le vaisseau abdominal présente de chaque côté, vers son extrémité postérieure, une ouverture garnie de valvules, par laquelle le sang pénètre dains deux conduits veineux situés de chaque côté de l'intestin, et que c'est par ces derniers vaisseaux que ce liquide vient vers un grand sinus situé sous le caur. Suivant toujours le même naturaliste, les œufs éclosent dans une espèce de poche située sous le thorax, et les jeunes Mysis y demeurent pendant les premiers temps de la vie; on les y trouve serrés les uns contre les autres, ayant la tête dirigée vers le sternum de leur mére, et le corps recourbé en avant. Leur forme s'éloigne beaucoup de celle des individus adultes. Les plus jeunes ont la tête très-grosse et le corps pyriforme; on leur voit de chaque côté deux petits membres styliformes. Bientôt l'extrémité postérieure s'allonge et se bifurque; le nombre des membres augmente; les yeux pédonculés et les antennes se montrent, et les divisions entre la tête, le thorax et l'abdomen, deviennent distinctes. Ce n'est qu'après la sortie de la poche ovifère qu'ils acquièrent tout-à-fait la forme qu'ils doivent conserver, et que la branche interne de leurs palpes présente une tige terminale multiarticulée. Ces Crustacés sont très - nombreux, car on les trouve souvent réunis en troupes considérables, et paraissent surtout abonder vers le Nord; et ce seraient ces petits Crustacés, suivant Othon Fabricius, qui serviraient d'aliment principal aux Baleines. M. Edwards, auquel nous avons emprunté tout ce qui vient d'être dit plus haut, divise ainsi ce genre :

Espéce dont la lame médiane de la nageoire caudale est bifurquée :

1. Mysis spinosulus. (Pl. 5 , fig. 17.) Leach, Trans. of the Linn. Societ., t. XI, p. 350 ; Praunus Flexuosus, ejusd,, Edinb. Encycl.-Mysis Spinosulus, Dess., Consid. génér. sur les Crust., p. 242. EDw., op. cit., t. II, p. 457. - Mysis Leachii, Tномps., Zoologic. Research., t. I, part. 1, p. 27. - Long. 10 lig. - Le rostre; déprimé et triangulaire, n'a environ que le tiers de la longueur des pédoncules oculaires; la carapace s'étend sur l'avantdernier anneau thoracique; le pédoncule des antennes internes est gros et court; l'appendice lamelleux des antennes externes est étroit, de même longueur jusqu'au bout, et cilié seulement en dedans et au bout; la lame médiane de la nageoire caudale est garnie d'épines sur les bords latéraux, et profondément échancrée au bout; les lames internes des appendices latéraux se rétrécissent graduellement vers le bout, et les lames externes sont très-obtuses; la couleur est brunâtre, avec une petite étoile au milieu de chacun des anneaux de l'abdomen. - Celte espèce a été trouvée dans la Manche et sur les côtes de la Vendée.

Espèces dont la lame médiane de la nageoire caudale est entière au bout :

\section{MYSIS LONGICORNIS.}

Thompson, Zool. Research., t. I, part.1, p. 30 , pl. 4. fig. 1 à 12 - EDw., op. cit., t. II, p. 459 , pl. 26 , fig. 7 à 9. - Long. 6 lig. - Le rostre est très-court; les antennes internes sont longues; leur pédoncule est grêle et allongé; l'appendice lamelleux des antennes externes est pointu au bout et cilié sur les deux bords; la lame médiane de la nageoire caudale est ciliée plutôt qu'épineuse sur les côtés, se rétrécit graduellement vers le bout, et est terminée par une pointe obtuse; les quatre lames latérales sont assez larges à leur base, mais sont extrêmement étroites dans leurs deux tiers postéricurs. - Se trouve à $\mathrm{Na}$ ples.

\section{MYSIS FRONTALIS.}

EDw., op. cit., t. II, p. 459. - Long. 1 pouc. - Le rostre est grand et dépasse notablement les pédoncules oculaires; les pédoncules des antennes externes sont grêles et très-longs; l'appendice lamelleux des antennes externes est arrendi un peu 
élargi au bout, et sans cils sur le bord externe; les lames de la nageoire caudale diminuent graduellement de largeur depuis la base jusqu'à l'extrémité, mais sont gènèralement plus allongées. - Habite la mer de Nice.

\section{CYNTHia, Thompson, Edw.}

Sous ce nom générique, $M$. Thompson désigne un genre de Crustacé qui a la plus grande analogie avec les Mysis, mais qui s'en distingue cependant par des caractères assez tranchès. - Le corps est grêle, avec la carapace plus petite que chez les Mysis, et se terminant antérieurement par un petit prolongement rostral. - Les yeux sont gros, courts, et de longueur médiocre.Les antennes de la première paire sont excavées à leur base, pour faire de la place aux yeux; leur pédoncule est gros, et leurs filets terminaux sont au nombre de deux; les antennes de la seconde paire sont petites et s'insèrent au-dessous des précédentes. - L'appendice lamelleux qui en recouvre la base est moins long que le pédoncule des antennes supérieures; la conformation de l'appareil buccal est à peu près la mème que chez les Mysis. - La tige palpiforme des mandibules est très-grande, et les mâchoires de la seconde paire sont lamelleuses et divisées du côté interne en plusieurs lobes. - Les huit paire qui font suite aux mâchoires doivent être toutes considérées comme des pattes natatoires; mais M. Edwards ne partage pas l'opinion de M. Thompson, et il croit que la première paire de ces organes appartient encore à l'appareil buccal et constitue des pieds-mâchoires; en effet, dit le même auteur, ces appendices, quoique plus allongés que ceux des Mysis, sont de même reployés en dedans au-dessous des mâchoires, et leur branche interne se termine par un article élargi qui est propre à retenir les alimens pendant la mastication, tanàis que les pattes se terminent par un petit ongle crochu; la tranche moyenne de ces pieds-mâchoires est conformée comme chez les Mysis, mais le fouet ou branche extérieure qui, chez ces derniers, constitue une grande lame membraneuse, paroît manquer complétement. - Les membres thoraciques de la première paire diffèrent aussi un peu des six dernières paires de pattes; ils sont plus élargis et se terminent par un article lamelleux dont les bords sont ciliés; mais néanmoins, à raison de leur longueur et de leur position, ils doi- vent être considérés comme servant à la locomotion; du reste, ces organes, par leur structure et par leurs fonctions, ne différent pas notablement de ceux des Mysis; leurs deux branches sont également trèsdéveloppées; seulement le pénultième article de la tige interne est plus fort, ne se rétrécit pas vers le bout, et n'est pas annelé de manière à paroître multiarticulé, et l'angle terminal est plus gros. - Labase des pattes postérieures, chez le mâle, offre une petite lame qui représente l'appendice flabelliforme. - L'abdomen est semblable 'à celui des Mysis, si ce n'est que les fausses pattes fixées aux cinq premiers anneaux sont très-développées, et à peu près de même forme que chez les Salicoques; chacun de ces membres se compose d'un article pédonculaire très-gros, et de deux lon. gues lames multiarticulées sur les bords. - Les appendices branchiaux attachés à l'extrémité des pédoncules de ces fausses pattes, en arrière des lames terminales, consistent en un cylindre membraneux bifurqué près de sa base, et dont chacune de ses branches s'enroule sur elle-même.

Ces Crustacés, qui paroissent avoir les mêmes habiludes que les Mysis, car on les trouve souvent ensemble, sont de très-petite taille.

\section{CYNTHIA ARMATA.}

Enw., op. cit., t. II, p. 463. - Long. 8 lig.-Le thorax est très-grêle antérieurement; le rostre est pointu et plus long que les pédoncules oculaires; les antennes in. ternes sont très-longues, le troisième article de leur pédoncule est fort grand, et porte du côté interne un grand lobe arrondi sur le bord, et garni d'un grand nombre de poils disposés en brosse; l'appendice lamelleux des antennes externes n'atteignant que le milieu du troisieme article pédonculaire des antennes internes; les trois derniers anneaux du thorax sont presque entièrement à découvert; la lame médiane de la nageoire caudale est étroite, arrondie au bout, et garnie d'épines tout autour; les lames externes sont beaucoup plus longues que les lames mitoyennes, et ont leur bord externe garni de petites épines dans toute sa longueur; le bord interne des lames mitoyennes est garni de longs poils.-Cette espèce a été trouvée près de Noirmoutiers.

\section{THYSANOPODA, Edw. , LaTr.}

Ces Crustacés; par leur forme exté- 
rieure, ressemblent beaucoup aux Mysis. Leur corps présente les mêmes divisions que chez la première famille des Crustacés, c'est-à-dire des Décapodes Macroures. - La carapace qui recouvre la tête cache aussi tout le thorax; et l'abdomen, dont la longueur excède beaucoup celle du céphalo-thorax, est étendu en arrière, et se compose de sept segmens dont les trois médians présentent à leurs bords postérieur el supérieur une petite épine dirigée en arrière antérieurement. - La carapace est terminée par un petit rostre paintu qui n'atteint pas le niveau de l'extrémité des yeux, dont les pédoncules sont gros et courts. - Les antennes, au nombre de quatre, s'insèrent sur deux lignes, et leur longueur est à peù près égale; les supérieures ont un pédoncule recourbé à la base pour recevoir les yeux, et composé de trois articles cylindroïdes; elles se terminent par deux tiges filiformes assez longues. - La base des antennes inférieures est recouverte par une écaille lamelleuse, dont l'extrémité et le bord interne sont ciliés. - La bouche, située à peu de distance du point d'insertion des antennes inférieures, est entourée d'un labre assez gros, d'une languette bifide, et d'une paire de mandibules. - Ces derniers organes sont armés, sur leur bord interne, de quelques dents aiguës, et portent un palpe court, aplati, et divisé en trois articles, - Deux paires de mâchoires entrent également dans la composition de l'appareil buccal, et sont appliquées sur les mandibules et la languette; celles de la seconde paire n'offrent rien de remarquable; les se. condes sont composées de trois articles lamelleux dont les deux premiers sont bilobés du côté interne.-Les huit paires de pattes qui suivent les mâchoires n'entrent en aucune manière dans la composition de l'appareil buccal ; mais toutes sont propres à la locomotion; ces pattes, à l'exception de celles de la dernière paire, sont longues, grêles et bifides comme chez les Mysis. Leur article basilaire, gros et court, porte en dedans une longue tige garnie de poils nombreux, et en dehors un palpe ou branche moyenne composé de deux pièces, dont la dernière est mince, lamellaire et ciliée sur les bords; la longueur de ces pattes natatoires augmente un peu depuis la première jusqu'à la cinquième paire, puis diminue; enfin, celles de la huitième et dernière paire manquent de tige interne, et ne consistent que dans la branche externe ou palpe. - Les cinq premiers seg- mens de l'abdomen supportent aussi des petites pattes natatoires formées d'un pédoncule cylindrique portant deux lames allongées et ciliées sur les bords, dont l'interne, moins longue que l'externe, porte à son tour un petit appendice cylindrique. - Les membres du sixième anneau de l'abdomen et le septième segment devenu lamelleux constituent une nageoire en éventail, dont la pièce médiane, étroite et pointue, se termine par trois épines acérées; et les latérales, également étroites, sont garnies sur les bords de longs poils.

L'espèce type de ce genre est le

THYSANOPODA TRISCUPIDA.

EDw., op. cit. , t. II , p. 466 ; ejusd. , Ann. des Sc. nat., t. XIX. — GuérIN, Icon. du Règ. anim. de Cuv., Crust., pl. 23, fig. 1.-Long. 15 lig. - Cette espèce a été trouvée dans l'Océan Atlantique.

\section{LEUCIFÉRITES.}

Pattes thoraciques au nombre de quatre paires, et dépourvues de palpe et de fouet. - Bouche très-éloignée de la base des antennes.

Genre : Leucifer.

\section{LEUCIFER, Thompson, Latr., EDW.}

Ce genre, établi par M. Thompson, est très-remarquable et diffère des précédens par la longueur excessive de la portion anrérieure de la tête, la brièveté extrême de la partie du corps occupee par la bouche et constituant le thorax, et le grand développement de l'abdomen. - La forme générale du corps est presque linéaire. - Les yeux et les antennes sont portés à l'extrémité d'un long prolongement grêle et cylindrique, qui est beaucoup plus long que tout le reste de la portion céphalo-thoracique du corps, et qui paraît être formé principalement par l'anneau antennaire; une petite carapace recouvre toute la portion postérieure du céphalo-thorax, et présente à peu près la même forme que chez les Mysis. - Les yeux sont gros et portés à l'extrémité de pédoncules cylindriques extrêmement longs. - Les antennes de la première paire sont grêles, courtes, et terminées par une tigelle multiarticulce, rudimentaire; celles de la seconde paire s'insèrent au-dessous, tout près des précédentes, et sont éga. lement grêles; on voit près de leur base un petit appendice lamelleux. - La bouche 
est saillante, et située en arrière de la base du prolongement qui porte les yeux; on y trouve des mandibules fortes et dentées, mais dépourvues de tiges palpiformes; deux paires de mâchoires portant chacune deux lames; deux paires de pieds-mâchoires courts et lamelleux, et une paire de piedsmâchoires externes qui sont longs, pédiformes et reployés contre la bouche. A la suite de ces organes, on voit quatre paires de pattes natatoires, longues et grêles, qui s'amincissent graduellement vers le bout, et sont garnies de poils épars. L'abdomen est très-étroit et se compose de sept anneaux, mais il acquiert un développement tout-à-fait anormal, car chacun de ces segmens est au moins aussi long que la portion céphalo-thoracique du corps, où sont situées la bouche et les pattes. - Les cinq premiers anneaux sont à peu près égaux entre eux, et portent chacun une paire de fausses pattes très-longues, composées d'un article basilaire cylindrique et d'une ou deux lames natatoires allongées, multiarticulées et ciliées. Chez lesindividus présu- més être mâles, les fausses patles de la première paire présentent vers le milieu de leur article basilaire, un appendice charnu d'une forme bizarre.-Le sixième anneau est comprimé, très-long et denté en dessous. - L'abdomen est terminé par une nageoire caudale composée de cinq lames disposées en éventail.

\section{HECCIFER REYNAUDi.}

Evw., op. cit., t. II, p. 469, pl. . 26, fig. 10. - Long. 4 lig. - L'extrémité antérieure de la carapace est distincte du prolongement oculifère; la pièce médiane de la nageoire caudale est très-petite, comprimée et échancrée en desous; les lames latérales. sont beaucoup plus longues que les mitoyennes. -- Cette espèce a été trouvée dans l'Océan Indien.

Consultez, pour les autres espèces, le t. II de l'Hist. nat. des Crust., par M. Edwards, et l'Atlas du Voyage autour du Monde, de Krusenstern (en langue russe), pl. 22, fig. 9 à 11 .

\section{DEUXIÙME FAMULLE.}

\section{U N I G U I A S S E S,}

Latreille.

Caractères. Pattes de formes diverses; celles de la première paire très-grandes et constituant des pattes ravisseuses; celles des trois paires suivantes courtes, et terminées par une petite main substyliforme; celles des trois dernières paires grêles et natatoires. - La plupart des anneaux du thorax complets et distincts. - Abdomen trèsdéveloppé. - Cette famille renferme deux groupes : les Ericthites et les Squillites.

\section{ERICTHITES.}

Ayant la carapace sans divisions et armée d'un rostre styliforme. - Point de plaque rostrale, mobile, et des branchies généralement rudimentaires. - Les Crustacés qui composent ce groupe ne se rencontrent guère que dans la haute mer, et n'ont été trouvés jusqu'ici que dans les régions Tropicales. mus.

Genres: Squillericthus, Ericthus, Ali-

\section{SQUILLERICTHUS, EDW.}

Cette nouvelle coupe générique, qui a été créée par M. Edwards, établit le passage entre les Squilles et les Ericthes; voici les caractères qui lui ont été assignés par cet auteur, et que nous reprodnisons d'après lui : - La carapace est armée de prolongemens spiniformes et recouvre lá base des antennes internes; mais en arrière elle ne dépasse pas (les épines non comprises) le dernier anneau du thorax. - Les yeux sont gros, pyriformes et articulés, à angle droit. sur un pédoncule cylindrique très-grêle et assez long. - L'anneau oplithalmique n'est pas distinct de l'anneau antennaire, comme chez les Squilles, mais le mode d'insertion des antennes est le même que chez ces derniers et les Ericthes. - Les antennes de la première paire sont dirigées en avant; les externes sont dirigées en dehors, et présentent aussi un gros pédoncule portant à son extrémité une grande lame ovalaice, 
ciliée toul autour, et donnant inserlion, par son bord antérieur, à une tigelle trèscourte et composée de deux articles pédonculaires et d'un filet terminal. - La bouche est peu éloignée de la base des antennes, et située vers le milieu de la carapace ; la lévre supérieure est grande, demicirculaire et saillante. - Les mandibules sont dirigées en bas, comme chez les Squilles; on y remarque aussi une grosse dent denticulée ; et un prolongement également denté sur le bord, qui remonte vers l'estomac; mais la tige palpiforme est nulle ou rudimentaire. En arrière des mandibules on trouve une lèvre inférieure bilobée, puis deux paires de måchoires dont la forme est la même que chez les Squilles. - Les appendices qui correspondent aux pieds-mâchoires de la premiére paire ne présentent rien de remarquable; ils ont la forme d'une tige longue et grêle, et, de même que les Crustacés de cette famille, ne paraissent pas faire partie de l'appareil buccal. - Les membres de la paire suivante sont trèsgrands, et constituent des pattes ravisseuses exactement semblables à celles des Squilles; leur pénultième article est élargi et épineux vers la base; leur griffe terminale est courte et armée de dents spiniformes sur le bord préhensile. Les pattes des trois paires suivantes s'insèrent sur une ligne transversale courbe, immédiatement en arrière des pattes ravisseuses, et sont habituellement appliquées contre la bouche, chacune d'elles portant à sa base une vésicule aplatie en forme de disque, et se terminant par une main chélifère ovalaire. - Les trois dermiers anneaux thoraciques sont complets et libres au-dessous de la carapace, qui en recouvre les deux premiers ; les trois paires de pattes correspondantes sont de grandeur médiocre, et conformées comme chez les Squilles; seulement leur dernier anneau n'est pas sétifère.- L'abdomen est grand et ressemble beaucoup à celui des Squilles, si ce n'est que son dernier segment est beaucoup plus grand et recouvre habituellement les membres du pénultième anneau. Ces derniers organes se composent, comme chez les Squilles, d'un article pédonculaire qui se prolonge inférieurement en une grande lame, et porte deux appendices insérés sur les bords, près de sa base; l'appendice interne consiste en une grande lame ciliée; l'exterue se compose de deux articles dont le dernier est ovalaire, et le pénultième armé d'épines sur le bord externe. - Les fausses pattes suspendues aux cinq premiers anneaux de l'abdomen sont grandes et formées d'un article pédonculaire presque carré, et de deux grandes lames ovalaires à bords ciliés; la lame interne porte sur son bord interne un petit appendice rudimentaire, et l'externe donne insertion, près de sa base, à une grande branchie rameuse. - Ces Crustacés habitent les mers d'Asie. Parmi les deux espèces qui composent ce genre, nous citerons :

\section{SQUILLERICTHUS TYPUS.}

Edw., op. cit., t. II, p. 499, pl. 27 , fig. 1 a 8 . - Long. 15 lig. - Le rostre dépasse le pédoncule des antennes internes; on aperçoit une grande épine horizontale sur le milieu du bord postérieur de la carapace, et de chaque côté un autre prolongement spiniforme plus long, naissant de l'angle de la carapace; enfin une pointe assez forte vers le milieu du bord latéral de la carapace, et une autre au-dessus de la base des antennes externes; les griffes des patles sont ravisseuses, armées-de quatre dents ( $y$ compris la pointe terminale); le dernier anneau thoracique n'est pas recouvert par la carapace, et l'abdomen est trèsgrand; son dernier segment est beaucoup plus long que large, et armé de trois paires de dents marginales. - Cette espece se trouve dans les mers d'Asie.

\section{ERICTHUS, Lam., Latr., Desm., Edw. ; Squilla, Fabr.; Smerdis, Leach.}

La carapace est grande, bombée, et armée de prolongemens spiniformes; elle recouvre en entier la base des pédoncules oculaires ainsi que des antennes, et s'étend en arrière plus ou moins loin au-dessus de l'abdomen, qui est court et gros. Les yeux sont gros, pyriformes, et ne sont pas portés sur une tige grêle et allongée. -Les pieds-mâchoires de la premiere paire sont extrêmement grêles et de longueur médiocre; ils ne s'élargissent qu'à peine vers l'extrémité, et portent au bout un ongle rudimentaire. - Les pattes ravisseuses sont peu développées; leur griffe est presque droite et sans dentelures, et le pénultième article est grêle, allongẻ, droit et dépourvu d'épines. Les pattes des trois paires suivantes sont conformées de la même manière que chez les Squilléricthes, mais s'insèrent les unes à la suite des autres; la vésicule aplatie, fixée à la base de chacun de ces organes, ainsi que les membres dcs 
deux paires précédentes, est très-grande. Les pattes thoraciques des trois dernières paires sont peu développées et manquent quelquefois d'appendice styliforme; d'autres fois elles sont tout-à-fait rudimentaires, et ne se composent que d'un petit pédicule, terminé par deux artícles, à peu près comme les fausses pattes abdominales, mais beaucoup plus petites. - L'abdomen est large et court; la nageoire caudale qui le termine est disposée comme chez les Squilléricthes, et les fausses pattes des premières paires sont grosses et terminées par deux grandes lames ovalaires, sur l'une desquelles on trouve une branchie rudimentaire.

\section{ERICTHUS VITREUS.}

LATr., Règ. anim. de Cuv., $\Lambda^{\text {re }}$ édit., t. III, p. 43, et $2^{e}$ édit., t. IV, p. 110. LaMr., Hist. des Anim. sans vert., t. V, p. 189. - Desn., Consid. génér. sur les Crust., p. 225, pl. 44, fig. 2. - Edw., op. cit., t. II, p. 504. - Smerdis Vulgaris, LEACH, Voyage du cap. Tuckey, appendice, pl. 18, fig. 6, et Journ. de Phys., t. LXXXVI, p. 305, fig. 6. - Squilla Vitrea, Faвr., Suppl. Ent. Syst., p. 17. - Long. 6 lig. - La carapace est courte, faiblement bombée, renflèe latéralement, avec une dent de chaque côté près de l'extrémité antẻrieure des bords latéraux; les angles du milieu de ces bords sont prolongés, et terminés par une forte dent; la supérieure des deux des angles postérieurs des mêmes bords est beaucoup plus longue que l'inférieure et spiniforme; le bord postérieur du dernier segment est sensiblement plus large que les parties adjacentes, et tronqué sur les côtés. - Cette espèce habite l'Océan Atlantique austral. Voyez, pour les autres espèces, le tome II de l'Histoire naturelle des Crustacés, par M. Edwards.

\section{Alima, Leacr, Latr., Desm., Edw.}

Caractères gẻnéraux du genre précédent, mais en différant par l'allongement extrême du corps et de la queue, ainsi que par celui du test ou bouclier céphalo-thoracique.-La carapace est très-mince, fort allongée, plus large en arrière qu'en avant, terminée antérieurement par trois pointes dont l'intermédiaire est fort longue et très - aiguë, et en arrière par trois pointes dont les deux externes sont formées par les angles latéraux, et dont la moyenne fait une petite saillie au-dessus du bord tronqué de cette partie. - Les antennes intermédiaires ont un pédoncule fort long, composé de trois articles cylindriques dont celui de la base est un peu plus grand que les autres, terminées par trois filets cylindriques, inégaux, et dont le plus grand est moins long que le pédoncule. Les antennes extérieures sont plus courtes que la lame ovale, non ciliée, et qui est annexée à leur base. Les yeux sont très-gros, portés sur un pédoncule très-mince, et faisant un angle avec lui. - La bouche est située fort en arrière, entourée d'appendices, disposés comme ceux de la bouche des Squilles, et dont les deux plus grands, ou les serres en genou, sont très-grêles, linéaires, avec leur dernière pièce, ou ongle, repliée, courte, trèsmince, aiguë, et sans dentelures sur son bord. - Le corps et la queue sont très-allongés, grêles, mais néanmoins un peu plus larges en arrière qu'en avant; le premier segment est sans pieds; les second, troisième et quatrième sont pourvus de trèspetits appendices à peine visibles, qui représentent les trois dernières paires de pattes ambulatoires des Squilles; les cinq segmens suivans sont munis chacun d'une paire d'appendices natatoires, consistant en un pédoncule assez allongé, qui supporte deux lames membraneuses très-minces, ovales et non ciliées. Le dernier article de la queue est grand, aplati, mince et trèstransparent, arrondi à sa base, à bords latéraux parallèles, unidentés, et terminé par quatre pointes dont les deux intermédiaires sont les plus postérieures.

Leach, Journ. de Phys., t. LXXXVI, avril 1818, p. 305, fig. 7.- DesM., Consid. génér. sur les Crust., pl. 44, fig. 1. Latr., Encycl. Méthod., t. X, p. 475 , pl. 354, fig. 8. - EDw., op. cit., t. II, p. 507. - Long. 13 lig. - Le rostre est moins long que le pédoncule des antennes internes; la carapace est brusquement relevée au-dessus de la partie postérieure du thorax, avec ses angles latéraux médiocrement prolongés; l'abdomen est long et grêle, avec son dernier article très-grand. Le corps de cette espèce est d'un roussâtreclair transparent. - Du port Praya, au CapVert en Afrique.

\section{SQULLITES.}

Ayant la carapace divisée en trois lobes, avec une plaque rostrale mobile et des branchies très-développées. 
Genres : Squilla, Gonodactylus, Coronis.

\author{
SQUilla, Fabr., Oliv., Latr., Bosc, \\ Lam., Leach, Deshr., Roux, Edw.; \\ Cancer, Linn., Herbst.
}

La carapace est petite, mince et flexible, de forme trapézoîdale allongée, marquée de deux impressions longitudinales entre lesquelles se trouve la partie qui recouvre la région buccale, et au-dehors desquelles ses bords consistent seulement en une lame presque membraneuse qui protége la base extérieure des pieds. - Les antennes intermédiaires sont grandes, relativement aux latérales, formées de trois filets sétacés, dont le supérieur est plus long, et dont les inférieurs sont réunis à leur base ; tous sont portés sur un pédoncule long, cylindrique, composé de trois articles dont le premier est le plus gros et le plus court, et le second le plus long; ces antennes forment avec les yeux une saillie distincte du reste du corps, et sur laquelle s'étend une sorte de chaperon carré, mais arrondi sur ses angles, qui est articulé avec le bord antérieur de la carapace et de la tête. Les antennes extérieures sont placées à peu près sur le même plan que les intermédiaires, insérées de chaque côté entre le chaperon et l'angle externe de la carapace, formées d'un article baséal, large, anguleux, lequel porte : $1^{\circ}$ un second article vers son extrémité et en dehors, un peu moins fort, aussi anguleux, et muni lui-même extérieurement d'une lame très-allongée, ovoïde et ciliée sur son bord externe; $2^{\circ}$ le corps même de l'antenne, qui est sétacé, multiarticulé, et pourvu à son origine de deux ou trois articles cylindriques beaucoup plus grands que les autres. - Les yeux sont ovor̈des, transverses, obliques, portés sur un court pédoncule d'un diamètre moindre que le leur, insérés très-près l'un de l'autre au-dessus des antennes intermédiaires. La bouche est placée au sommet et en arrière d'une saillie pyramidale, comprimée, trẻs-apparente en dessus du test ; composée, en allant du dedans en dehors : $1^{\circ}$ d'une lèvre supérieure un peu arrondie, presque membraneuse, formant le sommet du cône, et ayant sa saillie tournée en arrière; $2^{\circ}$ de deux grandes mandibules très-solides, ayant leur partie triturante divisée en deux branches qui tombent à peu près à angle droit l'une sur l'autre, dont l'inférieure, qui se croise avec celle de la mandibule opposée, A.y. est tranchante sur son bord, un peu arquée à son extrémité et pourvue d'une seule sèrie de dents, au nombre de sept, comprimées. droites et peu aiguës, et dont la branche supérieure, à peu près horizontale, a sa tranche droite canaliculée et bordée de deux rangs de semblables dents, mais plus nombreuses et plus petites (la base de ces mandibules est renflée et caverneuse); $3^{\circ}$ d'un long palpe composé de trois articles filiformes, adhérant à chacune de ces mandibules, couchés sur les còtés et à la base du cône buccal ; $4^{\circ}$ de deux lames un peu bombées, placées au-devant des mandibules, ciliées el épincuses sur les bords, qui font l'office de véritables mâchoires, et qui sont considérées par M. Latreille comme des divisions de la languette; $5^{\circ}$ d'une paire de mâchoires aplaties, composées chacune de deux parties, l'une plus large, tronquée et garnie d'un rang de cils roides en dedans; et l'autre externe, palpiforme, aiguë, et finissant en pointe; $6^{\circ}$ de deux mấchoires plus extérieures, très-grandes, triangulaires, allongées, aplaties sur les autres parties de la bouche et les recouvrant longitudinalement, formées évidemment de quatre pièces de dimension à peu près égale, dont la première et la dernière sont triangulaires, et les autres à peu près carrées, avec leurs angles émoussés. - Les grands appendices (pieds-mâchoires des pieds proprement dits) sont au nombre de six, insérés très-près les uns des autres autour de la bouche : ceux de la première paire sont assez longs, très-grêles, terminés par un article lenticulaire, supportant un onglet. qui fait la pince en se reployant sur son bord; ceux de la seconde paire sont extrèmement grands, insérés plus en dehors que les autres, composés de six articles, comme les serres des Crustacés Décapodes ordinaires; savoir : deux pièces courtes à la base, un bras long et assez épais, canaliculé en dessous ; un carpe court, une pièce représentant le corps de la main, très-aplatie, et ayant sur son bord interne un sillon ou une série de cavités plus ou moins nombreuses et profondes; enfin un sixième et dernier article, qu'on peut considérer comme un ongle ou une pince mobile de forme allongée, arquée, se repliant sur la branche interne de la cinquième paire, et. ayant souvent sur son bord de fortes épines arquées, disposées de manière à loger leurs pointes dans les cavités de celles - ci ; ceux des troisième, quatrième et cinquième paires sont beaucoup moins grands, mais assez 
épais, diminuant progressivement de force, ayant Jeur avant-dernier arlicle assez gros, plat et arrondi, supportant le dernier, qui est aigu, petit, arqué et replié sur lui en forme de crochet. - Le corps est très-long, un peu plus large en arrière qu'en avant, forme de onze segmens dont le premier, plus court et plus étroit que les autres, ne donne attache à aucune patte; le second, le troisième et le quatrieme ayant au contraire chacun une paire d'appendices ou de pattes allongées, grêles, grandissant graduellement d'avant en arrière, terminées par un pelit article mince, triangulaire, cilié sur son bord interne, et ayant un filet styliforme attaché à la base de leur troisième article, contre lequel il est soudé ; la dernière de ces trois paires est pourvue à son origine, dans quelques individus, d'une tige assez longue, cylindrique, inarticulée et dirigée en dedans; les cinq segmens suivans de l'abdomen sont munis en dessous d'une paire de pieds-nageoires, courts, dont les articles terminaux sont en palettes ovales, ciliés sur les bords, et qui supportent à leur origine une branchie composée de nombreux filets cylindriques disposẻs comme une houppe; le onzième et dernier segment est aplati et en forme d'écaille en dessus, ayant la partie anale ouverte sur sa face inférieure, et représentant la lame intermédiaire de la nageoire caudale des Crustacés Macroures proprement dits; deux nageoires latérales sont attachées chacune à l'angle postérieur de l'avant-dernier segment, et composées d'une pièce principale, solide et aiguë postérieurement, qui porte en dehors un appendice mobile, formé de deux lames aplaties, ovales, ciliées, et en dedans une lame également garnie de cils, mais unique et de forme très-allongée.

Les Squilles présentent de grandes anomalies dans leur organisation, surtout lorsqu'on la compare à celle des Crustacés que nous avons déjà décrits plus haut.

C'est par les noms de Crangones et Crangines que les Grees distinguaient les Squilles. Elles sont aujourd'hui vulgairement nommées Mantes de mer (PregaDieous), à cause de la ressemblance de leur grande paire de pieds avec les premières pattes des Orthoptères du genre Mante. Les pêcheurs leur donnent en Provence le nom de Gatero, qui veut dire Mille-Pattes, Scolopendre.

Les Squilles se tiennent ordinairement dans les profoudeurs de trente à cinquante mètres; elles fréquentent volontiers Jes lieux sablonneux et fangeux, parce qu'clles s'y procurent une nourriture facile, qui a paru composée, suivant M. Roux, d'Annelides et de fragmens de l'Actinia Effeta. C'est à l'époque du printemps que ces animaux s'unissent. Les femelles, dit M. Risso, se cachent sous les rochers lorsqu'elles veulent se débarrasser. de leurs osafs, qu'elles portent sous les appendices de l'abdomen, comme les Langoustes. Quoique munies de nombreux moyens de préhension et de défense, les Squilles, d'un caractère craintif, paraissent fuir avec précipitation dès qu'elles aperçoivent le moindre danger. Leur nataticn est, à peu de chose près, semblable à celle des Homardiens; mais elles font moins usage de leurs pattes pour se traîner.

Ce genre, assez nombreux en espèces, a été divisé par Mî. Edwards en deux sousgenres : les Squilles Fine-Taille et les Squilles Trapues.

\section{PREMIER SOUS-GENRE。}

\section{Squilles Fine - Taille. EDw.}

Ayant le corps svelte et rétréci au milieu, et la carapace courte, élargie en arrière, et laissant à découvert les trois ou quatre derniers anneaux thoraciques.

\section{SOVILLA MANTIS.}

Rondelet, Poissons, t. II , p. 307 . - Latr. Encyclopéd. Méthod., t. 10, p. 471, pl. 324, fig. 1 a $7 .-$ Ejusd. Wis*. nat. des Crust., t. VI, p. 278, pl. 55, fig. 3. - Desn., Consid. gén. sur les Crust., pI. 41, fig. 2. - EDw., op. cit., t. II, p. 520. - Long: 7 pouc. - Ongle mobile des grands pieds en pince, pourvu en dedans de six épines qui entrent dans autant de cavités du bord intérieur de la pièce précédente, dont la tranche est finement dentelée et garnie à sa base de trois épines mobiles; corps et abdomen ayant en dessus six carènes longitudinales terminées sur les deux avant-derniers segmens par autant de pointes dirigées en arrière; dernier segment ayant une seule carène dans son milieu, trois pointes latérales et deux terminales, son bord postérieur étant garni de dents très-régulières, enflées en dessus et crochues en dessous; sa surface présentant des séries de points enfoncés, d'un blanc nacré, nuancé de bleu et de violet; pattes d'un vert de mer; deux taches d'un bleu-violet sur le dernier segment 


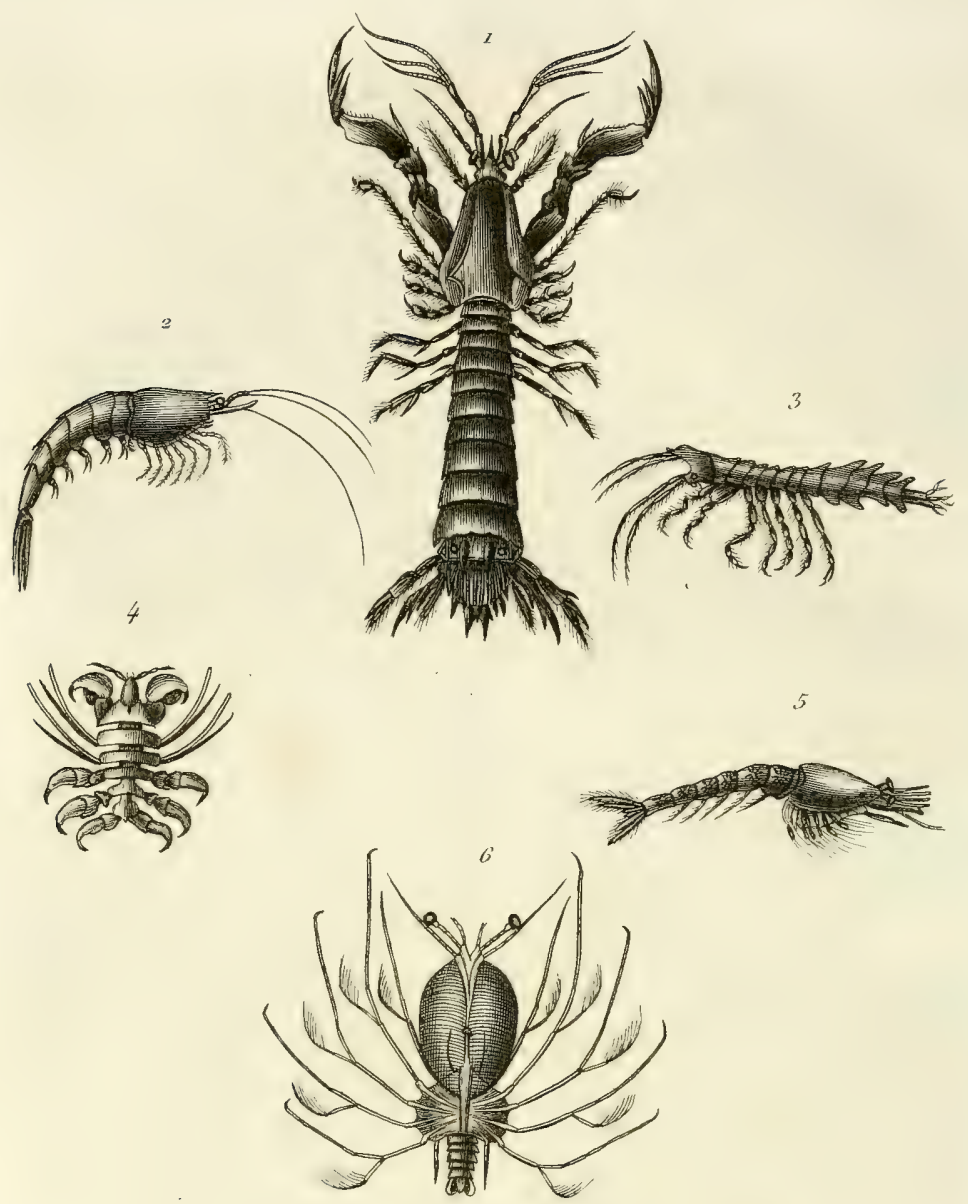

8
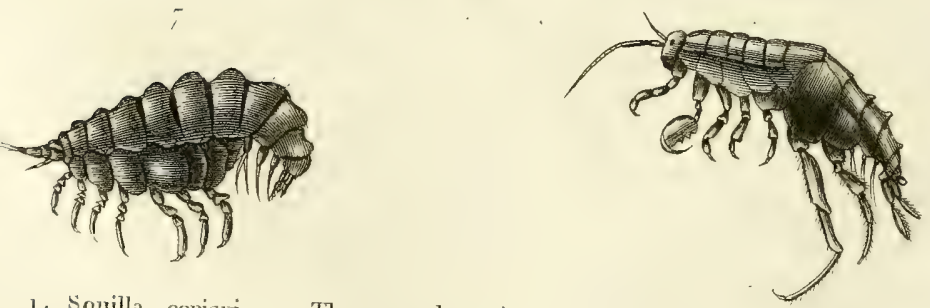

1. Squilla cerisyi, 2. Thysanopodus tricuspidatus. 3. Atylus carinatus .

4. Cyamus ovalis, 5. Mysis spinulosus, 6. Phyllosoma fieycinetii. 7.

Phlias serratus, 8, Orehestia Fischerii. 
de l'abuomen; la femelle, suivant M. Risso, est pourvue d'œufs nacrés en été.-Habite la Méditrranèe.

\section{SQULLA DESMARETI.}

Risso, Hist. nat. des Env. de Nice, pl. 2, fig. 8, p. 114. - Desm., Consid. génér. sur les Crust., p. 251. - Roux, Crust. de la Méditerr., pl. 2, fig. 1. - EDw., op. cit.; 1. II, p. 523. - Long. 4 pouc. - Le corps de cette espèce est teint de jaune verni de brun; la carapace est sillonnéc; les yeux sont marbrés de gris; les écailles latérales ciliées de rose; les pinces armées de cinq aiguillons d'un blanc rosé; les segmens de l'abdomen sont munis, de chaque côté, de deux arếtes; le pénultième en a quatre; le dernier caréné, terminé en pointe aiguë, ses bords ont six divisions pointues, dont les deux intermediaires dentelées; les écailles caudales extérieures ont leur premier article épineux; le second aiguillonné sur son bord supérieur; le troisième ovale, linéaire; les intermédiaires sont terminées par deux pointes; les inférieures linéaires ; les premières et les dernières de ces écailles caudales, ciliées de rose; les pattes, ainsi que les antennes, sont d'une teinte plus claire, ainsi que les autres parties du corps; les oufs que la femelle porte sont d'un jaune-brun. - C'est en mars et en avril qu'clle en est pourvue.

Cette espèce présente deux variétés, savoir:

A. D'un rose tendre. Habite alors, les bords coralligènes.

B. D'un jaune foncé peu varié de brun.

Les mouvemens de cette Squille sont vifs. Elle uage avec agilité, en se servant de ses nombreux feuillets dont est pourvu son abdomen. Elle replie assez souvent sa queue avec le corps, à la manière des Langoustes, et s'élance ainsi à reculons. Elle vit vingt-quatre heures hors de l'eau, agitant sans cesse les lames natatoires de son corps. C'est parmi les algues et les rochers peu profonds, eli société avec les Nikas et les Palemons, que vit la Squille de Desmarest. Elle se cache dans le jour et ne se montre que la nuit. On la mange frite, ainsi que les Salicoques.

\section{SOUILLA FERRUSSACT.}

Roux, Crust. de la Méditerranée, pl. 28 , fig. 1 à 3.-EDw., op. cit., t. II, p. 525. - Long. 4 pouc. - Une couleur purpurine lavée de verdâtre sur quelques parties du corps, domine sur le test de cette Squille; la partie supérieure, qui sert de bouclier à l'appareil buccal et qui peut être considérée comme la carapace, est un peu sinueuse ; le front est tronque.divisé en deux lobes peu échancrés; les pin, ces sont munies seulement de deux aiguillons; les huit premiers anneaux sont longitudinalement traversés par sept lignes élevées qu'interrompent les sutures de chaque segment; le pénultième n'en a que six, et sur le dernier, qui sert à l'insertion des nageoires de la queue, on n'en remarque que trois, y compris celle du milieu, qui est fortement relevée en carène; l'ècaille foliacée placée à la base desantennes extérieures, toutes les nageoires caudales, le dernier article des pattes et les piedsnageoires, sont bordés de cils d'un rouge purpurin.-Cette espèce, qui se tronve dans la mer de Sicile, vit dans les profondeurs de trente à soixante mètres.

\section{DEUXILME SOUS-GENRE.}

\section{Squilles Trapues. EDw.}

Ayant le corps trapu et sans rétrécissement notable vers le milieu, et la carapace peu ou point élargie en arrière, et se prolon: geant au-dessus de l'antépénultième anneau thoracique.

4. seuilla cerisyi. (Pl. 17, fig. 1.)

Roux, Crust. de la Médit., pl. 5, fig. 1. - Evw., op. cit., t. II, p. 527. - Long. 4 pouc. - Cette espèce diffère de ses congénères en ce qu'elle ne présente que deux aiguillons sur la griffe terminale de la première paire de pieds-mâchoires; trois autres aiguillons mobiles sont placés sur la partie interne de la main; les autres piedsmâchoires, terminés par un ongle crochu, sont ciliés de rose, ainsi que les pattes proprement dites; les segmens de l'abdomen sont entiérement lisses, excepté le pénultième, dont les bords sont munis de dix épines dirigées en arrière; le dernier est ierminé par sept pointes aiguës; il porte onze cannelures longitudinales fortement relevées en carène; la première des nageoires latérales de cette partie du corps est armée, vers son extrémité intérieure, de trois forts piquants; on apercoit en des$s u=$ un autre piquant vers la base, et quelques-uns très-rapprochés sur son bord extérieur donnent à cette partie un aspect cilié; la seconde lame natatoire n'est bordée que de poils; l'une et l'autre sont profondément sillonnées; la couleur générale de cette Squille est d'un jaune fauve ou verdâtre; les antennes et les cils des diversę 
parties du corps sunt roses; le bord postérieur des segmens de l'abdomen et les dix anneaux de cette partie du corps sont d'un rouge de brique.--Elle se trouve en Corse; elle a aussi été rencontrée aux environs de Toulon.

\section{SOUILLA STYLIFERA.}

LaMCK., Hist. nat. des Anim. sans vert., Ł. V, p. 189. Guér., Icon . du régn. anim. de Cuv.Crust.pl.24, fig.1-EDw., op. cit., t.1I, p. 526. - Long. 3 pouc. - La carapace est lisse et sans crêtes en dessus, ovalaire et sans rétrécissement notable en avant; la plaque frontale est ovalaire transversalement; les antennes internes sont grêles et extrêmement courtes, moins longues que les externes; leur second article dépassant à peine les yeux; les pattes sont ravisseuses, très-allongées et aplaties; le bord interne de la main est non dentelé, mais armé de deux ou trois épines mobiles; la griffe est grêle et armée de trois dents acérées; l'abdomen est bombé et lisse jusqu'ả l'avant-dernier article, qui est formé de six dents spiniformes; le dernier segment de l'abdomen est garni en dessus de sept crêtes minces, armé de chaque côté de deux fortes dents pointues, et de deux épines mobiles insérées près de la ligne médiane. - Habile l'Ile-de-France.

\section{GONODACTYLUS, Latr., Edw.;}

Squilla, Fabr., Latr., Lam., Desm.

Ce genre diffère du précédent par la forme des doigts et des serres; ils sont ventrus ou en forme de nœud a leur origine, et se terminent ensuite en une pointe comprimée, droite ou peu courbée. - La rainure de l'article précédent est élargie à son extrémité et simplement striée, ou sans den. telures ni épines. - Les yeux sont plus gros et plus arrondis, ou moins transversaux que dans les Squilles. - Le corps est presque cylindrique, et, à l'exception des deux derniers segmens, généralement lisse en dessus; ceux du therax sont proportionnellement plus courts et plus transversaux.

\section{GONODACTYLUS CHIRAGR.}

Latr., Encycl. Meth., t, 10, p. 473, pl. 325,fig. 2. -EDw., op. cit., t. II, p. 528. -Squilla Chiragra, FABR., Suppl. Ent. Syst.;-Desm., Consid. gén. sur les Crust., p. 251, pl. 43.-Cancer Chiragra, Henвst, t. II, p. 100, pl. 34, fig. 2. - Long. 4 pouc. - Cette espèce est d'un jauneverdâtre, avec les pouces souvent couleur de rose, et l'extrémité de l'article précé- dent bleuâtre; extrémité des nageoiı es postérieures rougeâtre; la pointe terminant le pouce un peu arquée; bouclier du support des antennes presque carré, terminé antérieurement par trois dents, les deux latérales formées par les angles; celle du milieu longue, avancée, spiniforme; dessus du corps jusqu'au pénultième segment inclusivement, entièrement uni ; six côtes longitudinales uni-épineuses au bout, sur ce segment; le dernier divisé profondément tout autour en quatre lobes triangulaires en formie de dents pointues, avec une arête ou côte longitudinale; le rebord des deux lateraux une fois interrompu; trois côtes arrondies dont l'intermédiaire plus forte sur le milieu du dos de ce segment. - Habite l'Ile-de-France.

Consultez pour les autres espèces 16 tome $2^{\mathrm{e}}$ de l'Histoire naturelle des Crustacés, par M. Edwards.

\section{CORONIS, LaTr., EDw.}

L'appendice latéral et postérieur du troisième article des six derniers pieds (les adactyles et thoraciques) en forme de lame (ou de palette) membraneuse, presque orbiculaire, et un peu rebordée.

\section{CORONIS SCOLOPENDRA.}

Latr., Encycl., t. X, p. 474.-Guér., Icon. du Règ. anim. de Cuvier, Crust., pl. 24, fig. 2. - EDw., op. cit., t. II, p. 531. - La forme de cette espece est plus étroite et plus déprimée que celle des Squilles; ses antennes et ses pieds sont plus courts; le corps est d'un brun foncé, généralement uni, avec quelques petites lignes élevées en forme de stries fines et longitudinales sur une dépression du milieu du dos de la plupart des segmens; le bouclier du support antennaire est presque triangulaire et pointu au bout; le dernier segmen est presque carré, un peu tronqué obliquement à chaque extrémité latérale et postérieure, d'ailleurs entier et sans dentelures ni épines distinctes; les deux serres sont blanchâtres et pointillées de brun; l'avantdernier article ou le poing est ovale, trèscomprimé, mais en même temps un peu plus convexe sur l'une de ses faces, avec la bord interne garni de cils très-petits, nombreux, spinuliformes, et armè à sa base de trois a quatre épines mobiles; le pouce ou la griffe est semblable à celui des Squilles, comprimé en faux ou arqué, et présente au côté interne une douzaine de dents aiguës; celle qui termine est la plus forte.Habite le Brésil? 


\section{B I C U I R A S S ÉS, \\ Latr., Edw.}

Caractères. Thorax déprimé et lamelleux. - Carapace foliacée, horizontale, ne s'appliquant pas entre la base des pattes, et en général ne recouvrant qu'une petite portion du thorax. - Article basilaire des pattes grêle et extrêmement long, de manière que le palpe naît très-loin de l'insertion de ces membres. - Abdomen généralement très-peu développé.

Genres : Phyllosoma, Amphion.

PHYllosoma, Leach, Latre, Desm., GứR., EDw.;

Chrysoma, Risso.

Le corps de ces singuliers Crustacés se divise en trois parties distinctes: la tête, le thorax et l'abdomen; il est formé de deux lames arrondies, minces, plates et transparentes, et auxquelles M. Latreille a donné le nom de boucliers. - La première lame, ou le bouclier antérieur, représen. tant la tête, et porte en avant les yeux et les anternes; il s'articule au-dessus du second bouclier, n'y étant fixẻ que par la ligne médiane, et présente vers son milieu dans les uns, et le plus souvent au tiers postérieur, à l'endroit où il recommence à se joindre au second, un petit tubercule qui est la bouche; le second bouclier, représentant le thorax, donne attache aux pieds-mâchoires, à dix pattes et à l'abdo. men.-Celui-ci est formè de cinq segmens dont les quatre premiers portent des appendices natatoires divisés en deux lames de forme variable; le dernier donnant attache à une nageoire composée de cinq feuillets. - Le bouclier antérieur est toujours de forme arrondie, quelquefois plus large que long, d'auires fois échancré en avant; mais le plus souvent il est allongé et rétréci en avant et terminé en pointe. Les yeux et les quatre antennes. forment un groupe situé sur la ligne médiane, à l'extremité antérieure de ce bouclier; ces organes sont placés sur une même ligne transversale chez les uns, et à des hauteurs diverses chez d'autres. - Les yeux sont insérés fort près l'un de l'autre sur une petite éminence; ils sont assez gros, globuleux ou, en forme de reins, et portés sur un pédicule composé de deux articles dont le premier est fort long et le second beaucoup plus court et élargi pour donner attache à l'œil; cette tige est articulée à sa base, et semble jouir de la faculté d'être dirigée à la volonté de l'animal ; l'œil est toujours d'un beau, bleu dans. l'état de vie. - Les antennes sont au nombre de quatre, deux intérieures et deux extérieures. - Les an. tennesintérieures prennent attache très-près des yeux, immédiatement à leur côté extérieur; elles sont toujours composées de trois articles dont les longueurs relatives varient suivant les espèces, et terminées par deux filets ciliés, égaux chez quelques espèces, et inégaux chez d'autres; ces filets semblent formés chacun d'un seul article cilié en dedans. - Les antennes sont composées du même nombre de pièces dans toutes les espèces du genre, et sont plus courtes que les pédicules oculaires; mais il n'en est pas de même des antennes externes; celles-ci varient beaucoup : ainsi, dans les uns elles se composent de six articles, et sont au moins aussi longues et souvent plus longues que les yeux, filiformes et terminées en massue, tandis que dans d'au. tres elles semblent n'être formées que d'une seule pièce plus courte que les yeux ; dans cette circonstance elles sont aplaties comme le corps du Crustacé, et présentent vers leur milieu un lobe ou une dilatation pointue et dirigée en dehors; ces antennes prennent naissance immédiatement à côté des. intermédiaires et un. peu plus bas. - La bouche a la forme d'un mamelon globuleux, diaphane sur les bords, obs. cur au centre et assez saillant; ce mamelon est composé de plusieurs pièces très-rapprochées les unes des autreset dont voici la description : A la partie supérieure du mamelon on observe un tubercule membraneux très saillant, globuleux, s'élargissant vers le bas, et presque tronqué dans cet endroit; ce tubercule, par sa forme et sa 
position, rappelle assez le labre des Squilles; à la suite de ce labre, on trouve deux mandibules assez grandes, très-crochues, et dont l'extrémité paraît être d'une consistance plus solide; cette partie est plate, contournée comme une aile de moulin, et coupée carrément; à l'angle supérieur on voit une forte épine, et il y en a trois plus petites à l'angle inférieur; la partie iranchante et presque droite qui forme l'intervalle entre ces épines, est armée d'un grand nombre de dentelures aiguës, spiniformes et disposées en dents de peigne; ces mandibules sont appliquées contre le labre; au-dessous de ces mandibules est située la languette ou lévre supérieure; elle est. membraneuse, formée d'une seule pièce, arrondie sur ses bords, et très-profondément échancrée dans son milieu.-On trouve ensuite comme appliquées sur cette languette, les premières mâchoires, qui sont membraneuses et transparentes; elles forment le coude comme les mandibules; mais leur extrémité courbée est divisée en deux lobes assez longs, ciliés, et dont le premier ou supérieur est terminé par trois fortes épines dentelées, tandis que le second n'en a que deux. Outre ces pièces, il y en a encore deux autres qui sont en forme d'oreilles aplaties, quelquefois cntières, d'autres fois échancrées en avant et en arrière, et bordées de poils très-fins; ces pièces, en forme de lames, sont articulées, et ressemblent à des prolongemens du deuxième bouclier; immédiatement après les deuxièmes mâchoires, on aperçoit deux autres petites pièces semblables, mais plus petites, et que M. Guérin compare aux pieds-mâchoires de la première paire; ces pièces sont suivies des deuxièmes pieds-mâchoires analogues aux grands bras ou pince des Squilles; ils sont portés sur une petite hanche, et se composent de trois articula. tions dans quelques espèces, et de quatre dans d'autres; le dernier article atteint ordinairement la hauteur du labre; il est toujours terminé par un crochet recourbé en dedans; qui représente le grand ongle des mêmes pieds dans les Squilles, et il a à la partie interne, ef en opposition avec ce crochet, de longs poils roides qui s'agglomèrent quand l'animal est desséclé. Une chose remarquable chez quelques espèces de cegenre, c'est que les deuxièmes pieds-mâchoires sont composés de quatre articles dans les espèces á antennes externes multi-articulées, et qu'alors il y a á lextrémité du premier une pièce composée d'un pédoncule d'un seul article, et terminé par un fouet divisé en un grand nombre d'anneaux ciliés intérieurement; tandis que chez les Phyllosomes à antennes externes courtes et d'une pièce, ces deuxièmes pieds-mâchoires n'ont que trois articulations et sont privés de ce fouet; on aperçoit seulement vers la base du premier article, et à sa partie externe, un petit appendice qui semble marquer l'endroit où auroient dû se trouver une articulation et un fouet. Une particularité remarquable que l'on observe aux pieds-mâchoires de tous les Phyllosomes, c'est que la partie comparée à la hanche par M. Guérin est toujours munie extérieurement, et un peu en dessous, d'un petit appendice aplati el divisé en deux lames analogues à celles du dessous de la queue. - Les troisièmes pieds - mâchoires sont insérés beaucouj) plus loin des seconds que ceux-ci ne le sont de la bouche; ils dépassent de beaucoup la hauteur des yeux, et ressemblent aux pattes proprement dites, au premier aspect. Chez les Phyllosomes à grandes antennes extérieures, ils sont composés de cing articulations, il y a un petit appendice foliacé au dessous de la hanche, un fouet à l'extrémité du premier article, et le dernier est velu ainsi que les précédens. Chez ceux qui ont les antennes externes courtes, ces pieds-mâchoires ne se composent que de quatre articles; il y a toujours l'appendice foliacé à la hanche, mais le flagre est remplacé, comme dansles deuxièmes pieds-mâchoires, par un petit appendice court et obtus, placé vers la partie inférieure du premier article; enfin l'avant-dernière pièce présente à son extrémité interne un groupe de poils plus courts que les autres, terminés en massue dentelée intérieurement, ce qui n'a pas lieu chez les premiers. - Les pattes proprement dites, au nombre de dix, sont distribuées à des distances égales autour du second bouclier; elies sont toutes composées de quatre articulations, outre la hanche, et terminées, à l'exception de la dernière paire chez quelques espèces, par un crochet plus ou moins grand, recourbé en dedans et armé de cils: elles ont à l'extrémité du premier article un appareil flagelliforme semblable à celui qu'on observe aux pieds-mâchoires de quelques espèces, et il n'y a que les postérieures qui en soient privées quand elles sont trèspetites. Dans cette circonstance, on observe à la base de ces derniéres un appendice prenant attache sur le devant de la 
banche, de forme conique, et comparable à la tige inarticulée placée à la base des derniers pieds des Squilles, et que l'on présume être les organes mâles de la génération; ces petites pattes dépassent rarement la longueur de la queué, tandis que les autres sont toujours plus longues que le corps, quelquefois armées d'épines et de poils aux articulations et dans toute leur longueur. - La queue, ou l'abdomen, est composée de cinq segmens bien distincts, transversaux et légérement dilatés à leurs bords extérieurs; les quatre premiers ont chacun en dessous deux appendices natatoires composés d'une tige ét de deux lames foliacées, arrondies, entières dans les uns, et dont l'interne est appendicée dans d'autres; le dernier segment est terminé par cinq feuillets, don in impair est placé au milieu et immobile, affectant diverses formes; et deux de chaque côté, portés sur un article radicaI, et ayant la facultẻ de se glisser l'un au-dessous de l'autre; le feuillet externe semble divisé en deux pièces dont l'antérieure, trés-petite, est terminée par une légère épine qui fait saillie au bord externe; cette queue ou abdomen est quelquefois bien distincte du thorax, beaucoup plus étroite que lui, et de même longueur à ses deux extrémités; d'autres fois elle est aussi large que le thorax à sa base, et va en diminuant vers l'extrémité.

Les mœurs de ces Crustacés sont entièrement inconnues; on sait seulement, par le rapport des voyageurs, qu'ils se trouvent à la surface de la mer, et qu'ils y nagent lentement en agitant les appendices flagelliformes de leurs pattes; ils sont transparents comme du verre, et on ne pourroit les apercevoir dans l'eau si leurs yeux d'un beau bleu ne les déceloient pas.

Les Phyllosomes se rencontrent dans toutes les mers des pays chauds; ils sem. blent y être dispersés indifféremment, car on trouve les mêmes especes dans les mers d'Afrique, des Indes et de la Polynésie; cependant, d'après les échantillons rapportés par $\mathbf{M}$. Lesson, il paroîtroit que ces Crustacés sont plus communs dans les mers de la Nouvelle-Hollande et de la Touvelle-Guinée que partout ailleurs.

M. Guérin, dans un travail inséré dans le Magasin de Zoologie, année 1853, et ayant pour titre:Mémoire surl'Organisation extérieure des Phyllosomes, et Monographie de ce genre de Cristacés, distribue les espèces qui le composer: ten deux grandes divisions, ainsi qu'il suit:
1. Antennes externes cyliudriques, plus longues que les pédicules oculaires, com posées de six articulations. - Pieds postérieurs très-courts. - Deuxièmes pieds-mâchoires de quatre articles; les troisièmes de cinq, avec un fouet; point d'épines dentelées à leur avant-dernier article.

\section{PHyLlosona Glavicoris.}

Leach, Journ. de Phys., 1818, avril, p. 307, fig. 11.-Guér., Mag. de Zool., pl. 7. - Evw., op. cit., t. [1, p. 478. Desm., Consid. génér. sur les Crust., p. 254 , pl. 44, fig. 4. - Long. 14 lig. Larg. 6 lig. - Les antennes externes ont environ neuf lignes de long; elles sont renflèes au bout, et sont presque trois fois plus longues que les pédicules oculaires; le bonclier an . térieur est de forme ovalaire, presque aussi long en avant qu'en arrière; les premiers pieds-mâchoires ont le lobe intermédiaire court et son extrémitè arrondie; les pattes sont épineuses, et l'extrémité des postérieures descend un peu plus bas que le bord du dernier segment de la queue.-Cette espèce habite les mers de la Nouvelle-Hollande et de la Nouvelle-Guinée; elle se trouve aussi dans les mers d'Afrique et dans celles de l'Inde.

\section{PHyLlosona comunis.}

Leach, Journ. de Phys., 1818, avril, p. 307 , fig. 11.-Latr., Encycl. Méth., t. X, p. 119, pl. 354 , fig. 1.-Guḱr., Mag. de Zool., année 1833, pl. 8, fig. 1.Desm., Consid. génér. sur les Crust., p. 255, pl. 44, fig. 5.-EDw., op . cit., t. II, p. 477 . - Long. 1 pouc. Larg. 5 lig. - Les antennes exterieures ont près de sept lignes de long, et sont environ deux fois plus iongues que les pedoncules oculaires, filiformes et non renflées au bout; le premier bouclier est ovale, un peu plus large en arrière, rétréci en avant; les secondes mâchoires et les pieds-mầchoires différent un peu de ceux de l'espèce précédente; les premiers pieds-mâchoires surtout sont beaucoup plus petits, et n'ont qu'un très-léger lobe de chaque côté; les appendices du dessous de la queue sont plus courts; leurs deux lames sont moins al longées, et l'interne ne présente aucune échancrure; la nageoire postérieure esı semblable à celle de l'espèce prècédente. - Se trouve dans les mefs d'Afrique et de la Nouvelle-Guinće.

3. MHYTHOSOMA AFTHUS.

Guér., Mag. de Zool., annce 1833, 
pl. 8, fig. 2. - EDw., op. cit., t. II, p. 478. - Long. 10 lig. Larg. 4 lig. Cette espèce est généralement plus petite que l'espèce précédente; ses antennes extérieures ont un peu plus de trois lignes, et ne dépassent pas la longueur des yeux; elles sont terminées en pointe, sans aucun renflement; le bouclier antérieur ressemble entièrement à celui du Phyllosome com. mun; toutes ses autres parties sont aussi semblables, mais les deuxièmes mâchoires sont à peine échancrées au bord antérieur, quoiqu'elles soient très-prolongées en arrière; et les premiers pieds-mâchoires sont tellement petits et rudimentaires, qu'on les aperçoit à peine au-devant des deuxièmes mâchoires; ils sont entiers et sans lobes ni échancrures; la nageoire du dernier segment de la queue est beaucoup plus courte; sa lame intermédiaire atteignant à peine deux fois la longueur du dernier segment qui la précède. - Habite les mers de la Nouvelle-Hollande et de la Nouvelle-Guinée.

4. Phyllosoma freycinetir. (PI. 17, fig. 6.)

Guér., Mag. de Zool., année 1833, pl. 9, fig. 1. - Evw., op. cit. . t. II, p. 479. - Long. 17 lig. Larg. 7 lig. $\frac{1}{2}$. - Les antennes externes de cette espèce ont six lignes de long, et dépassent les yeux de plus de la moitié de leur longueur; le premier bouclier est plus large antérieurement, arrondi à ce point, et terminé en arrière en pointe; la bouche est située dans le milieu de la longueur du premier bouclier; elle est très-éloignée des deuxièmes mâchoires et des pieds-mâchoires, et semble isolée et sẻparée entièrement des autres pièces; les premiers pieds-mâchoires sont assez grands, divisés en trois lobes, dont l'inlermédiaire plus long et les autres égaux ; l'extrémité des deuxièmes pieds-mâchoires atteint à peine la bouche; la queue est presque de la longueur du second bouclier; les angles postérieurs de ses segmens sont terminès en pointe aiguë, surtout ceux du dernier, et les feuillets externes de la nageoire ont une petite épine en dehors et vers l'extrémité postérieure.-Se trouve dans les mers de la Nouvelle-Guinée.

\section{DEUXIÈME DIVISION.}

II. Antennes externes pointues, aplaties, plus courtes que les pédoncules oculaires, ne paroissant formées que d'une seule pièce, et ayant au côté externe de la base un appendice en pointe. - Deuxièmes pieds-mâchoires de trois articles; les troisièmes de cinq. - Sans fouet. - Des épines dentelées à l'extrémité interne de leur avant-dernier article.

\section{PHYLLOSOMA BREVICORNIS.}

LEACH, Journ. de Phys., t. LXXXVI (1818). - Desur., Consid. génér. sur les Crustacés, p. 255. - Latr., Encycl. Métk., t. X, p. 119, pl. 354, fig. 3.Guḱr., Mag. de Zool. , année 1833, pl. 10-11, fig. 1. - EDw., op. cit., t. II, p. 482 . - Long. 1 pouc. 9 lig. Larg. 14 lig. - Les antennes extérieures sont minces, sans élargissement à leur base, et ayant le lobe externe très-petit et peu saillant; leur longueur n'égale pas la moitié de celle des pédicules oculaires; les antennes internes sont un peu plus longues que les externes, et conformées comme dans l'espèce précédente; le bouclier antérieur est transversal en avant; les deuxièmes mâchoires sont très-petites, entières, sans aucuns lobes, et leur forme approche assez de celle d'un trapèze dont les angles seroient arrondis; les premiers pieds-mẩchoires sont insérés plus bas; ils sont très-petits, de forme conique et ayant leur pointe dirigée en arant; l'échancrure du bouclier postérieur n'est pas très-large; la queue est très-petite ; son extrémité postẻrieure n'atteint pas le bord de l'échancrure du bouclier; les cinq segmens qui la composent sont peu distincts, aînsi que les appendices du dessous, que l'ont voit à peine, et qui sont réduits à l'état de petits tubercules épais, transversaux, et légérement lobés au milieu; la lame intermédiaire du dernier segment est petite, arrondie postérieurement; les lames latérales sont très-petites, n'atteignant pas la moitiè de sa longueur; elles sont arrondies en dedans, ne paroissant formées que d'une seule pièce, et semblant légérement échancrées extérieurement. Cette espèce varie beaucoup pour la taille. Elle est assez commune. On la trouve dans les mers d'Afrique, de la Nouvelle-Hollande et des Grandes-Indes.

\section{Phyllosoma punctata.}

GuÉR., Mag. de Zool., année 1833, pl. 11, fig. 2. - Long. 13 lig. Larg. 5 lig. - Le bouclier postérieur de cette espéce est beaucoup plus large, car il présente neuf lignes dans sa plus grande largueur, il ne paroît pas échancré postérieurement, 
PIIYLLOSOMA.

et la queue est petite; le premier bouclier est oblong, presque aussi large en avant qu'en arriere; le second est ovale, transverse; les yeux paroissent avoir leur pédicule aussi long que le premier bouclier, et les antennes sont représentées très-petites; tout le corps est transparent, d'un blanc satiné; il est couvert, dans toute sa surface, d'une infinité de petits points d'un rougecarmin assez vif; les yeux paroissent être d'un jaune-orangé. - Cet individu, qui a été dessiné par M. Lesson, a été pris dans l'Océan équatorial, à deux degrés de latitude Sud.

\section{PHyllosoma DUPEREYY.}

Gó́r. , Mag. de Zool., année 1833 , pl. 12 ; ejusd., Voy. de la Coquille, Crust., pl. 25, fig. 2. - EDw., op. cit., t. II, p. 485. - Long. 16 lig. Larg. 13 lig. - Les antennes sont peu élargies à leur base, et leur extrémité atteint presque la hauteur des yeux; les antennes internes sont aussi longues que les yeux; leurs filets terminaux sont recourbés en dehors, et l'interne, beaucoup plus étroit, est plus long que l'extérieur; le bouclier antérieur est presque aussi long que large, de forme carrée, 'avec les bords arrondis et la partie inférieure échancrée; les deuxièmes mâchoires sont très-grandes, avec le lobe extérieur prolongé et pointu et le lobe posterieur grand, recourbé en dedans; les premiers pieds-mâchoires sont assez grands, divisés en deux lobes, dont l'antérieur pointu et le postérieur presque carré ; les deuxiẻmes pieds-mâchoires dépassent la hauteur de la bouche, et les troisiemes sont d'une longueur presque double de celle du premier bouclier, qu'ils dépassent de beaucoup; les premières pattes sont moins longues que ces pieds-mâchoires; les trois paires suivantes sont à peu près de la même grandeur; toutes ces pattes sont armées d'épines aux articulations, et leurs divisions sont garnies de poils de diverses grandeurs; Ies pattes pos. térieures sont petites; elles dépassent un peu la longueur de la queue; le bouclier postéricur est beaucoup moins large que le précédent, presque carré; la queue est de la même largeur à sa naissance; elle diminue d'une manière très-sensible postérieurement, et ses segmens sont transversaux; les appendices des quatre premicrs sont assez longs, bifides à l'extrémité, et ne présentant pas de traces d'articulations; leurs deux branches sont accolées l'une contre l'autre; la lame intermédiaire de la na- geoire terminale est plus large que longue; ses côtés descendent presque droits, se terminent par un petit angle aigu, et son bord postérieur, circonscrit entre ces deux angles, est arrondi et sinueux de chaque côté; les lames des côtés sont grandes, de forme carrée et à angles arrondis. - Cette espèce a été trouvée au port Jackson.

\section{PHYLlosoma mediterRaNeA.}

Guér., Mag. de Zool., Ann., 1833, pl. 13, fig. 3. - Roux, Crustacés de la Méditerranée, pl. 23. - Kow., op. cit., t. II , p. 484. - Chrysoma Mediterranea, Risso, Hist. nat. de l'Europ. Mérid., t. V, p. 88, pl. 3, fig. 9.-Long. 1 pouc. Larg. 9 lig. - Voici la description que donne M. Risso de cette espèce de Phyllosome : Le corps est ovale en travers, mince, très-aplati, foliacé, transparent, lisse, traversé de quatre lignes à peine apparentes, qui s'étendent de la circonférence au centre; les antennes extérieures sont solides, bi-articulées, ornées d'une pointe en dehors; les intérieures, moins longues, ont chacune cinq articles inégaux; celui du sommet a deux filets inégaux; les yeux, en massue, sont facettés, noirâtres, situés sur un support étroit à six articulations presque égales; la bouche est arrondie, jaunâtre, située au bas du disque ellipsoïde, avec un petit pied-mâchoire bifide de chaque côté; la queue est subcordiforme, plus étroite que le corselet, diminuant insensiblement vers l'extrémité réunie au corps, traversée vers son milieu de dix segmens dont le dernier terminé par cinq petites nageoires arrondies, les deux intermédiaires armés d'une pointe; elle est munie en dessous de trois paires d'appendices latéraux, avec cinq pointes aiguës dechaque côté, les pattes, au nombre de cinq paires, sont subtiles, translucides, tachées de rouge, composées chacune de cinq articles inégaux; les deux premiers garnis d'un aiguillon; entre le troisième et le quatrième article se trouvent de longs appendices plumeux, ciliés, tres-mobiles; le dernier article finit par un seul crochet; la dernière paire de pattes courte, quadriarticulée.

Le Phyllosome de la Méditerranée, dit le même auteur, est transparent comme le cristal le plus pur, et a l'apparence d'une lame de mica. Sa vivacité, ajoute-t-il, est extraordinaire; il vit long-temps hors de l'eau en agitant continuellement les appendices plumeux de ses cuisses; sa natation est gracieuse; il remue sans cesse ses pieds 
et ouvre de temps en temps sa bouche. Sa nourriture doit consister en molécules médullaires qu'on trouve très-abondamment daus toutes nos eaux, à la surface desquelles ils se montre durant les jours de calme parfait, et son apparition à ordinairement lieu en juin et. juillet.

Voyez, pour les autres espèces, la monographie de M. Guérin, insérée dans son Mag.de Zoologie, année 1833, et le tome $2^{\mathrm{e}}$ de l'Histoire naturelle des Crustacés, par M. Edwards.

\section{AMPHION, Edw.}

La carapace est très-développée et entiérement lamelleuse; elle s'étend jusqu'à l'origine de l'abdomen et cache la base des pattes; son diamètre longitudinal est plus du double de son diamètre transversal, et de chaque côté elle se recourbe un peu en has; son bord antérieur est presque droit, et laisse à découvert l'anneau qui porte les yeux; il n'y a pas de trace de rosire; mais de chaque côté, l'angle formé par la réunion de ce bord avec le bord latéral, se prolonge en avant en manière d'épine; enfin le bord postérieur de la carapace, qui est court et presque droit, se continue avec Jes bords latéraux sans former d'angles bien marqués. - Les yeux sont très-gros; leur portion terminale a la même forme que celle des Phyllosomes; mais la tige ètroite, qui les supporte, au lieu d'être très-longue comme chez ces Crustacés, est extrêmement courte. - Les quaire antennes s'insèrent sur la même ligne, inmédiatement au-dessous et en arrière des pédoncules oculaires; celles de la première paire ont la même forme que chez les Phyllosomes; leur portion basilaire se compose de trois articles grêles et cylindriques, dont le premier et le dernier sont les plus longs; et elles se terminent chacune par deux petites tiges filiformes, dont l'interne est Irès. courte, et l'externe à peu près de la longueur de la portion basilaire. - Les antennes externes sont beaucoup plus développées, et ne ressemblent pas autant à celles des Phyllosomes; elles se rapprochent beaucoup, par leur forme générale, de celles des Alimes; mais, au lieu d'être dirigées en bas et en dehors, elles se portent directement en avant; leur premier article, qui n'est pas bien distinct, donne insertion en dedans à une tige cylindrique, et en dehors à un grand appendice lamel. leux et à peu près ovalaire; cette lame dé- passe de beaucoup le niveau de la portion basilaire des antennes internes; ses bords interne et antérieur sont ciliés, et son bord externe se termine par une épine. La tige est composée de deux petits articies basilaires très-courts et d'un long article terminal légérement renflé vers le bout ; sa longueur est d'environ le double de celle de la lame qui en recouvre la base. - La disposition de la bouche est à peu près de même que chez les Phyllosomes; elle est très-éloignée des antennes, et forme vers le tiers antérieur de la carapace un petit tubercule arrondi, de la partie postérieure duquel naît le thorax. Les parties qui entrent dans sa composition sont : un labre, deux mandibules, une languette, deux paires de mâchoires et deux paires de pieds-mâchoires. - Le labre est transversal et peu développé. - Les mandibules ne portent pas de palpes, et sont en grande partie cachées par la languette, qui est bilobée. - Les mâchoires de la première paire sont presque rudimentaires, et consistent en une petite lame cornée dont le bord est cilié; celles de la seconde paire se composent de deux articles dont le premier présente en dedans un prolongement garni d'épines. - Les pieds - mâchoires de la première et de la seconde paires, qui, chez les Phyllosomes, n'existent qu'á l'élat de vestiges et n'entrent pas dans la composition de l'appareil buccal, sont, au contraire, ici très-développés et appliqués sur les mâchoires ; ceux de la première paire présentent en dedans plusieurs languettes garnies de poils à leurs extrémités, et au côté externe de leur base on remarque un grand appendice foliacé et ovalaire. - Les pieds-mâchoires de la seconde paire sont beaucoup plus développés que les précédens; leur article basilaire est lamelleux, et porte à sa partie antérieure: $1^{\circ}$ une tige cylindrique composée de trois articles; $2^{\circ}$ un appendice flabelliforme, ou espèce de palpe, qui s'avance an côté externe de la tige et la dépasse. - Le thorax est aplati comme chez les Phyllosomes, mais étroit et complétement caché sous la carapace; il donne attache à six paires de pattes ayant exactement la même disposition que chez ces derniers Crustacés; toutes sont grêles et cylindriques, et à l'extrémité de leur deuxième article naît un appendice palpiforme composé d'un article cylindrique terminé par une soie multiarticulée et ciliée.-Les pattes de la première paire, celles qui correspondent aux pieds-mâchoires internes 
des Décapodes, s'insèrent très-loin de Ia bouche, et sont beaucoup plus courtes que Jes autres; leur deuxième article se termine en avant par une épine aiguë. - Les pattes des trois paires suivantes deviennent de plus en pluslongues, et ont au bord de leur troisième article, une, deux ou trois épines semblables à celle qui existe à l'extrémité du second article. - Les pattes de la cinquième paire, qui sont un peu moins longues que celles de la quatrième paire, pré. sentent la même disposition; enfin celles de la demière paire sont beaucoup plus courtes que les précédentes, et ne présentent pas d'épines bien distinctes. - L'abdomen est presque aussi long que la carapace, et se compose de sept segmens; sa forme est la même que ceile de l'abdo- men des Salicoques, et il se termine par unc nageoire en éventail, dont la pièce médiane (formée par le septième anneau) est lancéolée, et dont les pièces latérales ont ovalaires. Quarit aux appendices fixés sous les cinq premiers anneaux de l'abdomen, ils sont presque rudimentaires.

La seule espéce connue et qui sert de type a ce genre est:

\section{AMPIION REYNAUDI.}

EDw., Ainit, de la Soc. Ent. de France, t. I, p. 336, pl. 12, fig. 1, A ; ejusd., op. cit., t. II, p. 489, pl. 18, fig. 8.-Long. 1 pouc. - Les tégumens de cette espèce, à l'exception de ceux de son abdomen, sont diaphanes. - Habite les mers d'Asie.

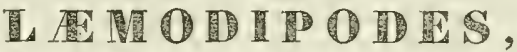

LATREILLE.

C'est à ces Crustacés que M. de Lamarck a donné le nom de Sessicoles, et que $\mathbf{M}$. Leach a désignés sous celui d'Edriophthalmes. Ce sont les seuls dont l'extrémité postérieure du corps ne solt pas terminée par une queue proprement dite, les deux dernières pattes étant insérées à ce bout, ou le segment leur servant d'attache n'étant suivi que d'un à deux articles trèspetits. Ils sont encore les seuls où les deux pieds antérieurs, et qui répondent aux seconds pieds-mâchoires, fassent partie de la tête.

Ils ont tous quatre antennes sétacées, placées entre la bouche et les yeux; une bouche présentant un labre, une paire de mandibules, deux paires de mâchoires, la langue et une lèvre suivie d'une pièce mobile, arec deux palpes. - Le corps, le plus souvent, est filiforme, linéaire, composé de sept à huit segmens, sans compter la tête; il supporte l'abdomen, les pattes, les branchies et l'appareil externe de la génération. - Les pieds sont terminés par un fort crochet; les quatre antérieurs, dont les seconds plus grands, sont toujours terminés en pince monodactyle ou en griffe. Dans plusieurs, les quatre suivans sont raccourcis, mous, articulés, sans crochet au bout, ou rudimentaires, ou nullement propres aux usages ordinaires. - Dans les uns, les branchies, au nombre de huit, sont annexées par paires aux extrémités des troisième et quatrième segmens. - Les femelles portent les œufs sous les second et troisieme segmens du corps, dans une poche formée d'écailles rapprochèes.

L'anatomie de ces Crustacés étoit encore peu connue; nous emprunterons à M. R. de Vauzème les observations suivantes, qu'il a été à même de faire sur le genre Cyame, dont il a donné la monographie des espèces qui le composoient, et dont la plupart étoient encore ignorées de la science. Nous allons examiner successiment le tube digestif, le foie, les organes génitaux internes, le système nerveux et une partie de l'appareil circulatoire. Le système digestif comprend les organes de la bouche, l'œsophage, l'estomac et l'intestin. L'œsophage esi un canal étroit contenu dans la tête; il se-renfle au niveau de l'insertion des pieds antérieurs, c'est-à-dire dans le premier segment thoracique, pour former l'estomac. A partic du pylore, le tube alimentaire se rétrécit de nouveau et se courbe à son passage dans le second anneau du thorax; là il présente un léger renflement duodénal, correspondant à l'insertion des vaisseaux du foie. L'intestin continue ensuite son trajet directement jusqu'à l'anus, oú il se icrmine en une 
pointe, dans une espèce de suture formée par trois valvules. L'estomac est pourvu d'un appareil de rumination; à droite et à gauche du cardia se trouvent deux colonnes charnues dans lesquelles sont implantées trois arêtes cartilagineuses qui, par leur extrémitè libre et bifide, se rencontrent audevant d'une pièce triangulaire, pour opérer la seconde trituration des alimens. Plus bas, les parois de la cavité stomacale sont transparentes et sontenues par des arceaux cartilagineux. Le tube digestif est formé de deux tuniques, dans lesquelles sont contenues les matières fécales noires; le foie, organe double, serpente le long du tube rudimentaire, en formant trois courbures principales, depuis le milieu du second anneau thoracique jusqu'au commencement du dernier, et finit en pointe libre; ses vaisseaux excréteurs s'abouchent dans le renflement duodénal de l'intestin par des digitations que voile en partie le second ganglion nerveux du thorax. Les organes générateurs mâles, également doubłes, sont placés immédiatement derrière le foie; ils s'étendent sur les côtés du canal digestif, depuis le milieu du troisième anneau jusqu'à la fin du dernier. Arrivés au milieu du dernier segment, ces organes se replient de bas en haut; bientôt ils quittent cette direction et pénétrent horizontalement dans les rerges situées à l'extérieur. Les ovaires, au nombre de deux, placés derrière le foie et parallèles au tube intestinal, commencent vers le milieu du second anneau et finissent à la partie moyenne du cinquième, au-dessus des valves où ils s'abouchent. Les oufs sont arrondis, unis entre eux, et maintenus dans leur totalité par une membrane pellucide fort mince, qui se termine en deux tubes, communiquant avec ces tubes du dehors en dedans.
Le système nerveux, occupant toute la longueur du tube digestif, se compose de neuf renflemens disposés par paires, enveloppés dans un névrilemne commun, et plus ou moins réunis par les deux chaines de communication. Le cerveau, organisé. en deux lobes convexes, placé entre la bouche et les yeux, fournit en avant les nerfs des antennes avec plusieurs filets minces, et en arrière des nerfs optiques. De sa, base partent deux cordons assez forts qui embrassent l'œsophage, ct forment en se réunissant deux ganglions sous - œsophagiens rapprochés, dont l'antérieur appartient à la tête et envoie quelques ramuscules aux organes buccaux, tandis que le postérieur, destiné au premier segment thoracique, fournit d'avant en arrière deux branches a la première paire de pattes. Le second ganglion du thorax, plus volumineux que les autres, anime les gros pieds monodactyles, et couvre en partie les insertions digitales du foie; les deux suivans tiennent sous leur dépendance les branchies et leurs accessoires. Les trois derniers. ganglions sont placés un peu en arrière du point central de leurs segmens respectifs, et les anneaux qui en partent se dirigent d'arrière en avant. Les cinquième, sixième et septieme se rendent aux trois paires de pattes ambulatoires. Le vaisseau dorsal, accolé au tube digestif suivant toute sa lon; gueur, est un canal transparent compose de fibres circulatoires, jamais affaissé sur luimêrne.

Tous ces Crustacés sont marins, et suivant M. Savigny ils avoisinent les Pycnogonides, et les uns et les autres condairoient aux Arachnides. Cet ordre a été divisé en deux familles : les Ovales et les Filiformes.

\section{PREMILRE FAMII.I.}

\section{O VA I, E S ,}

LATREILLE.

Caracteres. Corps ovale, avec les segmens transversaux et la tige des antennes sans articulations distinctes. - Pieds courts, peu allongés; ceux du second et du troisième segment se terminant par un long ar. ticle cylindrique et sans crochet au bout; à leur base est un corps vésiculaire allongé.

Genre : Cyamus. 
'CYAMUS, Latr, Lay., Desm.; Panope, Leach ; Larunda, Leach ; Oniscus, Pallas, Linn.; Squilla, Degeer Pycnogonum, FABR.

Le corps est large, orbiculaire, déprimé, solide et coriace; on peut le diviser en tête, thorax et abdomen. - La tète est petite, allongée, en forme de cône tronqué; on y remarque deux paires d'antennes, les organes de l'ouïe, la bouche et deux yeux composés. Les plus grandes ou intermédiaires se composent de quatre articles à base plus étroite que le sommet; les petites antennes ou antennes externes, à peine visibles, sont également formées de quatre articles, dont le premier est fort court, le second plus gros et cylindrique; le troisième a la même forme et moins de volume que le précédent; ledernier, à apparence conique, présente quelques soies fines au sommet; à la base des petites antennes, vers le côté externe et antérieur, se trouve un mamelon déprimé. - Le test crâuien présente en ce lieu une espèce d'évasement au fond duquel paraît cet organe, et que M. R. de Vauzème présume renfermer le sens de l'ouie. - Les yeux, au nombre de deux, forment une légère saillie demi-sphérique, entre les grandes antennes et le premier segment; ils sont composés de cristallins qui ne laissent pas d'empreinte sur la cornée; Iorsqu'on a enlevé cette membrane nue et continue de l'épiderme, l'œil paraîl au microscope comme un point, et même les cristallins ont une forme ovoïde; ils sont implantés, par le petit bout, dans un pigmentum noir, et ceux qui occupentle pourtour, traversés dans leur portion oblique par les rayons lumineux, représentent autour de l'œil ou sous la loupe une auréole de perles blanches et brillantes; ces yeux sont composés.-La bouche présente un labre, une paire de mandibules, deux paires de mâchoires, la langue, et une lèvre suivie d'une pièce mobile, avec deux palpes. - Le labre est situé sur la ligne médiane, en rapport latéralement avec les mandibules, et articulé en arrière avec le test crânien. - Sa face supérieure présente un onglet qui occupe environ le quart de son étendue; la partie moyenne de la face inférieure s'èlève en une espèce de crête ou apophyse labro-palatine, qui s'interpose entre les mandibules et se continue en arrière pour former les par. tie supérieure du pharynx, - Les man- dibules ont une forme irrégulièrement triangulaire; elles s'articulent par une base très-large sur le crâne à côté du labre; leur face externe est bombée et sans palpes; leur sommet présente deux divisions dont chacune est armée de cinq dents coniques; celles de la seconde rangée tiennent à une espèce de main mobile, d'où part une crête qui se porte en dedans et se termine par un prolongement auquel s'altache le muscle adducteur; les dentelures des deux mandibules se joignent au-dessous du labre, qui les couvre et les protége.-La première paire de mâchoires se trouve pres. que entièrement cachée par les mandibules et par la seconde paire; ce sont deux lames membraneuses en forme de croissant, qui ont avec la langue une telle adhérence qu'il est difficile de les en séparer; elles sont légérement cornées vers l'extrémité interne et libre; la seconde paire de mâchoires est très-forte, et contiguë par sa base avec la lèvre qui lui est intermédiaire; sur sa face dorsale on remarque un palpe à deux articulations. - Le sommet est armé de dents crochues et très-fortes au nombre de quatre, et plus bas on remarque une seconde rangée de trois dents pareilles, mais plus petites. - La langue, placée au milieu de la cavité buccale, est un corps allongé, musculeux, terminé par une extrémité bifide et légérement soyeuse. Située d'abord un peu au-dessous des griffes de la seconde paire, elle passe entre l'arcade que forment au-dessus d'elle les croissans de la première, et se perd dans le pharynx, qui est composé luimême par des membranes internes de Ia langue, du Iabre et des mandibules, réunies dans le gosier, en forme d'entonnoir. -La lèvre est impaire, sur la ligne médiane, entre les secondes mâchoires, mais plus en arrière et plus bas; elle se compose de deux pièces soudées l'une à l'autre par le bord interne et bombées en dehors; son sommet présente deux échancrures surmontées de quelques soies fines, articulées, palpiformes. Après s'être courbée en arrière, elle se termine sur une pièce évasée en cœur fixée aux deux prolongemens du crâne qui servent de support à la seconde paire; le tiers supérieur de la lère est mobile d'avant en arrière et continu par sa base avec le frein de la langue. Plus en arrière, sur la ligne médiane on voit deux palpes de cinq articles à peu près cylindriques, insérés sur une pièce échancrée, soyeuse, et mobile de bas en haut; dans l'état de repos ces deux 
palpes embrassent les parties latérales de la bouche et s'appliquent sur la face externe des mand.bules. - Le thorax est parlagé en sept auneaux ou segmens de formes diverses, portant l'abdomen, les pattes, les branchies et l'appareil externe de la génération; les anneaux, vus dans leur ensem. ble, augmentent de longueur jusqu'au quatrième, à partir duquel ils diminuent progressivement pour se terminer en pointe mousse; le premier segment est petit, globuleux, soudé à la tête et incliné dans sa direction; il s'articule en arrière avec le suivant. - L'estomac, contenu dans son intérieur, détermine sur l'enveloppe calcaire une bosselure qui ressemble au vertex; le second anneau, plus large que les autres, a pour ainsi dire la forme d'un arc tendu; le troisième et le quatrième sont transversaux et excavés latéralement pour le passage des branchies; le cinquième et le sixieme, arrondis sur leurs bords, ont une figure semblable, et ne different qu'en longueur. Le septième est plus petit que les précédens et pour ainsi dire pyriforme. A la base du dernier anneau thoracique est annexée une petite queue, ou segment abdominal, lerminée par nn anus circulaire que ferment trois valvules, dont deux latérales et une postérieure; ce rudiment gIobuleux reçoit l'extrémité de l'intestin, et donne issue aux matières fécales. - Les patles, au nombre de cinq paires, sont onguiculées. Jes pieds antérieurs, fixés au premier annean, sont grêles et de cinq articles. - La hanche est longue et fusiforme. - Le trochanter et la jambe, assez courts, sont suivis du carpe, qui présente une dent obtuse, formant pince en genou avec la griffe terminale; la seconde paire, plus forte que toutes les autres, attachée au second segment, se dirige d'arrière en avant; on $y$ compte quatre articles au lieu de cinq, parceque la piece qui représente la cuisse a disparu; la hanche est grosse, arrondie en dehors, et par-dessous prolongée en une plaque deniée; à son extrémité antérieure s'implante un trochanter pyriforme sur lequel paraît le carpe, qui est ovoïde, aplati et armé de deux dentelures profondes; une forte griffe monodactyle rend ces pieds plus aptes à la préhension qu'à la marche; les trois paires suivantes, ou ambulatoires proprement dites, issues des trois premiers segmens, ne diffèrent entre elles que par une diminution progressive de longueur et de volume, la forme des articles étant d'ailleurs exactement la même. Ces mem. bres se composent de cinq pièces: la pre. mière, ou la hanche, est un peu ronde en dessus, et couverte par le prolongement latéro-sternal dú segment; elle se montre en dessus échancrée sur deux de ses bords, ct arrondie sur l'autre. - Le trochanter est étroit et de forme triangulaire ainsi que la cuisse, qui a deux bords creusés, le troisième libre et convexe. - La jambe, longue, plate et courbée sur elle-même, se termine par une griffe robuste finement acérée. - Les branchies, au nombre de huit, sont annexécs par paires aux extrémités des troisième et quatrième segmens; la forme du canal branchifère peut être comparée à une sot: che qui, vers l'extrémité de chacun de ces anneaux, se bifurque en deux tiges cylindriques lisses, transparentes, inégalement longues, et croisées sur le dos de l'animal arec celles du côté opposé; au bas des fourches branchiales du tioisième segment, on aperçoit, chez les mâles, un appendice grêle et de moitié moins long que la seconde tige, dont il embrasse le contour; mais les doubles branchies du quatrième anneau difièrent de celles du troisième en ce que, au licu d'avoir à leur base un seul appendice, elles en ont deux inégaux. Les branchies de la femelle sont plus petites et ordinairement contournées l'une sur l'autre; les appendices qui existent chez les mâles ont disparu, et sont remplacées par Ies opercules des oufs, au nombre de quatre, deux pour chaque anneau. Ces petites valves, frangées sur leurs bords, se réunissent avec celles du côté opposé pour former une espèce de matrice externe dans laquelle les øufs sont contenus; chaque valve, appuyée par son pédicule sur le tronc commun des branchies, est composée de deux membranes transparentes formant un sac sans ouverture extérieure; les opercules des œufs ne servent pas à la respiration comme le pensait Treviranus : car, chez les mâles desséchés, les appendices ne sont pas organisés comme des branchies, mais cornés; tandis que les tiges branchiales proprement dites sont membraneuses et contiennent les vaisseaux afférens et efférens:; les appendices, avec leurs parois épaisses, ne sont nullement propresả permettre l'oxigénation; ils sembleraient se rapprocher davantage de la nature des pattes, et peut-être de ces organes qui ont été reconnus comme propres à entretenir chez certains crustacés l'humidité propre aux branchies. Quant aux opercules des œufs, 
fransformation des appendices en matrice externe, sans canaux pulmonaires, trop raste pour la petite quantité de fluide mis en circulation, il est certain qu'ils ne remplissent pas le rôle de poumons; l'appareil externe de la génération, double comme chez tous les Crustacés, paraît sur les mâles à la fin du dernier anneaı, entre les demières pattes, sous forme de deux verges coniques séparées à leur base, et dirergentes; ces tubes, dans lesquels viennent aboutir les extrémités des canaux déférens, sont appuyés sur un organe excitateur, à sommet bifide, en forme de gland, qui se replie sur lui-même en forme de verge, et va se confondre en haut et en arrriere avec le tubercule anal. Chez la femelle on trouve les deux vulves au milieu du quatrième anneau ; derrière les opercules des œufs elles se joignent sur la ligne médiane, en un cintre qu'on dirait formé de deux pyramides adossées par leur base; en écartant ces organes, et en les renversant, on aperçoit, au fond d'une espèce de cornet, deux ouvertures très-petites, communiquant par deux canaux obliques avec les ovaires; ces canaux ou oviductes sont dirigés de dedans en dehors et conformes à la direction des verges; sur le milieu des deux derniers segmens et la hanche des deux dernières pattes, on observe chez les deux sexes plusieurs tubercules coniques dont l'usage est probablement de fixer l'animal sur la baleine, ou pendant la copulation.

1. Cyamus ovalis. (Pl. 17, fig. 4.)

R. DE VAUZ, Ann. des Sc. nat,, t. I, p. 259 , pl. 8 , fig. 1 à 3 . - Cette espèce est de couleur blanchâtre; son corps est ellip- lique, aplati; les segmens sont rapprochés, et les branchies, inégales, sont au nombre de quatre paires; celles du troisième segment n'ont a leur base qu'un appendice courbe et grêle; celles du quatrième en ont deux inégaux. -- Elle vit agglomérée sur les éminences cornées de la tête des Baleines franches (Balcenc Mysticetus).

\section{CYAMUS ERRATICUS.}

Rouss. de Vauz., Ann. des Sc. nat., t. I, pl. 8, fig. 22. - La couleur est d'un rouge vineux; les segmens du thorax sont écartés; les crochets des pattes sont forts et acérés; les branchies sont simples, trèslongues, pourvues à leur base de deux appendices inégaux et pointus.

Cette espece erre sur la surface du corps, ou se réfugie dans les plis des sourcils, de la commissure des lèvres, du nombril, des régions génitales et anales; elle recherche aussi les plaies récentes et les fissures des anciennes cicatrices, n'importe où elles se trouvent,

\section{CYAMUS GRACILIS.}

Rouss. DE Vavz., Ann. des Sc.nat., t. I, p. 259, pl. 8, fig. 24. - La couleur est d'un jaune clair; le corps est petit, oblong; les anneaux du thorax sont échancrés sur leurs bords; les branchies, au nombre de quatre, sont pédiculées, et ont chacune à leur insertion deux appendices très-courts. Cette espèce demeure sur les protubérances de la tête.

Consultez, pour les autres espèces, la pl. 28 de l'Icon. du Rég. anim. de Cuv., par M. Guérin.

\section{DEUXIÈME FAMILLE。}

\section{FILIFOR M ES,}

Jat TREILle.

Caractères. Corps long et très-grêle ou linéaire, avec les segmens longitudinaux. - Pieds paraillement allongés et déliés, et la tige des antennes composée de plusieurs petits articles.

Genres : Leptomera, Naupredia, Caprella.

\section{LEPTOMERA, LATR., LAM., Desm.}

Les pieds, au nombre de quatorze, sont dispesés dans une série continue depuis la tête jusqu'à l'extrémité postérieure, dız corps, en y comprenant les deux premiers, qui sont annexés à la tête; ces pieds, trèsgrêles, ne paroissent pas tous pourvus d'ap. pendices en forme de sac vésiculeux à leur base, ou même n'en ayant pas du tout.

LEPTOMEPA VENTRICOSA.

Latr., Rég. anim. de Cuv., t. VI, p. 27. - Desra, Consid. génér. sar les Crasto 
p. 276, pl. 46, fig. 3. -Gúér., Iconogr. du Règ. anim. de Cuv., Crust., pl. 28, fig. 3. - Squilla Ventricosa, Muls., Zool. Dan. , tab. 56, fig. 1, 3. - Cette espèce présente un appendice en forme de lobe à tous les pieds, les deux premiers ex. ceptés. M. Latreille lui rapporte aussi l'espèce représentée par Slabber, Micros., tab. 10, fig. 2, et le Cancer Pcdatus, Monlagu, Transact. Linn., t. XI, pl. 2, fig. 6, qui en a tous les pieds pourvus, moins ceux de la première et des trois dernières paires.

\section{NAUPREDIA, LATr.}

Les pieds sont au nombre de dix, et tous sont dans une série continue; les seconds et les deux paires suivantes ont a leur base un corps vésiculaire.

Nous ne connoissons pas l'espèce qui a servi de type à ce genre. M. Latreille, Rég. anim. de Cuv., nouvelle édit., dit à la p. 128 : "Ce sous-genre a été établi sur une espèce de nos côtes qui me paroît inédite."

\section{Caprella, Lay., Latr., Leach, Desm. ; Cancer, Lrnv.; Gammarus, Fabr.}

Les pieds sont au nombre de dix, et ainsi disposés : deux petits annexés à la tête, terminés par une pince en crochet dont la main est un peu renflée; une seconde paire longue, avec des serres, dont la main est grande et oblongue, insérée sur le premier segment du corps; les second et troisième segmens sont dépourvus de pattes et n'ont que des appendices vésiculeux; les quatrième, cinquième et sixième segmens portent six pattes longues, grêles, et terminées par un ongle long, un peu arqué et crochu. - Le corps est très-grêle. - La queue est très-courte.

Ces Crustacès, qui sont tous marins, ont la plus grande analogie avec ceux qui for-ment les deux genres précédens, et portent comme eux leurs œufs placés dans une sorte de poche écailleuse, qui est située sous le second et le troisième segment du corps dans les femelles. Les Chevrolles se tiennent parmi les plantes marines, et surtout sur les éponges, marchent à la manière des chenilles arpenteuses, se redressent lentement en faisant vibrer leurs antennes, et nagent en courbant en bas l'extrémité de leur corps.

\section{Gaprella acutifrons.}

Desa., Consid. génér. sur les Crust, p. 277. - Caprella Atomos, Baster, Opusc. Subs., 1, tab. 4, fig. 2 à 50. - La tête est ovale, le front est pointu; les antennes inférieures sont très-ciliées; le corps est uni ; son premier segment est cylindrique, pas plus gros que la tète, donnant attache antérieurement aux seconds pièds, qui sont courts. - Se trouve sur les côtes d'An. gleterre.

\section{CAPREYLA ACUMinifera.}

Desy. , Consid. génér. sur les Crust., p. 277. - La tête est ovale ; les antennes sont presque sans cils; le corps présente en dessus des petits tubercules en forme de pointes; le premier segment est renflé postérieurement oú les pieds de la seconde paire prennent attache; ces pieds sont allongés, ont leur serre échancrée en forme de croissant et armée d'une forte dent en dessous.

\section{GAPRELIA IINEARIS.}

Desm., Consid. génér. sur les Crust. p. 278. - Cancer Linearis, Linn.-Squilla Quadriloba, Mulz., Zool. Dan., tab. 56 , fig. 4, 5, 6, mas; tab. 114, fig. 11, 12. La tête est allongée, rétrécie en arrière; le second segment du corps est renflé postérieurement ou les pieds de la seconde paire prennent attache; le second article de ces pieds est allongé, cylindrique, arec quelques pelites dents en dessus; leur serre est allongee, avec trois dents en dessous. - Se trouve sur les côtes de la Manche.

Voyez, pour les autres espèces, l'Icon. du Rég. anim., par M. Guérin, Crust. , pl. 28, fig. 1-2.

\section{QUATRILUE ORDRE.}

\section{AMP}

Latreille, Edwards.

Cel ordre, qui a été créé par M. La¿reille et qui a été adopté par M. Edwards a été ainsi caractérisé par ce dernier au. teur : Crustacés maxillés, dont le corps est 
divisé en treize ou quinze segmens mobiles et ne présente pas en dessous de bouclier céphalo-thoracique ou carapace; dont le thorax ne présente pas sur les côtés une cavité respiratoire renfermant les branchies; dont les sept paires de membres, situées immédiatement à la suite du labre, rentrent dans la composition de l'appareil buccal; dont les autres membres thoraciques ont la forme de pattes ambulatoires ou préhensiles, et n'ont jamais la forme de feuilles membraneuses, mais portent à leur base (celles de la première paire et quelquefois celles de Ia dernière paire exceptées) un appendice membraneux plus ou moins vésiculaire, qu'on peut regarder comme l'analogue du fouet, et qui parait remplir les fonctions d'un organe respiratoire; dont les membres abdominaux, au nombre de six paires, sont hétéromorphes, ceux des trois premières paires constituant des fausses pattes natatoires très-mobiles, terminées par de longues lames cornées, et ceux des paires suivantes presque immobiles terminés en général par des stylets ou des appendices foliacés, et concourant à former une espèce de queue; dont les yeux sont composés, sessiles, immobiles, et au nombre de deux; dont le système nerveux central consiste en deux chaînes ganglionnaires distinctes ou réunies, et occupant toute la longueur du corps; dont le cœur a la forme d'un vaisseau longitudinal placé dans le thorax ; dont les organes génitaux mâles s'ouvrent en dehors de chaque côté de l'arceau inférieur du dernier anneau thoracique; dont la femelle porte les œufs sous le thorax, et dont les petits naissent avec les formes gẻnérales qu'ils doivent toujours conserver. Ces derniers restent attachẻs au corps de leur mère jusqu'à ce qu'ils aient acquis assez de force pour pourvoir par eux-mêmes à leur subsistance.

Tous ces Crustacés de petite taille sont aquatiques ou terrestres; parmi les premiers il y en a de parasites. M. Latreille divise cet ordre en trois familles : les $C r e$ vettines, les Podocérides et les Hypérines.

PREMILRE FAMLLE.

\title{
CREVETTINES,
}

\author{
Latreille, Edwards.
}

Caractères. Pieds-mâchoires recouvrant soute la bouche, et formant une espèce de lèvre infẻrieure impaire, terminée par quatre grandes lames cornées et deux longues tiges palpiformes. - Corps grêle et allongé. - Tête petite.

Genres : Orchestia, Talitrus, Lysianassa, Gammarus, Amphithoe, Phlias, Isca, Leucothoe.

\section{ORCHESTIA, Leach, Desm. ; \\ Talitrus, Latr., Risso; Oniscus, Pallas.}

La lame épimérienne du cinquième anneau thoracique est presque aussi développée que celles situées plus antérieurement. - Les pattes antérieures sont beaucoup moins grandes que celles de la seconde paire, et se terminent par une petite main imparfaitement subchéliforme; celles des sixième et septième paires sont beaucoup plus longues que les autres.

ANw.
Ces Crustacés vivent sur le rivage, et ils ont la faculté de s'enfouir dans le sable avec beaucoup de rapidité.

\section{A. ORCHESTIA LITTORALIS.}

Leach, Edinb. Encycl., Trans. Societ. Linn., t. XI, p. 36. - DeSM., Consid. génér. sur les Crust., pl. 45, fig. 3.-Cancer Gammarus Littoreus, MonTag., Linn., Trans., t. VII, pl. 4.-Long. 7 lig. -D'un vert pâle nuancé de rougeâtre; tête petite; pattes de la sixième paire ayant à peu près la même grandeur que celles de la septième paire; point de gros tubercules sur le milieu du bord antérieur de la secons paire; bord antérieur de ces mêmes mains convexe, et suivant à peu près la courbure de la griffe; point de tubercule pointu sur le bord interne de la griffe des mêmes pattes de la seconde paire. - Se trouve sous les pierres ou sous les tas de plantes marines rejetées par les vagues, dans le midi de la France et dans le comté de Nice. 
2. ORChestia FischeriI. (Pl. 17, fig. 8.) Évw., Mém. de la Sociét. d'Hist. nat. de Paris, t. V, pl. 95, fig. 14; ejusd., Ann.

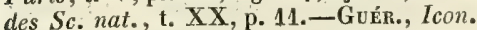
du Régn. anim. de Cuv., Crust., pl. 26, fig. 3. - Les antennes supérieures sont très-courtes, grossés et subulées; les infèrieures sont à peu près de la longueur du thorax; les yeux sont grands et circulaires; les mandibules sont dépourvues de palpes, comme chez les autres $\mathrm{Or}$ chesties; les pattes thoraciques de la première paire sont petites, non chélifères, et terminées par une petite main très-étroite; celles de la seconde paire sont au contraire très-grandes, et leurs mains ont à peu près la même forme que dans les précédentes; seulement, le bord antérieur présente une apophyse qui remplit une partie de l'espace compris entre elles et la griffe qui les termine, et qui est extrêmement grande; les pattes des trois paires suivantes sont petites; celles de la sixième paire acquièrent des dimensions très-considérables; la hanche s'élève bien au - dessus de son point d'articulation avec le corps, recouvre une grande partie de l'abdomen, et cache complétement la patte suivante; les autres articles sont très-longs, mais ont la forme ordinaire; les pattes de la septième paire n'atteignent pas l'avant-dernier article des précédentes, et leur article basilaire, quoique clypéiforme et aussi large que long, dépasse à peine l'espèce de bouclier dont nous venons de parler; les anneaux thoraciques et le premier anneau de l'abdomen sont arrondis et lisses en dessus; mais les deux segmens suivans portent à leur bord postérieur trois gràndes épines placées verticalement près l'une de l'autre et de chaque côté de la ligne médiane; le quatrième et le cinquième anneau de l'abdomen sont hérissés en dessus de pelites pointes, et les appendices qui représentent l'anneau caudal sont beaucoup plus développés que chez les autres Orchesties.

Pour les autres espèces, voyez M. S AvIGNy, Descript. de l'Egypte: à la pl. 11, fig. 7, est représentée $I^{\prime} O$. Montagui, Aod., à la pl. 11, fig. 8, l'O. Deshayesii, Aud.

TAlitrus, Latr., Bosc, Leach;

Astacus, Penn.; Cancer, Montagu;

Oniscus, Pallas.

Les pattes antérieures sont, en général, fortes ot terminées par un article gros et pointu qui n'est pas sisceptible de se re- ployer sur l'article précédent, et qui sert à l'animal pour creuser. le sol; tandis que celles de la seconde paire sont faibles et habituellement reployees sous le corps; mais quelquefois on rencontre une disposition contraire, et ce sont les paites de la seconde paire qui sont les plus fortes; mais elles ne se terminent jamais par une main préhensile et armée d'une griffe mobile. - La queue est composée de cinq articles dont le dernier est le plus petit. - La tête est nue, prolongée en forme de bec.

Les Talitres nagent de côté sur les bords de la mer, et se traînent sur le sable; ils s'assemblent en grand nombre sur les corps morts que le flot rejette, pour s'en nourrir. Ils sautent très - bien au moyen du mouvement de ressort qu'ils donnent à leur queue.

\section{TALITRUS SALTATOR.}

EDw., Ann. des $S$ c. nat., t. XX, p. 13. - Squilla Saltator, Klein, Crust., p. 68, fig. B, E, F.-Gammarus Saltator, Montagu, loc. cit., pl. 4 , fig. 3 , etc. Long. 6 lig. - Le corps est d'un cendré plus ou moins foncé, avec les antennes roussâtres, velues, ainsi que les trois dernières paires de pattes; les pattes de la première paire sont beaucoup plus fortes que celles de la seconde; l'ongle des secondes patles est inséré sur le bord supérieur de l'article précédent, et n'atteint pas son extrémité.-Très-commune sur les côtes, et surtout sur les plages sablonneuses.

Pour les autres espèces, voyez M. Savigny, Ouvrage d'Egypte, pl. 11; à la fig. 9, est représentée le Talitrus Cloquetii, EDw., Ann. des Sc. nat., t. XX, p. 13, Orthesita Cloquetii, Aud.

\section{LYSIANASSA, EDW.}

Les Crevettines placées dans cette nouvelle division générique par M. Edwards, se rapprochent des Talitres par la structure de leurs pattes, dont aucune n'est préhensile. - Celles de la première paire sont assez fortes, presque cylindriques dans toute leur longueur, et terminées par un article court et presque immobile. L La forme des divers appendices de la bouche est au contraire la même que dans les Crevettes. - Les antennes sont quelquefois trés-courtes, mais les supérieures sont toujours au moins aussi longues que les pédoncules des inférieures, et se terminent par deux tigelles annelées. 
LYSIANASSA COSTA.

Edw., Ann. des Sc. nat., t. XX, p. 14, pl. 10 , fig. 17.-Long. 3 lig.-Les antennes supérieures sont très grosses à leur base; elles diminuent rapidement de volume et se terminent par deux petites tiges annelées : l'une formée de six ou sept pièces, l'autre de trois ou quatre; les antennes inférieures sont extrêmement grêles; les yeux sont grands et réniformes; les pattes de la première paire sont courtes, très-grosses et terminées par un article grand et conique; celles de la seconde paire sont grêles, aplaties, allongées, contournées et faibles; leur extrémité est arrondie, et l'angle qui les termine est rudimentaire ; elles sont impropres à la locomotion et à la préhension; les suivantes sont grêles, et leur ongle est long, mince et un peu courbe; enfin, la hanche ou article basilaire des dernières pattes est très-élargie, et son bord postérieur est semicirculaire; les appendices de l'abdomen n'offrent rien de remarquable, si ce n'est que les stylets terminaux de ceux des trois derniers anneaux sont très-courts. - Se trouve parmi les fucus dans la baie de $\mathrm{Na}$ ples.

\section{GAMMARUS, Fabr., Latr, Leach, Desir., Edw. ; \\ Squilla, Degeer; Cancer, Linn.}

Les antennes sont insérées au-derant de la tête, entre les yeux, de médiocre grandeur, composées de trois articles principaux, et d'un quatrième sétacé, multiarticulé et terminal; les supérieures ayant à l'extrémité inférieure de leur troisième article un petit appendice sétacẻ, multiarticulé. - Les quatre pieds antérieurs sont terminés par une main comprimée, large, pourvue d'un fort crochet, ou doigt mobile, qui s'applique sur sa branche inférieure; les quatre pieds suivans finissent par un article simple, ou ongle un peu courbe; les six derniers plus longs, relevés sur les côtés du corps, et ayant leur article terminal mince et droit._- On aperçoit des filets longs, bifides, très-mobiles, de chaque côté du dessous de la queue, qui est terminée par trois paires d'appendices allongés, bifurqués, ciliés, étendus à peu près dans la direction du corps, et qui constituent une sorte de ressort dont l'animal se sert pour exécuter des sauts très-considérables, et pour nager en poussant l'eau derrière lui.-Le corps est oblong, très-comprimé, arqué, divisé en treize articulations, la tète étant comprise pour une; chacun de ces segmens est garni en dessous d'une lame crustacée, mince, demi-transparente, transverse, et les sept premiers d'entre eux étant accompagnès d'une pièce. Iatérale aussi crustacée qui recouvre la base des pattes.

Ces Crustacés, connus vulgairement sous le nom de Crevettes des ruisseaux, ou Che. vrettes, abondent en très-grandes quantités dans nos fontaines, nos bassins et nos sources. Ils nagent toujours au fond, couchés sur le côté, et leur principal moyen de pro. gression consiste dans la détente rapide et souvent renouvelée des appendices de leur queue. Ils sont carnassiers et paroissent vivre de la chair des poissons morts, et même de celle des individus de leur propre espèce. On les trouve souvent accouplés. Les mâles emportent leurs femelles, beaucoup plus petites qu'eux, entre leur jambes. Les femelles gardent leurs œufs jusqu'au moment oủ ils éclosent, et les petits qui en sortent se mettent pendant quelque temps à l'abri sous leur ventre ou sous les lames latérales de leur corps. Quelques espèces appartenant à ce genre sont marines.

\section{A. Gavimares logesta.}

Leach, Edinb. Encycl., et Trans. Soc. Linn., t. XI, p. 359.-DEsy., Consid. génér. sur les Crust., p. 267.-Guér., Icon. du Règ. anim. de Cuv., Crust., pl. 26, fig. 7.-Evw., Ann. des Sc.nat., t. XX, p. 16. - Cancer Gammarus Locusta, Montage, Linn: Trans., t. IX, p. 92. Le bord supérieur des trois premiers segmens de l'abdomen est droit, et ne se prolonge pas de manière à former unc grande épine médiane; les quatrième et cinquième anneaux de l'abdomen sont armés en dessus de petits faisceaux d'épines; les yeux sont plus ou-moins réniformes, mais ne présentent pas la forme d'un S romain; les antennes supérieures sont garnies seulement de quelques poils trèscourts; les fausses pattes abdominales de la sixieme paire sont beaucoup plus saillantes que celles des deux paires précédentes; le premier article des dernières pattes thoraciques est irrégulièrement ovalaire; les fausses pattes abdominales de la sixieme paire sont terminées par deux grands articles épineux. - Très-commune sur les côtes d'Angleterre, et un peu moins sur celles de France.

\section{2. gammarus ouivi.}

EDw., Ann.des Sc, nat, t. XX, p. 21.- 
Plus petite qué la précédente, et de couleur verte; de plus, eile est remárquable par la disposition de l'article terminal despattes de ia seconde paire, qui se reploie sur le bord de l'article précêdent dans les mouvemens ordinaires, et qui, dans la flexion complète, glisse un peu sur la face interne de la main; les yeux sont plus lunulés que chez la Crevetie Locuste, et les antennes au moins aussi longues; les supérieures sont peu ciliées; les appendices de la bouche ne présentent rien de remarquable; les pattes des deux premières paires sont à peu près de la même grandeur, et la main qui les termine est rétrécie antérieurement, de sorie que le bord sur lequel la griffe se reploie est plutôt inférieur qu'antérieur; les anneaux abdominaux ne présentent à leur face supérieure ni carène ni épine, et les trois derniers ne sont pas courbés de manière à former une espèce de coude avec les premiers; les deux petits appendices terminaux du sixième segment sont coniques, et les fausses pattes de la dernière paire sont beaucoup plus saillantes que celles de la cinquième paire, et ne portent qu'un grand stylet aplati et épineux; l'autre pièce qui les termine étant rudimentaire et à peine visible.- Se trouve sur les côtes de Naples.

\section{GaMmarus ornatus.}

EDw., Ann. des Sc. nat., t. XX, pl. 10 , fig. 1. - Long. 1 pouc. - Cette espèce diffère peu de la Crevette Locuste, mais si on l'étudie avec soin, on voit que la longue tige terminale de ses antennes inférieu. res présente une disposition très-curieuse. A la partie supérieure des neuf ou dix premiers articles de chacune de ses tiges, on trouve une petite cupule membraneuse, transparente, invisible à l'œil nu, légérement ciliée sur les bords, fixée à l'antenne par sa base, et entourée de quelques poils. On ignore à quel usage ces especes de ven. touses microscopiques peuvent servir. Les yeux sont presque linéaires et recourbés en avant; les antenues sont à peu près de la mẻme longueur; le pédoncule des supérieures est plus long que d'ordinaire, et leur second article n'est guère plus long que le premier; mais le troisieme n'est pas moitié aussi long que le second; la tige terminale est formée d'environ quarante articles un peu allongés et à peine ciliés; enfin l'appendice inséré au-dessus est assez long; on y compte environ dix articles; le pédoncule des antennes inférieures n'est guère plus long que celui des supérieures, et sả tige terminale est divisée en une vingtaine d'articles, dont les neuf ou dix premiers portent de petites cupules; on y remarque aussi un grand nombre de poils très-longs; les palpes mandibulaires sont grands, et leur dernier article est garni en dedans de poils roides et courts; les pattes sont réunies sur la ligne médiane, de manière à former une espèce de grande lèvre qui recouvre toute la bouche; les pattes des deux premières paires ont la même forme; mais les secondes sont notablement plus grandes que les premières, et garnies de plus de poils; la main n'est pas très-large ; son bord antérieur est oblique, mais bien distinct de l'inférieur, et garni d'une ou deux épines; les pieds de la troisième et de la quatrième paire ne présentent rien de remarquable; mais le premier article des trois paires postérieures, au lieu d'être à peu près ovalaire, a la forme d'un carré allongé ; on ne trouve au-dessus du thorax que deux rangs d'appendices lamelleux; les trois derniers articles de l'abdomen pré. sentent quelques épines situées sur la ligne médiane, près de leur bord postérieur; les six premières fausses pattes de l'abdomen sont longues et grêles; celles des quatrième et cinquième paires sont terminées par des stylets très-courts; celles de la sixième paire les dépassent de beaucoup, et portent chacune deux articles terminaux coniques et d'égale longueur; les appendices qui représentent le septième anneau abdominal, ou l'anneau caudal, sont trèspetits, dirigés en haut, et styliformes. Cette espéce a été envoyéc de Boston au Muséum de Paris, par M. Lesueur.

\section{Gamiares marines.}

Leach, Trans. Linn., t. XI, p. 359. Gammarus Pulex; ejusd., Edinb. Encycl., t. VII, p. 402-432. - Desu., Consid. génér. sur les Crust., p. 267. - Edw., Ann. des $S_{c . n}$ nat., t. XX, p. 16. - Le filet supérieur des appendices de la queue est trèscourt; l'avance de la tête, qui est entre les antennes, est plus prolongée et presque pointue; les fausses pattes adbominales de la dixième paire dẻpassent à peine les deux précédentes. - Habite les còtes de France et celles d'Angleterre.

\section{GAMMARUS FLUVIATILIS.}

Edw., Ann. des Sc. nat., t. XX, p. 17. - Gammarus Pulex, Drsu., Consid. génér. sur les Crust., p. 266 , pl. 45 , fig. 8. 
-Crevelte des ruisseaux; Groff., Ins. des environs de Paris, t. II, p. 667, pl. 21, fig. 6. - Squilla Pulex, Degéer, Ins., t. VII, pl. 33, fig. 1, 2. - Long. 7 lig. Iarg. 2 lig. - Couleur d'un jaune rouilte, avec les yeux noirs; le cinquieme anneau de l'abdomen est lisse en dessus, et ne présente pas d'épines; la griffe des secondes pattes s'infléchit sur le bord de la main, et non sur la surface interne; l'anneau caudal est représenté par deux petits articles styliformes dirigés en haut; le pédoncule des antennes supérieures ne dépasse pas le troisième article du pédoncule des antennes inférieures; les antennes supérieures sont à peu près de la longueur des inférieures. - Très commune dans les ruisseaux des environs de Paris.

\section{GAMMARUS ROESELII.}

Gervais, Ann. des $S$ c.nat., t. IV, p. 127. - Cette espèce diffère de la précédente par les segmens de son abdomen, qui présentent des épines. - Elle se trouve aux environs de Paris, mais seulement dans l'eau de puits.

M. Gervais a aussi observé une variété qu'il désigne sous le nom de Gammarus Pulex Minutus, et qui est remarquable par la petitesse de sa taille; cette variété, suivant le même naturaliste, est constamment étiolée, et les yeux, au lieu d'être noirs comme chez les espèces précédentes, sont toutà-fait sans pigmentum; cette variété est due à la différence du séjour.

Pour les autres espèces consultez l' $E x$. trait des recherches pour servir a l'Hist. nat. des Crustacés Amphipodes, par M. MilneEdwards, Ann. des Sc. nat., t. XX.

\section{AMPhithoe, Leach, Desir., Edw.;}

Gammarus, Latr.; Oniscus, Pallas;

Cancer, Montagu.

Ce genre diffère du précédent en ce qu'il n'offre point d'appendice sétacé à l'extrémité intérieure du troisième article des antennes supérieures. Les mœurs sont entièrement les mêmes.

\section{AMPHTHOE SERRATA.}

SAY, Journ. of Philadelph., vol. I. EDw., Ann. des Sc. nat. , t. XX, p. 24.Le front est dépourvu de rostre; les antennes supérieures sont aussi longues ou plus longues que les inférieures; les flancs sont dépourvus d'épines; le dos est sub-caqéné, ct présente de grandes dentelures vers la partie postérieure; les mains des quatre pattes antérieures sont armées en dessous de trois grandes dents épineuses.

\section{AMPHITHOE JURINEI:}

EDw., Ann. des Sc. nat., t. XX, p. 25.Le dos est arrondi, et ne présente ni carẻne ni dentelure; le premier article des six derniéres pattes sont sans dentelures notables vers le bord postéricur; les fausses pattes abdominales de la sixieme paire sont beau. coup plus saillantes que les précédentes, et terminées par deux articles au moins aussi longs que le pédoncule; le bord postérieur des derniers anneaux de l'abdomen. est sans épines.

\section{AMPHITHOE PaUSilipa.}

Edw., Ann.des Sc.nat. t. XX, p. 25. Les fausses pattes abdominales de la sixième paire sont terminées par deux petits-articles très-courts, et dépassent à peine les précédentes; le premier article des six dernières pattes est très-élargi et arrondi postérieurement; les mains des pattes antérieures sontà peu près de la grandeur de celles de la seconde paire; la tige terminale des antennes inférieures est beaucoup moins longue que le pédoncule, et formée environ par dix ou quinze segmens; les antennes inférieures sont beaucoup moins longues que les supérieures.

\section{AMphiтhoе costata.}

Evw., Ann. des Sc.nat.,t.XX, p.28.pl.10, fig. 14-16. - Chez cette espèce, l'enveloppe tégumentaire est beaucoup plus dure et plus épaisse, et de chaque côté du corps il existe une ligne saillante formée par une série d'éminences allongées qui occupent la partie inférieure du segment dorsal de chaque anneau thoracique, et se prolongent postérieurement en forme d'épines; les antennes supérieures sont plus courtes que les inférieures; leur pédoncule est formé de trois petits articles dont la longueur va en décroissant, et leur tige terminale est divisée en une trentaine d'anneaux; le pédoncule des antennes inférieures est beau. coup plus court que d'ordinaire, car il dépasse à peine celui des supérieures; mais leur tige terminale est très-longue, et composée d'environ cinquante segmens; les yeux sont circulaires; les palpes mandibulaires très-grands et formés de quatre articles; les pièces latérales des anneaux thoraciques ne sont pas très-grandes; mais au-dessus de chacune d'elles est un rebord saillant qui se prolonge postérieurement en pointe, en 
sorte qu'il existe de chaque côté du thorax une rangée d'apopbyses épineuses dirigées en arrière; les paites de la première paire sont un peu plus grosses que celles de la seconde; mais leur forme est la même, et Ja main qui les termine est arrondie et un jeu dentelée inférieurement; les trois preniers anneaux de l'abdomen sont élevés sur la ligne médiane et prolongés en forme de dents; les appendices abdominaux de la sixième paire sont terminés par deux grands articles, et dépassent de beaucoup les piécédens.

Cette espece, trourée à l'lle-Bourbon, fait partie des collections du Muséum d'Hist. nat. de Paris; pour tes autres espèces voy. M. Savigny, Ouvrage d'Egypte, pl. 14, fig. 4: c'est l'Amphithoe Fitosa, Aud.; et le Mémoire de, M. Edwards déjà cité ci-dessus.

\section{PHLIAS, Guér.}

Le corps est court, comprimé latéralement, composé de quatre segmens, non compris la tête. - Tếte petite, en grande partie cachée dans le premier segment. Les yeux sont saillans. - Les antennes supérieures, grandes, ont un pédonculerentlé et composé de trois articles; la tige étant détruite, il n'en restait que la base, et on voyait qu'il n'y avait pas depetitfilet supérieur comme dans les crevettes. -Les antennes inférieures, très-petites, sont insérées sous les précédentes, et ont une courte tige multiarticulée. - Les pattes sont filiformes et au nombre de quatorze paires; elles sont simples et monodactyles; les quatre premières paires égales entre elles ; sont plus courtes que les trois dernières, qui sont aussi égales entre elles. - Les appendices natatoires des trois premiers segmens del'abdomen sont de forme ordinaire; ceux du quatrième un peu plus petits, mais encore semblables, c'est-à-dire terminés par deux lames plus longues que la tige qui les supporte, ciliées; ceux du cinquième sont composés d'une tige 'plate terminée par deux petites lames ovalaires et plus courtes; enfin ceux de l'avant-dernier' segment ont leur tige plus courte, large et arrondie, et terminée par deux petites lames ovales et un peu pointues; le dernier seg- ment abdominal est très-court, transversal et un peu arrondi.

PhLias Serratus. (PI. 17, fig. 7.)

Guér., Mag. de Zool., 1836, pl. 19, fig. 1. - G'est la seule espèce que l'on connaisse; tous les segmens de son corps ont leur branche supérieure très-saillante, ce qui le rend fortement dentelé quand on le voit de profil; sa couleur est d'un jaune-brun opaque. - Elle a été trouvée pendant la traversée des îles Malouines au port Jackson.

\section{ISOEA, EDw.}

Dans ce genre, la forme générale du corps est la même que chez les Crevettes. - Les antennes supérieures se terminent aussi par deux appendices annelés; mais au lieu de n'avoir que les pattes des deux premières paires préhensiles, ces Crustacés les ont toutes terminées par une griffe mobile qui se reploie sur le bord de l'article précédent.

La seule espèce connue est l'Isœa de Montagu, Isøa Montagui, Edw., Ann. des Sc.nat., t. XX, p. 29. Nous ne connaissons cette espèce ni sa description.

\section{LEUCOTHOE; Leach ; Edw.}

Dans le genre Leucothoe, les antennes supérieures ne sont terminées que par une seule tige annelée, qui est plus courte que chez la plupart des Crustacés; il en est de même pour les antennes inférieures. - La structure des pattes de la première paire est très-remarquable; le pénultième arti. cle constitue une espece de doigt mobile qui s'applique sur le bord supérieur d'un long prolongement du pénultième article, et se termine par une griffe recourbée. La disposition des pattes des six dernières paires est la même que dans le genre Crevette. - L'extrémité de l'abdomen est recourbée en dessous.

L'espèce type de ce genre est :

LEUCOTHOE FURINA.

$\mathbf{S}_{A v}$ - Cette espèce a été figurée par M. Savigny dañs le grand Ouvrage d'Egyple, pl. 11, fig. 2. 



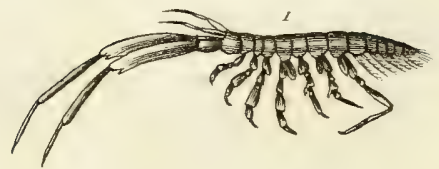

$=$
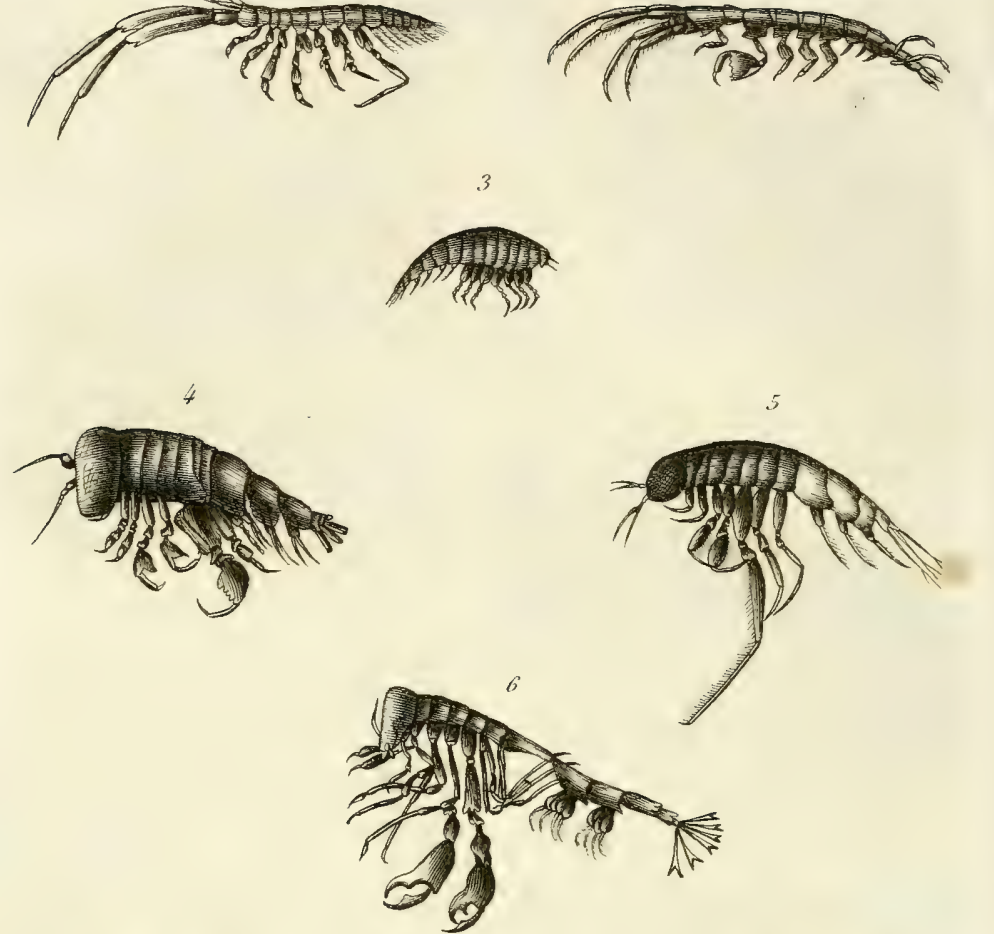

7
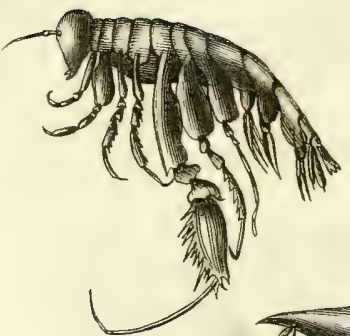
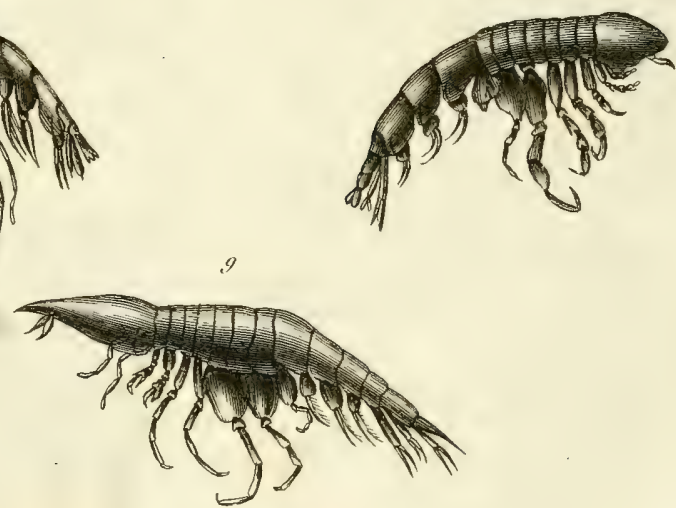

1. Cerapus tabularis. 2. Corophium longoicorne. 3. Hyperia haheillei.

4. Hieraconyx abbreviatus. 5. Themisto gaudichaudii.6.Phronima sedentaria,

7. Primno macropa. 8. Pronoe capito. 9, Osycephalus Oceanicus. 


\section{DEUXIEME FAMILLE.}

\section{P ODOCERIDES,}

\section{LATREILLE.}

Caractéres. Corps peu ou point comprimé sur les côtés. - Pattes thoraciques des quatre dernières paires point encaissées. - Extrémité postérieure du corps ne constituant pas un organe de saut.

Genres: Erichtonius, Atylus, Unciola, Cerapus, Podocerus, Corophium.

\section{ERICHTONIUS, EDW.}

Les Amphipodes appartenant àce nouveau genre ont beaucoup d'analogie avec les Leucothoés, dont ils ne diffèrent principalement que par l'état rudimentaire des pièces épimériennes des premièrs segmens thoraciques. Les antennes supéricures sont simples et à peu près de la longueur des inférieures. Les pattes de la seconde paire sont terminées par une main très-grosse formée par l'antépénultième article, et présentent en avant un prolongement sur. lequel s'appuie la griffe, qui est composée elle-même des deux derniers articles.

\section{ERICHTONIUS DIFFORMIS.}

EDw., Ann. des Sc. nat., t. XX, p. 31 .

Il n'y a pas de prolongement spiriforme sur l'anté-pénultième article des pattes antérieures.

\section{ATylUS, Leach, Desm., Edw.; Gammarus, FABR.}

Le corps est linéaire, sans épimères clypéiformes. - Le premier article des six dernières pattes est étroit comme aux pattes précédentes. - La main qui termine les quatre premières pattes est très-petite et formée par le pénultième article. - Les yeux sont petits, arrondis, placés de chaque côté de la tête, entre les points d'insertion des antennes supérieures et inférieures.-La queue est terminée par deux filets latéraux et un filet intermédiaire bifides à leur extrémité.

atylus carinatus. (Pl. 17, fig. 3.)

LeacH, Zool. Misc., t. II, p. 22, pl. 69 ; ejusd., Trans. Soc. Linn.. t. X, p. 357.-
Dessr., Consid. génér. sur les Crust., p. 262, p. 45, fig. 4.-GuÉR., Iconogr. di Règ. anim. de Cuv., Crust., pl. 25, fig. 6. - Gammarus Carinatus, $\mathrm{F}_{\mathrm{AbR}_{0},}, \boldsymbol{E}_{\text {. }}$. Syst., t. II , p. 515, Spec., 3. - Long. 14 lig. - Le rostre, formé par la partie antérieure et supérieure de la tête, est un peu infléchi; les cinq derniers segmens de l'abdomen sont carénés en dessus, et terminés un peu en pointe postérieurement. - La patrie de cette espece est inconnue.

\section{UNCIOLA; SAx, EdW.}

Les pattes de la première paire sont prehensiles et subchéliformes; celles de la seconde paire sont terminées par une main adactyle portant à son extrémité deux petịtes pointes crochues. - Le premier article des six dernières pattes est étroit.

L'UnciolaIrrorata, $\mathrm{S}_{\mathrm{AY}}$, op. cit., vol. I, p. 389 , est le type de ce nouveau genre.

\section{GerapUs, Say, Desk,; Eww.}

Les antennes supérieures sont grosses, aussi longues que les inférieures, et pédiformes comme elles, - Les pieds de la première paire sont petits, et terminés par un ongle simple, assez court; ceux de la seconde paire, au contraire, sont fort grands, ont une main large, aplatie, triangulaire, et pourvue d'wn pouce biarticulé correspondant à une pointe assez prononcée qui remplace le doigt immobile des Crustacés ordinaires; ceux des trois paires suivantes sont moyens et monodactyles; et les quatre derniers, plus longs, plus grêles, sont dirigés en arrière et en haut. - Le corps est long, linéaire, demi-cylindrique, composé de douze segmens; le dernier de ceuxci étant aplati, en forme de lame ovale, et muni de chaque côté d'un petit appendice bifurqué à l'extrémité. - La tête est terminée par un très-petit rostre. - Les yeux sont saillans.

Cerapus tubularis. (Pl. 18, fig. 1.) $\mathrm{S}_{\mathrm{AX}}$, Journ, of the Acad. of nat. Scient. 
of Philadelph., t. I, $\mathrm{n}^{\circ} 4$, p. 49, pl. 4 , fig. 7-11.-Desu., Consid. génér. sur les Crust., pl. 46 , fig. 2.-GuÉr., Icon. du Règ. anim. de Cuv., Crust., pl. 27, fig. 4. - Long. 6 lig. - Cette espèce vit dans un petit tube cylindrique, à la manière des Friganes, et n'en laisse sortir que sa tête, ses quatre grandes antennes et ses deux premières paires de pieds. - On la trouve en abondance dans la mer, près Egg-Harbourg, sur les côtes des Etats-Unis, au milieu des sertulaires, dont elle parait faire sa nourriture principale.

pODOCERUS, Leach, Desm., Edw.;

Jassa, LEAGH ; Corophium, LATR.

Les antennes supérieures sont presque aussi longues que les inférieures. - Les pattes de la première paire sont terminées par une main subchéliforme plus ou moins bien formée; le premier article des pattes postérieures est étroit comme aux pattes précédentes.

\section{PODOCERUS CYLINDRICUS.}

SAY, op. cit., vol. 4, p. 387.-Edw., Ann. des Scienc. nat., t. XX, p. 33.-Les mains des pattes antérieures sont beauconp plus petites que celles des pattes de la seconde paire; les mains de la seconde paire sont presque cylindriques.

\section{2. podocerus pulchellus.}

EDw., Ann. des Sc. nat, t. XX, p. 33. - Jassa Pulchella, LеAch, Linn. Trans., t. XI, p. 361.-Dess., Consid. génér. sur les Crust., p. 269.-Gammarus Fatcatus, MontaGe, Linn. Trans., t. IX, pl. 6, fig. 2. - De couleur blanche lavée de roux; la main des pattes antérieures est à peu près de la longueur de celle des pattes de la seconde paire; les mains sont ovalaires, sans échancrure semi-lunaire sur leur bord dentaire. - Cette espèce a été trouvée sur la côte méridionale du comté de Cornouailles, au milieu des varecs.

Voyez, pour les autres espèces, LraCH, Trans. Linn., t. XI, p. 361 .

\section{COROPHIUM, Latr., Leach, Desh., EDW.; \\ Astacus, Penn. ; Cancer, Linn.; Oniscus, Pallas.}

Les antennes sont composées de quatre pièces; les inférieures beaucoup plus grosses et plus grandes que les supérieures, ayant leur derniẻre pièce formée d'un à quatre articles, et paraissant se terminer par un petit crochet. - Les pattes de Ia première paire sont terminées par une petite main subchéliforme, et celles de la seconde paire constituent des organes fouisseurs. - Les yeux sont saillans, comprimés. - Les femelles présentent, près de la base inférieure des pattes, des lames membraneuses en forme d'écailles, dont la rainure forme une espèce de poche; elles servent à retenir les œufs, et même les petits jusqu'à ce qu'ils aient assez de force pour s'isoler.

COROPHA LONGICORNE. (PI. 18, fig. 2.) Latra, Règ. anim. de Cuv., t. IV, p. 123. - Desar. , Consid. génér. sur les Crust., p. 270, pl. 46, fig. 1. - GuĚR., Icon. du Règ. anim. de Cuv., Crust., pl. 27, fig. 2. - Gammarus Longicornis, FaBr., Ent. Syst., t. II, p. 515. - Le troisième article des antennes inférieures porte à l'extrémité de son bord inférieur une grosse dent spiniforme. Gette espèce, qui håbite dans la vase des bords de l'Océan, se trouve en quantité innombrable, et paraît se multiplier en grand nombre dans Ia belle saison. Ces Crustacés se nourrissent principalement de plusieurs Annélides, telles que les Néréides, les Aphrodites et les Arénicoles, etc., et leur font une guerre sans relâche. D'après les observations de M. d'Orbigny, on voit à la marée montante des myriades de ces petits Crustacés s'agiter en tous sens, batire la vase de leurs grandes antennes, la délayer pour tâcher d'y découvrir leur proie ; ontils rencontré une Annélide, souvent cent fois plus grosse que chacun d'eux, ils se réunissent, et semblent agir d'accord pour l'attaquer et ensuite la dévorer; ils ne cessent leur carnage que lorsque, ayant fouille et aplani toute la vasière, ils ne trouvent plus de quoi assouvir leur voracité; alors ils se jettent sur les mollusques et les poissons qui sont restés à see pendant la marée basse, et sur les moules qui se sont détachées des palissades des bouchots. On désigne ainsi par le nom de bouchots, dans le golfe de Gascogne, des espèces de pares à moules artificiels, formés par des pieux et des palissades, et avancés quelquefois d'une lieve dans la mer. Ces pieux et palissades sont tapissés de fucus, et les moules qui s'attachent à ces végétations marines sont recueillies par des pếcheurs qui portent le nom de boucheleux. Lorsque la marée est basse, le boucheleux se rend à son bouchot; mais pour y arriver, et afin de ne pas 
s'enfoncer dans la vase, il fait usage d'une sorte de nacelle qu'il dirige et pousse en mettant un pied dehors et s'appuyant obliquement sur le sol mou. Sans l'usage de cette nacelle la récolte des moules serait impossible. Pendant l'hiver, le vent, qui règne le plus souvent $d u$ sud au nordouest rend la mer très-grosse; la vase est délayée et inégalement amoncelée; le sol de l'intérieur des bouchots a l'aspect d'un champ préparé en sillons presque égaux, et souvent élevés de trois pieds. Lorsque la saison devient chaude, les sommets de ces sillons restant exposés à l'ardeur du soleil, se durcissent, et les petites nacelles des boucheleux ne pouvant surmonter de pareils obstacles, la pêche des moules devient impraticable. Ge que des milliers d'hommes ne parviendraient à exécuter dans tout le cours de l'été, les Corophies l'achèvent en quelques semaines; elles démolissent et aplanissent plusieurs lieues carrées couver- tes de ces sillons; elles délaient la vase qui est emportée hors des bouchots par la mer. A chaque marée, et peu de temps après leur arrivée, le sol de la vasière se trouve avoir une surface aussi plane qu'à la fin de l'automne précédent. A cette époque seuIement le boucheleux peut recommencer la pêche des moules. Soit que les Corophies s'enfoncent profondément dans la vase pour y passer l'hiver, soit que, à la manière de la plupart des Crustacés, elles se retirent pendant la saison froide dans des mers plus profondes, elles ne commencent à paraitre dans les bouchots que vers le milieu du mois de mai, et ce temps est celui où les Annélides dont elles se nourrissent sont les plus abondantes. C'est vers la fin d'octobre qu'elles quittent les bouchots; l'émigration est génẻrale, et il n'est pas rare alors de n'en plus rencontrer une seule où elles étoient très-nombreuses quelques jours avant.

\section{TROISIENE FAMILLE.}

\section{H Y E R INES, \\ Latreille, Edwards.}

Caractères. Pieds-mâchoires ne recouvrant pas la base des appendices précédens, et formant une espèce de lèvre inférieure impaire, terminée par trois lames cornées dépourvues de tiges palpiformes, ou 'n'en ayant que des vestiges. - Corps en général gros et bombé. - Tête généralement forte.

Genres : Vibilia, Hyperia, Phorcus, Lestrigon, Daira, Themisto, Hieraconyx, Dactylocerus, Anchylomera, Phronima, Primno, Tiphis, Pronoe, Oxycephalus.

\section{VIBILIA, EDw.}

Dans le genre Vibilia, le corps est grêle et allongé comme chez les Creveltines de la seconde tribu. - La tête est petite, tronquée en avant. - Les antennes supérieures sont grosses, courtes, non subulées, et arrondies au bout; celles de la seconde paire sont courtes et styliformes. - Le thorax est divisé en sept segmens. - Les pattes de la deuxième paire sont terminées par une petite main imparfaitement didactyle, dont le doigt mobile est formé par les deux derniers articles; les pattes la septième paire sont très-courtes, mais de même forme que les précédentes.

\section{VIBILIA PERONII.}

Eow., Ann. des Sc. nat., t. XX, p. 35. - Cette espèce est encore inédite.

\section{hyperi A, Latr. , Desm., Edw.}

La tête est grosse, arrondie. - Le thorax est divisé en sept segmens qui ont tous à peu près la même longueur. - Les antennes sont subulées, sans tige terminale annelée. - Les pattes sont grêles, non préhensiles, et ayant tontes à peu près la même forme. - L'abdomen porte comme d'ordinaire six paires de fausses pattes.

hy PERIA IATREILLEI. (Pl. 18, fig. 3.)

EDw., Ann.des Sc. nat., t. XX, pl.11, fig. 1-7. - Guék., Icon. du Règ. anim. de Cuv., Crust., pl. 25, fig. 5.-Long. 6 lig. - De couleur brunâtre; le corps, large et renflé antérieurement, se rétrécit beaucoup vers la partie postérieure, et se compose de quinze segmens, dont un céphalique, sept thoraciques, six abdominaux et un caudal ayant la forme d'une petite lame terminale; la tête est grosse, renflée et verticale; les yeux en occupent la plus grande partie, et présentent un grand nombre de petites fa- 
cettes ou cornéules hexagonales, au milieu de chacune desquelles on distingue un renflement lenticulaire; à la face antérieure de la tête, on remarque une fossette assez profonde et allongée, dans laquelle s'insérent les antennes; ces appendices sont courts, styliformes, et placés par paire près de la ligne médiane, mais assez loin les uns au-dessus des autres; ceux de la première paire sont un peu plus longs que les inférieurs, et lorsqu'ils s'infléchissent en bas, ils ne dépassent pas le labre; on leur distingue quatre articles : le premier est assez gros, les deux suivans sont très-courts, enfin le dernier est conique et sans divisions annulaires; les antennes inférieures ou de la seconde paire sont également styliformes, et portées sur un tubercule ovalaire, qui est placé au-dessus du labre, et qui paraît être formé par la soudure de leur premier article avec la tête; leur portion mobile se compose de quatre articles, dont le premier est le plus court et le dernier le plus long et sans divisions annulaires. La bouche est assez saillante; on y distingue un labre qui est bilobé et inséré à la base d'un tubercule arrondi, qu'au premier abord on pourrait prendre pour cet appendiceluimême; d'une paire de mandibules trèsfortes, portant chacune une longue tige palpiforme qui, dans la position naturelle, fait saillie au-devant de la tête, entre les deux antennes de la seconde paire; d'une languelte bilobée; d'une première paire de pieds-mâchoires, qui se terminent par deux grandes lames cornées, dont l'interne est armée de dents sur le bord antérieur; d'une paire de mâchoires externes, quisont moins développées et moins lamellaires que les antérieures, mais également bifides; et d'une paire de mâchoires qui sont réunies entre elles, de manière à former une espèce de lèvre inférieure conique, terminée par trois petites lames cornées, et ne recouvrant qu'une très-faible partie de la bouche. Le thorax est renflé en dessus, et divisé en sept segmens; chacun de ces anneaux est assez étroit, et leur arceau supérieur est formé presque en entier par la pièce dorsale; les épimères sont très-peu développées, et n'encaissent pas du tout la base des pattes. Ces organes sont au nombre de sept paires, dont les quatre premières sont dirigées en arant, et les trois dernières en arrière; ils ont presque tous la même forme, et aucun n'est préhensile; leur premier article est assez grand, mais point clypéiforme ; les articles suivans sont plus ou moins grêles, et légérement aplatis ; enfin les deux derniers forment une sorte de stylet aigu. Les pattes de la première paire sont les plus petites de toutes, et leur. antépénultième article est assez large; il en est de même pour les pattes de la seconde paire, tandis que pour les suivantes cette. pièce ne présente aucune dilatation notable; enfin ces dernières pattes sont toutes à peu près de la mêmelongueur. A la base de chacun de ces membres, ceux de la première paire exceptés, il existe une grande vésicule membraneuse, aplatie, et de forme presque ovalaire, qui est suspendue sous le thorax, et paraît servir principalement à la respiration. Ces appendices existent dans les deux sexes; et chez les femelles, on voit au-dessous d'eux, de chaque côté du sternum, une série de petites lames qui sont les analogues des palpes, et qui servent a retenir les oufs que ces animaux portent sous cette partie du corps. L'abdomen se compose de sis anneaux portant chacun une paire de membres, et donne attache, par son extrémité postérieure, à une larie qui représente un septième segment ou anneau caudal. Les trois premiers anneaux de l'abdomen sont très-développés, et leur arceau supérieur se prolonge de chaque côté, de manière à en cacher les fausses pattes correspondantes. Ces derniers organes ont à peu près la même forme que chez tous les autres Amphipodes: L'article basilaire ou pédoncule est gros et presque quadrilatère, et leurs deux lames terminales sont assez larges, annelées, et garnies sur les bords de longs poils ciliés. Le quatrième anneau de l'abdomen est encore assez gros et bien distinct, mais le cinquième et le sixième sont peu développés, et soudés entre eux, de manière à être difficiles à distinguer. La lame qui représente le septième anneau est pelite et triangulaire; enfin les trois paires de membres qui font suite aux trois paires de fausses pattes natatoires, et qui s'insèrent aux quatrième, cinquième et sixième anneaux de l'abdomen, forment avec cette lamelle horizontale une espèce de nageoire caudale; leur pédoncule est grêle et allongé, et les deux lames qui les terminent sont courles, de forme lancéolée, et dépourvues de poils. - Se trouve aux environs de La Rochelle.

\section{HYPERIA PELAGICA}

EDw., Ann. des Scienc. natur., t. XX, p. 36. - Lanceola Pelagica, $\mathrm{S}_{\Delta \mathrm{Y}}$, op. cit., 
p. 218. - Les branchies sont vésiculeuses, oblongues, au nombre de dix, placées à la base interne des pieds, excepté ceux de la première et de la septième paire; les appendices caudaux consistent en trois paires de styles lancéolés, doubles etsupportés par ঐles pédoncules déprimés, linéaires, annexés aux côtés des trois ameaux qui composent la queue; la bouche est pourvue de deux palpes triarticulés, filiformes, et de pieds-mâchoires bifides; les antennes sont composées de quatre articles, avec Je dernier non divisé; les intérieures sont les plus longues; les supérieures ont leur base cachée par le chaperon, qui est anguleux; les yeux sont allongés; le front est coneave; les pieds sont au nombre de qua. torze et simples; leurs deux premières paires sont comprimées, et la sixiéme est la plus longue; la tête est courte, transverse; le corps est mou et couvert de tégumens membraneux; la queue est déprimée, plus étroite que le corps, et son segment terminal est attézué entre les styles caudaux postérieurs. - Se trouve sur la côté d'Amérique, dans le Gulfstreane.

\section{PHORCUS, EDw.}

Dans cette nouvelle division générique les antennes inférieures sont tout-à-fait rudimentaires. - La tête est très-grosse. Le second segment du thorax est notablement plus développé qu'aucun des autres. - Aucune des pattes n'est préhensile, ni terminée par une main; celles des quatre premières paires sont courtes; les cinquièmes sont très-longues, mais filiformes, et ne peuvent guère servir à la locomotion; celles de la sixième paire, encore plus longues, sont au contraire très-fortes; enfin celles de la dernière paire sont rudimentaires.-La structure de l'abdomen est entièrement la même que dans le genre précédent.

\section{PHORCUS REYNAUdi.}

Edw., Ann. des Sc.nat., t. 20, p. 41.Cette espèce est encore inédite.

\section{LESTRIGON, EDw.}

La tête est très-grosse et renflée. - Le premier segment du thorax est rudimentaire. - L'abdomen est plus grand que le thorax. - Les antennes sont à peu près de même longueur, terminées toutes par une longue tige subulée, multiarticulée. -
Aucune patte n'est préhensile, mais celles de la seconde paire présentent une espèce de petite main formée par l'antépénultième article.

\section{LESTRIGON FABREI.}

Edw., Ann. des $S c$. nat., t. 20 p. 41. Cette espèce est inédite.

\section{DAIRA, EDW.}

La tête est grosse et renflée; les antennes sont styliformes et rudimentaires; le thorax est conique, très-étroit postérieurement et ayant le premier segment très-court; les pattes des deux premières paires portent une main imparfaitement didactyle, dont le doigt mobile est formé par les deux derniers articles; l'abdomen est comme dans le genre Hypérie.

L'espèce type de cette nouvelle coupe générique est :

\section{DAIRA GabErti.}

Evw., Ann. des Sc. nat., t. XX, p. 42. - Cette espèce est encore inédite.

\section{THEMISTO, GuÉr.}

Corps oblong, composé de douze segmens. - Tête occupèe entièrement par deux yeux à réseau, arrondie, non prolongée inférieurement en rostre, - Quatre antennes : les supérieures plus courtes que la tête, courbées au bout; les inférieures beaucoup plus longues. - Quatorze pieds : les quatre premiers courts, dirigés en avant, couchés sur la bouche, et représentant les deux dernières paires de pieds-mâchoires des Crustacés supérieurs; les quatre suivans beaucoup plus grands, terminés par un crochet dirigé vers la queue; la cin quième paire très-longue, dirigée vers la bouche, ayant l'avant-dernier article grêle, fort long, garni d'épines en dedans, et terminé par un crochet; les quatre derniers, de moitié plus courts, dirigés et conformés de même, mais sans dents à l'avant-dernier article. - Queue terminée par six appendices natatoires, longs, aplatis, bifides à l'extrémité. - Trois paires de filets également natatoires sous les trois premiers segmens de la queue.

THEMisto Gardichaddr. (Pl. 18, fig. 5.) Guér., Mém. de la Soc. d'Hist. nat. de Paris, 't. IV, pl. 23, fig. 1 ; ejusd., Icon. du Règ. anim. de Cuv., Crust., pl. 25, fig. 7 .- Long. 9 lig. - Le corps est al 
longé, composé de douze segmens, non compris la tête, dont sept forment le tronc et les cinq derniers la queue; la tète est aussi longue que large, arrondie, elle a en avant, et vers sa partie inférieure, une espece d'enfoncement dans lequel sont insérées les antennes; les supérieures sont presque de la longueur de la tête, plus épaisses à leur base que les inféricures, et composées de quatre articles distincts: le premier forme à peu près le tiers de la longueur totale de l'antenne; les deux suivans sont très-courts; enfin, le dernier est le plus long de tous; il se rétrécit en pointe courbée en dedans, et présente de très-légères apparences d'anneaux; les antennes inférieures ont le double de la longueur des précédentes; elles sont également composées de quatre articles, dont le premier très-court, le second plus long, le troisième aussi long que les deux premiers pris ensemble, et le quatrième plus long que les trois précédents; le dernier article semble composé, comme les antennes supérieures, d'un très-grand nombre de petites articulations; la bouche est composée : $1^{\circ} \mathrm{d}^{\prime}$ une lèvre supérieure, globuleuse, trilobée inférieurement et membraneuse ; $2^{\circ}$ d'une paire de mandibules trés-recourbées en dedans, terminées par deux divisions dentelées et ciliées à leur extrémité, et portant sur leur dos un palpe de quatre articles, beaucoup plus long qu'elles, et caché dans le repos en dessus et contre la lèvre supérieure, dont il embrasse la base et le contour; $3^{\circ}$ d'une lèvre inférieure large, profondément échancrée au milieu, ayant ses côtés dilatés et armés de cils au côté interne de ses deux lobes; $4^{\circ}$ et de trois paires de mâchoires, proprement dites, dont les premières, ou celles qui viennent après la lèvre inférieure, sont bifides, avec la division supérieure beaucoup plus étroite que l'inférieure, courbée, ciliée et terminée par deux épines aiguës; la division inférieure triangulaire, armée de longues épines et de cils très-nombreux; les mâchoires suivantes sont également bifides; la division supérieure ou extérieure est la plus large; elle est coriace, courbée en dedans, aplatie, arrondie et élargie à son sommet, qui présente inférieurement une épine forte et aiguë, suivie extérieurement de plusieurs petites dents; cette pièce recouvre presque entièrement la division inférieure, qui est coriace et divisée à son extrémité en quatre fortes dents cornées, accompagnées en dedans d'un rang de longs cils; enfin, la troisième paire de pieds-mâchoires représente une lèvre; les deux mâchoires sont réunies à leur base, et la pièce qu'elles composent est divisée supérieurement en trois lobes dont l'intermédiaire le plus court est bifideà son extrémité et bordé de cils; les deux lobes extérieurs sont également bordés de cils, surtout inférieurement; cette pièce est sans articulations; ces lobes sont membraneux, très-noirs et transparens; ils s'appliquent sur les autres pièces de la bouche, et concourent à la fermer. Toutes les pièces que nous venons de décrire prennent attache à la partie inférieure de la tète; celles que nous allons faire connoître, et quireprésentent les quatre pieds-mâchoires des Crustacés décapodes, prennent leur insertion au-dessous des deux premiers segmens du tronc; ces segmens sont un peu plus étroits que les suivans; le premier donne attache à une paire de petits pieds très-courbes, dirigés en avant, appliqués sur la bouche, et composés de cinq articulations, dont la première est aussigrande que les quatre dernières ensemble ; la seconde très-courte, plus étroite; la troi sième au moins deux fois plus longue que la seconde, plus large et dilatée vers son milieu; la quatrième de la longueur de la précédente, beaucoup plus étroite, cylindrique, et la cinquième très-petite et en forme d'épine ou de crochet; la seconde paire, ou les pieds-mâchoires extérieurs, ressemble à la précédente; elle n'en diffère que parce que le troisième article a son extrémité inteıne prolongée en une pointe courbée en dedans, et venant s'opposer au quatrième article, pour former une sorte de pince ou de main; ces deux petites pinces sont également crochues vers la bouche; les cinq paires de pieds, proprement dits, sont insérées sur les cinq segmens, qui, avec les deux premiers, dont nous avons parlé, semblent former le tronc; les segmens n'ont point d'appendices extérieurs; les quatre premiers pieds sont presque trois fois plus longs que les pieds-mâchoires extérieurs; ils sont également composés de cinq articles, dont le premier très-long, élargi vers sa partie supérieure, qui se rétrécit tout-à-coup, et donne attache au second article, le plus court de tous; celui-ci est étroit à sa base, et large à son extrémité; le troisième est deux fois plus long que le précédent, très-élargi à sa base et au côté inférieur, qui est armé d'épines et contre lequel peut s'appliquer le quatrième article; celui-ci est aussi long que 
le précédent, un peu courbé en dedans, beaucoup plus étroit, cylindrique, et terminé par fe cinquième article, ou le tarse qui forme un crochet aigu; ces deux paires de pattes ont leurs crochets tournés vers la partie postérieure de l'animal; la troisième paire est plus extraordinaire; elle est au moins trois fois plus longue que les premières; son premier article est aussi long que les trois premières des pattes précédentes, il a à peu près la même forme; le second est très-court, plus large à son extrémité, il donne insertion au troisième, qui est de la longueur des deux premières réunies, presque aussi large dans toute sa longueur ; le quatrième est beaucoup plus étroit, presque aussi long que les précédens réunis, aplati, de la même grosseur dans toute sa longueur; il est armé en dedans, ou du côté qui regarde la tête, d'un rang d'épines d'égale largeur, perpendiculaires, et qui leur donnent l'aspect d'un long peigne; le dernier article ou le tarse est très-petit et en forme d'angle ou de crochet ; ce crochet, ainsi que celui des deux pattes postérieures que nous allons décrire, est tourné vers la tête ou opposé à celui des deux paires de pattes antérieures; les deux paires de pattes postérieures ont cncore la même direction; elles sont de moilié plus courtes que la paire précédente, composées d'articulations semblables, mais n'ayant pas de peigne au côté iuterne du quatrième article; l'abdomen est composé de cinq segmens : les trois premiers sont grands, dilatés sur les côtés, repliẻs en dessous, el terminés postérieurement et de chaque côté par une petite épine; le quatrième est beaucoup moins long et bien moins large; enfin, le cinquième est encore plus petit, terminé postérieurement par un petit lobe triangulaire, qui a une apparence d'articulation ; les trois premiers anneaux donnent at tache á chacun une paire d'appendices natatoires, dont le premier article est court, presque quadrangulaire ; cet article supporte deux filets multiarticulés ayant presque le double de longueur, et garnis entièrement de longs poils qui sont euxmêmes ciliés; le quatrième article donne insertion postérieurement à deux appendices aplatis, composé d'un article basilaire ayant le double de sa longueur et portant à son extrémité deux lames aiguës, ciliées, appliquées l'une sur l'autre dans le repos, et qui s'étendent lorsque l'animal veut s'en servir pour manger; enfin, le dernier article donne attache á quatre appendices sem- blables aux deux précédens; ces six lames concourent à former une queue en éventail, qui doit servir à l'animal pour exécuter des sauts et des bonds dans l'eau._La couleur générale de cette espèce, dans l'alcool, esi le jaune pâle; sa tête seulement est un peu brunâtre.

\section{HIERACONYX, GuÉR。}

Le corps est court, ramassé, composé de treize segmens non compris la tête. - La tête est ovale, très-grosse, perpendiculaire, occupée en entier par les yeux. - Les antennes, au nombre de quatre, sont inégales; les supérieures sont de la longueur de la tête, cachées dans une fossette; les extérieures sont un peu plus longues; ces antennes sont composées d'un support plus épais, court, et d'une tige multiarticulée. - Les premier et second segmens du thorax sont réunis, et portent les deux paires de pattes.-Les deux segmens qui suivent sont égaux entre eux, et plus étroits que le premier ou les deux premiers, ils sont soudés; le cinquième segment est plus large, dilaté en arrière et en bas; les deux derniers sont étroits, cachés en bas par la dilatation du cinquième.-Les pieds des deux premières paires sont courts, simples, égaux entre eux, à articles aplatis; les troisième et quatrième sont terminés par une petite main imparfaitement didactyle, ayant le doigt mobile formé du cinquiẻme article et de l'angle aigu qui le termine; les cinquièmes pieds sont les plus grands de tous, ayant le premier article très-large et aplati; les deux suivans courts et transversaux; le quatrième est grand, ćpais, denté au côté intérieur; le cinquième est de la longueur du précédent, cylindrique et terminé par un ongle assez grand, aigu et un peu courbe; les sixiemes pieds sont plus courts, à premier article aplati; les deux suivans petits; le quatrième renflé, inerme; les pieds de la septieme paire sont encore plus courts, ayant le premier article grand, et les suivans cylindriques, moins longs ensemble que le premier, recourbés et cachés sous celui-ci dans le repos. - Les trois premiers segmens de l'abdomen sont grands, diminuant de grandeur et portant chacun une paire d'appendices natatoires; les trois segmens suivans une paire de lames plates, ovales, un peu échancrées au bout, mais d'une seule pièce.

IIERACONYX ADßREviatus. (P1. 18, fig. 4.) Guér., Mag. de Zool., 1836, pl. 17, 
fig. 2, - Le corps cst ovalaire, court, trapu, long et transparent, il est de couleur jaunâtre dans l'alcool. - Ce. Crustacé a été trouvé par. M. Gaudichaud, dans une traverséedes îles Malouines au Port - Jackson.

\section{DACTYlocerA, Latr., Edw.; Phrosina? Risso.}

Les antennes supérieures sont grandes et en forme de cuillers; les deux inférieures sont sétacées et très-petites. - Les dix pattes proprement dites sont monodactyles, formées de cinq articles aplatis; la première paire est courte, mince, crochue; la seconde est un peu moins longue que la troisieme; la quatrieme est fort grande, avec son premier article large, ovale; les devix suivans triangulaires; le quatrieme ovale, épineux, et le dernier long, aigu, arqué, falciforme; la cinquième paire de pieds est plus courte que la précédente, mais de même forme. - Le corps est oblong, un peu arqué, subarrondi sur les côtés, à segmens crustacès, transverses. La tête est prolongée sur le devant en forme de museau. - La queue est composée de cinq segmens, presque quadrangulaires, terminée par deux lames oblongues, ciliées, et une plaque intermédiaire courte, aplatie et arrondie au bout.

\section{DACTYLOCERA NICOEENCIS.}

EDw., Ann. des Sc. nat. t. XX, p. 42.Phrosina Semi-Lunata? Risso, Hist. de l'Europ. mérid., t.V, pl. 10 à 12 , fig. 3. Long. 8 lig. - Le corps est oblong, jaunâtre antérieurement, rouge postérieurement; la tête est pourvue de deux petites cornes qui forment une sorte de croissant; les yeux sont petits.

Se trouve dans la mer de Nice; cette espèce y est rare, apparaît au printemps, à l'époque de ses amours, et fait son séjour habituel dans les endroits où la mer est profonde et où le fond est sablonneux. Ses œufs sont transparens.

\section{ANCHYLOMERA, EDW.}

La forme générale du corps est entièrement la même que dans le genre précédent.- Les antennes sont très-courtes, sty. liformes ou nulles. - Le thorax est divisé en six segmens. - Les pattes des deux premières paires sont terminées par un article aplati et lancéolé; celles de la troisième et de la quatrième paire sont termiuées par une petite main formée par le troisième article. - Les pattes de la cinquième paire sont plus grosses et subchélifères; celles des deux dernières paires sont terminées par une tige grêle et cylindrique.

\section{ANCHYLOMERA BLOSSEVILLII.}

Edw., Ann. des Sc. nat., t. XX, p. 43.Les pattes de la première paire sont beaucoup plus courtes que celles de la seconde paire ; tels sont les caractères que nous connoissons de cette espèce.

\section{PHRONIMA, Latr., Edw.}

Les deux antennes sont sétacées, trèscourtes, composées d'un petit nombre d'articles. - Les quatre premiers pieds sont en forme de petits bras comprimés, finissant en pointes, et dentés en dessous; les deux antérieurs sont plus petits et annexés à la tête. - Les pieds de la cinquième paire sont les plus grands de tous, et terminés par une pince didactyle. - Six sacs vésiculeux divisés en trois paires sont placés à la base interne des six dernier's pieds. - La tête est trés-grande, cordiforme, verticale. - Le corps est très-mou, étroit et long. - - La queue est plus mince que le corps, terminée par six stylets allongés et fourchus au bout, pouvue en dessous de quatre ou six pattes natatoires disposées par paires; les pattes des quatre premières paires sont non préhensiles; celles de la cinquieme paire sont terminées par une grosse main didactyle bien formée ; les pattes des deux dernières paires sont didactyles.

Phronima sedentaria. (Pl. 18, fig. 6.)

I A Tr., Gener. Crust. et Ins., t. I, p. 56, tab. 2, fig. 2. - Cancer Gammarus Se dentarius, Herbst, t. II, tab. 57, fig. 8 . - Long. 1 pouc. - Le corps est mou, transparent, nacré et ponctué de rougen̂tre; le thorax est lisse, formé de plusieurs segmens; la tête est grosse, proboscidiforme, plane sur le devant, arrondie au sommet et pointillée de rouge sur les côtés; les yeux sont noirs, sessiles; les pattes sont tachetées de rouge de laque; la troisième paire est fort longue, à articles épars, terminés par des pinces arquées, inégales; les deux dernières paires sont courtes ct dentelèes sur le second article; l'abdomen est convexe et composé de quatre segmens terminés en pointe ; la pièce de l'extrérnité de la queue sert de support aux appendices bifides qui les terminent. 
Cette espèce, suivant M. Risso, vit dans l'intéricur du corps des animaux radiaires des genres Pyrosomes et Beroé. - Elle se trouve aux environs de Nice.

Pour les autres espèces, voyez M. Guérin, Iconogr. du Rég. anim. de Cuv., Crust. pl. 25, fig. 4.

\section{PRIMNO, GUÉr.}

Corps allongé, de quatorze segmens, sans compter la tête. - Tête ovale, trèsbombée, perpendiculaire et terminée en pointe. - Deux antennes plus longues que la tête, subulées, composées de deux articles, dont le premier court, et le second effilé vers le bout, et n'étant pas articulé. - Pieds de la première paire les plus courts de tous, a articles cylindriques, dépassant la tête de presque toute sa longueur, et terminés par un petit ongle pointu; secondspieds un peu plus longs, avec le premier article large et aplati ; les deuxièmes et troisièmes très-courts; les qua. trièmes el cinquièmes plus longs, el égaux entre eux, et le cinquième terminé par un pelit ongle pointu; troisiemes et quatrièmes pieds encore plus longs, simples, à articles cylindriques; cinquièmes pieds de plus du double plus grands que les précédens. - Le premier article grand, un peu aplati, presque aussi long que les pieds qui précèdent; le second court, armé d'une épine en arrière; le troisième également court, très-étroit à la base, renflé en clemi-lune, et aigu à son extrémité; quatrième article presque aussi grand que le premier, large et aplati, armé de fortes épines à son côté antérieur; cinquième grêle, plus long que le quatrieme, cylindrique et un peu courbé, terminé par un ongle assez long, très-aigu et un peu courbé; sixièmes pieds beaucoup plus courts, à premier article large et plat; deuxième court, inerme; troisième deux fois plus long; qua. trième aussi long que le premier, étroit et armé d'épines en avant; cinquième aussi long que le précédent, et terminé par un ongle aigu; septièmes pattes encore plus courtes, à premier article large et aplali, ayant les autres cylindriques et grêles, et la griffe du dernier renflée et arrondic, au lieu d'être aiguë comme aux autres pattes. - Trois premiers segmens de l'abdomen grands et arrondis en arrière, portant chacun une paire de pattes natatoires conformées comme dans les Phronimes; les suivans courts, plus étroits, et donnant atta- che à des lames natatoires simples, larges, un peu lobées au bout, mais n'étant point terminées par deux petits appendices, comme dans les Phronimes.

L'espèce type de cette nouvelle coupegénérique est:

Primo macropa. (Pl. 18, fig. 7.)

Guér., Mag. de Zool., 1836, pl. 17, fig. 1. - Le corps conservé dans l'alcool est. d'un jaune transparent. - Trouvé dans les mers du Chili par M. Gay.

TYPHIS, Risso, EDw.

La forme générale des Crustacés qui composent ce genre est semblable à celle des Anchylomères et des Hypéries. - La tête est très-grosse. - Le thorax renflé et l'abdomen rétréci. - Les antennes supérieures grosses, coudées et beaucoup moins longues que la tête, sont insérées a sa partie antérieure; celles de la seconde paire sont grêles, cylindriques, sétacées et formées de quatre tiges articulées bout à bout el se terminant l'une sur l'autre, de facon que dans le repos ces organes sont cachẻs lout entier sous. les parties latérales de la tête, bien que leur longueur totale soit plus grande que celle du thorax. - Les pattes de la seconde paire sont terminées par une petite main imparfaitement didac. tyle; celles des deux paires suivantes sont grêles et cylindriques; le premier article de celles des cinquième et sixième paires est au contraire clypéiforme et très-grand, tandis que les articles suivans sont grêles et cylindriques; enfin les pattes de la seplième paire sont très-petites et cachées sous les précédentes.

TYPHIS FETS.

EDw., Ann. des Sc.nat., t. XX, p. 44 , pl. 11 ,fig. 8. - Les pattes de la premiès $\mathrm{c}$ paire sont terminées par une main imparfaitement didactyle, comne celles de la scconde paire.

\section{PRONOE, GUÉR.}

Corps allongé, étroit, composé de quatorze segmens, en n'y comprenant pas la tête. - Tête grande, occupée par les yeux, arrondie, avancée, ayantle front très-bossu, creusé devant pour recevoir les antenues supérieures, avec le tubercule buccal peu saillant. - Antennes plus courtes que la tête, plates, paraissant composées de trois articles, dont les deux premiers très-courts. 
- Antennes inférieures insérées près de la bouche, grêles, cylindriques, sétacées et formées de cinq articles se reployant l'un sur l'autre. - Pattes simples et monodactyles, allant en augmentant de longueur depuis les premières jusqu'aux cinquièmes; les quatre premières paires ayant tous les articles cylindriques; premier article des trois dernières paires large, aplati et arrondi; sixiéme paire beaucoup plus courte; septième composée seulement du premier article et d'un petit tubercule qui semble le rudiment des autres. - Les trois premiers segmens abdominaux grands, arrondis et portant chacun une paire d'appendices natatoires; les trois segmens suivans ayant les appendices étroits, plats, allongés et terminés par deux petites lames arrondies au bout; le dernier segment court et triangulaire.

pronoe capito. (Pl. 18, fig. 8.)

GuÉr., Mag. de Zool., 1836, pl. 17, fig. 3. - Le corps est jaunâtre, comprimé, avec l'abdomen un peu plus épais et plus long que le thorax. - Se trouve sur les côtes du Chili.

\section{OXYCEPHALUS, EDW.}

Ce genre diffère de celui d'Hypérie par fa forme grêle et allongée de son corps, nar sa tête aplatie et lancéolée. - Les antennes sont semblables à celles des Typhis. - Les pattes des deux premières paires sont terminées par une main didactyle bien formée; les autres sont grêles, cylindriques et non préhensiles; celles de la septième paire sont très-courtes. - La disposition de l'abdomen et de ses appendices est assez semblable à ce qui existe chez les Hypéries.

OXYGEPHALUS OCEANICUS. (Pl. 18, fig. 9.) Gú́r., Mag. de Zool., 1836, pl. 18, fig. 2. - Corps allongé, assez grểle, un peu comprimé; tête grande, formant presque la longueur totale de l'animal, trois fois plus longue que large, terminée en pointe en avant, triangulaire, avec le dessous aplati; antennes supérieures plates, ovalaires, terminées par un pelit article aigu, insérées en dessous et près de l'extrèmité de la tête; les inférieures placées près de lâ bouche, et composées de cinq articles égaux; segmens thoraciques presque égaux; ceux de l'abdomen diminuant graduellement, terminés en pointe aux angles postérieurs; le dernier plus long que le précédent, plus long que large, et pointu en arrière; les appendices de ces segmens semblables à ceux des Hypéries, ceux de l'avant-dernier segment à peine aussi longs que ce dernier; cette espèce est entièrement transparente. - Elle a été trouvèe dans les mers du Chili.

\section{CINQUIÈME ORDRE.}

\section{面 SOD D $\mathbb{E}$,}

Latreille.

Le corps est gẻnẻralement aplati, ou convexe en dessus, ovale ou oblong, mais jamais plus haut que large, ni comprimé latéralement; dans quelques genres il est plus étroit et plus allongé, ou de figure linéaire. - La bouche se compose des mêmes pièces que dans les Crustacés précédens; mais ici celles qui répondent aux deux pieds-mâchoires supérieurs des Décapodes présentent encore plus que dans les derniers l'apparence d'une lèvre inférieure terminee par deux palpes. - Deux des antennes, les mitoyennes, s'oblitèrent presque dans les derniers Crustacés de cet ordre, qui sont presque tous terrestres, et diffèrent encore des autres par leurs organes respiratoires. - Les deux pieds antérieurs ne sont point annexés à la tête, et dépendent, ainsi que les suivans, d'un segment propre; ils sont toujours au nombre de quatorze, onguiculés, et sans appendices vésiculeux à leur base. - Le dessous de la queue est garni d'appendices très-apparens, sous la forme de feuillets ou de bourses vésiculaires, et dont les deux premiers ou les extérieurs recouvrent ordinairement, totalement ou en grande partie les autres. - Les organes sexuels masculins s'annoncent le plus souvent par la présence d'appendices linéaires ou filiformes, et quel- 
quefois de crochets placés à l'origine interne des premières lames sous-caudales. - Les femelles portent leurs oufs sous la poitrine, tantôt entre les écailles, tantôt dans une poche ou sac membraneux, s'ouvrant lorsque les petits sont éclos. Ces nouveau-nés ressemblent à leurs parens; quelques - uns cependant, les Cloportes, par exemple, ont un anneau de moins au thorax, et n'offrent dès lors que six paires de pattes, au lieu de quatorze. Cuvier a remarqué, à l'égard de ces derniers, que les deux cordons médullaires du système nerveux ne sont pas entièrement rapprochés, qu'on les distingue dans toute leur étendue, et que, non compris le cerveau, ils forment neuf ganglions, dont les deux premiers et les deux derniers très-rapprochés. Les branchies étant situées sous le postabdomen, c'est là aussi que doivent être les canaux branchio-cardiaques, apportant le sang qui a respiré des branchies au cœur. MM. Audouin et Edwards ont en effet observé que cet organe, au niveau des deux premiers segmens de la queue, recevait à droite et à gauche des petits vaisseaux paraissant venir des branchies. D'après les recherches faites sur les Ligies, le systeme veineux est moins complet que dans les Décapodes Macroures. Le sang chassé du cœur, qui a la forme d'un long vaisseau, élendu sur l'intestin, et qui jette trois artères en avant et d'autres sur les côtés, reviendroit, après avoir circulé, dans les lacunes de la face inférieure du corps, qui communiqueroient librement avec les vais. seaux afférens des branchies. Ce système circulatoire feroit le passage de celui des Crustacés Décapodes à celui de certains Crustacés Branchiopodes.

Cet ordre a été partagé en deux sections : les Anomaux et les Normaux.

\title{
premile segtion. - ANOMAUX, Latreille.
}

Ici il y a moins de sept segmens au thorax; pieds propres à la locomotion, soit au nombre de dix seulement, soit au nombre de quatorze, mais dont les deux antérieurs terminés en pince didactyle; là il y a sept segmens thoraciques, comme d'ordinaire, et les pieds sont aussi au nombre de quatorze, mais très-petits, nullement propres à la locomotion, l'animal étant constamment fixé sur les branchies de quelques es. pèces de Salicoques, et recouvert par une portion latérale ou renflee en manière de loupe de test.

Cette section renferme trois familles : les Hétéropodes, les Décempédes et les Epicorides.

\section{PREMIIRE FAMILLE.}

\section{HET E R P O D E S,}

\author{
LATrEiLi.r.
}

Caractères. Premier anneau du thorax confondu avec la tête; les six autres étant distincts. - Sept paires de pattes, dont les deux antérieures, annexées à la tête, présentent au bout une serre didactyle. Corps terminé postérieurement soit par des stylets courts et articuiés, soit par deux longs filets velus ou soyeux.

Genres : Tanais, Rhoea, Apseudes.

TANAIS, EDw.

Ce genre a été créé par M. Edwards, sur un Crustacé qui a été figuré par M. SaANN. vigny dans le grand ouvrage d'Egypte. Il est remarquable par la forme presque cylindrique de son corps, la brièvetè des appendices styliformes de son extrémité postérieure, et par les seconds pieds, qui ne different que par des proportions un peu plus allongées des suivans. Voyez, pour la description et la figure, Savigny, Description de l'Egypte, Crust., pl. XI, fig. 1.

RHOEA, EDW.

La tête n'eat pas séparée d'une manière très-distincte du premier segment thora- 
cique, et son extrémité antérieure se prolonge sous la forme d'un rostre pointu et légérement recourbé. - Les yeux, au nombre de deux, sont circulaires, très-petits, et insèrés sur les côtés de la tête, près de son bord antérieur et inférieur. - Les deux paires d'antenues sont insérées l'une au-dessus de l'autre; les supérieures ou moyennes, dent la longueur est moindre que celle du corps, sont tres-grosses, sulcout prés de lenr base; elles sont termines par deux filamens multiarticulés, pourvus de quelques poils assez courts; l'inférieur a environ deux fois la longueur du supérieur, et ne dépasse guère celle de leur pédoncule commun, qui est formé de trois articles, dont le premier (c'est-à-dire l'article basilaire) est le plus gros, et surpasse en longueur les deux autres réunis. Jes antennes inférieures ou externes, moins longues que les supérieures, sont formées d'un arlicle basilaire trés-court, et d'un second article allongé et presque cylindrique, auquel succède un lilament multiarticulè qui s'amincit très-rapidement, et qui porte une rangée longitudinale de poils roides et assez longs. - La bouche est garnie comme à l'ordinaire de pieds - mâchoires, dont les postèrieurs sont soudés entre eux près de leur base, et ont la forme de palpes garnis d'un grand nombre de poils; on distingue a chacun trois articles dont le dernier est arrondi. - Le corps est formé de deux portions assez distinctes: l'unc thoracique, l'autre abdominale. De sept anneaux qui forment la première, le plus antérieur est presque confondu avec Ia tête; le second est un peu moins large que le premier, se prolonge de chaque côté en bas et en avant, de manière à former une pointc un peu recourbée qui cache l'articulation de la patte correspondante; les autres segmens ne préseutent pas celte disposition, et ne sont point pourvus de pièces latérales distinctes de celle qui en forme la portion dorsale. Chacun de ces arceaux est pourvu d'une paire de pattes ambulatoires; en sorte: que le nombre de ces appendices est de quatorze. La première paire se termine par une pince dont le doigt immobile est fort large; la main est trés-courte; les deux articles suivans sont plus étroits, et le bras est remarquable par sa forme presque ovalaire. Les pattes de la deuxième paire, plus longues, mais moins larges que les premières, n'ont point de pinces; la main n'est ni renflée ni aplatie; elle présente sur son bord une série de quatuc épinesfortes, el une a son angle supérieur el antérieur; elle s'arlicule avec un ongle assez large à sa base, un peu crochu, et dentelé sur son bord inférieur. La longneur des autres pattes diminue graduellement d'arant en arrière; elles sont loutes assez minces, et terminées par un grand ongle crochu sans dentelures; l'avant-deroier article n'est pas épineux. mais supporte un grand nombre de poils; les cuisses ne sont pas élargies. - L'abdomen est formé de six anneaux, dont les cinq premiers sont trés-courts, et le dernier, au contraire, remarquable par sa longuem. Les premiers portent chacun une paire de fausses pattes dont le pédoncule cst assez court, et supporte deux lames ovalaires ciliées. Ces appendices sont assez gros, relativement au peu de déreloppement des segmens de l'abdomen auxquels ils appartiennent; aussi sont-ils pour ainsi dire presqup les uns contre les autres. L'article terminal de l'abdomen, dont la forme est allongée, est un peu aplatie, représente de chaque côté, vers l'angle postérieur, une petite échancrure où s'articule un pédoncule cylindrique et un peu recourbé en dedans, qui supporte à son tour deux filamens garnis de quelques poils; l'un assez court, l'autre, au contraire, presque aussi long que le reste de l'animal.

\section{RHOEA HATREILLEI.}

EDw., Ann.des $S_{c}$. nat., t. XIII, pl. 13, fig. 1. - De forme allongée, légérement comprimée, et presque linéaire. - La couleur générale est blanchâtre. - Cette espèce, qui a été trouvée à Port-Louis sur un banc $d^{2}$ huîtres, paroît vivre à des pro. fondeursassez considérables dans la mer.

APSEUDES, LaM., Latr., Leach ; Eupheus, Risso, Desm.;

Gammarellies, Leach; Cancer, Montago.

Le corps est allongé, formé de six articles. - 11 y a quatre antennes, dont les deux externes sont plus longues que les intermé. diaires, sétacées et multiarticulées. - L'abdomen (ou queuc) est allongé, conique, composé de quinze articles environ, et terminé par deux longues soies.-Les deux pieds antérieurs sont grands; et finissent par une pince à deux doigts, un peu renflée et bien formée; les deux qui viennent après sont aussi grands, tantôt comprimés et dentés, tantôt simples et grêles; les six pieds suivans sont minces et terminés par un 


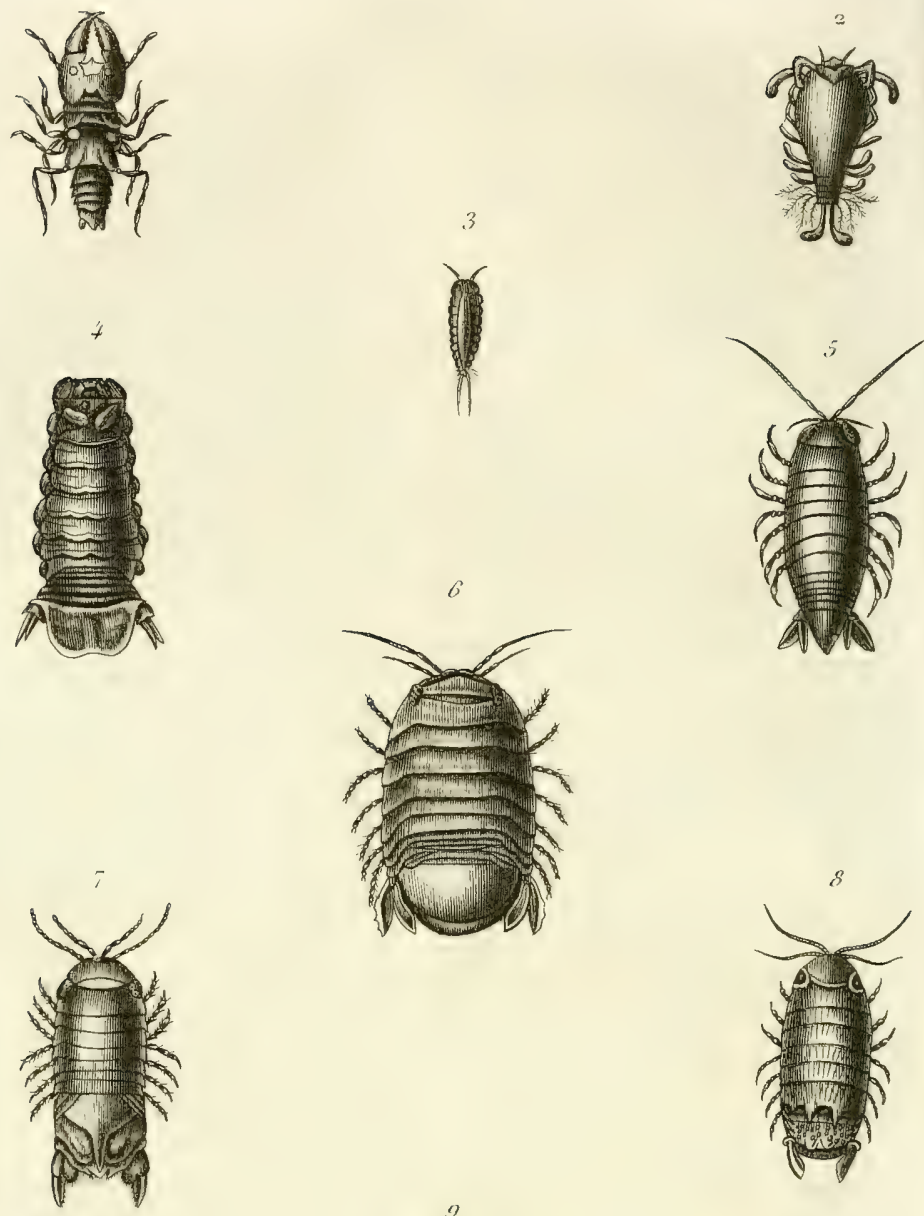

()

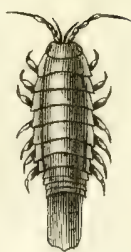

1. Anceus Forficularis. 2, 3. Ione thoracica, 4. Cymothoa orstrum .

5. Nelocira swainsoni. 6. Sphoroma serratum. 7. Nossea bidentala,

8. Cilicoea latreillei, 9, Idotea basteri. 
ongle un peu crochu; les quatre derniers, les plus couris de tous, dirigés en arrière, sont ciliés, et servent seuls pour la natation.

\section{APSEUDES LIGIOIDES.}

Noвrs, Eupheus Legioides, Risso, Crust. de Nice, p. 124, pl. 3, fig. 7. - Desar., Consid. génér. sur les Crust., p. 285. Long. 2 lig. - Le corps est allongé, cylindrique, presque aplati en dessus, et convexe en dessous, coloré de jaune, de blanc et de verdâtre; la carapace est assez grande : les segmens de l'abdomen sont ëtroits, et Je dernier se termine par deux courts appendices, portant chacun un long filet tresmince à son extrémité ; la tête est tronquée en devant; les yeur sont petits, noiråtres; les antennes extérieures sont longues; les antérieures beaucoup plus courtes; les pattes - sont ciliées; les deux antérieures sont gros- ses, épaisses, longues el didactyles. - Cette espèce, qui se trouve dans la mer de Nice, se plaît au milieu des plantes marines, et surtout des Ceramium.

\section{APSEUDES TALPM.}

LEACH, Edinb. Encycl., t. VII, p. 404; ejusd., Trans. Soc. Linn., t. XI. p. 372. - Eupheus Talpa, Desur, Consid. génér. sur les Crust., p. 285. - Cancer Gammarus Talpa, Montagu, Trans. Soc. Linn., t. IX, t. 4, fig. 6. - La tête est avancée en pointe; les segmens du corps présentent en dessus trois divisions longitudinales; le dernier article des quatre antennes est plumeux; les pieds de la seconde paire sont aplatis, très-larges, dentés; les quatre derniers pieds, les segmens de l'abdomen et les deux filets de la queue sont velus. Cette espèce habite l'Océan Britannique.

DEUXİ̀MF, FAMILLE.

\section{DÉ C.EM P E E S,}

Latieille.

Caractères. Ici on ne découvre que dix pieds proprement dits, et qui sont tous simples et allant en pointe. - Lc thorax n'offre que cinq ou trois segmens; et le post-abdomen, au lieu d'être terminé par des stylets ou par des soies, a de chaque côté, a son extrémité, une nageoire lamellaire.

Genres : Anceus, Praniza.

\section{ANGEUS, Risso, Latr., Drsm.; Gnathia, LEACH.}

Les antennes, au nombre de quatre, sont médiocrement longues; les extérieures étant plus courtes que les intérieures, et terminées par des articles déliés et en soie; les intérieures sont grosses et poilues. Les yeux sont au nombre de deux, et composés. - La tête des mâles est pourvue de deux grandes mandibules, arquées et épaisses en dehors, concaves, tranchantes et dentelées en dedans. - Le corps est oblong, déprimé, formé de cinq segmens, dont les deux premiers sont très-larges, sillonnés et soudès ensemble. - Les pieds, au nombre de dix, sont monodactyles; les six premiers sont assez courts, et dirigés en avant, e! les quatre derniers, plus longs, se portent en arrière. - L'abdomen est formé de quatre segmens, et terminé par une lame natatoire de chaque cóté, et une intermédiaire plus aiguề que celle-ci.

anceus forficularis. (Pl. 19, fig. 1.)

Risso, Crust. des envir. de Nice, p. 52, pl. 2, fig 10. - Dess., Consid. génér. sur les Crust., p. 283, pl.46, fig. 7. - GuÉR., Icon.duReg. anim. de Cuv., Crust., pl. 27, fig. 7. - Long. 3 lig. - Le corps est allongé, déprimé, d'une couleur blanchâtre; le thorax est carré, tronqué sur le devant, sinueux au milieu, avec une petite pointe émoussée; les yeux sont presque sessiles et à réseaux; les antennes extérieures sont longues; a derniers articles déliés et en soie; les intérieures sont grosses et poilues; la bouche est armée de deux espéces de mandibules très-longues, solides, en forme de faux, dentelées sur le côté intérieur, et terminées par une pointe; les palpes sont en forme de cuilleron et poilus; l'abdomen est presque aplati, formé de cinq segmens, dont les deux premiers sont très-larges, sillonnés et soudés ensemble; les 1 rois pre- 
mières paires de paltes sont couries: les deux dernières, placées sur le dernier segment, sont dirigées en arrière; la queue est composée de quatre pièces transversales; elle est terminée à son extrémité par trois lames natatoires, dont celle du milieu est la plus aiguë. - Cette espèce se tient dans ja région des Coraux, où elle se cache dans les interstices des Madrépores des côtes de Nice. Sa natation est assez vive.

\section{PRANIZA, Latr., Leach, Des3r., Westw:; Colino, Leach ; Oniscus, Montagu.}

La tête est pointue en avant, et légérement convexe. - Les quatre antennes sont insérées très-près l'une de l'autre; la paire interne a à peu près deux fois la longueur de la paire externe; ses deux articles basilaires sont courts et forts; les deux suivans sont heaucoup plus longs et plus minces, et le reste de l'antenne est composé d'une soie fine articulée. - Les antennes externes sont composées de plusieurs articles plus grêles jusqu'à leur extrẻmité.-La bouche est formée en dessous par une paire de palpes ou mâchoires, longs et forts ; chacun est composé de six articles, et insérés l'un près de l'au. tre : les deux articles basilaires sont courts; le troisième beaucoup plus long, dilaté et ovale; le quatrième un peu plus court; le cinquième encore davantage, et plus grêle ; enfin le dernier a la forme d'une grife allongée, aiguë et recourbẻe. Immédiatement au-devant de ces organes s'élève une autre paire de palpes à six articles, plus minces et plus courts; le troisième article de ces palpes est long et grêle, le quatrième très-court, et le cinquieme un peu plus long. - Le reste des mâchoires s'étend un peu au-devant de la tête, et forme plusieurs saillies qui se montrent en avant du front entre les antennes; les côtés de la tête sont hérissés de tubercules. - Le cou est très-court, et plus étroit que la tête. Les deux segmens thoraciques antérieurs sont plus larges que la tête, et un peu déprimés. - Lc reste du thorax n'est formé que d'une seule masse ovale et conrexe, couverte d'unc membrane, et d'une couleur plus foncée que le reste du corps; il en naît inférieurement trois paires de pattes de chaque côté. Dans d'autres individus, cette portion du thorax est oblongue, quadrilatère, un peu déprimée, légérement cornée comme le reste du corps, et divisẻe distinctement en trois segmens, dont le premier est un peu plus large que les deux autres; chacun de ces trois segmens est pourvu d'une paire de patles. Ces pattes, Iorsqu'elles ne sont pas étendues, sont repliées et serrẻes le long des côtés du corps. De mềme que les mâchoires, elles sont grêles, simples, et formées de six articles, dont le dernier a la forme d'un ongle allongé et recourbé. - L'abdomen est à peu près de moitié aussi long que le thorax, et composé de cinq anneaux transversaux déprimés, de largeur égale, et plus étroits que le thorax. - Les deux paires de plaques caudales et làtérales représentent le sixième anneau; erifin le septième anneau est remplacé par une plaque allongée, conique et aplatie. Cet ensemble, formé par ces deux derniers anneaux, constitue un appareil caudal natatoire composè de cinq articles. - Les organes subabdominaux et respiratoires consistent en lamelles aplaties, délicates, subovales et profondẻment ciliées, placées a la base des cinq anneaux de l'abdomen; chacun en possédant deux de chaque cồté. Ces organes sont tous de mème grandeur, si ce n'est ceux du cinquième anneau, qui sont un peu plus longs que les autres. Ils sont beaucoup plus petits que le segment duquel ils dépendent, et se replient sous l'abdomen.

Les différences sexuelles ne sont encore que trés-imparfaitement conuues.

Ge genre renferme environ six espèces; parmi elles nous citerons :

\section{PRANIZA MaCULATA.}

Westw., Recherch. sur les Crust. du genre Pranize. - Ann. des Scienc. nat., t. XXVII, p. 326, pl. 26, fig. 4.—GuÉr., Iconogr. du Règ. anim. de Cuv. , Crust., pl. 27, fig. 10. - Long. 1 lig. $\frac{1}{2},-D^{\prime}$ un blanchâtre obscur en dessus, arec l'abdomen tacheté de fauve; les yeux sont de même couleur. - Cette espèce a été trouvée à Shetland.

\section{PRANiza martra.}

Westw., op. cit., t. XXVII, p. 326 , pl. 6, fig. 1. - Oniscus Marinus, StabBER, Physicalisch belustigung oder microscop. warhnehmung. in und Auslandisch. wasser und landthierch., pl. 9, fig. 1 à 2, p. 37. - Long. 1 lig. $\frac{1}{2} .-D^{\prime} u n$ vert obscur, arec le thorax jaunâtre, marqué d'une croix, rouge antérieurement, leinté de vert postéricurement; l'abdomen présente deux lignes dorsales obscures. Cette espèce habite la même localité que la précédente.

\section{PIAYIZA FUSGATA.}

Jounst., Magaz. of Natur. Histor., 
n०28, t. V, p. 250. -- W Esrw., op. cit., t. XXVII, p. 331, pl. 6, fig. 26. - Long. 2 lig. - Elle est allongée, subcylindrique ; la tête, les deux segmens thoraciques an: téricurs, l'abdomen et les pattes sont incolores; les yeux sont noirs, et le grand segment thoracique est d'un brun rougeâ. tre. - Celte espèce, qui a été trouvẻe sur la côte de Berwickshire, marche leutement au fond de la mer; elle nage très-vite, et avance au moyen des mouvemens rapides de ses organes subabdominaux.

Consultez, pour les autres espèces, Je travail de M. Westwood, ayant pour titre : Extrait des recherches sur les Cruslacés du genre Pranize du doctour Leach, Ann. des $S c$. nat., t. XXVII, p. 316 , pl. 6.

\section{EP I C O R I D E S,}

LATREILLE.

Caractères. Les pattes sont excessivement petiles et recoquillées. - La bouche ne parait composée que de deux feuillets membraneux, en recouvrant un ou deux autres semblables; mais, suivant M. Edwards, il y a intérieurement d'autres parties, et la composition de la bouche est analogue à celle des Cymothoés. - Le corps est mou ou peu solide.

Ces Crustacés sont constamment appliqués sur les branchies de l'un des côtés du thorax de quelques autres Crustacés de la tribu des Salicoques. - La portion du test qui les recouvre est renflée en manière de loupe.-Le mâle, beancoup plus petit que la femelle, est errant et quelquefois cependant placé sous sa queue, et ce couple vit ainsi solitaire.

Genres: Bopyrus, Ione.

\section{bopyrus, Latr., Desm. ; Monoculus, FaBr.}

Le corps est ovalaire, déprimé, mou, avec une forte saillie longitudinale et médiane en dessous, marqué sur ses deux faces d'impressions transversales qui semblent séparer les segmens au nombre de sept. La têtẻ est oblongue, distincte seulement parce que son bord antérieur est plus large que ne le sont les bords latéraux des anneaux qui la suivent. - La queue est aplatie, oblique sur l'axe du corps, plus étroite que lui, découpée sur les bords, et marquée de rides transverses sur les faces supérieure et inférieure, de façon à paraître. divisé en six segmens très-étroits. - La bouche offre à l'extérieur deux valves qui la recouvrent comme des volets, formées chacune d'une pièce fixée antérieurement en cuillère dont la cavité est en dehors, et d'une semblable pièce plus membraneuse, annexée en arrière de la première; de deux pièces latérales molles, comprimées, placées comme des mâchoires ; une ouverture centrale qui peut être munie d'autres appendices, tels que les mâchoires et les mandibules, mais qui ne sont point visibles. On aperçoit quatre grandes lames presque membraneuses de chaque côté du corps en dessous, faisant suite aux deux valves qui recouvrent les parties de la bouche; elles se tiennent relevées par leur bord libre, imbriquées entre elles de façon à ce que les antérieures passent cn arrière des postérieures; ces lames forment par leur ensemble une sorte d'enceinte ovalaire sous le corps, destinée à contenir les œufs, et qui s'en trouve remplie vers la fin du printemps et dans les dernières saisons de l'année; la quatrième ou la dernière de ces lames est beaucoup plus longue que les premières, et se croise par son extrémité avec sa correspondante de l'autre côté; toutes sont aussi épaisses que les deux lames de la bouche, et, comme elles, variées d'une couleur brunâtre que l'on n'observe sur aucune partie de l'animal.Le dessous de la queue présente cinq paires de lamelles blanches et molles, disposées en recouvrement comme les lames branchiales des Cloportes et des autres Crustacés des genres voisins. On n'aperçoit pas d'yeux, ni d'antennes, ni d'appendices styliformes au bout de la queue.-Les pattes, au nombre de quatorze, très-petites, paraissent formées de quatre articles, et sont placées sur les côtés du corps, entre l'ex= 
trême bord et la base des lames imbriquées dont nous avons fait mention plus haut, chaque paire étant sur un anneau distinct. - Le mâle est très-petit, errant, à corps symétrique, allongé, linéaire, bombé en dessus d'un côté à l'autre, ayant une tête distincte, pourvue de deux pelits yeux noirs et ronds.-Un corps formé de six ou sept anneaux, et une queue de moitié plus courte que le corps, paraissant avoir des lamelles branchiales en dessous. - Les pattes, les antennes et les appendices styliformes de la queue sont inapercevables.

\section{HOPYRUS SQULLARUM.}

Desur., Consid. génér. sur tes Crust., p. 325, pl. 49, fig. 8 à 10 . - GuÉR., Icon. du Règ. anim. de Cuv., Crust., pl.29, fig. 1 et 1 b. - Monoculus Crangorum, FABR., Syst. Ent. Suppl., p. 306. - Fougrnoux de Bondaroy, Mém. de l'Acad. des Sc. de Paris, année 1772, p. 29, pl. 1. - Bopyre des Crustacés, Bosc., Hist. nat. des Crust., t. II, p. 216.-Long. $\$$ lig.-Cette espèce, qui est d'une coulcur pále blanchâtre, se trouvefixée sous le test des Palémons Squille et Porte-scie, accrochée àla mem. brane qui double le test en dessous, et le dos appliqué contre les branchies; ce Crus. tacé parasite paraît se nourrir de petits animaux que l'eau, attirée par le mouvement des organes de la respiration, apporte avec elle; sa présence sousle test des Palémons produit sur celui ci une protubérance d'au. tant plus grande que ce Bopyre est plus âgé, ou que ses cufs sont plus abordans; il n'y en a jamais qu'un seul sur chaque $\mathrm{Pa}$ lémon, placé indifféremment à droite et à gauche, et l'on en trouve dans toutes lessaisons de l'année; quelquefois sur la femelle on apercoit le mâle, qui est d'une petitesse extrême.

\section{2. hopyRus polowmonis.}

Risso, Crust. de Nice, p. 148. - Desir., Consid. génér. sur les Crust., p. 326.Long. 3 lig. - Cette espèce diffère de la précédente par son abdomen, qui est plus obtus; sa couleur est jaunâtre, mêlée de vert clair, avec deux lignes longitudinales brunes, dentelées; sa tête est surmontée de deux petits corps qu'on serait tenté de prendre pour des antenries:- Cette espèce a été trouvée par M. Rissso, près de Nice, sous le test des Palémons, où elle produit une tumeur remarquable, et il a observé qu'au lieu d'oufs, la femelle portait sous 902. ventre huit à neuf cents petits indivi- dus très-apparens et de couleur blanchegrisâtre.

IONE, Latr., Dess., Aud, et Edw.; Oniscus, Moxtagu.

Le corps est composé d'environ quinze articles, mais que l'on ne distingue que par des incisions latérales en forme de dents; il est ovalaire, inéquilatéral; les six derniers articles sont pourvus d'appendices latéraux, allongés, rameux, charnus et fasciculés. - L'extrémité postérieure garnie de six appendices simpleset recourbés, dont deux sont plus grands que les autres. - Quatre antennes courtes; les externes plus longues que les internes, et seules isibles lorsqu'on regarde l'animal par le dos. Les deux premiers articles. du corps sont pourvus chacun de deux nageoires (ou cirrhes) charnues, aHongées, aplaties et semblables à des rames; les autres articles sont garnis d'appendices analogues, mais plus courts.-Quatorze pattes très-courtes, crochues et cachées sous l'animal. - Les valves abdominales sont très-grandes; elles recouvrent toute la partie inférieure du corps et forment une espèce de réceptacle pour les aufs. - La seule espèce connue est :

IONE THoracices. (Pl. $₫ 9$, fig. 2, 3.) Latr., Rég. anim. de Cuvier, Crust., t. IV, p. 118.-A - et Evw., Mém. pour servir à l'Hist. nat. des Crust., part., 1, p. 16, pl. 49 , fig. 10, 11. - Guér., Iconog . du Règne. anim. de Cuvier, Crust., pl. 96, fig. 1 à 2. - Oniseus Thoracicus, Montagu, Trans. Soc. Linn., t. IX, p. 103, pl. 5, fig. 3, 4. - Le corps de cette espéce est d'une couleur orange, avec les appendices latéraux blanchâtres; la longueur des femelles, y compris les appendices postéricurs, està peine d'un demipouce; quelquefois le réceptacle est fortement distendu par plusieurs milliers d'œufs d'une couleur orangè-pâle. Le mâle est beaucoup plus petit que la femelle; sa forme est beaucoup plus allongée, et il est dépourvu d'appendices à la partie antérieure du corps; ceux dont sont pourvus les anneaux postérieurs ne sont pas rameux comme chez la femelle.

Cette espèce se trouve sous le test du Cancer Subterraneus (Callianasse souterraine), elle se cache entre la carapace et les parties charnues, et forme une tumeur d'un côté du corps. 


\section{Devxilut SEcrion. - NORMAUX, Latreille.}

Le thorax est partagé distinctement en sept anneaux portant quatorze pieds, propres à la locomotion; aucun d'eux ne se termine en manière de serre didactyle. La bouche est composé d'un Jabre, de deux mandibules cornées, d'une languette, de deux paires de mâchoires et de deux piedsmâchoires figurant plus ou moins une sorte de lévre inférieure, ou deux palpes contigus à leur origine.

Gette section renferme deux divisions.

\section{PREMILRE DIVISION.}

Elle renferme des especes toutes marines, dont la queue est toujours terminée par deux nageoires latérales, a antennes généralement disposées sur deux lignes, ordinairement sétacées et pluriarticulées. - A mandibules palpigères, sans pièce surnuméraire ou rudiment de flagre au cóte extérieur des pieds-mâchoires. - Cette première division renferme deux familles: les Cymothoadés et les Sphéromides.

\section{QUATRIEME FAMLLE. \\ C Y MO THOADE S,}

\section{ATHEILLE.}

Caracteres. La quene est formée de quatre à six segmens, at munic en dessous de plusieurs paires d'appendices formés de neuf sacs ovalaires, vésiculcux, portés suy un tubercule commun, paraissant remplir les fonctions de branchies, et disposés sur neuf rangs. - Les mandibules sont petites, peu dentées et sans saillie ou rameau au côté interne, ce qui les distingne de celles des familles suivantes, ou ces organes sont beaucoup plus robustes et fortement dertés au même côté; de plus, elles paraissent terminer une sorte de long pédoncule, portant les palpes, et dont la base est de niveau avec celles des deux pieds-mâchoires. - Suivant M. Edwards, ces palpes sont biarticulés. - La bouche des femelles diffère un peu de celle des mâles. Les pieds, ou ceux au moins des paires antérieures, sont courts, ou terminés par un fort onglet en crochet.-Des écailles membraneuses, imbriquées et pectorales, recouvrent les æufs.

Genres: Serolis, Cymothon, Conilera, Rocinela, OEga, Pterelas, Canolira, Anilocra, Olenicera, Nerocila, Livoneca, NeLocira, Eurydice, Cirolana, Limnoria.

\section{SEROLIS, LeAcH, DESM. ; Cymothoa, Farr.}

Les antennes supéricures sont formées de quatre articles plus grands que les trois premiers des antennes inférieures; le dernięr est composé de plusieurs autres plus petits. - Les antennes inférieures ont cinq articles; les deux premiers petits; le troisième et le quatrième surtout allongés; le cinquième est composé de plusieurs autres plus petits. - La seconde paire de pattes présente l'avant-dernier article élargi et l'angle très-allongé. - La sixieme paire de derrière sert à la marche, clle est un peu épineuse et son ongle est légérement courbè. - Les appendices antérieurs du ventre (ou lames branchiales) sont formés de deux parties égales, foliacées, arrondies à leur extrémité, garnies de poils à leur base, placées sur un pédoncule cominun.Les deux appendices postérieurs et latéraux sont petits et étroits, surtout l'intéricur, qui est à peine saillant.

\section{SEROLIS FABRICII.}

Leach, Dict. des Sc. nat., t. XII, p. 340. - Desm., Consid. génér. sur les Crust., p. 293. - Cymothoa Paradoxus, Fabr., Latk. - Cette espèce présente trois tubercules entre et derrière les yeux, disposés en triangle; le dernier anneau de l'abdomen est caréné à sa base et sa partie supéricure est marquée de chaque côté de deux lignes élevées : l'une, qui s'étend dans une direction oblique de la partic supérieure de la base du tubercule de la carene vers le côté; l'autre se dirigeant paralléle 
ment à l'anneau antérieur de l'abdomen, mais n'arrivant pas jusqu'à la carène.

\section{CYMOTHOA, FaBr., Latr., Leach, DESM. : \\ Oniscus, Linn.; Asellus, OLIv.}

Le dernier arlicle de l'abdomen est carré, transverse. - Les lames des appendices ventraux sont en forme de stylet, presque égales. - Les segmens du corps sont presque anguleux sur les côtés, et postérieurement avec les angles arrondis. - Les côtés des segmens de l'abdomen sont parallèles, épaissis en dessous. - La dernière jointure est transverse et presque coriacée.

Ce genre se compose d'un très-grand nombre d'especes, parmi lesquelles nous citerons :

\section{CIMOTHOA OESTREM. (P]. 19 ,} fig. 4.)

LATr., Gener. Crust. et Ins., p. 66, sp. 2.- LEAch, Dict. des $S$ c. nat., t. XII, p. 352. - DESM., Consid. génér. sur les Crust., p. 309, pl. 47, fig. 6 à 7.-Oniscus OEstrum, LinN.-Les carènes des huit der. niẻres cuisses sont acuminées, saillantes à leur base; la tête est carrée, iransverse; son extrémité est en quelque sorte rétrécie et droite; le corps est allongé, ovale, pres. que aplati, d'un blanc-grisâtre luisant; la queue est presque quadrangulaire, dilatée, et les appendices qui la terminent sont courts et aigus. - Habite les endroits fangeux.

\section{CYMOTHOA MATHAI.}

Leach, Dict. des Sc. nat., t. XII . p. 352. - Desı., Consid. génér. sur les Crust., p. 309. - Les carènes des huit dernières paires de cuisses sont brusquement saillantes; leur extrémité basilaire est obtusément proéminente; la tête est carrée, transverse, largement entaillée à son extrémité. - Celte espèce a été trouvée dans les mers de l'Ile-de-France.

\section{CYMOTHOA TRIANGULARIS.}

Leaci, Dict. des Sc.nat., t. XII , p. 353.- Desm., Consid. génér. sur les Crust., p. 309. - Les carènes des huit der. niẻres paires de cuisses sont subitement arquées ; la tête est triangulaire.

\section{Cумотhо nivitTata.}

Risso, Hist. des Crust. des env. de Nice, p. 143. - Desm., Consid. génér. sur les Cxust., p. 310. - Le corps est ovale, peu bombé, ayant ses irois premicrs segmens arqués en arrière; les trois suivans à bord postérieur droit, et le cinquieme échancré fortement; l'abdomen est formé de six sermens dont le dernier est tues-grand et large, de forme presque carrée, avec deux sinus à l'extrémité; et des appendices laléraux, à lames lancéolées, munies d'une pointe a leur base; la tête est petite, ronde et aplatie; les yeux sont nus, distincts; les trois premiers articles des antennes sont gros et renflés; la couleur générale est le gris d'ardoise luisant, interrompue par deux larges bandes longitudinales d'un blanc-jaunâtre, situées sur le dos.

Nous ajoutons avec doute à ces espèces les suivantes mentionnées par M. Risso.

\section{CYMOTHOA ROSACEA.}

Risso, toc. cit., pl. 3, fig. 9. - Dess., Consid. génér. sur les Crust., p. 310.Long. 15 lig.-Le corps est bombé; le segment terminal de la queue est très-grand, trapézoïdal, marqué de deux sillons longitudinaux et échancré en demi-lune au bout ; les appendices caudaux sont courts, ovales, oblongs, ciliés; les antennes extérieures ont leurs trois premiers articles aussi longs que les douze qui les terminent; la couleur est rose tendre, luisante, variée de fauve. - Se trouve dans la mer de Nice.

\section{CYBOTHOA NaVicularia.}

Risso, loc. cit., p. 142. - Dess., Consid. génér. sur les Crust., p. 311.-Long. 5 lig. $\frac{1}{2}$. - Le corps estallongé, un peu bombé, renflé au milieu et très-étroit aux deuxbouts; les sept segmens pédigères sont assez larges; les derniers ou ceux de la queue sont plus étroits et coupés en ligne droite; le sixiè. me de ceux-ci est grand, arrondi, ainsi que ses appendices latéraux; la tête est petite; les yeux sont trés-gros; les antennes intérieures sont plus petites que les extérieures; la couleur est un jaune serin.

\section{CYMOTHOA GIBBosus.}

Risso, toc. cit., p. 144. - Desu., Consid. génér. sur les Crust., p. 314. - Long. 1 pouc.-Cette espèce est très-bombée; les sept segmens du corps, proprement dits, sont inégaux; le dernier des six de Ja queue est large, arrondi au bout et pourvu d'appendices latéraux à lames oblongues, dont l'extérieure est aiguë et l'intérieurc obtuse ; la tête, de forme triangulaire, est arrondie à son sommet; les antennes extérieures sont formées de huit articles, presque égaux; les intérieures sont très- 
petites; la couleur est brune variée de rouge.

\section{CYMOTHOA RIGINOIDES.}

Risso, loc. cit., p. 145. - Desm, , Constd. génér. sur les Crust., p. 311.- - Long. 8 lig. - Le corps est ovale, bombé, formé de sept anneaux; la queue est composée de six segmens, dont les cinq premiers sont étroits et arqués, et dont le dernier est presque elliptique, avec les appendices latéraux à lame extérieure lancéolée et l'inférieure arrondie; la tête est arrondie en avant; les antennes sont courtes; la couleur ordinaire est grise, variée de blanchâtre, mais passant au blanc peu luisant dans quelques individus, et au brun-noirâtre dans d'autres.

Consultez, pour les autres espèces, Desm., Consid. génér. sur les Crust., p. 309; Risso, Hist. nat. des Crust. des environs de Nice, p. 139, et la pl. 29 de l'Ico. nographie du Régn. anim. de Cuvier, par M. Guérin.

\section{CONILERA, LEAGH, Desm.}

Les deux premiers articles des antennes supérieures sont presque cylindriques. Les yeux sont pelits, écarles, nullement proéminens. - Les cồtés des segmens de l'abdomen sont presque droits.

\section{CONILERA montagui.}

Leach, Dict. des Sc. nat., t. XII, p. 348.-Desm., Consid. génér. sur les Crust., p. 304. - Le corps est lisse, non ponctué; le dernier article de l'abdomen est plus long que large, avec ses côtés arqués vers leur milieu, et l'extrémité arrondie.-Se trouve sur les côtes du Devonshire.

\section{ROCINELA, Leach, Desa.}

Les deux premiers articles des antennes supérieures sont presque cylindriques. Les yeux sont très grands, un peu convexes, convergens antérieurement, et presque rapprochés.-Les côtés des articles de l'abdomen sont en forme de faux et proéminens.

\section{ROCINELA DANMONIENSIS.}

LEAcI, Dict. des Sc. nat., t. XII, p. 349.-Dess., Consid. génér. sur les Crust., p. 304.- La description de cette espèce nous est inconnue.

EGA , Leach, Desm. ;

Cymothoa, LATr., LAMCK.

Les deux premiers articles des antennes supérieures sont très-larges et comprimés. - Les yeux sont grands, légérement convexes, convergens antérieurement. - Les côtés des articles de l'abdomen sont imbriqués dans les trois seules espèces qui composent ce genre.-La lame intéricure des appendices du ventre est tronquée à son extrémité interne.

\section{AEGA EMARgINATA.}

LeAcr, Encycl. Brit. Suppl., 1, 428, t. XXII ; ejusd., Dict.des Sc.nat., t. XII, p. 349. - Desm., Consid. génér. sur les Crust., p. 305, pl. 47, fig. 4 à 5. - Le dernier article de l'abdomen latéralement est dilaté avant son milieu; son extrémitẻ est rétrécie en pointe, mais arrondie; la lame interne des appendices du ventre présente son extrémité échancrée extéricurement. - Nous ne connoissons pas la patrie de cette espèce.

\section{AEGA TRIDENS.}

Leach, Act. Soc. Linn., 11, 370 ; ejusd., Dict. des Sc. nat., t. XII, p. 349. Desm., Consid. génér. sur les Crust., p. 305. - Le dernier article de l'abdomen présente trois carènes qui sont prolongées au-delà de son extrémité et en forme de dents. - Se trouve dans les mers d'Ecosse.

\section{PTERELAS, GuÉr.}

Yeux très-visibles, composés d'un grand nombre de facettes. - Antennes supérieures plus courtes que les inférieures, insérées sur le bord antérieur de la tête, ayant leurs deux premiers articles grands, aplatis et larges, et le filet terminal inséré en arrière du deuxième article, composé de plusieurs petites articulations. Antennes inférieures deux fois plus longues que les supérieures, insérées au-dessous de cellesci, ayant leurs trois premiers articles courts, transversaux; les deux suivans grands, aplatis et larges, et le filet terminal composé d'environ dis articles cylindriques et allant en diminuant. - Mandibules allongées, terminées par un lobe triangulaire et portant un palpe plus long qu'elles, de deux articles cylindriques.-Pattes de la première paire terminées par un ongle fort et très-crochu; celles des deuxième et troisième paires en pince didactyle ; les quatre suivantes plus grêles, à article plus allongé et terminées par un simple onglet peu crocliu. - Abdomen composé de six segmens distincts; appendices latéraux du 
dernier segment composẻs de deux feuillets aplatis, et ne dépassant pas le dernier segment en longueur.

\section{PTERELAS WEBBII.}

GuĖr., Mag. de Zool., 1836, pI. 20, fig. 1. - Corps oblong, trois fois plus long que large; yeux grands, obliques, presque contigus en arant; premier segment thoracique plus large que les trois suivans, rétréci et échancré en avant, pour recevoir la tète; les cinquièmes et sixiènes au moins aussi larges que le premier; tous ces segmens ayant leurs angles postérieurs un peu prolongés en arrière, en pointe obtuse, et offrant sur les côtés une petite impression longitudiuale qui les fait paroître rebordés; abdomen ayant les cinq premiers segmens très-courts, terminés en pointe de chaque côté, et fe dernier aussi long que les cinq premiers, un peu rétréci en arrière, tronqué, et offrant une très-faible échancrure au milieu et une légère impression sur la ligne médiane; appendices latéraux presque égaux, l'extérieur ovale allongé, l'interne triangulaire, tronqué obliquement de dedans en dehors à son extrémité ; pattes assez courtes, les antérieures ayant le premier article aussi grand que les suivans; le second court, le troisième encore plus court, beaucoup plus large, le suivant plus étroit et à peu près de la même largeur, et le dernier plus long, terminé par un grand ongle crochu dans les premières seulement, et par le même ongle et un prolongement de son angle antérieur et inférieur dans les deux suivantes; les autres pattes ont leurs deuxièmes, troisièmes, quatrièmes et cinquiemes articles cylindriques, un peu épineux, presque égaux, et plus longs, pris ensemble, que le premier.-Se trouve sur les côtes du Portugal.

\section{Canolira, Leach, Desm.}

Les yeux sont peu granulés, convexes, écartés. - L'abdomen présente ses articles imbriqués sur les côtés; le dernier est un peu plus large à son extrémité.-Les pattes sont d'égale grosseur. - Les lames des appendices ventraux postérieurs sont presque égales, moyennes; les intérieures étant un peu plus longues que les extérieures.

Cavolina Rissoniana.

LEACH, Dict. des Sc. nat. t. XII . p. 350.-Dessr., Consid. génér. sur les Crust., p. 305. - Le dernier article de l'abdomen est largement arrondi a son ex. trémité.-Sa patrie est inconnue.

$$
\begin{aligned}
& \text { ANilocra, Leach., Desir. ; } \\
& \text { Cymothoa, Fabr., Risso. }
\end{aligned}
$$

Les yeux sont granulés, convexes, écartés. - Les côtés des derniers articles de l'abdomen sont presque involutes; le der nier article est plus étroit à son extrémitẻ. - Les pattes sont d'égale grosseur. - Les lames des appendices ventraux postérieurs sont inégales, allongées; les extéricures sont plus longues que les internes.

\section{ANilocra CuVieri.}

Leacn, Dict. des Sc. nat., t. XII, p. 350.-DesM, , Consid. génér. sur les Crust., p. 306.-Le dernier article de l'abdomen est légérement caréné, et son extrémité est graduellement acuminée et arrondie; couleur brunâtre, tachetée de noir ; le corps et l'abdomen ayant les bords postérieurs de leurs segmens plus pâles. - Se troure dans la mer de l'île d'Iviça.

\section{ANILOCRA MEDTTERRANEA,}

LeACH, Dict. des Sc. nat., t. XII, p. 350.-Desu., Consid, génér. sur les Crust., p. 306. - Cymothoa Albicornis, Risso, Crust. de Nice, p. 139.-Cymothoa Albicornis, FABr., Entom. Syst., 14, 509. - Le dernier article de l'abdomen est presque caréné, et de forme arrondie à son extrémité; couleur d'un brun foncé, cendré; les articles du thorax et de l'abdomen sont d'un jame-rose cendré; le dernier article de l'abdomen est finement tacheté de noir; la tête est arrondie; les antennes sont blanches et renflées à leur base.-Se trouve dans la Médilerranée.

\section{ANIIOGRA CAPENSIS.}

1.еach, Dict. des Sc. nat., 1. XII , p. 350.-Desur., Consid. génér. sur les Crust., p. 306 , pl. 48, fig. 1.- Le dernier article de l'abdomen se rétrécit toutà-coup, au-delá de son milieu, arrondi foiblement el presque carẻné; la dernière petite lame ventrale extérieure est trẻs-longue; couleur livide, d'un brun-olivâtre ou cendré; tous les articles bordés postérieurement de couleur testacée blanchâo tre. - Se trouve au cap de Bonne-Espérance. 


\section{olencird, Leach, Desh.}

Les yeux sont peu granulés, convexes. - Les côtés des segmens de l'abdomen sont imbriqués ; le dernier est allongé, pointu à son extrémité. - Les lames des appendices du ventre (surtout les extérieures) sont étroites, armées de piquans. Les paties de derrière sont graduellement plus longues que celles de devant.

\section{OLENGIRA IAMARCKII.}

Leach, Dict. des Sc. nat., t. XII, p. 350. - Dess., Consid. génér. sur les Crust., p. 307.- - Le dernier article de l'abdomen est terminé graduellement en pointe, jusqu'à son extrémité, qui est arrondie.-Patrie inconnue.

\section{NERoCila, Leach, Desm. ; Cymothoa, FABR.}

L'extrémité du dernier segment de l'abdomen est pointue ou arrondic.-Les lames des appendices ventraux sont foliacées, inégales; les extérieures étant les plus grandes. - Les côtés des segmens du corps et de l'abdomen sont terminés en pointe; ceux du dernier étant graduellement dilatés depuis sa naissance jusqu'á son milieu, et cnsuite arrondis.

\section{NEROCILA RLAINVILLII.}

Leacr, Dict. des Sc. nat., t. XII, p. 351.-Desu., Consid. génér. sur les Crust., p. 307. - Cymothoa Falcata, Fabr., Ent. Syst., 11, 504.-La lame extérieure des appendices du ventre est pointue. - Nous ne connoissons pas la patrie de cette espèce.

\section{Livoneca, Leach, Desm.}

L'extrémité du dernier segment de l'ab. domen est rétrécie et arrondie au bout.Les lames des appendices ventraux sont foliacées, à peu près égales, mais l'extérieure esi un peu plus longue que l'interne.-Les còtés des segmens du corps sont arrondis postérieurement; ccux des articles de l'abdomen sont parallèles, arrondis, épaissis en dessous; le dernier est rétréci vers son exIrémité, laquelle est arrondie.

\section{J.IVONECA REDMANII.}

Lescr, Dict. des Sc. nat., t. XII, p. 352. - Desar, Consid. génér. sur les Crust., p. 308. - Le dernier article de l'abdomen est arrondi, à partir de son milieu, environ jusqu'à son extrémité; les lames des appendices ventraux, sont considérablement saillantes, au•delà de l'extrémité du dernier article de l'abdomen, et tronquées intérieurement à leur extrémité. - Se trouve dans les mers de la Jamaique.

\section{LIVONECA DESMARESTI.}

LeacI , Dict. des Sc. nat., t. XII, p. 352. - Desu., Consid. génér. sur les Crust., p. 308. - Le dernier article de l'abdomen est demi-circulaire; les lames des appeudices ventraux sont presque linéaires, très-courtes, à pointe arrondie.

\section{LIVONECA RAFINESKII.}

Lrach, Dict. des Sc. nat., t. XII , p. 352. - Desu., Consid. génér. sur les Crust., p. 308. - Le dernier article de l'abdomen est dilaté sur chaque côté , derrieje son milieu, plus étroit et arrondi à son extrémité; les lames des appendices ventraux sont presque linéaires, arrondies à leur extrémité, et ne se prolongeant pas au-delà de l'article qui leur donne naissance.

\section{NELOCIRA, LeAch, Drsa.}

L'abdomen est composé de cinq articles. - Les yeux sont granulés. - Les petites lames des appendices ventraux postérieurs sont comme dans le genre suivant.

\section{Nerocina SIVAinsoni. (Pl. 19, fig. 5.)}

LEACH, Dict. des Sc. nat., t. XII, p. 347. - Desm., Consid. génér. sur les Crust., p. 302 , pl. 48 , fig. 2. - GoÉr., Icon. $d u$ Règ. anim. de Cuv., Crust., pl. 29, fig. 6. - Le corps est lisse, ponctué; l'abdomen ayant le dernier article triangulaire; les côtés étant légérement arqués, avec la pointe arrondie. - Se trouve dans la mer de Sicile.

\section{EURYDICE, LEACH, Desh. ; Cymothoa, LATr.}

L'abdomen est composé de cinq articles. - Les yeux sont lisses. - Les appendices postérieurs ont leur petite lame plus grande et plus large que l'interne; celle-ci est tronquée obliquement à son extrémité.

\section{EURYDIGE PULChRA.}

Leach, Trans. Linn. Soc., 11, 370 ; ejusd., Dict. des Sc. nat. , t. XII, p. 347.- 
Drss., Consid. génér. sur les Crust., p. 302. - Le corps est lisse; le dernier segment de l'abdomen est en demi-ovale; la couleur de cette espèce est cendrèe variée de noir. - Se trouve sur les plages sablonneuses du Devonshire en Angleterre.

\section{Girolana， Leach，Desir.}

L'abdomen est composé de six articles. - Les yeux sont granulés. - Les petites lames des appendices ventraux postérieurs sont conformées comme celles des genres Eurydice et Néloicre.

\section{Cirolana cranchit.}

LEACH, Dict. des Sc.nat., t. XII, p. 347 . - Dess., Consid. génér. sur les Crust., p. 303. - Le corps est lisse, ponctué; le dernier article de l'abdomen est triangulaire, arrondi à son extrémité. - Se trouve sur les côtes occidentales de la GrandeBretagne.

\section{LIMNORIA, Leach, Desm.; Cymothoa, Latri., Lair.}

Les yeux sont distincts, granulés. - La tête est aussi large que le premier segment du corps. - Le pédoncule des antennes supérieures est médiocre.- Deux lamelles sont visibles aux appendices du côlé de la queue.

\section{LIMINORIA TEREBRANS.}

LeAcH, Edinb. Encycl. , t. VII, p. 433 ; ejusd., Dict. desSc. nat., t. XII, p. 355.Desm., Consid. gén. sur les Crust. , p. 312. - Long. 2 lig. - Le corps est d'une couleur cendrée; les yeux sont d'un brun-noirâtre; la femelle est d'un tiers plus grosse que le mâle, reconnoissable à la poche dans Iaquelle elle porte ses aufs et ses petits, au nombre de sept, à neuf qui en proviennent.

Ce Crustacé se trouve dans diverses parties de l'océan Britannique; il perce les bois des vaisseaux avec une promptitude alarmante; on s'aperçut pour la première fois des dommages qu'il cause lors de la construction d'un phare sur les rochers de Bell, près de la côte d'Ecosse; plusieurs pièces de boisétaient percées en ligue droite dans toutes les directions par une multitude d'individus de son espèce, à l'exception des endroits où se trouvaient des nœuds. Lorsqu'on saisit ces Crustacés vivans, ils se roulent en boule.

\section{CINQTIEME FAMILLE.}

\section{S P H E R O M D E S,}

LATR. , EDW.

Dans cette famille, la queue n'est composée que de deux segmens complets et inobiles, mais dont l'antérieur offre des lignes imprimées et transverses, indiquant les traces des autres. - Le feuillet intérieur des nageoires latérales et terminales est seul mobile; l'autre ou le supérieur est formé par un prolongement interne du support commun. - Les mandibules sont fortes, et leur côté interne présente audessous de la pointe dentelée du sommet un avancement ou rameau pareillement denté; sous cette feuille est une protubérance tronquée en forme de dent molaire. - Les palpes de ces mandibules ont quatre ou cinq articles. - Les deux pieds-mâchoires sont beaucoup plus grands que dans la famille précédente, et ressemblent à deux palpes divergens, et fortement ciliés. - L'espace situè immédiatement audessus des antennes est triangulaire, gu en forme de cœur renversé. - Les appendices sous-caudaux sont formés de deux feuillets triangulaires, dont l'interne plus large, al lant en pointe, et portés l'un et l'autre sur un pédoncule dirigé transversalement. Ces Crustacés sont vagabonds, et, à l'exception cependant des Anthures, rapprochent en dessous les deux extrémités de leur corps, afin de se contracter en forme de sphéroïde.

Genres : Spharoma, Zuzara, Campecopca, Nesaa, Cilicar, Cymodocea, Dyna. mene, Anthura.

$$
\begin{aligned}
& \text { Sphoeroma, Latr., Lam., Leace, } \\
& \text { Desir.; } \\
& \text { Oniscus, Linn., Paldas; } \\
& \text { Cymothoa, Fabr. }
\end{aligned}
$$

Les appendices postérieurs de l'abdomen. présentent leurs deux lames saillantes, l'ex- 
tẻrieure étant plate et de même forme que l'intérieure. - Le corps est susceptible de se rouler en boule.

\section{SPHOEROMA CURTUM.}

Lescir, Dict. des $S$ c. nat., t. XII, p. 345. - Desm., Consid. génér. sur les Crust., p. 299. - Le troisième article de l'abdomen est largement échancré postéricurement; le dernier est pointu à son extrémité. - Se trouve sur la côte occidentale d'Angleterre.

\section{SPHOEROMA PRIDEAUXIANUM.}

LEACH, Dict. des Sc. nat., t. XII, p. 345. - Desm., Consid. ginér. sur les Crust., p. 299. - Le quatrième article de l'abdomen est arrondi à son extrémité et bicaréné antérieurement; les carènes sont oistuses et peu distinctes. - Se trouve sur les côtes occidentales du Devonshire en Angleterre.

\section{SHHOEROMA DUMERH.I.}

Leach, Dict. des Sc.nat., t. XII, p. 345. - Desu., Consid. génér. sur les Crust., p. 300. - Les quatrième et cinquième articles de l'abdomen sont bicarénés; les carènes de chaque article sont très-prononcées; le dernier segment est pointu a son extrémité.

\section{SPIIOEROMA TRISTENSE.}

LeAch, Dict. des Sc. nat., t. XII, p. 345. - Desur., Consid. génér. sur les Crust., p. 300. - Le corps est lisse, avec son septième article à peine visible; le dernicr - segment de l'abdomen se termine tout-àcoup en pointe obtuse, ayant à sa base deux tubercules allongés et peu distincts; sa couleur est d'un gris cendré, tacheté de rouge; ses segmens sont tachetés, et leurs bords postérieurs colorés de rouge; les antennes ont leur dernier article rougeâtre. - Se trouve à l'île Tristan d'Acunha.

\section{SPHOEROMA HOOKERI.}

Leach, Dict. des Sc.nat., t. XII, p. 345; ejusd., Edinb. Encycl., t. III, p. 433.Uesm., Consid. génér. surles Crust., p. 300. - Le corps est lisse; les deux derniers articles de l'abdomen sontbicarénés, avecles carènes à peine saillantes; le dernier segment est arrondi à son extrémité; sa couleur est d'un gris-cendré ou rougeâtre, parsemé de points noirs; ses antennes sont cendrées; les carènes du derıier segment de l'abdomen sont quelquefois in. terrompues, ou à deux tubercules. - Habite les côtes de Suffolk en Angleterre.

\section{SPROEROMI RUGICAUDA.}

LeacH, Ėdinb. Ëucycl., VII, 405 et 433; ejusd., Dict. des $S_{c .}$ nat., t. XII, p. 346. Desu., Consid. génér. sur les Crust., p. 300. - Le corps est lisse; le dernier article de l'abdomen est rugueux, son extrémilé est arrondie; sa coulewr est cendrée, tachctée et rayée de noir; elle varie en ce qu'elle a tout l'abdonien rugueux, ainsi que les articles postérieurs du corps. - Se trouve sur les côtes de France et de la GrandeBietagne.

\section{SPHOEROMA TRIGONA.}

Risso, Crust. des environs de Nice, p. 147. - Desm., Consid. génér. sur les Crust., p. 301. - Long. 3 lig. - Le corps est un peu convexe, formé de huit segmens presque égaux, terminés sur leurs bords en pointe émoussée, et d'une queue (ou dernier segment) presque arrondie, terminée par trois angles, avec des appendices lancéolés et unis dans leur contour; la tête est parallélogrammique, et les paties sont longues; Ia couleur est le fauve clair pointillè de noirâtre. - Habite au milicu des algues et des varecs, à peu de distance du rivage.

\section{SPHOEROMA SERRATUM. (Pl. 19,} fig. 6.)

Leacr, Dict. des Sc. nat., t. X II, p. 346. - Desm., Consid. génér. sur les Crust., p. 301, pl. 47, fig. 3.-Guér., Icon. du Rég. anim. de Cuv., Crust.. pl. 30, fig.1.-Onis. cus Serrat us, Fabr., Mant.Ins., t. I, p.242. - Oniscus Globator, PaLI., Spicil. Zool., t. IX, p. 70 , t. 4 , fig. 18 . - Sphoroma Cinerea, Risso, Crust., p. 146. - Le corps est lisse; l'abdomen est arrondi à son extrémité; la petite lame ventrale est arrondie en dehors; les yeux sont noirs, les antennes fauves, les pattes cendrées, et les ongles fauves, terminés de noir ; le corps est cendré ou blanchâtre, marbré de rouge et de gris foncé. - Cette espèce habite l'Océan et la Méditerranée ; elle vit en grandes réunions, et on la trouve souvent dans les pierres, parmi les cailloux roulés et les graviers.

\section{SPHOROMA GIGAS.}

LeAch, Dictionn. des Sc. nat., t. XII, p. 346. - Desm., Consid. génér. sur les Crust., p. 301. - Long. i ponc. - Le corps est lisse; le dernier article de l'abdomen est rétréci en pointe et arrondi à scn extrémité. 


\section{ZUZARA, Leach, Dess.}

Les appendices postẻrieurs de l'abdomen présentent leurs deux lames saillantes, l'extérieure étant plus grande que l'intérieure, et convexe en dessous. - Le corps est susceptible de se rouler en boule. - L'abdomen présente son dernier article échancré à son extrémité, avec une légère saillie sortant du fond de l'échancrure.

\section{1. zUZARA SEMI-PUNCTATA.}

Leacr, Dict. des Sc. nat., t. XII, p. 344. - Dess., Consid. génér. sur les Crust., p. 299. - Le corps est lisse, avec les segmens ponctués postérieurement; le septième est prolongé en arrière : ce prolongement, dirigé en bas, est ponctué en dessus, et granulé de chaque côté à sa base; la lame extérieure des appendices du ventre est terminée brusquement en pointe.

\section{2. zUZARA DIADEMa.}

Lrach, Dict. des Sc.nat., t. XII, p. 344. - Dessr., Consid. génér. sur les Crust., p. 299. - Le corps est lisse, avec son septième segment prolongé en arrière : ce prolongement dilaté est en forme de diadême: la lame extérieure des appendices du ventre finit graduellement en pointe arrondie à son cxtrémité. - Se trouve dans les mers de la Nouvelle.Hollande, parmi les Sertulaires.

CAMPECOPEA, Leach, Desm. ;

Oniscus, Montage; Sphoroma, Latr., LAM., Risso.

Les appendices postéricurs du ventre ont leur petite lame extérieure seule saillante, allongée et courbée. - L'avant-dernier article du corps est plus grand que le der. nier.

\section{1. campecopea minsuta.}

Leach, Dict. des Se. nat., t. XII, p. 341. - Desm., Consid. génér. sur les Crust., p. 294, pl. 47, fig. 1. - Guér., Iconog. du Règn. anim. de Cuv., Crust., pl. 30, fig. 3. - Oniscus Hirsutus, Montage, Trans. Soc. Linn., t. VII, pl. 6, fig. 8. - Long. 4 lig. $\frac{1}{2}$. - La conleur est brune; le dernier anneau de l'abdomen est marqué de quelques points d'un bleu pâle. - Se ẑrouve sur la côte de Devonshire en Anggleterre.

2. GAMPECOPEA CRANCHII.

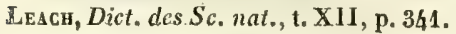

- Desy., Consid. génér. sur les Cinusı., p. 295. - Celle espèce diffère de la précédente en ce qu'elle est peu velue; le sixieme anneau du corps est simple et dépourvu d'épines. - Trouvée à Falmouth, sur la côle nord-ouest de l'Angleterre.

NESOEA, Leach, Desir. ;

Oniscus, Ad.MS; Sphoroma, LATR., LAM.

Présente les caractères généraux du genre précédent, et n'en differe qu'en ce que les appendices ventraux postérieurs sont droits et passablement longs, au lieu d'être courbés.

NESOZA BIDENTATA. (Pl. 19, fig. 7.)

Leach, Dictionn. des Sc. nat., t. XII, p. 342. - Desk., Consid. génér. sur les Crust., p. 295. - Gúxí, Iconog. du Règne anim. de Cuv., Crust., pl. 30. fig. 2.Oniscus Bidentatus, Adays, T'rans. Soc. Linn., t. VIII, tab. 2, fig. 3. - Long. 6 lig. - Le corps est lisse; le sixième anneau du thorax est rugueux, terminé postérieurement par deux piquans; l'abdomen est rugueux, et son dernier anneau présente deux tubercules vers son milieu; la couleur est cendrée, légérement striée de bleu et de rouge. - Cette espèce habite les rochers de la partie occidentale des côtes de France; on la trouve sous les pierres ou les thalassiophytes, à mer basse.

\section{Cilicoea, Leach, Desi.}

Les appendices postérieurs du ventre ont, comme les genres Campécopée et $\mathbf{N e}$ sée, la petite lame extéricure seule saillante. - Les deus derniers segmens du corps sont d'égale longueur. - Le premier' et le deuxieme article de l'abdomen sont très-courts, soudés avec le troisième, qui est grand; le dernier est échancré à son extrémité, avec une petite saillie dans son échancrure. - Les appendices ventraux postérieurs sont droits et assez longs.

cilicoea latreidlei. (Pl. 19 ; fig: 8.)

Leach, Dictionn. des Sc. nat., t. XII. p. 342. - Desr., Consid. génér. sur les Crust., p. 296, pl. 48, fig. 3. - Guér. Iconogr. du Règne anim. de Cuv., Crust., pl. 30, fig. 4.- Le dernier article de l'abdomen présente deux élévations en bosse ; la première, dans le mâle, est prolongée et pointue; la petite lame caudale extérieure a son extrémité échancrée postérieurement. - Patrie inconnue. 
CYMOdOGEA, Leach, Desh. ;

Cymodice, Leach; Oniscus, Montagu; Sphoroma, Latr.

Les appendices postérieurs du ventre ont leur deux lames extérieure et intéricure saillantes. - Le corps n'est pas susceptible de se rouler en boule. - L'abdomen ou la queue a son dernier article échancré à son extrémité, avec une petite lame dans son èchancrure, légérement aplatie, non foliacée, mais garnie de longs poils de chaque côté.

\section{CYMODOCEA EMARGINATA.}

Leaci, Dictionu. des Sc. nat., t. XII, p. 343. - Desar, Consid. génér. sur les Crust., p. 296. - Le prolongement terminal de l'abdomen est échancré à son extrémite; les troisième et quatrième articles de l'abdomen sont chacun pourvus de deux tubercules dont le dernier est le plus grand. Il y a des individus dont les sixième et septieme articles du thorax, l'abdomen, ainsi que les appendices du ventre, sont granuleux; il y en a aussi dont le thorax est uni et l'abdomen granulé. - Habite les côtes occidentales de l'Angleterre.

\section{CYHODOCEA TRUNCATA.}

LeACH, Dict. des Sc. nat., t. XII, p. 343. - Desir., Consid. génér. sur les Crust.. p. 297. - Oniscus Truncatus, Montag., M. 55, Cymodocea Truncata, Leacir; Edinb. Encycl. t. VII, p. 433 . - L'ab. domen est légérement granulé, et. son pro. longement terminal est entier et tronqué à son extrèmité; les troisième et quatrième articles de l'abdomen ont chacun deux tubercules dorsaux dont les postérieurs sont les plus grands. - Des côtes du Devonshire en Angleterre.

\section{CYMODOCEA BIFIDA.}

Leach, Dictionn. des $S c$. nat., t. XII, p. 343. - Desm., Consid. génér. sur les Crust., p. 297. - L'abdomen est granulé, et les troisième et quatrième articles ont ehacun deux tubercules sur le dos, les derniers étant les plus grands et bifides; le prolongement terminal du dernier article de l'abdomen est saillant et foiblement échancré. - Patrie inconnue.

4. CYMODOCEA IAMARCKU.

Leaci, Dictionn. des Sc.nat., t. XII, p. 3/33. - Desir., Consid. génćr. sur les Crust., p. 297, pl. 48, fig. 4. - Guén.,
Iconogr. du Règne anim. de Cuv., Crust., pl. 30, fig. 5. - L'abdomen est lisse, avec ses troisieme et quatrième segmens munis chacun de deux épines sur le dos; le dernier ayant son prolongement terminal étroit et sa pointe entière. - Se trouve dans la mer de Sicile.

$$
\begin{aligned}
& \text { DYNAMENE, Leach, Desm. ; } \\
& \text { Oniscus, Montagu ; } \\
& \text { Sphorioma, Latr., Lam. }
\end{aligned}
$$

Les appendices postéricurs du ventre ont leurs deux lames extérieure et intérieure saillantes, comprimées, d'égale grosseur, el foliacées. - Le dernier article de l'abdomen est marqué d'une simple fente à son extrémité. - Le sixième segment du corps est prolongé en arrière.

Ces Crustacés fréquentent les rochers des côtes, et semblent les préférer, à cause des petites cavités remplies de sable qu'ils présentent. On les rencontre parmi les thalassiophytes, surtout dans les petites faques d'eau qui restent dans Jes rocliers lorsque la mer est basse. Ils nagent arec beaucoup de vitesse et d'élégance, se lournent sur le dos comme les Sphéro. mes, et exécutent des évolutions rapides et variées.

\section{DYNAMENe MoNTAGui.}

Leaci, Dict. des Sc. nat., t. XII, p. 344. - Desir., Consid. génér. sur les Crust., p. 398. - Long. 3 lig. - Le corps est sublinéaire; le sixième anneau du thorax préspnte un prolongement aplati en dessus; le dernier article de l'abdomen est biarticulé; sa fente est presque d'égale largeur. - Se trouve sur les bords de la côte occidentale du Devonshire en Angleterre.

\section{DYNAMENE RUBRA.}

Lesca, Dict. des Sc. nat., t. XII, p. 344.-Dess., Consid. génér. sur les Crust., p. 298. - Le corps est sublinéaire; la fente du dernier article est presque égale en largeur dans toute son étendue; la couleur est rongeâtre. - Habite la côte occidentale de l'Angleterre.

\section{DYNAMENE VIRTDIS.}

LEACH, Dict. des $S c_{0}$ nat., t. XII, p. 344. - Desir., Conisid. génér. sur les Cirust., p. 298. - Le corps est presque ovale; la fente du dernier article de l'abdomen est très-élargie à sa base; la couleur est verdâtre. - Se trouve avec les espèces prècédentes et en très-grande quantité. 


\section{DyNamene Lesueuri.}

Desm., Consid. génér. sur les Crust., p. 298. - Spharoma Lesueuri, Risso, Crust. des env. de Nice, p. 147. - Le corps est oblong, bombé; la tête est pointue, traversée au sommet par des lignes profondes qui dessinent un cœur; le dernier article de l'abdomen est bombé, terminé par une pointe obtuse, relevée avec une petite dent de chaque côté; la couleur est grise, variée de points bruns; la queue est bordée de rouge. - Se trouve à Nice dans les cailloux roulés du rivage.

\section{ANTHURA, LeAcr ; \\ Oniscus, Montagu, Desm.}

Les antennes sont courtes, les intermédiaires étant un peu plus longues que les latérales. - Les pieds antérieurs sont pourvus d'un ongle mobile ou d'un pouce. Le corps est linéaire. - Les lames latérales de la queue sont foliacées.

\section{ANTHURA GRACILIS.}

Leach, Edinb. Encycl., t. VII, p. 404; ejusd., Trans. Soc. Linn., t. IX, p. 366. - Desm., Consid. génér. sur les Crust., p. 291, pl. 46, fig. 13. - GuÉr., Icon. dı Régne anim. de Cuv., Crust., pl. 30 , fig. 6. - Oniscus Gracilis, Montage, Trans. Soc. Linn., t. IX, tab. 5, fig. 6, - Gammarus heteroclitus, Viviani, Phosph. Maris, p. 9, tab. 2, fig. 11, 12.
Nous ne connoissons pas la description de cette espèce. Consultez, pour les autres espèces, l'Iconographie du Régne animal, par M. Guérin, où est figuré l'Anthura $C y$ lindrica, Guérin.

\section{DEUXIEME DIVISION.}

Dans cette seconde division, les quatre antennes sont insérées sur une même ligne transverse, et les intermédiaires sont trèspetites et de peu d'articles dans plusieurs; les mandibules, toujours fortes, dentelées, et offrant sous la pointe un avancement, n'ont plus de palpe; les deux pieds-mâchoires, qui ressemblent le plus souvent à une lèvre infèrieure lamellaire, couronnée par deux petits palpes triangulaires et coniques, ont, extéricurement, de chaque côté et à leur base, une petite pièce plus ou moins triangulaire, qui semble représenter le pédicule raccourci du flagre. La plupart de ces Isopodes sont marins; les autres vivent dans les eaux douces, ou hors de cet èlément; mais ceux-ci se tiennent généralement dans les lieux sombres, à l'abri de l'ardeur du soleil, et ils quittent souvent leurs retraites, lorsque après un temps sec l'air a été rafraîchi par des pluies. Tous portent leurs œufs dans une poche pectorale. Cette division comprend trois familles: les Idotéides, les Asellotes et les Cloportides.

\section{SIXIEME FAMILLE.}

\section{ID O TÉIDES,}

Latreille.

Caractères. Les antennes latérales se terminent par une tige sétacée et pluria:ticulée; les intermédiaires sont beaucoup plus courtes, filiformes, ou un peu plus grosses vers le bout, et divisées en quatre articles. La queue esi formée de trois segmens, dont le dernier beaucoup plus grand, sans appendices ni nageoires au bout; deux lames parallèles adhérentes aux bords latéraux de ce segment, longitudinales, biarticulées, appliquées l'une contre l'autre, par une ligne droite, au bord interne, formant deux espéces de volets ou de battants de porte, recouvrant les appendices souscaudaux et branchiaux, disposées, ainsi que de coutume, par paires et sur deux rangs: ils consistent chacun en deux sacs ovalaires, vésiculeux, mais aplatis et lamelleux; lorsque l'animal n'est point dans l'eau, ou que ces organes sont desséchés, et portès sur un tubercule commun.

Genres: Idotea, Arctura, Stenosoma.

Les Crustacés qui composent ces genres sont tous marins.

\section{IDOTEA, FAer., LATr., DESM.}

Oniscus, Pallas; Squilla, Degéer ; Cymothoa, Fabr.; Physodes, Duméril.

Les antennes postéricures ou latérales sont sétacées, médiocrement allongées, 
a acc un pédoncule de quatre articles, et leur extrémité multiarticulée; les intermédiaires, sur une même ligne horizontale et transverse, sont insérées un peu plus haut que les extérieures; beaucoup plus petites que celles-ci, filiformes, composées de quatre articles, le dernier assez gros. La tête, de la largeur du corps ou un peu plus étroite, est presque carrée. - La bouche est petite, formée d'un labre, de deux mandibules, de deux paires de mâchoires et de deux pieds-mâchoires extérieurs foliacés, de cinq articles qui remplacent par leur base la lévre inférieure. - Le corps est composé de sept anneaux proprement dits, transversaux, presque ègaux et unis, ordinairement marqués, de chaque côté, d'une impression longitudinale, qui, avec sa correspondante, divise l'anneau en trois parties. - Les pattes, au nombre de sept de chaque côté, ayant leur insertion en dessous de chacun des anneaux du corps, sont terminees par un petit ongìet très-pointu, un peu courbé; la première paire est la plus courte, les trois dernières sont les plus longues, et dirigées en arrière; les autres paires sont dirigées en avant.-La queue, presque aussi large que le tronc, est triarticulée à sa base, et sans appendices terminaux; elle recouvre les branchies et les lames qui protègent cellesci. - Les yeux sont ronds, composés, et peu saillants; le mâle est, suivant M. Desmarest, distingué de la femelle par deux petits filets élastiques qui ont leur attache entre les lames membraneuses de la queue, sur l'avant-dernier anneau du corps; il en diffère encore par les pattes, qui sont plus grosses, et par deux petites membranes ovales, placées l'une à côté de l'autre, audessous du premier des petits anneaux de la queue. C'est entre les pattes antérieures, sous les lames de la poitrine, que la femelle porte les cufs qu'elle dépose en été sur les plantes marines. - Les Idotées sont trèsmultipliées dans les lieux où la mer amasse des débris d'algues en putréfaction; elles choisissent les localités les plus abritées et les plus tranquilles, à un ou deux pieds sous l'eau; elles sont voraces: les poissons morts, les mollusques, les petites annélides et la plupart des matières animales, même en état de corruption, paraissent leur convenir; elles rongent les filets avec ardeur; elles sont essenticllement nocturnes; elles fuient la clarté du jour en se cachant à l'ombre des plantes marines, mais jamais sous les pierres; cen'est que la nuit qu'elles AwN. prennent leur nourriture; elles se réunissent en grand nombre sur les poissons morts qu'elles rencontrent, et rongent avec dextérité la chair de ceux pris dans les filets, sans toucher aux arêtes, et détruisent quelquefois dans une seule nuit toutes les espérances du pêcheur. Les Idotées marchent avec facilité au fond des eaux, et nagent en agitant les lames de leur queue; elles ne replient pas leur corps en boule comme les Sphéromes, mais elles en rapprochent assez facilement les deux extrémités en se courbant. Lorsque la mer est agitée, elles s'éloignent de ses bords ; mais si les flots, tout-à-coup soulevés par les vents, les surprennent au milieu des algues du rivage, où elles vivaient en toute sécurité depuis quelques jours de calme, il est curieux de les voir, sans cesse lancées sur les bords à sec, renversées sur le dos, se débattre et multiplier leurs efforts pour se débarrasser des algues qui les couvrent, regagner l'eau en toute hãte, en se laissant entrainer par les petits courants que la vague forme lorsqu'elle se retire, être de nouveau rejetées sur le rivage, et recommencer ce manége sans se décourager; enfin un moment de calme vient leur laisser un intervalle assez long pour lear permettre de trouver leur salut, en se plongeant bien avant dans les flots.

Ces Crustacés servent à la pêche; les poissons de la famille des Spares, tels que le Sparus Boops, Cantharus, Salpa, Sargus, Auratus, les Perca labrax, etc., en sont avides; aussi les emploie-t-on fructueusement comme appât à une pêche particulière qu'on nomme en Provence pesquo a la baboue.

\section{IDOTEA ENTOMON.}

Desw., Considér. génér. sur les Crustacés, p. 289. - Oniscus Entomon, Pallas, Spicil. Zool., fasc. 9, tab. 5, fig. 5-6. - Squilla Entomon, DEGÉER, t. VII, p. 32, fig. 12. - Long. 1 pouc. - Antennes extérieures à peu près égales aux intermédiaires; forme ovale. tronquée; queue longue et conique; couleur le brun-grisâtre en dessus, et le blanc sale mêlé de brun et de gris en dessous; tête insérée sur les côtés. - Des berds de la mer Baltique.

\section{IDOTEA TRICUSPIDATA.}

Dess., Consid. génér. sur les Crust., p. 289 , pl. 46 , fig. $11 .-$ Le corps est allongé, presque linéaire; la queue est ter- 
minée par une dent intermédiaire obtuse, plus large que les deux latérales, qui sont peu prononcées ou nulles; les antennes assez longues pour atteindre le troisième anneau du corps; la couleur est cendrée, ponctuée de brun, et souvent le dos est marqué d'une ligne longitudinale blanchejaunâtre. - Se trouve sur les côtes de France et d'Angleterre.

\section{IDOtEa Basteni. (PI. 19, fig. 9.)}

Aud., Descript. de l'Egypte, pl. 12 , fig. 6.-Guér., Iconogr. du Règ. anim. de Cuv., Crust., pl. 31, fig. 1.-Idotea Emarginata, Risso, Hist. nat. des Crust. de Nice, p. 135, sp. 1. - FABr., Suppl. Entom. Syst., p. 303, no 5.-Armida Bimarginata, Risso, Hist. de l'Europe Mérid., t. V, p. 109. - Long. 13 lig. - Le corps est allongé, brun, lisse, luisant, ponctué de noirâtre, tant en déssus qu'en dessous; les premiers anneaux ont leur bord latéral arrondi; les postérieurs sont en pointe aiguë; Ies rebords supérieurs de ces anneaux sont unis; la plaque caudale est légérement bombée, à peine carénée, terminée par deux échancrures peu profondes, qui lui donnent un aspect bidenté; la tête est arrondie, un peu tronquée sur la partie antérieure, où les antennes prennent naissance; les yeux ne sont point saillans; lés pattes ont leurs articulations munies de cils épineux; les postérieures sont les plus longues.-Cette espèce, qui se trouve sur les côtes de la Méditcrranée, offre trois ou quatre variẻtés.

\section{HOTEA OESTRUM.}

Leach, Trans. Soc. Linn, t. XI, p. 365. - Dess., Consid. génér. sur les Crust., p. 289. - Oniscus OEstrum, Pennant, Brit. Zool., t. IV, pl. 18, fig. 6.-Long. 1 pouc. $\frac{1}{4}-$ - Corps ovale, allongé; queue tronquée, échancrée; antennes égalant le tiers de la longueur totale de l'animal; couleur jaune-roussâtre ou cendrée, avec les côtés et le bout de la queue toujours plus pâles. - Se trouve sur les côtes d'Angleterre.

\section{IDOTEA pelagica.}

Leach, Trans. Linn. Soc., t. XI, p. 365. -Dess., Consid. génér. sur les Crust., p. 289.-Corps linéaire, ovale; queue arrondie, avec une dent trés-peu apparente dans son milieu; antennes ayant le tiers de la longueur du corps; tête échancrée en devant.-De la mer d'Ecosse.

\section{IDOTEA ACUSHYTA.}

Dess., Consid. génér. sur les Crust., p. 290. - Oniscus Balthicus, Pallas, Spicil. Zool., fasc. 9, tab. 4, fig. 6. - Le corps de cette espèce est ovale, oblong, plus étroit que celui de l'Idotea OEstrum; sa queue a une caréne assez aiguë sur le milieu du dos, et qui se prolonge postérieurement en une pointe; couleur jaunâtre ou roussâtre, avec trois rangées longitudinales de taches obscures; côtés du corps pâles; queue souvent noirâtre. - Habite nos côtes.

\section{IDOTEA VARIEGATA.}

Roux, Crust. de la Médicerr., pl. 30, fig. 1 à 9. - Long. 7 lig. - Le corps est lisse, luisant, noirâtre en dessus; une bande blanche s'étend sur les bords latéraux des anneaux, depuis la tête jusque vers l'extrémité de la queue, que pourtant elle n'atteint pas; tout le dessous du corps, et les pattes comprises, sont d'un gris-cendré, pointillé de brun; les antennes atteignent, dans leur longueur, le troisième segment du corps. - Cette espèce présente cinq ou six variétés assez remarquables. - Se trouve sur les côtes de la Méditerranée.

\section{IDOTEA PELOPONESIANA.}

Roux, Crust. de la Méditerr., pl. 30, fig. 10 à 12. - Long. 6 lig. - La saillie du bord latéral de chacun des anneaux du corps forme des échancrures profondes; les yeux sont saillans; les antennes, épaisses, atteignent à peine le troisième anneau; tous les anneaux du corps renflés et relevés; la queue bombée, arrondie et tronquée; la couleur de son corps, tant en dessus qu'en dessous, est un gris plus ou moins foncé, tacheté de noir, plus pâle sur le bord des anneaux antérieurs; lorsque le corps est d'un gris foncé, il est parsemé de taches blanchâtres irrégulières. - Se trouve sur les côtes de Morée.

\section{ARCTURUS, LATr.}

Ce genre est remarquable par la forme des seconds et troisiemes pieds, qui se dirigent en avant et se terminent par un long article barbu, et mutique ou foiblement onguiculé; les deux antérieurs sont appliqués sur la bouche et onguiculés; les six derniers sont forts, ambulatoires, rejetés en arrière et bidentés à leur extrémité. Sous le rapport de la longueur des antennes et de la forme du corps, ce genre se rapproche beaucoup de celui de Stenosoma. 
L'espèce type de ce genre, el dont nous ne connoissons pas la description, est :

\section{ARCTURUS TUberculatus.}

Latr., Ríg. anim. de Cuv., noutelle édit., t. IV, p. 140. - Se trouve dans les mers du Nord.

M. Westwood, dans les Transactions de la Société Entomologique de Londres, t. I, p. 72, pl. 9, fig. 1, a fait connoître une seconde espèce, qu'il désigne sous le nom d'Arcturus Longirostris. M. Guérin, dans son Iconographie du liègne animal de Cuvier, Crust., pl. 31, fig. 2, a représenté cette même espèce.

\section{STENosoma, Leaci, Desir. Idotea, LaTr. , LAMCK.}

Ce genre diffère de celui d'Idotée par les antennes extérieures, qui sont de la longueur du corps (la tête et le tronc, sans comprendre la queue), avec le troisicme article plus long que le quatrieme. - Le corps est linéaire, etroit.
1. Stenosoma LINEARE. (Pl. 20, fig. 2.) LeacH, Trans. Linn. Soc., t. XI , p. 336. - Desu., Consirl. génér. sur les Crust., p. 290, pl. 46, fig. 42.-Oniscu's Linearis, Penn, Brit. Zool., t. IV, pl. 18, fig. 2. - Long. 1 pouc. $\frac{1}{2}$. - La base $d u$ dernier segment de laqueue est un peu rétrécie, avec l'extrémité dilatée, tronquée, échancrée et pourvue d'une dent à chaque angle latéral ; d'un brun-noirâtre en dessus, blanchâtre sur les côtés. - Se trouve sur les bords de l'Océan.

\section{STENosoMA HECTICUM.}

Dess. , Consid. génér. sur les Crust., p. 291.-- Oniscus Hecticus, Pallas, Spicil. Zool., fasc. 9, tab. 4, flg. 10. -Idotea $V_{i}$. ridissima, Rrsso, Crust., p. 136, tab. 3 , fig. 8. - Long. 1 pouc.--Le corps est linéaire; le dernier segment de la queue est échancré, et les angles latéraux sont saillans; la couleur est un vert brillant. Cette espèce se trouve dans la mer de Nice, ovi elle habite les moyennes profondeurs.

\section{SEPTIEME FAMILLE。}

\section{A S E L L O T E S,}

LATREILKE.

Caractères. Les appendices sous-caudaux et branchiaux sont pareillement recouverts par deux feuillets, mais libres. La queue n'est formée que d'un seul segment, arec deux stylets bifides ou deux appendices très-courts, en forme de tubercules, au milieu de son bord postérieur. Il n'y a point d'ailleurs, sur les côtés, de nageoires. - Les quatre antennes se terminent par une tige sétacée, pluriarticulée. Quelques espèces vivent dans les eaux douces et stagnantes.

Genres : Asellus, Janira, Jora.

aSEllus, Geofr., Oliv., Lay., Latr. , DESM.;

Oniscus, Linn.; Squilla, Degeer ;

Cymothor, DaldorfF; Idotea, FABr.; Physodes, Cuv., Duméril.

Les antennes intermédiaires ou supérieures sont quadriarticulées, aussi longues que l'article terminal sétacé des extérieures; celles-ci formées de cing articles. - Les yeux sont petits, simples et latéraux. - Le pieds-mâchoires extérieurs sont réunis à leur base en forme de lèvre, et leur premiex article est grand et lamelliforme. Le corps est oblong, déprimé, formé de sept segmens pédigères et d'une queue d'un seul article fort grand et arrondi, portant deux appendices fourchus, composés d'une tige ciliée, cylindrique, biarticulée et terminée par deux filets coniques et divergens, ou deux petites pièces en forme de tubercule. - Les branchies allongées, aplaties, ovales, au nombre de six, recouvertes par deux écailles extérieures, arrondies et fixées par leur base, sont vésiculeuses. - Les pattes, au nombre de sept paires, sont terminées par un crochet simple; les dernières sont plus longues que les antérieures; les premières ont: leur avant-dernier article un peu renflé. -

asellus aQuaticus. (Pl. 20 , fig. 3.):

Geoff., Hist. des Inis., t. II, p. 672, pl. 22, fig. 2.-Guér, Icon. du liég. anim. de Cuv., Crust., pl. 31, fig. 3.-Ascl. 
lus Vulgaris, Desm., Consid. génér. sur les Crust., p. 311, pl. 49, fig. 1-2.-Squille Aselle, DeGÉEn, Miém. sur les Ins., t. VII, p. 496, pl. 31, fig. 1. - Fabr., Suppl. Ent. Syst., p. 303. - Long. 7 lig. Larg. 2 lig. $\frac{1}{2}$. - Ce petit Crustacé est trèscommun dans les eaux douces et stagnantes des environs de Paris, particulièrement dans les mares; sa démarche ordinaire est lente; mais lorsqu'il est poursuivi, il court très-vite; pendant l'hiver il se cache dans la cave, et ce n'est qu'au commencement du printemps qu'il en sort pour s'accoupler; dans cet acte, le mâle, qui est beaucoup plus gros que la femelle, porte celle-ci pendant une huitaine de jours environ sous son corps, la retenant, avec les deux pattes de la quatrième paire, exactement appliquée contre lui, et dans l'impossibilité d'échapper; quand il la quitte, cette femelle est chargée d'un assez grand nombre d'œufs qui sont placés sous son ventre et enfermés dans un sac membraneux ou une espèce de poche; les petits naissent dans ce sac, et ne tardent pas à en sortir par une fente qui s'ouvre naturellement dans sa longueur, et par la subdivision subséquente de ses parois en six parties ou lanières.

JANira, Leach, Desm.;

Oniscus, Montagu; Asellus, Latr., Laj.

Ce genre a beaucoup d'analogie avec le précédent, et il n'en diffère que par les erocheis terminaux des quatorze pattes, qui sont bifides. - Les yeux sont assez gros, placés plus près l'un de l'autre que ceux des Aselles. - Les antennes intermédiaires et supérieures sont plus courtes que l'article terminal sétacé des extérieures.

\section{JANiRA MACULOSA.}

Leaci, Edinb. Encycl., t. VII, p. 434, et Trans. Soc. Linn., t. XI, p. 573 . Dess., Consid. génér. sur les Crust., p. 315. - Cette espèce a le corps cendré, tacheté de brun. - Habite les côtes occidentales d'Angleterre, au milieu des varecs et des ulves.

JOERA, Leach, Desh.;

Oniscus, Montagu; Asellus, Latr., Lam.

Ce genre présente les caractères généraux des Aselles et des Janires, mais il en diffère en ce que les pieds antérieurs n'ont pas leur avant-dernier article plus gros et plus renflé que celui des autres picds, et en ce que les appendices latéraux de leur queue ne sont pas terminéspar deux pointes aiguës, mais ont la forme de deux simples tubercules.-Les yeux sont, ainsi que ceux des Janires, plus rapproches l'un de l'autre que ceus des Aselles.

\section{JOERA ALBIFRONS.}

I.EACH, Edinb. Encycl., t. VII, p. 434; ejusd., Trans. Soc., t. XI, p. 373. Desm., Consid. génér. sur les Crust., p. 316. - La couleur générale est cendrée; le front est blanchâtre. - Cette espèce est très-commune sur les côtes d'Angleterre, au milieu des varecs et sous les pierres.

\section{HUITIEME FAMILLE.}

\section{L O P O R T I E S ,}

Latreille.

Caractères. Les antennes latérales sont sétacées; les intermédiaires sont coniques, très-petites, peu apparentes, ou même indistinctes, et composées de trois à quatre articles au plus. - La queue est formée de six segmens, avec deux ou quatre appendices, plus ou moins en forme de stylet, au bord postérieur, sans nageoires latérales. - Les appendices sous-caudaux sont en forme de lames triangulaires, etimbriquées sur denx rangs, dans la plupart.

Les uns, faisant leur séjour dans la mer ou les eaux salées, ont leurs antennes exté- rieures ou laterales terminées par une tige pluriarticulée, de manière que le nombre total de tous les articles, à partir de la base, est de neuf au moins; leurs segmens thoraciques offrent latéralement une ligne enfoncée et longitudinale, ou l'apparence d'une division.

Genres: Tylos, Deto, Ligia, Philoscia, Oniscus, Porcellio, Armadillo.

\section{TYLOS, LATR.}

Le dernier segment de la queue est demi-circulaire, il occupe entièrement le vide 
formé par l'échancrure du précédent, et les appendices postérieurs sont très-petits et intérieurs; les branchies, dont les antérieures au moins découvertes, sont disposées sur la longueur en quatre paires de lames transversales, vésiculeuses, et coupées par des stries longitudinales. - Les antennes latérales sont composées de neuf articles, dont les quatre derniers forment la tige; deux tubercules enfoncés représentent les intermédiaires; l'espace intermédiaire est élevé. - Les Crustacés qui composent ce genre ont la propriété de se contracter en boule.

\section{TYLOS ARMADILLO.}

Latr., Rég. anim. de Cuv., t. IV, p. 142. - Guḱr., Icon. du Rég. anim. de Cuv., Crust., pl. 31, fig. 4.- Cette espèce a été très-bien figurée par M. Savigny dans le grand ouvrage d'Egypte, Crust., pl. 13, fig. 1.

\section{DETO, GUÉR.}

Les articles des antennes sont au nombre de neuf, dont les quatre derniers forment une tige beaucoup plus courte que le prècédent, et composée d'articles inégaux. - Le corps ne parait pouvoir se contracter que très-imparfaitement en boule. - Les appendices ou stylets postérieurs s'avancent au delà du dernier segment.

Ce genre a beaucoup d'analogie avec les Tylos; cependant on ne pourra le confondre avec ces derniers, en ce qu'ils ont les appendices postérieurs très-petits et entièrement cachés, et les quatre derniers articles des antennes égaux en longueur. $\mathrm{ll}$ a aussi beaucoup d'affinités avec les Armadilles et les Cloportes, mais on ne peut le confondre avec eux, parce que ceux-ci n'ont que sept ou huit articles aux antennes, et que ces articles vont en diminuant graduellement de longueur et d'épaisseur. L'espèce type de ce nouveau genre est :

\section{DETO ECIINATA.}

Guér., Mag. de Zool., cl. VII, pl. 44, 1837, fig. 1 à 5. - Long. 15 millim. Larg. 7 millim. - Le corps est assez aplati, ovalaire, d'un jaune-verdâtre, avec les bords un peu transparents; la tête et le milieu des sept segmens thoraciques sont couverts de tubercules assez saillans; la tête offre deux saillies latérales et une intermédiaire, ce qui laisse en avant deux échancrures dans lesquelles s'insèrent les antennes, qui ont à peu près la moitié de la longueur du corps; en arrière, la tête offre deux courtes épines un peu divergentes; les sept segmens du thorax ont en arrière et de chaque cóté une forte épine conique, dirigée en arrière et un peu en dehors: ces épines sont à peu près aussi longues que la moitié de l'espace qui les sépare sur le même segment; l'abdomen est lisse, avec le dernier segment court, ne dépassant pas le support. des deux filets terminaux, lesquels sont de moitié plus longs que ce dernier segment; les pattes sont courtes, de forme ordinaire, un peu épineuses, terminées par un simple crochet.

Ce singulier Crustacé a été rapporté d'Orient par feu Olivier.

\section{Ligia, Fabr., Latr., Desir.; Oniscus, Linv.; Asellus, OLrv.}

Les antennes sont placées sur une ligne transversale à la partie antérieure de la tête et près de la base du chaperon; elles sont très-rapprochées, et semblent partir d'une base commune; les latẻrales ou extérieures sont sétacées, de la longueur de la moitié du corps, formées de six articles, la plupart cylindriques, dont les deux premiers fort courts, et les trois derniers allongés; le sixième ou terminal est le plus long, composé de très-petits articles, et terminé insensiblement en pointe. - Les antennes mitoyennes s'insèrent au côté interne des précédentes; elles sont très-petites, filiformes, de deux articles comprimès, dont le dernier est obtus. - La tête est emboîtée dans une échancrure du premier seg. ment du corps; elle est en forme de cône transversal. -- Les yeux sont assez grands, arrondis, concares et composés d'un trèsgrand nombre de facettes hexagones. - La bouche est composée d'un labre, de deux mandibules, d'une languette et de deux paires de mâchoires. - Le labre, presque membraneux, est demi-ovale, un peu voûté au milieu, et fixé au bout de l'extrémité antérieure de la tête, qui représente une espèce de surlabre ou de chaperon transversal.-Les mandibules, qui soni crustacées, sont beaucoup plus épaisses à leur base, robustes, comprimées et brusquement arquées; le côté interne de leur extrémité est élargi, concave dans son milieu, avec la pointe supérieure comme écailleuse, noirâtre, et divisée en quatre dentelures obtuses; la mandibule gauche differe de la droite par ses dentelures, qui sont prononcées. - La languette est située immédia. 
tement en dessous el dans l'entre-deux des mandibules; elle se compose de deux pièces réunies en demi-cercle. - Les deux mâchoires supérieures sont presque membraneuses, dirigées obliquement et convergent ensemble; elles sont divisées à la base en deux pièces allongées, étroites, presque linéaires, comprimées, et dont l'une supérieure est un peu plus interne; celle-ci est plus petite et terminée par quelques longs cils réunis en faisceau pointu et dirigé brusquement en manière de crochet, vers l'extérieur de la bouche; l'autre division est écailleuse et dentelée à son extrémité supérieure, avec quelques cils en dessous sur le bord interne; les mâchoires suivantes sont membraneuses, en forme de valvules qui emboitent la face postérieure des mâchoires précédentes; leur bout est arrondi et sans dentelures, - Les deux pieds-mâchoires sont membraneux, très-comprimés, parallèlement concaves sur leur face antẻrieure ou interne, et divisés en six articles; le premier est beaucoup plus grand, en forme de carré-long, de sorte que les deux premiers articles, étant contigus l'un à l'autre, et par une ligne droite au bord interne, imitent une sorte de lèvre, leur extrémité supérieure et interne se prolonge comme une division labiale; les autres articles composent par leur réunion une pièce triangulaire ou conique, entièrement dentelée au côté interne, et armée extẻrieurement de quelques petites épines géminées ou terniées. - Le corps est allongé, ovalaire, convexe en dessus, composé de treize segmens transversaux, pointus en arrière de chaque côté, dontles sept premiers sont pédigères, et dont les six derniers constituent la queue; le treizième presque carré, avec le bord postérieur arrondi au milieu, et échancré latéralement, pour l'articulation des appendices. - Les pattes, au nombre de quatorze, sont portées par les sept premiers segmens antérieurs; elles sont insérées sur les côtés inférieurs du corps, et elles ont çà et là quelques petites pointes; elles sont composées de six articles, dont le premier se dirige vers la poitrine, et forme ensuite, avec le suivant, un coude ou un angle; le dernier article des pattes est écailleux, poilu au bout, avec une petite dent au-dessus; les dernières pattes sont un peu plus longues et vont en arrière. - Ce que l'on nomme la queue chez ces Crustacés est formé par les six segmens postérieurs; ils sont plus courts que lés précédents, cxcepté le dernier, qui est presque carré, avec le bord postérieur arqué, arrondi au milieu, et échancré de chaque côté; il donne attache à deux styles plus ou moins longs, dirigés en arrière, et composés chacun d'une pièce comprimée, tranchante sur les bords, et ayant à l'extrémité deux pointes coniques, allongées et presque égales, l'intérieure seulement un peu plus longue; il offre à son extrémité un très-petit arlicle allant en pointe; on voit sur la surface inférieure de chacun de ces six segmens deux feuillets membraneux, transparens, qui sont en triangle curviligne, et servent de nageoires et de branchies.-Les feuillets de la paire supérieure sont plus petits; les deux suivans dans les mâles, portent à leur base interne et inférieure un appendice membraneux, long et linéaire.

Ces Crustacés sont très-communs sur nos côtes; ils fréquentent les embouchures des rivières et des fleuves, et se cachent sous les pierres ou les amas d'objets et les plantes rejetées par la mer; ils sont trèsagiles, grimpent avec facilité sur les rochers et sur les constructions maritimes dans les endroits humides, et s'ils aperçoivent le moindre danger, ils se laissent tomber dans l'eau en repliant leurs pattes sous leur corps.

\section{Ligia oceanica.}

Latr., Génér. Crust. et Ins., t. XI; ejusd., Rég. anim. de Cuv., $2^{\mathrm{e}}$ édit., t. IV, p. 142.-Oniscus Oceanicus, Linn.-Drsm., Consid. génér. sur les Crust., p. 317, pl. 49 , fig. 3 à 4 . - Long. 18 lig. - La partie antérieure du corps est arrondie; les antennes extéricures sont de moitié plus courtes que le corps, le dernier segment est composé de petits articles; les styles de laqueue sont éganx entre eux, épais, de la longueur de celle queue; la couleur du test est d'un gris-verdâtre bordé de brun. - Très-commune sur nos côtes océaniques.

2. ligia italica. (P1. 20 , fig. 1.) Latr., Génér. Crust. et Insect., t. I ; ejusd., Règ. anim. de Cuv., $2^{\mathrm{e}}$ édit., t. IV, p. 142. - Desm., Consid. génér. sur les Crust., p. 318. - Guér., Icon. du Règ. anim. de Cuv., Crust., pl. 31, fig. 5.Roux, Crustacés de la Méditerranée. - Le corps est luisant, glaaque, finement pointillé de noirâtre; les yeux sont verdâtres; les antennes sont longues; leur dernière paire est formée d'environ dix-sept petits 
Tome ler lére partie Crustacés. Pl. 20.

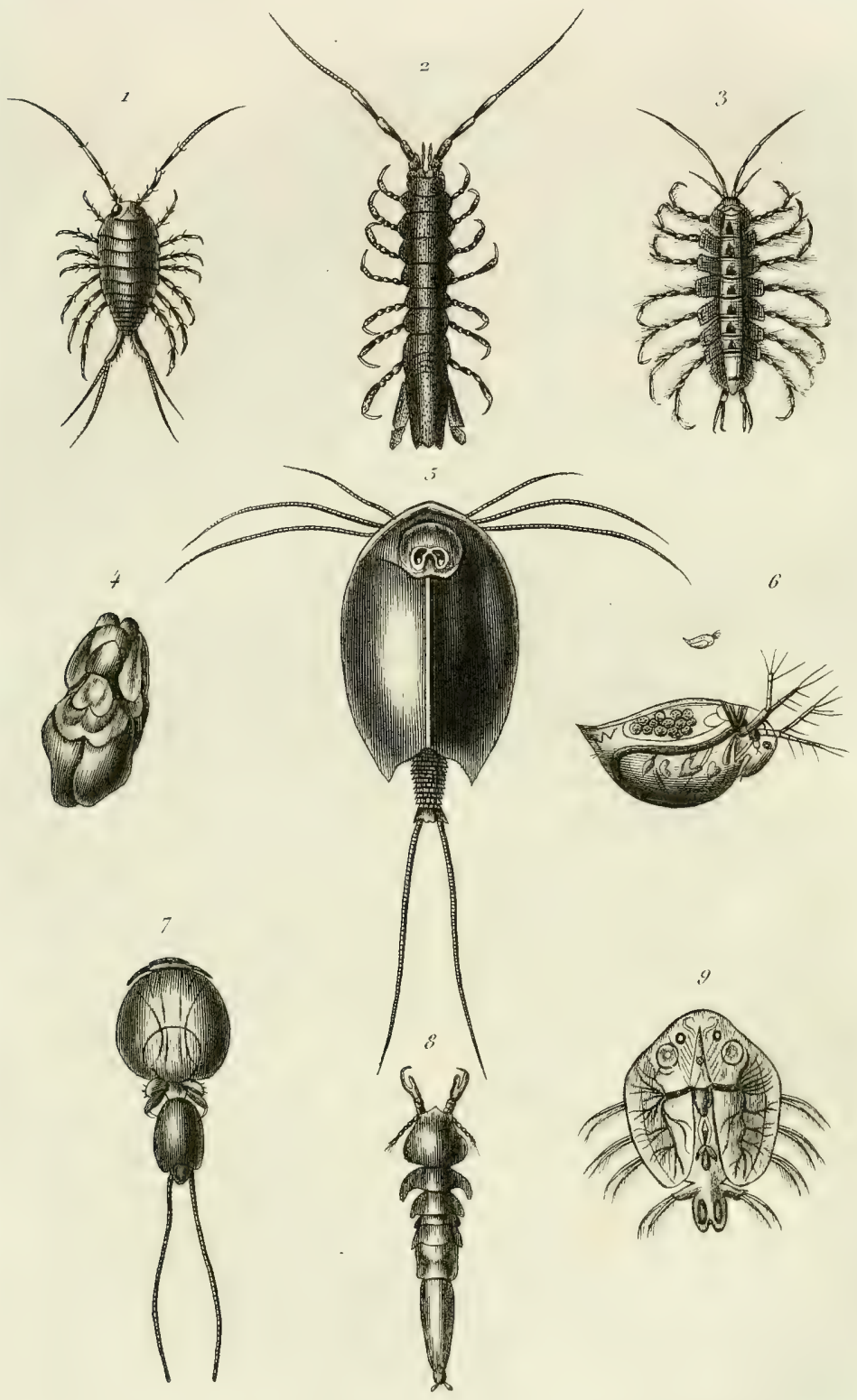

1. I.igia italica, 2. Stenosoma lincare. 3. Asellus aquaticus. 4. ('ecrops latreillei, 5. Apus cancriformis. 6. Daphnia pulex, 7. ('aligus mulleri, 8. Dichelesthum sturonis. 9. Argulus folianetr. 

articles; une grande tache blanchâtre occupe le milieu des cinquième, sixième et septième anneaux du corps; les pattes sont poilues vers leur articulation, variées de vert, de gris et de noirâtre; les styles caudigères sont égaux (l'extérieur est un peu plus court que l'intérieur), presque aussi long que le corps, ayant leur pédoncule comme étroit et allongé ; le bout postérieur des anneaux pédigères a des petites impressions qui lui donnent un aspect denté. Cette espèce vit toute l'année en société sur les rochers du littoral de la Méditerranée, mais rarement parmi les algues rejetées sur le rivage; elle court avec beaucoup d'agilité dans tous les sens, tantôt sur les flancs d'un rocher et tantôt suspendue à la voûte. Lorsqu'on veut saisir ces Crustacés, ils ne se roulent point en boule comme les Cloportes, mais ils fuient avec vitesse; ils se cachent dans les anfractuosités des rochers, se blotissent dans les moindres fissures et souvent s'y laissent écraser plutôt que de s'en retirer; ils se plaisent dans les lieux humides du bord de la mer, se tiennent de préférence dans l'ombre; cependant, lorsque les rayons brûlants du soleil viennent à les surprendre à l'heure de midi, on ne les voit pas moins rôder sans paraître incommodés de la chaleur; lorsqu'ils tombent dans l'eau, ils nagent avec assez de facilité, mais ils ne s'y plongent pas volontairement et se hâtent de gagner les bords. S'ils s'y tiennent pour se soustraire au danger qu'ils fuient, ils demeurent tranquilles ou y marchent lentement, le filet latéral de la queue écarté ; mais lorsqu'ils nagent, ils étendent ce filet mobile et le reunissent à celui intérieur. - La femelle pond des cufs d'un vert pâle.

\section{IIGIA EXOTICA.}

Roux, Crust. de la Médilerr., pl. 13, fig. 9. - Le corps est légèrement chagriné, d'un brun-verdâtre, livide sur le bord des anneaux du corps et des appendices; cette couleur est aussi celle des pieds; sa forme générale est allongée; la queue est proportionnellement plus rétrécie que chez les Ligia Oceanica et Italica. Les antennes sont plus longues que le corps, et le dernier article est composé de vingt-sept articulations; les filets de la queue sont presque aussi longs que le corps. - Habite Cayenne.

\section{LIGIA HYPNORUM.}

Litr., Génér. Crust. et Ins., t. I, p. 68, sp. 3 ; ejusd., líig. anim. de Cuv., t. IV, p. 142. - Desm., Consid. génér. sur les Crust., p. 318. - Ligie des mousses, Bosc, Crust., t. II, p. 190.-Oniscus Hypnorum, Guv., Journ. d'Hist. nat., t. II, p. 19, tab. 26, fig. 3, 4, 5.-Oniscus Agilis, Panz., Faun. Ins. Germ., fasc. 9, 24. - Les antennes sont plus courtes que la moitié de la longueur du corps, et leur dernière pièce est formée d'environ six petits articles; les styles de la queue sont apparens, et leur pédoncule est muni d'une dent et d'une scie à son extrémité et du côté interne; le corps est varié en dessus de noirâtre, de cendré et de jaunâtre. Habite les côtes de l'Océan.

\section{pHiloscia, Latr., Lamak, Desm. ; Oniscus, Linn., Fabr., Cuv.}

Les antennes extérieuressont découvertes à leur base, et les intermédiaires, sont non distinctes.-Le corps est ovale, à segmens transverses au nombre de sept. - La queue est formée de six segmens, brusquement plus étroits que le corps; les quatre appendices styliformes sont bien apparens et presque égaux entre eux, les extérieurs étant néanmoins un peu plus longs que les intermédiaires.

\section{PHinoscia Muscordi.}

Desm., Considérations générales sur les Crustacés, p. 309, - Oniscus Mus. corum, Guv., Journ. d'Hist. nat., t. II, p. 21 , tab. 26 , fig. $6,7,8$. - Le corps en dessus est d'un brun cendré, parsemé de petits traits et de petits points gris ou jaunâtres; en dessous il est blanchâtre; les pattes présentent quelques traits obsrurs. - Cette espèce est assez commune dans les bois humides, sous les feuilles mortes, ou sous les pierres, en France, en Allemagne, en Suède et en Angleterre.

\section{ONISGUS, Linn., Geoffr., Fabr., Latr, DESM.}

Les antennes extérieures sont seules apparentes, et leur base est recouvertc par les bords latéraux de la tête; celle-ci est moyenne, èchancrée dans le bord antérieur du premier segment du corps. - Les yeux sont composés, granuleux, latéraux. -Le corps est formé de sept segmens transversaux, dont les bords lateraux sont postérieurement terminés en pointe, etantérieu. rement arrondis, - L'abdomen (queue) est composé de six segmens, dont les cincy 
premiers sont étroits; les deux antérieurs sans prolongemens latéraux; les trois suiyans en ayant, au contraire, de très-prononcés, et le sixième ou le dernier est triangulaire, pointu et muni de quatre appendices. Les deux appendices latéraux de la queue sont très-forts, coniques et biarticulès; les intẻrieurs, situẻs au dessus de ceux-ci, sont grêles, cylindriques, d'un seul article, terminés par plusieurs petites soies, et laissant suinter un liquide visqueux. Les pieds insérés sur les côtés du corps ont leurs deux premières pièces grandes, et forment entre elles un angle vers la ligne médiane du ventre; tous sont terminés par un article ou crochet simple, et leur grandeur s'augmente graduellement depuis la première paire jusqu'á la dernière. - Les organes respiratoires sont placés sous la queue, et consistent en six paires de lames superposées, triangulaires, appliquées pour chaque paire exactement l'une contre l'au. tre, par leur côté interne, et formant ensemble une pointe plus ou moins prolongée en arrière.

Ces Crustacés habitent de préférence les lieux humides et obscurs, tels que les caves et les celliers, et se tiennent ordinairement dans les fentes des murailles, dans les joints mal réunis des cloisons, sous les pierres, etc. Ils paroissent vivre de fruits gâtés, de feuilles, de substances végetales en décomposition, et on en a vu aussi qui mangeaient des cadarres d'individus de leur espéce. Leur démarche est ordinairement lente; mais lorqu'ils éprouvent quelque crainte, ils courent assez vite. Les femelles portent leurs œufs dans une espèce de sac ovalaire, mince et flexible, placé au-dessous de leur corps et s'étendant depuis la tète jusque vers la cinquième paire de pattes. Les œufs éclosent dans ce sac, qui ne tarde pas à se fendre longitudinalement, et ensuite transversalement en trois lanières de chaque côté, pour laisser sortir les jeunes Cloportes, qui ne diffèrent de leurs parents qu'en ce qu'ils ont deux pattes et un anneau du corps de moins qu'eux; que leur tête et leurs antennes sont proportionnellement plus grosses que les leurs; que leur couleur est jaunâtre ou bleuâtre trèsclair, etc. Après leur naissance ces petits trouvent pendant quelques jours un refuge assuré au milieu des lames respiratoires qui garnissent le dessous de la queue de leur mère.

Les Cloportes ont été long-temps employés en médecine comme fournissant des remedes diurétiques, absorbans ou apéritifs; mais l'usage en a presque totalement cessé.

\section{ONISCUS ASELLUS.}

Desm., Consid. génér. sur les Crustacés, p. 320 , pl. 49 , fig. 6. - Clo. porte ordinaire, Geoffr., Hist. des Ins. des env. de Paris, t. II , p. 670, pl. 22, fig. 1. - Cloporte aselle, DEGÉER, Insect., t. VII, p. 547, pl. 36, fig. 3. -Long. 7 lig. - Cette espèce est légérement rugueuse en dessus, particulièrement sur la tête; la couleur est gris-obscur, avec les bords plus clairs et une série longitudinale de points jaunes, placée de chaque côté du corps; le ventre et les pattes sont d'un gris blanchâtre uniforme. - Très-commune dans toute l'Europe.

\section{PORGEllio, Latr., Leach, Desm.; Oniscus, Lxnn. , Geoff.}

Ce genre présente les caractères généraux du précédent, et n'en différent que par le nombre des articles des antennes, dont ceux qui forment les extérieures sont au nombre de sept.

Les mœurs sont entièrement semblables.

\section{Poncellio scaber.}

Desm., Consid. génér. sur les Crust., p. 321, - Guér., Icon. du Rég. anim. de Cuv., Crust., pl. 31, fig. 7.-Cloporte ordinaire, var. G, Geoff., Hist. des Ins., t. II, pl. 22, fig. 1 C._-Oniscus Granulatus, Lamck., Hist.des Anim. sans vert. , t. V, p. 154.- Le dessus de la tête et le segment du corps et de la queue est recouvert de granulations nombreuses; les quatrieme et cinquième articles des antennes sont striés dans leur longueur; la couleur est tantôt d'un cendré-noirâtre uniforme, tantôt d'un jaune clair, et varié de gris plus ou moins foncé. - Se trouve communément sur les murailles, sous les pierres et le bois pourri.

\section{PORGELIIO LEVIS.}

Desu., Consider. génér. sur les Crustacés, p. 321. - Cloporte ordinaire, var. B , Georf. , Hist. des Ins., t. II, pl. 22, fig. 1 B.-Oniscus Lavis, Laмск., Hist. des Anim. sans vert., t. V, p. 154. -Le corps est entièrement lisse ; les appendices de la queue sont plus grands que dans l'espéce précédente; la couleur est cendré-noirâtre, plus on moins nuancée 
de gris-jaunâtre. - Se trouve sous les pierres.

M. Guérin, dans le tome VI des Annales de la Société Entomologique de France (Bulletin entomologique, p. 6), a fait connoittre une nouvelle espèce de Porcellio, qu'il désigne sous le nom Poeyi, et qui se trouve très-communément dans les appartemens de la Harane.

\section{ArMadillo, Latr., Las., Leach, DESM. ; \\ Oniscus, Linn., Geofr., Ourv.}

Les antennes extérieures sont formées de sept articles, coudées, insérées de chaque côté, au-dessous d'une échancrure du chaperon, mais ayant leur base protégée en dessus par un prolongement de la tête en forme de voûte.-Les yeux sont granuleux, entièrement latéraux sur le dessus de la tête. - Le corps est bombé et arqué, composé d'anneaux qui ne se terminent pas en pointe sur leurs bords latéraux et postérieurs. - La quene est formée de six segmens, dont les deux premiers ne se prolongent pas jusqu'au bord extérieur, et dont le dernier est triangulaire et court; le second article des appendices latéraux de la queue est aplati, triangulaire et placé de manière à remplir l'espace qui existe entre le segment terminal et le bord postérieur de l'avant-dernicr. - Les pieds sont conformés comme ceux des Cloportes et des Philoscies, et terminés par un ongle court et simple. - Les écailles branchiales supérieures présentent une rangée de petits trous qui servent de passage à l'air.

Les habitudes naturelles de ces Crustacés ont les plus grands rapports avec celles des Cloportes; seulement ces animaux vivent plutôt à la campagne que dans les endroits habités. On les trouve dans les lieux humides et obscurs, qu'ils recherchent de préférence, comme les cavités souterraines, les creux des rochers exposés au nord, les caves, les celliers, etc. Souvent on en rencontre sous les vieilles écorces des arbres morts, ou sous les grosses pierres que l'on trouve dans les champs. Leur démarche est ordinairement très-lente. Ils s'engourdissent pendant l'hiver, et vivent de matières végètales desséchées ou humides. Dans le temps de la ponte, les femelles gardent leurs œufs sous les appendices lamelliformes de leur abdomen, comme le font les
Cloportes; les œufs y éclosent, et les petits paroissent sortir vivans du corps de leur mère. Leur accouplement est inconnu. Ils se dépouillent, au moins une fois dans l'année, de leurs peaux, dont on trouve les débris dans les lieux qui leur servent ordinairement de retraite.

\section{ARMadillo vUlganis,}

Dess., Considér. génér. sur les Crustacés, p. 323. - Oniscus Armadillo, Sulz., Hist. Insect., tab. 30 , fig. 13. Cuv., Journ. d'Hist. nat., 1792, t. II, p. 23, pl. 26, fig. 14-15. - D'un gris cendré sans taches, avec le bord des anneaux un peu plus pâle. - Cette espèce est trèscommune sous les pierres, et on la trouve dans tous les temps de l'année. Elle se roule en boule au moindre attouchement, et se laisse plutôt briser que de se dérouler; l'action du feu peut seule la forcer à s'ètendre.

\section{2. armadillo pusturatus.}

Dumér., Dictionn. des Sc. nat., t. III , p. 116. - DesM., Considér. génér. sur les Crust., p. 323, pl. 49, fig. 7. - Guér., Iconogr. du Régne anim. de Cuv., Crust., pl. 31, fig. 9.-Oniscus Pulchellus, Panz., Faun. Insect. Germ., f. 62, fig. 24. D'un gris cendré, avec des taches irrégulières, blanches ou jaunâtres, sur les anneaux. - Cette espece varie beaucoup pour la couleur, qui est tantôt noirâtre ou bleuâtre, et quelquefois presque blanche; les taches varient aussi par leur disposition, par leur forme et par leur couleur. - Elle est très-commune dans les caves peu profondes des habitations rurales, dans les carrières, sous les solives, etc.

\section{ARMADILLO OFFICINALIS.}

DuMÉr., Dictionn. des $S$ c. nat., t. III, p. 117. - Desm., Considér. génér. sur les Crust., p. 323. - De couleur grise, à second anneau du corps échancré, très-grand, plus long que les six derniers.

Cette espèce est celle qui nous vient d'Italie, et qu'on vend chez les apothicaires comme diurétique, fondante et apéritive. Les médecins n'emploient guère maintenant ce Grustacé, qu'on regardoit autrefois comme un remède souverain contre la jaunisse, et qu'on trouve encore indiqué comme pectoral dans quelques formulaires. 
SIXIEME ORDRE.

\section{I $\mathrm{C}$ - $\mathrm{A}$ P O $\mathrm{ES}$,}

LATREILle.

Les Crustacés que cet ordre renferme paraissent faire le passage des derniers Crustacés Edriophthalmes, ou dont les yeux sont pédiculés, et particulièrement des Mysis aux Cyclopes, et dès lors à cette division de la classe de Muller désignée sous la dénomination d'Entomostracés, ou insectes à coquille, qui a été appelée depuis Branchiopodes, et se composant du genre Monoculus de Linné et de Fabricius, auquel il faut adjoindre celui de Limulus de ce dernier. Dans la nouvelle édition du Régne animal de Cuvier, dit M. Latreille, nous avions même placé avec les Lophyropes les genres Condylura et Nebalia, que nous rapportons maintenant à l'ordre des Diclapodes. Les tégumens de ces Crustacés, ou des Gondylures au moins, sont évidemment d'une nature calcaire. Les appendices locomotiles sont plus nombreux que ceux des Cyclopes et autres genres Branchiopodes voisins des précédens. Les pieds-mâchoires sont appliqués, en tout ou en partie, sur la bouche. Il y a deux yeux distincts, et qui, même dans les Nébalies, semblent être un peu pédiculés. A ces deux genres ont été joints ceux de Cuma et Pontia de M. Milne Edwards. Le premier est, sans aucun doute, très-rapproché de celui de Condylure, et appartient dès lors à la même coupe ordinale. Le second a de grands rapports avec les Cyclopes; mais le nombre de ses yeux et de ses appendices thoraciques l'en éloigne. Ces Diclapodes paraissent être organisès, à cet égard, sur' le plan des Crustacés des ordres précédens. Ils ressemblent d'ailleurs à ces derniers Entomostracés, à raison des fonctions locomotiles; ils ne peuvent servir qu'à la natation et à la respiration, et quelques-uns d'entre eux au moins sont pareillement divisés en deux branches, et telle est l'origne de la dénomination de Diclapodes. La queue, encore nue en dessous, n'offre de fausses pattes que sous les premiers segmens. Le thorax, lorsqu'il est divisé, ne présente jamais plus de six segmens; de sorte que, comparativement aux Amphipodes et à la plupart des Isopodes, le premier des sept composant le thorax est ici confondu avec la tête, d'où il résulte qu'on n'en compte plus que six.

Tous les Diclapodes connus habitent nos mers.

Nous partagerons cet ordre en deux groupes : les Nébalites et les Cumites.

\section{NÉBALITES.}

Caractéres. Le test recouvre sans aucune division la tête et le thorax. Ce groupe ne comprend qu'un seul genre, celui de Nebalia.

\section{NEBALIA, Edw., Latr., Leach, Desir. ; Mysis, Latr., Oluv., Risso ; \\ Cancer, Orif., Fabr., Herbst ; \\ Monoculus, Montag.; Cyclops, Viviani.}

La carapace se prolonge jusqu'au-dessous de la portion de l'abdomen qui donne attache aux pattes natatoires (considérées à tort par les auteurs comme les analogues des pattes thoraciques des Décapodes); mais sa disposition est bien diflérente de ce qui se voit chez la plupart de ces Crustacés; en effet, le bouclier dorsal, au lieu de faire corps avec les anneaux qu'il recouvre, et de remplacer en quelque sorte les pièces tergales de l'arceau dorsal de ces segmens, ne fait que de se prolonger audessus, sans même y adhérer; chacun des premiers anneaux de l'abdomen et chacun des anneaux thoraciques ainsi cachés, sont aussi complets que chez les Malacostracés Edriophthalmes, nouvelle preuve que la carapace de ces Crustacés n'est autre chose que l'arceau dorsal de l'un des anneaux céphaliques qui s'est développé outre mesure, et qui a chevauché sur les parties voisines. Cette même carapace est bombée dans son milieu, et terminée antérieurement par un rostre pointu, arqué en dessous, et sous lequel sont deux yeux pédonculés et très-rapprochés. - Les antennes supérieures sont insérées au-dessous des yeux ; elles sont formées de deux soies médiocrement longues, et portées sur un pédoncule cylindrique. Les antennes inférieu- 
res sont longues, simples, sétacées, sans écailles à leur base, placées latéralement, et portées sur des pédoncules allongés. - La bouche est armée de mandibules, qui ont lesplus grands rapports avec celles des Décapodes; on y distingue une pièce basilaire, terminée par deux grosses dents recourbées en dedans, et un appendice palpiforme très-long et composé de trois articles. En arrière des mandibules on trouve deux petites écailles ciliées sur les bords, et réunies par un pédoncule sur la ligne médiane; on doit les considérer comme représentant la lèvre inférieure. A ces organes succède une paire de membres dont la disposition est très-remarquable; on leur voit un article basilaire se prolongeant en dedans sous la forme d'une lame ciliée sur les bords, à peu près comme les mâchoires de divers Edriophthalmes, et supportant une longue tige filiforme, qui se dirige d'abord en avant, puis se courbe en haut et en arrrière, et se prolonge jusqu'à l'extrémité du thorax, entre la face interne de la carapace et des flancs; cette tige est composée de plusieurs articles filifères; en arrière de ces organes se trouve une autre paire de mâchoires, dont l'article basilaire est profondément divisé en plusieurs lobes sur le bord interne; enfin à ces organes buccaux succède une série de huit paires de pattes lamelleuses et branchiales, dont l'appendice externe surtout est d'une texture molle et vasculaire. Ces pattes, extrêmement minces et très-serrées les unes contre les autres, sont fixées à huit anneaux thoraciques bien distincts, à la suite desquels on voit huit anneaux, et dont le diamètre diminue progressivement; les quatre premiers de ceuxci portent les quatre paires de pattes natatoires bifides, qui ressemblent beaucoup aux fausses pattes abdominales des Crevettines et même des Macroures; deux paires de membres rudimentaires se voient des cinquième et sixième anneaux post - thoraciques; le pénultième anneau ne porte pas d'appendice; et enfin le dernier en porte deux. - L'abdomen s'insère au-dessous de l'extrémité postérieure du test, et se compose de plusieurs articles, dont les premiers supportent deux petits filamens rudimentaires qui représentent les fausses pattes abdominales; le dernier article est terminé par deux stylets allongés, garnis de poils.

\section{NERAIIA GEOFFROVI.}

EDw., Ann. des Sc. nat., t. XIII, pl.-15, fig. 1.-Guér., Icon. du Rég. anim. de Cuv.,
Crust., pl. 32, fig. 2. - La têle n'est pas distincte du reste du corps, et toute l'extrémité céphalo-thoracique est recouverte d'un test qui descend sur les côtés, et qui, vu de profil, parait de forme ovalaire; l'extrémité antérieure de la carapace recouvre la base d'un rostre pointu et recourbé en bas; au-dessous de ce prolongement se remarquent deux yeux pédonculés assez gros, et de couleur brune; ils sont formés d'une cornée transparente, au-dessous de laquelle se trouve un grand nombre de petits cristallins logés dans une couche de matière colorante brunâtre; les antennes supérieures sont insérées au-dessous des yeux, et ont une forme très-singulière; les deux articles basilaires de ces appendices sont assez gros, et forment ensemble un angle à peu près droit; le dernier supporte une lame ovalaire cilièe, et un prolongement sétiforme multiarticulé et dirigé en bas; les antennes inférieures sont formées de quatre articles, dont le dernier est très-long, sétíforme et multiarticulé; en arrière de ces antennes, dont la base est cachée sous le test, se trouvent trois paires d'appendices qui entourent la bouche; à ceux-ci succèdent cinq paires de lames foliacées et ciliées, qui sont également cachées sous le test, et qui, par leurs mouvemens continuels pendant que l'animal est en repos, paraissent devoir servir à la respiration. Enfin, en arrière de ces pattes lamelleuses, se trouvent quatre paires de pieds bifides, ciliés, et propres à la natation. L'abdomen s'insère au-dessous de l'extrémité postérieure du test; il se compose de sept articles, dont les premiers supportent deux petits filamens rudimentaires qui représentent les fausses pattes abdominales; enfin le dernier article est terminé par deux styles allongés et garnis de longs poils. Celle espèce, qui a été trouvée sur !es côtes de Bretagne, vit parmi les petitscailloux et les débris de coquillages, et nage sur le flanc.

\section{CUMTTES.}

Caractéres. Dans ce groupe la tête est distincte du thorax ; les tégumens qui enveloppent ces deux parties du corps se partagent au plus en sept segmens, dont l'antérieur forme la tête.

Genres: Condylura, Cuma et Pontia.

$$
\text { CONDYLURA, LATr. }
$$

Les antennes inférieures sont plus longues، - Les côtés antérieurs du premier 
segment sont prolongés en pointe, et forment deux écailles rapprochées en manière de bec.-Les pieds se terminent en pointe soyeuse; quelques-uns des intermédiaires ont un appendice extérieur près de leur base. - La queue est étroite, de sept anneaux, dont le dernier, allongé, conique, s'avance entre les deux appendices latéraux, qui sont grêles, en forme de stylets, de deux articles, dont le dernier soyeux.-L'espéce type de ce genre est le:

\section{CORDYYURA ORBIGNYI.}

Latr., Règ. alim, de Cuv., t. IV, p. 153.- Nous ne connoissons pas la description de cette espèce, seulement nous savons qu'elle a a été trouvée sur les côtes maritimes de La Rochelle.

\section{GUMA, EDw.}

Tête distincte du corps et très-grande.Deux yeux sessiles. Antennessupérieures rudimenta res; antennes inférieures courtes. - Thorax composé de quatre segmens. Cinq paires de pattes natatoires. - Abdomen composé de six anneaux, et terminé par deux appendices portant chacun deux stylets.

\section{CIMIA AUDOUINI.}

Evw., Ann. des $S$ c. nat., t. , pl. 13, fig. B. - Long. 4 lig. - La forme générale de ce Crustacé est très-remarquable; son extrémité antérieure est grosse et arron. die, tandis que le thorax et l'abdomen sont formés d'une longue chaîne d'anneaux trèspetits; la tête paroît consister en un seul anneau convexe et allongé; le thorax est au contraire divisé en quatre segmens très-distincts dont le diamètre décroit assez rapidement; l'abdomen présente dans toute sa longueur à peu près la même grosseur; et on y compte six anneaux, dont le dernier supporte deux articles cylindriques et allongés, terminés chacun par deux appendices styloödes; les yeux sont sessiles, circulaires et placẻs de chaque côté supérieurement; les antennes supérieures sont rudimentaires et ne paroissent formées que d'un article garni de quelques poils; les antennes inférieures sont plus longues, on y distingue quatre articles dont le dernier est terminé par des poils; la bouche est recouverte par les deux premières pattes, qui sont très-développées, et s'appliquent contre la face antérieure de la tête. On distingue une paire de mâchoìres élargie et velue, suivie de six appendices que l'on doit rapporter aux trois paires de pieds-mâchoires des autres Crustacés décapodes. La premiere, très-petite, porte un appendice sétiforme; la seconde paire est allongée et formée de six articles dont le premier supporte un appendice flabelliforme, et le second est le plus long ; le dernier pied-mâchoire paroitlau premier abord terminé en pointe. mais, en l'examinant de plus près, on voit qu'il n'en est pas. ainsi ; ces deux derniers articles sont à peu près cylindriques et assez courts, tandis que celui qui les supporte présente en dedans un prolongement qui s'avance presque aussi loin que ceux dont nous venons de parler; enfin au lieu d'un filament grêle et allongé, inséré à la base de ce pied-mâchoire comme au précédent; on y remarque un appendice multiarticulé, assez gros et garni de poils; la première paire de pattes est très-allongée, et recouvre toute la bouche, de même que ce dernier pied-mâchoire, et ils sont bifides depuis leur base; l'appendice interne est droit. presque aussi long que l'externe, et formé de six articles; l'externe est peu courbé et s'applique contre la face inferieure de la tête dans toute sa longueur, on y distingue cinq articles dont les deux premiers sont très-développés; enfin son extrémité est garnie de quelques poils; cette première paire de pattes, ainsi que ta suivante, est suspendue au premier anneau thoracique, tandis que les trois dernières paires correspondent chacune à un segment distinct; elles sont toutes dirigées en avant et garnies de poils à leur extrémité; mais elles ne sont pas bifides comme la première, etleur longueur décroît successivement.La couleur de cette espèce est d'un blanc jaunâtre.

Elle a été trouvée près du Croisic, sur des rochers qui ne sont à découvert que lors des grandes marées.

\section{PONTIA, Edw.}

Tête distincte du thorax. - Deux yeux sessiles. - Quatre antennes, dont les supérieures sétacées et multiarticulées; les inférieures pédiformes et ciliées. - Thorax divisé en six anneaux. - Cinq paires de pattes bifides et natatoires. - Abdomen formé de deux segmens et terminé par deux appendices.

\section{Povtia savigryi,}

Edw., Ann. des Sc. nat., t. , pl. 14, fig. 1. - La tête n'est pas très - distincte du thorax; antérieurement, elle esf termi- 
nèe par un rostre aigu qui est peu mobile, et paroit formé de deux articles; les yeux sont au nombre de deux, assez petits et sessiles; les antennes supérieures sont trèslongues, sétacées et formées d'un grand nombre d'articles; les inférieures sont bifides, et garnies de poils à leur extrémité, qui esi plate et élargie ; elles sont dirigées en bas, et paroissent remplir l'office de pattes natatoires ou de pieds - mâchoires; le thorax est formé de six anneaux, dont les deux antérieurs sont les plus larges, et les autres diminuent progressivemant de grandeur; les cinq derniers supportent autant de paires de paltes qui sont bifides, ciliées, dirigées en arrière et propres seulement á la natation; le second segment thoracique, qui supporte la première paire de pattes, soutient aussi une paire d'appendices très-larges, bifides, et garnis d'un grand nombre de longs poils rameux; ces derniers appendices, que l'on doit considérer comme des pieds-mâchoires externes, sont dirigés en avant et cachent complétement la bouche, ainsi que les autres pieds-mâchoires ; ceuxci, au nombre de deux paires, diffèrent beaucoup par leur forme; la première, c'est-àdire celle qui recouvre les mandibules, est courte, large, garnie d'un assez grand nombre de poils et formée de quatre articles; la suivante est, au contraire, grêle et allongée; l'abdomen estdivisé en deux segmens: le premier supporte une paire de fausses pattes rudimentaires; le second est terminé par deux appendices en forme de spatule, biarticulés et ciliés.

Cette espèce est remarquable par la beauté de ses couleurs; le dos est d'un blanc argenté et nacré, entouré d'une bordure assez large. - Elle nage sur le ventre et se meut avec une vivacité extrême. - Se trouve sur les côtes du Croisic.

Tous les ordres suivans, moins celui des Trilobites, embrassent cette série de Crustacés que Müller nomme collectivement Entomostracea, mais qu'il est bien difficile de caractériser par un signalement simple et rigoureux. Tous ces animaux sont aquatiques, munis de pattes, en nombre variable, uniquement propres, sauf quelques exceptions, à la natation, et dans le plus grand nombre, en tout ou en partie, branchiales. Ils sont recouverts d'un test mince, corné, composant un bouclier supérieur d'une ou de deux picices, ou bien une sorte de coquille bivalve. On ne roil pas tout le dessous de la queue, ou.du moins sous ses derniers anneaux, d'appendices analogues à ceux que l'on y observe dans la plupart des Crustacés précédens. Les pattes postérieures des diverses espèces, telles que celles des Limules, des Caliges, quoique d'une forme très-singulière, ont plus de rapports avec les pieds thoraciques des Crustacés des premiers ordres. qu'avec les fausses pattes du dessous de leur queue ou de leur post-abdomen. Les uns se distinguent aisément de tous les autres Crustacés par leur bouche en sucoir, ou bien en ce qu'elle est composée de deux rangées de mâchoires formées par le premier article des pieds ambulatoires, ou ceux du premier bouclier; les autres, dont la bouche est analogue à celles des autres Crustacés des ordres précédens, s'en éloignent cepen. dant par la forme de leurs pattes, leur nombre, ainsi que celui des organes de la vision. Ainsi, dans ceux qui ont deux yeux, et quelquefois portés sur des pédicules, mais inarticulés, le nombre des pattes thoraciques est au moins de vingt, et elles sont toutes composées d'articles lamelleux ou foliacés; les autres n'ont qu'un seul æil. Le nombre des pattes, en y comprenant celles qui correspondent aux pieds-mâchoires, est de huit au plus; ceux des antennes au moins contribuent aussi à la locomotion; or, cet ensemble de caraclères ne convient à aucun des Crustacés des ordres précédens.

On avait d'abord cru que les organes sexuels masculins de quelques espèces étaient placés sur deux de leurs antennes; mais les observations de Jurine père ont détruit cette erreur, et il est reconnu que ces organes, ainsi que ceux de l'autre sexe, sont situés soit près de l'origine de la queue ou de l'abdomen (le second anneau ordinairement), soit, comme dans les Limules, aux deux premières patles du bouclier antérieur. Nous remarquerons cependant qu'on n'a encore à cet égard qu'un très-petit nombre d'observalions. Cette disette de faits est encore plas grande relativement au mode de la circulation et au système nerveux; toute généralisation serait par conséquent hasardée. Sous le rapport de la gestation, les Entomostracés différent aussi des autres Grustacés. Les femelles des uns portent leurs œufs dans deux capsules on dans deux sacs situés près de la naissance de l'abdomen; les œufs des autres sont rassemblés quelque temps sur le dos, au dessous du tégument, s'échappent ensuite par les issues extérieures des ovaires, et sont déposés dans les lieux convenables à leur conservation et éclosion. Il paroîtroit qu'une 
dessiccation prolongée ne leur ferait point perdre leurs propriétés. On a constaté, à l'égard de quelques espèces, qu'un seul accouplement suffit pour plusieurs générations successives. Ces Crustacés subissent dans leur jeune âge des changemens trèsremarquables, qui influent sur la forme générale de leur corps, ainsi que sur celle de leurs appendices locomoteurs et leur nombre. Ce sont de veritables métamorphoses. Les recherches de Ramdohr, de Jurine père et de Jurine fils, et surtout celles de M. Straus, ont ajouté beaucoup au précieux travail de Muller sur ces animaux; mais il reste encore bien des difficultés à éclairer et des détails d'organisation à connâtre.

D'après ce que nous avons dit plus haut, les Entomostracés se divisent naturellement en deux grandes sections, les Dentés et les Edentés. Les premiers ont une bou- che composée: d'un labre, de deux mandibules, d'une languette et de deux paires de mâchoịres, faisant quelquefois l'oflice de mains ou d'organes de préhension. La bouche des autres, ou des Edentés, nous présente deux types de conformation. Dans l'un, et dont les Limules nous offrent seuls un exemple. le premier article des pieds du bouclier antérieur sert de mâchoires. Dans l'autre type, et composé d'espèces parasites, un sucoir, formé à ce qu'il paroît de quatre pièces correspondantes au labre, aux mandibules et à la languette des Crustacés dentés, tient lieu de bouche; ce sont ainsi des animaux suceurs. Telles sont les premières bases de cette distribution. Nous signalons ensuite les ordres, d'après d'autres caractères secondaires, tirés du nombre et de la forme des pattes, des yeux, etc.

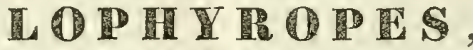

Latreille.

D'après les observations de Ramdohr, de Jurine père et de M. Straus, relatives aux organes de la manducation et de la locomotion, comparées avec celles que nous offrent ces mêmes parties, considérées dans les Crustacés des ordres précédens, il paroîtroit que la dernière paire de pattes thoraciques de ces Entomostracés seroit l'analogue de la troisieme paire des Amphipodes et des Isipodes, ou la première des Décapodes. Suivant Jurine, le nombre des pattes thoraciques est de huit; mais l'on voit d'après l'ordre successif des appendices qui les précèdent, que ccux quu'ils désigne sous le nom de mains répondent aux secondes mâchoires, et que dès lors les trois paires antérieures des pieds proprement dits représentent autant de piedsmâchoires. Les Daphnies, sclon M. Straus, ont dix pieds; mais ici les deux premiers correspondent aussi aux secondes mâchoires.

Cet ordre a été partagé en deux familles : les Séticéres et les Cladocéres.

\section{S E T I C E R S ,}

LATREILLE.

Caractères. Le thorax, plus ou moins ovoïde ou ovalaire, est divisé en quatre segmens, dont l'antérieur, beaucoup plus grand, et avec lequel la tête se confond, offre, en devant et dans son milieu, l'organe de la vision. - Les antennes supérieures sont longues, sétacées, simples et for- mées d'une multitude de petits articles, on n'en distingue guère que quatre aux inférieures; celles-ci sont fort courtes, filiformes, simples et fourchues. - Les mandibules portent un palpe, tantôt indivis, tantôt partagé en deux branches. - Immédiatement à la suite des pièces répondant aux 
deux mâchoires supérieures, viennent cinq paires de pieds, divisés en deux branches cylindriques, plus ou moins garnies de poils. - La queue est formée de six anncaux, avec deux stylets et des soies au bout. - L'on voit, sur le premier, dans la femelle, deux appendices en forme de petites pattes, et sur le second, dans les deux sexes, les organes de la génération, et les deux sacs ovifères et pédiculés.

Cette famille ne renferme qu'un scul genre, celui de Cyclops.

GYClOpS, Mull. , Latr., Lam., Leach, DEsM. ;

Monoculus, Linn., Geoff., Degéer, FABR. ;

Amymona et Nauplius, Mulc.

Le corps est plus ou moins ovalaire, mou ou gélatineux, se partageant en deux portions, l'une antérieure, composée de la tête et du thorax, et l'autre postérieure ou la queue. - Le segment précédent immédiatement les organes sexuels, et qui, dans les femelles, porte deux appendices en forme de pattes, peut être considéré comme le premier de la queue, qui n'est pas toujours bien nettement ou brusquement distinguée du thorax; elle est formée de six segmens ou articles: le second porte en dessous, dans les mâles, deux appendices articulés, tantôt simples, tantôt ayant au côté interne une petite division en branche de formes variees, et constituant tout ou partie des organes de la génération. - La vulve, chez les femelles, est située sur le même article; le dernier se termine par deux pointes en stylets formant une fourche, et plus ou moins garnies de soies ou de filets penniformes. - L'autre portion du corps, ou l'antérieure, est divisée en quatre segmens, dont le premier, beaucoup plus grand, compose la tête et une portion du thorax, qui sont aussi recouverts par une écaille commune. - Il porte l'œil, quatre antennes, deux mandibules munies d'un palpe simple, ou divisé en deux branches arliculées, deux mâchoires ou lèvres, avec des barbillons, et quatre pieds divisés chacun en deux branches cylindriques, garnies de poils ou de filets barbus; la paire antérieure, représentant les secondes mâchoires, diffère un peu des suivantes; elle est comparée à des espèces de mains par Jurine; chacun des trois segmens suivans sert d'attache à une paire de pieds. Deux des antennes sont plus longues, séta- cées, simples et composées d'un grand nombre de petits articles; clles facilitent par leur action les mouvemens du corps, et font presque l'office de pieds; les inférieures sont filiformes, n'offrent le plus souvent que quatre articles, et sont tantôt simples, tantôt fourchues; elles font, par leurs mouvemens rapides, tourbillonner l'eau. Dans les mâles, les supérieures, ou l'une d'elles seulement, présentent des étranglemens et un renflement suivi d'un article a charnière. Au moyen de ces organes, ou de l'un d'eux, ils saisissent soit les dernières pattes, soit le bout de la queue de leurs fe. melles, dans leurs préludes amoureux, et les retiennent, malgré elles, dans les situations appropriées à la manière dont ils sc fixent; elles emportent leurs mâles, lorsqu'elles ne veulent pas d'abord se prêter à leurs désirs. La copulation s'opère comme dans les autres Crustacés et pár des actes prompts et réitérés. On avoit cru, jusqu'alors, que les organes copulateurs des mâles étoient placés aux antennes supérieures, et cette erreur paroissoit d'autant mieux fondée, que les Arachnides présentent des faits analogues. De chaque côté de la queue des femelles est un sac ovale, rempli d'œufs, et adhérant, par un pédicule très-dilaté, au second segment, près de sa jonction avec le troisième, et où l'on voit aussi l'ovifère du canal déférent de ces œufs. La pellicule formant ces sacs n'est qu'une continuation de l'ovaire interne. Le nombre des oufs qu'ils contiennent augmente avec l'âge : d'abord bruns ou obscurs, ils prennent ensuite une teinte rougeâtre, et deviennent presque tous transparens lorsque les petits sont près d'éclore, mais sans grossir; ces œufs étant isolés ou détachés, du moins jusqu'à une certaine époque, le germe périt. Une seule fécondation peut suffire à plúsieurs générations successives. La durée du séjour des fœtus dans les ovaires varie de deux à dix jours, ce qui dépend de la température des saisons et de diverses autres circonstances. Les sacs ovifères présentent quelquefois des corps allongés, glandiformes, plus ou moins nombreux, et qui paroissent être des réunions d'animalcules infusoires. A leur naissance les petits n'ont que quatre pattes, et leur corps est arrondi et sans queue. Muller avoit formé, avec de jeunes individus, son genre Anynoma. Quelque temps après (quinze jours de février en mars), ils acquièrent une autre paire de pieds, c'est le genre Nauplius, du même; après la pre. 
mière mue, ils ont la forme et toutes les parties qui caractérisent l'état adulte, mais sous des proportions plus exiguës; leurs antennes et leurs pattes sont proportionnel. lement plus courtes. Au bout de deux autres mois, ils sont propres à la génération. La plupart de ces Entomostracés nagent sur le dos, s'élancent avec vivacité et peuvent se porter aussi bien en arrière qu'en avant. A défaut de matières animales, ils attaquent les substances végétales, mais le fluide dans lequel ils vivent ne passe point dans leur estomac. Le canal alimentaire s'ètend d'une extrémité du corps à l'autre.

\section{CYCLOPS CASTOR.}

Jur., Monog., p. 50, pl. 4, 5, 6.-Desur., Consid. génér. sur les Crust., p. 363, pl. 53, fig. 5. - Cyclops Ceruleus, MuLL, Ent., tab. 15, fig. 1-9. - Cyclops Rubens, ejusd., pl. 16, fig. 1-13.-Cyclops Laciniatus, ejusd., pl. 16, fig. 46. - Monoculus Caruleus, Fabr., Entom. Syst., t. II . p. $500, \mathrm{n}^{\circ} 46 .-$ Monoculus Rubens, ejusd., p. $500, n^{\circ} 47$. - Long. 1 lig. $\frac{1}{2}$ - - Le corps de cette espèce est allongé, peu renflé, formé de six segmens; la queue est assez courte, et en à dix; les antennes posté. rieures sont courtes, bifides; les œufs de la femelle sont bruns, forment une seule masse ovale, placée au-dessous de la queue; la couleur de la femelle est bleuâtre, celle du mâle est rougeâtre.

\section{CYCLOPS VULGAPIS.}

Desir., Consid. génér. sur les Crust., p. 362, pl. 53, fig. 1 à 4. - Monoculus Quadricornis, LrNN., Faun. Suec., nº 2049. -Monocle àqueue fourchue, Georr., Ins., t. II, p. 656, no 3.-DEGÉER, Ins., t. VII, p. 483, pl. 29, fig. 11, 12. - Cyclops Quadricornis, Mull., Entom., pl.18, fig. 1-14.Monoculus Quadricornis, Jur., Mon., p.1, pl.1; fig. 1-11; pl. 2, fig. 1-9; var. Albidus, pl.2. fig. 10,11 ; var. Viridis, pl. 3 , fig. 1; var. Fuscus, pl. 3, fig. 2. var. Prasinus, pl. 3, fig. 5. - Long. 2 lig. - Les antennes sont simples et sans divisions; les intérieures ont quatre articles, et leur longueur n'égale guère que le tiers des supérieures; le corps proprement dit est assez renflé et presque ovoïde ; la queue est étroite et de six segmens; la couleur varie beaucoup; les uns sont rougeâtres, les autres blanchâtres ou verdâtres. - Celle espèce est assez commune; on la trouve dans les eaux stagnantes.

\section{CYCLOPS STAPHYLINUS,}

DesM., Consid. génér. sur les Crust., p. 363, pl. 53, fig. 6. - Cyclops Minutus, MulL., Entom., pl. 18, fig. 1-7. - Monoculus Minutus, Fabr., Ent. Syst., t. II, p. 499, - Long. $\frac{5}{12}$ de lig. - Forme allongée; corps composé de six segmens, dont le premier oa l'antérieur est le plus grand, et dont le dernier est le plus petit, et terminé par une queue bifide; la couleur des femelles est d'un bleu-verdâtre, celle des mâles est d'un joli vert; les œufs sont d'un bleu-verdâtre, rassemblés dans une bourse pyriforme qui pend au-dessous du ventre de la femelle. - Cette espèce est remarquable en ce qu'elle tient ordinairement relevée l'extrémité postérieure de son corps sur l'antérieure, à peu près comme le font les insectes du genre Staphylin.

\section{DEUXIL̀ME FAMILIE.}

\section{L A D O E R E S,}

\section{LATREILLE.}

Caractères. Une grosse tête saillante, souvent terminée en pointe ou en manière de bec infẻrieurement, portant supérieurement un œil de grandeur variable, précédé d'ane tache noire oculiforme, ayant de chaque côté, près de sa jonction arec le thorax, une antenne toujours saillante, ordinairement fort grande, en forme de bras, servant de rame, divisée à la suite d'un pédoncule, en deux ou trois branches arti- culées, garnies de soies ou de filets. - Un test pliè en deux, mais sans charnière, enveloppant le thorax et les pattes, le plus souvent finissant en pointe à son extrémité postérieure. - Dix paltes plus ou moins divisées, et garnies de filets ou de soies au bout. - Une queue courte, se repliant en dessous, et toujours terminée par deux appendices coniques ou sétacés. - OEufs toujours intérieurs jusqu'au moment où la 
femelle les dépose dans l'eau, passant des ovaires situés sur les côtés dans une cavité dorsale, entre le corps et le test; tels sont les principaux caractères de cette famille, qui renferme trois genres. - Les espèces qui composent ces genres ont des mouvemens très-prompts et sautent pour la plupart.

Genres : Polyphemus, Daphnia, Lynccus.

'POLyPhemUS, Latr., Moll., Desh. ; Monoculus, Lins.; , Cephaloculus, Lar.

Le corps est court, globuleux, un pen comprimé, couvert d'un test s'ouvrant en dessous, mais dont la division en valves n'est pas bien apparente. - L'œil ou les yeux sont réunis, forment une seule masse fort groșse, figurant une espèce de tête, entièrement recouverte par le test, et portée sur un cou; deux petits barbillons composés chacun d'un article terminé par deux filets, sortant de la coquille au-dessous de l'œil; deux grands bras formés chacun d'un pédoncule surmonté par deux branches composées de cinq articles, et garnies de quelques soies biarliculées; un sillon transversal séparant la partie postérieure du corps de l'antérieure, à l'endroit du cou; une queue grêle, relevée sur le dos et bifurquée. - Huit pattes apparentes hors de la coquille, composées d'une cuisse, d'une jambe et d'un tarse à deux articles, de l'extrémité duquel sortent quelques filets (excepté de celui de la dernière paire). - Les œufs sont placés dans la coquille, sur le dos, et au nombre de dix an plus. - Les mâles sont inconnus.

\section{POLYPHEMUS STAGNORUM.}

Drsy., Consid. génér. sur les Crust., p. 365, pl. 54 , fig. 1 à $2 .-$ Polyphemus Oculus, Mout., Entom., pl. 20, fig. 1-5.Monoculus Pediculus, Linn., Faun. Suec., no 2048, DegéER, t. VII, p. 467, pl. 28, fig. 6-13; FABr., Entom. Syst., t. II, p. 502. - Monocle à queue retroussée, Geoff., Ins., t. II, p. 656, n². - Cephàloculus Stagnorum, LAM., Anim. sans vert., t. V, p. 130. - Long. $\frac{11}{24}$ de lig.La coquille de cette espèce est tellement diaphane qu'elle laisse apercevoir tous les viscères; elle est très-abondante dans les étangs et les marais du nord, où elle forme à ce qu'il paraît des réunions considérables; elle nage sur le dos, et emploie ses deux rames ou antennes pour se mouvoir.
DAPHinia, Muleer, Latr., Liy., DesM. ;

Monoculus, Linn., Degéer, Junire, Geoffli, F F Fr.

Le corps est allongé, comprimé, évidemment compris dans une coquille. - La co. quille est bivalve, dépendante de la peau, transparente, ayant son ouverture sous le ventre, et sa charnière sur le dos. - La tête est moyenne, très-distincte du corps, surtout en dessons, plus ou moins prolongcee, en forme de rostre infléchi, pointu ou obtus; cette tête est pourvue intérieurement d'un seul œil, médiocrement développé, formé d'une membrane sphérique qui renferme une vingtaine de petites aréoles transparentes, se détachant sur un fond noir.-Deux petits barbillons, ou antennes, placés ă l'extrémité du rostre que la tête forme en dessous, plus longs dans les mâles que dans les femelles. - Deux grandes antennes, ou pieds antérieurs, ou rames branchues, servant seulement à la natation; insérées aux deux côtés du cou, formées d'une première tige arrondie, conique, plus ou moins longue, et de deux branches terminales, dont l'antérieure est à trois articles, et la postérieure à quatre; supportant toutes deux un certain nombre de soies assez longues et ciliées. - L'abdomen, ou le corps proprement dit, est divisé en huit segmens (dont le premier très-grand); $a b-$ solument libre dans l'intérieur des valves, grêle et allongé, se portant d'abord horizontalement en arrière, et se recourbant ensuite en dessous, où il est terminé par deux petits crochets dirigés en arriere. La bouche est placée à la partie inférieure du corps, en dedans du bord antérieur des valves et à la base du bec; composée : $1^{\circ}$ d'un long labre, comprimé par les côtés ; $2^{\circ}$ de deux mandibules très-fortes, sans palpes ni branchies, dirigées verticalement en dessous, et ayant leur tranchant arqué et uni ; $3^{\circ}$ d'une paire de mâchoires dirigées horizontalement en arrière, pourvues à leur extrémité d'un disque qui supporte à son bord supérieur trois épines cornées, très - fortes, en forme de crochets, et recourbées. - L'œsophage, qui est étroit, se porte de bas en haut, et d'arrière en avant. L'estomac, ou intestin cylindrique, est assez gros, presque horizontal, comme le corps dans sa première partie, et se recourbe ensuite comme lui à son extrémité postérieure; deux sortes de cocum abou- 
tissant à cel estomac, prés du cardia. - Les pattes sont au nombre de dix, très-compliquées, et différentes entre elles par paires, taut pour la forme que pour la grandeur et les fonctions, mais ayant toutes leur second article vésiculeux; les deux premières paraissent plus spécialement distinctes à la préhension; les six suivantes (surtout les quatre dernières parmi celles ci ) ayant un de leurs articles comprimé, cilié fortement sur un de ses bords, et faisant fonction de branchie.Le cœur est situé dans la région dorsale antérieure, au-dessus de l'intestin.-Les ovaires sont placés le long des côtés de l'abdomen, depuis le premier segment jusqu'au sixième, oủ ils s'ouvrent séparément près du dos, dans une cavité qui existe entre la coquille et le corps, et où les œufs, dont la forme est sphérique, sont conservés quelque temps après la ponte; cette partie du test devenant opaque vers la fin de l'été, et se trouvant, à celte époque, pourvue sur chaque valre d'ampoules ovalaires, qui forment deux capsules contenant les œufs qui doir ent passer l'hiver. — Les organes mâles paraissent placés vers la queue, près de. la dernière paire de pattes.

Les Daphnies sont très-abondantes dans les eaux stagnantes, et quelquefois elles $y$ sont tellement multipliées, qu'elles leur donnent leur couleur propre. Une espéce de ce genre (Daphnia Pulex), dont la couleur est rouge, a quelquefois donné licu de croire que l'eau s'était changée en sang. Leur natation se fait par une suite de sauts qu'elles exécutent de moment en moment, au moyen de leurs bras ou antennes qu'elles agitent avec force de haut en bas.

La nourriture de ces Entomostracés, suivant Jurine, consiste en animalcules et en farticules végétales qui abondent dans les eaux des mares; ils les font parvenir à leur louchs en imprimant un mouvement de courant a cetue eau introduite dans l'inter. valle de leurs valyes, au moyen de leurs partes proprement dites, qui sont pour eux plutôt des organes de la respiration que des organes de la locomotion. Pendant le printemips et l'été, ils sont continuellement oc. cupés de la recherche de cette nourriture, ou livrés au besoin de la reproduction; mais dans la saison d'hiver, ils s'enfoncent dans la vase, et y restent ensevelis jusqu'au printemps suivant; et dans certaines années aussi, les mares où ils abondent se desséchant complétement par l'action du soleil, ces animaux se trouvent enterrés, et totalement privés d'eau quelquefois pendant plusieurs mois, mais ne périssent pas pour cela. Aussitôt qu'une pluie abondante vient remplir de nouveau les mares où ils existoient, on les voit paroître de nouveau, et reprendre leur activité ordinaire.

Pendant long-temps, on a cru que les Daphnies étaient androgynes; mais les observations de Müller, et principalement celles de Jurine, ont prouvé que chez elles les sexes sont séparés; que les mâles n'apparoissent que dans une saison de l'année, et qu'un seul accouplement donne lieu à plusieurs générations de femelles, qui toutes peuvent pondre des œufs productifs sans avoir besoin d'être fécondées de nouveau. Dans l'accouplement, qui dure au plus huit à dix minutes, le mâle se place d'ahord sur le dos de la femelle, et la saisit avec les lougs filets de ses paltes antérieu. res; puis, se portant vers le bord inférieur de la coquille de cette dernière, en rapprochant la sienne de son ouverture, il y introduit ses filets, ainsi que des crochets ou harpons dont ces mêmes pattes sont pourvues; après cela, jl rapproche sa queue de celle de la femelle, qui d'abord cherche à l'éviter, en nageant avec une grande vitesse, et le transportant partout avec elle ; mais bientôt après elle le recherche, et c'est alors que la copulation paroit aroir lieu. Les mâles, très-ardens, attaquent indistinctement toutes les femelles, même celles qui sont en état d'accouplement, ou celles qui sont dejà remplies d'œufs. Après la fécondation, chez les femelles qui ont été en räpport avec le mâle, ou après une mue, chez cellesqui, nées d'une femelle fécondée, doivent produire elles-mêmes sans fécondation, on voit d'abord dans les ovaires une matière colorée suivant les saisons, en vert, en rose ou en brun, laquelle se rend dans la matrice, ou cavité située sur le dos, entre le corps et la coquille, et s'y sépare en boules rondes, et plùs en été qu'en hiver. Dans cette derniere saison, on voit le premier jour l'œuf formé d'une bulle centrale, entourée d'autres plus petites, dont les intervalles sont garuis de molécules colorées; du second au troisieme jour, la partie externe de l'œuf devient plus transparente, parce que les molécules colorées se rapprochent du centre; cet œuf grossit, et prend la forme ovoïde dès le quatrième et le cinquieme jour; ce n'est que le sixieme que le fœtus commence a paroître, et déjá il a les bras détachés du corps; le septième, les rudimens des pattes proprement dites et de la tête peuvent être distingués; le hui- 
tième, l'œil parô̂l d'abord séparé en deux parties égales, et l'intestin se découvre; le neuvième, tous les organes sont visibles, et l'œil est plus noir et réticulé ; le dixième, le développement du fœtus étant terminé, il sort de la matrice, dont l'issue s'ouvre par l'abaissement de la queue de la mère, et il commence à nager dans l'eau en agitant ses petits bras. Ses formes ne sont en rien différentes de celles des parens dont il provient, à cela près que sa coquille a sa pointe postérieure très-allongée.

Bientòt cet animal croît, et à mesure que sa taille augmente il se dépouille plusieurs fois de la peau qui revêt toutes ses parties, même les plus ténues. Lorsque ces mues ont lieu, il se fixe avec ses bras sur une tige de conferve, ou descend dans la vase, et y reste dans la plus grande tranquillité. Sa tête sort la première, et ses pattes, ainsi que ses mandibules et ses bras ramifiès, sont dégagés les derniers, mais le sont avec une rapidité surprenante. Les mues se succèdent rapidement, et elles sont plus ou moins rapprochées, suivant les saisons. En été, elles ont lieu de deux jours l'un, et quelquefois il y a trois jours d'intervalle; en hiver, il n'est pas rare de les attendre huit ou dix jours. Elles se succèdent ainsi pendant toute la durée de la vie de l'animal.

Aux mois de juin et de juillet, l'activité du développement des Daphnies est telle, que les petites femelles, dès l'âge de sept jours, et après trois mues, ont déjà leurs ovaires remplis de matière colorée; celte rnatière passe dans la matrice dès le huitième jour, et se change en ouf, et le dixième jour les petits sortent de la matrice; ces générations, en rapport avec les mues, se renouvellent̂ ensuite de deux en deux, ou de trois en trois jours, et leurs époques ne s'éloignent qu'à mesure que l'arriere-saison arrive. Le nombre des petits qui naissent à chaque ponte est rarement le même; les premières n'en donnent guère que six; les suivantes en produisent davantage; et quand la femelle a acquis tout son développement, il n'est pas rare de lui en voir porier à la fois dix-huit dans la matrice.

Les mâles sont en très-petit nombre, comparativement à celui des femelles; au printemps et en été on n'en trouve que difficilement, tandis qu'en automne ils sont moins rares: ce qui, remarque Jurine, fait pressentir la nécessité de leur influence aux approches de l'hiver, sur les générations qui doivent se succéder arec rapidité, dès que les frimas auront cessé, et qui n'existeroient peut-être pas sans l'intervention masculine.

A certaines époques de l'année, notamment vers les mois de juillet et d'août, et même aussi en juin, les valves dé la femelle prennent après la mue de l'opacité vers leur partie supérieure, dans une étendue rectangulaire, et la couleur de cette partie finit par être d'un gris-noirâtre assez obscur. Ces taches, que Müller appeloit ephippium, et que Jurine a aussi nommées telles, en les considérant comme le produit d'une maladie, présentent, suivant M. Straus, « deux ampoules ovalaires transparentes, placées l'une au-devant de l'autre, et formant, avec celles du côté opposé, deux petites capsules ovales, s'ouvrant comme une capsule bivalve. Cet éphippium se partage, comme les valves dont il fait partic, en deux moitiés latérales, réunies par une suture le long de leur bord supérieur; et dans son intérieur on en trouve un autre semblable, mais plus petit, à bords libres, si ce n'est que le supérieur qui tient aux valves, et dont les deux moitiés jouent en charnière l'une sur l'autre, et offrent les mêmes ampoules que les battans extérieurs. Dans chacune de ces capsules on rencontre un œuf à coque cornée et verdâtre; mais du reste semblable aux æufs ordinaires, avec cette différence qu'il reste beaucoup plus long - temps à se développer, étant destiné à passer l'hiver avant que d'éclore. Cet éphippium, à l'époque de la mue, est abandonné avec la vieille peau dont il fait partie et les oufs qu'il contient ; les œufs y trouvent un abri contre la rigueur du froid, qui fait périr la plupart des individus vivans, ef au printemps, lorsque la température est devenue assez élevée, ils éclosent, et il en sort des petits absolument semblables à ceux des œufs ordinaires. $\triangle$

1. Daphin pulex. (Pl. 20, fig. 6.)

Desm., Considér. géner. sur les Crust., p. 372 , pl. 54 , fig. 3 a 5 - Pulex Aquaticus Arboreus, Swast, Bibl. Nat., pl. 31. - Monoculus Pulex, Lnvs., Faun. Suec., no 2047. - FAER., Syst. Entom., t. II, p. 491. - Jurine, Monocl., p. 85, pl. 8, 9, 10, 11. - Le Perroquet d'eau, Geofrr., Hist. des Ins., t. II, p. 455 . - Long. 1 lig. - La tête est moyenne, infléchie, non séparée du dos en dessus par un sillon transversal ou un étranglement; le test est ter- 
miné en pointe postérieurement. - Cette espèce, qui est d'un beau rouge au printemps, d'un rose tendre en été, et d'un blanc verdâtre dans les autres saisons, est très-commure dans les étangs, et se tient à peu de distance des bords, ou des corps, qui sont immergés.

\section{DAPHNIA LONGISPINA.}

Multer, Entom., p. $88, n^{\circ} 35$, pl. 12 , fig. 8-10. - Drsm., Consid. génér. sur les Crust., p. 372. - Straus, Mém.du Mus., t. V, pl. 29 , fig. 23, 24. - Long. 1 lig. - Un peu plus allongée que l'espèce précédente, et plus rare; le dos est presque droit, termine par une longue pointe mince, droite et épineuse. La couleur. est semblable à celle de la Daphnia-Pulex.

\section{DAPHNIA MAGNA.}

Straus, Mém. du Mus., t. V, pl. 29, fig. 21, 22. - DESM., Consid. génér. sur les Crust., p. 373. - Long. 2 lig. - Le test est terminé par une Iongue pointe mince et épineuse, comme celle de la précédente; le dos est arqué; le bord inférieur des valves est aussi très-arqué.

\section{DAPHNIA SIMA.}

Muller. Entom., pl. 12, fig. 11, 12. Dessy., Considér. génér. sur les Crust., p. 373. - Monoculus Simus, Jurinf, Monocl., p. 129, pl. 12, fig. 1, 2. - Monoculus Sexspinosus, Degéer, vol. VII, p. 457, n' 2, pl. 27, fig. 9-13. - Monoculus Lavis, Fabr., Entom. Systenr., t. II, p. 492. Daphria Vetula, Straus, Mém. du Mus., t. V, pl. 29, fig. 25, 26. - Long. $\frac{10}{12}$ de lig. - La tète est plus petite et moins pointue en devant que celle de la Daphnie Puce; la partie postéricure du test est arrondie, non guillochée, mais seulement garnie de petits traits dirigés transversalement, et presque imperceptibles.

\section{DARIVIA BRACHITA.}

Desm., Considér. génér. sur les Crust., p. 373. - Monoculus Brachiatus, Junine, Monocl. , p. 131 , pl. 12, fig. 3-4. Daphnia Macrocopus, Straus, Mém. du Mus., t. V, planch. 29, fig. 29, 30. Long. $\frac{7}{12}$ de lig. - Les antennes rameuses sont très-grandes et très-forles à leur base ; la tête est obtuse, grande, inclinée, séparée du corps en dessus par un sillon transversal profond ; les barbillons sont très-longs et grêles; le test est arrondi postéricurement, avec ses valves lisses. - Se trouve dans les mares des environs de Genève.

\section{DAPHVIA Nasuta.}

Desrr., Considér. génér. sur les Crust., p. 373. - Monoculus Nasutus, Jonine, Monocl., p. 133, pl. 13, fig. 1-2.-Long. 1 lig. $\frac{1}{2}$. - La tête est non séparée du corps en dessus par un sillon transversal; le front est arrondi, et terminé en dessous par une pointe obtuse, un peu relevée, qui figure un nez retroussé; les antennes sont rameuses, médiocres; les barbillons sont non apparens; les valves du test sont courtes, comme tronquées postérieurement, et striées longitudinalement sur leur facc externe; la coulear est jaunâtre. - Habite la mème localité que l'espèce précédente.

\section{DAPHNIA RECTIROSTRE.}

Mullex, Entom., pl. 12, fig. 1.3.Desu., Consider. génér. sur les Crust., p. 373.-Monoculus Rectirostris, $\mathrm{F}_{\mathrm{ABR}}$., Ent. Syst., t. I1, p. 493. - Jur., Monocl., p. 134 , pl. 10, fig. 3, 4. - Long. $\frac{s}{12}$ de lig. - Les yeur sont sans aréoles transparentes; la tête est distincte du corps en dessus par un sillon transversal; le museau est arrondi on apercoit une tubérosité sur la nuque; les barbillons sont très-apparens; la coquille présente en arrière une petite pointe, et est ciliée sur son bord inférieur; les œufs sont de couleur blanchátre.

\section{DAPHNIA MOYGICOLLIS.}

Dess., Considér. génér. sur les Crust., p. 374. - Monoculus Longirostris, Juk., Monocl., p. 136 , pl. 10, fig. $3-4$. Long. $\frac{1}{2}$ lig. - Cette espèce ne differe des deus précédentes que par l'allongement du cou; la saillie que forment en arriere les bords inférieurs des valves de son test; la longacur de ses barbillons, qui sont biarticulés et terminés par deux filets ciliés.

\section{DAPHAL MUCRGNTA.}

Míul., Entom., pl. 13, fig. 6-7.Desm., Considér. génér. sur les Crust., p. 374. - Monoculus Bispinosus, DEGÉER, vol. VII, p. $463, n^{\circ} 3$, pl. 28 , fig. $3-4$. FAzR., Ent. Syst., t. 11, p. 493, n $^{\circ} 17$. JuR., Monocl., p. 137, pl. 14, fig. 1-2. Long. $\frac{b}{14}$ de lig. - La tête est triangulaire ; la nuque, droite, oblique, est sèparée du dos par un sillon transversal; le front est un peu échancré; le bout du museau est relevé ; la coquille est courte, à bord inférieur droit, et terminé, pour cbaque valve, en une pointe aiguë, longue et droite; on apercoit une bande brune suivant ce bord. 
10. DAPINIA RETICULATA.

Desm., Considér. genér. sur les Crust., p. 374. - Monoculus Reticulatus, JUR., Monoct., p. 139, pl. 14, fig. 3-4. ' Long. $\frac{9}{24}$ de lig. - La tête est avancée, obtuse, séparée du corpns en dessus par une légère impression transversale; le test est court, arrondi et cilié sur son bord inférieur, terminé en arrière et en haut par une petite pointe, et ayant toute sa surface finement réticulée; les barbillons sont assez lougs.

\section{Daphía GLathrata.}

Drsm., Consid. génér. sur les Crust., p. 375. - Monoculus Clathratus, JuR:, Monocl., p. 141, fig. 5-6. - Long. $\frac{9}{24}$ de ligne. - Cette espece est assez semblable a la précédente; mais elle en diffère par sa tête, qui est plus profondément séparée lu tronc en arrière et en dessus; par son front, qui offre une sinuosité; par la pointe plus forte et dentelée de l'extrémité de son test, et par le manque de cils sur son bord inférieur; les bras sont grêles et lisses à l'extérieur; la coquille est réticulée.

\section{DApHivi Cornuta.}

Desm., Consid. génér. sur les Crust., p. 375. - Monoculus Cornutus, Jurine, Monocl., p. 142, pl. 14, fig. $8,9,10$. Long. $\frac{9}{24}$ de lig. - Le dos est tress-bombé ; la tête est longue, pointue, infléchie, et en forme la continuation; de plus, elle est armée en devant de deux longues cornes, que Jurine considère comme des barbillons articulés et mobiles; le test est lisse, et tronqué postérieurement.

LYNC EUS, Mull., Latr., Lam., Desm.; Monoculus, FABR., JuRINE; Chydorus, Leacr.

Le corps est arrondi, comprimé, renfermé, ainsi que celui des Daphnies, dans un test plié en deux, imitant les deux battans d'une coquille bivalve, dont le centre, qui forme une ligne saillante sur le dos, représente la charnière. - La tête est plus ou moins séparée du corps par une échancrure du test en dessous. - Les yeux sont placés au-devant l'un de l'autre, et non dans, une ligne transverse au corps de l'animal; il y a quatre antennes insérées au-dessus de la tête, toutes inégales et garnies de longs poils sur leur côté inférieur, qui servent plus directement à l'action natatoire. Les pattes, difficiles à compter, sont au nombre de huit ou de dix, terminées par des soies et accompagnées à leur base d'écailles barbues ou branchiales. - La queue est petite, pointue, ordinairement repliée sous le ventre et enfermée dans le test.Les œufs sont apparens sous celui-ci dans la région du dos, tantôt seuls, tantôt au nombre de deux par ponte; c'est au printemps qu'on les aperçoit comme des points noirâtres à travers le test.

Les Lyncées sont les plus petits de tous les. Entomostracés : ils habitent les eaux dormantes où croissent les plantes aquatiques. Ces Crustacés sont assez communs aux environs de Paris; cependant oe ne les rencontre pas si souvent que les Daphnies; du reste ils se propagent et muent conmme ces dernières.

\section{LYNCAUS ROSEUS.}

Desm., Consid. génér. sur les Crust., p. 376, pl. 54, fig. 8.-Monoculus Roseus, Jor., Monocl., p. 150, pl. 15, fig. 4, 5. Long. $\frac{5}{24}$ lig. - Couleur généralement rose, avec l'intestin d'un jaune-brunâtre, et les deux œufs contenus dans la matrice dorsale, roses, verts ou bruns; antennes et leur pédoncule longs; un grand filet attachẻ à la base de la branche supérieure de ces antennes; tête infléchie, pointue et terminée par deux barbillons crochus; test lisse, avec des petites épines sur les bords de son ouverture inférieure. - Cette espèce nage horizontalement dans les eaux.

\section{LYNCEUS LATICORNIS.}

Desm, , Consid. génér. sur les Crust., p. 376. - Monoculus Laticornis', JUR*, Monocl., p. 151, pl. 15, fig. 6, 7. Long. $\frac{5}{2+}$ de lig. - Assez semblable à l'espèce précédente, ayant entre autres la même forme de la tête; les antennes aussi longues (mais plus larges), et : pourvues d'un grand filet attachè au premier article de leur branche supérieure; œil postérieur plus grand, et visiblement pourvu d'aréoles; barbillons plus découpés à l'extrémité; bords intérieurs du test ayant des épines en bien plus grand nombre; couleur. rosée; membrane des œufs transparente.

\section{HYNCEUS ADUNCUS.}

Desm., Consid. génér. sur les Crust., p. 377. - Monoculus Adincus, JUR., Monocl., p. 152 , pl. 15 , fig. 8, 9. Long. $\frac{1}{4}$ lig. - Corps plus raccourci que celui des deux espèces précédentes, fort élevé sur le milieu du dos; tête prolongée en avant, courbée, pointue et terminée 
comme le bec d'un oiseau de proie; bras ou antennes très-courts, bifurqués comme à l'ordinaire; point de grand filet attaché a la branche supérieure de ces antennes; intestins décrivant deux circonvolutions avant de se rendreà la partie anale; test lisse, tronqué postérieurement et inférieurement, où ses bords sont hérissés de petites épines; œufs au nombre de deux, de couleur bistre claire.

\section{LYNCEUS STRIATUS.}

Desu., Consid. géner. sur les Crust., p. 377. - Monoculus Striatus, Jvr., Monocl., p. 154 , pl. 16 , fig. 1, 2.Long. $\frac{5}{24}$ de lig.-Corps comprimé, surtout en avant, ayant la carène du dos continue à celle de la tête, et formant une couche régulière; bord inféricur du test, droit; tête infléchie,pointue; antennes ayant leurs branches de grandeur inégale, et leur pédoncule entièrement caché dans la coquille, ce qui peut faire croire qu'il en existe quatre simples; barbillons sous forme de deux tubercules allongés, placés sous la tête, et portant à leur extrémité deux petits filcts; intestins faisant une circonvolution avant de se rendre à la partie anale ; test verdâtre, obliquement situé et fortement cilié en dessous; œufs au nombre de deux ou trois, presque ronds, et de couleur verte.

\section{LYVCAUS SPHARICUS.}

Mulz., Entom., pl. 9, fig. 7, 9.-Desм., Consid. génér. sur les Crust., p. 377. Monoculus Sphoricus, FABR., Entom. Syst., t. 11, p. 497. - Jur., Monocl., p. 157, pl, 16, fig 3 à 13. Chydorus Mulleri LBach, Dict. des $S$ c. nat., t. XIV, p. 341 . Long. $\frac{9}{24}$ de lig. - Globuleux ; tête trèsinfléchie, pointue; antennes à pédoncule caché dans le tesí, ne laissant voir audehors bien sensiblement qu'une seule de leurs branches; couleur du rostre très-claire; œufs verts, au nombre d'un ou deux seule ment. - Cette espèce semble plutôt sauter que nager dans l'eau; elle parcourt de suite, sans s'arrêter, un assez grand espace, ayant toujours l'ouverture de son test placée infẻe rieurement.

\section{HUITIËE ORDHE.}

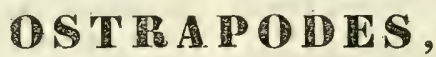

LATREILLE.

Trois cẻlèbres observateurs, Ramdohr, Jurine et M. Straus, et le'dernier surtout, nous ont dévoilé l'organisation des Cypris, qui, aveć le genre $C$ ythérëe, compose cette coupe ordinale. Müller, qui a formé l'un et l'autie, n'est entré dans aucun détail ap. profondi, et nous ne pouvons séparer le second de ces genres du premier qu'en admettant, avec Jui, qu'il y a une paire de pattes de plus, ou huit au lieu de six, et que les poils des antennes sont épars, tandis qu'ils se réunissent en une sorte de pinceau terminal dans les Cypris; mais ces deux genres ont pour tout le reste tant d'analogie qu'il serait possible que ce na. turaliste eût conșidérẻ comme les pieds des organes qui ne le sont pas. On n'accorde que deux antennes à ces Crustacés; mais peut-être que les organes que l'on a pris pour les deux pieds antérieurs sont; à raison de leur insertion, deux antennes, faisant, comme dans beaucoup d'autres Entomostracés, l'office de rames ou de pieds; peut-être aussi sont-ce de véritables pieds, suppléant les antennes ou rames. - Lies Cypris seraient donc des Crustacés têtrapodes, mais dont la natation serait facilitée par les appendices branchiaux des mandibules et des mâchoires supérieures.-Leur test forme une coquille bivalve ovalaire, comprimée latéralement, arquẻe et bombée dorsalement, et presque droite ou un peu échancrée au côté opposé, celui de l'ouverture. En avant de la charnière, dans la ligne médiane, l'œil se présente sous la figure d'un gros point noirâtre.-Les antennes, immédiatement insẻrées au-dessous, sont sétacées, plus courtes que le corps, de sept à huit articles, dont les deiniers plus courts, et terminés par un faisceau de filets servant de nageoires, et que, suivant Jurine, l'animal développe de différentes manières pour se mouvoir plus ou moins rapidement. - La bouche se compose d'un labre caréné, de deux mandibules dentées, portant chacune un palpe de trois articles, 
avec une petite lame branchiale et digitée sur le premier. On en voit une autre beaucoup plus grande, pectinée à son bord antérieur, sur le côté extérieur de deux inâchoires supérieures, qui ont au côté interne quatre appendices mobiles et soyeux; en dessous sont deux autres máchoires, composées de deux articles, avec un palpe court, inarticule et soyeux au bout. On observe plus bas une sorte de sternum. Ies pieds sont au nombre de dix, dont les denx antérieurs, beaucoup plus forts, dirigés en avant, terminés par deux articles, munis de soies roides ou de longs crochets, rassemblés en un faisceau, sont insérés audessous des antennes : peut-être que ces soies concourent autant à la natation qu'à la respiration; les quatre pieds en sont dépourvus; les seconds sont d'abord déjetés en arrière, arqués, et terminés par un long et fort crochet; les deux derniers ne se montrent point au dehors; relevés et appliqués sur les côtés du corps, ils soutiennent les ovaires, et se terminent par deux petits crochels. - Le corps n'offre aucune articulation distincte, et finit postérieurement par une quene molle, repliée en dessous, avec deux filets coniques ou sétacés au bout; ils sont armés chacun près de leur extrémité, de deux épines ou onglets, et dirigés en arrière. - Les ovaires forment deux gros vaisseaux, situés sur les côtés postérjeurs du corps, au-dessous du test et s'ouvrant à la partie antérieure de l'abdomen.-Les œufs sont sphériques.-Cet ordre renferme trois genres: Cythere, $C y$ pris et Cetochylus.

\section{CY'There, Mull., Latr., Desh.;}

Cytherina, LaM. ; Monoculus, Fabr.,

Le corps est renfermé dans un test bivalve, généralement réniforme, qui a beaucoup d'analogie avec celui des Cypris. La tête est non distincte; on n'aperçoit qu'un seul œil. - Les antennes sont au nombre de deux, simples, sétacées, formées de cinq ou six articles, et pourvues de quelques soies qui sont implantées à l'extrémité de chaque articulation. - Les pieds sont au nombre de huit, articulés, pointus et garnis de quelques soies; les antérieurs et postérieurs étant plus longs que les intermédiaires, et laissant 'tous voir leur extrémité hors du test.

Müller parait être le seul qui ait vu l'accouplement de ces animaux, et aucun naturaliste n'a encore découvert positive- ment leurs organes sexuels, quoique d'ailleurs la ponte et les mues de ces Crits. tacés ne soient pas moins nombreuses que celles des Cyclopes et des Daphnies. Les femelles déposent leurs ceafs en masse, et les fixent sur des plantes ou sur le limon avec une substance visqueuse ; cramponnées par le moyen de leurs seconds pieds, elles ne craignent pas les secousses de l'eau et emploient environ douze heures à faire leur ponte, qui, dans les plus grandes espèces, peut se composer de vingt-quatre øufs. Jurine, ayant isolé ceux d'une ponte ou d'un paquet, a vu éclore les petits et a obtenu une autre génération sans le secours des mâles. Une femelle qui avait sa ponte le 12 arril, a, jusqu'au 18 du mois suivant inclusivement, mué six fois. Le 27 du même mois, elle a fait une seconde ponte, et deux jours après une troisième. Cet auteur tire de la celte conséquence, que le nombre des premières mues est en rapport avec le développemeń graduel de l'individu.

\section{GYTHERE VIRIDIS.}

Mull., Entom., p. 64, tab. 7, fig. 1, 2. - Desm., Consid. génér. sur les Crust., p. 387. - Cytherina Viridis, Larr., Anim. sans vert., t. VI,'p. 123.-Long. $\frac{1}{6}$ de lig. -Le test est court, réniforme, verdâtre el tomenteux.

\section{CYTHERE IUTEA.}

Mulu., Entom., p. 65.-DEsy., Consid. génér. sur les Crust., p. 388, pl. 35, fig. 8.Cytherina Lutea, LAM., Anim. sans vert., t. V, p. 125. - Un peu plus grande que l'espèce précédente; le test est réniforme, plus allongé, jaune et glabre.

\section{CYTHERE FuAVIDA.}

Mulc., Entom., p. 66, tab. 7, fig. 5, 6. - Desm., Consid. génér. sur les Crust., p. 388. - De la taille de la Cythere Lutea; le test est encore plus allongé, ovalaire, non réniforme, ni échancré en dessous', jaunâtre, lisse. - Cette espèce se trouve fréquemment sur le Flustra Lineata.

\section{CYTHERE GIBBA.}

Mull., Entom., p. 66, tab. 7, fig. 8-9. - Desm., Consid. génér. sur les Crust., p. 388. - Long. $\frac{7}{2}$ lig. - Beaucoup plus grosse que toutes les espèces précédentes, quoiqu'elle n'ait pas plus d'une demi-ligne de longueur; le test est blanchâtre, hispide, court, avec une gibbosité très-forte sur le milieu de chaque valve. 
5. CYTHERE GIBBERA.

Mull., Entom., p. 66, pl. 7, fig. 11, 12. - Dess., Consid. génér. sur les Crust., p. 388. -- Aussi grande que l'espèce précédente; le test est raccourci, renflé antérieurement, et encore davantage en arrière, un peu étranglè dans son milieu, tant en dessus qu'en dessous; sa couleur est verdâtre et lisse.

CYPRis, Mull., Latr., Lam., leach, Straus, Desh. ;

Monoculus, Linn., Fabr., Geoff., JURINE.

Le corps, réuni à la tête, ne présentc aucune trace de segmens, et il est terminé par une quene molle, repliée en dessous, et munie de deux filets à son extrémité; il est placé dans un test bivalve dont la forme est plus ou moins ovalaire, comprimée, bombée en dessus sur la ligne moyenne ou la charnière, et plus ou moins échancrée en dessous ou sur le bord ouvert des valves. - Il y a un gros œil noir, sphérique, situé à la partie supérieure de la face antérieure du corps. - Deux antennes sont insérées immédiatement en dessous de l'œil, longues, sétacées, composées de sept à huit articles, et terminées par un faisceau de douze à quinze soies; elles se portent en avant, et sortent des valves des deux tiers de leur longueur. - Les pieds sont au nombre de six; les antérieurs sortent du test, et se dirigent en avant, beaucoup plus forts que les autres, insérés au-dessous des antennes, formés de cinq articles dont les deux premiers représentent la hanche des pattes ordinaires des Crustacés; le troisième, la cuisse; le quatrième, la jambe, et le cinquième, le tarse (l'extrémité de ces deux derniers étant garnie de quelques soies roides ou crochets); les pieds de la seconde paire, un peu plus foibles et plus courts, sont situés au milieu de la face inférieure du corps, derrière la bouche, ayant leur pointe sortie du test et dirigée en avant; les pieds de la troisième paire sont placés immédiatement en arrière de la seconde, ne paroissent jamais au dehors, sont recourbés en arrière et en dessus, embrassont la partie postérieure du corps, sont terminés par deux très-petits crochets, et serrent à soutenir les ovaires qui sont placés sur le dos. - La bouche est située vers la partie antérieure de la face inférieure du corps'; et composée d'un labre ou carène ; d'une sorte de sternum aussi comprimé, faisant l'office d'une lèvre inférieur'e, d'une grande paire de mandibules palpifèrcs et de deux paires de mâchoires; les palpes des mandibules sont biarticulés, munis de soies, et portent annexée au premier de leurs articles une petite lame branchiale divisée en cinq digitations; les mâchoires de la première paire pourvues sur leur bord interne de quatre appendices en forme de mamelons mobiles, terminés par une touffe de poils, et portant sur leur bord extérieur une grande lame branchiale dont la branche supérieure est divisée en dents de peigne; les mâchoires de la seconde paire sont beaucoup plus petites et sans lame branchiale. - L'œsophage est droit et dirigé en haut. - L'estomac est assez renfé, cylindrique, presque horizontal. - L'intestin est droit, oblique, gros surtout près de l'estomac, dont il est séparé par un léger étranglement.-Les ovaires, considérables, sont en forme de deux gros vaisseaux simples, coniques, terminès en cul-de-sac à leur origine, et placés extérieurement sur les côtés de la partie postérieure du corps; ils s'ouvrent, l'un à côté de l'autre, dans la partie antérieure de l'abdomen, où ils communiquent par le canal formé par la queue. - Les œufs sont sphẻriques.

Ces Crustacés nagent avec une grande facilité dans les eaux douces, tranquilles ou peu courantes, au moyen de leurs antennes et de leurs deux pattes antérieures. Leur nourriture consiste en substance animale morte et en conferves; leurs mues sont assez fréquentes, et dans cette opération ils se dépouillent de leur ancienne coquille, ce qui prouve évidemment que celle-ci est une dépendance de leur enveloppe générale, et non le produit inerte d'une sécrétion, ainsi que l'est la coquille des Mollusques Acéphales. On ne sait rien sur leur génération, quoique Ledermuller ait dit en avoir vu d'accouples; et, comme tous les indiridus que l'on observe se trouvent pourvus d'œufs, on a cru pouvoir en conclure que ces animaux étoient hermaphrodites. Il seroit possible néanmoins, ainsi que l'a fait remarquer M. Straus; que les mâles n'existassent qu'à une certaine époque de l'année seulement. Cet observateur attentif a cherché l'organe mâle, et ne l'a pas trouvé, à moins qu'on ne regarde comme tel un gros vaisseau conique qui cxiste audessons de l'articulation de chaque mandibule, et qui est rempli d'uue substance gélatineuse; mais ce vaissean, paroissanl communiquer avec l'cesophage par un canái 
étroit, pourroit plus vraisemblablement remplir les fonctions d'une glande utile pour la digestion.

Il paroît que les Cypris n'ont pas de métamorphoses, et que ces animaux ont, en sortant de l'œuf, la forme qu'ils doivent conserver toute leur vie.

En été, lorsque la chaleur dessèche les mares, les Cypris s'enfoncent dans la vase humide, et y restent vivans jusqu'a ce que les pluies les remplissent de nouveau.

Jurine a décrit les Cypris différemment de M. Straus; il leur trouve huit pieds, et attribue aux soies qui terminent ceux-ci des fonctions respiratoires. Nous allons donner un extrait du travail de Jurine sur la distinction des espèces.

\section{A. CYPris ornata.}

Mull., Entom., pl. 3, fig. 4-6.-Desm., Consid. génér. sur les Crust., p. 383. Monoculus Ornatus, Ju R., Monocl., pl. 17, fig. 1 - 4. - Long. $\frac{14}{1}$ de ligne. - C'est la plus grande connue. Sa coquille est d'un jaune-verdâtre, et marquée de bandes vertes, dont l'uis est transversale derrière l'cil, une seconde en double croissant, plus en arrière, et accompagnée d'une der. nière qui lui est parallèle.

\section{CYPRIS OVATA.}

Desm., Consid. génér. sur les Crust., p. 385. -Monocl. á coquille courte, Georr., Ins., t. 2, p. $658 \mathrm{n}^{\circ}, 5 .-$ Monoculus ovatus. Jur., Morocl., pl. 17, fig. 5 à 6. Long. 1 lig. - Le test est très-bombè en dessus, dans le point où est l'œil, de couleur verte, avec une tache ovale, oblique, plus claire de chaque côté.

\section{CYPRIS CONCHACEA.}

Desm., Consid. génér. sur les Crust., p. 383. - Monoculus Conchaceus, Linn., Faun. suec., n² 2050; Jur., Monocl., p. 171, pl. 17, fig. 7 à 8 . - Monocle a coquille longue, GEofF., Ins., t. 2, p. 657, $\mathrm{n}^{\circ} 4$. - Monoculus Ovatus Conchacens, DEGÉER, t. VII, p. $477, \mathrm{n}^{\circ}$ 2. - Cypris Delecta, Alucl., Ent., pl. 3, fig. 1. - Long. $\frac{13}{3} \frac{1}{2}$ ligne. - Le corps est assez régulièrement uniforme, comprimé, blanchâtre et lisse. Cette espèce se tient dans la fange des marais et nage de côté.

\section{CYPRis pUrera.}

Mulu., Ent., pl, 2, fig. 15:-Monoculus Puber, Jur., Monocl., p. 171, pl. 18, fig. 1 et 2.-Long. 1 lig.-Le test est comprimé, un peu obtus en avant, légérement sinueus au-dessus de l'œil, bombé dans son milieu, d'une couleur verte d'aigue-marine trèsclaire, un peu teinte de rose postérieurement, hérissé de poils placés à quelque distance les uns des autres, et marqué de deux bandes paralleles obliques qui naissent près de l'œil, el qui sont plus fortement colorées que le reste.

\section{Cypris margnata.}

Straus, Mém. du Muséum, t. VII, pl. 1, fig. 20 à 22.-Desm., Consid. génér. sur les Crust., p. 384. - Long. I lig. Les valves sont vertes, à marge blanchầtre, beaucoup' plus larges en arant qu'en arrière, également bombées aux deux extrémités, légérement échancrées en dessous, et hérissées de poils roides très-apparens; les soies des pattes antérieures sont trèslongues. - Se trouve aux environs de Paris.

\section{CYPRIS FUSCA.}

Straus, Mém. du Mus., t. VII, pl. 1, fig. 16. - Desm., Consid. génér. sur les Crust., p. 384, pl. 55, fig. 1.- Јовцот, Obs. d'hist. nat., t. I, part. 2, p. 104, pl. 13, fig. 5. - Ledermuler, Amus. micros., p. 58, pl. 73. - Long. $\frac{3}{4}$ de millim. - Les valves sont brunes, réniformes, plus étroites et plus comprimées en avant, couvertes de poils épars à peine sensibles; les antennes sont pourvues de quinze soies.

\section{CYPRIS RUBRA.}

Desm., Consid. génér. sur les Crust., p. 384.-Monoculus Ruber, Jur., Monocl., p. 172 , pl. 18, fig. 3 a $4 .-$ Long. $\frac{3}{4}$ lig. Forme générale de l'espèce précédente; le test est peu transparent, d'un rouge terne, avec une large zone plus colorée qui le tra. verse dans son milieu.

\section{GYPRIS AURANTIA.}

Dessr., Consid. génév. sur les Crust., p. 384.-Monoculus Aurantius, Jur., Mo. nocl., p. 173, pl. 18, fig. 5 à 12. - Long. $\frac{3}{4}$ lig. - Forme générale des deux espèces précédentes; elle cst également épaisse aux deux extrémités; la couleur est orangée uniforme; le test est parsemé de très-petits poils; les antennes sont courtes. Les jeunes individus ont leur coquille beaucoup plus étroite postérieurement qu'antérieurement.

\section{CYPRIS MONACHA.}

Muld., Ent., pl. 5, fig. 6 à 8, - Dess., Consid. génér. sur les Crust., p. 384, 
pl. 55, fig. 7.-Monoculus Monachus, J UR:, Monocl., p. 173, pl. 18 , fig. 13 à 14. Long. $\frac{z}{i z}$ lig. - Le test est court, comprimé, non réniforme, assez bombé en dessus et un peu en dessous; la couleur est blanchâtre, avec la partie antérieure et inférieure des valves noirâtre.

\section{CYPRIS VIRENS.}

Desm., Consid. génér. su. les Crust., p. 384.-Honoculus Virens, Jur., Monocl., p. 174 , pl. 18 , fig. 15 a 18 . - Long. $\frac{7}{12}$ lig. - Le iest est réniforme, légerement échancré en dessous, comprimé antérieurement, arrondi en arrière, non velu, d'un brun verdâtre, avec une tache triangulairé verte en dessus derrière l'œil, se prolongeant sur la suture des valves; le bord antérieur de celles-ci est également vert; le milieu de chaque valve est vert, avec deux bandes obliques, parallèles, vertes en arrière.

\section{CYPRIS PICTA.}

Straus, Mém. du Mus., t. VI, pl.: 1, fig. 17. - Desu., Consid. génér. sur les Crust., p. 385. - Long. $\frac{8}{5}$ de millim.Les valves sont plus bombées en arrière, non échancrées en dessous, couvertes de poils épars assez longs; le dos est nu; la couleur est verte, avec trois bandes grises, se terminant en pointe en dessous.

\section{CYPRIS FUSCATA.}

Desm., Consid. génér. sur les Crust., p. 385. - Monoculus Fuscatus, Jur., Monocl., p. 174 , pl. 19 , fig. 1 à 2. - Cypris Pilosa, Muls., Ent., pl. 6, fig. 5 à 6 . Long. $\frac{1}{2}$ lig. - La coquille est un peu plus épaisse en avant qu'en arrière, très-haute un peu derrière l'œil, très faiblement èchancrée en dessous, velue, avec une tache allongée, sinueuse, brune sur la suture postérieure, et une tache anguleuse de même couleur sur le milieu de chaque valve.

\section{CYPRIS PUNCTATA.}

Desu., Consid. gén. sur les Crust., p. 385. - Monoculus Punctatus, Jur., Mo. nocl., p. 175, pl. 19, fig. 3 a 4.-Long. $\frac{2 n}{48}$ de lig. - La coquille est élevée en avant de l'œil, à peu près également comprimée aux deux extrémités, peu échancrée en dessous, velue et parsemée partout de petits points bistrés.

\section{CYPRIS VIDUA.}

Mulz., Ent., pl. 4, fig. 7 à 9. - Desa., Consid. génér. sur les Crust., p. 385. Monoculus Vidua, Jvn., Monocl., p. 175, pl. 19 , fig. 5 à 6 . - Long. $\frac{13}{48}$ lig. - La coquille est réniforme, ayant sa plus grande saillie an milieu du dos, velue, blanchâtre, et marquée en dessus de deux bandes noires festonnées, transverses, parallèles entre elles, el qui n'atteignent pas son' bord inférieur.

\section{CYPRIS CANDIDA.}

Muls., Ent., pl. 6, fig. 7 à 9. - Dess., Consid. génér. sur les Crust., p. 385.-Monoculus Candidus, JuR., Monocl., p.176, pl. 19 , fig. 7 à 8 . - Long. $\frac{9}{2+}$ lig. - l. lest est réniforme, un peu plus étroit et cumprimé antérieurement, velu, blanc, avec une légère teinte rose en dessus, dans son milieu.

\section{CYPRIS UNIFASCIATA.}

Desm., Consid. génér. sur les Crust., p. 386. - Monoculıs Unifasciatus, Jur., Monocl., p. 176 , pl. 19 , fig. 9 et 10 . Long. $\frac{1}{24}$ lig. - Le test est velu, plus large antérieurement, également étroit et oblique sur ses deux bords supérieur et inférieur , vert clair, arec une bande transverse d'un vert foncé, derrière l'œil; cette bande est bifurquée à chacune de ses extrémitẻs.

\section{CYPRIS STRIATA.}

Desu., Consid. génér. sur les Crust., p. 386. - Monoculus Sirialus, Jur., Monocl., p. 177, pI. 19, fig. 11.-Long. $\frac{1}{3}$ lig. - Le test est court, réniforme, assez fortement échancré en dessus, et marqué de stries concentriques à ses bords, analogues a celles que l'on observe sur les coquilles du genre Mulette, Unio.

\section{CYPRIS STRIGATA.}

Mulu., Ent., pl. 4, fig. 4 à 6. - Desm., Considér. génér. sur les Crust., p. 386. -Monoculus Strigatus, Jor., Monocl., p. 177 , pl. 19 , fig. 12 à 13 . - Long. $\frac{1}{8}$ lig. - Le test est velu, allongé, èchancré en dessous, élevé en avant, et oblique depuis ce point jusqu'à sa partie postérieure, où jl est arrondi ; la couleur est blanche, avec deux bandes brunes transversales.

\section{CYPRIS VILLOSA.}

Desu., Consid. génés. sur les Crust., p. 386. - Monoculus Villosus, Jur., Monocl., p. 178, pl. 19 , fig. 14 à 15 . Long. $\frac{1}{7}$ lig. - Le test est court, réniforme, relevé au milieu du dos, avec ses extrémités égales, d'un vert uniforme, extrêmement velu.

\section{CYPRIS OPHTHAIMICA.}

Desu., Consid. génér. sur les Crust., 
p. 386. - Monoculus Ophthalmicus, Jur., Monocl., p. 178, pl. 19, fig. 16 a 17 . Long. $\frac{x}{4}$ lig. - Le test est court, très-relevé sur le dos et un peu antérieurement, légérement échancré en dessous, jaunâtre, avec quelques nuances rougeâtres au bord antérieur et derrière l'eil; celui-ci ayant une tache blanche dans son centre.

\section{GYPRIS OVUM.}

Desa. , Consid. génér. sur les Crust., p. 386.-Monoculus Ovum, Jur., Monocl., p. 179, pl. 29 , fig 10 et $19 .-$ Long. $\frac{1}{6}$ lig. -La coquille est arrondie, peu réniforme, régulière, tout-à-fait lisse, et d'une couleur blanchâtre rosée.

\section{CETOGHYLUS，R. De VAuZèMe.}

Le corps est oblong, recouvert dans sa moitié supérieure par un test corné presque diaphane, divisé en six segmens, dont le premier ou antérieur, plus étendu que les suivans et terminé en bec obtus, protège la tête, qui ne se distingue pas du tronc; les segmens postérieurs composant le thorax coirespondent à cinq paires de pieds natatoires. - La queue est forméc de cinq anneaux, dont le dernier bifurqué, confondue avec le tronc sous une voûte commune. - La tête porte deux yeux, quatre antennes, la bouche, et cinq paires de pieds mâchoires; les yeux, au nombre de deux, sessiles, placés en avant sur les parties latérales du premier segment, ont une forme ronde et sont granuleux; les grandes àntennes égalent en longueur la tolalitá du corps et se composent d'une suite d'articulations hérissées de petites soies fines; leur extrémité se divise en pénicillc rameux; les petites antennes, placées entre les précédentes, sous forme de filets très-courts, sont a peine visibles; au-dessous du premier segment se trouve la bouche, à laquelle on distingue un labre, deux mandibules et une paire de mâchoires. - Le labre est échancré en avant et bombé en dessus comme un casque.--Les mandibules sont denticulées, oblongues, légérement courbes et insérées sur l'article radical de la seconde paire de pieds-måchoires, laquelle peut être considérée comme un palpe mandibulaire. Les mâchoires se reconnaissentả deux pièces qui ferment l'ouverture buccale en manière de lèvre; les pieds-mâchoires sont au nombre de cinq paires, qui diffèrent toutes les unes des autres, et forment autour de la bouche, par l'entrelacement de leurs cilsbi- articulés, un chevelu difficile à démêler; la première présente un article radical sur monté de deux tiges biarticulées, pourvues de soies branchifères; la seconde, implantée sur les mandibules, est formée d'un article supporlant deux lirancliessimples, également soyeuses; la troisieme paire a une forme bizarre; elle ressemble à un tronc d'où partent six prolongemens obtus, hérissés de soies épanouies en éventail, celles de la saillie postérieure sont penniformes; la qua. trième, un peu courbe, se compose d'une seule tige ayant des cils très-longs, rangès d'un côté comme sur un peigne simple; la cinquième paire, plus longue que la précédente, a trois articles dont le dernier seul est barbu; les deux premières paires de pieds-mâchoires sont dirigées d'avant en arrière, $\mathrm{et} \mathrm{les} \mathrm{postérieures} \mathrm{d'arrière} \mathrm{en} \mathrm{avant.}$ - Le thorax est composé de cinq segmens indiqués par des lignes convexes, à peine dessinées sur le bouclier; à ces anneaux correspondent cinq paires de pattes natatoires, moitié bifides, ayant toutes la même forme et ne différant qu'en longueur et en volume. Chaque patte présente un article rudical évasé comme un cornet et prolongé en pointe extèrieurement; le second article, moins long et plus large, sert de base à deux bifurcations inégales, dont l'externe est formée de quatre articles moins volumineux rque les précédens, mais identiques pour la forme, al'exception du dernier, qui se termine en fuseau. La division interne plus courte n'a que trois articles, insérés bout a bout et sans pointes latérales; ces deux branches sont velues, et propres à la natation. - La queue présente cinq segmens, dont le second plus grand que les autres, le dernier bifide et sétigère. C'est avec doute que nous plaçons ce genre après celui de Cypris.

L'espèce qui a servi de type à cette nouvelle coupe générique est:

\section{CETOGHYLUS AUSTRAYIS.}

Rouss. de V Auz, Ann. des Sc.nat., t. I, p. 336. - Guḱn., Icon. du Rég. anim. de Cuv., Crust., pl. 32, fig. 5 et 5 a. - Long. 2 lig. - Corps d'un beau rouge; tête et thorax à moitié couverts par une écaille voûtée de six segmens; deux yeux sessiles; petites antennes très-courtes; grandes antennes égalant en longueur la totalité du corps; a la bouche, un labre, une paire de mandibules et deux mâchoires; cinq paires de pattes buccales (la seconde annexée aux mandibules), soyeuses et différant toutes les 
unes des autres; cinq paires de pattes natatoires, fourchues et ciliées; abdomen de cinc segmens dont le dernier bifide.

Ce Crustacé a été trouve dans la mer $\mathrm{Pa}$ - cifique et au milieu de l'Océan-Atlantique, sous le $42^{\text {e }}$ degré de latitude sud; il fourmille en bancs très-élendus, qui roügissent la mer, et servent d'aliment aux baleines.

\section{NEUVIELE ORDRE.}

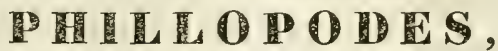

LATREILLE.

Le corps des Phyllopodes, tantôt nu, tantôt défendu par un test qui l'enveloppe en manière de coquille bivalve ou le recouvre supérieurement, sous la forme d'un bouclier en demi-ovale et échancré postérieurement, est divisé en un grand nombre de petits segmens qui, les derniers au plus exceptés, portent chacun une paire de pattes foliacées ou à articles lamelliformes; il est souvent terminé par une queue, ayant à son extrémité deux filets ou deux appendices en forme de nageoires, étroites et allongées. - La tête offre deux yeux, et même quelquefois trois, quatre à deux antennes, un labre, deux mandibules, quatre ou deux mâchoires et une languette

Certaines mares, des fossés remplis d'eau stagnante ou peu coulante, nous offrent, à une ou deux époques de l'année, ou dans quelques circonstances particulières, des masses considérables de ces animaux qui disparaissent bientôt après. Un fait très-remarquable à l'égard de quelques espèces, c'est que tous les individus que l'on a observés étaient des femelles, et que leurs mâles étaient encore inconnus; car M. Adolphe Brongniart, sur plus de mille individus (genre Limnadia) qu'il a observés, n'a vu que des femelles pleines d'œufs, et cet auteur est porté à croire que, dans les Limnadies, comme chez les Daphnies, une seule fécondation suffit pour plusieurs générations. Un naturaliste russe, M. Jean Krynicki de Charkown, a trouvé des mâles et des femelles et a pu voir leur accouplement, mais il n'a pu reconnaittre avec exactitude où sont placés les organes générateurs, parce que ces animaux, pendant l'accouplement, sont dans un mouvement continuel. Abstraction faite des Limnadies, les femelles portent leurs œufs dans deux capsules ou dans une espéce d€ sac, situés à l'extrémité du thorax proprenent dit, ou un peu plus en arrière vers l'origine de la queue; les petits éprouvent, jusqu'a ce qu'ils soient adultes, des changemens de forme très-remarquables.

Les Phyllopodes ont été partagés en deux sections. $1^{\circ}$ Ceux qui sont pourvus d'un test en forme de coquille bivalve, ou de bouclier, dont le nombre des pattes est au moins de quarante-quatre , et dont les yeux sont sessiles; $2^{\circ}$ ceux qui n'ont point de test bivalve ou clypéiformes, dont le nombre de pattes est de vingt à vingt-deux, et dont les yeux sont pédiculés; les premiers composent aeux familles : les Mytiloides et les Aspidiphores.

PREMİRE FAMILLE.

\section{I T I L O I D E S,}

LATREILLE。

Cette famille comprend deux genres: celui de Limnadia, qui a été établi par MI. Adolphe Brongniart, et celui de $C y z i$ cus, récemment créé par MI. Audouin.

Liminada, A. Brongiart, Latr., Desur. ;

Daphnia, Hermany.

Le corps est allongé, linéaire, inflechi en avant, entièrement renfermé dans un test bivalve, de forme ovale et très-comprimè.--La tête n'en est pas distinctement séparée; elle est pourvue de deux yeux placés transversalement à une petite distance l'un de l'autre, ayant leur face interne plane, et l'externe très-convexe, et couverte d'aréoles transparentes, placées sur un fond noir. - Il y a deux grandes 
ante unes attachées au-dessous des yeux, de m jitié aussi longues que le corps, ayant leur base ou pédoncule formée de huit articles assez gros et courts, et leur extrémité diviséc en deux filets sétacés, chacun de douze articles qui supportent quelques petites soies; il y a aussi deux petites antennes simples, élargies à leur extrémité, placées entre les grandes antennes. - La bouche, située au-dessus des antennules, est composée de deux mandibules renflèes, arquées et tronquées à leur extrémité inférieure, et de deux mâchoires foliacées, dont la reunion forme une sorte de bec ordinairement replié sous la tête. - L'abdomen ou tronc est divisé en vingt-trois anneaux, dont les vingt-deux premiers portent chacun une paire de pattes branchiales, et dont le dernier, qui forme la queue, est terminé par deux filets divergens. - Les pattes, toutes semblables entre elles, sont trés-comprimées, bifides, ayant leur division externe simple et ciliée sur son bord extérieur, et la division interne quadriarticulée, et fortement ciliée sur son bord i.ltérieur; les douze premières paires sont de même longueur el plus grandes que les autres, qui vont en diminuant progressivement jusqu'aux dernières; la quatrième et les deux suivantes sont pourvues à leur base d'un filet mince, remontant dans la cavité qui existe entre le doset la coquille, ct qui sert de support aux aufs. - Le cerveau est apparent entre les yeux et l'osophage. - Le canal dorsal du cœur est parallèle à l'instestin qui suit la courbure du corps. - Les ovaires sont situés dans l'intérieur du corps, sur les côtés du canal intestinal; entre la base de la première paire de pattes et celle de la dix-huitième, et ils paraissent avoir pour issue des canaux récurrens qui sont à la racine de quelquesunes de ces pattes. - Les œufs, placés après la ponte dans la cavité dorsale de la coquille, y sont attachés à de très-petits filets qui s'unissent eux-mêmes aux filets récurrens des patles; ces cufs, d'abord ronds et transparens, deviennent ensuite jaunâtres, puis obscursau centre, et prennent une formeirrégulière et anguleuse.

\section{LIMNADIA HERMANNI.}

Adolphe Brongniat, Mém. du Mus. d'Hist. nat., t. VI, pl. 13. - Dessr., Consid. génér. sur les Crust., pl. 56, fig. 1. - Guér., Mag. de Zool., 1837, pl. 21, fig. 12 a 13. -Daphnia Gigas, Heruan,, Mem. Apterol., p. 13i, tab. 5. - Long.
4 lig. - Les antennes extérieures sont presque la moitié de la longueur du corps, à filets composés de onze à douze arlicles; les antennes intermédiaires sont un peu en massue, dentées, de la longueur du support des antennes extéricures; les pattes branchiales sont simples, au nombre dt vingt-deux paires; la queue est tronquée obliquement, et ne présente en dessous des épines terminalesque deux faibles tubercules; les deux filets terminaux sont insérés en bas de la troncature, d'une longueur au moins quadruple des èpines supérieures; la couleur est blanchâtre transparente.

Cette espèce a été trouvée en grand nombre au mois de juin dans les petites mares de la forêt de Fontainebleau, par M. Ad. Brongniart.

\section{MMNADIA MAURITINA.}

Guśr., Mag. de Zool., 1837, pl. 21, fig.1 à 11 ; ejusd., Icon. du Rig, anim. de Cuv., Crust. pl. 33, fig. 2,2 a.-Long. 5 lig. $\frac{1}{2}$. Les antennes extérieures sont beaucoup moins de la moitié de la longueur du corps, à filets composés de neuf articles; les antennes intermédiaires sont en massue, plus courtes que les supports des extérieures ; les pattes branchiales, au nombre de dix-huit paires, sont simples; la queue, terminée en dessous par deux fortes épines, est tronquéc obliquement et présente en dessous deux épines saillantes assez fortes; elle présente aussi deux filets terminaux insérés au bas de la troncature, ct d'une longueur à peine iriple des épines supérieures.

Cette espèce, comme l'indiqueson nom, a été découverte à l'île Maurice par M. Julien Desjardins.

\section{LIMNADTA TETRACERA.}

Knynicki, Bull. de la Soc. Impér. des nat. de Moscou, t. II, p. 173. - Biblioth. Entom., publiée par Lequien, p. 357, pl. 12. - Gú́r., Magasin. de Zool., 1837. - Les antennes extéricures sont plus de la moitié de la longueur du corps, à filets composés de seize à dix-huit articles; les antennes intermédiaires grêles, dentelées, sont le double plus longues que le support des exlérieures; les pattes branchiales sont au nombre de vingt-sept paires, les quatre antérieures présentent une sorte de pince tridactyle dans les mâles; la queue est terminée par quatre filets bifurqués, divergents et presque égaux. - Se trouve aux environs de Charkow. 
Suivant M. Audouin, celte dernière espèce ne doit pas faire partie du genre Limnadia.

Ce même auteur désigne sous le nom de Cyzicus un genre de Crustacés qui se place après celui de Limnadia. Deux es. pèces composent ce genre.

\section{CYZICUS BRAVAISII.}

Aud,, Ann. de la Soc. Ent., t. VI, Bull., p. 103.-Cette espèce a été trouvèe par M. Bravais, officier de la marine royule a Arzew, près d'Oran, dans une petite mare d'eau légérement saumâtre.

\section{Cyzicus tetracerus.}

Aud., Ann. de la Suc. Ent. de France, t. VI, Bull., p. 10. - Limnadia Tetracer'a, Kny Bicki, Bull. de la Soc. des nat. de Mos. cou, t. II, p. 273.-Gú́n., Mag. de Zool., 1837.

\title{
DEUXILME FANILLE.
}

\section{A S P I D I P H O R E S}

\author{
LatreiLle.
}

Caractères. Trois yeux, dont un plus petit, groupés sur un test clypéiforme.-Deux antennes courtes et simples. - Une soixantaine de paires de pattes, portant près de leur base un corps vésiculaire, diminuant progressivement de grandeur, foliacées, dont les antérieures terminées par trois longs filets, multiarticulés, antenniformes, et dont les autres finissant en manière de pince, à deux doigts comprimés. - Deux feuillets circulaires, appliqués l'un sur l'autre, renfermant les æufs, et situés près de la naissance de la onzième paire. - Une queue composée de plusieurs articles, et dont les derniers sans pattes, avec deux filets à son extrémité postérieure.

Genres: Apus, Lepidurus.

APUS, Scop., Cuv., Latr., Desur. ; Binoculus, Geoff.; Limulus, Mull., LAM.; Monoculus, Linn., Fabr.

Le corps est allongé, conique, formé d'une quarantaine de segmens étroits, dont les sept ou huit derniers formant la queue ne portent pas de pattes. - La tête est confondue avec le corps, et recouverte comme lui par un vaste bouclier membraneux, formé de deux lames adhérentes entre elles dans toute leur étendue, mais seulement en avant; ce bouclier bombé, ovalaire, caréné dans son milieu et échancré postérieurement, porte en avant trois yeux simples, dont deux antérieurs plus grands, très-rapprochés, un peu en forme de croissans, et le troisième très-petit, ovale et placé en arrière de ceux-ci. - Le chaperon forme en dessous et en avant du sest une large surface à neu près triangu- laire sur le milieu du bord postérieur de laquelle est attachée une lèvre supérieure grande, à peu près carrée dans son contour, et légérement bombée dans son milieu, La bouche est composée, outre cette lèvre, $1^{\circ}$ de deux grandes mandibules arquées en voûte, minces, tronquées à leur extrémité, qui est droite et dentelée; $2^{\circ}$ de deux paires de mâchoires, dont les supérieures sont en forme de feuillets épineux et ciliés à leur extrémité, et les inférieures simplement velues, annexées à une pièce membraneuse, en forme de fausses pattes ; $3^{\circ} \mathrm{d}$ 'une languette profondément bifide, et munie d'un canal cilié qui conduit à l'œsophage. - Les antennes sont très-courtes, insérées près des mandibules; elles sont formées de deux articles, dont le second, plus long que le premier, est terminé par trois soies très-petites. - Les pattes de la première paire sont grandes, rameuses, pourvues de quatre soies articulées, dont les deux premières très-longues; les suivantes, au nombre de soixante paires env:ron, diminuant graduellement de grandeur, sont assez compliquées dans leur forme; elles ont leur base ciliée, et une grande lame branchiale sur un de leurs côtés, avec un sac ovalaire, vésiculeux en dessous; celles de la onzième paire sont pourvues d'une capsule à deux valves, renfermant les œufs, qui sont de couleur rouge. La queue est terminée par deux filets sétacées et multiarticulés.

Ces Grustacés paraissent plus ordinairement au printemps et au commencement de l'été. Ils fourmillent dans certaines mares ou dans des fossés dont les eaux sont dormantes, et s'y nourrissent de Tétards. 
Ils nagent le plus sourent sur le dos, et lorsqu'ilss'enfoncent ils élèvent leur queue; ils sont quelquefois enlevés par les vents tres-violents et tombent sous la forme de pluie; l'oiseau appelé vulgairement Lavandière en dévore un grand nombre.

APUS CANCRIFORMIS. (Pl. 20, fig. 5.)

DesM., Consid. génér. sur les Crust., p. 360, pl. 52, fig. 1. - GuÉR., Iconog. du Réry. anim, de Cuvier, Crustacés., pl. 34, fig. 2. - Limulus Palustris, Mult., Entom., p. 127, $\mathrm{n}^{\circ} 62 .-$ Le Binocle äqueue en filets, Georf., Ins. des environs de $P$ aris, t. II, pl. 21, fig. $4 .-$ Long. 1 pouc. $\frac{8}{2}$. - L'échancrure postérieure du test est trés-grande; la carapace dorsale est peu prolongée en pointe. - Se trouve en France, mais très-rarement aux environs de Paris.
LEPIDURUS, Leach, Desiz:; Apus, LaM., Latr.

Ce genre differe de celui d'Apus, parce $q u^{\prime} i l$ existe entre les filets de la queue une lame allongée, horizontale et de forme ovalaire, un peu tronquée et échancrée au bout.

\section{LEPIDURUS PRODUCTUS.}

Desm., Consid. génér. sur les Crust., pl. 52, fig. 2. - Guér., Iconog. dı Ríg. anim. de Cuvier, Crustacés, pl. 34 , fig. 3. - Monoculus apus, LrNs., Faun. Suec., Fanr.; Entom. Syst., Suppl., p. 305. - Moins grand que l'Apus cancriformis, mais généralement semblable, quoique un peu plus allongé; la carène du test est prolongée postérieurement en pointe. - Se trouve assez cominunément en France.

\section{CERATOPHTHALMES,}

LATTEILLE.

Caractéres. Les Crustacés qui composent cette famille n'ont pas de test, le nombre des pattes. est de vingt a vingt-deux; les yeux sont pédiculés.

Genres : Branchipus, Artemia, Eulimene.

BRANCHIPUS, Lamck., Latr., Leach, Desar. ;

Branchiopoda, LaMck., Latr., Bosc.;

Cancer, Linn.; Gammarus, Fadr.; Branchiopus, DuМÉR.;

Chirocephalus, BéNÉd., Prér.

Le corps est allongé, presque filiforme, írès-mou et sans test. - La tềte est distincte, munie d'antennes filiformes, droites, flexibles, composées d'une multitude d'articles presque imperceptibles, de la longueur de la tête, au nombre de deux ou de quatre.- Les yeux, au nombre de deux, sont a réseau, très-écartés; les latéraux pédonculés et mobiles. - Le front présente deux espéces de cornes, lesquelles sont beaucoup plus grandes et très-annelées dans les mâles. - La bouche est composée d'un chaperon bifide, arancé, d'une papille en forme de bec, et de quatre autres pièces latérales. - Les pieds, tous natatoires, sont d'égale longueur, placés au dessous et sur les côtés đu corps, formés de quatre articles, dont le premicr court et les trois derniers aplatis, ovales, ciliés sur leurs bords, et faisant fonctions de branchies et de rames. - La queue est composée de six a neuf anneaux, dont le premier est muni de deux feuillets allongés, pointus et ciliés sur leurs bords. - Les organes sexuels sont situés après la dernière paire de pattes, à l'origine de la queue, et aussi dans la femelle près de l'extrémité de celle-ci.

Les espèces qui composent ce genre vivent dans les petites mares d'eau de pluie, et y uagent renversés sur le dos, avec beaucoup de vèlocité, à l'aide de leurs pattes branchiales.

\section{BRANCAIPUS STAGNALIS.}

Latr., Hist. des Crust. et des Ins., t. IV, p. 297.-DEsм., Considér. génér. sur les Crust., p. 389. - Gammarus Stagnalis, Hensst., Cancr., tab. 35, fig. 3 à 10. -Long. 10 lig. - Les cornes du mâle sont horizontales; les nageoires de la queue sont larges; les antennes sont au nombre de 
quatre; les oufs des femelles sont bleus, renfermés, après la ponte, dans un sac ovale qui est placé sous la queue.

\section{2. branchipus paludosus.}

Desm., Considerations génér. sur les Crust., p. 389 , pl. 36, fig. 2 à 5. - Cancer Paludosus, Mulrer, Prodr. Zool. Dan., tab. 48, fig. 1. -C hirocepalus Diaphanus, BÉNÉd.-Prév., Journ. de Phys., messid. an II ; ejusd., Mémoire sur le Chi. rocéphale, joint au travail de M. Jurinesur les Monocles, p. 201, pl. 20, 21 et 22. Long. 1 pouc. $\frac{1}{2}$. - Les cornes du mâle sont perpendiculaires; les nageoires de la queue sont filiformes; les antennes sont au nombre de deux dans les deux sexes.

C'est sur cette espèce que $M$. BénédictPrévost a élabli son genre Chirocephalus, et nous allons donner, d'après cet auteur et M. Desmarest, quelques détails sur ses formes et sur ses mœurs.

La tête est séparée du corps par une sorte de col, que forme le premier anneau dépourvu de pattes. - Les deux antennes sont droites, cylindriques et terminées par une touffe de petits poils. - Les deux cornes des mâles (premiers doigts, BénédictPrévost), qui sont destinées à fixer la femelle lors de l'accouplement, sont formées chacune de deux pièces verticales, dont la dernière est étroite, courbéc en dedans pour correspondre à celle de la corne opposée, et constitue avec elle une sorte de tenaille à branches courbes.-Deux grands tentacules en forme de trompes molles (second doigt du Chirocéphale adulte, Bénédict-Prévost), mais non traversés par un canal, placés à la base des cornes en de. dans, mobiles, roulés en spirale, pourvus à leur racine, du côté extérieur, de quatre appendices charnus, cylindriques et parsemés de pelites épines, et d'une membrane triangulaire languetée, qui se déploie dans l'accouplement. -- Ces deux organes manquent dans les femelles, qui ont à la place des cornes en forme de pinces, deux simples protubérances coniques, assez avancées. - Les yeux sont fort grands, à réseau, ordinairement noirs, quelquefois bruns ou marbrés de blanc, portés sur des pédoncules assez longs. - La bouche est composée : $1^{\circ}$ de deux mandibules trèsgrandes, ayant leur extrémité triturante large, obtuse et garnie d'un grand nombre de petites dents ; $2^{\circ}$ de deux organes particu. liers (barbillons des mandibules, Bénédict-
Prévost) formés de deux pièces, l'une épaisse, et l'autre mince et garnie d'une vingtaine de filets très-déliès, qui sont placés de manière que les alimensqui arrivent aux mandibules doivent passer entre eux ; $3^{\circ}$ de deux petits appendices (papilles, Bénédict-Prévost) situés sous son corps, paroissant destinés à pousser les alimens entre les filets; $4^{\circ}$ d'une lèvre supérieure (soupape, Bénédict-Prévost), insérée à la base et au centre des parties de la bouche, un peu au-dessous d'une tache noire, triangulaire, qui est le rudiment des yeux lisses; cette lèvre s'étend sur les mandibules et les barbillons, et arrive jusqu'auprès de l'intervalle qui sépare les deux papilles. - Le corps, en forme de bateau ou de canot allongè, dont la carène est sur le dos est composé d'un anneau sans pattes, et de onze anneaux pédigères. - La queue consiste en neuf segmens, dont les deux premiers supportent les organes externes de la génération.-Les patles sont en nageoires, dont les trois derniers articles, allongés, ovalaires, sont très-ciliés sur leurs bords.-Les orga. nes extérieurs dı mâle sont en forme de deux corps conoïdes, obtus, et les inférieurs composés de longs vaisseaux spermatiques. - Les vulves des femelles sont placées tout-à-fait à l'extrémité de la queue, et ne servent pas à la sortie des cufs.- Les ovaires sont situés dans toute l'étendue de la queue à droite et à gauche du canal intestinal, et remontent jusqu'au second anneau, oủils communiquent avec une grosse poche extérieure, conique, remplie d'œufs, qui est ici l'analogue des sacs ou matrices extérieures des Cyclops, et dont l'ouverture est à sa pointe.-La queue est à lanières étroites, pourvues sur leur contour de soies qui, elles-mêmes, sont ciliées. - Le cœur consiste en un vaisseau dorsal, semblable à celui des insectes. - L'intestin est droit, présente deux csophages, et se termine à l'extrèmité du dernier anneau de la queue.

Les Chirocéphales, en sortant de l'œuf, ont le corps divisé en deux masses globuleuses à peu près égales. La première renferme un gros wil lisse, et donne attache : $i^{\circ}$ à deux antennes courtes, cylindriques et pourvues de poils au bout; $2^{\circ}$ a deux trèsgrandes rames dont l'extrémité est ciliée, et $3^{\circ}$ a deux pattes assez courtes et grêles, formées de cinq articles. Après la première mue, ils ont trois yeux, l'intermèdiaire lisse, et les deux latéraux composés; la partie postérieure du corps est allongée, coni- 
que, divisée en anneaux, et terminée par deux petits filets. Plus tard, et après plu. sieurs mues, les pattes se montrent et se développent de plus en plus, tandis que les rames s'atrophient et disparoissent; l'œil simple intermédiaire reste rudimentaire. Dans les jeunes encore, la lèvre supérieure ou soupape est ẻnorme, puisqu'elle recouvre le ventre, mais son volume diminue progressivement avec l'âge.

Les Chirocéphales se trouvent dans les petites mares d'eau douce, mais non corrompue, et souvent dans celles qui ont été formées momentanément à la suite des grandes pluies. Ils nagent sur le dos avec beaucoup de facilité, et paroissent continuellement occupés à manger de petits corps animaux ou végétaux que l'eau tient en suspension. Leur accouplement a de l'analogie avec celui des Libellules; c'est-ì-dire que le mâle, nageant au-dessous de la femelle, la saisit au cou avec les appendices qui munissent sa tête, et s'y tient fixé jusqu'a ce que celle-ci recourbe sur lui l'extrémité de sa queue, de façon à mettre en contact ses deux vulves avec les deux organes copulateurs qui doivent la féconder. Les œufs, jaunâtres, sphériques, irréguliers, ont une enveloppe épaisse et dure, qui les conserve en èté à sec et dans la poussière, ou dans la terre, jusqu'à ce qu'une circonstance favorable, telle que la présence de l'eau, en quantité suffisante, leur permette d'éclore.

Ce qui arrive pour ces œufs a lieu également pour ceux du Branchipe des étangs, et il faut que ces derniers aient une vitalité au moins aussi grande que la leur; car j'ai observé, dit M. Desmarest, des animaux de cette espèce dans les petites flaques d'eau pluviale sur les sommités des rochers de grès de Fontainebleau, qui sont ordinairement à sec, et exposés pendant plusieurs mois de l'été aux rayons ardens du soleil.

Les femelles des Chirocéphales font plu. sieurs pontes distinctes à la suite d'un seul accouplement, chacune à plusieurs reprises qui durent ensemble quelques heures, et jusqu'à un jour entier. Chaque ponte est de cent à quatre cents œufs; ceux-ci sont lancés au dehors avec beaticoup de vitesse, par jets de dix à douze, et avec assez de force pour pouvoir s'enfoncer assez avant dans la vase.

Consultez, pour les autres espèces du genre Branchipus, l'Icon. dı Rég. anim. de Cuv., Crust., pl. 33, fig. 3 a 4 .

AnN.
ARTEMIA, Leach, Desu., Latr.; Artemisus, LAM. ; Cancer, LINN.; Gammarus, Latr.

Je corps est ovale, à tểte non séparẻe, et caudifère postéricurement.-Les antennes, au nombre de deux, sont courtes, subulées.- Les yeux, aussi au nombre de deux, sont subpédonculés.-La bouche est placée sous le bord antérieur de la tête. - La queue est longue, terminée en pointe. Les pattes, au nombre de dix paires, sont lamelleuses, natatoires, ciliées, et se terminent par une soie.

\section{ARTEMIA SALINA.}

Dess., Consid. génér. sur les Crust., p. 393. - Cancer Salinus, Montagu, Trans. Soc. Linn., t. XI, p. 205. Artemisus Salinus, Laß., Anim. sans vert., t. V, p. 135 , tab. 14 , fig. 8,9 et 10. - L'espèce qui a servi de type à ce genre est un petit Crustacé que l'on trouve communément dans les marais salans lorsque l'évaporation de l'eau est très-avancée. Dernièrement M. Payen a communiqué quelques observations sur ces petits Crustacés à l'Académie des Sciences. M. Payen les a observés daus les salines des environs de Marseille. Quand l'eau commence à se saturer de sel, par suite de l'évaporation, ces petits animaux, qui se tenoient d'abord au fond, ne tardent pas à périr, à cause de la condensation du liquide, et montent à la surface, où leurs corps amoncelés répandent une odeur de violette, et communiquent aux salines une couleur rougeâtre qui presage la prochaine récolte du sel.

\section{EUlimene, Latr., Desh.; Artemia, Leach.}

Le corps est ovale, oblong et linéaire. La tête est transverse, avec les yeux noirs, latéraux, portés chacun sur un pédoncule assez grand et cylindrique.-Les antennes, au nombre de deux, sont presque filiformes, mais un peu plus menues au bout, simples, un peu plus longues que la tête, insérées entre les yeux. On aperçoit deux petits corps filiformes, semblables à des palpes placés à l'extrémité antérieure de la tête. - Le premier article du corps est élargi sur les côtés, et sert de cou. - Les pattes, au nombre de vingt-deux, sont placées sur les côtés du corps, et paroissent composées de quatre a cinq articles membraneux ou 
de lames, dont les trois premiers et le dernier plus petits, celui-ci allant en pointe, et aucun d'eux n'étant double; le dernier de la onzième paire est étroit vers son extrémité, qui est arrondie. - Une pièce arrondie et globuleuse est attachée vers le milieu des pattes comprises inclusivement entre la quatrième et la dixième paire.Une pièce renflée presque demi-globuleuse, remplie d'une matière noirâtre, termine le corps postérieurcment et remplace la queue, de laquelle sort un filet semblable à un boyau allongé, aussi noiràtre; que M. Latrcille soupçonne être un oviducte.

\section{EULIRIENE ALBIDA.}

LATR., Règ. anim. de Cuv., t. III, p. 68; ejusd., Noutv. Dict. d'Hist. nat., t. X, p. 333.-Dessr, Consid. génér. sur les Crust., p. 343. - Latk., fièg. anim. de Cuv., 2e édit., t. IV , p. 178.-Artemia Eulimene, Leach, Dict. des Sc. nat., t. XIV, p. 343. - Cette espèce est très-petite; la couleur est blanchâtre, avec l'extrémité postérieure du corps noirâtre. De la Méditerranée près de Nice.

\section{GRUSTACES ÉDENES,}

LATREILLE.

Tous les Crustacés, dont l'organisation buccale est établie sur un autre type que le précédent, composeront cette division. Là, comme dans les Xyphosures, plus de parties comparables par leurs formes aux mandibules et aux mâchoires. - L'article radical des six premières paires de pattes fait l'office de mâchoires, que j'avois distin. guées, dit M. Latreille, par l'épitbète dঞ sciatique. Ici, comme dans les Siphonosto. mes, une sorte de siphon ou de sucoir tient lieu de la bouche; dans les uns et les autres, quelques-unes au moins de ces pattes antérieures diffèrent singulièrement des dernières; elles servent à l'ambulation ou à la préhension.-Celles-ci, tantôt très-lar. ges, membraneuses, tantôt digitées ou multifides, sont natatoires et branchiales. C'est ce que M. Latreille a voulu exprimer en désignant collectivement ces Crustacés sous le nom de Pacilopodes, pattes variées. Comparé avec celui des Crustacés de la première division, le corps offre moins de segmens, et paroit manquer au moins de post-abdomen, ou cette arrière-partie du corps est remplacée par des appendices; à cet égard, ils semblent se rapprocher des $\Lambda$ rachnides. Le nombre des antennes est encore souvent réduit à deux. Si on excepte les Xyphosures, ils sont tous parasites, et se nourrissent du sang de divers pois. sons et batraciens.

Cette seconde division renferme trois ordres: les Xyphosures, Jes Syphonostomes et les Trilobites.

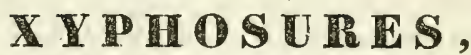

Latheille.

Cet ordre est ainsi caractérisé : absence de siphon. - Des mâchoires formées par un prolongement maxilliforme et épineux de l'extrémité interne et supérieure des hanches des six premières paires de pieds, et entourant le pharynx. - Un test de deux pièces; l'antérieure solide, grande, bomivée, semi-lunaire, ayant en dessus deux yeux à facettes et deux yeux lisses, offrant en dessous deux antennes en forme de serres didactyles, rapprochées ef insérées sur une saillie représentant une sorte de labre, et six paires de pieds, tous, à l'exception des deux ou quatre antérieures 
àu plus, et seulement dans les mâles, ter minés par deux doigts, et dont les deux postérieurs foliacés et portant les organes sexuels. Seconde pièce du test presque plane, en forme de triangle tronqué et échancré postérieurement, épineuse sur les côtés, et renfermant, dans une cavité inférieure, cinq paires de pieds-mâchoires en forme de grands feuillets, réunisà leur base interne, garnis à leur surface postérieure, d'une couche de fibres composant l'organe respiratoire ; enfin, un stylet très-dur, corné, mobile, inséré dans l'échancrure de la pièce précédente; tel sera le signalement général de cet ordre de Crustacẻs, auquel on a conservé le nom de Xyphosures, donné par Gronovius au genre dont il se compose, mais que nous appellerons Limules, avec la plupart des autres Carcinologistes.

Genres: Tachypleus, Limulus, Prosopistoma.

\section{TACHYPLEUS, LEACH, DESH. ;}

Limulus, Latr. ; Polyphemus, Lair.

Ce genre diffère du suivant par le dernier article des appendices des premiere et deuxième paires de pattes ambulatoires, qui est étroit à sa base, renflé intérieure. ment vers son milieu, et se terminant toutà-coup en pointe; de plus, deux doigts égaux terminent ceux de la quatrième et de la cinquième paire.

\section{TACHYPLEŨS HETERODACTYLUS,}

Dess., Consid. gén. sur les Crust., p. 357.-Limulus Heterodactylus, LaTr., Dictionn. des Scienc. natur. - Cette espèce est assez semblable, par les formes de son test, au Limule Polyphême, et présente, comme lui, trois épines sur la carène mitoyenne; les angles latéraux et postérieurs de la première paire sont plus aigus que dans les Limules; les épines mobiles latërales de la seconde sont plus grandes, et son échancrure est plus large; la queue est plus longue que le corps; la couleur est d'un brun-marron sur les individus dessé. chés.

LIMUlus, Farr., Latr., Leach; Desm. ;

Monoculus, LinN. ;

Xyphosura, Xyphotheca, Gronov.;

Polyphemus, Lam. ; Cancer, Guusius.

La première pièce du test, celle qui a la forme d'un bouclier semi-lunaire et voûté, est rebordée, repliée antérieurement en dessous en une fossette frontale, plane, triangulaire, et sous laquelle sont deux an. tennes palpiformes, - Le dos présente trois arêtes triangulaires, dont celle du milieu, séparée des deux autres par deux sillons longitudinaux, a à son extrémité antérieure, deux yeux lisses raporochés. - Leg yeux, à facettes, de forme ovale, sont adossés an côté extérieur des carènes latérales, près de leur bord antérieur, et plus ou moins élevé, en manière de dent. - La concavité inférieure du bouclier nous offre, de devant en arrière, les appendices suivans: un petit labre renflé, caréné au milieu, por: tant deux petites antennes en forme de palpes, ou deux chélicères, coudées, de deux articles, dont le second composant une petite main ou serre didactyle; ensuite, douze pattes rapprochées par paires, et sur deux lignes, dont la première, à l'exceplion de deux ou quatre antérieures, et dans les mâles seulement, terminées aussí en pince didactyle, dont la longueur augmente graduellement, avec l'extrémité interne de leur premier article ou des hanches, avancé, comprimé, et hérissé de petites épines; les huit premières sont composées de six articles, dont le dernier renflé, allant en pointe, aux deux ou quatre antérieures des mâles; celles de la cinquième paire ont un article de plus; sur le côté inférieur de l'article coxal ou du premier, et près de son articulation latérale, est un appendice dirigé en arrière, de deux articles, dont le premier beaucoup plus long, en forme de lame allongée, comprimée, subelliptique et obtuse; le cinquieme article est terminé par cinq petits feuillets mobiles, et deux doigts de la pince, plus petits que celles des pieds précédents, sont articulés à leur base, et pareillement mobiles ; dans l'entie-deux de ces deux pattes sont deux lobes maxilliformes, et qui me paraissent êfre, dit M. Latreille, des appendices isolés de ceux des mêmes pieds, et représenter la lèvre des Aranéides et la portion intermédiaire de celle des Scorpions; enfin les deux derniéres pattes, ou celles de la sixième paire, sont réunies sous la forme d'un grand feuillet coriace, presque demi-circulaire, dont la surface offre des lignes imprimées ou des espèces de su. ture, avec le milieu du bord postérieur échancré, et rempli par deux petites pièces lamelleuses, représentant les doigts internes des pinces; des sutures indiquent les 
autres articles de ces palles; à la face pos. térieure sont situés les organes sexuels; l'intérieur de ce bouclier est occupé en grande partic par les ovaires, dans les femelles, et par les testicules dans l'autre sexe. - La seconde pièce du test s'aritcule avec la précédente, au milieu de son échancrure postérieure, offre cinq paires de pattes natatoires, presque semblables a la dernière, mais unies simplement à leur base interne, et portant à leur face postérieure une couche de fibres nombreuses et serrées, disposées sur un seul plan, et constituant l'organe branchial. - Ces paltes remplissent la concavité inférieure, ct sont appliquées les unes sur les autres. Les bords latéraux de celte seconde pièce sont alternativement échancrès et dentés, et, à partir de la seconde, les échancrures ont chacune, dans leur milieu, une épine comprimée, allongée et mobile; cette seconde division du test est fortement écartee en manière d'angle, à son extrémité pos¿éricure, et au milieu de cette échancrure s'articule avec elle, et par gynglime, une pièce très-dure, en forme de stylet ou d'épèe, droite, souvent prismatique et trèspointue. Suivant M. Cuvier, le cour ressemblerait à celui des Stomapodes; un œsophage ridé remontant en avant, conduit dans un gosier très-charnu, garni ivtérieurement d'un velouté cartilagineux tout hérissé de tubercules, et suivi d'un intestin droit et large; le foie y verse la bile de chaque côté, par deux canaux.

Les Limules habitent généralement les rivages des mers des pays chauds, et plus particulièrement ceux des Indes-Orientales et de l'A mérique. Quelques individus ont jusqu'à deux pieds de long. Ils sont connus aux Etats-Ũis sous la dénomination de poisson-casserole, parce qu'ils en ont la ressemblance, et qu'en enlevant leurs patles, on s'en sert pour puiser de l'eau. On les donne à manger aux porcs. Lessauyages emploient leur stylet en guise de nèche, et on en redoute la pointe; on en mange les œứs à la Chine, et il paraîtrait que sur d'anciens zodiaques japonais, la figure de ces Crustacés est l'emblême de la constellation du cancer. Ces animaux sont t.ès-lents dans leurs mouvemens, ils ne viennent guère à terreque le soir, et seulement dans des lieux ou la plage est sablonneuse; lorsqu'ils marchent, ils parcourent une ligne droile, et l'on ne voit aucun de leurs membres hors des bords du test. Les femelles, qui sont plus grosses que les mâles, les porient souvent sur leur dos. On en a trouve de fossiles, et ils paraissent les premiers Crustacés dont uous ayons des analogues, ou ceux qui ont immédialement succédé aux Crustacés perdus, tels que les Trilobites.

\section{Limudes RolypHeMUs.}

Latr., Dictionn. des Scienc. natur. - Dess., Consid. générales sur les Crustacés, pl. 51, fig. 1. - Limulıs Americanus, LEACH, Dict. des Sc. nat., t. XIV, p. 537. - Cette espèce présente trois épines sur l'arête du milieu de chacune des deux pièces du test; l'exırémilé de la dernière de celle-ci est pourvue d'une échancrure simple; la queue est triangulaire, dentée en dessus; Ia couleur est blanche-jaunâtre dans les jeunes individus, et d'un brun-noirãtre dans les aciultes; chez les mâles les pinces des deux pieds antérieurs, sont renfiécs et terminées par un seul doigt. - Se trouve communément sur les côtes orientales de l'A mérique.

\section{LIMEILS SOIVERBI.}

LEACH, Zool. Miscel., t. II. Lab. S4; ejusd., Dict. des Sc. nat., t. XIV, p. 537. -Desm., Consid. génér. sur les Crusl., p. 355. - La queue est triangulaire, dentelée en dessus; l'échancrure terminale de la seconde pièce du test est pourvue d'une dent. - Patric inconnuc.

\section{IMULes Moreccines.}

Latr., Dictionn, des Scienc, nalur. - Desu. Consid. génér. sur les Crust., p. 355. - Cancer Moluccanus, Clusius, Exol., p. 128. - Scheffer, Monogí., tab. 7, fig. 4, 5. - Long. 2 pieds. - Ne présente pas d'épines sur l'arèle du milieu de la première piéce du test, laquelle se termine en avant par une pelite élévation fourchue; l'échancrure postérieure de la seconde pièce est sensiblement dentelée; la queue, plus courte que celle de l'espèce précédente, est triangulaire, avec sa caréne supérieure, armée dans une grande partie de sa longueur de dentelures nombreuses en scie. - Se trouve communément aux Moluques.

\section{LIMUIUS ROTUNDICAUDA,}

LATR., Dictionn. des Scienc, natur. -Desu., Consid. génér. sur les Crust., p. 355. - Présente des petites épines sur la carène moyenne de la première pièce du test, mais n'offre pas d'élévation dans son milieu; il n'y a pas non plus d'épines 
sur la seconde piece; les deux doigts terminaux sont allongés à tous les pieds (sans doute chez les femelles); la queue est plus courte que le corps, arrondie en dessus et sur les côtés; la coulleur est grise-verdâtre ou foncée, avec des points et des taches noirâtres. - Habite les Indes-Orientales.

\section{LIMULUS VIRESCENS.}

Latr., Dictionn. des Scienc. natur., Desur., Consid. génér. sur les Crust., p. 356. - Cette espèce a beaucoup d'ana. logie ayec le Limulus Moluccanus; elle n'offre-pas d'épines sur les arêtes de son test, qui est d'un brun-verdâtr'e; les deux pinces antérieures sont renflées, terminées par un seul doigt et gibbeuses en dessous.

\section{IMULUS MACLEAIr.}

LEAch, Dict. des Sc. nat., t. XIV, p. 537. - Desm., Consid. génér. sur les Crust., p. 356. - La queue est triangulaire et sans dentelures, et on aperçit une dent qui est placée dans l'échancrure de l'extrémité postérieure du test. - La patrie inconnue.

\section{HMULUS LATPEILIII.}

LEACH, Dict. des Sc. nat., t. XIV, p. 537. - Desm., Consid. génér. sur les Crust., p. 356. - La queue est allongée, iriangulaire à sa base, comprimée vers son extrémité, et présente en dessous une rainure ou sillon qui ne se prolonge pas jusqu'au bout; de plus, l'échancrure de l'extrémité de la pièce postérieure du test présente une dent. - La patrie de cette espèce est inconnue.

\section{PROSOPISTOMA, LATR.}

Le corps est ovoüdo-hémisphẻrique, recouvert presque entièrement par un bouclier divisé en deux segmens; l'antérieur plus petit, presque semi-circulaire, ayant en dessus deux yeux à réseau, écartés, et deux antennes très-petites, sétacées et simples; offrant en dessous deux paires de mâchoires, épineuses au bout, recouvcrtes par une lame semi-circulaire; le second segment est caréné longiludinalement dans son milieu, tronqué et échancré postérieurement. - Il y a trois paires de pattes filiformes, simples et mutiques, insérées sur les.côtés d'un plastron triangulaire, appliquées sur les cốtés de la poitrine et coudées. -L'abdomen est en forme de petite queue, composé de quatre segmens dont le dernier aplati, presque semi-circulaire, portant des filets barbus, branchiaux et rétractiles.

Ce genre, suivant M. Latreille, sembleroit devoir former à lui seul une famille particulière, terminant la division des Crustacés dentés ou munis de mâchoires; mais dans l'état actuel de la science il est impossible de lui assigner une place bien positive, son organisation buccale nous étant inconnue, et n'étant pas assurés qu'il n'existe point de siphon; aussi est-ce avec le plus grand doute que nous le plaçons près des Limules. - Deux espèces sont connues; l'unea été désignée sous le nom de :

\section{1. prosoristoma punctifrons.}

Latr., Nouv. Ann, duMus., t. II, p. 34. - Le Binocle à queue en plumet, GeorF., Hist. abrég. des Ins., p. 34, t. II, p. 660 , pl. 21, fig, 3.-Long. 2 lig. Larg. 2 lig. $\frac{2}{2}$. - D'un jaune-brun; le corps est rond, hémisphérique, presque aussi large que long et concave en dessous; entre les yeux, sont trois taches brunes, figurant un triangle; ce Crustacé, suivant l'historien des insectes des environs de Paris, se trouve dans les ruisseaux; il ressemble d'abord à un petit Coléoptère, mais sa démarche vive et sa queue qu'il agite précipitamment le décèlent bientôt.

Et l'autre sous celui de :

\section{2. prosopistoha Varifgatum.}

Latr., Nouv. Ann. du Mus., t. II, p. 34.-Gués., Iconogr. du Rég. anim. de Cuv., Crust., pl. 34, fig. 4. - Long, 2 lig. $\frac{1}{2}$. - Le corps est d'un brun foncé. terne, mélangé de jaunâtre, en devant et sur les côtés. - Habitc Madagascar. 


\section{ONZIEMB ORDRE.}

\section{SIP II ONOSTOMES,}

\section{LATREILLE:}

Un siphon ou suçoir plus ou moins apparent, quelquefois caché ou peu distinct, formé, autant qu'il est possible d'en juger par quelques observations particulières, de quatre pieces correspondantes au labre, à la languetie et aux mandibules des Crustacés édentés, compose exclusivement la bouche de ceux-ci; de tels organes indiquent qu'ils doivent être des animaux suceurs, et e'est en effet sur des poissons et quelques reptiles aquatiques de l'ordre des Batraciens qu'ils se tiennent habituellement fixès, du moins à une époque de leur vie; car ils peuvent nager et errer dans l'eau avant que de s'établir à demeure. -Lorsqu'ils se multiplient beaucoup sur l'un de ces animaux, ils l'épuisent telle- ment, qu'il finit par périr. Un propriétairø de nos départemens de l'ouest, dit M. Latreille, me consulta au sujet d'une perte considérable qu'il éprouvait à raison d'une mortalité extraordinaire des brochets de ses étangs, et m'envoya l'animal parasite auquel il l'attribuait, et que je reconnus pour être l'Argule foliacé, Crustacé de I'ordre des Siphonostomes; ajoutons que dans cet ordre le nombre de pattes, ne va jamais au-delà de quatorze, et que le test n'est jamais composé que d'une seule pièce, formant en devant une sorte de bouclier. Tous les Siphonostomes connus sont généra. lement de très-petite taille.

Cet ordre a été partagé en deux familles : les Caligites et les Lernaiformes.

PREMiere FAMILLE.

C ALIGIT E S,

LATRERLLE.

Caractères. Plusieurs de leurs pieds, ou les postérieurs au moins, sont propres à la natation, soit sous la forme de nageoires plus ou moins multifides, soit sous celle de larges membranes recouvrant le dessous de l'abdomen, ou l'enveloppant même en manière de fourreau ; cette partie postérieure du corps est privée d'un test clypéiforme ou semi-lunaire.

Cette famille renferme deux tribus : les Pinnodactyles et les Hymenopodes.

\section{PREMIÉRE TRIBU.}

\section{P I N O DA C T YLES, Latreille.}

Pieds postérieurs au moins terminés par des pinnules ou des digitations plus ou moins nombreuses, servant de rames ou de nageoires.

Genres: Argulus, Dolops, Caligus, Pan. darus, Nogats.

\author{
aRgULUS, Mulz., Latr., Leach, Jür. \\ Desm.; \\ Monocolus, Lrnn.; \\ Binoculus, Geoff, , Latr., Bosc.; \\ Ozolus, Latr.
}

Le test est presque membraneux, semitransparent, déprimé, généralement ovalaire, un peu émarginé de chaque côté antérieurement, couvrant le corps très-ample. ment, et n'y adhérant qu'en partie; de plus il est marqué de deux lignes enfoncées qui partent de ses bords antérieurs, et convergent vers son milieu. - La tête est assez séparée du corps par un cou. - Les yeux, au nombre de deux, apparaissent tant en dessus qu'en dessous, et sont placés en avant, dans l'intervalle qui existe entre les deux lignes enfoncées du test; ils sont distans entre eux, hémisphériques, et ont leur surface composée de petites facettes ovales et lisses, disposées par zônes concentriques au nombre de cinq ou six, dont 
les plus petites regardent le bord interne les yeux. - Les antennes, au nombre de quatre, sont petites, insérées sur la face inférieure de l'animal, un peu au-dessus des yeux, cylindriques et un peu velues; les supérieures ou les plus courtes, sont formées de trois articles, pourvues à leur base d'un crochet assez gros, terminé par une pointe forte et recourbée, qui a vers son origine une petite épine; les inférieures, plus longues, sont formées de quatre articles dont le premier est pouvu d'une petite dent. - Le test est placé sur la ligne moyenne et assez en arrière des yeux, entre les pieds de la seconde paire, et dirigé en avant, de forme conique allongée, renfermant un sucoir très-aigu et protractile. - Les pattes, au nombre de douze, sont de formes différentes; celles de la paire antérieure sont plus longues que les autres, terminées par une ventouse ou large disque circulaire, dont le bord a des stries convergentes et est dentelé; celles de la seconde paire ont une première pièce (ou cuisse) grosse, épineuse ; une deuxième (ou jambe) assez forte et presque cylindrique; un tarse formè de trois articles, et terminé par deux crochets et un petit corps saillant; celles des quatre dernières paires sont presque cylindriques, sans articulations bien distinctes, insérées sur les côtés de l'abdomen, terminées par deux doigts allongés, ciliés sur leurs deux bords, antérieur et postérieur; les deux premières de celles-ci sont pourvues d'un troisième doigt également cilié, mais récurrent, et non dans la direction des autres. - L'abdomen est cylindrique; pourvu antérieurement de deux petits crochets cornés un peu en arrière de la base de la trompe. - La queue est formée par une lame horizontale terminée par deux lobes arrondis au bout, et insérée dans une échancrure postérieure de la grande pièce qui forme le test.-Le cœur est apparent à travers le corps; il estformé d'un seul ventricule, et logé dans un tubercule solide, demi-transparent, presque cylindrique, dirigé en arrière, et placé derrière la base de la trompe, chassant le sang, qui est composé de globules diaphanes, vers l'avant du test, dans une seule colonne qui se ramifie, parcourt le corps dans diverses directions, et revient par une colonne unique de la partie postéricure du corps au cœur.-Les vaisseaux ne sont pas bien distincts. - Les organes de la respiration paraissent exister dans les cils des huit pattes postérieures. - Le canal alimentaire s'étend depuis la base de la trompe jusqu'a la bifurcation de la queue, où se trouve la partie anale; il est formé d'un æsophage très-court, d'un ec. tomac ovale, donnant naissance, dans sa partie antérieure, à deux grands appendices rameux, qui se portent dans les deux ailes du test, s'y subdivisent en deux branches inégales et flexueuses, qui se subdivisent elles-mêmes en une multitude de ramifications dans lesquelles pénètrent les matières alimentaires, qui les rendent apparentes, et de couleur bistrée; d'un pylore très-gros, long et musculeux; d'un cœcum pourvu de deux appendices vermiformes près de son origine; d'un rectum qui descend en se rétrécissant jusqu'à la partie anale. - Le cerveau paraît placé derrière les yeux, dans la ligne médiane du corps; il est composé de trois lobes égaux, un antérieur et deux latéraux d'un rouge rubis; lorsqu'on les observe sous certains aspects, les organes de la génération du inâle semblent résider dans deux vésicules placées chacune vers la face postérieure du premier article des pattes de l'avant-dernière paire; le même sexe présente à l'extrémité antérieure du premier article des pattes de la dernière paire, un crochet qui sert à retenir la femelle dans l'accouplement; les organes de la femelle consistent en un sac ou une matrice situé dans l'abdomen, au-dessus du canal alimentaire, et s'étend depuis l'origine de l'estomac jusqu'à la base de la queue, où il se termine par un oviducte très-court, dont l'orifice se trouve placé entre les deux dernières pattes, et est commun avec la partie anale.

On ne connoit encore qu'une seule espèce de ce genre, qui s'attache sous le corps des Epinoches ou Gastérotes, et des Tétards de Batraciens au moyen de ses ventouses, et qui suce le sang de ces animaux.

ARgulds Folaceus. ( $\mathrm{Pl}$. 20, fig. 9.)

Jur., Ann. du Mus., t. VII, p. 431, pl. 26. - Desu., Consid. génér. sur les Crust., p. 529, pl. 50, fig. 1. - Pou du Gastérote, Baкеr, Hicr., t. II, chap. 25, pl. 14. - Ozolus Gasterotii, Latr., Hist. nat. des Crust. et des Ins., t. IV, pl. 29. -Binoculus Gasterotii, IuATr., Gen. Crust. et Ins., t. 1, p. 14. - Long. 2 lig. $\frac{1}{2}$, - Le corps, déprimé et ovale dans ses contours, est d'un vert-jaunâtre clair, demi-transparent; la femelle, qui est toujours plus grande que le mâle, est caractérisée par deux points 
noirs sítués à la baso de sa queue, avant sa division en deux lobes.

Les Arrules se trouvent assez communément aux environs de Paris, dans les eaux stagnantes, ils attaquent avec beau. coup de violence les tétards de Grenouilles et de Crapauds, et causent souvent leur mort; ils s'attachent également aux Gastérotes ou Savetiers, petits poissons des eaux stagnantes, et inểme sur les parties molles des carpes, des tanches, etc., en appliquant leurs ventouses, et en enfoncant leur bec pointu dans les chairs de ces animaux, pour en sucer le sang; on les trouve aussi trèsfréqucmment libres et nageant avec beaucoup de vitesse au milieu des herbes aquatiques, telles que les lentilles d'eau, les charagnes, les ménianthes, etc. Les mâles sont très-ardens en amour, et très-souvent il leur arrive de prendre un sexe pour l'autre, ou de rechercher des feinclles pleines ou mortes. Dans l'accouplement, qui dure quelquefois plusieurs heures, le mâle se place sur le dos de la femelle, et s'y tient fixé au moyen de ses ventouses; la durée de la gestation est de treize à dix-neuf jours, après lesquels les femelles fixent leurs œufs (qui sont unis ou d'une forme ovale, sur un double rang, et souvent en ligne droite) sur les pierres ou autres corps durs, au moyen $d^{\prime} u n$ gluten. Ces $\propto u f s$, au nombre d'un à quatre cents, sont d'un blanc de lait, et sourent placés si près les uns des autres, qu'ils en recoivent une pression qui leur donne en quelque sorte la forme hexagonale; ils éclosent vers le trente-cinquième jour, et le petit qui en sort, lorsqu'il est développé, n'a pas plus de trois huitièmes de ligne de longueur. Sa forme est ovale, allongée; son test a peu de largeur, et sa queue est fort grosse; de chaque côté de la partie antérieure de son cnveloppe sortent deux longues rames, l'une placée devant, et l'autre derrière l'oil, et toutes deux terminées par deux fllets longs, égaux, pennés et flexibles (les rames antérieures en ont quatre, et les postérieures trois) ; les deux pattes antérieures, qui viennent après ces rames; sont fortes, coudées vers leur extrémité, et terminées par un crochet; les autres pattes, au nombre de dix, et surtout celles qui lui servent à nager, sont petites et peu saillantes. Deux jours après, ce petit change de peau, alors les rames disparaissent, et les pattes postérieures, qui servent à nager, apparaisseut, mais elles ne sont complètes que plus tard; il s'opère une autre mue au bout de trois jours, ce qui donne seulement plus de développement aux parties de l'animal. Deux autres jours suffisent pour amener une nouvelle peau, et arec elle des crochets, les crochets de la seconde paire de pattes et les rudimens des ventouses sur la base des pattes de la première paire. Après un intervalle semblable, l'animal se débarrasse de sa quatrième peau, et la paire de pattes antérieures est tout-à fait transformée en ventouses. Les organes de la génération ne sont apparens qu'après la cinquième mue. Les larves se dépouillent pour la sixième fois six jours après, et paraissent alors sous la forme de 17 dulte, sans pour cela qu'elles aient alteint toute leur grosseur, qui augmente du double après plusieurs autres mues qui on lieu régulièrement tous les six ou sept jours. Lorsque les mâles se sont accouplés, ils perdent la faculté génératrice jusqu'après la mue suivante, quỉ leur fournit de nouvelles vésicules séminales, en place de celles dont ils avaient fait usage, et qui s'étaient rompues pour l'épanchement du liquide qu'elles contenaient.

M. V. Audouin désigne sous le nom de Dolops un nouveaū genre de Crustacés qui vient se placer naturellement après celui d'Argulus. - L'espèce type de ce genre est le :

\section{DOLOPS LACORDAIRI.}

Aud., Ann. de la Soc. Entom. de France, t. VI, Butl., p. 13. - Ce Crustacé, qui a été trouvé à Cayenne par M. Lacordaire, est long d'un centimètre et demi; il vit parasite sur un poisson nommé Aymora, dont la chair est très-estimẻe, et qui se trouve dans toutes les rivieres; $\mathbf{M}$. $\mathbf{V}$. Audouin doit en donner une description détaillée et une figure.

\section{Galigus, Mull., Leach, Latr., Desm。}

Le corps est déprimé, avec sa partie antérieure recouverte d'un test membraneux en forme de bouclier, rétréci postérieurement. - L'abdomen est étroit, de forme ovale-allongée, ou presque carrée, et terminé par deux soies (tubes ovifères) allongées, cylindriques et simples. - Les antennes sont petites, coniques, au nombre de deux, situées sur le bord antérieur du test, et dirigées latéralement. - Les yeux, au nombre de deux, sont distans et situés a la base interne des antennes. - On apercoit un bec obtus placé en dessous iu test, 
å peu près au quart antérieur de sa longueur.

\section{1. caligus piscinus.}

Desir., Consid. génér. sur les Crustacés, p. 340. - Caligus Curtus, Mul., p. $180, n^{\circ} 65$, tab. 21, fig. 1., 2. - Monoculus Piscinus, Linn., Syst. Nat. - Long. 4 lig. $\frac{1}{2}$. - Le test est marqué de lignes enfoncées qui figurent la lettre $H$; les pieds de la première paire sont courts, simples, terminés par un seul article pointu et arqué, situés aux côtés du bec; ceux de la seconde paire sont grêles et ont leur partie terminale ou tarse formée de quatre articles minces, cylindriques, dont le dernier supporte deux ongles arqués, inégaux; ceux de la troisième paire sont de moitié plus courts, plus robustes et terminés par un tarse a deux articles, dont le dernier supporte deux ongles inégaux, arqués en dedans; les pieds de la quatrième paire sont à peu près de la force des précédens, et ont leur jambe courte et grosse; le tarse est formé de deux articles, dont le premier plus groset plus long que le second, qui est un peu arqué en dedans, terminé par deux points ou rudimens d'ongle, et muni sur sa face interne de trois filets plumeux, parallèles entre eux et récurrens; les pieds de la cinquième paire ont un article basilaire (ou cuisse) très-court, munien dedans d'un filet cilie; un second article (ou jambe), deux fois aussi long que large, et un peu comprimé, supporte un tarse bifide, formé de deux branches, chacune à trois articles, terminés par des filets plumeux ou ciliess, parallèles entre eux et dirigés en dedans; les pieds de la sixième paire sont membraneux, aplatis, situés sur la branche qui termine le test postérieurement et inférieurement, consistant en une seule pièce ovalaire, garnie sur son bord terminal et en dedans de cinq soies plumeuses et parallèles entre elles; les pieds de la sixième paire sont assez longs, insérés à la base du premier anneau de l'abdomen et en dessous, derrière le test, formés d'une jambe assez forte et un peu renflée dans son milieu, d'un tarse à peu près aussi long, et composés de deux pièces assemblées obliquement; de façon que l'inférieure se termine en pointe en dessous, et que la supérieure ou la terminale supporte à son extrémité trois soies roides, dont la plus grande est ciliée; en dessous, on apercoit deux petits crochets sur le milieu de la poitrine entre la base despattes de la troisieme paire et celle des pattes de la quatrième paire; la portion supérieure du test comprise entre les deux jambages postérieurs de la figure d'H, est de forme hexagonale, avec une forte échancrure sur chacun deses côtẻs latéro-postérieurs. L'abdomen propre. ment dit est plus long que large, et plus large en arrière qu'en avant, légérement bombé en dessus, et donne attache postérieurement aux deux filets, qui sont cylindriques et divisés fort ègalement par une multitude de petites lignes transverses; la queue, insérée entre les deux filetsà l'extrémité postérieure de l'abdomen, est formée d'une petite pièce étroite à sa base, renflée dans son milieu, bifurquée à son extrémité; chacune de ces bifurcations est terminée par trois soies; la couleur est d'un blanc jaunâtre, avec quelques points ou caractères d'un jaune obscur sur le test.

Cette espèce vit aux dépens des morues, des merlans, des saumons, etc. Lorsqu'on la détache, ou lorsqu'elle veut changer de place, elle court rapidement sur ces poissons. On la voit aussi quelquefois nager seule dans la mer avec assez de vilesse.

Caligus mullen. (Pl. 20, fig. 7.)

Leach, Encycl. Brit. Suppl., 1, p. 405, pl. 20 ; ejusd., Dict. des $S$ c. nat., t. XIV, p. 536. - Desm., Consid. génér. sur les Crust., p. 342, pl. 50, fig. 4. - Cette es. pèce difière de la précédente en ce qu'elle n'a pas d'appendice bifurqué en forme de queue à la suite de son abdomen. Sa couleur est pâle et sans taches. - Se trouve sur la morue.

PANDARUS, Leach, Desh.; Caligus, Latr., LaMr.

Chez ce genre, le corps est ovalaire, souvent très-allongé, et terminé par deux soies allongées et cylindriques, - Le test est elliptique en avant, et tronqué transversalement en arrière. - Le corps est recouvert de trois écailles à recouvrement, transversales, dentelées ou échancrées sur leur bord postérieur. - L'abdomen est en anneaus formés de lames. - La queue est ovalaire, et donne attache à deux longues soies.

\section{1. pardarus bosciI.}

T. Leach, Encycl. Brit. Suppl., 1, pl. 20, fig. 1 ; ejusd., Dict. des $S$ c. nat., t. XIV, p. 533. - DesM., Consid. génér. sur les Crust., p. 339. - Cette espece est allon- 
gée; sa couleur est d'un jaune pâle et livide; les soies de la queue sont une fois et demie aussi longues que le corps. Habite les mers d'Angleterre, et se fixe sur l'Emissole commun.

\section{PANDARUS BICOLOR.}

Leacr, Encycl. Brit. Suppl., 1, pl. 20 ; ejusd., Dict. des $S$ c. nat., t. XIV, p. 535. - Desu., Consid. génér. sur les Crust., p. 339 , pl. 50, fig. 5. - De forme allongée; la couleur est pâle livide; le test et le milieu des lames sont noirs; les soies de la queue sont deux fois aussi longues que le corps, - S'attache au Squale Milandre de nos mers.

\section{PANDARUS GARCTARTE.}

Leach, Dictionn. des Sc. nat., t. XIV, p. 535. - Desu., Consid. génér. sur les Crust., p. 339. - Ovale, noir; les angles postérieurs du test et les soies de la queue sont d'un jaune pâle et livide; ces dernières sont un peu plus longues que le corps. - Cette espèce vit sur le Requin.

\section{4. pandarus cranchir.}

LEACH, Dictionn. des $S$ c. nat., t. XIV, p. 535. - DesM., Consid. génér. sur les Crust., p. 339. - Ovale, noir; les angles antérieurs du test, son pourtour, et les deux espaces du dessus de sa partic antérieure, sont pâles, ainsi que les bords des lames de l'abdomen.

\section{NogaUs, Leacn, Desur.}

Deux courtes soies ou tubes ovifères à la queue, portant plusieurs styles à leur extrémité. - Les trois premières pièces de l'abdomen ayant les côtés arrondis, tandis que le quatrième et le cinquième les ont terminés en pointe. - Le test est en forme de fer à cheval.

\section{NOGAUS LATREILLET.}

Leach, Dictionn. des Sc. nat., t. XIV, p. 536. - Desn., Consid. génér. sur les Crust., p. 340. - Couleur pâle sans tache. - Se trouve dans les mers d'Afrique.

\section{DEUXIÈME TRIBU.}

\section{H Y MÉ N O PODES, Litr.}

Caractères. Les pattes abdominales, ou les quatre à six postérieures au moins, sont en forme de lames membraneuses, recouvrant le dessous de l'abdomen, et quelquefois même l'enveloppant aussi en dessus. Tous ont un siphon.

Genres: Dinemoura, Anthosoma et Cecrops.

\section{DINEMOURA, LATR.}

Les pattes membraneuses, simplement appliquées sur le dessous de l'abdomen, sont libres. - Le test ne présente pas en devant deux petites serres avancées et mo. nodactyles.

\section{DINEMOURA PRODUCTA.}

Latr., Cours d'Ent., $1^{\text {re }}$ année, p. 463. - Caligus Productus, Muluer. - Monoculus Salmoneus, Fabr. - Les pattes sont au nombre de douze?; les quatre ou six de devant sont terminées par des crochets, ou sont onguiculées; l'extrémité de l'abdomen est garnie de deux soies (ou tubes ovifères) allongées et cylindriques.

\section{ANThosoma, Leach, Desm.; Caligus, Latr., Lam., Rişo.}

Le test est arrondi en avant et en arrière. - Les antennes sont formées de six articles. - L'abdomen, beaucoup plus étroit que le test, est muni de deux lames foliacées sur le dos, et de six autres sous le ventre; celles-ci tiennent lieu des trois dernières paires de pattes: - Les pattes de la paire antérieure sont étendues en avant; leur ongle est crochu, et rencontre une petite dent, qui est située vers le sommet de l'article qui précède. L'ongle des pattes de la seconde paire est comprimé. Le derniex article de la troisième paire est trèsépais, denté antérieurement, et terminé par un ongle très-fort. - Le bec est inséré derrière les pattes de devant, et muni à son extrémité de deux appendices droits et cornés.

\section{ANTHOSOMA SMITHI.}

Leacr, Dictionn. des Sc. nat., t. XIV, p. 533 ; ejusd., Encycl. Brit., Suppl., 1, p. 406, tab. 20. - Desu., Consid. génér. sur les Crust., p. 335, pl. 50, fig. 3. Risso, Crust. des environs de Nice, p. 362. - Le corps est coriace, glabre, d'un vertjaunâtre; le test forme un ècusson allongé, conique, tronqué en avant, large et arrondi en arrière, finement dentelé sur son contour, et marqué sur son milieu 
d'une ligne brune; ses antennes sont formées de deux articles; ses deux pattes antérieures sont courtes, et les deux postérieures larges et aplaties; toutes sont terminées par deux ongles crochus; l'abdomen est étroit, composé de quatre segmens presque arrondis, garnis de chaque côté par trois lames foliacées; le dernier est terminé par deux courts filets aplatis. - Se trouve sur le Squale féroce.

\section{CEGROPS, Leach, Latr. , Desm.}

Le corps est ovalaire, déprimé, sans appendices postérieurs en forme de filets cylindriques. - Le test est coriace, séparé en deux; la portion antérieure est en forme de cœur renversé, profondément et largement échancré en arrière ; la postérieure est composée de trois autres pièces à recouvrement l'une sur l'autre, dont l'antérieure est la plus petite, l'intermédiaire moyenne, et la postérieure la plus grande; toutes sont échancrées postérieurement dans leur milieu. - Les antennes, composées de deux articles, sont terminées par un seul poil.-
L'abdomen est aussi large que le test. Les pattes de la paire antérieure sont biarticulées, et armées d'un ongle fort et recourbé; trois articles à la seconde paire, plus minces, et dont le dernier est bifide; la troisième paire est plus forte, et n'a qu'un seul article et un ongle très-fort; les quatrième et cinquième paires sont bifides; la hanche et la cuisse des sixième et septiéme paires sont très-dilatées, lamelliformes, et réunies par paires. - Le bec est insérẻ derrière les pattes antérieures, et présente de chaque côté de sa base un appendice ovale.

La femelle est munie de deux grandes pièces ovales contiguës, d'une substance coriacée, placées sous l'abdomen, qu'elles surpassent en longueur, et qui recouvrent ses œufs.

Cecrops latreillit. (Pl. 20, fig. 4.)

Leacir, Encycl. Brit. Suppl., 1, pl. 20, fig. 1, 3, mâle; 2, 4, femelle. - Desм., Consid. génér. sur les Crust., p. 338, pl. 50, fig. 2. - Cette espèce, qui est de couleur blanchâtre, vit sur le Thon et le Turbot.

\section{DEUXIÈME FAMILLE.}

\section{E R N OE I F O R M E S,}

\section{ATREILLE.}

C'est un groupe très-singulier d'animaux que Linné a désigné sous le nom générique de Lernœa, et qu'il crut devoir rapporter au type des Mollusques, parce que leur forme bizarre ne lui avoit pas permis de reconnoître leur véritable place. Cuvier a d'abord, à l'exemple de Linné, placé ces animaux parmi les Mollusques; mais plus tard il les a rapprochés des Entozoaires, et il les a confondus avec eux et les Planaires, bien que ceux-ci soient des vers extérieurs, dans la classe à laquelle il laisse le nom de vers intestinaux. Les Lernées sont en effet parasites; mais elles ne se fixent jamais dans la cavité intestinale des autres animaux, non plus que dans aucun de leurs organes; elles se tiennent au contraire attachées à leur surface extérieure; aussi Lamarck, qui n'a pas saisi les véritables rapports que les Lernées ont avec les Crustacés, a.t-il cru pouvoir en faire une classe à part, celle des Epizoaires; ce nom ex. primant l'habitude qu'elles ont de vivre sur les animaux. C'est à M. de Blainville que la science est redevable de la position véritable que ces animaux doivent occuper dans la série zoologique. Ce célèbre naturaliste a publié, en $\mathbf{1 8 2 2}$, dans le Journal de Physique, et en 1823, dans le Dictionnaire des $S$ ciences naturelles, un exccllent travail sur ces animaux, et il y a démontré qu'ils devoient être placés parmi les Crus. tacés, à côté des Caliges et des Argules. En 181.6, dans son prodrome d'une classification du règne animal, inséré dans le Bulletin de la Société Philomathique, M. de Blainville étoit arrivé à cette conclusion :

Les Lernées sont aquatiques, vivent aux dépens des autres animaux, des poissons principalement, et s'accrochent à diverses parties de leur surface postérieure; le tour des yeux et des branchies étant les endroits où elles trouvent une nourriture plus fa. cile, sont aussi ceux qu'elles affectionnent 
davantage, Pendant long-temps on n'a connu des Lernées que leur état parasitaire ; aussi leur véritable nature n'a-t-elle été constatée qu'avec peine. En effet, tels qu'on les observe le plus souvent, ces animaux sont complètement défigurés par l'ahondance des sucs nutritifs dont ils sont gorgés : ils ont perdu toute leur régularité. Les tissus adipeux qui se sont développés dans leur intérieur ont distendu leur peau, trop peu résistante pour conserver sa véritable forme; aussi les Lernées, bien qu'adultes et capables de se reproduire, ne sauroient néanmoins fournir, à cette époque, une idée exacte de leur espèce; clles sont profondément modifiées, comme cela se voit chez la plus plupart des parasites, parmi lesquels nous citerons seulement les larves d'Hydrachnes, les Ixodes et les Sarcoptes, chez les animaux articulés; les $\mathrm{Ni}$ cothoés, les Caliges, les Argules et les $\mathrm{B}_{0}$ pyres, parmi les Crustacés. Tous ces animaux sont parfaitement réguliers lorsqu'ils sortent de l'œuf, et ils présentent avec toute leur netteté les caractères des autres es. pèces de leur famille; mais dès qu'ils se sont fixés, ils commencent à se déformer, de telle sorte qu'ils peuvent arriver à tous les degrés possibles de la bizarrerie. C'est donc avant qu'ils aient commené à se fixer, ou peu de temps après qu'ils le sont, que ces parasites doivent être étudiés; mais c'est ce qu'il n'a pas toujours été possible de faire.

M. de Blainville, dont le travail sert de base à tout ce que l'on a écrit sur les Lernées, s'exprime ainsi (Dict. des $S$ c nat., t. XXVI, p. 113) au sujet de ces singuliers Crustacés : « Nous savons encore assez peu de chose sur l'organisation des Lernées. Leur enveloppe extérieure, ordinairement d'un blanc-jaunâtre transparent, est aussi quelquefois d'un brun-rougeâtre foncé. Elle est le plus souvent molle et flexible, en dessous surtout; mais il arrive aussi quelquefois qu'elle est dure, comme cartilagineuse, dans les différens points de son étendue, et surtout ả la partie supérieure de la première division du corps. Le corps des Lernées, constamment bien symétrique, mais du reste de forme assez variable, quelquefois très-allongé, d'autres fois large, ovale, aplati, est souvent divisé dans sa longueur par un étranglement plus ou moins profond, en deux parties. L'une, antérieure, plus petite, plus étroite, qui réunit la tête et le thorax, est quelquefois un peu subdivisée, de manière que la tête est aussi un peu distincte : c'est cette partle qui offre les premières traces de véritables appendices dans les crochets dont la bouche paroît armée, et même dans des rudimens d'antennes. L'autre partie du corps est l'abdomen ; presque toujours plus large que la première, sa forme varie également beaucoup : c'est celle dont la peau est la moins dure, la moins cornée; elle offre assez souvent des prolongemens appendiculaires, paires, placés de chaque côté, mais inarticulés ou immobiles, et quelquefois de sim. ples incisures. Quelques espèces m'ont offert des traces d'yeux sessiles ou des stemmates; plus souvent on trouve des indices d'antennes, même quelquefois subarticulés. Quant aux appendices, dans toutes les espèces que j’ai pu examiner avec soin, j’ai trouvé que la bouche étoit constamment pourvue d'une paire de crochets mobiles convergens, quelquefois de deux, et même d'une sorte de lèvre inférieure. Quant aux appendices vérițables, qui se joignent au thorax, ils sont généralement peu nombreux. Dans les espèces que leur grandeur m'a permis de distinguer, j’ai trouvé que la couche musculaire qui double l'enveloppe extérieure, le plus ordinairement fort simple et composée de fibres longitudinales soyeuses, se subdivise en portions latérales pour les subappendices et les appendices. Le canal intestinal est complet, c'est-à-dire étendu de la bouche à l'anus; il paroît même qu'il fait des replis ou des circonvolutions. La bouche, médiocre, située ordinairement à la partie inférieure du céphàlo thorax, est au milieu d'un espace dont la peau est molle; elle est constamment accompagnée, à droite et à gauche, d'un crochet court, aigu et corné; mais on ne le voit souvent qu'à l'aide d'une forte loupe. Le canal intestinal se termine en arrière dans un tubercule ou mamelon plus ou moins saillant ou médian. Je n'ai jamais pu désigner le système circulatoire ; mais il est certain qu'il existe, ou du moins les auteurs qui onl observé ces animaux vivans en parlent. d'une manière certaine. On ne peut cependant dire qu'il y ait d'autres organes de la respiration que les subappendices de la peau. Les organes de la gênération ne me sont peut-être pas connus complètement. On sait seulement que, dans toutes les espèces de ce groupe, il existe de chaque côté du tubercule anal une sorte de sac, de forme un peu variable, et qui est rempli par une infinité de corpuscules quelquefois ronds, d'autres fois 
subanguleux et même discoỉdes, qui sont indubitablement des œufs, comme nous l'apprend une obsenvation du docteur Surrinay du Hâvre: d'après cette observation, ces animaux naissent sous une forme qu'ils perdent par la suite en avançant en âge; et cette forme est beaucoup plus parfaite, moins anomale, que celle qu'ils acquièrent, en sorte que c'est une métamorphose en sens inverse de ce qui a lieu ordinairement. Nous ignorons, du reste, s'il existe des sexes distincts dans ces animaux. La place que nous croyons devoir leur assigner dans la série porte à le croire, tandis que leur adhérence parasite conduit à une opinion contraire. On trouve quelquefois des individus qui ne sont pas pourvus de sacs oviferes. Cela tiendrail-il à ce que ce sont des individus mâles, ou à ce que ces organes sont tombés par accident? C'est ce je n'oserais affirmer. Je ne puis non plus rien dire sur le système nerveux des Lernées; mais il paroît qu'il doit exister, puisqu'il y a des muscles distincts, et sa place ne peut être ailleurs qu'à la partie inférieure du corps.

Depuis la publication du travail de M. de Blainville, plusieurs naturalistes, el parmi eux M. Nordmann principalement, se sont occupés des Lernées. Le travail de M. Nordmann, publié en 1832 , renferme une foule d'observations intéressantes, et est accompagné de figures exacies. M. Lesueur a aussi publié la description de quelques espèces de Lernées; et tout récemment MM. Kollard et Burmeister ont fait connoître le résultat de leurs recherches sur plusieurs espèces de Lernées. MM. Nordmann, Kollard, beaucoup d'autres naturalistes, parmi lesquels nous citerons MM. Desmarets, Audouin et Milne Edwards, ont adopté l'opinion que les Lernées doivent être placées parmi les Crustacés.

Cette famille renferme maintenant les genres suivans : Nicothoe, Dichclesthium; Nemesis, Lerneocera, Lerneopenna, Lernaa, Lerneomyzon, Lementoma, Lernacantha, Lernopoda el Lerneanthropus.

\section{NICOTHOE, Aud, et Edw.}

Deux yeux, deux antennes, une bouche pourvue de mâchoires ; cinq paires de pattes : la première en crochet, les quatre au. tres en rames; un test formé de segmens transversaux ; l'abdomen droit, terminé par deux filets, et supportant (dans les femelles adultes) deux sacs oviféres' deux prolon- gemens sterniformes, en arrière et sur les côtés des anneaux visibles du thorax (ces prolongemens existant dans les individus que l'on trouve fixés ).

\section{NICOThOE ASTACI.}

Aud. et Edv., Mém, pour servir à l'His-

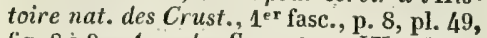
fig. 8 à 9 ; Ann. des $S_{\text {c. nat., t. IX, pl. } 49 .}$ - Long. $\frac{x}{2}$ lig. Larg. 3 lig. - Cette espece est de couleur de rosée; les expansions antérieures ont une teinte jaunâtre, et les grappes ovifères sont d'un rose tendre; elles adhèrent très-intimement aux branchies du $\mathrm{Ho}_{0}$ mard, et s'enfoncent profondément entre les filamens de ses organes.

Tous les Homards n'en présentent pas, et on les trouve en petit nombre.

MM. Audouin et Edwards ont publié sur ce petit Grustacé des observations pleines d'intérêt. Voyez le mémoire cí-dessus cilé.

\section{Dichelesthium, Herm., Desm.}

Le corps est presque cylindrique, plus étroit postérieurement qu'antérieurement, formé de sept segmens, dont le premier, ou le test, beaucoup plus grand que les autres, est à peu près rhomboïdal, tronqué en avant et en arrière. - Les antennes sont filiformes, formées de sept articles, dont le dernier est le plus long, couchées obliquement en arrière sur les cólés du test. - Le bec, placé au milieu du dessous de ce test, entre les pattes de la seconde paire, est composé d'un suçoir cylindrique, membraneux, creux, arrondi à l'extrémité, et de six sortes de palpes, dont deux sont gros à la base, biarticulés et bifurqués dans leur dernier article; deux grêles, triarticulés, et aeux très-courts, triarticulés. - Les yeux sont non dislincts. - Les pieds sont au nombre de douze : six attachés sous le test, quatre sous le second article du corps, et deux sous le troisième; les premiers pieds dirigés en avant, insẻrés derrière le bord antérieur du test, formé de quatre articles, dont le premier est un peu plus long que large, couvert en partie par le test, à extrémité antérieure oblique; les deux sujvans très-courts, et le dernier, ou le terminal, de forme ovale, pourvu à son extrémité d'un pouce inférieur, court, rétréci à sa base, mutique au bout, et d'un doigt muni d'un onglet courbé en bas; pieds de la seconde paire composés d'une cuisse assez allongéc et mutique, d'une jambe uni. 
dentée en dehors, et terminés par différens crochets divisés en deux masses distinctes; pieds de la-troisiéme paire insérés comme les précédens sous le test, présentant un article fort renflé, ventru, ovale, terminé par un crochet aigu et mobile; pieds des quatrième et cinquième paires attachés au second article du corps, formés chacun d'une pièce aplatie, presque orbiculaire, terminèe par deux doigts ovales, dont l'extérieur est le plus grand et muni de plusieurs crochets; sixième paire formée de pieds simples, entiers, rétrécis vers la base, semblables à des pinnules ou palettes, de forme ovale, divergentes, immobiles, attachées sous les côtés du troisième article du corps. - L'abdomen est formé de six articles, dont le premier est court, transversalement lunulé, et prolongé de chaque côté en papille obtuse; le second aussi court, mais moins large; le troisième presque carré, divisé par un sillon transversal en deux parties; le quatrième semblable en tout au troisième, mais plus parfaitement carré; le cinquième aussi long que les deux précédens ensemble, cylindrique, plus gros au milieu, rétréci vers les deux extrémités, et moins large à la postérieure; le sixième presque orbiculaire, assez petit, trois fois plus long que le cinquième, rétréci, et terminé au bord postérieur par deux appendices ou vésicules ovales, qui n'ont que la moitié de sa longueur.

DichelesthiUM sturonis. (Pl. 20, fig. 8.) Нвин., Mém. Apt., p. 125, pl. 5, fig. 7, 8. - Desm., Consid. génér. sur les Crust., p. 337, pl. 50, fig. 6. - Long. 7 lig. Larg. 1 lig. - Couleur de chair, avec une ligne brune longitudinale de chaque côté du corps, commençant vers le milieu de la longueur du test, et traversant tous les segmens, dont le sixième est d'une teinte plus blanche que chez les autres; les premiers pieds, couleur de chair pâle, sont recourbés vers l'abdomen lorsque l'animal ne s'en sert que pour se fixer.

Hermann fils a trouvé une douzaine de Crustacés de cette espèce sur des Esturgeous pris dans le Rhin, à la hauteur de Strasbourg; ils étoient fortement attachés au moyen de leurs deux pieds, et avoient pénétré assez avant dans la peau qui recouvre les arcs osseux des ouies de ces poissons; lorsqu'ils étoient détachés, ils couroient avec beaucoub de vivacité.

\section{NIMESIS, Risso, Rovx, Làtà̀}

Rostre renflé, triarticulé, graduellè ment acuminé; à premier article plus court que le second; le troisième le plus petit, contractile. - Antennes extérieures sétacées, aiguës, presque de la longueur du thorax; composées de sept à huit articles, le premier le plus long et le plus gros; point d'antennes intermédiaires; point d'yeux. Corps allongé. - Corselet ovale, relevé en baut, un peu rétréci postérieurement. Abdomen à huit segmens : le dernier muni de deux appendices très-courts; le quatrième de deux longs filets cylindriques faiblement annelés; le dessous des premier, deuxième ct troisième segmens, portant chacun deux expansions charnues, renflées; terminées par deux prolongemens trifides, articulés à leur base, et utiles sans doute à la locomation; quatre paires de pieds dont deux, la première et la troisième paire, armées d'ongles très-longs; les deux autres, soit la deuxième et la quatrième paire, membraneux, coriaces, dépourvus d'ongles, paraissant propresà la préhension; deux sans orifices globuleux placés, de chaque côté, au bas du quatrième segment de l'abdomen.

Les espèces qui composent le genre $\mathrm{Ne}$ mesis établi par M. Risso vivent en parasites sur les branchies de deux de nos poissons cartilagineux, qu'ils doivent cruellement tourmenter; mais telle est la volonté de la nature, qui a trouvé le moyen, même aux dépens du plus fort, de fournir l'existence, à l'abri de tout danger, à des êtres dont la faiblesse devait nécessairement être protégée.

\section{NEUESIS LAMNA.}

Risso, Hist. de l'Europ. Mérid., t. $\mathbf{V}_{\text {}}$ p. 139, fig. 25. - Roux, Crust. de la Méditerr., pl. 20, fig. 1, 2.- Le corps est opaque; allongé; sa couleur est le jaune-brun. - Le corselet est oblong, un peu rétréci en arrière; la tête se confond avec lui, elle porte deux paires de pattes onguiculées et une seule membraneuse; l'autre, dans ce dernier cas, a son insertion sous le premier segment de l'abdomen; la première paire de pattes, onguiculée, est plus courte que la troisième, qui est armée d'un ongle fort long et brun; les quatre premiers anneaux de l'abdomen sont d'égale dimension, échancrés à leur origine; les suivans diminuent progressivement et brusquement; une bande brune, interrompue, s'étend le long du dos; les sous-orifices sont noirs et globuleux; les 
deux filets qui portent le quatrième segment de l'abdomen ont quatre à cinq fois la longueur du corps, qui n'est que de huit millimètres. C'est sur les branchies du Lamna Cornucibus que se rencontre la $\mathrm{Ne}$ mesis Lamna, elle vit en société au nombre de vingt-cinq à quarante avec des Anthosoma Smithii et diverses espèces d'épizoaires.

\section{NEMESIS CARCHARIARUM.}

Roux, Crust. de la Méditerranée, pl. 20, fig. 10. - Diffère de la précédente en ce qu'clle est constamment plus petite, en ce que les soies vers l'extrémité de l'abdomén sont moins longues, en ce que la couleur est pâle et les ongles blancs; les expansions ventrales sont d'une forme carrée et non triangulaire; enfin le quatrieme article de l'abdomen, qui est brusquement rétréci, donne à son corps un aspect qui ne peut permettre de confondre la Nemesis Carchariarum avec l'espèce précédente. Cette espèce vit sur les branchies du Carcharias $V$ ulpes, Cuv.

Les genres que $\mathbf{M}$. de Blainville admet dans son travail sur les Lernées sont les suivans:

\section{LERNEOCERA, BuAINV.}

Corps plus ou moins allongé, renflé dans son milieu, droit ou contourné, couvert d'une peau lisse et presque cornée antérieurement; terminé en avant à la suite d'un long cou par un renflement céphalique bien distinct, armé de trois cornes immobiles; branchies à l'extrémité. - Bouche inferieure en suçoir. - Trois petits yeux lisses à la partie antérieure de la tête. - Aucune trace d'appendice au corps.

\section{LERNEOCERA BRANCHIALIS.}

Buaivv, Dict, des Sc.nat, tom. XXVI. - Desm., Considér. générales sur les Crust., p. 346. - Elle est de la gosseur d'une plume d'oie; son corps est courbé de manière que le ventre est inférieur; les sacs ovigères naissent bien en avant de l'extrémité postérieure et sont très-entortillés; sa couleur d'un blanc sale est quelquefois nuancée d'un brun-rougeâtre, à cause du sang dont est rempli son estomac.

Elle vit sur les branchies de plusieurs espèces de Morues, Gadus Barbatus et Elifinus, et s'y fixe à l'aide des cornes de sa tête. On assure que les Groënlandais, qui les prennent souvent sur les animaux littoraux, les recueillent pour s'en nourrir.

\section{IERNEOCERA CYCLOPTERIKA.}

Blainy,, Dict. des $S c$. nat.. to XXVI. - Desm., Consider. générales sur les Crust., p. 346. - Cette espèce ne diffère de la précédente qu'en ce que son cou est filiforme et se recourbe en haut, et qu'à l'extrémité du museau, en dessus, il y a deux orifices tubuleux, courts et opposés; la queue est aussi plus grêle, son extrémité n'est pas courbée; l'anus est transversal, et de chaque côté il y a deux lobes convexes.

Du Groënland, où elle vit sur les branchies du Cycloptere épineux.

\section{LERNEOCERA SURRIRENSIS.}

Brainv., Dict. des Sc. nat., t. XXVI. - Desar., Consider. générales sur les Crust., p. 346. - Le corps est droit, sub. cylindrique, pointu en arrière et surtout en avant, où il se joint par une sorte de cou distinct, avec un rétrécissement postérieur du renflement céphalique; celui-ci est armé de trois cornes simples; la bouche inférieure est pourvue de trois espèces de dents disposées en triangle, et au milieu d'une sorte de bourrelet labial; les ovaires sont cylindriques et tout-à-fait droits, naissant à peu de distance de l'extrémité postérieure; des œufs de cette espèce sortent des petits animaux semblables à des Monocles, pourvus de dix pattes larges et marqués de trois taches obscures sur le dos.

\section{LeRNeOcera GYPRINAGEA.}

Linn., Faun. Suec., tab. 11, fig. 1. Buarnv., Dictionn. des Scienc. natur., t. XXVI. - Desir., Considérations générales sur les Crustacés, p. 346. - Le corps est subcylindrique, droit, pellucide, divisé par un étranglement, en un abdomen claviforme, avec trois tubercules dont un est plus grand, et en un céphalothorax cylindrique dont l'extrèmité est pourvue de trois espèces de cornes molles, chacune en forme de croissant. - Trouvée en Suède sur le Cyprinus Carassus.

\section{LERNEOPENNA, BLAINV.}

Ce genre avoit été indiqué par Lamartinière sous le nom de Pennatula, employé pour des animaux d'un autre type; Oken l'a contracté en Pennella, et pour plus de symétrie M. de Blainville l'a remplacé par le nom de Lerneopenna. Ce genre est ainsi caractérisẻ : Corps allongé, cylindrique, subcartilagiueux, terminé antérieurement par un renflement céphalique, circulaire, 
uronqué, garni dans sa circonférence d'un grand nombre de mamelons, au milieu desquels est probablement la bouche, et pourvu d'une paire de cornes courtes, obliques en arrière; postérieurement appointé, et ayant de chaque côté des filets coniques creux, bien rangés, et imitant les barbes d'une plume, à la partie antérieure et supérieure de la série desquels sont deux filamens très-fins et très-allongés, servant probablement d'ovaires.

\section{LERNEOPENNA BOCCONICA.}

Blainv.; Dict. des Scienc. nat., t. XXVI. - Desar., Considérations générales sur les Crust., p. 346. - Hirudo, Boccone, Obs. Nat., p. 286, et Trans. Philos. - Pennatula, Lamart., Voyage de Lapeyr., t. IV, pl. 20 ; Encycl., pl. 78, fig. 5. - Cnsmisso el Eysenhandt, Nov. Ait. Cur. Nat., t. X, pl. 24, fig. 3. - Les tentacules ou mamelons de la bouche sont courts, selon Lamartinière, ou n'existent pas, selon MM. Chamisso et Eysenhardt.

L'individu recueilli par Lamartinière était enfoncé de plus d'un pouce dans le corps d'un Diodor.

\section{LERTEOPEYNA HOLTENI.}

Buarvy. Dict. des Sc. nat., t. XXVI. - Desu. , Considér. générales sur les Crust., p. 347. - Lernca Exoceti, HoLTEx, Act.Dan. Halm., 1802.-Point de tentacules à la tête, dont les cirrhes sont plus longs que dans l'espèce précédente.

\section{LeRNEOPENNA SAgITTA.}

Blainv., Dict. des $S_{c}$. nat., t. XXVI. - Desm., Considér. générales sur les Crist., p. 347 ; Pennatula Sagitta Eulxs, Trans. Phil., ann. 1763, t. LIII, fig. 16. - Le corps est filiforme, d'un pouce de long, à peu prẻs cylindrique, coriace, terminé antérieurement par la bouche, et postérieurement par une double série de seize espèces de plumules presque égales, renflées et percées à l'extrémité. - Sur une Lophie dans la mer de la Chine. Cette espèce paroît avoir été retrouvée par M. DeKai sur les côtes des Etats-Unis, et vivant sur le Diodon Pilosus de Mitchill.

\section{LERNEA, LINN., Buanv.}

Corps peu allongé, subcylindrique ou dŕprimé, sans trace de divisions ou de rudimens d'appendices sur les côtés. - Un renflement céphalique plus ou moins distinct. - La bouche inférieure pourvue d'une paire de crochets. - L'abdomen ter. miné par deux sacs ovifères plus ou moins prolongés.

\section{Lertea clavata.}

Mull., Z. D., t. I, p. 33. - BlaiN. ville, Dictionn. des Sciences naturelles, t. XXVI. - Desm., Considérations générales sur les Crustacés, p. 347.-Le corps est cylindrique, terminé antérieurement par une sorte de rostre crochu, ayant en dessous une bouche à trois plis; les deux sacs ovifères sont cylindriques, et de la longueur du corps. - Trouvé sur la Perche de Norwége.

\section{LERNEA BASTERI.}

Blainv., Dict. des Scicnc. natur. , t. XXVI. - Desm., Considérations générales sur les Crustacés, p. 347-Basr., Opusc., subst. II, p. 138, t.. VIII, fig. 2 . - Le corps est blanc, séparé en deux par un étranglement; l'abdomen est beaucoup plus gros, ovale; le renflement céphalique est globuleux; la bouche inferieure est pourvue d'une double paire de crochets, au moyen desquels l'animal adhère.

\section{LERNEA CYCLOPHORA.}

Blarnv., Dict. des Scicnc. natur., t. XXVI. - Desm., Considèrations gé. nérales sur les Crustacés, p. 347. Le corps est fusiforme, et porte à son extrémité antérieure un renflement dis. coide, au milieu duquel est la bouche; les sacs ovifères sont longs et cylindriques. Du Congo.

\section{LERN ÆOMIZON, BLAINY.}

Corps ovoïde ou déprimé, avec une sorte de céphalo-thorax en forme de cou étroit, cylindrique, terminé antérieurement par une bouche bilobée, pourvu en effet de mandibules ou crochets, et d'une lèvre inférieure.- Un suçoir plus ou moins protractile a la racine inférieure de l'ab. domen. - Deux sacs ovifères peu allongés.

Ces espèces de Lernées n'ont aucun appendice au corps, mais seulement à la bouche. Elles adhèrent aux poissons au moyen d'une espèce de suçoir, en sorte que l'on peut concevoir qu'elles peuvent, sinon cesser leur adhérence à volonté, du moins tourner sur cette espèce de pivot, pour porter la bouche à différents endroits.

\section{LERNEOMIZON UNCINATA.}

Buainv., Dict. des $S c$. nat., t. XXVI. - DESM., Considérations générales sur les 
Crust., p. 348 ; Lernea Uncinata. Mulz., Encycl., pl. 78, fig. 7. - Corps oblong, subdéprimé, mou, blanchâtre, avec un sillon longitudinal sur le milieu dı dos et deux latéraux se réunissant sous le ventre; la bouche terminale est bifide; la ventouse abdominale très-peu saillante; les ovaires claviformes. - Vit sur plusieurs Gades des mers du Nord.

\section{LERNAOMIZON PINNARUM.}

Blainv., Dict. des $S_{c}$. nat., t. XXVI. - DesM., Considérations génér. sur les Crust., p. 348 ; Lernea Pinnarum. J. Cн. Fabr., Itin Norwege, p. 282. Corps déprimé, plane, charnu, arrondi ; le dos? canaliculé, un appendice médian à sa partic antérieure, et pouvant se loger dans ce canal; la tête cylindrique, terminée par un rostre avec deux tentacules $1 i$. néaires bifides à l'extrémité; deux sacs ovifères allongés, cylindriques.

\section{LERNEOMIZON PYRIFORMIS.}

Brainv., Victionn. des Sciences naturelles, t. XXVII. - Desur., Considérations générales sur les Crustacés, p. 348 . - Abdomen renflé, pyriforme, terminé en avant par un sucoir conique fort saillant à la racine du céphalo-thorax, qui est arqué. cylindrique et recouvert en avant d'une sorte de plaque ovale écailleuse; bouche bilobée, la lèvre supé. rieure plus longue et pourvue de mandi. bules cornées; l'inférieure avec une paire de palpes; le tubercule anal fort saillant.

\section{LERNEOMTZON PERNETTYANA.}

Buainv, Dict. des Sc. nat., t. XXVI. - Desur., Considérations génér. sur les Crust., p.348.-PERNeTty, Voyag. aux Iles Malouines, t. 1, p. 93, pl. 1, fig. 5, 6.Corps cylindrique dans toule son étendue, et terminé en arrière par une paire de longs appendices qui accompagnent les sacs oviferes; deux paires d'appendices au milieu du corps, et dont l'inférieure, beaucoup jins grosse, sert à attacher l'animal; deux petilspoints noirs an-dessus de la bouche, el que Peruetty dit ĉtre des yeux.-Trouvè sur les opercules d'un Thon.

\section{LERNEOMIZON ELONGATA.}

Buarnv, Dictionn. des Sciences natur., t. XXV 1. - Desm., Consid. génér. sur les Crust., p. 348. - Corps cylindrique, allongé; tête peu renflée; deux mandibules ou cro. chets mobiles sur la lèvre supérieure; deux jalpes sur l'inférieure; sacs ovifères cylinANN. driques, fort gros, accompagnés d'un faisceau de deux paires d'appendices inégaux, mous, flexibles et d'une pièce médiane supérieure, plus courte. - Trouvé au Hâvre sur le Cheilodiptère aigle.

\section{LERNENTOM A, BLAINV. ; Entomada, LaM.}

Corps en général carrẻ, subdéprimé, avec des espèces de bras ou d'appendices de forme variable et inarticulés de chaque côté. - La tête plus ou moins distincte, pourvue de cornes et de crochets à la bouche. - Les sacs ovifères le plus souvent claviformes.

\section{IERNENTOMA RADHTA.}

Buarvv.; Dictionn, des Sciences natur., t. XXVI. - D Esm, Consid. génér. sur les Crust., p. 348.-Lernoea Radiata, Mulu., Zool. Dan., tab. 38, fig. 4. - Corps carré, déprimé, convexe et garni d'espèces de plaques dures en dessus, concave en dessous; trois paires de bras, dont une à chaque angle et deux en dessous; la tête distincte, armée de deux paires de cornes molles; des crochets à la bouche. - Cette espèce a été trouvée sur la cavité buccale du $\mathrm{Co}$ ryphana Rupestris.

\section{LERNENTOMA GOBIVA.}

Blainv., Dictionn. des Sciences natur., t. XXVI. - Desm., Consid. génér. sur les Crust., p. 349. - Lernaa Gobina, Mulu., Zoól. Dan., tab. 33, fig. 3.-Encycl., pl.78, fig. 8. - Corps déprimé, rhomboïdal, ayant a chaque angle une sorte de bras noueux et coudé à l'extrémité; tête très-distincte, avec une paire de cornesárquées en dedans; la bouche à trois lèvres; les appendices ovi. fères, cirrheux et entortillés. - Trouvẻ sur les branchies du Cotte-Gubie.

\section{LERNENTOMA NODOSA.}

Buainv., Dictionn. des Sciences natur., t. XXVI. - Drsit., Cunsid. génér. sur les Crust., p. 349. - Lernaca Nodosa, MuLz., Zool. Dan., tab. 33, fig. 5.-Le corps sub. carré, convexe en dessus, concave en dessous, avec cinq den is de chaque côté, dont la premiere se prolonge en dessous et forme un bras très-court; la tête assez distincte, avec deux tubercules de chaque côté; les ovaires claviformes; la bouche armée de crochets. - Se tient à l'entrée de la bouche de la Perche de Norwége.

\section{LERNENTOMA ASTLLIVA.}

Buaivv, Dictionn. des Sciences natur., 20 
1. XXVI. - Desk., Consid. génér. sur les Crust., p. 349.-Lerncea Asellina, Linv., Iter Westrog, tab. 3, fig. 4.- Abdomen déprimé, cordiforme, séparé du thorax, qui est semi-lunaire; la tête á l'extrémité d'une sorte de cou, et pourvue d'une paire d'appendices obtus; une autre paire au-dessous, à la racine de l'abdomen; les ovaires courts, claviformes. - Trouvé sur des branchies de plusieurs espèces de Gades de la mer du Nord.

\section{Lerinentoma thigLE.}

Blarnv., Dictionn. des Sciences natur., t. XXVI, - Desm., Consid. géner. sur les Crust., p. 349, - Abdomen aplati, carré, surtout en avant, convexe en dessus, concave en dessous; bordé en avant d'une paire d'appendices transversaux, digités, et sur les bords des quatre dents, dont la postérieure est la plus longue; la tête élargie transversalement et portée sur une sorte de cou long et cylindrique; les sacs oviferes cylindriques et médiocres; deux paires de crochets très-petits à la bouche. - Trouvé sur les branchies du Trigle ordinaire.

\section{LERTENTOHA CORNETA.}

Beatnv., Dict. des $S c$. nat., t. XXVT. - Dess., Considérations génér. sur les Crust., p. 349.-Leincea Cornuta, Muln., Zuol. Dan., tab. 33, fig. 6; Encycl., pl. 78, fig. 1.-Corps oblong; le thorax avec deux paires d'appendices droits et bifides à l'extrénité; la tête suborale et pourvue de trois cornes, dont une frontale; deux croclscts à la bouche; les sacs oviferes cylindriques et arqués.-Vit sur les branchies des $P$ leuronecies Platessa et Linguatula.

\section{LER ATTOMA DUFRESM.}

Brarvv., Dictionn. des Sciences natur., Ł. XXVI. - Dess., Consid. génér. sur les Crust., p. 349. - Corps blanc, mou, assez allongé, comme formè de quatre divisions ayant chacune une paire d'appendices rudimentaires ou des bras; les antérieur's et inférieurs doubles; tête distincte, à quatre pelites cornes; bouche inférieure ronde, armée de crochets; les ovaires fort longs, cylindriques et entortilles. - Cette Lernée, qui a quelques rapports avec les espèces du geure voisin, semble n'être formée que d'une peau molle, remplie d'un tissi comme bẻpatique; les œufs sont ronds et excessivement nombreux.

\section{LERNACANTHA, BLAINV; Chondracanthus, Delarocme.}

Corps gros, court, assez déprimé, pourvu de chaque côté d'appendices rudimentaires, aplatis, digités et cartilagineux. - La tête séparée du thorax par un sillon, et portant de chaque côté un rudiment d'antennes. Bouche inférieure accompagnée d'une paire de mâchoires ou de palpes. - Les sacs ovifères gros, courts et aplatis.

\section{LERNACANTIA DELAROCHIYA.}

Buarnv, Dictionn, des Sciences natur.; t. XXVI. - Desm., Consid. génér. sur les Crust., p. 349.- Chondracanthus Thynni, Delaroche, Nortv. Bull. de la Soc.Phil.-Le corps est formé de quatre zônes hérissées de tubercules pointus en dessus; et pouxvues en dessous d'appendices d'autant plus larges et digités qu'ils sont plus postérieurs.

Cette espèce, qui est le type de cegenre, a été trouvée pour la première fois dans la Méditerrance par Delaroche, sur les branchies du Thon. Depuis clle a été rencontrée sur celles des Squales et d'autres poissons; l'adhérence n'a lieu que par les crochets de la bouche.

\section{LERNEOPODA, BLAINV.}

Corps lisse, assez allongé, divisé en abdomen ovale et en céphalothorax aplati ct couvert d'un bouclier crustacé. - Une paire de palpes courts, gros, coniques et subarticulés, accompagnent la bouche. Deux paires de pieds articulés, subonguiculés, sous le thorax. - Les sacs oviféres courts et subcylindriques.

\section{UERNEOPODA BRONGNIARTI.}

Buainv., Dict. des Sc. nat., t. XXVI. -Desm., Consider. génér. sur les Crust., p. 350. - Son corps, d'un demi-pouce de long a peu près, est couvert d'une peau d'un brun-rougeâtre, assez épaisse, surtout sur le céphalothorax, qui ressemble assez bien au bouclier de quelques insectes, coupé carrément en avant; on y voit trèsbien deux espèces d'antennes ou de palpes coniques, avec des traces de cinq articles accompagnant la bouche; l'article basilaire m'a paru denticulé a son côté interne; sous le milicu du thorax est une premicre paire de pattes, qu'on ne saurait mieux comparer qu'a celles des Cyames; elle est courte, forte et courbèe en dedans; le crochet terminal est aigu; l'autre paire de 
pattes est formée de chaque côté par un Jong article grêle, cylindrique, un peu renflé à son extrémité et terminé par un petit crochet aplati triangulaire; dans la sépa. ration du thorax et de l'abdomen en dessous et dans la ligne médiane, est un ovifère évident; l'abdomen n'offre rien de remarquable : il est ovale, un peu aplati; les deux sacs par lesquels il se termine en arrière sont couverts d'une enveloppe cornée, un peu transparente, ce qui permettait de voir que leur intérieur était rempli d'une substance comme hépatique et entièrement semblable à celle qui était dans l'abdomen; les longs pieds étaient composés à peu près de même.

\section{LERVEOPODA SALMONEA.}

Buanv., Dictionn. des Sciences natur. 1. XXVI. - Desur., Consid. génér. sur tes Crust., p. 351. - Lernea Salmonea, Miyon; Nouveau Bullet. de la Soc. Phil., févr. 1834. - La bouche pourvue de deux lèvres horizontales, dont la supérieure est armée de deux crochets mobiles et durs, l'intérieure bifide; le thorax plus large que la tête, et ayant à sa base deux appendices linéaires, cylindriques, assez longs, réunisà leur sommet par un cartilage orbiculaire; une éminence transversale entre eux; l'abdomen ovale, plus large et plus convexe, avec un sillon orbiculaire en dessus et deux longitudinaux en dessous; les ovaires droits et longs.

Cette espèce se trouve sur les branchies des Salmo Carpionis et sur le corps des Gades.

\section{LERNEOPODA STELLATA.}

Mayor, Nouv. Bull. de La Soc. Phil. févr. 1834. - Desm., Consid. génér. sur les Crust., p. 351 . - Long. 7 lig. - Tête portant deux antennes à sa partie supé- rieure; bouche armée de deux mandibules ou palpes terminés chacun par deux pelits appendices sétacés; lèvre inférieure en forme de tubercule conique ; thorax poursu de deux longs bras qui se réunissent en un tube corné, terminé par un disque à cinq rayons, dont la surface inférieure est finement chagriné; abdomen ovale, allongé, marqué sur le dos de deux sillons longitudinaux, dans lesquels on remarque quatre ou cinq points enfoncés vers la partie postérieure; sacs ovifères, cylindriques, aussi longs que le corps, transparens, renfermant des petits corps ovoüdes, jaunes, placés sur cinq rangẻes. - Cette espèce a été trouvée en Norwège, fixée par son disque étoilé sur les nageoires d'un Esturgeon Sterlet.

\section{LERNANTHROPUS, BLANV.}

Corps ovale, assez peu allongé, divisé en deux parties. - Un bouclier céphalo thoracique et un abdomen prolongé en arrière par une large écaille débordant l'extrémité du trone. - Deux très-forts crochets ver. ticaux sous le front. - Trois paires de trèspetits appendices crochus et transverses sous le thorax proprement dit.-Une paire de bras simples, renflés, et une seconde bifide et comme branchiale sous l'abdomen. - Les sacs ovifères longs et cylindriques.

\section{LERTANTHROPUS MUSCA.}

BlaInv., Dictionn. des Sciences natur., t. XXVI. - Desm., Consid. génér. sur les Crust.,p. 351. - La couleur de l'espèce type de ce genre est d'un blanc-jaunâtre, si ce n'est l'extrémité des crochets, qui est brune, et un globule saillant, d'un beau noir, de chaque côté de la pointe de l'abdomen.

Cette espèce a élé trouvée implantée sous la peau d'un petit Diodon de Manille.

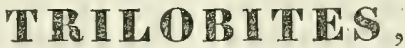

IATREILLE.

M. Al. Brongniart a donné le nom de Trilobitesà des animaux très-singuliers, que nous ne connaissons qu'ò l'état fossile, et qui se reconnaissent à leur corps, divisé en trois parties ou lobes par deux sillons pa. rallèles à son axe, et composé d'un certain nombre d'anneaux. Pendant long-temps il a régné une grande confusion dans l'histoire de ces débris organiques; mais depuis quelques années ils ont été le sujet de travaux approfondis, et les recherches que la science doit à M. Al. Brongniart ont aplani les difficultés que présentait lenx étude, en même temps qu'elles ont contri. 
Jué puissamment aux progrés de nos conhaissances dans cette bianche de la Zoolo. gie antédiluvienne. D’après ce naturaliste, les Trilobites doivent former une famille distincte, et présentent les caractères suivans : leur corps est divisé en trois parties plus ou moins distinctes.-L'antérieur, que nous nommerons bouclier, paraît offrir la réunion de ce qu'on appelle généralement dans les insectes la tête et le corselet; la partie moyenne du corps, divisée par des articulations transversales très-distinctes, peut êlre considérée comme l'abdomen, ou réunion du ventre et du dos; la partie postérieure, souvent séparée nettement de la moyenne, quelquefois aussi se confondant presque avec elle, dirisée pai des articulations ou plis transversaux, moins prononcés, portera le nom de post-abdo. men; tous les naturalistes l'ont appelé queue, par analogie avec la partie a laquelle on donne ce nom tout aussi improprement dans les Crustacés; le canal intestinal le traverse; mais comme il y a enire cette parlie une véritable queus, nous n'avons pu lui laisser ce dernier nom; c'est à l'extrémité de celte prolongation de l'abdomen, que se voit dans plusieurs espèces un appendice coriace ou crustacé, et allongé, soil sans articulations, comme dans les Limules, soit composé de plusie urs feuilles dis posées en éventail, comme dans les Ecrevis ses; cetle partie appendiculaire, ne renferinant aucun viscire, doit porter le nom de queue. - Les deux abdomens sont divisés longitudinalement dans tous les Trilobiles par deux sillons profonds, en troisparties ou lobes d'inégale longueur; celui du milieu est généralement le plus étroit, le plus dislinctement articulé, les latéraux plus larges, s'étendent même quelquefois sous forme (i'expansions presque membraneuses, qui semblent être soutenues par des côtés ou appendices durs et cordiformes, partant de l'abdomen et du post-abdomen. Nous appellerons flancs, avec M: V. Audouin, ces lobes ou parties latérales: nous avons dit que c'était le caractère essentiel des Trilobites; il ne manque dans aucune espèce, et ne se voit avec cette netteté dans aucun animal vivant connu. - Le bouclier est divisé en trois parties plus ou moins distinctes; une moyenne, qu'on peut appeler front, avec Walch, et deux latérales, auxquelles on peut conserver le nom de joues, qui leur est donné. On remarque sur ce front, ou partic moyenne du bouclier, deux ou plusieurs tubercules, et souvent sur les parties latérałes, ou joues, deux autres tubercules saillans très-différens des premiers, et qui ont été assimilés à des yeux. - Les articulations de l'abdomen ou du post-abdomen sont quelquefois prolongèes latéralement en appendices saillans; tantôt la queue n'existe pas, tantôt elle est formée par une membrane qui se termine en pointe, ou d'un appendice crustacé en forme d'alène. Enfin, dit M. Al. Brongniart, ni moi ni aucun des observateurs qui ont étudié ces animaux, n'avons jamais rien vu qui pût ètre comparé à des antennes. Le sa. vant que nous venons de citer, et les naturalistes qui l'avaient précédé, n'avaient également aperçu chez les Trilobites aucune trace de pattes, et M. V. Audouin, en appliquant a ces animaux les principes que lui avait fournis l'étude comparative de la structure du thorax des insectes, avait été conduit à penser qu'ils devaient nécessaire. ment en manquer, ou du moins ne présen. ter que des pattes branchiales; l'observation directe vient de confirmer celle opinion. M. Goldfuss a découvert chez l' $A$ saphus Pusiulatus, Schœnh., des vestiges de pieds qui paraissent avoị été natatoires ou branchiaux; ils sont très-petits, et quelques-uns semblent être articulés.

Les Trilobites sont tous des animaux marins; on les troure constamment associés avec les coquilles ou d'autres produc. tions maritimes. Leur nombre paraîl avoir été immense; car certains dépòts en sont remplis au point que la pierre semble ètre entièrement composée de ces animaux, dont plusieurs avaient la faculté de se contracter en boule, a la maniere des Sphéromes et des Armadilles. Plusieurs d'entre eux sont enfoncés dans les couches les plus profondes de la terre; ils paraissent d'abord presque seuls, et semblent avoir été les premiers habitans solides des premières eaux marines qui ont laissé des débris organiques; enfin ils ont cessé d'exister, sinon en totalité, du moins en très-grande partie, lorsque des Crustacés plus semblables à ceux qui vivent de nos jours, tels que des Limules ou des Idotées, ont commencé à paraître. Les couches les plus anciennes dans lesquelles on ait trouvé des Trilobites, sont des terrains de tiansitions schistoïdes du Contentin, de la Bretagne, d'Angers, de la Suede et de l'Amérique Septentrionalc; on en rencontre aussi dans un calcaire noirâtre appartenant aux terrains de transition, en Suède, en Angleterre ct en Bohême, dans le calcaire gris et com. 
pacte de Dudley, etc., qui renferme aussi des Térébratules; et dans des couches calcaires des terrains de sédiment inférieur, qui se trouvent près de Saint-Pétersbourg; mais il ne paraît pas qu'on en ait découvert dans des dépôts plus récens que ce dernier, qui est beaucoup inférieur à la craie. Les naturalistes n'ont pas toujours été bien d'accord sur la place que les Trilobites doivent occuper dans les méthodes naturelles; les uns regardent ces fossiles comme des coquilles à trois lobes; d'autres pensent que ce sont des animaux voisins des Oscabrions; et enfin la plupart des auteurs les plus récens les regardent comme étant des Crustacés; en effet, d'après les bêlles observations de MMI. Al. Brongniart, V. Audonin el Goldfuss, il est facile de voir maintenant que ces animaux apparlienneut véritablement a la classe des Crustacés.

Les Trilobites ont été divisés par M. Al. Brongniart en cinqgenres, ainsi dénommés : Calymene, Asaphus, Ogygia, Paradoxi. des et Agnostus.

\section{CALYMENE, Al. Brongniart.}

Le corps est contractile en sphère presque demi-cylindrique. - Le bouclier porte plusieurs tubercules ou plis, et deux tubercules oculiformes réticulés. - L'abdomen et le post-abdomen sont a bords entiers, le premier divisé en douze ou quatorze articles; il n'y a point de queue prolongée. Ces animaux sont généralement ellipsoïdes. presque demi-cylindriques dans leur épais. seur; leur bouclier surtout est très-recon. naissable: on y voit une sorte de chaperon ou de lèvre supérieure plus ou moins relevé, et offrant un petit sillon, lequel semble. rait indiquer une séparation entre la partie supérieure de cette espèce de lèvre et sa partie inférieure, et comme une ouverture entre les deux portions de la même partie; on y remarque encore un front garni de six tubercules rangés sur deux lignes longitudinales; enfin il existe en dehors de ce front deux éminences que l'on pourrait appeler joues, et qui supportent des yeux saillans, cornés, a structure réticulaire. L'abdomen, partagé transversalement en douze ou quatorze anneaux, est aussi divisé dans le sens de la longueur, en trois Jobes, par deux sillons profonds. - Les côtes, ou arcs costaux, ou lobes latéraux, ou flancs, sont aplatis de devant en arrière, et chacun d'eux est divisé par un léger sillon en deux pièces qui correspondent à l'épister- num et à l'épimère constituant aussi les flancs dans les insectes. - Le post-abdomen présente même ces arcs bifurqués vers leur extrémité, et ils semblent avoir soutenu une expansion membraneuse on coriace. - L'espèce type du genre est le:

\section{CALYMeve BHUMENBaCHYr.}

Az. Brongniart, Hist. des C'rust. foss., p. 11, pl. 1, fig. 1, A, B, C. - Fossile de Dudeey, Littl. Trans. Philosoph., ann. 1750, tab. 46, 48. - Trilobite, Kловк, t. IV, Suppl., pl. 9, fig. 1 à 5. - Entomostraciles tuberculatus, W AHL, no 6 . - Le chaperon ou levre supérieure présente un sillon parallèle à ses bords; cette lèvre est droite; les joutes sont peu saillantes, il y six tubercules arrondis sur le front, et quatorze articulations au dos; Ia queue est petite; le test est couvert de petits tubercules arrondis, d'inégale grosseur. - Celte espèce se rencontre principalement en Angleterre, dans le calcaire de transition de Dudley dans le Worces. lershire. Flle a encore élé trouvée aux Etats Unis d'Amérique, dans la province d'Ohio, et dans le canton de Genessée faisant partie de l'état de New-York.

\section{CALYMENE TRISTANi.}

A . Brongniat, Hist, nat. des Crust. foss., p. 12, pl. 1, fig. 22, K. - Tristan, Journ. des Min., vol, XXIII, no 133, p. 21. - Le chaperon ou lèvre supérieure est en forme de voûte ou de gouttière ren. versée; les joues sont très-grosses et laissent entre elles et le front un sillon profond; elles portent à leur extrémité les yeux, qui semblent avoir été très-saillans; le front est marqué de trois gros plis obliques arrondis à leur crête; le dos présente quatorze articulations; la queve est très-grande et ses parties latérales paraissent susceptibles d'une grande extension; l'aplatissement, en forme de lames, des côtés de l'abdomen et-la bifurcation de celles de la queue sont très-sensibles; la surface du test a tout-à-fait la texture de ce cuir qu'on nomme du chagrin.

Elle a été troutvée dans des roches de schiste argileux grisâtre ou jaunâtre de la Hunaudière, près de Nantes; on l'a aussi rencontrẻe à Brenville près de Briguebec dans le Contentin; à Siouville, dans un Phyllade pailleté presque Juisant et un peu carburé ; enfin dans plusieurs autres lieux des environs de Valogne et de Cherbourg. 


\section{CAIYWETE VARIOLARIS.}

A., Brongniant, Hist. nat. des Crust. foss., p. 14, pl. 1, fig. 3, A, B, C. - PAnkinson, Organic Remains, tab. 17, fig. 16. - Le chaperon semble divisé en trois masses hémisphériques; celle du milieu est la plis grosse, elle ne présente pas les six iubercules, et les sillons des espèces précédentes; les latérales font voir sur leur angle extérieur une sorte d'appendice qui se prolonge sur les côtés de l'abdomen, jusque vers la sixieme articulation; ces parties sont couvertes de petits grains ou boutons beaucoup plus nombreux et beaucoup jilus saillans que dans les espèces précédentes, et qui sont percés d'un petit trou à leur sommet, a la manière des tubercules cles Oursins du genre Cidarite, - Elle a ćté obsèrvẻe à Dudley.

\section{CALYMENE MACROPHTHALMA.}

Al. Brongniart, Hist. nat. des Crust. foss., p. 15, pl. 1, fig. 4, 5. - Cette espèce est remarquable par la grosseur et la saillie des protubérances qui sont situées sur le chaperon; elle se distingue encore par le prolongement en forme de bec de la partie intérreure du bouclier: le lobe moyen du bouclier est marqué sur les côtés de trois plis obliques qu'on observe sur le Caly. mene Trist ani; le dos, toujours très-distinct de la queve, porte douze à treize articulalions; la queue est courte, mais pointue et noffre aucune expansion.

Trouvé daus un schiste analogue à celui de la Hunaudière, et provenant, à ce qu'il yarait, de cilice; à Coal-Brook-Dale, en Shorpshire, et aux Elats-Unis d'Amérique.

\section{ASAPHUS, Al. Brongniart.}

Le corps est large et assez plat, avec le lobe moyen saillant et très-distinct. - Les flancs ou lobes latéraux sont chacun du double de la largeur du lobe moyen. - Les expansions submembraneuses dépassent les arcs des lobes latéraux. - Le bouclier est semi-circulaire et porte deux tubercules oculiformes réticulés. - L'abdomen est divisé en huit ou douze segmens. M. $\mathbf{A l}$. Brongniart a hésilé quelque lemps sur la fondation de ce genre, parce qu'il ne présente pas, à sonavis, un ensemble de caracteres suffisans pour le circonscrire avec netleté; en eflet, il a beaucoup d'analogie avec les Calymènes et les. Orgyies; genres qui diffèrent réeliement l'un de l'autre, et qui, si l'on n'eut pas distingne l'intermé- diaire dont il est ici question se seraient avoisinés au point de se confondre. - Les Asaphes, de même que tous les Trilobites, n'ont encore été vus que sur le dos; on a même ignoré long-temps la forme d'une très-grande portion de leur corps; et on n'a d'abord connu que leur post-abdomen, qui en général est détaché de l'abdomen.-Ce. lui-ci est composé de huit huit à douze articulat ons. Le nombe de celles du post-ab. domen est très-variable.

\section{ASAPHUS CORNIGERUS.}

Al. Brongniart, Hist. nat, des Crust. foss., p. 18, pl. 2, fig. 1, A, B, et pl. 4, fig. 10. - Trilobites Cornigerus, Schlotн., in Leonh. Tasch. Act., vol. IV, tab. 1, fig. 1. - Entomostracites Expansus, W AHLENE., Act. Soc. reg. Sc. Ups, vol. VIII, no 1. - Le bouclier et la queue ont, dans quelques individus, à peu près la même dimen. sion et la même forme; le premier est sans tubercules ni plis; sa surface paraît avoir été assez lisse, et sa division en trois lobes par des sillons longitudinaux, est presque insensible; on voit à son extrémité antèrieure comme une espèce de lèvre qui sem. blerait avoir été séparée des joues par une fente qui va du bord antérieur du bouclier à l'cil, et qui aurait permis a cette partie de se mouvoir de bas en haut à la manière de la lèvre supérieure d'une Carpe; cette structure n'est pas particulière à celte espèce, mais elle est ici beaucoup plus sensible; les protubérances oculiformes sont cylindriques, très-saillantes. Les individus que M. Al. Brongniart possède viennen: de Koschelewa près de Pétersbourg, et sont dans un calcaire compacte grisâtre rempli de petites lamelles cristallines et de petits grains noirs-verdâtres; il le suppose iaféricur à la craie. - Le Trilobite Cornigerus de $\mathbf{M}$. Scholhim a été trouvéaux eavirons de Préval près de Memel.

\section{ASAPIUS DEBUCHII.}

Al. Brongniart. Hist, mat. des Crust. foss., p. 20, pl.2, fig. 2, A, B, C.- PaRKINSON, Org. Remains, vol. 3, pl. 17 , fig. 13. - La forme générale de cette espèce est celle d'un ouf ; la têle est du côté du gros bout; le lobe moyen du bouclier est assez distinct, il se termine en pointe antérieurement, et paroît marqué de quelques tubercules, a peu près disposés comme dans les Calymènes; les lobes latéraux ou joues sont triangulaires; l'angle postérieur et extérieur est un peu prolongé; les tubercules oculiformes sont situcs dans 
lrangle antérieur; les arcs costaux des lobes latéraux du dos sont bien sensiblement doubles, ceux de l'abdomen caudal le sont moins sensiblement; la partie moyenne de cet abdomen est à peu près pyramidale; la membrane coriacée qui recouvroit les arcs les dépassoit et étoit striée longitudinalement vers son bord; les siries de la partie flottante paroissent moins serrées que celles de la partie portée par l'extrémité des arcs. - Cette espèce a été principalement rencontrée dans un psammite calcaire compacte, noir et micacé, à Dynwors-Park, dans le pays de Galles.

\section{ASAPHUS HAUSMANI.}

Al. Bhongniant, Hist, nat. des Crust. foss., p. 21, pl. 2, fig. 3, A, B. - La forme générale de cette espèce est celle de la moitié d'une ellipse; son lobe moyen représente un cône très-effilé; les arcs costaux des lobes latéraux, parfaitement distincts, paroissent simples; mais un caractère qui servira à la faire distinguer des autres, ce sont des petits points élevés, épars el par conséquent peu serrés, dont la peau ou épiderme étoit couverte comme l'est celle de la queue de l'Apus Cancriformis.-Cette espèce a été trouvée dans un calcaire de transition des environs de Prague.

\section{ASAPIUUS CACDATUS.}

Az. Brongniart, Hist. nat.' des Crust. foss., p. 22 , pl. 2 , fig. 4 A , B , C , D. Trilobus Caudatus, Breannich, in Kiab. Selsk Skrivt. nye Saml., 1, 1781, p. 392, $n^{\circ}$ 8. - Le bouclier parô̂t avoir eu un prolongement à son lobe moyen; ce lobe présente trois plis transversaux vers sa partie postérieure; les lobes latéraux ou joues, triangulaires et prolongés en pointe, par leur angle postérieur et extérieur, sont peu élendus et portent des protubérances coniques, tronquées, semi-Iunaires, à convexité extérieure, qui ne sont pas seulement ici oculiformes, mais de véritables yeux à réseau, comme ceux des Limules; le lobe du dos présente douze articulations bien distinctes, et éloigne cette espèce des précédentes par ce caractère; les lobes latéraux sont composés d'arcs bifurqués, dont les deux branches sont presque d'égale longueur; l'abdomen caudal est parfaitement distinct du dos ou partie supérieure de l'abdomen dorsal.- - Provient de Dudley en Angleterre.

\section{ASAPIUS LATICAUDA.}

Al. Brongniart, Hist, nat. des Crust. foss., p. 24, pl. 3 , fig. 8 . Entomostracites Laticauda, W AHLENB., $n^{*} 3$. tab. 2 , fig. 7 et 8 . - Les yeux sont placés vers les côtés de la tête, qui est trés-convexe; la queue est presque orbiculaire, ei le limbe en est très-large, plan, très-entier, marqué de plis superficiels rayonnans, Cette espéce a été Irouvée dans un calcaire blanc, dans l'Onnundberg en Dalécarlie.

\section{OGYGIA; Al. Brongniant.}

Les Ogygies ont la forme d'une ellipse allongée, terminée en pointes à peu près égales à ses deux extrémités; ils sont tous déprimés, et on ne peut guère attribuer cet aplatissement à la compression. - La tête et le corselet sont réunis en un bouclier assez étendu ; on voit sur la partie antérieure du chaperon un sillon droit, longitudinal, qu'on n'aperçoit sur aucun autre Trilobite, et sur les côtés deux sillons arqués. - Les protubérances oculiformes ne montrent point la structure réticulaire, ni l'espèce de rebord qui entoure la cornée, comme dans les autres Trilobites; ces proiubérances semblent indiquer la place des yeux, mais ne laissent voir rien qui puisse êlre comparé à ces organes; elles sont situées vers le milieu du bouclier; cette partie du bouclier est saillante, mais elle ne présente pas les tubercules qu'on observe dans les autres genres. - Le bouclier se prolonge de chaque côté en une pointe très-allongée, qui est tout-à-fait séparée du corps, et qui s'étend jusqu'à plus de la moitié de la longueur de l'animal. - L'abdomen est, ainsi que le post-abdomen, divisé en trois parties par deux sillons longitudinaux, et en un grand nombre d'articulations transversales. - Les articulations de l'abdomen sont constamment au nombre de huit; leur surface présente des stries partant en divergeant d'un angle des écailles. - Le post - abdomen est à peu près disposé comme l'abdomen ; on $y$ compte environ dix anneaux ou articulations; ses parties latérales paroissent avoir été beaucoup moins écailleuses, moins sen. siblement articulées, et par conséquent plus membraneuses que les parties latérales de l'abdomen; on voit sur les deax côtés de la queue deux paquets ovoïdes, beaucoup plus épais que le reste du corps; ces paquets, dont la structure est indéterminable, semblent cependant, par leur forme et leur position, indiquer la place des oufs, place 
et forme analogues à celles que présentent les paquets d'oufs dans plusieurs Entomostracés, tels que les Cyclopes et les Branchyopodes. A ces caracteres, nous ajouterons que les individus d'une même espèce ont entre eux de grandes différences de taille; en ne comparant que ceux qui sont évidemment de la même espèce, on en trouve qui out huit centimètres, et d'autres qui ont jusqu'à vingt-huit centimètres de long.

Les Ogygies ont été rencontrées en France, dans les schistes argileux des environs d'Angers.

\section{GgYGIA GUETTARDI.}

Al. Bnongriart, Hist. nat, des Crust. foss., p. 28, pl. 3, fig. 1, A, B.-Le corps de cette espece est elliplique, environ trois fois plus long que large; il est terminé en pointe aux deux extrémités, et les différentes parties qu'on y voit participent à son allongement.-Ou trouve cette espéce dans les schistes ardoisés des environs d'Angers, où elle estrare, dans un parfait état de con. servation, quoique les fragmens en soient très-communs; ces fragmens offrent de telles différences dans leurs proportions et dans leurs formes, que M. Al. Brongniart suppose qu'il existe plusieurs espèces distinctes, qu'il n'a pu eucore caractériser.

\section{OGYGIA DESHARETII}

A. Brongniart, Ifist. nat. des Crust. foss, , p. 28, pl. 3, fig. 2. - Le corps est ellipsoide, tout au plus une fois et demie plus long que large; le bouclier est arrondi et presque échancré antérieurement. - Cette Ogygie est remarquable par sa dimension, l'animal entier devant avoir au moins trente-cinq centimètres de long; il se distingue en outre par une plus grande largeur de toutes ses parties, ce qui lui donne une forme gènérale raccourcie.

\section{PARADOXIDES, Al. Brongniart.}

Le corps est très-déprimé, avec les flancs larges, par rapport au lobe moyen.Le bouclier est généralement arqué en avant, presque demi-circulaire. - Les lobes latéraux sont unis et ne paroissent point porter d'yeux réels, ni même de protubérances oculiformes. - Le lobe moyen est marqué de trois sillons transversaux, ou au moins de trois rides. - Le nombre des articulations du corps ou de l'abdomen proprement dit, ne paroît nas être moirs de douze ; celles du post-abdomen ne dépas. sent pas quatre ou cinq.

Les Paradoxides avoisinent beaucoup les Ogygies, par la forme déprimée de leur corps, par le manque d'yeux réticulés, et par la ténuité de leur peau; mais ils se distinguent essentiellement de ce genre et de tous ceux de l'ordre des Trilobites, par les arcs des flancs et surtout de la partie pos. térieure du corps, prolongès en dents, en pointe ou en épine, et dépassant la membrane qui les réunissent.

M. Al. Brongniart a divisé ce genre en deux sections, établies sur la forme du cha. peron.

A. Bord antérieur du chaperonà peu près en arc de cercle.

\section{1. paradoxides tessini.}

Al. Brongniart, Hist. nat. des Crust. foss., p. 31, pl. 4, fig. 1.-Entomostracites Paradoxissimus, WaHLen., no 9 , tab. 1, fig. 1.- Entomolithus Paradoxus, Linv., Mus. Tess., tab. 3, fig. 1.-Le chaperon, arrondi antérieurement, se pro. longe postérieurement en deux parties qui dépassent la moitié du corps; le lobe moyen ou la tête est arrovdi et dilaté en avant, et marqué de trois plis transversaux; les joues ou lobes latéraux semblent porter de chaque côté une protubérance oculiforme, mais non pas un oeil. - Cette es. pèce paroît acquérir une très-grande dimension; on en cile de plus de trois décimètres de long. Selon Wahlenberg, on ne l'a encore rencontrée qu'en W estrogothie, dans les couches d'ampélite alumineux, et seulement à une grande profondeur. On en a îrouvé quelques vestiges dans les exploitations de Damman,

\section{Paradoxides spivulosus.}

Ax. Brongniant, Hist nat. des Crust. foss., p. 32, pl, 4, fig. 2 et 3. - Entomolithus Paradoxus, Linn., Act. Stockh., 1759, tab. 1, fig. 1, 2, 3, 4. - Entomostracites Spinulosus, Wahlen., $\mathrm{n}^{\circ} 11$, tab. 1, fig. 3.- La tête égale presque en largeur la longueur de l'animal, elle est semi-circulaire; le lobe moyen est marqué de trois plis transversaux, disposés en chevrons ou en V renversés; il est plus étroit en avant qu'en arrière, ce qui distingue es. sentiellement celte espèce de la précédente; on ne voit sur les lobes latéraux aucune protubérance oculiforme, mais ces lobes montrent clairement des stries ondulées, à peu près transversales; ils se prolongent en deux pointes ou épines, quì attei. 
- gnent à peu près la moitié du corps; on compte donze articulations sur ce qu'on peut regarder comme l'abdomen, et six en tout, sur la réunion du post-abdomen, avec la véritable queue en E.-Cette espèce se trouve exactement appliquée sur un ampélite alumineux, dont le gisement paroît être d'Andrarum en Scanie.

\section{3. paradoxides scaraboides.}

Al. Brongniart, Hist, nat. des Crust. foss., p. 34, pl. 3, fig. 5. - Entomostracites Scaraboides. W AnL., n 13 , tab. 1 , fig. 3.-La tête est hémisphérique, arrondie en avant; le front est presque ovale, plus étroit antérieurement; le bord de la queue est sinueux et muni de trois dentelures; on voit sur les parties postérieures de la tête quelques lignes ou sillons transverses, très-superficiels; le lobe du bouclier est remarquablement étroit, par rapport à la tête ou lobe moyen; le lobe moyen de la queue ou post-abdomen est plus court que cette partie; il est marqué de trois anneaux. - Gette espece a été trouvée, mais en échantillons très-rarement entiers, dans les lits d'odeur fétide, dans l'ampélite alumineux.

B. Bord antérieur du chaperon en ligne droite ou comme tronqué.

\section{4. paradoxides gibbosus.}

Az. Brongniart, Hist. nat. des Crust. foss., p. 35, pl. 3, fig. 6. - Entomostracites Gibhosus, W AnL., no 12 , tab. 1, fig. 4. - La tête est tronquée antérieurement, presque plane; le front est oblong, et le lobe du dos comme bossu; la queue triangulaire, marquée de deux dents de chaque côté.-On la rencontre communément daus l'ampélite des mines d'Andrarum en Scanie. Les échantillons complets sont rares, et l'on trouve le plus ordinairement la tête el la queue séparées.

\section{PARAdoxides IaACIHIATUS.}

A l. Bhongniant, Hist. nat. des Crust. foss., p. 35, pl. 3, fig. 3. - Entomostracites Laciniatus, W AHL., n० 8. tab. 11, fig. 2.La têle est rectangulaire antérieurement, comme appendiculée ou ailée postérieurement; le lobe moyen ou front est couvert de ehaque côté de trois gros plis; la queue, bilobée sur les deux côlés, porte deux dou- bles plis. - On n'a encore trouvé que des vestiges de cette espèce dans les schistes argileux blancs, supérieurs, du mont Mỏserberg en Westrogothie.

MI. Rasoumowsky, qui a publié, en 1826 , un travail intéressant sur les Trilobites, dans les $A n n$. des $S_{c}$. nat., t. VIII, p. 186, parle d'une nouvelle espèce de Paradoxide voisine du Paradoxides Tessini, mais beaucoup plus petite. Elle vient des bords de la Yacusa, prés Moscou. 11 en donne une figure dans l'Atlas, 1826, des Ann. des $S c$. nat., pl. 28, fig. 2.

\section{Agnostus, Al. Brongniatit.}

Ce genre n'a presque rien de commun avec les autres genres de l'ordre des Trilobites, que la division trilobaire de son corps.

On ne connoît, jusqu'à présent, qu'une seule espèce.

\section{AgNostus PISIFORMIS.}

Az. Brongniart, Hist. nat. des Crust. foss., p. 38, pl. 4, fig. 4, A, B. - Entomostracites Pisiformis, WAнц., no 14 , tab. 1, fig. 5.-Cet animal, qui offre deux variétés, a la grosseur d'un pois, et représente une ellipse tronquée; il ligure assez bien une Casside ou quelques espèces de Chermès; son corps peut être partagé en lobe et en limbe; le lobe situé à la partie moyenne est demi-cylindrique, et divisé, par un sillon transversal, en deux parties: l'une antérieure et l'autre postérieure ; chacune d'elles offre des differences assez tranchées dans les deux variétés; le limbe entoure le lobe moyen en arrière et sur les côtés; mais il ne le dépasse pas en avant, et s'arrête aux angles antérieurs de ce lobe; il diffère peu dans chaque varièté et présente, sur toute l'élendue de sa circonférence, une sorte de gouttière ou de rebord; si on l'examine arec une forle loupe, il paroit finement chagriné et plus mince que le lobe moyen qui avoit probablement beaucoup de consistance. - Ces singuliers animaux se rencontrent en quantiié innom. brable dans un calcaire sublamellaire, noirâtre et fétide, venant d'Heltris en Suède. Ils varient en grandeur, mais dans la même couche ils sont toujours de mème grosseur. 



\section{ARACHNIDES.}

Les Arachnides forment la seconde classe des animaux articulés, et sont, de même que dans les Crustacés, dépourvues de squelelte intérieur, et d'un système nerveux cérébro-spinal ; leur enveloppe extérieure est composée dé tégumens ou anneaux analoguesà ceux des insectes; mais elle est d'une consistance bien moins solide que celle de ces derniers et des crustacés, Leur tête, de même que dans les Crustacés, paraît soudée avec le reste du corps, et a été désignée à cause de celte conformation sous le nom de céphalothorax; elle offre ordinairement une bouche,pourvue dans le plus grand nombre d'organes de mastication et composée de deux mandibules, d'une paire de mâchoires; supportant chacune un palpe composé de plusieursarticles, et d'une lèvre inférieure généralement toujours petite; les organes de la vue, toujours placésà la partie antérieure du céphalothorax et sur les côtés, ne consistent qu'en de simples petits yeux lisses, en nombre assez variable, de douze dans quelques-uns, de huit le plus ordinaireinent, quelquefois de six, de quatre et même entièrement nuls; ces organes ordinairement sont groupés de diverses manières. Le céphalothorax est toujours dépourvu d'antennes, et n'a encore offert jusqu'à présent aucun organe qui ait pu être comparé à celui de l'ouie. Tous les animaux qui composent celte classe sont dépourvus d'ailes; le numbre de leurs pattes ne varie pas; ces orgines sont toujours au nombre de huit, quelquefois cependant ils se modifient et se présentent plutôt sous la forme de palpes quie de véritables pattes. Du reste ces mêmes organes chez les uns servent de pattes am. bulatoires, tandis que chez d'autres ils servent à la natation. Les sexes sont toujours séparés, et les parties sexuelles, doubles, sont situees dans quelques - uns à l'extrémilé des palpes dans les mâles, mais le plus ordinairement placées sous le ventre. Euvisagées sous le rapport du système nerveirye, les Arachnides s'éloignent notablement des Crustacés el des Insectes; car si l'on exceple les Scorpions, qui, à raison des mouds ou articles formant leur queue, ont quelques ganglions de plus, le nombre de ces renfiements des deux cordons nerreux est de trois au plus, et même dans ces derniers animaux n'est-il, tout compris, que de sept.La respiration.s'opère chez les uns par des branchies aériennes, ou tenant lieu de poumons, composées de vingt et plus de petites lames semi-lunaires, unies, rapprochées comme les feuillets d'un livre, situées dans les poches latérales du ventre, qui s'ouvrent en dehors au moyen d'une fente transverse, et dont la place est souvent indiquée par une tache jaunâtre; le nombre de ces ouvertures pulmonaires ou stigmatiformes varie; quelquefois elles sont au nombre de huit, quelquefeis de quatre, et le plus ordinairement de deux. Chez d'autres cette respiration est cutanée, c'est-à-dire que les branchies sont sans ouvertures stigmatiformes, et enfin dans un assez grand nombre, la respiration s'opère par le moyen de trachées.-Le système circulatoire dans les uns est très-prononcé, tandis que dans d'autres, comme les Arachnides trachéennes, ces dernières ne présentent pas de circulation, ou si elles en ont, celte circulation n'est pas complète. Toutes les Arachnides (les Scorpions font exception) sont ovipares, et leurs œufs ẻclosent après la ponte; les petits qui en sortent ne subissent pas de métamorphoses, ils changent seulement de peau à différentes époques de leur víe, ce qui leur fait éprouver plusieurs modifications; mais ils conservent toujours la forme générale qu'ils avaient en naissant ${ }^{1}$. Dans quelques cas cependant deux de leurs pat-

\footnotetext{
${ }^{1}$ Nous en excepterons cependant les ifydrach nes, car suivant M. Dugès ces Arachnideséprouverit de véritables métamorphoses, c'est-b. dire qu'd la sortie de l'œuf, les nouveau-nés sont des espèces de larves à six patles et à trompe singnliere ; àcet élat ils se fixent sur les Népes, les Dytiques, etvivent parasites sur ces insectıs sans que ces derniers paraissent en être incommodés beau.coup. Plus tard, lor sque le corps commence às'allonger, lespattes et les palpes se retirent en dedans; à cet état c'est alors une nymphe qui, formée avec sa propre peau, remplace la larve, mais c'est ine nymphe qui se nourrit et qui s'accroî ; peu après les masses blanchátres qu'on distinguait à travers la peau de cette nymphe s'allongent et se courbent, ensuite la peau se déchire transversalement en deux portions pour laisser sortir lc nouvel animal, qui nage aussitôt avec vivacité.
} 
tes ne se développent qu'avec un clange, ment de peau, et en général ce n'est qu'à la quatrieme ou cinquième mue que les animaux de cette chasse deviennent propres à la génératione La plupart des Arachnides sont terrestres, quelques-unes cependant sont aquatiques; elles se nourrisent d'insectes qu'e'les saisissent virans, et sur lesquels elles se fixent, et dont elles sucent les humeurs; d'aulres vivent jarasiles sur des animaux vertébrés. Il en est ce. pendant que l'on ne trouve que dans Ia fa. rine, sur le fromage, et inème sur les végétaux.

Telle est en per de mots l'organisation des Arachnides, et maintenant que nousl'avons fait connaître d'une manière succincte, nous allons passer brièvement en revue leurs divers systemes organiques en com. mençant par l'enveloppe extérieure.

Le corps des Arachnides est formé d'anneaux peu nombreux, et l'ensemble de ces segmens forment en général la tête, le thorax et l'abdomen. La tête, que l'on a nommée céphalothorax, porte les yeux etles organes de la manducation; le thorax intérieurement renferme les visceres et extérieurement supporte les organes de la locomotion. - Les organes de la vue sont nombreux; chez les uns ils sont au nombre de douze, le plus ordinairement de huit, quelquefois de six, de qualre, de deux. et même nuls; ces yeux sont ordinairement lisses, et lorsqu'ils sont nombreux, ils sont dirigés en divers sens, c'est-á-dire antérieurement, postérieurement, supérieuriement et latéralement; cette disposition démonlre que ces animaux voient dans tous les sens sans avoir besoin de faire le moindre mouvement. Les mandibules, situées à la base du céphalothorax, sont au nombre de deux, placées horizontalement a côté l'une de l'autre, et ordinairement plus ou moins recouvertes par l'épistome; leur forme en général est plus ou moins triangulaire. Ces organes ne portent jamais de palpes, seulement à leur base ils sont armés dans quelques-uns seulement d'un onglet percé près de son extrémité d'un jetit trou pour le passage d'une liqueur vénéneuse; cet onglet ou crochet est très-acéréà son extrémilé, et se replie intérieurement dans une rainure de la mandibule; quelquefois ces manaibules sont didactyles et même en forme de su. coir rétractile. $\rightarrow$ Les mâchoires sont au nombre de deux comme les mandibules, placées sous ces dernières et sc mouvant comme elles horizon:alement; elles sup- portent un pajje à leur partie exlérieure; la forme cles mâchoires varie à l'infini suirant les espèces. - Lespalpes sont saillants, articu'és, mobiles et propres aux mâchoires; le nombre des articles qui les composent est peu variable et ordinairement au nombre de ciuq el ainsi désignés : sous-axillaire, huméral, cubital, radial et digital. Les fonc. tions mécaniques de ces organes pendant l'acte de la manducation paraissent être de maintenir en place les substances soumises à l'action des mandibules et des mâchoires. On les voit en effet les retourner dans tous les sens, les manier, les palper en quelque sorte, d'ou lcur vient le nom qu'ils ont recu. Dans les uns le demier article de ces organes est didactyle, et sert alors a la préhension. dans d'autres ces mêmes organes servent non seulement à la mastication, ils sont excitateurs et servent même comme organes de copulation.-Les pattes, aunombre de quatre paires, sont atlachées autour du céphalothorax ; ces organes se composent d'une suite d'arlicles tubuleux de la même nature que le reste des téguments, et articulẻs les uns avec les autres de manière à se prêter à tous les mourements nécessaires à l'animal; on y distingue cinq de ces articles qui sont: la hanche, l'exinguinal, le fémoral, le gênual, le tibial et le tarse. - La hanche est la pièce au moyen de laquelle la patte s'articule avec le céphalothorax; quelle que soit la forme, qui varie assez, mais qui cependant est le plus souvent globuleuse ou cylindrique, elle est recue dans une cavité de ce dernier, où elle est enfoncée plus ou moins profondément.-L'exinguinal est un article ordinairement assez petit situé entre la hanche et le fémoral, et's'articulant avec tous denx. - Le fémoral est la troisième articulation de la patte; il s'articule d'un côté avec l'exinguinal, de l'au. tre avec le génual; il varie peu pour la grandeur et la grosseur. - Le génual et le tibial n'offrent rien de particulicr. - Le tarse ou la partie terminale de la patte se compose ordinairement de deux articles et même quelquefois de trois; ils sont désignés sous le nom de métatarse, mésotarse et tarse; ces diffèrents articles varient sous le rapport de la forme et de la longueur; le dernier est toujours armé à son extrémité de petits crochets ou ongles ressemblant aux ongles des oiseaux, et dont l'auimal se sert pour s'accrocher aux corps sur lesquels il se trouve placé; quelquefois entre ces crochets il existe un petit appendice en forme de pe. lote. En dessous et tout-a-fait à la partie in- 
IEricure est un espace assez grand qui a été l'ésigné sous le nom de plastron sternal; l'abdomen, attaché au céphalothorax par un Irès-court pédicule et quelquefois même se confoudant avec lui, est tantôt composé d'anneaux, tout formé d'une seule masse globuleuse, flexible, et qui ne présente aucune apparence d'anneaux; il supporte ordinairement les organes de la génération et de la respiration; à son extrémité est situé l'anus, et quelquefois on distingue des appendices assez longs, en nombre variable, et qui ont été désignés sous le nom de filières; quelquefoisil est terminé par un appendice très-long, composé de plusieurs anneaux et dont le dernier est armé d'un crochet très-aigu- percé à son extrémilé pour le passage d'une liqueur vénéneuse ; d'auIres fois ce n'est qu'un long filament composé d'an grand nombre d'articles. - Les organes de la respiration, comme nous l'avons déjà dit plus haut, sont situés dans des poches latérales du ventre qui s'ouvrent en dehors et qui sont constatables à l'extérieur par une saillie jaunâtre; ces organes, dont le nombre est assez variable, se présentent quelquefois sous la forme de stigmates. La manière dont s'opere la circulation n'a pas encore été bien constatée; à en juger par ce qui se passe à cel égard dans lcs Crustacés, le cœur, qui est silué le long du milieu du dos de l'abdomen, étroit, allongé et rétréci aux deux extrémités, répand, au moyen d'artères, le sang dans les diverses parties du corps, d'où il revient aux branchies, et ou, aprés avoir respiré, il retourne au cœur par des veines pulmonaires. HI.Treviranus a observé dans le scorpion d'Europe ct diverses espèces d'arachnides des vaisseaux partant du cour et se rendant dir ectement au corps graisseux et au foie, où ils s'épanouissent et se ramifient à l'infini. Dans la Clubione Atroce, le cour, vers son extrémité postérieure, donne naissance à quaIre grands vaisseaux qui se dirigent cn arrière, et non vers les branchies, situées en avant, et se terminent ainsi en manière de réseau : ces vaisseaux sont donc artériels. Chaque poche branchiale du mêmescorpion offre sur son plan inféricur, au-dessous de l'organe respiratoire, les ramifications d'un vaisseau qui, par sa forme el sa nature, a paru au même savant différer de ceux qui vont du cour au corps graisseux. Dans cette arachnide les branchies élant plus nombreuses que dans les autres pulmonaices, et s'étendant dans toute la Iongueur des côtés de l'abdomen, ainsi que dans les Crustacés stomapoces et amplipocies, il est probable que le sang qui a respiré retourne au cour par des moyens analogues; mais comme dans les Aranéides ces branchies ne sont le plus souvent qu'au nombre de deux, et placées de chaque côlé de l'origine du ventre; il semble que le relour de ce fluide doit s'effectuer d'une manière un peu différente. M. Treviranus a effectivement observé de chaque côté du cœur un vaisseau longitudinal, paraissant aboutir, par son bout antérieur, aux sacs pulmonaires correspondans, et s'abouchant par l'autre avec le cœur vers le milieu de sa longueur ou un peu au-delà; les deux réunis forment une courbe elliptique. Dans une espèce au moins (l'Épéire Diadéme), ils jettent latéralement des petits vaisseaux qui s'anastomosent avec leurs extrémités; sont-ils destinés a recevoir le sang qui a circulé pour les transmettre aux branchies et de là au cœur? c'est ce que nous ne pouvons dire; mais toujours est-il certain que $\mathbf{M}$. Treviranus n'a rien observé de semblable dans le scorpion d'Europe. L'enveloppe du cour paraît ètre formée d'une double peau, dont l'extéricure musculeuse, du moins vers sa partie moyenne, et où son diamètre transversal a plus d'étendue; dans les scorpions, ou cette peau est entiérement de celte consistance, il est fixé latéralement par des mus. cles doni les expansions forment des espéces d'ailes semblables à celle du vaisseau dorsal des Insectes. On en voit aussi sur les côtés du cœur des Aranẻides; mais M. Treviranus soupconne que ce sont des vaisseaux tant dans les Scorpions que dans les Aranéides, seuls animaux de cetle classe dont on ait encore étudié l'organisation intérieure. Le tube alimentaire est droit, presque linéaire ou cylindrique, dilaté au plus vers l'estomac et la partie anale, avec l'cesophage allongé; il reçoit de droite et de gauche un certain nombre de paires de vaisseaux hépatiques venant d'un amas pulpeux de petiles glandes, remplissant la majeure partie de la capacité abdominale, et considéré comme le foie. M. Treviranus lui donne le nom de corps graisseux, et réserve la dénomination précédente à des petits vaisseaux frisés. Il se divise, dans les scor* pions, au moins en deux paires de grappes: deux vaisseaux biliaires et longitudinaux paraissent fournir, ainsi que dans les Aranéides, mais allant en sens contraire, la liqueur des glandes du venin:

Les appareils sexuels chez les Arachnides sont deables, tantôt situés à l'extrémité des 
palpes, mais le plus sourcnt sous le ventre; les organes mâles et ferselles n'existent pas à la fois dans le même individu. L'appareil générateur mâle est composé, pour chaque moitié du corps, d'un testicule, d'un canal afférent terminé par une verge, et de quelques appeudices accessoires. Dans les femelles, l'appareil de la génération se compose, pour chaque côté du corps, d'un ovaire, d'un oviducte et d'une vulve.

Ne pouvant entrer dans de plus grandes considèrations, nous renvoyons, pour plus de détails sur l'anatomie des Arachnides, aux ouvrages de MM. Treviranus, Marcel, de Serres et Léon Dufour. Nous suivrons pour les Arachnides, de même que pour les Crustacés, le cours d'entomologie de MI. La- treille : ce célébre entomologiste partage la classe des Arachnides en trois ordres.

Ier ordre. Les Pulmonaines. Cet ordre renferme deux familles: les Pédipalpes qui comprennent deux tribus : les $S$ corpionides et les Tarentules. La seconde famille est celle des Aranéides, qui renferment deux tribus: les Tétrapneumones et les Dipneumones.

II erdre. Aporobranches. Cet ordre a été divisé en deux familles: les Nymphonides et Pycnogonides.

HII ordre. Trachéennes. Cet ordre a été partagé en sept familles : les Faux-Scor. pions, les Phalangiens, les Trombidites, les Acarides, les Tiques, les Hydrachnelles et les Microphthires.

\section{PREMURE FAMLLE。}

\section{PÉ D I P A P E S,}

Latretlle.

Caractères. Deux grands palpes en forme de serres, terminés en pince didacıyle ou par une griffe. - Deux chélicères ou antennes - pinces, finissant de même. Un abdomen toujours revêtu, ainsi que le céphalothorax, d'une peau coriace, à segmens membraneux et bien distincts, sans filières au bout. - Les organes de la génération situés, dans les deux sexes, à la base du ventre. - Enfin, des yeux lisses, distribués en trois groupes écartés, dont deux latéraux et l'autre médian, et uniquement composé de ces deux organes, signalent sans équivoque cette famille, qui paraît exclusivement propre aux contrées intertropicales. - Le nombre des branchies et des stigmates est de huit à quatre. Les $\mathbf{S}$ corpions, qui font partie de cette famille, s'éloignent évidemment de toutes les autres Arachnides par le nombre de leurs branchies, qui est de huit au lieu de quatre ou de deux; par la manière dont se termine leur abdomen, la présence de cesappindices, situésà sa naissance, auxquels on a donné le nom de peignes, indiquant, à ce qu'il paraît, une organisation plus avancée que celle des autres animaux de la même classe. Ils conduisent naturellement au genre Thélyphone, qui n'offre plus, ainsi que celui de Phryne, venant immédiatement après, que deux paires de branchies.

Cette famille renferme deux tribus, les Scorpionides et les Tarentules.
PREMIERE TRIBU.

\section{SCORPIONIDES,} Latreille.

Caracteres. Deux grands palpes, en forme de serres, terminés par une main didactyle. - Chélicères formant une pince semblable. - Lèvre de deux pièces, et qui sont autant d'appendices de la base de la seconde paire de pattes; celles des deux dernières à hanches soudées. - $\mathrm{Ab}$ domen sessile, portant au-dessous, à son origine, les organes sexuels; ensuite deux peignes ou lames étroites et allongées, garnies, le long du côté postérieur, d'une rangée de dents articulées à leur base; puis sur chacun des quatre segments, venant inmédia. tement après, deux sacs branchiaux, un de chaque côté, avec une ouverture extérieure ou stigmate; segment suivant terminé brusquement par une queue mobile composée de deux nouds, dont le dernier ampulliforme, finissant en une pointe trèsaiguë servant d'aiguillon, et percé pour' le passage d'une liqueur venimeuse; tous les pieds ambulatoires, avec un tarse de trois articles munis au bout de deux crochets; les quatre derniers soudés entre eux à leur naissance.

Plusieurs savans se sont occupés de l'anatomie des animaux qui composent cette famille. MM. Treviranus, Cuvier, Léon Dufour et Marcel de Serres ont publie des mémoires très - imporlans sur cette 
matière. Nous allons donner ici, d'une manière abrégée, le résultat des travaux de ces habiles observateurs. Le système respiratoire, dans les Arachnides formant celte première tribu, est composé de poumons et de stigmates; les poumons, au nombre de huit, sont situés sur les côtés des quatre premières plaques ventrales; elles en offrent chacune une paire qui sont constatables à l'extérieur par autant de taches ovales, blanchâtres, de près d'une ligne de diamètre : ce sont les stigmales. Ces organes sont situés au-dessous d'une toile musculeuse qui revêt la surface interne du derme corné ou la peau de l'animal; mis à nu, le poumon paroît être d'un blanc laiteux, mat, et d'une forme presque semblable à celle de la coquille d'une moule. Il est formé de la réunion d'environ quarante feuillets, fort minces, ẻtroitement imbriqués, taillés en demi-croissant, et qui confluent tous par leur base en un sinus commun, membraneux, et ou s'abouche le stigmate. Le bord libre est d'un blanc plus foncé que le reste, d'où M. Léon Dufour présume qu'il est lui-même composé de plusieurs lamelles superposées, et que c'est lá que s'opère essentiellement la fonction respiratoire. L'organe de la circulation, que M. Léon Dufour nomme vaisseau dorsal, mais que l'on doit considérer, d'après les observations de M. Cuvier, comme un véritable cœur, est allongé, presque cylindrique, et s'étend d'une extrémilé du corps à l'autre en y compienant la queue de l'animal. Il fournit de chaque côté du corps quatre paires de vaisseaux vasculaires principaux qui le ramifient. II existe encore quatre autres vaisseaux qui croisent les premiers en formant avec eux un angle aigu, et qui, avec quatre branches moins considérables, reprennent le sang des poches pulmonaires, et vont le répandre dans différentes parties du corps : ce sont les artères. Avant que de s'étendre dans la queue, le caur jette encore deux rameaux vasculaires qui ne se rendent pas dans Ies poches pulmonaires, mais qui, distribuant ce sang dans diverses parties, doivent être considérés encore comme des artères. Le système nerveux est situé sous le tube alimentaire, le long du milieu du corps. Le cordon médullaire est formé de longs filamens contigus, mais distincts, et de huit ganglions lenticulaires. Le premier ou le céphalique est comme bilobé en avant, et semble être produit par deux ganglions réunis; il est placé justement en dessus de la base des mandibules vers l'origine de l'œsophage. Chacun des lobes de ce ganglion fournit deux nerfs optiques, dont l'un plus cour? va s'épanouir sur la bulbe du grand nil correspondant, et dont l'autre, plus long et plus antérieur, va se distribuer aux trois autres yeux latéraux. Un autre nerf part de cha. que côté du bord postérieur du même ganglion, en se dirigeant en arrière dans le voisinage du premier poumon. Le cordon médullaire s'engage ensuite sous une espèce de membrane tendineuse qui le continue jusqu'à l'extrémité de la queue. Dans ce trajet il présente sept autres ganglions, dont trois dans la cavité abdominale et quatre dans la queue; ccux de l'abdomen, plus distans entre eux que les autres, émettent chacun trois nerfs, dont deux la. téraux pénètrent dans le panicule muscu. leux, envoient des filets aux poumons correspondans, et dont le troisième, qui est inférieur, rétrograde un peu à son origine, et va se distribuer aux viscères. Les quatre derniers ganglions correspondent aux quatre premiers nœuds de la queue, et ne fournissent chacun de chaque côté qu'un seul nerf. Les deux filets des cordons s'écartent ensuite en divergeant, se bifurquent et se ramifient dans les muscles du dernier nœud ou de l'article à aiguillon. Les deux supérieurs se portent sur les muscles moteurs de la vésicule venimeuse, et les inférieurs pènètrent dans la vésicule même en se distribuant probablement dans les glandes de cet organe. Les muscles des scorpions sont assez robustes, formés de fibres simples et droites, d'un gris blanchâtre. Une toile mnsculaire, assez forte, revêt intérieurement les parois de l'abdomen, et enveloppe tous les viscères, à l'exception des poumons et peut-être du vaisseau dorsal ; elle n'adhère pas dans la plus grande partie de son étendue à ces parois. La région dorsale de cette toile donne naissance à sept paires de muscles filiformes qui traversent le foie par des trous ou conduits pratiqués dans la substance de cet organe, et vont se fixer à un ruban musculeux qui règne le long des parois ventrales en passant au-dessus des poumons Ces muscles, mis a découvert, ressemblent à des cordes tendues. Le cinquième anneau de l'abdomen, ou celui qui précède îmmédiatement le premier nœud de la queue, et qui n'a point de poches pulmonaires, est rempli par une masse musculaire très-forte, qui sert à imprimer à la queue les divers mouvements dont 
elle est susceptible; les nouds de cette queue ont un panicule charnu dont les fibres, disposées sur deux côtés opposés, se rendent obliquement à la ligne médiane comme les barhes d'une plume sur leur axe commun. On voit de chaque côté, à la base du dernier nœud ou celui de l'aiguillon, un muscle robuste: Le foie est partagé superficiellement en deux lobes égaux par une rainure médiocre où se loge le cœur ; il est d'une consistance pulpeuse et d'une couleur : brunâtre plus ou moins foncée; il remplit presque toute la capacité de l'abdomen et du céphalothorax, et sert de réceptacle au canal intestinal. Les vaisseaux heppatiques sont au nombre de huit paires, trois dans le céphalothorax, trois autres dans l'abdomen, et deux plus longues vers l'origine de la queue. Le tube alimentaire est grêle et se porte directement, sans aucune inflexion, de la bouche à l'origine du dernier noud de la queue, en traversant le foie, avec lequel il a des connexions an moyen de nombreux vaisseaux hépatiques; son diamètre est à peu près égal dans toute son étendue; cependant il prèsente une dilatation informe dans le céphalothorax et même avant la partie buccale.

Les organes de la géneration des Scorpionides sont doubles dans chaque sexe: ceux du mâle sont de deux sortes, les préparateurs et les copulateurs. Les organes préparateurs se composent : $4^{\circ}$ des lesticules, qui présentent une conformation sin. gulière, et qui n'a, avec celle qu'on observe dans ces mêmes organes desinsectes, qu'une analogie très-indistincte. Chaque testicule est un vaisseau spermatique, formé de trois grandes mailles à peu près semblables, anastomosées entre elles et courbécs le long du foie. Ces mailles sont constituées par un conduit filiforme, demi-transparent, he communiquant que rarement avec celle de l'autre organe préparateur, et aboutissant, par son extrémité postérieure, à un canal déférent, long de quelques lignes, et qui s'abouche à la base d'une vésicule spermatique insérée au côté externe de l'organe copulateur; $2^{\circ}$ de deux vésicules spermatiques d'une nature identique, et remplies d'un sperme plus ou moins blanchâtre; les vaisseaux spermatiques, formés par des canaux larges et cylindriques, naissent d'une des branches des glandes, descendent sur les parties Jatérales de l'abdomen en passant sous le réseau des vaisseaux hépatiques, et communiquent ensemble par des branches latérales arsez multipliées.
Lorsque la fécondation est sur le point d'avoir lien, les raisseaux sont remplis d'une humeur blanchâtre et épaisse, et leur diamètre paroit assez considérable. Les olganes copulateurs sont composés de deux verges, que M. Léon Dufour nommé armures sexuelles; elles sont acculées à droite et à gauche le long du bord externe du foie. Chacune d'elles se présente sous la forme d'une tige effilée et d'un étui mince, presque droit, de consistance cornée, d'un brun pâle, et enveloppée d'une substance comme gélatineuse. Leur extrémité antérieure, ou la plus interne, est bifurquée; la branche extérieure est courte et conoìde, pointue, d'un brun foncé, tandis que l'interne se prolonge en un cordon filiforme, blanchâtre, courbé de manière à former une anse en revenant en sens contraire de la première direction se coller entre le corps de l'organe. Son issue au-dehors du corps a lieu par l'ouverture bilabiée, située à la base de l'abdomen, entre les lames pectinées; la partie supérieure qui duit saillir hors du corps est tres. mince.

Les organes préparateurs de la femelle sont aussi doubles et placés à droite et à gauche dans l'intérieur du foie; ce sont les ovaires et les œufs. Chacun de ces ovaires est un conduit membraneux formé de quatre grandes mailles quadrilatères, anastomosées entre elles, ainsi qu'avec celles de l'ovaire opposé. Lorsque les germes ne sont pas apparens, cet organe ressemble beaucoup à l'organe preparateur mâle; mais, outre qu'il offre une maille de plus, il en differe encore par sa connexion intime et constante avec l'ovaire correspondant. Les mailles aboutissent a un conduit simple, peu allongé, un véritable oviducte qui, avant la réunion avec celle de l'ovaire opposé, offre constamment une légère dilatation. Un col exirêmement simple et commun aux deux matrices débouche dans la vulve. Les œufs sont ronds, blanchâtres; Rédi en a compté quarante, mais M. Léon Dufour, d'accord avec Maupertuis, en a vu jusqu'à soixante. Leur position est très-différente suivant l'é. poque de la gestation. Dans les premiers temps, ils sont logés chacun dans une bourse sphérique, pédiculée, flottant hors du conduit; vers la fin de la gestation et devenus plus gros, ils rentrent dans la matrice, se placent à la file les uns des autres, séparés par des étranglements bien marqués, e!lesbourses s'oblitèrent. L'organe co- 
pulateur se compose de la rulve qui est unique, placée entre les deux peignes et formée de deux pièces ovales, plates, séparées par une ligne médiocre enfoncée, et susceptibles de s'écarter l'une de l'autre. M. Léon Dufour a ohservẻ dans cet organe un corps oblong, corné, creusé en gouttière sur une face, caréné sur l'autre, et long d'environ une ligne: l'une de ces extrémités est libre, largement tronquée, et comme finement dentelée; l'autre, fixée au moyen de deux muscles assez longs, et qui paraissent insérés dans la partie dilatée de chaque oviducte, est terminée par trois lobes, dont les deux latéraux plus petits, courbés en crochets, et dont l'intermédiaire plus grand, en pointe mousse, donnent attache aux muscles précédens. On présume que les amours des scorpions sont nocturnes; ces animaux doivent aussi avoir un mode particulier d'accouplement nécessité par la forme et la situation des organes copula. teurs. Dès le commencement de l'automne, toutes les femelles sont fécondées; leurs œufs sont alors latéraux, petits et pédiculés; ils augmentent de volume pendant l'hiver, et au printemps leur volume est quatre fois plus grand. Leur gestation dure près d'un an, ce qui est fort extraordinaire com. parativement même à celle des animaux à sang rouge. Les œufs éclosent dans l'intérieur du corps de la mère; les petits en sortent tous formés.

L'organe destinè à sécrẻter l'humeur vẻnéneuse est revêtu extérieurement d'une membrane cornée et assez épaisse; il offre dans son intérieur deux glandes jaunâtres, très-adhérentes à la substance cornèe, et se prolongeant par un canal qui s'étend jusqu'à l'extrémité de l'aiguillon; ce canal est élargi vers sa base, et offre une sorte de réservoir pour l'humeur sécrétée par des glandes jaunâtresqui sont composées d'une infinité de glandules arrondies, très-serrées les unes aux autres et communiquant ensemble. M. Marcel de Serres, qui a fait ces observations, ne dit pas par quelle voie la liqueur vénéneuse arrive aux glandes qui en sont le réservoir, et comment elle y est entretenue; mais M. Latreille pense qu'elle dérive principalement de ces vaisseaux situés près de l'origine de la queue, que M Marcel de Serres présume être chylifères, et que M. Léon Dufour place au nombre des vaisseaux hépatiques. M. Marcel de Serres pense que les peignes des Scorpionides leur servent pour la marche, qu'ils élèvent leur corps au-dessus du sol,

AnN. et facilitent leurs mouvemens qui, sans ce secours, seraient rempans; au reste, on pourrait, comme le dit M. Latreille, s'assurer aisément si les peignes sont favorables pour la locomotion : on n'aurait qu'à les attacher avec du fil contre le corps, on pourrait voir alors si les mouvemens de ces animaux seraient plus gênés. Ce savant pense que la composition et la substance de cet organe, la diversité qu'il présente dans le nombre de ses lames ou dents et la position, paraissent indiquer d'autres fonctions qu'il est impossible de déterminer sans faire un grand nombre d'expériences à ce sujet. Peut-être, dit-il, ces peignes sontils un instrument hygrométrique qui leur fait connaître l'état de l'atmosphère, et leur évite des courses dangereuses et inutiles qu'ils pourraient faire dans l'intention de satisfaire aux premiers besoins.

Les Scorpionides habitent les pays chauds de deux hémisphères, vivent à terre ou dans les lieux sablonneux, se cachent sous les picrres ou d'autres corps, le plus souvent dans les masures, dans les lieux sombres et frais, ou même dans l'intérieur des maisons; ils courent vite en recourbant leur queue en forme d'arc sur le dos, et la dirigent en tous sens en s'en servant comme d'une arme offensive et défensive. Leurs serres leur servent à saisir les insectes qui doivent faire leur nourriture; ce sont ordinairement de crabes, des charançons, des cloportes, des orthoptères et d'autres insecies vivant à terre qui deviennent leurs victimes; ils les piquent avec l'aiguillon de leur queue, et les font ensuite passer a leur bouche pour les dévorer. Ces Arachnides sont si multipliées dans certain pays, qu'elles deviennent pour leurs habitans un sujet continuel de crainte, et que même, suivant quelques témoignages, on s'est vu forcé de leur abandonner le terrain. Les Scorpionides ont été connus par les anciens, et la constellation zodiacale du scorpion nous annonce que la connaissance de cet animal remonte à la plus haute antiquité. Pline expose dans son Histoirc naturelle toutes les fables que l'ignorance et la superstition ont enfantées pendant un grand nombre de siècles sur le compte de ces animaux.

Les Scorpionides varient beaucoup pour la grandeur; ceux d'Europe n'ont guère plus d'un pouce de long, tandis que ceux d'Afrique et de l'Inde atteignent jusqu'à cinq ou six pouces. On pense qu'ils sont venimeux; les Persans emploient contre les 
piqûres du Scorpion qu'ils nomment $A g r a b$, et que dans l'Indoustan on nomme Gargouali, la scarification et l'application d'un peu de chaux vive; quelques personnes se servent de l'huile où l'on a rassemblé et laissé digérer plusieurs de ces Arachnides, d'autres préfèrent écraser sur - le - chámp l'animal même et l'appliquer sur la plaie. Les anteurs modernes, tels que Nauperluis, Redi, Maccary, M, léon-Dufour et bcaucoup d'autres, ont fait des expériences pour savoir jusqu'à quel point ces Arachnides sont venimeuses. 11 résulte de tout ce qui a été dit à ce sujet que la piqûre des Scorpions d'Europe ne peut causer que des accidens légers et jamais la mort; cependant celle du Scorpion roussâtre ou de Sauvignargues produit, d'après les expériences que Maccary a faites sur lui-même, des accidens plus graves et plus alarmans, et le venin parait être d'autant plus actif que le Scorpion est plus âgé. Le Buthus Afer, qui vit dans les fentes des rochers on les creux d'arbres, et qui est quatre ou cinq fois plus grand que les précédens, peut causer la mort en moins de deux heures. Les seuls iemèdes sûrs contre sa blessure sont ceux que l'on emploie contre les serpens les plus venimeux; c'est l'alkali vola. til employé soit extérieurement, soit à l'intérieur, des cataplasmes de bouillon blanc et des sudorifiques.

Les Scorpionides portent leurs petits sur leur dos pendant un mois après qu'ils sont éclos. Dans quelques circonstances il les tuent et les dévorent à mesure qu'ils naissent. Si on en enferme plusieurs ensemble, ils ne tardent pas à se battre à mort et à se dévorer jusqu'à ce qu'il n'en reste plus qu'un.

Cette tribu a été divisée en trois genres; ce sont ceux de : Buthus, Scorpio et Androctonus.

BUTHUS, LEACI ;

Scorpio, Linn., Farr., Herbst, Latr.

Ce genre, qui a été créé par M. Leach, diffère de celui de $S$ corpio en ce que les yeux au lieu d'être au nombre de six sont au nombre de huit.-Ce genre renferme un assez grand nombre d'espèces dont quelques-unes se trouvent en Europe. Parmi elles nous citerons comme étant les plus remarquables :

1. ButhUS arer. (Pl. 1, fig. 3.)

Scorpio Afer, Linn., Fabr., SEba, t. I, pl: 70, fig. 1, 4. - Roeser, 1. III, tab. 65. Latr., Hist. nat. des Crust. et des Ins., t. VII, p. 120, tab. 1. - Guérin, Icon。 du Règ. anim. de Cuv. Arachn. pl. 3, fig. 2. - Long. 4 pouc. - Le corps est d'un brunmarron luisant, avec les articulations despattes ei des palpes blanches; les dents de chaque peigne sont au nombre de treize; les quatre premiers articles de la queue sont gros, courts, garnis de dentelures; le cinquième est long ainsi que le dernier; celui-ci est simple, recourbé, couvert de tubercules; le dernier article du vialpe est large, presque en cœur, et comprimé. - On trouve cette espèce en Afrique et aux grandes Indes.

\section{BUTHUS OCCITANUS.}

Lrach, Trans. Soc., 11, 391; ejusd., Encycl. Brit. Suppl., 1, 434; ejusd., Zool. Misc., t. III, 53, pl. 143. - Scorpio Occitanus, Am., Journ. de Phys., juillet 1789. - Latr., Génér. Crust. et lns., 1, 132. - Dur., Journ. de Phys. 1817, 439. Leach, Edinb. Encycl., 7, 428. - Long. 2 pouc. - Il est d'un blanc-jaunâtre sale ; son céphalothorax et sa queue ont plusieurs arêtes graveleuses; les bras sont terminés par une main petite, ovale, et dont les doigts sont longs; les peignes ont chacun vingt-huit dents; la queue est un peu plus longue que le corps, présente des arêtes graveleuses, et se termine par un anneau simple. - Cette espèce se trouve en Espagne et en Barbarie.

\section{BUTHUS TESTACEUS.}

Scorpio Testaceus, Degéer, Mém. sur les Ins., t. VII, pl. 41, fig. 11. - Seba, t. V, tab. 70, fig. 5. - Latr., Hist. nat. des Crust. et des Ins., t. VII, p. 125. Scorpio Griscus, Fabr.-Le corps est d'un jaune fauve; les peignes ont de vingt-six a vingt-huit dents; les serres sont oblongues, avec les doigts filiformes; la queue est plus longue que le corps, et son dernier anneau est simple.

Cette espèce a de grands rapports avec la précédente, mais elle s'en distingue en ce qu'elle est beaucoup plus pâle ct moins chagrinée; sa queue est proportionnellement plus allongée; sa longueur étant dou. ble de celle du corps, les nœuds, l'avantdernier surtout, n'offrent que de faibles arêtes, tandis que la queue du. B. Occitanus en a de très-fortes et de très-dentées: les doigts des serres sont plus courts que ceux de celui-ci, ils ne sont que de la lon- 
gueur du corps et des mains; de plus cette espèce est particulière à l'Amérique méridionale, et le $B$. Occitanus est de l'ancien continent.

\section{BUTHUS JUNGEUS.}

Scorpio Junccus, Herbst, t. II , fig. 2. - Latr., Hist. nat. des Crust. et des Ins., t, VII, p. 128. - Long. 2 pouc. $\frac{1}{2}$.-Cette espèce est cylindrique, d'un brun-roussâtre; le céphalothorax, la queue et les bras ont des lignes élevées, grenues ou finement denticulées; le bord antérieur du céphalothorax est èchancré; les peignes ont chacun seize dents; les doigts sont très-longs et filiformes; le dernier anneau ne présente pas de dent sous l'aiguillon. - Se trouve dans l'Amérique-Méridionale.

\section{BUTHUS IONGICAUDA.}

Scorpio Longicauda, LATr., Hist. nat. des Crust. et des Ins., t. VII, p. 126. Scorpion d'Europe, DegéER, Mém. sur les Ins., t. VII, pl. 41, fig. 5. - Scorpio Hottentota, Herist, tab. 3, fig. 4.-Long. 2 pouc. - Il est d'un brun très-foncè, presque noir; les peignes ont chacun dix huit dents; les serres sont allongées, avec des arêtes; les doigts sont courts et filiformes; la queue est plus longue que le corps, armée d'un fort aiguillon, avec une dent ou pointe à sa partie antérieure. Cette espèce a été trouvée à Cayenne.

\section{BUTHUS GRAGILIS.}

Scorpio Gracilis, Latr., Hist. nat. des Crust. et des Ins, , t. VII, p. 127. - Scorpion austral, Degéer, Mém. sur les Ins., t. VII, pl. 41, fig. 5.-Long. 3 pouc. 4 lig. -Brun, avec les pattes rousses et les peignes offrant trente-deux dents; les serres sont allongées, rousses, avec les doigts filiformes; la queue est plus longue que le corps, et l'aiguillon est armé d'une pointe à sa base; les mâles sont plus petits. - La patrie que Degéer donne à cette espèce est l'Amérique.

\section{Buthus PUNCTATUS.}

Scorpio Punctatus, Degéer, : Mém. sur les Ins., t. VII, pl. 41, fig. 1. - Latr., Hist. nat. des Crust. et des Ins., t. VII, p. 197. - Long. 1 pouc. $\frac{1}{2}$. - D'un brun roussâtre ou jaunâtre ponctué de brun obscur; les peignes ont chacun seize dents; les serres sont allongées, avec les doigts filiformes; l'aiguillon est armé d'une pointe à sa base; la queue est de la longueur du corps. - Cette espèce a été trouvée aux Antilles.

\section{RUTHUS ARETICANUS.}

Scorpio Americanus, Linn., Fabri., Rozset, t. III, tab. 66, fig. 5. - Seorpion tacheté, Degéer, Mém. sur les Ins., t. VII, pl. 41 , fig. 9 et 10. - Henest, tab. 6 , fig. 3. - Gette espèce est grêle, très-allongée, jaunâtre, mouchetéc de brun; les peignes ont chacun dix-huit dents ; les bras sont longs et menus; les doigts sont filiformes; la longueur de la queue est triple de celle du corps, et l'aiguillon est armé d'une pointe à sa partie inférieure. - Elle se trouve en Amérique.

\section{BUTHUS BaHIENSIS.}

Scorpio Bahiensis, Perty, Delect. Anim. articul., p. 200 , pl. 39, fig. 11.Le céphalothorax antérieurement est tronqué, droit, à peine échancré; il est entièrement fauve, granuleux, convexe, avec des lignes élevées, transverses; interrompues; Ies yeux sont noirs, les deux du milieu plus grands, et trois autres plus petits, situés antérieurement de chaque côté, près du bord. -Les palpes sont prismatiques, avec des lignes élevées, le dernier article renflé, avec les doigts filiformes; testacés, avec les tro:sième et quatrième articles, et les doigts noirâtres; l'abdomen est fauve, granuleux, avec une ligne médiane, longitudinale, élevée, et d'autres petites lignes élevées, transverses, interrompues, et plusieurs longitudinales sur le dernier segment; la queue est épaisse, avec les articles renflès, excavés postérieurement, carénés sur les côtés, avec les côtés de ces carènes crénelés; le dernier segment se termine un pei en pointe, avec son extrémité armée d'une épine ferrugineuse, recourbée; le dessous est testacé d'ocre avec les pieds; les peignes sont d'une couleur plus pâle, et les dents sont au nombre de vingt. - Cette espèce a étẻ rencontrée près de Bahia.

\section{SCORPIO, Linn., Fabi., IIerist, Latr.}

Les yeux sont au nombre de six.-L'ab. domen est sessile et offre en dessous et de chaque côté quatre spiracules, avec deux lames pectinées à sa base. - Les six derniers anneaux forment une queue noueuse, le dernier finit en pointe; sert d'aiguillon et est percé pour donner passage au venin. Les palpes sont en forme de serres d'Ecrevisse. - Les chélicères sont didactyles. Les pieds sont égaux. - La langue est divisée en deux jusqu'à la base. - Le corps est étroit et allongé. 
Ce genre se compose d'un très-grand nombre d'espèces propres a toutes les contrées du globe.

\section{SCORPIO EUROPOEUS.}

Herbst, S S corp., tab. 3, fig. 2. - Scopoli, Entom. Carn., no 1122. - Seba, Mus., t. I, tab. 70, no 9, 10.-Roesel, Ins., t. III ; Suppl., t. LXVI, fig. 1 et 2. - Latr., Hist. nat. des Crust. et des Ins., 1. VII, p. 118. - Le Scorpion janne a queue; DEGÉER, Mém. sur les Ins., t. V II, p. 339 , pl. 40 , fig. 11. - Long. 1 pouc. - Son corps est d'un brun trèsfoncé, noirâtre; ses bras sont anguleux, avec la main presque en cour, et l'article qui le précède unidenté; la queue est plus courte que le corps, menue; le cinquième nœud est allongé, le dernier est simple, d'un brun-jaunâtre, ainsi que les pattes; les peignes on chacun neuf dents.

Cette espèce se trouve dans l'Europe méridionale, vers le quarante-troisième degrès de latitude et au-delà, jusque dans.les maisons.

\section{ANDROCTONUS, Ehrenb. et HeMprich.}

Les yeux sont placés sur le front et sur les côtés latéraux, il y en a cinq de chaque côté et deux autres placés sur la partie antérieure du céphalothorax.

\section{ANDROCTONUS QUINOUE-STRIATUS.}

Ehrenb, et Heupr., tab. 1, fig. 5. - Les mains sont plus étroites que le bras; le dernier article de la queue est de la largeur du pénultième, qui est de double plus long que large et finement crénelé en dessous; celte espèce est d'une couleur brillante, légérement teintée de jaune, avec le dessus varié de taches brunâtres; de plus la partie médiane de sa queue et du pénultième article est noirâtre; le dernier article ou celui qui supporte l'aiguillon est armé d'une épine assez longue; les peignes ont trente-deux dents. - Cette espece a été trouvée en Nubie.

\section{ANDROCTONES IEPTOCHELYS.}

Ehrenb. et Hempr. - Les mains sont plus étroites que le bras, avec les doigts plus longs que la main; le dernier article de la queue est plus étroit que le pénultième; ce dernier est du double plus long que large, et on aperçoit une petile épine qui est de la longneur de la vésicule; la couleur est d'us facve pâle excepté la partie antérieure de l'épine qui est noirâtre; les peignes présentent vingt-sept dents. - Se trouve dans les montagnes du Sinaĩ.

\section{ANDROCTONUS SCABER,}

Enrenb. et Hespr., tab. 2, fig. 7. - Le céphalothorax est rouge avec sa partie supérieure de même couleur; cette espèce est longue á peu près de deax pouces, d'une couleur jaune fauve, roussâtre, avec la partie antérieure de la queue et une moitié de sa par. tie postérieure noirâtres; les doigts sont plus longs que les mains; le dernier arlicle de la queue est plus épais que le pénultième, ce dernier est plus long que large et du double plus long que haut; les peignes sont armés de vingt-huit dents.

\section{ANDROCTONUS VARIEGATUS.}

Guer., Mag. de Zool., cl. 8, fig. 2. Le céphalothorax est allongé, de forme trapézoīde, plus ètroit en avant, échancré au bord antérieur, avec un sillon profond au milieu el inégal sur toute sa surface; les deux gros yeux du centre sont situés un peu en avant du milieu, sur une éminence, et dirigés sur les côtés; les autres yeux sont placés tout-à-fait aux angles antérieurs et latéraux; chaque groupe est composé de cinq yeux dont les trois plus gros sont égaux, placés tout-à-fait sur le bord du céphalothorax, sur une élévation ovalaire; en dedans de ces trois yeux, et sur le bord interne du tubercule qui le supporte, on observe deux autres yeux de moitié plus petits, situés un peu plus bas, le postérieur plus près et audessous du dernier des trois gros, l'autre plus loin et entre l'avant-dernier et le dernier des précédens; les segmens de l'ab. domen sont transverses et présentent une petite carène au milieu s le dernier, ou celui qui précède la queue, en présente trois; les anneaux de la queue vont en aug. mentant de longueur jusqu'au dernier; ils sont creusés en sillon au milieu; leurs arêtes latẻrales supérieures sont très-saillantes, crénelées et terminées en arrière par une pelite pointe saillante; les deux premiers anneaux ont, sur les côtés et au-dessous de l'arète dont il vient d'être question, trois petites arêtes longitudinales; les pinces sont un peu plus longues que le corps, grêles; l'avant-dernier article est un peu élargi au milieu, il porte en dessus trois côtes lisses, et en dedars plusieurs petites dents; la main est grêle, avec les doigts courbés en dedans, ayant presque deux fois la longueur du poignet; les pattes sont allongées, aplaties; la couleur générale de cette es- 
péce est d'un jaune obscur, tout son corps en dessus est marqué de petites marbrures noirâtres; les pattes et les pinces sont comme annelées par des taches de la même couleur; la queue est plus uniforme de couleur, le dessous est plus pâle et trèspeu tacheté. - Celte espèce a été trouvée au Port-Praslin.

\section{DEUXIEME TRIBU.}

\section{TARENT ULES, Fabricius.}

Caractères. Cette tribu est composée du genre Tarentula de Fabricius, et d'espèces de celui de Phalangium de Linné et de Pallas. Ces Arachnides se rapprochent des $\mathbf{M y}$ gales, premier genre de la famille suivante, quant au nombre des sacs branchiaux et de leurs ouvertures, qui n'est plus de quatre; sous le rapport des chélicères, ou mandibules des auteurs, terminées en griffe ou par un crochet se repliant verticalement en dessous, et quant à l'abdomen rétréci et pédiculé à sa base; mais il est composé d'une douzaine d'anneaux très-distincts, protégés, du moins en dessus, par un derme coriace, et il est dépourvu de filières; il se termine, au plus, par un appendice filiforme, composé d'un grand nombre de petits articles; on ne voit pas de lames pectinées à l'origine du ventre. - Les palpes sont épineux, tantôt grêles et longs et terminés en griffe, tantôt plus courts, plus épais, avec une pince didactyle au bout, comme ceux des Scorpions. - Les yeux, au nombre de liuit, sont distribués en trois groupes : l'un composé de deux et porté sur un tubercule commun, et situé près du milieu du bort antérieur du céphalothorax, et les trois autres, un de chaque côté, près de ses extrémités latérales antérieures, et formés chacun de trois yeux disposés en triangle. - La lèvre est cachée entre les deux mầchoires, constituées de même que celles des Scorpions par l'article radical des palpes, et en forme de petit dard, corné, linéaire et droit.

Ces Arachnides different en outre de toutes celles du même ordre, par la forme des deux pieds antérieurs, qui semblent faire les fonctions de palpes ou d'antennes. Leurs tarses, souvent très-longs, sont composés d'un grand nombre de petits articles, mutiques et sans crochets au bout. L'animal porte ses pieds en avant. Toutes les espèces connues sont exclusivement propres aux pays des deux continens situés entre les tropiques, et forment deux genres : ceux de Thelyphonus et Phrynus.

\section{THELYPHONUS, LATR. ; \\ Tarentula, Fasr.}

Les yeux sont au nombre de huit, et ainsi disposés : la première paire est placée tout-à-fait à la partie antérieure du céphalothoras sur un petit tubercule ; les seconde. troisieme et quatrième paires sont placées sur les côtés latéraux du céphalothorax, ils sont très-éloignés de la première paire; les yeux sont petits, arrondis et peu éloignés les uns des autres. - Le céphalothorax a la forme d'un quadrilatère allongé, il est toujours plus long que large, terminé en une pointe arrondie antérieurement et brusquement tronquée postérieurement. - La bouche se compose inférieurement d'une paire de mâchoires formée par l'article radical de leurs palpes, et supéricurement d'une paire de crochets mobiles, servant, avec les mâchoires, à triturer les matières animales dont se nourrissent ces Arachnides. - Les palpes sont allongés, épineux, très-robustes et terminés en pince à leur extrémité.-liespattes, au nombre de quatre paires, sont très-remarquables et offrent entre elles des différences très-sensibles: la première paire est très-allongée, très-grèle, avec le dernier article n'offrant aucune griffe à son extrémité; cette première paire de pattes semble plutôt propre au toucher qu'a la marche; les pattes suivantes sont robustes et toutes terminées à leur extrémité par une griffe, conformation qui annonce que ces derniers organes sont propres à la marche. II y a aussi une différence très-sensible dans leur longueur relative; la première paire est la plus longue, la quatrième ensuite, la troisième après, et enfin la dernière est la plus courte. - L'abdomen est ovalaire, composé de neuf anneaux et terminé postérieurement par une queue en forme de soie, dont les deux premiers articles sont trèscourts, le troisième gros et allongé; les autres, au nombre de quarante environ, sont petits, étroits, cordiformes, et hérissés de poils; cette queue à son extrémité ne présente aucun organe vénéneux.

Les meurs de ces Arachnides sont pen connues, elles habitent l'Amérique Méridionale; les habitants de la Martinique les désignent sous le nom de vinaigrier, à cause de- l'odeur très-prononcée de vinaigrs. 
qu'elles répandent quand on les inquiète ou qu'on cherche à s'en emparer. On les troure ordinairement seus les pierres, à terre, dans les lieux humides. Ce genre est très-peu nombreux en espèces; mais nous en avons fait connoître plusicurs autres dans un travail ayant pour titre : Essai sur une Monographie du genre Thélyphone, et qui a été inséré dans le Magasin de Zoologie de M. Guérin. Nous citerons comme les plus remarquables :

1. TRELYPhoNus GigaNteus. (Pl.1, fig. 1.) Lucas, Mag. de Zool., cl. 8, pl.8. Long. 2 pouc. $\frac{1}{2}$. - Le céphalothorax est allongé, étroit antérieurement, plus large postéricurement el très-granuleux, surtout a sa partie antéricure; sa partie supérieure est assez déprimée ét présente quelques lignes transversales; les palpes sont très-allongés, robustes et très granuleux, avec le second article armé antérieurement de cinq épines très-apparentes, et intérieurement de deux; les pattes sont très-allongées, avec leurs derniers articles rougeâtres et hérissés de poils de même couleur; l'abdomen est ovalaire, avec des points stygmatiformes fortement marqués sur les anneaux; sa partie supéricure est granuleuse, tandis qu'inférieurement il ne présente aucune granulation; la queue est allongée, fliforme et hérissée de poils rougeâtres. - Cette espèce a été trouvée au Mexique.

\section{THELYPHONUS CAUDATUS.}

Latr, Rég. anim. de Cuv., t. IV, p. 266. - Guér., Icon. du Règ, anim. de Cuv., Arachn., pl. 3, fig. 3. - Lucas, Mag. de Zool., cl. 8, pl. 9, fig. 1. - TheIyphonus Proscorpio, Latr., Génér. des Crust., et des.Ins., t. I, p. 129; ejusd., Iist. nat. des Crust. et des Ins., t. VII, p. 132, pl. 60, fig. 4.- Phalangium Caudatum, Linn., Syst. Nat., t. 1, part. 11, p. 1029. - Tarentula Caudata, Fabr., Ent. Syst., t. II, p. 433. - Long. 15 lig. - D'un rouge-brun en dessus, d'un rouge clair en dessous, avec des granalutions moins apparentes que dans l'espèce précédente; le céphalothorax est long et étroit, avec les raies transversales bien marquées; leschélicères tont peu allongées, le premier article est armè d'une longue épine antérieurement, le second présente cinq épines supérieurement, et deux inférieurement, dont une a peine apparente; le troiíme article est cutierement lisse à sa par- tia supéricure, et présente intéricurement une petite épine; le quatrième article, de forme arrondie, est armé à ses parties antérieure et supérieure de deux épines, dont une trés-longue, et une autre un peu moins longue postérieurement; le cinquième article est terminé comme dans l'espèce précédente; l'abdomen est peu allongé, presque aussi large antérieurement que postérieurement; les anneaux présentent des points stigmatiformes, à peine marqués; le dessous, qui est d'un rouge plus clair que le dessus, présente un large anneau arqué postérieurement; le second, qui est étroit et strié, est un peu en croissant postérieure. ment; le troisième est très-étroit; les anneaux présentent des points stigmatiformes un peu plus marqués que ceux qui sont sur les anneaux de la partie supérieure; les pattes sont allongées. d'un ronge-brun en dessus, et d'un rouge-brun ciair en dessous. Cette espece se trouve à la Martinique.

\section{THELYPHONUS RUFIPES.}

Lucas, Mag. de Zool., cl. 8, pl. 9, fig. 2. - Long. 11 lig. - Le céphalothorax est d'un rouge-brun en dessus, peu allongé, arrondi à sa partie antérieure, plan supérieurement, et de forme arrondie postérieurement; les pinces qui terminent les palpes sont courtes, arrondies; leur premier article est d'un rouge-brun en dessus, d'un rouge plus clair en dessous, avec une épine trés-aiguë à sa partie antérieure; le second article est arrondi supérieurement, avec cinq petites épines, et deux petites inférieurement; le quatrième article est court, arrondi, armé .d'une forte épine supérieurement; l'abdomen est déprimé, d'un rouge-brun; les points stigmatiformes sont à peine apparents; en dessus il est entierement rouge; les pattes sont courtes et de même couleur. - La patric de cette espece est inconnue.

\section{THELYPHONUS ANGUSTUS.}

Lucas, Mag. de Zool., cl. 8, pl. 10, fig. 3. - Long. 8 lig. - Le céphalothorax est étroit, entièrement brun, avec sa partie supérieure arrondie; les yeux antérieurs sont d'un noir brillant, entourés d'un petit disque, rougeâtre; les yeux postérieurs sont rougeâtres; les chèlicères sont courtes, d'un rouge-brun en dessus, et d'un rouge plus clair en dessous; le premier article est armé d'une épine à sa partie antérieure; le second présente cinq épines supérieurement, et deux inférieu- 
Tome ${ }_{1}$ er ${ }_{1}^{\text {ère }}$ partie.

Arachnides, Pl. 1',

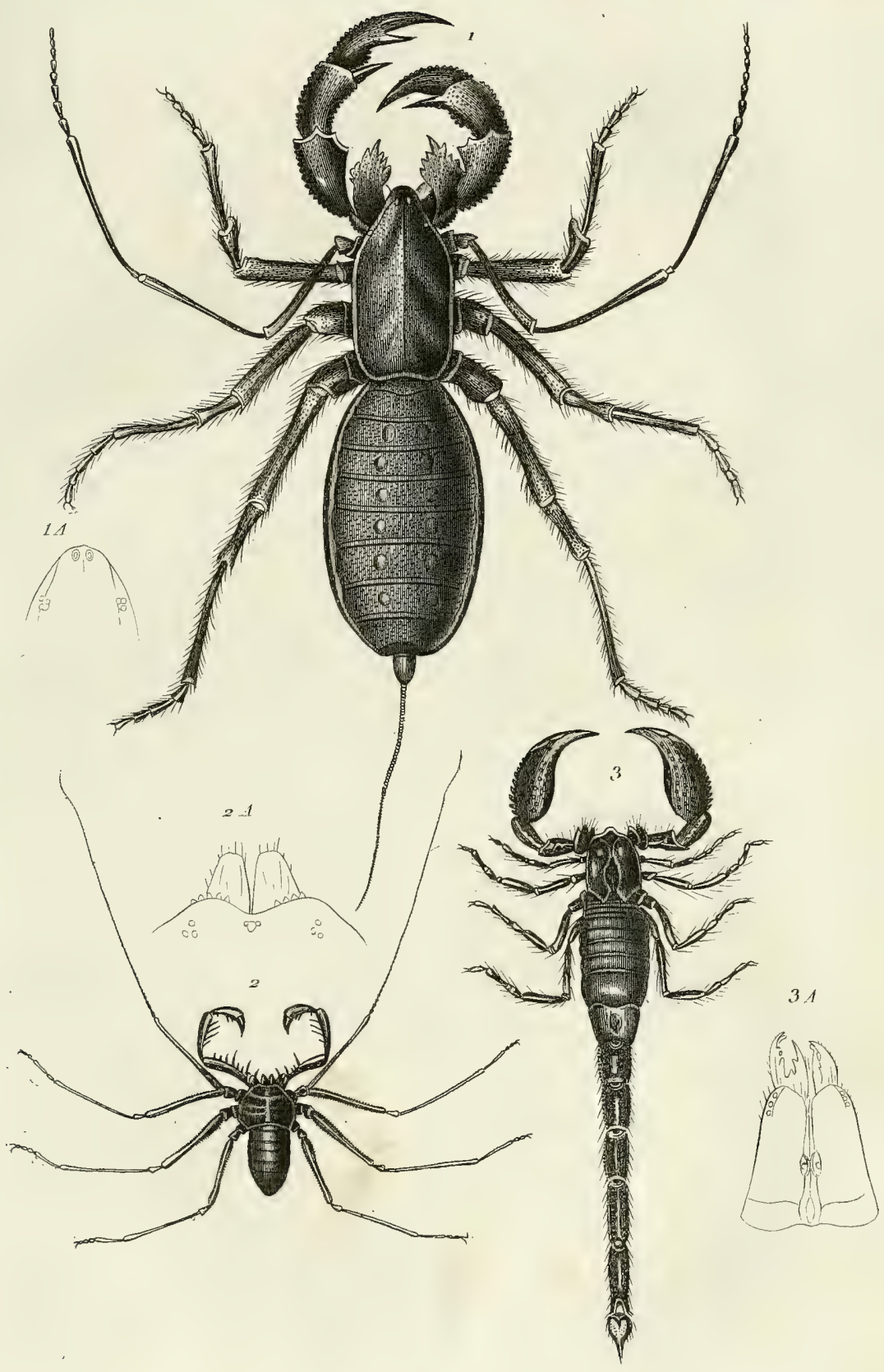

1. Thelyphomus giỏanteus.

. A . youx do Thelyph, caudatus.
2. $2 \Lambda$. Phryons reniformis .

33 A. Butus afer. 

rement; le troisième est entièrement lisse supérieurcment et armé d'une épine inférieurement; le quatrième article présente antérieurement une forte épine, qui ellemême est hérissée en dessous par d'autres épines très-petites; le cinquième article est court, semblable aux autres articles des espèces précédentes, exceplé qu'il est hérissé antérieurement de petites épines; l'abdomen, d'un brun un peu plus clair, est très-allongé; les points stigmatiformes ne sont visibles qu'aux trois premiers anneaux; le dessous diffère du dessus par la couleur, qui est d'un brun plus clair, par le premier anneau, qui est un peu plus large que les autres, et par les points stigmatiformes, qui ne sont point apparents; les pattes sont grêles, allongées, avec les premiers articles bruns, les suivans un peu plus clairs; la queue est entièrement brune.

Consultez pour les autres especes notre Monographie qui a été insérée dans le Magasin de Zoologie de M. Guérin.

\section{PHRYNUS, Oliv., Latr. Tarentula, Fabr.}

Ce genre diffère de celui de Scorpion et de I hélyphone, en ce que le corps n'est pas terminé par une queue, qu'il est ovale, oblong el déprimé, et que la bouche offre une pièce en forme de dard. - Le céphalothorax est large et son bord postérieur est échancré vers le milieu. - Il a la figure d'un rein ou presque celle d'un croissant. Les bras et les palpes sont souvent tresgrands et fort épineux; ils ne sont pas terminés par une main munie de deux doigts, mais par une ou deux pointes fortes ou un crochet. - Les mandibules ont à peu près la même conformation que celles des Scorpions et des Thély phones, mais une de leurs serres est beaucoup plus conrte que l'autre. - Les yeux sont au nombre de huit, dont deux sur un tubercule, près du milieu du bord antérieur du céphalothorax, et trois autres de chaque côté, groupés et formant un triangle. - La paire de pattes antérieures est trè-longue, fort menue et filiforme, sans crochets au bout; les trois autres paires ont leurs iarses courts, de quatre articles, et deux crochets à leur extrémité; celles de la seconde et de la troisième paire sont presque égales et un peu plus longues que la dernière. - L'abdomen est ovale, à anneaux distincts, et fixé au céphalothorax par une pelite portion de son diamètre transversal.

Les Arachnides qui composent ce genre sont propres aux contrées chaudes de l'Amérique et rle l'Asie. M. Déjardins, qui en a envoyé de Saint-Domingue, dit en avoir trouvé dans le détritus de vieux troncs d'arbres pourris. Les nègres de ce pays les. craignent beaucoup, mais M. Déjardins n'a jamais eu occasion de s'assurer si leur mos:sure était dangereuse.

\section{1. phryes unatus.}

Latr., Hist. nat. des Crust. et des Ins., t. V1I, p. 176. - Tarentula Lunata, FAsR. - Seb a, t. IV, pl. 99, fig. 13.-Phalangium Lunatum, PaLlas, Spicil. Zool., fasc. 9. tab. 3, fig. 5, 6. - Herst, tab. 3. - Cette espèce est remarquable par la longueur de ses bras, qui est triple de celle du corps, et elle se distingue des suivantes en ce que le troisième article et le quatrième, l'extrémité de celui-ci exceptẻe, n'ont pas d'épines remarquables; ces articles sont très-longs.

\section{2. phrýus reniformis. (Pl. 1, fig. 2.)}

LAтn., Hist. nat. des Crust. ct de Ins., t. VII, p. 136 . - GuÉn, Icon, du Règn. anim. de Cuv., Arachn., pI. 3, fig. 1.Phalangium reniforme, Linn., Pallas, Spicil. Zool. . fasc. 9 , tab. 13 , fig. 3,4 . - Henbst, tab. 5, fig. 1. - Tarentula reniformis, FABR. - Les bras sont très-épineux au côté interne; les troisième et quatrième articles sont allongés; le cinquième, ou celui qui dépend de la main, a quatre épines.

\section{3. phryvus variegatus.}

Perty, Delect. Anim. Articul., p. 300 , pl. 39, fig. 10. - Plus petite que le Phryne palmé de Herbst; les chélicères sont ferrugineuses; les palpes sont de même couleur; le second article est denticulé, court; le troisième allongé, prismalique en dessus, denté; le quatrième rugueux, à peine plus court que le précédent, armé à son extrémité de trois épines allongées; le cinquième unguiforme, bifide; les yeux sont seulement au nombre de six (1), deux situés antérieurement sur un tubercule méỏian, et deux autres situés de chaque côté du céphalothorax, très-rapprochés; le céphalothorax est cordiforme en devant, presque aussi long que large, ferrugineux, varié de roux, avec quelques impressions en forme d'X; l'abdomen est $d^{5} u n$ ferrugineux ocracé, varié de fauve, avec le dessous d'un fauve ocracé; les pieds-palpes sont plus longs que les pieds, ferrugineux; les pieds sont:

(1) Suirant M. Perty. 
d'une couleur d'ocre ferrugineux, avec les cuisses annelées de fauve. - Cetle espèce a été trouvée près du fleuve des Amazones.

Consultez pour les autres espèces le tome VII de l'Histoire naturelle des Crus. tacés, des Arachnides, et des Insectes, par M. Latreille, et les Élèmens de Zoologie, par M. Guérin.

\section{DEUXIEME FAMILLE.}

\section{A R A N É IDES,}

\section{LATREILLE.}

Les caractères qui distinguent cette famille de la précédente sont quatre ou six appendices cylindriques ou coniques, articulés, situès vers la partie anale, désignés sous le nom de filieres, parce que ces parties. à l'exception de deux, ont leur extrémité, soit percée d'un très grand nombre de trous, livrant passage à des fils soyeux, soit hérissée de petits mamelons d'où sortent aussi ces fils. De plus, tous les animaux qui composent cette famille ont un corselet d'une seule pièce réunie à la 1ête, qui se manifeste par la présence des yeux, au nombre de huit ou de six, et par les organes de la bouche placés au-dessous de la partie antérieure du corselet. Cet organe, a cause de sa conformation en une seule pièce, a recu le nom de céphalothorax. Les organes de la bouche présentent au-devant, sous le labre, deux mandibules ou pièces munies d'un seul onglet, deux mâchoires pourvues de deux palpes de cinq articles et quelquefois de sịx, séparées a leur base par une lèvre sternale et une languette velue, membraneuse, d'une seule pièce, insérée entre ces parties. - Huit pattes de sept articles chacune, terminées par deux ou trois griffes, sont attachées à l'entour du céphalothorax, à la partie postérieure duquel l'abdomen est suspendu par un pédicule court, cartilagineux; cet abdomen est mobile, d'une seule pièce ou sans division, et se termine par un petite saíllie, avec une fente au milieu, qui est la partie anale, et par quatre ou six mameJons charnus placés en dessous de la partie anale, destinés à élaborer la soie, qu'on a nommés filières. - L'abdomen présente en-dessous, et à sa partie antérieure dans Jes deux sexes, deux ou quatre fentes, et au milieu de l'espace qui les sépare, on remarque en outre dans les femelles une ouverture circulaire qui les distingue.

Tel est en peu de mots l'ensemble des caractères extérieuis communs à toutes les
Aranéides; maintenant nous allons passer à un examen plus détaillé de l'organisation de ces animaux, et à l'histoire de leurs habitudes.

Le céphalothorax est généralement ovoïde ou en cœur renversé, déprimé, ou légèrement élevé en carène vers le milieu du dos, avec l'extrémité antérieure de la pointe tronquée ou très-obtuse; mais ces formes ne sont pas toujours constantes, et nous offrent des modifications qui ont servi à l'observateur, à la classification, à l'établissement des genres et à la distinction des espèces entre elles.

Les yeux, généralement situés à la partıe antérieure du céphalothorax, sont toujours au nombre de huit ou de dix : la plupart en ont huit. La position de ces organes est très-variée, et c'est de cette variation qu'ont été tirés les caractères de genres les plus faciles, les plus apparens et les plus certains. Ces organes, dans quelques individus, sont ramassẻs, rapprochẹs en un seul groupe, sur le milieu de la partie antérieure du céphalothorax, tandis que chez d'autres, au contraire, ils sont disséminés entre eux. - Les mandibules, qu'on a désignées aussi sous le nom de chélicẻres, forcipules, antennes, pinces, serres, placées immédiatement vers le labre, se composent de deux pièces: la mandibule proprement dite et le crochet; la mandibule, qui est la plus grande, et surtout la plus grosse de ces deux pièces, est presque toujours cylindrique, plane à sa face interne, ct offrant le plus souvent, à l'extrèmité de son côté interne, une rainure dont les côtés sont armés de dents acérées, et dans la cavité de laquelle le crochet s'insère en se reployant. Ge dernier est mobile, arqué, très-dur, et généralement percé d'un petit trou qui livre passage à la liqueur véné. neuse avec laquelle l'araignée donne la mort aux insectes qu'elle attaque pour s'en nourrir. 
Les mâchoires et la lèvre sternale dans toutes les Aranéides se portent en avant et dans le sens de la longueur du corps. Les premiers de ces organes sont velus à leur extrémité, qui est plus ou moins arrondie et souvent tronquée obliquement au côté interne, ou retrécie en poinle : ici, ils sont droits; là, ils se courbent et s'inclinent sur la lèvre. Cette pièce est carénée dans les uns, triangulaire et demi-ovale, ou presque ovoïde, dans les autres.

Les palpes, portés par les mâchoires, s'avancent de chaque côté des mandibules, et comme ils font l'office de pattes ou de bras, on les a nommés pieds ou bras palpaires. Les articles qui les composent sont ordinairement au nombre de cing, et le plus souvent terminés par un crochet dans les femelles, par une massue arrondie ou ovalaire dans les mâles. La forme de ces articles est assez variée, et chacun d'eux porte différens noms. Le prenier article ou l'axil. laire est ordinairement court; le second, ou l'humėral, allongé; le troisième, ou cubital, court; le quatrième, ou radical, allongé; le cinquième, ou digital, plus ou moins allongé dans les femelles et armé d'une griffe à l'extrémité. Dans les mâles ce cinquième article n'a pas de grilfes, il est court et renflé, et contient dans une capsule arrondie, ovalaire, les organes de la gènération, compliqués et multiples et de formes variées, mais composés cependant toujours d'une ou deux valves membraneuses, susceptibles de gonflement, munies à leur surface interne de petites membranes ou filets cylindriques, arrondis, en pointe ou en croissant, contournés en vis, recourbés en crochets, entrelacés en nœuds, affectant un nombre de formes différentes, selon les genres, mobiles, rétractiles; se luméfiant et se grossissant dans l'acte de la copulation. On les a nommés conjoncteurs; mais ces organes, qui n'ont encore été qu'imparfaitement étudiẻs, ne sont développés que quand l'Aranéide est parvenue à l'âge adulte. Avant ce temps, ce dernier article est en forme de tire-bouchon plus on moins renfié, globuleux, sans cavités ni ouvertures. Quelquefois ces palpes présentent six articles, et nous avons désigné ce nouvel article sous le nom de métadigital.

La lève se présente sous la forme d'un parallélogramme plus ou moins allongé, et dont la base cst toujours plus large que l'extrémité. Elle varie beaucoup dans sa forme, selon les genres.
La languette est demi-cartilagineuse, velue sur les côtés et à son extrémité, et insérée entre les mandibules, les mâchoires et la lèvre, qu'elle dépasse le plů souvent par son extrẻmité.

Le plastron sternal, coriace, présente toujours la forme d'un cœur plus ou moins arrondi ou allongé, et dont la pointe est tournée vers la partie postérieure; il est découpé, ou festonné, par les portions de cercles formées par les échancrures que né. cessitent l'insertion des pattes.

Les pattes sont disposées presque circulairement à l'entour du céphalothorax, et se composent d'une hanche d'un seul article; d'une cuisse et d'une jambe formées chacune de deux articles, et d'un pied divisé de même en deux articles, à l'exception d'un seul genre, celui de Hersilia, qui en présente trois. Les divers articles composant ces pattes sont de formes différentes; ainsi la hanche est toujours tréscourte et adhérente au céphalothorax; la cuisse, qui se compose de deux articles, a été distinguée sous le nom d'exinguinal et de fémoral; la jambe, qui renferme deux articles, a été désignée. le premier article le génual, et le second le tibial; enfin le pied, qui se compose de deux articles, est distingué sous le nom de métatarse et de tarse. Plus haut nous avons dit qu'un seul genre, celui d'Hersilia, présentait un article de plus aux pieds : ce nouvel article a reçu le nom de métatarse; à l'extrémité du tarse dans la plus grande partie des Aranéides, se trouvent, presque toujours, deux ou trois griffes auxquelles on a donné le nom d'onglets; ces deux crochets courbés, insérés l'un à côté de l'autre, sont pectinés dans un grand nombre. Dans beaucoup d'Aranéides se trouve un troisième onglet, plus court, plus droit, non pectiné, qui est opposé aux deux autres. Cet onglet plus simple est nommé l'onglet inférieur, les deux autres les onglets supé. rieurs. Quelques Aranéides ont aussi les tarses terminés par des poils raides formant des espèces de pinceau ou de poils, ou des membranes charnues. Généralement ces organes sont plus forts, plus gros, plus rainassés chez les Aranéides chasseuses, errantes ou vagabondes, que chez celles qui sont sédentaires, et qui attendent que les insectes dont elles doivent se nourrir se soient pris aux grandes toiles qu'elles ont tissues. La longueur relative de ces mêmes organes differe non-seulement selon les genres, mois selon les sections du même genre; 
et, enfin; quelquefois, mais rarement, selon le sexe pour la même espèce.

L'abdomen, suspendu au céphalothorax au moyen d'un court pédicule cartilagineux, est celui des Gastéracanthes exceptées, mou, revêtu d'une peau continue, sans articulations, et formant un sac tantôt ovalaire ou globuleux, tantôt oblong ou cylindıoìde. $\AA$ l'extrémité postérieure est siture la partie anale, qui s'avance sous la forme d'un petit chaperon arrondi, ou presque demi-circulaire, et ayant une fente au milieu. L'on voit immédiatement au-des. sous, des petits appendices articulés, cylin. driques et rétrécis en pointe au bout, ou presque coniques, au nombre de six dans le plus grand nombre et de quatre dans les autres: on les a désignés sous le nom de filières; mais, comme l'ont remarqué Lyonnet, M. Savigny et Treviranus, deux de ces appendices, les plus extérieurs, ordinairement les plus longs, et divisés en trois articles, ne présentant à leur extrémité ni petits trous, ni petites papilles percées, ne méritent point une telle qualification. Les filières proprement dites sont courtes, disposées en carrés, tantôt droites, tantôt inclinées ou couchées et convergentes, de deux articles, dont le dernier très-court, en forme de mamelon arrondi, tout criblé de petits trous sur un espace circulaire, avec une échancrure donnant passage aux fils de la soie, ou hérissé de petites papilles, composant de petites filières propres.

De la respiration. Deux ou quatre taches blanchâtres ou jaunâtres, situées, par paires, de chaque côté de la base du ventre, décèlent extérieurement les organes respiratoires. Le bord supérieur de ces ouvertures est fixé par un arc cartilagineux, et une plaque de même consistance bouche l'entrée des cavités branchiales. Dans les Aranéides. Tétrapneumones, immédiatement au-dessous de ces cavités, on en voit deux autres renfermant des organes respiratoires semblables. Dans l'entre-deux des premières, et sur une espèce de plateau, sont situées les parties génitales dans les femelles.

De la circulation. Lorsqu'on a déconvert la peau du dos de l'Aranéide, et qu'on l'a debarrassée de l'épiploon, on aperçoit sur la ligne dorsale le vaisseau qui tient lieu de cœur, qui a la forme d'un tube allongé, et semble avoir également des muscles la. tẻraux qui forment des dilatations et des saill:es ailées, triangulaires, dans certaines espèces; ce tube est élargi à l'endroit où l'abdomen est attaché au céphalothorax; il l'est encore plus dans son milieu, mais il va en se rétrécissant à son extrémité inférieure. Deux vaisseaux particuliers s'insèrent à la partie antérieure, au-dessous de la première dilatation, et vont ensuite descendre dans son milieu, de chaque côté du cœur. De ce vaisseau sortent, dans les Aranéides de certains genres, un grand nombre de petits filets qui se perdent et se ramifient dans l'épiploon. La forme du cœur tubulé des Aranéides varie selon les genres; ainsi, dans la Clubione atroce, ces saillies du tube ne sont point ailées, elles sont arrondies, et la partie élargie est beaucoup plus courte; les deux vaisseaux latéraux sont aussi moins longs et plus écartés; ils sont dépourvus de filets latéraux, et ils vont se perdre ou se rattacher par leurs pointes sous la peau qui recouvre les branchies. Le tuyau étroit qui se rend à la partie analé est beaucoup plus allongé dans cette espèce que dans l'araignée domestique, et l'on voit à son origine quatre grands vaisseaux qui se ramifient en tous sens dans l'épiploon.

De la digestion. - En ouvrant l'extrémité du céphalothorax en dessus, on trouve au-dessous de la membrane qui le recouvre les muscles des pattes, qui sortent, en rayonnant, d'une membrane cartilagineuse, située dans l'enfoncement de ce même organe; et dans une fente de cette membrane, on aperçoit l'estomac, qui est placé entre ces muscles. L'estomac, placé dans la fente de cette membrane, consiste, dans l'araignée domestique (Tegenaria), en quatre sacs pelliculés, deux plus grands et deux plus petits. Les plus grands ont leur superficie appliquée l'une contre l'au. tre; ils sont formés d'une peau fine et mince : celle des deux petits est mucilagineuse. Ces sacs dans l'estomac communiquent par une seule ouverture dans l'cesophage, qui est court, d'une contexture délicate, et attaché à une avance arquée du muscle de la languette. Après sa jonction avec les sacs, l'œsophage, tuyau tendre, léger et étroit, descend en droite ligne le long du céphalothorax jusqu'à la partie antérieure de l'abdomen, et il s'y convertit sous la partie supérieure en un tissu pelliculé extrêmement tendre, tellement uni avec l'épiploon, qu'il n'est pas possible de l'en séparer; mais peu après le canal intestinal prend une contexture plus ferme, et il se montre comme un tuyau situé sons le cour. Ce tuyau a la forme d'un entop. 
noir, et son ourerture la plus étroite est dirigée vers la partie anale. Cetle partie étroite s'élargit en s'avançant vers la partie anale, et forme ainsi le rectum, qui s'unit avec un cœcum ovale, allongé, aboutissant à la partie anale. Dans ce cocum s'ourrefit quatre vaisseaux biliaires, disposés par paires, quị se réunissent en deux troncs avant d'arriver au cœcum. Ce dernier organe est d'une contexture très-ferme, et contient une matière blanche et fluide. Dans la Clubione atroce, le canal intestinal s'unit deux fois avec l'épiploon, tandis que dans l'araignée domestique il n'y a qu'une seule jonction de cette nature. Entre ces parties; deux vaisseaux salivaires appartiennent encore aux organes de la nutrition. Ils sont situés dans les mandibules, et ont leurs ouvertures au sommet de l'articulation antérieure de ces derniẻres. On les voit, après avoir ouvert le céphalothorax, saillir comme deux vessies blanchâtres des ouvertures postérieures de la tige des mandibules. Ces vessies, un peu courbées, ont une forme allongée, et se partagent par un tube étroit jusqu'à la pointe percée d'un trou de l'onglet de la mandibule. Ces vaisseaux sont formés de fils membraneux posés transversalement et un peu obliquement les uns sur les autres, et unis par une pellicule mince, mais forte. Cette conformation parait assez constante dans un grand nombre de genres d'Aranéides.

De la génération des Aranéides. -Plus haut, nous avons fait connaître les organes extérieurs de la génération des femelles dans les Aranéides, maintenant nous allons décrire les organes internes. Ces organes sont contenus dans l'abdomen, et consistent en deux tuyaux placés à côtẻ l'un de l'autre, aux deux côtés du canal intestinal. L'exirémité de chacun de ces tuyaux aboutit à l'ouverture extérieure, divisée par une cloison formant une proéminence placée au milieu de l'espace qui sépare les ouvertures des 'branchies. De ce point, ces tuyaux vont en s'élargissant, et c'est à leur superficie supérieure que les cufs sont suspendus en forme de grappe.

De même que l'orifice exlérieur de la génération des femelles, dans les Aranéides, varie un peu selon les genres, les organes intérieurs, surtout par l'extrémité des tuyaux ou oviductes, qui aboutissent a cet orifice, varient aussi ; ain'si, dans la Clubione, les tuyaux ou oviductes s'unis- sent à leur extrémité, et ne forment plus qu'un seul tube circulaire à l'endroit où ils aboutissent, à l'ouverture des organes de la génération. Rœsel a remarqué dans l'Epéirè diadéme, que le sac où sont contenus ces œufs est divisé daus le sens de sa longueur en deux réservoirs par une cloison, et chacun de ces réservoirs est aussi transversalement partagé par une autre cloison. Ces cloisons des ovaires sont formées d'une peau ferme, qui est atiachée par en haut à un arc membraneux; la division longitudinale n'a aucune ouverture, les deux transversales sont au. contraire perforées. Il n'y a donc aucune communication entre les deux chambres principales; mais il y a un passage de la division antérieure à la division postérieure, et les cufs qui se trouvent dans la première doivent arriver dans la seconde avant de pouvoir être évacués. Cette organisation, qui s'est retrouvée semblable dans les Aranéides de genres très-différens, explique pourquoi nombre d'espèces font des pontes á plusieurs époques distinctes et séparées par un intervalle de temps assez grand. Une palette ovale, aussi longue que l'abdomen, est mise en inouvement, suivant Rosel, pour l'expulsion des œufs.

Dans les mâles, à l'endroit de l'intérieur de l'abdomen où dans les femelles sont situés les oviductes, on trouve aussi deux longs filets pelliculés, contournés, qui de leurs extrémités postérieures sortent de l'épiploon, et qui à leurs extrémités antérieures s'ouvrent par deux orifices, dans deux petits enfoncemens entourés de muscles délicats. Ces deux cavités représentent donc la double ouverture de l'organe extérieur de la génération dans les femelles, et sont placées au même endroit ; mais, examinées avec le plus grand soin dans les Aranéides de plusieurs genres et de la plus grande dimension, ces cavités, dans les mâles, n'ont offert aucune ouverture extéricure, quoique au dehors on voie une légère éminence, et quelques raies obscures, qui marquent la place qu'elles occupent a l'intérieur. M. Treviranus, trompé par cette analogie, s'est persuadé que l'issue des organes de la génération dans les mâles d'Aranćides étoit la même que dans les femelles, et que, par conséquent, il n'étoit pas situé à l'extrémité des palpes, comme on l'avoit cru jusqu'à lui. Il a été amené aussi à conclure que les Aranéides s'accouploient par le ventre; que les organes qu'on observe dans les palpes des mâles n'étoient que des organes excitateurs; el qu'enfin ce 
que l'on a pris pour l'accouplement n'en étoit que le prélude.

Cependantil résulte, dit $\mathbf{M}$. Walckenaer, auquel nous empruntons ce qui suit, des observations que nous avons faites, et souvent répétées, sur quatre espèces d'Aranéides de genres différens, que le mâle, après de lentes approches et de longs pré. ludes, introduit successivement dans les ouvertures génitales de la femelle; placées sous le ventre, les conjoncteurs de ses palpes; qu'alors les vulves de cet organe se gonflent et deviennent transparentes; que tous les conjoncteurs principaux et surnuméraires se tuméfient en même temps; puis se lubrifient, et offrent des pulsations et un mouvement interne qui ne permet pas de se méprendre sur leur nature. Certaines Aranéides paraissent tellement absorbées par leurs sensations pendant cet état, qu'elles deviennent insensibles à ce qui se passe à l'entour d'elles, et qu'on peut les examiner sans qu'elles se dérangent ni se troublent. Cet accouplement, dans les petites espèces d'Aranéides, se renouvelle un grand nombre de fois pendant l'espace de plus d'une demi-heure, sans que jamais le mâle fasse subir à son abdomen aucun mouvement qui témoigne le désir, ou l'intention, de toncher avec son ventre celui de la femelle. Dans les genres Epaire et Tégénaire, le mâle, aussitôt après avoir terminé l'acte de la génération, s'éloigne avec rapidité, et s'il n'est pas assez prompt à fuir, il est aussitôt dévoré par la femelle; ce qui prouve que l'acte s'est accompli, que les désirs sont satisfaits, et que les palpes du mâle n'ont pas agi comme des organes excitatateurs, mais comme organes de fécondation.

Des organes qui produisent la soie dans les Aranéides. - On trouve dans l'abdomen des Aranéides des organes qui produisent la soie, dont plus haut nous avons déjà fait connoître les appareils extérieurs. A l'intérieur, ces organes sont placés à la partie postérieure de l'abdomen, et consistent en un petit nombre de vaisseaux contournés, assez allongés, inégaux, élargis dans le milieu de leur longueur, à J'extrémité desquels, et proche des filières extérieures, sort une multitude de petits vaisseaux semblables, mais beaucoup plus courts et plus petits, qui se pressent et se réunissent à une base commune sur laquelle s'appuient les filières extérieures, quoiqu'on n'ait pu encore découvrir leur connexion avec ces filières. La matière qu'ils

\section{renferment diffère de celle des grançs} vaisseaux.

Celte matière est semblable à une gomme ou à une colle transparente; elle ne se dis. sout ni dans l'alcool ni dans l'eau; elle se. casse si on la plie, et, comme le verre, elle ne peut être flexible que quand elle est divisée en fils fort déliés. La nature, à cet égard, y a bien pourvu, car Réaumur estime a plus de mille le nombre des fils qui: sortent des papilles qu'on remarque à l'extrémité des mamelons; mais l'Aranéide en. réunit plusieurs à leur sortie; de là, colléf à quelques objets, ces fils se dévident et se. durcissent à mesure qu'ils s'éloignent du. point d'attache. L'Aranéide les tire, lors. qu'elle en a besoin, avec ses pattes postérieures; elle les dévide encore par le seul poids de son corps; enfin, au besoin, avec ses pattes et sa bouche, elle les réunit en pelotes, et par ses mouvemens, les rallonge et les raccourcit a volonté. Mais il paraitrait que son corps en produit de différentes natures, qu'il peut émettre et en retirer; car dans les toiles que font les Orbitèles les fils qui sont en cercle contiennent un gluten ou matière visqueuse propre à retenir les insectes; celles qui sont en rayon, par où l'Aranéide descend, sont sèches et dépourvues de gluten. Enfin, les fils avec lesquels l'Aranéide compose le sac où elle se renferme, ou le nid oú elle enveloppe ses petits, ne paroissent pas de même nature que ceux qu'elle emploie pour attraper sa proie, ni que ceux dont elle se sert pour construire les cocons de ses œufs; ceux-ci, dans jlusieurs espèces, sont d'un tissu tellement dur et serré, qu'ils ressemblent à une pellicule ou à du parchemin. La même espéce recouvre encore ce cocon pelliculé d'une bourre de soie lâche et molle, qui semble encore différente.

Système nerveux. - C'est dans le céphalothorax de l'Aranéide que l'on trouve le cerveau et les ganglions pectoraux avec leurs nerfs. Une des pièces principales du système nerveux des Aranéides est un ganglion, qui repose sur la partie inférieure du céphalothorax au-dessus des muscles, d'où sortent les nerfs des pattes, comme des petits cônes en rayonnant. Les nerfs qui pénètrent dans les pattes sont, d'après le travail de MI. Straus, en grande quantité, et ont un nombre si prodigieux de ramifications, surtout vers les extrémités, que la sensibilité de cette partie doit être exquise dans les Aranéides, et que le toucher chez 
relles et les impressions nerveuses doivent pouvoir supplèer au sens de l'ouie et même de l'odorat. Des organes si déliés devroient être sensibles à toutes les impressions et variations de l'air.

Sur la partie antérieure du céphalothorax, au-dessous de la courbure qui soutient la languette, est le cerveau; il consiste en deux parties piriformes séparée par une cloison. L'extrémité postérieure paroît être unie avec le nœud principal, et del'extrémité antérieure sortent deux paires de nerfs qui aboutissent aux muscles qui font mouvoir les pattes.

Des sens des Aranéides. - Ce que l'on sait du systìme nerveux des Aranéides ne permet pas de douter que le sens du toucher doit être chez elles très-développé, surtout dans les palpes et dans les mamelons sétifères. Par son exquise sensibilitè, aux moindres vibrations de l'air, le tissu des nerfs supplée-t-il au sens de l'ouĩe, ou ce sens chez les Aranéides est-il un organe distinct? C'est la une question à laquelle nous ne pouvons répondre. Cependant plusieurs observateurs ont démontré qu'elles étoient sensibles à la musique. Grétry raconte dans ses mémoires, qu'à sa maison de campagne, une araignée se rendoit sur la table de son piano lorsqu'il se meltoit à jouer, et disparoissoit lorsqu'il avoit cessé de toucher le clavier. L'anecdote de Pélisson démontre aussi que l'araignée n'est pas moins sensible aux sons rauques de la musette, qu'aux sons doux et flûtés d'un piano.

L'organe de l'odorat, dans les Aranéides, n'est pas mieux connu que chez les autres insectes, quoique nombre d'observations semblent démontrer qu'il existe dans tous.

Les organes de la rue s'apercoivent facilement dans les Aranéides, puisqu'ils sont toujours situés antérieurement sur le céphalothorax et quelquefois sur les côtés. Mais les recherches de MM. L. Dufour et Straus n'ont pu encore éclaircir leur organisation, et ces profonds investigateurs ne s'accordent pas sur la manière dont s'opère la vision dans les Aranéides.

Des toiles des Aranéides. - Les viscères des Aranéides ont la facultè de sécrëter deux liqueurs, dont l'une est un venin qui s'infiltre et se verse par leurs mandibules, et l'autre qui se transsude par leurs filières. A vec la première, elles engourdissent instantanément les insectes qui servent à leur nourriture ; avec la seconde, elles produisent une soie qui leur sert à marcher sans se heurter sur les corps les plus âpres, à glisser sur les plus polis, à se précipiter à terre, à monter verticalement, à tendre des fils pour surprendre leur proie, ou à tapisser leurs demeures, à construire des cocons qui doirent garantir les œufs et les protéger contre les atteintes d'un climat trop rigoureux. Cette prodigieuse multitude de fils d'Aranéides que l'on voit dans le mois de septembre, ce nombre immense de toiles anciennes et nouvelles que recèlent les forêts, les campagnes, continuellement baignées par les brumes humides de l'arrièreraison, s'agglomèrent et s'amoncèlent en Jongs écheveaux qui, séchés par le solei let l'air, acquièrent une blancheur extraordinaire; puis, agités par les vents, ils s'enlèvent dans l'air, et forment les longs filamens blancs nommés fils de la Vierge. Les jeunes araignées répandues de tous côtés, qui se trouvent accrochées par ces fils, ne peuvent s'en débarrasser, ou y restent volontairement, et voyagent au loin par ce moyen; aussi n'est-il pas rare de voir dans les contrées méridionales, où les Aranéides sont grosses et très-abondantes, les étangs, les rivières, et les prairies en être quelquefois couverts.

Du venin des Aranéides. - Quelque su. bit, quelque violent que soit l'eflet du venin que l'Aranéide verse dans la piqûre qu'clle fait à l'insecte qu'elle saisit, ce venin, dans les espèces les plus grosses du nord de la France, ne produit aucun effet sur l'homme. "Je me suis fait piquer, » dit M. Walckenaer, par les espèces d'araignées les plus grandes des environs de $\mathrm{Pa}-$ ris, sans qu'il en résultât ni douleur, ni enflure, ni rougeur. Ces légères piqûres ne m'ont fait éprouver d'autre sensation que celle qu'auroit produite une aiguille ou uue épingle fine, dont j'aurois enfoncé la pointe dans mon doigt. o Ainsi, le venin de l'araignée n'a pas, sur l'homme, des effels aussi fâcheux que celui de la punaise, de la guêpe, de l'abeille, du cousin, de la puce, et autres insectes encore beaucoup plus petits.

La famille des Aranéides a étépartagée en deux tribus, les Tétrapneumores et les Dipneumones : les genres qui la composent ont été distribués en deux sous-tribus : les Terrestres et les Aquatiques, partagées en quatre grandes sections: les Vagabondes, les Errantes, les Sédentaires et les $\mathrm{Na}$ geuses, et divisées ensuite en treize soussections: les Latébricoles, les T'ubicoles, les Cellulicoles, les Coureuses, les Volti- 
geuses, les Marcheuses, les Niditèles, les Fi litèles, les Tapiteles, les Orbitèles, les $\mathrm{Na}$ pitèles, les Raptitèles et les Aquitéles.

PREMIERE TRIBU.

\section{TETRAPNEUMONES,}

\section{LÉon Dufour, Latreille.}

Caractéres.C'està M. L. Dufour que nous sommes redevables de l'établissement de cette division naturelle. On avoit bien, ilest vrai, remarqué que les Mygales différoient des autres Aranéides, en ce qu'elles avoient quatre spiracules, ou ouvertures stigmatiformes, donnant dans pareille quantité de sacs pneumo-branchiaux, mais on n'avoit point déterminé quelles sont les autres Aranéides offrant les mêmes caractères, et c'est ce que M. L. Dufour a fait.

Cette tribu des Tétrapneumones, ainsi désignée à cause du nombre des ouvertures stigmatiformes, qui sont au nombre de quatre, comprend la première famille des Áranéides de $\mathbf{M}$. Walckenaer, ou ses araignées Théraphoses. Les Aranéides Tétrapneumones ont, comme beaucoup d'autres de la tribu suivante, trois crochets au bout des tarses, dont les deux supérieurs et constans sont cependant peu ou point dentelés. - La quatrième paire de pattes, et ensuite la première, sont les plus longues. - Les crochets sont fléchis en dessous ou sur leur côté infërieur. - Les filières sont au nombre de quatre, dont deux grandes et deux petites.

\section{PREMIÈE SOUS-TRIBU.}

\section{Les Terrestres, W ALcK.}

Habitant sur terre, susperidues dans l'air on dans des cavités de roche, de bois, de plantes ou autres, ou dans des trous en terre.

\section{PREMIËRE SECTION.}

\section{Les Vagabondes, W ALck.}

Sortant et courant souvent hors de leurs lemeures pour chasser et attraper leur proie.

\section{PREMIERE SOUS-SECTION.}

\section{Les Latébricoles, WaLcK.}

Se cachant dans des trous ou des fentes.
Genres : Mygale, Atypus, Eriodon, Actinopus, Calommata, Fitistata, Dysdera.

\section{MYGALE, Latr., WaLCK.}

Les yeux sont toujours au nombre de huit, presque éganx entre eux, groupés et ramassés sur le devant du céphalothorax, trois de chaque côté formant un triangle irrégulier, dont l'angle le plus aigu est en avant; les deux autres yeux sont situés entre les précédens et sur une ligne trans. verse. -La lévre est petite, presque nulle, insérée sous les mâchoires.-Les mâchoires sont allongées, cylindroïdes, divergentes, creusées longitudinalement à leur côté interne. - Les palpes sont allongés, pédiformes, insérés á l'extrémité des mâchoires. - Les pattes sont allongées, fortes, peu égales entre elles.

Les Aranéides qui composent ce genre sont toutes chasseuses; elles courent après leur proie, elles se renferment dans l'intérieur des feuilles, des creux des arbres, des rochers, et dans des retraites qu'elles se creusent en terre.

Ce genre a été partagé en trois groupes.

\section{PREMIER GROUPE.}

\section{Les Plantigrades, WaLcK.}

Les pattes sont terminées par un tarse court, obtus et charnu, et velouté en dessus, à griffes insérées en dessus. - Le céphalothorax est grand, arrondi.--Les mandibules sont inermes ou dejpourvues de râteaux.

Ces Aranéides se renferment dans les cellules, sur les plantes, dans les creux des arbres et des rochers. Le cocon est arrondi, déprimé.

\section{MYGALE FASCIATA.}

Walck, Hist. nat. des Aran., fasc. 6, 1 ; ibid., Hist. nat. des Ins. apt., t. I, p. 209. - HAHN, Monogr. der Spinn.: 1820, p. 15, pl. 3; ibid., Die Arachn., t. II, p. 63 , pl. 57 , fig. 187 . - Long. 2 pouc. $6 \mathrm{lig.} \mathrm{-} \mathrm{Elle} \mathrm{est} \mathrm{d'un} \mathrm{brun} \mathrm{fauve} \mathrm{rougeâ-}$ tre, avec une bande ovale, festonnée, plus claire, longitudinale, sur le milieu du céphalothorax. - Se trouve à Ceylan.

Cette espèce, dit Séba, ne file point de toile, et se trouve sur les grands arbres. Elle dévide un gros fil au moyen duquel elle descend lentement, à la manière des chenilles, qu'elle imite aussi en formant un nid ovale où elle dépose ses oufs; elle en. 
châsse ce nid si fermement entre les branches d'arbres qu'il est difficile de l'en tirer.

\section{MYYGAYE BLONDII.}

Latr., Dict. d'Hist. nat., t. XV, p. 304, $2^{\mathrm{e}}$ édit. - W $\mathrm{WLCK}_{\text {, }}$ op. cit., t. I, p. 210. - Palisot de Beauv., Ins. d'Afrique, pl. 3, fig. 2, p. 185. - Long. 2 pouc. 6 lig. - Elle est d'un brun-rougeâtre uniforme, avec deux taches rougeâtres, allongées et pointıes, sur le quatrième article des pattes formées par l'absence des poils; les mâchoires sont prolongées en pointe au côté interne; les organes générateurs mâles sont ovales, cylindriques et resserrés dans leur milieu; les filières sont allongées.

Habite Cayenne, Saint-Domingue, la Martinique et le Brésil. Suivant Palisot de Beauvois, la Mygale de Leblond se tient dans les champs, y pratique un trou où elle attend sa proie; mais elle ne se confie pas à ce seul moyen de pourvoir à sa nourriture : elle sort le soir et le matin, elle grimpe aux arbres, pénètre dans les nids des colibris et des oiseaux mouches, suce leurs rufs ou le sang de leurs petits. Son cocon est de :la grosseur d'un ouf de pigeon. MM. Spix et Martius rapportent que celte espéce se cache sous les pierres, dans les bois pourris, et visite souvent dans la nuit les lits des voyageurs.

\section{MYGALE VERSICOLOR.}

WALGK., op. cit., to I, p. 211.-Aranea Hirtipes, Fabr., Ent. Syst., p. 428, n $^{\circ} 77$. - Long. 1 pouc. 8 lig. - La femelle est très-velue; le céphalothorax est arrondi, recouvert de poils courts ou de duvet d'un beau vert bouteille, d'un éclat métallique; l'abdomen est ovale, plus gros à sa partie postérieure, et dont l'épiderme est recouvert en dessus d'un poil ou duvel noir de velours, et de longs poils d'un beau rouge ferrugineux, qui, du côté du ventre, vus à un certain jour, ont un reflet violet; les pattes sont allongées, revêtues de poils noirs en dessus, et les palpes de poils vert bouteille; tout le dessous est d'un beau noir velouté. Le mâle est plus petit et un peu plus allongé que Ja femelle; le céphalothorax est très-grand et d'une couleur noire de velours ; l'abdomen est d'un rouge ferrugineux; les pattes antérieures sont pourvues a l'extrémité du fémoral de deux appendices ou épines rouges et courbes; les organes excitateurs sont globuleux à leur base et terminés par un double filet à double courbure; les filiẻres supéricures sont composées de quatre articles et assez allongées; les inférieures, insérées plus en avant, sont beaucoup plus courtes et n'ont que trois articles. - Habite la Guadeloupe et la Martinique.

\section{MYGALE CONCERIDES.}

W ALCK., op. cit., t. I, p. 214. - Long. 1 pouc. 8 lig. - Les yeux sont en carré comme dans l'espèce précédente, mais plus écartés entre eux ; les postérieurs intermédiaires sont les plus petits, et sont placés plus bas que les extérieurs latéraux; les antérieurs intermédiaires sont plus gros et ronds; les quatre extérieurs ou les latéraux sur les deux lignes sont ovales; les filières, les palpes et les pattes sont aussi plus allongés; les mandibules sont plus allongées, et leur premier article est plus gros vers l'extrémité; les pattes s'amincissent vers leurs extrémités; la couleur générale de cette espèce est d'un brun fauve uniforme, avec des poils d'un fauve-rouge ardent. Se trouve à la Martinique et au Brésil.

\section{MYGALE WALGKENAERI.}

Perty, Voyag. de Spix et Martius, pl. 38, fig. 2. - W ALCK., op. cit., t. 1, p. 217 - Long. 1 pouc. - Le céplalothorax, aussi long et aussi large que l'ábdomen, est d'un brun foncé, couvert de poils allongés d'un brun plus pảle; Ja tige des mandibules égale la moitié de la longueur du céphalothorax, et les onglets sont noirs; les derniers articles des palpes sont d'un rouge sanguin à leur extrémité; cette espèce est bien caractérisée par les belles couleurs des anneaux d'un rouge sanguin, dont les articulations des pattes et des palpes sont recouvertes; les tarses sont élargis et rouges à leur extrémité; les pattes antérieures et postérieures sont presque égales; les deux paires de pattes antéricures ont les anneaux rouges aux artîculations beaucoup plus larges, et quatre des articulations sont ainsi entourées, tandis qu'il n'y a que trois anneaux rouges aux pattes postérieures. - Habite le Brésil.

\section{MYGALE AVICULARIA.}

Latr., Mém. pour servir à l'Hist, nat. desIns., t. VII, p. 313, pl. 38, fig. 8, 9, 10. - Waцck., Tab. des Aran., p. 4, pl. 1, fig. 3 ; ibid., op. cit., t. 1, p. 218. Ibid. . op. cit., t. 1, p. 218. - Long. 2 pouc. - Les yeux sont portés sur une gibbosité brusque, et sont assez ramassés; ils figurent par leurs lignes extérieures presque un carré; les yeux postérieurs 
sont très-rapprochés, et les postérieurs intermédiaires plus petits que les postérieurs extérieurs, et placés un peu plus bas; tous ces yeux sont ovales, excepté les intermédiaires intérieurs, qui sont gros et ronds; ils sont tous d'une couleur pâle blanchâtre; l'abdomen est d'un brun uniforme ou noirjaunâtre, sans taches sur sa partie supérieure; les paltes sont très-grosses, très. velues, et à jambes et tarses dilotés; la quatrième paire est plus longue que la seconde paire, la première ensuite, la troisième est la plus courte; les palpes sont gros, allongés; les organes générateurs mâles ont la forme d'un globule comprimé, et se terminent en filet délié, à double courbe. - Cette espèce se trouve dans l'A mérique Méridionale, à Cayenne et à Surinam.

Suivan. M. Walckenaer, cette espèce fait dans les gerçures des arbres, les interstices des masses de pierres, sur la surface des feuilles, à la campigne, dans les lieux solitaires, dans les habitations, une cellule d'une soie très-blanche, fine, demi-transparente, qui a la forme d'un tube rétréci a son extrémité postéi ieure; c'est un ovale allongé, tronqué antérieurement, qui a deux décimètres a long sur six centimètres de large. Le coc un est enveloppé d'une soie de trois couches, dont l'intermédiaire est plus mince et n'est pas recouverte de bourre; la femelle place son cocon près de sa demeure, et y veille assidûment; la toile de cetie espéce est toujours propre, et jamais on n'y a trouvé des débris d'insectes. L'araignèe chasse pendant l'absence du soleil sur l'horizon. Suivant M. Moreau de Joannès, elle enveloppe ses œufs dans une coque de soie blanche, au nombre de dixhuit cents à deux mille, et les fourmis rou. ges mangent les jeunes lorsqu'ils sont éclos.

\section{MYGALE MURINA.}

W ALCK., op. cit., i 1, p. 220. - Long. 2 pouc. - Entièrement noire; le céphalothorax est velu, et les yeux, qui sont situés sur sa partie antérieure, forment un carré long, transversal, étroit dans sa hauteur; ces yeux sont d'un rouge-brun; les quatre de la ligne antérieure sont les plus gros; les yeux intermédiaires de cette ligne antéricure sont presque sur la même ligne que les extérieurs ou latéraux, grands et plus gros, tandis que les latéraux sont ovales; les yeux intermediaires de la ligne postérieure sont les plus pelits, placés plus bas, ou sur une ligne moins reculée que les laléraux extérieurs, très-rapprochés d'eux, d'un rouge pâle, et un peu enfoncés et aplatis; les pattes antérieures sont remarquablement plus grosses et plus renflèes que Ies postérieures. - La paticie de cette espèce est inconnue.

\section{DEUXIENE GROUPE.}

\section{Les Digitigrades inermes, WaLcK.}

Les pattes sont amincies à leur extrẻmité. - Les tarses sont allongés, avec des griffes terminales. - Les mandibules sont inermes ou dépourvues de râteaux.

Ces Aranéides sont chasseuses et courent après leur proje.

\section{MYGALE ZEBRA.}

W alck., Ann. de la Soc. Ent. de France, t. $1 \mathrm{~V}$, p. 637, pl. 19. - Mygale veinée. Latr., Vues génér. sur les Aran., Nouv, Ann. duMus., t. 1, p. 161.-Long. 1 pouc. 5 lig. - Cette espèce est très-remarquable et se distingue de toutes les autres Mygales par ses coulcurs, qui sont bariolées et semblables ả celles d'un zẻbre; le céphalothorax est d'un brun-noir; les yeux forment un parallélogramme transversal, allongé, tous d'un jaune d'ambre brillant; les intermédiaires postérieurs sont plus petits et moins reculés que les latéraux extéricurs, les intermédiaires antérieurs arrondis; les pattes ont an fémoral, au génual et au tibial des parties nues et rouges; la première paire de pattes est plus longue que la quatrième, la deuxième ensuite, la troisième est la plus courte de toutes; l'abdomen présente sur sa partie supérieure, sept bandes transversales d'un rouge ferrugineux, les quatre premières élant interrompuss dans leur milieu; les filières sont assez allongées. - Se trouve au Brésil.

\section{MYGALE SEVA.}

WaLck., op. cit., t. I, p. 222. - Long. 1 pouc. - Le céphalothorax est un peu dèprimé, d'un brun fauve; les palpes sont peu allongés, le dernier article est globuleux, recouvert par une touffe de poils d'un fauve clair; les mandibules sont tombantes, courbées en bas, diminuant de grosseur vers leurs extrémités; les poils sont d'un fauve clair, très-longs; les yeux forment un trapèze dont le plus long côté est transversal; les intermédiaires postérieurs sont les plus petits, et sont plus reculés que les latéraux postérieurs, mais très-rapprochés d'eux; les intermédiaires antérieurs, ou les yeux de la seconde ligne, sont ronds 
et beaucoup plus reculés que les antérieurs, qui sont les plus gros et ovales; l'abdomen est ovale, allongé. - Habite l'Amérique Méridionale.

\section{MYGALE HIRSUTA.}

WaLck., op, cit., t. I, p. 223. - Long. $6 \mathrm{lig}$. - Les yeux sont presque égaux entre eux, et forment un trapéze ; les intermédiaires postérieurs étant les plus petits, et un peu plus èlevés ou plus reculés que les latéraux postërieurs, les intermédiaires antérieurs sont aussi beaucoup plus reculés que les latéraux antérieurs; les quatre yeux latéraux sont les plus gros; tous ces yeux sont d'un jaune brillant, et portés sur une forle gibbosité; les mandibules sont minces, comprimées sur les côtés, subitement courbées à leurs extrémités; les pattes sont allongées, très-velues; les cuisses sont grosses, mais les extrémités fines, la quatrième paire est la plus longue; l'abdomen est allongé et de la longueur du céphalothorax, ce dernier est aplati; elle est rouge, trèsvelue, surtout les organes de Ia locomotion. - Habite l'Amérique Méridionals.

\section{MYGALE GAFRERIANA.}

WaLck, op. cit., t. I, p. 225, pl. 5, fig. 1, D. - Long. 13 lig. - Couleur génèrale rouge clair, uniforme dans la femelle, gris de souris dans le mâle; les yeux forment un trapèze éleré en hauteur; les intermédiaires postérieurs sont plus petits et sont très-élevés, plus reculès vers la partie postérieure que les extérieurs latéraux; les intermédiaires antéricurs sont aussi plus petits et plus reculés que les antérieurs latéraux; ils sont tous portés sur une élévation; les intérieurs ou les plus petits sont bruns; la lèrre est courte, large; les pattes sont armées de griffes sans dents apparentes, et ces mêmes griffes sont insérées un peu au-dessus de l'extrémité du tarse; dans le mâle, le tibial des pattes antérieures est terminé par une forte épine cornée, courte, la quatrième paire de pattes est plus longue que la troisième; le céphalothorax est ovale, allongé, convexe ou relevé en carène dans le milieu; les organes générateurs sont piriformes, tcrininés par un filet peu allongé, courbe, et légérement recourbé à l'extrémité; l'abdo. men est aussi ovale; allongé dans le mâle, moins long et moins large que le céphalothorax, peu velu, mais garni de poils courts et serrés; le dessous est noir. Les filières qui sont placćes à l'extrémité de

A Nv. l'abdomen sont peu allongées. - Habite le cap de Bonue-Espérance.

\section{MYGALE FUNEBRA.}

W ALCK., op. cit., t. I, p. 226. ... $M y$. gale Atra o, Latr., Vues génér. sur les Aran. Nouv. Ann. du Mus., I. I, p. 64. - Long. 14 lig. - Elle est entièrement noire; les yeux intermédiaires postérieurs sont plus reculés que les latéraux, mais très-rapprochés d'eux, les intermédiaires antérieurs ont les yeux de la seconde ligne ronds, très-reculés, et écartes des yeux latéraux antérieurs, ou de ceux de la première ligne, qui sont ovales, et dont l'axe visuel est dirigé latéralement ; l'espace occupé par les yeux forme un carré ou tra. pèze, plus long en hauteur que dans sa largeur transrersale; les quatre yeux antérieurs sont les plus gros, les quatre postéricurs les plus petits; l'organe génératenr est petit, globuleux à sa base, et terminé par un crochet court, renflé à son insertion; la quatrième paire de pattes est la plus longue, la première ensuite. - Habite le cap de Bonne-Espérance.

\section{MYGALE AUSTRALIANA.}

W alck., op. cit., t. 1, p. 227. - Long. 1 pouc. - Le céphalot labrax et les pattes sunt d'un brun-rougeâț̂e, uniforme; les yeux figurent un carré long, transversal. les extérieurs latéraux, plus gros, sont ova. les, arrondis, luisans; ceux de la ligne antérieure plus rougeâtres, les intermédiaires postérieurs les plus petits de tons, plus blancs et plus clairs; ils sont sur la même ligne que les latéraux extérieurs, et rapprochés d'eux, mais non connivens; les intermédiaires antérieurs sont un peu plus reculés du labre que les latéranx, et plus petits qu'eux; les quatre intermédiaires sont ronds; les pattes sont fiues, peu allongées, la quatrième paire est la plus longue, la seconde surpasse sensiblement la première, la troisième est la plus courtc; ces pattes sont peu velues, et sont pourvues de griffes très-allongées, très-courbées, pectinées à leur base, avec un ergot opposé ; la griffe des palpes est de même trèsapparente; les mandibules sont rougeâtres, très-allongées, proéminentes, fortes et dépourvues de râteau; l'abdomen est ovale, d'un brun-verdâtre. - Se trouve au Port-Jackson.

\section{Mygare Valenciaya.}

L. Dur., Ann. des $S c$. de phys., t. V, p. 27, pl. 73, fig. 1 à 2. - W 
cit., t. I, p. 228. - Long. 10 lig. - Les yeux figurent un carré long, transversal, les intermédiaires postérienrs sont les plus petits, et trésécartés entre eux, ils sont tres-rapprochés des latéraux ou y eux extérieurs postérieurs, et plus reculés vers la partie postérieure du céphalothorax; les mandibules, vues à un forte loupe, présentent, près de leur extrémité interne, deux ou trois petites épines cachées par des poils; le dernier arlicle des palpes, dans le mâle, est arrondi, ovale, terminé en bec droit ct non recourbé; les griffes terminales sont pectinées près de leur insertion; la quatrième paire de pattes est la plus lon. gue; les grilles des tarses sont presque ca* chées par le duvet; elles sont dépourvues d'ergots, mais le côté externe paraît au microscope à sabase pourvu de quatre dents, et le côté interne de sept à huil dentelures; la couleur générale est un brun-noir uniforme. - Se trouve en Espagne dans les lieux déserts et arides de Moxente.

\section{MYGALE CALPETANA.}

W alck., T'ab. des Aran., p. 5, pl. 11, fig. 1, 2. - Ibid., Hist. nat. des Aran., fasc. 1, pl. 8, 9. Hbid. op. cit., t. 1, p. 229. - Long. 10 lig. - Les yeux, portés sur une forte gibbosité du céphalothorax, sont de couleur jaune, ils tigurent un trapéze plus étroit par en bas, et plus allongé transversalement; les quatre latéraux extérieurs sont ovales et plus gros que les quatre intermédiaires; les intermédiaires postérieurs sont les plus petits de tous, et sont moins reculés que les lalèraux extérieurs; le céphalothorax, d'un brun-rougeâtre, clair, est ovale, allongé, un peu déprimé; les organes générateurs sont fusiformes, terminés par un filet long et fin, qui surpasse les deux tiers de la longueur des palpes; les pattes sont allongées, fines; la quatrieme paire est la plus longue, la première et la seconde sont égales, la troisième est la plus courte ; l'ab. clomen est ovale, allongé, un peu plus gios à sa partie postérieure, et tenant au céphalothorax par un pédicule très-gros et tres-allongé; le milieu du centre présente deux gibbosités carrées. - Se troc ve aux euvirons de Gibraltar.

\section{MYGALE NOTASIANA.}

Walck., Tab. des Aran.. p. 5, pl, 1, fig. 5 ; ibid., op. cil., t. I, p. $230 .-$ Long. 10 Jig. - Le céphalothorax est brun; les yeux sont portés sur une très-lí. gère gibbosité du céphalothorax; les quâtre yeux des deux lignes postérieures sont réunis par paires; les deux yeux de la ligue antérieure sont plus gros, en ovale arrondi; les yeux intermédiaires antévieurs sont les plus petits de tous, ronds et presque sur la même ligne que les latéraux; la lève est carrée, plus hante que large; les grifles des pattes sont pectinées; l'abdomen est ovale, brun, bordé de gris. Se trouve au Port-Jackson.

\section{MYGAIG ANTIPODIANA.}

W ALGK., op. cit., t. 1. p. 230. - Long. 1 pouc. 2 lig. - Le céphalothorax est mar. qué d'une ligne noire longitudinale, qui part des yeux et aboutit au point enfoncé du milieu, il est de couleur rougeâtre; les quatre yeux des deux lignes postérieures sont disjoints; les intermédiaires postériears sont les plus pelits, et sont moins reculés que les latéraux postéricurs; les yeux intermédiaires antéricurs sont les plus gros, et sont sur la même ligne que les latéraux extérieurs ; les quatre yeux intermédiaires ou antérieurs sont ronds, les extérieurs ou latèraux ovales, arrondis; l'espace occupé par les yeux forme un carré long, transversal; les mandibules sont noires, très-courbées et peu avancées en avant, grosses et renflées dans leur partie médiane; les palpes sont rougeâtres, velus, médiocrement allongés, et pourvus d'une grifle pectinée; l'abdomen est bombé en dessus, en dessous il est aplati; les ouvertures stigmatiformes sont arrondies, trèslarges, et ont une tache brune dans leur milieu; la couleur en dessus comme en dessous est d'un rouge pâle; les filières sont allongèes, avec les quatre derniers articles diminuant de grosseur, depuis le premier jusqu'au dernier; les deux filièresen dessous sont moins allongées, el sont composées de trois articles; les pattes sont robustes, rougeâtres: la quatrième paire est la plus longue, la première est ensuile la plus allongéc; tontes sont terminées pa! des tarses de couleur noire, petits, peu distincts. - Habite la Nouvelle - Zélande.

\section{TROISIEME GROUPE.}

\section{Digitigrades mineuses, $\mathrm{W}_{\mathrm{ALCK}}$.}

A ce groupe appartiennent les Aranéides qui se creusent un trou en terre formé herméliquement par une porte qui s'ourre ct se ferme à volonté. Parmi ces espèces remarquables nous citerons : 


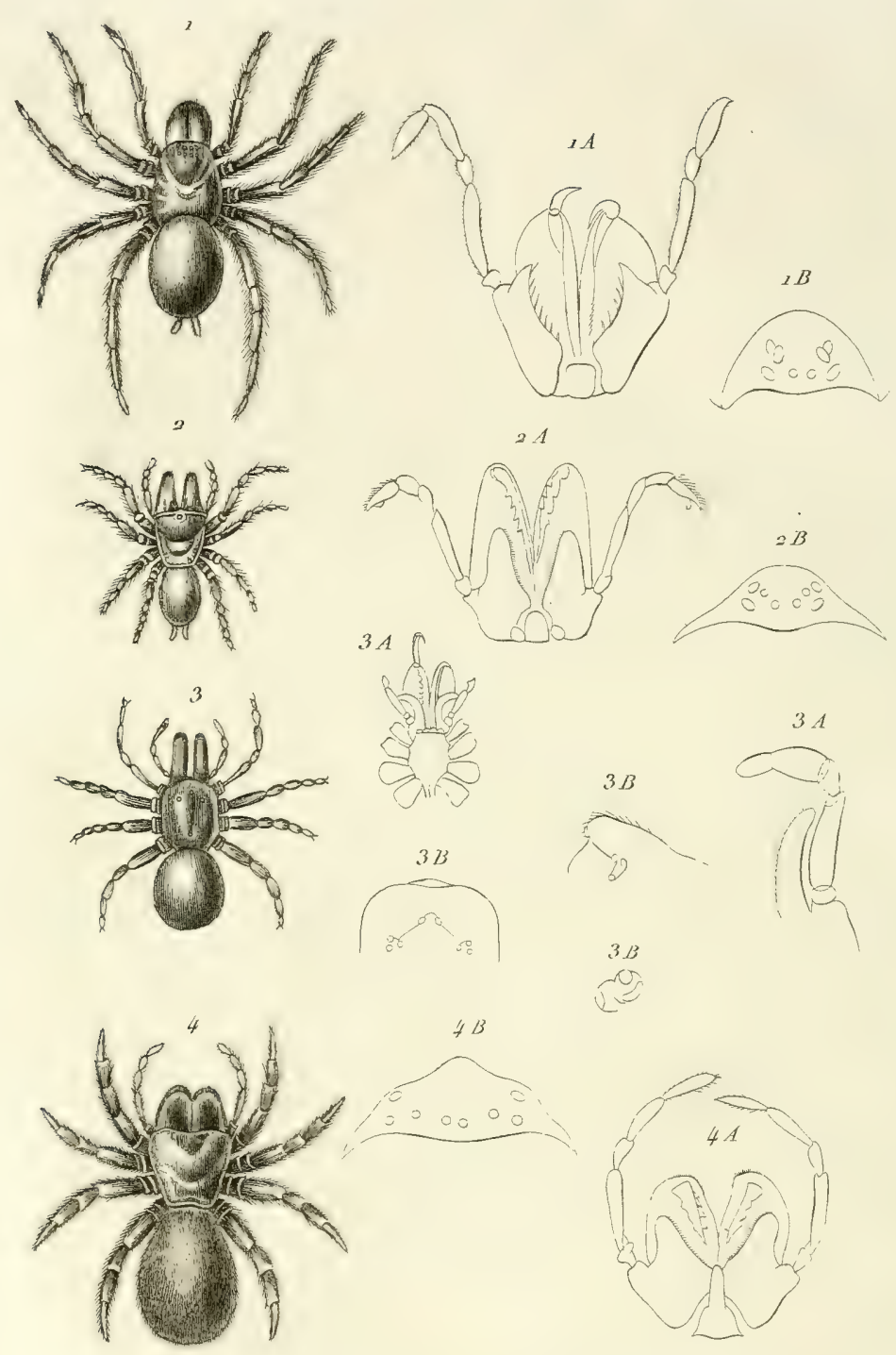

证

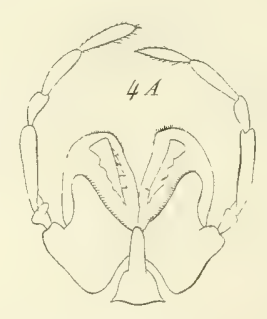

1. Mygale fodiens. IA. i B. mâchoúres et yena do la M. Notasiana.-

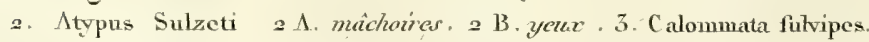
3 A. 3A. mâchoires, 3 B : 5B, 3B, yeuv, 4. Friodon occatorius. 4 A. mâchoiras. 4 B. yeux. 
13. MYGALE CCBMENTARIA.

Watck., Tub. des Aran., pl. 1, fig. 5, 6 et 7. Ibid. op. cit., t. 1, p. 235. - Ibid. Hist. des Aran., fasc. 3, pl. 10.-Aran. de Franc., p. 2,no1.-Duf., Ann. des $S$ c.phys., t. V, p. 29, pl. 73, fig. 5.-Dugès, Allas du Reg. anim. de Cuv., Arach., pl. 1, fig. 1 đ', $1 h$. - Donthez, Trans, of the Limn. Soc., vol. II, pl.17, fig.6.-Aranea Sauvagesii, Latr.. Mém. de la Soc. d'Hist. nat., 1. 121. - Gú́n., Iconogr du Régn. anim. de Cur., Arachn., pl. 1, fig. 2 (mâle). - Long. 3 lig. - La couleur de celte Mygale est un roux de poix plus ou moins foncé et plus ou moins dénué de poils suivant l'âge ; le céphalothorax, dans les individus bien adultes, est brunâtre, luisant, avec les bords plus clairs; vers sou centre on aperçoit une fossette transversale; les yeux sont groupés sur une légère érninence, ordinairement noirâtres; les mandibules sont noirâtres, garnies vers l'extrémité de leur région dorsale, de piquans noirs, courbés en avant, mobiles, servant de griffes à l'animal pour s'accrocher; ces piquans, entremêlés de soies assez roides, varient pour leur longueur et sont en nombre indéterminable ; celles qui garnissent l'extrémité de la mandibule sont plus longues, plus distinctes, et on en compte pour chaque cinq, dont la plus interne esi plus courte; sur le dos de chaque mandibule on aperçoit une raie glabre, longitudinale, offrant l'apparence d'une strie superficielle; une autre raie semblable, mais sujette à s'effacer, s'observe aussi sur le côté externe; la rainure, qui sert à loger le crochet, oflre, à son bord interne, seulement six à sept dents courtes; l'abdomen a un duvet gris de souris, serré, soyeux, parsemé dans l'animal vivant de mantelures plus foncées, qui semblent affecter une disposition transversale; les plus longues filières ne dépassent que peu le contour postérieur de l'abdomen; les pattes, d'un roux livide plus pâle que le corps, sont, de même que les palpes, velues et armées de plusieurs piquans noirâtres; les genoux ont à peu prés la longueur du ti * bial, excepté dans la paire postérieure; le premier article des tarses offire des piquans dans toutes les pattes; ils esi en outre, dans les deux paires antérieures seulement, revêtu d'une brosse spongieuse; celle-ci s'observe parcillement au premier article des tarses de ces mêmes paites; les ongles ont à leur base un croché ou ergot caché par les poils, mais existant dans toutes les patıes; chaque grife offre une double rangée de quatre cents aiguẻs, séparées par une coulisse. Cette espece, qui se trouve à Montpellier, établit plus particulièrement sa demeure contre des tertres secs, com. pactes et exposes au midi, sur la route qui mène de Montpellier aux coteaux de Castelnau. M. Dufonr, a qui nous avons emp'unté cette description, nous a montré, dans un mémoire très-jntéressant ayant pour titre: Observations sur quelques Arachnides quadripulmonaires, insérées dans le $5^{\mathrm{c}}$ vol. cles Amn. génér. des Scienc. phys., p. 96, lés moyens dont il fallait se servir pour s'em.parer de cette Aranéide. Voici comment je m'y prenais, dit cet habile observateur, pour faire la chasse à ces Mygales; sans avoir besoin de les poursuivre jusqu'au fond de leur tanière, qui est souvent à deux pieds de profondeur et tellement fléchie qu'il est très-facile d'en perdre la trace. Il faut un cil exercé pour découvrir l'opercule circulaire du terrier, tant la rainure capillaire, qui en dessine le contour, a de finesse : si cette rainure est tant soit peu béante, c'est une preuve que la Mygale est placee en sentinelle derrière la porte; si vous tentez alors, à la faveur de la pointe d'une épingle, d'ouvrir cette dernière, l'araignée s'accroche unguibus et roslro à sa partie interne et bombée, et vous sentirez une résistance qui s'effectue par saccades. Pendant que d'une main on provoque les efforts réitérés et inouïs de la courageuse Mygale, on enfonce de l'autre une forte lame de couteau à un pouce environ au-dessous de la trappe, de manière à traverser horizontalement le diamètre du temier; la retraite de l'habile ouvrière se trouve ainsi coupée; on soulève et on lance la portion de terie placée au-dessus du couteau, et la paurre Mygale, toute stupéfaite de cette trahison, se laisse prendre sans résistance. M. Léon Dufour pense que la Mygale cardeuse, $\boldsymbol{M}$. carminuns, Latr., Dict. d'Hist. nat., nouv. édit. tom. XXI, n'est autre que le mâle de lá Mygale maçonne; il a observé ce mâla en Espagne et dans le midi de la France.

19. MYGALE FODIENS. (Pl. 2, fig. 1.)

Walck, Aran. de France, p. 4, pl. 2, fig. 2 a. - Ibid. op. cit., t. 1, p. $237 .-$ Migale Sauvagesii, Dur., Ann. des Scienc. phys., t. V, p. 27. n०2, pl. 75, fig. 3.Mygale Fodiens, Aud., Ann, de laSoc. Ent. de France, t. 1I, p. 69, pl.4, fig. 1. - Aranea Sauvagenii, Rossi, Faun. Etrusc., 
t. II, p. 438, n 983, pl.9, fig. 11.-Latr., iMém. de la Soc. d'Hist. nat., p. 125-Long. 10 lig.-Elle est d'un brun clair uniforme et sans mouchetures sur son abdomen ; les mandibules sont plus grosses, plus inclinées que celles de la IIyg. comentaria; le râteau dont elles sont armées se compose de cinq ou six épines principales qui garnissent leur bord supérieur, et de quelques autres moins prononcées, situées au debors des premieres; la rainure, qui recoit le crochet dans sa rétraction, a, de chaque côté, cinq dents noires, fortes et courtes; Ies pattes sont simplement velues, mais les tarses des deux paires antérieures et les articles correspondans des palpes sont garnis de deux piquans remarquables Ces ongles offrent cela de particulier qu'ils n'ont qu'une seule dent a leur base; le tarse se termine par un ergot, et les filières sont bien plus longues que chez les espèces précédenies. Celte espèce, qui se trouve enCorse, a été le sujet d'un mémoiı eplein d'intérêt sur la maniere dont son nid est construit, par M. V. Audouin, Amn. de la Soc. Entom.de France, Ł. 1 , p. $69, \mathrm{pl} . \overline{4}$, fig. 1 . Ces nids, sur lesquels M. Latreille a fait à leur égard une remar. que judicieuse, c'est que, rapprochés comme ils le sont les uns des autres, ils doivent faire présumer que cette espèce ne craint pas la société ou le voisinage de ses semblables. Quoi qu'il en soit, dit M. Audouin, la motte de terre qui renferme ces tubes est composée d'une terre argileuse d'un rouge de brique; les tubes ont, comme la masse dans laquelle ils sont creusés, trois pouces de hauteur et dix lignes de largeur; droits dans les deux tiers de leur étendue, ils deviennent légérement obliques vers leur extrémité inférieurc, peut-ètre même se recourboient-ils davantage en se prolongeant beaucoup plus avant dans la terre; toujours est-jl certain qu'en les enlevant on ne les a pas obtenus dans leur entier. En examinant un de ces tubes avec quelque soin, j'ai remarqué qu'il n'é1ait pas simplement creusé dans la terre argileuse qui l'enveloppoit, comme le seroit une excavation ou un trou de sonde qu'on pratiqueroit dans la terre, mais qu'il étoit construit à la manière d'un puits, c'est-àdire qu'il avoit des parois propres formées par une espèce de mortier assez solide, en sorte qu'on peut, ainsi que je l'ai fait, le dégager entièrement de la masse qui l'entoure. Si, pour l'étudier avec encore plus de soin, on en fend un dans le sens de la longyeur, on voit que son intérieur est tapissé par une étofle soyeuse et trés-mince, dousce au toucher, et qu'il n'existe aucune des inégalités qu'on devroit s'attendre à rencontrer sur des murs faits avec une terre grossiére. En effet, cette paroi intérieure semble avoir été crépie avce un mortier plus liu; et, de plus, elle est unie et lissée comme si une truelle eût été habilement passée dessus; mais les soins que prend l'araiguée pour terminer son ourrage ront encore plus loin :-ce que nous faisons pour nos tentures de quelque prix, elle le pratique dans sa demeure souterraine; cette sorte de papier-satiné qui orne son habitation, elle ne l'a pas posé le premier; mais elle a appliqué d'abord sur les murailles une toile, ou, pour parler plus exactement, des fils grossiers, et c'est sur eux qu'elle a collé ensuite son étoffe soyeuse.

Tout cela est bien fait pour exciter l'admiration; mais ce qui a le droit de nous surprendre davantage, e'est la manière dont cette chambre à boyau est ouverte et fermée au gré de celui qui l'habite. Si l'araignée n'avoit eu rien à craindre de la part d'autrés animaux, eu bien si elle avoit été asseż courageuse et assez forte pour les attendre de pied ferme et les vaincre, elle auroit pu sans inconvénient laisser libre? l'entrée de sa maison, cela lui eût été plus commode pour aller et venir; mais il n'en est pas ainsi, elle a tout à redouter de la part d'une foule d'ennemis, et son caractère timide, joint au peu de moyens qu'elle possède pour leur résister, l'ỏblige d'être sans cesse sur la défensive. Alors, comme tous les êtres foibles, elle emploie la ruse pour se soustraire au danger, et son industrie supplée d'une manière merveilleuse à ce qui lui manque en force et en courage.

Nous avous déja dit plus haut que l'araignée maçonne avait un couvercle pour fermer le tube qu'elle habitait; l'araignée de Corse ou la Mygale pionnière em. ploie à peu près les mèmes précautions, mais elle montre plus de perfection dans son onvrage, et comme l'édifice qu'elle coustruit est plus vaste dans l'ensemble et dans les détails, la description que nous allons en faire en donnera une idèe très-exacte. Pour clore nos demeures, nous avons des portes qui, roulant sur des gonds, viennent s'appliquer dans une feuillure, et y sont retenues ensuite par un moyen quelconque; l'araignéc pionnière ne s'enferme pas autrement chez elie; à l'orifice extérieur de son tube est adaptée une porte maintenue en place par une charnière et reçue dans une sorie d'é- 
vasement circulaire qu'on ne peut nicux cotsparer qu'à une véritable feuillure. Cette porte, ou si l'on aime mieux ce couvercle, se rabat en dehors, et l'on concoit que l'araignée, lorsqu'clle veut sortir, n'a besoin que de la pousser pour l'ourrir. Mais le moyen qu'elle emploie pour la fermer est vraisuent remarquable: voici ce que $M$. Audouin nous a encore appris; à en juger par son aspect, on croiroit, dit cet auteur, que ce couvercle est formé d'un amas de terre grossièrement pètrie et revêtue, du còté qui correspond a l'intérieur de l'habitition, par une toile solide; mais cette structure, qui dejà pourroit surprendre chez un animal qui n'a pas d'instrument particulier pour construire, est bien plus. compliquée qu'elle ne le paroît d'abord. En cllet, je me suis assuré, en faisant une coupe verticale au couvercle, que son épaisseur, qui n'a pas moins de deux à trois lignes, résultoit d'un assemblage de couches de terre et de couches de toile au nombre de plus de trente, emboitées les unes dans les autres, et rappelant assez bien, à cause de cette disposition, ces poids de cuivre en usage pour nos petites balances, et dont les divisions; qui ont la forme de petites cupules, se reçoivent successivement jus$q u$ 'à la dernière.

Si on examine chacune de ces couches de toile, on remarque qu'elles aboutissent toutes à la charnière, qui se trouve ainsi d'autant plus renforcée, que la porte a plus de volume. La rainure elle-même, sur laquelle la porte s'applique, et que nous avons nommée précédemnient la feuillure, est épaisse, et son épaisseur est due au grand nombre de couches qui la constituent. Ce nombre paroît même correspondre à celui que présente le couvercle.

N'ayant pas vu l'araignée construire son habitation, et Rossi, bien qu'il ait eu pendant quelque temps des individus vivans à sa disposition, n'ayant pu jouir non plus de ce spectacle, nous sommes réduits à faire des conjectures sur la manière dont elle $s^{\prime} y$ prend pour confectionner les parties dont il vient d'ètre question. Supposons l'araignée à l'œuvre, et voyons-la commencer son travail. Elle aura d'abord ourdi la première toile circulaire qui forme la porte de si demeure, puis, sans discontinuer, elle aura étendu cette toile sur la charnière et l'aura prolongée aussitôt sur la feuillure. On peut expliquer de cette manière pourquoi chacune de ces trois parties fait suite l'uve à l'autre, et l'on conçoit facilement com- ment celte manœuvre s'étant répétée, la porte, la charnière et la feuillure se trouvent a la longac formées par un grand nombre de couches. Mais comme il existe, entre celles qui constituent la porte, des lits de terre, il est présumable que l'araignée aura interrompu chaque fuis son tissage pour les en pétrir convenablement. Quoi qu'il en soit, le travail ayant eu lieu de cette manière, il doit nécessairement exister une proportion toujours égale entre le volume du couvercle el la force de sa charnière, puisque relle-ci se trouve augmentée d'une couche à mesure que le premier en reçoit une nourelle.

Mais plus on étudie avec soin l'arrangement de ces parties, plus on découvre de perfection dans l'ourrage. En effet, si on examine le bord circulaire de l'espèce de rondelle qui remplit en tout les fonctions d'unc porte, on remarque qu'au lieu d'être taillé droit, il coupe obliquement du dehors en dedans, de maniere à représenter, non pas une rondelle de; cylindre, mais bien la rondelle d'un cône; et d'une autre part., on observe que la portion de l'orifice du tube qui reçoit ce couvercle est taillée elle-même en biseau et en sens inverse.

Le but de celte disposition est facile à saisir. Si le couvercle avoit $\mathrm{cu}$ un bord droit, il n'auroit rencontré, en se rabattant, comme il le fait dans l'orifice du tube, aucune partie sur laquelle appuyer ; et, dans ce cas, la charnière seule se seroit opposée à ce qu'il pénétrât plus profondement dans son intérieur; mais quand bien même cette partie délicate auroit du supporter, sans éprouver de relâchement, ce poids continuel et le choc assez fort que produit le couvercle chaque fois qu'il se rabat, il eut été à craindre que quelque pression accidentelle du dehors ne fût enfin venue la rompre. C'est pour obvier à ce grave ibconvénient que l'araignée a pratiqué à l'orifice de son habitation une feuillure contre laquelle vient appuyer la porte, et qu'elle ne sauroit franchir. Mais cette feuillure est faite avec un tel soin, et le couvercle s'applique si exactement sur elle, qu'il faut y regarder de très-près pour reconnoître le point où les deux parties se rencontrent. Au reste, l'instinct de l'animal le porte à suivre cette jonction aussi parfaite que possible; car non-seulement il lui importe de clore solidement sa demeure, mais il a le plus grand intérêt à en cacher l'ouverture aux yeux de ses ennemis; c'est évidemment dans cette intention que l'araignée a crépit 
extérieurement la porte de son habitation avec une terre grossière. En cela, elle ne fait qu'imiter l'instinct admirable qu'ont une foule d'insectes de tromper le regard en fabriquant avec des substances variées, et très-souvent avec les feuilles des plantes dont ils se nourrissent, des espèces d'habits ou de fourreaux sous lesquelsils se cachent, ou bien en fixant sur ces mêmes plantes des cocons ou d'autres demeures qui, par leurs couleurs et leur apparence, se confondent avec les tiges, les feuilles, les bourgeons et les fleurs. La Mygale pionniere, je le répète, a recours à une ruse semblable en crépissant la porte qui clôt son habitation avec la terre qui forme la surface du sol, et en la rendant tellement rugueuse et joègale, qu'elle se confond arec lui; mais en agissant ainsi, elle semble avoir prévu un autre genre de nécessité : dans l'habitude où elle paroît être, de sortir souvent de sa demeure et d'y entrer précipitamment au moindre danger, il lui a fallu pouvoir en ouvrir facilement la porte; or, cette manœuvre, qui auroit été pénible, et plus ou moins longue, si la surface extérieure du couvercle eût élé lisse, devient très-facile à cause des nombreuses inégalités qu'on y trouve, et qui donment toujours prise aux crochets dont l'animal est pourvu.

L'araignée se trouve dans la nécessité d'ouvrir elle-même sa porłe; lorsqu'elle vient du dehors, elle n'a pas à s'eu inquiéter pour la fermer; soit qu'elle sorte, soit qu'elle rentre, cette porte se ferme toujours d'elle-mème, et c'est là encore une des observations les plus curieuses que fournit l'élude attentive de cette singulière habitation.

Quand on cherche à ouvrir ces nids, on sent que ce n'est qu'avec quelque effort que l'on parvient à soulever assez le couvercle pour qu'il devienne vertical, c'est-à-dire, pour qu'il forme un angle exactement droit avec l'orifice du tube. Si on le renverse encore plus, de manière à ouvrír cet angle davantage, la résistance devient encore plus grande; mais dans ce cas, comme dans le premier, le couvercle abandonné à luimême retombe aussitôt et ferme l'ouver. ture. La tension et l'élasticité de la charnière sont les principales causes de cet effet; mais en admeltant que cette élasticité h'existât pas, il se produiroit encore, et le couvercle, soulevé de manière à dépasser un peu la ligne verticale, pourroit retomber de lui-même et fermer naturellement l'o2iffce du tube. Ce fésultat curietrx est dû à une résistance sensible qui existe dans son épaisseur. Si on l'examine avec soin sous ce rapport, on remarque que la partie voisine de la charnière est plus épaisse, et comme bosselée intérieurement. Ce surcroît de poids, qui, s'il avoit eu lieu loin de la charnière, eût porté le couvercle, chaque fois qu'il auroit été soulevé au-delà de la ligne verticale, à se renverser en dehors, se trouvant au contraire placé tout près du point d'attache et du côté où il se ferme, agit en sens inverse, et tend sans cesse à le faire retomber.

Comme nous l'avons déjà dit plus haut, la surface intérieure du couvercle qui clôt l'babitation de la Mygale pionnière ne ressemble en rien à celle du debors. Autant celle-ci est raboteuse, autant l'autre est unie; de plus on a vu qu'elle éloit tapissée, comme les parois de l'habitation, d'une couche soyeuse très-blanche, mais beaucoup plus consistante et ayant l'apparence du parchemin; nous ajouterons que cette surface intérieure est surtout remarquable par l'existence d'une série de petits trous. Ces petits trous, qu'on poarroit au premier abord négliger de voir, forment un des traits les plus eurieux de l'histoire de l'araignée pionnière, car c'est par leur moyen qu'elle peut, lorsqu'on veut forcer sa porte, la maintenir exactement fermée. Elle y parvient en se cramponnant d'une part à l'aide de ses pattes aux parois de son tube, et de l'autre en iniroduisant dans les trous de son couvercle les épines et les crochets cornés dont sont munies ses mâchoires. On comprend que Ja porte de son couvercle se trouve alors retenue par un moyen en quelque sorte aussi bon que celui que nous obtenons lorsque nous poussons un verrou dans sa gâche. Mais ce qui doit exciter davantage uotre admiration, c'est la manière dont ces trous ont été disposés : on croira peut-être que l'araignée n'en a pas épargné le nombre, et que pour ne pas se trouver au dépourvu, guand la nécessité la force à en faire nsage, elle en a criblé la face interne de son couvercle. Ce n'est cependant pas là ce qu'on observe. Ces trous sont peu nombreux, on en compte au plus une trentaine, et au lieu de les avoir dispersẻs au hasard, ils se trouvent tous réunis dans une place déterminée, et qui est exactement la même dans les quatre nids que j'ai pu observer. Nais cette place est très-convenable et telle que nous l'aurions choisie nous-mêmes, après y avoir bien réfléchi ; en cfret, ils sont situés tout près du bord du 
courercle, ct toujours au côlé opposé ḋ la charnière. Il est clair que l'araignée trouı e un grand avantage dans cette disposition, car dans l'action de tirer à soi ce couvercle, elle opère bien plus efficacement en se cramponnant loin de la charnière que si elle eût agi dans son voisinage. L'instinct de l'animal semble l'avoir si bien instruit sur ce point, qu'il n'a pas pris la peine de faire un seul trou, soil au milicu du couvercle, soit au voisinage du point où il s'attache, et que toutes les auvertures qu'on y observe sont disposées sur.une ligne demicirculaire, très-étroite.

M. Audouin, auquel nous avons $\mathrm{em}-$ prunté ces intéressantes observations, dit à la suite de ce Mémoire : Je n'ajouterai, à ce sujet, qu'une simple remarque, c'est que plus nous avons vu de perfection dans l'ouvrage de l'araignèe de Corse, plus nous somines forcés de reconnaître que tous ces actes dérivent exclusivement de l'instinct; car, si on admettoit que l'animal pût les exécuter avec quelque réflexion, il faudroit lui accorder non-seulement un raisonnement trés-parfait; mais encore des connoissances d'un ordre fort élevé, et que l'homme lui-même n'acquiert que par un Iong travail d'esprit, et parce qu'il a mis à profit l'expérience successire de ses devanciers.

Le rôle de l'araignée se réduit donc à opérer sans calcul ni combinaison, mais sous une influence étraugère et irrésistible; et quant aux lecons que pourroit lui fournir l'expérience, elles sont entièrement nulles, comme chez tous les insectes, c'est-à-dire, gu'après avoir vécu des mois et des années, elle n'en sait guère plus et n'en fait pas davantage que lorsque, sortant de l'œuf, elle s'est mise incontinent à construire.

\section{ATYPUS, LATR.; Oletera, Walck.}

Les yeux, au nombre de huit, forment un groupe ramassé sur le devant du céphlıIothorax, entre les mandibules, et sont ainsi posés : trois de chaque côté en un triangle dont l'angle le plus aigu est dirigé en avant; les deux autres yeux sont situés entre les précédens sur une ligne transverse, plus grands et plus ronds. - La lèvre est petite, presque nulle, insérée sur les mâchoires. - Les mâchoires sont allongées, uniques, dilatées à leur base, et se terminant en pointe à leur extrémité. - Les palpes, courts et non pédiformes, sont minces, insérés sur les côtés des mâchoires et à l'extrémité de leur dilatation. - Les paltes sont allongées, fines; la quatriẻme et la premiere paire sont presque égales entre elles, mais Ja quatrieme est la plus longue, et la troisième la plus courte.

Ces Aranciides sont chasseuses, conrent après leur proie et se renferment dans des trous garnis de soie.

1. ATYPUS SULzerr. (Pl. 2, fig. 2.)

Litr., Gënér. Crust. et Ins., 1. I, p. 85 , lab. 5, fig. 2. - Dufoun, Amm. des Sc. phys., t. 5, p. 34, pl. 73, fig. 6-- НАнN, monogir. der spinn., 2 Ilelt., pl. 1.Dugìs, Atlas duRég. anim., Arachn., pl. 5, fig. 3. - Oletera Atypa, - WaLck., Tab. des Aran.. p. 7, pl. 1, fig. 8, 9 el 10 ; ibid., Faun: Franc., p. 7, pl. 2, fig 3. - Ibid. IIist. nat. des Aran., fasc, 2, $\mathrm{n}^{\circ} 6$. Aranea picea, Sulzer abgekurt Geschichte, Ins., p. 254, pl. 30, fig. 2.-Aranea Subterranea, Ricm. gener. Ins., pl. 30 fig. 2. Long. 9 lig. - Le céphalothorax est grand, plus large à sa partie antérieure que postérieurement, où il se rétrécit graduellement; les mandibules sont fortes, proéminentes, arrondies, ayant à la base du crochet et pres de son insertion trois pointes obluses ou trois proéminences qui ne sont visibles que lorsque l'araignée a ses crochets reployés; la quatrième et la premiére paire de pattes sont presque égales, mais la quatrième est la plus longue, la troisième est la plus courte; les tarses sont petits et pectinés; l'abdomen est ovoïde et va eu grossissant vers la partie anale ; la couleur générale estrougeâtre; le mâle, qui se trouve plus communément que la femelle, diffère de cette dernière en ce qu'il est d'un noir luisant; les organes de la locomotion sont grêles et plus allongés; les palpes sont aussi plus allongés et terminés à leur extrémitẻ par un prolongement bifide et crochu, armé d'une petite épine.

Cette espèce, qui se trouve aux environs de Paris, construit, dans les endroits un peu. humides, une galerie souterraine, d'abord horizontale, mais qui s'incline ensuite; elle file dans l'intérieur de ce trou un tuyau de soie blanche très-serrée, qu'elle fortifie avec des brins d'herbe et de mousse, et au fond duquel elle pond ses œufs, qui présentent une masse ovoïde, enveloppée d'une toile blanche et fixée aux deux bouts avec de la soie; elle laisse pendre une partic de son tube en dehors du trou pour en proléger l'entrée. Cetic partie externe a deux ou trois pouces de longueur; le tissu: 
de cette espèce de tuyau est très-serré et très-fin, très-blanc, et ressemble an cocon ie plusieurs Chrysalides. 11 est partont d'unc largeur égale, et se termine un peu en pointe à son extrémité inféríure; cefte 'xtrémité est attachée à un paquet de bourre de soie, entrelacée arec des fibres des jlantes. Ainsi le fond de ce tuyau se trouve garanti par cette bourre de l'humidité de ja terre. M. Walckenaer, auquel nous avons emprunté ces observations, a trouvé éclos les petits de cette espèce à la mi-septembre dans son nid, au nombre de trentedeux.

\section{ATYPUS hicoroR.}

Lucas, Ann. de la Soc. Ent. de France, 1. V, p. 243, pl. 5, fig. 5. - Long. 6 lig. - Le céphalothorax est entièrement noir; Jes mandibules sout très-fortes, de même couleur que le céphalothorax; en dessus elles sont arrondies et hérissées de quelques poils noirs, en dessous et au côté interne clles sont déprimées et très-dentelées; les mâchoires sont allongées, noires, et présentent à leur côté interne des poils roussâtres; les palpes sont peu allongés, de couleur noire; les pattes sont de longueur moyenne, d'un rouge vermillon, couvertes de poils de même couleur; l'abdomen est court, entièrement noir et plus large dans son milieu que postérieurement. - IIabite l'Amérique du Nord.

\section{ACTINOPUS, PERTY; \\ Pachyloseelis, Lucas; Sphodros, Walck.}

Les yeux, au nombre de buit, forment un groupe dilaté transversalement sur le devant du céphalothorax, entre les mandibules, et ces organes sont ainsi disposés: trois de chaque côté, formant un triangle dont l'angle le plus aigu est dirigé en avant, Jes deux autres sont situés entre les latéraux antérieurs sur une ligne transverse presque droite. - La lèrre est allongée, étroite, et s'avance entre les mâchoires. - Les mâchoires sont divergentes, allongées, fusiformes ou cylindriques. - Les palpes sont très-allongés, pédiformes, insérés latéralement vers l'extrémité des mâchoires; ces organes dans les mâles sont composés de six articles.-Les pattes sont grosses, robustes et très-renflées.

Ces Aranéides sont chasseuses, courent après leur proie, et se creusent des souterrains qu'elles garnissent d'un sac de soie. cont la moitie sort du sol, et dans lequel elle se renferment. Dans un Mémoire qui a été inséré dans Jes $A n n$. de la Soc. Ent. de France, nous avons partagé ce genre en deux sections ou groupes.

\section{PREMIER GROUPE.}

A. Espèces ayant les mandibules peu arrondies à leur extrémité, mais terminées en pointe ou lame à plasieurs piquans.

Cette section comprend trois espèces parmi lesquelles nous citerons :

\section{ACTINOPUS RUFIPES.}

Lucas, Ann. de la Soc. Ent, t. VI p. 376.-Pachyloscelis Rufipes; ejusd., op. cit., t. III, p. 362. - Cratoscelis Rufipes, ejusd., op. cit., t. III, p]. 7, fig. 1, c.-Sphodros Lucasii, W ALck., Hist. nat. des Ins. apt., t. I, p. 250. - Long. 1 pouc. - Cette espèce est d'une couleur entièrement brune; son céphalothorax, plus łarge à sa partie antérieure, moins allongé et moins rètréci à sa partie postérieure, est couvert de poils fauves; les yeux ne sont pastous disséminés sur la partie antérieure du céphałothorax et forment un carré plus long que large; les mandibules sont robustes, terminées antérienrement par un crochet en pointe non mobile, assez allongè et hérissé d'une quantité innombrable de petites épines; Jes palpes sont pédiformes, allongés, insérés sur les côtés des mâchoires, d'une couleur rousse foncée et couverts de poils de même couleur à leur extrémité ; la premiẻre et la seconde paire de pattes sont grêles, couvertes de poils fauves; la troisième et la quatrième paire, très-robustes, sont de même couleur que les palpes; l'abdomen est globuleux, de forme ovalaire, couvert de poils fanves en dessus; le dessous est semblable au dessus. - Cette espèce a été trouvée au Brésil.

Le mâle, qui habite la même localité, diffère de la femelle en ce qu'il est généralement plus petit et beaucoup plus grêle; ses palpes sont très-allongés, composés de six articles; son céphalothorax est assez large antérieurement, avec sa partie postérieure rétrécie et arrondie; la couleur générale est un brun-verdâtre.

\section{ACTINOPUS AUDOUINI.}

Lucas, Ann. de la Soc. Ent. de France, t.Vl, p. 387.pl. 133,fig.1à 4.-Long. 32 mill. - Le céphalothorax est cordiforme, d'un roux foncé, plus long que large, avec sa partie antérieure très-relevée, laquelle est terminée en pointe, et hérissée d'épines et de poils d'un roux très-foncé; sa partie mé- 
diane offre une fissure assez profondément marquée, et postérieurement on en aperçoit d'autres placées çà et là, mais très-peu marquées; les yeux sont placés à la partie antérieure du céphalothorax; la première paire est grosse, la seconde, qui est plus petite, n'occupe pas tout-à-fait la même ligne que la premiére paire, la troisième paire est placée derrière la seconde paire, enfin la quatrième paire, qui est de même grosseur que la première et la seconde paire, est située sur la même ligne que la troisième; les mandibules, d'une couleur roussâtre foncé, sont robustes, avancées, arrondies latéralement, terminées à leur base par un prolongement en forme de pointe ou de lame, laquelle est hérissée d'une quantité innombrable de petites épines; les crochets sont allongés, arqués et placés, dans le repos, dans une rainure longitudinale des mandibules, et dont les bords sont hérissés de petiles épines trèsaiguës; la lèvre est courte, large à sa base, arrondie et terminée en pointe antérieurement, et parsemée cà el là extérieurement de petites épines; les mâchoires sont larges, allongées, arrondies au côté extérieur, et couvertes de longs poils à leur côté interne; les palpes sont pédiformes et d'une couleur roussâtre clair; les pattes sont allongées, robustes, surtout les deux dernières paires; les quatrième et troisième son! les plus longues, la première ensuite, la seconde est la plus courte; ces pattes présentent entre elles des différences assez sensibles, surtout la troisième paire, qui est remarquable, et qui diffère de toutes les autres par le tibial, qui est très-comprimé à sa naissance, dilaté à sa base, laquelle est hérissée d'une quantité innombrable de petites épines; le plastron sternal est plus long que large, tronqué ;antérieurement et terminé en pointe postérieurement; l'abdomen est plus allongé que le céphalothorax, et y est attaclé par un très-court pédicule; cet organe est très-gros, large dans sa partie médiane, arrondi antérieurement et postérieurement; sa couleur est d'un gris cendré ou d'un jaune mélangé de grisâtre; en dessus et en dessous, il est légérement ridé trans. versalement, et couvert de poils très-courts et clairement parsemés; les ouvertures stigmatiformes qui sont placés en dessous et sur les côtés latéraux antérienrs, sont 1rès-apparentes à cause des taches d'un jarne sale qui les circonscrivent; les filières, au nombre de deux paires, sont peu allongèes, composées de trois articles, d'un jaune sale. - Elle a été trouvée dans l'Amérique du Nord.

\section{DEUXIEME GHOUPE.}

B. Espèces ayant les mandibules non terminées en pointe à leur extrémité, mais arrondies.

\section{ACTIYOPUS MIGRIPES.}

Lucas, Ann. de la Soc. Ent. de France, t. VI, p. 377. - Pachyluscelis Nigripes, ejusd. , op. cit., t. 111 , p. 364. Cratoscelis Nigripes, pl. 7. p. 2 d. Sphodros Abbotti, W AICK., Hist. nat. des Ins. apt., t. I, p. 247. - Le céphalothorax est très-relevé à sa partie antérieure, cordiforme et tronqué postérieurement; les yeux, peu éloignés les uns des autres, sont placés sur la partie antérieure du céphalothorax; les mandibules sont allongées, robustes et arrondies; les palpes sont noirs, grêles, très-allongés, plus longs que les pattes antérieures, et composés de sis articles; les pattes, de même couleur que les palpes, sont allongées, la première paire est plus longue que la seconde, la troisième ensuite, la quatrième est la plus longue de toutes; l'abdomen est peu allongé, de couleur noire, avec la surface oule dessus de couleur fauve. - Habite le Brésil.

\section{ACTINopUs TARSALIS.}

Perty, Delect. anim. qua in itin. per Brasil. Spix et Mart., Colleger., p. 198, pl. 39, fig. 6. - Pachyloscelis Tarsalis, Luc., Magas. de Zool., cl. 7, ann. 1836. Sphodros Lucasii, W ALCK., op. cit. , t. I, p. 250. - Long. 4 lig. - Le céphalotho. rax est large, coupé en ligne droite à sa partie antérieure, rétréci et arrondi à sa partie postérieure, plus large, plus long que l'abdomen; les yeux sont presque égaux entre eux, les quatre antericurs sont sur une ligne droite, les quatre postérieurs sont disposés par paires et très-rapprochés; le crochet des mandibules est fléchi longitudinalement; la lèvre est allongée, ovalaire; les palpes sont très-allongés, de six articles, d'un brun-noir, avec le dernier article ovale et très-ćchancré; la première et la quatrième paire de pattessont très-allongées, la troisieme est la plus courte; l'abdomen est ovalaire, arrondi. - Cette cspèce a été trouvée dans la province de Peauhicns.

$$
\begin{gathered}
\text { Calommata, Lucas; } \\
\text { Pachyloscelis, Euesd. }
\end{gathered}
$$

Les yeux sont au nombre de huit; la pre. 
mière paire est isolée et placée à la parlie antérieure du cépbalothorax, lequel est trèsrelevé; la seconde, la troisième et la quatrième paire sont très-éloignées de la première, disséminées entre elles, et placees sur les côtés latéraux et à la base de la partie relevée du céphalothorax. - Les mandihules sont robustes, trés-allongées, arrondies et très-saillantes au-delà de leur naissance. - Les mâchoires sont très-allongécs, courbées extérieurement, épaisses à leur base, grêles et terminées en pointe arrondie. - La lévre est très-petite, arrondie à sa partie antérieure.-Le plastron sternal est plus long que large, tronqué antéricurement et terminé en pointe postévieurement. - Les palpes sont grêles, assez allongés. - Les pattes sont peu allongées, robustrs, surtout la seconde, la troisieme el la quatrième paire; la première est grêle et presque filiforme. - L'abdomen est peu allongé, de forme arrondie. -- Les mœurs de ce genre nous sont inconnues.

Calonuata Fulvines. (Pl.: 2, fig. 3.)

Locas, Ann. de la Soc. Ent. de France; t.V I, p. 378, pl. 13, fig. 6 a 11.-Pachyloscclis Fulvipes, ejusd., Mag. de Zool., cl. VII, pl. 14, fig. 1 à 7. - Le céphalothorax est tronqué, peu épais, et présente postérieurement une éminence en forme de triangle, dont la partie médiane est saillante, arec les côtés latéraux et postérieur dẻprimés; les ycux sont placés sur celte ëminence; la première paire est située sur la partie saillante et assez rapprochée; la seconde est placée sur les côtés latéraux de cette éminence, elle est plus grosse que la première paire, et très-écartée; la troisième est placée audessus et un peu en arrière de la seconde paire, elle est trés-petite; enfin la quatrième, qui est un peu plus grosse, est placée tout-à-fait en arrière et an dessous de la troisième paire; les yeux, qui forment la seconde, la troisième et la quatrième paire, sont très-rapprochés, et semblent, à la première vue, être réunis ensemble; les mandibules sont allongées, plus longues que larges, très-comprimées, elles sont saillantes au-delà de leur naissance, arrondies en dessus, et présentent à leur extrémité quelques poils d'un roux clair ; à leur côté interne, elles sont dentelées et hérissées de poils d'un roux clair; les crochets des mandibules sont noirs, en croissant, trèsallongés, saillantsau-delà de leur naissance, et très-aigus à leur extrémité ; les mâchoires sont très-allongées, amincies à leur partie antérieure, củ clles sont terminées en une pointe arrondie; ces mâchoires sont légérement coubées au côté externe, et au côté interne elles sont hérissées de poils de même couleur que ceux des mandibules; la lèvre est tres-petite, plus large que haute, un peu concave antérieurement, où elle présente des poils de couleur fauve; le plastron sternal est grand, un peu ovalaire, postéricurement il se continue pour servir d'attache an pédicule de l'abdomen; les palpes sont peu allongés, insérés â la base des mâchoires; le premier article est allongé, le second très-court, le troisième un peu plus long et légérement élargi, enfin le quatrième, de même longueur, est terminé en une pointe mousse à son extrémité ; ces palpes sont remarquables en ce que, à leur côté interne, íls sont très-déprimès et arrondis à leur côté externe; les pattes sont courtes, robustes, surtout la troisième et la quatrième paire; la première paire est grêle et moins allongée que la seconde, dont les premiers articles sont robustes; la troisième paire est plus longue que la seconde; les articles qui la composent sont très-robustes, surtout les premiers; la quatrième est la plas longue de toutes, avec ses articles un peu moins robustes que ceux de la troisième paire; ces pattes ainsi que les palpes sont hérissés à leur extrémité de poils blonds; l'abdomen est ovale, globuleux ct courert de poils blonds : cet organe est attaché au céphalothorax par un très-court pédicule; la couleur générale est un fauve clair, avec les organes de la manducation et de la locomotion plus foncés.-Trouvée aux environs de Bahia.

\section{ERIODON, LATR.; Missulena, WaLCK.}

Les yeux, au nombre de huit, sont dis. séminés sur le céphalothorax, et forment un triangle dont la base est dirigée en avant et la pointe en arrière. - Les deux autres yeux sont situés entre les précédens sur une ligne transverse. - La lèvre est allongée, elle s'avance entre les mâchoires en parallèlipède étroit, et elle est distinguéc de la plaque sternale par un sillon transversal. - Les mâchoires sont larges, grandes, rhomboĩdes, dilatées à leur base, divergentes vers leur extrémité, qui se projette en pointe arrondie. - Les palpes sont allongés, pédiformes, insérés sur les côtés des mâchoires, et à l'extrémité de leur di- 

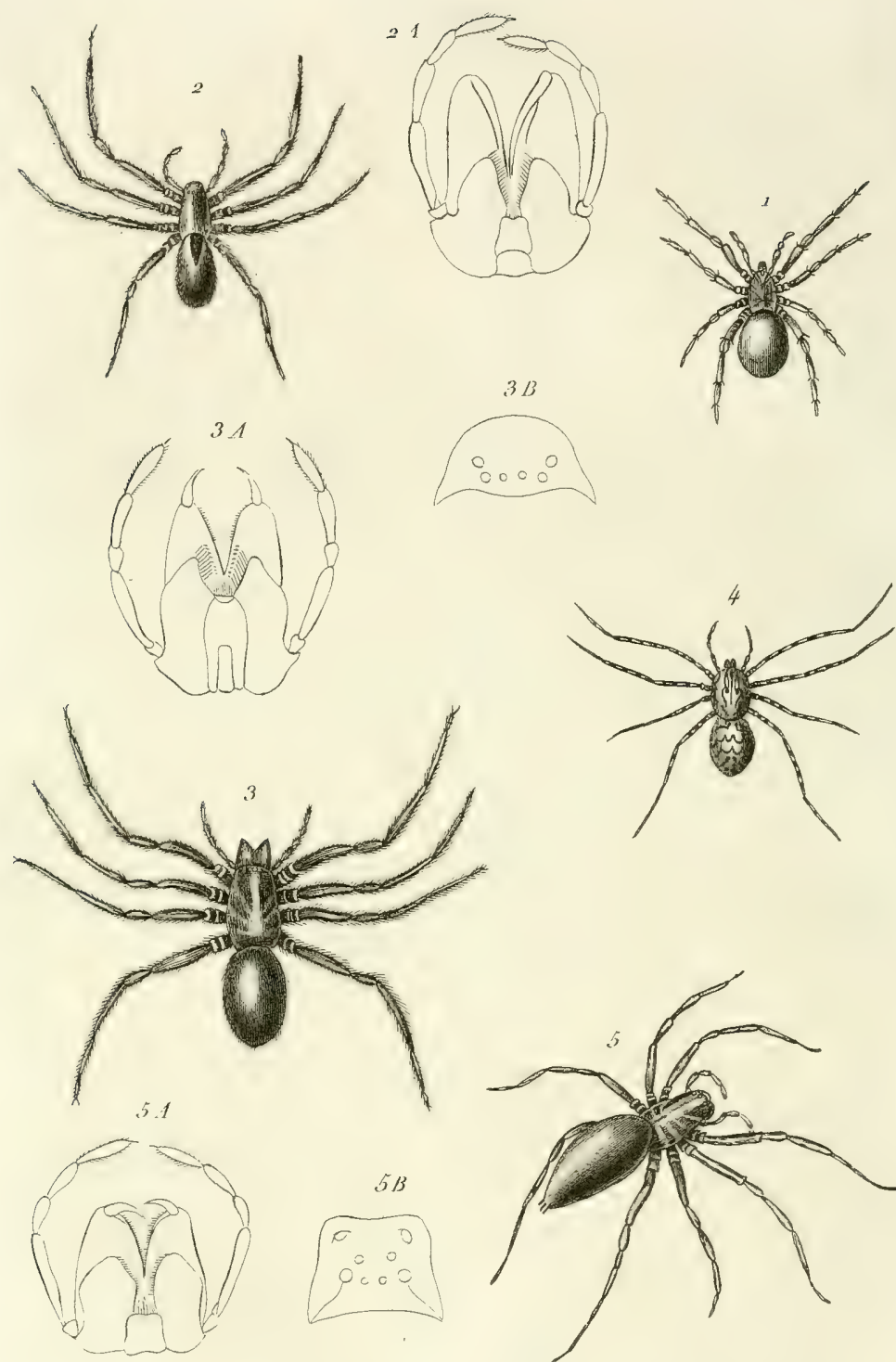

31

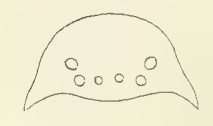


hatation. Les pattes sont courtes, robustes assez renflées; les postérieures sont les plus longues.

Les mœurs de ce genre nous sont inconnues.

1. eriodon OCGatorius. (Pl. 2, fig. 4.) Latr., Regn. auim. de Cuv., $2^{\circ}$ édit., t. IV , p. 233. - GuÉr., Iconogr. du Rènne anim. de Cuv., Arachn., pl. 1, fig. 1. - Missulena Occatoria, Walck. Tab. des Aran., p. 8, pl. 2, fig. 11, 12. - Ibid. op. cit., t. 1, p. 252. - Le céphalothorax, de couleur brune, est tres-grand, presque carré, aussi large à sa partie antérieure qu'à sa partie postérieure, èlargi dans son milieu, très-relevé à sa partie antérieure, sur laquelle sont silués les yeux, qui en occupent toute la largeur, et sont proprotionnellement très-petits; les mandibules sont brunes, luisantes, courtes, grosses et renflées, et ne sont point déprimées sur les côtés extérieurs; à l'extrémité de leurs tiges, et près de l'insertion des crochets, elles sont munies de deur rangs de pointes courtes et fortes; les pattes sont courtes et renflées, les deux paires postérieures sont plus allongées que Jes antérieures, et ont leur fémoral très-ren1lé; la quatrième et la troisième paire sont presque égales entre elles, la première surpasse notablement la seconde en Iongueur, qui est la plus courte; l'abdo. men, de couleur brune, est ovale, guère plus long et plus large que le céphalothorax. - Habite la Nouvelle-Hollande.

Filistata, Latr., L. Duf., Walck.

Les yeux, au nombre de huit, sont inégaux, groupés sur le devant du céphalothorax, et ainsi disposés : trois de chaque côté, ovalaires, disposés en triangle, et deux intermédiaires fort petits, ronds. La lèvre est indistincte, remplacée par un prolongement ovale pointu de la plaque sternale du cépbalothorax. - Les mâchoires sont courtes, inclinées, pressées mutuellement, et appliquées contre les mandibules. - Les mandibules sont inclinées, presque horizontales, petites, étroites, contiguës, comme soudées, et à crochet d'une extrême pelitesse. - Les palpes sont de longueur médiocre, insérés dans un léger sinus de la base des mâchoires, et à J'extrèmité de leur dilatation, très-rapprocliés entre eux, resserrant et cachant les mandibules : ces organes sont renflés et courts dans les femelles, très-allongés dans les mâles.

Ces Aranéides sont tubicoles, lucifuges, et sortent la nuit pour courir après leur proie.

Firistata micolor. (Pl. 3, fig. 1.)

Latr, Régn. anim. de Cuv, $2^{\mathrm{e} e}$ edit. t.VI, p. 234. - Walck., Faun. franç., Aran., p. 10 , pl. 6 , fig. 1,3 ; ibid., op. cit., t. I, p. 254, pl. 6, fig. 1, $a, c, d$.-L. Duf., $A n n$. de la Soc. Ent. de France, t. V, p. 534. -Dugìs, Atlas du Règ. anim., Arachn.,pl.6, fig. 1. - Long. 7 lig. - Le cèphalothorax est d'une conleur testacée livide, et presque glabre; il présente, depuis l'éminence oculifere jusque vers une fossette centrale de sa région dorsale, un espace en triangle lancéolé, limité par deux traits noirs, formés à la loupe par des poils de cette couleur tout-à-fait couchés, ainsi qu'une fine bordure extérieure. Celte même région ofre aussi de fort légères impressions rayonnantes. Les six yeux principaux sont d'une couleur blanche cristalline très-prononcée; la plaque sternale offre quelques poils couchés, grisâtres, assez rares, qui ne masquent pas la lividité du fond; les pattes, ainsi que les palpes, ont des poils couchès, dont la disposition est parfois telle qu'il en résulte des lignes longitudinales glabres, que l'on prendroit pour des stries; l'exinguinal a une teinte livide plus claire; les tarses sont plus foncés, et presque d'un gris de sourîs comme l'abdomen; l'abdomen est feutré d'un duvet court et serré, d'un gris de souris ou ardoisé uniforme, soit en dessus, soit en dessous, et offrant parfois des reflets soyeux.

Cette Aranéide est propre aux contrées méridionales de la France; suivant $\mathbf{M}$. Du. four, elle fuit le grand jour, et tout en recherchant les lieux secs, elle se tient toujours à l'abri du soleil. «En novembre 1810 , dit le même-auteur, je la trouvai pour la première fois sous la voûte d'un rocher, an voisinage de Miora, dans la Basse-Catalogne. L'orifice évasé de sa demenre avoit un pouce et demi de diamétre. Je l'ai ensuite observée, à diverses reprises, dans le royaume de Valence, soit sous des pierres crevassées, soit dans le creux de vieux oliviers; cnfin, je l'ai rencontrée aussi en France, aux environs de Narbonne. ”

\section{DYSDERA (1), WALCK., LATF。}

Les yeux, au nombre de six, sont pres.

(1) Ce genre, par la manière dont les espèces. quile composent font leur toile, devrait so rasi- 
que égaux entre eux, rapprochés sur le devant du céphalothorax, et sur deux lignes; les postérieurs, au nombre de quaire, sont contigus; les antérieurs sont disjoints et écartés. - La lèvre est allongée, aussi large ou plus large à sa base que dans son milieu, terminée en ljgne droite ou à extrémité arrondie, entière ou échancrée dans son milieu. - Les mâchoires sont droites, allongées, ayant à leur base une dilatation qui recoit le palpe; elles sont dilatées ou arrondies à leur côté interne, pointues à leur extrémité. — Les pattes sont de longueur moyenne; la première paire est la plus longue, cnsuite la quatricme ou la seconde; la troisième est la plus courte.

Ces Aranéides se renferment dans.un sác oblong, d'un tissu blanc, serré, ou dans des tubes de soie, sous les pierres, ou dans les cavités des murs.

Les espèces qui composent ce gcnre ont été divisées en trois groupes.

\section{PREMIER GROUPE.}

\section{Les Agones, Walck.}

Les yeux de la première ligne sont plus gros. - La lèvre esı échancrée à son extrémité. - Les mâchoires sont divergentes et pointues à leur extrémité. - Les mandibules sont dirigées en avant.

\section{DYSDERA ERYTHRINA.}

Walck., Tab. des dran., pl. 5, fig. 49 ; 59. - Ibid. op. cit., 1. 1, p. 161. - DuF., (bserv. sur quelques Arachn., Bruxcl1es, 1820, pl. 73. - I InN, Die Arachnid., 4. I, p. 7, tab. 1, fig. 3. - Dugès, At. $d u$ Rég. anim. de Cuv., Arach., pl. 5, fig. 4.-Long. 6 lig. - Le céphalothorax est rouge de corail, glabre, ellipsoide, grand, aussi Jarge ct presque aussi long que l'abdomen ; les yeux forment une lunule anguleuse, dout les deux cornes sont dirigés en avant; les quatre yeux postérieurs sont placés sur la ligne posterieure de l'épistome; les deux antérieurs, plus gros, sont placés sur l'épistome même, qui est très-étroit et presque nul dans cette espèce; les mandibules sont rouges, glabres, fortes et grandes, dirigées en avant; elles sont en forme de cône allongé, et ont sur leur surface des petits poils blanes épars, rares, très-fins,

ger dans la deuxième sous-section ou les Tubicoles; mais nous n'avons pu l'y placer' à cause des sacs pulmonaires ou ouveriures stigmatiformes qui sout au nombre de quatre. disposés régulièrement, el visibles qu'arec l'aide d'une forte loupe; elles s'écartent latéralement, et divergent; leurs crochets sont très-allongés, d'un rouge-brun, peu courbés; les mâchoires, de même couleur que les mandibules, sont glabres, presque horizontales, ou faisant un angle très-ouvert avec le céphalothorax; elles sont allongées, écartées, bombées et dilatées à leur base, pour recevoir les palpes, élargies dans leur milieu, pointues à leur extrémité, et garnies de poils fauves à leur côté interne; les palpes sont rouges; les pattes sont allongées; elles sont d'un rouge plus pâle que le céphalothorax, surtout les postérieures, glabres, et n'ayant que des poils rares et des piquans aux derniers articles; la plaque sternale est r'ouge, glabre, avec des poils blanchâtres, rares, en ovale allongé, et pointue aux deux bouts, avec des éminences à la naissance des pattes; l'abdomen est allongé, cylindroïde, se rétrécissant un peu vers la partie anale, moins large que le céphalothorax, quand cet organe n'est pas gonflé par les œufs, d'un gris rougeâtre uniforme, qui devient d'un rouge très-pâle par le séjour dans l'alcool; en dessus, il est plissé en raies arrondies, parallèles et concentriques; en dessous, la couleur est la même, mais plus pâle, uniforme, ayant quatre ouvertures stigmatiques, rapprochéęs et parallèles; les filières sont d'un rouge pâle, les supérieures un peu plus saillantes que les inférieures.

Lie mâle est entièrement semblable à la femelle par la forme et la couleur; il est en général plus petit, mais son céphalothorax est plus robuste; et ses mandibules plus fortes et plus allongées. Le digital du mâle est armé d'un conjoncteur principal, globuleux, articulé à un court pédicule, qui est muni d'un conjoncteur auxiliaire, en cône, allongé, pointu, percé à son extrémité.

Cette espéce est très-commune dans toute la France, et plus au midi en Espagne, et dans le nord de l'Afrique et cn Igypte; mais elle n'a jamais été rencontrée en Suède, ni dans les contrées froiles. Elle est ordinairement errante, et on la trouve depuis le mois de mai jusqu'en novembre. Intrépide el féroce, elle attaque souvent d'autres espèces d'araignées qui sont quelquefois bien plus grosses qu'elle. Elle se renferme dans des sacs de soie sous. les pierres.

2. DYSDERA LATA.

Reuss, Zool. Miscell., Museum Sen- 
thenbergian., t. I, p. 251. - Dysdera Erythrina, Ád., S Sv., Descript. de l'Egypte, Arachn., pl. 5, tig. 3. - Long. 6 iig. - Cette espèce diffère de la précédente par son céphalothorax, qui est large, très-bombé, d'un rouge cramoisi, et d'un tiers plus court que celui de l'Erythrina, et par là proportionnellement plus large ; par son abdomen, qui est ovale, court, d'un gris-noirâtre, et plus garni de poils. - Se trouve en Egypte.

\section{DEUXIÈM GROUPL.}

\section{Les Agores, WaLcK.}

Les yeux de la première ligne sont plus gros. - Les mâchoires sont arrondies à leur extrémité. - Les côtés intérieurs sont parallèles et non divergens. - Les mandibules sont inclinées perpendiculairement.

\section{DYSDERA SOLERS.}

W Alck., op. cit., t. I, p. 263. - Long. 5 lig. - Le céphalothorax est glabre, allongè, très-bombé, chagriné, rouge; les yeux sont d'un rouge-brun; les latéraux sont très-rapprochés; les mandibules sont brunes, rougeâtres; les mâchoires, de couleur pâle, sont peu convergentes; la lève est très-échancrée, d'un rouge-brun, et noire à son extrémité ; l'abdomen est ovale, allongé, cylindroìde, d'une couleur fauve pâle. - Se trouve à Carthagène.

\section{DYSDERA HOMBERGII.}

WALCK., op. cit., t. I, p. 263. - Dysdera Parvula, Duf., Ann. des $\boldsymbol{S}$ c. phys., t. V, p. 40 ; ibid., Ann. des Sc. nat., 1831, t. XXI1, p. 370, pl. 11, fig. 4.-Dysdeia Gracilis, Reuss. Museum Sackenbergianum, t. I, p. 200, pl. 14, fig. 1, $a, b, c$. Aranea Hombergii, Scopol., Entom. Carniol., p. 409, no 111. - Long. 2 lig. $\frac{1}{2}$. Le céphalothorax est allongé, bombé, noir; les yeux sont d'une couleur d'ambre jaune; les mandibules sont noires, cylindriques, bombant perpendiculairement, et non dirigćes en avant; les mâchoires sont allongées, étroites, d'un rouge-brun, trèsrenflèes, légérement dilatées, et arrondies à l'extrémité de leurs côtés internes, et se terminant un peu en pointe; la lèvre est étroite, trẻs-allongèe, terminée en ligne droite, d'un rouge-brun, ovalaire, peu élargie à sa base, mais à côtés presque parallèles, bombée, et séparée du céphalothorax par uire rainure; les palpes sont d'un rougre uniforme, sans taches brunes vers leurs extrémilés, el garnis de piquans; la plaque sternale est ovale, large, d'un brun-marron foncé, avec des éminences a la naissance des pattes; ces dernières sont fines, allongées, alternativement blanches ou jaune-verdâtre et brun; les grandes taches brunes sont à la fin des cuisses, au commencement des jambes, et deux autres plus petiles au commencement et à la fin de l'avant-dernier article; les pattes antérieures ont des taches plus brunes que les postérieures; la première paire est plus longue que les autres; la quatrième ensuite, quuoiqu'elle diffère de la seconde; la troisième est beaucoup plus courte; l'abdomeu est cylindrique, d'un brun-marron en dessus, velouté, avec quelques pointsplus obscurs; en dessous, il est rose dans le milieu, avec une ligne brune longitudinale, et d'un blanc-jaunâtre près des filières et du céphalothorax; les filières sont peu proéminentes.

Le mâle diffère de la femelle en ce qu'il est plus petit. Son céphalothorax est d'un brun-marron ou noir, proportionnellement beaucoup plus court que l'abdomen, qui est cylindrique et assez al ongé. Les mâchoires sont plus allongées et un peu plus pointues que dans la femelle; la lèvre est entière el non échancrée; les mandibules sont cylindriques, d'un brun-rougeâtre, mais légérement portées en avant; les palpes sont rougeâtres; le radial, ou l'avantdernier article, est trés-allongé ; le digital est pourvu d'un conjoncteur ovale, pyriforme, terminé par un crochet brun.

Cette espece, qui se trouve en France, en Allemagne et en Espagne, vit sous les pierres, et se fabrique dans leurs cavités un petit tube de soie où elle se renferme.

\section{TROISILUE GROUPE.}

\section{Les Ariadnes, WaLCK.}

Les yeux intermédiaires de la ligne postérieure sont les plus gros.-Les mầchoires sont arrondies à leur côté extérieur; les côtés intérieurs sont parallèles et non di. vergens. - Les mandibules sont inclinées perpendiculairement.

5. DYSDERA ixsidiatrix. (Pl. 3, fig. 2.)

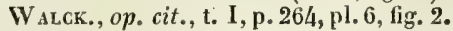
- Ariadne Insidiatrix, $\mathbf{S}_{\mathrm{AV}}$, Descript. de l'Égyple, Arachn., p. 109, pl. 1, fig. 3. - Long. 3 lig. - Le céphalothorax est bruncendré; les mandibules sont très-inclinées, à enfoncemens ou goutticres courtes, sans den- 
telures, et à crochet très-court; les mâchoires sont peu convergentes; les palpes sont renflés; la levre sternale est allongée, et trèsarrondie àson extrémité; les pieds sont roussâtres; ; les tarses de la paire antérieure sont bruns; l'abdomen est d'un cendré clair, soyeux, marqué à sa base d'une tache oblongue, plus obscure. Cette espèce se retire dans des trous, et s'y enferme dans un tube de soie, - Se trouve en Egypte.

Suirant M. Savigny, cette Aranéide habite l'intérieur des maisons d'Alexandrie, et elle a des habitudes semblables à l'Aranea Insidiatrix de Forskaël, c'est-à-dire qu'elle se retire dans des trous, qu'elle s'y renferme dans un tube de soie, et, à la circonférence que forme l'ouverture de ce tube, elle fait aboutir des fils dirigés en tous sens, de même que les Segestria.

\section{DEUXIEME TRIBV.}

\section{DIPNEUMONES,}

Latreille, L. Dufour.

Caractères. Les Aranéides renfermées dans cette tribu ne présentent que deux sacs pulmonaires, avec une ouverture extérieure pour chaque, et situés, un de chaque côté, à la base du ventre. - Le crochet des mandibules est toujours replić sur la face interne de la pièce avec laquelle il s'articule. - Les appendices articulés de la partie anale, dont quatre composent les filières propres, sont au nombre de six. La languette est toujours saillante entre les coxomaxiles, ou les mâchoires, qui portent sur leur côté extérieur les palpes; ces derniers organes sont divisés en cinq articles. - L'organe copulateur est ordinairement très-compliqué, et logé, du moins en partie, dans une cavité interne du dernier article. - La disposition des organes de la vue et les habitudes sont très-diversifiées. Cette tribu renferme un très-grand nombre de genres.

Genres: Segestria, Uptiotes, Scytodes, Lycosa, Dolomedes, Storena, Ctenus, Hersilia, Sphasus, Dyction, Dolophones, Myrmecia, Eresus, Chersis, Attus, Arlsys, Delena, Thomisus, Selenops, Erypus, Philodiomus, Olios, Sparassus, Clastes, Clubiona, Desis; Drassus, Clotho, Enyo, Latrodectus, Pholcus, Artena, Tegenaria, Lachesis, Agelena, Nyssus, Epeira, Gasteracantha, Uloborus, Zozis, Lyniphia, Argus, Episina, Theridion, Erygone, Argyroneta.

\section{DHUXIEME SOUS-SECTION.}

\section{Les Tubicoles, Walck.}

Se renfermant dans les tubes de soie.

$$
\text { SEGESTRIA, WaLck., Latr. }
$$

Les yeux, au nombre de six, sont pres. que égaux entre eux, rapprochés sur le devant du cephalothorax, et sur deux lignes; les postérieurs, au nombre de deux, sont placés sur les côtés, et écartés; les antérieurs, au nombre de quatre, forment une ligue droite ou légérement courbée en avant, transversale. - La lèvre est allongée, cylindroïde, plus étroite à sa base que dans son milieu, et légérement échancrée à son extrémité. - Les mâchoires sont droites. allongées, dilatées à leur base, et arrondies à l'extrémitẻ de leur côté interne. - Les paltes sont fortes, allongées; les deux paires antérieures sont les plus longues.

Les Aranéides qui composent cè genre sont tubicoles et vagabondes; elles forment dans les interstices des murs et des rochers en plein air, ou dans les cavités souler. raines, une toile peu étendue, horizontale, à tissu serré, à la partic supérieure de laquelle se trouve un tube cylindrique, où elles se tiennent immobiles; à l'embonchure de ce tube sont dirigés, extérieurement, des fils comme autant de rayons divergens. Le cocon est globuleux ou de forme ovoïde.

Les espèces qui le composent ont été divisés en deux groupes.

\section{PREMER GROUPE.}

\section{Les Divergentes, Walck.}

Les mâchoires sont dilatées, et arrondies à leur extrémité extérieure, divergentes, et coupées obliquement à leur extrémité interne.

SEGESTRII PERFIDA. (Pl. 3, fig. 3.)

WaLck., Tab. des Aran., pl. 5, fig. 51. el 52 ; ibid., Faun. franc., t. I, p. 197 , pl. 8, fig. 5; ibid., op. cit., t. I, p. 267, pl. 6, fig. 3 et 4. - S S Arach., pl.1, fig. 2.-Dugès, Atl. du Régn. anim., Arach., pl. 7, fig. 3. - Segestrie, descaves, Dufour, Ann. des Sc.nat., t. II, p. 108, pl. 10, fig. 5.-Segestria Florentina HaHx, Die Arachnid., in-8 $8^{\circ}$ p. 5, tab. 1 , fig. 1. - Aranea Florentina, Rossi, Faun. 
Firusc., t. II, p. 133, tab. 9, fig. 3. Long. 9 lig. - Le céphalothorax est grand, moins long et moins large que l'abdomen, bombé et relevé vers les yeux, n'ayant à sa partie postérieure qu'un léger enfoncement à peine serisible, d'où rayonnent des sillons larges, peu apparens, qui aboutissent à la naissance des pattes; sa couleur est brun rougeâtre, glabre et rougeâtre vers la partie antérieure, avec un duvet peu serré de poils fauves à la partic postérieure; les mandibules sont grandes, fortes, bombées, dirigées en avant, d'un beau vert boutcille, et d'un éclat métallique, et hérissées de poils fins et longs, implantés sur leurs côtés internes, et qui se dirigent en avant; le crochet est très-courbé, robuste, rouge à sa base et à son extrémité, noir dans son milieu, et se reployant dans une rainure armée de trois dents de chaque côté, les deux extrêmes pointues, tandis que la dent est large et bifide; les mâchoires sont glabres, rougeâtres, et semblables a celles de la $S$. Senoculata; la lévre est large, rouge-brun; fortement échancrée à son extrémité, et a la même élévation ovale, partant de la base dans son milieu; les palpes sont courts, de même conleur que la lève; le dernier article est filiforme, beaucoup plus mince que les autres, et hérissé de poils jaunâtres; la plaque sternale est ovale, allongée, pointue à sa partie postérieure, glabre, rougeâtre, avec des éminences à la naissance des pattes, séparées par des sillons profonds; les pattes sont allongées, fortes; le fémoral et le génual sont renflés, et d'une couleur brunfoncé-rougeâtre; le tibial, le métatarse et le tarse sont d'un rouge-clair; ceux-ci ayant deux onglets terminaux, courbés, allongés, non cachés par les poils, et armés de dents fines el égales, semblables à celles d'un peigne, au nombre de six à sept, puis un troisième article à la base des deux autres, mais courbé et caché en quelque sorte par des poils; les pattes sont glabres en dessus, mais sur les côtés et en dessons elles ont des piquans longs et forts, et dont les pointes sont dirigées à la partie inférieure; le tibial, le métatarse et le tarse des pattes antérieures présentent à l'intérieur des poils fins, courts et serrés, qu'on ne remarque pas aux deux pattespostérieures; le fémoral et le tibial sont, à leurs côtés internes, hèrissés de poils jaunâtres, fins; l'abdomen est al. longé, cylindrique, plus large à sa partie antérieure, et arrondi postérieurement; la partie supérieure ou le dessus est glabre, et mon velu comme dans le mâle, de coulcur brune uniforme, sans aucune figure apparente dans les adultes. Dans d'autres plus jeunes, on aperçoit une ligne noire longitudinale que nous décrirons dans le mâle, mais qui, dans la femelle, est obscure et peu visible. La partic inféricure ou le dessous est brune sur les côtés, au milieu d'une couleur rouge pâle, avec deux lignes fines jaunâtres, longitudinales, parallèles, bordant de chaque côté cette partie plus claire. Les filières sont d'un rouge clair.

Le mâle diffère de là femelle par le céphalothorax, qui est plus grand, aussi long et aussi large que l'abdomen, moins bombé et plus pointu vers la partie antérieure, et par une couleur brune plus foncée ; par les mandibules, qui sont moins fortes, quoique plus longues et moins velues à leur intérieur; par la lèvre, qui est un peu plus large à son extrémité ; par les mâchoires, qui son un peu plus grêles; par l'abdomen, qui esi moins allongé, moins renflé, et qui présente sur sa partie supérieure une ligne noire dentée; par les lignes blanches qui la traversent sans se joindre, de maniere a former des espéces de demi-cercles noirs, entourés de blanc ou de gris, si les lignes blanches ou grises n'étoient point disjointes à la partie antérieure comme à la partie postérieure. Les côtés sont blancs ou gris, ou rougeâtres, comme dans la $S$. Senoculala. Le dessous est de couleur grise ou rougeâtre sale, avec les deux traits fins longitudinaux de couleur plus claire, qui, comme dans la femelle, commencent aux ouvertures stigmatiques, et se terminent aux filières. Les pattes sont plus brunes, plus fortes et plus allongées, et ces organes different de ceux de la femelle par leur longueur relative, la troisieme paire élant sensiblement plus longue que la quatrième. Dans les individus jeunes, quoique grands, les pattes sont glabres, et peu couvertes de poils: mais j'ai vu, dit M. Walckenaer, des individus très âgés dont les pattes étoient garnies de poils épais. Les palpes, dans les mâles de la $S$. Perfida, sont semblables à ceur de la $S$. Senoculata, et présentent un orģne générateur unique, sans aucune complication, et articulé a la base interne du dernier article, de forme ovale, piriforme, finissant en pointe allongée, fine, et légérement recourbée à son extrémité. Le der. nier article sur lequel est inséré cet organe est filiforme, et plus mince que dans la fe. melle, excepté à sa base, où il présente un pelit renflement globuleux. Les premiors 
articles des palpes, comme ceux des pattes, sont plus bruns que les derniers, qui sont d'un rouge clair, ainsi que l'organe générateur. - Se trouve communément à Paris et dans ses environs.

Cette espèce file dans les trous des murs un tube de soie blanche, terminé à l'extérieur par un grand nombre de fils divergens, qui sont autant de piéges tendus aux insectes dont elle fait sa proie. Lorsque le trou qu'elle a choisi est étroit, la couche de soie dont elle se revêt en prend la forme; dans le cas contraire, elle proportionne l'ampleur de son tube á la grosseur de son corps, et elle le fixe par des soies nombreuses aux parois du mur. Au lieu d'être droit, ce tube renflé au milieu, ẻt cit à l'ouverture, en pointe à l'extrémité inférieure, prend exactement la forme d'une nasse de pêcheur. C'est de cette espèce d'embuscade, les six premières paires de pattes en avant, et les yeux attentifs, que cette espèce guette les insectes qui osent aporocher de sa retraite. Elle se tient totjours à une assez grande distance de l'orifice, sans doute pour ne recevoir que foiblement les rayons de la lumière, car ses habitudes sont nocturnes, et c'est lui faire violence que de l'obliger à sortir de son tube pendant le jour. Le soir, au contraire, après une journée chaude, il est commun de voir la Segestrie perfide sortir d'ellemême, et courir de côtés et d'autres dans le voisinage de leurs habitations. C'est sans doute aussi pendant la nuit que leur accouplement a lieu. Le mâle, qui n'a jamais été rencontré dans ces tubes, se voit fréquemment vers le soir aux environs des lieux habités par les femelles. 11 court avec vivacité, et on le distingue facilement de la femelle, par ses formes plus grêles et les coúleurs moins foncées de son abdomen. Touslcs mâles que j'ai pu prendre pendant la nuit, dit M.Walckenaer, s'étoient filéun tube grossièrement travaillé dans l'angle d'une muraille, à l'abri de la pluie, et quelques-uns même s'étoient tout simplement emparés de la toile d'une Tégénaire domestique. Cette paresse des mâles à se construire une habitation est en quelque sorte commune aux femelles. Elles aiment aussi à trouver des trous déja tapissés et une ancienne toile. Le long d'un mur habité par un assez grand nombre de ces Ségestries, plusieurs trous bien percés éloient restés inhabités, tandis que d'autres moins égaux et moins allongés servoient de demeure aux plus grosses et aux plus belles d'entre elles, qui y sembloient à l'étroit. On détruisit quelqucs-uns de ces tubes, et l'on prit les araignées qui s'y trouvoient : on tes laissa dans un état de désordre qui sembloit les rendre inhabitables; mais quelque temps après, on vit tous ces tubes réparés et peuplés de nouveau, et on y distinguoit parfaitement les reprises de soie nouvelle faites au tissu noir et vieilli des anciennes habitantes. Les trous neufs étoient au contraire restés dans leur ancien état, sans tubes et sans habitans. Il semble que ce soit pour cette espèce une peine trop grande que de filer un tube nouveau dans son entier. Ceux de cette sorte qu'on rencontre, ont toujours été construits par de jeunes individus, trop petits pour s'emparer d'une ancienne demeure. Ces tubes, au lieu d'êire moelleux et étoffès comme ceux des femelles, sont clairs et foiblement tissus. La Ségestrie perfide ne se laisse arracner de sa toile qu'avec violence, et alors on est presque certain de la blesser; mais pour l'en faire sortir, il suffit de jeter dans son trou une fourmi vivante. A peine celle-ci a-t-elle fait quelques pas dans l'intérieur de Ja toile, que vous voyez la Ségestrie entrer dans une agitation extraordinaire, frappant violemment sa toile de ses pattes antéricures, se remuant de toutes ses forces, et faisant de grands efforts pour effrayer son hôte incommode. Enfin, la fourmi pénétrant de plus en plus, la Ségestrie sort précipitam. ment, et s'arrête a deux ou trois pouces hors de son trou, pour observer le parti que prendra la fourmi. Si cette dernière, comme il arrive le plus souvent, parvient à se dégager des fils qui la retiennent, et se laisse tomber à terre ou s'enfuit, la Ségestrie rentre jmmédiatement à reculons dans son trou. La même espèce, qui s'effraie d'un aussi petit insecte, attaque les plus grosses mouches; et Homberg atteste l'avoir vue se saicir d'une guêpe très-vive. M. Walckenaer, auquel nous avons emprunté ces détails, n'a vu qu'une fois le cocon de la Ségestrie perfide, au mois de juillet 1827. Il étoit placé entre le tube construit par l'araignée et la paroi du mur, qui laissoit dans cet endroit un intervalle assez fort pour le soutenir. Les œufs, qui ne sont pas en très-grand nombre, sont gros, blancs, et transparens. La forme du cocon est un ovale aplati. La soie qui le compose est de la blancheur la plus éclatante, et le tissu en est serré et brillant, quoique presque transparent. Cette araignée, lorsqu'on veut se saisir de son cocon, montre un très. grand courage à le défendre. 
2. SEGESTTIA RUTICEPß.

Guên., Voy. de Duperrey, p. 54 ; ibid., IIagas. de Zool., classe VIII, pl. 1. WALCK., op. cit., t. I, p. 267. - Long. $8 \mathrm{lig} .1 .-$ - Cetle cspéce est remarquable par une belle tache rouge que présente le devant de son céphalothorax, et par la couleur rouge-brun de tout son corps; les pattes sont grandes, velues, plus obscures que le cephalothorax, avec les articulations rougcâtres; les mandibules sont robustes, d'un heau vert brillant, arec la base rouge; le crochet des mandibules est de couleur noire; l'abdomen est brunâtre, soyeux.Cette espèce a été trouvée à Sainte-Catherine, au Brésil.

\section{SEGESTRIA SEYOCULATA.}

Walck., Faun. frunc., p. 19/4; ibid., Hist. nat. des Aran., fasc. 7, fig. 1 et 5 $9 ; 2$ et 4 đ. - Ibid., op. cil., t. I, 1). 268 . - H A HN. Die Arachn., 1831, in $-8^{\circ}$, t. 1 , pl. 9, tab. 1, fig. 6. Araneus Anomalus, Aran. Angl. Lister, p. 74 , tit. 24, fig. 24.-Long. 6 lig. $\frac{1}{2}$-Le cépha!othorax est grand, allongè, aussi large et presque aussi long que l'abdomen, trés-bombé et peu élargi à sa partie postérieure, qui est arrondie à son extrémité, d'un brun-marron clair, glabre, avec des poils blancs dorés sur les côtés; les yeux sont d'un blanc aqqueux, ovalaires, disposés par paires, contigus, une couple intermédiaire et deux latéraux sur le bord supérieur de l'épistome ; ces yeux forment par leur ensemble une courbe en croissant, les pointes étant en arrière; les deax intermédiaires antérieurs sont rapprochés et contigus, et les latéraux antérieurs rapprochés des latéraux postérieurs, sont portés sur une légère éminence; les mandibules sont fortes, allongées, bombées près de leur insertion, cylindriques, d'un brun-marron foncé, glabres, mais ayant à leur superficie de longs poils blanes très-fius; les mâchoires sont droites, allongées, dilatées et bombees à leur base, arron dies à leur extrémité cxtérieure, coupées obliquement et divergentes à leur exirémité interne, d'un rouge clair brunissant légérement; la plaque sternale est ovale, très-allongée, et pointue aux deux bouts, relevée en carène dans son milieu, et d'un brun-marron; Ja lèvie, de même couleur que la plaque sternale, est allongée, ovalaire. ayant à partir de sa base, jusqu'a la moitié de sa longuetr, un renflement ovale, qui est comme une prolongation de la plaque steruale; les pattes Axx. sont fortes, allongécs; la premièc paire est la plus longue, la seconde cnsuite, la lroisicme est la plus courte dans les femelles, mais dans les mâles c'est la quatrieme; elles sont blanchatres ou fauve-verditre, annelées de brun et pea velues; les palpes sont de même couleur, moins fortement annelés que les pattes, et lavés de brun à leur cxtrémité; l'abdomen est allongé, cylindroîde, velu, avec une raie longitudinale noire, dentée sur la partic superieure, formée d'abord par une raie triangulaice noire, simple, et ensuite par quatre ou cinq petits trapèzes, ou ronds qui se touchent par leurs points ou circonférences, et dont les postérieurs ont un point ou trait blazc at milieu; quelquefois la raic noire se continue du céphalothorax jusqu'a la partie auale, et présente à la parlie antérieure un rond noir, et de petits points blancs rentrans, formant une dentelure, mais ne se joignant pas, el ne terminant point les trapèzes; les côtés latèraux sont d'un fauveblanchâtre, parsemés de petits points noirs ou bruns ; le dessous est blanchâtre et présente deux lignes parallèles, formées par des points noirs dans quelques individus; dans d'autres, cette ligne se réduit à deux traits noirs pres de la partie anale; les filières sont blanchâtres, entourées d'un petit cercle noir, petites, convergentes, ou se joignant par leur extrémité.-Se trouve communément à Paris et dans ses environs.

Suivant M. Walckenaer, cette espèce construit dans ies trous des murailles, sous les saillies des murs, des tubes de soie, ouverts aux deux bouts, où elle se tient les six pattes antiricures en avant, ramassces, et passées par dessus le céphalothorax, sortant du tube par la plus grande des deux ouvertures, et reposant par leurs extrémités sur autant de fils très-fins détachés de la superficie des parois où ces fils sont tendus, el attachés à une assez longue distance de la circonférence du trou où ils aboutissent. Cette espèce résiste à de très-grands froids, et daus l'hiver de 4830, M. Walkenaer en a trouvé un individu sous l'écorce d'un arbre, encore très-vivant, au mois de janvier, lorsque le thermometre marquait de. puis huit jours quatorze degrés au-dessous de zéro.

\section{1)EUXIÈME GROUPE.}

Les Convergentes, WaLck.

Les mâchoires sont rẻtrécies à leur ex23 
trémité, et à côtés internes légérement convergens.

\section{SEGESTRIA SEVA.}

W ALCK. , op. cit., t. I, p. 269. - Long. 4 lig. $\frac{1}{2}$. - Le céphalothorax est aussi long, mais pas aussi large que l'abdomen; il est bombé, glabre, d'un fauve-brun; les mandibules sont brunes, non luisantes, rongeâlres, et légérement dirigées en avant; l'abdomen est d'un fauve pâle; sa partie supérieure présente dans son milieu six taches carrées, d'un noir mat, disposées longitudinalement, sur deux lignes parallèles, auxquelles aboulissent des lignes latérales également noires sur les côtés; le dessous est brun dans sa partie médiane, et d'un fauve pâle sur ses côtés latéraux. - Habite la Nouvelle-Zélande.

\section{TROISIÈHE SOUS-SECTION。}

\section{Les Cellulicoles, Warck.}

Formant des petites cellules où elles se renferment.

\section{SCYTODES, LATR, WALCK.}

Les yeux, au nombre de six, sont rapprochès et disposés par paires; les deux antérieurs sont sur une ligne transverse, les deux latéraux de chaque côté sont écartés des antérieurs, et placés sur une ligne longitudinale inclinée, de sorte qu'en la prolongeant elle forme un angle dont la pointe est en avant; la lèvre est trianguliforme, plus haute que large, bombée et élargie à sa base; les mâchoires sont ẻiroites, allongées, très-inclinées sur la lèvre, cylindroîdes, élargies ou courbées à leur base; les pattes sont fines, allongèes; la première et la quatrième paire sont presque égales et plus allongées que les autres; la troisieme est la plus courte.

Ces Aranéides errent lentement; elles tendent des fils lâches qui se croisent en tous sens et sur plusieurs plans différens; le cocon est arrondi, enveloppé de bourre.

Les espêces qui composent ce genre forment trois groupes.

\section{PREMUER GROUPE.}

\section{Les Gibbeuses, WaLcK.}

Le céphalothorax est très-bombé à sa partie postérieure; les mandibules sont pekiles, colirtes.
1. SCYTHones tnoRacica. (Pl. 3, fig. 4.) LaTR., Génér. des Crust. et des Ins., t. 1, p. 198, tab. 5, fig. 4. - W WLCK., $_{\text {, }}$ Hist. nat. des Aran., 1, fig. 10; ibid., Tab. des Aran., pl. 8, fig. 81 et 82 ; ibid... op. cit., t. I p. 271 . pl. 11, fig. $3 d .-S_{A V}$, Descrip. de l'Égyple, p. 152, pl. 5, fig. 1 , 2. - Guér., Iconogr. du Régn. anim. de Cuv., Arachn., pl. 1, fig. 3.-Dugès, Atlas du Règ. anim. de Cuv., Arach., pl. 19, fig.4. -Long. 2 lig. $\frac{1}{2}$; - Le céphalothorax est trésbombè, sans aucune fissure enfoncée dans son milieu et sans sillons rayonnans; de plus il est voûté à sa partie postérieure, ế présente deux taches noires qui figurent une crosse; les yeux sont d'un jaune bril. lant, et les deux antérieurs sont placés sur une petite tache noire; les mandibules sont naturellement dirigées en avant, petites, coniques, resserrées à leur insertion, plus grosses dans leur milieu, non luisantes, et recouvertes en quelque sorte d'un épiderme de couleur pâle et blanc-rougeâtre, comme le reste du corps, arec une tache d'un noir foncé dans le milieu : les crochets des mandibules sont très-petits, et à peine visibles; les pattes, annelées de noir et de blanc, sont allongées., très-grêles; la pre. mière paire est la plus longue, la quatrième ensuite, la troisième est la plus courte; l'ab. domen est g]obuleux, et présente deux ran. gées longiludinales de points noirs; en dessous il est sans tache et d'un rouge pâle.

Cette espèce se trouve à Paris, dans les maisons; elle a été aussi trouvée en Afrique, et elle nous a été envoyée de Belgique par M. Vanbeneden, professeur a Louvain. Suivant M. Walckenaer, elle porte son cocon dans ses mandibules. Le 9 septembre il ouvrit un de ces cocons, les petits étaient déjà éclos, ils étaient au nombre de trente-deux, et ces jeunes, quoique blancs, présentaient déja les raies nojres sur le céphalolhorax, et sur l'abdomen, qu'on remarque dans les individus adultes. Le cocon est de la grosseur d'un petit pois, recouvert de soie lầche et peu serrèe.

\section{DECXILME GROUPF.}

Les Déprimées, WaLck.

Le céphalothorax est arrondi, déprimé. -Les mandibules sont fortes, cylindriques.

\section{SCYTODES RUFIPES.}

Lucas, Magas. de Zool., classe 8, pl. 6, fig. 1. - Gcrus Omosites, Walck., Ann. de la Soc.Entom. de France, t. II, p. 348. - Scytodes Omosites, ibid., op. cit., t. 1, 
p. 173. - Long. 4 lign. - Le céphalothorax est rougeâtre, un peu gibbeux, de forme arrondie, un peu épais à sa partie antérieure, qui supporte les yeux qui sont presque égaux entre eux; les palpes sont allonges; le premier, le second et le troisieme article sont jaunâtres, le quatrième est rougeâtre ; le cinquième est de même couleur, et hérissé de poils jaunes a l'extrémité; les mandibules sont rougeâtres, un peu arrondies et dilatées à leur naissance, et étroites à leur base; quelques poils jatines couvrent les parties internes de ces mandibules; les crochets sont trés-petits, de couleur noire, dilatés à leur naissance, un peu inclinés sur la lèvre, cylindriques et élargis a leur base; la lère est triangulaire, couverte de quelques poils, et dilatée dans son milieu; les pattes sont fines, roussâtres ; la quatrième et la première paire sont les plus longucs, Ja troisieme est la plus courte; l'abdomen est globuleux, ovale, de couleur jaune, parsemé en dessus d'une quantité innombrable de tubercules imperceptibles à la vue simple; le dessous est d'un jaune sale; les filières sont de même couleur et un peu allongées. Celte espèce a été trouvée dans la province du Guatimala, au Mexique.

\section{SGYTODE RUFESCENS.}

Duf., Arin. des Sc. phys., t. III, p. 203, pl., 76, fig. 5. - Savig., Descrip. de l'Égyple, Arachn., p. 153, n 2, pl. 5, fig. 2. - WaLCK., op. cit., t. 1, p. 274.-Long. 4 lign. $\frac{1}{2}$. - Le céphalothorax est un peu bombé, assez allongé, d'un rouge pâle ; les yeux sont placés sur le dos du céphalothorax, et les antérieurs sont assez éloignés du bord antéxieur du labre; ils sont petits et d'un rouge de topaze; les mandibules sont allongées, fortes, cylindriques; la lèvre est ovalo-triangulaire, allongée; les mâchoires sont étroites et courbèes autour de la lèvre; les pattes sont fines, allongées; l'abdomen, marqué de petifes taches pentagonales entourées de jaune, est ovale, allongé, piriforme, ou renflé à sa partie postérieure.

M. L. Dufour a trouvé plusieurs fois cette espèce sous les débris calcaires des montagnes du royaume de Valence, principalement aux environs de l'antique Sagonte.

\section{TROISILME GROUPE.}

\section{Les Mythras, WaLck.}

Les yeux sont au nombre de six, sépa- rés entre eux; disposés sur le bord anté. rieur du céphalothorax, par paires, sur trois lignes; les deux antérieurs plus rapprochés, les deux intermédiaires plus écartés; les deux postérieurs encore plus écartés.

\section{SCytodes paradoxa.}

Scytodes Mithras, WALCK., op. cit., t. I, p. 975, pl.22. fig. 2d.-MilhrasParadoxus, Koci, dans H. Scriefeer, Deutschlands, Ins., fasc. 123, fig. 9.-Long. 3 lig. - Les quatre yeux latéraux sont sur une ligne inclince, les deux qui viennenta près sur une ligne transverse, les deux antérieurs sont plus petits que les autres, et les deux yeux intermédiaires latéraux un peu plus grands; le céphalothorax cst petit, trapézoïde, pointu vers les yeux, et d'un fauve-brun sur les côtés; les pattes et les cuisses sont renflées; elles sont d'un fauve-verdâtre, marquées de noir aux cuisses et aux jambes, et avec des tarses rouges; la première paire de pattes parait la plus longue, la quatrième ensuite, la troisième est la plus courte; l'abdomen est globuleux, renflé en dessus, avec deux tubercules latéraux d'un fauve terreux, lavé de brun sur les côtés, et trois ou quatre lignes transversales, brunes, festonnées irrégulièrement, ou tremblées.

Cette espèce a été trouvée par M. Koch vers le milieu de septembre, dans la forêt de Ǩæchinger, près d'Ingolstadt; elle avait attaché un fil plusieurs fois doublé a travers un sentier de la forêt, et y reposait suspendue. Suivant le même auteur, les habitudes de cette espèce sont lentes.

\section{UPTIOTES, WALCK.}

Les yeux sont au nombre de huit, et placés sur trois lignes; les antérieurs sont petits, les quatre postérieurs plus gros; les deux de la ligne postérieure plus écartés que ceux de la seconde ligne, gros et portés latéralement sur une petite éminence du céphalothorax. - La lèvre est trianguliforme. plus haute que large, non resserrée à sa base, arrondie à son extrémité. - Les mâchoires sont droites, courtes, dilatécs et arrondies, recouvrant la lèvre, et se touchant presque par les côtésinternes, qui sont droils. - Les pattes sont robustes, renflées ct médiocrement allongées.

\section{UPTIOTES SCHREBERI.}

WALCK., op. cit., t. I, p. 277. - Long. 1 lig. $\frac{1}{2}$. - Le céphalothorax est petil, d'un brun-rougeâtre, renflé et épais; les 
mandibules sont resserrées entre les pałpes, allongées et cylindriques; les paltes antérieures sont renflées et assez grosses; les deux paires intermédiaires sont plus minces et plus courtes que les deux autres; elles sont toutes noirâtres, avec des taches d'un jaune clair à leur extrémité; l'abdomen présente postérieurement quatre tubercutes ou épines cornés, assez brillans. Cette espèce, qui a ćté trouvée une scule fois au bois de Boulogne, suspend in fil lâche entre les plantes ou buissons assez écartés; ce fil est d'une belle couleur blan. che, et quand on le touche, l'Aranéide lui communique un mouvement de trépidation, se laisse tomber a terre avec son fil, et disparait dans les broussailles; sa démarclie est assez lente.

\section{QUATRIEME SOUS-SECTION.}

\section{Les Coureuses, WaLck.}

Courant avec agilité pour attraper leur proie.

\section{LYCOSA, WALCK, LATR.}

Les yeux, inégaux entrc eux, et au nombre de huit, forment un parallélogramme allongé; ils sont placés sur le de. vant et les cotés du céphalothorax, sur trois lignes transverses presque égales en longueur; la première ligne est forméc par quatre yeux, et chacune des deux anties par deux; les yeux de la ligne intermédiaire sont sensiblement plus gros que les autres. - La lèvre est carrée - est légérement creusée à son extrémité. - Les mâchoires sont droites, écartées, plus hautes que larges, dilatées dans leur milieu, et coupées obliquement à leur cồté interne. - Les pattes sont allongées, fortes; la quatrième paire est sensiblement plus longue que les autres, ensuite la première; la troisième est la plus courte.

Ces Aranéides chassent pour attraper leur proie, et portent leur cocon attaché a la partie anaie, soignent leurs petits et les portent sur leur dos.

Elles ont été divisées en trois groupes.

\section{PREMIER GROUPE.}

\section{Les Terrénides, WaLCK.}

Les yeux antérieurs ne forment pas une Ligne plus large que la ligne intermédiaire.
Les espéces qui constituent celle famille, se relirent dans des trous en terre, ou dans les fentes des pierres et des arbres.

\section{IYYCOSA TARENTULA.}

Latr., Génér. des Crust. et des Ins., t. I, p. 119.-Rossi. Faun. Etrisc., t. 11, p. 13, n 974. - Guér., Icon, du Kèg. anim. de Cuv., Arach., pl. 1, fig. 6; ibid., Trait. élém. de Zool., p. 41, fig. 6. WALck., op. cit., t. I, p. 281. - Lycosa Fascii ventris, Dur., Ann. des Sc, nat., 1835, t. 111, p. 101.-Long. 2 pouc. 2 lig. - Le céphalothorax présente sur ses côtés deux lignes rougeâtres, mais fixes, qui se détachent sur un fond noir et aboutissent aux yeux latéraux de la première ligne; les mandibules et les palpes sont-revêtus en dessus et à leurs extrémilés de poils roussâtres; les pattes sont grises en dessus et en dessous, marquées par des lignes d'un blanc vif, et d'un noir très-foncé au fémoral et au tibial; l'abdomen en dessus est d'un fauve-brun, marqué de cinq ou six chevrons noirs qui se joignent, bordés de fauve clair ou de blanc-rougeâtre, dont les pointessont tournées vers le céphalothorax; les deux antérieurs sont en triangle et en fer de lame; le dessous est d'un rougefauve, avec une large bande transversale noire dans le milieu, et une tache de même couleur, mais veloutée près des organes de la génération; les ouvertures stigmatiformes et les parties sexuelles sont séparées par une fine ligne noire transversäle.

Cette espèce se trouve dans le royaume de Naples, dans la Pouille el assez communément aux environs de l'ancienne Tarente. Elle a été aussi rencontrée en Espagne, anx environs de Valence, de Bologne, de Florence et de Rome.

Cette espèce étant très-célébre, a été figurée par une foule d'auteurs, mais si mal, qu'il semble que plusieurs d'entre eux se soient plus à exagérer ses formes hideuses, afin d'inspirer plus d'horreur pour elle, et d'accréditer, par ce moyen, les absurdités qu'ils ont débitćes sur les propriétés de son venin. Il serait trop long de mentionner ici les noms des auteurs qui ont parlé de la Tarentule, et qui l'ont figurée. Nous dirons seulement que, selon les uns, son venin produit des symptômes qui approchent de ceux de la fievre maligne; selon d'autres, il ne procure que quelques taches érysipélateuses, et des crampes légères on des fournillemens. La maladie que le vulgaire croit que la Taren. 
fule produit par sa morsure a reçu le nom đe Tarentisme, et l'on ne peut la guérir que par les secours de la musique. Quelques auteurs ont poussé l'absurdité jusqu'à indiquer les airs qu'ils croient convenir le plus aux Tarentolati : c'est ainsi qu'ils appellent les malades. Samuel Hafenreffer, professeur d'UIm, les a notés dans son traité des maladies de la peau. Baglivi a aussi écrit sur les Tarentules du midi de la France; mais on est bien revenu de la frayeur qu'elle inspirait dans son temps, et aujourd'hui il est bien reconnu que le venin de ces araignées n'est dangereux que pour les insectes dont la Tarentule fait sa nourriture.

Si cette espèce a été célèbre par les fables dont elle a été l'objet, elle ne l'est pas moins par ses mœurs, qui sont vraiment curieuses. Noüs empruntons à M. L. Dufour, qui a été à même de l'ètudier en Espagne, les observations suivantes : La Lycose tarentule, dit cet auteur, habite de préférence les lieux decouverts, secs, arides, incultes, exposés au soleil. Elle se tient ordinairement, au moins quand elle est adulte, dans des conduits souterrains, dans de vérita. bles clapiers qu'elle se creuse elle-même; ces clapiers, signalés par plusieurs auteurs, ont été imparfaitement saisis et mal décrits: cylindriques et souvent d'un pouce de diamètre, ils s'enfoncent jusqu'à plus d'un pied dans la profondeur du sol; mais ils ne sont pas peipendiculaires, ainsi qu'on l'a avancé. L'habitant de ce boyau prouve qu'il est en même temps chasseur adroit et ingénieur habile; il ne s'agissoit pas seulement pour lui de construire un réduit profond qui pût le dérober aux poursuites de ses ennemis, il falloit encore qu'il établit là son observatoire pour épier sa proie et s'élancer sur elle comme un trait. La tarentale a tout prévu : le conduit souterrain a effectivement une direction d'abord verticale, mais à quatre ou cinq pouces du sol il se fléchit à angle obtus, il forme un coude horizontal, puis redevient perpendiculaire; c'est à l'origine de ce coude que la Lycose s'établit en sentinelle vigilante, ne perd pas un instant de vue la porte de sa de. meure; c'est là qu'à l'époque où je lui faisois la chasse, j'apercevois ses yeux étincelans comme des diamans, lumineux comme ceux du chat dans l'obscurité.

L'orifice extérieur du terrier de la Tarentule est ordinairement: surmonté par un tuyau construit de foutes pièces par elie. même, et dont les auteurs ne font pas men. tion; ce tuyau, véritable ouvrage d'archiiecture, s'élève jusqu'à un pouce au-dessus du sol et a parfois deux pouces de diamètre, en sorte qu'il est plus large que le terrie* lui-même. Gette dernière circonstance, qui scmble avoir été calculée par l'industrieuse Aranéide, se prête à merveille au dévelop. pement obligé des pattes au moment où il faut saisir la proie. Ce tuyau est principalement composé par des fragmens de bois secs unis par un peu de terre glaise, et si artistement disposés au-dessus des autres, qu'ils forment un échafaudage en colonne droite, dont l'intérieur est un cylindre creux. Ce qui établit surtout la solidité de cet édifice tubuleux, de ce bastion avancé, c'est qu'il est revêtu, tapissé en dedans d'un tissu ourdi par les filieres de la Lycose ef qui continue dans tout l'intérieur du terrier. 11 est facile de concevoir combien ce revê. tement si habilement fabriqué doit être utile, et pour prévenir les éboulemens, les déformations, et pour l'entretien de la propreté, et pour faciliter aux griffes de la Ta. rentule l'escalade de sa forteresse. J'ai laissé entrevoir que ce bastion du terrier n'existoit pas toujours; en effet, j'ai souvent:rencontré des trous de Tarentule où il n'y en avoit pas de traces, soit qu'il eût été détruit accidentellement par le mauvais temps, soit que la Lycose ne rencontrât pas toujours des matériaux pour sa construction, soit enfin parce que le talent de l'architecte ne se déclare peut-être que dans les individus parvenus au dernier degré, à la période de perfection de leur developpement physique et intellectuel. Ce qu'il y a de certain, c'est que j'ai eu de nombreuses occasions de constater ces tuyaux, ces ouvrages avancés de la demeure de la Tarentule; ils me représentoient en grand les fourreaux de quelques Friganes. Cette Aranéide a voulu atteindre plusieurs buts en les construisant; elle met son réduit à l'abri des inondations, elle le prémunit contre la chute des corps étrangers qui, balayés par les vents, finiraient par l'obstruer; enfin elle s'en sert comme d'une embûche en offrant aux mouches et autres insectes dont elle se nourrit, un point saillant pour s'y poser. Qui nous dira toutes les ruses employées par cet adroit et intrépide chasseur? Disons maintenant quelque chose sur la chasse assez ainusante de la Tarentule. Les mois de mai et de juin sont la saison la plus favorable pour la faire. La première fois que jedécouvris les clapiers de cette Aranéide es. 
que je constatai qu'ils étaient habités, en l'apercevant en arrêt au premier étage de sa demeure, qui est le coude dont j'ai parlé, je crus, pour m'en rendre maitre, devoir l'attaquer de vive force et la pousuivre a outrance; je passai des heures entières a ouvrir la tranchée avec un couteau de plus d'un pied sur deux de largeur, sans rencontrer la Tarentule; je recommençai cette opération dans d'autres clapiers et toujours avec aussi peu de succès; il m'eût fallı une pioche pour atteindre mon but, mais j'étois trop éloigné de toute habitation en Espagne. Je fus donc obligé de changer mon plan d'altaque et je recourus a la ruse. La nécessité est, dit-on, la mère de l'industrie; j'eus idee, pour simuler un appât, de prendre un chaume de graminee sur. monté d'un épillet et de frotter, d'agiter doucement celui-ci à l'orifice du clapier; je ne tardai pas à m'apercevoir que l'attention et les désirs de la Lycose étoient éveillés; sèduite par cette amorce, elle s'avancoit à pas mesurés et à tâtons vers l'épillet, et en retirant a propos celui-ci un peu en dehors du trou pour ne pas lui laisser le temps de la réflexion, elle s'élancoit souvent d'un seul trait hors de sa demeure, dont je m'empressois de lui fermer l'entréc; alors la Tarentule, déconcertée de sa liberté, était fort gauche à éluder mes pour. suites, et je l'obligeois à entrer dans un cornet de papier que je fermois aussitôt. Quelquefois, se doutant du piege, ou moins pressée peut-être par la faim, elle se tenoit sur la réserve, immobile, à une petite distance de sa porte, qu'elle ne jugeoit pas à propos de franchir. Sa patience lassoit la mienne; dans ce cas, voici la tactique que j'employois : après avoir bien reconnu la direction du boyau et la position de la Lycose, j'enfoncois avec force, et obliquement, une lame de couteau, de manière a surprendre l'animal par derrière et à lui couper la retraite en barrant le clapier; je manquois rarement mon coup, surtout dans des terrains qui n'étoient pas pierreux. Dans cette situation critique, ou bien la Tarentule, efrayée; quittoit sa tanière pour gagner le large, ou bien elle s'obstinoit à demeurer acculée contre la lame de couteau. Alors, en faisant exécuter à celleci un mouvement de bascule assez brusque, on lançoit au loin et la terre et la Lycose, et on s'emparoit de celle-ci; en employant ce procédé de chasse, je prenois parfois jusqu'à une quinzaine de Tarentules dans l'espace d'une heure.
Dans quelques circonstances où la Tarentule étoit tout-á-fait désabusée du piége que je lui tendois, je n'ai pas été peu surpris, lorsque j'enfonçois l'épillet jusqu'à le tourner dans son gîte, de la voir jouer avec une espece de dèdain avec cet épillet et le repousser à coups de pattes, sans se donner la peine de gagner le fond de son réduit.

Les paysans de la Pouille, au rapport de Baglivi, font aussi la chasse à la Tarentule, en imitant, à l'orifice de leur terrier, le bourdonnement d'un insecte, au moyen d'un chaume d'avoine. Ruricola nostri, dit-il, quando eas captare volunt, ad illarum latibula accedunt, tenuisque avenaceco fistula sonum, apum murmuri, non absimilem modulantur, quo audito ferox exit Tarentula ut muscas vel alia hujus modi insecta quorum murmur esse putat, captat; captatur tamen ista a rustico insidiatore. Baglivi, opera oพnia, p. 356.

La Tarentule, si hideuse au premier as. pect, surtout lorsqu'on esi frappé de l'idée du danger de sa piqû́re, si sauvage en apparence, est cependant très-susceptible de s'apprivoiser, ainsi que j'en ai fait plusieurs fois l'expérience.

Le 7 mai 1812 , pendant mon séjour à Valence, en Espagne, je pris sans la blesser une Tarentule mâle d'assez belle taille, et je l'emprisonnai dans un bocal de verre clos par un couvercle de papier, au centre duquel $\mathrm{j}$ 'avois pratiqué une ouverture à panneau dans le fond du vase; javois fixé le cornet de papier dans lequel je l'avois transportée, et qui devoit lui servir de demeure habituelle; je plaçai le bocal sur une table de ma chambre à coucher, afin de l'avoir souvent sous les yeux; elle s'habitua promptement à sa réclusion, et finit par devenir si familière, qu'elle renoit saisir au bout de mes doigts la mouche vivante que je lui servois; après avoir donné à sa viclime le coup de la mort avec le crochet de ses mandibules, elle ne se contentoit pas, comme la plupart des araignées, de lui sucer la tête, elle broyait tout son corps en l'enfonçant successivement dans sa bouche au moyen de ses palpes; elle rejetoit ensuite les tégumens triturés et les balayoit loin de son gîte. Après son repas, elle manquoit rarement de faire sa toilette, qui consistoit à brosser avec les tarses de ses pattes antérieures, ses palpes et ses mandibules, tant en dehors qu'en dedans, et après cela elle prenoit son attitude de gravité immobile. Le soir et la nuit étoient pour elle le temps de la promenade; je l'entendois sou- 

Tome zer ,ere partie.

Arachnides, $\mathrm{Pl}$. 4 .

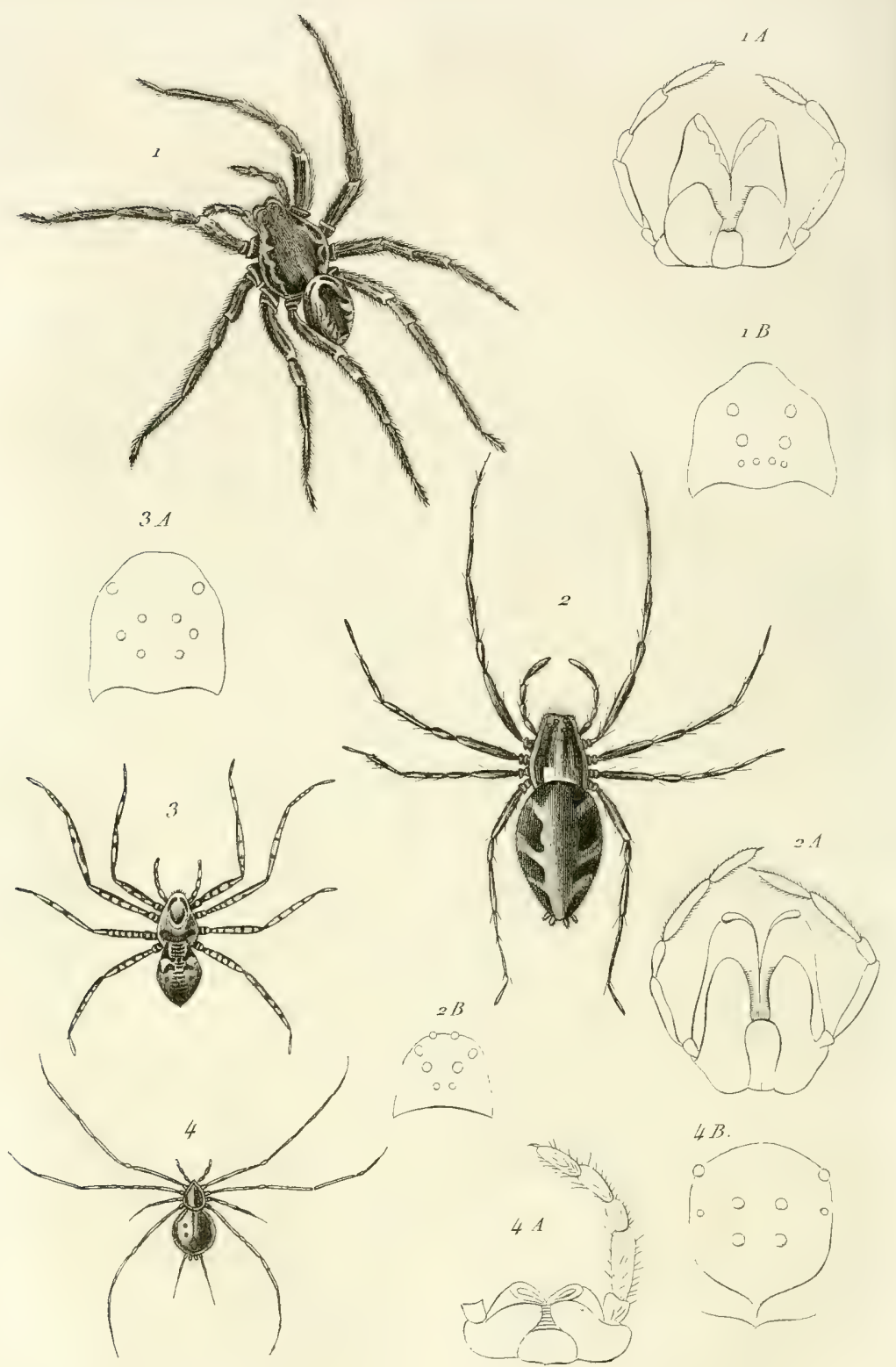

1. Lycosa narbonensis. 1 A. máchoires. „B. yeux de la I. Vorax. 2. Sphasus alexandrinus. 2A. mâchoires. 2 B B. zetav du S. Indicus. 3. Philodromus jejunus. $3 \mathrm{~A}$. yeur du P. oblong̊us. 4. Hersilia ündica. 4 A. matchoires. 4 B. yeu du $\mathrm{H}$. caudata . 
vent gratter le papier du cornet; ces habiiudes nocturnes confirment l'opinion, déjà émise ailleurs par moi, que la plupart des Aranéides ont la faculté de voir pendant la nuit et le jour, comme les chats.

Le 28 juin, ma Tarentule changea de peau, et cette mue, qui fut la dernière, n'altéra d'une manière sensible, ni la couleur de sa robe, ni la grandeur de son corps. Le 14 juillet, je fus obligé de quitter Valence, et je restai absent jusqu'au 23 . Durant ce temps, la Tarentule jeûna; je la trouvai bien portante à mon retour. Le 20 août, je fis encore une absence de neuf jours que ma prisonnière supporta sans alimens et sans altération de santé. Le $\mathbf{4}^{\mathrm{er}}$ octobre j'abandonnai encore la Tarentule sans provision de bouche. Le 21 de ce mois, étant à vingt lieues de Valence où j'étois destiné à demeurer, j'expédiai un domestique pour me l'apporter. J'eus le regret d'apprendre qu'on ne l'avoit pas trouvée dans le bocal, et j'ai ignoré son sort.

Je terminerai mes observalions sur la Tarentule, continue M. L. Dufour, par une courte description d'un combat singulier entre ces animaux. Dans le mois de juin 1810, un jour que j'avois fait une chasse heureuse à ces Lycoses, je choisis deux mâles adultes et bien vigoureux que je mis en présence dans un large bocal, afin de me procurer le spectacle d'un combat à mort; après avoir fait plusieurs fois le tour du cirque pour chercher à s'évader, ils ne tardèrent pas, comme à un signal donné, à se porter dans une attitude guerrière; je les vis avec surprise prendre leur distance, se redresser grave. ment sur leurs pattes de derrière, de manière à se présenter mutuellement łe bouclier de leur poitrine; après s'être observés ainsi face à face pendant deux minutes, après s'être sans doute provoqués par des regards qui échappoient aux miens, je les vis se précipiter en même temps l'un sur l'autre, s'entrclacer de leurs pattes, et chercher dans une lutte obstinée à se piquer avec les crochets des mandibules. Soit fatigue, soit convention, le combat fut suspendu; il y eut une trève de quelques instants, et chaque athlète, s'éloignant un peu, vint se replacer dans sa posture menaçante. Celle circonstance me rappela que dans les combats singuliers des chats, il y a aussi des suspensions d'armes; mais la Jutte ne tarda pas à recommencer avec plus l'acharnement entre nos deux Tarentules; J'une d'elles, après avoirlong-temps balancé la victoire, fut exfin terrassée et blesséc d'un trait mortel à la tête; elle devint la proie du vainqueur, qui lui déchira le crâne et la dévora. Après ce combat singulier, j'ai conservè vivante pendant plusieurs semaines la Tarentule victorieuse.

2. lycosa nardonensis. (Pl. 4, fig. 1:) W alck., Faun. franc., p. 12, pl. 1, fig. 1, 2, 3.-Lycosa Melanogaster, Latr., Nouv. Dict. d'Hist. nat., 2 e edit., t. XVIII, p. 291.-Ibid., op. cit., t. 1, p. 282, pl. 8, fig. 1. - Hahn., Die Arachn., 1833, in. $8^{\circ}$, t. I, p. 102 , pl. 26 , fig. $76 .-$ Long. 12 lig. - Cette espèce diffère de la précédente par son abdornen, qui est d'un faurebrun en dessus, marqué de chevrons noirs, transversaux; la partie postérieure présente trois triangles de même couleur, dont les bases et les sommets se touchent et formentune bande oblongue dentée sur ses bords; en dessous il est d'un noir velouté uniforme; les pattes en dessous sont marquées de larges taches blanches et noires. - Se tronve dans le midi de la France, et surtout aux environs de Montpellier et de Nîmes; elle a élé aussi rencontrée en Italie, en Morée, en Barbarie et en Alle. magne.

\section{LYCOSA LIGURIENSIS.}

WALCK., op. cit., t. I, p. 288. - Long. 1 pouc. - Le céphalothorax eșt rougeâtre, entouré d'une bande très-large de poils gris, qui occupent tout le devant de la partie antérieure du céphalothorax; les mandibules sont fortes, garnies de poils roux; les palpes sont grêles, petits, rougeâtres en dessus et en dessous, coupés par delarges taches noires et rougeâtres; les pattes sont longues et de même couleur que les palpes; la plaque sternale est d'un noir velouté en dessous; il y a une tache obscure, allongée, de couleur plus foncéo en dessus et proche le céphalathorax, et terminée par deux points noirs; de plus on apercoit deux points de chaque côté de la partie de l'abdomen qui touche au céphalothorax, et qui sont presque cachés par lui. - Celte espèce habite l'I talie.

\section{Lycosa captans.}

W alck., Tab. des Aran., p. 14; ibid op. cit., t. I, p. 306 . - Lycosa Fabrilis, Косн., dans Panz., Forgesezt, 21, 120, 11. - Lycosa Melanogaster, Hann, Die Arachn., t. I, p. 102, tab. 26, fig. 76. Long. 7 lig. - Le céphalothorax est brun, arec la région des yeux de couleur noire; les mandibules sont couvertes de poils rour: 
Ia lèvre et les mảchoires sont d'un fauve clair ; les palpes et les pattes sont jaunâtres; les pattes ont quelques taches irrégujières, d'un noir pâle ; l'abdomen est ovale, allongé, et présente en dessus plusieurs taches, dont deux prés du céphalothorax forInent une soite de croissant; les trois taches postéricures se réunissent au sommet, et dessinent la raie longiludinale qui les sépare, et qui se trouve ètre creusée et for. mée de petits triangles; les côtés de l'abdomen sont mélangés de fauve et de brun; le ventre ou le dessous, aur deux cólés du triangle isoscéle noir, est fauve; à la pointe ou au sommet intérieur de ce triangle noir est une marque de couleur fauve, qui présente une espéce de croissant; dans les individus qui ne sont pas encore parrenus à l'âge adulte, le dessous est pâle, le triangle noir n'existe pas, mais on y trouve tou. jours le V. - Cette espèce se trouve en Italie et dansles environs de Paris.

\section{IYYOSA vORAX.}

Walck., Aran. de France, p. 22 ; ibid., op. cit., t. I, p. 315 . - - Long. 6 lig.-La couleur générale de cette espèce est un fiuve-rougeâtre; la ligne antérieure des veux est courbée en avant; l'abdomen pré. enie sur sa partie médiane une tache longitudinale, allongée, ovale, pointue à sa partie postérieure, brune ou fauve-brun, cntourée de fauve clair, et deux bandes longitudinales noires sur les côtés du dos, faisant suite aux bandes de même couleur qui sont sur le céphalothorax, et formant un ovale allongé qui entoure le premier.

Cette espèce, qui habite les lieux arides et sablonneux, présente selon le sexe, l'âge et les localités, plusieurs variétés qu'on peut prendre facilement pour des espèces différentes, quand on n'a pas observé cette Aranéide dans toutes ses variations et dans toutes ses nuances intermédiaires.

\section{IYYCOSA AGILIS.}

Walck., Aran. de France, p. 25, n० 11 , pl. s, fig. 6. - Ibid., op. cit., t. I, p. 318. - Lycosa Alpica, Kоси, dans Sсновғт., 122, 123. - Lycosa Alpina, $\mathrm{H}_{\mathrm{AHN}}$, Die Arachn. : t. II, p. 57, pl. 63 fig. 146.-Long. 5 lig.-Le céphalothorax est allongé, noir en dessus et rouge au-dessous des yeux; l'abdomen est allongé, à fond rougeâtre, avec une petite figure ovale, droite, bordée de noir proche le céphalothorax; de plus on aperçoit des raies noires, isolées, funes, transverses, plus en arrière, et deux Iignes Iongitudinales de mêine coutJeur de chaque côté, quí deviennent plus fines vers la partic anale; la couleur générale de cette espéce est un brun-rougeâtre. - Se trouve en France, dans les Alpes.

\section{LYCOSA SACCATA.}

Walck., Aran. de France, p. 27, no 16 ; Ihid., op. cit., t. I, p. 326. - НАнN, Dic Arachn., t. I, p. 108, pl. 27, fig. 81.Araneus Amentatus, Cresck, p. 96, pl.4, tab. 8, fig. 2. - Long. 3 lig. - Le céphaJothorax est brun, allongé, d'un fauverougeâtre dans sa partie médiane; les pattes sont annelées; l'abdomen est tantôt d'un brun de suie, tantôt d'un brun-fauve, avec deux rangées de points alternativement noirs et fauves à la partie postérieure, et une petile touffe de poils blancs proche le céphalothorax; en dessous il est d'un gris cendré. Cette espèce est excessivement commune dans le nord de la France; elle se trouve dans les bois, dans les champs et dans les jardins potagers. C'est une des premières qui paraît au printemps, en avril ; on la rencontre aussi assez souvent dans le mois de janvier; son cocon est aplati, de couleur verdâtre, tantôt tirant sur le blanc, tantôt sur le gris, avec un cercle blanc plus pâle et d'un tissu moins serré; elle le porte avec elle attaché à sa partie anale, et si on le lui arrache, elle s'arrête, et tourne aútour des doigts ravisseurs pour tâcher de le reprendre. - Très-commune en France, en Allemagne et en Suède.

\section{LYCOSA ALLODROMA.}

Walck., Aran. de France, p. 15, nc 3 , pl. 2, fig. 6 ; ibid., Hist. nat. des Aran., fasc. 1, tab. 4. - Ibid., op. cit., t. I, p. 330. - Lycosa Cinerea, Sundevalu, p. $190, \mathrm{n}^{\circ}$ 17. - Lycosa Lynx, $\mathrm{H}_{\mathrm{AHN}}$, Die Arachn., t. II, p. 13, tab. 42, fig. 104. - Lycosa Picta, ibid., t. I, p. 106, tab. 27, fig. 79. - Long. 6 lig. Le céphalothorax est rouge, avec une tache noire à la partie où sont placés les yenx; la ligne des veux antérieurs s'infléchit un peu en arrière, et les youx intermédiaires de cette ligne sont sensiblement plus gros que les latéraux antérieurs; les pattes sont annelées de noir et de rougeâtre; l'abdomen en dessus est varié de gris, de rouge el de noir; il y a quatre taches allongées, pâles, grises; celle qui est près du céphalothorax est la plus grande; les autres sont plus petites, alternativement brunes et grisos, et forment arec elles deux lignes longitudi- 
nales qui convergent un pen vers la partie anale; quatre autres taches plus, petites, renfermées entre les quatre grandes; en dessous il est d'un gris pâle. - Celte espèce, suivant Latreille, se retire dans les fentes des murs, qu'elle ferme au temps de la ponte par une toile fine, de près de deux pouces de longueur, très-lisse à l'intérieur, fortifiée et déguisce a l'extérieur par des parcelles de sable imitant la coque de cerlains bombyx; son cocon est sphérique, gros et blanc; elle court après lorsqu'on lui enlève; elle fait une première ponte vers la fin d'avril ou le commencement de mai.Gette espece se trouve aux environs de Paris.

\section{IYCOSA AUDAX.}

WALCK., $u p$. cit., t. I, p. 335 . - Long. 6 lig. - Le céphalothorax est brun, revêtu de poils fauves; la partie antérieure de la tête n'est pas perpendiculaire, mais arrondie, de sorte que les yeux antérieurs et les bords de l'épistome sont avancés; la ligne des yeux antérieurs est un peu plus large que celle de la seconde ligne; les yeux intermédiaires de cette ligne sont plus gros que les latéraux; cette ligne est presque droite, ou se courbe très-légérement en avant; tous les yeux sont couleur d'ambre jaune; les mandibules sont grandes et robustes, noires, revêtues de poils fauves, bombées à Jeur partic supérieure; les mâchoires, la lèvre et la plaque sternale sont noires; les palpes et les pattes sont rouges, avec des taches brunes, des poils gris trèscourts, et des piquans noirs; l'abdomen est ovale. un peu piriforme, a dessus brun, revêtu de poils fauves, plus abondans et plus uniformes, et d'une teinte plus vive dans le mâle; une teinte plus claire sur la partie antérieure dans les femelles; en dessous il est d'un noir foncé velouté. - Se trouve en Europe.

\section{LYCOSA ERYTHIOGNATHA.}

Lucas, Ann. de la Soc. Ent. de France, t. III, p. 522, pl. 15 , fig. $b$. - Lycosa Tiaptoria, Walck., op. cit., t. I, p. 338.Long. 9 lig. $\frac{1}{2}$. - Le céphalothorax est un peu allongè, étroit antérieurement, large sur les côtés latéraux et légérement tronqué postérieurement; dans son milieu on apercoit une raie longitudinalé, d'un fauve clair, et sur les côtés, qui sont d'un fauve foncé, sont trois autres petites raies transversales d'un fauve très-clair; les yeux sont noirs; entourés de rouge; les mandibules sont peu allongées, converies de poils rouges j̇ leur partie extćricure, et de poils noirs à leur base; les crochets des mandibules sont noirs et légérement arqués; les palpes sont allongés, assez grêles, mélangés de fauve ct de rouge; les mâchoires sont allongées, noirâtres, couvertes de poils de même couleur; la lèvre est petite; noire, avec sa partie antéricure tronquée ct légérement roussâtre; les pattes sont allongèes, grêles; la quatrième paire est plus louguc que la première, la seconde ensuite, la troisieme est la plus courte; ces pattes sont mélangées de fauve et de noir, et hérissées d'épines de celte dernière coulcur; la plaque sternale est noire ct revêtue de poils de même couleur; l'abdomen est court, ovalaire; en dessus il est d'un fauve foncé, avec des taches noirâtres sư son milieu, entourées de fauve clair ; ses côtés latẻraux sont aussi de cette dernière couleur, avec le dessous entièrement noir; les filières sont très-courtes, d'un fauve foncé et hérissées de poils noirs. La femelle est semblable au mâle, cependant elle en diffère par des caractères assez tranchés : le céphalothorax est un peu moins allongé ; la raie fauve longitudinale qu'on apercoit en dessus est d'une couleur plus foncée, ainsi que les raies transversales; les taclies fanves qui sent sur les côtés latéraux, et la bande fauve clair qui entoure le céphalothorax, sont bien moins marquées que chez le mâle; les mandibules sont plus allongées et plus robustes; les poils rouges qui les recouvrent sont d'une couleur bien plus foncée, et les poils noirs qu'on aperçoit à leur base sont aussi bien marqués; leurs crochets sont courts et entièrement roussâtres; les palpes sont moins allongés; les poils rouges dont ils sont couveris sont d'une couleur plus foncé, et le dernier article à la base est légérement noiràtic; les mâchoires sont plus allongées et de couleur noire; la lévre est un peu plus robuste et de mème couleur que les mâchoires; la plaque sternale ou le dessous est bien moins large que chez le mâle; les pattes sont moins allongées et un peu plus robustes; leur couleur est d'un fauve un pen plus foncé que chez le mâle, ainsi que les taches noires qui sont en dessous; l'abdomen en dessus est entièrement fauve, et diffère de celui du mâle en ce qu'il est sans apparence de taches noires; en dessous, il est semblable au mâle, c'est-à-dire entièrement noir. - Se trouve au Brésil.

Cetle espéce présente une variété assez 
remarquable et qui diffêre par les mandibules, qui au lieu d'ètre revêtues de poils d'un beau rouge, sont d'un fauve clair, avec leur base légérement noirâtre; les palpes sont aussi d'un fauve clair, et les taches noires qui sont sur les pattes sont bien moins marquées; enfin l'abdomen est entièrement faure en dessus, avec le dessous d'un noir très-clair. - Cette variété a été trouvée à Montevideo.

\section{DEUXIIMB GROUPE.}

\section{Les Corsaires, WALCK.}

La ligne antéricure des yeux est sensi. blement plus large que la ligne intermédiaire. L'abdomen est orné de taches ou de raies d'un blanc éclatant. Les filières sont peu saillantes.

Ces Aranéides courent sur la surface des eaux. Leur cocon est aplati.

\section{Iycosa PIRATICA.}

Watck., Faun. frans., p. 30, no 18. Ibid., op. cit., t. 1, p. 341. - Hawn, Die Arachn., t. I, p. 107, pl. 27, fig. 80. - Lycosa Palustris, Косн., 131, 13 ‥Aran. Piraticus, Clerck, Aran. Suec., p. 102 , spec. 10 , pl. 5 , tab. 4. Jै; ibid., Aran. Piscatorius, p. 103, spec. 14, pl. 5, tab. 5, …- Long. $4 \mathrm{lg}$. - Le céphalothorax est verdâtre, bordé par une raie d'un blanc très-vif; l'abdomen est ovale, d'un fauve-brun en dessus, entourè de chaque côté d'une raie blanche un peu azurée irès-distincte, et de deux taches oblongues peu marquées, d'un blanc azuré, disposées longitudinalement; en dessous il est d'un gris uniforme. - Se trouve sur les bords des étangs et des marais.

\section{LYCOSA NAUTICA.}

WALCK., op. cit., t. I, p. 340.-Le cépha. lothorax, le plastron sternal, la lèvre et les mâchoires sont fauves; les mandibules sont rougeâtres; les pattes sont d'un fauve uniforme; la ligne antérieure des yeux est droite et non courbée en avant, et dépasse par ses yeux latéraux la seconde ligne ou cclle des gros yeux; l'abdomen est ovale, court, reuflé dans son milieu, d'un brunrougeâtre en dessus, avec une raie longitunale d'un fauve clair dans la moitié de la partie antérieure; il y a quatre points ou lobes ronds, d'un fauve clair, disposés en carré, les postérieurs étant beaucoup plus larges; les côtés sont fauves, avec le dessous entiẻrement de mème couleur. - Se trouve dans la Nouvelle-Zélande.

\section{TROISILME GROUPE.}

\section{Les:Porte-Queue, Walck.}

Les yeux antérieurs forment une ligne fortement courbée en avant, qui n'est pas. plus large que la ligne des yeux intermé. diaires, mais disposés en deux paires écar. tées l'une de l'autre.-Les filières sont peu apparentes. - Ces Aranéidts courent a terre, et se cachent sous les pierres. - Leur cocon est sphérique.

\section{LYCOSA ALBIMANA.}

Walck., Faun. franc., p. 31, no 19. Ibid., Tab. des Aran., p. 14, fig. 19.-Ibid., op. cit., t. I, p. 341. - Lycosa Albimana, Косн, 12, 121, 15, J.- Long。 1 lig. $\frac{1}{2}$. - Le céphalothorax est déprimé, d'un brun-noir luisant, entouré d'une raie fine; d'un blanc très.vif, formée par des poils; les mâchoires sont d'un rouge sale, avec la lèvre plus foncée; l'abdomen est ovale, couvert de poils fauves roussâtres, avec une petite raie blanche à la partie antérieure, qui fait suile avec celles du céphalothorax; les pattes sont rougeâtres; le mâle diffère de la femelle par son cépha. lothorax, ses cuisses, ses pattes antérieures qui sont très-noires, et par son abdomen qui est d'un fauve-brun en dessus, avec des petits points blancs disposés sur deux lignes longitudinales qui aboutissen parlie anale ; les trois paires de pattes postérieures sont fauves. - Cette espèce, qui se retire sous les pierres, a été trouvée au bois de Boulogne.

\section{DOLOMEDES, WALGK.}

Les yeux, inégaux entre eux, et au nombre de huit, sont placés sur le devant et les côtés du céphalothorax sur trois lignes; quatre sur la ligne antérieure et deux sur chacune des deux postérieures; la ligne intermédiaire est beaucoup plus courte que les deux autres. - La lèvre est carrée, aussi large que haute. - Les mâchoires sont droites, écartées, plus hautes que larges. - Les pattes sont longues et fortes; la quatrième paire est la plus longue ; la seconde et la première sont presque égales; la troisième est la plus courte de toutes.

Ces Aranéides sont chasseuses, courent après leur proie, construisent à l'époque de la ponte, à l'entour des plantes, une toile dans l'intérieur de laquelle elles déposent leur cocon, qu'elles gardent assidùment, ainsi que leurs petits, même longtemps après leur éclosion; elles emportent 
leurs cocons fixés sous la partie sternale lorsqu'elles sont forcées d'abandonner leur demeure.

Ce genre peu nombreux en espèces a été divisé en trois groupes.

\section{PREMIER GROUPF.}

\section{Les Campestres, WaLGK.}

Les yeux anterieurs forment une ligne courbée en arrière, et sont pı esque égaux entre eux ; les yeux des lignes postérieures sont plus gros qu'aucun de ceux de la ligne antérieure.

\section{DOL OMEDES FIMBRIATUS.}

WaLcK., Faun. franc., p. 33, $\mathrm{n}^{\circ} 1$ et 2. - Ibid., op. cit., t. I, p. 3455, - Dolomedes Limbatus, Dolomedes Fimbriatus, $\mathrm{H}_{\text {ABN }}$, t. I, p. $14, \mathrm{pl} .4$, fig. 10 et 11. - Araneus Undatus, Cursck, p. 100 , pl. 5, tab. 1. - Araneus Fimbriatus, Clenck, p. 106, spec. 18, pl. 5, tab. 9.Aranea Mairginata, Panz., 71, 22.-Long. 8 lig. - Le céphalothorax est brun, avec les côtés latéraux bordés d'une large bande jaunâtre; l'abdomen est d'un brun-rougeâtre, bordé également d'une bande de même couleur; les points qui sont placés en dessus sont sur deux rangs; le mâle est plus petit; la couleur de ses pattes et de son corps est plus pâle; les yeux postérieurs placès sur une petite éminence sont de couleur noire. Cette espèce présente beaucoup de variétés; les bandes et les points sont souvent jaunâtres, grisâtres ou verdâIres; lorsqu'elle n'est pas encore parvenuc à l'âge adulte, toutes ses couleurs sont plus marquées; son abdomen est d'un brun ve. louté, et ses pattes d'un rert livide; quelquefois les points blancs du milieu s'oblitèrent. - Elle se trouve aux environs de Paris, et parait se plaire beaucoup aux bords des ètangs et des marais; elle court avec vitesse sur la surface des eaux, qui ne leur mouille ni le corps ni les pattes, pas même quand elle entre un peu dans l'eau, et quand, poursuivie, elle descend sur les plantes aquatiques. Quand elle se tient en repos sur l'eau, ses pattes sont toujours étendues et appliquées tout de leur long sur la surface de l'eau; clle se précipite sur les mouches sans avoir tendu de toiles. Au moment de la ponte, elle se rend sur quelques plantes ou arbustes près de l'eau; là elle file une grosse toile irrégulière, dont les fils s'éiendent sur plusieurs tiges ou branches à la ronde. Elle pond ses œuls au mi. lieu de celte toile, et elle les enferme dans un cocon ovale qu'elle ne quitte jamais, à moins que les petits ne soient éclos.

2. DoloMedes hippoMene. (Pl. 3 , fig. 5.)

Sav., Descrip. de l'Egypte, Arach.,p.148, pl.4, fig. 9.-Dolomedes Lycana, WaLCK., op. cit.; t. I, p. 349.-Long. 2 lig. ${ }_{\text {i० }}^{1}-$ Le céphalothorax est allongé et arrondi sur sa partie postérieure, il est presque aussi long et aussi large que l'abdomen, bordé d'une ligne grise ou fauve près des pattes, et ayant deux lignes grises longitudinales sur les côtés, qui s'élargissent en ovale à la partie postérieure; les mâchoires sont d'un blanc pâle, écartées, bombées, cunẻiformes à leur extrémité; les yeux de la seconde ligne sont les plus gros, et les latéraux antérieurs sont les plus petits; la lèvre est semi-circulaire, avec une petite raie transversale à sa base; les mandibules sont d'un blanc pâle; les pattes sont fines, allongées ; les cuisses sont blanches, avec des petits points bruns, très fins, plus abondants en dessous; le fémoral et le métatarse sont bruns; les tarses sont rougeâtres ; l'abdomen est ovoïle, allongé, un peu déprimé, grossissant légérement vers sa partie postérieure, de couleur fauve très pâle, parsemé de points ou traits bruns, très-fins, plus abondans sur les côlés, et formant à la partie antérieure deux raies qui se touchent presque proche le céphalothorax; en dessous il est d'un fauve pâle, avec des points bruns, presque imperceptibles sur les côtés; le mâle a des points plus foncés, et une bande continue qui entoure le dos. - Se troure en Europe et en Afrique.

\section{DEUXILME GROUPE.}

\section{Les Crypticolles, WaLcK.}

Les yeux antérieurs forment une ligne courbée en arrière, et sont inégaux entre eux; les yeux des lignes postérieures sont plus gros qu'aucun de ceux de la ligne an. térieure. - Le cẻphalothorax est large et cordiforme, - L'abdomen est ovoïde.

\section{DOLOMEDES ATALANTA.}

Dolomedes Ocyale, Walck., op. cit., t. I, p. 353.-Ocyale Atalanta; SAv., Descript. de l'Egypte, p. 149 et 150, pl. 4, fig. 10.Long. 5 lig. - Le cèphalothorax est brun. rougeâtre, court, rétréci et tronqué verticale. 
ment en devant, en crem inverse, à épistome élevé et en forme de triangle ; les pattes sont d'un roux-fauve, réguliẻrementannelées de noir ; la quatrième paire est la plus longue; la seconde ensuite, mais celle-ci n'excede que très-foiblement la première; la troisieme paire est la plus courte; l'abdomen est cylindroïde, jaune-olivâtre, avec le dessous pâle et bordé de deux raies oñscures, peu marquées; postérieurement il est terminé par six filières biarticulées, peu saillantes; les deux antérieures plus épaisses et plus courtes que les deux postérieures. - Cette especce a éte trourée aux environs de Jaffa.

\section{TROISILUE GHOUPE.}

\section{Les Sylvains, WaLck.}

Les yeux antérieurs forment une ligne droite, ils sont très-inégaux entre eux, et dont deux sont aussi gios ouplus gros que ceux des deux lignes antérieures.

\section{DOLOMEDE MIRABILIS.}

W.aLcK., Faun. franc., p. 34, et $35, n^{\circ} 3$, pl. 4, fig. 1. - Ibid. op. cit., t. I, p. 356 . - Araneus Mirabilis, Cherck, 1. 108, Spec. 19, pl. 5, tab. 10: - Long. 5 lig. - Le céplualothorax est d'un fauve carmélite clair, recouvext de poils blancs plus abondans sur les côtés, et divisé longitudinalement par une ligne fine d'un fauve plus clair ; sa partie antéricure offre deux taches angulaires de chaque côté d'un blanc éclatant, formées par des poils trèscourts; entre les yeux on aperçit quelques poils fauves parsemés ça et là; les paties; très-longues, sont d'un fauve gris en dessus, d'un rouge brun en dessous; l'extrémité des pieds est noire; l'abdomen est ovale, bordé de chaque côté d'une bande festomnée, d'un blanc très-vif, et on aper. coit dans le milieu des chevrons plus foncés et de même coileur; en dessous il est d'un faure plus clair, avec quelquespoints blancs sur les còtés.--Gette espece fait sa ponte en août; elle entoure pour cet effet les extréinités des branches ou des herbes d'une toile cn dôme ou en ballon, de la grosseur du poing, ouvert par en bas, et elle place au milieu son cocon, qui est globuleux, d'un blanc un peu jaunâtre, et cle la grosseur d'une groseille; quand elle quitte sa demeure, elle cmporte avec elle son cocon; elle le tient serré entre sa poitrine et une partie de son rentre, au moyeu de ses mancibules $\mathrm{el}$ de ses palpes. Dans son nid, elle ne quille point sespetits qu'ils ne soient éclos; lorsqu'elle es: sur son cocon, rien ne l'effraie, et elle laisse prendre plutôt que de l'abandonner; dans tout autre temps elle est farouche et elle fuit avec rapidité. Quand les petits sont éclos, ils restent agglomérés dans une des moitiés da cocon ouvert ou dans une partie de son nid; si on secoue ce nid, les jeurıes Dolomèdes quitlent aussitôt la portion du cocon où elles étoientbloties, et errent dans lout l'intérieur du nid et de la toile. La femelle est alors souvent sur la surface extérieure de ce nid, sans :qu'on puisse la contraindre à quitter sa toile ou à entrer dedans.

\section{STORENA, WALCK.}

Nous ne connoissons ce genre que d'après M. Walckenaer : voici les caractères qu'il. lui assigne.

Les yeux, au nombre de huit, presque égaux entre eux, occupent le devant et les. côtès du céphalothorax sur.trois lignes; ceux de la ligne antérieure, au nombre de deux, sont écartés entre eux, et assez loin de l'épistome et de la seconde ligne, qui est composée de quatre yeux; les internédiaires sont plus rapprochés entre eux qu'ils ne le sont des latéraux; la troisicme ligne composée de deux yeux plus rapprochés en. tre eux que les intermédiaires de la seconde ligne ne le sont entre eux, et plus rapprochés de ces intermédiaires de la seconde ligne que ceux-ci ne le sont des quatre autres; de sorte que ces intermédiaires de la seconde ligne, et les yeux postérieurs de la troisième ligne, forment un quadrilatère plus étroit qu'cn lıaut. La lèvre est ovale, allongrée et arrondie à son extrémité. - Les mâchoires sont alIongées, cylindriques et inclinées sur la lèvre. - Les pattes sont de longueur médiocre; les antérieures sont les plus longues. - Les cuisses-sont renflées; la première paire est la plus longue, ensuite la: seconde, et après la troisieme. - L'espèce type de ce genre est :

\section{STORENA CYANEA.}

WaLck., Tab. des Aran., 1S05, p. 83, pl. 9 , fig. $85 \mathrm{et} 86$; op. cit., t. I, p. 361 : - Long. 3 lig. - Le céphalothorax est bonabé à sa partie antérieure, d'un rouge vif et un peu lavé de noir aux yeur; la lèvre el les mâchoires sont rouges; les mandibules sont coniques; les pattes sont rougìs, un peu lavées de noir à lcur extrémité ${ }_{j}$ 
J'abdomen est d'un bleu-fauve ct tachetè. - Celle espèce, dont les mœurs sont inconnues, a pour patrie l'A Astralie.

\section{CTENUS, WALGK:}

Lcs yeux, inégaux entre eux, occupent le devant et les côtés du céphalothorax, et sont places sur trois lignes; deux sur la ligne antérieure, assez rapprochés entre eux pour former un carré avec les yeux intermediaires de la seconde ligne, qui sont au nombre de quatre; cette seconde ligne, tantôt droite, tautôt courbée en avant, selon la position des yeux latéraux placés sur une élévation qui leur est commune avec les yeux de la troisieme ligne; ceuxci, au nombre de deux, sont très-écarlés entre eux, de manière a former la ligne la plus large; ces huit yeux figurent un carré intermédiaire, projetẻ en avant et accompagné de chaque côté de deux yeux laléraux, dont le postérieur est toujours plus reculé que les yeux postérieurs du carrẻ intermédiaire. - La lèvre est carrée, plus haute que large, rétrécie à sa base et dilatée dans son milieu. - Les nâchoires sont droites, écartées, plus haules que larges, coupées obliquement, et légérement échancrées à leur côté interne. - Les pattes sont allongées, étendues latéralement. - Les cnisses sont assez reuflées; la première paire est plus longue que la seconde, et la seconde que la troisième.

Ces Aranéides courent après leur proie, et se renferment dans des feuilles qu'elles rapprochent pour pondre leurs aufs. Le cocon est orbiculaire, aplati.

Ce genre peu nombreux-en espèces a été partagé en trois groupes.

\section{PREMIER GROUPE.}

\section{Les Ambiguēs, Walck.}

Les yeux latéraux de la seconde ligne sont plus bas que les yeux intermédiaires de la même ligne, et forment avec eux une ligne courbée en avant.

\section{CTENUS FIMBiatus.}

WaLcK., op. cit., t. I, p. 274. - Long. 8 lig. - D'un brun rougcâtre, carmélite; le céphalothorax est ovalaire, allongé, èlargi dans son milieu, avec une bande jaune, large et fortemeut tranchée; les quatre yeux postérieurs sont les plus gros; ces yeux sont ronges de feu; ceux de la li- gne intermédiaire sont blanclıatres; les latéranx ont leur axe visuel dirigé de côlé; les mâchoires sont brunes, larges, arquécs à leur intéricur, el arrondies à leur côté externe; le plasiron sternal est déprimé et couvert de poils roux ; les pattes son grandes, fortes, à cuisses renflées, armées de piquans très-Iongs el de même couleur que le corps; la qualrième paire est. la plus longue, la seconde ensuitc, la troisième est la plus courte; l'abdomen est ovale, bombé, un peu plus long que le céphalothorax, et entouré comme lui par une bande d'un blanc-jaune très-clair. - Se trouve au cap de Bonne-Espérance.

\section{DEUXIEME GRUUPE.}

\section{Les Franches, Walck.}

Les yeux latéranx de la seconde ligne sont au niveau des yeux intermédiaires de la même ligne, et forment avec eux une ligne droite.

\section{CTENUS SANGUINOLENTUS.}

WaLcK., op. cit., t. 1, p. 369. - Long. 10 lig. $\frac{1}{3}$ - Le céphalothorax est ovale, très-épais, d'un brun rougeâtre velouté; les yeux postérieurs sont les plus gros; l'axe visuel des quatre yeux antérieurs est dirigé en avant; les antérieurs latéraux, qui sont les plus petits, ont leurs axes dirigés en bas, tirant sur les côtés; ceux des postérieurs sont dirigés en arriere; ces yeux sont d'un rouge-noir ; les mandibules sont fortes, allongées, bombées à leur partie antérieure, recouvertes de poils longs et noirs mélangés de poils blanchâtres ou fauves; elles sont noires a leur extrémité et dépourvues de poils; les pattes sont allongées, fortes, les antérieures les plus longues; la seconde paire et la quatrième ne different pas sensiblement; la troisième est la plus courte; ces pattes sont d'un brun-rouge, mais les postérieures sont d'une couleur plus claire, et ont la troisième paire de pattes toute rouge; de plus ces pattes sont courertes de poils fauves, avec des épines trés-longues et très-abondantes aux tarses; l'ablomen est ovale, allongé, d'un rouge-trun en dessus, d'un rouge clair en dessous. - Se trouve au Brésil.

\section{TROISIÈME GROUPE.}

\section{Les Phoneutres, Walck.}

Les yeux latéraux antérieurs sont très- 
reculés des intermédiaires, très - rapprochés des latéraux postérieurs, et forment avec les yeux intermédialres une courbe très-fortement prononcée en arrière, el laissant isolés les yeux qui formenţ le carré antérieur.

\section{GTENÙS ReFrbandis.}

WaLck., op. cit., t. I, p. 369.: - Pho. neutria Rufibarbis, Penty, Delect. Anim. qua in itin. per Brasil. Spix et Martius colleg., p. 196 et 197, tab. 9, fig. 2.-. Long. 14 lig. - Le céphalothorax est allongé, étroit, figurant un parallélogramme légérement arrondi sur les côtés, et élargi à sa partie postérieure; la lèvre est arrondie; les pattes sont allongées; la première et la quatrième paire sont presque égales; la troisième es: beaucoup plus courte ; l'abdomen est ovoìde, pas plus allongé que le céphalothorax, de couleur jaune rougeâtre, ayant en dessus trois ligne de points blancs disposés longitudinalement. - Cette es. pèce se trouve au Brésil.

\section{4. ctenus rufus.}

WALCK., op. cit., t. I, p. 367. - Long. 5 lig. - Le céphalothorax est allongé, coupé en carré a sa partie antérieure, rougeâtre, avec un sillon très-fin, Iongitudinal dans son milieu; les yeux sont noirs, saillans, très-inégaux en grosseur; les mandibules sont robustes, d'un rouge ferrugineux, bombées antérieurement, avec des poils rougeâtres sur le côté ; les mâchoires et la lèrre sont de même couleur que les mandibules; les pattes sont allongées, d'un ronge ferrugineux, et armées d'épines de couleur noire; l'abdomen est ovoüde, al. longé, de même longueur et de même largeur que le céphalothorax, grossissant peu à peu postérieurement, très-bombé en des. sus, entièrement glabre, et d'un rouxorange foncé; en dessou's il est de même couleur. - Ilabite la Guiane.

\section{5. cTExus oudinoti.}

WALCK., op. cit., t. 1, p. 369 ; pl. 11 , fig. $4 d$. - Long. 3 lig. - Le céphalothorax est court, cordiforme, de couleur noire, et rayé de couleur blanche; les pattes sont blanchâtres, avec des taches noires. heris. sées de poils et armées d'épines; l'abdomen est ovale, allongé, pointu postérieurement, de couleur noire, rayé de quatre lignes blanches longitudinales, dont les deux intermédiaires s'écartent l'une de l'autre dans le milieu et se rapprochent en angle a leur extrémité; les deux latérales sont festonnées. - Cette espèce a été trourée ne seule fois aux euvirons de Paris par M. Oudinot.

\section{Hersilia, Sav., , Walck., Lucas.}

Les yeux, au nombre de huit, sont inégaux entre eux, rassemblès sur une émi. nence du céphalothorax, disposés sur deux lignes transwerses; recourbées en arrière; les intermédiaires antérieurs sont plus grands; les latéraux antérieurs sont trèspetits; Jes quatre intermédiaires ligurent un carré parfait, et les quatre latéraux deux lignes parallèles. - La lèvre est courte, large, transverse, arrondie sur les côtés, et très-foiblement rétrécie au sommet. Les mâchoires sont convergentes, très-inclinées sur la lèvre, petites, oblongnes, rétrécies et contiguës à leur sommet. -Les pattes sont allongées; les antérieures les plus longues, avec la troisieme la plus courte de toutes.

Ce genre, dont les mœurs nous sont inconnue $s_{s}$ est remarquable par ses tarses qui offrent trois articles.

\section{Hersilla GaUdata.}

Sav., Descript de l'Égypte, p. 114, pl. 1, fig. 8.-Lucas, Mag. de Zool., 1836, 8, 12, fig. 1 à 7.-W -WLCK., op. cit., t. I, p. 371 . -Long. 3 lig. - Le céphalothorax est sousorbiculaire, rétréci et élevé verticalement sur le devant, roux, marqué de deux bandes dorsales brunes, et bordé de taches de la même couleur ; les mandibules petites, coniques, à gouttière oblique, sont abaissées perpendiculairement, armées d'un seul rang de dentelures et à crochet trèsrelevés dans le repos; les pattes sont trèsallongées, grêles, à l'exception de la troisieme paire, qui est très-courte; leurs tarses sont armés de deux griffes supérieures tridentées à la base, d'un ongle inférieur simple, et de deux dentelures en scie; l'abdomen est ovale, déprimé, varié sur le milieu de deux rangées contiguës de taches cannelées, brunes, et sur les côtés de trails bruns, obliques; les filières sont très-allongées, surtout la première paire. - Celte espèce a été prise aux environs du Caire, par M. Savigny.

\section{IEERSILIA INDICA.}

Lucas, Magas. de Zool., 1836, t. VIII, p. 7, pl. 13, fig. 2. - WaLck., op cit., t. I, p. 372. - Long. 3 lig. - Le céphalothorax est d'un jaune salc, tiqueté de brun, avec sa partie antericure noire; les. 
mandibules sont petites, jaunátres, hérissées de poils de même couleur, avec leur base légérement noirâtre; les mâchoires ainsi que la lèvre sont jaunes; les pattes sont grêles, allongées, d'un jaune sale, plus ou moins annelées de brun et de noir; l'abdomen est peu allongé, plus large antérieurement que postérieurement, sa coulcur est d'un jaune sale, mèlangé de brun les côtés latẻraux présentent une raje légérement arquée, d'une couleur brune foncée, ne se réunissant pas; sur le milieu on aperçoit une autre raie d'une couleur brune moins foncée, partant de la partie antérieure, et aboutissant au milieu de l'abdomen, qui présente une tache plus ou moins ronde, de couleur brune; de chaque côté de cctle tache sont deux points noirs profondément marqués; en-dessous il est d'un jaune clair, avec son milieu tiqueté de brun et de jaune plus foncé; prés des filières sont de petites taches brunâtres; les filières sont d'un janne sale, peu foncé; le mâle differe de la femelle par son corps, qui est plus allongè et plus grèle. - Se trouve a Bombay.

M. Walckenaer, dans son Histoires naturelle des Insecles aptères, regarde comme une variélé l'espèce à laquelle j’ai donnẻ le now de.Hersilia Savignyi, pl. 4, fig. 4; mais ayant eu depuis à ma disposition plusieurs autres individus, $j^{\prime}$ ai été a même de voir que ce n'était pas une variété, mais une espèce bien distincte.

\section{SPHASUS, WALCK.}

Les yeux, au nombre de huit, sont inégaux entre eux, placés sur le devant et les côtés du céphalothorax sur quatre lignes, par paire, figurant un pentagone allongé. - Les deux yeux antérieurs sont les plus rapprochés de tous, et ceux de la troisiéme ligne les plus écartés, pouvant être considérés comme formant avec ceux de la ligne postérieure une seule et même ligne très.courbée en avant. - La lèvre est allongée, étroite, dilatée à son extrémité, et plus étroite. à sa base. - Les mâchoires sont étroites, allongées, cylindriques, droites, arrondies à leur extrémité; les deux côlés formant des lignes droiles, parallèles. Les pattes sont allongées, fines.

\section{SPHASUS HETEROPHTHALMUS.}

WALck., Faun. franç., 1. 1, p. 36, sp. 1 ; ibid., Hist. des Aran., fasc. 3, tab. 8; op. cit., t. I, p. 373, - Ibid., op. cit., t. I, p. 357. - Oxyopes T'ariegatus, Kocr $131,4\left(\delta^{\star}\right), 2(q)$ - Oxyopes Variegalus, Latr., Génér. des Crust. et des Ins., t. 1, p. 116, tab. 4, fig. 9. Нан, Die Arach., t. II, p. 36, pl. 52 , fig. 12. - Long. 4 lig. $\frac{1}{2}$. L Le céphalothorax est ovoïde, étroit; velu, presque aussi long que l'abdomen, et tronqué antérieurement ; sa couleur est grise; les côtés latéraux et le dessous sont recouverts de poils gris, surmontant quatre raies longitudinales, dont les latérales sont les plus larges.'Ces raies sont séparées par trois lignes fines de couleur rnugeâtre et irréguliẻrement tachées de bistre clair. Les mandibules sont perpendiculaires, terminées par un crochet assez petit; les pattes, armées d'épines, sont fauves, annelées et velues; l'abdomen est ovoīde, allongé, devenant plus mince vers la partic anale, de couleur rouge dans la femelle, noir dans le mâle, ayant en dessus un ovale entouré d'une bande blanche, une ligne blanche courbée sur les côtés, et à la partie postérieure cinq ou six chevrons blancs. - Cette espèce se trouve dans le midi de la France, en Allemagne, aux environs de Nuremberg et de Ratisbonne.

\section{SPIASUS ITALICUS.}

WaLck., Aram. de France, p. 37, pl. 4, fig. 2 ; ibid., Hist. nat. des Aran., fasc. 4, lab. 8 ; op. cit., t. I, p. 374. - Long. 5 lig. - Le cephalothorax est rouge; l'abdomen est fauve, avec trois raies longitudinales brunes sur la partie supérieure, celle du milieu renfermée dans les deux autres, et dentée des deux côtés; les raies latérales sont festonnées sur leurs bords externes. - Se trouve en Italie.

\section{SPHASUS IIYEATUS:}

Walck., Aran. de France, p. 37, n०2; ibid., op. cit., t. I, p. 375. - Oxyopes Variegatus, Latr., Génér. des Crust. et des Ins., 1. I, p. 117, sp. 1. - Long. 3 lignes $\frac{2}{2}$ - Le céphalothorax présente trois raies longitudinales d'un jaune roux; les mandibules sont de même couleur, avec une raie noirâtre; l'abdomen est d'un brun foncé, rayé dans tonte sa longueur de roussâtre clair. - Se troure dans le midi de la France.

\section{SpHASUS mDicus.}

Walck., Tab. des Aran., pl. 3, fig. 23 et 24 ; ibid. op. cit., 1. I, p. 376 . Loug. 5 lig. - Le céphalothorax est ferru. gineux; les pattes sont très-longues, ferru- 
gineuses, revêtues d'ćpines assez nombreuses et apparentes; la quatrième paire est la plus longue, la seconde ensuite; l'abdomen est ferrugineux, bordé de noir.-- Se trouve aux Indes-Orientales.

5. SPHASUS ALEXavdrives. (Pl: $4, \mathrm{fig} .2$. ) Sav., Descript. de l'Egyple, p. 142, pl. 4, fig. 1. - WALck., op. cit., t. I, p. 376. - Long. 4 lig. - Le céphalothorax est soyeux, biun, avec trois bandes blanchâtres, deux exaclement marginales, étroites, et une intermédiaire large, terminée en pointe près des yeux; les pattes sont annelées de brun, de roux et de blan. châtre, hérissées de quelques poils noirs ; leś yeux les plus lateraux, ou ceux de la troisième ligne, sont trés-écartés entre cux; l'abdomen est soyeux, brun en dessus, avec une large bande longitudinale d'un brun beancoup plus clair, surtont vers les bords, à laquelle aboulissent trois raies blanchâtres qui traversent obliquement-les còtés; en dessous il est blanchatue, avec une bande obscure aboutissant à la partic anale. Cette espèse habite l'Egypte.

\section{DYCTION, W ALCK. Megamyrmekion, Reuss.}

Les yeux, inégaux entre eux, sont placés sur quatre lignes, les trois premières lignes étanl rapprochées entre elles, et formant une bande figurant un $X$ très-étalé, ou une croix de Saint-André; les deux yeux intermédiaires de la seconde ligne ont de chaque còlé, en avant et en arrière, de petils yeux rapprochés d'eux qui forment un carré long, dans lequel ces deux intermédiaires sont placés. A une certaine distance de ce groupe de six yeux, se trouvent deux auires yeux sur la partie antérieure du céphalothorax, et plus rapprochés entre eux que les deux intermédiaires antérieurs. La lèvre est petite el carrée. - Les mâchoires sont grandes. larges, plates, entourant la lèvre, qu'elles dépassent beaucoup en hauteur. - Les pattes sont allongées, fines; la quatrième paire est la plus longue, les autres presque égales, mais la troisième un peu plus longue que la seconde; la première paire est la plus courte.

\section{DYCTION CAUDATUR.}

Dyction Reuss, WaLck., op. cit., t. I, p. 381. - Megamyrmekion Caudatum, Reuss, Zool. Miscell., dans le Mus. Senckenberg., t. I , p, 217, pl. 18, fig. 12. - Long. 7 lig. - Le céplialothorax est grand, glabre, vôté vers la parlic antěricure, arrondi et déprimé à sa partie pustérieure; sa couleur est fauve; les denx yeux de la seconde paire sont beaucoup plus gros que les autres, et ceux qui se trowvent auprès d'eux sont très-petils; les deux yeux pestérieurs sont ovales; les mandibules sent pelites, peu allongées, velues; le crochet est petit; les palpes sunt gièles, hérissés de poils et d'épines; les pattes sont fauves; l'abdomen est comprimé, ovale, d'un jaune-verdâtre, pâte, terminé par des filières assez groses, allongées, cylindriques et blanchầtres. - Se trouve en Afrique.

\section{DOLOPIIONES, WALCK.}

Les yeux, au nombre de huit. sont inégaux cutre eux, et places sur quatre lignes; les deux lignes anterieures longues. trèsrapprochées, et formées par de petits yeux latéraux presque connivens, placés daus les angles antérieurs de l'épistome, qui est très. relevé ct resserié vers son sommet; les dcux yeux de la ligne postérieure sont plus gros que les au'res, plus écartés que ceux de la ligne intermédiaire, et moins que ceux de la bande antérieure. - La lèvre est triangulaire, plus haute que large, terminée en pointe arrondie et bombée. Les mâchoires sont allongées, ovalaires, plus hautes que larges, grossissant vers leur estrémitê, arrondies a leurs côtés externes, et très-échancrées à l'extrémité de leurs côtés internes. - Les pattes sont allongées, aplaties; la première et la quatrieme paire sont presque égales; la troisieme est la plus courte.

Ces Aranéides courent après leur proie, mais Jorsque vient le moment de la ponte, elles font une toile irrégulière entre les feuilles.

\section{DOLOPHONES ROTACANTHA.}

WaLck.;op. cit., t. 1, p. 383. - Aranca Notacantha, Quox el Gararard, Voyage de l'Uranie et de la Physicienne, Zoot., p. 544 , pl. 82 , fig. $6,7,8$ - Long. 4 lig. - Le céphalothorax est large, convexe, trèsélevé vers la partie antérieure, flanqué a sa partie postérieure par l'abdomen, gui forme une espèce de chaperon arrondi, festonnè à-sa partic antérieure, qui le recouvre en partie, et dans lequel il est enfermé; du milieu de l'abdomen, le chaperon s'élève perpendiculairement; les palpes sont fauves, velus, courts, terminés par un dernier article en ovale allongé, pointu, 

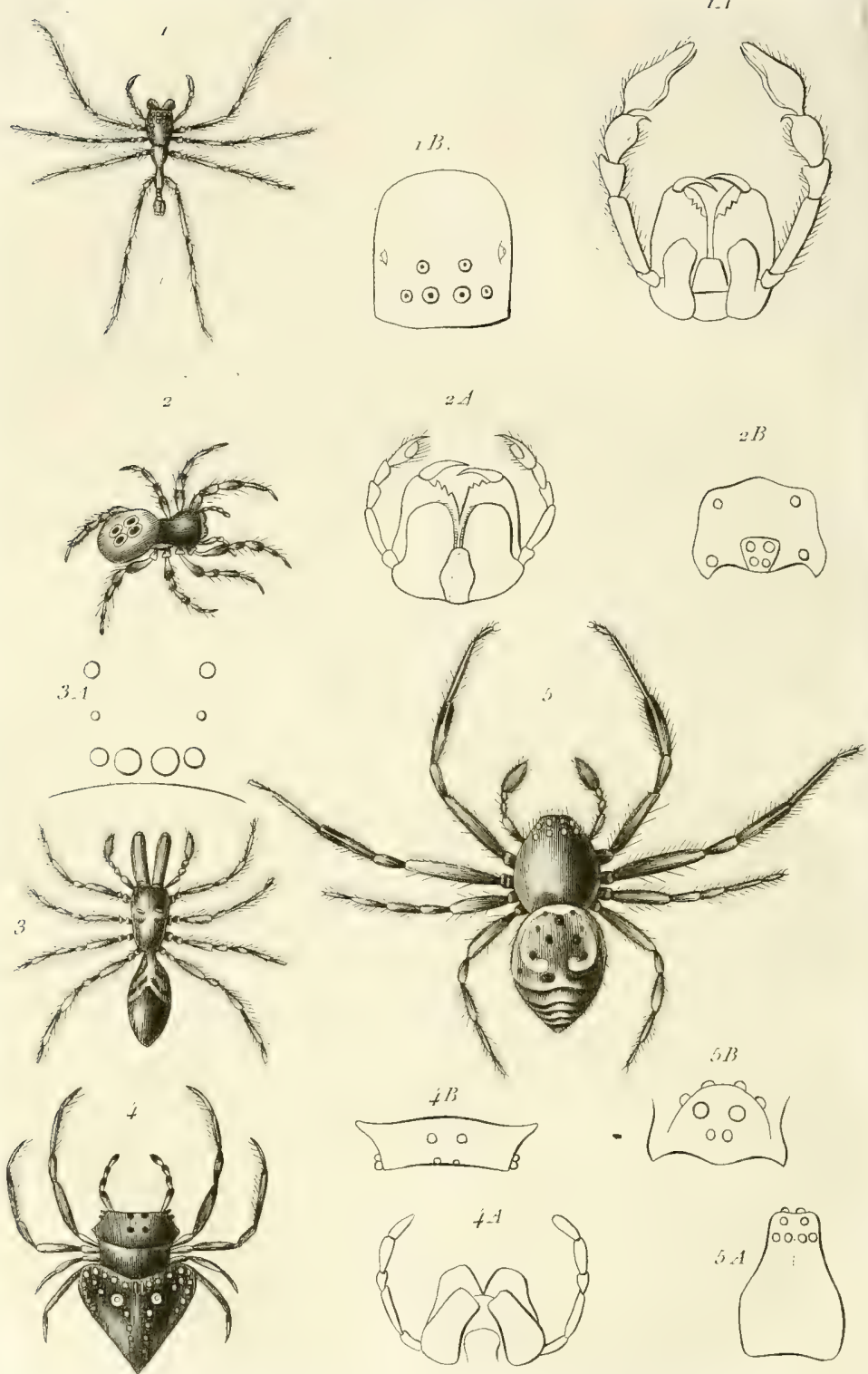

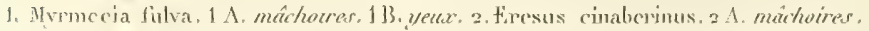
2B. yeux, 3. Allus formicarius, 3A, yeux. 4. Arkis lancearius. 4 A mâchoires, 4 B, yeux. 5. Thomisus atomarius. 5A. Céphutlothorax du T. Ruģosus. 5B. yeux" 
un peu dilaté en cuiller, et ne renfermant aucun corps calleux; la lévre et les mâchoires sont d'un rouge pâle; l'abdomen est cylindrique, et terminé par des callosités brunes; la couleur générale est un fauvc rougeâtie pâle, presque uniforme. - Cette espèce a été trouvée à la Nouvelle-Hollande.

\section{CITQUILUE SOUS-SECTION.}

\section{Les Voltigeuses, WaLcK.}

Sautant et voltigeant avec facilite pour attraper leur proic.

\section{MYRMECIA, Latr, WALCK.}

Les yeux, au nombre de huit, sont inégaux entre eux, placés sur trois lignes sur le devant du céphalothorax; l'antérieure formée par quatre yeux, légérement cou:bée en arrière; la ligne intermédiaire est plus courtc, et formèe par deux yeux faisant un carré avec les intermédiaires anté. rieurs; la troisième ligne est formée par deux yeux; les yeux latéraux de la ligne anterieure forment une ligne plus longue que cette dernière. - La lèvre est ovale, allongėe. - Les mâchoires sont droites, allongées, dilatées et arrondies à leur extrémité.-Les pattes sont allongées, grêles; la quatrième et la première paire sont les plus longues, la seconde ensuite; la troisième est. la plus courte.

L'espèce type de ce genre est la:

\section{1. myrmecia furva. (Pl. 5, fig. 1.)}

Latr., Ann. des Sc. nat., t. Ill, p. 27 ; Règn. anim. de Cuv., $2^{e}$ édit,, t. IV', p. 261. - W ALCK., op. cit., t. I. p. 385. - Long. 8 lig. - Le céphalothorax est divisé en trois ou quatre parties; la portion antérieure, plus large, presque carrée, épaisse, qui porte les yeux et forme la tête, est comme chagrinée; puis cette partie se prolonge postérieurement en un tuyau cylindrique, qui a trois ou quatre nouds ou renflemens semblables aux pédicules de certaines fourmis, de sorte que les pattes postérieures ont les hanches en saillie et non cachées sous le céphalothorax; les yeux intermédiaires de la ligne antérieure sont plus gros que les lateraux et les postérieurs; les mandibules sont fortes et perpendiculaires ; l'abdomen est petit, carré, n'a que deux lignes de long, et a comme

$$
\text { Axw. }
$$

une plaque grisâtre sur la partie supérieure. La couleur générale est rougeâtre. - Cette espèce habite le Brésil.

\section{MYRMECIA VERTEBRATA.}

WALCK., op. cit., t. I, p. 386 . - Long. 5 lig. - Le céphalothorax est rouge, allongé, nu, chagriné, bombé en voû́te, en s'arrondissant et s'inclinant vers les yeux, sur les côtés et par derrière, à quatre étranglemens, terminé par un vertébral allongé, annelé, reçu dans un tube court, cylindrique, que projette l'abdomen; les mandibules sorit verticales, rouges; les pattes, d'un rouge uniforme, sont grêles, allongées, surtout les postérieures, qui ont le tarse renflé à l'extrémité, et terminé par une petite brosse de poils roides; ces pattes sont très-inégales en longueur; la quatrième paire est plus longue que la première, la seconde ensuite; la troisième est la plus courte; l'abdomen est ovale, allongé, rouge et glabre sur le dos à la partie aniérieure, et brun a sa partie postérieure. - Patrie inconnue.

ii. Perty, dans le Delect anim. du Voyage de MiM. Spix et Martius, a figuré une jolie espece de ce genre, à laquelle il a donné le nom de Myrmecia Nigra, p. 199, pl. 39 , fig. 9.

\section{PALPIMANUS, L. Dufour; Platyscelum, Aud.; Chersis, Latn., WaLcK.}

Les yeux, inégaux entre eux, sont placés sur quatre lignes, formées chacune par deux yeux ; ceux des lignes antéricures et postérieures sont plus écartés entre eux que ceux des deux lignes intermédiaires, et les huit forment denx carrés ou trapèzes renfermés l'un dans l'aulre. - La lèvre est allongée, triangulaire, pointue à son extrémité. Les mâchoires sont larges, dilatées, conniventes à leur extrémité, et rétrécies vers leur base. - Les paltes sont de Jongueur médiocre, peu inégales entre elles; la paire antérieure est la plus allongée, avec le fémoral et le génual plus gros et plus renflés.

Les habitudes des Aranéides qui com. posent ce genre sont de se retirer sous des pierres.

\section{palimanes gibiulus.}

L. Dufour, Ann. des $S c$. phys., t. IV, p. 12, pl. 69, fig. 5. - Chersis Gibbulus, Walck., Ifist. nat. des Ins. Apt., t. I, 
p. 190. - Long. 3 lig. $\frac{1}{2}$ - Le céphalothorax est d'un brun-marron, très-épais et peu arrondi; les mandibules sont verticales et peu bombées; les deux yeux de la seconde paire sont beaucoup plus gros que les six autres; les pattes antérieures sont grosses et très-renflées, et ne présentent pas de griffe, mais le tarse de ces pattes, au lieu d'être articulé bout à bout avec le métatarse, est inséré sur le côté de l'extrémité de ce dernier; l'exinguinal de cette première paire de pattes est gros et bombé; le fémoral est renflé et cambré : par une exception remarquable à la règle commune, le génual est non-seulement plus gros, plus renflé, mais plus allongé que le tibial; le derme est très-coriace. Cette espèce est revêtue par tout le corps d'une sorte de duvet ou de feutre composé de poils grisâtres, égaux entre eux. Les individus qui ne sont pas encore parvenus à l'âge adulte ont une couleur de brique claire. Elle a été trouvée sous les pierres dans les montagnes arides et désertes de Moxente, aux confins du royaume de Valence; elle a été aussi rencontrée en Grèce.

I'espèce qui a été figurée par Koch, dans $\mathrm{H}_{\mathrm{AHN}}, \mathrm{t}$. III, p. $21, \mathrm{pl} .80$, fig. 178 et 179 , sous le nom de $P$. Homatinus, n'est qu'une variété du $P$. Gibbulus de M. Léon Dufour.

M. Walckenaer, dans son Hist. nat. des Ins. Apt., t. I, p. 391 et 392, fait connoître deux autres espèces, dont la première est désignée sous le nom de Chersis Savignyi, WaLc, et qui est la même espèce que le $F$ latyscelum Savignyi, AUd, Explication des planches de l'Egypte, p. 167, pl. 7, fig. 6 et 7. Cette espèce se trouve en Afrique; la seconde a recu le nom de Chersis Dubius, WaLcK.; cette dernière a été rencontrée dans le royaume de Naples.

\section{ERESUS, Latr., Walck.}

Les yeux, au nombre de huit, sont inégaux cntre eux, placés sur le devant et les côtés du céphalothorax, et ainsi disposés : quatre sur la ligne antérieure, et deux sur chacune des deux autres lignes postérieures; les intermédiaires de la ligne pos térieure et les deux yeux de la seconde ligne sout tellement rapprochés entre eux, qu'ils forment un petil carré ou trapèze renfermé dans un plus grand figuré par les yeux latélaux de la ligne antéricure el les deux yeux de la ligne postérieure. La lèvre est allongce, triangulaire, et termince en pointe.- Les mâchoires sont ovales, allongées, dilatées, et arrondies à leur extré. mité. - Les pattes sont grosses, de longueur médiocre, propres au saut et à la marche.

Cies Aranéides, qui ont été divisées en deux groupes, épient leur proie, renfermées dans un fourreau d'un tissu serré, tendant des fils irréguliers entre les arbustes épineux, ou se pratiquant sous les pierres une retraite en soie fortement tissue.

\section{PREMIIR GROUPE.}

\section{Les Rusées, WaLck.}

Les yeux de la ligne postérieure sont presque aussi écartés entre eux que les yeux latéraux de la ligne antérieure, et forment avec eux un quadrilatère dont les côtés supérieurs et anlérieurs sont presque égaux.

\section{EResus civabenivus. (Pl. 5, fig. 2.)}

Walcк., Hist. des Aian., fasc. 2, pl. 10 ; I bid. Aran. de France, p. 38, pl. 4, fig. 7 et 8 ; Ibid. Tab. des Aran., p. 21 , pl. 3 , fig. 29 et 28 ; Ibid. Faun. Parisienne, t. II, p. 249 ; Ibid. op. cit o, t. I, p. 395. - If and, Monogr. der Spinn., 2, Heft., pl. 2, fig. A ; ibid., Eresus Annulatus, fig. B, var., ibid., Eresus Quatuorguttatus Annulutus, die Arachn., t. I, p. 45 et 47 , pl. 12 , fig. 35 et 36.-Aranea 4-guttata, CoQves., Illustr. Icon. des Ins., dec. 3, p. 122, pl. 27, fig. 12. - Rossi, Fauna Etrusca, t. II, p. 135 , pl. 1, fig. 8 à 9. - Aranea Moniligcra, Devilu, Ent., t. IV, p. $128, n^{\circ} 119$, pl. 11, fig. 8.-Araignée rouge, OuIv., Encycl.méthod., t. IV, p. 221 , no 85, pl. 340, fig. 17. - Eresus Audouinii, Bnulué, Expéd. scient. de Morée, p. 51, pl. 28, fig. 10. - Long. 4 lig. $\frac{r}{2}$ - - Le céphalothorax est arrondi, convexe vers la partie antérieure, épais, presque aussi large que l'abdomen, coupé perpendiculairement et offrant une figure rhomboïdale; il est noir et bordé de rouge postérieurement; les yeux de la seconde ligne ou les yeux postérieurs du carrẻ intermédiaire sont plus gros que tous les autres, ils sont luisans et ont un iris distinct; les yeux postèrieurs ou ceux de la dernière ligne sont presque aussi écartés entre eux que les latéraus de la ligne antérieure, et forment avec eux un carré; les mâchoires sont noires; les palpes sont de même couleur, avec leur dernier article bordé de deux anneaux blancs ils sont courts et ve- 
lus; les mandibules sont robustes, droites, courtes, cylindriques, non renfoncées sous le céphalothorax et le dépassant un peu ; les pattes antérieures annelées de blanc trèsvif sont d'un noir velouté; les postérieures sont revêtues de poils de couleur rouge à l'exinguinal, au fémoral, au génual et au tibial; l'abdomen est ovale, déprimé, d'un rouge écarlate ou couleur brique en dessus; il offre quatre taches noires sur sa partie supérieure, disposées en carré et bordẻes d'un cercle blanc; a la suite de ces quatre taches sont deux autres points noirs plus petits; tout-à-fait postérieurement le rouge se trouve bordẻ de quelques points et de petits traits d'un blanc très-vif. - Cette espèce se trouve aux environs de Paris; elle se rencontre aussi en Bavière, en Italie, en Hongrie et en Morée. Elle varie quelquefois dans ses couleurs, mais pas assez pour n'être pas facilement reconnue. Quand l'Erese Cinabre marche, elle saute très-peu, elle relève souvent en l'air ses pattes antérieures, et lorsqu'elle a saisi sa proie, elle l'entraîne de côté.

\section{ERESUS FRONTALIS.}

WaLck., Aran. de Franc., p. 39, pl. 1 , fig. 3 à 4; lbid., op. cit., t. I, p. 396. Latr., Nouv. Dict. d'Hist. nat., $2^{\mathrm{c}}$ édit., t. X, p. 393. - Long. 5 lig. $\frac{x}{2}$. - Le céphalothorax est bombé, rhomboĩdal, aussi long que l'abdomen, couvert de poils rouges, ferrugineux antérieurement; les man. dibules sont revêtues de poils roux à leur origine, et de poils noirs à leur extrémité; elles sont larges, courtes et fortes; les màchoires sont brunes, rougeâtres, avec quelques poils d'un roux ferrugineux à leur base; les palpes sont courts, velus, avec des poils d'un noir soyeux et des poils rouges aux articulations, mais seulement en dessus; les pattes sont robustes, courtes, noires, velues, surtout en dessous; l'abdomen est ovale, allongé, arrondi aux deux bouts, deux fois plus long que large, d'un noir mat et velouté, avec des points enfoncés, petits, blancs ou rougeâtres, disposés longitudinalement et au nombre de huit, c'est-à-dire quatre de chaque côté, qui forment deux lignes ct tendent à se rap. procher vers la partie anale ; en-dessous il est noir, à l'exception cependant des ouverlures stigmatiformes, qui sont couvertes de poils d'un roux ferrugineux de couleur vive. - Elle se trouve aux environs de Mon Lpellier; elle a été aussi rencontrée en Espagne.

\section{DEUXILME GROUPL.}

\section{Les Subliles, Walck.}

Les yeux de la ligne postérieure sont sensiblement plus rapprochés entre eux que ne le sont entre eux les yeux latéraux de la ligne antérieure, et forment avec eux une quadrilatère à côtés supérieurs et inférieurs inégaux, et plus étroit en haut qu'en bas.

\section{ERESUS ACANTOPnIUS.}

L. Duf., Observ. génér. sur les Arachn., Ann. des $S$ c. phys., t. V1, p. 14, pl. 95 . fig. 3 le 0 , et 4 la \&. - Érese rayé, Walck., Aran. de Franc., p. 40, pl. 4. fig. 3 et 4. - Ibid. op. cit., t. I, p. 399. - Latr., Nouv. Dict. d'Hist. nat., t. X, p. 393. - Long. 6 lig. - Le céphalothorax est carré à sa partie antėrieure et sur les côtés, très-épais et arrondi en dessus; sa partic antéricure est noire, avec des raies longitudinales, blanches, entre les yeux et dans le milieu; les yeux sont d'un rouge jaunâtre, les intermédiaires sont inégaux entre eux, et les latéraux de la première ligne sont portés sur une éminence tuberculeuse; leur axe visuel se dirige latéralement et en bas ; la lèvre est arrondie à son extrémité, èt le contour extérieur des mâchoires est droit; le plastron sternal est ovale, noir, entouré de poils fauves; les mandibules sont hérissées de poils fauves, mélangés de poils gris; les palpes sont tachetés de fauve, de brun et de gris, avec des petits anneaux blancs aux articulations; les pattes sont grandes, robustes et de même couleur que les palpes.

Celte espèce, qui se trouve en Espagne, dans le royaume de Valence et dans la Basse-Catalogne, établit constamment son domicile sur les plantes et les arbustes trèsépineux, tels que le Genita scorpius, l'Asparagus horridus, etc. Elle tend enire les branches, d'un arbrisseau à l'autre, des fils qui forment un réseau très-irrégulier, lié par de nombreux fils à un fourreau long de plus d'un pouce, tissu d'une étoffe serrée et enclavée dans l'aisselle des rameaux au milieu des épines. C'est dans ce fourreau que l'Érése Acantophile se tient en embuscade. Elle attaque et tue tous les insectes même les plus forts, qui se trouvent engagés dans ses fils; des Mouches, des IIyménoptères, des Coléoptères, et même jusqu'à des Sauterelles. 
4. ERESU DUTOUR.

Sav., el A ud., Descrip. de I'Égypte, p. 151 , pl. 4, fig. 12.-W ALCK., op. cit., 1. I, p. 400. - Long. 2 lig. - Le céphalothorax est peu bombé ; la lèvre est large; les mâchoires sont courtes, arrondies, plus larges près de leur insertion, coupées à l'intérieur en lignes moins droites et moins inclinées, et par conséquent moins conniventes et très-peu dilatées à leurs côtés externes; l'abdomen est ovoïde, plus gros à sa partie postérieure, s'amincissant à sa parlie antérieure, ayant en dessus une bande longitudinale plus foncée, écbancrée sur les deux côtés; il y a deux raies fines, plus Ioncées, presque réunies, proche le céphalothorax, et s'écartant à mesure qu'elles avancent vers le milieu de la partie supérieure ou du dessus qu'elles ne dépassent pas; il y a aussi quatre petites raies transversales vers l'exirémilé postérieure de la tache, dans la région anale, de couleur plus foncée, interrompues dans leur milieu, et formant autant de cherrons disjoints, renversés, dont la pointe est tournée vers la partic anale. - Cette espèce a été trouvée en Égyple.

\section{ATTUS, WALCK, ; Salticus, Latr.}

Les yeux, au nombre de luit, sont iné. gaux entre eux, ils occupent le devant of les côtés du céphalothorax, et sont placés sur trois lignes et ainsi disposés : quatre sur la ligne antérieure, et deux sur chacune des deux lignes postéricures. Les deux intermédiaires de la ligne antérieure sont toujours plus gros, et les deux de la seconde ligne sont beaucoup plus petits que les auires. Tous fgurent un quadrilatere ouvert postérieurement el arrondi antérieurement. - La lèvre est allongée, ovale, obtuse ou tronquée à son extrémité.-Les mâchoires sont étroites, plus hautes que larges, arrondies et dilatées à leur extrémité. - Les pattes sont variables dans leur longueur relallve, et propres au saut et à la course. Ces Aranéides épient leur proie, la saisissent a la course ou en saulant, se renferment dans un sac de soie très-fine, entre des feuilles qu'elles rapprochent, ou dans l'intérieur des coquilles vides, des réceptacles de fruits, de fentes; et de cavités de pierres et de rochers.

Ge genre est sans contredit le plus nombreux en espèces de la famille des Aranéides, ot l'on peut dire aussi que c'est le plus difficile à étudier pour la distinclion des espèces. M. Walckeuaer, dans son ouvrage que nous arons déjà cité tant de fois, en décrit cent quarante-cinq especes, et ce célébre entomologiste, pour rendre plus facile à l'étude ce genre si nombreux , en a classé une partie d'après la longueur relative des organes de la locomotion et une autre d'après la position des organes de la vue.

Les espéces qui composent ce genre ont eté divisées en çuatie groupes.

\section{PREMER GROUPE.}

\section{Les Sauteuses, WaLck.}

Les paltes sont grosses et courtes dans les fomelles.

\section{ATtus scericus.}

W Alck., Aran. de Franc.; p. 44, n० 5 , fig. 11 à 12 le mâle; ibid. : op. cit., t. I, p. 406. - IAun, Die Arachn., t. 1, p. 57 et 58, pl. 45 , fig. 43 , le mâle, fig. 44 , la femelle. - Alraignée d bandes blanches, Dégeer, t. VII, p. 287, pl. 17, fig. 8 à 10. - Aranea Cinereus, Lister , De Aran., titr. 31, p. 87, tig. 31. - Aranea Scenica, Cuenck, p. 117, no $3, \mathrm{pl} .5$, tab. 10. Attus Scericus, Sund, p. 202, no 1. Aranea Cingulata, Panz., fasc. 40, tab. 22. - Long. 3 lig. - Le céphalothorax est entouré sur les côtés d'une ligne blanche, et à en dessus deux petites virgules blanches au-dessus d'une figure d'un blanc moins vif, qui sont comme deux segmens de cercle, réunis par une ligne transverse; les yeux de la seconde ligne sont plus rapprochés de la ligne antérieure que de la ligne postérieure; la partie antérieure du céphalothorax deborde les mandibules, et est couverte de poils blancs tant dans la région des yeux qu'au bandeau, où ils sont fort longs et se prolongent entre les mandibules; ces derniers organes sont courts, perpendiculaires et de couleur brune; les palpes sont assez robustes, velus et blanchâtres; les pattes sont brunes, et ont un grand nombre de poils blanes qui leur donnent une couleur légérement grisâtre; la quatrième paire est la plus longue, la troisième ensuite, clle surpasse peu la première; la seconde paire est la plus courte; l'abdomen est d'un brun-faure et quelquefois doré, avec trois chevrons blancs au milieu sur le dos, dont les angles ne se joignent pas : ainci ces chevrons forment six traits blancs par paire, inclinés les uns sur les autres; 
entre ces bandes, on voit: des taches:grises, et la pointe vers la partie anale est blanchâtre.

Cette espèce, une des plus communes, se trouve dans toute l'Europe. Elle se renferme dans les fentes des murs, des poutres ou des arbres, et y file aux approches de l'hiver une toile très-serrée; formant un tuyau ou un ovale percé des deux côtés, dans lequel elle se reuferme, et d'où elle sort vers la fin de février, lorsque la chaleur du soleil commence à se faire sentir.

\section{ATTUS SEMLIMBATUS.}

Haun, Monogr. des Arachn., fasc. 4, pl. 3, fig. 3. - WALck., op. cit., t. I, p. 408. - Long. 7 lig. - Le céphalothorax est grand, noir, bordé de blanc sur les côtés de sa partie postérieure; les palpes et les pattes antérieures sont noirs, marqués de blanc; les pattes postérieures sont marquées de fauve; l'abdomen est court, çuadriforme, peu allongé, dèprimé, d'un hrun-fauve, avec des poils noirâtres, qui forment un carré proche le céphalothorax, dans le milicu duquel est un point brun; derrière ce carré sont quatre ou cing chevrons entourés d'un ovale festonné dont les festons ont leur parlie concave tournèe extérieurement, ou en dehors, le dernier chevron formant, avec la pointe de l'ovalc, un trapèze au milieu duquel est un point de couleur brunc. - Cette espèce a été trouvéc en Italie dans le royaume de Naples.

\section{ATtUS XaNTHOGRAMMA.}

WaLcK., Aran. de Franc., p. 59, n 12 ; Ibid. op. cit., t. 1, p. 415. - Salticus Xanthogramma. Latr., Nouv. Dict, des Scienc. nat., t. XXX, p. 103.--Araneus Sub/lavus, Lister, p. 90, 1itr. 3.-Long. $3 \mathrm{lig.} \mathrm{-} \mathrm{Le} \mathrm{céphalothorax} \mathrm{est} \mathrm{couvert}$ d'un duvet fauve-rouge en dessus, entouré sur les bords d'une bande d'un jaune clair ; les pattes sont d'un jaune clair, non anne. lées, mais parsemées de taches noires; l'abdomen est ovale, déprimé, pointu, d'un rouge capuciné, brillant sur les côtés; dans le milieu sont deux lignes d'un jaune pâle; interrompues postéricurement et bordées de noir, qui tendentà se réunir à leur base, ct sur chacune desquelles sont des points enfoncés. - Cetle espèce se trouve aux environs de Paris, en Angleterre et en Italic.

\section{ATTUS FRONTALIS.}

Walck, , Faun. Jaris., t. II, p. 246.

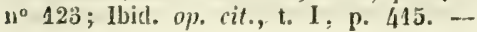

Zab. des Aran., p. 24, 10 21. - Eriophrys Frontalis, KocH, dans Schosfrer, 123, 8. - Long. 3 lig. - Le mâle, qui est plus petit que la femelle, a le céphalothorax d'un noir foncé uniforme, avec des poils d'un rouge orangé; les deux premiers articles des palpes sont noirs, avec le dernier loug et enflé ; l'abdomen est d'un fanve rougeâtre en dessus, avec deux petits traits noirs parallèles, suivis de cinq ou six triangles noirs dilatés, dont les tarses touchent au sommet de ceux qui les suivent; les pattes de la première paire sont noires dans ce carré qui est fauve, ainsi que toutes les pattes postérieures; dans la femelle, le céphalothorax est d'un jaunefauve lavé de brun vers la tête, et entouré de noir; les palpes et les pattes sont d'uin fauve clair ; l'abdomen est ovale, nois, avec une large tache jaune proche le céphalothorax mélangé de noir; puis deux séries de taches jaunes, grandes, ovalaires, nu nombre de cinq ot six sur chaque ligne, inclinées l'une vers l'autre, et formant des chevrons disjoints qui vont en diminuant de grandeur en approchant de la partic anale. _- Se trouve aux envizons de Paris.

\section{ATTUS CRUCIGERUS.}

WaLcK. Aran, de France, p. 59, n²3, WaLcK., op. cit., t. I, p. 420. - Araneus Sanctus, Moufret, Théatr. des Ins., p. 254. - Salticus Crux, II ans, Die Arach., t. I, p. 69 , pl. 7, fig. 52, - Allus Crucifer, Suxd., p. $215, \mathrm{n}^{\circ}$ 13. - Long. 3 lig. $\frac{3}{2}$. Le céphalothorax est moins long et moins large que l'abdomen, noir et recouvert en dessus de poils d'un fauve doré; les yeux de la seconde ligne sont les plus rapprochés de la ligue postérieure que de la ligne antérieure; Jes palpes sont jaunâtres: les pattes antéricures ont les cuisses renflées, la première moitié des cuisses est d'un fauve rougeâtre; le génual et le tibial sont d'un brun foncé; le tarse d'un fauve rougeâtre; la troisieme paire de pattes est plus longue, et la quatrième ensuite, la première est égale presque à la quatrième, la scconde est beaucoup plus courte; l'abdomen est ovoïle, un peu déprimé, mais gros el épais; le fond es d'un brun-noir, entouré sur tousles côlés de poils gris-blanes, ayant dans la partie médiane une ligne blanche, formée de quatre points blancs allongés, croisés par deux pelits ares de cercles blancs, opposés par leur côté convere, qui coupent doublement cette ligne cu croix ; l'arc le plus rap. proché du céplablothorax esi moins apparen: 
et souvent oblitéré. - Se trouve aux environs de Paris et dans les Pyrénées.

\section{6. atTUS maculatus.}

WaLCK., Aran. de France, p. 60, no 24 , pl. 5, fig. 7; ibid. op. cit., t. 1, p. 421. - Attus Pulchellus, $\mathrm{H}_{\mathrm{AHN}}$, Monogr., pl. 1 , fig. 6. - Long. 3 lig. - Le céphalothorax est rougeâtre; les yeux de la seconde ligne sont plus rapprochés de la ligne postérieure que de la ligne antérieure; les pattes sont rougeâtres, la quatrième paire est la plus longue, la troisième ensuite, la denxième et la première presque égales, mais la première est plus longue; l'abdomen est ovoìde, légẻrement dẻprimé, rond, un peu renflé postérieurement, presque tronqué en ligne droite antérieurement, et pointu vers la partie anale; sa couleur est verdâtre ou d'un fauve rougeâtre, pâle, parsemė de petites taches ou mouchetures noires, qui forment sur le dos trois lignes longitudinales, parallèles, qui vont se joindre à la partie anale; il y a un petit triangle noir et trois chevrons ou accens circonflexes à la partie postérieure. - Se trouve en France, en Italie, en Allemágne, et aux environs de Paris.

\section{ATtus Paykulir.}

Sav. et Aud., Descrip. de l'Égypt., p. 172 , pl. 7, fig. 22. - WALCK., op. cit., t. I, p. 426. - Long. 4 lig. $\frac{1}{2}$. - Le céphalothorax est grand, allongé; sa partie médiane présente une bande ovale, blanche, qui fait suite à celle de l'abdomen; les pattes sont peu allongées, la quatrième est la plus longue de toutes, la troisième ensuite, la seconde est la plus petite; l'abdomen est ovoìde, allongé, avec une bande blanche sur le milieu du dos, large et dilatée à sa partie postérieure, entourée de deux grandes bandes brunes qui se joignent à la partie anale; il y a deux traits fauves, obscurs, qui rompent transversalement les bandes postérieurement. - Cette espèce a été trouvée en Égypte.

\section{8. attus crictus.}

WALck., op. cit., t. I, p, 430. - Long. 3 lig.-Le céphalothorax est grand, aplati, d'un brun-marron, entouré près des pattes d'une ligne blanche de poils blancs; les yeux de la seconde ligne sont plus rapprochés des yeux postérieurs que des yeux antéricurs; les gros yeux antérieurs sont verdâtres, avec un iris jaune; les palpes sont garnis à leur extrémité d'une touffe de poils jaunes; les mandibules sont noires, courtes, coniques; les pattes sont d'un fauve blanchâtre, la quatrième est plus longue que la troisième, la deuxième ensuite, la première est la plus courte; l'abdomen est ovoìde, déprimé, un peu renflé vers son extrémité, couvert en dessus de poils orangés, mélangés de poils bruns ou noirs, mais entourés d'une ligne ovale de poils noirs. - Habite la Guiane.

\section{ATtus Monsitans.}

Bosc, Mss., p. 23, pl. 4, fig. 5.- Аввот, p. 11 du Mss., fig. 89 à 90. - WaLcK., Tab. des Aran., p. 13 , n० 1; ibid., op. cit, t. I, p. 432. - Long. 9 lig. - Le céphalothorax est grand, presque aussi large que l'abdomen, entourẻ de poils blancs sur les côtés; les yeux de la seconde ligne sont plus rapprochés des antérieurs que des postérieurs; les mandibules sont d'un vert doré brillant, qui devient rouge à la partie antérieure; les palpes sont d'un fauve rougeâtre, garnis de longs poils blancs, qui couvrent les mandibules; les pattes sont courtes et robustes; celles de là première paire sont très-renflées; la première est la plus longue, la quatrième ensuite; la seconde est plus courte que la troisieme; ces pattes sont brunes, hérissées de longs poils fins; l'abdomen est ovale et plus large dans le milieu; il est noir en dessus, avec une tache blanche en croissant dans le milieu, et deux autres de même couleur sont près de la partie anale sur les côtés; les côtés et le dessous sont entourés de poils blancs très-longs, beaucoup plus courts vers le céphalothorax, et formant là un demi-cercle : on aperçoit entre ce demi-cercle et le croissant, ou tache triangulaire, six points blancs disposés sur deux lignes, et se rapprochant pour former un angle dont la pointe est tournée vers le céphalothorax; le dessous est noir, avec les cốtés blancs. - Se trouve dans la Caroline.

\section{0. attus vaniegatus.}

Salticus Variegatus, Lucas, Ann. de la Soc. Ent. de France, t. II, p. 478, pl. 13, fig. $a, b,-$ Long. 5 lig. $\frac{1}{2}$. Le céphalothorax est brun, parsemé de long poils noirs, avec deux taches formées de poils blanchâtres sur les côtés latéraux ; les mandibules sont dilatées extérieurement, arrondies à leur extrémité, et remarquables par leur belle couleur métallique, qui est d'un vert cuivré; les crochets des mandibules sont bruns, en forme de croissant et trèsaigus à leur extrémité ; les mâchoires sont 
brunes, ovales, terminées en ligne droite à leur extrémité ; les palpes sont courts, avec le premier article parsemé de poils blancs, et ceux qui suivent recouverts de poils noirs; les pattes sont robustes, allongées, surtout la première paire, qui est la plus Iongue, la quatrième ensuite, la seconde après, la troisième est la pluscourte; ces pattes sont noires, hẻrissées de long poils, avec les derniers articles annelés de taches formées par des poils blancs; l'abdomen est court, aplati, étroit et tronqué antérieurement, terminé en pointe postérieurement, plus large dans son milieu, qui offre une belle tache formée par des poils blancs, serrés entre eux, et qui est séparée par une foible ligne qui est de couleur brune; en dessus il est entièrement noir. - Cette espéce a été trouvée à la NouvelleOrléans.

Les espèces qui ont été désignées dans ce mémoire sous le nom générique de Salticus doivent être maintenant dénommées sous celui d'Attus.

\section{ATtUS PUICHER.}

Аввот, fig. 201, p. 18. - WALCK., op. cit., t. I, p. 439. - Long. 8 lig. Le céphalothorax est carré, large, d'un blanc-jaunâtre, avec une figure noire sur le milieu; les mandibules sont vertes, recouvertes de poils blancs à leur partie antérieure; les paltes sont courtes, d'un fauve jaunâtre pâle; l'abdomen est ovale, gros, renflé, d'un blanc-jaunâtre ou fauve pâle à la partie antérieure, mais d'un rouge fauve dans le dernier tiers de la partie postérieure; au milieu du dessus est une figure disposée longitudinalement, qui est brune, resserrée dans son milieu; au milieu de la partie large est une grande tache jaune, et au-dessus, en dehors de la figure, sont deux ronds ovales jaunes. inclinés l'un vers l'autre; de chaque côté de la tache brune, vers la partie anale, le dessus est d'un beau rouge orangé. - Se trouve en Géorgie.

12. Attus photenves.

Аввот, fig. 402 , p. 32 . - WАLск. op. cit., t. 1, p. 443 . - Long. 5 lig. Le céphalothorax est court, carré, brun dans le milieu, entouré sur les côtés et à la partie postérieure d'une large bande blanche, de sorte que le milieu brun du céphalothorax simule la figure d'un vase; les palpes sont de couleur orangée, avec le dernier article d'un noir pâle; les pattes sont annelées de fauve orangé et de brun; la paire antéricure a les cuisses renflées et noires, le reste annele de fauve orangé et de brun. - Se trouve en Géorgie.

\section{ATTUS PEREGPINUS.}

Аввот, fig. 409 , p. 33. - W АLск., op. cit., t. 1, p. 445, - Long. 5 lig. Le céphalothorax est grand, carré, d'un blanc-jaunâtre sur les côtés, noir dans le milieu; la partie noire s'évasant vers les yeux et se rétrécissant vers l'abdomen; les palpes sont blancs, avec le dernier article noir, ovalaire et crochu; les pattes sont blanches, finement annelées de points noirs; l'abdomen est orale, un peu renflè vers la partie postérieure, noir dans le milieu, avec quatre taches d'un rouge orangé, disposées en carré; la partic antérieure, proche le céphalothorax, est bordée d'une large raie d'un blane-jaunâtre, en demicercle; sur les côtés de la partie postérieure est une tache d'un blanc-jaunâtre, et une autre d'un rouge sanguin, tachée ellemême d'uu point noir, taches qui resserrent et diminuent en la festonnant la figure noire du milieu; en dessous, l'abdomen est entierrement noir. - Se trourc en Géorgie.

\section{ATtUOS DissimLiator.}

Aввот, fig. 408 , p. 33 . - Walck., op. cit., t. I, p. 453. - Long. 5 lig. $\frac{1}{2}$. - Le céphalothorax est noir, carré, trèsgros; les mandibules sont très-renfoncées sous le céphalothorax, et d'un vert foncé ; les palpes sont entierement noirs; les deux derniersiarticles arrondis, moniliformes; l'abdomen est ovale, un peu renflé vers sa partie postérieure, à dessus d'un rouge orangé sur les côtés, et en devant, au milieu, une figure d'un vert doré, longitudinale, resserrée dans son milieu; dans cette partie étroite est une tache rouge, carrée, qui se partage en deux; vers la partie postérieure sont quatre points ou taches d'un rouge plus pâle, en carré, et a la partie antérieure deux taches d'un rouge pâle; le dessous de l'abdomen est entièrement noir.- - Se trouve en Géorgie.

\section{ATTUS CIIRYSIS.}

Walck., Tab. des Aran., tab. 25, n० 34; ibid., op. cit., t. I, p. 454. - Long. 5 lig. - Le céplalothorax est très-large et trés. épais à sa partie antérieure, d'un vert doré, rouge, brillant, et d'un éclat métallique; les yeux latéraux de la première ligne sont si reculés, qu'on pourroit les considérer comme étant sur une ligne distincte àes deux yeux intermédiaires; ces yeux lutéraux étant considérés comme les extrémi- 
tés courbẻes en arrière de la première ligne, les yeux de la seconde sont plus rapprochés de cette ligne antérieure que de la postérieure; les mandibules sont coniques et portées en avant; les mâchoires sont droites, peu dilatées à leur's extrémitês; la lèvre est ovale, mais échancrée et coupée à son extrémité; les palpes sont allongés, bruns, fins, noirâtres, terminés par un digital dont la cupule est épzisse, courte, cylindroìde, et comme tronquée à son extrémité ; le conjoncteur est divisé en deux, et a la forme d'une agrafe; les pattes sont peu allongèes; la quatrième paire est plus longue que la première, la seconde ensuite, la troisième est la plus courte; l'abdomen est petit, conique, très-pointu vers la partie anale, avec six points enfoncés sur le dos. - Se trouve à la Caroline.

\section{ATtUS GaLATHEa.}

Walck., Tab. des Aran., p. 23, n० 4 ; ibid. , op. cit., t. I, p. 456. - Aranea Galathea, Bosc, Mss., p. 22, pl. 1, fig. 4. Аввот, Georg. Spid., fig. 405, p. 32. Long. 2 lig. - Le céphalothorax est épais, étroit, presque cubique, avec quatre taches plus foncées; les mandibules sont brunes et robustes; les palpes et les pattes sont de couleur pầle, annelés de brun, velus en dessus ; l'abdomen est ovale, allongé, avec le dessous couvert de poils gris, mêlés de poils noirs, ayant lwit taches blanches, les quatres antérieures inclinées longitudinalement, les quatre postérieures transversales; sur les côtés, on aperçoit deux ou trois autres petites taches de même couleur, mais beaucoup plus prononcées; en dessous, il est d'un brun pầle, avec une bande brune longitudinale, noirâtre dans le milieu. - Cette espèce habite la Caroline et la Géorgie.

\section{ATTUS SPIENDiDUS.}

Walck., Tab. des Aran., p. 25, n० 33 ; ibid., op. cit., t. I, p. 458. - Long. 3 lig. $\frac{1}{2}$. - Les yeux de la seconde ligne sont beaucoup plus rapprochés des yeux postérieurs que des antérieurs; les palpes sont courls, revêtus de poils blancs; les pattes sont courtes, noires et blanches, avee les postéricures beaucoup plus longues; l'abdomen est peu allongé, à côtés paralléles et droits, formant un carré long, aplati, avec la couleur du fond vert d'ean, et brillant d'un éclat métallique; la partie postéricure présente deux lignes vert-pré transfersales; surmontées de deux ronds de même couleur; il y a six taches d'un rouge vif dans le carré postérieur que des. sinent les deux lignes transversales; trois lignes longitudinales dans le carré de la partie antérieure, les deux latérales rouges, l'intermédiaire noirâtre, et rouge seulement à la partie antérieure; en dessous l'abdomen présente des lignes courbes alternativement orangées et rouges, disposées longitudinalement. - Elle a été trouvée à Timor.

\section{ATTES URVILLET.}

WaLcK., op. cit., १. I, p. 459. - Long. 5 lig. $\frac{1}{2}$. - Le céphalothorax est noir, trèsbombé, rhomboïdal, au moins aussi large que l'abdomen; les yeux sont blancs; ceux de la seconde ligne sont placés plus près des yeux antérieurs que des yeux postérieurs, et derrière les latéraux antérieurs on aperçoit une petite gibbosité, qui est glabre; les mandibules sont courtes, glabres, d'un brun-marron, avec les crochets d'un rouge clair; la lèvre et les mâchoires sont noires, bordées de rouge; les pattes sont assez allongées, noires, à extrémité rougeâtre ; les deux paires antẻrieures plus grosses et plus renflées; ces pattes sont sensiblement inégales entre elles; la troisième paire est visiblement plus Jongue que les autres, la quatrième ensuite, la seconde est de beaucoup plus courte; l'abdomen ovale, allongé, se rétrécit à sa partie antérieure; en dessus, il est d'un noir brillant, avec une bande courbe transversale, à poils irisés, et à reflet métallique, formant une ligne fine près du céphalothorax et s'ẻlargissant peu sur les côtés; on aperçoit aussi une autre raie transversale, plus étroite que la première, plus blanche, irisée, élargie sur les côtés en deux taches blanches triangulaires; il y a deux petits traits fins, inclinés, à la suite de cette bande et près des filières; en dessous, il est noir, recourert de poils gris, courts. - Se trouve à la Nouvelle-Guinée.

\section{ATtus DIARDr.}

WaLcK., op. cit., t. I, p. 460 . - Long. 5 lig. - Le cẻphalothorax est noir, carré, large, moins long que l'abdomen, entouré de poils jaunes sur les côtés, proche des pattes, et sur les côtés en dessus; les yenx de la seconde ligne sont plus rapprochés de ceux des antérieurs que des postérieurs; il y a des poils jaunes, allongès, qui bordent le front au-dessous des yeux; ces yeux sont d'un jaune pâle, el entourés de poils 
d'un rouge-jaunâtre cuivré, à reflet métallique; les mandibules, d'un brun foncé rougeâtre, sont bombées, saillantes, et héríssées de poils jaunes à leur insertion; la plaque sternale et la lèvre sont velues, couvertes de poils jaunes, ainsi que les mâchoires, qui sont verdâtres à leur extrémité; les palpes sont filiformes, hérissés de poils blancs; les pattes sont courtes, robustes; la première paire est la plus allongée, avec la quatrième surpassant à peine la troisième paire; la deuxième est la plus courte de toutes; l'abdomen est ovale, allongé, renflé à sa partie postérieure, à fond d'un brun-noirâtre, avec un demi-cercle de poils jaunes entourant la partie antérieure, proche le céphalothorax et les côtés; de plus, ayant dans le milieu deux raies légérement courbées, de couleur jaune-roux, opposées par leur côté convexe; deux autres raies inclinées, avec un chevron à la suite, et deux petites courbes, d'un jaune vif, à la suite des chevrons, immédiatement au-dessus des filières, opposées par leur côté concave; en dessous, il est brun, avec une ligne longitudinale plus brune dans le milieu, et deux plus jaunes et larges de chaque côte. - Elle a été trouvée en Cochinchine.

\section{ATTUS TARDIGRADUS.}

WaLck., Faun. franc., p. 61 ; n० 25 , pl. 5, fig. 10 ; ibid., Hist. nat. des Aran., fasc. 5, pl. 4. - Ibid. op. cit., t. 1, p. 461. - Salticus Rumphii, H $\mathbf{A H N}_{\text {, Die }}$ Arachn. , t. 1, p. 56 , pl. 45 , fig. 42. - Le céphalothorax est aplati, plus large que l'abdomen, et s'élargissant beaucoup antérieurement; il est noir tout à l'entour, près des pattes, avec deux bandes ovoïdes sur les côtẻs, pointues antérieurement, ets'élargissant graduellement postérieurement; les yeux du milieu de la ligne antérieure sont verts, et beaucoup plus gros que les latéraux, qui sont rougeâtres; les mandibules sont courtes, brunes; la lèvre est plus haute que large, arrondie en pointe à son extrémité; les mâchoires sont très-arrondies par le bout. brunes et d'un fauve rougeâtre sur les hords; les palpes sont trèsvelus, et se replient sur les mandibules; ils sont d'un fause clair, avec des poils noirs très-longs; la plaque sternale est brune. velue; les pattes sont courtes; la première paire est plus grosse que les autres, et a les cuisses renflées, très-velues en dessus, annelées de faure et de noir, avec un grand nombre de poils el d'ćpines noirs, qui dé- passent les autres; en dessous, les hanches sont d'un blanc-rougeâtre couleur de chair, sans poils, ainsi que le commencement des cuisses, où l'on remarque des poils rares, gris, conrts ; les pattes antérieures sont plus grosses, et ont les cuisses renflées; la quatrième et la première pairc sont presque égales entre elles, de même que la seconde et la troisième; mais cependant la quatrieme paire est la plus longue de toutes, ét la seconde est la plus courte; la première paire surpasse sensiblement la troisieme; l'ablomen est ovale, allongé, plus gros vers le céphalothorax, varié de poils fauves, rouges et noirs, avec une bande grise longitudinale dentelée sur les côtés, et des poils noirs plus longs que les autres; les côtés de l'abdomen et mème du dessous sont noirs, avec le milieu de ce dernier d'un gris rougeàtre, mouchelé de petits points noirs. - Cette espèce se trouve assez communèment aux environs de Paris.

\section{ATtUS CYLINDRICUS.}

WaLCK., op. cit., t. I, p. 464. - Long. 5 lig. $\frac{1}{2}$. - Le céphalothorax est allongé, d'un brun-rougeâtre, mais beaucoup plus foncé entre les yeux; ces derniers sont de couleur jaune, et ceux de la seconde ligne sont beaucoup plus rapprochés des antérieurs que des postérieurs; les mandibules sont hérissées de longs poils jaunes; les mâchoires, d'un jaune pâle, sont droites, parallèles, arrondies, mais peu dilatées à leur extrémité ; la lèvre, de même conleur que les mâchoires, est allongée, triangu. laire, et terminée en pointe arrondie; les palpes sont peu allongés, dilatés, ovalaires, velus en dessous, et ne présentent aucune trace de conjoncteur; ils sont d'un jaune pâle uniforme en dessous; les pattes, peu allongées, sont rouges, annelées de brun; la premiere paire, qui est plus courte que la quatrième, est renflée et plus fortement annelée; la seconde paire est ensuite plus allongée; la troisième est la plus courte de toutes ; l'abdomen est très-allongé, cylindrique, d'un brun obscur en dessus; le dessous et les côtés sont jaunâtres, avec une bande longitudinale; les ouvertures stig. matiformes ct la plaque qui recouvre les partics sexuelles sont d'un blanc bruni, mais a éclat argenté; de plus, on aperçoit une suite de petits points nombieux, disposés sur deux lignes parallèles. - Cette espèce a été trouvée à la Guiane.

22. ATTUS DEREESGUS.

Walck., Aran. de France, p. $69, \mathrm{n}^{\circ} 33$; 
Araigree aplatie, ibid, Faun, Paris., t. II, p. 242, n $^{\circ} 112$; ibid., op. cit., t. I, p. 469 ; Atte aplalie, ibid., Tab. des Aran , p. 27, $\mathrm{n}^{\circ}$ 46. - Long. 1 lig. $\frac{\mathrm{I}}{\mathrm{s}}$. - Le céphalothorax est aplati, arrondi, brun, couvert de poils fauves, moins long et moins large que l'abdomen, avec deux lignes d'un fauve obscur, courtes à la partie postérienre, qui fait suile à celle de l'abdomen; les pattes sont courtes; la première paire présente la jambe brune et le tarse blanc; les suivantes sont blanches, avec une raie brune longitudiuale qui court le long de la cuisse et de la jambe ; l'abdomen est aplati, peu allongé ; il s'élargit et s'arrondit vers la partie anale, ensuite il est coupé en droite ligne près du céphalothorax; sa partie supérieure est d'un rouge sale ; mais antérieurement on aperçoit deux lignes longitudinales $d$ 'un fauve clair, qui se terminent vers le milieu de la partie supérieure, ou le dessus, par deux crochets de couleur noire : à l'exception de cette ligne, toute cette partie antérieure jusqu'aux crochets est d'une couleur plus foncée que la partie postérieure; le dessotis est rougeâtre, et marqué de brun vers la partie anale. - Cette espece qui, au premier aspect, ressemble à une petite punaise des bois, se trouve aux environs de Paris.

\section{DEUXIEME GROUPE.}

\section{Lcs Voltigeuses, WaLck.}

Les paltes sont allongées, de grosseur médiocre, propres à la course et au saut. - Les palpes sont allongés, filiformes; le dernier article à digital peu renflé dans les mâles, et un peu dilaté dans les femelle.

23. attus Fonmicanius. (Pl. 5, fig. 3.)

WaLck., Aran. de France, p. $62, \mathbf{n}^{\circ} 27$, pl. 5, fig. 1. la femelle; fig. 2 a 3, le mâle; ibid., op. cit., t. I, p. 470. - L'Araignée fourmi, DegéER, Mém., t. VII , p. 293 , $\mathrm{n}^{\circ} 29$, pl. 18 , fig. 1 à 2 , la femelle. Long. 3 lig. - Le céphalothorax est allongé, aussi large que l'abdomen, plus court cependant que lui, noir dans toute sa partie antérieure et dans la partie où sont placés les yeux, et d'un rouge clair uniforme postérieurement: on apercoit une bande transverse de blanc très-vif entre.] deux yeux postérieurs, qui sépare le carré noir de la partie antérieure de la portion rouge-clair, qui est la partie postérieure; cette dernière partie est encore séparée de l'autre par une sorte d'incision; les yeux de la seconde ligne sont plus rapprochés de la ligne des antérieurs que des yeux postérieurs; les mandibules sont rougeâtres; les palpes sont courts, avec les deux premiers articles de couleur rougeâtre; les autres sont bruns et garnis de poils; le dernier article est très-dilaté dans les femelies; les pattes sont allongées, rousses, avec quelques taches noires; la quatrième paire est la plus allongée, la première après, la troisieme ensuite, la seconde est la plus courte ; l'abdomen est allongé, fusiforme, grossissant légérement vers la partie anale; sa moitié anlérieure est d'un fauve rougeâtre, avec deux bandes transversales brunes, formant des chevrons disjoints; la moitié postérieure est noire.

Le mâle diffère de la femelle par ses mandibules, qui sont aplaties, dirigées en avant, presque aussi longues que le céphalothorax; par son abdomen, qui est plus court; et par les couleurs, qui y sont plus vives et beaucoup plus tranchées, tandis qu'au contraire la partie an térieure du céphalothorax est moins noire.

Cette espèce, qui se trouve aux environs de Paris, a tout-à-fait le faciès d'une fourmi. Elle se retire sous les pierres et dans les cavités des arbres; elle construit une petite coque de soie blanche ouverte par les deux bouts, dans laquelle elle se loge, et qu'elle quitte dès qu'elle se voit découverte, en glissant par terre au moyen d'un fil de soie attaché à sa partie anale.

\section{ATtus Venator.}

Lucas, Mag. de Zuol., cl. 8, pl. 15. Walck., op. cit., t. I, p. 471. - Lòng. 1 lig. $\frac{1}{2}$. - Le céphalothorax est bronzé antérieurement, avec sa partie antérieure lẻgérement noirâtre; sa forme est celle d'un carré allongé, qui, antérieurement et supérieurement, seroit entièrement plan, avec sa partie postérieure arrondie el déprimée; les yeux diffèrent entre eux, en ce que la première paire est la plus grosse, la seconde ensuite; la troisième est trèspetite, et la distance qui la sépare de la seconde paire est moins grande que celle qui la sépare de la quatriẻme paire, qui est un peu plus saillante que les autres; les mandibules sont d'un jaune sale; peu allongées; les palpes sont peu allongés, d'un jaune clair, avec le dernier article légérement renflè et hérissé d'épines, surtout à la base; les autres articles sont d'un jaune clair, et couverts de poils de même couleur; les pattes sont pen allongées; la quatrième 
paire est plus courte que la première, la troisième ensuite; la seconde est la plus courte de toutes : ces pattes sont généralement d'un jaune clair; l'abdomen est allongé, fusiforme, ovale, de couleur noire antérieurement et postérieurement, roussâtre dans sa partie médiane, qui est étranglée transversalement, et sur lequel étranglement on aperçoit une bande blanche se rétrécissant dans son milieu, mais s'élargissant à ses deux extrémités; en dessous il est roussâtre antérieurement et postẻrieurement, ensuite d'un jaune clair au milieu; les filières sont jaunâtres, peu allongées, hérissées de poils de même couleur.

Le mâle diffère de la femelle, en ce qu'il est plus allongé et plus étroit, et en ce que ses pattes antérieures sont un peu plus longues et beaucoup plus robustes; les palpes sont moins allongés; l'abdomen est plus allongé et plus étroit, et la bande blanche qu'on aperçoit dans sa partie médiane est bien plus marquée, et l'étranglement bien plus apparent que chez la fe. melle.

Nous avons trouvé pour la première fois cette espèce dans les îles de la Marne, près Charenton; depuis, nous l'avons prise sous les écorces des pins au Jardin des Plantes, ensuite à Villeneuve-Saint-Georges, et dans les bois de Meudon et de Vincennes. Sa démarche est très-vive. Au premier abord, nous l'avions prise pour une fourmi, et ce n'est qu'à ses mouvemens brusques et prompts que nous nous aperçumes que c'étoit une Aranéide.

A ce groupe appartientl'Attus Gueriniz, Lucas, espèce très-remarquable, qui a été trouvée par M. Guérin dans les bois de Meudon, et qui a été figurée par ce même naturaliste dans son Iconographie du Règ. anim. de Cuv., Arash., pl. 2, tig. 2.

\section{ATTUS LEPIDUS.}

Guér., Mag. de Zool., cl. VIII, pl. 7.WALcK., op. cit., t. I, p. 478, - Long. 3 lig. $\frac{\mathrm{I}}{2}$. - Le céphalothorax est grand, large, long, carré a sa partie supérieure, rélréci et arrondi à sa partie postérieure, de couleur noirâtre; les yeux de la seconde ligne sont plus rapprochés des yeux postérieurs que des yeux antérieurs; les mandibules sont coniques, recouvertes de poils brillans, d'un vert-bleuâtre argenté irisé ; les pattes sont allongées, inégales; la troisième paire est la plus allongée, la première est presque aussi longue qu'elle, la quatrième est la plus courte; les pattes antérieures sont renflées; l'abdomen est petit, ovale, arrondi, d'un jaune soyeux, garni vers les bords d'écailles métalliques d'un doré verdâtre à reflets argentés. - Se trouve au port Doey, dans la Nouvelle-Guinée.

\section{T'ROISIENHE GROUPE.}

\section{Les Longimanes, WaLCK.}

Les pattes sont allongées, égalant près de trois fois la longueur du corps, dont les articles se replient les uns sur les autres, et dont le fémoral est dilaté en forme de rame.

\section{6. atTuS PHRINOIDES.}

WaLc., op. cit., t. I, p. 479, pl.12, fig. $1 d$. - Long. 4 lig. - Le céphalothorax est aussi long et aussi large que l'abdomen, très-relevé vers la partie antérieure, déprimé à la partie postérieure, et hérissé de poils fauve dorẻ; les yeux sont de couleur d'ambre jaune; ceux de la seconde ligne sont un peu plus près des yeux antérieurs que des yeux postérieurs; les palpes sont peu allongés, relus, avec le dernier article ovalo-cylindrique, peu renflé, et muni d'un conjoncteur aplati; les mandibules sont courtes, rougeâtres, creusées à leur insertion, et très-bombées à leur extrẻmitẻ, comprimées sur les côtés et en dessous, et ayant un crochet court, qui s'enfonce assez profondement dans la rainure ; les mâchoires sont droites, allongées, écartées, peu dilatées à leur extrémité, mais à bords extérieurs plus courbes que les côtés internes, hérissées de poils fauve doré; la lèvre est allongée, un peu élargie dans son milieu, tronquée en ligne droite à son extrémité. d'un brun-rougeâtre, recouverte de poils fauve doré; les palpes sont rougeâtres; les pattes sont de même couleur, très-allongées, surtout les antérieures; l'abdomen est allongé, ovalo-cylindrique, d'un brun-fauve uniforme, tant en dessus qu'en dessous, recouvert de poils fauve doré. - La patrie de cette espèce est inconnue.

\section{QUATRIEME GROUPE.}

\section{Les Caudées; Walck.}

Les filières supérieures sont très-allongées.

27. ATtus Bos.

Sund., Consp. Arachn. Lond. Goth., 8833 , p. 27. - WALCK., op. cit., t. $I_{3}$ 
p. 480. - Le céphalothorax est grand, arrondi, convexe, pourvu de deux cornes, formées par huit à dix soies, arquées, qui s'èlèvent verticalement de dessous les petits yeux latéraux de la seconde ligne; le céphalothorax et l'abdomen sont entourés par une bande de couleur blanche. - Se trouve au Bengale.

\section{SIXIEMIE SOUS-SECTION.}

\section{Les Marcheusbs, WaLcK.}

Marchant de côté et en arrière; et tendant occasionellement des fils pour attraper leur proie.

\section{DELENA, WALĆK. ; \\ Thomisus, ejusd.}

Les yeux, au nombre de huit, sont presque inégaux entre eux, placés sur deux lignes, rapprochées sur le devant du céphalothorax, et dilatées transversalement. La lèvre est large, carrée, échancrée ou coupée en ligne droite à son extrémité. Les mâchoires sont droites ou légérement écartées, et divergentes à Jeur côté interne, inclinées sur la lèrre, qui est arrondie. Les pattes sont de longueur inégale; les antérieures sont les plus longues. - Les mœurs nous sont inconnues.

Ce genre a été établi par M. Walckenaer aux dépens de celui de Thomisus, et renferme environ cinq ou six espèces, qui ont été divisées en cinq groupes.

\section{PREMIER GROUPE.}

\section{Les Cancérides, WaLcK.}

Le céphalothorax est aplati. - Les man. dibules sont renflées à leur naissance, courtes et cunéiformes. - La lèvre est courte. - Les mâchoires sout courtes, inclinées. Les yeux intermédiaires antérieurs sont plus rapprochés entre eux que les intermédiaires postérieurs. - Les pattes de la seconde paire sont les plus longues.

\section{DELEYA CANCERIDFS.}

WaLCK., op. cit., t. I, p. 490. - Thomisus Cancerides, ibid., Tab. des Aran., p. 29, pl. 4, fig. 29 et 30. - Long. 14 lig. - Le céphalothorax est très-aplati, plus large et moins long que l'abdomen, avec une fossette très-profonde dans le milieu, et deux sillons en forme de $\mathrm{V}$ dessinant la partic antérieure; la région où sont placés les yeux est noire; les mandibules sont fortes, très-larges, dirigées en avant, bombées, glabres à leur naissance, avec des poils roux vers leur extrémité; de plus, elles sont courtes et cunéiformes; les mâchoires sont rougeâtres, fortes, inclinées, en carré long, coupées en ligne inclinèe à leurs côtés internes, et légérement dilatées à leur insertion; la lèrre, de même couleur que les mâchoires, est large et coupée en ligne droite à son extrémité ; les pattes antérieures sont légérement plus grosses que les postéricures; les deux paires postérieures diffèrent peu de la première pour la longueur, mais la seconde paire est beaucoup plus longue que les autres; l'exinguinal, le fémoral, le génual et le tibial sont rougeấtres et armés d'ćpines; le métatarse et le tarse sont garnis à l'intérieur de poils noirs serrés en forme de brosse, qui est plus dense et plus compacte à l'extrémité des pattes; l'abdomen est ovale, allongé, coupé en ligne droite à sa partie antérieure, plus élargi à sa partie postérieure, déprimé, de coulenr fauve, entouré sur les côtés et en devant de lignes noires qui forment un carré ; de plus, en dessus on apercoit cinq ou six points noirs, disposés en triangle isocèle. - Celle espéce a été trouvée dans. l'ŝle de Van-Diémen.

\section{DEUXI}

\section{Les Plaguses, Walck.}

Le céphalothorax est aplati. - Les mandibules sont renflées et bombées dans leur milieu. - La lèvre est allongée. - Les mâchoires sont courtes, allongèes, rétrécies à leur base, écartées et très-divergentes à leur extrémité. - Les yeux intermédiaires sont rapprochés. - La seconde paire de pattes est la plus longue.

\section{DELEYA PIAGESIA.}

WaLcK., op. cil., t. I, p. 492 . - Thomisus Plagusius, ibid., Tab. des Aran. , p. 29. - Long. 11 lig. - Le céphalothorax est brun; les mandibules sont très-bombées, courtes, noires, luisantes; les mâchoires sont arrondies à leur côté externe, et pointues à leur extrémité ; l'abdomen est ovale, allongé et déprimé. - Cette espèce a été trouvée au Port-Jackson.

\section{TROISIBITE GROUPE.}

\section{Les Crabroüdes, WaLcK.}

Le céphalothorax est aplati. - Les mandibules sont courtes, cunéiformes et non 
renflées. - La lèvre est aussi haute que large, échancrée à son extrémilé. - Les mâchoires sont écartees, mais légérement courbées sur la lèvre. - Les yeux intermédiaires antérieurs sont plus gros que les autres, et plus écartés que ne le sont entre cux les intermédiaires postérieurs: - La seconde paire de pattes est la plus longue.

\section{DELENA CRABRoIDES.}

WALCK., op. cit., t. I, p. 492. - Long. 8 lig. - Le céphalothorax est rougeâtre, arrondi, aussi large, mais beaucoup moins long que l'abdomen; les mandibules sont noires, courtes, coniques; les mâchoires et la lèvre sont rougeâtres, la plaque sternale est rougeâtre et cordiforme ; les pattes sont de longueur médiocre; mais les postérieures sont sensiblement plus courtes que les antérieures; après la seconde paire, c'est la première qui est la plus longue; la troisième est la plus courte de toutes; l'abdomen est ovale, aplati, allongé et à côtés parallèles; la partie antérieure, ou celle qui est près du céphalothorax, est coupée en ligne droite, avec le dessus mélangé de gris et de brun, mais irrégulièrement, par la présence de trois bandes brunes longitudinales et parallèles, avec des raies brunes transverses; le dessous est d'un fauve pâle. - Se trouve à la Nouvelle-Hollande.

\section{QUATRIEME GROUPE.}

\section{Les Forcipulées, WaLcK.}

Le céphalothorax est bombé.-Les mandibules sont fortes, allongées, cylindriques. - La lèvre est allongée, carrée. - Les mâchoires sont rétrécies à leur base, inclinées sur la lèvre, et courbées ou dilatées à leur extrémité interne. - Les deux premières paires de pattes sont presque égales, mais la première surpasse un peu la seconde en longueur.

\section{Delena peronianus.}

WaLGK., op. cit., t. I, p. 493. - Long. 13 lig. - Le céphalothorax est bombé, cordiforme, plus large et presque aussi long que l'abdomen, entouré d'une bande orangé vif, et de poils de même couleur dans la partic où sont placés les yeux; les ycux sont sessiles, gros; ceux de la ligne antérieure sont rapprochés entre eux; les latéraux antérieurs sont un pcu plus gros que les autres; ccux de la ligne postérieure sont égaux ; les pattes sont ruugeâtres, couvertes de poils fauves; la quatrième paire est la plus longue; la troisième ensuite; la plaque sternale est ovale, velue, hérissée de poils fauve-rouge ; l'abdomen est ovale, allongé, coupé en ligne droite à sa partie antérieure, diminuant vers'la partie anale, qui est d'un fauve dorć uniforme en dessus et en dessous.- - Habite la Nouvelle-Hollande.

\section{GINQUILME GROUPE}

\section{Les Renflées, WaLcK.}

Le céphalothorax est renflé, globuleux. - Les mandibules sont cunéiformes. aplaties. - La lèvie est arrondie, dilatée, resserrée à sa base. - Les mâchoires sont droites, écartées, resserrées ì leur insertion, arrondies à leur côté externe, tronquèes et divergentes à l'extrémité de leurs côtẻs internes. - Les yeux intermédiaires sont plus petits que les autres, et les intermédiaires antérieurs sont plus rapprochés que ne le sont entre eux les intermédiaires postérieurs.

\section{DELENa hastifGRA.}

WALCK., op. cit., t. I, p. 495. - Epeira Hastifera, Perch., Mag. de Zool., cl. 7, pl. 4. - Guér., Icon. du liég. anim. de Cuvier, Arachnides. - Long. 3 lig. - Le céphalothorax estrouge glabre, semi-globuleux, luisant; les yeux sont noirs et saillans, placés sur deux lignes formant un croissant étroit et très-étoilè ; les mandibules sont ron. ges etsontà leur base coupées en ligne droite; les mâchoires sont très-rétrécies et trèsbombées à leur insertion; elles sont rougeâtres ainsi que la lèvre; les palpes sont très-courts, de couleur noire; les pattes sont très-inégales, glabres, assez allongées; le fémoral est cylindrique, d'un brun-noir; le génual est renflé, noir; le tibial et le métatarse sont fauve-rougeâtre à la seconde paire, et noir aux pattes postérieures; l'ab. domen est très-déprimé et orné de couleurs vives; en dessous il est aplati. - La patric de cette espèce est inconnue.

\section{ARKYS, WALCK.}

Les yeux sont au nombre de huit, pres. que égaux entre eux, placés sur deux lignes occupant le devant du céphalothorax et ainsi disposés : les quatre intermédiaires forment un quadrilatere ; les latéraux écartés sur les côtés de la tête et rapprochés entre cux.-La lèvre est courte, arrondie à son extrémité et légérement étranglée à sa base. - Les mâchoires sont allongées, 
inclinées sur la lèvre, cylindriques, arrondies à leur extrémité, et légêrement creusées sur leur côté interne. - Les pattes sont allongées, étendues latéralement ; les deux paires antérieures sont beaucoup plus grosses et plus allongées que les postėrieures; la première paire est la plus longue, la seconde ensuite, et la troisième est la plus courte. - Les habitudes de ces Aranéides nous sont inconnues.-L'espéce type de ce genre est :

ankys Lavceanius. (Pl. 5, fig. 4.)

WALCK., op. cit., t. I, p. 497. - Long, 4 lig. - Le céphalothorax est fauve, rougeâtre, large, divisé par un étranglement ou sillon transversal; les yeux intermédiaires d'en bas sont plus petits et plus rap: prochés que ceux d'en haut; les deux latéraux sont très-écartés des intermèdiaires, très-rapprochés entre eux, et placés dans les angles antérieurs du cèphalothorax; la lèvre et les mâchoires sont rouges; les pattes sont armées d'épines; les postérieures sont grêles, courtes et ne présentent ni poils ni piquans; l'abdomen, d'un fauve foncé, est court, large, et creusé à sa partie antérieure, qui est renflée ct arrondie sur les cộtés, et diminue rapidement en pointe à sa partie postérieure, ayant la forme régulière d'un cœur, à bords ornés à l'entour de sa moitié antérieure de petites taches rondes, d'un jaune pâle, au nombre de seize environ; trois autres taches rentrant dans le milieu; les deux plus externes, beaucoup plus grosses, forment le commencement de deux lignes longitudinales de dix taches jaunes (cinq de chaque côté), et qui se réunissent en forme d'angle vers la partie anale. - Se trouve à Rio-Janeiro.

\section{THOMISUS, WaLCK., LaTR.}

Les yeux, an nombre de huit, presque égaux entre eux, occupent le devant du céphalothorax, et sont placés sur deux lignes en croissant ou en segment de cercle. - La lèvre est grande, plus haute que large, triangulaire, et arrondie à son ex. trémité. - Les mâchoires sont allongées, inclinées sur la lèvre, conniventes à leur extrémité. - Les mandibules sont courtes, cunéiformes ou cylindroïdes. - Les pattes, articulées pour être étendues latéralement, sont trèsinégales entre elles; les deux paires postérieures sont sensiblement plus courtes que les deux paires antéricures.

Ces Aranéides marchent de côtẻ arec lenteur, épient leur proie, tendent des fils solitaires pour l'arrèter, et se cachent dans les feuilles qu'elles rapprochent pour faire leur ponte. Le cocon est aplati, et elles le gardent avec la plus grande assiduité.

Le genre Thomise est très-nombreux en espèces; $M$. Walckenaer, dans son ouvrage, en décrit plus de soixante. Ce genre parait être répandu sur toute la surface du globe; il a été divisé en dix groupes.

\section{PREMIER GROUPE.}

\section{Les Brevipèdes, WaLcK.}

Les yeux sont en segment de cercle; les quatre latéraux sont portés sur une saillie de la tête. - Les pattes sont courtes; les an. térieures sont les plus grosses, la deuxiène paire est plus longue que la première; la troisième est la plus courte. - Le céphalothorax est concave, semi-circulaire et légérement déprimé.

\section{ThOMISUS Rotundatus.}

Walck., Avan. de France, p. 71, n० 1 , pl. 6, fig. 4 ; ibid., Hist. nat. des Aran., fase. 2 , pl. 7 ; ibid., op. cit., t. I, p. 500 . - Thomisus Rotundatus, Sav. et Aud., Egypt., p. 166, pl. 7, fig. 34. - Aranca Globosa, Fabr, Ent. Syst., t. I1, p. 411, no 13. - Aranea Irregularis, P'Anz.-, Faun. Ins. Germ. fasc. 74, no 20. -Thomisus Globosus, Нану, Die Arachn., t. I, p. 24, tab. 9, fig. 28. - Long. 2 lig. $\frac{1}{2}$. Le cephalothorax et les mandibules sont noirs; cependant l'épistome et une partie des mandibules sont souvent d'un jaunebrun; l'exinguinal et le fémoral des patles antérieures sont renflés; toutes les pattes sont un peu velues; les quatre antéricures sont noires, avec le génual, - le tibial et les tarses entrecoupés de brun et de blanc jau. nâtre: les quatre dernières sont de cette dernière couleur, avec des taches d'un brun-noirâtre; mais dans certains individus toutes ces parties sont de couleur noire; l'abdomen est noir tant en dessus qu'en dessous; mais en dessus il est borde d'un cercle rouge, quelquefois jaune ou orangè, qui projette vers l'intérieur quatre lignes sinueuses et transversales de même couleur, et qui vont en décroissant vers la partie anale; souvent ce cercle rouge est un peu interrompu dans le milieu; le dessous est noir, arec des lignes transversales inclinées, rougeâtres. - Cette espèce se trouve assez communément aux environs de Paris sur les fleurs. 


\section{DEUXILNE GROUPE.}

\section{Les Obscures, WalcK.}

Les yeux sont en croissant; les quatre la. téraux sont portés sur des saillies de la tête; les antérieurs latéraux sont un peu plus gros que les autres. - Les pattes sont courtes; les antérieures sont plus grosses; la deuxième paire est plus longue que la première; la quatrième est la plus courte.

\section{THOMISUS FUCATUS.}

Walck., Aran. de France, p. 73, $n^{\circ} 4$; ibid., op. cit., t. I, p. 505. - Thomisus liobustus, Hahn, Die Arachin., t. I, p. 50, pl. 13, fig. 98, $a, A, C$. - Thomisus $O b$ scurus; ibid., Monogr., fasc. $7, \mathrm{pl} .4$, fig. C. - Aranea Fusco Marginata, DEGÉER, t. VII, p. 301, n ${ }^{\circ} 31$, pl. 18, fig. 23 et 24 . - Long. 4 lig. - Le céphalothorax est plus large postéricurement gu'antérieurement, avec une bande longitudinale rougeấtre, plus claire dans le milieu et s'élargissant vers la partie antérieure, de plus il est parsemé de grains noirs; les yeux sont petits, noirs; les deux latéraux antérieurs surpassant les deux autres en grosseur; les mandibules sont brunes, avec une tache rougeâtre; les måchoires sont étroites, très-inclinées, pointues à leur extrémité, et tachées de points noirs à leur base et à leur sommet; la lèvie est triangulaire; les pattes ont les hanches, l'exinguinal et le fémoral blanchâtres; mais les autres articles sont tachés de brun, avec des sinuosités noirâtres; l'abdomen est ovale, arrondi, un peu plus large à sa partie postérieure, rugueux, d'un brun uniforme, tant en dessus qu'en dessous. Le mâle diffère de la femelle en ce qu'il est ordinairement plus petit; en ce que les pattes et le céphalothorax sont d'une couleur plusfoncée, avec une raie plus claire, située à la partie antérieure et formée par des lignes qui entourent les yeux. - On trouve cette espéce assez communément aux environs de Paris ; son cocon est rond et aplati.

\section{TROISIENE GROUPE.}

\section{Les lianules, WalcK.}

Les yeux, en croissant, sont sur deux lignes parallèles; les intermédiaires des deux lignes sont écartés entre eux, et rapprochés des latéraux de manière à former deux trapézoïdes écartés l'un de l'autre; les deux yeux antérieurs sont plus gros et portés sur un tubercule. - Les deux paires de pattes antérieures sont renflées, beaucoup plus longues et plus grosses que les postérieures; la première surpassant trèspeu la seconde, et la quatrième surpassant aussi de très-peu la troisième. - Le cépha. lothorax est bombé.

\section{THOMISUS MAUGI.}

WaLck., op. cit., t. I, p. 507. - Long. 4 lig. - Le céphalothorax est d'un rouge brillant, non aplati sur les côtés; les mandibules sont cunéiformes, aplaties, noires, avec une grande tache rouge sur un côté; les palpes sont rougeâtres, à digital noir, mais peu rentlé; la plaque sternale est rouge; les cuisses et les jambes des deux premières paires de pattes sont noires; les tarses sont d'un jaune-blanchâtre, avec des piquans de couleur noire; l'abdomen est ovale, plus gros postérieurement, de couleur noire, avec une croix jaune ou rouge sur le milieu en dessus; sur la ligne transversale de la croix qui est près de la partie anale, on aperçoit deux points enfoncés très-distincts. - La patrie de çctte espèce est inconnue.

\section{QU ATRIENE GROUPE.}

\section{Les Hispides, Watck.}

Les yeux sont en croissant, très-anguleux, sessiles, avec les latéraux postérieurs très-reculés en arrière ; les latéraux antérieurs sont plus gros que les autres. - Les pattes sont courtes; les antérieures sont presque égales entre elles; la deuxième paire est la plus longue, la première ensuite, la troisieme est la plus courte.-Le céphalothorax est convexe et cordiforme. - L'abdomen est court, large, arrondi à sa partie postéricure, et hérissé de piquans.

\section{THомIsUs HIRTUS.}

Sav. et Aud., Descript. de l'Egypte, p. 164 , pl. 6 , fig. 11 , 1; le mâle; 11,2 , la femelle. - Latr., Dict. des Sc. nat., t. XXXIV, p. 40. - Thomisus Claveatus, WALGK., op. cit., t. I, p. 510. - Long. 1 lig. $\frac{x}{2}$. - Lie céphalothorax est petit, ragueux, arec cinq raies longitudinales obscures, alternativement fauves et brunes, dont la plus visible et la plus large est celle du milieu, qui est fauve; les yeux sont bruns; les latéraux postérieurs, plus pelits que les latéraux aniéricurs, sont plus 
gros que les internédiaires; les mandibules sont d'un fauve pâle, un peu rugueuses; les mâchoires, d'un fauve-brun clair, sont oblongues, cylindroïdes; la plaque sternale est ovale, d'un fauve clair ou brun, formant une sorte de rebord à la lèvre, qui est en cône allongé ; les pattes sont brunes, mélangées de fauve, hérissées de longs piquans; les antérieures sont renflées; l'abdomen est fauve, aussi large que long, cependant un peu plus large dans sa partie médiane, coupé en ligne droite, proche le céphalothorax et plus arrondi postérieurement que sur les côtés; la couleur du fond est fauve, mais il y a en dessus des poils robustes, cylindriques, noirs, courts, séparés $\mathrm{I}$ ar des intervalles réguliers; ces poils sont plus épais à leur extrémité, et sont placés sur des bandes brunes transverses, un peu festonnées, qu'on remarque sur le fond fauve; ces poils sont abondans surtout sur les côtés et vers la partie postérieure; de plus on apercoit six points enfoncés dans le milieu, dirigés parallèle. ment et transversalement. - Cette espèce habite l'Afrique et le midi de la France. Son cocon est aplati et de forme lenticulaire.

\section{CINQUIEME GROUPE.}

\section{Les Echancrées, WaLcK.}

Les yeux sont en croissant; les latéraux postérieurs sont portés sur des tubercules, les autres sont plus petits. - Les pattes sont courtes; les antéricures sont les plus grosses, la première paire est plus longue que la seconde; celle-ci surpassant en longueur la troisième, qui est elle-même plus longue que la quatrième.-Le céphalothorax est cordiforme.

\section{THOHISUS MARGIVATUS.}

Walck., Aran. de France, p. 74, n5; ibid., Faun. Paris., t. II, p. 230, n $^{\circ} 88$; ibid., op. cil., t. I, p. 512. - Le céphalothorax est moitié moins large et moins long que l'abdomen, fauve dans le milieu, noir sur les côtés, entouré de poils gris sur les bords; sa partie antérieure est velue, recouverte de poils fauves; les yeux latéraux sont en forme de pyramide, c'est-àdire portés sur les angles du céphalothorax; les suivans sont petits et cachés par des poils; les mandibules sont perpendiculaires, brunâtres, recouvertes de poils fauves; les palpes sont courts, filiformes, annelés de fauve et de noir, et armés d'épines de cette dernière couleur ; la lève est cordiforme, plus haute que large, un peu échancrée à son extrémité, ainsi que les mâchoires qui l'entourent ct qui la recouvrent; les pattes sont fauves, tachées de noir, surtout à l'exinguinal et au fémoral, qui sont armés d'épines assez fortes; l'abdomen est ovoïle, plus large postérieurement, cordiforme antérieurement, avec une échancrure ou un sillon au milieu de cette partie qui touche le céphalothorax; du milieu de ce sillon sort une petite touffe de poils blanchâtres, dont la pointe se dirige vers le céphalothorax; en dessus il est brun, avec des petites taches d'un vert pâle, figurant dans le milieu une pyramide allongée dont la pointe est tournéc vers la partic anale; sur les côtés sont des taches transverses de même couleur, formées par des petites lignes rapprochées entre elles; en dessous il est d'un gris-verdàtre, avec des taches longitudinales d'un brun-rougeâtre. - Se trouve aux environs de Paris.

\section{SIXIIME. GROUPE.}

\section{Les Crustacéides, WaLcK.}

Les yeux sont presque égaux entre eux et en croissant large. - Les pattes antérieures sont renflées; la première est la plus longue, la seconde ensuite, la troisième est la plus courte. - Le céphalothorax est cordiforme, convexe.-L'abdomen est très-large et arrondi postéricurement.-Le corps est enticiement rugueux.

\section{THOMISUS RUGOSUS.}

Walck., Tab. des Aran., p. 38, no 18 ; ibid., op. cit., t. I, p. 513. - LATR., Dict. des Sc. nat., t. XXXIV, p. 62. Long. 4 lig. - Elle est fauve, avec les deux pattes postérieures d'un jaune-rougeâtre, et le derme chagriné ou tuberculé. - Elle a été trouvée à l'île de France.

\section{SEPTII:ME GROUPE:}

\section{Les Malacostracéides, WALCK.}

Les yeux sont groupés sur une éminence du céphalothorax, en croissant resserré; les latéraux antérieurs sont sensiblement plus gros que les autres. - Le cephalothorax est aplati et cordiforme. — L'abdomen est oblong.

\section{THOMISUS MALACOSTRACEUS.}

W alck., Tab, des Aran., pl.5, fig. 31. 
el 32 ; ibid., op. cit., t. I, p. 513.- Latr. Nouv. Dict. d'Hist. nat., t. XXXIY, p. 42. - Long. 4 lig. - Le céphalothorax, les pattes et l'abdomen sont d'un jaunebrun; les tubercules, semblables à ceux du chagrin, dont tout le corps de cette espéce est couvert, sont aussi d'un jaunebrun mélangé; les cuisses de la prcmière paire de pattes sont trés-renflèes. - Se trouve à la Nouvelle-Hollande.

\section{IUUTIEME GROUPE.}

\section{Les Spinoïles, Watcb.}

Les yeux, en croissant, sont courbés en arrière el resserrés en avant; les latéraux de la premiere ligne sont plus gros que les autres. - Le corps est rugueux. -.. L'abdomen est découpé et projeté horizontalement dans tous les sens, en pointes coniques épineuses. - Les pattes sont courtes; les antéricures sont plus grosses et plus fortes. - Les mandibules sont courtes et cylindriques.

\section{THONISES STEILOIDES.}

Walck., op. cit., t. I, p. 514. - Long. 5 lig. - Le céphalothorax est cordiforme, couvert de petits tubercules, d'un fauvebrun assez relevé à sa partie postérieure, qui est rougeâtre; les yeux sont en croissantrecourbé en arrière, dont quatre sont placés de face; les latéraux de cette première ligne sont plus gros que les intermediaires antérieurs; en dessous de ces quatre yeux, le céphalothorax présente une espèce de rebord, qui ne permet pas d'apercevoir les quatre yeux posterieurs, placés sur une ligne courbe en arrière; ceux-ci sont de la même grosseur à peu près que les deux intermédiaires antérieurs; les mandibules sont courtes, cylindroîdes, d'un rouge pâle, avec des poils fauves, à fond glabre et non rugueux; les mâchoires sont rougeâtres, inclinées sur la lèvre, arrondies à leur extrémité et armées de poils jaunes très-longs; a lèvre, qui est de même couleur que les mâchoires, est triangulaire, terminèe en pointe arrondie à son extrémité, et couverte de poils jaunes; les palpes sont courts, aplatis, d'un fauve-brun mélangé de taches plus claires; la plaque sternale est concave et couverte de poils jaunes; les pattes sont d'un fauve-brun, mélangé de taches plus claires; les antérieures sont les plus longues, grosses, robustes et rugueuses; l'abdomen est aplati, terminé par cinq tubercules horizontaux, figurant imparfaitc-

$$
\text { AN. }
$$

ment une étoile; le tubercule postéricur est le plus allongé, les latéraux les plus grands ensuite, et ceux qui sont près du céphalothorax les plus courts; tous ces tubercules sont terminés par des petites pointes fines, excepté le postérieur, qui se termine par des rugosités ou des plis; en dessus il est fauve, avec une ligne longitudinale plus pảle; en dessousil est d'un fauve plus pâle qu'en dessus, arec les côtés postérieurs beaucoup plus bruns que le reste. Elle a été trouvée dans l'île des Torlues.

\section{NEUVIEIE GROUPE.}

\section{Les Crabroïdes, WaLcK.}

Les yeux sont en croissant; les quatre latéraux sont pyramidaux ou portés sur des angles ou des tubercules de la partie antérieure du céphalothorax; ce dernier est cordiforme; les pattes sont plus ou moins allongées; les antérieures sont presque égales entre elles, beaucoup plus longues et plus grosses que les postéricures; la première paire de pattes est la plus longue, mais excède bien peu la seconde; la troisième est la plus courte.

\section{THOMISUS TRUNCATUS.}

Walck., Aran. de France, no 6, p. 75, pl. 6, fig. 6. - HAHN, Monogr.der Aran., fasc. 7, pl. 3, fig. C. - Aranea Horrida, FABR-, Ent. Syst., p. 411, n० 16. - Aranea Truncata, Pallas, Spicil. Zool., p. 47 , fasc. 9, pl. 1, fig. 15.-Thomisus Martyni, Sav. et Aud., Descrip. de l'Egypte, Arachn. p. $163, \mathrm{pl} .6$, fig. 9 ; la femelle, fig. $9 ; 2$, le mâle. - Long. s lig. — Le céphalothorax est large, court, déprimé, arrondi, d'un gris-rougeâtre, tacheté de brun; on re. marque de chaque côté deux triangles bruns, dont la pointe aboutit a chacun des yeux extérieurs, et dont les deux bases vont se réunir vers l'abdomen, ce qui forme une bande longitudinale plus claire, avancée vers les yeux, d'un brun-noirâtre; les mandibules sont rougeâtres, piquetées de brun; la lèvre et les mâchoires sont d'un rouge sale; les pattes sont de la couleur du céphalothorax, mouchetées de rouge brun, avec des piquans noirs; les pattes postérieures sont d'une couleur plus pâle; les palpes sont de la même couleur que les pattes; l'abdomen est court, trés-large, tronqué postérieurement, d'un gris-rougeâtre tacheté de brun; il a la forme d'une pyramide tronquée, quadrangulaire, dont la base est vers la partie anale, coupéc en- 
suite en ligne droite à sa partie antérieure, près du céphalothorax; en dessus il est d'un gris-rougeâtre, coupé par trois sillons transverses; on apercoit deux bandes noires latérales lavées de gris qui convergent rersle céphalothorax; le milieu et les côtés sont gris, mais la partie antérieure ou la base de la pyramide est brune et entourée de noir; en dessous il est d'un gris-rougeâtre, moucheté de brun sur les côtés, et brun dans le milieu; les bords de la pyramide en dessous sont d'un brun-jaunâtre. - Se troure dans les bois, aux environs de Paris.

\section{THOMISUS ABRREIATUS.}

Walck., Aran. de France, p. 76, no 7; ibid., op. cit., t. I, p. 516. - Thomisus Diadema, HАн, Die Arachn., t. I, p. 49, pl. 13, fig. 37. - Long. 3 lig. - Le céphalothorax jaune, avec les côtés bruns, est plus allongé, plus bombé, plus anguleux à sa partie antérieure que dans l'espèce précédente; les yeux latéraux sont portés sur des angles du céphalothorax et sont très-saillans; les pattes sont jaunes et annelées de rouge; les deux paires antérieures ne prèsentent pour la longueur aucune différence sensible; l'abdomen est large et arrondi postérieurement, coupé en ligne droite antérieurement, mais relevé en angle sur les côtés, avec sa partic supérieure jaune, et souvent on aperçoit une tache irrrégulière et large sur la partie antérieure; la partie postérieure et les côtés de l'abdomen sont entourés par des bandes roses, qui se réunissent aux côtés antérieurs de l'abdomen, et forment une teinte pleine et sans division; mais ces taches roses souvent s'oblitèrent, et l'abdomen est le plus souvent d'un jaune uniforme. - Se trouve dans la France Méridionale.

\section{THonisus ONUSTUs.}

Walck., A'an. de France. p. 77, pl. 6 , fig. 5 ; ibid., Hist. nat. des Aran., fasc. 3, no 7 ; ibid., op. cit., t. I, p. 518. - Thomisus Peronii, $\mathbf{S}_{\Delta \mathrm{v}}$, et $\Lambda$ Ud., Descript. de l'Egypte, Arachn., p. 163, pl.6, fig. 7. Long. 4 lig.-Le céphalothorax est convexe, cordiforme, de couleur jaune; les yeux latcraux postérieurs sont portés sur destubercnles très-saillans; les pattes sont jaunes; $l$ 'abdomen est jaune, court, arrondi à sa partie postérieure, et présente en dessus deux tubercules. - Cette espèce a été trouvée aux environs de Lyon.

\section{THOVIISES CRISTATUS.}

Walck., Alan. de France, p. $77, \mathrm{n}^{\circ} 9$; ibid., op. cit., t. I, p. 521. - Airaneus Cristatus, Cцencк, p. 36, pl. 6, tab. 6. - Thomisus Ulmi, Hans, Monogr. der Aran., fasc. 6, pl. 2, fig. A. - Thomisus Lateralis, ibid., fig. B.-Thomisus Pini, ibid., fig. C. - Thomisus Sabulosus, ibid., Die Arachn., t. I, p. 28, pl. 8, fig. 34. - Thomisus Viaticus, ibid., t. I, p. 35, fig. 29. - Xysticus Audax, Kocu, fasc. 129, 16, 17. - Xysticus Mordax, ibid., 130, 19.-Thomisus Clerchii, Sav. et Aud.,Descrip. de l'Egypte, Arachn., p.165, pl. 6, fig. 13. - Aranea Liturata, EABr., Ent. Syst., t. II, p. 416, no 33. - Thomisus Lituratus, WaLck., Aran. de France, p. 83, $\mathrm{n}^{\circ} 16$. - Long. 4 lig. Le céphalothorax esi large, aplati, presque aussi long et aussi large que l'abdomen, ayant deux raies en croissant, brunes sur les côtés, marbrées de fauve, et plus brunes à leur partie postérieure; de plus il est entouré d'une ligne jaune, fine près des pattes, et présente une bande longitudinale, d'un fauve clair dans le milieu, formant un triangle allongé, dont la base est vers la partie antéricure; sa partie antérieure est d'un fauve-grisâtre; les mandibules sont de même ceuleur; la lèvre est terminée en pointe allongée, elle attcint l'extrémité des mâchoires, qui, arrondies en haut, se joignent par une ligne droite de couleur orange; les palpes sont fauves dans les femelles, bruns dans les mâles; ceux-ci ont le dernier article très-renflé; les pattes sont fauves, marquetees de taches noires; la cuisse et la moitié de la jambe, bruns ou noirs; le reste gris ou fauve pâle; l'abdomen est déprimé en dessus, très-renflé en dessous, de couleur fauve le plus ordinairement, mais variont depuis le brun jusqu'au blanc, ayant en dessus en couleur plus claire la figure d'une crête, forméc par une bande brune qui entoure les côtés, et projelte des lignes intérieures; celte bordure est d'un brun-fauve, et quelquefois rougeâtre dans la femelle plus on moins pâle et foncé, et de même aussi dans le mâle ; mais dans celui-ci elle varie jusqu'au brun foncé et même au noir. Cette espèce est très-commune aux environs de Paris; elle passe l'hiver sous terre et dans les mousses. Le mâle est entièrement semblable à la femelle, mais plus petit et d'une couleur plus foncée. Le Thomise crêté a des mouvemens lents et Jourds; il se renferme dans des feuilles, et tend quelques fils isolés à l'entour, anxquels il se suspend quelquefois. La femelle pond, dans la retraite 
qu'elle s'est praliquée, des œufs, qu'elle renferme dans un cocon trés-blanc, aplati. L'aranéide se place dessus, et ne l'abandonne que lorsqu'on la touche.

13. Thomisus atohanies. (Pl. 5, fig. 5.) WaLck., Alan, de France, p. 79, no 10 ; ibid., op. cit., t. I, p. 523. - Aranea Atomaria, Panz., fasc. 74, pl. 19. - Thomisus Lyucceus, LaTri., Génér. Crust. et Ins., t. I, p. 112, spec. 3 ; ibid., Nouv. Dict. d'Hist. nat., t. XXXIV, p. 39. Thomisus Similis, Reuss. et WIDER, MIus. Senckenberg, p. 275, pl. 18, fig. 8. Thomisus Diana, SAv, et Avo., Descript. de l'Egypte, Arachn.. p. 165, pl. 7, fig. 1. - Long. 3 lig. - Le céphalothorax est cordiforme, avec deux bandes longitudinales brunes sur les côtés; les yeux latéraux antérieurs sont plus gros; l'espace qui existe entre les quatre ycux latéraux est d'un beau jaune; la lèrre, les mâchoires et les mandibules sont d'un jaune orangé uniforme, sans taches; les palpes sont d'un jaune paille pointillé de no:r; les pattes sont de même couleur que les palpes; l'abdomen est court, plus large à sa partie postérieure, coupé en ligne droite à sa partie antérieure, proche le céphalothorax, et d'un jaune orangé plus foncé sur les côtés; en dessus il est parsemé de points noirs fins, disposés sur quatre lignes; la troisième ou la plus large ayant quatre ou cinq points très-apparens, les autres deux; en dessous il est jaunâtre, arec des points noirs sur les côtés. - Se trouve en France et en Afrique.

\section{THOMISUS CITREUS.}

Walck., Tab. des Aran., p. 31, n 7 , pl. 4, fig. 34 et 35 ; ibid., Aran. de France, p. 79, fig. 11. - Thomisus Calycimus; ibid., Tab., n०.8, ibid., Aran. de France, p. $81, \mathrm{n}^{\circ} 12$. - Araignée jaune-citron, DeGÉER, t. VII, p. 298, pl. 17, fig. 17. Aranea Quadridentata, Linv., Syst. nat., p. 1032, $n^{\circ}$ 19. - Aranea Catycina; ibid.. Faun. Suec., p. 486, no 996. - Araneus Vatius, Clerck, p. 126, pl. 6, tab. 5, (mâle). - Araignée citron, Geoff., Ins. des env. de Paris, t. II, p. 642, no 12 , pl. 21, fig. 1.-Thomisus Dauci, WaLcK., 'Tab. des Aran., p. 32; ibid., Faun. Paris., t. II, p. $232, \mathrm{n}^{\circ} 96$; ibid., Aran. de France, p. 81, no 13.--Dugès, Atlas du Règ. anim., Arach.,pl. 11, fig. 4.-Long. 4 lig.-Dans la femelle, l'abdomen présente deux points enfoncés sur le milieu, disposés en angles ou en pyramide, de couleur vert pâle, ou blanche, ou jaune uniforme, ou ayant sur les côtés deux bandes longitudinales plus ou moins rouges; toutes les pattes sont d'une couleur rerte uniforme; dans le mâle, l'abdomen est ovale, globuleux, d'un jaune-verdâtre, et entouré d'une portion de cercle rouge-jaune, ou brun foncé sur la partie antérieure, et présentant à la partie postérieure, à partir du milieu du dessus jusqu'a la partie anale, deux lignes longitudinales et parallèles; les jambes et les tarses sont annelés de brun ou de noir. Se trouve assez communément aux environs de Paris.

\section{THOMSUS DIANA.}

Walck., Aran. de France, p. 72, no3, pl. 6, fig. 7. - Thomisus Tricuspidatus; ibid., p. $83, \mathrm{n}^{\circ} 15,-$ Thomisus Diana, Haxn, Monogr, der Spinn., pl. 3, fig. A ; ibid.s Die Arachn., t. I, p. 31, tab. 9, fig. 26。 - Thomisus Her mani; ibid, Monogr. der Spimn., pl. 3, fig. B. - Aranea Tricuspidata, FABr., t. II, p. 414; no 26. - Thomisus Delicatus, Walck., Aran. de France, p. 82, no 94.-Araignée mignarde; ibid., Faun. Paris., t. II, p. 232, n? 18. - Long. 2 lig. - Dans la femelle, l'abdomen est piriforme, jaune, entouré en dessus, à sa partie postérieure, d'un croissant rouge, et ayant à sa partie antérieure une tache de même couleur; quelquefois le croissant d'en bas rejoint la tache d'en haut, et alor's l'abdomen est entouré d'une bande rouge; dans le mâle, les palpes sont courts, aplatis en dessous, avec un disque arrondi, ayant une petite cavité ronde dans le milieu, les pattes de la première paire surpassent en longueur celles de la seconde dans les deux sexes, mais d'une manière plus sensible dans les femelles; dans les deux sexes, la partie antérieure du céphalothorax est d'un jaune-citron; l'abdomen est de couleur vert d'eau en dessus, brillant, n'étant pas lisse, mais à derme rompu comme des écailles; sur les côtés et à la partic anale est une bande rouge qui entoure lc dos; sur sa partie postérieure on aperçoit un trait transverse, légérement enfoncé, et deux points semblables a la partic postérieure; en dessous il est d'un jaune pâle. - Se trouve aux environs de Paris.

\section{THOMISUS FLORICOLENS.}

Walck., Aran. de France, p. 84, fig. 18. - Ibid., op. cit., t. I, p. 532. - 
Aranea Dorsata, FaBr., Ent. Syst., t. II, p. 443, no 22. - Thomisus Dorsatus, HaHN, Monogr. der Aran., pl. 4, fig. 6; ibid., Die Arachn., t. I, p. 44, pl. 11, fig. 34. - Long. 3 lig. - Le céphalothorax, cordiforme, est d'un beau vert, pres. que aussi long que l'abdomen; les mandibules et la lèvire sont rertes; les palpes et les pattes sont de couleur verte; les deux paires de pattes antérieures, qui surpassent beaucoup les postérieures, sont presque égales entre elles; cependant la première paire est plus longue; de même la troisième ne diffère pas beaucoup en grandeur de la quatrième; l'abdomen en dessus est entouré par une bande verte ou jaune, dont le milieu est d'un rouge foncé ou grisâtre, avec un espace plus clair ou jaune, figurant un $\boldsymbol{X}$ renversé sur le milieu de la partie antérieure, et dessillonsjaunes ou plus clairs vers la partie anale. - Se trouve sur les fleurs aux environs de Paris.

\section{THOMISUS VILLOSUS.}

WALCK., Aran. de France, p. 85 , $\mathrm{n}^{\circ}$ 20. - Ibid. op. cit., t. I, p. 535, - Latr., Nouv. Diction. d'Hist. nat., t. XXXVI, p. 11. - Thomisus Bufonii, SAv. et Aud., Description de l'Egypte, Arachit., p. 164, pl. 6, fig. 10. - Long. 2 lig. - Le céphalothorax.est relevé en carène, rétréci vers la partie antérieure, allongé, rouge, avec une ligne jaune longiludinale dans sa partie médiane; les yeux sont en croissant, très-petits, mais brillans; les latéraux de la ligne antérieure, étant plus proéminens, paraissent un peu plus gros; les palpes et les mandibules sont rougeâtres; la plaque sternale, les mâchoires et la lévre sont d'un fauve pâle, avec des poils moins longs; les pattes antérieures de la première paire ont les cuisses fortes et renflées; cetle paire est la plus longue, ensuite la seconde; la troisième paire est la plus courte; les deux paires postérieures sont très-courtes; l'abdomen est arrondi, d'un fauve pâle, jauneverdâtre, tout couvert et hérissé de longs poils fauve pâle, de même couleur que le fond, très-allongés entre eux et fins; ces poils sont plus abondans en dessus, où on aperçoit neuf points enfoncés, disposés longitudinalement sur deux lignes; le cocon est de couleur fauve-blanchâtre, ainsi que le dessous. - Se trouve dans la France Méridionale.

\section{DIXIEME GROURE.}

\section{Les Anguleuses, WaLcK.}

Les yeux sont en segmens de cercle. La lèvre et les mandibules sont très-allongées. - Les pattes antérieures sont allongées; la première paire est la plus longue, la seconde ensuite, la troisième est la plus courte. - Les mandibules sont cunéifo mes. - L'abdomen est en pyramide trol quée, quadrangulaire.

\section{THOMISUS PIGER.}

Walck., Aran. de France, p. $86, \mathrm{n}^{\circ} 21$; ibid., Tab. des Aran., p. 34, pl. 4, fig. 37; ibid., op. cit., t. I, p. 536 . - Long. 2 lig. - Les pattes sont rougeâtres; l'abdomen est allongé, plus gros à sa partie postérieure, rougeâtre en dessus, entouré de noir; les mâchoires sont cylindroìdes, et entourent la lèvre; le mâle a la cupule du digital assez large, arrondie, aplatie en dessous, de conleur rougeâtre.-Se trouve aux environs de Paris.

\section{ERIPUS, W ALCK: Thomisus, Latr.}

Les yeux, au nombre de huit, sont dis. posés à l'entour de deux tubercules verticaux, et disposés de la manière suivante? deux yeux placés sur l'épistome en avant des deux tubercules; deux placés sur les deux tubercules de devant et à moitié de leur hauteur, plus écartés que les antérieurs, qui sont sur l'épistome; quatre yeux placés derrière les tubercules, savoir : deux en haut, et deux en bas, ces derniers plus rapprochés que ceux d'en baut. - La Jèvre est allongée, ovale, triangulaire, tronquéc en ligne droite, ou en ligne légérement arquée à son extrémité. - Les mâchoires sont allongées, droites, élargies à leur $\in \mathrm{x}$ trémité, à côté externe droit ou légérement convexe, et à extrémité interne échancrée.-Les mandibules sont courtes, cunéiformes. - Les pattes sont étendues latéralement; les deux paires antérieures sont beaucoup plus longues que les postérieures; la première paire surpasse peu la seconde; la quatrième paire est plus longue que la troisième.

Ce genre, dont les mœurs nous sont in. connues, a été le sujet d'une note mono. graphique, que nous avons insérée dans le Magasin de Zoologie, de M. Guérin. Nour arons fait connoître dans ce petit travail, 


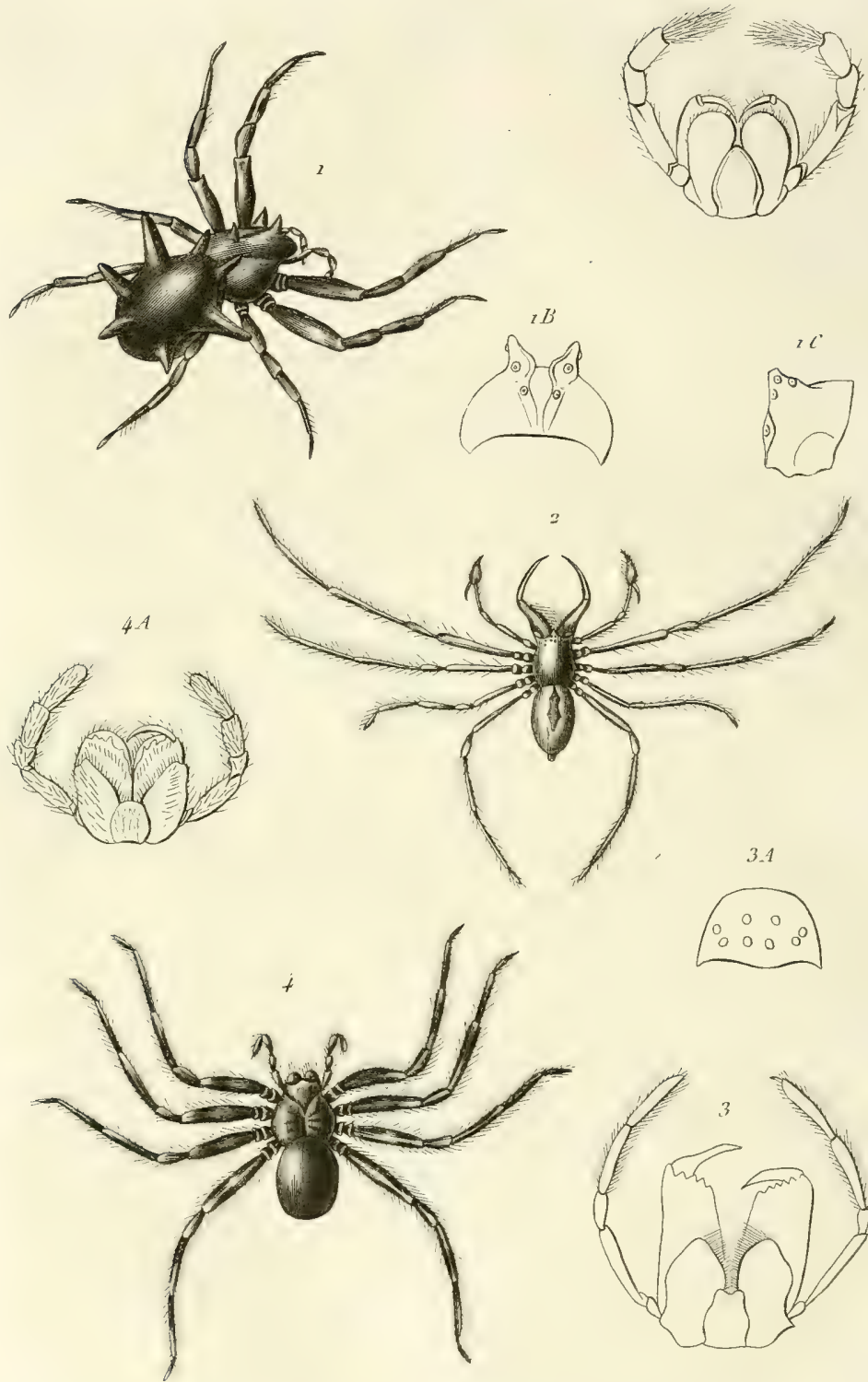

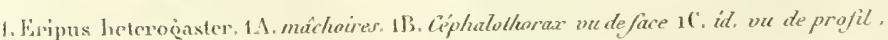

2. Clubiouna mutrix, 3, mấchoires du Sparassus smaragidulus, 5A.yeuz. 4. Solcnops fugitiviss. 
deux espèces, dont une n'est regardèe par M. Walckenaer, dans son Hist. nat. des Ins. Ant., que comme variété. Pour la distinction de ces espèces, qui est assez difficile, nous avons basé nos caractères spécifiques sur la position qu'occupent les épines sur l'abdomen, leur longueur relative et leur distance plus ou moins rapprochée .ou plus ou moins éloignée. La première es. pèce a été désignée sous le nom de Lripus Brasiliensis, et la seconde sous celui de $\boldsymbol{E}$. Audouinii. Au nom spécifique, on voit au premier abord qu'elle est la patrie de la première ; la seconde habite la Guiane française.

ERIPUS IETEROGASTER. (Pl. 6, fig. 4.)

W ALCK.; op. cit., t. I, p. 441, pl. 12, fig. 6. - Thomisus Heterogaster, Guér., Icon. du Règ. anim. de Cuv., Arachn., pl. 1. fig. 4.-Thomise hétérogastre, Latr., Cours d'Entomologie. - Long. 8 lig. Le céphalothorax, couvert de petits tubercules brillans, est jaune; ses côtés latéraux sont renflés, avec des ligues longitudinales assez profondément marquées; sa partie antérieure est de même couleur; sa partie supérieure est d'un fauve plus clair, avec le tubercule médian peu saillant; les tubercules antérieurs sont grisâtres; la première paire d'yeux est roussâtre, les suivantes sont de couleur noire; les articles des palpes sont d'un rouge carmin peu marqué, à l'exception du dernier article, qui est légérement grisâtre, avec des poils d'une couleur jaune trẻs-foncé; les mandibules sont jaunes à leur naissance, roussâtres à leur extrémité; les mâchoires et la lèvre sont d'un jaune sale, avec des poils d'un jaune brillant à leur côté interne; les articles des pattes jusqu'au gẻnual sont jaunes, tandis que le tibial, le métatarse et une partie du tarse sont d'un rouge carmin; l'extrémité du dernier article est roussâtre ; l'abdomen est peu renflé, sa couleur en dessus et sur les côtés latéraux est d'un fauve foncé; les tubercules antérieurs sont allongés, d'une belle couleur rouge carmin; les tubercules médians sont très-allongés, avec les latéro-postérieurs un peu moins allon: gés et de même conleur que les antéricurs; l'espace occupé par les ouvertures stigmatiques est légérement grisâtre; les filières sont d'un jaune foncé, avec des poils de même couleur. - Gelte espèce habite le Brésil.

SELENOPS, SAV,, WALCK.

Les jeux, au nombre de huit, sout ola. cés sur deux lignes; la ligne antéricure est courbée en avant, et formée par six yeux; la ligne postérieure est très-rapprochée de l'autre, plus longue que l'antérieure, et indiquée à ses extrémités par deux yeux seụIement, de manière qu'il y a quatre yeux intermédiaires sur une ligne droite, et deux yeux latéraux de chaque côté, l'un plus avancé, l'autre plus reculé que la ligne intermédiaire. - La lèvre est arrondie, semi-circulaire ou ovalaire. - Les mâchoires sont allongées, droites, écartées et divergentes à leur extrémité. - Les pattes, ètalées latérạlement, sont allongées, fortes, presque égales; les postérieures sont aussi longues ou plus longues que les antérieures. Ces Aranéides courent avec vélocité, les pattes étendues latéralement.

Les espèces qui composent ce genre ont été divisées en trois groupes.

\section{PREMIER GROUPE.}

\section{Les Omalosomes, WaLck.}

La lèvre est courte, semi-circulaire. $T$ Les mâchoires sont ovalaires, écartées, divergentes, resserrées à leur base.-La quatrieme paire de pattes est la plus longue; la troisieme ensuite, la première est la plus courte.

\section{GELENOPS ONALOSOMA.}

L. Def., Ann. génér. des Sc. phys. de Bruxelles, 1820, p. 7, pl. 69, fig. 4. W ALCK., op. cit., t. I, p. 544. - Dugès, Atlas du líg. anim. de Cuv., Arachn., pl. 12, fig. 1. -- Long. 4 lig. - Le céphalothorax est large, aplati, d'un fauverougeâtre, brun sur les côtés, avec des sillons rayonnants au centre; les yeux latéraux antérieurs sont plus rapprochés de la ligne intermédiaire que les postérieurs; ils sont noirs larğes et entourés d'un jaune vif brillant; les yeux antéricurs sont placés sur le rebord du céphalothorax; les mandibules sont rougeâtres, avec une ligne noire qui commence en haut, se dirige ensuite du côté externe en ligne droite, se courbe et s'arrondit après au milieu; les mâchoires sont resserréesà leur hase et écartées; la lèvre est brune à sa base et jaunâtre à son extrémité; les pattes sont d'un fauve-jaunâtre, avec des taches brunes; la quatrième paire est sensiblement plus longue que les autres; elles sont presque égales entre elles; l'abdomen est d'un jaune pâle uniforme. - Celle espèce se trouve et. Espagne. 
2. SELEvops Fugitivus. (Pl. 6, fig. 4.)

WALCK., op. cit., t. I, p. 546. - Long. 6 lig. - Le céphalohlorax est grand, aplati, rougeâtre, sans taches; les yeux sont rougeâtres; les mandibules sont rouges, d'un brun foncé, glabres, très-bombées, et un peu dirigées en avant, sans aucune tache; les pattes sont fortes, longues, brunes, avec des petites taches plus brunes et des anneaux d'un jaune pâle au commencement et à l'extrémité du tibial. - Se trouve en Cafrerie.

\section{IEUXILME GROUPE.}

\section{Les Aisses; WaLcK.}

La Jèvre est courte, semi-circulair.. Les mâchoires sont droites, peu resserrèes à leur base. - La seconde paire de pattes est la plus longue, la troisieme ensuile, la quatrieme est la plus courte.

\section{SEIENOPS AISSUS.}

WAlck., op. cit., t. I, p. 547. - Long. 6 lig. - Le céphalothorax est grand, large, cordiforme, avec des sillons rayonnans aux pattes, et aboutissant au centre, creusé en large fossette; les yeux sont noirs, saillans, excepté les latéraux antérieurs; qui sont renfoncés, petits rougeâtres; les quatre yeux de la ligne intermédiaire sont presque aussi gros que les latéraux postérieurs; Ies mandibules sont courtes, renflées, pyriformes, d'un rouge-noirâtre, avec une rainure dentée pour recevoir les crochets, qui sont très-grands; la lèvre est large, en demi-cercle, d’un rouge-brun à sa base, et d'un rouge plus pâle sur les bords; la plaque sternale est rougeâtre; les palpes sont courts, un peu plumeux, légérement renfiés à leur extrémité; les pattes sont fortes, rougeâtres, allongées; l'abdomen est plus long que large, plus étroit que le céphalothorax, en ligne droite a sa partie antérieure et sur les côtés, arrondi et pointu à sa partie postérieure; en dessous il est d'un brun-fauve uniforme. - Cette espèce a été trouvée à la Martinique.

\section{TROISI LIIE GROUPE.}

\section{Les Aphartères, WaLcK.}

La lèvre est allongée, ovalaire. — Les mâchoires sont très-converes à leur côté interne, pointues à leur extrémité, qui est creuséc en ligne concave au côté interne, étroites a leur base, creusćes intéricure- ment, et entourant la lèrre. - La seconde paire de pattes est la plus Jongue, la troisième cusuite, la première est la plus courte.

\section{SELENOPG SPIXII.}

Penty, Delect. Anim., p. 195, pl. 88, fig. 12, - Selenops Brasiliensis, Walck., op. cit., t. I, p. 548. - Long. 7 lig. Le céphalothorax est plus long que large, arıondi, aplati, de couleur faure-jaunâtre; les yeux de la ligne antérieure touchent presque aux mandibules; ils sont petils et jaunâtres, et on aperçoit entre eux des poils noirs, roides et verticaux, parsemés çà et là ; les mandibules sont très-courtes, singulièrement renflées à leur partie antérieure, et comme globuleuses, dépassant ainsi le bord antérieur du céphalothorax par leur convexité; elles sont de couleur fauve sale, lavées de noir, parsemées de poils roides et de piquans très-longs à l'extrémité; les palpes sont courts, minces, fauves, annelés de noir, hérissés de poils de même couleur, roides, et de piquans très-allongés; les pattes sont d'un jaune fauve doré, avec de larges anneaux noirs ; la deuxième paire est la plus longue, la troisieme ensuite, la quatrieme est plus longue que la première, qui est la plus courte de toutes; l'abdomen est ovale, noir, avec des pinceaux de poils près des filières; en dessous, il est noir. Le mâle, sujvant M. Perty, est déprimé, gris, זarié de brun; les cuisses sont annelées; les tarses sont velus. - Se tronve au Brésil.

\section{PIILODROMUS, WALGK. ; Thomisus, ejusd.}

Les yeux, au nombre de huit, presque égaux entre eux, occupent le devanı dı céphalothorax, et sont placés sur deux-ligues en croissant, sessiles, ou n'ctant pas portés sur des tubercules ou des éminences de la tête. - La lèvre est triangulaire, terminée en pointe arrondic, ou coupec à son extrémité. - Les mâchoires sont ètroitis, allongées, cylindriques, inclinées sur la lévre, rapprochées à leur extrémité. - Les mandibules sont cylindroïdes ou cunéiformes. - Les patles, arliculées pour être étendues latéralement, sont allongées, propres à la course, et presque égales entre elles.

Ces Aranéides courent avec rapidité, les pattes étendues latéralement, épiant lcur proie, tendant des fils solitaires pour la rea 
tenir, se cachant dans des fentes ou dans des feuilles ponr faire leur ponte.

Ce genre a été partagé en trois groupes.

\section{PREMIER GROUPE.}

\section{Les Cirabes Longipèdes, WaLck.}

Le céphalothorax est aplati, large à sa partie antérieure. - L'abdomen est court, et très-large postérienrement: - Les deus paires de pattes intermédiaires sont les plus allongées. - La lèvre est terminée en pointe arrondic. - Les mandibules sont cunéiformes.

\section{PIIMODROMUS TIGRITUS.}

Walck., Aran. de France, p. 87, n० 1 ; T'homise tigré, ibid., Tab. des Aran., 1). 34, n²2; Araignée tigrée, ibid., Faun. Paris., t. 1I, p. 230, n॰ 86 ; ibid., op. cit., t I, p. 551. - Aranea Laevipes, Linn., Fanu. Suec., $2^{\mathrm{e}}$ edit., p. 225. - Long. 3 lig. - Le céphalothorax est très-Jarge, aplati, cordiforme, d'un fauve rougeâtre, brun sur les côtés et à sa partie postérieure, laquelle est arrondie et de couleur blanclâtre; les mandibules sont noirâtres; les mâchoires sont allongées, étroites, fortcment inclinées sur la lèvre, et se touchant par leur extrémité rougeâtre; la lèvre inférieure est rougeâtre, grande, triangulaire et pointue à son extrémité ; les pattes sont longues, grêles, rougeâtres, marquées de brun et de points fins de même couleur, et ayant des poils blancs à la partie antérieure de l'exinguinal et du fémoral; la deuxième paire surpasse loutes les autres en longueur, ensuite c'est la troisième qui est sensiblement la plus longue; la première et la quatrième paire n'offrent pas de différence sensible, cependant la première est plus longue; l'abdomen large, aplati, paroît former un pentagone, à cause de la pointe qui marque sa partie anale, et a ensuite sa partie antérieure coupée en ligne droite, et on aperçoitquelquefois une petite échancrure dans le milieu; en dessus, il est revêtu de poils roux, bruns, et blanc brillaut, ce qui offre à la vue un aspect tigré ; il est bordé de brun sur les côtés, et a dans le.milieu de sa surface quatre ou six points enfoncés; en dessous, il est blanchâtre, avec des poils gris.

Celte espèce se tient sur les arbres, les cloisons des bois, les murailles, ayant les pattes étendues, et comme collée sur la surface des corps sur lesquels elle se trouve; mais des' qu'on la touche, elle s'enfuit avec une extrême rapidité, ou se laisse tomber à terre par le moyen d'un fil de soie qui se dévide de ses filières. Mous l'avons rencontrée très-communément sur les treillages et sous les écorces des pins au Jardin des Plantes.

2. Philovromus Jejurus. (Pl. 3, fig. 4.)

Walck., Aran, de France, p. $97, \mathrm{n}^{\circ} 1$ bis; ejusd., op. cit., t. I, p. 551.-Aranea Jejuna, Panz., 83, 21.-Araignée tigrée, DEg., t. VII, p. 302, pl. 18, fig. 25.-Ara. neus Margaritaceus, CuERcK, p. 130, c. 7 , spec. 2, pl. 6, tab. 3. - Thumisus Lavipes, Hain, Die Arachn., t. I, fig. B, p. 120 , tab, 34, fig. 90 ; ibid., Monogr., 4, heft., pl. 3, fig. B. - Long. 3 lig. $\frac{1}{2}$. - Le céphalothorax est arrondi, rétréci subitement vers la partie antérieure, d'un jaune-blane en dessus, avec deux taches noires qui se rejoignent, et forment un angle à la partie postérieure : antérieurement, et vers la région des yeux, ces deux taches noires se rejoignent, et forment un angle a la partie postérieure; les yeux sont en croissant: les quatre de la courbe antéricure du croissant sont un peu plus rapprochés entre eux, et en deux paires; les quatre yeux de la courbe postérieure du croissant sont au coniraire a égale distance les uns des autres; les quatre antérieurs, étant plus rapprochés entre eux, sont éloignés des latéraux postérieurs; ces deruicrs sont saillans, et portés sur une légère élévation du céphalothorax; les mandibules sont droites, cunéiformes, brunes à leur base et à leur extrémité, et traversées par une bande jaune; de plus, elles sont recouvertes de quelques poils blanchâtres; les mâchoires sont en carré long plus haut que large, légérement inclinées sur la lèvre, disjointes à leur extrémité, et brunes; la lèvre est brune, triangulaire, échancrée a son extrémité, plus haute que large; la plaque sternale est cordiforme, velue, d'un brun-rougeâtre; avec des poils jaunes trèsfins; les pattes sont allongées, étalées latéralement, la seconde paire est la plus lon gue de toutes, la troisième ensuite, la quatrième est la plus courte : ces pattes sont blanches ou jaune clair; l'abdomen est pyriforme, déprimé en dessus, plus long que large, rétréci et coupé en ligne droile a sa partie antérieure, d'un blanc-jaunâtre ou verdâtre, avec deux taches noires inclinées, une de chaque côté, proche le céphalothorax; sa partie médiane présente deux larges raies noiles, qui traversent une partie du dessus sans se joindre catre elles; 
au milieu de l'espace jaune ou blánc est un petit trait noir, fin et longitudinal postérieurcment on apercoit un ou plusicurs points ou lignes voires, qui ne se rejoignent pas dans le milieu; les côtés latéraux du dessous sont entourés de noir, avec des petits traits ou points blancs ou jaunes; en dessous, il est très-aplati, et d'un gris pâle, avec deux petites bandes longitudinales obscures, qui partent des parties sexuelles; ces parties sont brunes, et la portion de l'abdomen qui est au-dessus, proche le céphalothorax, est d'un jaune plus pâle que le reste. - Cette espèce, qui se trouve aux environs de Paris, est très-agile, et marche latéralement.

\section{DEUXIEME GROUPE.}

\section{Les Filipédes, WaLcK.}

Le céphalothorax est aplati, large et cordiforme. - La deuxième paire de pattes est ła plus longue, ensuite la première, la troisième est la plus courte. - La lèvre est triangulaire, tronquée. - Les mâchoires sont bombées ou coudées à leur base, trèsinclinées sur la lèvre. - Les mandibules sont cylindroìdes.

\section{PIILOdromus dispar.}

WaLck, Aran. de France, p. 89, no 9 ; ibid., op. cit., t. I, p. 554. - Thomisus Griseus, Шан, Monogr. der Spinnen., fasc. 4, pl. 3, fig. A. - Philodromius Fallax, Sund., p. 226, n 4. - Long. 3 lig. - Le céphalothorax est cordiforme, grisâtre, avec deux bandes brunes longitudinales sur les côtés; les yeux sont placés comme dans le $P h$. Tigrinus; les mandibules sout plus allongées, verdâtres et cylindriques; les mâchoires sont très-inclinées, bombées et dilatées à leur base, se terminant en pointe arrondie à leur extrémité; les pattes sont fines, verdâtres; les cuisses sont tachées de noir; l'abdomen est allongé, piriforme, couvert de poils courts, épais, grisâtres dans le milieu de la partie antérieure, noirs ou bruns sur les côtés', d'un fauve doré verdâtre à la partie postérieure; en dessous, il est d'un gris-blanchàtre sur les côtés, et noirâtre dans le milieu. Le mâle a la même forme que la femelle, mais il en diffère par les couleurs : le céphalothorax et.l'abdomen en dessus sont noirs et entourés d'une ligne blanche; les pattes et les palpes sont verdâtres, mais ceux ci sont terminés par un article glo- buleux, fort, ct de couleur noire. - Se trouve aux environs de Paris.

\section{4. philodromus pallidus.}

WaLcK., Aran. de France, p. $90, \mathrm{n}^{\circ} 13$; ibid., op. cit., t. I, p. 554. - Thomisus Griseus, НАнN, Dic Arachn., t. I, p. 121, tab. 34, fig. 91. - Long. 2 lig. - Le céphalothorax est plus large que l'abdomen, d'une couleur pâle-rougeâtre, avec l'intervalle des yeux d'un jaune clair, luisant; les yeux sont semblables à ceux de l'espèce précédente; les mâchoires sont très-inclinées sur la lèvre, coudées et dilatées á leur base, et se terminant en pointe arrondie, d'un jaune plus pâle que la lèvre; les palpos sont d'un jaune pâle, à dernjer article trèsrenflé et aplati; les pattes sont de même couleur que les palpes, avec des anneaux d'un rouge clair aux articulations des jambes; l'abdomen est ovoïde, allongé, petit, un peu déprimé, plus large dans son milieu, pointu vers la partie anale, ayant à la partie postérieure, et proche le céphalothorax, une légère échancrure; sa longueur ne dépasse pas beaucoup celle du céphalothorax; sa couleur est fauve, avec des mouchetures plus foncées, et on aperçoit en dessus deux lignes brunes, obscures, parallèles, recouvertes en partie par des poils jaunes; de plus, sont deux taches d'un noir très-vif en dessus, de chaque côté de la partie anale; le dessous est d'un jaune pâle. - Se trouve aux environs de Paris.

\section{PHLOdRoMUs nufus.}

WaLck., Aran. de France, p. 91, n० 4 ; ibid., op. cit., t. I, p. 555.-Long. 2 lig. $\frac{3}{2}$. - Le céphalothorax est de couleur pâle; les yeux sont comme dans les espèces précédentes; les mandibules sont d'un blancrougeâtre sans taches; les mâchoires sont légérement inclinées, arrondies à leurs côtés externes, creusées à leurs côtés internes, bombées à leur base, resserrées dans leur milieu, de couleur fauve pâle, parsemées de points plus foncés; la lèvre est allon. gée, étroite, échancrée, coupée en ligne droite à son extrémité; les palpes sont jaunes, rougeâtres, arec le dernier article renflé, ovoïde, pointu à son extrémité, et velu en dessus; les pattes sont de même couleur que les palpes; l'abdomen est allongé, cylindrique, étroit, un peu plus large, coupé en ligne droite à sa partie antérieure, d'un fauve-rougeâtre uniforme, sablé de petits points imperceptibles plus foncés, qu'on aperçoit aussi à la plaque 
sternale, aux cursses et aux palpes; en dessous, il est d'une couleur plus pâle. - Se trouve aux environs de Paris.

\section{TROISIÈME GROUPE.}

\section{Les Vigilantes, WaLcK.}

Le céphalothorax est arrondi, convexe. - La deuxième paire de pattes est la plus longue, la première ensuite, la quatrième est la plus courte. - La lèvre est triangulaire, arrondie à son extrémité. - Les mâchoires sont très-inclinées sur la lèvre, amincies vers leurs extrémités, bombées à leur base. - Les mandibules sont cylindroïdes.

\section{6. philodronus aureolus.}

Walck., Aran. de France, p. $92, \mathrm{n}^{\circ} 6$; ibid., op. cit., t. I, p. 556. - Philodromus Aureolus, Kоcн, 130, fig. 21 (le mâle), fig. 22 (la femelle). - Thomisus Aureolus, $\mathrm{H}_{\mathrm{AHN}}$, Dic Arachn,, t. II, p. 57, fig. 144 (le mâle), et fig. 145 (la femelle). - Araneus Aureolus, Clerck, p. 135, pl. 6 , tab. 9. - Araignée brune bordée, DEGÉER, t. VII , p. 301, pl. 18 , fig. 23 et 24 . Long. 3 lig. - Le céphalothorax est cordiforme, aussi large que long, d'un jauneverdâtre dans son milieu, d'un rouge-brun sur les côtés; les mandibules sont d'un blanc pâle ou grises, avec le crochet de même couleur, cylindriques; l'abdomen est piriforme, renflé postérieurement, marbré de brun, de rouge et de jaune; sur les côtés, les taches jaunes forment des rayons en forme de larmes ou de flammes, qui partent du haut, se dirigent latéralement ; le milieu est d'un jaune-verdâtre, lavé de taches obscures; du côté du céphalothorax sent quatre points noirs enfoncés, se détachant sur un fond plus jaune que le reste, et au milieu une ligne longitudinale de même couleur, moins foncẻe ; en dessous, il est pâle et sale, parsemé de taches brunes sur les côtés; dans le milieu est une ligne longitudinale sablée de gris, avec deux rangs de points ronds, verts, parallèles, peu distincts. Le mâle diffère de la femelle par son céphalothorax qui est plus large, moins bombé, et par son abdomen qui est plus brun, allongé, cylindroïde, de couleur fauve doré, avec une teinte ardoisée à la partie antérieure. - Cette espèce, qui se trouve aux environs de Paris, court arec assez d'agilité.

\section{OUATRIẼME GROUPE.}

\section{Les Surveillantes, WaLck.}

Le céphalothorax est arrondi. - L'abdomen est allongé. - La seconde paire de pattes est la plus longue, la quatrième ensuite, la troisième est la plus courle. - Les yeux, en croissant, sont à cornes très-aiguës; les postérieurs latéraux sont très-reculés en arrière; les intermédiaires postérieurs sont rapprochés entre eux ou rentrés dans l'intérieur du croissant, de manière à former un carré avec les antérieurs intermédiaires, ou un croissant se composant de trois ou quatre lignes d'yeux. - La levre est courte, semi-circulaire.-Les mâchoires sont très -inclinées sur la lèvre, et bombées à leur base. - Les mandibules sont cylindriques.

\section{7. philodromus oblongus.}

WaLck., Aran. de France, p. 94, n० 7, pl. 6, fig. 9 ; ibid., Hist. nat. des Aran., fasc. 4, fig. 5 ; ibid., Tab. des Aran., pl. 4, fig. 9 ; ibid., op. cit., t. I, p. 558. Thomisus Oblongus, $\mathbf{H}_{\mathrm{AHN}}$, Die Arachn., t. I, p. 110, tab. 28, fig. 82. - Philodromus Trilineatus, Sund., p. 227, $\mathbf{n}^{\circ} 5$. Long. 3 lig. $\frac{1}{+}$ - Le céphalothorax est plus large que l'abdomen, en ovale arrondi, pointu antérieurement et échancré postẻrieurement, jaunâtre, avec deux raies Iongitudinales brunes, formant un $\mathrm{V}$ allongé dans le milieu; sa partie antérieure est arrondie, d'un blanc jaunâtre, avec quelques poils noirs ou bruns dirigés en avant; les palpes sont blanchâtres, terminés dans le mâle par un article ovoïde, sans ouverture; les mandibules sont courtes, hlanches, dirigées en avant; les mâchoires sont courtes, d'un blanc uniforme, coupées en ligne dioite à l'extrémité, et recouvrent la lèvre; la plaque sternale est blanche, piquetée de brun; les pattes sont jaunes en dessus, blanches en dessous, avec des poils et des piquans noirs ; l'abdomen est cylindrique, ou en cône très-allongé, dont la pointe est vers la partie anale; il est jaune, avec une raie longitudinale brune dans le milieu, qui se rétrécit vers la partie anale ; on apercoit aussi deux autres raies pareillement longitudinales plus étroites sur les côtés; y a aussi des points bruns sur le milieu du dos, dont deux sont plus marqués; en dessous il est d'un gris-blanc uniforme. - Se trouve aux environs de Paris. 
8. PHLODRGHUS PHOMBIFLRENS.

Walck., Aran. de France, p. 95, n० 9 , pl. 6, fig. 8 ; ibid., op. cit., t. I, p. 559.I'homisus Fabricii, Sav. et $\Lambda$ do., Descript. de l'Egypte, Arachn., p. 141, pl.6, fig. 3.Philodromus Albini, $\mathbf{S}_{\Delta \mathrm{v}}$, el Avd, Descrip. de l'Egypte, Arachn., pl. 6. fig. 4,-Philodromus Rhombiferens, $\mathrm{S}_{\mathrm{Av}}$, et AcD., Descript. de l'Egyple, Arachn., pl.6, fig. 5. Thomisus Rhomboicus, HaHn, Die Arachn., t. I, p. 111, pl. 28, fig. 83.-Araneus Formicinus, Crerck, p. 134 , pl. 6 , tab. 2. Philodromus Formicinus, Sund., p. 229 , no 7. - Long. 3 lig. $\frac{1}{2}$. - Le céphalothorax est cordiforme, plus large, mais moins long que l'abdomen, couvert de poils rouge-brique dans le milieu et proche des pattes; les côtés sont lavés de brun; sa partie antérieure est arrondie, rougeâtre, avec quelques poils noirs à sa base; les yeux de la ligne postérieure du croissant sont plus gros; les antérieurs sont presque imperceptibles; les mandibules sont rougeâtres; les pattes sont longues, rouges, avec des piquans noirs; les palpes sont de même couleur que les pattes; la plaque sternale est velue, revêtue de poils gris et noirs; l'abdomen est ovoïde, plus pointu vers la partie anale, d'un rouge de brique clair en dessus, el ayant un trapèze allongé, proche le céphalothorax, d'un noir de velours; Jes poils qui sont rangés de chaque côté dépassent ceux du corps; ils sont noirs à leur base, gris à leur extrémité, et se dirigent vers la partie anale ; en dessous, il est d'un rouge plus pâle, avec trois lignes enfoncées, longitudinales, qui se réunissent à la partie auale. - Se trouve sur les arbustes aux environs de Paris.

\section{OLIOS, W ALCK. ; \\ Thomisus, LATR.}

Les yeux, au nombre de huit, sont élalés sur deux lignes parallèles, l'antérieure étant plus courte. - La lèvre est large ou quadri. forme, ou tronquée en ligne droite à son extrémité. - Les mandibules sont allongées, cylindroïdes. - Les pattes sont presque égales entre elles, allongées, robustes; les postérieures, comme les antérieures, articulées pour être étendues latéralement ct portées en avant.

Ces Aranéides tendent quelques fils, et marchent dans une position renversée dans les bois ou l'intérieur des habitations, attaquant les kakerlacs, les gros insectes, et mêne les pelits lézards.
Ce genre a été divisé en huil groupes.

\section{PREMIER GROUPE.}

\section{Les Robustes, WaLck.}

Les yeux sont sur deux lignes paralleles; la ligne antérieure est plus courte. - La lèvre est courte, quadriforme, tronquée ou légérement arrondie. — Les mâchoires sont écartées, disjointes à leur extrémité, inclinées sur la lérre. - Les mandibules sont fortes, allongées, cylindroïdes. - Le cẻphalothorax est large, cordiforme. - Les patles sont presque égales entre elles; les premiéres sont les plus longues.

\section{OLIOS GWAPSUS.}

Walck., op. cit., t. I, p. 564. - Long. 8 lig. - Le céphalothorax est convexe, mélangé de bistre clair ou de bistre brun foncé; les yeux latéraux de chaque ligne sont un peu plus gros que les autres, et les deux lignes se courbent un peu en sens opposé, c'est-à-dire la ligne postérieure en avant, l'antéricure un peu en arrière, mais très-légérement ; les mandibules sont d'un beau bleu-ciel azuré, recouvertes de poils fauves clairsemés; les pattes postérieures sont presque aussi longues que les antérieures, avec l'exinguinal et le fémoral renflés; le dessous de ces paltes est d'une couleur fauve uniforme; l'abdomen est ovale, allongé, ayant en dessus et à sa partie anlérieure des taches noires sur un fond fauve, peu distinctes, et à la partie postérieure, des chevrons, ou taches anguleuses formées par deux lignes noires, parallèles; en dessous, il est entierement fauve. Habite la Nouvelle-Hollande.

\section{OLIOS PINNOTHERES.}

Walck., Tab. des Aran., p. 36, fig. 29; ibid., op. cit., t. 1, p. 563. - Thomisus Lamarckii, Latr., Génér. Crust. et Ins.. t. 1, p. 115. - Le céphalothorax est grand, cordiforme, d'un fauve-jaunâtre sale, avec des poils noirs et une ligne d'un blanc trèsvif sur les bords antèrieurs du céphalothorax; les yeux sont sessiles, sur deux lignes, les latéraux antérieurs sont plus gres que les autres; les mandibules sont brunes, recouvertes de poils fauves rares, avec deus lignes longitudinales sur le côté de chaque mandibule d'un blanc très-vif; la lèvre est larğe, carrée; les mâchoires sont légérement inclinées sur la lèrre, divergentes à leur extrémité, aplaties; les palpes sont d'un faure clair; les pattes sont fortes, al- 
longées, les postérieures égalant presque les antérieures; les cuisses sont renflées, surtout celles des pattes antérieures; la quatrième paire égale presque la première, le tibial de la première paire est annelé de noir en dessous; l'adodomen est ovale, allongé, couvert de poils faures ou junne sale en dessus; en dessous, il est d'un noir de velours, avec la plaque sternale et la bouche de même cauleur. Le mâle diffère de la femelle par l'abdomen, qui est plus petit, et par ses pattes, qui sont beaucoup plus grêles. - Cette espèce a élé trouvée au port Jackson.

\section{OLIOS LEUCOSIUS.}

W ALCK., op. cit., t. 1, p. 567. - Thomisus Venatorius, Latr., Génér. Crust. et Ins., t. I, 114, spec. 7. - Sloane, Hist. of Jamaic., p. 185 ; t. II, p. 335, fig. 1 à 2. Araneus Venatorius, LinN., System. nat., p. 1035. - Long. 14 lig. - Le céphalothorax est rouge longitudinalement, avec des sillons en rayon aboutissant aux pattes, marqués par des poils bruns; il y a aussi une tache brune rehaussée par du jaune vif proche de l'abdomen; l'épistome a une raie transverse, formée par des poils jaunes citron; les mandibules sont rougeâtres, rayées longitudinalement de noir; les pattes sont de couleur fauve doré, avec des épines de couleur noire; l'abdomen est ovale, allongé, plus étroit que le céphalothorax, d'un brun-fauve uniforme, avec des points enfoncés en dessus; en dessous, il est d'une couleur plus pâle. Le mâle diffère de la femelle par son céphalothorax, quj est d'un brun-marron à sa partie postérjeure, et qui est entonré d'une bande jaunâtre qui rejoint celle de l'épistome; il est aussi plus petit. - Se trouve à l'lle-de-France, aux Antilles et au Brésil.

\section{DEUXIENE GROUPE.}

\section{Les Intrépides, WaLcK.}

La ligne antérieure des yeux est un peu courbée en arrière et en forme de croissant. - Les mâchoires sont droites, allongées, cylindroïdes. - La lèvre est grande, carrée, comme pentagonale à cause du resserrement de sa base, coupee en ligne droite à son extrémité. - La seconde paire de pattes est la plus longue, la çuatrième ensuile; la troisieme est la plus courte.

\section{OLIOS TAPROBAFIUS.}

WaLck, op. cit., t. I, p. 570, - Long.
12 lig. - Le céphalothorax est roux; les mâchoircs et la lèvre sont d'un fauve pâle; les patles sont longues, fortes; la deuxième paire est plus longue que la quatrième, la première ensuite, la troisième est la plus courte; ces pattes sont genéralement hérissées de piquans; l'ablomen est ovale, plus gros à sa partie postéricure, d'un gris sale uniforme; le dessous est de même couleur. - Cette espèce a été trouvée à Cieylan.

TROISILME GROUPE.

\section{Les Energiques, WaLCK.}

Les yeux sont sur deux lignes parallẻles; les latéraux sont plus gros. - Les mâchoires sont larges, bombées, ècartées, quadriformes, resserrées el un peu coudées à leur bâse, et s'inclinant légérement sur la lèvre. - La lève est large, courte, coupée en ligne droite à son extrèmité, légérement creusée sur les côtés. - La seconde paire de pattes est la plus longue, la quatrième ensuite, la troisième est la plus courte.

\section{OLIOS COLGMBIANES.}

WALCK., op. cit. t. I, p. 571. - Long. 8 lig.-Le céphalothorax est d'une couleur fauve uniforme, large, arrondi à sa partie postérieure, resserré et quadriforme à sa partie antérieure, un peu déprimé, d'un fauve plus foncé que les pattes, lavé d'une couleur plus brune à sa partie postérieure, qui ressort par la portion d'un jaune clair, qui touche à l'abdomen; les mandibules sont d'un fauve-rougeâtre; les mâchoires et la lévre sont d'un jaune pâle; les palpes sont filiformes, minces, rougeâtres; les pattes sont d'un fauve uniforme; la plaque sternale est ronde, d'un fauve pâle uni, sans sillons ni éminences, revêtue de poils fins; l'abdomen, de même couleur que le céphalothorax, et plus petit que lui, est ovale, cylindrique, revètus tous deux de poils ayant l'apparence d'un duvet.

\section{OUATRIEME GROUPE.}

\section{Les Vigoureuses, WaLck.}

Les yeux sont sur deux lignes parallèles, les antérieurs latéraux sont les plus gros, et cnsuite les postérieurs intermédiaires. - La lèvre est courte, quadriforme. - Jes mâchoires sont courtes, dilatées vers leur estrémilé externe, échancrées ou très-di. 
vergentes à leur extrémité interne, et légérement inclinées sur la lèvre. - Les pattes sont robustes, la deuxième paire est la plus longue, la première easuite, la troisième est la plus courte.

\section{6. olios castaneus.}

Walck., op. cit., t. I, p. 571. - Thomisus Castaneus, Latr., Dict. d'Hist. nat., t. XXXIV, p. 30. - Long. 12 lig. - Le céphalothorax est d'un brun foncé rougeâtre, large, bombé, avec le sillon longitudinal recouvert de poils; les mandibules sont fortes, projetées en avant, recouvertes de poils fauves; les palpes sont courts, filiformes, couverts de poils de même couleur que ceux des mandibules; l'abdomen est ovale, bombé, plus renflé à sa partie postérieure, d'un brun foncè rougeâtre.Celte espèce se trouve au cap de BonneEspérance.

\section{CINQUIIEME GROUPE.}

\section{Les Courageuses, WaLCK.}

Les yeux sont sur deux lignes parallèles, les latéraux antérieurs élant plus gros; les ycux de la ligne postérieure sont égaux. - La lèvre est allongée, carrée, trcnquée ou légèrement creusée à son extrémité. Les mâchoires sont droites, écartées, légérement dilatées et arrondies à leur extré. mité externe, échancrées obliquement à l'angle interne. - La première paire de pattes est sensiblement plus longue que la quatrième, laquelle est plus longue que la seconde; la troisième est la plus courte.

\section{OIIOS LONGIPES.}

WALcK., op. cit., t. I, p. 572. - Long. 5 lig. - Le céphalothorax est grand, glabre, parsemé de quclques poils fauves et rares; les yeux postérieurs intermédiaires sont un peu plus gros que les latéraux de la même ligne; les mandibules sont noirâtres a leur naissance, et revêtues de poils d'un noir vif ; les pattes sont très-allongées, d'un brun-noirâtre; la première paire est la plus longue, la quatrième ensuite, la troisième est la plus courte; l'abdomen est d'un brun-noirâtre, couvert de poils fauves très-allongés.-Cette espèce a été trouvée aux îles Mioluques.

\section{SIXIİ⿴E GROUPE.}

\section{Les Musculeuses, WaLcK.}

Les yeux sont égaux entre eux, placés sur deux lignes très-rapprochées, et cour- bées en arrière de manière à former un croissant étroit et anguleux. - La lèvre est courte, plus large que haute, en carrélong, transverse. - Les mâchoires sont cylindroĩdes, resserrées dans leur milieu, dilatées à leur base, arrondies à leur extrémité et inclinées sur la lèvre.

\section{OLIOS FUSCUS.}

WaLck., op., cit. t. I, p. 573. - - Long. 12 lig. - Le corps de cette espèce est entièrement brun; le mauvais état de conservation nous empêche de donner d'autres détails descriptifs. - Sa patrie est inconnue.

\section{SEPTLLME GROUPE.}

\section{Les Sparassoides, WaLck.}

Les yeux, presque égaux entre eux, sont sur deux lignes rapprochées; l'antérieure est droite, avec la postérieure un peu courbée en avant. - La lèrre est courte et semi-orbiculaire. - Les mâchoires sont dilatées, arrondies à leur côté externe, et légérement inclinées sur la lèvre. - Les pattes sont allongées et veloutées en dessous; la seconde paire de pattes est la plus longue de toutes, la première et la quatrième sont égales, la troisième est la plus conrte. - Le céphalothorax est arrondi, très-large.

\section{9. olios spongrtarsus.}

WaLck., op. cit., t. 1, p. 574.-Microm. mate à tarses spongieux, L. Dur., Ann. des Sc. phys., p. 17, pl. 9, fig. 6.-Long. 4 lig. $\frac{3}{2}$. - Le céphalothorax est bombé, non déprimé sur les côtés, roussâtre, paroissant presque glabre, mais couvert d'un léger duvet ; les pattes sont étalées et dirigées en avant; l'abdomen est fauve, avec une bande longitudinale jaunâtre, dilatée en une tache ronde dans le milieu, et e n ovale allongé à sa partie postérieure, bordée de noir sur les côtés, et deux petites lignes jaunes, fines, sur la partie noire, proche le céphalothorax. - Cette espéce a été trouvée dans un jardin à Barcelone.

\section{IHUITIEME GROUPE.}

\section{Les Délénoides, WaLcK.}

Les yeux sont sur deux lignes, renfoncés en dessous du céphalothorax. - Les. mandibules sont allongées, cylindriques, renfoncées en dessous. - Le céphalotho. rax est aplati, large et cordiforme. 
10. OIIOS PROVOCATOR.

WaLck, op. cit., t. I, p. 575. - Long. 7 lig. - Le céphalothorax est très-aplati, large, cordiforme, couvert de poils gris et blancs, avec des petites ligues longitudinales fines passant entre les yeux ; les yeux latéraux antéricurs sont plus gros que les autres; les yeux postérieurs sont égaux entre eux, et plus petits que les antérieurs intermédiaires; les mandibules sont allongées, glabres, luisantes, ayant deux lignes d'un blanc vif intérieurement, qui se détachent sur un fond noir; les pattes sont fauves, le tibial et le génual sont mèlés de brun et de blanc; l'abdomen est ovale, allongé, plus ètroit que le céphalothorax et couvert comme lui de poils à fond brun et fauve; en dessous il est d'un noir velouté, entouré de fauve sur les côtés; de plus on aperçoit deux points ovales d'un foncé vif dans le milieu de la bande noire.-Ciette espèce a été trouvée au cap de Bonne-Espérance.

\section{GLASTES , WALCK.}

Les yeux, au nombre de huit, sont presque égaux entre eux, placés sur deux lignes; la ligne postérieure très-courbée en avant; la ligne antérieure droite; toutes deux formant un demi-cercle dont le diamètre est en avant. - La lèvre est courte, dilatée ę large à son extrémité, qui forme une ligne legérement courbée et subitement resserrée dans une partie de sa longueur jusqu'à sa base. - Les : mâchoires sont presque articulées horizontalement, écartées à leur base, bombées et divergentes, ensuite droites et parallèles resserrées dans leur milieu; à leur extrẻmité elles sont échancrées au côté interne, arrondies au côté externe, coudées et se terminant en angle obtus. - Les mandibules sont articulées pour être portées en avant du céphalothorax. - Les pattes sont très-allongées, très-inégales entre elles; la première paire est la plus longue, la quatrième ensuite, la troisième est la plus courte. - Ces Aranéides ne se font pas de toile, mais tendent des fils, épient et chassent après leur proie, et se cachent dans des feuilles et les fleurs de différentes plantes.

\section{CLASTES FREYCINETIY.}

Walck., op. cit., t. I, p. 578. - Long. 9 lig. - Le céphalothorax est court, en forme de cœur arrondi, déprimé à sa partie postéricure, convexe ou bombé à sa partie antérieure; les yeux sont bruns, gros et saillans, et placés sur un fond glabre et plus rouge que le reste du céphalothorax; les mandibules sont fortes, allongées, portẻes en avant et courbées extérieurement, ou divergentes vers leur extrémité ; les paites sont fauves, rougeâtres, comme le corps, sans poils, mais ayant des épines très-allongées ct couchées; l'abdomen est allongé, étroit, cylindrique, se rétrécissant vers la partie anale, d'un fauve-jaunâtre, avec six petits traits d'un rouge carmin, disposés longitudinalement. - Habite l'île de Guam et la Nouvelle-Guinée.

\section{SPARASSUS, WALCK, ; Micrommata, Latr.}

Les yeux sont au nombre de huit, apparens, occupant le devant du céphalothorax, placés sur deux lignes, dont l'antérieure est la plus courte. - La levre est courte, large, semi-circulaire ou cllipsoĩde. - Les mâchoires sont écartées, droites, cylindroïdes, à côtés droits et parallèles, et à extrémité arrondie. - Les pattes sont allongées, fortes, étalées et divergentes, peu inégales entre elles. - Ces Aranéides épient leur proie, courent après, se renferment pour pondre entre des feuilles qu'elles ploient, ou dans les cavités des plantes, les interstices des pierres et des rochers, où elles se construisent de longs fourreaux de soie.

Ce genre a été partagé en quatre groupes.

\section{PREMIER GROUPE.}

\section{Les Micrommates, WaLGK.}

La lèvre est semi-circulaire. - Les mâchoires sont larges. - Les yeux latéraux de la ligne antérieure sont plus gros que les autres; les intermédiaires de la ligne antérieure sont écartés entre eux et rapprochés des yeux latéraux de la première ligne. - Les pattes sont presque égales; la seconde paire est la plus allongée, la quatrième ensuite, la troisième est la plus courte.

Les espèces qui appartiennentà ce groupe se tiennent, pour faire leur ponte, dans l'interieur des feuilles, qu'elles entourent en grottes ou en berceaux. Le cocon est globuleux.

1. Sparassus smaraginulus. (Pl. 6, fig. 3, $3 \Lambda$.)

Walck., op. cit., t. I, p. 582.-(La 
femelle), Aranea Virescens, Crekuк, p. 158, pl. 6, tab. 4. - Araignée toute verte, DeGÉER, t. VIl, p. 252, pl. 18, fig. 6 à 16. -Aranea Smaragdina, FABr., Ent., t. II, p. $412, \mathrm{n}^{\circ}$ 18. - Micrommata Smaragdula, Latr., Génér. Crust. et Ins., t. I, p. 115, spec. 1. - (Le mâle), Araignée Rose, Watck., Faun. Paris., t. II, p. 226 , n० 78. - Sparasse Rose; ibid., Aran. de France, p. 103, no 1, pl. 7, fig. 3. - Araneus Roseus, Crerck, Aran. Suec.,p. 137, spec. 6, pl. 6, fig. 7. - Long. 6 lig. - Le céphalothorax est cordiforme, bombé, arrondi à sa partie postérieure, il présente un sillon longitudinal auquel se joignent deux sillons latéraux moins creusés, formant un $V$ et marquant la partie antérieure; il est vert; nu, avec quclques poils grisâtres très-noirs; les yeux sont entièrement noirs; les mandibules sont vertes, à reflet rougeâtre, avec quelques poils noirs, mais courts et rares; la lèvre et les mâchoires sont vertes; les palpes sont de même couleur, avec l'extrémité tachée de brun; lespattes sont grandes, fortes, propres à la course, vertes, arec des poils fins aux jieds; l'abdomen est ovale, allongé, arrondi à sa partie antérieure, plus large dans son milicu, se terminant en pointe vers la partie anale, d'un vert jaunâtre, avec une ligne longitudinale plus rerte sur le milieu $d u$ dos, qui, ayant une tache élargie à son commencement, près du céphalothorax, diminue insensiblement, et se termine en pointe en s'approchant de la partie postérieure; en dessous il est plus pâle, excepté la plaque abdominale qui reçoit l'attache du cephalothorax, laquelle est aussi plus verte que le reste du ventre. Le mâle diffère de la femelle, par son céphalothorax, ses pattes et ses palpes qui sont verts; l'abdomen est pâle, cylindroïde, râyé sur le dos, dans toute sa longueur, par cinq bandes alternativement jaune clair et pourpre. Le cocon est de la grosseur d'une noiselte, formé d'une toile fine et transparente; les oufs sont tous agglutinés entre eux, d'une belle couleur verte; les petits, en sortant de l'œuf, sont d'un vert pâle et jaunâtre; les palpes et les pattes sont blancs; mais au bout de quelques heures ils prennent une couleur brunâtre obscure. Cette espece, qui se trouve aux environs de Paris, court et même saute avec agilité zans l'herbe pour attraper sa proie.

\section{WLUXIEME GROUPE}

\author{
Opticiennes, WaLCK.
}

La lévre est semi-circulaire. - Les mâchoires sont larges. - Les yeux, sur deux lignes, sont presque égaux, les latéraux antéricurs n'étant pas plns gros que les la. téraux postérieurs. - Les pattes sont presque égales entre elles; la seconde paire est la plus allongée, la quatrième ensuite, la troisième est la plus courte.

Les Aranéides qui appartiennent à ce groupe se tiennent, pour faire leur ponte, dans les cavités des pierres et des rochers, et s'y construisent unc tente en soie où elles se renferment.

\section{SPARASSUS ARGELASIUS.}

Walck., op. cit., t. I,' p. 584; ibid., Aran. de France, p. 108, $\mathrm{n}^{\circ} 3$, pl. 7, fig. 1; (le mâle); ibid., Hist. nat. des Airan., fasc. 4, fig. 2.-Micrommate Argelas, DuF., Observ. sur les Arachil., p. 11, pl. 95, fig. 2. - (La femelle) Philodromus Linnai, Sav. et Aud., Descrij. de l'Egypie, Arachn., p. 160, pl. 6 , fig. 2 (le mâle).-Long. 6 lig. Le céphalothorax est grand, convexe, d'un fauve pâle, garni d'un duvet clairsemé grisâtre ; les yeux sont d'un rougeâtre brillant; les mandibules sont assez fortes, noirâtres; les pattes sont hérissées d'épines noires, avec des anneaux noirs au génual et au tibial; l'abdomcn est ovalaire, couvert d'un duvet très-serré, d'un gris cendré; sa partie supéricure ou le dessus présente à sa base une petite bande grise cixconscrite par deux petites lignes noires; les côtés latéraux sont tiquelés de noir, avec le mi'ieu du ventre occupé par une grande tache très-noire, échancrée extérieurement. Le mâle est plus petit; son céphalothorax est d'un vert-jaunâtre en dessus; les inandibules sont jaunâtres à leur partie supérieure, noires à leur extrémité ; l'abdomen est ovale, allongé, pointu vers son extrémité; en dessus sont denx courbes opposées, noires, qui se terminent en angle à la partie anale; le dessous est uni, d'une couleur uniforme, excepté les ouvertures stigmatiformes, qui sont plus pâles; les pattes sont d'un vert-jaunâtre, avec des épines noires; elles sont inégales entre elles; la seconde paire, sensiblement plus longue que la première, surpasse un peu la quatrième, la troisième est la plus courte; les palpes sont courts, verdâtres, excepté le dernier article, qui est ovale, allongé, très- 
gros et entièrement noir. - Cette espèce, qui se trouve aux environs de Paris, a été rencontrée par M. L. Dufour, dans le royaume de Valence. Elle court avec vélocité, les pattes étendues latéralement: la conformation de ses pelotes onguiculaires lui donne la faculté de s'accrocher sur les surfaces les plus lisses, les plus verticales, et d'y circuler dans toutes les direclions.

\section{TROISIEME GROUPE.}

\section{Les Clubionides, W ALCK.}

La lèvre est triangulaire, large à sa base, arrondie à son extrémité. - Les mâchoìres sont allongées, droites, écartées, légérement dilatées et arrondies vers leur extrémité externe, et ayant une petile échancrure à leur extrémité interne. - Les yeux sont presque égaux entre eux, placés sur deux lignes qui se courbent légérement l'une vers l'autre, et portés sur un légère élévation. - Les pattes sont allongées, minces, la quatrième paire surpassant ou égalant la première en longueur, laquelle est plus loague que la seconde paire; la troisième paire est la plus courte.

\section{SPARASSUS FUSCUS.}

WALCK., op. cit., t. I, p. 586. - Long. 2 lig. $\frac{1}{2}$. - Le céphalothorax est ovoïde, allongé, moins long et moins large que l'abdomen, bombé, aplati sur les côtés, avec un ovale rougeâtre dans le milieu, et un autre transversal vers les yeux, mais obscure; l'espace qui existe entre les yeux est noirâtre; les mandibules sont allongées, verticales, d'un brun-noirûtre; les palpes sont courts, minces, fauve-rougeâtre, noires à leur extrémité ; les pattes sont verdâtres, marquées de brun; la plaque sternale est noire, avec des élévations ả la naissance des pattes; l'abdomen est ovale, allongé, brun sur les côtés, avec une large tache brune dans le milieu, entourée de fauve. - La patrie de cette espèce est inconnue.

\section{QUATRIİME GROUPE.}

\section{Les Tégẻnairides, W ALGK.}

La lèvre est ovale ou ellipsoïde. - Les mâchoires sont allongées, étroiles. - Les yeux sont saillans, presque égaux entre eux, sur deux lignes rapprochces, dont l'antérieure est légérement courbée en arrière. - Les pattes sont de longuenr moyenne; la quatrième pairc est la plus allongéc, la première après, la troisieme est la plus courte - Les Aranéides renfermées dans ce groupe se retirent sous les pierres.

\section{SPARASSUS Spinicrus.}

Walck., op. cit., t. I, p. 586. - Avanea Spinicrus, L. Duf., Am, des Sc. nat, 1834, p. $7, \mathrm{n}^{\circ} 3$, pl. 10, fig. - Long. 4 lig. - Le céphalothorax est ovale, convexe, peu ou point comprimé sur les côtés, marqué en dessus de quelques mouchetures ob. scures; les mandibules sont verticales, cy. lindroïdes; les mâchoires sont droites, assez écartées, armées intérieurement dc . raies crochues bien prononcées; la lèvre est du double plus courte que les mâchoires; les palpes sont d'un gris-cendré uniforme; les jambes des deux premières paires de pattes sont armées, de chaque côté de leurs bords, d'une rangée de six à sept soies longues, droites, roides, dirigées en avant, appliquées dans le repos entre les jambes, et mobiles sur leur base, qui est marquée d'un point noir; le premier article des tarses de ces mêmes pattes offre aussi de chaque côté trois soies pareilles; l'abdomen est allongé, étroit, d'un griscendré, avec des mouchetures et trois petits chevrons en dessus; les filières forment un mamelon saillant et sont trosiquées.

Cette espèce a été trouvée dans lesmon. tagnes de Moxente.

\section{DEUXIÈME SECTION.}

\section{Les Errantes, WaLcK.}

Errant à l'entour des nids qu'elles ont construits, ou des fils qu'elles ont tendus pour attraper leur proic.

\section{SEPTIEHE SOUS-SECTION.}

\section{Les Nitideles.}

Errantes, mais se faisant de leur nid une toile où aboutissent des fils pour attraper leur proie.

\section{CLUBIONA, W $\triangle$ LCx.}

Les yeux, au nombre de huit, presque égaux entre eux, occupent le devant du céphalothorax, et sont placés sur deux lignes rapprochées. - La lèvre est allongée, ovalaire, dilatée dans son milieu, terminèe en ligne droite, creusée à son extrémité, ou large, courte et échancrée. Les mâchoires sont étroites, allongées dila. tées vers leur extrémité. - Les paltes sont fortes, allongées, propres à la course, de longueur variable. - Ces Aranéides épient leur proie et courent aprés, tendent des fils à l'entour des cellules de soie, ou elleg 
demeurent enveloppées, dans l'intérieur des feuilles, les cavités des murs et des pierres. La plupart vivent long-temps dans leur nid, après la ponte, en société avec leurs petits.

Ce genre a été divisé en six groupes.

\section{PREMIER GROUPE.}

\section{Les Dryades, W aLcK.}

Les yeux, sur deux lignes rapprochées, sont étalés sur le devant du céphalothorax; les postérieurs du carré intermédiaire sont plus écartés entre eux que les antérieurs, les latéraux, non rapprochés entre eux, sont très-obliques - La lèvre est allongèe, avec l'extrémitẻ arrondie sur les côtés et légérement creusée dans son milieu. - Les mandibules se portent en avant.-Les pattes de la quatrième paire sont plus longues que les autres dans les femelles, la troisieme est la plus courte.

Les espèces qui composent ce groupe se tiemnent dans des cellules entre les feuilles et derrière les écorcesdes arbres, ou les interstices des pierres et desrochers. Leur cocon est ordinairement aplati.

\section{CLUBiona HOLOSORICEA.}

W aLck., Aran. de France, p. 112, no 1 , pl. 7, fig. 8 : ibid., op. cit., t. I, p. 590. -Araignée Satinée, Degéer, Mém. sur les Ins., t. VII, p. 226, pl. 15, fig. 15 et 46. - Clubiona Holosoricea, ШанN, Monogr., fasc. 5, pl. 4, fig. A ; ibid.,. Die Arachn., t. I, p. 112 , pl. 29 , fig. 84 . - (Le mâle), Aranea Holosoricea, Linv., Faun. Suec., édit. 2, $\mathrm{n}^{\circ}$ 2015. - Long. 4 lig. - Le céphalothorax est grand, ovale, allongé, arrondi, un peu bombé, surtout à la partie antérieure; il est brunâtre, recouvert de poils gris, et d'un aspect soyeux ; les mandibules sont noirâtres, légérement bombées à leur naissance, et un peu dirigées en avant; les mâchoires et la lèvre sont rougeâtres; les pattes sont assez allongées, recouvertes de poils gris soyeux; l'abdomen est ovale, allongé, s'amincissant à la partie postérieure, recouvert en dessus de poils courts, soyeux, d'un gris satiné; il y a quatre points enfoncés sur le milieu du dos, mais très-peu distincts. - Cette Aranéide, très-commune dans les jardins, construit un sac de soie remarquable par sa finesse, sa blancheur et sa transparence, et s'y ménage une ouverture par où elle sort lorsqu'elle est effrayée. C'est dans cette cellule qu'elle pond ses æufs, les renferme dans un cocon de soie aplati, large, ou ils forment de petips saillies. Lorsqu'clle a fait sa ponte, cisene quitte plus sa demeure et garde assidûment sa progéniture. Le mâle et la femelle sont entièrcment semblables, et habitent ensemble la même cellule dans le temps des amours; le tube est alors divisé en deux par une cloison en soie, et ils se tiennent chacun dans leur cellule, l'un au-dessus de l'autre.

\section{CLUBIONA EPIMEIAS.}

WaLcK., Aran. de France, p. 121, n० 5; ibid., op. cit., t. I, p. 592. - Clubiona Rubripes, $\mathrm{H}_{\mathrm{AHN}}$, fasc. 4 , pl. 5 , fig. C. -Long. 5 lig. - Le céphalothorax est grand, allongé, arrondi, d'un brun-marron foncé, presque noir antéricurement, avec des poils gris-blancs à la base, rougeâtre postérieurement et veiné de noir sur les côttés; les mandibules sont noirâtres, fortes, trèsrenflées dans leur milieu, glabres, luisantes, saillantes au-delà de leur naissance, ayant des poils gris blancs sur le côté intérieur, et la rainure du crochet hérissée de quelques poils rougeâtres; la lèvre et les mâchoires sont d'un brun-noir, mais de couleur plus claire et rougeâtres sur les bords, bombées, glabres, luisantes, et bordées de poils roux, longs, à l'échancrure de leur bord interne; les palpes ont les deux premiers articles rougeâtres, terminés par un anneau brun; les pattes sont fortes, d'un rouge-brun plus clair, annelées de blanc ou de rouge clair, et de noir ou de brun, avec quelques épines noires, la plaque sternale est noire, avec des poils roux assez longs; l'abdomen est allongé, cylindrique, noir, tant en dessus qu'en dessous, recouvert de duvet jaunâtre, mais en dessous les poils sont pâles et tirent sur le gris; les filières sont égales entre elles, rougeâtres, resserrées en faisceaux.-Celte espèce se ireuve en France.

\section{CLUBIONA CORTICALIS.}

WALck., Aran. de France, p. 118, no 3 ; ibid., op. cit., t. 1, p. 593. - Araignce Corticale; ibid., Faun. Paris., t. II, p. 429. - Long. 4 lig. - Le céphalothorax est rouge pâle, plus resserré antérieurement et plus bombé dans sa partie médiane ; les mandibules sont rougeâtres, renflées à leur naissance, et tombent perpendiculairement; les mâchoires, la lève, les palpes, les pattes et la plaque sternale sont rougeâtres; l'abdomen est ovale, allongé, grossissant vers la partie postérieure, brun, avec une ligne longitudinale plus brune à sa partie antérieure, bordée de jaune- 
rougeătre sur les côtés, êt entrecoupèe a sa partie postérieure par des chevrons transversaux, alternativement noirs et jaunes, qqui se prolongent sur les côtés; en dessus, et dans sa partie médiane on aperçoit deux points enfoncés; en dessous il est d'un jaune pâle. Le mâle ressemble à la femelle par Ies couleurs; mais les pattes sont beaucoup plus allongées; son abdomen plus mince, plus allongé et plus étroit que le céphalothorax, et se termine en pointe; les filières sont aussi beaucoup plus apparentes et plus prolongées, de couleur pále; les latérales supérieures sont les plus longues. - Se trouve aux environs de Paris.

\section{DEUXIÈME GROUPE.}

\section{Les Hamadryades, W ALCK.}

Les yeux sont ramassés en demi-cercle, ceux de la ligne antérieure élant très-rapprochés; les postérieurs du carré intermédiaire sont plus écartés entre eux que les antérieurs; les latéraux sont non rapprochés entre eux. - La lèvre est allongée, bombée, épaisse, terminée en ligne droite a son extrémité, ou légérement courbée. - Les mâchoires sont peu diiatées vers leur extrémité. - Le céphalothorax est rétréci à sa partie antérieure et relevé en carène dans sa partie médiane.

Les espèces renfermées dans ce groupe se tiennent dans les interstices des pierres, ou se renferment dans des feuilles qu'elles approchent, et où elles habitent lorsque ces feuilles sont mortes et desséchées sur l'arbre.

\section{Clubioni accentuata.}

WaLcK., Aran. de France, p. $124, \mathrm{n}^{\circ} 6$; ibid., Faun. Paris., t. 11, p. 226. Ibid., t. 1, p.594. - Косн, 121, n' 6. -Clubiona Punctata, HАн, Die Arachn., t. II, p. 8, pl.39, fig. 99. - Long. 5 lig. — Le céphalothorax est court, petit proportionnellement à l'abdomen, arrondi à sa partie postérieure, resserré et pointu antérieurement, trèsconvexe et relevé en carène dans sa partie mẻdiane, déprimé sur les côtẻs, de couleur fauve-gris ou rouge ferrugineux, ondè de brun sur les côtés; les mandibules sont rougeâtres et non portées en avant; les mâchoires sont d'une couleur fauve pâle; la lèvre est bombée, allongée, terminée en ligne droite à son extrémité, elle est d'un fauve-brun et d'une coulcur plus foncée que les mâchoires; les pattes sont d'un gris rougeâtre clair, un peu plus brun, avec des Asi. épines noires; la première paire est ordinairement la plus longue; l'abdomen est ovale, allongé, grossissant un peu vers sa partie postérieure; en dessus il est couvert d'une couleur fauve ou rougeâtre. avec deux petits chevrons noirs l'un sur l'autre dans la partie médiane. Le mâle diffère de la femelle par le céphalothorax et l'abdomen, qui ont des taches noires plus prononcèes sur les côtés, et les pattes qui sont plus allongées; la première étant beaucoup plus longue que la quatrième, et celle-ci surpassant la seconde; la couleur est aussi plus uniformément brune. - Celte espèce se trouve très-communément aux environs de Pais.

\section{Clubiona Rupicola.}

W aLcK., Aran. de France, p. 126, no 7; ibid., op. cit., t. I, p. 595. - Long. 5 lig. $\frac{1}{2}$. - Le céphalothorax est rétréci antérieurement, d'un fauve-rougeâtre , presentant sur les côtés deux bandes brunes, et une ligne trés-fine longitudinale de même couleur dans sa partie médiane; les mandibules sont allongées, coniques, et diminuent de grosseur vers leur extrémité, les mâchoires sont allongées, bombées à leur base et assez écartées entre elles; la lèvre est large, presque carrée, terminée en ligne droite a son extrẻmité; les patles sont rougeâtres et obscurément annelées; l'abdomen est plus grand et plus allongé que le céphalothorax, ovale, renflé dans sa partie médiane, très-pointu aux deux bouts, surtout postérieurement, d'un fauveroux dans sa partie médiane, et bordé sur les côtés et postérieurement d'une bande ovale, noire, un peu festonnéeà l'intérieur. ct présentant deux petites échancrures anguleuses dans son milieu; dans l'espace renfermé par cette bande noire est une petite ligne longitudinale près du céphalothorax, grossissant un peu à sa parlie pos. térieure, et accompagnée de deux points noirs placés au milieu; à la suite sont six chevrons ou accens circonflexes noirs, entourés vers la partie anale par la baude noire; en dessous il est brun. Le mâle est plus petit; son céphalothorax est presque aussi long que l'abdomen, d'un noir mat sur les côtés, et noir anterieurement; dans sa partie médiane il est d'un fauve clair, avec une large bande longitudinale, formée par des poils de celle couleur, rétrécie dans son milieu à l'endroit du point enfoncé, qui est de couleur noire; les palpes sont d'un fauve clair, arec des taches noires; la 
lèvre est noire, allongée, ovalaire, arrondie à son extrémité et échancrée dans son milieu; les pattes sont longues, fines, étalées latéralement; l'abdomen cst ovoïde, un peu renflé dans son milieu, pointu pos. térieurement, d'une couleur fauve-noirâtre, avec une suite de petits chevrons blancs ou d'un fauve clair qui commencent aux deux tiers de sa longueur, la partie proche ie céphalothorax étant entiérement noire; en dessous il est noir. - Cette espece se trouve aux environs de Paris.

\section{CiURIONA NEGATOR.}

WALGK., op. cit., t. I, p. 497.-[ong. $8 \mathrm{lig.} \mathrm{-} \mathrm{Le} \mathrm{céphalothorax} \mathrm{est} \mathrm{allongé,}$ brun, glabre, luisant, avec deux bandes noires sur les côtés du milieu, une autre bande plus brune, et une raie fine, blanche sur le bord externe; sa partie antèricure est de couleur noire; les mandibules sont fortes, bombées, noires, courtes, avec des poils fauves peu serrés; les mâchoires, al. longées, droites, bombées, arrondies à leur côté externe, coupées obliquement à leur extrémilé interne, sont hérissées de poils rouges; la levre est large, ovalaire, tronquée en ligne droite, légérement creu. sée à son extrémité, d'un brun-rougeâtre ; les pattes sont forles, rougeâtres; la quatrième paire est la plus longue, la première ensuite, la troisième est la plus courte; la plaque sternale est ovale, glabre, luisante, noire, arec des poils fauves à l'entour, sans tubercules; l'abdomen est ovale, bombé, en ligne droite à sa partie antérieure, renflé vers sa partie postéricure, d'un fauve-brun uniforme; en dessous il est de même couleur, avec un carré formé par des lignes jaunes très-fines, et deux lignes parallèles dans le milieu. - Cette espèce a été trouvée dans l'île de VanDiemen.

\section{TROISIEME GROUPE.}

\section{Les Furies, Walcr.}

Les yeux, ramassés sur le devant du céphalothorax, sont sur deux lignes courbées en avant; les quatre intermédiaires des deux lignes forment un carré étroit, presque régulier; les latéraux étant non rapprochés entre eux, les intermédiaires postérieurs sont plus rapprochés entre eux qu'ils ne le sont des latéraux de la même ligne; les intermédiaires antérieurs sont rapprochés des latéraux de la même lignne. - La Jevre est ovale, allongée, large, terminée presque en droile ligne, ou légérement arrondie à son extrémité. — Les máchoires' sont droites, ècartées, allongées à leur base, dilatées dans leur milieu. - La quatrième paire de patles est la plus longue, la première ensuite, la troisieme esi la plus courte. Les Araneides composant ce groupe se renferment dans une toile fine sous des pierres. Leur cocon est arrondi.

\section{CLUBIONA LAPIDICOIENS.}

Walck., op. cit., t, I, p. 598. - Arai gnée Lapidicole; ibid., Faun. Paris., t. II, p. 222, n० 20 ; ibid., Tab. des Aran., p. 44, n० 12, pl. 5, fig. 48. - Clubiona Lapidicola; ibid., Aran. de France. p. 129, n० 7. - Latn., Génér. Crust. et Ins., t. I, p. 91, no 1, tab. 5, fig. 98, c. HaHx, Die Arachn., t. II, p. 29, pl. 40 , fig. 100. - Long. 7 lig. - Le céphalothorax est ovale, allongé, relevẻ el bombé, arrondi à sa partic antéricure, relevé en carène dans sa partie médiane, comprimé sur les côtés, avec un sillon longitudinal très-fin postérieurement; les mandibules sont d'un rouge pâle, perpendiculaires', longres, fortes et divergentes; les mâchoires sont d'un rouge-brun pâle, droites, écartées, peu dilatées à leur extrèmilé et bombées à leur base; la lèvre est allongèc, grande, ovale, large à son extrémité et légérement velue; les palpes sont fins, filiformes, allongés, lavés de noir à leur extrémité; les pattes sont fortes, allongées; la quatrieme paire surpasse de leaucoup la première en longueur; cette dernière est plus longue que la scconde, et la troisième est la plus courte; ces pattes sont hérissées de quelques poils noirs, et d'épines de mème couleur; le plastron sternal est en ovale allongé, avec des poils fauves et la partie médiane rougreâtre; l'abdomen est ovale, allongé, un peu plus gros dans sa cartie médiane, d'une couleur grise uniforme; en dessous il est de même couleur, mais plus pâle; les filières sont allongées, de couleur grise.- Cette espèce se trouve assez communément aux environs de Paris.

\section{QUATRIEME GROUPL.}

\section{Les Nymphes, WaLck.}

Les yeux sont étalés sur la partie antérieure du céphalothorax et sur deux lignes, les quatre intermédiaires forment un carré presçue régulier, mais les postérieurs sont un peu plus écartés entre cux que les anté- 
xieurs; les lalèraux sont rapprochés et portés sur une même éminence du cćphalo. thorax; la ligne tracée entre les points du milieu de l'espace qui sépare ces derniers traverse le milieu du carré intermédiaire. - Lalérre est triangulaire, élar. gie dans son milieu, terminée en ligne droite, ou légérement creusée dans so! milien. - Les mâchoires sont droites, allongées, dilatées vers leur extrémité. - Le céphalothorax est large, bombé. - Les pattes sont allongées; la première paire est la plus longue de toutes, la seconde ensuite, la troisième est la plus courte.

Les espèces qui composent ce groupe se renferment dans des feuilles, qu'elles rapprochent, et font de grands nids.

8. Chubiovi nuthix. (Pl, 6, fig. 2.)

WaLcK., Aran. de France, p. 135, n* 8; ibid., op. cit., t. I, p. 601. - Drassus Maxillosus (le mâle); Revss,, Mus. Senckenbergian, p. 209, pl. 14, fig. 8. - Long. 9 lig. - Le céphalothorax est verdâtre ou tirant sur le rougeâtre, à sa partie antérieure il est très-large et très-bombé, comprimé sur les côtés, couvert seulement d'un court duvet; les mandibules sont grandes, fortes, et tombent perpendiculairement; elles sont rouges dans la plus grande partie de leur longueur, mais noires à leurs extrémités; la lèvie est brune; les mâchoires sont rougeâtres, et les bords sont entourés d'une bande noire plus large à leurs extrémités; les pattes sont fortes, allongées, d'un rouge pâle uniforme, tirant quelquefois sur le verdâtre, lavées de noir á leur extrémité; l'abdomen est ovale, bombé, plus gros antérieurement, d'un verdâtre obscur, uniforme, avec quatre points enfoncés sur le milieu du dos, qui offre quelquefois, après la pointe, un petit enfoncement ou sinuosité près du céphalothorax. - Cette espèce se trouve aux environs de Paris.

\section{CINQUIEME GROUPE.}

\section{Les Satyres, WalcK.}

Les yeux sont ramassés sur le devant du céphalothorax; les antérieurs du carré intermédiaire sont plus rapprochés entre eux que les postérieurs; Ies latéraux sont rapprochés entre eux; la ligne tracée entre le point du milieu de l'intervalle qui les sépare passe un peu au-dessous des bordsinférieurs des yeux intermédiaires postérieurs. - La lèvre est ovalaire, bombée, étroite, et échancrée à son extrémité. - Les mâchoires sont courtes, carrées, bombées. écartées, légérement inclinées sur la lèvre. - Les mandibules sont hombées à leur naissance. - Le céphalothorax est rétréci et bomleé antérieurement. - Les paltes sont plus allongées, la première paire est la peu longue, la quatrième ensuite, la troisieme est la plus courte.

\section{Clubroka Fallax.}

Walck., Aran. de France, p. 142, n¹0; ibid., op. cit., t. 1, p. 603. - Long. $4 \mathrm{lig}$. - Le céphalothorax est de grandeur mèdiocre, glabre, rouge, élargi à sa partie postérieure, resserré vers la tête, qui est bombée, déprimée sur les côtés, et ayant un point enfoncé vers la partie postérieure; les mandibules sont fortes, rouges, glabres, bombées à leur insertion, écartées latéralement et non conniventes; les mâchoires sont courtes, fortes, larges, bombẻes, foiblement inclinées sur la lévre, et d'une couleur rouge; la lèvre est large, courte, ovale, de mểme couleur que les mâchoires, glabre, très-bombée et coupée en ligne droite ; les palpes sont allongés, très-minces, sétacés, avec leurs deux derniers articles ciliés; les pattes sont fortes, rouges, presque glabres, avec les côtés ciliés par des poils longs et fins de couleur fauve; la qua. trième paire est la plus longue, la première ensuite, la troisième est la plus courte; l'abdomen est ovale, allongé, grossissant postérieurement, très-bombé, d'un jaune rougèâtre et ‘erminé en pointe postérieurement; en dessus sont quatre points qui forment une espèce de carré; en dessous il est d'une couleur jaune, un peu velu et hérissé de quelques poils; les filières sont rouge-pâle, peu allongées; les inférieures sont plus grosses et un peu plus allongées que les supérieures. Le mâle diffère de la femelle en ce qu'il est moins grand et moins gros, et en ce que son abdomen est beatcoup plus étroit et plus allongé._- Cette espèce se troure en France.

\section{SIXIENE GROUPE.}

\section{Les Parques, Walck.}

Les yeux du carré intermédiáire sont sessile;; les antérieurs sont plus rapprochés entre eux que les postérieurs; les latéraux sont rapprochés entre eux, et portés sur une éminence du céphalothorax; la ligne tracée entre les points des intervalles qui séparent ces derniers passe par le 
bord postérieur des yeux intermédiaires. - La levre est grande, ovalaire ou tronquée, et terminée en ligne droite ou légérement creusée à son extrémité. - Les mâchoires sont allongées, droites, écartées, s'élargissant graduellement vers leur extrémité, arrondies à leurs côtés internes comme à leurs côtés externes. - Les mandibules sont très-bombées à leur insertion. - Les pattes sont médiocrement allongées; la première paire est la plus longue, la quatrième ensuite, la troisième est la plus courte. - Le céphalothorax est bombé à sa partie antéricure.

Les Aranéides composant ce groupe se renferment dans une toile fine, pratiquée dans les cavités des murs, les caves et les lieux obscurs, le plus souvent collée contre Jes parois.

\section{CLUBLoNa ATRox.}

Walck., Aran. de France, p. 146, $\mathrm{n}^{\circ} 1$, pi. 7 , fig. 5,6 ; ibid., op. cit., $\mathbf{t}$. I, p. 605.- - Hans, Die Arachn., t. I. p. 145, pl. 30, fig. 87. - Latr., Génér. Crust. et Ins., t. 1, p. 93, $\mathrm{n}^{\circ}$ 4, tab. 3, fig. 7. Araignée Atroce, DeGÉER, t. VII, p. 253, pl. 14, fig. 24, 25, - Avanea Atrox, Trev, Uher di Bau der Arachn., p. 38, fig. 37 a 40.-Araneus Nigricans, Lister, p. 68, titr. 21, fig. 21. - Long. 5 lig. - Le céphalothorax est épais, bombè, nuirâtre an. térieurement, avec un trait enfoncé postérieurement, qui forme la pointe d'une grande tache brune, qui enveloppe toute Ja partie antérieure, tranchant avec la couleur plus pâle de toute la partie postérieure; les mandibules sont bombées, saillantes au-dela de leur naissance, très-velues, recouvertes de poils noirs, avec un reflet rougeâtre; les mâchoires et la lèrre sont d'un rouge-brun; les palpes sont de longueur médiocre, rouge pãle, de couleur plus foncée vers leur extremité ; la plaque sternale est ovale, allongée, pointue à sa parlie postérieure, plate et sans éminences à la naissance des pattes, et d'une couleur pâle rougeâtre; les pattes sont de longueur médiocre, assez régulièrement mêlées de rouge et de brun pâle, légérement velues, avec quelques épines noires; les antérieures sont plus rouges vers leu s extrémités; l'abdomen est ovale, allongé, légérement renflé vers sa partie postérieure, déprimé, ayant à sa partie antérieure une tache en carrè long, noire, èchancrée sur les bords; l'espace qui l'eatoure est de couleur jaune paille clair; en dessus et dans sa jartie mé- diane on aperçoit quatie points dont les deux antérieurs sont beaucoup plus marqués; en dessous il est d'une couleur pâle rougeâtre dans le milieu, avec deux lignes longitudinales de points bruns et des points noirs ou bruns sur les côtés; les filières sont trés-courtes, peu apparentes et de couleur: blanchâtre. Le mâle diflère de la femelle en ce qu'il est beaucoup plus petit; son céphalothorax, les pattes, les mâchoires, la levre et la plaque sternale sont d'une couleur plus claire que dans la femelle; l'abdomen est aussi beaucoup plus petit.

Cette espèce tapisse les murs des jardins, des caves et des lieux ombragés on obscurs, d'une toile lâche, formée de fils frisés d'un blanc sale, et en désordre, semblable à des lambeaux; elle se renferme dans des trous, des cavilés, et s'enveloppe pour passer l'hiver, ou dans des tubes, comme le $C$. Sericea, mais dans des espècos de maillots blanchâtres. Lorsqu'on la touche, elle se laisse tomber subitement, et sans se suspendre à un fil comme beaucoup d'autres Aranéides, et tombée à terre, elle retire ses pattes entre son corps, et fait la morte. Elle pond au mois de juin et de mai. Elle est alors très-hardie, et se jette avec férocité sur les objets qu'on lui présente, cherchant ì les mordre.

\section{CLUBIONA FEROX.}

Walck., Arall. de France, p. 150, fig. 12. - Ibid., op. cit., t. I, p. 606. - Aranca Terrestris, Reuss., Wider, Mus. Senckei$b e r g$, p. 215 , pl. 14 , fig. 10 , $a$ et $b .-C l u-$ biona Claustaria, $\mathrm{H}_{\mathrm{AHN}}$, Die Arachn., t. I, p. 114, pl. 30, fig. 86. - Long. $6 \mathrm{lig} . \frac{3}{2}$. - Cette espèce est remarquable par le dessus de son abdomen qui présente sur sa partie antérieure une ligne souvent dilatée en ovale allongé, d'un jaune pâle, bordé par une ligne noire, qui elle-même est entourée par un espace jaune, lequel s'élargit postérieurement; viennent ensuite quatre clevrons jaunes, formés par buit points jaunes inclinés l'un vers l'autre, séparés par une ligne noire ; ces chevrons diminuent de grosseur en s'approchant vers la pariie anale. Le mâle est semblable à la femelle, sculement il a les pattes plus allongées; l'abdomen en dessous, dans les deux sexes, est brun, entouré de lignes blanches ou jaunåtres qui dessinent un carré. - Se trouve assez communément dans les caves. 


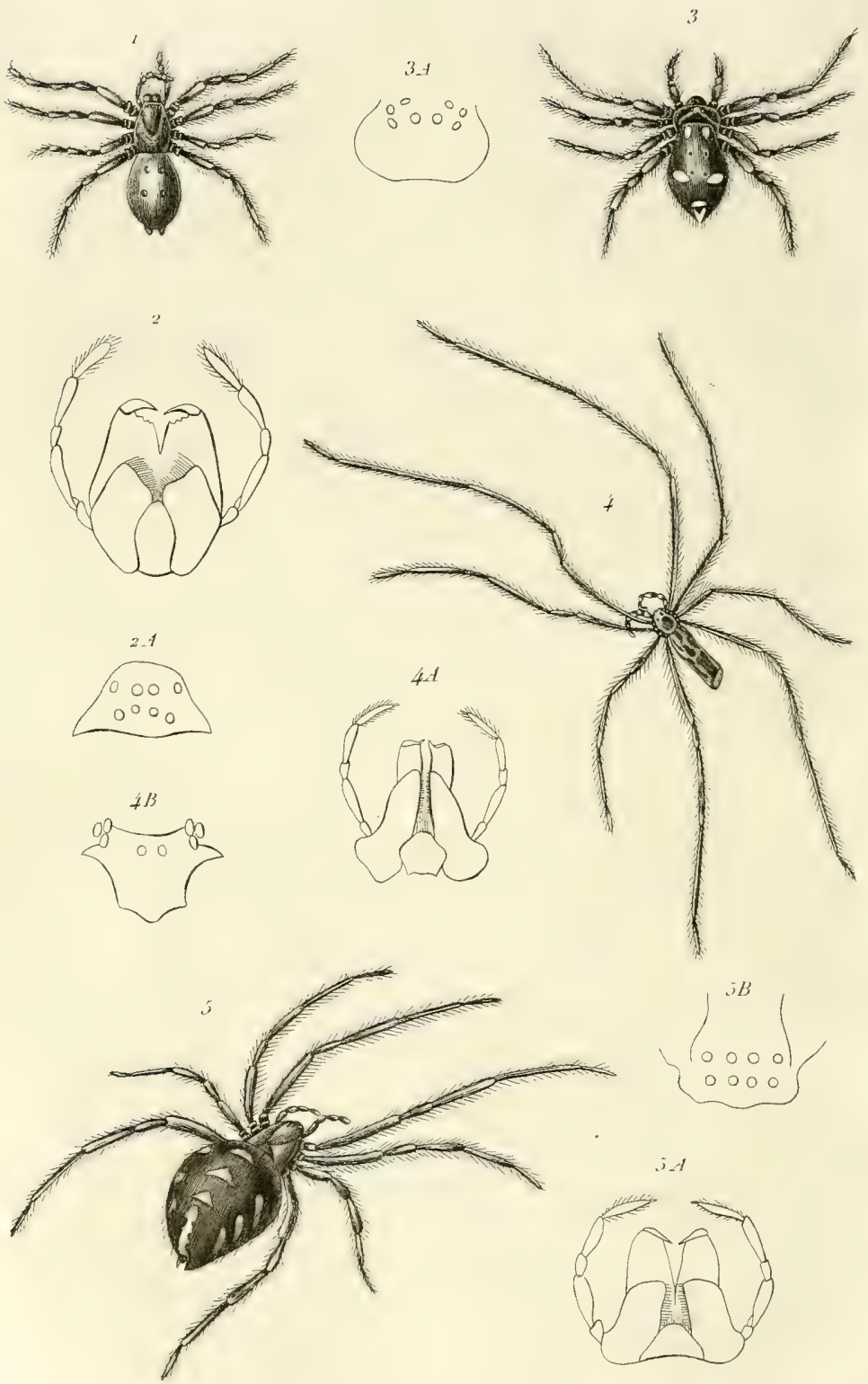

1. Drassus hucifugus, 2, mâchoúes, 2A, yeux. 3. Clotho Duraudii, 3A. yerux, 4-4

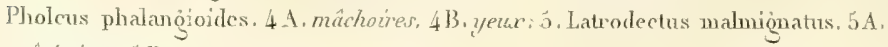
mâchoires. 5 B. yeux. 


\section{DESIS, WaLCK.}

Les yeux, au nombre de huit, sont sur deux lignes, l'antéricure étant très-rapprochée du bord antérieur du céphalothorax, courbée en arrière et formant un crnis. sant évasé ; les yeux du carré intermédiaire sont plus gros que les yeux latéraux, qui sont portés sur un tubercule peu élevé. La lèvre est allongée, à côtés parallèles, fortement échancrée a son extrémilé. Les mâchoires sont droites, divergentes, dilatées à leur base, pointues à leur extrémité. - Les pattes sont fortes, propres à la course; les antérieures plus allongées que les postérieures; la première paire la plus longue, la seconde ensuite, la troisième la plus courte.

Les mœurs de ces Aranéides sont inconnues. L'espèce type est le :

\section{DESIS DYSDEROIDES.}

WALck.,op. cit., t. I, p. 61A. - Long. 4 lig. - Le céphalothorax, d'un rouge corail, est aussi long et aussi large que l'abdomen, à côtés presque parallèles, et presque point resserré à sã partie antéricure, déprimé ; les mandibules sont très-fortes, d'un rouge corail, dirigées en avant, trés-longues, cylindroïdes, avec les crochets d'un rougebrun, allongés, demi-ouverts, et non entièrement reployés dans la rainure qui est dentelée; les dents de cetie rainure sont saillantes et au nombre de huit ou de neuf; les palpes sont d'un rouge corail; les paltes sont de même couleur, ont trois griffes aux tarses, dont un très-court et presque caché par les poils. - Cette espèce habite le Brésil.

\section{DRASSUS, WALCK.}

Les yeux, au nombre de huit, sont presque inegaux entre eux, sur deux lignes, et occupent le devant du céphalothorax. La lèvre est allongée, ovalaire, pointue ou légérement arrondie à son extrémité. - Les mâchoires sont allongées, inclinées ou courbées sur la lèvre qu'elles entourent. - Les pattes sont renflées, propres à Ja course.

Ces Aranéides se renferment dans des collules formées de soie très-blanche, sous les pierres, dans les cavités des murs et dans l'intérieur des feuilles et sur leur surfac

Les espèces qui le composent constituent cinq groupes.

\section{PREUIER GROUPE}

\section{Les Lithophiles, W ALcK.}

Les yeux sont sur deux lignes divergentes ou courbées; les latéraux sont écartés ; les intermédiaires postérieurs sont beancoup plus rapprochés entre eux qu'ils ne le sont des latéraux de la première ligne. - Les mâchoires sont dilatées dans leur milieu. - La lérre est ovale, allongée, arrondie à son extrémité. - Les pattes sont courtes, renflées, la quatrième paire est la plus longue, la première ensuite, la troisième est la plus courte. - Le céphalothorax est pointu antéricurement.

Les espèces renfermées dans ce groupe se tiennent derrière les pierres ou les cavités des murs.

1. Drassus rugifugus. (Pl. 7, fig. 1, 2, 2 A.)

Walck., Aran, de France, p. 155, no 1 ; ibid., Tab. des Aran., p. 45, n 1, pl. 5, fig. 46 et 47 ; ibid., op. cit., t. I, p. 613 . - Drassus Melanogaster, Latr., Génér. des Crust.et des Ins., t. I, p. 87, spec. 1, tab. 3, fig. 10. - HaHN, t. II, p. 111, pl. 41, fig. 102. - Filistata Femoralis, Reuss et Wrder, Museum Senkerbergian., t. I, p. 206, pl. 14, fig. 10. - Le céphalothorax et les pattes sont d'un brun rougeâtre, avec les cuisses de ces dernières d'un rouge plus clair ; les yeux intermédiaires forment un carré très-étroit; les yeux latéraux postérieurs sont écartés et reculés en arrière, de sorte que la ligne postérieure des yeux est plus large et plus couchée que la ligne antérieure; l'abdomen est ovale, allongé, d'un noir satiné, déprimé et élargi postérieurement; en dessus il est marqué, surtout dans le mâle, de quatre taches plus noires, en carré, trèsobscures.-Cette espèce se trouve dans les caves, sous les pierres.

\section{DEUXILME GROUPE.}

\section{Les Cauhées, WaLck.}

Les yeux sont sur deux lignes parallèles, les latéraux étant disjoints; les intermédiaires postérieurs sont plus écartés entre eux qu'ils ne le sont des latéraux de la même ligne. - Les mâchoires sont allongées, peu ou point dilatées dans leur milieu. La lèrre est allongéc, ovalaire, aussi large ou plus large à son extrémité qu'à sa base. - Les pattes sont courtes; les antérieures 
renflées; la quatrième paire est la plus longue; la première et la seconde paise sont presque égales entre elles; la troisième est la plus courte.

Les espèces qui composent ce groupe se tiennent dans les feuilles ou se cachent sons les pierres et d'autres lieux obscurs. Leur cocon est le plus souvent arrondi.

\section{DHASSUS NoCTERUES.}

WaLcK., Avan. de France, p. 157, $\mathrm{n}^{\circ} 2$; bid., Faun. Paris., t. II, p. 221.-Sund., Svinks. Spind., 1831, p. 30, fig. 3. Aranea Nocturna, Linn., Faun. Suec., 2 "édit., p. $489, n^{\circ} 2010$, ibid., Act. Upsal., édit. 1736, p. 38, n० 11.--Schranck, Faun. Ins. Austr., p. 528, $\mathrm{n}^{\circ}$ 1096.-Long. 6 lig. -Le céphalothorax est d'un noir rougeâtre, ovale, allongé, convexe, et relevé en carène dans son milieu, pointu et un peu resserré vers sa partie antéricure, qui est noirâtre, déprimée sur les côtés, noire et glabre, ayant de petites impressions qui se dirigent d'un seul centre en rayon vers les pattes; les mandibules sont noires, luisantes; cylindriques, perpendiculaires, et reuflées à leur insertion; les mâchoires sont de même couleur, courbées, à côtés parallèles, légérement échancrées à leurs extrémités; la lèvre est allongée, noire, élargie antérieurement, un peu en spatule, arrondie à son extrémité, qui présente dans son milieu une légère échancrure cordiforme ; les palpes sont filiformes, courts, minces et noirs, hérissés de poils et d'épines de même couleur ; ies pattes sont de longueur médiocre, avec les cuisses renflees et les hanches d'un noir uniforme; le reste est annelé de noir et de rouge; ces pattes sont hérissées de poils noirs allongés, et d'épines de même couleur; l'abdomen, d'un beau noir mat et en ovale allongé, est coupé carrément près du céphalothorax et élargi ensuite vers la partie anale, et présente en dessus quelques lignes blanches; en dessons il est fauve, jaunâtre dans son milieu, et noir sur les côtés; les filières sont trés-apparentes. - Cette espece se trouve en France.

\section{DRASGUS RUBENS.}

Walck., Aran. de France, p. 160 ; ibid., op. cit., t. I, p. 617. - Drassus Montanus, Hans, Die Arachn., t. II, p. 12, pl. 41 , fig. 103 . - Drassus Muri. wus, ibid., t. 11, pl. 61, fig. 141. - Dras. sus cinereus; ibid., fasc. $7, \mathrm{pl} .2$, fig. 144. - Filistala Incerta; Reuss el Wroer,
Mus. Senckerb., p. 208, pl. 14, fig. 7 a.Long. 7 lig.-Le céphalothorax esi glabre, rouge, pointu antérieurement, large dans sa partie médiane et postérieurement, aplati en dessus, avec les côtés arrondis et non dẻprimés; les mâchoires sont d'un rougebrun, allongées, arrondies à leurs extrémités, et bordées de poils; les mandibules sont fortes, coniques, rouges, dirigées en avant; la lévre est ovale, étroite, allongée, arrondie à son extrémité, et d'un rouge-brun; les palpes sont courts, minces, glabres, rouges, légérement noirâtresà leur base; les pattes sont fortes, courtes, renflées, surtout les inférieures, glabres, rougeâtres, arec des poils et des épines noirâtres; la quatrième paire est sensiblement plus longue que la première, celle-ci excède la seconde en longueur, la troisième est la plus courte; le plastron sternal est ovale, allongé, pointu à ses deux extrémités, glabre, rougeâtre, avec des poils rares, jaunâtres on bruns dans sa partie médiane ainsi que sur les côtés; l'abdomen est ovale, allongé, déprimé, terminé en ligne droile, un peu arrondi antérieurement, élargi dans son milieu, d'un gris jaunâtre, soyeux en dessus et sans taches; en dessous il est de mème couleur, mais plus pâle; les filières sont cylindriques, d'un ronge pâle, assez apparentes, les intérieures étant les plus longues. - Se trouve en France.

\section{DRASSUS ATER.}

LATR. Génér. Crust et Ins., t. I, p. 87, spec. 3, pl, 3, fig. 11. - Walck, Aran. de France, p. 162 et 163 ; ibid., op. cit., t. I, p. 618. - Hanv, Monogr. des Aran,, fasc. 7, pl. 2, fig. $d_{\text {, }} c$. ibid., Die Arachn., t. II, p. 34, pl. 61, fig. 440.-Long.3 lig. $\frac{3}{2}$. - Toute noire; le céphalothorax est pointu à sa partie antérieure, allongé, égalant l'abdomen en longueur et en largeur, noir, glabre, déprimé sur les còtés; les mandibules sont noires, cylindriques, bombées, et dirigées en avant; les mâchoires sont allongées, d'un brun-noir, avec leur estrémité rougeâtre; les palpes sont filiformes, per allongés, de couleur noire; les pattes sont courtes; l'exinguinal et le fémoral sont renflés, surtout ceux des pattes antérieures; la quatrième paire de pattes est la plus longue, ensuite la première, la troisième est la plus courte; elles sont toutes noires, excepté l'exinguinal et le fémoral, qui sur leurs côtés sont rougreâtres; de plus elles sont garnies de poils épais, courts, et d'épines assez 
fortes ct couchées; le mâle ne difère de la femelle que par son abdomen, qui est proportionnellement plus petit, et par ses palpes, dont le dernier article est renflé, ovale et pointu à son extrémité. - Celle espèce se troure assez communément aux environs de Paris, sous les pierres, et dans les chemins de traverse.

\section{TROLSİ⿴囗十 GROUPL.}

\section{Les Hábiles, WaLcK.}

Lesyeux sont sur deux lignes courbées en avant, concentriques ou parallèles; les ycux latéraux sont disjoints; les intermédiaires nostérieurs sont plus écartés entre eux qu'ils ise le sont des latéraux de la même ligne. - Les mâchoires sont inclinées, entourant la lèvre, très-bombées à leur base, courbées en avant et rétrécies dans Jeur milieu. - La lèvre est allongée, ovalaire, diminuant vers son extrémité. - Le céphalothorax est resscrré, et bombé antérieurement. - Les pattes sont allongées, la quatrième est la plus longue, la seconde et la première ensuite, la troisieme est la plus courte.

Les Aranéides qui appartiennent à ce groupe construisent, dans l'herbe, sous les pierres et dans les endroits cachés, une petile toile et un cocon hémisphérique, ou cn forme de coupe forméc par un opercule.

\section{DRAsSUS FUIGENS.}

Walck., op. cit., t. I, p. 622.-Drasse Brillante; ibid., Faun. Paris., t. II, P. 222, n० $7 \mathrm{I}$; ibid., Tab. des Aranéid., p. 46, no 5. - Ibid., Aran. de France, ․ 164. n०7.- Drassus Relucens, Latn., Gener: Crust, et Ins., t. I, p. 88, spec. 4 . - Hann, Die Arachn., t. 11, p. 55, pl. 61, fig. 143.- Risso, Hist. de l'Europe Mérid., t.V, p.162, n० 31.-Macaria fulgens, Kocr, 129, 14. - Long. 2 lig. $\frac{1}{2}$. - Le céphalothorax est allongé, un peu étroit vers la partie antérieure, rougeâtre, couvert d'un duvet bijllant, d'un jaune verdâtre, plus abondant entre les yeux, et deux petits traits d'un jaune clair, formant un petit chevron, dont l'angle est vers la partic antérieure; les pattes sont de la couleur du céphalothorax; les hanches sont allongées, avec les cuisses renflées; celles des pattes antérieures étant de couleur brune; l'huméral des palpes est aussi renflé et d'une couleur plus foncée; l'abdomen est ovale, allongé, bombé, un peu plus gros posté- rieurement et légérement poinfu vers la partic anale; en dessus il est revêtu de poils dorés, verdâtres ou bleuâtres foncés, avec quatre traits dorés ou cuivrès sur le milieu, inclinès en chevrous disjoints, et deux autres plus courts antérieurement, proche le céphalothorax; ces traits se détachent sur un fond noir violacé, qui forment comme deux régions transversales en dessus, entrc lesquelles la couleur est pâle, dorée; en dessous les poils verdâtres sont sur un fond noir. Le mâle diffère de la femelle par son abdomen, qui est plus allongé et plus cylin. drique.

Celle espèce, suivant M. Walckenaer, construit dans l'herbe et dans les cavités des picrres une tente formée d'une toile fine et serrée, ovale, et ayant deux issues. Celte toile en renferme une autre d'un lissu plus fin et encore plus serré. Cette seconde tente a la forme d'une voûte; c'est sous cette roûte qu'elle place son cocon, qui a environ une ligne trois quarts de diamètre, et qui cst composé de deux parties, une coupe et son opercule : la coupe est hémisphérique, profonde, d'une blancheur éclatante, et formée d'une pellicule mince, à tissu Irès-serré. C'est dans cette coupe qu'elle dépose quinze à vingt œufs rouges orangés, parfaitement isolés, qui sont bien loin de remplir la cavité du cocon. Elle ferme ensuite ce cocon avec un opercule ou feuillet plat, qui n'est pas collé sur les bords de la coupe et quí peut s'en détacher. C'est sur ce cocon qu'elle se tient; mais auparavant elle recouvre la cavité de la pierre d'une toile d'un tissu làche et transparent, ce qui lui forme au-dessus de la voûte une seconde chambre qui communique avec la premiere.

\section{QUATRIEME GROUPE.}

\section{Les Spéophiles, WaLck.}

Les yeux sont str deux lignes courbées en avant; les latéraux sont portés sur une éminence et paroissent rapprochés; les intermédiaires posterieurs sont moins écartés entre cux qu'ils ne le sont des latéraux de la même ligne, et plus écartés que les intermédiaires antérieurs : tous sont placés sur le devant du céphaloihorax - Les mâchoires sont larges, peu allongées, peu arrondies à leurs côtés et à leur extrémité externes, tronquées obliquement à leurs côtés cxternes. - La lèvre est large, ovalaixe, légérement échancréc à son extróe 
milé. - Les mandibules sont coubées à leur naissance. - Le céphalothoras est jarge, arrondi et bombé antérieurement. - Les pattes sont de longueur médiocre, renflées; la quatrième paire est la plus longue; la troisieme ensuite, la deuxième est la plus courte.

Ces Aranéides se tiennent sous les pieryes et dans les intervalles des rochers et des murailles, et y construisent un tube élargi en forme de sac ouvert. Leur cocon est rond et aplati.

\section{DRASSUS TRUCIDATOR.}

Walck., Aran. de France, p. 172, n०9; ibid., Hist. nat. des Ins. apt., t. 1, p. 630. - Agelena Montana, Kосн, 125, 11. Loug. 6 ]ig. $\frac{1}{2}$. - Le céphalothorax est glabre, d'un brun-noir sur les côtés et rouge dans ie milieu; les deux lignes des yeux occupent plus l'espace en largeur, et sont posées sur un plan peu incliné, assez avancées el assez près du bandeau; les yeux antérieurs intermédiaires sont assez saillans; les palpes sont allongés, robustes, rouges et jrésentent des poils de couleur noire à leur extrémité; les pattes sont rouges, robustes et assez renflées, et l'exinguinal et le fémoal de la quatrième paire sont presque aussi renflés que ceux de la première ; l'abdomen est ovale, allongé, déprimé en dessus et diminuant de grosseur vers la partie anale; dans certains individus, il est même presque cylindrique, et un peu plus gros antérieurement; en dessus il offe une ligne jaune rougeâtre, longitudinale, dilatée et bifide à son extrémíté; la branche du milieu se prolonge en ligne fine, jaune rougeâtre, comme la bande large dont elle émane, presque jusqu'à la partie anale, et est traversée par quatre ou cinq chevrons le même couleur qui se réunissent à elle; de plus cette bande offre dans son milieu une raie noire, longitudinale; les côtés de l'abdomen présentent de petites raies brunes très-serrées, ondulées daus le sens longitudinal; en dessous it est d'un fauve rougeâtre, et d'un jaune grisâtre uniforme.Se trouve aux environs de Paris.

\section{CINQUIEHE GROUPE.}

\section{Les Phytophiles, Walck.}

Les yeux sont sur deux lignes courbes, les latéraux étant rapprochés. - Les mâchoires sont larges, et rétrécies à leur base et à leur extrémité, à côtés externes arqués, à côtés internes courbés sur la lèvre et l'entourant. - Les pattes sont courtes. fines; la première paire est la plus longue, la seconde ensuite, iu troisième paire est la plus courte. - Le céphalothorax est petit, mais rétréci et bombé à sa partie antérieure.

Ces Aranéides construisent sur la surface des feuilles une toile fiue, blanche, transparente, à tissu serré, sous laquelle elles se tiennent, et recouvrent leurs œufs d'un tissu lâche, en forme de cocon aplati.

\section{DRASSUS VIRIDISSMMUS.}

Walck, Faun. Paris., t. II, p. 212,-Drasse Vert, ibid., Aran. de France, p. 176, n $^{\circ} 11$; ibjd., Hist. nat des Aran., fasc. 4, fig. 9 ; ibid., op. cit., t. I, p. 631. - Long. 1 lig. $\frac{1}{2}$. - Le céphalothorax est rougeâtre, entouré de jaune, avec des poils gris à sa partie antérieure; les yeux sont saillans et assez apparens; ]es mâchoires sont robustes, allongées, dépassant peu la Jèvre, droites, et à cótés parallèles vers leur base, qui est bombée; inclinées sur la lèvre vers l'extrémité, anguleuses à leur' côté externe, au sommet et au côté interne, sans échancrures latérales pour recevoir Ies palpes qui sont insérés sur le dos de ces mêmes mâchoires , et sont toujours de la même couleur que le céphalothorax, c'està-dire rouge verdâtre dans certains individus, et très-rouggeâtres dans d'autres; la lèvre est triangulaire, allongée et de même couleur que les mâchoires; les pattes sont courtes, d'un vert jaunâtre, sans poils ni épines; l'abdomen est ovale, allongé, plus renflé dans son milieu, arrondi antérieurement, pointu vers la partie anale, très-bombé sur le dos, qui recouvre la partie postérieure du céphalothorax, d'un brun-vert pomme foncé, avec des arcs et des lignes obliques, jaunâtres ou d'un vert plus pâle que le resle. - On rencontre assez fréquemment cette espèce aux environs de Paris.

\section{SEPTIËME SOUS-SECTION.}

\section{Les Filitéles, Warck.}

Errantes, mais tendant de longs fils de soie, dans les lieux ou elles se meuvent pour attraper leur proie.

\section{CLOTHO, WALCK., LATR.; Uroctea, L. Dufoun.}

Les yeux, an nombre de huit, sont sur deux lignes; la ligne postérieure est trescourbée en avant; l'antérieure légérement 
cruarbée dans le même sens ou droite; les deux yeux antérieurs intermédiaires sont plus gros que les autres; les intermédiaires postérieurs sont très-écartés entre eux, et posés assez près de l'alignement des latéraux postérieurs et antérieurs pour former avec eux une courbe latérale de chaque côté des deux gros yeux intermédiaires; tous ces yeux sont placés autour d'un épistome élevé. - La lèvre, large à sa base, diminue de grosscur vers son extrémité, qui se termine en pointe, ou est échancrée ou arrondie. - Les mâchoires sont courtes, très-inclinées sur la lèvre, conniventes et arrondies à leur extrémité. - Les pattes de la quatrieme paire sont sensiblement plus longues que les autres et presque égales entre elles.

Ces Aranẻides se construisent sous les pierres un nid derrière une toile où elle habite avec leurs petits.

Ce genre a été divisé en trois groupes.

\section{PREMIER GROUPE.}

\section{Les Uroctées, WaLCK.}

Le céphalothorax est large, court, en croissant. - Les yeux intermédiaires postérieurs sont très-rapprochés des Jatéraux de la même ligne, et dont la tangente intérieure touche à leur orbite; la ligne antéricure est courbée en avant. - La lèvre est Jarge, triangulaire, pointue à son extrémité. - Les mâchoires sont courtes, à côtes parallèles , diminuant en pointe arrondie.

Ces Aranéides se construisent, sous les pierres ou entre les rochers, une toile à tissu serré, attachée seulement par ses prolonge. mens anguleux, et á plusieurs couches superposées entre elles; et, entre ces couches, elles construisent un nid à plusieurs valves, où elles se tiennent renfermèes avec leurs petits.

1. сцотнo nurandi. ( $\mathrm{Pl} .7$, fig. 3,3 A.) Latr., Génér. Crust. et lns., t. II, p. 370 ; ibid. . Rég. anim. de Cuv.. t. IV, p. 336. - Sav., Descript. de l'Égypte, Arachn., p. 134, pl. 3, fig. 6. - WaLck., op. cit., t. I , p. 636. - Uroctea Quinque Maculula, L. Defour, Ann. génér. des Sc. Phys., Bruxelles, t. V, p. 43, pl. 76 , fig. 1. - Long. 5 lig. - Le céphalothorax est beaucoup plus large que long, en croissant uniforme, d'un brun noirâtre, bordé d'une raie jaune clair; les palpes, peu allongés, se reportent sur ies mandibules qu'elles masquent; ces dernières sont minces, longues, insérées en bas d'un épistcme élevë, articulées verticalement, mais cependant ayant entre elles une sorte de cohésion, oblongo-cylindriques, amincies et à onglet petit; les pattes sont de la même couleur que le eéphalothorax; l'abdomen est ovale, allongé, pointu vers la partie anale, noir, avec cinq taches fauves ou jaunes, figurant, en les joignant par des lignes, un pentagone dont la pointe seroit dirigée vers la partie anale; les filières, au nombre de dix, sont allongées surtout la première paire, les deux autres paires sont courtes et velues.

Cette espèce qui, se trouve dans le midi de la France, en Dalınatie, en Espagne et en Egypte, établit, dit M. L. Dufour, à la surface des grosses picrres ou dans des fentes de rochers, une coque en forme de calotte ou de palette, d'un pouce de diamètre. Son contour présente sept à huit échancrures, dont les angles seuls sont fixés sur la pierre, au moyen de faisceaux de fils, tandis que les bords sont libres. Getle singuliére tente est d'une admirable texture: l'extérieur ressemble à un taffetas des plus fins, formé, suivant l'âge de l'ouvrière, d'un plus ou moins grand nombre de doublures. Ainsi, quand cette Aranéide, encore jeune, commence à établir sa retraite, elle ne fabrique que deux toiles, entre lesquelles elle se tient à l'abri. Par la suite, et je crois à chaque mue, elle ajoute un certain nombre de doublures. Enfin, lorsque l'époque de la reproduction arrive, elle tisse un appartement tout exprès, plus duveté, plus moelleux, où doivent être renfermés et les sacs et les œufs, et les petits récemment éclos. Quoique la calotte extérieure ou le pavillon soit, à dessein sans doute, plus ou moins sali par des corps étrangers qui servent à en masquer la présence, l'appartement de l'industrieuse fabricante est toujours d'une propreté extrême; les poches ou sachets qui renferment les œufs sont au nombre de quatre ou cinq, ou même de six pour chaque habitation. Ces poches sont en forme lenticulaire, et ont plus de quatre lignes de diamètre. Elles sont d'un taffetas blanc comme la neige, et fournies en dedans de l'édredon des plus fins. Ce n'est que vers la fin de décembre et au mois de janvier que la ponte des œufs a lieu. Il falloit prémunir la progéniture contre la rigueur des saisons et les incursions ennemies. Tout a été prévu: le réceplacle de ce précieux dé- 
pôt est séparé de la toile, immédiatement appliquée sur la pierre, par un duvet moelleux, et de la calotte extérieure, par les divers étages dont j'ai parlé. Parmi les échancrures qui bordent le pavillon, les unes sont tout-a-fait closes par la continuité de l'étoffe, les autres ont leurs bords simplement superposés, de manière quel' $U$ roctée (Clotho), soulevant ceux-ci, peut à son gré sortir de sá tente et y rentrer. Lorsqu'elle quitte son domicile pour aller à la chasse, elle a peu à en redouter la violation, car elle seule a le secret de ses échancrures impénétrables et la clé de celles où l'on peut s'introduire. Lorsque les petits sont en état de se passer des soins maternels, ils prennent leur essor et vont établir ailleurs leurs logemens particuliers, tandis que la mère vient mourir dans son pavillon. Aussi ce dernier est en même temps le berceau et le tombeau de l'araignée.

\section{DEUXILHE GROUPE.}

$$
\text { Les Enyo, WaLcK. }
$$

Le céphalothorax est ovale, allongé. - Les yeux intermédiaires postérieurs sont assez écartés des yeux latẻraux de la inême ligne pour que leur tangente inférieure laisse un intervalle entre elle et l'orbite des mêmes yeux latéraux postérieurs; la ligne antérieure est ovale. - La lèvre est grande, ovalaire, arrondie à son extrémité. - Les mâchoires sont larges, creusées extérieurement vers leur base, arrondies à leur extrémité interne, légérement inclinées, à côtés internes droits, et à extrémités rapprochées, mais non conniventes. - Les pattes sont de longueur médiocre, la quatrième paire est la plus grande, la troisième ensuite, la seconde et la première sont presque égales. - L'abdomen est globuleux.

\section{CLOTHO Nitida.}

WaLcK., op. cit., t. I, p. 539.-Enyo Ni. tida, Sav., Descript, de l'Égypte, Arachn., p. 135, pl.3, fig, 7.-Long. 3 lig.-Suivant M. Savigny, l'abdomen est globuleux, trèsbombé, d'un gris de lin très-foncé et chatoyant, terminé par des filières blanches à la base, noires à la pointe; les pieds sont noirs, avec un anneau blanc à la base des jambes et un autre plus grand à celle des quatre cuisses postérieures; les yeux postérieurs sont médiocrement écartés des latéraux. - Cette espéce a été trouvée en Sevpts.
TrOISILIE GROUPE.

Les Zoditions, WaLck.

Les ycux intermédiaires postérieurs sont écartés des yeux latéraux de la même ligne, de mąnière à ce que leur tangente extérieure laisse entre elle et l'orbite de ces mêmes yeux latéraux un assez grand espace; ces mêmes yeux sont assez reculés en arrière et sur les côtés pour ne former, avec les yeux postérieurs et antérieurs, qu'une ligne latérale pea courbée, la ligne transverse des y eux antérieurs étant courbéc en avant, - La lèvre est large, courte, tronquée à son extrémíté.-Les mâchoires soni très-inclinées, courtes, formant un coude a leur base, cylindriques, diminuant vers leur extrémité, qui est arrondie.- - Les pattes sont allongées, fines; la quatrieme paire est sensiblement plus longue que les autres, la première en. suite est la plus longue. - L'abdomen est ovoüde.

\section{CLOTHO EONGIPES.}

WaLck., op. cit., t. I, p. 640,-Enyo Lon. gipes, $\mathrm{S}_{\mathrm{Av}}$, Descrip. de l'Égyple, Arachn., p. $136, n^{\circ} 8$, pl. 3, fig. 8. - Long. 1 lig. - Le céphalothorax est petit, ovalaire, rétréciantérieurement, bombé, glabre, d'un rouge-brun: les palpes et les pattes sont d'un fauve-rougeâtre, avec les hanches de ces derniers organes d'un blanc jaunâtre; le plastron sternal est de même couleur; l'abdomen est ovoïde, très-convexe en dessus, d'un brun-marron, d'un rouge-brun plus foncé que le céphalothorax; en dessous il est d'un blanc sale, avec les filières blanchâtres et saillantes. - Cette description appartient a la femelle. qui a été trouvée par M. Walckenaer au bois de Boulogne, sous une pierre. Le même auteur regarde comme le mâte de cette especce l'individu qui a été décrit et figuré par M. Savigny dans les magnifiques planches de l'Égypte, et dont la description est : céwhalothorax brun; abdomen d'un cuivré noirâtre. Trouvé aus environs du Caire.

\section{LATRODECTUS, WALGK.}

Les yenx, au nombre de hnit et presque égaux entre eux, sont placés sur deux lignes écartées et légérement divergentes; les ycux latéraux étant un peu plus écartẻs entre eux que ne le sont les intermédiaires, 
et portés sur des éminences du céphalothorax. - La lèvre est triangulaire, grande et dilatée à sa base. - Les mâchoires, inclinées sur la lèvre, sont allongées, cylindriques, arrondies vers leur extrémilé externe, terminées par une pointe interne, et coupées en ligne droite à leur côté interne. - Les pattes sont allongées, inégales entre elles; la premiere paire est plus longue que la quatrieme, celle-ci est sensiblement plus allongée que les deux in. termédiaires, la troisieme paire est la plus courte.

Ces Aranéides filent dans des sillons. sous les pierres, des fils en nœuds ou en filets, où les plus gros jnsectes se trouvent arrêlés. Le cocon est sphéroide et pointu à l'ex. trèmité.

\section{LATRODECTUS MAIMTGNATUS. (Pl. 7,} fig. $5,5 \mathrm{~A}, 5 \mathrm{~B}$.)

Walck., Tab. des Aran., p. 81, pl. 9, fig. 83 et 84; ibid., op. cit., t. 1, p. 642 . - Aranea tredecim-Guttata, Rossi, Faun. Etrusc., t. 11, p. 136, no 982, pl. 9, fig. 10 . - Fabr., Ent. System.. p. 409, n०8. Luigr Totr, Att. dell' Acad. delle Scienz. di Siena, t. VII, p. 145.-A. T. DE BERNeAUD, Voy. á l'Ile d'Elbe, p. 66 à 67 , pl. 1, fig. 1, 2. - Long. 6 Jig. - Le céphalothorax est petit, déprimé, resserré vers sa partie antérieure et de couleur noire; les yeux sont fauves; l'abdomen est gros, renflé, globuleux, pointu vers la partie anale, de couleur noire; proche le céphalothorax, il y a une large bande transverse, d'un rouge sanguin, ensuite quatre autres de même couleur, dont deux placées longitudinalement, et deux transversalement sur les côtés; celle qui est le plus près du cercle est pentagonale, celle qui est dervière et qui est au milieu du dos est triangulaire, et les deux latérales sont ovalaires; derrière la grande tache triangulaire est une ligne longitudinale, formée de deux ou trois autres taches triangulaires ou arrondies et jointes, qui aboutissent à la partie anale el qui est aussi d'un rouge sanguin ; de chaque côté sont deux grandes taches de même couleur; ces taches, surlout celle du milieu, sont, dans quelques individus, traversées par un point noir, qui s'oblitère nvec l'âge; en dessous il y a deux taclies rouges transverses, couleur de sang.

C. Ite Aranéide, dit M. Thiebaut de Berneaud, dans un ouvrage ayant pour titre: Voyage a l'Ile d'Elbe, p. 66, pl. 1, tend sa toile a terre et en rase campagne, et se jette avec une vitesse prodigieuse sur sa proie; elle attaque surtout avec fureur le Scorpion et se repaît arec délices de son sang; elle fait sa compagnic de ses semblables. Elle s'accouple vers la fin de l'été, et elle enveloppe ses oufs, au nombre de deux à quatre cents, dans une coque de soie blanche, serrée et peu tenace. L'hiver elle se cache parmi les grosses pierres, dans les fentes des rochers ct sur les vieux murs, où elle attend, engourdie, les chaleurs du printemps. Sa morsure est très-dangereuse, elle est mortelle, même pour l'homme. Son venin, trés-subtil, le devient encore plus à raison de l'in. tensité de la chaleur. Je n'ai point appris qu'elJe ait fait du mal à l'île d'Elbe, sans doute faute d'observations particulières de la part des médecins; car je sais que dans le Volterra plusieurs habitants de la campagne, et des animaux domestiques sont morts des suites de la morsure. - Cette espèce est trés-commune en Corse, en Sardaigne et en ltalie.

\section{YATR ODECTUS ARGUS.}

Sav., Descript. de l'Égypte, Arachn., p. 137, pl. 3, fig. 10. - Latrodoctus Oculatus, WaLck., op. cit., t. I, p. 645 . Long. 3 lig. $\frac{1}{2},-$ Le céphalothorax est d'un bruu-noir ; les yeux occupent toute la longueur du céphalothorax, et débordent des deux côtés de la ligne extérieure des mandibules; les yeux intermédiaires antérieurs, comme les latéraux, sont réunis par deux tnbercules contigus; les palpes et les pieds sont noirs; l'abdomen est d'un noir bleuâtre, chatoyant, avec la base entourée par deux bandes contiguës, rougeâtres, encadrées de blanc; le dessus est orné de onze à douze taches rouges, cerclées de blanc, distribuées sur trois séries longitudinales; la série intcrmédiaire est formée de six taches, dont la seconde est plus grande, triangulaire, et dont les trois dernières, comme enchaînées l'une à l'autre, atteignent près dc la partie anale les séries latérales, formées de quatre taches isolées; le dessous est bordé sur les côtés par trois taches semblables à celles du dessus, mais moins colorées, et traversées en arrière des ouvertures stigmatiformes par une première bande blanche, suivie d'une seconde presque imperceptible. - Cette espèce a été frouvée cn Égypte, aux environs d'Aa lexandrie. 
3. IATRODECTUS FORMIDABHLIS.

Аввот, Aran. d'Am., pl. 18, fig. 191. - W $\Delta$ Lск., op. cit., t. I, p. 647. - Long. 7 lig. $\frac{1}{2}$. L Le céphalothorax et les pattes sont de couleur noire; l'abdomen est globuleux, de même couleur que le céphalothorax, avec trois grandes taches d'un rouge sanguin, disposées longitudinalement: la première est proche le céphalothorax et en losange ; celle du milieu est penta. gonale et plus grande; la tache postérieure est en pentagone très-pointu à son extrémité supérieure, et dont la base se prolonge jusqu'à la partie anale. Il y a quatre points enfoncés plus noirs, disposés en carré autour de la tache du milieu, et entourés d'un petit cercle blanchissant ou plus pâle. - Habite l'Amérique Septentrionale.

\section{PHOLCUS, WALCK.}

Les yeux, au nombre de huit, sont presque égaux entre eux, groupés sur une éminence antérieure du céphalothorax par deux et par trois et ainsi disposés : deux yeux intermédiaires antérieurs rapprochés ; 1rois yeux latéraux plus gros, très-rapprochés, connivents et groupés en triangle de chaque côté des petits yeux intermédiaires, et un peu plus reculés que ceux-ci. - La lèvre est grande, resserrée à sa base, dilatée dans son milieu, arrondie à son extrémité. - Les mâchoires sont étroites, allongées, cylindriques, légérement creusées et amincies à leur extrémité externe, inclinées sur la lèvre et contiguès. - Les pattes sont très-allongées, grêles; la première paire est la plus allongée, la seconde ensuite, la troisième est la plus courte.

Ces Araneiides, presque sédentaires, forment une sorte de réseau très-lâche, composé de fils flottans ou très-écartés, très-fins, tendus sur plusieurs plans différens; leurs œufs sont agglutinés en une masse ronde et nue, qu'aucun tissu ne recouvre, et elles les transportent ainsi entre leurs mandibules.

Les espèces qui constituent ce genre ont été divisées en deux groupes.

\section{PREMIER GROUPE.}

\section{Les Cylindroides, WaLCK.}

L'abdomen est cylindroïde, plus gros à sa partie postérieure.
1. PHorcus mazhagionds. (PJ. :, fig. 4. $4 \mathrm{~A}, 4 \mathrm{Br}$.

Waxck, Hist. nat. des Aran., fase. 5 , pl. 10 , le mâle et la femelle. - Araignée Phalangide, ibid., Faun. Paris., t. II, p. 212 et $213, \mathrm{n}^{\circ} 43$. - Pholque Phalangiste, SAv., Arachn. d'Égypt., p. 141, pl. 3, fig. 13. - Aranea Pluchii, Scopoli, Faun. Carn., p. 104. - L'araignée Domestique a longues pattes, Geofrr., Ins., t. II, p. 551, n०17.-Aranea Opilionides, SснR., Enum. Ins. Austria, p. 530, no 1103. Long. 4 lig. - Le céphalothorax est orbiculaire, d'un gris pâle et transparent, avec des taches plus obscures; de p'us l'épistome est allongé et anguleux, prolongé perpendiculairement; les pattes sont livides, rembru nies à leurs deux principales articulations, entourées chacune d'un anneau blanchâtre; l'abdomen est allongé, cylindrique, grossissant un peu vers la partie anale, nu, mou, d'un blanc terne, transparent, avec une bande longitudinale, ramifiée, pâle, qui atteint aux deux tiers du dos; les côtés sont gris, marqués de taches noires. Le mâle est semblable à la femelle, il en diffère seulement par l'abdomen, qui est plus cylindrique et plus grêle, et par des taches hrunes sur sa partie supérieure.

Cette espéce, qui se trouve assez communément dans les maisons, vibre avec violence sur les fils qu'elle a tendus dès qu'on y touche.

\section{DEUXIEME GROUPE.}

\section{Les Allongées Coniques, WaLck.}

Les yeux latéraux sont connivens. L'abdomen est allongé, conique.

\section{2. pholcus caudatus.}

L. Dufour, Ann. Génér. des Sc. phys., t. V, p. $53, \mathbf{n}^{\circ} 5, \mathrm{pl} .76$, fig-2. -W Al.CK., op. cit., t. I, p. 654 . - Long. 9 lig. $\frac{3}{2}$. Les pattes sont pâles et velues, avec un anneau plus clair à l'extrémité de l'exinguinal et du fémoral, du génual et du tibial; les palpes chez le mâle sont très compliqués; le troisième article est renflé et cambré, le quatrième se termine par deux crochets inégaux; l'abdomen est allongé, diminue de grosseur vers son exirémité et se prolonge en queue au-delà de la partic anale, qui forme en dessous, avec les filières, une saillie conoïde; en dessus il est d'un gris argenté. avec quelques traits obliques, pea apparens, de claque côlé, quelquefois d'un 



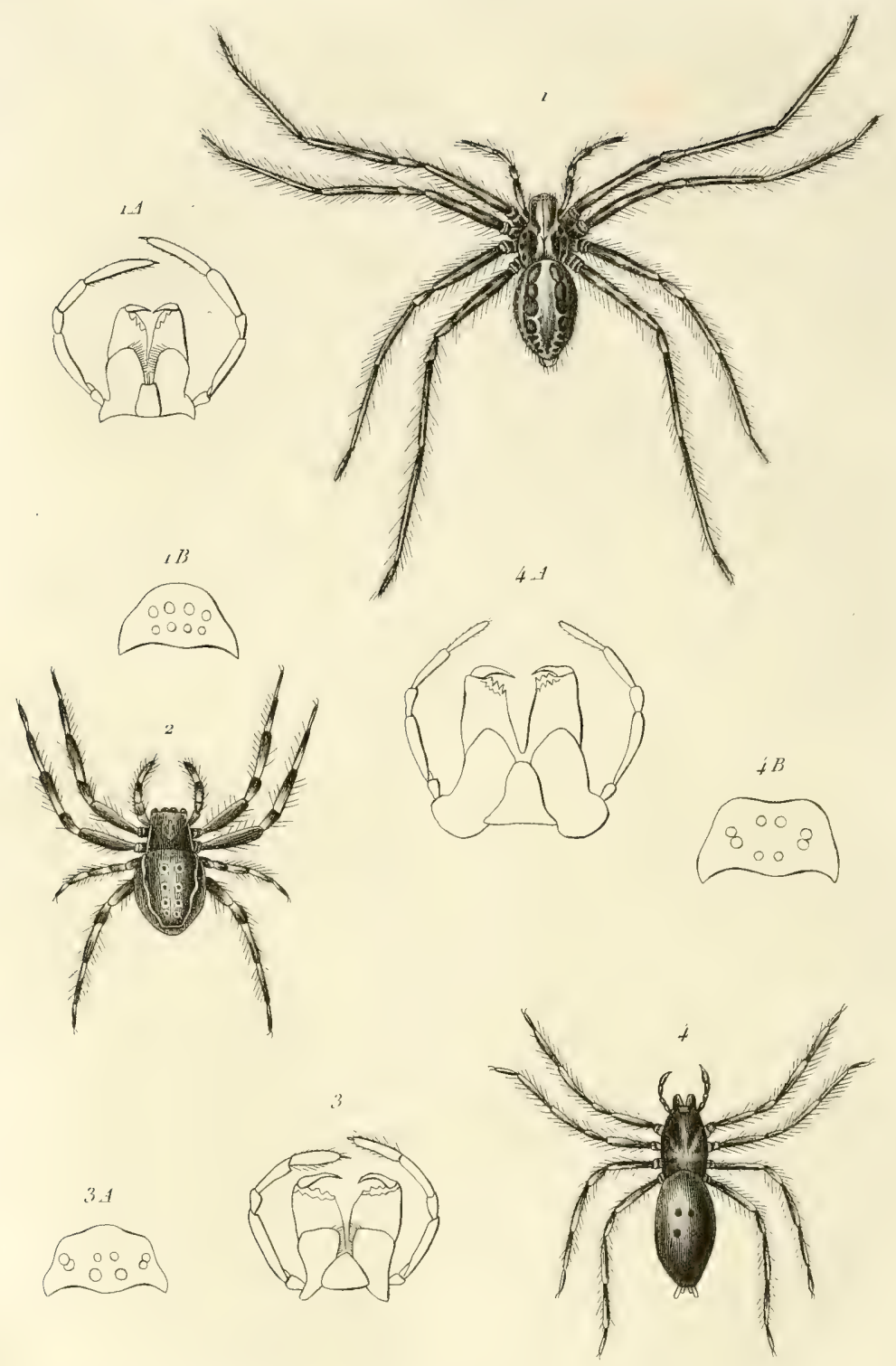

1. Tejenaria domestica, 1A. mâshoires, 1B. yeų, 2. Epeira uwbraticola. 5. mâchoires

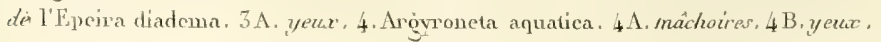


gris uniforme; la partie sternale et le milieu du ventre sont noirs.

Celte espèce a été trouvée par M. L. Dufour, en Espagne, dans le royaume de Valence et de Moxente; dans les fentes des rochers. M. Duges, dans l'Atlas du Règne animal de Cuvier, a donné les caractères d'une nouvelle espèce qu'il désigne sous le nom de $P$. Sexoculatus, DrGÈs, Arachn., pl. 9, fig. 7.

\section{ARTEMA, WALCK.}

Les yeux, au nombre de huit, presque égaux entre eux, sont placés sur deux lignes courbées en arrière ; les interméçiaires postérieurs sont plus écartés entre eux que les intermédiaires antérieurs, et plus rapprochés des latéraux qu'ils ne le sont entre eux. - La lèvre est grande, élargie à sa base, diminue vers son extrémité, qui est arrondie ou tronquée. - Les mâchoires sont allongées, étroites, inclinées sur la lèvre, à côtés parallèles, grossissant un peu vers leur extrémité, dont les côtés internes sont coupés perpendiculairement et contigus.-Les pattes sont très-allongées, grêles ; la première paire est la plus longue, la quatrième ensuite, la troisième est la plus courte.

Les mœurs de ces Aranéides sont inconnues.

\section{ARTENA MAURICLNA.}

Walck., op. cil., t. 1, p. 657. - Le céphalothorax est rond, aplati, très enfoncé daus sa partie médiane, d'un fauve rougeàtre; les mandibules sont courtes, coniques, réunies à leur base par une petite crète; les pattes sont très-allongées, d'un rouge pâle, avec des anneaux bruns aux articulations; l'abdomen est globuleux, pointu vers la partie anale, à fond pâle, arec des stries ou bandes grisâtres, formant des losanges et des stries plus régulières sur les côtés; le mâle différe de la femelle par ses mandibules, qui sont excessivement renflèes sur le dos, bifides, et terminées par une pointe acérée, dont le dos est armé d'une petite tige cylindrique, droite, où est le crochet, qui est très-petit; elles sont d'un brun rougeâtre ; les derniers articles des palpes sont irès gros et vésiculeux; l'abdomen est globuleux, petit, d'un gris de souris. - Cette espèce habite l'intérieur des maisons de l'lle.de.France.

\section{TROISIENE SEGTION.}

\section{Les Sédentaires, W $\mathrm{WLCK}_{\text {. }}$}

Construisant de grandes toiles pour attraper leur proie, et se tenant au milieu ou à côté.

\section{NEUVIEME SOUS-SECTION.}

Tapitéles, WaLcK.

Fabriquant de grandes toiles à tissus serrés, en hamacs, el y résidant pour attraper lęur proie.

\section{TEGENARIA, WALCK. ; \\ Aranea, Linn., Fabr., Latr.}

Les yeux, au nombre de huit, sont pres. que égaux entre eux; ils occupent le devant du céphalothorax sur deux lignes rapprochées, presque parallèles, la postérieure étant légérement courbée, et l'antérieure droite. - La lèvre est grande, carrée, plus haute que large, échancrée à son extrémité, bombée et légérement arrondie sur les côtés. - Les mầchoires sont droites, allongées, écartées, bombées, plus étroites à leur base que vers leur extrẻmité, légérement arrondies au côté externe, et légérement creuséesà leur extrémité interne. - Les vattes sont allongées, fines: la première ou quatrième paire plus longue quo les autres, la troisieme est la plus courte.

Ces Aranéides sédentaires forment, dans l'intérieur des bâtimens, des cavités souterraines, et dans lesintervalles des pierres une toile horizontale, grande, à tissu serré, à la partie supérieure de laquelle est un tube cylindrique où elles se tiennent immobiles. Le cocon est globuleux, recouvert par des détritus de plâtre, de gravier et de terre agglutinés, et des toiles extérieures.

1. tegenaria domestica. (Pl. 8 , fig. 1 , $1 \mathrm{~A}, 1 \mathrm{~B}$.

Walck., Aran. de France, p. 205, pl. 8, fig. 1 la femelle, fig. 2 le mâle. - draignée Domestique, ibid., Faun. Paris., t. II, p. 276. - Araneus Domesticus, CLenck, Aran.Suec., p. 76, pl. 2, tab. 9.-Tegenitria Domestica, SAv., Descript. de l'Egyple, Arachn., t. I, pl. 1, fig. 5. - raignée Découpée, Dumér., Consid. génér. sui la cl. des Ins, 1823 , pl. 55, fig. 1. - Araigriée Domestique, Linn., Faun. Succ., p. 87, n०2000.-Aran. Domestica, Fabr., Eillom. Syst., t. I1, p. 412, $\mathrm{n}^{\circ}$ 21.-Arai- 
gnée Domestique, Larn., Génér. Crust. et Ins., t. I, p. 96, no 2.-Dugès, Atlas du Rìg. anim., Arachn., pl. 8, fig. 4.-Long. 8 lig. -Le céphalothorax est plus étroit et moins allongé que l'abdomen, arrondi et déprimé à sa partie postérieure, couvert de poils fauves, formant duvet, mais bordé près des pattes d'une ligne noire découpée ou formée par trois petits triangles noirs, qui se touchent à leur base; deux traits bruns. mais formés par des taches non contiguës, disposées longitudinalement, se remarquent sur les côtés et vers la partie antẻrieure, de sorte qu'avec les lignes marginales il y a quatre raies noires et trois raies fauves, longitudinales; les mandibules, d'un rougebrun, sont forles, verticales, allongées, cylindroïdes, mais cependant amincies vers leurs extrémités, ou en cône allongé, sans être renflées prés de leur insertion; la lèvre est grande, rougeâtre, glabre, bombée, plus haute que large, plus élargie à sa base, et diminuant graduellement de largeur vers son extrémité, qui est légérement creusée; les mâchoires sont droites, écartées, allongées, grossissant de la base aux extrémités, d'un rouge-brun, glabres, avec une tache à l'épistome d'un jaune pâle; les palpes sont minces, filiformes, rougeâtres, bruns vers leur extrémité qui est garnie de poils fauves; les pattes sont fines, allongées, les premières ayant une fois deux tiers, et souvent plus de deux fois la longueur du corps; elles sont rougeâtres ou verdâtres en dessus, avec des taches d'un brun rougeâtre plus foncé, peu marquées, a égale distance, mais ne formant pas des anneaux distincts; en dessous ces taches, surtout à l'exinguinal et au fémoral, sont peu marquées; l'abdomen est velouté, grand, allongé, ovoïde, trés-bombé, à surface arquée, resserré sur ses côtés et vers sa partie antérieure, et un peu plus renflé postéricurement; le dessus, daus son milieu, présente une bande Iarge, longitudinale, d'un rouge pâle, qui est bordée de chaque côté de sept taches, qui sont d'autant moins grandes, qu'elles se rapprochent plus de la partie anale; elles sont bordées de noir ou de brun, plus foncé extérieurement; les côtés latéraux sont d'un fauve rougeâtre, parsemés de petits points bruns; le dessous est d'un jaune plus pâle et plus clair que les côtés, et il est parsemé de points noirs, ronds et disposés longitudinalement; les ouvertures stigmatiformes sont brunes et hordées de jaune; le mâle diffère de la femelle par ses couleurs, qui sont beaucoup plus brunes et beaucoup plus tranchées. - Cette espéce, qui se trouve très-communément dans les maisons, à Paris et lans ses environs, construit dans les angles ou dans les intervalles des murailles de grandes toiles horizontales, à lissu fin, mais serié, rele. vées vers les bords, enfoncées dans leur milieu, soutenues en dessus, et garnies aussi en dessous de longs fils isolés, qui ressemblent a un hamac qui serait suspendu et ga. ranti du balancement par un grand nombre de cordes en haut et en bas. Cette toile se termine à son extrémité el dans l'angle du mur par un trou rond, à double ouverture; l'une tournée vers le dessus de la toile, l'autre se retournant par en bas. L' $\Lambda$ ranéide se tient ordinairement dans son trou, immobile, la tête tournée vers le dessus de sa toile, épiant les mouches et les insectes qui s'y premnent, se précipitant sur eux avec une grande rapidilé, et les emportant dans son trou, souvent malgré leur vive résistance. Lorsqu'on l'effraie, ou que quelque danger la menace, elle se retourne aussitôt, s'enfuit par l'ouverture du trou, qui est dirigé en bas, et disparoît. Dans le temps d'orage ou dans le moment de l'accouplement, elle se promène souvent sur la superficie de sa toile avec rapidité, ou aussi pour en raccommoder quelque partie qui aurait été rompue. Cette toile est sourent très-grande. J'en ai vu, dit M. Walckenaer, auquel nous empruntons ces intéressantes observations, une, ou plutôt deux contiguës, construites par la même araignée, qui avaient trois pieds de large. Lorsque cette espèce est prête à pondre, elle se retire vers le soir à peu de distance de sa toile; elle file d'abord une espèce de bourre de fil brun, et à tissu large, auquel elle donne la grosseur d'un noyau de cerise, qu'elle suspend en l'air par quelques fils lâches, perpendiculaires, attachés au plafond. Ce flocon n'est point son cocon, car, après l'avoir construit, elle n'a point diminué de grosseur, c'est seulement le leste du sac qui doit contenir le cocon. Ce sac, formé d'une soie claire, est arrondi par en bas en forme de besace; il entoure le flocon, qui alors est dilaté et éparpillé au fond du sac par l'araignée, et chargé de plâtras et de terre, de graines, de détritus de petites coquilles de limaçons, de débris solides d'insectes. Le poids empêche le sac d'être balloté ; il est d'ailleurs fixé par des fils placés en haut, en bas et de côté, aux parois du mur, et se rattache par d'autres fils plus isolés, plus allongés, avec la de- 
moure principale, ou la toile de l'araignée placée a une distance plus ou moins grande. C'est au millieu de ce sac, qui a environ un ponce et demi, et quelquefois deus pouces de long, et autant à son orifice, que l'araignée place son cocon. Il ne touche point au fond, mais il y est attaché par des fils, ainsi que sur les côtés, et suspendu par d'autres fils à une petite toile construite sur l'orifice du sac. C'est sur cette dernière toile que l'araignée se tient constamment aprẻs qu'elle a pondu, abandonnant alors sa grande toile et son ancienne demeure, ou n'y retournant qu'occasionnellement. M. Walckenaer en a observé quatre dans cette position. Alors il trouva les cocons ouverls et sans araignées; mais il y en avoit un dont le cocon etait entier, renfermant les jeunes nouvellement éclos, et des œufs qui ne l'élcient pas encore. M. de Théis en a trouvé un autre à l'entrée du soupirail d'une cave, qui renfermoit encore tous Ies petits, éclos depuis plus de dix jours; enfin j'ai, dit M. Walckenaer, dans un nid semblable, trouvé un cocon avec des jeunes déjá éclos, dans le bois de Boulogne. Le cocon de celte Aranéide est globuleux. très-grand, entouré d'une soie mince et transparente; il est gros et a à peu près six lignes de diamètre. Les cufs qui restaient dans les cocons que j'ai examinés étaient libres et noo agglutinés entre cux: L'araignèe ne construit pas en un seul jour la demeure de sa postérité ; elle commence d'abord par filer, puis tourner el retourner pendant deux heures le flocon, qui est le principe et le commencement de l'édifice; puis, après l'avoir suspendu, elle se retire dans sa demeure habituelle. Elle travaille le lendemain à éparpiller le flocon, à fabriquer la bourre pendant la nuit, et cesse vers les neuf heures du matin, se retirant de nouveau dans la toile. Elle se remet ensuite à l'ouvrage vers les sept heures du soir; le lendemain matin, tout est terminé, et on la trouve placée sur son petit hamac, couvrant de son corps son cocon, suspendu an-dessous d'elle au milieu de la bourre ou du sac. Ce sac, les fils qui l'entourent, et le hamac, d'un tissu beaucoup plus lâche et moins serré que les grandes toiles de l'araignée, sont formés de fils beaucoup plus gluards. Le mâle n'approche de la femelle qu'avec crainte, parce que, quand elle ne cède pas à ses désirs, elle cherche à le saisir pour le dévorer. C'est lui cependant qui la recherche, et il se rend sur sa toile pour l'accouplement; on le voit souvent en au- tomne parcourir, comme égaré . l'intérieur des habitations, et alors on est presque toujours certain d'avoir une grande pluie vingtquatre heures après.

\section{TEGeidati CiviLís.}

Wícк., Aran. de France, p. 218, pl. 8 , fig. 3. - Araignée Privée, Walck., Faun. Paris., t. II, p. 216. - Tégénaire Privée, ibid., Tab. des Aran., p. 49, no 2. Tegenaria Civilis, ibid., Hist. des Aran., t. V, p. 5. - Araignée Privée, Latr., Hist. nat. des Crust. et des Ins., t. VII, p. $928, n^{\circ} 18$. - Long. 6 lig.-Le céphalothorax est de même forme que dans l'espèce précédente, rougeâtre et bordé d'une ligne nojre, fine, non dentée, et ayant sur les côlés deux larges bandes longitudinales d'un noir pâle; les mandibules, la lèvre et les mâchoires sont comme dans la Tegenaria Domestica; les palpes et les pattes sont rougeâtres, jaunes ou verdâtres, obscurément annelès de brun ou de noir aux cuisses et aux jambes; la quatrième paire de pattes est plus longue que la première, et cette diffërence est encore plus marquée dans le mâle que dans la femelle; la première ensuite est la plus longue, la troisième est la plus courte; l'abdomen, d'un fauve rougeâtre, est aussi de la méme forme, mais il est moins allongé proportionnellement au céphalothorax; sa couleur est d'un rouge ou jaune pâle ou blanchâtre, moucheté régulièrement de taches d'un noir pâle, séparées, très-distinctes; le dessous est de même couleur, et il y a sur deux lignes Iongitudinales, parallèles, des points zoirs qui séparent son milieu des côtés; les ouvertures stigmatiques sont bordées de brun à l'extérieur; les filières sont d'un blanc uniforme. Le mâle ne diffère de la femelle que par l'abdomen, qui est plus étroit, plus allongé et moins large que le céphalothorax, qui est couvert d'un léger duvet de poils gris; les pattes sont plus allongées, plus fortes, et sans annelures, d'un rouge brun, surtout les cuisses, qui sont plus renflées que dans la femelle; les mandibules, les mâchoires et la lèvre sont aussi plus grandes et d'un rouge plus fonce. - Se trouve aux environs de Paris.

Lorsque la Tégénaire Civile vient de changer de peau, son abdomen est d'un blanc mat, et l'on aperçoit à peine quelques traces de taches noires. Celte espèce, qui se trouve a Paris et dans ses environs, construit dans les cares, sous les pierres, dans les endroits obscurs et re!irés des édiflces 
une toile semblable a celle de l'espèce précédente, mais proportionnellement plus pe. tite. J'ai vu, dit M. Walckenaer, à l'époque de l'accouplement, deux trous ronds, ou retraites en soie sur la même toile : l'une de ces retraites contenait le mâle et l'autre ta femelle. Je les vis s'accoupler vers la fin de juin ; un mois après, la femelle pondit ses œufs qu'elle enveloppa d'une soie blanche, lâche et transparente.

\section{TEGENARIA AGRESTIS.}

WAClk., Aran. de France, p. 220, pl. 8, fig. 3. - Araignée Agreste; ibid., Faun. Paris., t. II, p. $216, \mathrm{n}^{\circ} 38$; ibid., Tab. des Aran.., p. 50, no 3.--Araignée Agreste, Latr., Hist. nat. des Crust. et des Ins., t. VII, p. 208, $\mathrm{n}^{\circ}$ 19.-Araignée Agreste, kं ขща., pl. 14 (le mâle). - Aranea Liliigera, Ross1, Faun. Étrusc., t. II, p. $130, n^{\circ} 970$. - Longueur $8 \mathrm{lig}$. - Le céphalothorax est rouge clair, plus foncé vers la partie antérieure, avec des sillons bruns assez profonds, qui partent de la raie creusée du milieu; ils divergent vers la circonférence sans raie marginale brune, dentée, mais une raie très-fine, brune, sur l'cxtrême bord; les mandibules, les mâchoires et la lévre sont comme dans la Te. genaria Domestica; les pattes sont allongées, glabres, d'un rouge clair ou verdâtre, uniformes, et sans annelures ni taches; la quatrième paire est la plus longue, la seconde ensuite, la troisieme est la plus courte; l'abdomen est de même forme que dans la Tegenaria Domestica, et paroît néanmoins un peu plus large ou plus arrondi postérieurement; il est velouté, de couleur brune, à fond fauve, jaunâtre ou verdâtre, mais parsemé de points ou de petits traits très-rapprochés sur les côtés en dessus; sur la même partie est une raie fine, de couleur jaune, et qui est un peu plus large vers le céphalothorax; à cet endroit on aperçoit quatre petites taches jaunes, ensuite quatre ou cinq chevrons formés près des lignes pâles qui se joignent en angle à la ligne intermédiaire, puis se recourbent sur les côtés, et forment ainsi cinq triangles bruns entourés de jaune, et traversés longitudinalement par la ligne du milieu ; en dessous il est d'un fauve jaunảtre, avec des points nou dsséminés sur les côtés; les filières sont d'un rouge-brun. - Cette espèce construit dans les champs, au pied des vignes, des arbres et des chaumes élevés, et dans les roches disséminées, dans les champs, ou les tas de pierres, une toile de grandeur médiocre, avec un tron ou retraite ronde ; mais e'est sous les pierres et dans les endroits cachés qqu'elle dispose son cocon, qu'elle abandonne parce qu'il est formé avec une industrie admirable et suffit pour garantir sa postérité. Ce cocon est gros, sphérique, de cinq à six lignes de diamètre, d'une éclatante blancheur, et se trouve en assez grand nombre sous les pierres où il y a de la terre humide; il est formé d'une triple enveloppe: la première est mince, très-blanche, fortement tissue; sous cette enveloppe on trouve du sable, de la terre et des débris d'insectes que l'araignée a dévorẻs : le tout réuni est agglutiné par des fils presque impercelibles. Sous cette couche de terre est un second cocon d'un beau jaune oranger, d'un tissu serré, qu'il faut pour le bien voir, séparer de la terre qui s'y trouve agglutinée; ce second cocon, qui est encore à l'intérieur d'un rouge-oranger plus foncé, renferme une bourre lâche et peu serrée qui contient les œufs; ceux.ci sont jaunâtres ou blanchâtres, et au nombre d'environ quarante, de fa même grosseur que ceux de la $T$. Domestica, mais ayant une surface un peu gluante. Souvent ces cocons sont isolés, au nombre de cinq on six. peu éloignés les uns des autres; souvent aussi il s'en trouve deux réunis sous une toile commune, fine et transparente. Ainsi, quatre toiles renfermées les unes dans les autres et une couche de terre et cle sable défendent des dangers extérieurs la postérité de celte-araignée. C'est en juillet et au commencement d'août que j'ai trouvé, dit M. Walckenaer, sous les pierres les cocons en grand nombre dans le bois de Boulogne; mais alors les petils n'y étaient pas, et étaient sortis par une ouverture blanchâtre que l'on voit au cocon, qui conserve sa forme. C'est le 14 octobre que j'ai trouvé plusieurs femelles pleines, et que j'en ai saisi une qui venait d'atticher son cocon, d'une blancheur éclatante, à une pierre assez lourde; il s'y trouvait fixé par des fils et par une petite toile blanche d'un tissu serré. L'araignée avait commencé à couvrir ce cocon de terre qu'elle enlevoit du sol humide, car les parois de la pierre étoient propres et sans terre. Je transportai la pierre chez moi, et avec elle l'araignée, qui ne chercha pas à s'enfuir ni à quitter son cocon; je l'enfermai sur cette pierre, sans la déranger, en y plaçant un verre a boire renversé que je soudai sur la pierre avec de la craie. Je vis aussitôt l'araignée travailler à agrandir la toile qui attachaii 
Se cocon à la pierre. Elle continua ensuite à le couvrir arec de la terre humide que j'avais eu soin de placer sous le bocal. Wille promenoit ses filières sur cette terre et la liait par des fls très-fins, mais apparens; elle continua toute la journée avec une grande ardeur à filer sur la surface de son cocon, puis elle l'élaloit, l'arrondissoit, l'égalisoit en une masse globuleuse, et filoit ensuite au-dessus quelques fils réguliers pour fortifier son adhérance. Vers le soir l'araignée commenca à filer une nouvelle toile sur cette couche de terre; le lendemain matin le cocon se trouvoit entouré de sa dernière enveloppe, etla terre globuleuse étoit converte d'un tissu fin et blanc. Par dessus le cocon elle fabriqua encore une petite toile blanche, qui attachoit le cocon à la motte de terre, pareille a celle qui l'attachoit à la pierre. Il est probable que cet exces de précaution lui étoit suggéré par la position dangereuse ou elle se trouvoit, car tous les cocons que j'ai trouvés sous les picrres étoient simplement attachés à leurs parois, mais ne ienoient au sol par aucune toile et aucun lien. Le $\mathcal{1}^{\text {er }}$ novembre, quoiqu'ayant été depuis treize jours sans avoir mangé, l'araignée s'est remise au travail, et elle a construit une toile blanche, mais a tissu fin et serré comme celle de la $T$. domestica. Cette toile ressembloit à une coupe trèsévasée, elle remplissoil presque tout l'orifice du verre et étoit attaclıée au bord de cet orifice par des fils, de mavière, cependant, à ce que les bords de la toile étoient à égale distance des parois du verue. Cette toile étoit double près du bord et formait comme deux hamacs arrondis, surperposés l'un sur l'autre. Ces deux toiles étoíent encore superposés à celles du cocon, qui se trouvoit ainsi couvert et défendu par quatre couches de toiles. A côté du cocon elle construisit, non pas un trou ou retraite ronde, mais un arc trés-baissé dont la superficie se prolongeoit presque sur la toile qui couvroit le cocon. C'est sous cette arcade, enfermée sous la double toile, qu'elle se retiroit lorsqu'on cherchoit à l'effrayer. Cette arcade, ainsi que son prolongement sur le cocon même, étoit formée d'une soie plus épaisse et d'un blanc plus mat. L'araignée se mouvoit avec une grande facilité au milieu de tous ces compartimens, ef couroit quelquefois sur sa toile avec une grande rapidıté. Le 17 novembre, je la trouvai foible ct ne montant qu'avec peine entre les parois du verre; le 20 novembre elle etoit morte et n'avoit rien mangé durant trente-

ANN. trois jours de captivité. - Elle se trouve aux environs de Paris.

M. Guérin a figurè, dans son Iconogaphie du liegne anim. de Cuvier, Arachr., pl. 2 . fig. 1, une espèce très-remarquable qu'il désigne sous le. nom de T. Guyomii: ello a éti trouve dans notre colonie $\mathrm{d} A \mathrm{Jer}$ (Bone).

\section{LACIIESIS, SAV.}

Les yeux, au nombre de huit, sont rassemblés sur le bord antérieur du céphalothorax, disposés sur deux lignes transverses, courbées en devant, et sensiblement inégaux; les intermédiaires antérieurs, pt, après eux, les latéraux postérieurs, les plus gros de tous, les quatie intermediaires figurent un trapéze foiblement rétréci en arrière, et les quatre latéraux deux lignes très-divergentes. - Les mandibules sont légérement avancées, renflées, peu coniques, sans dentelures, à crochets courts, tres-aigus, ayant la pointe retournée et saillante au bas, dans le repos. - Les mâchoires sont convergentes, un peu courbées, pointues, fortement carénées à leur face supérieure, à palpe assez grand. - La lèvre est plus haute que large. - Les pattes, robustes, décroissent graduellement, du moins dans le mâle, de la quatrième paire à la première, à tarses munis de deux ongles supérieurs exactement et finement pectinés, et d'un ongle inférieur simple, courbé dès sa base, recourbé en dessus à la pointe. - L'espèce type de ce genre est :

haCHESIS PERVERSA, SAV., Descrip. ae l'Egyjte,Arachn., pl.1, fig. 4, dont le corps est. d'un roux sans tache; l'abdomen d'un roux plus cendré; les pieds sont d'un roux plus pâle.-Cette espèce a été trouvée aux environs du Caire.

\section{A GELENA, W ALCK. ; Arachne, $\mathrm{S}$ Av.}

Les yeux, au nombre de huit, sont presque égaux entre eux, et placés sur deux lignes très-courtes en avant; les latéraux antérieurs sont beaucoup plus rapprochés des mandibules que les intermédiaires de la même lignne. - La lèvre est carrée, presque aussi large que haute. - Les màchoires sont peu allongées, légérement inclinées sur la lèvre et arrondies vers leur extrémité. - Les pattes sont de longueur médiocre; la quatrième paire est sensible. 
ment plus longue que la première, laquelle surpasse la seconde; la troisième est la plus courle.

Ces Aranéides sont sédentaires, et forment sur les herbes, les buissons, les plan. tes, une toile grande, horizontale, à tissu serré, a la partie supérieure de laquelle est un tube où clles se tiennent immobiles.

AGEIENA IABYRINTHICA.

W alck., Aran. de France, p. 226, pl. 9 , fig. 1. - Araiqnée Labyrinthe, ibid. , Fulu Par., t. II , N. 217, no 60; Tabl. des tran., 2, 31, no 1, pl. 6, fig. 55 et 56 . - Araneus Labyrinthicus, Clenck., Aian. Succ. , t. II, p. 79, pl. 2, tab. 8. - Aranea Labyrinthica, Livs., Faun. Suec., $2^{e}$ édit., p. $487, \mathrm{n}^{\circ} 2003$. - Aranea Riaseli, Scop., Faun. Carn., p. $395 . n^{\circ} 1087$. - Aranea Labyrinthica, Latr., Génér. Crust. et Ins., t. I, 2, 95, spec. 1. Long. 7 lig. - Le céphalothorax est élevé, carré et resserré près de la partie antérieure, moins allongé et moins large que l'abdomen; il est velouté et couvert de poils, formant cinq lignes longitudinales, larges, bien distinctes; les mandibules sont peu allongées, fortes, rouges jusque vers leur extrémité, qui est noire; elles sont couvertes de petits poils fins et gris; la lèvre est carrée, de couleur pâle-rougeâtre; les pattes sont de longueur médiocre, assez fortes et ayant les cuisses un peu renflées, velues, avec des poils fins, allongés, fauves, ct des épines noires inclinées, mais non couchées, elles sont de couleui fauve-rougeâtre; l'àbdomen est allongé, ovale, bombé sur le dos, renflé vers le céphalothorax, dans son milieu et sur les côtés; il est d'un brun-noir, d'un velouté brillant; le dessous, qui est un peu bombé dans son milieu, est bordé sur les côtés par des bandes faures, longitudinales, très-larges, un peu festonnées sur les bords, puis ensuite sont deux bandes brunes divisées longitudinalement par une bande jaune, fine et plus courte, et enfin une bande d'un fauve doré, vif comme les latérales dans le milieu, le tout velonté, de sorte que le dessous présente sept raies longitudinales, deux très-larges jaunes sur les côtés, deux brunes de médiocre largeur, deux étroites et jaunes, deux assez larges d'un brun plus pâle, et une large dans le milieu, d'un jaune vif; les ouvertures stigmatiformes sont couvertes de noils fauves et courts; les filières sont c'un brun-noir en dessis, un peu rougeâfres en dessouls.
Le mâle diffeire de la femelle en ce nu'il est plus petit; son abdomen est plus allongé, moins bombé, moins renflè sur les côtés, plus pointu vers la partie anale; son céphalothorax est aussi d'une couleur plus sombre.

Cette espèce fait une toile horizontale en hamac, avec un trou rond, ou retraite $c y$ lintrique, où elle se tient renfermée. En mai, lorsqu'elle est jeune, cette toile est élablie sur les herbes, ensuite sur des chaumes nlus élevés, puis enfin, lorsqu'elle a atteint toute sa grandeur, sur des buissons et des haies. Cette toile, qui est très grande, enveloppe souvent par les côtés les plantes sur lesquelles elle est posée, et en dessus des fils isolés, comme les cordes d'un navire, s'élèvent à quatre pieds de hauteur, ils précipitent sur la toile horizontale les insectes qu'ils arrêtent, par les elforts mème qu'j!s font pour se dégager. L'araignẻe sort de son tron, fond sur sa proie avec une extrème rapidité, et l'emporte dans sa retraite. Elle parcourt souvent le soir et le matin, ou lorsqu'il fait un beau soleil, les bords de sa toite, mais elle s'enfuit dans son tube aussitôt qu'elle esi effrayée. Ses mouvemens sont très-vifs, elle attaque les plus gros insectes et est très-avide. On la trouve dans les vignes, les genêts, les haies qui bordent les chemins, mais toujours dans les lieux découverts; elle garantit son nid par des feuilles sèches, qu'elle enduit des deux côtés d'une toile, et qui forme un abri contre les rayons du soleil et un corps imperméable à l'eau. Son cocon est rond, aplati, un peu comprimé, de couleur jaune-oranger. - Cette espece se trouve aux environs de Paris.

\section{NYSSUS, W_ALCK.}

Les yeux, au nombre de huit, sont presque eraux entre cux et occupent le derant du céphalothorax: - La lève est carrée; aussi large que haute. - Les mâchoires sont carrées, légérement inclinées sur la lèrre, coupées en lignes droites à leur extrémittó - Les pattes sont de longueur médiocre: Ja quatrieme paire est la plus longue, la premiere ensuite, la troisième est sculcment un pea plus courte que la seconde.Les mœurs de ces Aranéides sont inconnues.

Ce genre, qui a élé établi par M. Walckenae: dans son Tablean des Aranéides, p. 52 , pl. 6 , fig. 57 et 58 , a pour type le Nyssus Coloripes. Cette espèce n'ayant pas 
encore étẻ décrite et ne la possédant pas, nous ne pouvons en donner la description. - Elle est originaire de la Notasie.

\section{DIXIEME SOUS-SECTION.}

\section{Orbitiles.}

Tendant des toiles à mailles ouvertes, régulières, en cercles ou en spirale, et se tenant au milieu ou à côté pour âtraper leur proie.

\section{EPEIRA, WaLck. , LATR.}

Les yeux sont au nombre de huit, presque égaux entre eux, placés sur deux lignes occupant le devant du céphalothorax; les quatre intermédiaires formant un carré, les latéraux étant très-rapprochés. - La lèvre est large, arrondie à son extrémité. - Les mâchoires sont courtes, larges. arrondies, trés-étroites à leur insertion et écartées. - Les pattes sont de longueur ınédiocre; la première paire est la plus longue, ensuite la seconde; la troisième est la plus courte. - Ces Aranéides sédentaires forment une toile á réseaux réguliers, composés de spirales et de cercles concentriques, croisés par des rayons droits qui partent d'un centre à l'autre où l'araignée se tient immobile. - Le cocon est ovoïde; les oufs sont agglutinés.

Ce genre, trés-nombreux en espèces, a é:é divisé en dix groupes.

\section{PREMIER GROUPE.}

\section{Les Allongées Cylindriques, WaLcK.}

Les mâchoires sont courtes, arrondies.La levre est aussi large que haute. - Le céphalothorax est bombé antéricurement, pourvu de deux petits tubercules dans son milieu. - L'abdomen est allongé, cylindrique. - Les pattes sont très-allongées.

\section{1. epeira chrysogaster.}

W Alck., Tabl. des Aran., p. 53.-Aranea Chrysogaster, Latr., Hist. nat. des Ins., t. V II, p. 274, n०85. - Aranea Plumipes, FAвr. - Le céplialothorax est noir, revêtu d'un duvet soyeux doré en dessus et de deux tubercules assez saillans; les organes qui composent la bouche sont noirs; les pattes sont d'un noir foncé, excepté les articulations des jambes et des cuisses, et hérissées de petites épines; l'abdomen est long, brun, avec deux bandes et une raie dans l'entre-deux, longitudinales, paralléles et blanchâtres le long du dessus; les cótés latéraux of̂rent des traits ou des raies et le dessuus des points de la même couleur. - Elle se trouve aux Indes-Orientales.

\section{EPEIRA GLAVIPES.}

Walck. , Hist. nat. des Aran., fasc. 1, pl. 1 et 2 ; ibid., Tabl. des Aran., p. 54 . - Aranea Clavipes, Linn., Syst, nat., édit. 12, Holmice, p. 1034, n 27. - Aranea Comnuia, Pallas, Spicil. Zool., fasc. 9, p. 44, tab. 3, fig. 13. - Aranea Fasciculata, Degéer, Mém. sur les Ins., t. VII, p. $316, n^{\circ} 2, p l .39$, fig. $1,2,3,4$ Ar. a brosses, Oriv., Encyclop. Meth., t. IV, p. 201, no 13. - Latr., Hist, nat, des Crust. et des Ins., t. VII, p. 273, $n^{\circ} 84$. - Le céphalothorax est recouver't en dessus de poils courts, épais, soyeux, argentés, brillans, et présente deux points enfoncés derrière deux tubercules élevés; la partie antẻrieure est carrée, recouverte de poils blancs; les mandibules sont larges, noirâtres, avec des poils blancs; les mâchoires et la lèrre sont allongèes, d'un brun-rougeâtre; les palpes sont filiformes, minces, rougeâtres, avec des poils noirs; les pattes sont longues et fines, d'un rougebrü, noires à leur extrémité; le troisième article de la première, seconde et quatrième paire de pattes, sont pourvus de poils longs, séparés, mais moins épais et moins abondans à la seconde qu'à la première et la quatrième; l'abdomen en dessus est d'un jaune doré, sans poils, avec des taches rondes argentées, plus abondantes sur les côtés, formées par des poils soyeux bril. lans; proche le céphalothorax est un croissant argenté, formé par des poils semblables; de plus, on apercoit six points enfoncés, noirs, disposés longitudinalement et parallèlement par paires, mais d'autant plus écartés qu'ils se rapprochent davantage de l'extrémité postérieure; en dessous il est d'un jaune doré, avec deux rangées de points de même couleur sur les côtés qui se joignent à la partie anale; les ouvertures stigmatiformes et les filières sont d'un rouge-brun. - Cette espèce est très-commune à la Jamaique, dans l'Archipel indien et à l'Ile-de-France.

\section{EPEIRA PLUMIPES.}

WaLck., Tabl. des Arain., p. 54. Aranea Plumipes, Latr., Hist, nat. des Ius., 1. VII, p. 275, no 86. - Noire, avec des taches ou des points soyeux et argentés sur le céphalotorax; la partie médiane du dessus de cette partie du corps présente 
deux tubercules ou deux dents; bien plus saillants que dans l'espèce précedente; les pattes sont brunes, avec des tarses noirs; l'extrémité des quatre jambes antérieures et celle des postérieures ont une plus grande abondance de poils, une sorte de brosse; le dessous du corps est noir; les bords seuls des mâchoires sont d'un brun-rougeâtre; on aperçoit une pelite dent en pointe à la plaque sternale, sous la lèvre inférieure; l'abdomen n'est pas trés-allongè, il est d'un jaunâtre-bran, avec des points enfoncés. - Cette espèce a été trouvée dans les îles de la mer du Sud.

M. Latreille pense que c'est cette espécc dont M: Labillardière a parlé dans son voyage, et que les habitans de la NouvelleIlollande mangent après l'avoir fait rôtir.

\section{DEUXIEME GROUPE.}

\section{Les Zonées, WaLck.}

Les maichoires sont courtes, arrondies, aussi larges que hautes. - Le céphalothorax est tres-plat, revêtu de poils ai gentés. L'abdomen est ovale, traversé en dessus par des bandes de différentes couleurs.

Ces Aranéides forment un cocon qui a la figure d'un ovoïde tronqué.

\section{EPEIRA FASChita.}

WalcK., Aran. de France, pl. 9, fig. 2 ; ibid., Tabl. des Aran., p. 55. - Araignée Fasciée, Ous.. Encyclop. méth., t.IV, p. 198.-Epeire Fasciée, Latr., Règ. an. de Cuv., t. IV.-Avanea Phramits, liossi, Faun. Etrusc., t. II, p. 205; Epeiera Fasciatr. Dugès, Atlas du Règ. anim., Arachn., pl. 11, fig. 1.- Long. 10 lig. - Le céphalothorax est court, aplati, resserré vers la partic antérieure, arrondi postérieurement, avec un point enfoncé dans le milieu, couvert de poils argentés; les mandibules sont coniques, peu fortes, un peu renfoncées sous l'épistome, jaune pâle ou jaune-rougeâtre, et quelquefois brunes a leur partie supérieure; la lèvre est demi-circulaire, un peu pointue dans le milieu de la courbure, brune à sa base et jaune à son extrémité; les mâchoires sont écartées, arrondies, brunes à leur base, entourées de jaune, ciliées de longs poils a leur intérieur. qui se joignent aux poils de la languette, laquelle est terminée en pointe et dépasse la lèvre; les palpes sont jaunes, avec des épines noires assez fortes, surlout vers l'extrémité; le cubital est court, le radial long, et le digital terminé par un ongle pectiné ; les pattes sont allongècs, fortes, jaunes ou jaunerougeâtre, annelées de brun aux jambes : lavées de noir aux cuisses et aux tarses; l'abdomen est plus large que le céphalo. thorax et va en grossissant un peu vers la partie postérieure; en dessus il est jaune, élégamment bariolé de bandes transversales brunes et noires: ces bandes sont à des distances trẻs-rapprochées les unes des autres; en dessous il est renflé et présente cint bandes longitudinales, deux noires de chaque côté coupées par deux traits fins, jaunes, deux bandes longitudinales d'un jaune vif, une large bande veloutée, noire dans le milieu, qui a six petits points jaunes disposés par paires; les filières sont rougeâtres et entourées de jaune à leur base.

Le mâle differe de la femelle en ce qu'il est beaucoup plus petit; son abdomen est cylindrique, moins large que le céphalothorax, avec deux bandes longitudinales d'un gris testacẻ sur un jaune pâle argenté. - Celte espèce est commune dans toute la France, l'ltalie, l'Espagne, et l'orient de l'Europe. Je l'ai rencontrée assez communément à Lyon, sur les bords du Rhône. Elle habite les buissons, le long des haies et des fossés; elle se tient an centre d'un filet vertical, et au temps de la ponte elle enferme ses œufs au milieu d'une bourre trés-fine, dans un grand cocon de près d'un pouce de longucur, ayant la forme d'un ballon ovoīde tronqué par son petit bout, qui est formé par un opercule.

\section{EPEIRA FASTUOSA.}

Walck., Tabl. des Aran., p. 55.-Aranea Fastuosa, OLIv., Ekncyclop. méth. . t. IV, p. $202, \mathbf{n}^{\circ} 15$. - Le céphalothorax est revêtu d'un duvet argenté, luisant; les pattes sont pâles, annelées de brun; les palpes sont d'un jaune très-clair;-l'abdomen est ovale, oblong, avec dix bandes transversales bien marquees; les quatre premières sont d'un blanc argenté, la cinquième est jaune, avec trois petites taches argentées; la sixième est argentée et les suivantes sont jaunes : ces dernières sont terminées par des lignes transrersales d'un rouge d'ocre qui les séparent les unes des autres, mais la troisième est interrompue par une tache argentée; en dessous il présente une tache noire placée dans la partie médiane, el une raie jaune de chaque côté marquée de quelques points argentés.

\section{FPEIRA I ATREILIANA.}

Walck, Hist, nat, des Aran, , fasc. 4, 
ibid., Tab. des Aran., p. 55. - Long. z lig. - Le céphalothorax est aplati , carré antèricurement, revêtu de poils argentés; les pattes sont longues, fines, entrecoupées d'anneaux bruns, de piquans et de poils noirâtres; l'abdomen est ovale, avec trois ou quatre, ou cinq bandes transversales de couleur carmélite elair, séparées par autant de bandes brunes sur lesquelles se détachent des points blancs, argentés, disposés régulièrement; en dessous il est noir, avec des taches blauches argentees. - Cette espèce se trouve au Bengale.

\section{EPEiRA aurantia.}

Argyope aurantia, Lucas, Ann. de la Soc. Ent. de France, t. II, p. 87, pl. 5, fig. 1, 1a. - Long. 9 lig. - Le céphalorax est plat et revêtu de poils argentés; les mandibules sont brunes, avec le côté interne jaunâtre; leurs crochets sont de couleur noire; les palpes sont jaunâtres, avec le dernier article légérement brun et allongé ; les pattes sont poilues ; les anterieures et les postérieures les plus longues; le second article de ces paties est légérement orangé; les articles suivants sont de couleur noire; l'abdomen est ovale, tronqué, ayant à sa partie antérieure deux espéces de tubercules bruns, en avant, et orangés en arrière; le fond est brun, avec des taches et des bandes d'une belle couleur orangée, placés principalement en dessus, et sur les côtés quatre taches principałes, de méme couleur, au milien de la plaque brunâtre qui occupe toute la ligue mé. diane; le dessous est à peu près semblable au-dessus, c'est-à-dire qu'il cxiste deux bandes orangées latérales placées sur un fond brun, qui en occupe tout l'iniervalle; les filières sont rongeâtres. - Celte espèce a été trouvée dans l'Amérique-Septentrionale.

\section{TROISILNE GROUPE.}

\section{Les Oculcies, - WaLck.}

Les mâchoires sont trés-courtes, aussi larges que haules. - Le céphalothorax est plat, revêtu de poils argentès. - Les :ix antéricurs sont portés sur des tubercules avances.

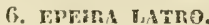

Warск. 'Tabl. des Asan., p. 56.-Ara. nen Latro, Fari., Ent. Syst., t. $11 \mathrm{I}$, p. 412, $n^{\circ} 19$. - Le céphalothorax est n:ale, pubescent, revêtu de poils cendrés; les organes qui comprosent la bouclin sont pâles; les pieds sont noirs, avec les fémurs pâles; l'abdomen est ovale, pointu, noir, taché de ferrugineux. - Cette espèce a été trouvée en Amérique.

\section{QUATRIEME GROUPE.}

\section{Les Festonnées, W ALck.}

Les mâchoires sont courtes, arrondies, aussi larges que hautes. - Le céphalothorax est trés-plat, couvert de poils argentés. - L'abdomen est festonné ou mamelonné. - Ces aranéides forment un cocon qui a la figure d'un ovoïde tronqué.

\section{EPEIRA MAMMATA.}

WaLcк., Tabl. des Aran., p. $56 .-$ Aranea Mammala, Degéer, Mém. sur les Ins., t. VII, p. 318, no 3, pl. 39, fig. 5.Le céphalothorax est d'un brun-roussâtre, cntièrement couvert de poils qui formen: un duvet blanchãtre; les pajpes sont d'un jaune clair grisâtre; les pattes sont longues, surtout les antérieures et les postérieures, mais celles de la troisième paire sont les plus courtes de toutes: ces pattes sont d'un brun-roussâtre, avec une tache grise blanchâtre sur les jambes, et les tarses d'un brun obscur; l'abdomen est orale, garni de rugosités et d'élévations, et vers les còtés de mamelons charnus, dont il y en a trois de chaque côté plus apparens que les autres : en dessus cet abdomen est d'un grisblanchâtre antérieurement, également couvert de poils argentés, et d'un jaune-grisâtie postéricurement; en dessous il est d'un brun obscur, marqué dans la partie médiane d'une bande transversale d'un blanc sale. - Elle a été trourée en Pensylvanie.

\section{HELITA SERGEA.}

W arcк., Tabl. des Aran., p, 56.-Aranea Sericea, OLiv., Encycl. méth., t. IV, p. $198, n^{\circ} 2$. - Le céphalothorax est petit, légérement aplati, et revêtu d'un duvet cotonneux, blanchâtre, argenté; les yeux sont noirâtres; les pattes sont allongées, annelées de roux livide el de noir; l'abdomen est grand, couvert du même duvet que le céphalothorax; son contour est presque circulaire, mais festonné; on y apercuit huit tubercules on élérations mamelonnés, arrondis, dent quatre de chaque cóté; le dessous - est obscur, mélangé de jaune et de noir clans le milieu.

Celle espice, qui se trouve en Provence suivant Olivier et qui a été aussi rípportée du Sénégal, construit dans les bois de gran. des toiles verticales à réseau. 


\section{GINQUILIF GROUPL.}

\section{Les Triangulaires Gibbeuses, WALCK.}

Les mâchoires sont très-courtes, arrondies à leur extrémité. - La lève est arzondie, aussi large que haute. - Les yeux intermédiaires postérieurs sont plus rappro. chés el plus petits que les intermédiaires antérieurs. - Le céphalothorax est convexe. - L'abdomen est ovale, triangulaire, revètu en dessus à sa partie antérieure de deux tubercules charnus, coniques, ayant en dessous des courbes jaunes ou blanches opposées.

Ces Aranéides forment une toile verticale.

\section{1. epeira argelata.}

WaLck., Tabl. des Aran., p. 57 ; ibid., Histoire nat. des Aranéides, fasc. 6. - di'a. nea Angulata, Clercx., pl. 1, tab. 1, fig. 1, 2. P. 22, n* 1. - DEGÉER, t. VII, p. 221,

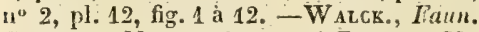
Paris., t. Il, p. 189, n० 1.-Fabr., t. II, p. 414,29. - Cette espèce a les quatre ycux du milieu en un carré, dont les deux d'en haut sont un peu plus rapprochés et jlus gros, et les latératix, de chaque côlé, rapprochés, coniques et ül niveau de l'intcrmédiaire d'en bas; le céphalothorax est rougeâtre, aplati, avec un point enfoncé dians le milieu ; antéricurement il est revêtu de poils roux; les mandibules sont rougeâtres, avec des poils gris-bruns à leur extrémité; la lèvre est brune, bordée de blanc; łesmâchoires sont brunes, bordées de blanc; les pattes sont longues, annelées de noir st de rouge; l'abdomer est ovale, al. longé, bistre dans la femelle, noir dans le màle, avec deux tubercules élevés, coniques à la partie antérieure; deux bandes plus foncées, ou festons anguleux, qui partent des deux tubercules et vont se réunir à l'angle de la partie anale. Celte espèce offre plusieurs variétés : dans les unes, l'abdomen est.d'un bistre clair, sans taches, faune; dans les autres, l'abdomen est d'un Listre foucs, noirûtre, sans taches, jaune; enfia, il y en a dont l'abdomen est d'un bistre foncè, noirâtre, avec une tache d'un jaune vif à la partie antérieure. - Cette Aranéide fait une toile grande, verticale, dans les bois; elle pond environ cinquante æuf́s jaunâtres, dans le mois de septembre, sone les feuilles, mais ne construit pas de nid.

\section{ERITA COREUTA.}

Walck., Hist nal. dis Aran., fasc. 7; ibid, Tab. des Aran., p. $57, \mathrm{n}^{\circ} 23$. Long, 9 lig. - Le céphalothorax est d'un brun foncé, avec la partie anterieure rougeâtre; les pattes sont rougeâtres, annelées de noir; l'abdomen est armé de deux tubercules coniques a la parlie antérieure; sa couleur est brune, arec deux bandes latérales festonnées, blanches, qui se rejoignent à la partie anale; sur le milieu du dos, est une croix blanche, festonnec; il y a quatre points enfoncés vers la partie antérieure, disposés en carré; les antérieurs, ou ceux qui sont les plus près du céphalothorax, sont les plus rapprochés; il y a des points jaunes sous le ventre; chez le mâle, l'abdomen est beaucoup plus petit que chez la femelle, et la figure du dos est très-peu marquée; les palpes sont courts et l'organe sexuel présente un globule large et gros; on remarque en dessons de la cuisse de la seconde paire de pattes une épine cornée, courte, forte et conique, et une autre un peu plus allongée au côté intérieur de la uroisieme articulation de la mème paire de partes; dans le milieu du ventre on apercoit un $\mathbf{X}$ jaune ou blanc, ou une ligne blanche ou jaune, coupée en haut et en bas par deux lignes de même couleur.-Cette espèce a été trouvée près de Turin.

\section{Werma micomis.}

Wazck., Tab. des Alan. : 1. 57; ibid., IIist. nat. des Aran., fasc. 2. - Aranea Bicornis; ibid., Faun. Paris., t. Il. p. $190, n^{\circ} 2$. - Le céphalothórax et la naissance des mandibules sont recouverts de poils roux, plus obscurs sur les côtes chez le céphalothorax; la plaque sternale est brune; l'abdomen est ovale, allongé, avec deux tubercules élevés, couiques a sa partie postérieure, de coulenr verte, avec deux bandes ou festons anguleux, noires, foncées, qui partent des tubercules et vont aboutir en angle à la parlie anale. - Sc trouve aux environs de Paris, souvent sur la mousse des arbres, à laquelle elle ressemble pour la couleur.

\section{EPEIPA GIBBOSA.}

Walck. Tabl. des Aran., p. 57. Aranea Gibbosa, 引hid., Faun. Paris., t. II, p. $190, n^{\circ} 3 .-$ L'abdomen est orale, allongé, revèlu de deux tubercules élevés, coniques à la partic antérieure, vert sur les côtés, rouge dans le milieu, et coupe longitudinalement en deux parties égales par 
ane large bande d'un noir vif. - Se troure aux euvirons de Paris.

\section{5. ePEIRA crucitit.}

W Alck., Tabl. des Aran., p. 57.-Aranea Cruciala, ibid., Faun. Paris., t. II, p. $190, n^{\circ} 4$. - L'abdomen est ovale, allongè, revêtu de deux tubercules à sa partie antérieure, avec une croix d'un jaunerougeâtre, formée par quatre triangles opposés à leur base ét occupant le dessus du dos presque en entier.-Se trouve aux environs de Paris.

\section{EPEIRA TUBERCUIATA.}

WaLck., T'ubl. des Aran., j. 58. - Ara. nea Tuberculata, ihid., Faun. Paris., 1. 11, p. 191, n* 5. - L'abdomen est ovale, large, fauve, avec deux tubercules pointus, mais peu élevés; la partie antérieure est séparée de la postéricure par une raie élevée, anguleuse, transverse entre les tubercules. plus foncée, déprimée, arec des taches jaunes proche le céphalothorax. - Celle espèce; qui se trouve aux environs de Paris, fait sa toile dans l'herbe.

\section{EPEIRA DHOUTADEHA.}

Walck, Tabl. des Aran., p. 58.-Aranea Uromaderia, ibid., Fann. Paris., t. II, p. 191, n' 6.-Sch EEF., Icon., t. II, p. 172, fig. 7. - L'abdomen est ovale, large, fauve, avec deux ubercules pointus, mais peu élevés; la partie antérieure est séparée de la postérieure par une raie élevée, anguleuse, transversale entre les tubercules, plus foncée et reprimée, avec des aches jaunes proche le céphalothorax; de plus on apercoit deux festons latéraux et des lignes tuansversales de même conleur à la partie postérieure. - Se trouve aux environs de Paris.

\section{SIXILME GROUPE.}

\section{Les Oialaires a mâchoires coirtes, arron-} dies, W A LCK.

Les mâchoires sont courtes, arrondies à leur extrémité: - La lérre est anssi large que haute. - Les yeux intermédiaires postéricurs sont plus rapprochés que les intermédiaires antérieurs. -- Le céphalothorax est convexe. - l'ablomen est ovale, sans lubercules, découpures ni épines; le dessous présente deux courbes, jaunes ou blanches, opposées.

18. cpeIRA Diangha. (Pl. 8, fig. $3,3 \mathrm{~A}$.) W stck., Tabl. des Aran., p. 58. - A'a- nea Diadema, Schosfr., Elém. Ins.,pl. 21, lig. 2. - Clenck., Aran. $S_{\text {Hec. }}$, p. $2 /$, n०2, pl. 1, tah. 4. - Degéen, t. VII. p. $218, \mathrm{n}^{\circ}$ 1, pl. 11, fig. 3à 8. - Elle est 1'oussâtre, veloutée; les palpes et les pattes sont lachetés de noir ; l'abdomen est trèsvolumincux dans les femelles, surtout lorsqu'elles sont' sur le point de faire leur ponte; d'un brun foncé ou d'un roux-jaunàtre, avec un tubercule, gros et arrondi, de chaque côté du dos près de sa base, et une triple croix formée de petites taches ou points blancs.

If $y$ a des individus dont l'abdomen est rougcâtie, d'autres oủ l'abdomen est mélangé de rouge et de brun, avec des taches jaunes; il y en a aussi chez lesquels ce inême organe est noir avec des taches jaunes, et d'autres ou il est noir avec des points blancs. - Cette espèce est Irés-commune, en automne, dans les jardins, sur les murs et contre les fenêtres; elle s'accouple en été, mais le mâle n'approche de la femelle qu'avec beaucoup de circonspection, et ce n'est qu'après des tâtonnemens souvent réitérés qu'il ose enfin l'approcher pour operer l'acte auquel la nature l'a destiné.

\section{EPEIRA MELATTARIA.}

W alck., Tabl. des Aran., p. 59.-Ara. iea Mellitagria, ibid., Fam. l'aris., 1. II, p. 191, n 7.-L'abdomen est ovale, allongé, avec trois bosses légèes, peu ou poinl apparentes, à sa partie antéricure; il est jaune, réticulé de brun ; une bande jaune, très-large, festonnée de chaque côté en dessus. - Se trouve aux environs de Paris.

\section{EPEIRA MYAGRTA.}

Warck., Tabl. des Arah., p. 59.-Al'anea Myagria, ibid., Famn. Paris., t. II, p. 192, no 8; Clenck, Alran. Suec., pl. 1, tab. 5. - L'abdomen est ovale, allongé, avec deux éminences laterales, peu on point marquées, d'une conleur fauve, avec une ligne jaune, longitudinale dans le: milieu en dessus, bornee par des taches ovales, jaunes, détachées; en dessous il est entierement fauve. - Se trouve aux environs de Paris.

\section{FPEIRA MISINE.}

W atck., Tabl. des Air(th., p. 59.-Ara-1 nea Ilsine, ibid., Faun. Paris., t. II, p. $193,10^{\circ}$ 10.-L'abdomen est ovale, allongé, jaune oranger, arec des lignes festonnces, ronge-oranger, latérales, aboutissant en angle vers la partie anale; de plus, on apercuil deux taches anguleuses, bог. 
dées de noir à la partie antérieure du céphalothorax. - Se trouve aux environs de Paris.

\section{EPEIRA DRYPTA.}

WaLck., Tahl. des Aran., p. 59.-Aranea Drypta, ibid., Faun. Paris., t. II, p. 198, no 15. -ScвовғF, pl. 49 , fig. 5 à 6 . - L'abdomen est ovale, arroudi, rougeferrugineux, avec deux taches noires, oblongues, latérales sur la moitié de la partie postérieure, et se réunissant en angle à la partie anale. - Se trouve aux environs de Paris.

\section{3. epeira cratera.}

Walck., Tabl. des Aran., p. 59.-Aranea C'ratera, ibid. . Faun. Paris., t. II. p. $197, n^{\circ} 9$, Schoеf , pl. 49 , fig. 5, 6. - L'abdomen est globuleux, large, pointu vers la partie anale, arrondi à sa partie antérieure, pubescent, rougeâtre, avec une bande longitudinale plus foncée dans le milieu, bordée de jaune et accompagnée d'autres bandes latérales bordées de même. - Cette espèce, qui se trouve à Paris et dans ses environs, fait une toile verticale entre les gramens, les lys et les plantes élevées des bois et des jardins. Elle se fabrique un nid recouvert en dessus seulement de quelques fils, mais dont le fond imite une coupe ou le nid d'un oiseau : elle s'y tient immobile, les pattes ramassées.

\section{EPEIRA AGALEV.}

Walck., Tabl. des Alan., p. 59.-Aranea Agalena, ibid., Faun. Paris., t. II, p. 197, n० 16.-Aranea Notatus, Clerck, p. $46, \mathrm{n}^{\circ} 14$, pl. 2 , tab. 5 ; Albin., p. 49 , jl. 10, fig. 49. -L'abdomen est globuleux, large, d'un brun obscur, pubescent, avec une tache d'un blanc vif, formant un accent circonflexe proche le céphalothorax. Cette espèce présente une varièté chez laquelle l'abdomen offre une ligne brune bordée de blanc, accompagnée de lignes latérales bordées de même couleur. - Se trouve aux environs de Paris.

\section{EPEIRA MYYBORA.}

Walck., Tabl. des dran., p. 59. Aranea Myabora, ibid., Faun. Paris., t. II , p. 198, $\mathbf{n}^{\circ}$ 17. - L'abdomen est ivale, pubescent, large, un peu déprimé , jaune-oranger, avec quatre points noirs en dessus. - Se trouve aux environs de Paris.

26. EPEIRA TPKETTATA.

W ALek., Tabl. des Aran., D. 20-Ala- nea Triguttata, ibid., Fann. Paris., t. II, p. $198, n^{\circ} 18$. - FABR., t. II, p. $419, n^{\circ} 46$. - L'abdomen est ovale, large, pubescent, d'un roux-fauve, uniforme ou avec trois taches triangulaires, d'un jaune-citron, proche le céphalothorax.

Cette espèce présente trois variétés : dans l'une, l'abdomen est sans taches; dans l'autre, ce même organe offre, au contraire, des taches jaunes; enfin, dans la troisième, l'abdomen présente bien trois taches, mais au lieu d'être jaunes elles sont d'une couleur blanche.-Se trouve aux environs de Paris.

\section{EPEIRA SCALARIS.}

WALcK., Tabl. des Aran., p. 60 ; ibid., Faun. Paris., t. II, p. 194.-MART., Engl. Spid.. pl. 3, fig. 10; Panz., Faun. Germ., 4, 24; Aramea Pyramidatus, Clenck, p. 34 , pl. 1, tab.2 ; Aranea Betulæe, Suczin, p. 254, tab. 29, fig. 14 - Le céphalothorax est blanchâtre; les yeux latéraux sont au niveau de ceux d'en haut; l'abdomen est ovale, allongé, d'un jaune-citron, avec une figure oblongue, dentée, noire à la partie postérieure, et deux points noirs au dessus. - Celte espèce offre plusieurs variètés: chez les unes, l'abdomen est d'un jaune citron, avec la tache noire; les pattes sont blanches, amnelées de rouge; chez les autres, l'abdomen est jaune, avec une tache blanche en trèfle au-dlessus de la tache noire; il y eu a aussi où l'abdomen est jaune, avec la tache noire divisée longitudinalement dans la moitié de la partie antérieure; et d'autres enfin où l'abdomen est vert, avec une tache noire.

Cette espèce, qui sc trouve aux environs de Paris, devient aussi grosse que l'Epeira Diadema; comme elle, elle se cache sous les feuilles et ne construit pas de nid; sa toile est grande, verticale. On la trouve dans les bois, et surtout sur les bords boisés et buissonneux des étangs et des ruisseaux.

\section{8. epetra Pallida.}

Walck., Tabl. des Aran., p. 60.-Aranea Pallida, Ourv., Encyclop. méth., Hist. nat., t. IV, p. 200, ${ }^{*} 6$. - Le céphalothorax est petit, peu aplati; les yeux sont obscurs; les mandibules sont fauves, avec leur crochet noir; les pattes sont assez courtes, d'une couleur pâle, avec des anneaux d'un fauve obscur; J'abdomen est attaché au céphalothoras par un pédicule très-court; il est grand, très-relevé de chaque côté de sa base, ce gui lui donne une forme a peu 
près triangulaire: on aperçoit dans sa parise médiane quatre points enfoncés, formant ensemble un carré, et à la base une croix formée par des points argentés, trẻsbrillans

Cielte espèce, suirant Olivier, file une toile verticale, régulière, sur les arbres fruitiers, les arbrisseaux et les buissons ; elle construit à côté de sa toile. entre deux ou trois feuilles qu'elle rapproche et qu'clle joint ensemble par le moyen de fils assez forts, une retraite où elle se tient ordinairement cachée: on la voit rarement au milieu de sa toile.-Elle se trouve en Provence, dars les jardins et dans les champs.

\section{EPEIRA ACAIYYPHA.}

W stck., Tabl. des Aran., p. 60.-Aranea Acalypha, ibid., Faun. Paris., t. II, p. 199 , no 20 . - L'abdomen est ovale, allongẻ, blanchâtre, luisant, avec trois raies longitudinales de points noirs sur la partie posłérieure en dessus, et quatre autres de même coulcur, délachés, proche le céphalothorax. Cette espece présente une variété dout l'abdomen offre deux raies de points noirs à la partie postérieure, la partie proche le céphalothorax étant sans points. Se trouve communément aux environs de Paris, dans les piés, les bois, les jardins.

\section{EPEIRA CEROPEGIA.}

Walck., Tab. des Aran., p. 60,-Aranea Ceropegia, ibid., Faun. Paris., t. II , 1. $199, n^{\circ} 21 .-$ Le céphalothorax est plus large et les yeux latéraux sont proportionnellement plus rapprochés que dans les espèces précédentes; l'abdomen est ovale, allongé, roux, divisé longitudinalement par une figure oblongue, bordée de jaune, se terminant en pointe à la partic anale et formant deux triangles surmontés l'un par l'autre à la partie supéricure. Elle offre denx variétés dont l'abdomen de l'ume présente la figure burrlée de jaune; se prolongeant sans interruption jusqu'a la partie anale, el dont l'abdomen de l'autre offre la même figure, mais terminée par deux petits cercles jaunes vers la partic anale.-Se trouve dans les bois aux environs de Paris.

\section{EPEIRA ADIANTA.}

Walck., Tabl. des Aran., p. 60, - Aranea Adianta, ibid., Faun. Paris., t. II, p. $201, n^{\circ} 23$. - L'abdomen est ovale, rougeâtre, divisé dans sa partic médiane par une figure oblongue, bordée d'un jaune vif, qui diminue el se réunit à l'angle anal, et est festonnée el cntourée de noir. Cetle espèce offre deux variélés: chez l'une, l'abdomen est-rougeâtre, avec la figure Iongitudinale, mais interrompue et bordée de jaune et de noir; chez l'autre, l'abdomen est jaunâtre et verdâtre, avec une figure longitudinale, festonnée, bordée de noir, interrompue à la partie antéricure.Se trouve dans les bois aux environs de Paris.

\section{EPEIRA DIODIA.}

WALcK., Tabl. des Aran., p. 60.-Ara. nea Diodia, ibid., Faun. Paris., t. II, p. $200, n^{\circ} 23$. - L'abdomen est ovale, allongé, jaunâtre, d'un brillant souvent argentẻ-jaunâtre, avec quatre taches brunes en carré à la partie supérieure, et une figure pyramidale brune à la partie postérieure, formée par des lignes transversales et se terminant en angle à la partie anale. -Cette espèce, qui se trouve aux environs de Paris, fait une toile verticale au pied des orlies et autres plantes qui bordent les chemins.

\section{TPEIRA OUADRATA.}

Walck., Tab. des Aran., p. 61.--Aranea Quadrata, ibid., Fann. Paris., t. II, p. 193, no 11. - Fabn., Syst. Entom., p. 419, 45. - DegÉER, t. VII, p. 223 , no '3, pl. 12 , fig. 16. - Clenck, p. 27, t. III, pl. 1.Aranea Regalis, PAnz, Faun. Germ., p. 40, pl. 21. - Albin., Spid., pl. 27, fig. 131. - Le céphalothorax est bordé de brun, avec une raie brune, longitudinale dans sa partie médiane; l'abdomen est orale, globuleux, avec quatre taches jaunes ou blanches, ovales, en carré; de plus, on aperçoit des points et deux lignes festonnées, aboutissant en angle à la partie anale, de même couleur. Celle espèce présente quatre à cinq variétés : chez les unes, l'abdomen est d'un beau rouge-amaranthe, ou verdàtre, ou jaunâtre, ou blanchâtre, avec des taches blanches; chez les autres, il est ovale, allongé, pas plus large que le cêphalothotrax; les paltes sont aussi très-longues (mâle). Non-seulement elle varie par la couleur, mais aussi par le dessin du dos de l'abdomen; quelquefois les lignes festonnées, latérales, se joignent à chacune des deux taches postérieures, et quelquefois elles ne s'atleignent pas. Il en est enfin où ces liqnes manquent totalement, mais les quatre taches sont tonjours conslantes. Ces variétés se trouvent ensemble dans les mêmes lieux et dans les mêmes temps. 
Cette espèce fait une toile trẻs-grande, verticale, et se fabrique en soie serrée un nid ou dôme, ouvert par en bas, où elle se tient; de ce nid part un fil qui aboutit au centre de la toile, et par le moyen duquel l'araignée monte et descend à volonté. Elle pond ordinairement en automne. On la trouve aux environs de Paris, dans les bois et les lieux humides.

\section{EPEIrA MARMOREA.}

Walck., Tabl. des Aran., p. 61.-Aranea Marmorea, Clenck, p. 29, $\mathrm{n}^{\circ} 4, \mathrm{pl} .1$, tab. 6. - DEGÉER, t. VII, p. 222, n' 3 , pl. 12, fig. 16 et 17. - Le céphalothorax, les palpes et les pattes sont d'un blanc-rosegrisâtre, avec des taches et des raies d'un brun obscur; le plastron sternal est de couleur noire; l'abdomen est gros, d'un jauneoranger, présentant une infinité de petits traits brunâtres, et le long dês côtés latéraux une grande tache rouge-oranger, découpée en forme de feuille et bordée d'une ligne brune; entre ces taches on en apercoit d'autres beaucoup plus petites, rouges, placées en carré, et dans la partie médiane est une suite de petites taches jannes qui se touchent; la partie antérieure est ornée d'une tache allongée, également couleur d'orange et burdée du mème brun; enfin, en dessous il présente une large bande inégale de couleur noire.

\section{EPEIRA ApOCLISA.}

WaLcK., Tabl. des Aran., p. 61. I.. Dufour. Ann. des Sc. nat., t. II, pl. 11, fig. 2. - Araneus Subflavus, Lister, Aran., p. 24, tab. 1, fig. 1.-L'Araignée à fenille coupée, GeofF., Ins., t. II, p. 647, pl. 21, fig. 2. - L'Araignée Portefeuille, ibid., Ins., t. II, p. 646. - Aranea Um. bratica, Osw., Encycl. Méth., n० 10 . Aranea Foliata, ibid., Encycl. Méth., no 11. - Long. 5 lig. - Le céphalothorax, d'ui roux testacé plus ou moins foncé, est revêtu de poils écailleux blancs, tout-à-fait couchës et dirigés en avant de manière a représenter a la loupe des espèces de stries; un filet blanchâtre formé par ces mèmes poils plus rapprochés, lui forme très-fréquemment une bordure; les yeux sont noirs, saillans; le carré du centre a son côté inférieur un peu plus grand que le supévieur; les mandibules, tantôt noires, tantôt brunes, sont gibbeuses à leur base, et hérissées de quelques poils blancs; le crochet est Hrun et reçu dans sa flexion dans une coulisse bordée a droite et à gauche de trois dents; les mâchoires, ainsi que la lèrre. sont courtes et très-arrondies; les pattes, herissées de quelques poils assez courts, sont roussâtres ou pâles, avec quelques bandes plus foncées; les cuisses sont pâles dans leur moilié postérieure, avec souvent quelques poils noirs; les ongles des tarses sont noirs, médiocrement arqués, munis vers leur milieu d'une dent bien prononcée, puis de quelques petites aspérités; l'abdomen est parfaitement ovale, tomenteus, mais non hérissé ; son fond est tantôt d'un blanc assez pur, tantôt roussître ou d'un gris-blond, ce qui rend plus ou mois tranchantes les taches qui ornent sa région dorsale; depuis le milieu de celle-ci jusqu'à la partie anale, il y a deux rubans noirs ou bruns festonnés, confluens en arrière, de manière qu'ils interceptent un espace triangulaire; la base de l'abdomen offre trois taches noirâtres dont les latérales sont parfois réniformes, et dont l'intermédiaire est le plus souvent pointue aux deux bouts; en dessous il est constamment noirâtre au cen. 1re, avec une tache annelée, jaunâtre de chaque cồté.

Fle se troure aux environs de Paris; elle a été aussi zencontrée ä Saint-Sever.

36. EpLMa UmRticoLA. (P]. 8, fig. 2.)

Latri., Gener. Crust. et Ins., t. I, p. 105. - L. Drpoun, Ann. des Sc. viat., i. 11, p. 12. - Long. 5 lig. - Le céphalothorax est bruu, assez luisant, revêtu de poils blancs tout-a-fait couchés et pas assez fournis pour cacher la couleur du fond; il est parfois noirâtre à sa partie postérieure, sa région dorsale est plane; la portion qui représente la tête est plus large que dans beaucoup d'autres espèces, coupée carréinent à son bord antérieur, et marquée sur les côtes de deux impressions obliques qui viennent converger à une fossette centrale, transversale; les yeux latéraux sont abrités par une saillie de l'angle antérieur du céphalothorax, et presque contigus; ceux qui forment le ceur du milieu sont plus grands que les latéraux et placés aux angles d'une légère éminence quadrilatère; les denx anterieurs du carié sont un peu plus distans entre cux que les deux postéricurs; les mandibules sont noirâtres, courtes, robustes, gibbeuses en devant et velues; leur crocliet est recu dans une rétraction entre deux rangées de trois petites dents fort courtes; les mâchoires sont larges, courtes, avec leur bord roussâtre, assez épais; la lerre est courte, arrondie, pareillement 
roussätre à son tord; les pattes ont un duvel court, et sont hérissées de quelques piquans et poilsroides : les quatre antérieures sont à peu près égales entre elles, mais bien plus longues el plus fortes que les au. tres, surtout que la troisicme ; Jeurs cuisses sont noirâtres; les jambes c les tarses plus ou moins brunâtres, avec des annelures plus claires; les ongles sont finement pectinés; l'abdomen est ovale, triangulaire, déprimé, garni d'un duvet grisâtre bien sensible à la loupe; de chaque côté on voit une ligne festonnée, noire, bordée en dessous d'un pea de blanc; les deux lignes convergent en arrière; quatre paìes de fossettes orbiculaires, dont le fond est noir et glabre, s'observent sur le dessus de l'abdomen; la seconde paire de ces points ombiliqués est bien plus grande que les attres, et la dernière est fort petite; cn dessous il est noir au centre, et, de chaque côté de ce centre noir, il y a une tache jaune un peu arquéc. - Cette espéce se trouve aux environs de Paris, sous lesécorces des arbres; nous l'avons irouvée assez communément au Jardin des Plantes, dans les fentes des pieux qui soutiennent les treillages; M. L. Dufour l'a aussi recontrée à Saint-Sever.

\section{SEPTIIIE: GROUPE.}

\section{Les Ovalaires à mâchoires allongées,} WALCK.

Les mâchoires sont allongées, droites à Jeur extrémité. - La lèvre est plus haulo que large. - Les yeux intermédiaires d'n bas sont plus rapprochés que les intermé. diaires d'en haut. - Le céphalothorax est énvexe. - L'abdomen est ovale, sans découpures, tubercules ni épines, ayant sous le ventre deux lignes droites, paralleles, d'une couleur plus pâle.

\section{FPEIRA CAIOPHYI.A.}

Warck.; Tabl des Aran., P. 61.-Aranea Calophylla, ibid., Faun. I'aris., t. II, p. 200, n०25. - Lister, de Aran., p. 47, tit. 10, fig. 10. - Schorr., pl. 42. fig. 13. - Les mâchoires sont peu larges et peu arrondies; les yeux sont gros, Jes Jatéraux pcu écartés et peu obliques; l'abdomen est ovale, arrondi, déprimé, avec une feuille arrondie, festonnée sur le dos, d'une cou. leur plus foncée sux les bords et vers la pointe; elle offre trois variétés chez lesquelles l'abdomen est blane el noir, ou varié de-vert, de rouge, de noir el de jaune, ou arec le milicu de la feuille luisant et ar- genté. - Cette espèce, qui se trouve aux environs de Paris, fait une toile verticale, où elle ne se tient ordinairement que de nuit; le jour elle se retire dans un tube de soie blanche qu'elle a pratiqué au-dessus de sa toile. ('est à l'entour des maisons, et même dans leur intèrieur, sous les hangards, dans les écuries, qu'elle se plaît: on la trouve plus souvent en ces lieux qu'en pleine campagne.

\section{EPEIRA TUBULOSA.}

W alck., Tab. des Arain., p. 62 ; ibid., Faun. Paris., t. 11, p. 200, n²4 ; Lister, p. 40, tit.7, fig. 7; Aranea Hamalus, ClencK, p. 51 , n. 2, pl. 3 , tab. 4 ; AlbiN, pl. 55, fig. 174. - L'abdomen est ovale, cylindrique, brun, divisé en dessus longiiudinalement par une raie jaune, traversée dans le milieu par quatre raies de même conleur. Elle fait sur les buissons et dans les blès, une toile verticale, et elle pratique à la partie supérieure, sous une feulle, un petit tube assez long de soie blanche et serrée, où elle se tient en attendant sa proie. - Elle se trouve aux environs de Paris.

\section{BPEIRA INCIINATA.}

Walck., Tabl. des Aran., p. 62.-Aranea Inclinata, ibid., Faun. Paris., t. II, p. 201 , no 26 ; LISTER, p. 24 , tit. 1 ; $A r a-$ neus Segmentatus, Clerck, p. 45, no 13 , pl. 2, tab. 6, fig. 1, 2; SсноеFF., Iconogr., pl. 158, fig. 7.- Aranea Reticulata, LiNs., Syst. nat., p. 1030. - Les mâchoires sont peu arrondies; les yeux latéraux sont peu écartés et au niveau de ceux d'en haut et peu oblífues; l'abdomen est ovale, allongé, blanchâtre, ponctué de noîr, avec des raies tıansversales plus blanches a sa partie pos. térieure, et un triangle blanc dans son milieu. Chez le mâle, l'abdomen est cylindrique; allongé, moins large que le céphalothorax, qui est roux ; les pattes sont rouges. et très-longues. Il y a des individus chez lesquels l'abdomen est varié de blanc, de jaune et de noir; ou de vert, de rouge et de jaune, ou enfin de jaune-oranger et de noir.

Cettc espèce, qui se trouve anx environs de Paris, fait une toile orbiculaire inclinée à quarante-cing degrés , et presque jamais. rerticale ni horizontale.

\section{EPEIRA ANTRIADA.}

Warck., Tab. des Aran., p. 62.-Aranca Antriada, ibid., Faun. Paris., t. I1, p. 201, n*27. - Lesyeux, les mâchoires el la forme 
comme dans la précédente, à laquelle, au reste, elle ressemble beaucoup; mais clle est peu grande, elle a des couleurs plus foncées et des points noirs sur les cuisses; son abdomen est ovale, allongée, oranger. brun, ayant dans le milieu une figure plus claire, representant un fer de lance renversé. Quelquefois on rencontre des individus où l'abdomen est oranger clair ou oranger-noirâtre. - Cette espèce fait une toile inclinée aux soupiraux des caves et des lieux obscurs.

\section{EPEIRA FUSCA.}

Warck., Hist. nat. des Aran., fasc. 1 ; - ibid., Tab. des Aran., p. 63, pl. 6, fig. 61 et 62. - Epcira Menardii, Latr., Gener. Crust. et Ins., t. I, p.108, spec. 12 ; - ihid., Hist. nat. des Crust. et des Ins., 1. VII, p. 206, $\mathrm{n}^{\circ} 78$. - Araignée brune, OLiv., Encysl. meth., Hist. nat., t. IV, p. $189, \mathrm{n}^{\circ} 20$; et p. $204, \mathrm{n}^{\circ} 20 .-$ Aranea Fusca, Degéer, Mém. pour servir á l'Itist. nat. des Ins., t. VII, p. 255, n 9, pl. 11. - Long. 7 lig. - Le céphalothorax présente en dessus une bande longitudinale et des traits transversaux de couleur noire; les pattes sont tachetces de noir et de fauve; l'abdomen en dessus est d'un fond brun mêlé d'un peu de jaune en avant, et parsemé d'un grand nombre de taches et de nuances noires, velues, qui le rendent comme marbré, particulièrement sur les côtẻs; le mâle est semblable à la femelie mais son abdomen est plus petit et plus allongé ; les deux derniers articles de ses pal. pes, ou les parties sexuelles, sont tzrminés par une masse noire, ovale, velue, et accompagnée à la base d'une pièce allongée, un peu courbe, en forme de crochet; au printemps, il accompagne ordinairement la femelle, qui se tient ordinairement un peu a l'écart; et il se promène souvent sur sa toile sans qu'elle cherche à lui faite aucun mal.

Le cocon a près d'un pouce de diamètre; il est composé à l'extérieur d'une bourre douce et très-fine d'un blanc terne, dont la demi-transparence permet d'apercevuir une seconde enveloppe qu'elle recouvse; cette seconde enveloppe contient les cufs; cette espece attache aux murs son cocon, arec un pédicule soyeux, long d'un pouce: clle le transporte et le rattache, s'il vient à tomber; dans les premiers jours de leur naissance, les petits se réfugient dans le co. con, comme dans une retraite. - Cietle espéce se plait dans les licux obscurs el humides.

\section{EPEIMA CUCURBITIYi.}

Walck., Tabl. des Aran., p. 63.-Aranea Cucurbitina, ibid., Faun. Paris., t. II, p. 202. - Latr., Hist. nat. des C'rust. et des Ins., t. 7. p. 265, no 76. - DUMÉR., Dict. des Sc. nat., 1804, t. II, p. 331, n" 12. - Linv., Syst. nat., p. 1030, 3. - Degéen, Mém., t. VII, p. 233 , n' 8 , pl. 14, fig. 1, 2.-Clenck, Aranea Suecica, p. 44, no 12, pl. 2, tab. 4. - Schoerf., lcon., pl. 196, fig. 6 et pl. 124 , fig. $6 .-$ Georfn., lus. des env. de Paris, t. II, p. 648. - Le céphalothorax est glabre, d'un jaune transparent, comme de l'ambre, de couleư foncée; les mâclioires sont comme dans la précédente; les yeux intermédiaires d'en haut sont plus gros et plus rapprochés que dans toutes les autres especes; les latéraux sont an niveau de ceux d'en bas; son abdomen est ovale, arrondi, d'un beai vert, festomé, avec des points noirs enfoncés sur les côtés el dans le milieu. Le mâle a l'abdomen très petit, d'un vert plus foncé : les pattes sont très-longues, rouges et annclées de noir ou de vert de vigne; le céphalothorax est bordé de même conleur. - Cette espèce, qui se tronve aux environs de Paris, fait une toile horizontale et toujours extrêmement petite; elle pond, vers la fin de juin, environ quárante cufs, recouvre son cocen d'une boure jaunâtre, et l'enveloppe dans une feuille qu'elle plie et auprès de laquelle elle se tient.

\section{EPEIRA CIRCULATA.}

Walck., IIist. nat. des Aran., fasc. 5; ibid., Tub. des Aran., p. $65, n^{\circ} 47$. Long. 5 lig. $\frac{1}{2}$. - Le céphalothorax est bombé à sa partie antéricure, avec deux sillons qui dessinent un triangle; sa couleur est d'un jaune rougeâtre, ainsi que la plaque slernale, qui cst glabre, bombée, cordiforme, les mandibules sont d'un jaune rougeâtre, hérissées de poils rares; les pattes sont de mème couleur, mais annelées de brun; l'abdomen est ovale, arrondi, d'un gris rerdatre, uniforme en dessous et sur les côtés, mais ayant en dessus une tache ovale, trapéziforme, jaune, dans le milieu de laquelle se trouvent plusieurs points enfoncés, dout quatre sont plus visibles que les autres; sur les côtés de cette tache sont quafre points arqués noirs, et à l'extrémité deux glo'ules bombés, parfaitement ronds, diaphanes et luisants, et entourés d'un cercle de couleur d'or brillante. - Cette es jece a été trouvée à Cayerne. 


\section{IUITIKME GROUPE.}

\section{Les Irrègulières, WАLск.}

L'abdomen est de forme irrégulière, et terıniné en tous sens par des tubercules charnus.

\section{EPEIRA COVICA.}

Walck., Tabl. des Arah., p. 64; ibid., Faun. Paris., t. II, p. 202 ; ibid., Mist. nat. des Aran., fasc. 3. - LaTr., Hist. nat. des Crust. et des Ins., t. VII, p. $266, n^{\circ} 77$. - Duméril, Dict. des Si. nat., t. II , p. 331. - DegÉer, Mém. sur les Ins., t. VII, p. 231, n 7. - Le céphalothorax est noir, glabre et luisant, bordé par une rangée très-fine de poils blancs et gris; le plastron sternal est cordiforme, brun, revêtu de poils gris; les yeux latéraux sont élevés et assez éloignés des mandibules; ces derniers organes sont arrondis; les palpes sont noirs à leur extrémité ; les paites sont fines, blanches, annelées de noir; l'abdomen est arrondi et renflé proche le céphalothorax, mais la partie postérieure et le dessous se terminent en cône; ce dernier a une base beaucoup plus large et une pointe moins aiguë; en dessus il est d'un blanc gris, mélangé de noir et de vert; il y a deux lignes noires en angle dont la pointe se dirige vers le ventre; la région de la partie anale, qui est arquée comme le dessus, est mouchetée de noir et de vert, avec une raie jaunâtre dans son milieu et deux taches rouges à sa base; le milieu du ventre est noir, avec deux lignes jaunes en angle droit qui entourent les parties sexuelles. - Cette espèce fait une toile très-grande, verticale, dans les bois ombragés. Elle se trouve aux environs de Paris.

\section{EPEIRA OCULATA.}

WaLck, Tabl. des Aran., p. 64.-Aranea Oculata; ibid., Faun. Paris., t. II, p. 428, Ilist. nat. des Aran., fasc. 7, fig. a, $b, c, e, f, g$. - Long. 3 lig. - Les yeux sont en général proportionnellement très-gros et très-saillans; les deux du milieu antérieur sont portés sur des tubercules coniques qui avancent et sont dirigés en bas ; lesyeux latéraux sont sur la ligne des intermédiaires d'en haut; le céphalothorax est d'un noir luisant, trés-pointu vers la partie antérieure; les palpes, dans le mâle, sont terminés par une masse globuleuse très-renflée; les pattes sont noires; les cuisses sont tachécs de blanc à leur base ; les jambes et les tarses sont annelés de noir et de roux; l'abdomen est noir, avec une tache dentée, formée par deux raies noires en zig-zag; sur les côtés de la partie postérieure il est revêtu de cinq tubercules, dont deux placés sur la partic antéricure du dessus, et trois qui terminent la partie postérieure; celui du milieu est bifide. - Elle se trouve aux environs de Paris, mais très-rarement; elle est plus commune en Piémont.

\section{EPEIRA OPUNTIF.}

L. Dur., Anr. génér. des Sc. phys. de Bruxelles, t. V, p. 359 , pl. 89 , fig. 3. Long. 6 lig.-Le céplialothorax est revêtu de poils blancs en avant, et sensiblement rètréci pour la demarcation de la tête; les yeux, tant ceux qui forment le carré du centre que les latéraux, sont placés sur une éminence bien marquée; ces derniers, quoique rapprochés, sont bien distinctemént siparés l'un de l'autre; les pattes sont d'une moyenne longueur et assez fortes; outre les poils écailleux, blancs et couchís qui les revêtent, elles sont hérissées de cils plus longs, clair semés, redressés, les uns blanes, les autres noirs; leur article thoracique est roussâtre en tout ou en partie, et quelques mouchetures de cetle couleur, mais peu distinctes, se remarquent auss: aux jambes et aux tarses; l'abdomen, ovale-quadıilatère, a sa région dorsale ordinairement déprimée et munie, de chaque côté, de deux tubercules pyramidaux, pointus, dont l'un est antéricur el l'autre se trouve à peu près vers le milieu du bord de cette partie; deux tubercules obtus, arrondis, séparés par une large échancrure, terminent l'abdomen en arrière; la face posterieure de chacun de ces tubercules pyramidaux offre une tache triangulaire, d'un beau blanc de neige nacré; ces taches se lient entre elles et avec une ou deux autres qui leur sont postérieures par des lignes blanches, tracées en zigzag, quelquefois presque effacées; en dessous il est bigarré de jaune, et les filières sont groupéesen un mamelon.-Cetle espècevaJie un peu pour sa couleur; le fond en est noirâtre, roussâtre, ou comme saupoudré de blanc; dans quelques individus le dessus est joliment bigarré de lignes blanches qui s'anastomosent avec les taches nacrées; enfin, il y en a d'autres qui offrent des stries fort élégantes, d'un blanc pur.

Celte espèce, dit M. L. Dufour, est fréquente dans le royaume de Valence et la Catalogue; elle habite constamment au mi- 
licu des feuilles de l'Agave el de l'Opuntia, mais plus en particulier sur cette dernière plante, aux environs de Sagonte et d'Almenara; elle se montre dès le commencemeut de juin, jusqu'à la fin de décembre; elle établit ses filets au moyen d'un rèsea: dont les fils sont lâches et irrégulièrement entrelacés; tantôt elle se tient les pattes étendues au milieu du réseau pour épier sa proie, tantôt lorsque le vent sonflle avec violence, et que le temps est aombre, elle va se blottir derrière un faisceau d'épines, où viennent aboutir plusieurs fils de son canevas; les coques qui recèlent la progéniture sont ovales, blan. châtres, de quatre ou cinq lignes de diamètre; l'une des faces est convexe, et n'adhère à l'autre, qui est plus ou moins aplatie, que par un enchevêtrement de fils, lesquelscèdent facilement à la traclion; chaque coque est formée de deux tuniques dont l'extérieure est d'un tissu plus serré et dont l'iitèrieure, qui est séparée de l'autre par une bourre assez abondante, et plus particulièrement la capsule des œufs; j'ai souvent rencontré à la file l'une de l'autre, sept, huit et même dix de ces coques; je ne pense pas qu'elles soient toutes l'ouvrage đu même indívidu; dans ce cas, ces Epeires vivaient en société, et de bonne intelligence; ce qu'il y a de sûr, c'est que j'en ai souvent observé un grand nombre vivant sur le même pied d'Opuntia, et dans le voi sinage les unes des autres; les æufs sont ronds, d'un blanc un peu jaunâtre; les petites araignées qui en naissentn'ont point à l'abdomen les tubercules qui caractèrisent les individus adultes; ce dernier est ovale, hèrissé de quelques poils blancs; leur céphalothorax est noir, luisant, glabre; le carré central des yeux est proportionnelle. ment plus grand; les pattes sont annelées de brun et de pâle.

\section{GASTERAGANTHA, LATr. ; Epeira, WALCK.}

\section{Plectana, ibid., Acrosoma, Perty.}

Ce genre, confondu autrefois avec celui a'Epeira, en est bien distinct par son ab domen, qui est toujours irrégulier, revêtu de tubercules cornés, pointus, semblables à des épines: - Les mandibules sont trèscourtes et renflèes à leur insertion. - Le céphalothorax est relevé antérieurement.

1. gasteracantila curvicauda. Epeiva Curvicauda. - Vavtr., Ann. des
Sc. nat., 1. 1, 1824, pl.12, fig. 1 à 6. - D.jGÈs, Atlas du Règ. anim. de Cuv., Arachn., pl. 11, fig. 3.-Long. 15 lig.-Le céphalothorax est noir, très-bombé, le double plus large que long, de forme trapézoïdale, ayant son bord antérieur sinué, légérement arrondi sur les côtés, et hérissé entièrement de poils blancs assez roides; antérieurement, et sur un tubercule de couleur noire, sont placés quatre yeux très-brillans, dont les deux antérieurs plus petits et plus rapprochés entre cux, dechaque côté sont deux tubercules de même couleur à l'extrémité desquels est placée une paire d'yeux très-rapprochés entre eux; les palpes sont d'un brun foncé, avec le dernier article terminé par un petit ongle noir; les mâchoires sont noires, lisses, armées d'une double rangée de dents inégales; les pattes sont velues, de couleur testacée: la première paire est la plus longue, ensuile la seconde, la troisième beaucoup plus courte, la quatrieme de la longueur de la seconde; l'abdomen est d'un jaune-rougeâtre, de forme triangulaire, sa partie antérieure tronquée est légèrement sivuée et donne attache au céphalothorax; les côtés sinues portentả la partie antérieure une petit épine noire, près de laquelle s'attache une grande corne rugueuse, garnie de poils noirâtres, recourbée en dedans, de couleur rouge brique à sa base, noirâtre à son extrémité ; le bord postérieur est légérement courbé en dehors; au-dessus de ce bord se trouve un fort pli aux extrémités duquel sont placées dans un enfoncement deux ta. ches noires, tuberculeuses; sur deux éminences de ce mème pli sont attachées deux épines brunes, plus longues que celles des parties latérales et dépassant le rebord; l'abdomen en outre est rebordé généralement, concave, ayant dans sa partie médiane une éminence arrondie; il porte à sa surface vingt-trois taches Juisantes, de forme ovale, dont le bord est saillant, avec un petit tubercule élevé au centre; en dessous il est nuancé de brun, de rouge et de jaune, plissé, avec les filières de couleur noire. - Se trouve à Java.

\section{Gasteracavtha GRacilis.}

Epeira Gracilis, Walck., Tab.des Arar., p. $65, \mathrm{n}^{\circ} 50$; ibid., Hist.nat. des Arane., fasc. 3 , pl. 5 , fig. 1. - Long. 6 lig. - Le céplialothorax est d'une couleur brune, carré; les pattes sont filiformes, brunes; les cuisses minces et très-allongées; l'abdomen est allongé, plus étroit en arrière, enfoncé dans son milieu, releré en bosse à sa 
partie poslérieure, et vers la partie antérieure bordè de jaune, armé de dix épines courtes, dont les deux antéricures proches le céphalothorax sont droites et verticales; les deux du milieu sont horizontales, cou. chées de chaque côté ; la partie postérieure est bifide, et chacune des bifurcations est armée de trois épines disposées longiludimalement et en éventail; celle du dessous est plus petite que les deux autres; la couleur est jaunâtre, avec des points enfoncés et parsemés sur les côtés; les pattes sont filiformes, brunes; les cuisses sont minces et allongées. - Habite la Caroline dans l'A. mérique-Septentrionale.

\section{GASTERACANTHA LEPELLETIERII.}

Guér., Voy. de la Coquille, Zool., t. II, $2^{\mathrm{e}}$ partie, $1^{\mathrm{re}}$ division, p. $12 .-$ Long. 4 lig. $\frac{1}{2}$. - Le céphalothorax est très-luisant, ḋun noir à reflets violets; les palpes et les pattes sont d'un rouge brique, arec l'extrémite des tarses bruuâtre; l'abdomen est transversal, un peu bombé, de forme hexagonale; ses quatre angles postérieurs portent une épine épaisse à la base et rétrécie brusque. ment en pointe aiguë, au dessus des deux latérales, qui sont les plus longues et qui atteignent presque une ligne de longueur, il y en a de chaque côté une autre très-petite, conique et dirigée un peu en avant; toutes ces épines sont dépourvues de poils; les deux latérales sont très-rapprochées entre elles; les postérieures sont plus éloignées des latérales qu'elles ne le sont entre elles; le dessus de cet abdomen est jaunâtre, marqué de vingt-deux points noirs, dont dixhuit placés autour, et quatre au milieu. Cette espèce a été trouvẻe dans les bois, aux environs de la rade de Cayelé, dans l'île de Bourou; on la trouve aussi à Taïti, $\Lambda$ mboine et autres îles voisines.

\section{Gasterocantha rubrospinis.}

Guér., Voy. de la Coquille, Zool., t. II, $2^{\text {e }}$ partie, $1^{\text {re }}$ division, p. 53.-Long. 4 lig. - Cette espèce ressemble beaucoup à la précédente, mais son céphalothorax n'offre pas de reflets violets ; son abdomen est peu large proportionnellement à sa longueur; il est très-petit en dessous, d'un blanc un peu jaunâtre, entouré du même nombre de points noirs, et ayant son bord antérieur peu arqué ; les six épines sont coniques, et diminuent insensiblement d'epaisseur pour se terminer en pointe aiguë; elles sont courtes, les latérales ayant une demi-ligne de longueur, de couleur rouge brique, et garnics de poils noirâtres; les latérales sont aussi distinctes entre clies que les postérieures; les pattes sont noires, avec les cuisses ronges jusque près du genou. Trouvée à Offak, dans l'île Waigiou.

\section{GASTERACANTHA FASCIATA.}

Gurn., Voy. de la Coquille, Zool., t. II, $2^{\text {s }}$ partie, $1^{\text {re }}$ division, p. 53. - Long. 4 lig. $\frac{1}{2}$.

Diflère de la précédente en ce qu'elle est un peu plus grande, d'un jaune plus ou moins rougeâtre; en ce que son abdumen est convexe, et surtout par la presence de deux bandes noires, transversales, interrompues, et dont l'antérieure est plus large; les deux individus sur lesquels cette description a été faite varioient un peu en. tre eux : l'un ètoit armé d'épines un peu plus grandes, avec sa bande antérieure interrompue seulemen t au milieu; dans l'au. tre, la couleur ètoit moins vive, et la bande antéricure trois fois interrompue ; en dessous. ces deux individus étoient noirs et tachés de jaune. - Trouvée dans l'île de Guam et dans l'une des Mariannes.

\section{GaSTERACANTHA THEISII.}

Gứr., Voy. de la Coquille, Zool., t. II, $2^{\mathrm{e}}$ part., $1^{\mathrm{r}} \mathrm{div}$., p. 54. - Long. 4 lig. Le céphalothorax est entièrement noir. luisant ; ses pattes sont d'un noirâtre tirant au ferrugiueux; l'abdomen est noir,'arec rles taches d'un beau jaune qui varientbeaucoup par la forme et l'ètendue : dans les individus où ces taches sont le mieux marquées, elles semblent représenter à peu près un oiseau vu sur le dos et les ailes étendues; cet abdomen présente buit côtés égaux, les six postérieurs portent chacun une épine à leurs angles; les deux antérieurs sont les plus petites, elles sont parfaitement coniques; les deux suivantes sont les plus grandes, leur longueur égale à peu près une demi-ligne, les postérieures sont un peu plus courtes ; ces quatre épines commencent par être cylindriques et deviennent ensuite brusquement coniques; elles sont toutes garnies de petites spinules courtes et dirigées en dehors; ces épines sont toutes placées à des distances égales enire elles. Se trouve à la Nouvelle-Guinée.

\section{GaSTERACANTHA RHOMBOIDEA.}

Guér., Voy. de la Coquille, Zool., t. II, 2e part., 1 re div., p. 54. - Long. 3 lig. : - L'abdomen est tout-à-fait transversal, au moins deux fois aussi large que long, non compris les épines; il est aplati, arrondi en a vant, anguleux en arriere; les épines sont noires; les latérales sont très- 
inrgales, les supéricures étant très-petites, coniques; Ies suivautes cylindriques et pointues au bout, longues d'un peu plus d'une demi-ligne, velues; les deux postérieures sont très-élojgnées des précédentes, de moitie plus petites et coniques; le dessus de cet abdiomen est d'un beau jaune d'ocre, marqué de points noirs ordinaires. mais en ayant quatre plus gros, suivant une ligne parallèle au bord antérieur placée audessus des grandes épines latérales; le céphalothorax, les palpes et les pattes sont noirs. - Trouvée à l'île de France.

\section{Gasteracantha hiveata.}

Guér., Voy. de la Coquille, Zool., t. II ,

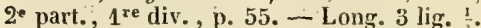
- Remarquable par la forme arquée de son abdomen; les angles latéraux se relèvent en avant et sont un peu plus avancés que le milieu; le bord postérieur est presque parallèle au précédent, un peu plus elargi au milieu; sa longueur est presque trois fois dans sa largeur; les épines sont velues, noires, les latérales antérieures sont tres-petites, coniques; les suivantes sont beaucoup plus grandes, cylindriques, brusquement termicees en pointe, velues, uon pas placées comme chez toutes les espèces que nous avons décrites, à l'angle postéeieur, mais entre cet angle qui est arrondi et l'épine antérieure, dont elle est rapprochée; les deux épines postérieures sont très-petites, coniques, placées à une trèsgrande distance des précédentes et également velues; les points arrondis du dessus de l'abdomen sont grands et de couleur noire; le céphalothorax, les pattes et le dessous de l'abdomen sont noirs. - Trouvée dans l'île de Timor.

\section{GaSteraGantha AUDOUIN.}

Guér., Voy. de la Coquille, Zool., t. II, $2^{\circ}$ part., $1^{\text {re }}$ div., p. 55 . - Long. 3 lig. $\frac{1}{2}$. -L'abdomen est d'une forme ovale transverse, étroit, rétréci et tronqué de chaque côté, armé de deux épines dont l'antérieure très-petite conique; la postérieure beaucoup plus grantle. noirâtre, épaisse, cylindrique, comme arrondie au bout, mais ayant une pointe conique cachée dans les poils, sa longueur est d'une ligne; le bord postérieur de cel abdomen présente des vestiges des deux pointes postérieures, mais elles sont réduites à deux petits tubercules; le dessus est jaune, avec des points ordinaires noirs; le dessous est noi๘ầ̆łre, avec quclques taches pâles; le cépha. lothorax est noir; les pattes sont ferrugineuses, avec l'extrémité plus nbscure. Trouvée dans l'île d'Amboine.

\section{Gastefacanta gEMINATA.}

Epcira Geminata, Walck., Hist. nat. des Avar. , fasc. 6. - Aranea Geminata, Fabr., Suppl. Entom. Syst., p. 292, $\mathrm{n}^{\circ}$ 38-9.-Epeire géminée, WaccK., Tabl. des Aran., p. $66, n^{\circ}$ 59.-Long. 4 lig. Le céphalothorax est noir en dessus, rougeâtre en dessous; les mâchoires et la lèvre sont rongeâtres; les mandibules sont noires; l'abdomen est très-large, aplati, à six épines courtes, les quatre latérales accouplées deux à deux, rapprochées, parallèles; les taches sont rondes, proéminentes, d'une substance cornée en dessus; la quatrième paire de pattes largement annelée de rouge et de noir. - Trouvée aux Indes-Orientales.

\section{Gasteracantui Cangriformis.}

Epeira Cancriformis, Walck., Hist. nat. des Aran., fasc. 4. - Aranea Cancriformis, Lins., Syst. nat., édit. 10, t. I, p. $624, n^{\circ} 38 .-\mathrm{F}_{\mathrm{ABR}}$, Entom. Syst., t. II, p. $408, n^{\circ} 6 .-$ Araignée Cancre, Ourv., Encycl. Méth., Hist. nat., t. IV, p. 190, $n^{\circ} 25$, et p. 205, $n^{\circ} 25$. - Latr., Hist. nat. des Crust. et des Ins., t. VII, p. 206, $\mathrm{n}^{\circ}$ 90. - Epeire Cancriforme, WaLck., Tabl. des Aran., p. 65, nº 56. - Epeira Cincriformis, Latr., Génér. Crust. et Ins., t. I. p. 103, sp. 3.-Long. 4 lig, Le céphalothorax́ est carré, noir; l'abdomen est large, presque hémisnhérique, armé de six épines horizontales, courtes, rougeâtres, presque égales, deux de chaque côté, dont les antérieures un peu plus courtes, deux postéricures égales à celles du milieu; on apercoit quatre points noirs enfoncés au milieu du dos, entourés d'une rangée circulaire d'autres points de même nature, au nombre de dix-huit ou vingt. Trouvée ả la Jamaïque.

\section{Gasteracantha CLYPEATA.}

Epeira Clypeata, Walck., Tabl. des Aran., p. 67, $\mathrm{n}^{\circ} 62$; ibid., Hist. nat. des Aran., $2^{\circ}$ fasc., pl. 3, fig. 1.-Long. 4 lig.Lecéphalothorax est rouge, petit, glabre, lui. sant, avec des points enfoncés sur les côtés, étroit dans le milieu, avec la partie antérieure rougeâtre : les mandibules sont rouges; les mâchoires et la lèvre sont courtes; l'abdomen est très-plat, revêtu en dessus d'une espèce de bouclier dur, ovale, arrondi, ayant une forte échancrure en demi- 
rercle à la partie antérieure, et une autre semblable à la partie postérieure; sa circonfèrence est armée de dix épines petites et courtes, trois de chaque côté de l'échancrure postérieure, une de chaque côté de l'antericure, et une dans le milieu de chacun des côtés; sa surface, qui est chagrinéc, a quarante-quatre taches oculées plus ou moins grandes; la première ligne de ces taches se courbe vers le céphalothorax, la seconde et la troisième sont droites, les quatre lignes postérieures sont courbées dans le sens du côté postérieur; ces taches paroissent aussi en dessous, mais en moins grande quanlité. - La patrie de cette espèce est inconnue.

T'outes les Epeires clésignées par M. Walckenaer dans son tableau des Aranéide, sous les noms de : Mililaris, Guttata, Spinosa, Stellata, Curviformis, Hexacantha, Tetracantha, Transversalis, Lata, et scutiformis, appartiennent au genre Gasteracantha; celles qui ont été désignées par M. Perty dans le Delectus animalium articulatorum, que in initere per Brasiliam, Spix et Martius collegerunt, sous le nom de : Acrosoma suctatum, vigorsï, Schreibersii, Swainsonii, Kirbyi, appartiennent aussi au genre Gasteracaulha.

\section{TETRAGNATHA, WALCE. ;} Eugnatha, SAv.

Les yeux sont presque égaux entre eux, placès sur le devant du céphalothorax. La lèvre est large, arrondie, petite et arrondie. - Les mâchoires sont très-allongées, cylindriques, un peu dilatées vers Jeur extrémité. - Les pattes sont très-allongées, trés-fines, presque toujours dirigẻes en avant et en arrière loıgitudinalement: la première paire est la plus longue, la seconde ensuite, la troisième est la plus courte.

Ces Aranéides sont sédentaires, et for ment une toile à réseaux irréguliers composée d'une spirale croisée par des rayons droits qui partent du centre, où elles se tiennent immobiles, les pattes étendues longitudinalement.

TETRAGNATIA EXTENSA.

Walck., Tab. des Aran., p. 68, pl. 7, fig. 64.- Aranea Extensa, Degéer, Mém. sur les Ins., t. V II, p. 236, no 10, pl. 19, fig. 1, 2, 3, 4. - Listen, p. 30 , t. III, fig. 3. - ScuceFF., Icon. Ins., pl. 49, fig. 7 à 8, et pl. 113, fig. 9. - Aranea So.

$$
\text { ANN. }
$$

Landiri, Scopol., Entom. Carn., p. 397, no 1095. - L'abdomen est allongé, cylindrique, d'un rert argenté en dessus, noir et bordé par deux lignes jaunes, minces, de couleur verte. - Cette espèce varie beaucoup pour les couleurs, car on trouve des individus chez lesquels l'abdomen est d'un rert argenté, ou d'un rouge-vert ou jaune. Le mâle présente, sur la parlie antéricure des mandibules, une épine pointue qu'on n'apercoit pas dans la femelle.

Cette espèce, qui se trouve aux environs de Pais, construit sur le bord des eaux, dans les bois et Jes lieux humides, une toile grande, verticale. Suivant Lisler, elle en. velople ses œufs dans un cocon de soie d'un vert-bleuâtre, qu'elle s ccouvre d'une soie plus lâche et d'une coulcur plus sombre; elle l'attache ensuite aux joncs et autres plantes aquatiques. Lorsque cette araignée est en repos, elle se tient toujours les quaire pattes antérieures allongées et étendues en avant, et les postérieures en arrière.

\section{ULOBORUS, LATr.}

Les yeux sont au nombre de huit; les quatre postérieurs sont placés à intervalles égaux sur une ligne droite, et les deux latéıaux de la première ligne plus rapprochés du bord antérieur du céphalothorax que les deux compris entre eux, de manjère que cette ligne est arquée et en arrière. Les mâchoires s'élargissent un peu au-dessus de leur base et se terminent en forme de palette ou de spatule. - Les tarses dis trois dernières paires de pattes se terminent par un seul onglet; le premier article des deux postéricures a une rangée de petits crins.

Ces Aranéides ont le corps allongé et cy. lindrique : placées au centre de leur toile, elles portent en avant et en ligne droite les quatre pieds antérieurs, et dirigent les deux dernicrs dans un sens opposé : ceux de la troisième paire sont étendus latéralement. Leurs toiles sont lâches et horizontales; ellesemmaillotent, en moins de trois minutes, le corps d'un petit coléoptère qui s'est pris dans leur filet. Leur cocon est étroit, al. longée, anguleux sur les bords et suspendu verticalement par un de ses bouts à un réseau ; l'autre extrémité est comme fourchue, ou terminée par deux angles prolongés, dont l'un plus court et obtus; chaque côté a deux angles aigus. 
ULOBORUS IVALCKENAERIUS.

I.ATk., Génér. Crust. et Ins., t. I, 1). 109 ; ibid., Rég. anim. de Cuv., 2 édit., i. $1 \mathrm{~V}$, p. 246. -. Dugès, Atlas du Règ. alim. de Cuv., Arachn., pl. 16, fig. 4. — Long. 5 lig. - D'un jaunâtre-roussâtre, couvert d'un duret soyeux, formant sur le dessus de l'abdomen deux séries de petits faisceaux; des anneaux plus pàles aux pieds. - Se trouve dans des bois des environs de Bordeaux et autres départemens méridionaux.

Ici vient se placer le genre Zozis de M. Walckenaer; ne connaissant pas l'espèce qui le compose, nous ne pourons indiquer les caractères génériques et spéciliques.

\section{ONZILIE SOUS-SECTION.}

\section{Les Napitéles, WaLck.}

Faisant des toiles étendues, en napes suspendues au milieu de réscauxirréguliers.

\section{LINYPHIA, WALCK.}

Les yeux, au nombre de huit et presque égaux entre eux, occupent le devant du cćphalothorax et sont ainsi placés: quatre au inilieu formant un trapèze dont le côté postérieur plus large, et occupé par deux yeux beaucoup plus gros et plus écartés; les quatre autres sont groupés par paires, une de chaque côté et dans une direction oblique.-La lèvre est triangulaire, large à sa base et arrondie à son extrémité. - Les màchoires sont droites, carrées, très-dilatées a leur extrémité et Irès-étroites à leur base. - Les pattes sont allongées, grêles; la prenière paire est la plus longue, la seconde ensuite, la troisieme est la plus courte.

Ces Aranéides sédentaires forment une coile à tissu serré, horizontale, surmontée d'une autre toile à réseaux irréguliers formés par des fils tendus en tous sens sur plusieurs plans différens, se tenant le plus souvent sur la toile horizontale dans une position renversée.

\section{GIYPHIA TRIANGULARIS.}

WV ALCK., Hist. nat. des Aran., t. V; ibid., Tabl. des Arari., p. 70, pl. 7, fig. 66; Aranea Triangularis, Faun. Paris., t. II, p. 214, n 54. - Aranea Resupina Sylveslris, Degéer, t. VII, p. 244, no 2, pl. 14, fig. 13 a 22. - Clerck, n० $71, n^{\circ} 12$, pl. 3, tab. 2, fig. 1, 2. - Long 4 lig.
- Le céplualothorax est d'un brun-ronssâtre clair, avec trois lignes noires; les yeux sont placés sur des taches noires; j'abdomen est ovale, court et presque globuleux, avec une bande brune, marquée de petites taches blanches, découpées sur le bout, le long du milieu du dos.

On trouve celte espèce aux environs de Paris dans les bois de Boulogne, Vincennes et Meudon; on la rencontre sur les buissons, les genévriers, les pins, ou bieu sur les fenêtres et les coins des murailles; elle y construit une toile horizontale tendue entre les branches, si c'est un arbre, mince, et dont l'étendue varie à raison de la proximité ou de l'éloignement des points d'attache: pour la maintenir parfaitement horizontale, elle tend par dessus des fils perpendiculaires et obliques, qu'elle fixe sux lieux envirommans. Elle se tient ordinairement au milieu de sa toile, dans une position renversée, ayant l'abdomen en haut. Un insecte a-t-il le malheur de se laisser engager dans ce filet, le propriétaire accourt, le perce arec les crochets de ses mandibules à travers la toile, et ensuile $\mathrm{y}$ fait une déchirure afin de le passer et de le sucer; ce qu'il fait sans l'envelopper cie soie, l'insecte étant mort ou affoibli par l'eflet du venin.

\section{LIVYPIIA MONTANA.}

Walck., Tabl. des Aran,, p. 70, pl. 7, fig. 65 et 66 ; ibid., Faun. Paris, t. II, p. $215, n^{\circ} 55$.-Aranea Montara, DeGÉEI, Mém. pour servir à l'Hist. nat. des Ins., t. VII, p. 251, 13. - Long. 4 lig. $\frac{1}{2}$. L'abdomen est ovale, blanchâtre, avec des taches cendrées; les pattes sont tachées de noir. - Se trouve aux environs de Paris.

\section{DOUZILME SOUS-SECTION.}

\section{Les Rétitèles, W aLcK.}

Formant des toiles à mailles ouvertes, à réseaux irréguliers, et se tenant au milieu, ou à côté, pour atraper leur proie.

1. Walckenaer dans son tableau sur une nouvelle classification des Aranéides, indique sous le nom d'Argus une nouvelle coupe générique dont nous ne connoissons pas les caractères ni l'espèce sur laquelle elle a été formée.

\section{EPISINUS, LATr.}

Les yeux, au nombre de huit, sont disposés de manière à former un segment 
transverse d'un cercle; ils sont égaux, et placés sur une éminence. - Les mâchoires sont longitudinales, peu droites ou convergentes, un peu dilatées a leur base, avec leur partie antérieure arrondie. - La lèvre est semi-circulaire, un peu plus large que longue. - Les pattes sont très-allongées; la première paire, ensuite la quatrième sont les plus longues; la troisieme est la plus courte.

\section{ERISINUS TRUNCATUS.}

Latr., Gener. Crust. et Ins., t. VI, p. 371.-Le céphalothorax est cordiforme, un peu plus Jong que large, pointu antérieurement, petit, d'un brun noirâtre en dessus; sa partie inférieure ou le plastron sternal est roussàtre; l'abdomen est brun, pyramidal, échancré antérieurement, tronqué postérieurement en forme d'un triangle renversé; la surface est $t$ - iangulaire ; ses angles prostérieurs sont prolongés; la troisième paire de pattes est blanche; les autres sont brunes; la partie antérieure de la première et de la quatrième paire sont blanches à leur base. - Cette espèce a été trouvée aux environs de Paris et en Italie.

\section{THERIDION, WaLck., LATR.}

Les yeux, au nombre de huit, presque égaux entre eux, occupent le devant du céphalothorax et sonî ainsi disposés: quatre au milieu en carré, dont les deux antérieurs placés sur un petite éminence, et deux de chaque côté situés ainsi sur une élévation commune. - La lèvre est courte, plus largeà sa base et de figure variable. Les mâchoires sont inclinées sur la lèvre, allongées, étroites et cylindriques. - Les pattes sont allongées, fines; la première paire est la plus longue, la quatrième ensuite, la troisième est la plus courte.

Ces Aranéides sédentaires forment une toile à réseaux irréguliers composés de fils qui se croisent en tous sens sur plusieurs plans différens. Ce genre a été partagé en huit groupes.

\section{PRENIER GROUPE.}

\section{Les Ovales, WaLcK.}

Les yeux latéranx se touchent. - Les mâchoires sont légérement dilatées à leur extrémité. - La lévre est carrée à son extrémité. - L'abdomen est ovale, allongé.

Les Aranéides renfermées dans ce groupe recouvrent leurs œufs d'une bourre lâche et peu serrée, habitent les plantes, et en rapprochent les feuilles pour s'y renfermer au temps de leur ponte.

\section{THEBTHON LINEATUR.}

Walck., Tab. des dian., p. 73. - Alienea Lineata, ibid.,Faun. Paris., t. II. p. 210, n० 19. - G LERCK, p. 60, n 8, pl. 3, 1ab. 10. L'abdomen est allongé, jaune, avec des points noirs très-marqués sur les côtés, et une bande noire longitudinale sous le ventre. Le mâle a l'abdomen et les pattes plus allongées; le crochet de ses mandibules est plus long et n'est courbé qu'à son extrémité ; ces dernières ne sont pas creusées ni dentées, et il y a près de leur naissance, du côté interne, une petite épine courbe. II y a des individus chez lesquels l'abdomen est blanc ou jaune. - Cette espece, qui se trouve aux environs de Paris, fait sa toile sur les plantes peu élevées, telle que la mille-feuilles; mais elle ne s'enferme dans les fenilles des arbres que pour pondre ses œufs。

\section{THERIDION REDHTTUM.}

Walck., Tabl. des Aran., p. 73, p]. 7 , fig. 67 et 68. - Arrnea Redimita, ibid., Faun. Paris, , t. 11 , p. 211, n $^{\circ} 50 .-$ Clerck, p. 59, nn 7, pl. 111, tab. 9. DegÉER, t. VII, p. $242, \mathrm{n}^{\circ} 11, \mathrm{pl} .14$, fig. 4 à 11. - L'abdomen est ovale, allongé, jaune, avec des points noirs sur les côtés, et le dessus entouré d'un cercle rouge ; en dessous il présente une raie noire, longitudinale. Il y a des individus chez lesquels le cercle de l'abdomen est rose, rouge, carmin, rouge avec une ligne longitudinale de même couleùr dans le milicu, et enfin quelquafois ce cercle est vert. - Cette espèce, dont les mours sont semblables a la précédente, se trouve aux environs de Paris.

\section{TIMRIDIOT OVATEM.}

Walck., Tubl. des Aran., p. 73. - Aranea Ovata, ibid., Faun. Paris., t. II, p. 211, no $51 .-$ ClerCK, p. $58, n^{\circ} 6$, pl. 'ै3, tab. 8. - Georf., Ins. des env. de Paris, t. II, p. $648, n^{\circ} 12$. - L'abdomen est ovale, allongé, jaune, avec des points noirs sur les côtés; de plus, on aperçoit un orale rouge, carmin en dessus, et une ligne longitudinale noire en dessous. Il y a des individus chez lesquels l'abdomen présente un ovale rouge sur le dessus entier, de même couleur, mais interrompu dans son milieu, rouge, avec deux points d'un jaune vif dans le milieu. - Se trouve aux environs de Paris. 


\section{DEUXIEME GROUPE.}

Les Arrondies, WaLcK.

Les yeux latéraux se touchent. - Les mâchoires sont peu dilatées à leur extrémité. - La lèvre est très-large à sa base, carrée à son extrémité. -L'abdomen est en ovale, arrondi.

Ces A ranéides recouvrent leurs oufs d'une bourre lâche et peu serrée, habitent l'intérieur des bâtimens, le dessous des pierres, les lieux sombres et obscurs.

\section{THERIDION 4-PUNCTATUM.}

Walck., Tabl. des Aran., p. 73, pl. 7, fig. 69 et 70.-Aranea 4-Punctata, ibid., Faun. Paris., t. I, p. 210, no 48.-F FBr., p. $436, \mathrm{n}^{\circ} 34$. - DEGÉER, Ins., t. VII, p. $255, n^{\circ} 16$, pl. 15, fig. 1. - L'abdomen est arrondi, déprimé, brun, avec un demicercle à la partie antérieure et une ligne longitudinale dansle milieu, plus pâle; en dessous il est d'un jaune pâle. Les cufs sont rouges, pâles, légèrement agglutinés ensemble et recouverts seulement d'un peu de soie. - Se trouve aux environs de Paris.

\section{TROISIÈME GROUPE.}

\section{Les Renflées, Walck.}

Les yeux latéraux sont rapprochés. Les mâchoires sont cylindriques, peu dilatées à leur extrémité. - La lève est arrondie, semi-circulaire. - L'abdomen est globuleux, renflé à sa partie postérieure.

Ces Aranéides enferment leurs æuls dans une enyeloppe de soie d'un tissu serré, formant un cocon globuleux, habitant les plantes et l'intéricur des bâtimens ou les cavités naturelles.

\section{THERIDION PAYKELIANUM.}

Walck., Hist, nat. des Aran., fasc. 4. - Theridion Maculatum, ibid., Tabl. des Arant, p. 74, no 5. - Le cépholothorax est noir, pointu a sa partie antérieure; les pattes et les palpes sont d'un brun uniforme; ces derniers sont terminés par un ovale assez marqué, mais fort allongé ; l'ab. domen est ovale, globuleux, peu comprimé sur les côtés, d'un brun noir, avec un demicercle d'ur blanc vif, entourant sa parite supérieure; on aperçoit une ligne de même couleur sur le milieu du dos, coupée par quatre chevrons très-blanes et formant aussi une triple croix; au-dessus de cette croix et du côté du céphalothorax, on remarque un point blanc. - Cette espèce a été trouvée sous les pierres dans le bois de Vincennes.

\section{THERIDION SYSIPHUM.}

Walck., Hist. nat. des Aran., fasc. 3 , pl. 9 ; ibid., Tabl. des Aran., p. 74, $\mathbf{n}^{\circ} 9$. - Latr., Génér. Crust. et Ins., t. I, p. 97 , sp. 1. - Ar. Sysipha, WaLck., Faun.Paris., t. II, p. 206, no 32.-Latr., Hist. nat. des Crust. et des Ins., t. VII, p. $229, n^{\circ} 22$. - Ar. Lamellée, Ouv., Encycl. Méth., t. IV, p. 191, n' 42, p. 210. - Ar. Rufus Sylvicola, Lister, De anim. angl., p. 53, tit. 14, fig. 14..Ar. Sysiphus, Grenck, Aran. Suec., p. 54, 31, 4, pl. 3, tab. 5.-Le céphalothorax esi petit, noir, convexe et presque cylidrique du côté des yeux; les pattes sont grêles, d'un beau blanc, avec quelques anneaux d'un noir très-vif ; l'abdomen est globuleux supérieurement, pointu inférieurement; en dessus sont deux lignes d'un blanc vif, se dirigeant du côté du céphalothorax ef formant un angle sur le milieu de sa partie médiane; deux autres encore plusblanches, mais moins larges, se dirigent vers l'extrè. mité postérieure; à la jonction du sommet de ces deux angles est une tache noire, deux autres de même couleur, mais plus grandes, sur les côtés; sur la partie postérieure est une grande tache orange, ovale; le reste est noir, marbré de points blancs; le dessous est tout noir, avec trois petites taches jaunes, l'une au bas des parties sexuelles, les deux autres de chaque côté, proche le céphalothorax.

Le mâle diffère de la femelle par son céphalothorax et ses pattes qui sont rouges, et par son abclomen qui est entièrement noir et sans aucun mélange d'autre couleur.

Cette espèce construit dans les bois, à l'entour des maisons et des murs, une as. sez grande toile, dont les fils se croisent en tous sens; elle se forme un nid composé de feuilles sèches, de détritus de végétaux ou de plâtrasqui, suspendus au milieu d'une toile irregulière, ont l'air d'y être tombés par hasard. C'est dessous cette espèce de nid qu'elle se tient. Elle paroît dès les premiers jours du printemps, s'accouple vers la fin de juin; elle fait ensuite deux ou trois pontes, et enveloppe ses æufs dans un cocon rond et rougeâtie, et quelquefois verdâtre, dont le tissu est serré, et qu'elle 
ouvre avec ses mandibules lorsque les petits sont éclos ou près d'éclore.

\section{THERIDION NERVOSUM.}

Walck., Tab. des Aran., p. 74. -Aranea Nervosa, ibid., Faun. Paris., t. II, p. $207, \mathrm{n}^{\circ} 35$. - IISTER, p. 51, fig. 48 . Aleir, p. 23 , pl. 15 , fig. 74 . L'abdomen est globuleux; on apercoit deux bandes brunes, rougeâtres, qui entourent le dessus et qui sont compees par des traits blancs, parallèles. Cetle espèce varie pour les couleurs : le mâle est verdâtre; la femelle se fait un nid où elle amasse des provisions pour ses petits, qui éclosent ordinairement en juin. On la trouve plus communément sur les branches de chêne. Son cocon est d'un vert sale; elle le retient toujours entre ses pattes, et il est difficile de le lui faire abandonner.

\section{THERTDIOY DENTICULATUN.}

WaLck., Tab. des Aran., p. 74. - Aranea Denticulata, ibid., Faun. Paris., t. II, p. 208 , n' 37 . - ListeR, p. 56 , tit. 16 , fig. 16. - L'abilomen est globuleux, d'un gris-noirâtre, avec une bande longitudinale, dentée, d'un gris-rougeâtre, où correspondent sur les côtés des petites lignes noirâtres, transversales. - Se trouve aux environs de Paris.

\section{THEFIDION TIVCTUM.}

Walck., Tabl. des Aran., p. 75. - Aranea'Tinctr, ibid., Faun. Paris., t. II, p. 208 , $n^{\circ}$ 38.-- L'abdomen est globuleux, avec un demi cercle noir à la partie postérieure du dessus; la partie postérieure est blanche, tachée de rouge. - Se trouve aux environs de Paris.

\section{THERIDION PULCHEYLIM.}

Walck., Tabl. des Aran., p. 75.-Aranea Pulchella, ibid., Fuun. Paris., t. I!, p. 208, n³9._Loug. 1 lig._L'abdomen est globuleux, jaune, avec une ligne longitudinale, festonnée, rouge dans le milieu.Celte espèce, qui se trouve aux environs de Paris, pond en juin, et fait un cocon entièrement rond, d'un blanc extrêmement vif.

\section{TIERIDION GAROLINUM.}

Walck., Tabl. des Aran., p. 75.-Aranea Carolina, ibid., Faun. Paris., t. II, p. $208, \mathbf{n}^{\circ} 40$. - L'alsdomen est globuleux, jaune; en dessus il est jaune, entouré d'un cercle rouge. - Se truuve dans les bois; aux cuvirons de Paris.
12. THMIDION ISPIDUR.

Walck., Tabl. des Aran., p. 75,-Ara. nea Lepida, ibid. . Faun. Paris., t. II, p. 208, $n^{\circ}$ 41.-L'abdomen est globuleux, jaune, entouré d'une bande jaune, découpée en zig-zag dessus. - Se trouve aux environs de Paris.

\section{QUATRIÈME GROUPE.}

\section{Les Crypticoles, WALCK.}

Les yeux latéraux sont rapprochés et se touchent. - Les mâchoires sont courtes, carrées. - La lèvre est carrée, plus large que haute. - L'abdomen est globuleux, renflé.

Ces Aranéides enveloppent leurs œufs d'une hourre lâche, habitent les caves, les licux sombres et humides.

\section{THERIDION GRYPTICOLENS.}

Walck., Tab. des Aran., p. 75, pl. 8, fig. 75 et 76. - Aranea Crypticolens, ibid., Faun. Paris..t. II, p. 207, n 33. - L'abdomen est glubuleux; la couleur du fond est rouge, pâle, avec des lignes noires, pâles. - Celte espèce, qui se trouve à Paris et dans ses environs, est assez commune dans les caves.

\section{CINQUTHE GROUPE.}

\section{Les Triangulilabres, WaLCK.}

Les yeux latéraux sont disjoints. - Les mâchoires sont cylindriques. - La lèvre est grande, triangulaire, plus haute que large. - L'abdomen est globuleux, nu.

Ces espèces enveloppent lcurs œufs d'une bourre lâche et peu serrée, forment une toile composée de fils lâches et flottans dans l'intéricur des bâtimens.

\section{THERIDION THINGULIFER.}

Walck., Hist, nat. des Aran., fasc. 3, pl. 6 ; ibid., Tabi. des Aran., p. $75, \mathrm{n}^{\bullet} 19$, pl. 8, fig. 73 el 74. - Araignée Triangulifëre, Walck., Faun. Paris., t. II, p. 207, no 34. - Araignée Triangulifére, Latr., Hist. nat. des Crust. et des Ins., t. VII, p. 230 , no24. - Long. 3 lig.-Le céphalothorax est arrondi, d'un brun-jaunâtre; lespalıes sont fines et de même coulour; l'abdomen est globuleux, avec ure suile de triangles blanes ou jaunes, formés par deux bandes longitudinales, rongeâtres, en zig-zag; en dessous il est jamnâtre.

L'abdomen de la femelle se trouve très. 
rétréci et très-défiguré après la ponte; il jrésente sur le dos une suite de taches rouges en trapèze; les côtés sont presque entièrement bruas et n'offrent que des taches brunes.

Cette espèce, qui est assez rare, se trouve dans l'intérieur des maisons, particulièrement dans l'intérieur des armoires; elle fait sa ponie versle commencement de septem. bre ; son cocon est de la grosseur d'un pois, et est composé d'une soie blanche et molle; elle l'attache au haut de sa toile, formée par des fils d'un tissu très-clair, låche et flasque.

\section{TKERIDION PUECTATUM.}

Walck., Tabl. des Al'an., p. 76.-Aranea Punctata, ibid., Funn. Paris., t. II, p. $210, n^{\circ} 46$. - L'abdomen est giobuleux, brun, ponctué de jaune, entouré par une bande en zig-zag, avec des lignes noires, transverses à la partie postérieure. - Se rouve aux environs de Paris.

\section{THERDION URTYCE.}

Walck., Tabl. des Aran., p. 77.-Aranea Urlica, ibid., t. II, p. $210, \mathrm{n}^{\circ} 47$. L'abdomen est ovale, globuleux, avec ries taches blanches sur les côtés et tout à l'entour, deux plus marquées vers le céphaloihorax, trois chevrons rouges, obscurs à la partie postérieure. - Se trouve sur les orties, aux environs de Paris.

\section{THERIDION LUGUBRE.}

L. Dup., Ann génér. des Scienc. phys, t. V, p. 355, pl. LXIX, fig. 1.-Long. 6 lig. - La conleur générale est un noir obscur, uniforme; son corps et ses pattes sont hérissés de poils très-courts et tous de même grandeur; le céphalothorax est arrondi sur les bords; très-modérément convexe, et plus ou moins marqué des impressions radiées; les yeux sont disposés sur deux lignes transversales, parallèles, arrondis, à peu près égaux entre eux, parfaitement séparés et proéminens; la série antérieure, un peu plus courte que la postérieure, est séparée du bord mandibulaire ou de l'èpistome par un espace assez grand; cet espace, d'abord creusé en gouttière au dessous de la première rangée d'yeux, se renfle cnsuite de manière à former, audessus de l'origine des mandibules, une sorte de chaperon ou bourrelet; les yeux latéraux sont placés, chacun isolément, sur une éminence bien plus marquée que dans les autres especes; les mandibules sont ver. ticales, conoides, de médiocre grandeur, dépourvues de dents et armées d'un crochet assez petit, simple; la lèvre est triangulaire, plus large que haute, et n'est qu'une continuation, un lobe du plastron sternal; les mâchoires, inclinées sur la lèvre qu'elles tiennent enchâssées, sont obtuses, comprimées, armées intérieurement de soies très-courtes; lcs palpes s'insèrent à la base des mâchoires dans un sinus, et sont hérissés de poils; les pattes sont assez longues, quoique fortes; les antérieures ont un peu plus de longueur que les postérieures; cel. les-ci plus que la seconde paire; enfin la troisième paire est beaucoup plus courte que les autres; les cuisses et les jambes sont fortes et d'une grosseur égale, ainsi que le genou; les tarses sont brusquement plus grêles, et leur premier article a trois fois au moins la longueur du dernier; les poils courts et assez roides qui les revêtent sont, ainsi que dans tout le membre, inclinés en avant; la griffe est formée de trois crochets ou ongles presque entièrement cachés; is sont arqués, simples, c'est-à-dire dépourvus de dentelures; le crochet supplémentaire ou l'espèce d'ergot placé au dessous des deux autres, est dirigé vers la base du tarse; l'abdomen est fort gros, ovale, trèsarrondi en avant et en arrière, et trèsélevé au-dessus du céphalothorax; les filièreśne sont pas saillantes; la paire la plus antérieure est grosse et tronquee. - Celle espece a été trouvée sous les pierres, par M. L. Dufour, dans les montagues de la Catalogue, aux environs de Mora et de Villikfranca. Ce Théridion se fabrique une petile toile en forme de sac qui lui sert de reuaite; lorsqu'on le surprend dans son réduit, loin de prendre fa fuite-il contrefait le mort en abritant son corps sous ses pat= tes repliees.

\section{SIXIÈUE GROUPL.}

\section{Les Cachées, WaLcK.}

Les yeux forment un quadrilatère trèsallongé, marqué par une ligne saillante; les latéraux, portés sur la mêne élération, sont rapprochés, mais ne se touchent pas. - Les mâchoires sont courtes, cylinàriques. - La levve est large, surtout à la base, en pointe obtuse et arrondie rers son extrémité. - L'abdomen esi ovale, rond.

Ces Aranéides se cachent sous les pierres et les champignons, forment, pour envelopper leurs cufs, un cocon sphérique 
composé d'une bourre dense, compacte, unie, mais ne formant pas tissu.

\section{THEHDION OBSGURUM.}

Walck., Tabl. des Aran., p. 76.-Aranea Obscura, ibid., Faun. Fran., t. II, p. $209, n^{\circ} 44$-- L'abdomen est ovale, rond, un peu déprimé, de couleur noire; les paltes sont de cette dernière couleur. Se trouve aux environs de Paris, sous les picres, les champignons : son cocon est rond, d'une couleur très-blanche.

\section{THERIDION SIGNATUM.}

W alck., T'ab. des Aran., p. 76.-Aranea Signata, ibid., Fann. Fran., t. II, p. 209, n' 45. - L'abdomen est ovale, rond, un peu déprimé, brun, avec quatre traits jaunes placés sur le haut, le bas et les côtés. Se trouve aux environs de Paris.

\section{SEPTIEME GROUPE.}

\section{Les Minimes, WaLct.}

Les yeux latéraux sont rapprochés.--Les mâchoires sont cylindriques. - La lèvre est grande, en triangle, tronquée en ligne droite à son extremite. - L Labdomen est ovale, arrondi.

Ces Aranéides, qui sont très-petites, forment une petite toile sur les feuilles ou en. tre les raisins, enreloppent leurs œufs dans un cocon aplati et lenticulaire, formé d'un tissu fin et serré.

\section{THER!DION - HENGGUM.}

WaLcK., Hist. nat. des Aran. , fase. 5 , pl. 5. - Araignée Bienfaisante, ibid., Fann. Paris., I. II, p. 209, n० 43.-Latr., Hist. nat. des Crust et des Ins., t. VII, p. 233. - Duméril, Dict. des Sc. nat., t. II, p. 333.-Dugès, Allas du Règ. anim. de Cuv., Arachn., pl, 10, fig. 1. - Araneus Cinereus e Minimis, Lister, de Anim. Angl., p. 55, tit. 15. - Long. 2 lig. Le céphalothorax esı moins large et moins long que l'abdomen, d'un brun glabre; la partie antérieure est convexe, brune, couverte de poils gris; les yeux latéraux sont rapprochés, mais non réunis ; les mandibules sont cylindriques, d'un brun pảle ; les mâctoires sont cylindriques; la lèvre est grande, trianguliforme, coupée en ligne riroile à son extremité; les pattes sont de longueur médiocre; l'abdomen est ovale, globulcux, fauve, arec des poils gris borfiant à la parlie supérieure près du céphalodhorax un carré noir; les taches transver- sales sont de même conleur à la partie postérieure; les côtés latéraux sont d'un faure uniforme, avec le dessous brun.

Cette espèce est très-commune, surtout dans les jardins et les potagers; elle finit une petite toile irrégulière qui, quoique très-fine, suffit pour préserver İes raisins de la morsure des autres insectes. Il est rare que l'on ne serve de ces fruits en aulomise sans qu'il y ait plusicurs Théridions bienfaisans, et les personnes les plus dégoûtėes en ont bien des fois àvalé avec leur cocon. sans s'en apereevoir.

Cette espèce se plaît aussi à tendre des fils sur la surface des feuilles, entre les fleurs en corymbe, à l'extrémité des bruyè. res, des gramens et d'autres plantes. Lí femelle fait trois pontes différentes en été: elle enveloppe ses œufs dans un tissu serré, d'un blanc très-éclatant, formant un cocon aplati et lenticulaire. Le mâle et la femelle cohabitent ensemble sur la même feuille.

\section{HUITILME GROUPE.}

Les Tuberculées, WaLcK.

Les yeux latéraux sont rapprochés au niveau de ceux d'en bas. - La lèvre est grande, triangulaire,-Les mâchoires sont étroites, cylindriques. - L'abdomen est ovale, globuleux, renflé à sa partie supérieure, qui est surmontée de lubercules.

\section{THERIDION ARHANe.}

WaLcK., Tabl. des Aran., p. 77.-Aranea. Aphane, ibid., Faun. Paris., t. 11, p. 205. no31. - Long. 2 lig. $\frac{1}{2}$. - Celte espèce est globuleuse; son abdomien est ovale, avec quatre tubercules à sa partic supérieure. - Se trouve assez communément aux envirous de Paris, surtout au bois de Vincennes.

\section{ERIGONE, Sav., Aud.}

Les yeux sont rassemblés sur le sommet antérieur de la convexité du céphalo thorax, disposés sur deux lignes transverses, un peu courbées, l'antérieure moins que la jostéHeure; ces yeux sont presque égaux, les intcrnédiaires antérieurs un peu plus gros, les quatre intermédiaires figurant un carré parfait, et les quatre autres latéraux deux ligues divergentes. - Les mandibules sont abaissées perpendiculairement, ou plutôt dirigées sensiblement en arricre, renllées a leur base supérieure, trìs-rétrécies et comme étranglées près du crochet, garnies sur le cốé extérieur, mais dans le mâle d'une rangée d'épines, potrrvues d'une gotit. 
lière très-oblique, bordée de denx rangs ile longues dentelures et d'un crochet très. yelevé dans le repos. - Les mâchoires sont convergentes, très-inclinées sur la lèvre, Jarges et renflées à leur base, terminées mesque en pointe et contiguës au sommet, a palpe grand: chez le mâle, ce dernier organe est tres-grand, ayant l'article hıméral long, courbé, épinenx; le cubital dilalé en appendice et tronqué au sommet, egal au radial, qui sist un peu moins diJaté, mais égaleruent tronqué; la ralve dirilale interne, ovale, oblongue, échancrée postérieurement à son bord supérieur, munie à sa base externe d'une apophyse cornée, recourbée, dilatée rers le bout, et le bouton excitateur égal à la valve libre, corné, reuflé, pourvu à son sommet de trois conjoncteurs saillans en avant; le principal très-articulé, à article gros et compliqué, à dernier arícle légérement courbé, pointu; le premier auxiliaire oblong, terminé par trois pointes obtuses; le second auxilinire demi-membraneux, spatulé.-La lèvre est inclinée, très-épaisse, très-haute a son hord antérieur, qui est arrondi au sommet et surmonle de beaucoup la plaque sternale, ciliée sur son arète doræale, ct munie d'une épine assez près du bout. - La plaque sternale est moins longue que large, trèsarrondie des deux côtés, presque dès sa base, ćchancrée au sommet, et à sous-palais étroit. - Les pattes sont assez grandes, moires, différant de longueur dans les deux sexes. Dans le mâle, la première paire, la seconde, la quatrième, la troisième; dans la femelle, la quatrième, la première, la se. conde et la troisième successivement plus courtes; les cuisses de la premiere paire du mâle sont garnies d'une rangée d'épines en dessous. - L'espèce type de celte coupe génerique est :

\section{ERIGONE VAGANS.}

Sav. et Aud., Descr. de l'Egyp., Arachn., pl. 9, fig. 9, t. 1, p.319.-Chez cette espèce, le céphalothorax est rouge, testacé; les pattes sont aussi de cette dernière couleur; l'abdomen est d'un brun-noirâtre, soyeux. - Elle a élé trouvée dans des jardins au Caire; elle a été retronvée depuis, par M. Savigny, aux environs de Paris, dans le parc de. Versailles.

\section{DEUXIEME SOUS-TRIBU.}

Les Aquatiques, WaLcK.

IIabilant au milieu de l'eau, dans uno ccliule remplie d'air.

\section{QUATRLHE SECTION.}

\section{Les Nageuses, WaLcK.}

Nageant dans l'eau et y tendant des fils pour attraper leur proie.

\section{TREIZIEHE SOUS-SECTION.}

\section{Les Aquitéles, $\mathrm{W}_{\text {ALCK. }}$}

Tendant des fils dans l'eau pour attraper leur proie.

\section{ARGYRONETA, LATR. , WALCK.}

Les yeux, au nombre de huit, presque égaux entre eux, occupent le devant du céphalothorax; les deux intermédiaires de la ligne postéricure sont dirigés en haut, les deux latéraux sont dirigés de chaque côté, et les deux intermédiaires de la ligne antérieure sont dirigés en bas et comme cachés sous une avance du céphalothorax. La lève inférieure est convexe, plus haute que large, en triangle et arrondie à son extrémitè. - Les mâchoires sont plus hautes que larges, écartées et seulement inclinces un peu sur la lèvre, dilatées au côté externe de leur base, et recevant les palpes à l'extrémité de cette dilatation.-Les palpes sont filiformes dans les femelles, trésallongés dans les mûles, avec le dernier article globuleux. - Les mandibules sont cylindriques, fortes, ayant à leur-intérieur deux rangs de dents courtes et fortes, écartées, mais sans cavités entre elles, et armées d'un crochet court et grand, se pliant sur le côté interne, mais toujours visible ct non caché dans une cavité. - Les pattes sont fortes, de longueur médiocre; la première paire est la plus longue, la quatrième ensuite, la troisième est la plus courte.

Ces Aranéides nagent dans l'eau, l'abdomen enveloppé dans une bulle d'air, formant au milien de l'eau une coque ovale, remplie d'air, tapissée de soie, on elles se tiennent enfermées, et où aboutissent des fils dirigés en tous sens.

ARgyoneta aCdatica. (P1. 8, fig. 4, $4 \mathrm{~A}$, 4 B.)

W aLck. , Tab. des Aran., p. 84, pl. 9, fig. 87 et 88 . - Nranea Aquatica, ibid., Faun. Paris., t. II, p. 234. - Guérin, Iconogr. du Règ. anim. de Cuv., Arachn., pl. 2, fig. 5.-Duces, Allas du Règ. anim. de Cuv., Arachn., pl. 9, fig. 3.-DEgéER, Mém. pour servir a l'llist. nat. des Ims., t. VII, 
p. 303, n० 33, pl. 19, fig. 5 à 43. - Clenck, Aran.Suec, p. 143, pl. 6, t.V III, fig. 1 a 2. -Geols, Hist. nat. des Ins., t, 11, p. 644, n० 7. - D'un brun - noirâtre, arec une tache oblongue, brune, peu marquée sur la partie supérieure du dos, et quatre points enfoncés dans le milieu. Le mâle differe de la femelle, en ce qu'il est plus grand, plus robuste et a l'abdomen plus allongé, Jes organes de la locomotion plus grands et plus forts.

Cette especce vit dans les eaux tranquilles, mais non dormantes; et comme elle ne saurait respirer que de l'air, le moyen qu'elle emploie pour s'en procurer mérite d'être décrit C'est dlans l'eau que l'on ren. contre cette Aranéide, et c'est à la surface de ce liquide qu'elle vient pour le recueillir: pour cet effet, elle élève au-dessus de l'eau son abdomen, qui est revêtu d'une grande quantité de poils, et qui entraîne alors une quantité assez considérable de bulles d'air ; au moyen de cette provision elle peut rester sous l'eau, s'y nourrir, s'y accoupler et y reproduire son espèce.

Lespiéges de cette Aranéide consistent en des filets soyeux disposés en différens sens, fixés d'une part à des plantes aquatiques, et de l'autre a une soite de coque centrale aussi de nature soycuse, ovale, hémisphérique, ouverte à la partie inféricure. Celte coque, qui a été comparée avec raison à une cloche à plongeur, est remplie par l'air que l'araignée y a successiv ement introduit, en rassemblant avec ses pattes celui q̨ui revêt son corps. Pour remplir cette coque, elle fixe quelques fils à des plantes aquatiques : ces fils tiennent en position la coque soyeuse; ensuite, montant à la surface, l'industrieuse Argyronite met son abdomen hors de l'eau, puis elle le retire vivement, et cet abdomen entraine avec lni une quantité innombrable de bulles d'air, qui, réunies, peuvent remplir une partie de la coque; alors elle retourne faire un second voyage, en rapporte de nouvel air, qu'clle porte à sa cloche, ce qui en augmente le volume; elle répète ce manége jusqu'à ce que cette cloche soit pleine d'air et capable de la contenir. G'est alors qu'on la voit y entrer, en sortir et y rapporter les insectes qu'elle prend pour les dévorer. L'usage de cetle cloche fournit à l'araignée une retraile qu'elle peut habiter long temps, à cause du fluide respirable gni s'y trouve approvisionné. Lorsque cette Aranéide veut changer cet air qui a été vicié par la respi. ration, elle renverse sa cloche, et la remplit de nouveau par le moyen que nous avons décrit ci-dessus. Telles sont les de meures que les femelles se construisent elles y passent, dit-on, l'hiver après en avoił fermé l'ouveriure, et y pondent des œufs qu'elles envelopent d'un cocon d'un blanc éclatant. - Cette espèce se trouve maintenant très-rarement aux environs de Paris, mais plus communément en Champagne.

\section{DEUXJEME ORDRE.}

\section{A D 职 O}

\section{LATREILLE.}

M. Latreille désigne sous ce nom un ordre d'animaux qui composent, dans la seconde édition du Régne animal de Curier, la seconde famille des Aranéides trachéennes, celle des Pycnogonides (Pycnogonides). Les caracteres principaux de cet ord: $\mathrm{e}$ sont : corps composé de guatre segmens, occupant presque tonte la longueur du corps, terminé à chaque extrémité par un article tubulaire, dont l'anterieur plus grand, tantôt simple, tantôt accompagné d'antennes fines ou de palpes, ou d'une senle sorte d'organe constituant la bouche. Les deux sexes ont huit pieds propres à la course; mais les femelles offrent en outre deux fausses pattes, gitućes près des deux anté- rieures, et scrvant uniquement à porter les œufs. Ces animaux, qui sont marins, dit M. Latreille, ne pouvoient se ranger dans l'ordre des Pulmonaires, ni dans celui des Trachéennes; car l'absence, pour la respiration, de toute ouverture, ainsi que d'autres caractères extérieurs, ot surtout les deux pattes surnuméraires qui, dans les-femelles, portent uniquement les œufs, sont des considérations qui sans doute auront obligé $\mathbf{M}$. Latreille à former un ordre sous le nom d'Aporobranches, c'est-àdire, branchies sans ouverture stigmatiforme. Par le nombre des organes de la locomotion el des appendicesaccompaguan? le siphon, ils se rapprocheroient, suivant 
M. Savigny, des Lemodipodes; mais cette comparaison est uniquement fondée sur la supposilion que les Arachnides sont des Cisuslacés sans tête. Enfin, M. Edıvards, dans son Ilistoire naturelle des Crustacés, forme, arec les genres qui composent cet ordre, sa légion des parasites marcheurs qui ne renferme giu'un seul ordre, celui des Aranéiformes.

D'aprés quel iues observations récentes, coutinue MI. Latreille, ces $\Delta$ rachnides auroient des vaisseaux pour la circulation; mais il est d'autant plus aisé de se méprendre à cet égard, que les mouvemens qu'on a remarqués dans les pattes peuvent ètre produits par les dilatations des expansions latérales du canal intestinal, et s'y présentant sous la forme de vaisseaux noirâtres, que M. Edwards a observés dans ces or- ganes. Ceux de la respiration s'alfoiblissant à mesure que l'on arrive aux deruières limites d'une coupe, ou ils doivent offrir un autre mode de composition, il seroit possible que les Aporobranches fussent dans ce cas, et qu'ils respirassent, ainsi que diverses Annelides et dirers crustacés, par quelques parties de leur peau : ils ont d'ail. leurs une grande affinité avec les Faucheurs, genre dont ils faisoient anciennement partie. Le siphon paroît être formé par les mâchoires et la lèvre soudées ensemble. Ces Arachnides se trouvent parmi les plantes marines, sous les pierres, près des rivages, et quelquefois aussi sur des arbres.

M. Latreille partage cét ordre en deux familles: la Nymphonides et les Pycrogarides.

\section{PREMİ̃E FAHLLE.}

\section{N Y MPHONIDES,}

\section{ATREILLE.}

Caractères. Le siphon est accompagné d'appendices consistant en deux chélicères, et souvent aussi en deux palpes. - Le corps et les pattes sont longs. chilus.

Genres: Nymphon, Ammothea, Phoxi-

\section{NYMPHON, FABR., LATr.}

Le corps est long, très-étroit, grêle, et compose entièrement le thorax; à sa partie anterieure on apercoit un suçoir tubulaire portant les mandibules et les palpes. - Les mandibules sont didactyles ou en pinces; elles sont beaucoup plus longues que le sucoir; ce dernier est tubulaire, et M. Latreille pense qu'il pourroit bien être une rainure des mâchoires et de la lèvre inférieure prolongées et soudèes. - Les palpes sont composés de cinq articles et terminés par un petit crochet. - Les yeux sont lisses et portés sur un petit tubercule. - Les pieds sont composés de neuf aiticles; les antérieurs sont organisés de manière à por. ter les œufs quand l'animal les a pondus. L'abdomen est représenté par un peit ar. ticle en forme de queue. - Ce genre renferme très-peu d'espèces. Fabricius dit que l'une d'elles ( $N$. Grossipes) s'insinue dans les valves des moules, et épuise l'animal à force de lesucer.
1. NYMPHON GROSSIPES. (Pl. 9, fig. 1:) Fasn., Eittom. System., t. IV, p. 417. - Latr., Gener. Crust. et Ins., t. I, p. 143. - lbid., IIistoire des Crust. ct des Ins., t. VII, p. 333, pl. 65, fig. 2, 3, 4. -Guér., Iconogr. du lièg. anim. de Cuv., Arachn..p].4, fig. 3.-Phalangium Grossipes, Lrs. - System. Nalur., édit. \$3, t. I, p. 2, pag. 1027.-Pycuogonum Grossipes, Mull., Zool. Dan., t. II, p. 67 ct 119 , fig. 5 à 9. - Отн. FAвr., Faut. Groenl.. p. 229.- Long. 6 lig.- Le corys est cylindrique et présénte de chaqque côte quatre inclsions ou crénclures qui forment, indépendamment de la tète, quatre anneaux mieux distincts au-dessous du corps qu'audessus, et dont le premier est grand, et les autres insensiblement plus étroits; sur le dos du premier annean s'eleve un picuant droit, à la base duquel sont placés de chaque côté deux petits yeux noirs, ayant le milieu blanc ; au dernier anneau est altachée une queuc courte, horizontale, droite ou cn cylindre, dont l'extrémité es: amincie et percee d'un trou qui est probablement l'ouverture de la partie anale; les pattes antérieures sunt insérćes à la base du col. elles sont pilns grêles que les autres, filiformes, une fois plus longues que le corps el composées de dix pièces, dont les trois premieres grosses, très-coutes; 


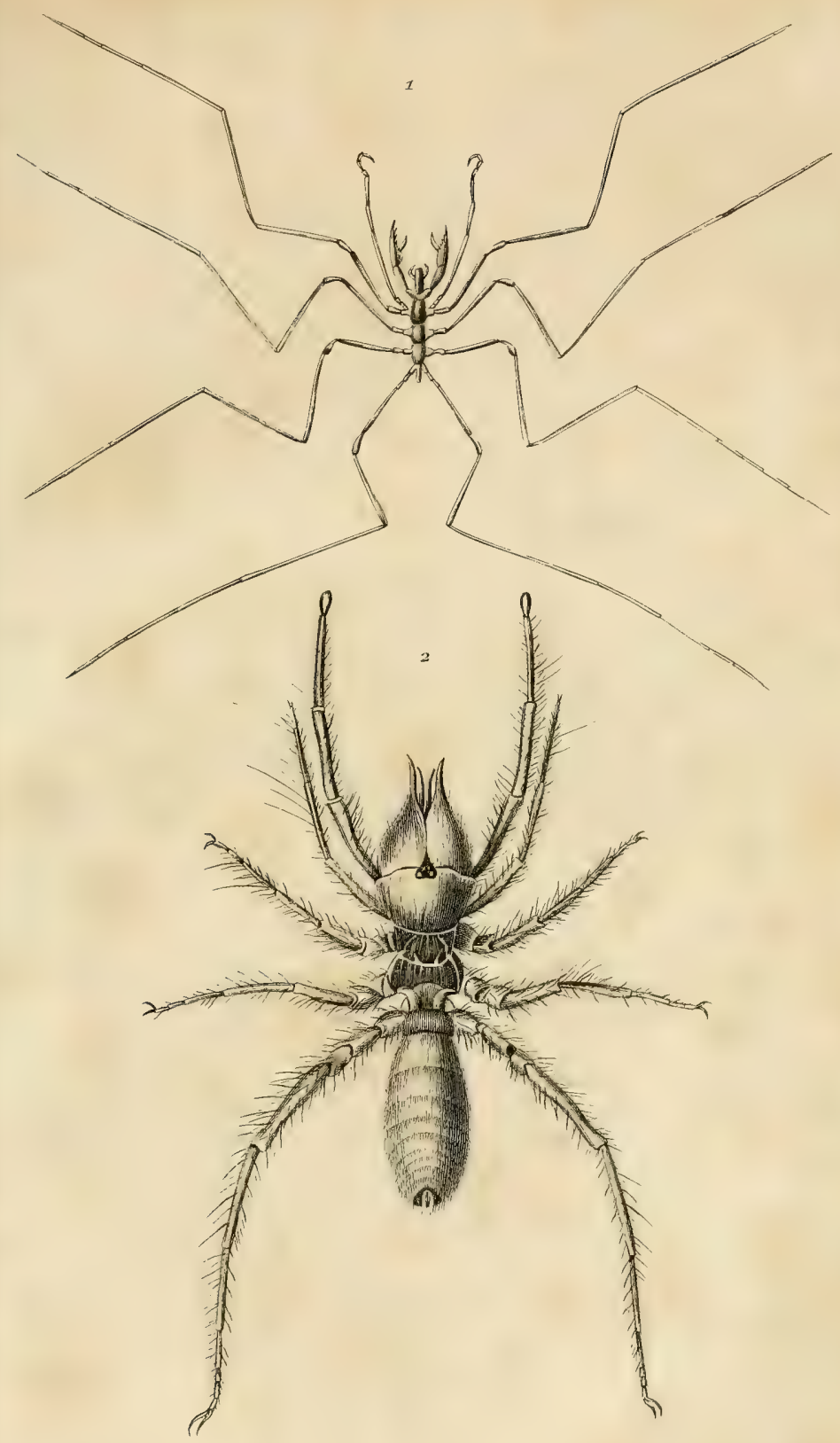

1. Nymphon grossipes.

2. Galeodes araneoides. 


\section{.}


les deux suivantes très-longues, minces: denx ensuite beaucoup plus courles, et trois un peu plus courtes, dont la desnière terminée par un ongle très-aigu; ces pattes sont appliquées contre l'abdoinen, elles servent aux mêmes usages que les fausses pattes des crabes et des écrevisses, c'est-à-dire qu'elles sont destinées à servir d'attache aux oufs de la femelle; les huit autres pattes sont deux fois plus longues, grêles, presque égales entre elles; il en part deux de chaque côté du thoras, une de chaque côté; tout le corps est couvert d'une membrane lisse, un peu dure; la couleur est tantôt rougeâtre, tantôt blunchâtre, quelquefois, mais rarement verdâtre. Les œuís sont de la couleur du corps.

Cette espéce se trouve parmi les ulves capillaires, les conferves et sous les picries du bord de la mer, en Norwége et dans le Groënland; elle se tient particulièrement vers les racines des grandes espèces d'ulves; elle fait sa nourriture de petits vers marins et d'autres animaux qu'elle saisit avec ses pinces. C'est dans le mois d'octobre que les fenelles ont des œufs renfermés dans un sac léger et attaché aux pattes antérieures; en déccmbre, les œuís sont venus grands et faciles à détacher, ce qui fait soupçonner que c'est vers cette époque que l'animal éclot. Leach, dans le second de ses Mélanges de Zoologie, donne la figure de deux espéces que l'on trouve dans les mers de la Grande-Bretagne, qui ont été olservées par M. d'Orbigny père, sur les côtes de la Vendée; mais l'une d'elles (N. Gracile) semble être la même espèce que celle que nous venons de décrire.

\section{NYMPHON FEMORATUM.}

Lrach, Zool. Mis., t. I, p. 45, pl. 19 , fig. 2. - Long. 5 lig. - Cette espece est roussâtre; ses fémurs sont dilatés et comprimés. - Elle a été trouvée dans les mers de la Grande-Bretagne.

\section{AMMOTHEA, LEACH.}

Le corps est quadri-articulé, avec tous les segmens pédigères, l'antérieur avancé en saillie an dessus de la base de l'article antérieur, on la bouche portant un tubercule avec des yeux distincts de chaque còté. - Le ventre est cylindrique, tubuleux, plus long que le corps, annexé au-dessous du s"gment antérieur de ce dernier. - Les mandibules sont plus courtes que le ventre, ả articles égaux, le second didactyle, avec les \&oigts arqués, connivens antérieurement. Les palpes sont de neuf articles, plus longs que le ventre, insérés près des mandibules, le troisième article étant très-allongé.-L- Les pieds sont au nombre de huit, avec le second article des tarses fort court. - L'espèce type de ce genre est :

\section{AMMOTHEA CAROJIMENSIS.}

Leach, Zool. Mis., t. I, p. 34, pl. 15 . - Chez cette espèce, le corps est entièrement d'un brun testacé, arec trois tubercules en triangle sur le dos. - Elle a étẻ trouvée dans les mers de la Caroline.

\section{PHOXICHILUS, Latr.}

Ce genre ne présente pas de palpes. Les mandibules sont au nombre de deux. - Les pieds sont fort longs. - Le premier segment du corps n'est pas rétréci postérieurement en manière de col; il est court, transversal, de sorte que les deux paltes antérieures et celles qui, dans la femelle, portent les œufs, sont insérées près de la base du siphon, et que les yeux sont dès lors plus antérieurs. - Ce genre renferme deux ou trois espèces; parmi elles nous citerons :

\section{pHoxichilus PHAI.ANgIOIDES.}

Lstr., Nouveau Dictionn. d'Hist. nat. - Long. 5 lig. - D'un brun obscur, avèc les pattes environ trois fois plus longues, un peu velues et tuberculées.-Cette espéce a été trouvée dans les mers de l'Océanis.

R. Guérin, dans son Iconogr. du Règ.an. de $C u v$., a figuré une seconde espèce sous le nom de Phoxichilus Aculeatus, Mont., Arachn., pl. 4, fig. 2. M. Latreille rapporte à ce genre le Pycnogonun Spinipes d'Othon liabricius, sa variété du P. Grossipes sans antennes; les Phalangium Aculeatum, Spinosun de MIontagu ( Linn. Trans.); le Nymphon Femoratum des Actes de Ja Société d'Histoire naturelle de Copenhague (1797); le Nymphon Hirtam de. Fabricius, qui peut-ètre ne diffère pas des Phalangium Spinipes et Spirosam. 


\section{DEUXIEMF FAMILLE.}

\section{P Y C NOGONIDES,}

\section{Latreillig.}

Caractères. Cette famille diffère de la précédente en ce que le genre qui la compose est privé de mandibules et de palpes, seuls caractères qui permettent de la distinguer.

Genre : Pycnogonon.

\section{PyGNOGONON, Brunn., Farr., Latr.}

Ce genre ne présente pas de mandibules ni de palpes; il est pourvu d'un suçoir en forme de cône allongé et tronqué. - Le corps est presque ovale, point linéaire. Les pattes sont de longueur moyenne, de sept articles; les fausses pattes ovifères de la femelle sont très-courtes, - La seule espèce connue est :

\section{PYCNOGONON BALENARUM.}

Fabr., Eutom. Syst., t. IV. p. 416. pycnogonon des Baleines, LATR., Hist. nat. des C'rust. et des Ins., t. VII, p. 552; ibid., Gener. Crust. et Insect., t. I, p. 144.
- Ibid., Nouveau Dictionnaire d'Hist. natur. - GuÉr., Iconogr. du Rég. anim. de Cuv., Arachn., pl. 4, fig. 1, - Long. 6 lig. $\frac{1}{2}$. - Dans l'alcool elle est d'un jaune sale; le siphou est allongé et arrondi à son extrémité; un peu plus en arrière est un tubercule sur lequel sont placés les yeux; les segmens présentent tous un tubercule assez saillant, de forme arrondie ; les fausses pattes ovifères sont courtes en compäraison des pattes proprement dites, elles sont composées de neuf ariicles à peu près de même longueur; cependant, le derniex est allongé et plus grêle, et présente à son extrémité un ongle peu allongé, légérement courbé et terminé en pointe aiguë à son exirémité ; les pattes, proprement dites, sont robustes, peu allongées et terminées à leur extrémité par un ongle assez allongé et recourbé. - Cctie espèce se trouve sur les côtes de l'Ocćan Européen, sous Ies pierres.

\section{TROISIEME ORDRF.}

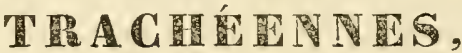

\section{LATMEILLE.}

Cet ordre, créé par M. Latreille, correspond au troisième ordre des Arachnides, Jes Trachearice du Règne animal de Cuvier. Les animaux qui composent cet ordre sont généralement d'une extrême petitesse, et leur céphalothorax est souvent très-petit, comparativement à l'abdomen, qui est confondu avec lui, formant une masse plus ou moins arrondie ou ovoïde, et n'offrant dans la plupart aucune trace d'anneaux ou d'articulations. Les stigmates, au nombre de deux et ordinairement peu perceptibles, sont placés, dans les uns, près de l'origine externe de quelques-unes des pattes, et, dans les autres, sur le ventre, où ils. se présentent, lorsqu'ils sont plus distincts, comme dans les Ixodes, sous la forme de points écailleux et ombiliqués. Le nombre des yeux, invisibles dans quelques-uns, est de quatre au plus; celui des pattes est de huit à dix dans les deux sexes. Ces animaux diffèrent des Pycnogonides par l'absence des pattes ovigères, la forme du corps et le volume de l'abdomen. Quelques-uns exceptés, ils sont généralement très-petits, et plusieurs mêmes microscopiques; mais ils n'en jouent pas moins un rôle très-important dans la nature, puisqu'ils rongent et corrompent plusieurs de nos substances alimentaires, qu'ils se fixent sirr divers animaux, ou ils se multiplient d'une manière si effrayante qu'ils peurent les faire périr. L'bomme lui même n'est pas à l'abri de leurs attaques, et quelques sarans leur attribuent l'origine de certaines maladies, comme la gale, la dysenterie, ctc.; du moins peuvent-ils propager la première. Qrelques espèces sont simplement phyllophages.

Linné, dit M. Latreille, comprenoit ce 
Arachnides dans les genres Phalangium et Acarus; elles composent, dans le Mémoire Aptérologique d'Hermann, la seconde famille des Aptères, celle des Holètres, mais à laquelle il faut joindre les genres Galéode et Pince, qu'il met dans la suivante, où il comprend les Arachnides Pulmonaires avec les Crustacés. Malgré ce désordre, son travail sur les Acarus est des plus remarquables pour le temps où il a été rédigé, et a été notre unique ressource avec celui de Degéer. Mais depuis cette citation de M. Latreille, que nous rapportons textuellement, est paru un travail fort remarqua- ble sur ces animaux, et la science est redevable a son auteur d'avoir retiré du chaos ces A rachnides dans lequel elles élaient plongées. Ln effet, comme on Je verra lorsque nous traiterons des Acariens proprement dits, le travail de $\mathbf{M}$. Dugès sur ces aninaux est rempli d'observations intéressantes, et ces Arachnides, toutes petites qu'elles sont, méritent bien à tout égard l'attention du naturaliste.

Get ordre a été divisé en sept familles : Faux-Scorpions, Phalangiens, Trombidites, Acarides, Tiques, Hydrachnelles, Mi. crophthires.

\section{PREMIITRE FAMILLE.}

\section{FAUX-SGORPIONS,}

\section{Latreille.}

éaractères. Le thorax est articulé, avec le segment antérieur beaucoup plus spacieux, en forme de corselet. - L'abdomen est très-distinct et annelé.-Les palpes sont très-grands, en forme de pieds ou de serres. -Les pieds sont au nombre de huit dans les deux sexes, avec deux crochets éganx au bout des tarses, les deux antérieurs au plus exccplés; il y a deux antennes-pinces ou chẻlicères anparentes, terminées par deux doigts et deux mâchoires formées par le premier article des palpes. - Ces A rachnides sont terrestres et ont le corps ovale ou oblong. - Cette famille renferme trois genres répandus dans l'Europe, l'Afrique et l'Amérique.

Genres: Galeodes, Chelifer, Obisium.

\section{GALEODES, OLIV., LATR. ; Solpuga, Fabr., Herbst.; Phalangium, PaLL.}

Le corps est allongé, oblong, recouvert presque entièrement de poils longs, soyeux et roides, et divise en trois parties distinctes: la tête, une sorte de thorax et l'abdomen. -- La tête, qui semble comprendre les premiers anneaux du thorax, supporte les yeux et donne insertion à deux fortes mandibules; chacune d'elles représente une véritable pince; la branche inférieure est fort grêle, allongée, très-mobile, dentelée et terminée par une dent aiguë, cour. bée en haut; elle s'articule avec la branche supérieure; elle n'est pas beaucoup plus forte que l'inférieure; elle offre des dents pius nombreuses, et présente à sa partie supéricure et antérieure un petit tubercule, sorte de crête cornée et arrondie, au-devant de laquelle on remarque, dans plu. sieurs individus, un appendice grêle, corné, flexueux, qui se dirige en haut et en arrière: l'usage de cette piècen'est pas counu; il est probable qu'elle caractérise l'un des sexes et qu'elle sert à quelque chose dans l'acte de la copulation. Lesautres parties de la bouche sont les mâchoires, dans la composition desquelles entrent plusieurs parties, mais qui sont principalement formées par la base des palpes, dont l'article radical est prolongé en pointe à son bord interne et supéricur, de manière à se dilater en avant pour former une petite languette bifide, terminée par deux appendices soyeux, et située cntre les mandibules, à leur base; les autres articles des palpes sont cylindroī. des, plus gros que ceux des pattes, et le dernier est arrondi. - La première paire de pattes a beaucoup d'analogie avec les palpes; elle est terminée comme eux par un article simple qui ne ressemble en au. cune manière à un tarse ct qui esi dépourvı de crochets; la deuxième, la troisieme et la quatrième paire présentent loutes des crochets; mais elles offrent une particularité remarquable quant au nombre des articles des pattes; la deuxième et la troisième n'en ont que quatre, mais la dernière paire, qui est aussi plus Jongue que les autres, e» 
présente sept; les deux dernières pattes correspondent à la partie désignée plus particulièrement sous le nom de thorax: on ne distingue pas le sternum proprement dit; l'article basilaire des palpes paroit en tenir lieu. M. Latreille a découvert un stigmate à droite et gauche de la poitrine, près de la seconde paire de pattes. En arrière des pattes postérieures et au-dessus des hanches, on voit deux petits appendices dont on ignore l'usage et qui rappellent les peignes des Scorpions: ils consistent en une rangée de petiles écailles très-minces, translucides, de forme triangulaire, larges, pliées en deux, mobiles et fixées sur un pédicule. - L'abdomen est mou, oblong, cou. vert de poils et composé de huit anneaux assez distincts; il n'est terminé par aucun appendice. - Ces Arachnides sont pronres aux pays chands et sablonneux de l'ancien continent. On les trouve en Asie, en Afrique, dans le midi de l'Europe; M. L. Dufour en a recueilli une espèce en Espagne; elles se rencontrent aussi, suivant Pallas. dansla Russie méridionale; M.de Humboldt en a même découvert une petite espèce dans les contrées équatoriales de l'Amérique. Du reste, nous donnons la description de deux espéces, dont l'une a été trouvée au Mexique ế l'autre à Cuba. Les Galéodes, quoique répandues dans une très-grande étendue de pays et très-communes, sont fort mal connues sous le rapport de leurs mours; seulement on - sait qu'elles ne filent pas, qu'elles aiment lobscurité, qu'elles courent généralement très-vite, et attrapent leur proie avec agilité; elles ont la réputation d'être venimeuses; mais Olivier, qui a en occasion d'en voir beaucoup dans' son voyage en Perse, n'a jamais pu constater un fait authentique sur le danger de leur blessure. ie genre, sous le rapport des espèces, est encore très-mal connu, cependant nous allous en faire connoître quelques-unes.

1. Gaiedodes araneoides. (Pl.9, fig, 2.) Oliv., Encyclop. méth., t. VI, p. 580, pl. 541, fig. 6 à $7 .-S_{A v}$, Descript. de 1'Egypte, pl. 8. fig. 7.-Galéode Arénoüde, Matr., Hist. nat. des Crust. et des Ins., t. VII, p. 313 ; ibid., Gener. Crust. et Ins., t. I, p. 135.-Pallas, Spicil.Zoolog., asc. 9 , p. 36 , tab. 3, fig. $7,8,9 .-S o l-$ puga Arachnoides; Lichtenst, Cat. Hamb., 1797, 151, 196. - Sotpuga Araneoides, Fabr., Supplem. Entom. System., p. 294. -Solpuga Arachnoides, Hernst., Monogr.
Solpug., tab. 1, fig. 8.-Sesa, t. 4, tab. 99. fig. 14. - Long. 2 pouc. - Le céphalotho rax est large antérieurement, plat en des. sus, se rétrécissant ensuite peu à peu à sa partic postérieure qui est arrondie ; sa couleur est d'un jaune sale foncé sur les côtés latéraux et postérieurement; mais en dessus, de chaque côté des yeux, il est d'un brun assez foncé; cependant cette couleur n'existe pas sur toute la surface, car elle est divisée dans le milieu du céphalothorax par une raie d'une couleur beaucoup plus claire : on aperçoit cà et là quelqques poils blonds; les mandibules sont allongées, trèsrenflées à leur naissance, planes en dessus, arrondies et très-convexesaux côtés externes; elles sont d'une couleur jaune sale, qui devient plus foncée près des crochets et aux côtés internes; de plus, elles sont hérissées de longs poils blonds peu serrés entre eux; les crochels, d'une coulcur rousse foncée. sont trés-robustes, surtout l'inférieur ou celui đøui est mobile, et très-recourbés à l'extrẻmité; à leurs côtés internes ils sont armés chacun de trois fortes dents, excepté cependant la médiane, qui est un peu moins robuste; leurs côtés externes et internes sont hérissés de poils blonds très-serrés entre eux; les palpes sont très-allongés, robustes, d'un jaune sale; le premier article est de cette dernière couleur, cependant sa partie médiane en dessus est d'une couleur un peu plus foncée, et hẻrissée inférieu. rement et da côté interne, d'épines trèsallongées, parmi lesquelles on en aperçoit d'autres beancoup plus petites; le second article, un pcu moins allongẻ et moins robuste que le précédent, est d'un brun foncé et d'une couleur jaune clair à sa naissance et a sa base; il est de même armé que la précédente de longues et de petites épines; le troisième article est encore plus court, diminuant de grosseur jusqu'a son extrémité ; sa partie antérieure est d'un jaune clair, ensuite d'un brun foncé, tout le reste de même couleur que la partie antérieure; il est, de même que dans les articles précédens, hérissé d'épines; le quatrième article est très-court, globuleux à son extrémité, d'un jaune clair et sans épines, ni en dessus, ni a sa base; de plus, les articles composant les palpes sont couverts de poils blond clair dans les uns et dont la plus grande partie sont courts, peu serrés entre eux, tandis que les autres sont très-allongés; la première paire de pattes est grêle, plus allongée que la seconde, qui est la plus courte de toutes; la quatrième est excessivement 
allongẻe, ensuite la troisicme: ces pattes sont d'un jaun clair, à l'exception du quatiième article de la quatrième paire, qui est d'un brun foncé; elles sont hérissées de poils blond clair dont les uns sont beaucoup plus allongés que les autres, avec leur's derniers articles armés d'épines assez allongées et d'un tarse avec deux crochets recourbés à leur extrémité; la première paire de pattes ne présente pas cette conformation, car les articles qui la composent ne présentent pas d'épines et le dernier article est entierement mousse à son extrémité ; seulement ils sont hérissés de poils de même couleur que dans les pattes précédentes; l'abdomen est très-allongé, d'un jaune assez foncé en dessus, avec les côtés jatéraux et le dessous d'une couleur un peu plus claire; il est revêtu de poils peu allongés, mais serrés entre eux, qui sont de même couleur que l'abdomen: le dessous du céphalothorax est d'un jaune sale, un peu moins foncé qu'eu dessus, et les pre. miers articles de la quatrième paire de pattes présentent chacun de chaque còté cinq papilles trianguliformes portées sur de longs pédicules. - Se trouve en Egypte.

\section{GALEODES DORSALIS.}

Latr., Nouv. Dict. d'Hist. nat, nouv. édit., t. XII, p. 373. - Galeodes intrepida, L. Dufour, Ann. génér. des Scienc. phys. de Bruxelles, t. IV, p. 370, pl. 69, fig. 7. - Long. 10 lig. - Le céphalothorax est formé de deux segmens principanx; le premier ou l'antérieur doune attache à la première paire de pattes, et le postéricur aux deux autres paires; les mandibules, un peu plus longues que la tête, sont horizontales et didactyles; les branches de la pince sont armées de dents irrégulières, plus ou moins crochues; il n'y en a que trois a l'inférieure, et un nombre double à la supérieure ; vers le bord supérieur et interne de cette dernière branche de la pince, on remarque une petite pièce membranocornẻe, mince, lancéolée, articulée sur un point discoîdal, autour duquel elle joua comme un pivot; cette piece singulière est réflẻchie, de manière que son bord supérieur est replié en dedans, et forme une rainure avec le corps de le mandibule lors. qu'elle est appliquée entre celle-ci ; la branche inférieure de la pince mandibulaire se ment de bas en haut sur la supérieure : elle offre, ainsi que cette derniere, quelques poils à sa base; les palpes sont compo. sés chacun de quatre pieces princioales al- longées, et de deux arlicles basilaires conrts; les palpes antérienrs, bien plus grands que les autres, se terminent un peu en massue arrondie au bout. Indépendamment des poils courts et des piquans, et des petites épines qui les hérissent, on y observe d'autres poils rares, longs, et d'une extrềne finesse ; le dernier article, qui est très-court et articulé d'une manière serrée avec celui qui le précède, recẻle dans son extrémité un organe qui n'existe point dans les autres; le bout de cet organe parait fermé par une membrane blanchâtre ; mais lorsque l'animal est irrité, cette membrane. qui n'est qu'une valvule repliée, s'ouvre pour donner passage à un disque ou plutôt á une cupule arrondie, d'un blanc nacré : cette cupule sort et rentre au gré de la Galéode comme par un mouvement élastiqrie ; elle s'applique et paraît s'élever sur la surface du corps comme une ventouse; son contour, qui semble en être la lèvre, est marqué de pelites stries perpendiculaires; et l'on voit, par les contractions qu'il exerce, que la texture est musculeuse. M. Léon Dufour ignore entièrement quel est l'usage de cel organe; les palpes postérieurs, ou la première paire de pattes, n'offrent rien de rcmarquable, seulement ces pattes à leur extrémité ne présentent pas de griffes; la troisieme et la quatrième paire de pattes sont robustes; elles sont formées de quatre pièces principales : la cuisse, la jambe, et un tarse eomposé de deux articles; les griffes, qui terminent les tarses, ont deux cro. chets fort grêles et foibles, peu arqués, sar.s dents ni épines; les pattes postérieures ou la cinquiéme paire de pattes, beaucoup plıs longues et beaucoup plus fortes que celles qui les précédent, portent, en dessous de leurs hanches, des appendices triangulifornies; l'abdomen est oblong, cylindroïde, formé de six segmens distiucts, dont le dernier est obtus. Cette espèce n'a offert à M. Lèon Dufour qu'une paire de stigmates; ceux-ci sont linéaires, placés obliquement sur les côtés du céphalothorax, entre la seconde et la troisième paire de pattes. Cette espèce a été trouvée aux environs de Madrid, et ensuite sur les coteaux arides dis Paterna, près de Valence; elle court avec une grande agilité : lorsque je voulus la saisir, dit M. Léon Dufour, je ne fus pas peu surpris de la voir s'arrêter pour me faire face, se redresser sur les pattes de derrière, et me menacer intrépidement de ses palpes. 


\section{GALEODES BIELANUS.}

OLrv., Voyage dans l'Emp. Ottom., i. III, p. 443 , pl. 42 , fig. 5. - SAVIGN., Descript. de l'Egypt., pl. 8, fig. 9, t. I, p. 419. - Long. 16 lig. - Le céphalothorax est plan en dessus, arrondi antérieurement et sur les côtés latéraux, et tronqué pôstérieurement; sa couleur est d'un beau noir, avec des poils peu allongés, de même couleur, placés çà et là; les mandibules, plus longues que le céphalothorax, sont légérement renfiées à leur naissance, arrondies en dessus, et sur les côtés latéraux de couleur noire, et revètues de longs poils ferrugineux; les crochets sont peu allongés, robustes, en croissant, très-aigus à leur exirémité, de même couleur que les mandibules; le supérieur, moins allongé que l'inférieur, est armé à sa naissance de dents assez robustes; l'inféricur, un peu plus allongé, est aussi armé de dents, mais ces dernièressont en moins grand nombre; les palpes sout allongés, robustes; le premier et le second article sont d'un jaune-roussâtre, revêtus de poils de même couleur; le troisième et le quatrieme article sont robustes, moinsallongés que le précédent, de couleur noire ot hérissés de poils assez allongés, de même couleur; les pattes sont peu allongées et généralement peurobuste; Ja quatrieme et la troisieme sont les plus longues; la première ensuite, la seconde est la plus courte; la première paire de pattes, qui offre la même conformation que les palpes, est aussi entièrement semblable pour la couleur; les pattes proprement dites sont d'un jaune-roussâtre, revêtues de poils de même couleur ; la quatrième paire de pattes offre en dessus et seulement à ses prernicrs articles ces petites lames trianguliformes dont le nombre, pour chaque patte, est de cinq; l'abdomen est allongé, robuste, sa partie supérieure ou le dessus présente une large bande noire, longitudinale, qui se rétrécit antérieurement et postérieuremen l; ses côtés latéraux et le dessous sont d'un jaune-roussâtre, et ce dernier segment de l'abdomen est entièrement noir. - Sc trouve en Egypte.

\section{Gileodes Limbata.}

Lucas, Magas. de Zool., cl. VIII, pl. 5. - Long. 8 lig. - Le céphalothorax est plat, allongé, tronqué et étroit à sa partie antérieure, plus large dans son milieu et ar. rondi postérieurement; les mandibulessont filiformes, courertes de poils bruns, avec les crochets rougeâtres à leur naissance $\mathrm{et}$ noirs a le ur base ; les paipes sont très-allongés, formés de quatre articles, dont le dernier est un peu plus gros à l'extrémité ; l'abdomen est brun, hérissé de poils de même couleur, très-allongé, étroit antévicurement, plus large et arrondi postéricu. rement; en dessus il offe une bande d'un brun très-clair, qui le traverse dans toute sa longueur; les bords latéraux sont entourés par des raies larges. d'un brun foncé et hérissé de poils' fauves; en dessous il est brun et couvert d'une quantité innombrable de poils de même couleur; les pattes ne sont pas très-allongées, la quatrième paire est la plus longue de toutes, avec son premier article d'un brun très-clair à sa nais. sance; les suivans sont bruns, à l'exception du dernier, qui est entièrement blond ; la troisième paire de pattes est plus longue que la première, la seconde est la plus courı; toutes sont de même couleur que la prémière paire.-Elle a été trouvée au Mexiqus.

\section{GAIEODES GUBR.}

Lugas, Magas. de Zool., cl. VIII, pl. 11. - Long. $10 \mathrm{lig.} \mathrm{-} \mathrm{Le} \mathrm{céphalothorax} \mathrm{est}$ jaune, plat, triangulaire, tronqué postérieurement et arrondi sur les bords latéraux; les yeux, qui sont placés sur la partie antérieure, sont ronds, globuleux, assez gros et de couleur noire; les mandibules sont conrtes, épaisses, de couleur jaune, couvertes de poils de mème couleur à leur sommité ; les crochels sont jaunâtres à leur naissance, roussâtres à leur extrémité; les palpes sont courts, robustes, composés de quatre articles, dont le dernier est le plus court de tous; ces palpes sont d'un brun foncé, surtout à la partie antérieure de chacun des articles, et couverts de poils brunâtres; les pattes, hérissées de poils blonds, sont peu allongées, robustes; la quatrième paire est la plus longue de toutes, avec son premier article court, robuste, d'un brun foncé à l'extrémitć; les second, troisième et quatrième article sont courts, de même couleur; on aperçoit à l'extrémité de chacun de ces articles un poil trés-allongé, dont la couleur est blonde; la seconde paire est la plus courte de toutes; ces pattes sont généralement d'un brun clair; l'abdomen, d'un jaune sale et couvert de poils blonds, est ovale, très-allongé; on aperçoit sur la partie supérieure, à partir du second segment, un point rougeâtre, plus large que long, profondément marqué sur chaque segment; en dessous, l'abdomen est entierement d'un jaune sale, couvert de quel- 
ques poils blonds. - Cette espéce a été tronvée dans l'île de Cuba.

M. Guérin dans son Iconogrophie du Règ. anim. de Cuv., Arachn., pl. 5, fig. 4, a donné la figure d'une espéce fort remar. quable, qu'il désigne sous le nom de : $G a$ leodes Spinipalpis, Guérin.

\section{OBISIUM, Leach, Latr., Thérs ; Chelifer, Geofr.}

Les palpes sont allongés, en forme de bras, terminés par une pince didactyle. Les mâchoires sont formées par la réunion des deux articles inférieurs des palpes. Les mandibules sont allongées, droites, épaisses, dépassant sensiblement te thorax.-Les yeux sont au nombre de quatre, superposés aux deux côtés du céphalothorax. - Ce dernier est plus long que large et quelquefois rétréci postérieurement.

Les Obisies sont de très-petites Arachnides que l'on trouve sous les mousses ou sous les picrres placées à terre.

\section{OBISTUM ISCHNOCNELES.}

THÉrs, Ann. des S c. nat., t. XXVII, pl. 1, fig. 3._Chelifer Ischnocheies, Неr., Mém. Apt., p. 148, pl. 6, fig. 14. - Chelifer Trombidioides, Latr., Gener. Crust. et Ins., t. I, p. 433. - Obisium Trombidioides, LEACH, Trans. Jinn. Soc., t. II. p. 391; ibid., Encycl. Brit., t. I, p. 433, pl. 23. - Long. 1 lig. - Le céphalothorax est èlargi, tronque postérieurement, se rétrécissant jusqu'au point de son insertion avec l'abdomen; les yeux, au nombre de quatre, et disposés longitudinalement aux deux côtés du céphalothorax, un peu en arrière des mandibules, sont faciles à apercevoïr, à cause de leur couleur claire qui se détache sur un fond châtain; les bras sont allongés, amincis, d'un fauve jaunâtre: le premier article est très-court, presque globuleux; le troisième triangulaire ou en cône renversé ; le quatrième, ou l'article portepinces, légẻrement bombé à sa partie inférieure, et ne formant au bord extẻricur qu'une ligne presque directe jusqu'à l'extrémité des doigts, qui ne sont pas recourbès, et n'ont que quelques poils rares plus allongés au point où se réunissent les doigts, dont la dentelure est assez prononcée; les articles suivans sont presque glabres, sauf l'intermédiaire allongé, dont le bord extérieur offie quelques poils, moins longs ceAN. penciant que ceux du dernier article; les mâchoires sont droites, triangulaires, surmontées par deux lobes étroits, terminées par des poils roides et allongés au milieu dcsquels est la bouche; les mandibules sont fortement saillantes au dessus de la bouche, de la lèvre et des mâchoïres ; les pattes, très-allongées, sont composées de six articles, et terminées par un crochet didactyle; le premier, triangulaire, appliqué contre la poitrine, donne naissance à un article globuleux, d'où sort la cuisse, qui est sensiblement plus longue que l'article suivant; de celui-ci nait un article un peu moins allongé, que suit un beaucoup plus court; le dernier, enfin, est aussi long que les deu: précédens réunis; les deux paires postérieures ont les cuisses beaucoup plus renflées que les antérieures, et offrent quelques différences dans la longueur relative des articles; elles n'ont toutes que quelques poils rares et assez courts; l'abdomen, d'un fauve assez vif, est divisé en onze anneaux de couleur plus sombre; il est sensiblement aminci dans le rnilieu, s'élargit vers son extrémité postérieure, et se termine en s'arrondissant brusquement; il y a quelques poils blancs, allongés, qui naissent du dernier anncau de l'abdomen, quelquefois du dixième et même du neuvième; ceux-ci s'étendent alors sur les côtés; aux deux côtẻs du dos, on aperçoit une bande marginale, d'un blanc-jaunâtre, qui se confond avec l'abdomen au point où il s'élargit postéricurement; le dessous offic la répétition des bandes supérieures, il est seulement d'une couleur plus claire.

Cette espèce se trouve, mais rarement, sous les pierres. Lorsqu'on sonlève une pierre et que l'on regarde avec attention la surface qui était appuyẻe, mais non collee contre le sol, on apercoit quelquefois cette petite Arachnide, dont les bras et les pattes sont repliés contre le céphalothorax et l'abdomen. Lorsqu'on veut la saisir, elle s'élance à reculons avec une extrême vitesse, et franchit ainsi une distance assez considẻrable.

\section{OBISIUM MUSCORUM.}

Leacn, Zool. Miscelt., tab. 141, fig. 3 ? TuÉrs, Amn. des Sc. nat., t. XXVII, pl. 1, fig. 4. - Long. 2 lig. - Le céphalothorax, de forme presque carrée, est d'un brunmarron, tirant sur le rouge, et les quatre yeux blanchâtres, situés comme dans toutes les espèces de ce genre, s'y laissent parfaitement apercevoir; les palpes porte-pinces 
sont allongés, d'un fauve vif, couver's dans toute leur longueur de poils soyeux, blanes, brillans et longs : le premier article est arrondi, concave et glabre à son bord inférieur; le second est allongé, très-entier, s'épaississant légèrementjusqu'au point de son insertion avec le troisième, qui est implanté sur le précédent par un pédicule allongé et ovoide à sa partic antérieure; le dernier est bombé, d'un fauve brillant, ayant les doigts très-allongés, recourbés et d'un rouge-brunâtre ; les mâchoires sont triangulaires, allongées, pointues à leur cxtrémité antérieure et surmontées par une languette velue; les mandibules sont moins fortes que da:s l'espèce précédente, et remarquables par un crochet qui termine le doigt extérieur, et par des appendices de couleur blanchâtre el en forme de membrane qui en garnissent le bord inférieur; l'abdomen, ovale, allongé, est d'un brun-rougeâtre, quelquefois violâtre, avec onze anneaux d'un jaune de paille clair, et une bande marginale de même couleur; au dernier anneau de l'abdomen, on aperçoit un petit appendice blanchâtre qui est articulé; la grosseur et la longueur relatives des pattes est la même que dans l'espèce précédente, mais elles sont proportionmellement plus fortes, et garnies de poils droits et allongés; toutes se terminent par un crochet didactyle; le dessous est entièrement semblable au dessus. - Cette espèce se trouve assez communément dans la mousse humide qui recouvre les vieux chênes.

3. ORISIUM CARCINOIDES. ( $\mathrm{Pl}, 10$, fig. 2.) T'ย́Is, Ann. des Sc. nat., t. XXVII, pl.2, fig. 1. - Long. 1 lig. $\frac{i}{4}$ - — La forme de ses bras, de son céphalothorax, de ses mandibules et de ses mâchoires est absolument la même que dans l'espèce précédènte, mais elle s'en distingue au premier aspect, par son abdomen d'un brun-noirâtre, uniforme, marqué seulement par des lignes transversales de couleur plus foncée; cet abdomen, qui s'élargit dès le deuxième et troisième anneau, est tronqué à son extrénité postérieure; l'épaisseur des cuisses des deux der. nières paires de pattes est aussi moins sensible que dans l' $O$. Ischnocheles et l' $O$. Mus. corum, et elles sont en général un peu plus allongées; la couleur des palpes et des mandibules paraît aussi moins foncée dans quelques individus.

\section{OBISIUM WVALKENAENII.}

T'Hérs, Ann, des $S$ c. nat., t. XXVII, p. 12 , p]. 2, fig. 2. - Long. 1 lig. $\frac{1}{+}$ - Celte espèce est remarquable par la grosseur déme. surée de la cuisse de la quatrième paire de pattes, qui est appliquée contre l'abdomen, et lui donne un port différent de celui de toutes les autres espèces de ce genre; la ligne tirée depuis l'œil jusqu'à l'extrémité de l'abdomen est tout-à-fait droite postérieurement, et le corps est tronqué plus carrément que dans l'epèce prédédente; les anneaux qui composent l'abdomen sont au nombre de neuf. - Cette espèce a été trouvée, ainsi que la précédente, sous ia mousse, par M. de Théis, dans la forêt de Saint-Gobain (département de l'Aisne).

\section{OBISIU⿴⿱冂一⿰丨丨一𧘇卜 ORTHODACTYLUM.}

Leacr, Zool. Miscell., t. 11I, p. 51, pl. 141, fig. 2. - Chelifer Trombidioides, Latr., Gener. Crust. et Ins., t. I, p. 435. - Olisium Trombidioides, Leach, Trans. Linn. Soc., 1. 11, p. 391; ibid., Encycl. Ent., t. 1, p. 433 , pl. 23. - Chelifer Ischnochelus? Hera., Mém. Aptérol., p. 48, pl. 6 , fig. 14 ? - Long. 1 lig. $\frac{1}{2}$ - D'une couleur souvent entièrement pâle ; elle varie pour l'abdomen, qui est livide et borclé de pâle; les pieds postérieurs sont testacés; les antérieurs ainsi que le thorax sont d'un brun ferrugineux; les seconds pieds ont leur troisième article cylindrique qui est un peu plus épais au sommet, le second court et conique, le dernier cylindrique; les doigts sont longs et droits. Se trouve assez communément sous les pierres.

\section{OBISIUM MARITIMUM.}

LEACH, Zool. Miscell,, t. III, p. 52, pl. 141, fig. 1. - Long. 2 lig. $\frac{1}{2}$. - La couleur est d'un fauve livide, avec les picàs antérieurs d'un pâle ferrugineux, et les postérieurs entièrement pâles; le céphalothorax antérieurement est entièrement ferrigineux ; les seconds pieds ont leur deuxième article cylindrique, le troisième ovale; le quatricme est également ovale, attènué à la base; les doigts sont courts et courbés. Cette espèce a été trouvée en Angleterre entre les rochers, sur les bords de la mer.

Consultez pour les autres espèces, le grand ouvrage d'Égypte, où ont été figurées les Chelifer Beauvoisii, Sav. et Aud. . Lermanii, Sav. et Aud., Descript. de l'Egypt., Arachn., pl. 3, fig. 5, 6, et qui appartiennent au genre Obisium.

Consultez aussi Koch, Faune Allemande, où sout figurées les espèces suivantes: $O b$. 


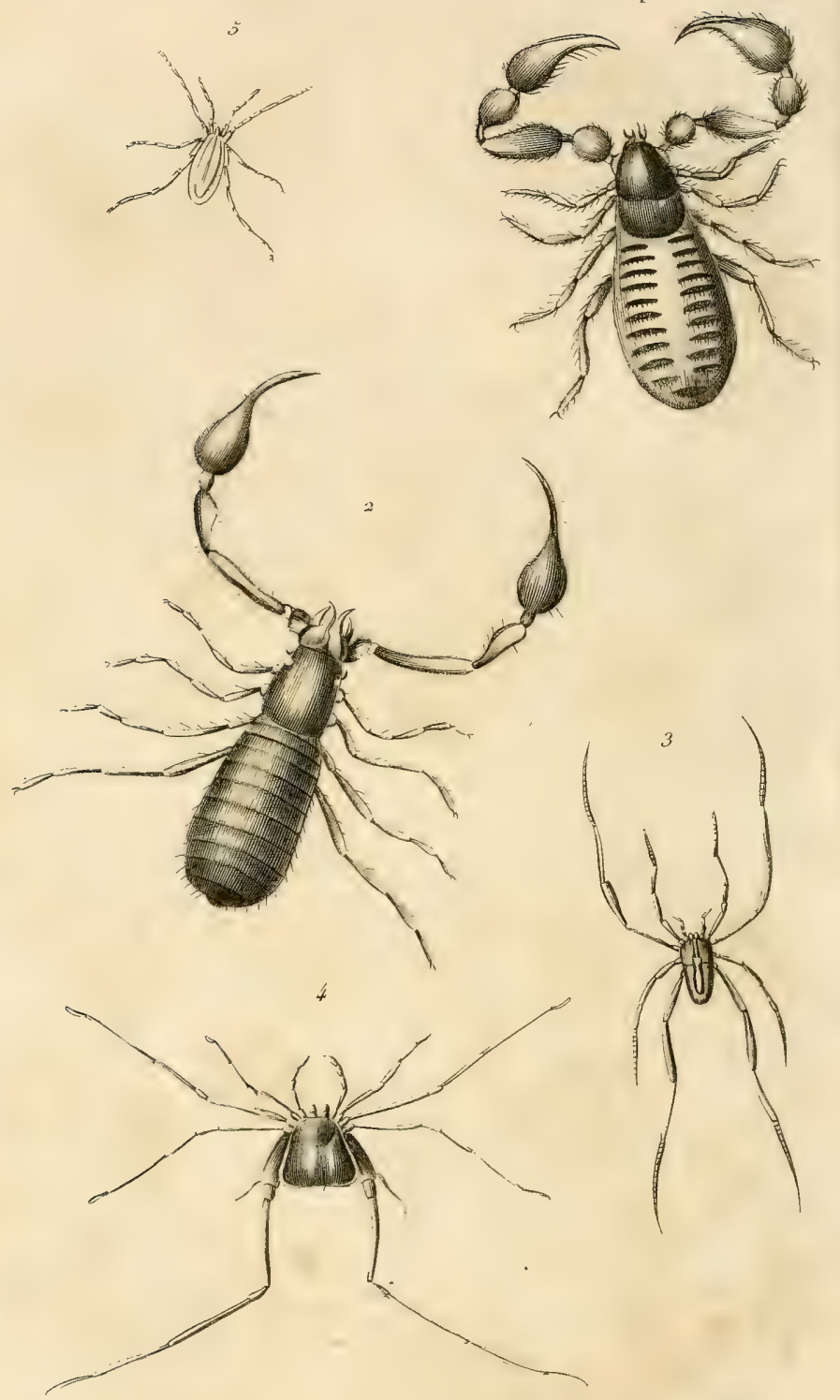

1. Chelifer scorpioides.

3. Phatangium tricuspidatum .

2. Obisium carcinoides.

4. Gonvleptes armatus.

5. Trogulus nepœiformis , 
Syluaticum, tab. 2, fig. 11 ; Obisium Dumicola, tab. 2, fig. 2.

\section{CHELifER, Geoff., Latri., Ledch, THÉIS.}

Les yeux sont au nombre de deux. Les mandibulessont terminées par un stylet articulé.- - Le céphalothorax est divisé transversalement par un sillon profond. - Les pattes sont peu allongées et de grosseur à peu près égale.

Ces Arachnides vivent en général dans les lieux écartés et humides, dans les endroits peu fréquentés des maisons, sous les pierres et les pots de fleurs des jardins, dans les vicux livres et les herbiers.

\section{Chelifer Gancromes.}

Latr., Gener. Crust. et Insect., t. 1, p. 132. - Pince Cancroide, ejusd., Hist. nat. des Crust. et des Ins., t. VII, p. 141, pl. 61, fig. 2.-Chelifor Cancroides, Thérs, Ann. des Sc. nat., t. XXVII, p. 13. pl. 3, fig. 1. - Le Scorpion Alaignée, Georf., IIist. des Ins. . t. II, p. 618. - Le faux Scorpion d'Europe, Degéke, Mém. pour servir a l'Hist. nat des Ins., t. V II, p. 355, pl. XIX, fig. 1.-Phalangium Cancroides, Linn., Syst. nat., édit. 13, t. I, pars secund., p. 1028; ejusd, Faun.Suec., édit.2, no 1968. - Scorpio Cancroides, Fabr., Entom.System, t. II, p. 436. - Obisie Cancroïde, W $\Delta$ Lck., Faun. Paris, t. II. p. 251, no 1. -Long. 1 lig. $\frac{1}{4}$ - Le céphalothorax, arrondi superieurement, va en s'élargissant insensiblement jusqu'à sa jonction avec l'abdomen; il est, comme dans toutes les espèces de ce genre, partagé dans sa partie mẻdiane par un sillon transversal ; les yeux, au nombre de deux, fixés un peu au-dessus de l'insertion des palpes de chaque côté du céphalothorax, sont blancs, arrondis et assez faciles à distinguer; les bras sont épais, allongés, d'un brun-rougeâtre de couleur d'écaille foncée; le premier article, presque globuleux, triangulaire, et arrondi postérieurement, n'a que quelquefois des poils rares et lins; le second allongé, très-entier, en cône à sa partie inférieure, légérement tronqué a sa partie supérieure, qui est plus claire et comme transparente; le suivant est presque aussi long, un peu plus bombé dans son milieu. et, comme le précédent, aminci au point ou se fait son insertion inférieure ; ces deux articles ont aussi un léger duvet qui n'est visible qu'au moyen d'une forte lonpe; le dernier article, en forme de pince, est épais, d'un brun foncé; les pinces, rougeâtres, ont au point de leur jonclion quelques soies allongees, fines, blanches, et l'article entier est légérement iclu; les mandibules, dèpassant sensiblement la lévre supérieure, sont terminées par deux stylets courts; la lèvre inférieure est profondément échancrée, et les mâchoires, sur lesquelles les palpes en forme de bras sont insérés, sont larges, triangulaires, et, comme toutes les parties de la bouche, d'une couleur d'ambre jaune, ou de corne transparente; les pattes, composées de cinq articles, sont velues, épaisses, et terminẻes par un crochet didactyle ; l'abdomen, divisé en onzeanneaux, est aplati, denticulé sur les côtés, et il offre, dans son milieu, une ligne étroite d'une couleur moins foncée que le reste da corps; cette bande présente de chaque côté deux rangées de points noirâtres; le dessous offre, sur un fond plus clair, les répétitions de la surface opposée. - On trouve assez communément cette espèce sous les écorces et sous les feuilles humides.

2. CHELIFER SCORPLOMES. (P1. 10, fig. 1.) T'uers, Ani. des Sc.nat., t. XXVII, p. 17, pl. 3, fig. 2. - Pince Scorpioide, Henm., Mém. Apt., p. 116 , pl. 5, fig. L, M, N. - Long. 1 lig. $\frac{1}{2}$. - Le céphalothorax est de même forme et de même couleur que dans l'espèce précédente, et les yeux, au nombre de deux, sont très-difficiles à apercevoir, à cause de la couleur qui est entièrement semblable à celle du céphalothorax; les bras, beaucoup plus épais que dans l'espéce précédente, sont à proportion moins allongés; ils sont garnis de poils courts et assez forts, jusqu'a la jonction des doigts des pinces, ou prennent également naissance quelques soies fines et allongées; l'article basilaire a la même forme que dans le $C$. Cancroïdes, mais les deux du milieu sont sensiblement plus couris et plus profondément échancrés à leur côté interne; dans les individus jeunes, ces derniers articles sont très-entiers et tout-à-fait glabres; les organes de la manducation ne présentent pas de stylet à l'extrémité des mandibules, et les mâchoires sont tronquees plus carrément à leur extrémité supérieure; les pattes sont d'un brun-jaunâtre; les cuiso ses de la quatrième paire sont légẻrement renflées; comme dans l'espèce précédente, elles sont velues et terminées par un crochet double ; l'abdomen, dans quelques individus. est d'un beau jaune-oranger, et 
dans d'autres, d'un brun-jaunâtre ; il est divisé, dans le sens de sa largeur, par des bandes d'un rouge-brique, interrompues dans leur milieu, ce qui forme sur le dos une ligne longitudinale bien prononcée; il y a des individus oú la troisième bande de l'abdomen est très-étroite; généralement toutes ces bandes sont garnies de poils blancs et brillans qui se dirigent en bas ; audessous elles sont moins prononcẻes, et au nombre de neuf; un peu en arrière de la quatrième paire de pattes, est une petite élévation dont les diverses parties sont très. difliciles à distinguer, et qui peut-être appartient aux organes de la génération. Cette espéce, beaucoup plus rare que la précédente, se trouve pendant l'hiver sous les écorces des arbres.

\section{CHELIFER NEPOMES.}

Hermann, Mém. Aptérol., p. 116, pl. 5, fig. 9. - LeAcH, Zool. Miscell. - THÉrs, Annales des Sciencesnaturelles, t. XXVII, p. 19 , pl. 3, fig. S. - Long. $\frac{3}{4}$ lig. Les palpes sont allongés, glabres, d'un brun-rougeâtre, ayant seulement quelques soies longues et rares à la jonction des doigts du dernier article, qui est moins bombé et un peu moins recourbé que dans les deux espèces precédentes; celui qui le précede immédiatement forme un triangle allongé, dont la pointe est asssez saillante; l'article basilaire est épais, bombé, arrondi à sa partie supériéure et formant de même un triangle dont la pointe se dirige intérieurement; le suivant est le plus long, glabre et très-entier; les mâchoires et les mandibules n'offrent point de différence sensible d'avec celles du C. Cancroides; ces dernières sont de même terminées par un onglet mobile, ayant à sa base quelques poils rourts; le céphalothorax est d'un brun-rougeâtre, plus foncé que les bras, s'élargissant sensiblement jiusqu'à sa jonction avec l'abdomen, divisé daus son milieu par un sillon profond, audessus duquel, et à la naissance du premier article des palpes, sont placés les yeux au nombre de deux, petits et très-difficiles à apercevoir; l'abdomen est pyriforme, plus élargi à sa partie inférieure, arrondi et tronqué à son extrémité ; il est d'une couleur de brique, ou d'ocre rougeâtre, 2vec la ligne du milieu, les côtés et les interstices des segmens, d'un jaune paille clair; en dessous, et près de l'endroit où est attachée la ouatrième paire de pattes, sont deux points de la même couleur que le reste de l'abdomen, qui se détachent sur un fond jaune; le des- sous de l'abdomen offre la répétition des ban' des supérieures, mais la première n'existe pas, et la seconde et la troisième sont faiblement indiquées; les pattes sont glabres, d'un jaune d'ocre un peu plus foncé aux cuisses et aux articulations; leur longueur relative ne diffère pas de celle des espèces précédentes.

\section{CHELIFER HERMANVII.}

LeacH, Zool. Miscell., t. III, p. 49', pl. 142 , fig. 3. - Long. 1 lig. $\frac{1}{2}$. - D'un ferrugineux testacé, avec le bord de l'abdomen et les segmens pâles; les seconds pieds ont leurs troisieme et quatrieme article allongés, grêles, s'épaississant peu à peu de la base vers le sommet, avec le cinquième article allongé, giêle; les doints sont longs. - Trouvé sous l'écorce des arbres.

\section{CHELIFER LATREILLII.}

Leach, Zool. Miscell., t. III, p. 49, pl. 142, fig. 5. - Long. 1 lig. $\frac{3}{4}$. - Ferrugineux, arec le bord de l'abdomen et les côtes des segmens pâles; le céphalothorax et les seconds pieds sont fauves; le troisième arlicle des seconds pieds s'épaissit peu à peu de la base jusqu'au sommet; le quatrième article est allongé, ovale; le cinquième est ovale, atténué à la base; les doigts sont médiocres. - Celte espère a été trouvée avec la précédente, et peut-être n'est-elle qu'un autre sexe.

\section{CHELIFER OLFERSII.}

LeACH, Zool. Miscell., t. III , p. 50, pl. 142 , fig. 2. - Long. 1 lig. $\frac{3}{4}$. - Ferrugireux, avec l'abdomen brunâtre et les segmens bordés de pâle; le troisième article des seconds pieds est médiocre, arec le quatrième ovale; le cinquième épais, ovale; les doigts sont courts. - La patrie de cette espèce est inconnue.

\section{CHELIFER GEOFFROYI.}

LeACH, Zool. Miscell., t. 3, p. 150 , pl. 142, fig. 1.-Chelifer Fasciatus ; ibid., Trans. Linm.Soc., t. II, p. 391 ; ibid., Encycl. brit., Suppl., t. I, p. 433, pl. 22 . - Chelifer Fuscus, abdomine lineis transversis, GÉoffr., Hist. des Ins. des Env。 de Paris, t. II, p. 808.-Long. 1 lig. $\frac{3}{+} .-$ D'un brun ferrugineux, avec le bord de l'abdomen et les côtes des segmens pâles; les pieds postérieurs sont d'un testacé livide; le thorax et les pieds antérieurs sont d'un brun ferrugineux; les seconds pieds ont leur troisieme article cylindrique, le 
quatrième ovale, le cinquième épais et ovale; les doigts sont courts. - Se troure sous l'écorce des arbres. Peut-être n'es!elle qu'un autre sexe de l'espèce précédente.

\section{CHELIFER MUSCORUM.}

Leach, Zool. Miscell., t. 11I, p. 50, pl. 142, fig. 9. - Long. $\frac{3}{+}$ de lig.-Le troisième article des seconds pieds est allongé, cylindrique; le quatrième est en forme de nœud; le cinquième est ovale, fortement atténué à la base; les doigts sont médiocres.
- Cette espèce se trouve très-communément dans les prairies.

Consuliez pour les autres espèces le grand ouvrage d'Égypte où est figuré avec beaucoup de détails le Chelifer Sesamoides, Sav. et Aud., Arachn., pl. 8, fig. 4.

Gonsultez aussi pour les autres espèces Koch, Faune Allemande, dans laquelle sont figurés les $C h$. Degeerii, tab. 2, fig. 3; Fabricii , tab. 2. fig. 4. Schrankii, tab, 7, fig. 3. Ixoides, tab. 7, fig. 4. Angustus, tab. 7, fig. 5. Panzeri, tab. 7, fig. 6.

HUITIEME FAMILEE.

\section{P H A A N G I E N S,}

\section{LATREILLE.}

Caracteres. Les chélicères sont toujours tỉdactyles, extéricures dans Je plus grand nombre, el recouvertes dans les autres par un avancement antérieur de la tête, en forme de capuchon, et visibles en dessous; l'abdomen présente aussi, du moins en dessous, des anneaux ou des plis, mais les palpes sont filiformes, grêles et terminés par un petit crochet; il n'y a jamais que deux yeux; les stigmates, dans ceux ou on les a découverts, sont situés à la naissance des pieds postérieurs, et cachés par leurs banches. - Cette famille renferme un assez grand nombre de genres, dont quelquesuns ont été établis par M. Kirby, mais Ja plus grande partie par M. Perty, dans le Delectus animalium du voyage de MIM.Spix et Martius.

Genres : Gonyleptes, Ostracidium, Eusarcus, Stygnus, Goniosoma, Dolichoscelis, Cosmetus, Discosoma, Phalangium, Caculus, Cryptostemma et Trogulus.

\section{GONYLEPTES, KIRBY.}

Le céphalothorax est trianguliforme, épineux postéricurement. - Les yeux sont portés sur un tubercule commun. - Les palpes sont épineux, terminés par un onglet robuste, avec les deux derniers articles presque ovalaires et presque de grandeur égale. - Les hanches des deux pieds postérieurs sont fort grandes, soudées et formant une plaque sous le corps. - Ces pieds sont en outre éloignés des autres et rejetés en arrière. - L'abdomen est plus ou moins caché par le céphlalothorax.
1. GoNTEPTES ACULEATUS.

Kirbx, Trans. de la Soc. Linn. de Londres, t. XII,p. 452. - Long. 6 lig. - Le corps est glabre, lisse, obscur, d'un brunroussâtre; le tubercule portant les yeux est élevé, pointu, incliné, le céphalothorax est sombre en dessous, noduleux transversalement, terminé postérieurement dans son milieu par une épine robuste, courbẻe, pointue, tridentéc à sa base, du côté gauche, et unidentée du côté droit; les pieds sont pâles; les hanches sunt brunes; les pénultièmes articles pectinés postérieurement, avec un peigne à six dents; les postérieurs armés extérieurcment par une épine trèsrobuste, tridentée; les fémars de derrière sent bruns, noduleux, armés à leur base d'une épine très-robuste, obtuse, et de plusieurs autres beau coup plus petites; les genoux sont bi-épineux intérieurement ; les tibias de derrière avec les deux premicrs articles noduleux, et épineux intérieurement; l'abdomen est retiré entre les hanches. Se trouve au Brẻsil.

\section{GOVYIEPTES HORRInÚs.}

Kiney, Trans. de la Soc. Lim. de Londres, t. XII, p. 152, pl. 22, fig. 16. Long. $6 \mathrm{lig} . \frac{1}{2}$. - Le corps est d'un brunfauve, glabre, lisse, obscur; Ja tête est élevée, avec le tubercule oculifère très-court et bidenlé; les dents sont distantes; Ie thorax présente en dessus postérieurement. deux tubercules élevés, avec des points saillans, pâles sur le côté; sur le thorax sont encore d'autres points assez élevés; les pieds sont allongés; les banches de derrière sont 
terminẻes extérieurement par une épine allongée, courbée; les trochanters et les fémurs de derriẻre sont épineux; plusieurs épines varient pour la longueur; le sternum est très-caréné; l'abdomen est découvert, avec les segmens dorsaux marqués de points élevés, calleux, de couleur blanchc. - Se trouve au Brésil.

\section{GONYLEPTES SCABER.}

Kirzy, Trans. de la Soc. Lim. de Londres, t. XII, p. 453. - Long. 8 lig. $\frac{1}{2} .-$ Le corps est gris, obscur; la tête présente le tubercule oculifère élevé et bi-épineux; le thorax postérieurement est marqué de quatre grands tubercules oblongs; les aniérieurs plus petits, et de quatre autres petits, hémisphériques, rangés longitudinalement par paires; sur le bord lateral et aux angles postéricurs sont des points élevés, pâles, presque ocelliformes; les hanches de derrière sont armées et recourbées; les fémurs sont très-épineux, avec une épine trèsallongée à leur base; l'abdomen est presque vertical. - Se trouve au Brésil.

\section{GONYLEPTES SPMIPES.}

Perty, Delect. Anim. Articulat. dul Foy. de MIM. Spix et Mfiartius, p. 205, pl. 39, fig. 12. - Long. 3 lig. - Le céphalothorax est triangulaire, déprimé, testacé, ru. gueux par la présence d'une grande quantite de petits points fauves, offrant des yeux très-petits, noirs, et postéricurement une épine de chaque côté, avec deux autres médianes élevées; les palpes sont plus longs que le corps, avec les deux derniers articles épineux; les pattes sont allongées, testacées, avec les hanches postèrieures Jegérement épineuses; le dessous est testacé, glabre. - Celte espèce a été trouvée á Bahia.

5. Govyleptes ardatus. (Pl. 10, fig. 4.) Penty, Delect. Anim. Artic. du Voy. de MMI. Spix et Martius, p. 205, pl.39, fig. 13. - Long. 3 lig. - Un peu plus grande que la précédente, peu convexe; le céphalothorax est trianguliforme, ferrugineux, hérissé de petites granulations, ayant deux petites tiges allongées, portant à leur extrémité les yeux, derrière deux petits tubercules élevés, et postéricurement de chaque côté en dessous armé d'une lon. gue épine légérement recourbée; les palpes et les chéliceres sont jaunes, les premiers ayant les deux derniers articles tesracé3; les pattes sont peu allongées; les anférieures sont testacées, les postéricures d'un brun ferrugineux, avec les hanches courtes, couvertes d'aspérités; en dessous il est glabre et entièrement ferrugineux. Cette espéce a été trourée près du Rio Negro.

\section{GONYIEPTES ASPER.}

Perty, Delect. Anim. Arlicul., p. 202. -D'un testacé sale, déprimé, légérement raboteux, ayant de chaque côté latéral une épine postérieure, courbée ả son sommet; de plus on apercoit deux spinules postérieures géminées dans leur milieu; les hanches posterieures sont spinulées de toute part. - Se trouve au Brésil.

\section{GONYLEPTES CERVispina.}

Penty, Delect. Anim. Articul., p. 202.-Testacé, déprimé, glabre, ayant de chaque côté latéral une épine postérieure brune, longue et courbée. - Se trouve aus Brésil.

\section{GONYLPTES ELEGANS.}

Perty, Delect. Anim. Articul., p. 202. - D'un testacé olivâtre; la surface oculaire est fauve, saupoudrée de blanc vers les côtés; le céphalothorax postérieurement présente quatre points blancs et des épines noires; les hanches postérieuresont mutiques à leur sommet. - Trouré au Brésil.

Le Faucheur Acanthope, qui a été décrit et figuré dans le Voyage de l'Uramie et de la Physicienne, p. 546. pl. 82, fig. 2 ot, $3 \ddagger$, appartient au genre Gonyleptes. ${ }^{2}$. en est de même pour le Vaucheur Acanthurus qui a été figuré dans l'Atlas du Dict. d'Hist. nat., pl. 60.

\section{OSTRACIDIUM, - Рerty.}

Les palpes sont plus courts que le corps. - Le pénultième article et le dernier épineux : celuí-ci étant armé à son extrémité d'une forte épine recourbée. - Les chélicères sont courtes. - Le céphalothoras est déprimé, glabre, clypéiforme, couvert de petites granuiations, étroit aniérieurement, diłaté postérieurement, arrondi sur les côtés, tronqué à sa partie postéricure et mutique.-La partie antérieure, où les six pattes sont insérées, est séparée de la postérieure par une impression profondement marquée. - De chaque côte est la tige ocu. lifère, arec deux petits yeux, dont les deux médians granuleux. - Les picds sont pen allongés; les antérieurs sont éloignés des postérieurs; ces derniers avant leurs han. 
ches peu épaisses, couvertes de petites aspérités et denticulées. - L'abdomen est en tièrement caché par les plis du céphalothorax. - L'espèce type de ce genre est :

\section{OSTRACIDIUM FUSCUM.}

Perty, Delect. Anim. Articulat. du Voy. MM. Spix et Martius, p. 206, pl. 40, fig. 1. - Long. 4 lig. $\frac{1}{3}$. - Le cepphalothorax est fauve, avec les yeux de couleur de soufre, et deux lignes transverses assez profondément marquées; les palpes sont d'un jaune pâle; les pattes sont fauves, avec los tarses pâles; en dessous il est d'un fauve légérement olivâtre. - Trouvée près diu Rio Negro.

\section{2, OSTRACIDIUM SUCCINEUM.}

Perty, Delect. Anim. Anticul., p. 202. - Entièrement glabre, testacé, avec le bord latéral et les hanches postérieures fauves et raboteux. - Se trouve au Brésil.

\section{EUSARCUS, Penty.}

Les palpes sont plus longs que la moitié du corps, avec le pénultiéme et dernier arlicle épineux; celui-ci onguiculé. - Les chélicères y sont jointes et glabres. - La t:ge oculifère est épineuse ou tuberculée. - Les deux yeux sont placés extérieurement a la base des tubercules. - Le corps esi ovale en dessus, épais, convexe, étroit antérieurement. - Le céphalothorax est profondément sillonné transversalement par la troisieme paire de pattes, dilaté postérieurement, et armé en dessus à sa partie postérieure par deux tubercules ou par une seule épine.-L'abdomen, prolongé par la partie céphalothoracique, forme en dessus deux segmens, et montre en dessous cing ou six plis. - Les pattes sont inégales: la première paire est la plus courte, la seconde est plus longue que la troisième, enfin la quatrieme paire est la plus longue de toutes. - Getic dernière paire est éloignée des autres, avec les hanches mutiques, plus épaisses que les précédentes.

\section{Fusarcus grandis.}

Perty, Delect. Anim. Articulat. du Voy. de MLI.S pix et Martius, p. 206, pl. 40, fig. 2. - Long. 5 lig. $\frac{2}{3}$. Les chélicères sont glabres, d'un gris testacé; les palpes sont de même couleur; les yeux sont noirs, avec deux tubercules au milieu; te céphalothorax est $d$ un fauve-ferrugineux, glabre, obscur, avec deux points élevés postérieurement; l'abdomen est inné avec le cephalothorax, le dessus ayant trois cercles élevés indiquant les segmens; en dessous il est d'un ferrugineux couleur de sang, arec six plis abdominaux; les pattes sont d'un ferrugineux sale; les antérieures plus pâles; les hanches postérieures sont mu. tiques. - Cette espèce a été trouvée darıs la province de Piauhia.

\section{2. eUsarcus penmito.}

Penty, Delect. Anim. Articul., p. 205.D'un brun-fauve; le céphalothorax présente postérieurement une épine médiane. - Cette espèce, quí est du double plus petite que la précédente, a élé trourée près du fleuve St,-François.

\section{3. eUsarcus armatus.}

Perty, Delect. Anim. Articul., p. 203. - D'un brun-fauve, opaque; le céphalothorax présente postérieurement de chaque côté une épine latérale et médiane; les hanches postérieures ont leur premier article lobé extérieurement.- Cette espèce, qui est de la grandeur de la précédente, se trouve au Brésil.

\section{4. eUsarcus MUTicus.}

Penty, Delect. Anim. Articul., p. 205. - D'un gris opaque, fauve ; le céphalothorax est mutique; les pieds sont courts. - Cettc espéce, qui a été trouvée au Brésil, est plus petite que la précédente.

\section{Stygnus, Penty.}

Les palpes sont plus longs que le corps, avec le pénultième et dernier article épineux; celui-ci uni avec le précédent et onguiculé. - Les chélicères sont éloignées du corps, très-grandes, épaisses, glabres et luisantes. - Les deux yeux sont écartés, avec une épine intermédiaire. - Le céphalothorax est subquadriforme, mutique, postérieurement sur les côtés, avec deux épines élevées et pointues dans le milieu. L'abdomen est entièrement courbé et présente en dessus des vestiges de deux ou trois segmens, et en dessous quelques plis. - Les pieds sont inégaux, peu allongés ; la première paire est courte et grêle; la seconde, plus allongée que la troisième, est aussi très-grêle; la troisième a ses articles, surtout les premiers, un peu moins grêles; enfin la quatrieme paire, qui est la plus longue de toutes, est éloignée des autres, ei formée d'articles beaucoup plus robustes, avec des hanches épaisses el légérenuen épineases. 
STYGXUS ARMATUS.

Perty, Delect. Anim. Artic. du Voy. de MM. Spix et Martius, p. 207, pl. 40, fig. 3. - Long. 4 lig. - Les chélicères sont très. glabres, luisantes et couleur châtaigne ; les palpes sont testacés; le céphalothorax est d'un fauve-ferrugineux, avec les deux yeux très-éloignés, et une épine intermédiaire élevée; deux épines postérieures droites, et deux horizontales plus petites; les pattes antérieures sont d'un fauve couleur châtaigne; les postérieures sont ferrugineuses, avec les hanches poueuses à leur sommité, et deux séries de petites épines. - Celte espèce a été trouvée près du Rio Negro.

\section{goniosomi, Perty.}

Les palpes sont de la longueur du corps, peu épais, avec le pénultième et dernier article épineux ; celui-ci onguiculé. - Les chelicères sont robustes, unies à la bouche. - La tige oculifère est très-épineuse. Les deux yeux sont placés extérieurement à la base des épines. - Le céphalothorax est subtriangulaire, profondément sillonné transversalement à son insertion par la troisième paire de patles, déprimé, avec des épines très-courtes sur les côtés latéraux, et armẻ dans son milieu d'épines droites, assez grandes. - L'abdomen est cachè par une grande partie du céphalothorax, et offre seulement trois plis. - Les pattes sont inégales, très-allongées : les postérieures assez éloignées des autres, avec les hanches mutiques et allongées; la première paire de patles est très-courte et grêle. la seconde ensuite est plus allongée que la troisieme, la quatrieme est la plus longue de ioutes.

1. gonosiona vanick. (Pl. 11, fig. 1.) Pertr, Delect. Anim. Artic. du Yoy. de MMI. Spix et Martius, p. 208, pl. 40, fig. 4. - Long. 5 lig. - Les chélicères sont lisses, couvertes de poils; les palpes sont testacés; les yeux sont petits, jaunes, pellucides, avec deux petites épines élevées; le céphalothorax est d'un brun ferrugineux sale, avec des taches et quelques lignes bleues, armé postérieurement de deux épines élerées; en dessous il est roussâtre, glabre; les plis de l'abdomen, cachés sous le céphathorax, sont verdâtres; les pattes sont d'un lorun-ferrugineux, plus pâles vers les tarses. - Ciette cspèce a été trouréc prés du lleure des Amazones.

\section{GONIOSOMA EQUALIDUM.}

Perty, Delect. Anim. Articul., p. 202. -L'abdomen est entièrement caché, d'un gris fauve, couvert d'un très-grand nombıe de points blancs. - Se trouve au Brésil.

\section{GONIOSOMA FERRUGINEUM.}

Perty, Delect. Anim. Articul., p. 202. -L'abdomen, en partie caché par le céphalothorax, spinulé en dessus, est d'un brun entièrement ferrugineux, avec les pieds plus pâles. - Trouvé au Brésil.

\section{GONIOSOMA SULPIUREUM.}

Perty, Delect. Anim. Articul., p. 202. - D'une couleur soufre-verdâtre, unicolore; le céphalothorax présente de chaque côté une spinule et deux médianes, dons l'une est tournée antérieurement en dessư et l'autre postérieurement en dessous. Se trouve au Èrésil.

\section{5. gONIOSOMA CONSPERSUM.}

Per'ty, Delect. Anim. Articul., p. 202. - L'abdomen est en partie libre, d'un brun ferrugineux, saupoudré en dessus de points blancs, avec la surface oculaire biépineuse ; postérieurement sont deux épines. droites. - Se trouve au Brésil.

\section{Goniosoma noridur.}

Perty, Delect. Anim. Articul., p. 202. - L'abdomen est entièrement caché; le céphalothorax est déprimé, varié de faure et de testacé, saupoudré de points blanes; la surface oculaire est bi-ćpineuse. - Se trouve au Brésil.

\section{GONIOSOMA PATRUEIE.}

Perty, Delect. Anim. Articul., p. 202. - L'abdlomen est cntièrement caché; le céphalothorax est déprimé, d'un fauve ocracé, rarié de pâle, tronqué postérieurement, bi-épineux en dessous, vers les hanches. - Habite le Brésil.

'8. GONIOSOMA MODESTUM.

Perty, Delect. Anim. Articul., p. 202. - L'abdomen est entièrement caché; le céphalothorax est légérement convexe, d'un roux ocracé, varié de pâle; de plus il est arrondi postérieurement et mutique. - Se troure au Brésil.

\section{GONIOSONA VERSICOLOR.}

Pentr, Delect. Anim. Articul., p. 202. - L'abdomen est entierement caché; le céphalothorax est très - déprimé, d'un faure-jaune, varié; les pieds sont fauves annelés de jaune. - Habite le Brésil. 


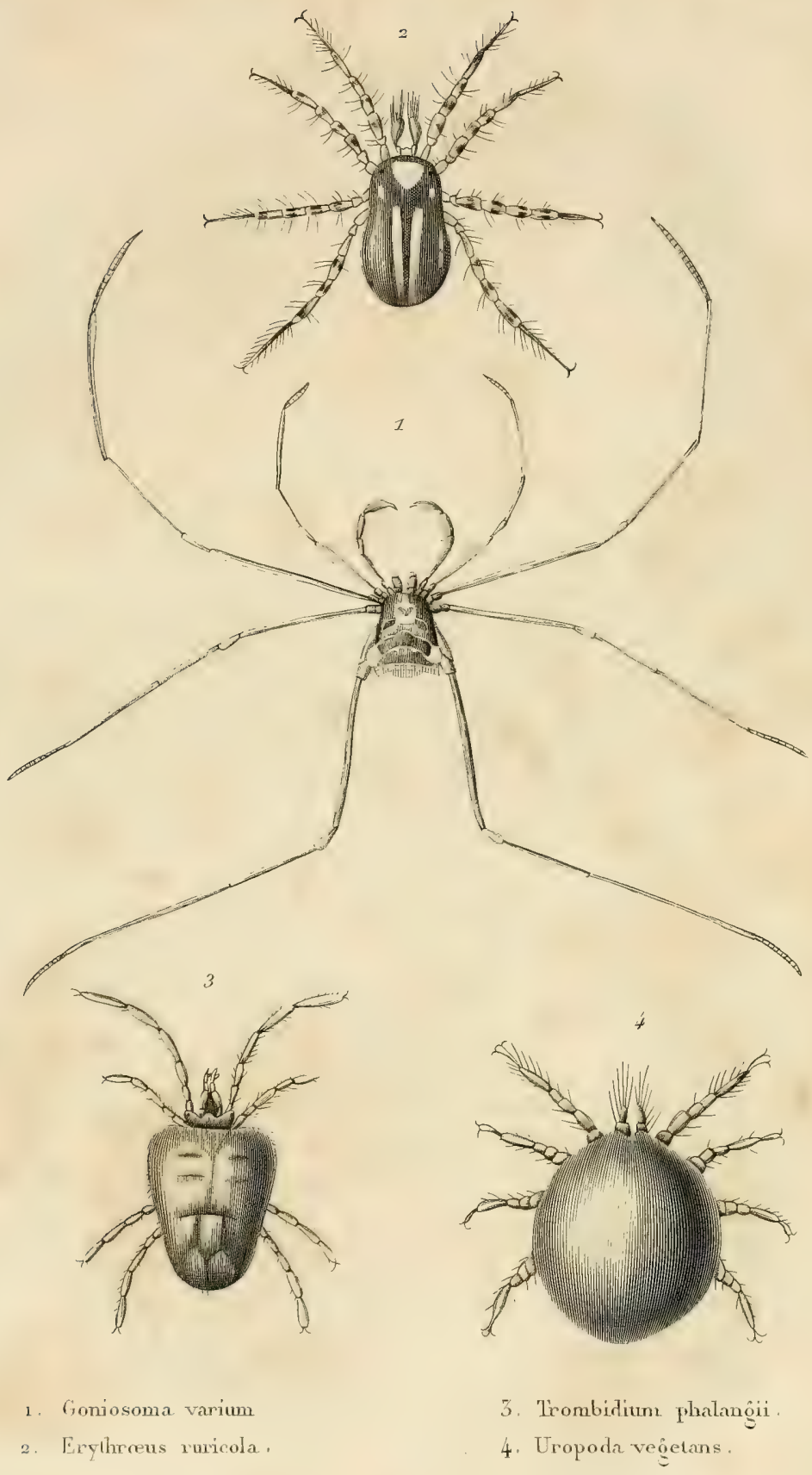



10. Goviosona Junceum.

Pertx, Delect. Anim. Articul., p. 202. - L'abdomen est entièrement caché, d'un grisâtre-fauve, opaque, avec les pieds d'un gris-blanc. - Se trouve au Brésil.

\section{1. goniosoma Obscurum.}

Perty, Delect. Anim. Articul., p. 202. - L'abdomen est entierement caché ; d'un fauve ferrugineux, opaque, avec les chélicères en forme de corne, et les palpes blancs. - Se trouve au Bresil.

\section{DOLICHOSCELIS, HOPE.}

Corps triangulaire en dessous, déprimé, avec les angles antérieurs arrondis, tuberculés en dessus, avec les côtés latéraux épais. - Céphalothorax profondémert échancré antérieurement, le sommet armé cxtérieurement à la base des deux cornes oculifères. - Yeux presque arrondis. - Mandibules de deux articles, attachées à un court pédoncule, ayant le premier article triangulaire, dilaté à son sommet; le second ovale, en forme de pince. - Palpes de cinq articles, recourbès : premier article très petit; le second presque trois fois plus grand, épineux au côté interne; le troisième égalant à peine la moitié du précédent, épais à son sommet; le quatrième cylindrique, plus épais à sa base, avec son sommet rétréci, armè de petites épines serrées, en forme de soies; le dernier ovale, déprimé, épineux, avec son sommet armé d'un ongle long, recourbé et pointu.-Pieds au nom. bre de huit; les antérieurs très-courts, presque trois fois plus longs que les antécé. dens; les pénultièmes du double plus longs que les antérieurs; les postérieurs très-allongés, pas très-éloignés des autres, mais six fois plus longs que les antérieurs. - Tibias composés de trois articles: le premier plus épais, le second plus long, le troisième très-allongé. - Tous les tarses onguiculés, de onze articles : le premier égalant les quatre suivans, les autres diminuant de grandeur.

\section{DOLICHOSCELIS HAWORTHI.}

Hope, Trans. Linn. Soc. of Lond., t. XVII, p. 799, pl. 16, fig. 1 à 5.-Long. $3 \mathrm{lig} \cdot \frac{x}{2}$. - Jaune; partie antérieure ayant une corne droite, oculifère, de chaque côté, avec les pieds postérieurs très-allongés; céphalothorax profondément échancré, avec une cornedroite de chaque côté, oculifere; yeux d'une couleur plus obscure; corps jaune, bordé, ayant le bord extéricur élevé, l'intérieur orné de tubercules jaunâtres; dessous de même couleur; disque convexe dans le milieu, couvert de tubercules jaunâtres, très-nombreux; abdomen très-court, libre; pieds au nombre de huit, inégaux: la quatrième paire est la plus longue, la seconde ensuite, la troisieme après, enfin la première est la plus courte; les genoux de toutes ces pattes sont épais. Cotte espèce a été trouvée au Brésil.

\section{cosmetus, Pentr.}

Les palpes sont plus longs que le corps, comprimés, mutiques, appliqués sur les chélicères, l'animal se reposant, celles-ci les metiant a couvert. - Le tubercule oculifère est mutique. - Les yeux sont au nombre de deux. - Le céphalothorax est trianguliforme, légérement convexe, mutique postérieurement sur les côtés, et armé de deux épinez dans son milieu. - Tous les pieds sont inégaux, longs, grêles; les postérieurs sont éloignés des autres, avec les hanches à peine épalsses et mutiques.

\section{Cosmetus pictus.}

Perty, Delect. Anim. Artic. du Voy. de MM.Spix et Martius, p. 208, pl.40,fig. 5.Long. 3 lig. - Entièrement ferrugineux, avec les palpes et les pattes plus pâles; les yeux sont noirs; le céphalothorax antérieurement présente la figure d'un $V$ qui est de couleur jaune et ponclué de noir; postérieurement sont des points jaunes dispersés, avec deux épines élevées; le dessous est ferrugineux, sans taches. - Cette espèce a été trouvée près de Rio Negro.

\section{Cosmetus BipUnctatus.}

Perty, Delect. Anim. Articul., p. 203. - D'un brun ferrugineux; le céphalothorax présente deux points blancs. - Cette espèce, qui est plus petite que la précédente, se trouve au Brèsil.

\section{COSMETUS CONSPERSUS.}

Perty, Delect. Anim. Articul., p. 203. - D'un brun abondant, saupoudré de points jaunes, - Trouvé au Brésil.

\section{Cosmetus Lagevarius.}

Perty, Delect. Anim. Articul., p. 203. - D'un fauve - brun; le céphalothorax ayant une figure jaune représentant la forme d'un bouclier. - Se trouve au Brésil.

\section{COSHETUS ADREA.}

Perty, Delect. Anim. Articul., p. 203. 
- D'un brun-notr; le céphalothorax ayant son bord latéral jaunâtre, et représențant en dessus, dans sa partie médiane, une croix de St.-André de même couleur. Celte espèce a été trouvée au Brésil.

\section{Cosmetes U-mLAvum.}

Perty, Delect. Anim. Articul., p. 203. -D'un fauve-brun, le céphalothorax ayant une fisure jaune représentant la lettre $\mathrm{U}$. - Habite le Brésil.

\section{COSHETUS vaRINS.}

Perty, Delect. Anim. Articul., p. 203. - Fauve, avec le bord et des points dorsaux très-nombreux, blancs de toute part. - Trouvé au Brésil.

\section{Cosmetus marginatis.}

Pretry, Delect. Anim. Asticul., p. 203. - D'un brun abondant, avec le bord latéral saupoudré de blanc. - C Cette espèce a été trouvée au Brésil.

\section{Discosoma, Perty.}

Les palpes sont du double plus courts que Je corps, mutiques, déprimés, placés sur les chélicères, l'animal se reposant, et les recouvrant. - Les chélicères sont placées sur la bouche. - Les yeux sont au nombre de deux, placés sur un tubercule qui se voit à peine. - Le céphalothorax est discoïdal, un peu convexe, mutique. - L'abdomen est presque caché sous le céphalothorax, offrant en dessus un segment et un vestige du second et en dessous quelques plis.-Les pieds sont très-allongés, grểies, semblables; les postérieurs éloignés des autres, à peine distincts d'eux, avec les hanclies mutiques.

\section{DISCOSOMA CIVCTUM.}

Penty, Delect. Anim. Articul. du Toy. de MM. Spix et Martius, pl. 40, fig. 6. ¿ong. 2 lig. $\frac{1}{+}$. - Le corps est entièrement d'un gris-brun, glabre, avec le bord du céphalothorax entièrement blanc; les palpes ct les pattes sont plus pâles; ces dernières avec leur dernicr article couvert de poils. - Trouvée à Bahia.

PIALANGIUM, Linn., Fafr., Latr.

Le corps est coupé à sa partie antérieure ; cetle coupe, presque circulaire et perpendiculaire, est formée par une membrane, $\mathrm{ti}$ visée dans son milieu et dans le sens de sa \$auteur par une cloison linćairc, coriacée, se prolongeant en forme de lèvre supérieure; c'est de cette cloison que partent, de chaque côté, les mandibules, au nom: bre de deux; elles sont coriaces, presque écailleuses vers l'extrémité, rapprochées, parallèles dans le repos, grandes, souvent de la longueur du corps, creuses, mobiles de bas en haut ou se portant en avant, de deux pièces; celle de la base est plus courte, cylindrique, comprimée un peu sur les côtés, lisse, quelquefois tuherculée, droite; la seconde pièce est articulée, avec celle-ci à angle aigu, et clle est ramenée dans l'inaction le long de la poitrine; elle est presque cylindrique, aplatie sur sa face antérieure, vers l'extrémité principalement; deux serres ou pinces écailleuses, dont l'extérieure, qu'on appelle doigt, est plus forte, arquée, plus dentelée et mobile, la terminent. - Les pinces sont coniques, armées au côté intérieur de petites dents, pour mieux retenir les objets qu'elles ont saisis, elles font l'office de tenailles. - L'eztrémité supérieure de la seconde pièce des mandibules a, dans l'espèce désignée sous le nom de $P h$. Cornutum, un prolongement supérieur, formant une pointe aiguë, peu arquée; la mandibule entière figure alors une espèce de $T$. On remarque au milieu du bord antérieur de la coupe du céphalothorax, une pièce foiblement coriacée, presque triangulaire, tenant lieu de lèvre supérieure.-Les deux palpes insérés sur les côtés des mandibules, à la base extérieure des premières màchoires, sont minces, filiformes, de la longueur de la moitié du corps dans le grand nombre, arqués, de cinq articles presque cylindriques, dont le premier très-court, le second tonjours allongé, le troisiène et quatrième courts, souvent un peu plus gros, et presque coniques; le dernier ordinairement long, menu, cylindrique, oitus, et terminé par un petit crochet écailleux, arqué; ils sont coudés à l'articulation de la troisième pièce, qui se rapproche avec les suivantes de la poitrine. - Les mâchoires sont disposées sur trois rangs, celles du premier et du second sont réunies deux à deux par leur base, portées sur une pièce qu'on peut signaler comme un article, très. courtes, molles; elles présentent un corps arrondi, concave au côté intérieur dans l'inaction, se gonflant prodigieusement et en forme de vessie, membraneux; la surface, dans les premières, paroît composée de trois plans, dont l'intéricur plus grand et a'une consistance plus membraneuse, en 
pointe au sommel, ayant quelques poils noirs, et en outre sur le dos une petite pièce triangulaire, membraneuse, un peu relue; les mâchoires du second rangr sont un peu plus grandes, striées au côté antérieur, dont la membrane est susceptible d'une grande dilatation, ce qui donne alors une figure très-bombée; le contour est un peu cilié et noirâtre, étranglé vers la partie interne; les extrémités des mâclıoires du premier rang reposent sur celles-ci, et c'est entre elles qu'est placée l'ouverture de l'œ. sophage. Viennent ensuite deux languctes membraneuse, coniques, un peu velues, couchées obliquement au-dessous des précćdentes; elles répondent à la naissance de la seconde paire de pattes. Immédiatement au-dessous est une pièce membraneuse, petite, plane, carrée, arrondie et échancrée au milieu du bord supérieur, supportée par une pièce aussi carrée, mais p! us grande, et celle-ci sur une troisieme plus courte, plus large, cintrée. On peut considérer ces derniers organes comme ceux qui tiennent lieu de lèrre inférieure. L'abdomen est ovoïde ou arrondi, souvent déprimé, rebordé, renfermé sous une envcloppe continue, d'une substance parcheminée. - Le céphalothorax, qui occupe environ un tiexs de sa grandeur, n'est distingué de l'abdomen que par une ligne transversale, et son contour est anguleux : en examinant avec attention la partie qui se trouve au-dessus de la naissance des deux pattes antérieures, on aperçoit de chaque côté un stigmate, distingué par un fond plus rembruni. La coupe est ovale ou presque circulaire, et rebordée; les deux tiers antẻrieurs de la surface sont occupés par une membrane blanche, et l'autre l'esí par un prolongement intérieur du rebord; une fente transversale, qui se trouve dans l'entre-deux, est destinée au passage de l'air. En séparant doucement la voûtc supérieure du céphalothorax de l'inféricure ou de celle qui répond à la poitrine, on mettra à découvert trois ou quatre tuyaux cylindriques, formés de plusieurs fibres roulées sur elles-mêmes, d'une couleur argentine, quise divisent postérieurement en deux faisceaux très-ramifiés, dont l'un va aboutir à une tache noirâtre en dessous du stigmate, et l'autre se rend près de l'origine du tubercule dorsal oculifère; ce tubercule est creux, et en le considérant au grand jour, on voit tres-bien la iransparence et le brillant des cornées des deux youx. On observe aussi trois ou guatre miscles plus remarquables, ayant leur attache inférieure au-dessous de l'insertion des mandibules, el se réunissant près du support oculaire. - L'ouverture de la bouche est entre les premières mâchoires. - Les intestins se replient en une infinité de détours ou de zig-zag, au-dessous de la poitrine et sur l'abdomen; ils sont noirs, trèsmenus, impossibles à suivre dans leur marche, remplis d'une matière terreuse, séparée en deux ou trois parties, cylindriques et excrémentitielles, près de l'anus. - Celui-ci est caché sous une pièce du chaperon, formé de plusieurs demi-cercles concentriques, la capacité de l'abdomen est occupée en grande partie par l'ovaire. Les œufs sont lenticulaires, blancs et innombrables. - Les anneaux de l'abdomen ne sont que les plis de la peau, celle-ci étant d'une seule pièce qui recouvre lout le corps. - Les pattes, au nombre de huit, sont très-longues relativement au corps, et trés-dilatées; celles de la seconde et de la quatrième paire sont les plus longues. Aussi ces Arachnides paroissent-elles montées sur des échasses. Chaque patte est composée: $1^{\circ}$ d'une hanche courte, grosse, ayant à son extrémité une petite pièce, avec laquelle la cuisse est articulée; $2^{\circ}$ de cette cusisse, plus grosse ordinairement dans les pattes antérieures; $3^{\circ}$ de la jambe, formée de deux articles, dont le premier plus court; $4^{\circ}$ d'un tarse, dont la longueur égale au moins celle de la cuisse et de la jambe prises ensemble, d'un grand nombre d'articles, de quatre à trente, mais rarement au-dessous de treize; le premier est excessivement long, et le dernier est muni d'un petit crochet, arqué, simple; toutes ces pièces en général sont menues et cylindriques.

Les Faucheurs ont recu des pattes aussi longues non-seulement pour pouvoir marcher plus facilement sur les buissons, sur les plantes, mais encore pour mieux échapper a la poursuite de leurs ennemis, et pour être avertis de leur présence; placés sur un mur, sur le tronc d'un arbre, ils les étendent d'une manière circulaire, et ils occupent ainsi un espace assez considèrable; quelque animal vient-il à toucher quel. qu'une de leurs partics, ils se relèvent anssitôt; les pattes forment autant d'arcades sous lesquelles l'animal passera, s'il est petit; mais si le danger est pressant, il a bientôl sauté à terre. La fuite est prompte, car dans l'espace d'une seconde, ils parcoureas un sixicme de mète cnviron; îs s'ébapo 
pent aussi sourent des doigts qui les ont saisis, et c'est ordinairement en y laissant quelques-unes de leurs pattes, qui conservent encore long-temps après avoir été arrachées les mouvemens, en se pliant et en se dépliant alternativement. On concevra facilement la raison de ce phénomène, en considérant les dispositions intérieures des pattes; ce sont autant de tuyaux creux, occupés dans toute leur longueur par une espéce de filet tendineux et très-délié, sur lequel l'air exerce son action, dès que la patte esı séparée du tronc de l'animal. $\mathrm{Ou}$ tre les deux stigmates antérieurs placés sur le céphalothorax, l'abdomen en présente deux autres qui sont cachéspar les hanches des pattes postérieures, à peu de distance de leur origine. L'ouverture est grande et très-sensible; elle est formée de deux demi-ovales, dont l'extérieur, plus petit et plus étroit, est acculé dans sa longueur au plus grand; la séparation est un diamètre ou un plan membraneux, qui se perd obliquement sur le bord extéricur; l'autre demi-ovale est chambré. L'espace contigu au diamètre est rempli par une substance filreuse, blanche, argentée, dont on voit la tranche roulée en spirale, et qui semble y former deux ouvertures. Dans la partie la plus latérale, on découvre aussi les extrémités d'autres trachées, mais plus petites, roulées sur elles-mêmes, et en dessous, une cavité profonde; tout l'intérieur est blanc et d'une consistance molle; à une des extrémités de l'ovale est inséré un muscle replié en dessous à sa naissance, et formant dans son prolongement trois branches, dont les deux Iatérales, plus menues, se subdivisent en plusieurs rayons, et qui se perdent toutes sur la membrane abdominale.

On trouve ordinairement au printemps des petits faucheurs qui proviennent des œufs déposés l'automne précédeut. Ce n'est guère que vers la fin de l'été qu'ils ont pris tout leur accroissement, et c'est alors qu'ils s'accouplent. L'accouplement n'a pas lieu quelquefois, surtont dans l'espèce la plus commune aux environs de Pa. ris, le Faucheur des murailles, sans un combat entre les mâles, el sans un peu de résistance de la part des femelles. Quand celle-ci se rend au désir du mâle, ce dernier se place de manière que sa partie anténieure est contiguë à celle de la femelle, face contre face; il saisit les mandibules avec ses pinces; le plan inféricur des deux corps est sur une même ligne; alors l'or- gane du mâle obtient celui de la femelle, et l'accouplement a lieu; il dure trois ou quatre secondes; après l'accouplement, la femelle dépose dans la terre, à une certaine distance de sa surface, des cufs de la grosseur d'un grain de sable, de couleur blanche, entassés les uns auprès des autres.

Quoique les Faucheurs soient très-roisins des Aranéides, ils ne vivent cependant point, comme elles, pendant plusieurs années; presque tous périssent à la fin de l'automne.

\section{1. matargiun CRISTATUM.}

Ourv., Encyclopédie méthodique. Latr., Hist. nat. des Fourm., p. 375. Long. 4 lig. - Le corps est ovale, obscur en dessus, cendré en dessous; la partie an. térieure du céphalothorax est épineuse; il y a un avancement dorsal, tranchant, échancré, recevant un tubercule oculifère; les pattes sont d'un gris obscur, avec quelques pointes très-courtes sur les cuisses.Se trouve dans les champs, aux environs de Paris.

\section{PHALANGIHM SPIVOSUB.}

Latr., Hist. nat. des Fourm., p. 375. Phalagnium Quadridentatum, Cuv., Mag. Encycl. - Latr., Hist, nat. des Crust. et des Ins., t. VII, p. 322 ; ibid., Gener. C'rust. et Ins., t. 1, p. 140. - Fabr., Suppl. Entom. System., p. $293 .-$ Long. 2 lig. $\frac{T}{2}$. - L'abdomen est arrondi, plat, d'un gris cendré, quelquefois jaunâtre en dessous; il y a une pointe conique sur le milieu du bord antérieur du céphalothorax; le tubercule oculifere est presque lisse; il y a deux rangs de tubercules sur l'abdomen, parallèles, disposés longitudinale. ment; il y a quatre pointes, d'autres latérales plus petites postérieurement ; les han ches et les cuisses sont épineuses. - Se tronve sous les pierres, aux environs de Paris et à Bordeaux.

\section{PHALAVGIUM HISTR IX.}

Latr., Hist. nat. des Fourm., p. 376; ibid., Gener. Crusi. et Ins., t. I, p. 140. - Ibid., Hist, nat. des Crust. et des Ins., t. VII, p. $323, \mathrm{n}^{\circ}$ 5. - Hers., Nim. Aptérol., p. 107, pl. 7. fig. 1. - Long. 4 lig. - Le corps est ovale dans les mâles, arrondi, déprimé dans les femelles, d'un gris-jaunâtre ou cendré en dessıs, blanc-jaunâtre en dessous; les bords du céphalothorax sont épje 
nerx; il y a un avancement sur le milieu du bord antéricur, formè de plusieurs épines disposées en rayon; le tubercule oculifére est presque lisse; il y a une tache noirâtre, carrée sur le dos, dans la femelle; les incisions de l'abdomen sont peu marquées en dessus; les pattes sont pâles; les cuisses sont presque cylindriques, armées de petits piquans. - Cette espèce a été trouvée à Brives.

\section{Phalangrem mimaculatum.}

Lатв., Hist. nat. des Fourm., p. 376. -Hist. nat. des Crust. et des Ins., t. VII, p. 323. - Opilio Bimaculatus, Herbst., Monogr. des Opil., tab. 3, fig. 3 et 4 . - Long. 1 lig. $\frac{i}{2}$ - Le corps est presque globuleux, d'un noir mat; les mandibules sont un peu cornues; les palpes sont luisants; le pénultième article est courbe, le dernier est ovale; le tubercule oculifère est légérement dentelé; il y a deux taches blanches, oblongues. sur Ja base de l'abdomen, une de chaque côté; il y a une petite ligne marginale plus bas; les hanches sont crénelées latéralement; les tarses sont noirâtres; le premier article est fort long et contourné. - Se trouve sous les pierres.

\section{Phalangium cornutum.}

đૅ, Latr., Hist. nat. des Fourm., p. 377. -Lrvn., System.nat., édit. 13, t. I, pars 2, p. 1028. - Latr., Genér. Crust. et Ins., t. I, p. 138. - Schozfғ., Elem. Entom., tab. 99. - Iconogr. Ins., tab. 39, fig. 13. - Faucheur Cornu, DEgéER, Mém. pour servir à l'Hist, nat. des Ins., t. VII, p. 173, pl. 10, fig. 12. - Phalangium Cornutum, Fabr., Entom. Syst., t. II, p. 430.IInrist, Naturg. Opil., t. I, fig. 3. Ненu, Mím. Aptérol., p. 102, pl. 108, fig. 6. - + , Phalangium Opilio Linn., Sytem. Natur., édit. 13, t. I, pars 2, p. 1027. - Faun. Suec., édit. 2, n 1992. - Faucheur des murailles, DEgéer, Mém. pour servir à l'Hist. nat. des Ins., t。VII, p. 166, pl. 10, fig. 1. - Phalangium Opilio, Faвf., Entom. System., t, II, p. 429. Hensst, Naturg. Opil., tab. 1, fig. 1. Heru., Mém. Aptérol., p. 98. - Long. $5 \mathrm{lig}$. - Le mâle a le dessous du corps d'un gris-roussâtre un peu plus foncé au milieu; les mandibules, les palpes et le des. sous du corps sont blanchâtres; les mandibules s'élèvent en pointe.

I a femelle a tout le dessus du corps d'un brun grisâtre, marqué de iraits obscurs et de quelques points blanchâtres; ie dessous est d'un brun-gris, avec quelques nuances vers les côlés le l'abdomen; les mandibules et les palpes sont grisâtres, tachetés de brun; les yeux sont placés de ciraque côté sur un tubercuie lisse. - Se trouve dans toute l'Europe, très-communément en automne dans les jardins et les bois a Paris et dans ses environs.

\section{PHALANGIUM MUSCORUM.}

LATr., Hist. nat. des Fourm., p. 877, ibid., Hist. nat. des Crust. et des Ins., t. VII , p. $322, \mathbf{n}^{\circ}$ 3. - Long. 4 lig. Le corps est ovale, d'un cendré jaunåtre et nuancé d'obscur en dessus, pâle en des. sous; le tubercule oculifère et dentelé; il y a une bande dorsale, longitudinale, noirâtre; les cuisses sont anguleuses.-Cette espèce a été trouvée sous les mousses à Brives; elle a été aussi rencontrée dans le midi de la France.

\section{Pilalangium palmatum.}

Latr., Hist. nat. des Fourm., p. 178 ; ibid., Histoire naturelle des Crust. et des Ins., t. VII, p. 324, n० 7. - Long. 4 lig. $\frac{1}{2}$. - Le corps est ovale, un peu đéprimé, d'un blanc jaunâtre, notamment à la base de l'abdomen; il y a une grande bande en carré long d'un noir mat, qui occupe tout le dessus; les palpes sont courts, pâles; le tubercule oculifère est granulé; les paties sont longues; les cuisses et les jambes sont anguleuses, légèrement armées de piquans; il y a une petile pointe sur les hanches des trois paires antérieures. - Cette espèce a été trouvée dans les montagnes du Cantal et dans les Alpes.

\section{PHal ANGIUM ANNULATUM.}

Oriv., Encyclopédie méthodique. Latr., Hist. nat. des-Fourm., p. 378; ibid., Histoire naturelle des Crust. et des Ins., t. VII, p. 325, no 7. - Long. 4 lig. ${ }^{2}$ - Le corps est arrondi, d'un noir mat en dessus, pâle en dessous, glabre, lisse; les palpes sont blancs; les serres sont noires à leur pointe; le tubercule oculifère et lisse; les pattes sont menues, cylindriques, très - longues, ayant plus d'un décimetre, de couleur noire; l'extrémité des cuisses et des jambes a un anneau blanc; les tarses sont noirâtres, à articles très-nombreux. - Se trouve dans les Alpes et les Pyrénées.

\section{Phalangium rotondum.}

Latr., Hist, nat. des Fourm., p. 179; 
ibid., Gener. Crust. et Ins., p. 13, Hist. nat. des Crust. et des Ins., t. VII, p. 325. - Herbst, Naturg. Opil., tab. 4.-Heki., Mém. Aptér., p. 109, pl. 8, fig. 4. Lister, de Aran., p. 95, tit 36. - Long. 2 lig. $\frac{1}{2}-$ Le corps est rond, presque globuleux, roussâtre en dessus, pâle jaunâtre, et souvent nuancé de rouge en dessous; le tubercule oculifère est lisse; les pattes sont très-longues, très-déliées, cylindriques, glabres, noirâtres; l'extrémité des cuisses et des articles de la jambe est blauche. - Cette espèce se trouve communément dans la forêt de Saint-Germain. en-Laye.

\section{Phalangium tricuspidatum. (Pl, 10.} fig. 3.)

L. DuF., Ann. des $S_{c}$. nat., t. XXI I, pl. 10 , fig. 5. - Long. 3 lig. $\frac{1}{2}$. - Le des. sus du corps d'un gris obscur, avec une raie blanchâtre tout le long de la ligne méciane; le dessous, ainsi que les pattes et les palpes, est d'un gris testacé uniforme; les maudibules sont de médiocre grandeur, brièvement velues, testacées, avec l'extrémité de la pince de couleur noire; les palpes, moins longs que le corps, sont hérissés de poils courts, mais roides; leur dernier article est légérement renflé en massue vers la pointe; le céphalothorax présente au milieu du bord antérieur trois pointes conoïdes bien distinctes, un peu redressées; les bords latéraux, surtout à partir de l'articulation de la seconde paire de pattes, sont comme rouges et inégalement denticulés; le tubercule oculifère est lisse; l'abdomen a unc forme plus oblongue que celui des espèces précédentes; la région dorsale offre de chaque côté de la ligne médiane, qui est blanchâtre, une raie longitudinale noire, qui n'atteint pas la partie anale; les pattes ont leurs hanches hérissées de quelques piquans; les cuisses amincies de l'extrémité tibiale à la thoracique sont hérissées à la loupe de pelites aspérités filiformes; les jambes sont tétragones, et les tarses ont un nombre indéterminé d'articles. - Cette espèce a été trouwée sous les pierres aux environs de Barcelone.

\section{1. phalatgium crassum.}

L. Duf.. Ann. des Sc. nat., t. XXII, p. 33 , pl. 10 , fig. 4.-Long. 4 lig.-Cette espèce a le corps plus grosque dans la précédente, et les parties proportionnellement plus courtes; son céphalothorax demi-circulaire offre au milieu de son bord anté- rieur une pointe obfuse, briévement bifide; ses bords latéraux présentent quelques points tuberculeux; l'abdomen, en ovale carré, est parfois comme ridé en tra. vers, et, à la faveur de la loupe, on aperçoit dans cette même direction des séries de trés-petits points assez distans entre eux. - Trouvée sous lespierres, dans le royaume de Valence.

\section{Phalangium hineola.}

L. Duf., Ann. des Sc. nat, t. XXII, p. 34. - Long. 1 lig. $\frac{1}{4}$ - Le céphalothorax est d'un gris obscur, plus clair sui les bords; les palpes, d'un gris cendré, offrent cela de particulier, que le troisième et le quatrième article ont leur extrémité prolongée au côté interne en une petite dent; la région dorsale de l'abdomen qui, en avant, se prolonge jusqu'au tubercule oculifére, s'amincit en arrière. -Trouvée sous les pierres dans les montagnes du royau. me de Valence.

\section{Phalangidm bicolor.}

Opilio Bicolor, Hensst, Honogr. des Opil. , p. 18. - Le corps est grand, arrondi en dessous, plan, noir en-dessus, cendré en dessous; les palpes sont cendrés ; les mandibules sont de même couleur, noires a leur sommet; les pieds sont très-allongés, avec les genoux testacés à leur sommet. - Cette espèce a été trourée en Suisse.

\section{PHALATGIUM HELWIGI.}

Latr., Hist. nat. des Crust. et des Ins., t. VII, p. 326. - Opilio Helwigii, Hendst, Monogr. des Opil., p. 18, t. 1, fig. 4. Entièrement noir, avec le corps arrondi en dessous, et les angles du thorax proéminens et arrondis; l'abdomen est tronqué postérieurement en dessous, non bordé; le céphalothorax antérieurement est voûté, avec deux tubercules dans le milieu peu distans qui portent les yeux qui sont d'une couleur blanche; le bord antérieur du céphalothorax est échancré, avec une épine prolongée dans l'intervalle; le céphalothorax postérieurement est dilaté, avec ses côtés latéraux plissés et ses bords élevés; les serres sont glabres, médiocrement renflées, avec le doigt allongé, fléchi, tridenté, le pouce plus droit et bidenté; les palpes sont quadriarticulés; les pieds sont au nombre de huit: le premier article est court, conique; le second plus court, globuleux; le troisième peu grêle, cylindrique, s'épaississant un peu au sommet. lc quatrième court, plus épais, les cin- 
quième et sixième filiformes; Ies dernicrs pieds sont très-allongés. - Se trouve en $\Lambda$ llemagne.

\section{PhataggiUgi monacaviha.}

Opitio Mlonaintha, Hersst, Mlonogr. des Opit., p. 18, tab. 2, fig. 1. - Le corps est testacé, d'un fauve varié, voûté en dessous; le céphalothorax est conique, tronqué postérieurcment, non bordé; les yeux sont rapprochés, globuleux, d'un noir brillant; l'abdomen est coriace, avec une épine droite, robuste en dessus, la partie anale est fléchic et obtuse, les pieds sont au nombre de huit: le premier article est allongé, robuste, avec deux lignes en dessous, longitudinales, lactées; les autres articles sont très-allongès, filiformes, livides; les palpes sont courts, quadri-articulés; le dernier article est filiforme, obtus à son sommet; les mandibules sont courtes. - Trouvé dans l'Inde Orientale.

\section{PHALAYGIUV IISPIDUM.}

Opilio Hispidus, Herbst, Monogr. des Opil., p. 20, tab. 3, fig. 1, 2. - Le corps est d'un gris-brun, blanc en dessous ; le céphalothorax est semi-lunaire, avec le front armé de chaque côté de trois épines blanches, écartées; le tubercule des yeux est placé sur le milieu du thorax, et est entouré de petites épines; l'abdomen présente des points élevés et des lignes transverses; les mandibules sont lisses, avec les doigts noirs; les palpes sont quadri-articulés, soyeux, avec une bande noire sur les côtés; le second et le troisième article sont épais, globuleux, avec une ligne longitudinale élevée en dessous; le dernier article est filiforme, arqué, obscur, poilu, unguiculé à son sommet; les premières paires de pieds antérieurs très-courtes, le premier article et le second armés à leur bord antérieur d'une épine.

\section{7. pilalargium lovgtpes.}

Opilio Longipes, Herbst, Monogr. des Opil., p. 20, tab. 2, fig. 2. - Le corps est testacé, blanc en dessous; le céphalothorax est plan, rugueux, avec le bord antérieur échancré; l'abdomen est anguleux; les mandibules chéliformes sont lisses, jaunâtres, avec les doigts d'un brun obscur; les palpes sont quadri-articulés, couverts de petits points rudes de couleur noire; les pieds sont très-allongés, ceux de la première paire sont plus épais, plus courts; cenx de la seconde très-allongès, grêles; les troisième et quatrième égaux entre eux: le premier article est rugueux, le second et le troisième avec des points noirs, les derniers articles sont capillaires.

\section{PIALANGUM Fasciatum.}

Opilio Fasciatus, Hersst , Monogr. des Opil., p. 21, tab. 4, fig. 1, 2. - Le corps est d'un pâle varié de pourpre; le céphalothorax est plan, finement bariolé, avec les bords noirâtres : le bord antérieur est échancré, avec l'espace et les angles prolongés; les yeux sont rapprochés, ovales, noirs; les palpes sont quadri-articulés, pâles, poilus, avec une bande rougeâtre au sommet; la base des pieds est noire, varjée de roux, avec une tache sur les côlés et le bord antérieur noir; les articles des pieds sont grêles, d'une couleur obscure, les tibias ayant une bande blanche à leur sommet; à leur base les pieds présentent quarante-quatre articles, dont les trente derniers très-courts, vont en décroissant; les pieds de la seconde paire sont très-allongés, arec quatre-vingt-neuf articles à leur extrémité, dont les quarante-six derniers sont très-courts et capillaires.

\section{Phalangium grossipes.}

Opilio Grossipes, Herbst, Monogr. des Opil., p. 22, tab. 6, fig. 1. - Le céphalothorax est lisse, noir; le tubercule des yeux est séparé en deux et élevé sur le milieu du thorax; le front est voûté longitudinalement, tronqué antérieurement, avec les angles de chaque côté prolongés; le bord lateral du céphalothorax est échancré près de la base des pieds, replié, jaunâtre; les mandibules sont chéliformes, cylindriques, jaunâtres; les sommets des doigts sont noirs; les palpes sont robustes, lisses, jaunes, tachés de noir à leur sommet, velus, le troisiême article d'un brun-noir; les pieds sout inégaux, la deuxième paire est la plus longue, la quatrième ensuite, la troisième après, la première est la plus courte; la base des pieds est épaisse, jaunâtre, poilue; les fémurs sont d'un jaunenoirâtre, hérissés et très-prolongés; les tibias sont plus obscurs à leur sommet; l'abdomen est varié de jaune et de noir, avec les côtés rugueux, plissés; les segmens en dessus sont granuleux.-Cette espèce a étẻ rouvée en Saxe.

\section{0. phalaigium alpigum.}

Opilio Alpinus, MeREST, Monogr. des Opil. p. 23, tab. 6, fig. 2. - D'une couleur obscure; le bord antéricur du céphalothorax est arrondi; le front préscnte de 
chaque côté trois épines blanches, écartées; le tubercule des yeux est sur le milieu du céphalothorax; les yeux sont jau. nes, pellucides; les palpes sont quadri-articulés, jaunâtres, le premier article est cylindrique, Je second atténué postérieurement, plus large antérieurement, accompagné d'une dent obtuse; le troisième article est cylindrique, atténué postérieurement, plus large au sommet, arrondi, soyeux; le dernier article est filiforme, unguicule en forme de hameçon, soyeux; les mandibules sont chéliformes, courtes, avec les doigts noirâtres à leur sommet; les pieds sont courts, épais, testacés: les trois premiers articles sont prismatiques, avec une ligne élevée, longitudinale, couverte de soies brunes, très-courtes; les derniers articles sont filiformes, obtus à leur sommet; le second article des pieds, portant le genou, est armé d'une épine ì son sommet. - Cette espèce a été trouvée en Suisse.

\section{1. phalanguum palpinale.}

Opilio Palpinalis, Herist, Monogr. des Opil., p. 25, tab. 7, fig. 1. - Le céphalotharax est d'un gris-brun, le plus souvent noir; le tubercule oculifère est noir et placé sur la partie médiane; les yeux sont noirs, brillans, l'intervalle présente une double série de trois épines; le bord antérieur du céphalothorax est échancré; le front est armé de trois épines pâles, droites; les palpes sont pâles, renflés, avec tous les articles ciliés intérieurement; les mandibules sont chéliformes, jaunâtres, avec les doigts noirs à leur sommet; les pattes antérieures sont courtes, avec le premier article court, armées de fortes épines à leur sommet; le second plus allongé, le troisième plus court, le quatrième plus long, tous renflés et épineux; l'ongle est recourbé, noir; les seconds pieds sont trèsallongés, avec le premier article biépineux; les second, troisième et quatrième comme dans les premiers, mais canaliculés; les pieds de la troisième paire sont un peu plus longs que les premiers; la derniere paire de pieds est semblable, mais un peu plus Jongue, tous sont pâles, tachés obscurément ; l'abdomen est noir, taché de pâle, hémisphérique, fléchi.

\section{Phalatgicm SPINosum.}

Opilio Spinosus, Henbst, Monogr des Opil., p. 26, tab. 9, fig. 1. - Le corps est petit, noir, avec sa partie antérieure vaziée de jaune; le céphalothorax est semi- lunaire, échancré postérieurement, trèsfinement ponctué; le tubercule oculifère est noir et placé sur le milieu; les yeux sont noirs, brillans; les palpes sont noirs, jaunes à leur sommet; les pieds sont noirâtres, avec les articles plus épais à leur base, testacés, couverts de beaucoup d'épines; les pieds de la première paire sont plus épais, courts; l'abdomen est arrondi, un peu plus large à son sommet; des épines droites, noirâtres, sont placées en double série sur un disque; le bord postérieur est arrondi, armé de six èpines blanches. Trouvé en Saxe.

\section{PHALANgium TPIANgulare.}

Opilio Triangularis, Herest, Monogr. des Opil., p. 27, tab. 10, fig. 1.- Le disque du thorax est entouré postérieurement par une ligne élevée, de plus il est voûté et obscur dans son milieu; le tubercule oculifère est plus épais que dans les espèces précédentes; les yeux sont distans, noirs; les orbites en dessus sont armés de petites épines droites, avec l'intervalle canaliculé ; les palpes sont longs, avec le premier article cylindrique, le second et le troisième attẻnués à leur base et dilatés à leur sommet; le quatrième est filiforme, arquẻ ; les pieds sont médiocres, ceux de la seconde paire sont les plus allongés, pâles, noirâtres à leur sommet, avec les femurs finement spinulés; l'abdomen est ovale, voûté dans son milieu, carẻnẻ, obscur, ponctué de pále.

\section{TROGULUS, LATr.;}

\section{Phalangium, Linn., Latr.; Acarus, Scopoli.}

Lesparties de la bouche sont situées dans un enfoncement que recouvre le prolongement antérieur de l'enveloppe du corps. - Ce dernier est très-aplati, dur. - Les yeux sont écartés l'un de l'autre et peu sessiles. - Leurs pattes sont proportionnellement plus courtes que celles des faucheurs, et leurs tarses n'ont pas au-delà de six articles ${ }^{2}$. - L'espece qui a servi de type à ce genre est :

1 Suirant M. L. Dufour, la pièce que les entomologistes appellent premier article des tarses est absolument ilentique par son organisation avec la jambe, revêtue des mêmes poils rudes et grisâtres que celle-ci. Elle n'est pas, suivant le même auteur, une dépendance du tarse, mais bien de la jambe ou tibia, qui se tronverait alors composée de trois articles, au lieu de deux. Les 
ThOGU.US NEPOETOMIS. (Pl.10, fig. 5.) Latr., Gener. Crust. et Ins., t. 1, p. 142, tab. 6, fig. 1. - Guér., Iconogr. du Lì̀. anim. de Cuv., Arachn., pl. 4, fig. 6. - Trogule Népiforme, Latr., Hist. nat. des Crust. et des Ins., t. V I I, p. 327; ibid., Hist, nat. des Fourm. et recueil de Mém., p. 274. - Phalangium Tricarinatum, Lins., Syst. nat., édit. 13, t. I, pars 2, p. 1029. - Acarus INepeformis, Scopol., Entom. Carn., n¹070. - Phalangium Carinatum, FABR., Entom. Syst., t. II, p. 431.-W -WLCK., Faun. Paris., t. I1, p. 232. - Long. 4 lig. - Le corps est ellipsoïde, d'un cendré teareux, chagriné; l'avancement antérieur du céphalothorax est 1. iangulaire; les palpes sont forts, petits ; on re distingue pas d'anneaux à sa partie infé. rieure; les tarses sont de quatre articles, dont le premier un peu renflé à son extrémité, avec l'angle extérieur prolongé en forme d'épine. - Cette espèce se trouve sous les pierres, particulierement dans la France méridionale. Voyez pour les autres espéces, Косн, Faune Altemande, tab. 4, fig. 7, tab. 4, fig. 8 .

\section{CECULUS, L. Duf.}

La bouche est cachée avec la lèvre et les mandibules sous le chaperon. - I a lèvre est semi - circulaire. - Les mandibules,

Téritables tarses du Trogule, les tarses légitimes, Dnt une forme, une textare, une couleur qui leur sont propres, et qui les distinguent organiquement et fonctionnel lement des jambes. Leurs articles sont revêtus d'un duret Irè-fin., spongieax ou veloulé, très-favorible au sens du toucher, et d'une teinte noirâtre ou enfumée. Par une inadvertance, sans doute, continue M. L. Dnfour, M. Latreille ne donne dans son Genera que trois articles aux tarses du Trogule, tandis que dans son Ifistoire des Insectes, antérieure au Genera, il les dit composés de quatre. Ce savant avait presque raison dans son ouvrage, en comprenant dans les articles du tarse, celui que je regarde comme dépendant de la jambe. Je dis presque raison, car le tarse des pattes antérieures a un article de moins que les autres; et ce trait était resté inaperçu. Ce tarse n'en a done que deux : les autres en ont trois. Celui de la seconde paire de pattes offre encore cette particularité, que son premier article est rudimentaire, et que les deux autres, qui sont parfaitement cylindriques, ont une longueur comme double de celle des tarses suivants. Enfin, j'ajouterai comme un fait omis, que l'article où s'insère le tarse légilime de cette seconde paire ne se prolonge pas à son extrémité, en une saillie dentiforme comme selui des autres pattes.

ÁN. placées sur la lévre, sont oblongues, petites, terminees par un ongle simple. - Les palpes sont nuls. - Les yeux sont invisibles. - Les pieds sont ambulatoires et au nombre de huit, insérés sur les côtés latéraux du tronc, les antérieurs étant un peu plus longs. - Les tarses sont uniarticulés, armés de deux ongles simples. -- Le corps est ovale, déprimé, coriace, glabre, pourvu d'un thorax en forme de bouclier. - L'abdomen ne se distingue du thorax que parce qu'il ne donne pas insertion aux pattes, et que l'arête latérale du tronc ne s'y continue pas.

\section{C.RCULUS ECHITIPES.}

L. Duf., Ann. des Se. nat., t. XXV, p. 289, pl. 9, fig. 1 à 3. - Long. 1 lig. Le corps est noir, ovale, déprimé, et d'une consistance uniformément coriacée; le tronc, ou cette partie du corps qui donne attache aux pattes et qui recèle la bouche, est plus grand que l'abdomen, dont aucun étranglement ne le distingue et avec lequel il est continu; il présente en dessus, et à peu près dans sa moitié antérieure, une sorte de plaque unie, plane, ou légérement déprimée, de texture un peu plus serrée, qui forme comme un simulacre de corselet; elle se prolonge en avant en un lobe arrondi semblable a un chaperon, et ce trait offre une analogie frappante avec celui qui caractérise le genre Trogulus. Neis, malgré des explorations soigneusement réitérées avec les secours des plus forts verres amplifians, M. L. Dufour n'a pu découvrir a cette Arachnide la moindre trace d'yeux; dans sa moitié postérieure, le tronc présente en dehors, de chaque côté, un pli saillant, longitudinal, une sorte d'arête; la bouche est tout-à-fait inférieure et placée sous le chaperon comme dans le genre Trogulus, mais un peu plus en arrière et dans la position naturelle de l'Arachnide, elle est absolument invisible. Quand on observe celle-ci renversée sur le dos, on voit que la bouche forme une saillie comme un museau court; on y apercoit distinctement une lèvre demi-circulaire, de même texture que le reste du corps, séparée du plastron sternal par une articulation linéaire qui lui permet un mouvement borné d'élévation et d'abaissement. Cette lèvre, légérement concave en dessous et vraisemblablement convexe en dessus, est le support, le réceptacle des autres parties de la bouche; deux mandibules petites, oblongues, y sont logées, non didactyles, mais ter- 
minées par un seul crochet. Au reste, l'extrême petitesse de la bouche ne m'a pas permis de constater très-rigoureusement la conformation des mandibules. Des soies assez longues, roides, très-disinctes les unes des autres, garnissent soit le contour de la levre, soit le voisinage de la bouche. M. Dufour, malgré les recherches les plus minutieuses, n'a pu apercevoir de palpes. Il ne faut pas prendre pour tels deux soies grềles, inarticulées, qui débordent le contour du chaperon, et qui ont leurs insertions un peu en arrière de ce contour, non loin de la bouche. Ces soies ne diffèrent que par un peu plus de longaeur de celles que j'ai dit garnir les environs de la bouche. Elles sont roides, cornées, et peu susceptibles de mouvement; les pattes sont uniquement ambulatoires, au nombre de huit, d'une composition uniforme pour toutes, et remarquables par les soies de diveises configurations qui les hérisscnt; leur longueur est médiocre; les antérieures sont un pez plus longues que les autres, qui sont égales entre elles; la région anterieure ou pectorale du tronc présente une structure analogue à celle des Phalangiens, on y voit de chaque côté quatre plis allongés, conoïdes, bien moins saillans que dans les Faucheurs, et assez semblables sous ce rapport à ceux du Trogule. Ces plis, que la plupart des entomologistes désignent sous le nom de hanches, ne sont point des articles particuliers dépendant des pattes, mais de simples reliefs parfaitement immobiles, fournis par le segment pectoral. La véritable hanche ne consiste qu'en un seul article, assez grand, plus gros même que la cuisse; elle est tout-à-fait découverte, et soninsertion a lieu immédiatement sur lé bord latéral du tronc; celle des quatre: pattes de devant présente au côté interne ou antèrieur une soie ovale, spatulée, roussâtre, implantée sur une saillie conoîde ; la hanche de la troisieme paire offire une apophyse latérale; la cuisse ressemble à la jambe des Phalangiens, car elle se compose de deux pièces à peu près semblables, étroitement contiguës bout à bout, dont la premiẻre cst un peu plus courte que l'autre; elle est obscurément tétragone, et les an. gles ou arêtes sont bordés de soies roides, cornées, d'un roux testacé, qui diffèrent cntre elles par leur configuration; le côté interne des deux paires antérieures est garni de cinq à six piquans, longs et grêles, implantés sur une espéce de bulbe conö̈le bien prononcé; le côté externe en a de sem. blables, mais moins nombreux et moins ap. parens. Ces longs piquans bulbeux ne s'ob. servent pas aux autres cuisses, el servent sans doute à l'Arachnide à saisir on à enlacer sa proie. D'autres soies courtes, ovales - spatulées, garnissent les bords et les arêtes de ces cuisses et des autres; la jambe, moins grosse que la cuisse et presque aussi lorigue qu'el!e, est d'une seule pièce; les quatie antérieures présentent à droite et à gauche trois piquans bulbeux et des serres de soles ovales-spatulées, les quatre postérieures offrent de ces dernières au côlé interne des soies non bulbeuses; le tarse n'est que d'un seu! article allongé, plus grêle et plus court que la jambe, bordé de cils simples. Le trait d'un tarse uniarticulé distingue ce genre des précédens; les tarses se terminent tous par deux ongles trèssimples, médiocrement arqués, mais bien distincts, insérés au bout mème du tarse et non sur le côté; l'abdomen est plus court que le tronc, il ne se distingue guère de celui-ci que parce qu'il ne donne pas insertion aux pattes, et que l'arête latérale du tronc re s'y continue pas; il offre à son origine comme un segment transversal, et ensuite quclques rides à peine distinctes; son extrémité est légérement échancrée ; il est noir en dessus et d'un ronx testacé en dessous. Cette dernière conlenr s'étend à la ligne médiane de la puitrine. - Cette espèce a été trouvée sous les pierres dans les montagnes arides de Moxente, aux confins mèridionaux du royaume de $\mathrm{Va}$ lence.

\section{CRYpTOSTEMMA, Guér.}

C'est un genre qui a été établi par M. Guédin dans sa Revue Zoologique, et qui par son organisation appartient à la tribu des Phalangiens; il est très-voisin du genre Trogulus; comme lui il a l'extrémité anté. rieure du céphalothorar avancée en forme de chaperon; mais M. Guérin n'a pu lui voir aucune trace d'yeux, et les antennespinces sont saillantes, en forme de pattes et plus courtes que celles-ci. - Le céphalothorax est distinct de l'abdomen, de forme carrée. - Les pattes sont très-inégales en longueur, aplaties, terminées par des tarses de quatre et cinq articles grenus, dont le dernier est le plus grand. - La seconde paire est la plus longue, ensuite la troisième, puis la quatrième, et enfin la première qui est la plus courte. - L'abdomen est de la largeur du céphalothorax, deux fois plus 
long, aplati et un peu enfoncé en dessus, convexe en dessous, et paraissant divise en quatre segmens. - L'espece type de ce genre est :

\section{GRYPTOSTEMMA WVESTERMANII.}

Gứr., Revue Zool., n' 1, janvier 1838, p. 11. - Long. 3 lig. - Le corps et les pattes sont d'un gris terreux, couverts de nombreuses aspérités; le chaperon est plus large en avant, rebordé, avec un faible silIon longitudinal au milieu; le céphalothorax est un peu bombé, rebordé sur les côtés et en arrière, avec un sillon longitudinal au milieu, beaucoup plus profond en arrière, et une forte impression oblique de chaque côté; l'abdomen est à bords très-relevés, avec deux impressions obliques a la base de chaque segment.-Cette espèce a été trouvée en Guinẻe (1).

(1) M.Guérin, dans l'ouvrage ci-dessus cité, fait connaître un nouveau genre d'Aranéide qu'il désigne sous le nom d'Acanthodon, et qui avoisine les My gales fouisseuses et les Eriodons de Latreille; comme dans ces deux genres, les palpes sont insérés à l'extrémité supérieure des mâchoires, les chélicères sont saillantes, et leurs crochets sont repliés en dessous, le long de leur tranche inférieure, et non en dedans et sur leur face interne; les chélicères ont en avant, et comme chez la Mygale Maçonne, une sorte de râleau; mais ce genre differe de ceux auxquels nous le comparons, par ses palpes anssi forts, et presque aussi longs que les pattes $\left({ }^{*}\right)$, dont les deux derniers articles sont un peu aplatis, et armés en dessous d'épines fories el courtes, formant un râteau, organe qui se troure également sous les deux derniers articles des premières et secondes pattes, et par ses yeux, qui, au lieu d'ètre réunis, en forment deux bien distincts, ce qui n'a pas encore été observé dans les Arachnides pulınonaires; ils sont ainsi disposés : deux yeux trèsrapprochés sur le bord antérieur du céphalotho. $\mathrm{rax}$, et six beaucoup plus en arrière, formant un ovale transverse très-étroit. - La seule espèce connue et qui a servi de type à ce genre est :

\section{ACAYTHODON PETITIK}

Guér., Revue Zool., n 1, janvier 1838, p. 11. - Long. 15 lig. - Le corps est d'un brun marron luisant, avec l'abdomen velu et d'un brun pûle terne; les palpes et les pattes sont semblables; ce qui lui donne l'apparence d'une araignée à dix pattes; la quatrième paire de pattes est la plus longue, la premiere ensuite, la troisième après, et enfin la deuxieme est la plus courte; la troisieme paire de pattes est plus épaisse que les autres, et on aperçoit des lignes longitudinales plus foncées sur les pattes; ces lignes sont formées par un duvet brun, très serré. - Cette espèce a été trouvée au Brésil. - M. Gué. rin doit donner des descriptions et des figures détaillées de ce genre et du précédent dans son Magasin de Zoologie.

(") Celte organisation rapprocherait cette nourelle coupe générique de celle d'Actinopus, Perty, Pachylos. celis, Lucas, Sphodros, Walck, elle avoisine aussi, pat les organes de la vue, notre genre:Calommata.

\section{TROISIENE FANILLE.}

\section{T ROMBIDIT E S,}

Latreille.

Caractcres.-Les palpes sont terminés en pointe, avec un appendice mobile ou une espèce de doigt en dessous. - Les chélicères finissent simplement en une pointe très-aiguë, ou monodactyle. - Le corps est mou, sans anneaux distincts. - Les habitudes des espèces composant les genres renfermés dans cette famille, sont vagabondes.-Gen. res: Tetrarychus, Pachygnathus, Raphignathus, Megamera, Rhyncholophus, Trombidium, Erythrocus.

\section{TETR ANYCHUS, L. DUF.}

Le corps est ovalaire, pourvu d'un sucoir à deux acicules sans soie et qui ont un peu plus de longueur. - Les palpes sont aussi à crochet fort court et épais, mais cux. mêmes en totalité gros, courts, conoïles. appliqués sur une lèvre triangulaire, et formant avec elle une sorte de tête obtuse et bifurquée. - Il y a des yeux latéro-antérieurs, des hanches insérées, de chaque cóté, en deux groupes, un pour les deux antérieurs, un pour les deux postérieurs; des pattes dont la paire antérieure est toujours la plus longue, et dont la cuisse offre des dimensions de beaucoup supérieures à celles des autres articles, terminées enfin par deux crochets fort petits et fort courbés, attachés à un septième article de petites dimensions, dépassés par quatre soies roides, grosses. - Les espéces qui composent ce gemre vivent es société nombreuse.

\section{TETRANYCHUS LINTEARIUS.}

L. Dor, , 1mu. des $S_{c}$, nat., t. XXV; 
pl. 9, fig. 4. - Acarus Lintearius, Lins.. Trombidium Telarium, Hena., Mem. Aptérol., p. 40, pl.2, fig. 15.-DuGìs, Noun. Annales des Sciences naturelles, t. 1, p. 20. - Trombidium Socinm, ibid., Ilćm. Aptérol., p. 43, pl. 2, fig. 13. - Long. $\frac{1}{3}$ lig. - Celle espèce se troure sur le tilleul; elle a été rencon. trée dans le nord et dans le midi de la France, sur la rose trémière, l'acacia rose, le broussanetia, le rosicr, le sureau, le charme, le chêne, le liseron des champs ę celui des haies; ces végétaux en avaient plus ou moins souflert; des points rouillés et innombrables indiquaient le mal fait par la piquire de ces animalcules; le liseron offrait une singularité de plus, les Tétranyques habitaient, comme d'ordinaire, la face inférieure de ses feuilles; la supérieure était couverte d'une poudre blanche; à en juger par la forme et les babitudes, ces habitans de plantes diversesétaient bien de la même espèce; il n'en eût pas été ainsi à en juger par la couleur; les uns étaient verdâtres et marqués seulement de taches brunes sur les côtés du corps: taches variables et évidemment dues aux matieres alimentaires contenues dans les cœcum latéraux de l'appareil digestif; les autres élaient rouillés, rougeâtres, rouge-brique; tels élaient surlout ceux de l'acacia rose; mais sur la rose trémière, M. Dugès a trouvé à la fois des individus offrant presque toutes lesnuances qui sont probablement liées a quelques circonstances de nutrilion; ces animalcules sont fort petits,à peine visiblesà l'œilnu; leux corps est ovalaire, plus étroit en arrière, un peu saillant en arant, quelquefois sinueux sur les flancs, leur peau garnie de poils rares et longs; les pieds sont peu longs, même les antérieurs; les hanches peu écartées; les tarses offrent au plushaut degré les caracières des pieds tisseurs, les quatre soies roides se meuvent avec le sixieme article; les crochets du septième semblent uniquement destinés à conduire les fils sécrétés par une papille conique, assez forte, ế située en dessous et en arrière, très-près de l'extrẻmité de l'abdomen : tous ces détails se voient avec beaucoup de peine.

Les fils sécrétés par ces filières sont si fins, que la loupe même ne les fait apercevoir que quandils sont réunis en toile ou du moins en réseau; quoique, devant la construction de cette toile ou réseau, toutes les pattes de l'animal suspendu à sesfils agissent avecbeaucoup d'activité, il ne court pas avec une grande vitesse, il a même de la peine à marcher sur des corps polís ei durs, le verre, par exemple; sur les feuilles, ou plutôt sur la face inférieure, ils trouvent à leurs soies terminales un point d'appui plus commode; c'est là que, abrités par la toile qu'ils ont tendue sur le sommet des poils qui hérissent celte surface, ils se nourrissent et se multiplient; de temps en temps on les voit incliner leur bec vers la feuille, relever presque verticalement l'extrémité posterieure du corps, plonger ainsi, sans doute, leurs acicules dans les cellules végétales pour en pomper durant quelques minutes le suc et la matière verte; aussi leurs excrémens sont-ils liquides, quelquefois gommeux et incolores, d'autres fois mêlés de matière épaisse et d'un vert foncé.

Cette espèce de camp ou de ville, constituée par une seule feuille, est habitée par de nombreux individus de tout âge et de tout sexe: on peut prendre pour les mâles des individus de petite tailie, mais à huit pieds et de forme un peu ramassée, de couleur plus verdâtre que les grands, sur le dos desquels M. Dugès, auquel nous avons emprunté les observations précedentes et celles qui suivent, Jes a vus plus d'une fois montés, comme pour opérer l'accouplement. Les femelles jettent cà et là leurs œufs sphériques, incolores, volumineux, mais pas plus gros que celui qu'on trouve unique dans l'abdomen de celles qu'on écrase; de cet cuf sort une larve à six pattes, pellucide, petite, marchant avec lenteur, peu dissemblable de l'adulle quant à la forme; ils passent sans doute, comme ceux dont nous parlerons plus loin, à l'état de nymphe immobile avant d'acquérir leurs huit pieds. Il y a lien de croire que ces petits êtres passcnt l'hiver sous les pierres, et s'y cachent dès que tombent les feuilles qui les ont nourris. J'en ai trouvé dans un jardin près Paris plusieurs cachés au mois d'octobre; ils étaient d'un rouge brique uniforme, et n'avaient encore rien perdu de leur agilité, ni de leur aplitude à filer ; c'est même sur eux que j'ai le mieux observé la papille abdominale.

Ces Tetranychus deviennent souvent Ia proie d'autres animaux, tels que les larves d'Iiémérobes, qui font les plus grands ravages, et qui souvent en trés-peu de temps détruisent des peuplades entières.

\section{TETRANYchus prunicolor.}

Dugès, Nouv. Ann. des Sc. nat., t. I, p. $25, \mathrm{pl} .1, \mathrm{fig} .3$ à $6 .-\mathrm{Un}$ peu plus grand que le précédent; le corps est plus allongé, 
plus rétréci en arrière, saillant et conoïde en avant ; la couleur est d'un brun-violet uniforme, avec les pieds pâles; les palpes un peu moins gros et moins serrés que ceux du $T$. Lintearius; les acícules sont plus longues et se courbent en bas; il y a deux rangs de poils sur le dos; les yeux sont noirs; les hanches sont en deux groupes bien écartés pour chaque, les deux postérieures sont même séparées l'une de l'autre par un léger intervale; les pattes sont de structure analogue à celle de l'espèce précédente, mais cependant plus longues; l'agilité est aussi beaucoup plus grande. Cette espèce a été trouvée en société aux mois de juillet et août sous les feuilles du poirier, du prunier. Les oufs sont ronds, jaunâtres, la femelle n'en porte aussi qu'un à la fois, et il en est de même des espèces suivantes; les petits à six pattes sont rerdâtres.

\section{TETRANYCIIUS CBistatus,}

Dugès, Nouv. Ann. des Sc. nat., t. I, p. 24. - De même taille que l'espèce précédente, un peu moins agile, à pieds plus grêles et dont les antérieurs sont extrêmement longs; les hanches sont bien séparées en deux groupes latéraux, avec les tarses à soies moins fortes que dans les espèces précédentes; le bec et les palpes sont peu saillans; le corps est ellipsoïde, un peu atténué en arrière, relevé en crête tout autour du dos; la couleur est d'un brun noirâtre nuancé de rouge sale, quelquefois presque tout de cette couleur, et ayant plusieurs rangs de points blancs sur le dos et sur les bords; les yeux sont d'un rouge foncé.

Cette espèce a été trouvée par M. Dugès sur beaucoup de végétaux et sous les pierres. Dans le midi de la France, dit ce même auteur, je l'ai vue en famille dans le duvet léger qui garnit la face inférieure des feuilles du prunier; elle se trouvait là avec des autres rouges et globuleux, des petils ì six pattes, rosés d'alsord et pellucides, puis rouge brique; la paire de pieds postérieurs est insérèe fort en arrière des antérieurs. Il y avait également là des nymphes aussi grandes que les adultes, immobiles, collées sur la feuille; autour d'elles étaient des dépouilles blanches de nymphes déjà écloses. A Paris j’ai trouvé en automne, sous les pierres des promenades publiques, des familles entières, ce qui m'a fait penser qu'ils quittaient volontiers les arbres, du moins dans cette saisun, pour multiplier ailleurs avec plus de sécusié : là j'ai pu distinguer le mâle a sa petitesse, à sa couleur plus rouge, à la longueur pỉas grande de ses pattes antérieures, trois fois aussi longues que le corps même; il m'a paru se placer sous la femelle dans l'accouplement et s'accrocher à son dos à l'aide de ses iongues pattes repliées; c'est aussi avec ces longues pattes qu'ils se livraient des combats entre eux. Les mâles senblaient souvent couver les nymphes immobiles, comme s'ils avaient attendu l'éclosion d'une femelle pour s'en emparer aussitôt. - Cette espèce, ainsi que la suivante, ne filent pas.

\section{TETranychus gaddatus.}

Dugès, Ann. des Sc. nat., t. I, p. 25. - Cette espèce a été trourée en famille dans le duvet de la face inférieure du laurier-thym, avec des œufs jaunâtres et des larves à six pattes et de couleur très-pâle; elle est fort petite, même à l'état adulte, elle se distingue des précédentes par sa forme allongée, rétrécie en arrière, saillante en avant, et par sa couleur jaune orangé; les paltes sont d'un jaune pâle, peu longues; leur course est assez rapide; il y a quatre grosses soies roides, courtes, écartées, lui formant une sorte de queue.

\section{TETRAYYGIUS TERMIPES.}

Dugès, Aim. des Sc.nat., t. I, p. 40. - Les couleurs sont plus ternes fauve et noirâtre) que dans l'espèce précédente à laquelle elle ressemble beaucoup par la forme du corps et des membres; seulement elle n'a pas de rebord anguleux, ni de corselet distinct; les pattes sont plus grêles encore, mais dans les mêmes proportions; les palpes sont également droits, courts et gres, peu visibles en dessus; dans les mandibules, le mordant fixe est très-court, et le mobile ou l'acicule est très-long.

6. Tetranycius masor. (Pl. 12, fig. 6.)

Dugès, Ann. des Sc. nat., t. I, p. 40, pl. 9 , fig. 57.- - Le dos est plat, strié transversalement, épaulé, un peu prolongé en avant et hérissé de quelques soies, soit en avant, soit autour; il y a deux rangées longitudinales en dessus; le bec en dessous est d'un beau rouge, ainsi que les pattes, et une tache au milieu du dos; le reste est d'un bean noir; les deux yeux sont rougeâtres ou blanes, latéro-antérieurs; au milicu de l'abdomen en dessus, il y a une vulve rouge, bilabiéc, d'où la compression fait sortir des tubes courts et incolores; les 
palles antérieures sont plus longues que les autres; les cuisses sont longues partout, le sixième article aussi, le seplième est rudimentaire, à deux griffes, avec une papille olivaire; les palpes sont gros, courts, à peine courbés, à troisième article plus long que les autres; les mandibules sont composées chacune d'un corps épais, terminé par un cône surmonté d'un ongle pointu; à la base du cône s'articule un grand mordant mobile, étroit, recourbé, représentant parfaitement en petit l'acicule du Tetranychus Cristatus.

\section{TETRANYCHUS TROMRIDINUS.}

Dugès, Ann. des Sc. nat., t. 1, p. 42 . - Cette espèce porte deux yeux blancliâtres sur l'avance du tronc qu'elle offre comme la plupart des espèces précèdentes; Jes palpes sont moins serrés sur le bec que dans les congénères, ils sont assez courts et conoïdes; les mandibules ont l'ongle mobile très-grand, il ressembl à celui du $T e$ Iranychus Major, mass il est encore moins prolongé et sans mordant fixe à l'opposite; les deux pointes font simultanément saillie hors du bec quand on comprime l'animal.

\section{TETRANYCHES URTICA.}

Kocn, Faun. Allem.. tab. 1, fig. 10. Cette espèce est blanche, avec une tache humérale noire de chaque côté, carrée postérieurement et striée de blanc obliquement.

\section{TETRANYCHUS EIMI.}

Kock, Faun. Allem., tab. 1, fig. 11. Elle est peu allongée et hérissée d'épines brunes; sa couleur est ferrugineuse, avec le thorax et les pieds blanchâtres, ces dir-rniers à leur base; la bande médiane de l'abdomen est large et plus pâle.

\section{PACHYGNATHUS, Dugès.}

Les palpes sont coniques, à peine onguiculẻs. - Les mandibules sont épaisses, cheliformes. - Le corps est entier, alténué antérieurement. - Les hanches sont distantes.-Les pattes sont propres à la marche: le sixième article est très-long, le seplieme très-court; les pattes antérieures sont plus longues et plus épaisses.

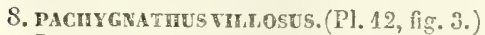
Dugìs, Ann. des $S_{c}$. nat., t. Il, p. 37, pl. 8, fig. 52 à 54. - Cetie espèce est punctiforme, de couleur roussâtre; les poils plats, courbés, courts, et assez nombreus qui la recouvrent, lui donnent à la loupe un aspect velouté; les pattes et les palpes sont hérissés de poils courts et roides; le sixième article des tarses a l'aspect d'un chardon à carder; le corps est renflé, épaulé, rétréci en avant; cette portion rétrécie porte deux gros yeux saillans et brunâtres; les inscrtions des pattes sont de chaque côté en deux groupes peu distans et peu éloignés de la ligne médiane ; les antérieures sont beaucoup plus fortes et plus longues que les autres; viennent ensuite les postérieures ; celles de la deuxième paire sont les plus petites; toutes sont conoïdes, épaisses el si peu longues, que la postérieure ne dépasse pas le bout du ventre; toutes ont une cuisse assez renflée, un sixième article fort long, un septième fort court et mince; il n'y a que deux grandes griffes sans caroncules apparentes; le bec est saillant; les palpes courbés, serrés contre la lèvre, dont ils ont à peu près deux fois la longueur, conoides, assez semblables à ceux des Tetranychus, mais un peu plus longues, et ayant leur dernier article beaucoup plus considérable qu'aucun desautres; les palpes s'agitent quand l'animal marche; lesmandibules sont en pince à mordant mobile rebroussé, parallèlement à la courbure du mordant immobile; elles ont une base très-épaisse et sont très-volumineuses, relativement à la taille de l'animal : quand on le presse entre deux verres au foyer du microscope, les mandibules s'échappent aisément en rompant les parois de la lèvre ou de la cavité buccale. - Celte espèce a été trouvée en assez grand nombre, en aucomne, sous les pierres humides.

\section{RAPHIGNATHUS, DUGÈS.}

Les palpes sont à peine onguiculés. Deux acicules pour des mandibules, courtes, insérées sous un bulbe charnu, cachées sous une Jèvre large. - Le corps est cnlier. - Les hanches sont contiguës. Les pieds sont propres à la course; les antéricurs sont plus longs. - Le dernier article est le plus long de tous. - La larve est hexapode et très-semblable à l'adulte.

\section{PAPIIGTATHUS RUBERRIUUS.}

Dugks, Ann. des Sc. nat., t. 1, p. 18, p). 1 , fig. 1 à 2. - Très-petite, représentant un point allongé et d'un beau rouge; le corps est evale, aplati, lisse et presque sans poils, et semble se terminer en avant par unc avance conique; cette avance n'est autre chose qu'une lève triangulaire, con- 


\section{MEGAMERUS.}

cave et longeant l'appareil mandibulaire; un double bulbe charnu, dans lequel s'insèrent deux acicules légérement recourbées et accompagnées chacune d'une soie roide, composent cet appareil, qui ne pa- roît pas susceptible de rentrer dans le corps en deca de la cavité labiale; par la compression entre deux verres, on pouvait faire sortir cet appareil de la lèvre, soit par un de ses côtés, soit par une déchirurc de sa base; on séparait ainsi difficilement l'un de l'autre les deux bulbes charnus portant chacun leur alène et leur soie parallèles; les palpes sont grands, renflés; l'onglet du quatrième article est fort court; le cinquieme est fort long, elliptique; souvent allongés au-devant du corps, ces palpes font paraître l'animalcule plus effilé qu'il ne l'est réellement; le plus souvent ils sont recourbés en dessous; un pelit œil d'un rouge foncé, de forme arrondic, occupe, de chaque côté, la région antérieure du corps; les pattes antérieures, un. peu plus longues que les autres, l'emportent à peine sur les postérieures; dans toutes le dernier article est le plus long, il est aussi un peu plus mince que ceux qui le précèdent, garni de poils couchés, et terminé par deux ongles rétractiles; le troisième article, ou la cuisse, est peu considérable; les hanches, larges, plates, adhérentes, sont toutes contiguës les unes aux autres.

La marche de ces animalcules est médio. crement rapide, comme le faisoit pressentir la médiocre longueur et la forme de leurs pieds; cependant il doit leur être bien facile de se rendre sur les végétaux, oủ ils vivent en raison de l'organisation de leur hanche. Ils ne passent sans doute sous les pierres que la première partic de leur vie. Fn effet, c'est immédiatement après leur métamorphose qu'ils ont la taille qui leur a été assignée, et cette taille est à peu près la même avant la métamorphose; c'est, à peu de chose près, celle de l'animalcule sortant de l'œuf. Cet cuf disséminé en quantité considérable sur les pierres abritées du soleil, les parsème d'une foule de petits points blancs, où, à la loupe, il se montre sous la forme d'une petite cupule arrondie, crétacée, fermée par un couvercle de même nature, un peu conique et marqué de cannelures radiées comme un parasol; écrasant cet œuf, il en sort un pulpe rouge si le fotus y est encore; mais, aprés son éclosion, il conserve la même apparence. Le petit en sort effectivement en soulevant le couvercle sans le détacher entièrement, et c'est l'extrémité postérieure du corps qui sort la première. Cie petit est rouge; c'est une larve qui n'a que six pattes et marche ave lenteur. Elle ne tarde pis a se retirer dans quelque enfoncement de la pierre où elle est née; là elle devient immobile, sa peau se détache de la superficie de son corps et forme une enveloppe pellucide à la nymphe, qui, quelques jours plus tard, rompant ces langes, en sort avec huit pattes, et par conséquent à l'ètat parfait.

\section{MEGAMERUS, Dugès.}

Les palpes sont onguiculés, longs, libres. - Le corps est étroit. - Les hanches sont distantes. - Les pieds sont propres à la marche.-Le fémur est très-grand, stırtout dans la quatrième paire de pattes.-Le septieme article est court. - Les larves sont hexapodes, semblables à l'adulte.

Les espèces composant ce genre courent avec vilesse et sautent quelquefois; la force de leurs cuisses, et surtout de la postérieure, explique cette particularité. Quelques-unes sont carnivores; mais il en est dont l'intestin coloré en vert, atlestent qu'elles se nourrissent de végétaux.

\section{Mrgamerus LONGIPES.}

Dugìs, Ant. des Sc. nat., t. J J, p. 34, - Trombidium Longipes, Henßs.; Mem. Aptér., p. 31, pl. 1, fig. 8. - L'abdomen est rougeâtre, pãle inférieurement ct sur les côtés. - Les mandibules sont didacty. les, et les hanches sont en deux gronpes; mais les deux postérieures sont ensemble et distantes des deux antérieures.

\section{MEGAMERUS IVFLATUS.}

Dugìs, Ann. des Sc. nat., t. II, p. 34 . - Le corselet est bien séparé; le ventre est très-convexe, obovale; il est de couleur isabelle, et tantôt ses bords sont transparens, tantôt c'est le milieu qui offre une ligne longitudinale ou en $\mathbf{Y}$ de couleur blanche; quelquefois il est vert : tout cela dépend du degré de la plénitude des organes digestifs et de la nature des matières qu'ils renferment; les palpes, les mandibules et les cuisses sont bien caractérisés; les pattes antérieures sont démesurément longues et grếles; elles sont blanchâtres et assez molles. -Cette espece est très-petite: on la trouve ordinairement en peuplades assez nombrenses, quelquefois isolce; toutes ont 
deux petits points de couleur blanche sur les côtés du corselet.

\section{MEgARERUS OVALIS.}

Dugès, Ann. des Sc. nat., t.1I, p. 35, pl. 8, fig. 43 à 45 .-Cette espèce se rapproche de la précédente par la forme renflee de son corps, et par des yeux blancs qu'on aperçoit sur les angles antérieurs du corselet; ce dernier est marqué que par une ligue enfoncée qui le circonscrit et en fait un triangle à pointe postérieure, et plus ou moins déprimé, selon la plénitude ou la vacuité du ventre; le corps est noir, avec un mélange variable de rouge vif; les pe. tits sont tout rouges, et le noir paroît dépendre de la couleur de l'intestin rempli de matières végétales, de la croûte verte des pierres humides que ces animalcules raclent avec activité ; les pattes et le dos. sont rouges; les pattes antérieures sont les plus longues, mais dépassent peu la longueur du corps; les cuisses sont partout longues aussi, mais non renflées comme lans les autres espèces, et les insertions des hanches sont en deux groupes, mais assez peu éloignées; les grifles sont très-gxandes, et il y a entre elles une papille mobile; les mandibules sont armées d'un petit crochet très-court et mobile, très-courbe; opposé à un mordant conique et droit.

\section{MEGAMERUS GASTANEUS.}

Dugès, Ann. des Sc. nat., t. II, p. 35. - Le corselet est distinct ; le corps est élargí en avant, avec sept à huit soies à la queue; le rorps est brun; les pattes sont rouges; Jes anlérieures sont un peu plus longues que le corps; les yeux sont blancs; clle est fort petite et n'est pas rare; M. Dugès l'a trouvée souvent en société. Cette espèce diffère de la suivante par la rareté des poils qui sont sur le corps.

5. Megamerus GELER. (Pl. 12, fig. 4.)

Dugès, Ann. des Sc, nat., t. Il. pl. 8, fig. 4-5 à 49.-Trombidium Celer, Hens., Mém. Aptérol.-D'un gris-jaunâtre; le corselet plus long que large; sa partie antérieure estallongée, terminée en pointe arrondie, en. suiteil s'élargit un peu, puis il se rétrécit et se termine en diminuant peu à peu de grosseur postérieurement, ou on aperçoit trois longues soies terminales; la lévre est bifide; les mandibules sont à ongle mobile, allongé, pointu et peu courbé.

\section{MEGAMEEUS ROSEUS.}

Dugès, Ann. des Sc. nal., t. II, p. 36, pl. '8, fig. 50. - Cette espèce est grande, assez rare et ordinairement isolée, très-agile et carnivore; l'intestin est brunâtre; le reste du corps d'un rose sale; les yeux latéraux antérieurs sont d'un gris-ardoisé. Pour la forme, ceite espèce ressemble à la précédente, mais les membres sont encore plus robustes et le corps plus hérissé ; plusieurs de ses grands poils sont aplatis; les mandibules sont très-fortes, en pince d'écrevisse, à mordans très-courbes et aigus ; les palpes sont grands, à grand appendice, à griffe longue, fine et peu courbe, ils sont le plus souvent pliés en dessous, comme chez toutes les espéces de ce genre; le dernier article des tarses est court, mais élargi; jes deus griffes sont très-fortes et crochues.

\section{MEGAMERUS FALLAX.}

Dugès, $A n n$. des $S c_{\text {。 }}$ nat., t. 1I, p. 36, pl. 8, fig. 51. - Cette espèce est assez grande, d'un noir velnuté, avec une tache blanche sur le dos; des yeux rougeâtres ou blancs, saillans, placés au-dessus de l'insertion de la deuxième patte ou un peu plus en arrière; des pattes et un bec rouges; un corps élargi eñ avant, épaulé, aplati, sans corselet bien distinct; les mandibules ont le mordant très-courbé et crochu.

\section{RHYNCOLOPHUS, DUGES ;}

Acarus, DeGÉER.

Les palpes sont grands, libres. - La lèvre est couverte de poils. - Les mandibules son uniformes, très-longues.-Le corps est entier. - Les hanches sont très-distantes. - Les pieds sont en forme de palpes, renflés à leur extrémité; les postérieurs sont les plus longs. - Les larves éprouvent plusieurs changemens; les nymphes sont immobiles.

\section{RHYNCOLOPHUS DEGEERIX.}

Dugès, Ann. des $S$ c. nat., t. I, p. 26. - Acarus Phalangiades, Degéer, t. VII, pl. 8, fig. 7 à 11. - Trombidium Phalangivides, Heru., Mém. Apterol., p. 33, pl. 1, fig. 10. - Il est presque globuleux ou ovale, d'un rouge-canelle, plus clair le long du dos et garni de poils noirs et plats, assez longs, légérement courbés; les yeux sont au nombre de quatre, en deux groupes latéraux, de couleur rouge; il y a deux soies roides sur l'avance rétrécie diu coips; les proportions et la forme des pattes difièreat peu; les antérieures n'ont guère 
plus de grosseur que les autres, mais le trochanter est remarquable par sa forme globuleuse à toutes les pattes; ces dernières sont rouges, ainsi que le bec et les palpes; elles sont couvertes de poils noirs et plats immédiatement appliqués à leur surface. - Ciette espèce a été trouvée sous les écorces des arbres, dans les bois des Ardennes.

\section{IHYNCOLOPIUS CINEREUS.}

Dugùs, $n n$. des $S_{c}$. nat, t. I. p. 27, pl. 1 , fig. 7,7 bis. - Long. 1 lig. -Le corps est presque quadrilatère, déprimé, un peu moins large en arrière, avancé en cône obtus, maculé de brun et de gris-blanchâtre, cette dernière teinte dominant surtout en avant et au milieu du dos; la première varie en étendue selon que les cœcum latéraux et lobuleux de l'appareil digestif sont plus ou moins remplis de matiere alimentaire dont la coulcur est brune; les découpures régulières, arrondies, rappellent celles de l'intestin de quelques hirudinées; à l'œil ce corps semble peu velu, mais au microscope on le voit hérissé, aussi bien que les pattes, de poils peu serrés, longs, plats et en forme de spatule recourbée; sur la région latéro-antérieure sont, de chaque côté, deux yeux rouges, ronds, rapprochés, l'antérieur plus petit et plus en dedans que l'autre; les articulations des pattes sont grandes; la dernière, médiocre englongueur, est comprimée, élargie de haut en bas, garuie de deux grifies rétractiles, colorées d'un beau ronge: ceci se remarque surtout aux pattes antérieures, qui sont a peine plus fortes que les autres; ce sont aussi les plus longues après les postérieures, dont l'étendue est démesurée; les huit hanches sont partagées en quatre groupes très-écartés et insérés vers les flancs; deux en arant, deux en arriere; ces hanches sont plates, peu Iarges, écailleuses, rougeâtres, fixes ; entre les groupes postérieurs se voit en dessous une fente longitudinale bilabiée, ouverture gènitale que suit immédiatement un anus étroit et arrondi; le corps des femelles contient des æufs en assez grand nombre ; les palpes grands, libres, à grand crochet, à appendice pyriforme, sont rougeâtres, attachés comme de coutume sur les côtés de la lèvre; celle-ci, attachée au corps entre les groupes des hanches antérieures, est subtriangulaire, allongée en avant en forme de goulot, dont te bout e:t garni de deux petits panaches lanugineux; les mandibu. les sont étroites et longues, tranchantes et aiguës, en forme d'épée your la moitié an. téricure, élargies en arrićre, et concares de manière à constituer, par leur reunion bord à bord, une gouttière propre à con. duire dans le pharynx les liquides sucés, et qui sont probablement des humeurs animales.

Les métamorphoses de ces Acariens sont multiples; du moins il s'en fait encore une après que leurs huit pattes sont déjà développées. On trouve, dans les creux des mêmes pierres, des nymphes immobiles, velues comme l'adulte, et assez grandes, aplaties, lenticulaires, et qui portent à leurs extrémités les restes d'une peau bien recomnoissable à ses poils, aux fourreaux de ses huit pattes, mais ressemblant parfaitement aux adultes. Ceux qui n'ont pas encore subi cette métamorphose, et qu'on peut croire impubères, sont plus arrondis, plus renflés et d'une couleur rougeâtre plus uniforme; on les trouve aux mêmes endroits et avec des dimensions qui varient depuis celle d'une petite tête de camion jusquu'à une longueur de trois quarts de ligne; II. Dugès n'en a vu aucun à six pattes.

Cette espece est commune durant l'été, aux environs de Montpellier; on les trouve en petites sociétés à l'ombre et autour des pierres dans les fossés herbeux, le long des routes et sur la lisière des champs ou des prairies; les pattes sont très-longues, el elles leur servent à parcourir le terrain, à la manière des Faucheurs, avec assez de célérité; elles se meuvent convulsivement, comme celles des Aranistes, quand on écrase l'animal.

\section{RHYYCOLOPIUS PUBESCES}

Dugk̀s, din. des $S_{c}$. nat., t. I, p. 29.Cette espèce est plus rare que la précédente, d'une taille un peu moindre, de couleurs plus vives; le fond est d'un rouge obscur; les pattes sont toutes rouges, à partles deux ou trois premiers articles; les poils sont aigus et pen ou point aplatis; les pattes sont un peu moins longues que dans la précédente; les antérieures sont trois fois plus épaisses que les autres; l'animal s'en sert continuellement pour palper, explorer et même pour repousser l'ennemi; les or'ganes génitaux, les œufs intéricurs ne diffèrent pas de ce qui a été indiquẻ daus l'espèce précédente.

4. RAPYNCOLORIUS TRIACUMATUS.

Kocr. Faun. Allem., tab. 1, fig. 3. Trombidium Trimaculatum, Hermane, Hém, Aptérol, p. 27, 29, pl. 1, fig. 6. 
Le corps est plus íong que large, terminé en pointe antérieurement, large et arrondi sur les côtés latéraux, où on aperçoit deux taches blanchâtres, se rétrécissant ensuite et arrondi postérieurement; là on apercoit une troisième che qui est de même couleur que les deux précédentes; les pieds postérieurs dépassent à peine la longueur du corps.

\section{RHYTCOLOPHUS NEMORUM.}

Косн, Faun. Allem., tab. 1, tig. 4. -Le corps est plus long que large, terminé en pointe arrondie antérieurement, lobé sur les côtés latéraux et postérieurement; la couleur du corps est d'un ronge obscur; les pattes ainsi que les palpes sont jaunes.

\section{TROMBIDIUM, FABR.}

Les palpes sont grands, libres. - Les mandibules sont onguiculées. - Le corps est renflé et présente quatre hańches postérieures, avec la saillie étroite, mobile, portant les yeux, quatre hanches antérieures et le rostre. - Les pieds sont en forme de palpes ou palpeurs, les antérieurs sont plus longs. - Les larves sont hexapodes, parasites, et différentes de l'adulte.

1. Trombidim PHAIANGir. (Pl. 11, fig. 3.) Dugès, Ann. des Sciences naturelles, t. I, p. 32 , pl. 1 , fig. 19 à $21 .-$ D'un beau rouge oranger et égalant à peine une graine de moutarde dans son plus grand développement; le corps est ovalaire, renflé, luisant; vers les angles antérieurs arrondis se trouvent deux yeux petits, brunâtres, ovales, fort écartés l'un de l'autre; il y a fort peu de poils sur le corps, un peu plus sur les membres; ceux-ci consistent en six pattes d'autant plus courtes, et situées plus en avant, par rapport au corps, que l'animal est plus volumineux; il en conserve néanmoins l'usage tant qu'il vit en parasite, et peut changer de peau sur sa victime, même avec quelque agilité ; ces six pattes, terminées par un article assez long, grêle et armé de deux grandes griffes, sont implantées latéralement et en avant par les quatre plus antérieures, à quelque distance en arrière, et d'aulant plus que le ventre est plus ample, pour les deux posiérieures; du reste, rien de semblable à l'avant-train lorsque cette espèce est parrenue à l'âge adulte. M. Dugès, qui a observé la larve de ce Trombidium, dit que lorsqu'elle est détachée spontanément du corps du faucheur, elle meurt si elle tombe dans l'eau, bien qu'elle puisse revivre si on l'en tire au bout de quelques heures; c'est la terre qu'elle cherche, et que je lui ai fournie dans des vases clos; là, cachée plus ou moins profondement dans les interstices des plus petites mottes, elle est devenue immobile et est restée ainsi pendant vingt jours; $\mathrm{j}$ 'ai pu voir à travers la peau se former ou du moins se perfectionner les huit pattes; de cette nymphe ovoïde, lisse, semblable a un petit œuf d'un jaunerouge, est sorti un Trombidium de couleur écarlate; le corps renflé, d'une circonscription subtriangulaire, mais à angles obtus, d'aspect velouté, est effectivement hérissé de poils lamelleux, et qu'un très-fort grossissement montre comme plumeux, c'est-à-dire à barbes latérales. Ce corps se ride, s'enfonce en divers points, selon les mouvemens que se donne l'animal, et cela a lieu en dessous comme en dessus; l'aranttrain, les pieds, le bec sont safranés, demitransparens; deux yeux, d'un rouge foncr, m'ont paru portés, non au bout d'un pédor. cule épais, mais sur une expansion latéra'e en forme d'acicule; les banches courtes, cylindriques, fixes, sont insérées, les antèrieures sous l'avant-train, les postérieures sous les flancs; les articles des pattes ront successivement croissant jusqu'au dernier, qui est même plus long, du moins plı̧ épais que les précédens; de ces pattes, toutes onguiculées, les postérieures sont de beaucoup les plus longues et les plus fortes: elles servent de tentacule; les Trombi dium récemment éclos les ont presque de la longueur du corps, les postérieures vien. nent ensuite; quant aux dimensions, celles de la troisieme paire sont les plus courtes; entre les hanches antérieuress'insère le bec, formé d'une lévre mobile, triangulaire, portant deux palpes ravisseurs épais, ren. flés, à crochet grand et fort, à appendice piriforme et grand; dans la lèvre sont cnfermées deux mandibules épaisses et armées d'un crochet mobile. - Cette espèce se trouve sur le Phalangium Cornutum, espèce que l'on trouve assez communément aux environs de Paris.

\section{TROMBIDIUN ELONGATUM.}

Dugìs, Ann。 des $S_{c}$. nat., t. 1, p. 35.Iong. $\frac{3}{4}$ lig. - Le corps est d'un ronge cramoisi, velouté et étroit, en forme de languette, arrondi en arrière et en avant, échancré vers le milieu, là où s'insèrent les quatre pattes postérieurcs; les antérieures 
sont les plus longues, renflées au bout et onguiculées; les postérieures, quoique plus longues que les intermédiaires, sont loin d'atteindre le niveau de l'extrémité du corps; les poils du corps et des pattes sont touffus, longs et plats, en forme de spatule courbee en arrière ; leurs bords semblent frangés à un très-fort grossissement; l'avanttrain, comme les pieds et le bec, est d'une couleur pâle, il est glabre, grêle, et porte, sur deux èlévations, des yeux assez rappprochés, ronds, saillans, d'un brun-rouge; les palpes sont très-velus; leur appendice est long et grêle; la lèvre et les mandibules sont comme dans l'espèce précédente. - Celle espèce a été trouvée par M. Dugès dans le midi de la France, au mois de juillet, sous les pierres.

\section{TROMBIDIUM GLABRUM.}

Dugès, Ann. des Sc. nat., t. I, p. 35.Gette espèce est un peu moins allongée que la précédente, elle est rouge aussi, mais non veloutée; du reste, excessivement petite, à peine visible à l'œil nu; les palpes sont ravisseurs; les mandibules sont onguiculées; la lèvre est triangulaire; les hanches sont distantes; les pattes ne sont pas sensiblement renflées à leur extrémité.- - Trouvée sous les pierres, dans les lieux humides.

\section{TROMBIDIUM HOLOSORICEUM.}

Fabr., Herimann, Mém. Aptér., pl. 1, 2, el pl. 2, 1. - Latr., Rég. anim. de Cuv., 2 édit., t. IV, p. 284 . - D'un rouge couleur de sang; l'abdomen est presque carré, rétréci postérieurement, et présentant une échancrure; en dessus il est chargé de papilles velues à leur base, et globuleuses à leur extrémité. - Se trouve très-communẻment au printemps dans les jardins.

\section{TROMBIDIUN PUNICEUM.}

Косн, Faun. Allem., tab. 1, fig. 1. Plus long que large, soyeux; les côtés latéro-antérieurs sont larges, découpés; Ies papilles sont très-courtes; les pieds sont courts; le tarse des pattes antérieures est grand, ovale; la coulcur générale de cette espèce est rouge.

\section{TRONBIDIUM SYLVATICUR.}

Kocr, Faun. Allem., tab. 1, fig. 2. Large, d'une couleur pourpre, avec une tache orangée, triangulaire à la partie antérieure; les papilles sont courtes ainsi que les pieds, surtout les antéricurs, épais.

\section{TROMBDIUY CORDATUM.}

Kocu, Faun. Allem. táb, 6. fig. 7 -
Cette espèce est cordiforme, d'un rouge pourpre, avec l'article terminal des pieds antérieurs épais et ovale.

\section{TROMBIDIUM TRIGONUM.}

Hermanu, Mém. Aptérol, p. 26, fig. 9. - Косн, Faun. Allem., tab. 6, fig. 8. - Le corps est cordiforme, terminé en pointe postérieurement, il est rouge, soyeux, avec deux sillons transverses, flexueux, dont deux au sommet se joignant par devant; les pieds sont grêles, courts.

\section{TROMBIDIUM FASCIATUM.}

Косн, Faun. Allem., tab. 6, fig. 9. Cordiforme, allongé, d'une couleur minium, avec deux bandes médianes et cinq taches postérieures blanches.

\section{ERYTHRAUS, LATR.; Trombidium, HeRr.}

Les palpes sont grands, libres, bionguiculés. - Les mandibules sont onguiculées. - Le corps est entier. - Les hanches sont contiguës. - Les pieds sont propres à la course, unguiculés, longs, avec le demier article grêle et trẻs-allongé ; les postérieurs sont plus longs.

4. erythireus RURicola. (Pl. 11, fig. 2.)

Dugès, Ann. des $S$ c. nat., t. I, p. 36, pl. 1, fig. 22 à 25. - KocH, Faun Allem., tab. 1, fig. 5. - Cette espèce est colorée d'un rouge de carmin, souvent trèsvif, quelquefois noirâtre vers le milieu du corps, mais laissant presque toujours le long du dos une bande plus claire, demitransparente, et offrant en avant un grand espace égalenent pellucide, aussi bien que quelques points vers les flancs; les palpes et les pattes sont incolores, mais chaque article, excepté ceux qui avoisinent le corps, est marqué d'une tache d'un carmin trèsvif; le corps est entier, c'est-à-dire sans avant-train, il est déprimé, à peu près ovale, mais échancré superficiellement sur les côtés, et un peu plus large en arrière qu'en avant; quelques poils rares sont disséminés à Ja surface ; deux yeux noirs, peu distincts, fort écartés et sessiles, occupent les angles antérieurs obtus de ce corps; les hanches sont insérées surtout vers la partie antérieure, et paroissent peu écartées les unes des autres; la cuisse est à peine supérieure en dimension à l'article suivant, ê de beaucoup inféricure aux deux derniers; le septième surtout est remarquable par sar 
longueur, qui fait presque le tiers de la patte; il est effilé, atténué, et couvert de poils couchés, dont trois dépassent les deux forles griffes divergentes qui le terminent; les poils courbés, insérés presque à angle droit, garnissent les autres articles; les pattes antérieures sont les plus grosses, les postérieures sont les plus longues; elles ont presque le double de la longueur du corps, loutes ont, au reste, des dimensions considerables; le bec se compose d'une lèvre triangulaire contenant deux mandibules onguiculées comme celles des Trombidium, mais à corps bien plus allongé, à crochet bier plus courbe; les palpes sont renflés; le crochet du quatrième article est très-allongé, grêle, émoussé; vers le milieu de sa longueur, il porte un petit ongle mobilc dans le sens de la concavité; le cinquième article ou l'appendice est elliptique, grand, velu, et dépasse la pointe du quaIrième.

Celte espèce se trouve communément sous les pierres, le long des chemins et des endroits un peu secs, aux environs de Montpellier; M. Dugès en a vu quelquefois unc douzaine réunis sous une sorte de dais de soie blanche, sans savoir s'il était leur ouvrage ou celui d'une araignée, et s'ils travailloient à la multiplication de l'espèce: le plus souvent ils sont isolés, et donnent la chasse aux Acarides plus petits qu'eux ; ils les saisissent et les emportent rapidement avec leurs palpes ravisseurs pour les ciévorer; il m'a même paru qu'ils n'épargnoient pas les individus foibles de leur propre espece; les plus foris d'entre cux sont loin toutefois d'être bien grands, on ne les découvriroit même pas à la vue simple sans leur course tourbillonnante et comparable à celle d'un grain de poussière cmporté par le vent. Cette course est toujours suivie d'un temps d'arrêt, durant lequel on peut observer l'animalcule à la loupe ou le saisir pour l'examiner ailleurs. La manière d'y réussir, pour des êtres si menus, si frèles et qui s'échappent arec tant de vélocité, vaut bien la peine d'être exposée pour l'avantage de ceux qui voudront se livrei à des observations de ce geure. Un flacon contenant une petite quantité d'cau est le meilleur inoyen de lransport; on peut y souller l'Acaride dans un moment de repos, pourvu que le goulot suit suffisumment large; on peut cucore, arec un pen d'adresse, l'engluer au bout d'une paille, d'une feuille de graminée monillée ce salive; mais veut-on l'observer libre, vivant, alerte, il faut le précipiler par le souffle dans un flacon bien sec et fermé en. suite avec exactitude; on l'en fait sortir pour le recevoir sur une lame de verre ou un carton bien blanc, bien uni, sur lesquels on l'emprisonne dès qu'il s'arrête, en Je couvrant d'un petit verre de montre ou d'une plaque de cristal excavé.

\section{ERYTHRAUS FLAVUS.}

Dugès, Ann. des $S$ c. nat., t. 1, p. 38 , pl. 1, fig. 28. - De la couleur indiquée par son nom, à pieds plus pâles, hérissé sur le dos de poils rares, mais longs et forts; tient le milieu, pour la forme, entre celui qui va suivre et celui qui vient d'être décrit, c'est-à-dire qu'ił est plus raccourci que l'espéce précédente; mais il a les pattes proportionnellement plus fortes encore et plus longues; les poils en sont abondans, couchés; le sixième article est plus grand que le septième, qui est effilé et a trois grandes griffes; deux yeux ronds, d'un rouge-brun, sont latéro-antérieurs; le bec est saillan'; les palpes grands; l'appendice long barbu; les crocheis du quatrieme artic; n’arrivent qu'à la moitié de sa longueul : les crochets, le grand et le petit, articuli:s l'un et l'autre sur le quatrieme article; mandibules sont étroites, longues; lel crochet médiocrement courbé; la lèvre lors enferme dans l'état de repos. - Cette e. pèce a été rencontrée dans le midi de la France; M. Dugès en a trouvé plusieurs fois dans le Nord qui ont paru lui appartenir.

\section{ERYTHIDUS IGVIPES.}

Dugès, Ann. des Sciences naturelles t. I, p. 39 ; pl. 1, fig. 26, 27. - Plis trapu ct à membres plus courts que l'espèce précédente; elle court avec une grande vitesse, et on la trouve commune. ment dans les lieux exposés au soleil, à terre, sous les pierres, dans les herbes, M. Dugès l'a trouvée aussi sur des rosier 3 chargés de puccrons : dans le corps d'u individu de cette espèce, il a compté juss qu'à une vingtaine d'œufs ovales; le corps. est subtétragone, dépriné, un peu pliss large en arrière, marbré de gris et de jaune-rougeâtre; les pieds, le bec et les palpes sout orangés; les quatre yeux, en deux groupes latéro-antérieurs, sont petits et d'un rouge vif; les hanches sont rapprocliées, aplaties, fixes, formant une sorle de plastron; les pattes postérieures sont les plus longues; le dernier arlicle de toutes est le plus grand, clile, garni de poils cou- 
chés el terminé par deux grands ongles divergens, que dépassent trois soies roides; les poils des autres articles et ceux du corps sont rares et redressés; lo bec est formé, $1^{\text {c }}$ en dessous, d'une lévre triangulaire, des côtés de laquelle peuvent s'échapper les mandibules lorsqu'elles se sont un peu avancées; $2^{\circ}$ en clessus, d'un opercule couleur jaunâtre, à trois pointes obtuses: il est souvent caché par le corps renflé de l'animal; $3^{\circ}$ latéralement, de deur palpes portés sur la lèvre et ressemblant à ceux des espèces décrites ci-dessus; mais le quatrième article est plus court, plus épais, ce qui fait paraître les deux crochets comme sessiles, et partant du même point que l'appendice, qui est plus épais que chez l'Erythrceus Flavus, mais à peu près aussi grand; les mandibules ressemblent à celles de l'Erythrceus Ruricola, et ont une grandeur proportionnée à celle de cet Acarien. Les individus de cette espèce ne s'épargnent guère entre eux, à ce qu'il paroît; car deux enfermés dans la même boîte, le plus foible a été trouvé quelques heures plus tard flétri et probablement sucé. M. Dugès a constaté que les taches noires sont dues à la plénitude des organes digestifs; ils paroissent essentiellement constitués par deux cœecum latéraux, lobuleux, à peu près comme ceux des Rhyncolophus, réunis par une branche transversale, à laquelle aboutit d'un côté l'œsophage, de l'autre, un intestin impair, probablement le rectum, qui se porte en arrière, et va sans doute jusqu'a la partie anale en ligne droite. - Cette espece a été trouvée dans le Languedoc.

\section{ERYTHR AEUS CORNIGERUS.}

Dugés, Ann. des Sc. nat., t. I, p. 40. Trombidium Cornigerum, Hermann, Mém. Aptérol., p. 40, pl. 2. fig. 9.-D'un rouge presque cerise, avec une double écharpe noire qui manque quelquefois; cette espèce court avec assez de vélocité, et habite surtout les prairies; le corps, presque trapézoïde, un peu déprimé, ne semble d'abord porter que deux occlles fort rapprochés; il est presque parsemé de grands poils blancs et redressés sur le dos; les hanches sont rapprochées; les pattes couvertes de poils couchés; la dernière paire est la plus Jongue; l'avant-dernier article est un peu plus grand que le septième; celui-ci, mince dans un sens, est un peu élargi dans l'autre, c'est-à-dire verticalement; mais ce qui le rend remarquable, c'est que, outre deux grandes griffes divergentes, il est encore garni de deux ilocons ou appendices comme laineux, qui se monirent sur les côtés de ces grifics, et d'une expansion membraneuse, incolore, en languette élargie, sans être infundibaliforme, qui se trouve entre elles; le bec oflre deux petites cornes, qui par la compression semblent sortir de la base du bec; elles paroissent analogues aux pointes mousses de l'opercule bifide dans l'Erythrous Igripes, mais se montrent ici plus étroiltes et comme cylindriques; le quatrième article des palpes est assez gros, court, plus épais en avant qu'en arrière; il porte dáns le premier sens un appendice ou cinquième article grand et fort, allongè, un peu conique, articulé avec lui par une base assez large, en ligne droite et non latéralement, comme l'appendice des palpes ravisseurs est ordinairement placé; mais le quatrième article est armé de trois crochets transparens, presque égaux, parallèles, mobiles tous trois, et de longueur égale seulement à celle de leur support commun, qui ne fait que le quart de l'article qui le suit; les mandibules sont semblables à celles des Erythrées en général; le corps en est piriforme; le crochet grêle et peu courbe; la lèvre forme un triangle fort allongé, elle est bien plas longue que chez l'Erythraus Ignipes. Les Eryihrées Cornigères ne paroissent pas devenir parasites dans leur jeune âge; M. Dugès en a trouvé de couleur orangé, avec six ou huit pieds, et de taille variée depuis la plus petite jusqu'à la plus grande, conservant d'ailleurs, à part le nombre des pieds, tous les carac. tères de l'adulte, les palpes, les mandibules, les hanches, les appendices du tarse, etc. Parmi ceux dont les pieds étoient déjà au nombre de huit, les deux postérieurs étoient quelquefois très-grêles et très-courts, comme s'ils n'eussent pas encore acquis tout leur développement, la troisième paire étant même aussi proportionnellement moindre qu'à un âge plus avancé; un de ces jeunes à huit pattes, conservé quelques jours dans un tube, y a filé un réseau lâche de soie très-fine à laquelle il s'est suspendu; les pattes se sont roidies et dirigées en avant. L'animalcule devenu immobile s'est constitué nymphe. - Cette espèce a été trouvée dans le département des Ardennes et dans celui de I'Ain. 


\section{QUATRIIME FAMILLE.}

\section{A C A R I D E S,}

1.aTheille.

Caractères. Les palpes sont grêles, surnuméraires à la lèvre.-La lèvre est échancrẻe. - Les mandibules sont en forme de pince. - Les yeux sont nuls. - Les hanches sont distantes. - Les pieds sont caronculés.

Les Arachnides qui composent cette famille sont très-petites, microscopiques, parasites et pullulant beaucoup. Quelquesunes vivent sur des insectes, nolamment sur les Coléoptères orduriers ou fonisseurs; d'autres rongent les provisions de bouche, comme la farine, le vicux fromage, les viandes desséchées : les collections d'insectes placées dans les lieux froids et humides sont exposées à leurs ravages. On attribue à quelques espèces la maladie de la gale, tant celle de l'homme que de divers animaux domestiques. Quelques Acarides propres à quelques mammifères peuvent aussi se multiplier sur l'homme et l'incommoder violemment. D'autres espèces sont errantes et se trouvent sur les plantes, les écorces des arbres, dans la terre, sous les pierres, etc. Plusieurs naissent avec six pattes; les deux autres se développent peu de temps après; leurs tarses se terminent souvent de di. verses manières.

Les genres que cette famille renferme sont au nombre de sept, et sont ainsi designés : Dermanyssus, Gamasus, Uropoda, Pteroptus, Argas, Hypopus, Sarcoptes, Oribates, Acarus.

\section{DERMANYSSUS, DugÈS ; Acarus, Degéer, Hera.; \\ Gamasus, Laxr.; \\ Smaridia, DuMértL.}

Le cinquìme article des palpes est très₹etit. - La lévre est pointue. - Les mandibules sont en forme de pince dans les mâles, avec l'ongle très-allongé; ils sont uniformes dans les femelles. - Le corns est 'mou. - Les pieds antérieurs sont les plus longs. - Les hanches sont contiguës.

Les larves sont hexapodes, à peine differentes de l'adulte.
1. Denmayyssus avium. (Pl. 12 , fig. 5.) Dugès, Ann. des $S c$. nat., t. II, p. 2, pl. 7, fig. 1 à 4.-Acarus Gallinœ, DEGÉER, Mém. pour servir a l'Hist. nat. des Ins., t. VII, pl. 6, fig. 13. - Acarus Hirundinis, Hermany, Mém. Aptérol., p. 83, pl. 1, fig. 13. - Le Pou de pivoine et le Pou d'une sorte d'émérillon, Lxonnet, Mém. Mus., t. XVIII, pl. 5, fig. 11, 12 . - Gamasus Gallince, Gamasus Hirundinis, Latr., Règ.anim. de Cuv., t.IV,p. 285.-Le Smaride des petits oiseaux, Du MÉRIL, Dict. des $S$ c. nat.-Dans les deux sexes, le corps est ovalaire, déprimé, un peu plus large en arrière, quelquefois légérement échancré à sa partie postérieure, et ẽvidé latéralement; entre la couleur brune que leur donnent deux groset longs cœecum latéraux, dont on peut observer à la loupe les mouvemens péristaltiques, on remarque encore, vers le milieu du corps, une tache blanche, ordinairement en $\mathrm{V}$, formée parles dernières portions des sacs digestifs remplis d'excrémens; et en effet, des excrémens laiteux, mêlés d'un peu de noir, couvrent, sous forme de petits points, les parois de leurs habitations, et M. Dugès les a vus sortir de la partie anale; cette petste ouverture est en dessous et en arrière ; l'orifice génital est sans doute situé beaucoup plus en avant; dans les pattes se montrent des prolongemens tubuleux du canal intestinal, mais qui soe? bien rarement, et jamais en-entier, remplis d'un sang avalé ; ce sont des cœcum qui ne reçoivent peut-être que la partie nutritive des alimens; la transparence de la peau et la rareté des poils permettent d'observer ces particularités. et de reconnoitre aussi de nombreuses trachées, rameuses, et prenant leur origine de plusieurs troncs, nés d'un stigmate ouvert derrière l'insertion des dernières pattes; de ces pattes, les deux antérieures sont toujours les plus longues et les plus grosses, et servent de tentacules; toutes ont leur septième article muni d'une caroncule membraneuse, bilobée, et de deux crochets; le sixième article est plus long que les autres; le troisième ou la cuisse cst plus gros 
qu'aucun et assez long; la banche est renflée et probablement mobile; la bouche constitue une sorte de tête mobile, attachée sous le bord antérieur du corps; elle est

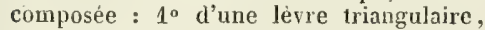
pointue en avant, et portant les deux palpes; $2^{\circ}$ de ces palpes, dont le sixième article est le plus fort, le cinquième, le plus petit, est accompagné d'une courte et grosse soie, nobile, située en dehors; $3^{\circ}$ de deux mandibules qui diffèrent d'un sexe a l'autre : chez le mâle, on peut voir dans le corps, et faire sortir de la bouche, deux bras charnus, composés principalement de deux articles, dont le dernier se termine, en dedans, par une pointe fixe, et supporte en dehors un troisième article mobile, étroit, corné et rougeâtre; c'est un très-grand ongle aigu, tranchant, falciforme et ondulé, destiné èvidemment à percer et non à saisir : chez la femelle, ces deux bras, forts réduits, peu séparables, pen ou point exsertiles, portent une lame élargie à la base, subitement rétrécie en forme d'épée; ces deux lames droites et accolées rappellent celles des Rhyncolophes: il faut une forte pression pour les désunir; une pression modérée en fait saillir simultanément la piointe hors de la bouche.

Cette espece se trouve en toute saison dans les cannes creuses qui servent de perchoirs aux petitsoiseaux chanteurs (Linotte, Chardonneret, Verdier) que nous conservous en cage. Dans les cavités profondes, le Dermanysse des oiseaux vit en peuplades nombreuses; mais il s'en échappe furtivement la nuit, très-probablement du moins, pour aller sur les oiseaux endormis sucer le sang dont se montrent remplis les organes digestifs chez tous les individus jeunes et adultes. C'est le rouge qui donne à ces animalcules leur couleur foncée, purpurine ou brune. Dans les mêmes retraites se trouvent une multitude de dépouilles ou peaux blanches, assez fines pour décomposer la lumière, et attestant des mues assez multipliées : dans cet amas se voient aussi des œufs incolores, ellipsoïdes, égalant á peu près en longueur la cinquième partie de l'animal adulte, qui n'a guère qu'un tiers de ligne au plus; ces œufs paroissent grossir en mûrissant, et prennent graduellement, comme ceux des araignées, la forme d'un petit qui va nâtre. Le nouveau-né a six pieds seulement; son ventre est beaucoup plus allongé, plus renflé que celui des individus qui, avec la même tailie, ont déjà leurs quatre paires de membres ambulatoires; ces derniers, plus sveltes, plus agiles, et dont le ventre est dépassé de beaucoup par les pieds postérieurs, sont encore pellucides, incolores comme les premiers; mais ils ne tardent pas à aller charger leurs estornacs de la nourriture qui le colore en rouge vif d'abord, puis terne, puis brunâtre, à mesure ģu'il s'al lère et se digère davantage. M. Duges a fait éclore les œuís; il a vu apparoitre ensuite la paire de pieds en déficit, et il a acquis la certitude que c'étoit la plus postéricure; c'est deux jours après l'éclosion que ces pieds se sont montrés brusquement après s'être complétés sous la peau, à travers laquelle le mème auteur les a vus (par aplatissement et écrasement graduel) situés sous l'abdomen et repliés, le tarse en avant, derrière la troisième paire. C'est un changement de peau qui les met en liberié ; ils ont alors la même longueur proportionnellement aux autres, que chez l'adulte. Dans ces mêmes demeures, M. Dugès a trouvé des couples d'adultes réunis comme Degéer l'a vu pour les Ixodes, c'est-ä-dire ventre à ventre, le mâle en dessous, et emporté par la femelle qu'il embrasse, et dont il dépasse l'abdomen de la moitié du sien. Ce mâle est beaucoup plus petit, un peu plus velu que sa com. pagne.

M. Koch dans sa Faune Allemande, tab. 4, fig. 14, regarde comme une espèce distincte l'individu qui a été désigné par Degéer sous le nom de Acarus Galline.

\section{DERMANYSSUS MURINUS.}

Dugès, Ant. des Sc. nat., t. II, p. 5, pl. 7 , fig. 5. - Le bec est presque aussi long que les palpes, et représente aussi une sorte de tête mobile, à base large, ovalaire ou subpentagonale, insérée entre les premières hanches et portant les palpes; puis rétrécie en forme de gaîne fendue en dessus, et servant à conduire deux lamellles aiguës, fines et tranchantes; cette espèce a le corps plus régulièrement ovale que dans l'espèce précédente, il est de mềme un peu aplati et hérissé de quelques poils roides et de longueur médiocre; elle offre les mêmes particularités de coloration, la même forme de pattes, et des proportions analogues. - Cette espèce a été trouvée sur le Vespertilio Murinus.

\section{DEREANYSSUS CONVOLVULI.}

Dugès, Ant, des Sc. nat, , t. $\mathrm{II}, \mathrm{p} .7$. 
- La taille, la forme générale, celle des pattes et des palpes sont semblables à l'espèce précédente; mais leur couleur est d'un gris-verdâtre, et en eflet. l'intestin et même ses prolongemens dans les pattes jusqu'au sixieme article, sont remplis d'une matière verte; elle est pourvue d'un bec large et court contenant denx fortes lames. - Celte espece se trouve sur les feuilles du liseron.

\section{DERMATYSSUS ORIBATTS}

Drgès, Ann. des Sc. nat., t. II, p. 7.Il est aussi grand et aussi agile que les précédens, plat, marbré de gris et de blanchàtre, échancré latéralement, élargi en arriè'e; les cœcum et leurs prolongemens dans les pattes étoient pleins d'une matiẻre de couleur grise; les pattes antérieures sont proportionnellement fort longues; les palpes sont velus; la lèvre a la moilié de leur longueur; la compression fait saillir chez les plus grands individus deux lames longues, étroites el qui se courbent fortement en sortant du bec.-Elle a été trouvée Jogée en assez grand nombre dans les nids de l'Oribates Ciastaneus.

\section{DERMANYSSUS MUSCULI.}

Kocir, Faun. Allem., tab. 4, fig. \&3.D'une couleur blanche, ayant trois taclies postérieuressur le thorax (la partie médiane cordiforme, les côtés latéraux obliques), et l'abdomen couleur de pourpre, avec une cannelure courbe et blanche par devant.

\section{GAMASUS, LATR. \\ Acarus, Degéer, Hermann.}

Iie cinquième article des pattes est trèspetit. - La lèvre est bifide. - Les mandibules sont en forme de pince, à doigts denticulés. - Le corps est scutiforme. - Les pieds antérieurs sont les plus longs.

1. Gamasus coleoptratorum. (Pl. 12, fig. 1.)

Dugès, Ann. des $\boldsymbol{S} c$. nat. , t. II, p. 8, pl. 8, fig. 26, 27.-Acarus Coleoptratorum, Livv. - Acarus Fucarum, Degéer, Mém. pour servir à l'Hist, nat. des Ins., I. VII. - Cette espèce se distingue facilement, en ce que le dos est couvert des deux plaques blondes, séparées par un sillon transversal, et dont la postérieure, triangulaire, est de moitié plus petite que l'antérieure; la peau blanchâtre, molle, qui sépare ces plaques, ou les entoure, se montre plus ou moins largement, selon la plénitude de l'abdomen; en dessous il n'y a qu'une plaque allongée, à peu près triangulaire, entre les insertions des six premières pattes; les poils du corps et des pattes sont courts et peu nombreux, ils sont quelquefois aplatis et recourbés, comme cliez certains Trombidions, Rhyncolophes, etc.; les hanches antéricures sont insérées à une perite distance de celles de la deuxieme paire ; les pattes qu'elles supportent sont tentaculaires, longues et grêles, mais terminées néanmoins par un tarse parasitique; les palpes sont médiocres, armés de la soie mobile déjà mentionnée pour les Dermanysses; ils servent principalement à nettoyer les mandibules; la levre est large, elle embrasse les bras mandibulaires quand ils sortent, et se termine par une pointe médiane, et deux crochets latéraux; les bras mandibulaires ont une pince courte, simple, un peu dentelée, à mordant mobile placé en dessus; ils sont formés essentiellement de deux articles en partie charnus et qui peuvent rentrer l'un dans l'autre, comme des tubes de lunetles; la pince est fort comprimée et assez aiguê pour percer comme une lancette quand ces deux mordans sont serrés; la bouche est recouverte en dessus d'une sorte de labre triangulaire, comparable à l'avancemert qui se voit chez les Erythrées. - Cette espèce cherche à fuir, quand on sáisit les Coléoptères qu'elle suce; elle court alors avec rapidité. En hiver on la trouve sous les pierres.

\section{GAMISUS MARGIVATUS.}

Dugès, Ann. des $S c$. nat., t. II, p. 9. - Acarus Marginatus, Нвка., Mém. Aptér., t. V 1, p. 6.-Les pattes antérieures prẻsentent un article caronculé, mais grêle et rudimentaire. Cette espèce est couverte d'un toit ou bouclier enté sur le dos et de couleur brun-marron; la peau, molle et blanche, lui forme une bordure de largeur variable; sous le corns il y a trois plaques cornées, assez grandes, surtout la postérieure; celle-ci est presque elliptique transversalement, la moyenne est semi-lunaire, l'antérieure est irrégulièrement hexagonale, à bords échancrés; la lèvre est étroite, allongẻe, bifide, non embrassante; les bras mandibulaires sont armés d'une pince noirâtre, longue, à mordans étroits et courbés, dentelés; à la base d'un mordant mobile est inséré un peît appendice. - Cette espèce se trouve sur les bousiers; elle a été aussi rencontrée sur une mouche. 



\section{GAHAUS TESTUDHNARUS.}

Dugès, Alll. des Sc. nat., t. 11, p. 10. - Acarus Testudinarius, Некn., Mém. aptér., p. 80 , pl. 9 , fig. 1.- Macrocheles Testudinarius, LAtr. Rég. anim. de Cuv., t. IV, p. 282. - Diffère peu de l'espèce prècédente, maìs la lèvre est plus large, et ses crochets latéraux sont brisés en trois articles.

\section{GaMASUS Crassipes.}

Dugès, Ann. des Sc.nat., t. II, p. 10 . -Acaris Crassipes, Herm., Mém. aplér.., p. 80, pl.3, fig. 6, et pl.9, fig.2, R.-M. Dugès n'a pu examiner que morte et flétrie cette espèce; il a seulement conservé les figures de l'extrémité d'une des mandibules et du petit appendice bilobé qu'elle portait ; une des pièces est lamelleuse, l'autre est cylindroïde et armée de deux petites soies.

\section{GaMASUS TETRAGONORES.}

Dugès, Ann. des Sc.nat., t. II, p. 10 , pl. 8, fig. 28 à 32 . - Le corps de celte espèce est brunâtre, écailleux; la deuxième patte est ausi trés-renflee; la cuisse surtont est très-grosse et porte un fort éperon crochu; le sixième article atténué porte aussi une grosse ẻpine recourbée; les caroncules membraneuses des tarses sont bilobées; les hanches des deux pattes antérieures sont mobiles; la deuxième est fort large ; le labre est large, très-visible, presque carré; les palpes ont un premier article long et courbé, le cinquième fort petit et accompagné d'un stylet ou grosse et courte soic; le quatrième article est grand, et porte un appendice comme bifurqué ou plutôt composé de deux portions, une très-courte en griffe, l'autre obluse et courbe ; cet organe, qui n'existe pas dans les deux sexes, rappelle bien la disposition des organes sexuels des araignées mâles; d'un autre côté, il a de l'analogie avec les appendices des Galéodes. Ces derniers n'existent pas ici ; les bras mandibulaires sont terminés par une pince courte, très-comprimée, à mordans peu courbés et dont l'un n'a qu'une dent saillante, l'autre (le mobile) étant au contraire bien garni de dentelures inclinées en arrière.

\section{Gayasus giganteus.}

Dugès, Ann. des $S_{c}$. nat., t. II, p. 11. - Cette espéce est brume, écailleuse en dessus; elle a en dessous plusieurs plaques; mais le pourtour du corps est revêtu d'une peau molle, un pen velue, à poils cylindriques. Chez l'animal desséché toutes les parties de la bouche étoient repliées en

$$
\text { A.v. }
$$

dessous ; un labre mobile, écailless, recouvroit la base; la lèvre sembloit formée de deux portions latẻrales, écailleuses; les palpes filiformes et écailleux sont simples; les patles étoient composées de six articles écailleux et bruns, terminés par un septième blanchâtre, cutané, flétri, en formc cle massue, mais sans griffes apparentes; le sixième article é ait le plus long de tous, le deuxième le plus gros, excepté la deuxième paire, qui avait en totalité une grosseur considérable; la première paire étoit très-longue. - Cette espèce a été trouvée au Brésil, sur le Copris Mimas.

\section{GAMASUS LAGENAIRE.}

DUgès, Ann. des $S c$.nat., t. II, p. 11. - Elle est allongée, fort rétrécie vers l'insertion des pattes antérieures, de couleur blonde, mais fort transparente et permettant souvent de vo:r ses cœcums en forme d'X complexe, contenant une matière rouge, probablement due à d'autres $A c a$ rides dévorés par celle-ci; les poils sont nombreux, spatulés; le bec est saillant; le labre est Jarge et trapézoïde; la lèvre est pointue, avec deux crochets latéraux simples, mais mobiles; les palpes à premie. article long et courbe, à dernier très-petit et accompagné d'un stylet velu lui-même ; la pince des mandibules est noirâtre et fort longue, à mordans étroits, courbés, dente lés; un pore à la base du mordant mobile ; les pattes sons comparables à celles du Gamasus Coleoptratorum; les antérieures grêles, hérissées de longues soies, comme chez le Gamasus Testudinarius, et à tarse rudimentaire; ses hanches sont longues et mobiles.-Trouvee sous les pierres.

\section{GAMASUS BREVIS.}

Dugès, Ann. des Sc. nat. , t. II, p. 11. -Très-petit, d'un rouge-cannelle, terne et opaque; il ressemble au précédent par les pattes, les poils, la lèvre, Jes palpes; il est de même rétréci en avant, mais beaucoup plus large et plus court; la carapace est brune sur le dos, et divisée en deux plaques comme chez le Gamasus Coleoptratorum; les mandibules sont à pinces assez courtes, denticulées et crochues; les deuxièmes pattes sont plus grosses que les autres. - Se trouve sous les pierres.

\section{GAMASUS FOTUNDATUS.}

Dugès, Ann. des Sc. nat., t, II, p. 11 . - Il est petit, raccourci, rougeâtre et velu comme le précédent; mais son cos écailleux n'a pas de sillon transversal; il 
est régulièrement atlénué, mais non renversé en avant; d'ailleurs, il a des pattes assez courtes, coniques, grosses, surtout la deuxième paire; les antérieures sont longues, mais non grêles, et terminées par un pinceau de poils roides et deux griffes saus caroncules; les tarses des autres sont à caroncules bilobées et à double griffe ; les palpes ont le stylet voisin du cinquième article; leur deuxième article est le plus long; les mandibules sont médiocres, leurs mordans étroits et courbés.

\section{GAMASUS MONACIUS.}

Kocн, Faun. Allem., tab. 2, fig. 8. Ovale, pointu antérieurement, testacé, avec l'abdomen plus obscur; une croix oblique antérieurement et une grande tache noire postérieurement; second article des pieds égal et épais, denté et unilobé.

\section{1. gaMrasUS CELER.}

Косн, Faun. Allem., tab. 2, fig. 7.D'une couleur testacée, avec une double ligne médiane et une bande oblique humérale fauve sur le thorax et sur l'abdomen; la ligne ovale pointue postérieurement et d'une couleur testacée.

\section{UROPODA, LATE. ; Acarus, Degéer.}

Palpes courts et infères. - Corps en forme de bouclier. - Pieds antérieurs un peu plus longs. - Pédoncule ovale, caduque.

q. uropoda vegetans. (Pl. 11, fig. 4.)

Dugès, Ann. des $S_{c}$. nat., t. I, p. 13, pl. 8, fig. 33à 37.-A carus Vegetans, DEG., Mém., t. VII, pl. 7, fig. 15-19.-M. Dugès a trouvé cette espèce fixée par son pédicule sur plusieurs Colẹ́optères fouisseurs; il l'a tronvée aussi libre sous les pierres; ce pédicule est un filament corné, roide, élastique quand il est sec, flexible dans l'eau, sans s'y dissoudre; on n'y voit ni cavité, ni fibres, ni rien de vraiment organisé; fixé fortement sur les segmens du Coléoptère par un empâtement, elle en offre un autre au bout opposé, et celui-ci recouvre exactement une ouverture transversalement oblongue, située audessous du bord postérieur du corps et qui paraît être l'anus; ce ne seroit donc pas là une matière soyeuse filée par des orga. nes spéciaux, comme le pensent quclques zaturalistes, mais des excrémens yisqueux et desséchés dont l'animal peut aisément se débarrasser par une nouvelle excrétion; c'est effectivement de son côté qu'il se détache du pédicule qui reste adhérent au Coléoptère: Un large bouclier demi-transparent, lisse, convexe, de couleur brune, de forme un peu ovale courre le dos et sert au besoin de protection à tous ses mem. bres, qui se retirent sous cet abri au moindre danger : on voit alors que les pattes sont resserrées et fléchies en formant chacune un anneau presque complet, le tarse en avant; les pattes assez courtes, grosses, conoïdes, ont toutes un sixième article bien plus long que les autres, et un septième caronculè et à deux griffes; les antéricures sent les plus longues; elles sont tentaculaires; le sixième article est hérissé d'un pinceau toufu de soies, dont une plus forte se prolonge beaucoup au-delà des autres, et parmi lesquelles se cache le septième article très-grêle, assez long et à grilfes plus ou moins visibles; la cuisse de cette patte est grosse et longue; le trochanter plus gros encore, de même qu'aux autres pieds; les hanches sont rondes, enfoncées, contiguës d'avant en arrière, écartées de la ligne médiane; leur insertion occupe en étendue les deux tiers ou les trois quarts de la longueur du corps; la bouche est serrée entre les deux hanches antérieu. res; en dessus on n'aperçoit rien de cette bouche, seulement quand l'animal marche on voit saillir le bout des poils pliés ou demi-brisés qui forment une houppe sur le dernier article des palpes; ces deux palpes peuvent même être vus en partie, quand on les redresse par la compression; il faut écraser l'animal pour le voir complètement, aussi bien que les mandibules; les palpes sont filiformes, assez courts; les mandibules intérieures, en forme de bras comparables à ceux des Gamases, mais dont le deuxième article est long, atténué et terminé par une pince très-pctite, trèscomprimée, dont le doigt mobile est courbe et aigu.

\section{UROPODA OPACA.}

Kocr, Faun. Allem., tab. 4, fig. 23. Opaque, ocracé, avec le dessus irrégulièrement sillonné longitudinalement de chaque côté.

\section{UROPODA NITIDA.}

Kocn, Faun. Allem., tab. 4, fig. 24. Ovale, d'une couleur testacée pâle, avec le front armé de deux soies, et les pieds conrts. 


\section{PTEROPTUS, L. DuFour.}

Corns déprimé, coriace, annelẻ, privé de têle, d'antennes et d'yeux. - Palpes au nombre de deux, distincts, filiformes, quadriarticulés, mutiques. - Pieds au nombre de huit, articulés, seulement propres à la course, robustes, semblables, insérés sur les côtés inférieurs du corps. Deux ongles très-petits.

\section{1. pteroptus vespertikionis.}

Duf., Ann. des Sc. nat., t. XXVI, p. 98 , pl. 9 , fig. 6,7 . - Long. 1 lig. Le corps est essentiellement constitué en dessus par une sorte de test ou de carapace d'une seule pièce, à peu près plane, de texture uniformément coriacée, glabre, de forme ovale, rhomboïdale, arrondie en avant, prolongée en arrière, dans les plus adultes, en une sorte de queue courte et -obtuse, hérissée de soies longues. Dans les individus qui n'ont pas acquis tout leur developpement, cette queue est presque nulle et n'est pas sensiblement velue. Une forte lentille du microscope dénote un pointillé presque imperceptible sur cette carapace, mais son pourtour semble toutà-fait lisse, plus mince et demi-pellucide; quelques taches très-noires, fort variables pour leur nombre, leur configuration et leur confluence, forment, sur un fond d'un roux pâle, des espèces d'hiéroglyphes; on ne distingue ni tête ni yeux; au-dessous du bord antérieur de la carapace on remarque, en élaguant les pattes, deux palpes bien apparens insérés au bout d'un support commun, assez gros et court, que l'on peut considérer comme un sucoir. Celui-ci ne peut être constaté qu'en étudiant l'insecte par sa région inférieure; les pálpes sont filiformes et se composent chacun de quatre articles, dont le premier, fort court, est invisible en dessus; les autres articles sont oblongs, et le dernier, un peu plus allongé que les précédens, est trèssimple, c'est-à-dire sans aucun vestige de pièce didactyle ni de crochets. On y aperçoit, avec le secours du microscope, quelques poils noirs; les pattes sont au nombre de huit, toutes semblables entre elles, robustes, ct de longueur médiocre; il y en a quatre dirigées en avant et quatre en arrière; elles sont roussâtres et hérissées de quelques soies assez longues et roides. Quand on étudie l'insecte renversé sur le dos, on voit que les articulations des pattes sont disposées, au pourtour de la face in- férieure de la carapace, de manière à ètre également rapprochées les unes des autres. Ces pattes sont composées de six articles, dont le premier est inapercevable en dessus, et dont le dernier, un peu plus long et moins gros que ceux qui le précèdent, se termine par une pièce distincte, renflée, comme turbinée, peut-être en partie vésiculeuse, au bout de laquelle il y a deux ongles presque droits, si excessivement petits, qu'ils se dérobent à la loupe. Cette pièce s'insère à l'extrémité oblique du tarse au moyen d'un fort petit article qui lui permet des mouvemens très-variés. Cette espèce a été trouvée sur le vespertilio muriuus, Cuv.

\section{PTERoptus acuminatus.}

Kocr, Faun. Allem., tab. 4, fig. 21. Court, testacé, avec la partie anale conique, une strie courbée en avant, et une fente noire transversalement.

\section{PTEROptUS abdonivalis.}

Kocr, Faun. Allem., tab. 4, fig. 22, Allongé, contracté avant la partie anale, testacé, avec des stries transverses antérieurement et en forme de croix postérieurement.

\section{ARGAS, LATR.;}

\section{Acarus, Fabr.; Rhynchoprión, HeRM.}

La bouche est inférieure. - Les palpes n'engaînent pas le suçoir, ont une forme conique et sont composés de quatre articles.

\section{1. argas refuexus.}

Latr., Gener. Crust. et Ins., t. VI, p. 3 ; ibid., Hist. nat. des Crust. et des Ins., t. VIII, p. 53. - Acarus Marginatus, FaBr., Ent. Syst., t. IV. p.427.-Co. QUEBERT, Illust.Icon., Ins., dec. 3, tab. 27, fig. 11. - Herm., Mém. aptér., p. 69, pl. 4, fig. 10, 11. - D'un jaunâtre pâle, avec des lignes couleur de sang foncé, ou obscures et anastomosées. - Cette espèce se trouve sur les pigeons, dont elle suce le sang.

2. argas pipistrell. (Pl. 13, fig. 2.) Aud., Ann. des Sc. nat., t. XXV, p. 401, pl. 14, fig. 1.-Caris Vespertilionis? Latr., Gener. des Crust. et des Ins., t. VI, p. 181. - Caris de la Chauve-Souris, jbid., Hist. nat. des Crust. et des Ins., t. VIII, p. 55. - Long. 1 millim. - La tête, qui est fort petite, se termine par un suçoir assez al. longé, ne paraissant pas denticulé; au 
moins, s'il existe des denticules aux lamel. les qui le composent; doivent elles ètre trés-fines; les palpes m'ont semblé, dit M. Audouin, auquel nous empruntons cette descrupton, formés par quatre articles, dont trois à peu pres égaux, et le quatrieme plus petit et plus rrêle; a chaque arliculation se voyoient quelques poils; les pattes, au nombre de six, étoient pelites el fixées sur des hanches ou plaques sternales qui, en s'écartant, laissaient entre elles un espace triangulaiı. J'ai compté à ces pattes cn tout neuf articles : celui qui s'articule avec la hanche est peu distinct et petit; le troisieme, le quatrième et le cinquième sont de moyenic longueur; le sixieme, qui peut-être constitue le premier article du tarse, est assez aliongé, il fait corps avec le suivant ou le septieme, qui luimème ne se distingue pas du huitième, si ce n'est par une légère sondure et par deux poils principaus qui accompagnent toutes ces articulations. Ce huitieme article est effilé d'une manière remarquable à un bout, auquel s'insère la neuvième ou dernière pièce dont l'extrémité élargie est garnie de deux petits crocliets; le corps est sensiblcment ovoide et tronqué antérieurement. MI. Audouin a remarqué en avant et sur le dos deux stries ou légers enfoncemens longitudinaux qui occupoient la place du thorax. Supérieurement aussi, le milieu du corps ctoit d'un rouge tirant sur 3e brun, et il en partoit, en divergeant, des lignes de même couleur interceplées par des stries pointillées; les bords du corps, la tête, les pattes et leurs plaques sternales itoient d'un blanc transparent; la couleur rouge du dessous avoit une petite interruption figurant une petite lunule à son centre. - Celte espèce a été trouvée par M. Audouin sur une chaure-souris, vespertilio pipistrellc, non pas adhérente à ses ailes, mais a son corps. Ellle étoit cachée par les poils et avoit le bec enfoncé dans la peau de son ventre et de son dos.

\section{ARGAS PERSICUS.}

Érsci., Mém. de la Société Impériale des Naturalistes de Moscou, t. V1, p. 282, tab. $23, n^{\circ} 9$. - Aup., Description de l'Egyple, Arachn., pl. 9, fig. 8. D'un rouge sanguin clair, parsemé sur le dos de points élevés blanes; les pieds sont pâles. Cetle espèce, suivant M. Fischer, a à peu près la forme d'une punaise; mais son corps est plus ovale, plus allongé, plus rétréci en arant et plus gros; tout le dos est garni de petits grains blanchâtres, comme chagriné; le bold est très-peu ourlé en avant, avec une légére échancrure des deux côtés; le suçoir est en dessous du corps, a l'endroit à peu près où se trouve en haut la légère échancrure du bord, dans un petit enfoncement; les palpes qui l'accompagnent sont gros à la pointe, et arnincis à la base; le corps est aussi granulé à l'entour, et oflre, par deux plis latéraux, une élévation au milien; dans le pli se trouvent insérés les pieds à six articulations, presque cylindriques; ils soni d'un jaune pâle; l'articulation onguéale est très-mince, courbée et munie de deux doigts trés-fins, blancs et crochus. - Se trouvent en Perse.

Les autres espèces qui appartiennent à ce genre sont:

Argas Savignyi, Aud., Explie. des pl. de l'Ouv.d'Eg., Arach., pl. 9, fig. 5.

Argas Fischerii, ibid., pl. 9, fig. 6.

Argas Hermanni, ibid., pl. 9, fig. 7.

\section{HYPOPUS, DUGÈ ; Acarus, DegéEr.}

Il y a un suçoir étroit, pourvu de deux soies roides faisant sailie au-devant du bord antérieur, et paroissant composé d'une lèvre soudée aux palpes. - Les mandibules sont cachces. - Les pieds sont très-courts, épais. - Le corps est entier, déprimé, un peu roide.

IYPOPUS SPINITARSUS.

Dugùs, Ann. des Sciences naturelles, t. II, p. 20. - Acarus Spinitarsus. Heru., Mém. aptérol., p. 85, pl.6, fig. 5. - Le corps est ellipsoïde, aplati , lisse, et de coaleur brun pâle, avec une demitransparence et une consistance d'écaille ; les pieds antérieurs sout les plus longs, les autres dépassant à peine, ou même pas du tout, la circonféreuce du corps. On compte a tous sept articles distincts, successivement décroissans jusqu'au sixième, qui est le plus mince, mais aussi le plus long de tous; le septième est à caroncules et à griffes, les autres sont hérissés de poils roides, mais peu nombreux; les hanches, fort lar. ges, presque contiguës sur la ligne mé. diane; forment de chaque côté deux groupes bien distincts, mais peu éloignès l'un de l'autre; derrière chacune des hanches postéricures, on voit un point pellucide; deux soies mobiles, saillant au-devant du bord antérieur, sont tout ce qu'on peut voir de la bouche à l'état libre : par l'ècra- 
sement M. Dugés a vu qu'elles partoient de l'extrémilé d'une pièce mobile, en forme de parallélogramme, à milicu membraneux et à bords épais; le même auteur n'a pu trouver d'autres palpes, ni apercevoir les mandibules qui sont cachées à l'intérieur du corps. - Cette espèce a été trou. vée sur un Hister.

\section{SARGOPTES, LATR.; Acarus, Degéer.}

Le corpps est arrondi, comme comprimé de chaque côté, testudiniforme, strié, blanc, hérissé de papilles rigides sur le dos. - Les pieds sont au nombre de huit, dont quatre antérieurs disposés autour de la lête et comme palmés, et quatre postérieurs distans; les quatre antérieurs munis au moins d'ambulacrum.

1. SAncoptes homisis. (Pl.14, fig. 1.)

Rasp., Bull. génér. de Thérapeut., t. VII. liv. supp. p. 176, pl. 1 , fig. 1 a 7 . - Acarus Scabiei, Renuccr, Theso inaug., 1835,pl.2,fig. 2,3.-Suivant M. Raspail, cet insecte est blanc à la vue simple; avec de bons yeux on distingue sur une portion de sa circonférence quelques points brunsrougeâtres; il a environ un demi-millimétre de diamètre. A la simple loupe, on peut déja compter ses pattes et distinguer son museau; mais c'est surtout à la faveur de divers mouvemens que fait l'insecte vivant qu'on arrive à découvrir bien des choses; el cet insecte vit long-temps, quelquefois jusqu'à cinq et six jours. Lorsque l'insecte marche et qu'on l'observe de champ, au microscope, il paroît aplati, et dans les endroits transparensil offre des stries courbes et parallèles, qui lui donnent l'aspect d'une écaille de poisson vue au même grossissement. Ses pattes antérieures et sa tête sont susceptibles de se cacher sous le corps en se courbant en dessous, et l'on diroit alorsque ces cinq organes sont rentrés dans la carapace, comme le font les membres analogues de la tortue; ce qui favorise ce mouvement, c'est la conformation de la surface dorsale de l'insecte, qui déborde tout le corps, s'avance comme un toit sur les pattes antéricures et la tête. La portion postérieure clu corps de cet animal, placé dans la même position, offre huit poils inégaux graducllement et plus courts vers l'anus; quatre de ces poils appartiennent aux quatre pattes, et les quatre autres sont insérés, deux de chaque côlé de l'anus, sur quatre petits tubercules qu'on ne distingue bien qu'sa les faisant saillir au dehors par la pression de la pointe d'une aiguille. Sur le disque de cette surface dorsale on distingue un système de points brillans dont M. Raspail a imite la disposition et presque le nombre en les comparant sur un individu qui avoit séjourné dans l'acide acétique concentré. Si l'on se contentoit de l'observation sous ce jour, on seroit porté à regarder l'insecte comme étant aplati, et ces points comme étant de simples petits cercles; mais on se détrompe facilement en observant l'animal de profil. On s'assure alors que la grande tache du centre présente une grosse brosse, que la surface antérieure et la surface postérieure sont bombées également, et que chacun de ces petits cercles du dos est surmonté d'un toit transparent inflexible. Les quatre rangées de points qui descendent vers la partie anale et vers la tête offrent les poils les plus longs. Les contours du corps offrent des lobes de différentes formes, selon les mouvemens del'animal et les positions qu'il affecte. M. Raspail a représenté celles qui se présentent le plas généralement. Dans l'acide acétique concentré, ces contours finissent par se réduire. Quant aux stries, dont M. Raspail a parlé plus haut, elles couvrent la superficie du corps. On auroit tort de croire que ce sont de simples plis de la peau : e'est un vaste réseau cellulaire, dont les cellules sont linéaires et en crenx; et les interstices que M.Raspail appelle vasculaires sont en relief. Ce réseau oppose une grande résistance anx instrumens tranchans, et on le trouve sur beaucoup d'autres animaux inférieurs, tels que l'Ascaris Vermicularis, ou principalement sur l'épiderme d'une foule de plantes. La résistance dont je parle est si forte, dit M. Raspail, qu'il seroit difficile a l'observateur, avec la meilleure volonté, de tuer l'insecte avec la poinle d'une aiguille, lotsqu'il procède à son extraction : car il m'est très-difficile, à la loupe ct à l'aide de mes instrumens de dissection, de parvenir à l'écraser et à le diviser; il glisse et bondit sur l'instrument, et les poils roides quit hérissent son dos ne servent pas peu à compliquer la difficulté de son anatomie. On sent alors que non-seulement son corps jouit d'une certaine dureté, mais que ses pattes et son museau, auxquels la réfraction de la lumière prête une délicatesse apparente en les rendant diaphanes, sont écailleux et cornés, et ne ploient pas sous l'instrument. T'el est l'aspect général et detaillé de l'insecte, observé lorsqu'il mara 
che et qu'il présente le dos à l'œil de l'ob. servateur; mais lorsqu'on le renverse sur le dus pour l'observer sur la surface inférieure du corps, son organisation se complique et demande une étude plus minutieuse. On voit très-bien alors que les quatre pattes antérieures et la tête sont implantées dans tout autanl de fourreaux, dans lesquels cependant il leur est possible de rentrer. Ces fourreaux forment une espece de plastron d'un effet singulier.

La tête est insérée dans un angle dont le sommet se prolonge sur le thorax en une ligne d'un rouge doré; celte tête est d'une assez grande simplicité, purpurine et courbée en dessous par un suçoir, qui n’a paru formé à M. Raspail d'aucun système visible de pièces mandibulaires. Dans l'a. cide acétique, on observe sur ses deux côtés deux vésicules transparentes qu'on prendroit volontiers pour les deux yeux; on observe sur la nuque deux paires de gros points surmontẻs chacun d'un poil; ces poils, lorsqu'ils dépassent la tête courbée, ont l'air d'être inégaux, parce que deux sont insérés sur la paire postérieure et deux sur la paire antérieure. Les bords de fourreau des deux pattes les plus voisines de la tête se prolongent en deux lignes rougeâtres, et se rapprochent jusqu'à la hauteur de la ligne qui part du cou de l'animal ; les bords du fourreau des deux autres se réunissent en lignes rouges à la convexité des lignes dont nous venons de parler, sorte de travail qui imite une espèce d'éventail. Les pattes se composent de quatre articulations et d'une pièce basilaire oblique, qui ofĩre comme un triangle dont l'hypothénuse est tournée du côté de la partie postérieure du corps; chacune de ces articulations est hérissée de poils dont on n'aperçoit que ceux qui se placent sur le côté ; la dernière articulation est hérissée de piquanstrès-durs, et armée en dessous d'un poil roide qui est terminé par un évasement flexible et susceptible de faire le vide, comme les pelotes visqueuses de certains animaux supérieurs, tels que les Rainettes; ces pelotes lui servent, en s'appliquant contre les surfaces, à se fixer sur tous les plans. Les articulations sont peu distinctes, et il faut de longues observations pour les compter. Les cinq membresantérieurs sont recouverts à moitié par la saillie dorsale du corps. Sur le ventre on apecoit deux paires l'autres organes, que Degéer a rendus par quatre poils enflés vers leur base et attachés au rentre. Ces quatre prétondus poils sont les quatres jambes postérieures qui, quoique plus courtes de beaucoup que les antérieures, possèdent la même organisation principale, seulement elles sont privées de l'appareil propreà la marche, et que M. Raspail désigne sous nom d'ambulacrum : à part cette légere circonstance, on y retrouve tout ce qu'on a observé sur les pattes antérieures; ici les ambulacrum sont remplacés par des poils très-longs; en tout, cel. les de ces pattes postérieures qui se trouvent les plus voisines de la tête, sont plus développées que les deux postérieures. Quand on observe à la loupe, ce système de pattes rappelle très-bien la figure de Degéer, et la ligne rouge qui borde le fourreau semble être un poil qui s'enfle en une vésicule rouge à la région de la patte, et s'effile en poil blanc au sommet de la vésicule. L'anus est tantôt saillant et tantôt caché; mais pour le rendre très-sensible à la vue, on n'a qu'à laisser dessécher l'insecte; alors le derme reste avec sa forme, à cause de sa dureté, l'abdomen se retire, et la direction de l'anus se dessine à traver's la transparence du derme. La couleur extérieure de cet animal est d'un blanc de neige, à part les pattes et le museau ; mais si on l'observe par réfraction, il paroît jaune, ainsi que tous les tissus blancs des animaux; ce qui provient de la décomposition des rayons lumineux qui traversent la substance organique, décomposition en vertu de laquelle les rayons les moins réfrangibles, tels que le jaune, arrivent seuls à l'objectif. Quoique les poils des membres antérieurs de cet insecte soient dirigés en avant, on conçoit qu'ayant la falcuté de replier ses pattes et son museau en dessous, ces poils ne forment aucun obstacle à sa marche lorsqu'il fouille la peau; mais ce qui lui rend ce travail facile, c'est la présence des papilles si dures qui hérissent son dos, et qui, dirigées en arrière, servent à opérer une résistance en arrière, et à rendre le recul impossible ; surtout c'est la dureté écailleuse de l'enveloppe externe Gui lui forme comme une espèce de carapace de tortue. La surface ventrale est siriée comme la surface dorsale. - Cette espèce se trouve sur les hommes attaqués de la gale.

L'insecte que nous venons de décrire est le véritable Acarus de la gale, comme nous l'a très-bien démontré M. Raspail, dans un travail ayant pour titre : $\boldsymbol{M l} \dot{c}$ moire comparatif sur l'Histoire naturelle de l'Insecle de la gale, Bulletin général 
de Thérapeut., t. VII, liv. supp. Dans ce iravail, M. Raspail démontre clairement que l'Acarus, décrit par M. Galès et regardé depuis comme celui de la gale, par les auteurs modernes, n'est pas ce dernier, mais bien celui du fromage, qui appartient à un genre différent. Voyez, au reste, pour plus de détails, le travail de M. Raspail, cidessus cité, et la Thèse inaugurale de M. Renucci, ayant pour titre: Découverte de l'Insecte qui produit la contagion de la gale, du prurigo et du phlyzacia; présentée et soutenue à l'Ecole de Médecine, le 6 avril 1835 .

\section{SARCOPTES EQUI.}

Raspail, Bull. génér. de Thérapeut., t. VII, liv. supp., p. 180, pl. 2, fig. 3.-Acarus Equi, Renuc., Thès. inaug., 1835, pl.1, fig. 1. - Cette espece, dit i月. Raspail auquel nous avons déja emprunté la description précédente, a les plus grands rapports d'organisation avec celle de la gale de l'homme, et les diliérences qu'elle présente sont de la nature de celles qui constituent, en Hisvire naturelle, une espèce et non un genre. Elles nous autorisent à penser que l'espèce de ces parasites varie avec l'espece d'aninal galeux, et qu'en conséquence le mouton galeux doit offrir une espèce différente à celle $d u$ bouc, etc. Les trois différences du Sarcoptes Equi se trouvent dans les dimensions et l'insertion des quatre pattes postérieures, dans la présence des ambulacrum sur les huit pattes, et enfin dans les deux articulations de ces ambulacrum, tandis que ceux du Sarcoptes Hominis ont la tige simple et flexible. Sous le rapport des dimensions du corps, de sa couleur blanc de neige et de la couleur purpurine des pattes et du museau, le Sarcopte du cheval ne diffère pas de celui de l'homme. La femelle a un sezième de ligne en longueur et un dix-septieme en largeur. Le mâle est plus petit, et je crois d'une conformation extérieure un peu différentc. Le corps de l'animal forme moins l'écaille de tortue que celui de la gale de l'homme, et les stries du dos sont moins apparentes; les articulations des pattes sont plus faciles à compter que sur ce dernier; l'extrémité des tarses est teruninéc par deux longs poils; les deux paires de pattes postérieures sont très-longues, inégales comme dans le Sarcopte de l'homme, insérées non sur le ventre, mais sur les côtés du corps. L'anus est placé entre quatre poils, qui s'insẻrent deux par deux sur un tubercule placé de cliaque côté de cet organe. Pour le plastron, le Sarcopte du cheval differe encore essentiellement de celui de la gale de l'homme. Dans le cours des observations que j'ai eu occasion de faire sur ces insectes, il m'est souvent arrivé de les surprendre accouplés, et ils se tenoient alors anus contre anus, les pattes posterieures cachées sous le ventre, et peut-être leur servant à s'entretenir mutuellement dans l'acte de la copulation.- Se trouve sur les chevaux galeux.

M. Koch, dans sa Faune Allemande, fait connoître deux autres espèces qu'it désigne ainsi :

\section{3. sarcoptes panduhinus.}

Kocir, Faun. Allem., tab. 5, fig. 12. Blanche, avec la tête épaisse; l'abdomen court; l'anus contracte, fendu; les pieds pâles, épais, courts.

\section{SARCOPTES MUSCULINUS.}

Kocri, Faun. Allem., tab. 5, fig. 13. Blanche, oblongue, avec les côtés latéraux bilobés; les quatre pieds antérieurs grêles, les quatre postérieurs renflés.

\section{ORIBATES, LATr.}

Les palpes sont fusiformes, cachés sous le rostre. - Les mandibules sont en forme de pince. - Le corps est couvert d'une peau ferme, coriace ou écailleuse. - Les yeux sont à peine visibles, - Les hanches sont à peine distantes. - Les pieds sont propres à la course.

1. onibates clavipes. ( $\mathrm{Pl}$. 12, fig. 2.)

Dugès, Ann. des Sc. nat., t. II, p. 29, pl. 8, fig. 40 à 42. - Notaspis Clavipes, Hermane, Mém. aptérol., p. 88, pl. 4, fig. 7. - Le corps est sphérique, noir luisant; sur le dos on aperçoit une sẻrie de soies circulaires; le corps est distinct et la lèvre est bifide; le dernier article du palpe est plus court que l'avant-dernier; les pieds sont plus longs que le corps, à articles en massue, garnis de soies; l'abdomen est sinué des deux côtés á la partie antérieure; l'apophyse latérale du corselet présente deux cornes. - Se trouve sous les mousses.

\section{ORIBATES DASYPUS.}

Dugès, Ann. des Sc. nat., t. II, p. 30 . - Il est gros comme un grain de moutarde, d'un brun-châtain très-lisse, arrondi, mais un peu comprimé et plus large en arrière qu'en avant; quand on l'examine à la loupe, on voit que cette earam 
pace globuleuse n'est interrompue qu'en bas et en avant, dans un quart au plus de sa surface; dans le creux qui existe en cet endroit, l'animal retire les pattes et les couwre en grande partie sous son corselet mobile, oblong, et qui forme alors une sorte de couvercle à la boîte représentée par la carapace ; les pattes courtes, relativement au colume du corps, sont conoïdes et terminées par un seul crochet fort grand et trèscourbé; le sixième article est assez long, les autres sont courts, le troisieme gros et allongé, tous d'une venue et non claviformes comme chez le plus grand nombre des Oribates; les derniers sont garnis de longues soies qui font de chaque patte une sorte de pinceau; aussi le nom de $D_{a}$ sypus convient-il à cette nouvelle espèce, tant à cause de celte circonstance que de la manière dont elle s'abrite sous son test; Jos palpes ressemblent beaucoup à ceux de l'espèce suivante; leur deuxième article est plus court et plus mince, tous sont hérissés de quelques soies; les mandibules ont également deux grosses pinces à morlans robustes et dentelés. - Celte espèce a été trouvée dans les Ardennes.

\section{ORIBATES CASTANEUS.}

DugÈs, Ann. des Sc. nat., t. II , p. 3, pl. 7, 6g. 24, 25. - Notaspis Castaneus, IекM., Mém. aptér., p. 89 , pl. 7, fig. 4 . - L'appareil buccal est séparé du plastron ventral et des hanches antérieures par un sillon transversal; il est tout-à-fait infère; il se compose des mêmes parties uue chezles autres Acariens, savoir : $1^{\circ}$ une lève large, triangulaire, obtuse, un peu festonnée à son angle antérieur, qui avoisine le bout du museau ou pointe antérieure du corselet; $2^{\circ}$ deux palpes attachés sur les côtés de sa base, fusiformes et à cinq articles, dont le premier très-petit, le deuxième gros, renflé, faisant en longueur presque la moitiẻ de tout le palpe; les autres s'atténuent progressivement; mais le dernier est un peu ovalaire et plus allongé que les précédens; ils sont tous velus en dehors seule. ment; $3^{\circ}$ deux mandibules en pince d'écrevisse à mors dentelés, crochues, cachées par la lèvre. Nous avons parlé du plastron ventral; toute la région inférieure est écailleuse; elle porte en arrière une ouverture très-visible, c'est l'anus; une autre ouverture, sans doute génitale, se voit derrière et presque entre les hanches postérieures; un sillon transverse sèpare les deux paires de hanches postérieu- res des deux paires antéricures; ces hanches sont rapprochées de la ligne médiane, assez grosses; il en est de même du deuxième article des pattes ou trochanter, qu'on ne voit pas en regardant l'animal en dessus; la cuisse est très-renflèe; la jambc l'est un peu moins; le cinquieme, le sixieme et le septième article bien moins encore, les deux derniers sont fort longs; chaque membre est terminé par trois grands ongles ou crochets; la carapace, brune et souvent noirâtre, n'est pas dètachée du dos comme les élytres soudées de certains coléoptères, des Gibbium par exemple ; c'est la peau du dos durcie séparée seulement du plastron abdominal par un espace de peau molle, blanchâtre, cachée dans l'état ordinaire, mais élargie en forme de bande, quaud l'abdomen est distendu par des æufs; celte carapace, très-bombée en arrière, est séparée, par un sillon transversal très - profond, d'un corselet conoïde et imparfaitement sousdivisé lui-même en deux parties; de la postérieure partent deux grosses soies ou cornes plates, aiguës, dirigées en avant, ei à la base de chacune desquelles M. Dugès a vu une tache obscure qui pourroit être une paire d'yeux cachée sous une peau cornee et translucide; sous la partie antérieure est située la bouche.

M. Dugès a trouvè, à la surface dequelques grosses pierres, dans des creux capables de contenir un pois, les nids de l'Oribates Castaneus; ils étoient plus ou moins exactement fermés par une croûte mince de matière papyracée et d'un gris sale. Là étoient rassemblés une quarantaine d'in. dividus adultes, dont les plus grands n'avoient toutefois qu'une demi-ligne de longucur; il s'y trouroit aussi beaucoup de peaux blanchâtres, et des petits dont la plupart, n'ayant qu'un quart de dimension de de l'adulie, en avoient pourtant toutes les formes; ils étoient seulement un peu plus apllatis; leurs yeux, bien visibles à cause de la demi-transparence du corps, qui a permis à M. Dugès d'observer d'autres détails d'organisation, étoient d'un gris bleuâtre; d'autres, plus petits encore, et un peu plus aplatis, n'avoient que six pattes, et ces pattes étoient moins élégamment renflées que celles de l'adulte, onguiculées du reste de la même manière ; ces deux paires antérieures s'attachoient également sous le corselet, qui portoit deux gros yeux bien détachés par leur couleur d'ardoise sur un fond châtain-clair. 
4. oribates calgaratus.

Косн, Faun. Allem., tab. 2, fig. 13. Globulcux, noir, brillant, avec le thorax trẻs-épineux; les pieds sont jaunâtres, aiguillonnés.

\section{ORIHATES OVALIS.}

Isосн, Faun. Allem., tab. 3, fig. 5. Orale, convexe, noir, brillant, avec les hanches noirâtres, pointues en avant; les pieds sont testacés.

\section{ORIBATES oRBICULABIS.}

Kосн, Faun. Allem., tab. 3, fig. 6. Noir, arec l'abdomen circulaire, et une petite tache rouge antérieurement; les hanches sont petites; les pieds sont ferrugineux.

\section{ACARUS, Link, Degéer, Herif.}

Labre et palpes cachés par les mandibules.-Corps entre le second et le troisieme pied, entouré par un sillon, mou. légérement renflé. - IIanches à peine distantes. - Troisième pied plus petit que le quatrième.-Caroncules membraneuses, pointues. - Larves très-semblables à l'adulte.

\section{1. acarus domesticus.}

DugéER, Mém. pour servir a l'Hist, nat. des Ins., t. V I1, pl. 5, fig. 1 a 8. - Dugùs, Ann.des Sc.nat., t. 1I, p. 23, pl. 7, fig. 13 . - Le corps mou, pellucide, renflé, luisant et d'un blanc nacré, garni de poils rares et longs, offre un corselet bien marqué et formant à peu près son quart antéJieur; les pattes et le bec paroissent écailleux, brunâtres; l'insertion des lianches se fait en deux groupes séparés, mais non très-distans; elles sont fort grosses, fixes et rapprochẻes de la ligne médiane; le sixieme article est long et mince; le septième est caronculè, membraneux; le troisième article, ou la cuisse, est plus long et plus gros que ceux qui l'avoisinent; les pattes antérieures sont remarquables par leur grosseur chez le mâle, qui est plus petit et plus agile que la femelle; la troisiene paire est la plus grêle de toules et la plus courte; le bec est en forme de tête conoïde, on y trouve deux grosses mandibules con. fusément aperçues par quelques auteurs, et que M. Dugès a pu séfarer et examiner à
Joisir; elles se composent d'un article mou, rétractile et intérieur; d'un deuxième article renflé, non rétractile, semblable au mordant fixe de la main d'une pince d'ècrevisse, et enfin d'un mordant mobile pareil at pouce de ce crustacé ; ces mordans sont courts et dentelés. Ces grosses pinces peuvent s'avancer isolément ou simultanément, s'écarter ou se rapprocher comme elles le sont dans l'état de repos, formant alors comme un toit au-dessus de la lèrre; celle-ci quadrilatère, allongée, échancrée au bout, amincie en avant et au milieu, épaisse sur les bords, qui semblent cornés et artieulés, a paru à $\mathbf{M}$. Dugès résulter de la soudure d'une lèvre proprement dite et de palpes filiformes à quatre ou cinq articles; c'est par l'extrémité du corps et bout à bout que cette espèce s'accouple; les œufs, les petits à six pattes se trouvent abondamment avec les adultes dans la pous. sière du vieux fromage, et, comme tous les Acariens à métamorphose, c'est la quairième paire qui paroît se développer plus tardivement que les autres.

\section{ACARUS DIVIDIATES.}

HeRu., Mém. aptéral., pl. 85, pl. 6 , fig. 5. - Dugès, Ann. des Sc. nat., t. II , p. 24. - Les palpes sondés offrent (quelques poils en dehors; le bec est fléchi en dessous; la quatrieme paire de patter est aussi grêle que la troisième paire, lo dernier article de tous présente une confor. mation bien remarquable; la caroncule étai sessile, arrondie, pellucide, et il en sortait une seule griffe ou crochet mobile, et très recourbé, bien plus fort que ne le sont or dinairement les deux ongles des Acarierg parasites.

\section{ACARUS FoRvarius.}

Kосн, Faun. Allem., tab. 5, fig. 4.Oblong, blanc, avec une raic humérale de chaque côté, el qualre autres beaucoup plus courtes situces à la partic anale; de plus on apercoit en dessus deux taches noires, dorsales, placées l'une après l'autre.

\section{ACARUS PLUMiger.}

Kocu, Faun. Allem., tab. 5, fig. 15. Blanc, avec l'abdomen entièrement colsvert de soies longues, plumeuses. 


\title{
CINQIIISNE FAMILLR.
}

\section{T I O U E S ,}

\author{
LATTEEILLE.
}

Caractères. Celte famille a pour type principal le genre Ixodes, formé d'espè cesque les Latins désignoient sous le nom de ficinus, et que nos piqueurs appellent Louvettes, $\mathrm{Ti}$ ques, etc.; les unes, dont le corps est enlièrement mou, muni de deux yeux distincts, dont les palpes sont toujours libres, ont les lames du sucoir, qui est toujours avaucé, membraneuses et sans dentelures. - Ces Arachnides sont toujours vagabondes, et se composent de quatre genres; les autres Tiques semblent être aveugles, ou n'ont point d'yeux bien apparens. - Tantôt les palpes sont extérieurs et engainent le suçoir, ou s'appliquent sur ces cốtés, tantôt ils sont libres, mais intérieurs, et ne paraissent pas, l'animal étant vu en dessus. - Les lames du suçoir sont écailleuses et dentées. - Le corps, toujours ovoïde ou presque orbiculaire, est très-plat, lorsque l'animal ne s'est point repu, et représente en devant, dans la plupart, une petite plaque écaillense, arrondie postérieurement, portant à son bord antérieur le siphon. Ces Tiques se tiennent, soit sur les végétaux, particulièrement dans les bois, les landes, avec les six dernières paltes étendues, soit dans l'intérieur des maisons. Les premières s'accrochent, lorsqu'elles en trouvent le moyen, à divers animaux, tels que les bœufs, les chevaux, les chiens, les tortues et mème à des oiseaux, engagent profondément leur suçoir dans leur chair, $s^{\prime} y$ gorgent tellement de leur sang, que leur corps devient très-voluminenx et prend la forme d'une petite vessie; on ne peut les en détacher qu'en soulevant la portion adherente de la chair; elles s'y multiplient d'une manière prodigieuse, de sorte que ces animaux peuvent périr d'épuisement. - Les tarses des uns se terminent par une petite pelote portée sur un court pédicule, et dans les autres par deux crochets.

Genres : Bdella, Smaridia, Scirus, Irodes.

BDELLA, LATR.;

Scirus, Herm.; Acarus, Linn.

Le corps des espèces qui composent cc genre est mou, renflé, à corselet conoìde, et portant une soie transversale, mais mince ct très-courte. - Il y a deux yeux de chaque côté.-Le bec, saillant et triangulaire, est composé comme celui du genre suivant, mais la lèvre égale en longueur les mandibules à l'état de repos. Cette Ièvre, comprimée entre deux verres, se bifurque d'a. bord légérement, puis un bout s'épanouit en une double caroncule garnie de barbes. -Les palpes sont toujours de cinq articles: le premier fort court et globuleux. en partie masqué par l'épaisseur de la lèvre quand on ne la dégare pas par la compression; le deuxieme fort long, les troisième et quatrième très-courts; le dernier long, cylinrique ou en massue, et portant deux grosses soies terminales et mobiles. - Les mandibules, épaisses à leur base, un peu atténuées vers le sommet dans plusieurs espèces, ont été généralement prises pour des piẻces simples, piquantes et tranchantes, ce qui ne s'accordoit guère avec leur forme. - Les. hanches sont à peine séparées, plus néanmoins en certaines espèces.-Ce que leurs pattes présentent de plus remarquable, c'est la longueur du septieme article, qui est effilé.

\section{BDELLA VUMGARIS.}

Dugès, Ann. des Sc. nat., t. I I, p. 28, pl. 7, fig. 19, 20. - Scirus Vulgaris, Hепя., Mém. apt., p. 61, pl. 3. fig. 9, et pl. 9, fig. 8. - Acarus Longicornis, LINN.-Long. $\frac{1}{2}$ lig. -D'un rouge-écarlate, arec les pieds plus pâles; le suçoir est en forme de bec allongé et pointu; les palpes sont de cinq articles, dont le premier et le dernier plus longs, celui-ci un peu plus court et terminé par deux soies. - Se trouve communément aux environs de $\mathrm{Pa}$ ris, sous les pierres.

\section{BDELIA CORRULIPES.}

Dugès, Ann. des $S c$. nat., t. II, p. 20, pl. 7, fig. 21. - Le bec est court, gros; les mandibules sont épaisses, mousses et à mordans robustes, dont le mobile est un peu plus court que l'autre; les pieds sont Heus et le corps est rougcâtre. 


\section{SHAIIDIA, LATR.}

Les palpes sont grêles, portés sur un sucoir rétractile. - Les mandibules sont uniformes. - Le corps est entier, atténué antérieurement. - Les hanches sont très-distantes; les antérieures sont insérées sur une avance immobile du corps. - Les pieds sont en forme de palpes; les antérieurs sout les plus longs.

\section{1. smaridia papillosa.}

Dugk̀s, Ann. des Sc. nat., t. I, p. 30 , pl. 1, fig. 13 à 16. - Trombidium Papillosum, Ilerman, Mém. aptérol., p. 29 , pl. 2, fig. 6.-Long. $\frac{1}{2}$ lig. - Le corps estallongé, rétréci en arrière, élargi en avant, à part une avance tronquée qui porte le bec et les quatre premieres pattes, et sur la base duquel sont portés deux yeux rouges, arrondis, médiocrement écartés; cette avance, tronquée carrément en dessus, se continue de ce côté sans interruption et sans pli avec la peau du dos; en dessous, par moment, un pli la sépare du reste du corps; la peau est toute couverte de grains durs, arrondis, subpédiculés, noirâtres ou demi-transparens; sur les pattes et les palpes sont, au contraire, des écailles pareilles à celles des Rhyncolophus, mais plus nombreuses et plus grandes; les pattes antérieures sont à pen près aussi longues que le corps; elles servent autant à palper qu'à marcher; Je dernier article renflé, foncé en couleur, porte deux griffes fortes et très-courbées; les autres sont renflées aussi au bout, mais moins notablement; les postérieures sont également plus longues que les intermédiaires; les hanches, très-courtes, sont fixées dans des enfoncemens en quatre groupes fort distans; les deux premiers attachés sous l'avance du corps, les deux postérieurs sous les flancs et vers le milieu du tronc; le deuxième article de toutes est aussi fort court, les suivans longs et étroits, le dernier un peu plus long; le bec est à peine visible en dessus dans l'état de repos; les palpes mêmes se voient mal; mais si l'on presse le corps sans l'écraser, on voit se développer un long sucoir, dont la majeure partie est molle et rentrée en ellemême comme un tube de lunette; dans son plus grand allongement, ce suçoir égale le corps en longueur, son tiers antèrieur, plus étroit que le reste, est flanqué parles palpes, terminés par un petit évasement membraneux; le tiers moyen est soutenu par une lame cornée en forme de gouttière ou de tube incomplet, bifide en arrière, où elle donne attache à des muscles; dans son intérieur jouent deux mandibules très-aiguës, en forme d'épée, élargies vers la base comme celles des lihyncolophus; un canal membraneux parcourt toute la longueur de ce suçoir, da moins à partir de la base; les palpes, inséxés sur la lame cornée labiale, sont courts relativement à la longueur du bec; ils sont peu renflès; le deuxième article est fort long; le quatrième a la forme d'un mordant fixe d'une pince d'écrevisse, dont le cinquième article on appendice court, étroit, émoussé, formerait le pouce mobile; sur cette serre se trouvent plusieurs poils écailleux, larges et courts. La couleur de cette espèce ést d'un rouge-roussâtre, quelquefois avec une ligne longitudinale plus claire. - Elle a été trouvée en assez grand nombre par M. Dugês dans les points ombragés des bords de la rivière qui avoisine la ville de Montpellier.

\section{SIAARIDIA VILIOSA.}

Dugès, Ann. des Sc. nat., t. I1, p. 42. - D'un rouge vif, ayant le bec (dans l'état de repos), les palpes, les pieds et le corps, à peu de chose près, de même forme et de même proportion que la Papilleuse; mais toutes ces parties sont couvertes de poils longs et aplatis comme des feuilles de graminées; sur les derniers articles des pattes, les poils sont roides et serrés en brosse; les yeux sont bruns et situés sur le devant du corps, qui n'offre pas une avance bien saillante; le bec, au contraire, forme un cône allongé, très-saillant entre les palpes re'il porte; il est velu et ne s'est pas déployé par la compression, il s'avançoit seulement un peu au dehors; les palpes, au contraire, étoient susceptibles d'élongation; leurs articles sembloient rentrer un peu l'un dans l'autre, le dernier surtout dansle quatrième : aussi leur épaisseur étoit-elle assez notable, et lear aspect claviforme dans l'état de rétraction; dans le bec on remarque la pièce en cuiller et les deux autres lanceltes mandibulaires.

\section{SCIRUS, Herm.}

Les palpes sont courbés, falciformes an. térieurement. - Les mandibules sont onguiculées, - La lèvre est courte.-Le corps. est entier. - Les yeux sont au nombre de deux. - Les soies sont longues, transverses et sorlent de chaque côté. - Les hạa ches sont rappruchées. 


\section{SCInUS ELAPHUS.}

Dugks, Ann. des Sc. nat., t. II, p. 26, pl. 8, fig. 38. - Très petit, d'un rouge de carmin, à reflets variés; le corps, mou et rexisé, est divisé en deux parties par un sillon qui circonscrit un corselel; sur ce dernier se voit de chaque côté un reil arrondi, noirâtre; une longue soie transversale, vibratile, part du voisinage, sinon de la surface de cet cil même; deux autres soies se dirigent longitudinalement en avant, parties de la face dorsale du corselet comme les éminences de plusieurs Oribates; des poils bien plus courts partent de quelques points du ventre, el chez quelques individus cette parlie a montré en arrière deux papilles obtuses; les pieds ne diffèrent guère pour l'insertion et pour la forme de ce qui a èté vu chez les Bdelles; le bec, reuflé à sa base, bientôt atténué après la naissance des palpes, est compose d'une lève triangulaire, épaisse, qui n'a guère en longueur que la moitié du bec mềme; de deux mandibules dont l'adossement constitue seul la moitié la plus avancée de ce bec; la lèvre porte deux palpes écartés, forts et longs, à cinq articles, clont le deuxieme est le plus gros, les autres vont successivement en décroissant d'épaisseur jusqu'au dernier, qui est courbé, aigu, et porte deux épines: on en voit une aussi sur le premier, lc troisième et le quatrieme article. Cette disposition aussi bien que la grandeur des palpes, et l'habitude qu'a ce petit animal de les tenir fort sourent courbés, rejetés en haut et en arrière, lui donne l'aspect qui lui a valu son nom spécifique; les mandibules épaisses à leur base, singulièrement amincies en arant, sont terminées par un ongle mobile, épais, très-crochu et se fléchissant en dessus. Cette espece se trouve sous les pierres, clans les lieux humides; elle marche habituellement avec assez de lenteur ; mais, si on la touche, elle court à reculons avec une extrême rapidité.

\section{IXODES, LATR.; Cynorhastes, Heri.}

Le corps est presque orbiculaire, en ovale, très-plat quand l'animal est à jeun, mais d'une grandeur démesurée quand il est repu; le bec est obtus en avant, il consiste en un support formé d'une petite vince écailleuse, servant de boìte à la base du sucoir, et reçue dans une échancrure pratiquée au-devant du corselet, en une gaine de deux pièces fort courles, écailleuses, concaves au côté interne, arrondie, et même un peu plus large à leur extrémité; chacune de ces pièces, vue à la loupe, paroît coupce transversalemént, et il est facile de voir que ce sont deux palpes qui se sont allongés et qui se sont transformés en gaînes. - Enfin, la bouche prèsente, entre ces deux palpes ou pièces de la gaîne, le suçoir, qui est composé de trois lanies cornées, très-dures, coniques, dont les deux latérales sont plus pelites et en recouvrement sur la troisieme, qui cst grande, large, moins colorée, un pen transparente, obtuse, mais remarquable en ce qu'elle porte un grand nombre de dents en scie el très-fortes; et c'est au moyen dic ces dents que l'insecte s'attache fortement à la peau des animaux qu'il suce. Cette lame a un sillon dans son milieu, et ses côtés, ainsi que toute sa surface extérieure, sont armés de dents; de chaque côté dı bec sont placées des dents à peu près à égales distances les unes des autres; elles augmentent insensiblement de grandeur à partir des premières ou antérieures. - Les. pattes sont composées de six articles, dont les deux derniers forment un tarse conique qui est terminé par une pelote et garni de deux crochels au bout; cetle partic est d'un grand secours a ces Arachnides pour se fixer sur les animaux qui se trouvent à leur portéc. - Le dessous de l'abdomen présente un petit espace circulaire et écailleux qui parô̂troit indiquer les organes de la génèration. Les Ixodes, malgré leurs organes de locomotion assez fortement constitués, n'ont pas une démarche vive; au contraire, leurs mouvenens sont lents et pesans; mais ils ont une grande facilité à s'attacher avecleurs pattes aux objets qu'ils rencontrent, même au verre le plus poli ; quand ils sont posés sur des végélaux, ils se tienuent dans une position verticale, accrochés simplement avec deux de leurspattes, el lenant les autres étendues. Un animal quelconque vient-il à s'arrêter dans leur voisinage, ils s'y accrochent avec les pattes qui restent libres, et quittent facilement la branche où ils n'étoient fixés que par deux de leurs pattes. M. Latreille a observé que les Ixodes d'Europe habitent de prédilection les genêts, mais on en trouve aussi sur d'autres plantes. En Amérique, ces Arachnides attaquent l'homme; clles se trouvent dans les bois en quatités innombrables, et se ticnnent sur les plantes, les buissons, et surtout sur les feuilles seches dout le sol 
est jonché. Si l'on s'arrête un instant dans ces endroits, et qu'on s'asseoie sur ces feuilles, on en est bientôt couvert, et elles cherchent aussitôt à fixer leur suçoir dans le corps pour pomper le sang. Les Ixodes sont connus en France sous le nom de Tique; l'espèce qui tourmente les chiens de chasse est désignée par les piqueurs sous le nom de Louvette ou Tique des chicns. Une autre nuit beaucoup aux bœufs et aus moutons, si on la laisse multiplier. Elles pullulent tellement sur les bœufs, que M. Latreille a vu un de ces animaux rongé par elles, au point qu'il en succomboit presque, tant il était maigre et affoibli. Aussi les bergers doivent-ils visiter avec soin les bestiaux, afin de les débarrasser de ces Arachnides, s'il ne veulent pas les voir se multiplier à l'infini et nuire a la santé de leurs troupeaux. Les Ixodes pondent une énorme quantité d'œufs et par la bouche, suivant MI. Chabrier ${ }^{2}$. Ces Arachnides ontla vie très-dure, et elles donnent même des signes d'existence long-temps après qu'on leur a retranché les partics qui semblent être essentielles à la vie.

Nous citerons, comme étant les plus remarquables du genre, les espèces suivantes :

\section{IXODES REDUVIUS.}

Degéer, Mém. sur les Ins., t. VII. Aud., Ann. des Sc. nat., t. XXV, p. 22, pl. 14, fig. 4. - Long. 1 lig. -- La couleur de cette espèce est brune, violacée, grisâtre, avec des taches plus foncées, mais peu

- Nous avons été à même d'examiner ce fait, et voici comment celte ponte a lieu et que les œufs sont expulsés hors du corps. Il existe chez les Ixodes, a la partie antérieure du ventre, non loin de la gaine dans laquelle sont renfermés les organes de succion, une espèce de canal en forme de cornet, qui est terminé en pointe à sa partie antérieure et très-près de la cavité buccale; postérieurement, ce canal s'élargit peu à peu, et finit par se confondre avec l'abdomen, qui, lorsque l'animal est.repu de sang, est d'une grosseur démesurée. C'est par ce canal ou plutôt par cet oviducte que les œufs sont expulsés au dehors; ces derniers, aussitôt sorís, s'attachent à l'abdomen et finissent par former des masses considérables, lesquelles, parleur pesanteur, ne pouvant toujours rester fixées à l'abdomen, se détachent, et comme ces œufs sont toujours agglomérés entre eux et qu'ils ont une certaine tendance à s'attacher aux corps étrangers, ils peuvent se fix ${ }^{\circ}$ facilement aux parties sur lesquelles ils tombent. Voyez, pour plus de détails, notre notice qui a été insérée dans le tom. $v$ des $A n$ rales de la Société Entomologique de France, p. 629. visibles à l'cil nu; la plaque do:sale est très-développée, elle s'étend sur tout le dos, et elle est fournie de poils rares, dorés et soyeux; l'extrémité postérieure de son corps présente une bordure d'une conleur jaune assez claire qui se prolonge sur les côtés; le dessous du corps est brun, un peu soyeux, principalement près des lianches; les pattes, au nombre de huit, different en longueur, les deux dernières sont les plus longues, et les deux paires intermédiaires les plus courtes; les palpes maxillaires sont assez gros, aplatis, spatuliformes, et les mandibules, qui en présentent aussi de très-compliquées, ont cela de remarquable, qu'elles s'écartent brusquement l'aue de l'aulre, de manière à former un angle presque droit avec leur tige. Cettc espèce a été trouvée sur l'herbe dans le bois de Mleudon.

2. IXODES ERNAGEI. (P]. 43, fig. 3.)

Aud., Ann. des Sc. nat., t. XXV, p. 15, pl. 14, fig. 2. - Long. 1 lig. $\frac{1}{2}$. - La tête est irrégulièrement quadrilatère, elle offre en dessus et en arrière deux enfoncemens triangulaires, en dehors desquels M. Aiidouin a cru voir deux petits points noirs ayant l'apparence d'yeux, mais qui ne sont autre chose que des saillies plus ou moins cornées de la tête ; cette dernière est portée sur un cou plus étroit qu'elle; les parties de la bouche se composent de deux appendices que l'on nomme palpes maxillaires, situés de chaque côté de la tête; dans cette espèce, ils sont aplatis, plus larges à leur milieu qu'aux deux extrémités, el ne paroissent composés que de deux pièces; cependant, il seroit possible qu'il y cût à leur milieu une articulation indiquée par une sorte de fissure, ce qui porleroit à trois le nombre des articles; ils dépassent un peu le suçoir qu'ils recouvrent dans le repos, et sont garnis de quelques poils. Le suçoir proprement dit est formé: $1^{\circ}$ d'une espèce de palette ou lamelle aplatie, dentée sur ses bords, correspondant à la lèvre sternale des araignées, et composée de deux parties semblables jointes intimement sur la ligne moyenne; ces dentelures ont pour usage de fixer fortement l'animal sur sa proie, et peut-être de la déchirer; $2^{\circ}$ de deux pièces situées au-dessus de la précédente, lameiliformes, adossćes l'une a l'autre, mais non soudées entre elles, et représentant, suivant M. Audouin, les forcipules ou mandibules des araignées. Dans l'individu que $M . \Lambda$ th- 
douin a examiné, et probablement chez tous ceux de cette espèce, ces mandibules offrent cela de remarquable, qu'elles ont entre elles une longueur différente, et qu'elles ne s'écartent pas assez l'unc de l'antre pour dépasser d'une manière sensible la lèvre, ce qui fait qu'on ne les distingue pas facilement. Ces forcipules n'atteignent guères en longueur que la moitié de la lèvre; chacune d'elles est bifide au bout et dentée sur les côtés; la division interne représente une lamelle dont la pointe seroit obtuse et sert peut-être à entamer les chairs; tandis que les dents extérieures, $s^{\prime} y$ enfonçant de còté, semblent plutôt avoir pour fonction de les lacérer. M. Audouin ignore comment se fait la succion, et quel trajet suit le sang pour arriver dans l'œesophage. Y a-t-il un canal qui parcourroit la lèvre inférieure, et les forcipules concourrent-elles à le former, ou bien est-ce entre celles-ci que ce conduit existe? La plaque écailleuse ou thoracique du dos de l'animal a la forme d'un losange tronqué à son bord antérieur qui correspond à la tête; les pattes, au nombre de huit, sont de médiocre longueur, les postérieures plus longues que les antérieures et assez grêles; dans l'état de vacuité, c'est-à-dire lorsque l'animal n'est pas encore tuméfié par les alimens, elles sont insérées sur deux rangs à peu près parallèles et contigus ; au contraire, quand il s'est gonflé en prenant beaucoup de nourriture, les hanches s'écartent, et, au lieu de former deux lignes parallèles, elles forment une sorte de $V$ renversé ou de triangle ouvert en arrière; en tout, ces pattes sont composées de dix articles : le premier et le second sont courts; le troisième, le quatrième et le cinquième ont à peu près la même longueur; viennent ensuite des articles beaucoup plus grêles qu'on pourroit considérer comme faisant partie du tarse; le sixieme et le septième sont assez semblables entre eux, ils ont à peu près la même longueur que ccux qui précèdent; au contraire, le huitième et surtout le neuvième sont en Tout très-petits; à ce neuvième article est inséré un dernier renflé et muni de deux petits crochets ; l'abdomen, qu'il soit court et aplati comme dans l'état d'abstinence, ou bien allongé et distendu, offre en des. sous quatre petits points arrondis, dont deux latéraux en arrière des pattes, un en avant entre les hanches et un postérieur. M. Audouin pense que ce dernier correspond à la partie anale; il est formé par deux petites ralvules cornćes, qui sont ailongées, réniformes et supportées par ut petit pédicule, lequel est adhérent à la peau et reçoit l'insertion des muscles moteurs. Le petit oscule antérieur a paru à M. Audouin être l'ouverture génitale, il est ovale; les deux oscules latéraux sont évidemment les stigmates ; leur structure est admirable; en effet, leur surface cornée et un peu sphérique présente, entre l'ouverture principale située, non pas au centre, mais plus près du bord interne que de l'externe, une foule de petites plaques irrégulièrement bosselées, perforées au centre, ayant la forme d'une étoile, et qui luisent comme autant de petiles perles. Cet appareil, pour l'introduction de l'air, offre une grande analogie avec ce qu'on voit dans les larves de certains diptères. Chaqque grande plaque stigmatique est comme enchâssée dans la peau; et cette peau qui, à la loupe, est ridéc sur tout le corps, présente à sa surface des poils courts, rigides et espacés. Indépendamment de ces oscules, d'autant plus visibles ici que l'abdomen est presque incolore, on voit inférieurement quatre lignes enfoncées, dont deux partent de l'ouverture génitale antérieure ou interfémorale, et les deux autres de l'anus; toutes se dirigent vers le bord postérieur de l'abdomen. - Gette espèce se trouve sur le hérisson; lorsque son corps est renflé, elle esi globuleuse, ovale, un peu plus amincio en avant qu'en arrière.

\section{IXODES TRABEATUS.}

Aud., Ann. des Sc.nat., t. XXV, p. 20, pl. 14, tig. 3. - Long. 1 lig. - Sa tête, y compris les pièces de la-bouche, forme, lorsqu'on l'examine en dessus, le quart de la longueur da corps, et, vue en dessous, elle en a le tiers : cela dépend de ce que supérieurement elle est en partie cachée par le thorax; cette tête est aplatie, pentagone; à chacun des angles antérieurs s'insèrent le deux palpes maxillaires, allongés, aplatis, garnis de poils sur leurs bords, plus larges vers le milieu qu'à leur extrémité et qu'à leur origine. M. Auduoin ne leur a pas distingué d'article basilaire nettement séparé; mais il est possible qu'il soit soudé, et que ces parties, au lieu d'être composées d'une seule pièce, le soient réellement de plusieurs. Quoi qu'il en soit, ces appendices sont un peu plus longs que le succoir, et dans l'ëtat de repos ils le recouvrent. La bouche, proprement dite, est formée des même pièces que celle de l'es- 
pèce précédente; la lèvre inférieure ou sternale, placée au-dessous des deux mandibules, est une lame de consislance cornée, aplatie, large vers son extrémité, rétrécie près de sa base, et pourvue sur ses bords de dents aiguës dirigées en arrière; une ligne assez large, d'une couleur plus pâle, occupe son milieu et semble indiquer l'existence d'un canal de succion qui existeroit dans sa longueur; les forcipules ou mandibules sont assez grêles, aplaties, plus courtes que la lèvre; dans l'etat de repos elles sont adossées l'une à l'autre dans la plus grande partie de leur longueur, et peuvent s'éloigner ou se rapprocher en se mouvant latéralement, mais ce rapprochement ne sauroit avoir lieu pour leur tiers antérieur; en effet, leur ex|rémité s'écarte assez brusquement en faisant un angle obtus avec la tige; cette extrémitẻ est bifide, et les deux divisions sont très - différentes entre elles; l'une, supérieure, est munie de dents aiguës dirigées en arrière et très-propres à s'altacher aux chairs età les lacérer; l'autre, inférieure, est mince, comme lamelleuse, et ressemble à une lancette. M. Audouin a cru distinguer à sa surface une sorte de canal qui concourt peut-être à effectuer la succion. Le dessus de la tête est marqué de deux pelits enfoncemens; la plaque dorsale, qui occupe environ la moitié du corps, est ovalaire ; en avant on voit un sillon demi-circulaire qui dessine les limites d'un petit espace relevé sous lequel est placée la tête, et d'où partent deux autres petites lignes longitudinales atteignant le milieu de cette plaque ; lespattes, au nombre de huit, sont, lors de l'état de vacuité du ventre, plus longues que lui et insérées sur deux lignes longitudinales et parallèles partant de la tête et se prolongeant jusqu'à la moitié du corps ; six articles entrent dans leur composition: les deux premiers sont courts; le troisième, le quatrième et le cinquième sont à peu près d'égale longueur; le sixième est le plus long de tous, et sous ce rapport il y a une grande différence entre ces pattes et celles de l'espèce précédente dont le sixième article est remarquablement couri; le septième est très. petit, les huitième et neuvieme sont d'une exiguité excessive, enfin le dixième est élargi et terminé par deux crochets; des poils garnissent les pattes, ils sont surtout visibles au côlé interne; les pattes antérieures et les postérieures ensuite sont les plus longues, les intermédiaires les plus courtes; le premier article de la première paire de paltes est plus petit que ceux des autres, qui vont en augmentant de largeur; le dessus de l'abdomen présente quelques poils; le dessous offre les mêmes ouvertures que dans l'espèce précédente. - Cette espece a été trouvée dans les bois, sur les graminées. A l'état de racuité elle est trèsaplatie; la tête, les pièces de la bouche, la plaque thoracique et les pattes sont noires; l'abdomen est d'un brun-rougeâtre, ct on apercoit une ligne un peu plus claire qui borde les côtés.

\section{IXODES PLUMBEUS.}

Dug, Ann. des Sc. nat., t. II, p. 16. A jeun, il ressemble à une graine flétrie, plissée longitudinalement, mais sans crénelure sur les bords; les plis qu'il présente alors et qui s'effacent en partie par la distension, répondent exaclement aux poches cœcales de la cavité digestive, et, en exa. minant de jeunes individus, M. Dugés a pu en reconnoître parfaitement la disposition, vu la demi-transparence que prennent alors les intervalles des cœcums. On voit aussi que les poches sont oblongues, au nombre de douze; huit grandes dirigées en arrière, quatre plus petites dirigées en avant et partant d'un centre commun ; leur disposition et celle des sillons entassés qu'elles circonscrivent pourront sans doute, dans un examen comparatif, fournir des lumières pour la caractéristique des espèces. Outre ces sillons, la peau, vue à la loupe, présente encore une foule de stries parallèles comparablesà celles de la peau de l'homme dans la paume des mains, au bout des doigts. On y voit de plus quatre ouvertures; deux sont latérales, situées vers le milieu du corps, formées d'une plaque cornée, ovale, fendue longitudinalement au milieu; c'est un stigmate qui a été bien vu par Degéer, Lyonnet et M. Audouin; deux autres sont médianes et inférieures; l'unc, siluée un peu plus en arrière que le milieu du corps, arrondic et entourée d'un bord brun, est l'anus; l'autre, plus petite et sans rebord coloré, est l'orifice génital. M. Dugès a remarqué que la situation est variable; l'individu est-il plat et vide, l'orifice est au niveau de la deuxième et même de la troisième paire de hanches; l'intestin estil fortement distendu, cet orifice est repoussé au-devant de la deuxiẻme paire, et par conséquent se rapproche de la bouche. Je dois dire pourtant que j'ai trouvé la première disposition très-marquée scule- 
ment chez les individus fort jeunes, et la deuxième chez de grands individus; peutêtre l'âge ou le même sexe entre-t-il pour quelque chose dans ces différences. Quoi qu'il en soit, cette proximité de l'organe sexuel et la bouche explique comment on a pu croire que les Ixodes rendoient leurs cufs par cette dernière ouverture. Les pattes sont insérées en dessous et sur les côtés du corps à distances a-peu-près égales, la dernière un peu plus en avant que le niveau du stigmate : les antérieures sont les plus longues, les postérieures viennent ensuite. La hanche, brune et cornée comme les autres articles, est un peu élargie, adhérente au corps : a celle de la première patte est en dehors une forte épine dirigée en arric̀ce. Une sorte de tête brune, écailleuse et triangulaire, occupe en dessus le devant du corps; elle est formée de plusieurs pièces: $1^{\circ}$ la plaque déro-céphalique pentagone, à angle postérieur arrondi, à milieu convexe, à bord latéraux relevés, articulés en avant le bec; $2^{\circ}$ ce bec, offrant d'abord un support quadrilatère plus large que long, il est marqué en dessus de trois stries longitudinales; au-devant de cette piéce vient une sorte de toit formé par les deux palpes écartés seulement à leur base et laissant voir ainsi un pelite portion des mandibules. Les palpes engaînent mème les parties latérales de ces mandibules, ct recouvrent en dessous la lèvre avec les cils longs, roides et serrés qui partent transversalement de leurs bords inféricurs et se rencontrent sur la ligne médiane. On $y$ distingue facilement trois pièces mobiles, larges et concaves; une quatrième, restée inaperçue jusqu'ici, est au contraire arrondie et glandiforme; c'est l'article terminal ; il est légérement velu, et ne se voit bien que du côté du bord inférieur. Ces palpes s'écartent et laissent à nı la lèvre et les mandibules, quand l'animal enfonce le bec dans la peau du vertèbrẻ auquel il s'attache. Les mandibules sont en forme de bras exsertiles; le premier article est charnu, blanc, caché habituellement dans l'épaisseur du labre ou support du bec; le deuxième est corné et brun, il se voit à découvert en écartant les palpes; son extrémité antérieure est terminée en partie par une lame tranchante ct en partie articulée avec la troisième pièce qui représente l'onglet, le mordant mobile de la pince des Gamasus; cet onglet est mobile en effet, crocliu et dentelé sur son bord. La lèvre, qui reçoil en dessous les mandibules, est écailleuse, mais pâle et transparente, hllongée, concave, en cuillère, un peu iètrécie, mème à sa base, lisse et marquée d'un sillon longitudinal en dessus, c'est-àdire du côté concave, garnie en dessous de nombreuses et courtes dentelures dirigées en arrière, faisant peu de saillie vers les bords; ces dentclures n'en sont point moins aptes à retenir le suçoir fixé dans la plaie; aussi n'arrache-t-on pas le parasite sans enlever au moins une portion de l'épiderme qui reste quelque temps entre les palpes et le bec proprement dit.Cette espèce s'attache sur les chiens, et les quitte quand elle est complétement repue ; elle acquiert alors une forme ovale, comparable à celle d'une petite fève; sa surface est lisse, luisante, d'un gris-plombé, sans aucune tache ni marbrure; elle devient rouge-brun dans l'alcool.

\section{IXODES RETICUIATUS.}

Latr., Hist. nat, des Crust. et des Ins., t. VI 51.-Fiscu., Mém. de la Soc. Impér. des Nat. de Moscou, 1. VI, p. 279. - Acrrus Reticulatus, FABR., Ent.Syst., 4, 428. - Roescrer, Gener. Ins., 1, 29, fig. 7. Acarus Reduvius, Schraxк, Enum. Ins. A usir., no 1043, t. III, fig. 1, 2. - Cette espece est assez grande, et s'attache surtout aux bœuis ; la couleur en est différente par la succion; mais les pattes sont noires.

\section{Ixones hispanys.}

Latr. Hist. nat. des Crust. et des Ins., t. VIII, p. 52, no 3. - Fiscн., Mém. de la Soc. Impér. des Nat. de Moscou, t. VI, p. 279. - Acarus Hispanus, Fabr.-Noir; les pattes sont rouges, avec les articulations blanches.

\section{IXODES EGYPTIUS.}

Fiscu., Mèm. de la Soc. Impér. des Nat. de Moscou, t. VI, p. 279.-Noir, bordé de blanc. - Se trouve en Egypte.

\section{IXODES NIGUA.}

LATr., Hist. nat. des Crust. et des Ins., t. VIII, p. 52, no 5. - Acarus Americanus, Linn. - Mitte Tique, Degéer, Mém. Ins., t. VII, pl. 37, fig. 9, 10.-Il est ovale, aplati, rouge, avec une tache blanche sur le dos, et les jointures des pattes blanchâtres.-Cette espèce est le fléau des hommes et des bêtes dans l'Amérique tant Septentrionale que Méridionale.

\section{IXODES RHINOCERIS.}

Latr., Hist. nat. des Crust. et des Ins., t. VIII. p. 52. - Frsch., Mém. de la Soc. Imp. des Nat, de Moscou, t. VI, p. 279.-- 
ग. 279. - Milc du Rhinocéros, DégéER, Mlém. Ins., t. VII, pl. 38, fig. 5 à 6. - II est arrondi, aplati, brun, avec des taches et des nuances faures. M. Sparmann a observé cette espèce au cap de Bonne-Espérance, sur le rhinocéros.

\section{IXODES CAMELINUS.}

Fiscr., Mém. de la Soc. Impér. des Nat. de Moscou, t. VI, p. 281, pl. 23, fig. 1, 2. - Le corps est allongé, d'un rouge-brun; les pieds sont courts et distans entre eux; la seconde pairc de piedsa une articulation très-renfléc. - Se trouve sur les chameaux dans les steppes.

\section{IXODES SYLVATICUS.}

Latr., IIist. nat. des Crust. et des Ins., 1. VIII. - Mite des buissons, Degéer, Mém. Ins., t. YII, pl. 38, fig. 7, p. 55, no 7. - Fisch., Mém. de la Soc. Imper. des Nat. de Moscou, i. VI, p. 281. - D'un brun-marron, foncé luisant.-Celte espèce, qui se trouve au Cap, s'atlache sur la peau des animaux.

\section{SIXIIUEE FAMILLE.}

\section{Y D R A C H N E L L E S,}

\section{Latheille.}

Caractires. Leur corps est presque ovoïde ou globuleux, très-mou et se rétrécit ensuite postérieurement. - Les palpes sont toujours à articles fort inégaux, mais dont le deuxième n'est pas plus grand, et toujours terminé par un article crochu ou épineux, propre à servir d'ancre ou de grappin, tant pour saisir une proie vivante que pour fixer l'animal sur un corps solide ou sur les eaux.

Toutes ces Arachnides ont d'ailleurs une sorte de plastron formé par des hanches plates, larges et adhérentes, toujours disposées en quatre groupes séparés par des petites distances et quelquefois contiguës sur la ligne médiane. Deux de cesgroupes, un de chaque côté, appartiennent aux hanches antérieures, deux aux postérieures.

Genres: Atax, Diplodontus, Arrenurus, Eylais, Limnochares, Hydrachna.

\section{ATAX, FABr.; Hydrackna, Невir.}

Le corps est ovoïde, assez ferme, lisse; il y a une fente génitale, bordée de deux plaques, sur chacune d'elles se montrent trois tubercules transparens, lisses, arrondis, assez gros,en forme de stemmates. - Les - hanches antérieures, en partie contiguës sur la ligne médiane, serrant la lévre entre elles et formant aussi ensemble an groupe unique; les deux groupes des hanches posiérieures écartés; la quatricme hanche extrêmement large, contiguë à toute la longueur de la troisieme. - Des palpes dont le quatrième article est fort long, atténué , un peu excavé vers le bout pour recevoir le cinquième dans une extrême flexion; ce cinquième en forme de doigt pointu. Des mandibules formées d'un corps épais, creux, coupé en bec de plume à son extrémité postérieure, tronqué au bout antérieur, sur lequel s'articule et se fléchit vers le haut un grand et fort crochet ou ongle peu courbé et fendu ou crensé en canal pour loger en partie et sontenir cette mandibule, - Une lèvre en cuilleron, bifide en avant.

Les œufs des espéces qui composent ce genre (Alax Histrionicus) sont disposés en couche transparente et d'aspect gommeux; les petiles larves qui en sortent sont aquatiques, aplaties, en forme de graines de courge et d'amende, pourvues de deux gros yeux ronds, latéro-antérieurs et peu écartés, et d'un gros sucoir contenant des mandibules à crocket comme celles de l'adulte. - Les palpes sont rentlés et terminés par un cinquième article en forme de longue grilfe recourbée.

1. atax histrionicus. (Pl. 13, fig. 5.) Dugès, Ann. des Sc. nat., t. I, p. 4 , pl.10, fig. 14, 17.-Iydrachuallistrionica, Hera., Mém. Aptérol., p. 55 , pl. 8, fig. 2 . - In beau bleu colore les plaques génitales el toutes Ies parties de la bouche, mềme les mandibules; le reste du corps est d'un beau rouge vif nuancé de noir ; cette dernice couleur est due a celle des viscères aperçus confusément à travers Ja peau; deux gros coecum latéraux, ondulés ou plissés et repliés mème en dessous. 
produisent les taches latérales; leur intervalle laisse le long du dos une bande plus claire; ils naissent des deux côtés d'une cavité transversale, et c'est aux intervalles plus ou moins distincts qui séparent cette bande des latérales, que sont dues les branches de I'Y, qu'on remarque sur tant d'espèces figurées par Muller; enfin, de cette bande transverse partent aussi en avant trois cœcum courts; les petits espaces qui les séparent constituent des lignes longitudinales plus claires, et qui, chez cette espèce, passent au niveau des yeux; ceux-ci sont ronds, formés d'un point noir entouré de rouge, situés en avant sur le point déclive du dos, ils sont peu saillans, et derrière eux on en aperçoit deux autres plus petits et touta-fait sous la peau, qui, en général, est fort lisse; de plusieurs points du dos cette peau laisse sortir une matière visqueuse qui se réduit en filamens soyeux, entre les doigts qui tiennent l'animal à l'air libre. Cette espèce présente encore quelques particularitès; ainsi, la quatrième paire de pattes, plus longue que les autres et ciliée comme de coutume, est tout-a-fait sans griffes et terminée en pointe obtuse; en second lien, sous le-deuxième article des palpes, qui sont grands et même plus robustes que la jambe extérieure, on voit une saillie d'où la pression fait sortir une papille conique dont l'usage est inconnu.

\section{ATAX LUTESCENS.}

Dưgès, Annales des Sciences naturcl. les; t. I, p. 3. - Hydrachna Lutescens, HER, Mém. Aptérol., p. 57, pl. 6, fig. 7 . - Le quatrième article des palpes est armé d'une petite pointe; la mandibule porte une légère avance du côté opposé au crochet; les yeux sont au nombre de deux, assez écartés, réniformes et comme triangulaires, mais composés en réalité chacun de deux stemmates placés au même niveau ,et dont l'interne est plus grand que l'autre; la peau est transparente, fort lisse, et laisse apercevoir facilement, à Ja loupe, une couche de trachées qui la double à l'intérieur; toutes les pattes sont onguiculées, bleuâtres ou verdâtres.

\section{ATAX nUNICUS.}

Dugìs, Ann. des $S c$. nat., t. I, p. 13. -Hydrachna runica, THÉIs, Ann. des $S$ c. nat., t. XVII , p. 4, pl. 1, fig. 2. - Son abdomen, qui est ovale, est d'un rouge vif, parsemé de taches et de stries noires; le dessous est rouge, également virgulé de noir'; l'épigyne est saillant enire la première paire de pattes. On y voit une fente longitudinale entourée de petits points noirs au nombre de six; les pattes sont fines, rougeâtres, la première est plus courte que la seconde, plus courte elle-même que la troisième; la quati ieme est la plus longue. Les yeux, au nombre de deux, sont trèsdifficiles à apercevoir; arec un très-fort grossissement ils paroissent composés. Ciette espèce a été trouvée dans une petite rivière, aux environs de Laon.

\section{Atax falcatus.}

Косн, Faun. Allem., tab. 7, fig. 9. Jaunâtre, avec des taches noires; la médiane très-grande et carrée, avec les latérales et les dorsales formant deux bandes en forme de faux; les pieds sont verts.

\section{ATAX FIGURALIS.}

Kocri, Faun. Allem., tab. 8, fig. 10. Jaune, avec des taches noires; la médiane large, courte; les latérales recourbées; les dorsales larges et rapprochées, munies antérieurement d'une dent latérale; les pieds sont verdâtres; la seconde paire privée de soies.

\section{ATAX VERNALIS.}

Kocr, Faun. Allem, tab. 7, fig. 11. Iydrachina Vernalis, Mulc., Hydr., p. 48, $n^{\circ} .18$, tab. 5, fig. $1 .-D^{\prime}$ un jaune-verdâtre, avec des taches noires; la médiane subarrondie, avec les latérales et les dorsalesse joignant; de plus est une belle bande de couleur minium, large et fourchue.

\section{ATAX ELEGANS.}

Косн, Faun. Allem., tab. 7, fig. 12. Jaunâtıe, avec des taches noires; les antérieures presque contiguës; les dorsales rapprochées antérieurement et embrassant les antérieures; les pieds sont longs, verts.

\section{ATAX himosus.}

Kocri, Faun. Allem., tab. 7, fig. 12. D'une couleur d'ocre fâle, avec le bord transparent et des taches d'un noir-brun; la médiane grande; les latérales obliques; les dorsales se joignant arec les taches angulaires antérieures et postérieures; la strie dorsale est large; les bras sont grêles.

\section{9. atax rastuosus.}

Kocr, Faun. Allem., tab. 7, fig. 14. Verdâtre, jaunâtre en dessus, avec des taches noires; les antérieur es grandes, ovales, arcc les dorsales se joignant étroitement entre elles; ces dernières, se mi-circulaires, con- 
vcrgeant postérieurement avec un appendice grand, transversal.

\section{ATAX pictus.}

Ко осн, Faut. Allem., tab. 7, fig. 14. Blanc, avec des taches ovales d'un noirbrun; la médiane grande, arrondie, tronquée postérieurement; les latérales triangulaires, avec les dorsales réniformes extérieurement, divergeant postérieurement, et se joignant.

\section{ATAX HYATIYUS.}

коси, Faun. Allem., tab. 7, fig. 16.Transparent, ovale, arec des taches noires; la médiane longue, étroite, arrondie et dilatée antérieurement; les latérales en forme de croissant, obsolètes; les dorsales écartécs, également en forme de croissant, divergeant postèrieurement, avec la sticie dorsale de couleur d'ocre; les pieds sont d'un fauve clair, bruns à la base.

\section{ATAX LOBATUS.}

Косн, Faun. Allem., tab. 7, fig. 18. Ovale, blanc, avec des taches fauves; la médiane arrondie, avec les latérales transverses, placées plus en arrière que de coutume, renfermant une tache blanche cordiforme; les dorsales sont larges, bilobécs extérieurement; la strie dorsale est blanche.

\section{ATAX DIAPIANUS.}

Kocn, Faun. Allem., tab. 7, fig. 19. Ovale, subtronqué postérieurement, blanc, avec des taches d'un brun-olivâtre, foutes jointes, bilobées latéralement; la strie est fourchue, jaune.

\section{ATAX minhes.}

Kocu, Faun. Allem., tab. 7, fig. 20.Ovale, subtronqué postérieurement, blanc, jaunâtre en dessus, avec des taches; la médiane ovale, libre; les latérales transverses, adhérentes intérieurement, avec la dorsale subarrondie.

\section{ATAX CRASSIPES.}

Kосн, Faun. Allem., tab. 7, fig. 21.Obovale, tronqué postérieurement, à argle pointu; blanc, avec des taches noires; les antérieures petites, longitudinales; les dorsales larges, avec la branche antérieure transverse et étroite; la strie esı fourchue et de couleur minium; les palpes et les pieds antérieurs sont blaucs, les autres sont verts.

\section{6. atax truncatus.}

Kock, Faun. Allem., lab. 7, fig. 22. -
Obovale, tronqué jostéjieurement, à angle pointu; blanc, jaunâtre en ciessus, avec des taches noires; la médiane pelite; les latérales courtes, transverses; les dorsales éloignees, avec la branche antẻrieure oblique, formant avec les latérales une tache semicirculaire.

\section{ATAX ALBIDUS.}

Kocn, Faun. Allem., tab. 7, fig. 23. Ovale, tronqué postéricurement, à angle pointu, d'un blanc diaphane, avec des taches noires; la médiane allongée; les latérales obliques et étroites, adhérentes par une branche grêle, oblique, avec les dorsales allongées, tronquées obliquement postérieurement.

\section{ATAX CONFLUENS.}

Kocн, Faun. Allem., tab. 7, fig. 24. Ovale, ıronqué postérieurement, tuberculé dans le milieu; d'un blanc-jaunâtre, avec des taches noires; la médiane petite; les laté. rales se joignant avec les dorsales de chaque côlé par une bande incisée dans son milieu; les pieds sont d'un vert pále.

\section{ATAX FRENIGER.}

Косн, Faun. Allem., tab. 2, fig. 20. Subglobuleux, vert, avec le dessus jaune; une tache semi-circulaire entre les yeux, et une autre enchaînée et courbée postérieurement, noires.

\section{DIPLODONTUG, Dugk̀s.}

Les palpes sont un peu allongés; le quatrième article est le plus long, avec le cinquième étendu, formant une espèce de pince. - Les mandibules, bidentées, sont chéliformes. - Le rostre est court. - Le corps est déprimé.-Les yeux sont distans. -Les larves sont hexapodes, terrestres, très-diflérentes de l'adulte.

\section{DIPLODONTUS FILIPES.}

Dugès, Ann. des $S$ c. nat., t. I, p. 5, pl. 10, fig. 1 à 4.-Il est elliptique, déprimé, en forme de gâteau, d'un rouge clair, marbré parfois de brun foncé, les taches sont dues aux organes digestifs; les yeux sont au nombre de quatre, deux de chaque côté tout-à-fait sur le bord antéricur et un peu latéralement, de manière qu'on les yoit mieux en dessous qu'en dessus; chacun des deux groupes est aussi à une distance de l'autre; les yeux de chaque groupe sont voisins et l'un au dessus de l'autre, mais non contigus; la peau est finement gra- 
nulée, sans poils; la vulve, située entre les deux groupes des hanches postérieures, est bordée de deux valves formant ensemble une sorte de cœur et chargées de globules plus serrés sur le bord externe. M. Dugès a vu partir, de la fente qui les sépare, un oviducte membraneux ; les hanches, un peu jaunâtres, supportent des pattes croissant en longueur cue la premiere a la dernière, terminées par deux grands crochets ciliés de mamière à remplir l'office de rame; mais ces rames sont si fines, bien qu'assez longues, qu'on ne les voit pas agir á l'óil nu, et que l'animal semble au premier coup d'œil se mouvoir par quelque mécanisme intérieur et caché ; le bec, d'un rouge vif, est conoīde, un peu bifide, formé d'une assez grande lévre en cuilière, contenant deux mandibules à crochet courbé, grand et fort, opposé à une pointe fixe presque aussi grande et un peu aiguë; les palpes, très-courbés en dessous, peu visibles en dessus, ont à leur quatrieme article une pointe droite, aiguë, longue; le cinquième article, long aussi et courbé, est semblable à celui des Ataces.

\section{DIPLODONTUS FALYAX.}

Dugr̀s, Ann. des $S_{i}$. nat., t. I, p. 6. Un peu plus.grand que le précédent, auquel il ressemble au premier aspect, mais il s'en distingue facilement par le mouvement de ses pieds, l'écartement de ses yeux, sa couleur rouge plus foncé, sa forme plus elliptique; son corps est quelquefois obscurci par un sablè noirâtre, qui ne forme pas des taches proprement dites; ses pieds sont rouges; ses yeux sont médiocrement écartés, antérieurs et margiuaux, assez grands, noirâtres au centre, rouges autour, réniformes, ou plutôt composés chacun de deux stemmates; les pattes sont plus grosses que dans l'espèce prècédente, ciliées, onguiculées.

3. Diplodontus scapularis. ( $\mathrm{Pl}, 13$, fig. 4.)

Dugès, Annales des Sciences naturelles, t. I, p. 7, pl. 10 , fig. 5 à 12. -Sa taille est assez grande; les plus grandes femelles ont jusqu'à une ligne et demie de longueur; toutes sont en dessous d'un rouge violacé; en dessus elles ont la moitié antérieure toute noire ou à peine se: mée de quelques petits points rouges, la postérieure d'un rouge-écarlate, mais partagée par une bande noire longitudinale, ce qui lui donne l'aspect d'un insecte co- léoptère; le corps est déprimé, sublétragone; la peau séchée paroît, à la loupe, finement granulée; au microscope, on voit que ces granulations sont pointues, la peau ressemble à du chagrin. On y voit très-bien l'anus et les stigmates; le premier situé à quelque distance de la vulve; des seconds, les antérieurs plus rapprochés que les yeux et plus avancés encore sur le bord du tronc, les postérieurs immédiatement derrière les dernières hanches; ce sont des petits trous en forme de points; les yeux petits, quoique saillans, très-écartés, posés sur les angles arrondis de l'extrémité antérieure du corps, sont noirâtres, composés de deux stemmates soudés; le bec est formé : $1^{\circ}$ d'une lèvre courbèe en dessous, élargie en arrière, terminée en avant par une sorte de tube comme charna, ouvert à son extrémité; $2^{\circ}$ de deux mandibules à corps égais, allongé, creux, coupé en long biseau ou bec de plume et courbé à son extrémité postérieure, couché intérieurcment dans le repos au-dessus et entre les hanches des pattes. Les mandibules ont un crochet ou ongle mobile, rouge comme elles, long; peu courbé, redressé vers la pointe el cannelé dans sa longueur; les deux ongles sont paralléles et peuvent sortir de la lèvre pour piquer ensemble ou séparément : il y a pourtant à l'opposite une avance pointue, mais qui n'a que le quart de la longueur de l'ongle mobile; $3^{\circ}$ de leux palpes assez courts, dont le deuxième et le troisicme article sont fort gros; le quatrième allongé, terminé en crochet assez court et épais; le cinquième obtus, courts, épais.

M. Dugès a été témoin de l'accouplement, et il a pu auși reconnoître le mâle et la femelle; celle-ci est-toujours beaucoup plus grande, souvent triple et même quadruple en diamètre. Le corps du mâle est plus aplati, plus allongé, les couleurs plus tranchées et plus vives, les pattes proportionnellement plus grosses et plus longues; il est plus vif et résiste plus longtemps à la dessication. Du reste, l'apparence extéricure des parties génitales est assez foible; les plaques da mâle sont seulement plus grandes, plus séparées.

L'accouplement s'opère ventre à ventre ; il est prolongé et souvent répété; les deux individus se tiennent et se roulent étroitement embrassés, et si on les sépare, on voit une humeur blanche et visqueuse épanchée autour des organes de la génération; de ceux de la femelle semblent partir 
plusienrs gros canaux blancs, rameux, visibles à travers la peau. Au reste, les individus de cette espèce aiment la société de Icurs semblables; ils sont souvent pelotonnés quatre à cinq ensemble, et MI. Dugès en a vu passer des heures entières embras. sant les nymphes et semblant attendre leur éclosion. G'est ainsi en société qu'ils aiment à s'avancer' sur le bord humide de la vase qui les renferment; il leur arrive mème alors de s'écarter, en rampant ainsi, de leur élément nécessaire, au point de ne pouvoir plus y entrer et de périr desséchés an bout de quelques heures. Cette sociabilité se manifeste encore dans l'acte de la ponte; c'est sur les tiges, les feuilles des végétaux glabres contenus dans l'eau, sur les parois du vase qu'elles habitent; que les femelles vont pondre leurs oufs; elles

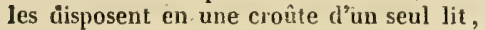
et les petits oufs, extrêmement abondans, rouges, ovoïdes, posés verticalement côtes à côtes, sont enduits et recouverts d'une couche de matière muqueuse bientôt condensẻe, mais blanchâtre, opaque, et non transparente comme celle des Ataces. Quand une croûte est ainsi commencée, il est rare qu'elle ne soit pas élendue et con. tinuée par d'autres femelles, de sorte que des milliers d'œufs se trouvent ainsi réunis et peuvent revêtir exactement toute la surface d'une feuille, un long bout de tige, etc.

Après deux semaines, de petites larves, fort différentes de l'adulte, sortent de ces cufs; elles ressemblent à un point presque imperceplible, d'un rouge fort vif. Au microscope, elles se montrent hérissées de longs poils; leur corps ovale, tronqué en avant, porte quatre yeux médiocres en deux groupes latéro-antérieurs, six pattes longues et grosses, dont le septième article est fort mince, mais garni de deux griffes très-grandes; deux paires sont dirigées en avant, une en arrière ; leurs insertions sont peu distantes; le sncoir est volumineux, mobile sur le trone, au-derant duquel il s'insère, armé de deux soies grosses et courtes, flanqué de deux gros palpes auxquels M. Dugès a reconnu un crochet et un apprndice velu, vrai palpe ravisseur , comme celui des Trombidiens. Dans le sucoir: M. Dugès a cru apercevoir deux lames reployées en arrière comme le seroient les ongles mandibalaires de l'adulte; d'antres fois il a paru au même observateur qu'on trouvait lá deux mandibules semblables à celles des Trombidions : détails dif- ficiles à constater vu l'extrême petitesse des objets.

Cies animaux procurèrent à M. Dugès, la première fois qu'il les a observés, un spectacle des plus agréables; ils nageoient avec une extrême vivacité, gagnoient la surface du liquide, s'y reposoient quelque temps pour se sécher tout-a-fait, puis, trouvant sur cette surface un plan suffisamment résistant pour supporter le poids d'une masse aussi légère, ils la parcouroient avec la même vélocité qu'ils l'auroient fait sur une surface plus solide; toutefois, si le liquide formoit, vers les bords du vase, un plan incliné par son adhésion aux parois, M. Dugès royoit ces petites larves s'épuiser en vains efforts, glisser perpétuellement vers le centre; si le niveau étoit rétabli par l'augmentation de la quantité d'eau contenue dans le vase, elles s'échappoient promptement, et couroient sans aucune difficulté et en tous sens sur le cristal le mieux poli.

L'analogie, dit M. Dugès, nous porte à penser que, comme les larves du Limnochare, celles-ci vont vivre en parasites sur des insectes amis des eaux, peut ètre sur Ies Libellules, les Tipules, les Cousins, dont les petites mites rouges ont étẻ décrites comme des Acarides a six paltes. Une occasion favorable se présentera fácilement ainsi a elles pour retourner dans leur ancienne patrie poir y subir plusieurs métamorphoses. Je dois effectivement les croire multiples d'après les faits suivans.

1. J'ai trouvé dans l'eau un très-petit individu tout rouge, à huit pattes, offrant du reste tous les caractères de forme générale et d'organisation particulière propres an Diplodonte Scapulaire; on doit croire qu'il venoit de subir une premièretransformation; $2^{0} \cdot j^{\prime}$ 'ai rencontré bien souvent, entre les petites tiges rapprochées du chara; des nymphes toujours bien plus forles que ce petit individu. rougeâtres, parfois marbrées de noir, portant fréquemment des restes de paltes et quelquefois les huit fourreaux : de ces nymphes sort un Diplodonte Scapulaire de la taille, à peu près, qu'ont les mâles adultes, et il n'en diffère que par les couleurs; le noir, au lieu d'ètre rassemblé- sur des régions particulières et circonscrites, semble disséminé en nuées fuligineuses sur le fond rouge du corps. J'avois pris d'abord ces individus pour ceux d'une espèce diflèrente; mais frappé de leurs ressemblance, quant à l'organisation, je les ai conserves 
vivans, et jai vu la couleur se dessiner bientôt d'une maničrc plus nette, en même temps que le corps prenoit de plus grandes dimensions ; enfin, j'ai vu l'accouplement s'opérer entre des individus à tcinles mélangées et à couleurs nettes.

Cies animaux semblent, de même que ceux des genres voisins, disparaître en automne et en hiver : on peut conjecturalement supposer qu'ils s'enferment alors dans la vase; aucun d'eux ne peut sans doute, comme les Hydrachnes, passer l'hiver à l'élat de larve, puisque les insecies sur lesquels nous supposons qu'elles vivent ne résistent point eux-mêmes aux preıniers froids de cette saison.

\section{ARRENURUS, DugÈs.}

Les palpes sont courts, en forme de næud; le quatrième article est le plus Jong ct le plus épais; je cinquiène est en forme de faux. - Les mandibules sont onguicuJées. - Le rostre est court. - Le corps est cuirassé, caudé clans le mâle. - Les ycux sont distans.-Les hanches sont très-laiges.

1. AREENERUS VInIDIS. (P1. 13, fig. 7.)

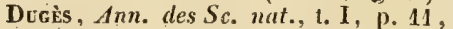
pl. 10 , lig. 18 et 19. - Cetle espèce est d'un vert-blenâtue; la fcmclle est tronquée en arrière; le mâle offre, au contraire, un prolongement rétréci du côté du tronc, terminé par deux angles pointus et par un hord sinueux dans leur intervalle; au milieu de ce bord est saspendu un appendice pistiliforme, perforé a son extrémité; deux pointes crochues occupent le dessus de ce prolongement; dans l'un et l'aulre sexe, le dos oflre nne ellipse régulière qui senible circonscrire une portion de la peau plus molle, plus mobile que le reste; presque lout, effectivement, est dur, crustacé, chagriné, épineux; les yeux, an nombre de deux, noirâtres, écartés, situés sur la partie la plus avancée du corps, semblent caches sous cette peau, dont la demi-transpâs rence les laisse apercevoir; elle permet aussi de reconnoître assez bien la distribution des cœcum intestinaux qui forment des narbrures brunes sur la couleur dominante du corps; la bouche est en dessous, formée d'une lèvre petite, et qui a paru à M. Dugès percée d'un tron rond. Une des singularités de ce genre, c'est l'habitude de vejeter en dessus et en avant leurs longues paltes posiérieures; toutes sont, du reste, ciliécs et onguiculées, comme aux genres voisins; mais le septicme article est plus grand que le sixième. Le mâle les a toutes plus fortes que la femelle; les postéricures se font remarquer encore chez lui par la longueur du cinquième article, qui est armé d'une épine ; les hanclies, surtoul lespostérieures, sont d'une longueur considérable; elles se touchent presque sur la ligne médiane; les antéricures se touchent daus la moité de leur longueur; derrière le milieu. de celle de la quałrième pajre, on distingue un stigmate; entre elles on voit chez la femelle un espace elliptique transversalement, bivalye. à peau molle; c'est la vulve: une saillie oblongue et couverte de pointes pellucides en pait obliquement de chaque côté : le mâle n'a que deux saillies, elles sont plus petiles et arrondies.

\section{AmRENURS PUSTULATOR.}

Kocu, Faun. Allem., tab. 2, fig. 21.Hydrachina Pistulator, Muгs., p. 32 . tab. 3, fig. 3. - Trombidium Pustulator, Fabr, Eutom. System., t. II, p..403, $\mathrm{n}^{\circ}$ 21. - Vermillon, angruleux antérieuremenf, avec la partie úorsale renfléc, bisinuée postérieurement, avec un appendice grêle; les pieds et les palpes sont testacés.

\section{ARERTURUS TRICUSPIDATOR.}

Косн, F(u). Allem., tab. 2, fig. 22. Hydrachna Tricuspidator, Muls., p. 35 , tab. 3, fig. 2.-Trombidium Tricuspidator, Fabr., Entom. System., t. II, p. 402, $\mathrm{n}^{\circ}$ 19. - Vermillon, avec les pieris et les palpes plus pâles, légérement sillonné antérieurement; la queue est 1ricuspide, avec une tache antéricure orale el deux médianes, anguleuses, de coulcur noire.

\section{ARRENURUS RUMGTYOEUS.}

K̈ocn., Faun. Allem., tab. 2, fig. 23. Globuleux, jaunâtre, avec la partie dorsale saupoudree de ferrugineux, et des tiches de même couleur, trois antéricures, les latélales transverses, deux de chaque côté, lineaires, transverses, et un grand crochet de chaque côté postéricur.

\section{ARRENURE GAUDATUS.}

Kंocr, Fuzn. Aliem., tab. 2: fig. 24. Acurus Candatus, Degér., t. VII, p. 58, 2:3, tab. 9, fig. 1.- Hydrachna Buccinator, Mulz., p. 30, t. III, fig. 1. - Trombidium Caudatum, Fabr., Entom. System., t. II , p. $399, n^{\circ} 4$. - Verdâtre ; la partie antérieure, et une tache dorsale (marginée de ferrugineux en arrière) jaunes; corps postérieurement un peu plusétroit; trois ta- 
EYLAIS.

chies de chaque côlé plus olsscures; la queue cst jaune, avec la base noirâtre, resserrée.

\section{EYLAIS, LATr.}

Les palpes sont un peu allongés; le quatrième article est le plus long; le cinquième est obtus, légẻrement renflé et épineux. - Les mandibules sont onguiculées. - Le rostre est très-court, avec la bouche arrondie. - Le corps est déprimé. - Les yeux sont rapprochés. - Les hanrhes sont étroites; la quatrième éloignẻe de la troisième. - Les larves sont hexapodes, aquatiques, différentes de l'adulte.

EYLAIS EXTENDENS. (Pl. 13, fig. 6:)

Dugès, Ann. des Sc.nat., t. I, p. 13, pl. 10, fig. 24 à $34 .-$ Elle est ordinairement d'un rouge très-vif, coloré en vert sur toute la surface du dos; cette teinte n'est due qu'à un enduit fort adhérent el bien lisse de matière végétale conferroïde. Quelquefois le fond rouge est marbré de brun, selon la plénitu de du cœecum de l'appareil digestif et la couleur des substances qu'il renferme. Ces substances, qui sont des sucs animaux, paroissent ordinairement prendre dans cet appareil une coulcur rouge, car l'écrasement fait répandre presque toujours une grande quantité de pulpes de celte couleur, indépendamment du pigment rouge: de la peau. G'est un phénoméne assez remarquable et qui est aussi bien sensible chez certains Tétraniques, bien qu'ils se nourrissent de sucs végétaux; là il est facile de voir que c'est surtout dans l'intestin que siége la matière de leurs taches ronges ou rouillées; mais celte matière doit subir un bien grand changement pour l'acte de la digestion, car elle est blanche lorsqu'elle sort de l'anus. Le corps est ovale, aplati; la pointe du dos est déprimée; les yeux sont rapprochés et bilobés; les pattes sont cilićes, onguiculées, l'animal les tient étendues en nageant; les pattes antérieures ne sont pas ciliées et leur longucur augmente graduellement depuis la première jusqqu'a la quatrième paire. La peau se montre, au microscope, sillonnée de rides transversales analogues à celles qu'on voit au bout des doigts de l'homme; leur direction peut servir à faire micux découvrir les stigmales préoculaires, et ceux qui sont placés derrière les hanches postérieures; on en découvre aussi deux autres, chez les sujets de grande taille, entre les deux groupes de hanches, de chaque côté, non loin de la vulve, mais un peu plus en arrière. Les stries se dévient à leur pourtour, plusieurs les contournent même complètement; entre les groupes fort écartés des hanches antéricures, on voit une saillie bilobée, en partie cachée par les palpes qui s'y attachent; c'est la lèvre dont la moitié postérieure est percée d'une ouverture circulaire, ciliée, et où l'eau bouillonne de temps en temps quand on tient l'animal à l'air libre. La moitié antérieure de cette lèvre forme un capuchon cutané qui, sans doute, est destiné au jeu antérieur des pièces mandibulaires. Ces palpes insérés à la base du capuchon ont leurs trois premiers articles fort courts, le quatrième long et renflé, lc cinquième en forme de doigt lancéolé, garni de quatre à cinq fortes épines mobiles. Quand on cherche par l'ecrasement à déterminer l'organisation intérieure de cettte bouche; on lécouvre un appareil fort compliqué dont M. Dugès a eu bien de la peine à se faire une idée exacte et complète. Les parties les plus essentielles a noter comme caractéristiques, sont deux mandibules non considérables, si on les compare à celles des genres précédens, mais exactement de la même forme que chez les Diplodontes, c'est-ì-dire, composées d'une pièce longue et épaisse, recourbée à son extrémité postérieure, qui donne altache à des muscles; et d'un ongle très-aigu, mobile par gin. glyme, sur le bout antérieur de la piece principale. Aussi M. Dugès a-t-il vu l'Elaïde, de même que les $\Lambda$ taces, saisir des Daphnies d'une assez grande taille, et les emporter, suspendues à la bouche, pour en sucer les humeurs. Sous la peau résistante qui forme le capuchon et le contour de la bouche, M. Dugès a découvert une grande pièce cornée ou cartilagineuse, élargie et de forme comparable a celle du car: tilage thyroïde de l'homme: Elle supporte une espèce de pharynx à parois épaisses et denses, auquel fait suite un œsophage mem. braneux. En arrière et en avant, les angles prolongés de celte pièce donnent attache à des muscles, et dans le dernier sens elle porie des palpes en s'avançant au-delà de la bouche. Ces connexions prourent jusqu'a l'évidence qu'elle représente la pièce hasilaire des insectes, picce supportant et les maxilles et la lèvre, qui, le plus souvent, chez les Acariens, est soudée, confondue avec elle, ici seulement bien distincte et telle que nous l'avons d'abord décrite, comme forméc sous la peau. La vulve n'of- 
fre ici presqne rien de semblable aux plaques rrustacées qu'on voit aux Diplodontes; cest une fente longitudinale, a peine bordice; elle est située fort en avant, presque eutre les hanches antérieures.

C'est aussi à la surface des corps submergés que la femelle dépose ses nufs en couches rougeâtres, enduites d'une matière transparente, et qui leur sert de défense contre les attaques des animalcules qui rampent souvent à la surface de cctle croûte, et qui n'épargnent pas cenx des IIydrachnes; de ces œufs soetent des petites Jarves qui nagent dans le liquide, a l'aic!c de leurs six pattes velues, dont les postérieures sont longues et insérées très-loin des antérieures; le corps est rougeâtre, pellucide, allongé; les yeux, au nombre de yuatre et très écartés; la bouche formée d'un suçoir qui a l'aspect d'un donble tube creux; il supporte deux palpes qui ont paru terminés en pointe à M. Dugès. Ces petits animaux se desséchent, meurent à l'air libre. M. Dugès n'a point suivi leur déreJoppement ni leur transformation; mais il a paru à ce unéme observateur qu'ils devoient arriver de boune heure á l'état parfait, car on trouve des Fylaïdes étendeuses de trés petite taille, le volume d'un grain de moutarde, par exemple. Les plus grandes ont, au contraire, jusqu'a une ligne et demie de longueur, ce qui prouve assez que, comme tous les autres Acariens, ccuxci s'accroissent encore après leur métamorphose, contradictoirement à ce que l'observation démontre exister chez les insectes.

\section{EYLAIS CIIRYSIS.}

IIydrachna Chrysis, 'T'ÉIs, Ann. des Sc. nat., t. XXVII, p. 2, pl. 1, fig. 1. L'abdomen est ovale, allongé, d'un vert doré, métallique, avec quelques enfoncemens noirâtres formant deux lignes le long du dos; le ventre, les paties ei les palpes sont du plus beau rouge carmin, et ccitc couleur s'étend en dessus sur les côlés de l'abdomen; Ies yeux sont au nombre de quatre, occupent la région supérieure de la tête, et séparés des palpes par une espèce de bandeau, de couleur semblable an fond sur lequel ils sont placés et très-difficiles à apercevoir ; ces yeux paroissent simples au premier aspect, mais au soleil $\mathrm{ct}$ avec une forte loupe, on reconnoit qu'ils sont doubles, à la manière des latéraux des Epeiires; en dessus sont deux points brillans, qu'on seroit tentè de prendre pour d'autres ycux, si leur extrême petitesse ne leur donnoit plutôt l'apprarence de stemmates, qu'a découverts Aluller dans quelques especes d'A rachnides; les palpes sont trés-courts, de trois articles, dont le dernier est le plus allongé, plus grêle, et terminé en pointe; entre la derniere paire de pattes et un peu en dessous est un rgane, que M. de Théis suppose être l'épygine, composé de deux petiles valvules ovales-allongées, et se détachant en rouge sur un fond obscur; la quatrième paire de pattes est la plus Iongue, la première est la plus courte, la troisieme et la quatrième paire sont ciliées intérieurement, les deux autres paroissent plus glabres à la vue simple, et n'ont que quelques touffes de poils airx articulations; ces dernières sont dans l'ordre de longueur de l'espece précédente.

Celle espece a été trouvée par M. de Theis dans un marais aux environs de Laon; elle ne rage pas très-vite, et elle descend nn se roulant sur elle-même jusqu'au fond de l'eau. Lorsqu'elle nage, ses palpes sont a peine visibles; quand on l'a tenue quelque temps hors de l'eau, on voit se contracter des petits points ou enfoncemens qu'elle a sur le dos, et l'on pourroit supposer qu'elle respire au moyen des gonflemens et contractions alternatifs de ces es. péces de stigmates.

\section{LIM NOCII ARES, LATR.}

Les palpes sont petits, filiformes; le cinquième article est menu. - Le rostre esa eylindrique, grand. - Le corps est mou. - Les yeux sont rapprochés. - Les hanches antérieures sont plus grandes que les postérieures, tontes cachées sous la peau. - Les pieds sont propres à la marche.

Les larves sont terrestres, parasites, différentes de l'adulte.

\section{LNYNOCHARES AQUATICUS。}

Dugès, Ann. des Sc. nat., t. 1, p. 16 , pl. 11, fig. 38 a 40. - Acarus Aquaticus Hulosoriceus. Degŕen, Mćm. pour servir à lihist. nat. des Ins., t. VII, pl. 9, fig. 19. - Trombidium Aqualicum, II впз., Mém. Aptérol., p. 35, pl. 1, fig. 2.-Le corns est irrégulièrement ovoĩde, un peu pisiforme; conoïle en arant, très-mou, susceptible de déformations spontanées, et variant d'un moment a l'autre; la peau est d'un ronge de cinabre terne chez tous les sujets âgés, vif chez les jeunes; elle est couverle de très-petites granulations transparentes, coniques, et qui, au microscope, lui donnent 


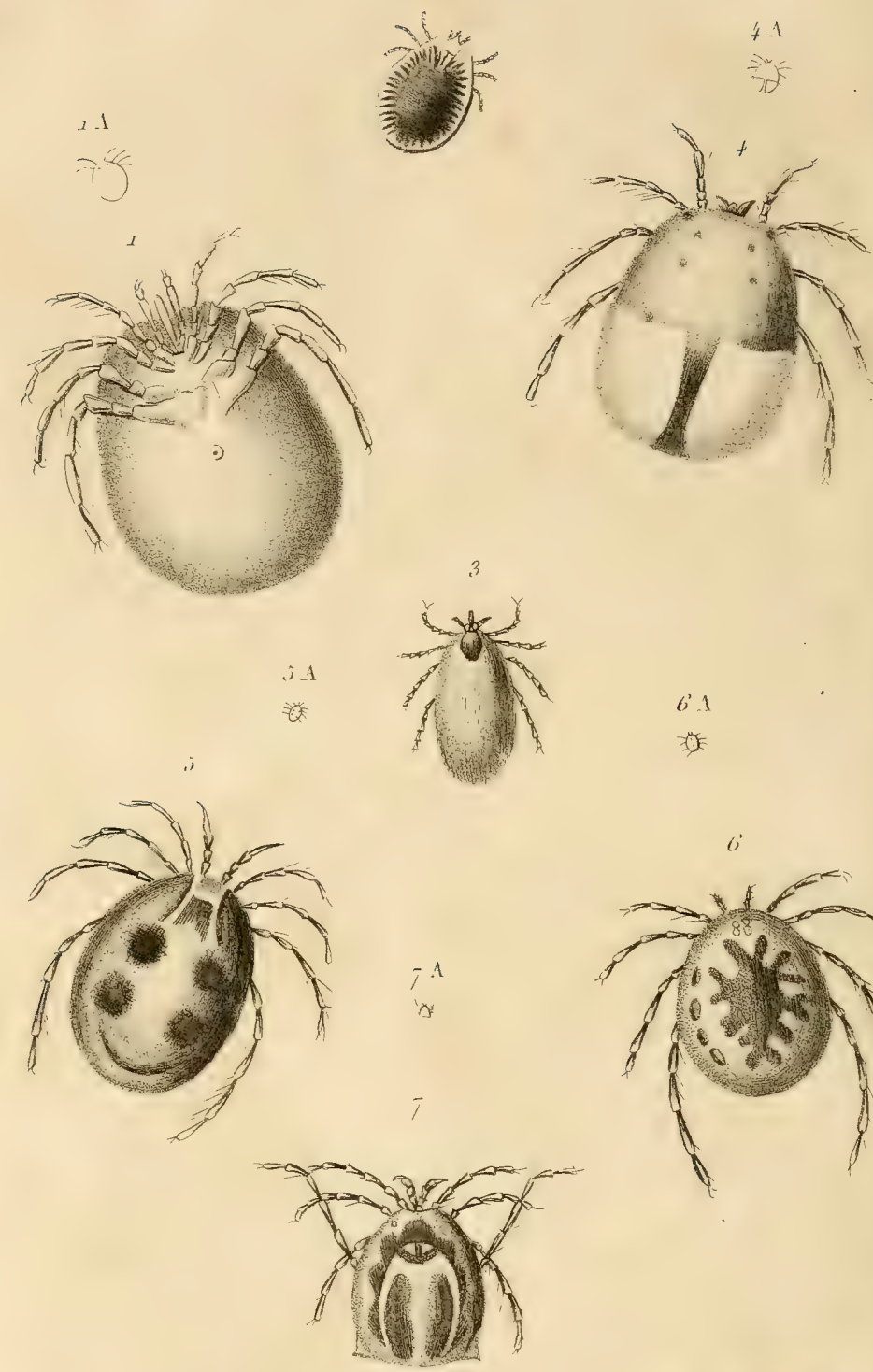

$$
\begin{aligned}
& 6^{3} 1 \\
& \text { 涼 }
\end{aligned}
$$

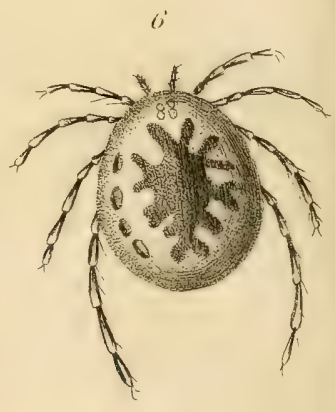

I. 1. Ilydrachrıa ğiobosa.

2. Arôas pipistrelloe.

5 Irodies Erinacei.
4. A. Diplodontas scapriaris.

5. 5 A. Atax histrionicus.

6.61. Evlais extendens . 
Paspeci du chagrin; il n'y a des poils qu'aux pattes, et ils y sont rares; Jes yeux grands, très-rapprochès, situés sur l'angle antérieur du corps, triangulaire, d'un rouge foncé; sont composés de deux ocelles conoìdes, entourés de quelques poils : on ne les voit que par la compression. et l'on reconnoit alors qu'ils sont attachés à une pièce écailleuse, lancéolée; le bec est en partie caché sous la peau : on n'entrevoit en dehors et sous l'angle antérieur que la moitié au plus; cette moitic est cylindrique et accompagnée de deux trés-petits palpes, à peu près filiformes, et terminés par un cinquième article très-grêle et émoussé ; par la compression on fait sortir d'un pli de la peau la base élargie du bec, qui offre alors l'aspect d'un cône tronqué. Son sommet est effectivement percé d'un point obscur. M. Dugès n'a pas très-bien distingué le bec; mais il a cru le voir doublé a l'intérieur d'une plaque analogue à celle de l'Eyla's Extendens, et la briéveié du rostre et des palpes semble indiquer qu'il renferme aussi des mandibules onguiculées et arec des lames. L'insertion des pattes est tellement cachée sous la peau, qu'on n'en distingue que cinq articles de libres; c'en est assez pour faire voir que les postérieures sont bien plus longues que les antérieures. Du reste, les articles sont à peu près disposés comme chez le genre suivant; les deux griffes terminales, rétractiles, et supportées par un tarse trèsépaissi. Si l'on presse le corps entre deux verres, on voit que sous la peau se cachent les hanches, disposées en quatrr groupes, et que la cuisse est attachée à ces hanches par l'intermédiaire d'un trochanter assez volumineux; les hanches des quatre pattes antérieures sont plus grandes que les autres : c'est le contraire chez les Ataces et le genre suivant. Les groupes antérieurs sont aussi fort rapprochés l'un de l'autre sur la ligne médiane; les postérieurs sont fort éloignés des premiers et aussi près l'un de l'autre, puisqu'ils se rapprochent beaucoup des flancs.

Dergéer, ayant conservé vivans deux Limnochares, leur a vu pondre des cufs disposés au fond d'un rase sous forme d'une croûte blanchâtre, mélèe de rouge; il en a vu sortir des Acariens rouges, à six paltes allongées, à corps ovale, à tẻle en forme de museau, et garnie de deux palpes, qu'il appelle deux autres paties plus courtes. Ces petites larves couroient sur l'eau ou nageoient à volonté au milieu du liquide. Dcgéer, dans ses mémoires, ne dit pas ce que deviennent ces larves; mais Mr. Dugès a vu ce qu'elles devenoient, et c'est encore à lui que nous empruntons l'observation suivante. C'est sur le Gerris Lacustris, hémiptère fort commun à la surface des eaux tranquilles, que la larve du Limnochares va chercher sa subsistance; c'est là que M. Dugès l'a trourée sur la lin de juillet, fixée sur divers poinls, mais le plus sourent prés de la tète. Ces larves, très-petites et d'un ronge vif, ont un gros suçoir mobile, en forme de tête, portant deux gios palpes. Les six pattes sont velues. terminées par deux grifles; les hanches sont groupées vers la partic antérieure du corns; la partic postérieure s'élargit et s'étend dlavantage; il y a deux yeux noirs latéro-antérieurs; en un mot, la ressemblance est grande entre elle et les larves du Trombidium Phalangii. Parvenues à la grosseur d'une tète de camion, ces Jaries se détachent, tombent dans l'eau, y marchent comme auparavant, bien que leurs pieds soient plus courts, relativement à l'ampleur du corps, s'enfoncent dans quelques anfractuosités des pierres submergẻes, deviennent des nymphes immobiles. et au bout de quinze jours, laissent éclore un fort petit Limnochare d'un rouge éclatant, à huit pattes, et arec toutes les formes apparentes des plus grands.

\section{IYYDR ACINA, Muller; Acurus, DegéER.}

Les palpes sont un peu allongés; le troisieme article est le plus long; les quatrieme ct cinquieme chéliformes. - Les mandibules sont cunéiformes. - Le rostre est de la longueur des palpes. - Le corps est arrondi. - Les yeux sont distans. - La vulve est cachee par le bouclier.

Les larves sont aquatiques, parasites, différentes de l'adulte.

HVDRACnva guerosa. (Pl: 13, fig. 1.)

Dugès, Ain. des Sc. nat., t. 1, p. 18, pl. 11, fig. 41 à 56.-Acarus Aquaticus Globosus, Degćcr, Mćm. poit serie à l'Hist. nat. des Ins., t. V 11, pl. 9, fig. 10, 11. Iydrachna Cruentala, Muleer. - Hydiachna Cilobula, Heв., Mím. Aptérol., p. 56, pl: 6, fig. 10. - Elle acquie t une assez grande taille ; car la femelle, parvenue a son plus grand développement, a jusqu'à deux lignes un quart de grand diamétre. Bien que gुlobulcuse au premicr aspect, celte Hydrachne a en réalité la forme d'un ovoíde émoussé, lisse, et à. 
peine marqué sur le dos de qualques dépressions musculaires; elle est d'un rouge vineux, tirant parfois sur le brun-marron. $\Lambda$ un grossissement médiocre, la peau paroît salinée. en raison des trachées fines qui la doublent, et dont la demi-transparence permel d'apercevoir la couche blanchâtre et brillanle ; cette même diaphanéité laisse voir, chez certains sujets, une tache blanche en dessus et en dessous; la dernière est située un peu en arrière el au roisinage de la partie anale; elle est intestinale; la première est plus antérieure; pent-être n'appartient-elle qu'au mâle, et est-elle due à l'appareil génital. Vue à un très-fort grossissement, la peau semble composée de grains, ou plutôt de petits compartimens arrondis, régulièrement engrainés et serrés comme dans celle préparation qu'on nomme galuchat. A la partie antérieure ol supérieure est une double plaque cruslacèe, stbtriangulaire, grenue etrugueuse, épaisse et d'une conleur plus foncée que le reste, formée d'une agrégation de grains microscopiques et opaques, bien plus gros que ceux de la peau; elles donnent atlache aux muscles des palpes et des autres parties de la bouche. M. Dugès a vu mu petit trou on point transparent près de leur extrémité antérieure, et un sillon profond dans la longueur de leur angle postérieur; en devant, elles sont réunies par une petite portion écailleuse, an centre de laquelle se montre un tres-petit stemmate arrondi et d'un rouge pâle; en dehers de chacune est un æil à deux cornées infiniment plus considérable. Ces yeux, sur l'animal vi. vant, sont d'un rouge foncé, en forme de rein; ils sont médiocrement écartés, et regardent en haut quand le corps est peu distendu, en avant quand il l'est davantage chez des femelles remplies d'œufs. Au-derant de chaque oil, et un peu en dedans. est un poil court et conique, partant du centre d'une petile élévation étoilée; il rappelle le poil antenniforme des Galéodes. Ces détails ne se voient bien que sur la peau que l'animal a dépouillée dans sa mne; mais ce qu'on voit micux au contraire sur le vivant, c'est aussi au-devant de chaque nil, et un peu plus bas, un pore d'où suinte un peu d'eau quand on tient momen. tanément l'animal à sec. Cic sont sans doute de très-pelits stigmates; on en voit d'autres derric̀re les hanches postérieures, et sans cloute il y en a d'auties encore entre ccllesci el le sroupe de hanches antérieures, cumme chez !es Eylais. Des plas reculés,
M. Dugès a manifestement vu naître des faisceaux de trachées excessirement fines, soyeuses et blanches, mais qui, au plus fort grossissement, ne montrent point le filet spiral des insectes; elles forment une couche presque contincte sous la peau, et on peut en suivre dans chaque patte. L'eau qui sort en petite quantité des stigmates est-clle absorbée par les trachées? Cela peut être en partie; mais voici des remarques qui semblent prouver que l'animal absorbe plus d'air que d'eau, soit par les stigmates, soit par les pores invisibles de la peau. $1^{\circ}$. En repos, dans l'aisselle des feuilles du Potamogeton fluviatile, les $\mathrm{Hy}$ drachnes agitent continuellement l'eau avec leurs pattes postérieures pour établir un courant hors de leur corps. $2^{\circ}$. Pour peu que l'eau soit croupie, elles viennent volontiers sur le bord comme les Diplodontes, et laissent hors de l'eau la majeure partie de leur corps, qu'elles humectent seulement de temps à autre, en passant sur le dos leurs longues pattes postérieures. Un desséchement total leur seroit en effet plus promptement funeste encore (trois quarts d'heure) qu'aux Diplodontes. $3^{\circ}$. Une IIydrachne, jetée dans l'alcool, y a vécu et nagé pendant plus d'une demi-heure; rendue á l'eau, elle s'est rétablic en peu d'instans : on peut croire qu'il n'en eût pas été ainsi si clle cût été absorbée par l'alcool. La houche est formée d'un bec à hase assez large bientôt allongé en forme de gouttière, fortement inclinéc sur sa base, fendue en dessus, et renfermant la partie la plus mince de deux lames mandibulaires piquantes, tranchantes, et qui peuvent elles - mêmes former par la réunion un autre gouttière intérieure ; elles-s'écartent en s'enfoncant dans le corps an-dessus de l'insertion des pattes, et la, épaissies, elles donnent allache à leurs muscles motenrs. Ces parties, observées par IIermann, dans l'IIydrachne géographique, ont été par lui mal comprises et mal figures. Sur les côtés de l'élargissement de la gâne s'insèrent les palpes, comprimés, fléchis vers la base. a articles fort inégaux, dont le premier est fort gros, le deuxième très-courbe, le troisième long ef aplati dans un sens, èlargi dans l'autre; le quatrième court, et ter. miné en crochet épais et raccourci ; le cinquieme enfin en forme de crochet lnimêrne, mobile sur le précédent, ct faisant grappin plutôt que pince avec lui, puisquic les combures de l'un et de l'autre sont parallèles. C'est avec cet aprareil que l'ani- 
mal attaque les tiges du. Potamogeton; mais est-ce pour sa nourriture? M. Dugès l'a vu non moins souvent rouler entre ses pattes et fouiller avec son bec les flocons d'animalcules microscopiques qui flottoient au fond de l'eau; M. Dugès ne l'a pas vu attaquer les gros insectes, ni les Naîs ou les Daphnies qui habitent avec lui. Le même auteur n'a rien pu trouver dans ses organes digestifs qui indiquât un genre de nouriture; il n'a meme pas pu ici bien démêler les cœeum laićraux que l'analogie doit faire supposer, mais il a mieux ru que chez d'autres genres d'Acariens l'intestin impair qui représente le rectum; il est médian, yenflé en sac fusiforme, et plein d'excrémens d'un blanc de lait; il s'ouvre à l'anus arrondi, qu'on voit un pen plus en arrière que le milieu du corps. Des huit pieds, les antérieurs sont fort courts, les postérieus bcaucoup plus longs; les trois paires postévieures seules sont ciliées de manière à scrvir à la natation; toutes sont pourvues de deux grands ongles crochus, rétractiles en se renversant sur le bout obliquement tronqué et excavé du larse; le pénultième article est le plus long de tous; le trojsième on la cuisse est le plus épais. Les hanches èlargies, aplaties, adhérentes, forment sous le corps une sorte de plastron; elles sont distribuées en derx groupes pour chaque côté. Entre les deux antérieures s'insère le bec; entre les postérieures se trouve l'orifice des organes génitaux. Ponr ce qui conccrne ce dernier, M. Dugès n'a io établir la difference qui distingue les mâles d'avec les femelles; aussi est-ce de cclles-ci que nous avons parlé jusqu'à présent, d'après les observations de M. Dugés, et que nous parlerons encore. La plaque crustacéc qui recouvre cet orifice est d'me seule piece en forme de cœur, à pointe tournée en arrière; clle est fonccie en couleur et granuléc; sous sa pointe est une ouverlure que la plaque découvre en s'inclinant en asant. et d'où pent sortir un tube d'un demi-millimètre de longueur et pentêtre mème davantage : il le faut, en elfet, pour que l'animal dépose commodément ses æufs dans lieu de son choix, et cette opération n'est pas la moins curiense dans son genre. C'est dans le centre des tiges spongicuses du Potamegeton que M. Dugès les a vues les insinuer après y avoir, à l'aide de leur bec, percé un trou rond, tel que le feroit une épingle. Les xufs donnent à la tige une opacité qu'clle n'a pas d'ordinaire; ils sont rasscmblés en graude quan- tité, et l'on peut dire par centaines : leur forme est oblongue; leur longueur d'un huitième de ligne à peu près; leur couleur d'un rouge-brun. La femelle meurt après la ponte; son ventre est devenu flasque et ridé. Ces œufs ne sont pas couverts d'une enveloppe protectrice comme dans les genres précédens; aussi, lorsqu'ils sont mis à nu, voit-on quelques espèces de Naïs et de Dérostomes les attaquer, et remplir en les suçant leurs organes digestifs d'un pulpe rougeâtre. La ponte commence vers le mois de mai ; il faut beaucoup de temps, plus de six semaines, pour que l'éclosion ait lieu; les tiges du Polamogeton attaqué sont alors morles, à demi décomposées, et les nou reau-nés s'en échappent sans peine. Ces nouvean-nés sont des larves à six pattes et à trompe singulière, comme Muller l'avoit dit au sujet de quelques IIydrachnes; les six pattes sont fort rapprochees a leur origine, et attachées à des hanches quadrilatères, adhérentes, disposées sur deux rangs et presque contiguës; les tarses sont terminés par deux crochets rétractiles, et ciliés pour la nage. Les pieds sont rouges; le corps rougeâtre, ovale, trés-plat en dessous, convexe en dessus; on y voit en avant une sorte d'écusson lisse, saillant, presque elliptique, tronqué, et portant sur ses angles antérieurs deux gros yeux ronds et noirâtres. Le bec représente une grosse tète mobile de haut en bas, subpentagonale, terminée par une bouche étroite, et côtoyće par deux gros palpes demi-transparens, dont le quatrieme article est en griffe, et le cinquieme remplacé par deux crochets plus petits, articu. les sur la base de celui-ci. M. Dugès ignore combien de temps ces petits animaux vivent librement dans l'eau; ils n'en peuvent alors sortir sans périr, et c'est lá d'ailleurs qu'ils doivent tronver leur subsistance. Fixés sur le corps d'un insecte aquatique. et passés à l'état de nymphe, ils peuvent au contraire être avec lui emportés à l'air sans danger. Dès la fin de l'été, et durant l'automne, on en trouve déjá fixés sur le corps ou les membres, sur les filels caudiformes, sur les élytres de la Népe cendrée, tantôt aux parties cornées qu'elles perforent d'un trou fort étroit, mais bien reconnoissable à l'aide d'une forte loupe. Elles. attaquent aussi les Ranâtres, et diverses. especes de Dytiques, le Bordé et celui de Roesel, par exemple; M. Dugès en a même trouvé sur le grand Hydrophile; mais str ces coléopteres elles n'attaquent que les. parties membrancuses, La partie posté- 
rieure du corps ne tarde pas s'allonger ; d'abord c'est en pointe qu'elle se dessine; lc petit animal cncore aplati devient fusiforme dans son contour; plus tard, c'est une cllipse allongéc qu'il représentc: arivivé à de grandes dimensions, il est en forme de poire bien renflée, recourbée du côté inférieur, et colorée en ronge-violet. Ce n'est que durant l'hiver que les jeunes $\mathrm{Hy}$. drachues acquierent cetle taille, c'est-àdire une longueur de denx millimètres, un pen moins d'une ligne. Une chose remarquable, c'est que, malgré cet accroissement considérable du corps, l'écusson et les pattes ne grandissent pas; aussi trouvet-on toujours avec les mêmes dimensions, et toujours situés vers le bout antérieur, quand l'auimalcule s'est accru le plus possible, et le suçoir en forme de tète, et l'écusson avec le simulacre tles/yeux et ies trois paires de hanches. Mais bien souvent les palpes, les pa'tes même ont disparu en partic ou en totalité, surtout si ce parasite ćtoit à découvert et porté par un insecte très-robuste et très-actif, sur les pattes d'un Dytique, par exemple; alors aussi l'espace membrancux qui unit le sucoir au corps s'est allongé en forme de cou. Ces singula. rités s'expliquent, quand on examine attenlivement les choses. De très-bonne heure, c'est-à-dire dès que le corps commence à s'allonger, les pattes et les palpes se retirent en dedans; ils suivent le corps dans le sac que forme en arrière la peau distendue; ils abandonnent ainsi leurs fourreanx. que des violences extérieures peuvent dès lors facilement rompre. C'est donc une nymphe qui, formée sous sa propre peau, a remplacé la larve, mais c'est une riymphe qui se nourrit et s'accroît; l'œesophage n'a flas cessé de traverser le suçoir enfoncé dans les tégumens de l'jnsecte nourrisseur ; un prolongement membraneux en forme d'entonnoir. qui a pénétré peu à peu jusque dans les chairs mêmes de cet animal, y retient si foriement le sucoir. qu'il y reste encore altaché, avec une portion des enveloppes, après l'éclosion de la nymphe. Toutes ces assertions et celles qui vont suivre sont fondées sur l'inspection directe et positive; et, par exemple, M. Dugès a vu les fourreaux des palpes vidés à divers degrés chez des individus différens; les pattes sont un peu plus précoces dans cette opération : puis, en laissant un moment dessécher la surface de Ja nymphe, pour la plonger ensuite dans l'huile, M. Dugès a pu conslater et dessiner ce qui se passe sous la peau derenue transparente. On trouve alors les rudimens rétractés et blanchâtres des membres fu¿urs, représentés par dix masses oblongues blanchâtres, rangées régulièrement sur deux lignes, et d'autant plus considérables et plus ararcées qu'elles sont postérieures. De ces dix masses, huit sont sont destinées aux pattes, denx anx palpes; une tache blanche indique le siége futur des organes génitaux; et l'on peut apercevoir plus profondément le canal intestinal recourbé en arrière, renflé vers son bout inférieur, et communiquant par un canal étroil avec l'anus, situé au milieu de la face rentrale; il est plein d'une matière blanche, mais environné d'un pulpe rouge qui, sans doute, occupe des cœcum latéraux, comme chez l'adulte. l'eu après, les masses s'allongent, se courbent, dirigent leur bout aminci et libre en arant et vers la ligne médiane, prennent enfin l'aspect de membres, en s'amincissant à mesure qu'ils s'allongent ; en même temps aussi se forme le bec, et toutes ces parties se colorent en rouge, aussi bien que la peau de l'Hydracne cachée dans la nymphe. A travers la peau de cclle-ci, on peut aussi reconnoître les yeux de l'animal futur, et l'on a pu, dés les premiers changemens de forme, reconnoitre qu'ils rétiogradoient dans la même proportion que les. membres, en abandonnant leurs anciennes cornées, qui restent risibles aux angles de l'écusson ; on les voit fort bien encore, de même que les hanches, sur la peau de la nymphe éclose, et cette peau se montre toute cannelée de stries transversales, épaisses, et assez consistante pour conserver en partic sa forme; ordinairement elle sc déchire transversalement en deux portions pour laisser sortir le nouvel aninal, qui nage aussitôt arec vivacité. Les Nèpes et Ics hanâtres sont si souvent chargées de ces parasites. qu'il seroit étonnant qu'on ne les cût déja pas bien remarqués. La plapart des observateurs les ont pris pour des œufs. Swammerdam les nomme des lentes, des œufs qui s'accroissent par succion, etil en a tiré une petite Hydrachne (Biblia nat., tab. 2. fig. $4, g$, et fig. 5). Cetle opinion a été celle de M. L. Dufour, ainsi que celle de Degéer (Mém. pour' servir a l'Hist. nal. des Iirs., t. VII, pl. 9, fig. 7, 8, 9). II en a vı aussi naître des petites Hydrachnes; et Roesel parnit avoir fait la même observation. Sonnini a trouvẻ ces nymphes sur les Neèpes en Egypte, et il les a prises également pour des œufs (t. J, p. 411). M. Audouin (Mém. de la Soc. d'Hist. nal. de Paris, t, I) a re- 
gardé ces parasites comme derant constituer un genre nouveau d'A rachnides à six pattes, qu'il a nommé Achlysie. M. Mannerheim (Aun. des Sc. nat., t. II, p. 498) a observé une espece d'Achlysie qui appartient probablement à une autre espèce. Telles étoient les diverses manières de voir des autcurs au sujet de ces parasites avant les observations de M. Dugès, auquel la science est redevable d'avoir retiré du chaos ces Arachnides, dont les divers états étoient encore inconnus aux observateurs de la na. ture. A près les métamorphoses dont nous venons de retracer les détails, d'après $\mathbf{M}$. Dugès, l'animal n'est pas encore adulte; il a une mue et un changement à subir encorc. En effel, non-seulement ces jeunes Hydrachnes ont une forme plus ovoïde, presque en poire, et une taille beaucoup au-dessous de celle des adultes, ils ont aussi quelque chose de particulicr dans les parties visibles des organes génitaux; au lieu d'uve plaque cordiforme, on ne voit qu'une dépression en forme de fente superficielle; sur les côtés, à quelque distance, sont deux plaques ovales grenues, et qui, au microscope, et par réfraction, semblent ou perforees de trous nombreux, ou garnies de nombreux et très-petits stemmates régnlièrement disposés. Ces plaques ont beaucoup d'analogie avec celles qui sont perforées en écumoire ou granulées de gemmicules transparentes qui environnent les stigmates des Ixodes. M. Dugés ignore quel est l'usage de ces plaques perforées. $A$ près avoir vécu ainsi quelques semaines et pris un notable accroissement, ces individus impubères ou présumès tels vont se fixer à l'aisselle d'une feuille de Potamageton; ils enfoncent leur bec dans la tige et y accrochent leurs palpes; alors ils deviennent imnobiles; leurs pieds, leur bec est ses dépendances se retirent encore une fois sous la peau du corps, abandonnant leurs fourreaux cutanés. Ces parties éprouvent encore une fois la même élaboration, c'est-à-dire que d'abord épaisses, informes, courtes et pulpeuses, elles s'allongent, s'amincissent, se dessinent et se durcissent peu à peu; c'est toujours en avant que leur extrémité libre se dirige, et elles sont rangées parallèlement, de manière à occuper le moins d'espace possible; leurs griffes, leurs cils et leurs poils, tout se forme avant cette troisieme éclosion, qui s'opère à travers une fente de la peau du dos, et qui donne enfin le jour à un animal parfait. La dépouille qu'il abandonne nous a déja fourni quelques détails d'organisa. tion; on peut y reconnoitre même les ancicnnes mandibules, qui sans doute, ètant tout à-fait cornécs, se reproduisent dans leur totalité. Celte remarque, continue II. Dugès, a soulevé dans mon esprit la même question relativement aux autres membres. Sont-ce bien ceux dont se servoit primitivement l'animal qui se retire pour se perfectionner sous la peau? Ce que j'ai pris pour un fourreau cutané ne seroit-il pas le meinbre sphacélé et remplacé intérieurcment par un nouveau formé de toutes pièces? Cette théorie, que la reproduction des membres perdus chez les Crustacés, les Axaignées, les Salamandres, permettoit au moins d'admettre comme possible, a été renversée par l'expérience; j'ai coupé deux pattes dans un point et d'un côté déterminé et enregisiré avec la date, chez trois Hydrachnes du deuxieme agge, c'est-ì-dire ayant encore à subir la dernière transformation, celle qui vient de nous arrêter; cette mélamorphose s'est opérée comme de coutume, et mes sujets d'expériences sont sortis de leur nymphe secondaire avec des mutilations exactement en rapport avec celles que je leur avois fait subir plusieurs semaines auparavant, seulement les moignons n'étoient pas brusqucment tronqués comme après l'amputation, mais terminés en cône. Il en est donc ici comme du Papillon, dont les pattes longues et cffilées se forment pourtant des élémens de ces crochets courts et coniques qui arment le corselet de la chenille; si bien que, avant la première transformation de l'insecte, on trouve déjá dans chacun de ces crochets une patte longue, mais repliée, ratatinée, et qu'on peut déplisser par une dissection convenable.

\section{ITYDRACHNA GEOGRAPHICA.}

Muller, p. 59 , tab. 8 , fig. $3,4,5$. Latr., Hist. nat. des Crust. et des Ins., t. V III, p. 33, pl. 67 , fig. 2, 3 ; ibid., Gener.Crust.et Ins., t. I, p. 159; ibid., Rig. anim. de Cuv., nouv. édit., t. IV, p. 289. -Trombidium Geographicum, FaBr., Ent. Syst.. t. II, p. 405. - Cette espèce, qui est d'une taille assez grande, a son corps légérement tomenteux; clle a quatre taches el quatre points rouges situés sur le dos; cha. que point est marqué d'un autre petit point noir dans son centre; les yeux sont rouges, très-petits; les antennules sont composées de trois articles, et de la longueur des trois premières paires de pattes; celles-ci sont noires, plus courtes que le corps, velues et 
composées de six pièces. Dès qu'on touche cette espece, elle feint d'être morte penclant quelques instans. - Se trouve aux environs de l'aris.

M. Koch, dans sa Faune allemande, désigne trente-deux nouvelles coupes génériques, mais il ne leur assigne aucuns caractères; elles sont ainsi dénommées: $T$ ydeus,
Zercon, Sejus, Lolops, Nesta, Limnesin, Amonia, Caligonus, Spio, Thyas, Tiph s, Marica, Notaspis, Iphis, Hoplophora, Damous, Zetes, Pelops, Nothrus, Oppia, Cepheus, Carabodes, Celceno, Mypochlhonius, Murica, Eremarss, Actineda, Bryobia, Penthaleus, Scyphius,-Linopodes, Eupodes.

\section{SEPTILHE FAMILLE.}

\section{I G R O P H T H I R E S,}

\section{LATFeILle.}

Caractères. Cette famille comprend les A rachnides qui n'ont constamment en tout temps que six pieds.

Genres : Caris ${ }^{1}$, Leptus, Achlysia, Ocyprete.

\section{LEPTUS, IATR.}

Les pattes sont au nombre de six. - Il y a un suçoir avancé. - Des palpes apparens, courts et presque coniques. - Le corps est trés-mou et ovale. Ces Arachnides, qui sont excessivement petites, ont le corps ovale, renflé; la partie anterieure présente comme une tête, ayant de chaque cóté un point noir qui représente peut-être les yeux. - La peau qui couvre le corps est souple, bien tendue et luisante; l'animal la fronce et la ride quelquefois.

Ces petites Arachnides sont parasites.

\section{LEPTUS AUTUMNALIS.}

Latr., lićg. anim. de Cuv., nouv. édit., t. IV, 1). 290. - Acarus Autumnatis, Susw., Zool. Misc., t. II, pl. 42. - Cette espèce est très-petite, d'une coulcur rouge; elle grimpe et s'insinue dans la peau, à la racine des poils, el cause des démangeai-

(1) Nous ne décrirons pas le genre Caris de M. Latreille, l'arant rapporté au genre Argas; il en est de même de celui d'Achlysia, qui n'est qu'une larve d'IIydrachna. C'est avec doute que nous regardons comme parvenues à l'état parfait ies Arachnides composant les genres Leptus et $O c y$ pete. sons très-vires et presque aussi insupportables que celles produites par la gale; elle est connue vulgairement sous le nom de Rouget par les habitans des campagnes. M. Quoy nous a appris qu'elle est trèscommune, à l'époque des vendanges, dans Ic département de la Charente-Inférieure, où elle est connue sous le nom de Vendan. geron. M. Latreille dit avoir apaisé les dé. mangeaisons produites par la piqûre de ces Arachnides en lavant les endroits irrilés avec de l'eau mêlée d'un peu de rinaigre.

\section{OCYPETE, Leach.}

Les caractères assignés par $\mathbf{M}$. Leach à ce genre s:nt les suivans: Pieds arnbulatoires. - Des mandibules. - Palpes ayant un appendice mobile à leur extrémité. - Deux yeux portés sur un pédicule. - Corps comme divisé en deux portions, dont l'antérieure porte la bouche, les yeux et les deux paires de pieds antérieurs. - Six pieds.

L'espèce qui a servi de type à ce genre est :

\section{OCYPETE RUBRA.}

Leaci, Trans. Lini. Societ., t. XI, p. 396. - Son corps est garni de poils d'un cendré roussâtre; ceux dı dos sont longs et rares; ceux des pattes sont très-courts ; les yeux sont d'une couleur noirâtre. Elle se trouve très-communẻment sur lcs Diptères de la famille des Tipulaires. 
M. Latreille désigne sous lé nom de My. riapodes ${ }^{1}$, ces insectes que l'on appelle vulgairement mille-pieds ou cent pieds, et que les anciens désignoient sous celui de centipèdes. Ces animaux, qui forment maintenant une classe, sont ainsi caractérisés : terrestres, articulés extérieurement, à segmens nombreux; un ganglion nerveux et plus souvent une paire de pattes articulées pour chaque anneau du corps; le système ganglionnaire infẻrieur au canal intestinal et placé sur Ja ligne médiane.- Point d'abdomen distinct du thorax et apode.--Point d'ailes. - Tête pourvue de deux antennes.-Bouche composée de plusieurs paires d'appendices. Les deux ouvertures du canal intestinal terminales et opposées - Yeux stemmatiformes, composés ou nuls. - Circulation incomplète. - Respiration trachéenne. Génération bisexuée, dioïque, ovipare ou ovovivipare. Tels sont les caractères de celte classe bien distincte de la suivante ou de celle des insectes.

Les organes masticateurs des animaux qui composent cette classe ont été étudiés avec soin pour quelques espècesseulement. Chez les Chilognathes, Glomeris, Iules, etc., on remarque, d'après M. Latreille, deux mandibules épaisses, sans palpes, très-distinctement divisees en deux portions par une articulation médiane, avec des dents imbriquées et implantées dans une convexilé de son extrémité supérieure; une lèvre (languette, suivant M. Latreille; lèvre infericure composée de deux paires de mâchoires, selon Mi. Savigny), située immédiatement au-dessous d'elles, les recouvrant, crustacée, plane, divisée à la surface extérieure par des sutures longitudinales el des échancrures en quatre aires principales, tuberculées au bord supéricur', et dont les deux intermédiaires, plus étroites et plus courtes, situées à l'extrémité supéricure d'une autre aire, leur servent de base commune. Chez les Chilopodes, au contraire (Scolopendres, Lithobies, Scutigères), la bouche est composée de deux mandibules munies $d^{3} u n$ petit appendice en

' $\mu$ upens sans nombre, dix mille el $\pi 005$, $\pi 0$ Soj, pied. forme de palpe, ofrant dans leur milicu l'apparence d'une soudure, et terminées en manière de cuillère dentelée sur les borûs ; d'une lère quadrifide dont les deux divisions latérales, plus grandes, annelées transversalement, semblables aux pattes membraneuses des Chenilles, les deux palpes ou pelits pieds réunis à leur base, onguiculés au bord, et d'une seconde lève formée par une seconde paire de pieds dilatés et joints à leur naissance, et terminis par un fort crochet mobile et percé sous son extrémité d'un trou pour la sortic d'une liqueur vénéneuse. Cetle définition, que nous empruntons à M. Latreille, differe sous quelques rapports de celle qu'avoit donnée antérieurement M. Savigny, et qui repose sur de patientes et laborieuses observations; Degéer avoit déjà entrepris de décrire et de représenter les appendices qui composent la bouche des Scolopendres. Les figures que M. Savigny a données dans les belles planclies de la Description de l'Egypte, sont les plus complètes que l'on puisse citer. M. Guérin a étudié, depuis, le même organe dans une espèce du premier ordre, le Pollyxène, et a consigné dans son Iconographie du Rigne animal de Cuvier, pl. 1, Je résultat de cetle élude, qui fait mieux comprendre qu'on ne l'avoit fait jusqu'alors la bouche de ce Myriapode.

Après les appendices qui font partie de la bouche et qui servent à saisir la nourriture ou à la broyer, nous devons parler de ceux du tronc; ceux-ci, qui sont les membres ou les pieds, sont composés d'articles plus distincts; on voit que leur grand nombre a déterminé le nom que porte ces animaux. Les caractères qu'ils présentent ne sont pas moins utiles pour la classification que les précédens; car ils confirment ce qu'avoient indiqué les précédens, et justifient la séparation des Myriapodes en deux groupes.

Tous les anneaux du tronc (sans distinction de thorax et d'abdomen) sont ponrvus de patles; et dans tous les Chilopodes, chaque anneau présente une paire de pattes insérée sur les parties latérales; mais les Chilognathes ont ordinairement deux paires de paltes pour chaque anneau, 
et clez eux c'est à la partie intéricure du corps que s'insèrent ces appendices. Nous prendrons pour exemple les Polydesmes, animaux les plus voisins des lules, mais qui s'en distinguent par un moins grand nombre d'anneaux au corps, et par suite de pattes; les segmens toujours consistans el plus ou moins carénés sur leurs bords sont an nombre de vingt, sans comprendre la tète; le premier, qui est celui de la nuque, manque de pattes, et les trois suivans en ont chacun une paire; il semble quelquefois que l'anneau ventral, bien qu'incomplet, possède une paire de pattes, et que le suivant, au contraire, en soit dépourvu. Quant aux autres, ils ont chacun deux paires d'appendices, et le dernier, on l'anal, en est loujours dépourvu. Parfois un ou plusieurs anneaux offrent trois paires de pattes chacun; mais c'est un cas anomal. l'alisot de Beauvois en a représenté un cxemple dans son ouvrage sur les insectes d'Afrique et d'Amérique. Chez certains Iules, deux segmens par anneaux sont parfois apodes; mais ceci n'a pas constamment lieu, et se voit plus volontiers chez les individus qui n'ont point encore pris tout leur développeinent : les Glomeris et les Polyxènes, à cause du peu de consistance de leur derme, semblent offrir moins de régularité sous ce rapport.

Les pieds des Myriapodes sont plus ou moins longs; c'est chez Ies Scutigères qu'ils prennent le plus grand développement de. longueur; quant au nombre, ils ne présentent pas de moins grandes différences, non-seulement suivant les espèces, mais suivant l'âge des individus; sous ce dernicr rapport, les espèces qui, dans l'élat parfait, en possèdent le moins, sont les Polyxines, qui n'en ont que douze paires. Dans le mème ordre certains lules en prèsentent près de trois cents. Mème variation pour les Chilopodes; les Lithobies et les Scutigères u'en ont que quinze paires; et chez un Gẻophile désigné sous le nom de Walckenaerii, Gerv., espèce des environs de Paris, M. P. Gervais en a compté trois cent trente-six.

La forme du corps est toujours en rapport avec la disposition des appendices, et les anneaux qui le composent se montrent sous différentes formes; assez mous chez les Polyxènes, ce n'est qu'en dessous qu'ils oflrent cette disposition; chez les Glomeris, ils sont latéralement et en dessus d'une grande consistance. Ceux des Iules sont entièrement durs et cylindriques; ceux des
Cambalas et des Platyules sont déprimés. Chez les Scolopendres, is affectent de mème diverses dispositions; les Géophiles les ont à peu près égaux entre eux, car ils semblent constamment formés d'un segment plus petit et d'un autre plus grand, ce dernier étant seul pédigère. Dans les Scolopendres ils sont uni-partis et tous pédigères, mais ils sont alternativement plus ou moins longs; l'alternance est marquée chez les Lithobies, mais seulement à la face dorsale; enfin chez les Scutigères, ils semble exister en dessous un plus grand nombre de segmens qu'en dessus, parce qu'à cet!e partie les plus petits ont cessé d'être apparens. Les antennes qui président au toucher sont au nombre de deux; celles de Chılognathes n'ont jamais plus de sept articles, el celles des Chilopodes cri ont toujours un plus grand nombre: les Gẻophiles en ont quatorze; les Cryptops et les Scolopendres dix sept ou vingt environ, leurs articles étant greuus. Chez les Scutigères elles sont au contraire filiformes et extrèmement allongees. Certains Myriapodes manquent d'yeux, (Polydesmes, Blaniules, les Cryp. tops et Géophiles); chez les Scolopendres, les Platyules et les Lithobies, ces organes sont stemmatiformes et plus ou moins nombreux; Les Iules les ont plus rapprochés; tels sont encore les Polyxènes et les Zéphronies. Enfin, ils ont dans les Scutigères l'aspect des yeux composés de la jlupart des Crustacés. Une particularité bien remarquable signale le developpement de ces organes chez quelques espèces qui ont été éludiées par M. P. Gervais; les yeux, beaucoup moins nombreux dans le jeune âge, apparoissent successivement à mesure que les autres organes se développent.

Si nous étudions maintenant les organes internes de ces animaux, nous verrons que les Myriapodes ont leur système nerveux parfaitement conforme aux autres animaux articulés; ils sont même un exemple au moyen duquel la disposition normale de tout le type peut être le mieux comprise; les nerfs prinçipaux forment sur la ligne médiane du corps, au-dessous du canal in. testinal, une série de ganglions, et chacun de ces ganglions correspond à un des anneaux du corps; tous donnent naissance à des filamens plus ténus qui s'en échappent lateralement; le nombre des ganglions principaux est donc proportionncl à celui des anneaux du corps, et comme dans cer. taines espèces ceux-ci sont incomparable- 
ment plus nombreux chez les adultes que chez les jeunes sujets. les ganglions varient eux-mèmes en nombre. M. Treviranus a fait comoître avec soin ce système important de l'écunomie des Myriipodes. ainsi que celui de plusieurs autres especes, dans son mémoire sur l'analomie de quelques especes: de celle classe.

Tousces animaux respirentl'air en nature, et ils sont pourvus de lrachées; ces nrgaucs s'ourrent sur les côlés de leur corps par des stignates; leur systéme vasculaire, de même que celui des animaux trachéens, est fort incomplet; le lube digestif chez ces animaux esí tout-à-fait droil et ne dépasse par conséquent pas la Iongueur du corps; dans les Lithobies, l'œsophage et le jubot ne forment qu'un même tube d'un diametre uniforme, cylindrique, enveloppé par les glandes salivaires ef atteiguant à peine la seconde plaque dorsale. MIM. Treviranus et Marcelle de Serres n'admettent point de jabot; mais l'analogie le fait supposer à M. L. Dufour, d'un léger bourrelet à l'origine du ventricule chilifique; ce bourrelet, qui semble être l'indice d'une valvule annulaire, vient prêter un grand poids à l'induction par analogie. Cette valvule prouve que les alimens ne doivent pénélrer dans la poche qu'elle précéde qu'après avoir subi une elaboration préliminaire dans le ventricule en question: le ventricule chilifique forme a lui seul les trois quarts de la longueur de tout le tube digestif; sa cavité renferme une pulpe alimentaire homogène, d'un gris-roussâtre. L'intestin, bien moins large et cylindroïde, paroît cannelć suivant sa longueur, lorsqu'il est vide et contracté sur lui-même; arant de se terminer à l'anus, il offre un cacum à peine sensible qui est caché par les derniers segmens de l'abdomen. Il n'y a chez les Lithobies qu'une paire de vaisseaux hépatiques; ils s'insèrent un de chaque côté et par un bout légérement renflé au bourrelet valvuleux cité plus haut, comme étant en arrière du canal chylifique. Chez les Scutigères l'appareil digestif diffère trèspeu de celui des Lithobies; l'œsophage est d'une briéveté exirême; le jabot n'est qu'une petite dilatation; le ventricule chy. lique est cylindroïde et occupe environ les trois quarts de la longueur du corps; il a une capacité assez vaste; ses parois sont assez épaisses et d'une texture remarquable; l'intestin paroit plus musculeux que le ventricule chylifique; un peu en avant la terminaison du rectum existe nne sorte d'ap.

AnN. pendice cocal; le tube alimentaire des lules est, à neu de chose près, le même que celui des Lithobies et des Scutigères, les dişositions générales élant fort analogues.

La reproduction des Myriapodes est ovipare ou dans quelques cas ovovivipare. Degeer a étudié les Iules des sables sous ce rapport, et voici comment il s'exprime: Celui dont je viens de domner la description etait une femelle; car elle pondit un grand nombre d'cufs d'un blanc sale. en un tas les uns auprès des autres; ces œufs sont petits et de figure arrondie.

La ponte n'a été observée dans aucun au tre cas, que je sache, dit M. P. Gervais; je dois néanmoins rappeler que it. le professeur Audouin a bien voulu me communiquer qu'il avait recueilli les produits de celle d'une espece du véritable genre Scolopeudre, voisine des Scolopendres mordantes; une femelle de celle espèce, placée, encore vivanle, dans un flacon d'alcool, y pondit non des œufs, mais des pelits déjà développés, que M. Audonin a bien voulu me faire voir; la génération a donc été ovovivipare : est elle scmblable chez toutes les especes? c'est ce que l'observation pourra seule apprendre. Chez les Myriapodes oripares un phenomène remar. quable se présente. Je n'esperois, contiune Degéer, que nous cilions plus haut, voir des pretits sortir de ces cufs, car il étoit in. cerlain si la mère avoil èté fécondée ou non; cependant après quelques jours, c'étoit le premier du mois d'août 1746 , de charue œuf il sortit un petit Iule blanc, qui n'avoit pas une ligne de Jongueur; j'examinai d'abord au microscope les coques d'œuls vides, et je vis qu'elles s'étoient fendues en deux portions égales, mais qui ienoient ensemble vers le bas. Ces jeunes Iules, nourellement éclos, me firent vour une chose à laquelle je ne m'attendois nullement; je savois que les insectes de ce genre ne subissent point de métamorphoses, qu'ils ne deviement jamais insectes ailés; ainsi j'étois comme assurc que les jeunes Iules devoient être semblables en figure, à la grandeur près, à leur mère, et par conséquent je croyois qu'ils étoient pourvus d'autant de pattes qu'clle; mais je vis toute autre chose; chacun d'eux n'avoit que six pattes, qui composoient trois paires, ou dont il $y$ avoit truis de chaque côté du corps; ils avoient beaucoup de ressemblance avec des vers ou des larves hexapodes, telles que celles qui doivcut se transformer en insectes ailés. Ce qu'il y a 
de certain, e'est que ces jeunes Iules naissent avec six paltes seulement, et qu'en quatic jours de temps il leur vient encore quatre paires de pattes, de surte qu'alors ils en ont sept de chaque côlé. J'ai aussi observé d'autres changemens sur ces lules âgés d'environ quatre jours, qui sont de même très-remarquables, et qui semblent demander davantage d'être précédés d'un changement de peau. Les antennes se sont beaucoup développées; elles sont devenues plus longues et moins grosses a proportion, et elles ont pris deux articulations de jlus, elles en avoient six, et d'abord n'en avoient eu que qualre.

A ces délails que nous avons eu occasion, poursuit M. P. Gervais, de confirmer daus plusieurs points et d'étendre sur plusieurs autres, nous devons néanmoins, pour être complets, oppuser ceux qu'a publiés M. Paul Savi, qui dit tout le contraire de ce qu'a avancé Degéer; car il admet que les Jules n'ont pas de palles lorsqu'ils éclosent. Degéer a aussi constaté que le Pollyxine, qui a douze paires de pattes lorsqu'il est adulte, en présente,un moins grand nombre à une époque moins avancée. Quclques-uns de ceux qu'il obscrva u'avoient que six paires de pattes, ct d'auties trois seulement. 11 est à remarquer , dit l'auteur, que les pattes des jeunes lules sont plus grandes. à proportion du volume du corps, que celles de ceux qui ont acquis Jeur juste grandeur.

J'ajouterai un fait curieux, et que j'ai moi-méme observé, dit toujours le mème naturaliste, a ceux que $j$ 'ai cités plus haut sur les lules, c'est que chez les animaux de ce genre les variations occasionées par l'àge portent non-seulement sur le nombre des pattes et des anneaux du corps ou sur celui des antennes, mais encore sur celui des yeux; c'est ainsi que les jeunes Iules que j'ai observés avoient un moins grand nom. bre de ces organes que ceux qui éloient plus adultes.

J'ai constaté un fait analogue chez les Lithobies, espèces fort communes dans nos contrées, et, quoique je n'aie pas suivi exactement le développement de ces. Myriapodes, je dois rapporter ce que leur étude m’a présenté. Cies animaux, que tout porte à supposer ovipares, bien qu'on n'ait réellement point encore décrit leurs œufs , ont ègalement les anneaux du corps et par suite les pattes moins nombreux dans leur premier âge. Toutefois, on se tromperoit gravement si l'on essayoit de cousidérer cette particularité comme génêrale ; car lę Scolopendres qu'a observées M. Audouin ont, ainsi qu'il me l'a dit, leurs pieds déjà complets, et les anneaux de Jeur corps sont tous développés. Un pourroit peut-être admettre que celte difference entre deux animaux si voisius tient ellemêne à leur mode de parturition, et que l'ovoviviparité des Scolopendses propre. ment diles explique le déı eloppement déjà fort avancé de leurs petits.

Les mours des Myriapudes varient selon la nature des familles auxquuelles ces animaux appartiennent. Certaines espèces sont frugivores, comme les lules, les Gloméris, etc. ; d'autres attaquent au contraire des animaux pour s'en nourrir; telles sont les Scolopendres. Celles du vrai genre Scolopendre se servent en même temps, pour relenir leur proic, de leurs crochets postérieurs et de ceux dont la bouche est armée; ceux-ci ont à leur extrémité une petite ouverture par laquelle s'écoule la sécrétion d'une glande spéciale. C'est à la présence de ce liquide que Jes Scólopendres doivent la cruelle irritation qui ne tarde pas a s'y développer; toutefuis elles ne sont pas réellement dangereuses. Celles des petites espèces, Lithobies et Géophiles, qui vivent dans le Ford, sont bień moins irritantes. C'est dans les lieux humides, sous les mousses qui courrent le pied des arbres, sous les écorces de ces derniers, et quelquefois dans les habitations, que virent les Myriapodes ; la plupart craignent la sécheresse, et ne tardent pas à périr s'ils y restent exposés pendant un certain temps; mais, placés dans des conditions plus favo. rables, ils sont au contraire tris-vivaus, et il suffit, pour les conserver ainsi pendant plusieurs mois, de les tenir à l'ombre dans un vase rempli de terre ou de mousse; ils s'y cnfermeut aisement, et se creusent dans toutes les directions des chemins qu'ils on besoin de traverser. 11 est facile d'observer combien la plapart d'entre eux sont lucifuges : ils passent tout le jour sous la terre ou au milieu de la mousse, et quand le s.jir est venu, ils s'agitent à la surface. Quelques Scolopendres sont électriques, ou mieux phospborescentes, c'est-à-dire qu'à certaines époques de l'année elles transsudent une matiere lumineuse, qui marque en une raie plus ou moins bril. lante le passage qu'elles viennent de quitter : une de nos espéces a recu, à cause de cette particularité, la dénomination de Geophilus Electricus; une autre est appe- 
lée Phosphorcus; celle-ci cst cxotique et pen conuue, mais la précédente est uue de celles qu'on reucontre le plus fréquemment chez nous; le Geophilus Cupophages présente parfuis la mème proprièté. C'est surtout entre les anneaux et au-dessous du ventre que la sécrélion cutanée des Scolopendres se fait en plus grinde abondance. Chez les lules ces urganes sont plus évidens, car ce sont des especes de sacs placés sur les côtés de chaque annean du corps, au-dessus du stigmate de la trachée; la partie de la peau qui les environne est le plus sourent d'une couleur fort tranchée, et qui a plus ou moins d'analogie avec celle de la matière sécrélée. Cielle-ci est toujours assez fortement odorante, et dans les diverses especes indigines, elle imile, à s'y méprendre, l'odeur du gaz acide nitreux. M. P. Gervais a cherché a s'assurer de la nature de ce produit dans le Iulus Lucifu-

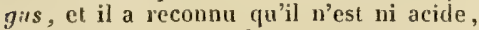
comme on pourroit le croire, ni alcalin d'une manière positive. Cette matière, en petite quantite, et il n'est pas facile d'en ramasser davantage, est sans action sur le papicr bleu de tournesol.

Un des traits les plus curieux de la phy. siologie des Myriapodes, et surtout des Scolopendres, est la manière dont ils résistent aux plus grandes mulilations. J'ai conservé, poursuit M. P. Gervais, des Géophiles pendart un et mème deux jours dans l'eau, et ils n'o at point cessé de vivre; et j'ai vu un des fragmens postérieurs de ces animaux remuer encore environ quinze jours après avoir été séparé du reste du corps. Quand on arrache la tête à un Géo. phile, on le voit aussitôt marcher dans le sens de la queue, el il peut vivre ainsi pendant quel(que temps; si on lui euleve ensuite l'extrémité anale, il recommence d'abord a marcher en sens contraire, comme pour fuir l'objet qui vient de le blesser, mais on peut bientôt remarquer qu'il n'a plus alors de direction bien déterminée. car il s'avance tantôt d'avant en arrière et tantôt d'arrière en avant. Les Iules sont beaucoup moins vivaces que les autres auimaux de celle classe.

La distribution à la surface du globe des espèces de la préserte catégorie est encore bien loin de pouvoir être indiquée d'une manière posilive; car on connaît encore un trop petit nombre de celles qui y existent pour rien dire de général sur ce sujet.

Quclques espèces habilent un espace assez considérable; c'est ainsi, par exemple,
Gu'on rencontre le Scutigèrc Arénoìde de. puis le nord de l'Europe jusqu'en Egypte et en Barbarie; mais c'est à lorl que l'on a précndı qu'il en étoit, comme de la Sco. lopendra Morsicans, de communes aux parlies chaudes de l'ancien et noureau monde. On a, en effet, confondu sous le raême nom de Morsicans des animaux sans aucun doute congénères, mais entre lesquels il est facile de reconnoilre des différences spécifiques. Nous laisserons le num spécifique de Morsicans à l'espece du nord de l'Afrique et de l'Europe méridionale.

Les Myriapodes qui se trousent en France appartiennent aux deux ordres de la classe, et représenlent à peu près tous les genres de cette derniere. l'Jus nombreux au sud qu'au nord, ils ont dans les contrées méridionales une grande analogie avec cenx de l'llalie et cle l'Espagne, et deux d'entre eux se retrouvent mème dans tout le nord de l'Afrique; ce sont la Scolopendre Mordante et la Scutigère Arénoïde; nous avons lieu de croire que le Géophile (ie Walckenaer, espece fort remarquable yecueillie à Paris mème, existe aussi en Barbarie.

Quant à la répartition géographique des genres, elle est moins réguliere; car la plu: part de ceux qui possedent plusieurs espèces se troutent en même temps représentés par des espèces dilférentes, il est rrai, des régions bien distincles. Certains genres sont propres, nop-seulement à un continent ou deux, mais ils peuvent être cosmopolites. On trouve des Scolopendres dansl'ancien et le nouveau monde, maisnous n'en connoissons pas de l'Australie. Quant aux Polydesmes, nous en avons vu d'Europe, d'Asie, d'Afrique, de l'Amérique septentrionale et de l'Ainérique méridiona!e ainsi que de la Nouvelle-Iloliande. Les Scutigeres, que nous citions plus haul, sont aussi une espece australienne et d'autres asiatiques.

La classification des Myriapodes h'est pas un des sujets les moins curieux de leur histoire. La classe parfaitement naturelle que composent ces animaux n'a pas été considérée par tous les naturalistes comme. offrant les mèmes affinités ; tous- sont d'accord, comme on le pense bien, pour la rap: porter au type des animaux articulés; mais auprès de quelle autre classe doit-ellc prendre place? Dans ce cas comme dans beaucoup d'autre;, les singulieres diver: gences quel'on remarque entre les anteurs, tiennent plutỏt aux principes sur lesquels 
reposent leurs déterminations ou au but qu'ils se proposoient dans leur classification, qu'i la nature elle-meme du sujet.

Quelques uns admetlant à priori plutôl qu'après une ample information, que toute disposition sériale est impraticable et qu'elle seroit coutraire à l'ordre naturel, ont vu dans les Myriapodes une nouvelle confirmation de leur thérie, et les Myriapodes ont élé pour eux des animaux intermédiaires en même temps à la plujart des autres classes du deuxieme type. Aussi ces naturalistes ont-ils eu sur les Myriapodes l'opinion la moins arrêtée qu'il soit possible d'avoir ; c'est ainsi que Latreille les a successivement envisagés comme formant un groupe à part, la classe des Mitosata de Fabricius; puis comme elant de véritables Arachnides, ce qui rerenoit a la maniere de voir du célèbre Lamarck ; cnsuite, il Jes considéra comme devant rentrer dans la même classe que les insectes à six pieds. les rapprochant des Thysanoures, avec lesquels MM. Stuauss, Dugès, ctc., supposent qu'ils ont de véritables affinités; mais depuis, en reconnoissant toujours leur rapport avec les Thysanoures, Latreille (Cour's d'Entomologie), venant à considérer les Myriapodes comme constituant une classe particulière, les place entre celle des Hexapodes et celle des Arachnides.

D'autres savans, au contraire, ayant admis que la disposition sériale est pralicable dans certaines limites, rangent les animaux articulés sur deux séries parallèles, et reportent les Arachnides et les Crustacés sur une de ces lignes, tandis que les Insectes, les Myriapodes et les Annelides forment l'autre; ils sont conduils à regarder les seconds comme intermédiaires anx premiers et aux troisièmes (Strauss, Consid. génér., p. 29). On ne sauroit en eflet nier que les Myriapodes n'offient avec les Annelides, et particulièrement avec les Chétopodes, des analogies évidentes; la forme générale du corps et celle de chacun de ces segmens, la marche rampante, etc., doivent faire comparer ces deux groupes d'animaux, et conduiront jusqu'à un certain point é établir que les Myriapodes sont les analogues terrestres des vers pourvus de soies laterales. Mais, en admettant ce raisonnenent que l'élude du genre Péripate rend hors de doute, doit-on également reconmaîre que d'autre part les Thysanoures (Lépismes, Podures, etc.) sont les animanx qui se lirnt mieux aux Myriapodes? c'est ce que n'admet pas un savant zoologisie, AI, de
Blainville, à l'opinion duquel, dil Mr. Gervais, nous croyons devor nous ranger.

Les Crustacés présentent certains genres tous pourvus de quatorze palles, el au nombre desquels on compte les Cloportes, qui on certainement avec les Myriapodes de la famille des Glomérites, beaucoup plus d'analogie que n'en ont ceux-ci avec les Thysanoures; et cela est si vrai que $\mathrm{Fa}$. bricius rapportoit i sa classe des Mitosata, non-seulement les Scolopendres et ies Iules, mais encore les Cloportes auxquels sont mêlés, dans son système, plusieurs espèces de Gloméris. Olivier et $G$. Cuvier ont les premicrs fait disparaitre celle légère incorrection. Curier, dans son tableau élémentaire (p. 464. 1798), ne laisse que deux genres parmi les Mitosales; ceux des Iules, parlagés en trois sections comme l'a. voit indiqué Fabricius, et des Scolopendres; il les intercalle entre les Cirustacés et les Arachnicles. Il paroît donc démontré que les Crustacés tétradécapodes (a quatorze pattes), et les Annelides Chéıopodes, étant tes animaus qui se lient le micux aux Myriapodes, on ne sauroit micux faire que de placer ceux-ci entre les uns et les autres, puisque eux-mèmes $s^{\prime} y$ rapportent naturellement, et que cetle determination permet en même temps de recon. noître les affinités qui unissent entre elles les diverses autres classes.

La position naturelle des Myriapodes une fois déterminée, la disposition de ces animaux est elle-même très-facile à établir ; car elle doit nécessairement être une conséquence de la premic̀re. Les espèces qui seront te plus semblables par leur forme aux Cloportes (Crustacés tétradécapodes), seront plus rappruchées d'eux queles antres, et à la fin seront confinés des genres qui semblent plus analogues aux Amnelides. M. Strauss reconnoît dans le Pollyxene le Myriapode le plus voisin des Chétopodes, il le compare aux Léodices; nous pensons au contraire qu'il a des rapports bien plus éridens avec les Cloportes; et qu'au lieu d'ètre iaplroché des Annelides, il doit au contraire en être éloigné plus qu'aucun autre. Les pieds du gen e Pollyx ène. moins nombreux que ceux du reste des Myriapodes, le rendent sousce point de vue plus analozue aux Cloportes, dont il a le faciès. Les yeux sont aussi semblables à ceux de ces animaux, et tout en lui semble indiquer une espèce formant le passage des. Clopories atux Glomeris. Apres les Pollyxènes, se placeront donc les Glomeris, et si l'on 
continue à consulter les antennes, la forme du coris ainsi que le nombre et les modes d'insertion des pattes, et quelques caractères tiré: de l'absence ou de la présence des yeux et de leur disposition, en évalıant chacun des caractères que fournissent ces organes a sa juste valeur, on devra, ce nous semble, placer tnstuite les Polydesmes, puis les Iules proprement dits, et ceux de ces animaux dont le corps est déprimé au lieu d'être circulaire, et qu'on pourroit appeler Platyules. Latrcille a fait de ces divers genres, qu'il dispose un peu différem. ment, un premier ordre sous le nom de Chilognathes. Dans un second groupe sont placés les Scolopendres et les Scutigères, auxquels l'auteur applique la désignation commune de Chilopodes. Cet ordre correspond au genre Scolopendra de Linné et de Degéer, el le premiér à celui des Iules.

C'est ainsi, continue M. P. Gervais, que Leach et Latreille ont conçu les rapports des Myriap des entre eux; mais comme le principe fondamental de toute disposition systématique est que la série des genres d'un mème groupe soit élablie de telle sorte que les animaux doivent êlre plus ou moins rapprochés entre eux, selon qu'ils ont plus ou moins d'analogie, et que ceux qui commencent la série doivent être plus semblables aux dernières espèces du groupe précédent, et semblablement pour les derniers échelons de cette série. avec les premiers de la suivante, M. Gervais a pensé que la disposition ci-dessous était la plus naturelle. Comme nous suivons la classification qui a été indiquée par M. Gervais, dans un mémoire ayant pour titre : Etudes pour servir à l'Hist. nat. des Myriapodes, les Pollyx ènes y seront placés les premiers, parce qu'il les considere comme les plus semblables anx Cloportes qui les précèdent dans la méthode, et il est assez facile de passer ensuite d'un genre donné à celui qui Jui succède; un intervalle semble exister entre le premier et le second ordre; mais aucune méthode ne sauroit éviter cet inconvénient, et il n'en reste pas moins démontré, pour M. P. Gervais, que les Iules et genres vosins sont plus analogues aux Crustacés, que les Scolopendies paroissent plus intimement liés au contraire avec les Annelides, et que les Scutigères, qui seront a la tète des Scolopendres, ne sont pas sans analogie avecles derniers genres de l'ordre des Iules. Un caractère remarquable existe dans les tarses des Scutigeres, qui sont multi-articulés a la manière de ceux des Hexapodes.

La classe des Myriapodes, d'après le travail ci-dessus cité, a été divisée en deux ordres.

Ier ordre. Cuilognaties. Cet ordre a été divisé en trois familles: les Pollyxénites, les Glomérites et les Iulites.

Ile ordre. Chilopones. Cet ordre renferme deux familles : les Sculigérites et les $S$ colopendriles.

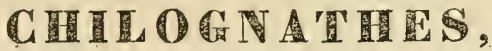

\section{ATREILLE.}

Caractères, 11 renferme le genre Iulus de Linnè, formé de Myriapodes, dont le corps est généralement crustacé, cylindrique, muni de pieds très-courls, distribués par paires uniques sur les anneaux antérieurs, par paires doubles sur les autres, toujours terminés par un seul crochet et de deux antennes fort courtes, un peu plus grosses vers le bout on presque filiformes, et composées de sept articles. - Les mandibules sont crustacées, sans palpes, de trois articles, arec des dents mobiles et imbriquées au bout. - La langue, terminant intérieurement la tête, se présente sous l'ap. parence d'une lame ou d'un feuillet, divisée ả la surface extérieure par des sutures longitudinales et des échancrures, en quatre aires principales, couronnées supérieurement par des tubercules, dont les deux intermédiaires plus étroites et plus courtes, situées au-dessus d'une autre aire, leur servant de base commune. Mais ce qui caraclérise encore mieux cet ordre, c'est que les organes sexuels ne sont pas situés à l'extrémité postérieure du corps, mais vers sa partie antérieure; ceux du mâle sont placés sur le sixième serment, après la septième paire de pattes, et ceux de la femelle derriere 
c: ux de la seconde paire. - Les stigmates, qu'il ne faut pas confondre, d'après les observations de M. Savi, avec des pores latẻranx, destinés à la sortie d'une liqueur acide et d'une odeur pénétrante que répandent ces animaux, sont silués alternarativement en dehors de l'origine de chaque naire de pieds. tris petils on pen apparens. On remarque encore que ces dern ers segmens sont contigus à leur naissance on insérés sur la ligne medlane et inféricure du corps, tandis que dans l'ordre suivaut, ils sont latéranx ou séparés par la largeur des segmens. Le premier article, ou la hanche des quatre antérieurs, est allongé, comprimé, lamelliforme. Le premier segment du corps dans les uns, le second dans les atıtres. et précédé alors d'un demi-segınent clypéiforme, est ordinairement plus grand que les suirans; le pénultıéme, dans les espéces anguiformes, se termine souvent en pointe, et le dernier de l'anal est partagé longitud nalement en deux valvules; enfin les yeux lisses sont beaucoup plus nombreux que dans l'ordre suivant.

M. Savi a observé que les ouvertures de la respiration communiquent interieurement as ec une double sẻrie de poches pneumatiques, disposces longiludinalement en chapelet, le long du corps, et d'où parient les branches trachéennes, se répandant sur les autres organes. Suivant lui, les amours de l'lule commun commencent vers la fin de décembre et finissent vers la mi-inai. Les organes sexuels masculins n'apparoissent que Jorsqu'il a acquis je ticrs en iron de sa laille ordinaire, el leur place esı juş̧u’alors occupée par une paire cle paltes. Ils m'ont paruformés, dit M. Latreille, de deux mamelons, terminés chacun par un crochet écailleux el contourne. Deux autres mame lons, mais sans crochet, placés derrière la naissance des secondes pattes, caractérisen: ceux des femelles. Dans l'accouplement, ces animaux redressent et appliquent l'une contre l'autre, face à face, l'extrémité an. térieure de leur corps, et s'entrelacent infrieurement. Celui des individus qui vien. nent de maître est en forme de rein, uni et sans appendices. Dix-huit jours apres, suivant M. Savi, ces animaux subissent une première mue; mais ils n'ont encore que ingl-deux segmens el vingl-six paires de pattes, dont les dix-huit premières servent toutes à la lucomotion; a la seconde mue, l'animal en offre trente six, et à la troi. sieme quarante-trois; le corps est alors com. posé de trente segmens. Enfin, dans l'étal adulte, le mâle en a trente-neuf, et la femelle soixante-quatre. Deux ans après ils muent encore, et c'est alors seulement quo se montrent au-dehors les organes de la génération. Depuis la naissance, qui a cu lieu en mars, jusqu'en norembre, ou M. Savi a cessé ses obier ations, ces changemens se renouvellent de mois en mois. Plus haut, nous avons déjà fait remarquer que ces observations ne s'accordoient pas avec celles de Degéer, qui dit avoir ru de jeunes individus n'ayant que trois paires de pattes et huit anneaux. N'y auroit-il pas, dit M. Latreille, dans les observations de M. Savi quelques lacunes? celles, par exemple, qui seroient interm diaires entre le moment de la naissance et celles qu'il considère comme une première mue.

Les Chilognathes marchent très-lentement, et se nourrissent de substances végétales ou animales. Une très-petite espèce allaque les fraises, une antre ronge la chicorée, d'autres se fiennent sous les écorces humides des arbres. Cet ordre a été divisé en trois familles : les Pollyxénitẹs, les Glomérites et les Iulites.

\title{
POLLYXENITES,
}

\author{
Nonis.
}

Caractères. Le corps est mou, oblong, muni postirieurement èt sur les côtés de peliles écailles formant de petis pinceaux. - Le nombre des pattes est de douze pares ou de vingf quatre pattes. - Cetle famille ne renferme qu'un seul genre, qui est celui de Pollyxenus.

\author{
POLLYXeNUS, Latr., Leacu; \\ Scolopendia, Linn., Geofy., Fabr.; \\ Iulus, Degéer, Oliv.
}

Le corps est membraneux, allongė, li néaire; déprimẹ. - La tête antérieurement 
est pénicillée de soies roides au sommet.Les antennes, insẻrées sous le bord antérieur de la tête, sont composées de huit articles d'inégale longueur, ainsi le premier, le troisième, le cinquième et le huitieme sont courts, surtout le dernier qui est terminé par trois petites soies, ensuite les second, troisième, quatrieme et cinquieme sont allongés; tous excepté cependant le dernier sont entiè ement lisses. - Les yeux sont agrégés. - Les bords latéraux des segmens sont hérissés de pelites soies allongèes, et le segment postérieur est terminé par deux petits pinceaux formés de soies beaucoup plus allongées. - Les pattes sont au nombre de douze paires.

\section{Pollyxenus hagurus. (Pl. 2, fig. 5.)}

Latr., Gener. Crust. et Ins., t. I, p. 77; id., Reg. anim. de Cuv., t. IV, p. 335 ; id., Hist. nat. des Crust. et des Irs., t. VII, p. 82 . p.. 59, fig. 10 à 12. Leach, Zool. Nísc., t. Ill, p. 38, tab. 135, B. - Risso, Hist. de l'Europse mérid., t. V, p. 152. - Guén., Icon. du lieg. anim. de Cuv. Ins.. pl. 1, fig. 5. T. F. Gray, Anim. Kingdom. Ins., pl. 1, fig. 1. - Grev., Ann. des Sc. nat. t. VII, ann. 1837 , p. 41 ; id., Dict. d'Hist. nat., pl. 399, fig. 1. - Inlus Lagurus, Or.rv., Encyclop. méthod., t. V11, p. 417. Scolopendia Lagura, Lins., Syst. nat., édit. 12. t. I, pars 2, p. 8062; ibid., Faun. Suec. édit. 2, n० 2063. - Farr., Ent. Syst. t. II, p. 389. - La Scolopendre en pinceau, Geoff., Hist. nat. des Ins., i. 11 , p. 677 , pl. 28, fig. $4 .-$ Iule ciqueue en pincean, Degéer, Mém. pour servir à l'Hist. nat. des Ins., I. V1I, p. 512 pl. 36, fig. 1, 2, 3. - Long. 2 millim. - La tête est grisâtre, hérissée de pelites soies de même couleur, mais plus foncée; le corps est d'un cendré clair, sans taches; les antennes sont filiformes, de mème couleur que la têle; le corps est déprimé, termini par deux appendices formant deux petits pinceaux, et dont les soies qui les composent sont serrées entre elles, et d'une belle couleur blanche argentine; on remarque pareillement de chaque côté des segmens des touffes ou aigreltes de soies beancoup plus fortes que celles qui composent les ap. pendices postérieurs, beaucoup moins Jo!:gues et dont la couleur est la même que celle du corps, seulement un peá plus foncée; en dessous il est d'une couleur beaucoup plus claire. - Cette espece se trouve trés-communènent à Paris et dans ses environs, sous les vieilles écorces des arbres un peu humides et quelquefois aussi sous les mousses.

\section{POHLYXNUS FAsGiculatus.}

SAY, Journ. dcad des Sc. nat. de Phila: delph., t. II, p. 108; id., OEuvr. Ent., édit. Lequien, I. I p. 90_-GERV., Ann. des $S c$. nat., t.VII, ann.1837, p. 41. -Long.1 lig. $\frac{1}{4}$. - Le corplss est d'un brun pâle, linéaire ; les segmens sont lisses, ciliés aux incisures, et fasciculés de soies brunes de chaque côté ; les houppes terminales sont cendrẻes; la tête est semi-orbiculaire, déprimèe, profondèment et abondamment ciliée de soies sur le bord; les yeux sont petits, ovales, proéminens, placés obliquement dans le milieu du bord latéral; les antennes sont très-courtes, épaisses, d'un brun-rougeâtre: les pattes sont blanches. - Cette espèce, qui est assez rare, se trouve sous les pierres et dans les lieux humides (Amérique Buréale).

\section{DEUXI QHUE FAMILLE.}

\section{GL OMÉRITES,}

NoBIs.

Caractères. Leur corps est crustacé, sans appendices pénicilliformes, ovaleoblong, susceptible de se contracter en boule, el composé, outre la tête. de douze segmens, dont l'antérieur plus étroit, formant une sorte de collier en demi - cercle transversal, et dont le second plus grand, ainsi que le dernier, que les autres; celuici ost voûté et arrondi au bout; on voit de chaque côté, en dessous, à partir du second, jusqu'au dernier exclusivement. une rangée de dix petiles écailles lamelleuses. - Le nombre des pattes est de trente-quatre dans les mâles et de quarante dans l'autre sexe.

Les genres qui composent cetle famille se trouvent sous les pierres, particulicrement dans les parties montagneuses ou élerées et couvertes de bois. 
Genres: Glomeris, Zephronia.

GLOMERIS, LATR. ; Iululs, Linv., Fabr. Oliv. ; Oniscus, Grovov., Fabre; Armadillo, Cuv.

Le corps, convexe en dessus et concave en dessous, présente le long de chacun de ses côtés inférieuis une rangée de petites écailles, analogues aux divisions latérales des 'J rilobites; il n'est composé, la tête comprise, que de treize segmens ou tablettes, dont le second. plus étroit. forme une sorle de collier en demi - cercle transversal, et dont le suivant et le dernier sont les plus grands de tous; celui-ci est voûtẻ et arrondi an bout. - Le nomire des pattes. est de quarante dans les femelles et de trente quatre dans lès mâles; les organes sexuels remplacent la paire qui manque. Les yeux sont an nombre de huit, disposés en ligne sur chaque côté de la tète.

Ces animaux sont terrestres, se roulent en boule. et vivent sous les pierres dans les terrains montueux.

\section{Glomeris pustulata.}

Fanr., Ent. Syst., t. 1I, p. 396. no 2. Gerv., Aun. des Sc.nat., t. VII, ann. 1837, p. 42. - Oniscus aimadillo, Scopol., Ent. Carniol., p. 415, no 1144. - BrandT, Prodrom., Bull. de la Soc. impér. des nat. de Moscon, t. VII, p. 197, no 1. - Oniscus Pustulatus, Ross, Fann. Etrusc., 2, 5, 688. - Le corps est noir, brillant, avec qualre points rouges sur cbaque anneau, dont denx su le dos, el un de chaque eôté, plus petits, sur le bord extérieur; le dernier seulement n'a que deux points un peu plus gros; les pattes sont noires; les antennes sont courtes. - Se trouve en Europe (Allemagne).

\section{GLOMERIS GUTTATA.}

Risso, Hist. de l'Europe Mérid., t. V, p. 148. no 3.- Branot, Prodiom., Bull. de la Soc. imp. des nat. de Moscou, t. VI, p. 196, no 3.-Gerv., Aun. des Sc. nat., t. TIJ ann. $\{837$, p. 42.-Cetle espèce suivant M. Kisso. est très-lisse, fort luisante, d'un beau noir orné de quatre lignes longitudinales de taches jaune-foncé régulierement disposies; le derujer segment présente deux taches ovales jaune-safran; les antennes et les pieds sont tachetés de violâtre. - Se tronve en Esplagne, dans la Fance méridionale et en Egypte.

\section{GLOMERIS ELUGI.}

Branpt, Prodrum., Bulletin de la Soc. simpér, des nat de Moscou, t. V I, p. 195, no 1. - Gerv., Anu. des Sc. nat., t. ViI, ann. 1837, p. 42 . - Le dessus est couleur vermillon el tacheté de noir; la tête est de cette dernière couleur. - Se trouve en Egypte ou en Syrie.

\section{GLOMERis tetrasticha.}

Brand, Prodrom., Bulletin de la Soc. imp. des nat. de Moscou, t. VI, p. 196. Gerv., Ann. des Sc.nat., t. VII, ann. 1837, p. 42.-Le dessus est noir, avec quatre séries de points blancs: le segment de la nuque est biponctué. - Elle se trouve en Europe (Allemagne).

\section{GLOMERIS QUADRIPUNCTATA.}

Brandr, Prodrom., Bulletin de la Sor. imp. des nat. de Moscou, t. V1, p. 197. Grev., Aun. des Sc. nat.. t. VII. ann. 1837, p. 42. - Le dessus est d'un brun noir, avec quatre séries de points inégaux d'un grisbrunâtrè. - Se trouve en Europe.

\section{GIONIERIS MEXASTICHA.}

Brandt, Prodrom. Bull, de la soc. imp. des nat. de Moscou, t. VI, p. 197, n० 10.Gerv., Amr. des Sc.nat., t. VII ann. 1837, p. 42. - lie dessus est d'un brun-noir, avec le premier segment de cetle dernière partie jusqu'au dernier présentant six séries de taches d'un brun-jaunâtre; le dernier est bimaculé. - Se trouve en Europe.

\section{GLOMERTS LEPIDA.}

Fichwald, Zoot. spéciral. p. 2, pl. 123, no 26. - Brandt, Prodiem., Bull. de la Soc. imp. des nat. de Miscon, t.VI, p. 197, no 11. - Gerv., Ann. des $S$ c. nat., t. VII, ann. 1837. p. 42.-Le dessus est d'un noirbrun, avec le premier segmesit présentant jusqu'au dernier six séries de taches jaunâtres, paralleles; le dernier segment est quadrimaculc. - Se trouve en Podolie.

\section{8. glomeris mafginata. (Pl. 1 ,} fig. $1,1 \mathrm{~A}$.)

LeACH, Zool.Misc., t. 1 II, p. 32, pl. 132. - Brande, Prodrom., Bull. de la Soc. des nat. de Moscou, t.V I, p. 195. - Gerv., Ann. des Sc. nat., t. VII. amn. 1837. p. 42. T. F. (íва, Anim. Kingd., hıs. pl. 1, fig. 4. 4a, 4b. - Oriseus Marginatus, Wild., Eut., t. IV, p. 187. Iab. 11. fig. 15.-Iulus Maryinatus, Ourv. Encycl. Méth., t. VII, p. $414, n^{\circ}$ 5. - Les antennes sont noires; la tête est de la mème couleur, avec le bord extérieur rouge; le premier segment 


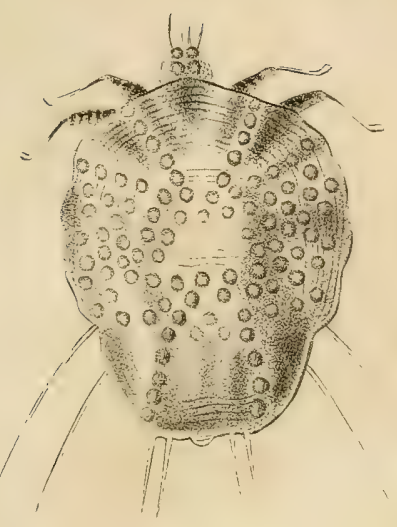

1. Srrootes Homimis.
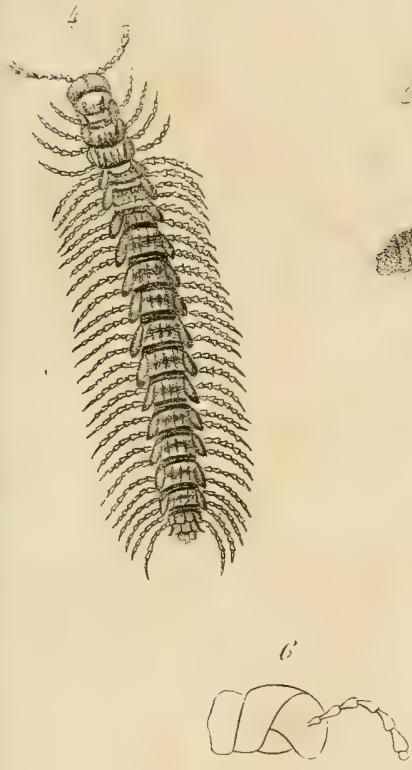

3. IA. Glomeris maröinata.

2, 2A. Zep̧hronia javanica.

3.31. Polydesmas virọiniensis .

(a)

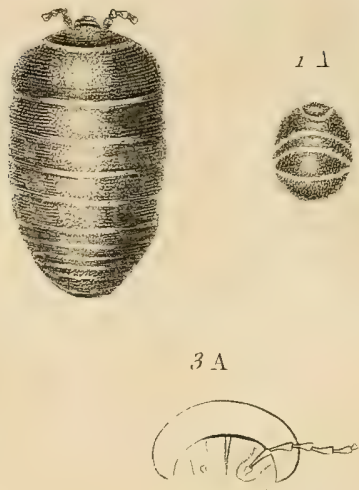

$2 \Lambda$
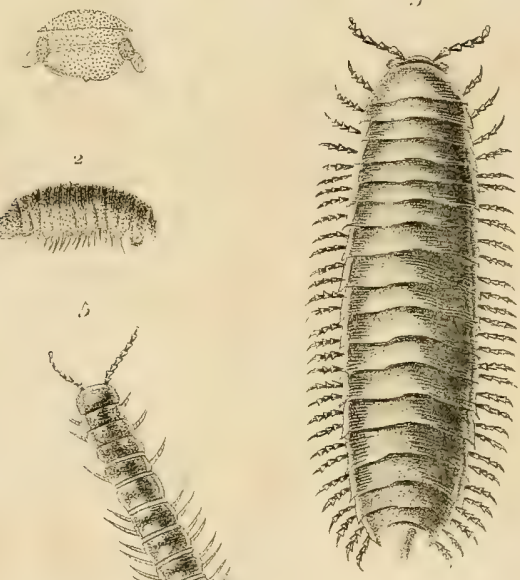

1)

17

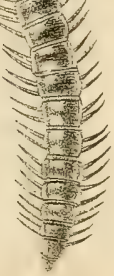

4. Polydesmas complamatrs .

5 Polydesnzas pallipes.

6 Blaniulus ỏnttulatus. 

est noir, entièrement bordé de rouge; les autres sont noirs, avec le bord postérieur et latéral rouges. - Se trouve dans le midi de la France.

\section{GIOMERIS LIMBATA.}

Genv., Ann. des Sc. natır., t. VII. ann. 1837. p. 42.-Iulus Limbafus, Otrv., Enc. Méth., t. VII, p. 414, n. 6. - D'un noir plombé, avec le bord des anneaux légérement blanchâtres. - Se trouve aux environs de Paris.

\section{GLOMERIS Gastanea.}

Risso, Hist. de l'Europe Mévid.; t. V, p. 148, n. 2. - Branot, Prodrom., Bull. de la Soc. imp. des nat. de Moscon, t. VI, p. 196, n. 3. - Genv., Ann. des Sc. nat., t. VII, ann. 1837. p. 42. - Le corps est luisant, très-lisse, châtain, avec les bords des segmens beaucoup plus pâles et moins foncés. - Se trouve a Nice et dans la France méridionale.

\section{GLOMERIS ANNULATA.}

Brannt, Prodiom., Bulletin de la soc. imp. des natur. de Mloscou, t. VI, p. 196, n.6. - Gerv., Ann. des Sc.nat., t. VII, ann. 4837, p. 42. - Le dos est noir, avec les bords postérieurs des segmens entourés de zônes larges de couleur oranger. - Se trouve dans la France méridionale et en Italie.

Les espèces décrites par M. Koch, Dentschland Crustaceen Myriap., etc., fasc. 4, lab. 1 et tab. 2 , sous les noms de G. Nobilis et Transalpina, ne semblent être que des variétés de l'espèce précédente.

\section{Giomeris Marmorea.}

Gerv. Annales des Scierices naturelles, t. VII, ann. 1837, p. 42. - Iulus Marmoreus. Orrv., Encyclopédie Methodique, t. VII, p. 114, n. 7. - Celte espece, ressemble à la précédente; elle en différe en ce que le corps est d'un noir plombé mélangé de jaurie. - Trouvé aux environs de Paris, sux le bord des paux, sous les pierres.

Le Glomeris Marmorata, BR+NDT, Prodrom., Bull. de la Soc. impér. des nat. de Moscou. t. VI, p. 196, ne semble être qu'une variété de cette espèce.

\section{GLOMERIS PIUMRE.}

Gerv., Annales des Sriences naturelles, t. VII, ann. 4837 , p. 42. - Iulus I'lumbeus, Ouv., Encyclopédic Méthodique. t. V II, p. 414. n. 3. - Le corps esI d'une conleur plombée claire, avec le bord des anneaux et tout le derrière pâles. - Sc trouve dans le midi de la France, dans les lieux ombragés et humides.

\section{ZEPHRONIA, GrAY; \\ Spharotherium, BrandT; \\ Sphoropeus, ejusd.}

Les segmens sont semblables à ceux des $G$ lomeris, mais au nombre de quatorze, la tête comprise. - Les pieds sont au nombre de vingrt environ de chaque côté. - Les yeux sont agrégés et placés sur une éminence de chaque côté de la tête.

\section{ZEPHRONIA OVALIS.}

T.-F. GraY, Anim. King., lns., pl. 135 , fig. 5. -Genv., Ann. des Sc. nat., t. V 11, ann. 1837 , p. 42.-Cette espéce a été figu. rée par MI. T.-E. Gray dans l'Anim. Kingdom, mais il n'a pas donné de description. - Sa patrie nous est inconnue.

\section{ZEPHRONIA ROTUNDATA.}

Gerv., Annales des Sciences naturelles, t. VII, ann. 1837 , p. 42 . - Sphorotherium Rotundatum, BRANDT, Prodrom., Bulletin de la Société impér. des natur. de Muscon, t. VI, p. 198, n. 1. - Le corps est oblong, glabre; les anneaux dorsaux sont au numbre de onze, Ies antérienrs sont marqués de points nombreux, serrés, trèspetits, visibles à l'œil nu; le dernier segment du corps est convexe, marqué de points plus rares, mais plus grands que ceux des autres segmens. - Se trouve au cap de Bonne-Espérance.

\section{ZEPHRONIA COMPRESSA.}

Genv., Annales des Sciences naturelles, t. VII, ann. 1837 , p. 43. - Spherotherium Cumpressum, Brandt, Prodrom., Bulletin de la Société impér. des natur. de Moscou, . VI, p. 198, n. 2. - Le corps est oblong, glabre; les segmens dorsaux sont marqués en dessus de points petits, assez dispersés; le dernier segment du corps est comprimé latéralement et à peine ponctué.-Trouvé au cap de Bonne-Espérance.

\section{ZEPIRONIA ICITENSTEINII.}

Gerv., Annales des Sciences naturelles, t. VII, ann. 1837 , p. 43. - Spharolherium Lichstenteinii, BRandt, Prodrom., Bulletin de la Soc. impés. des natır. des Moscou, t. VI, p. 199 , n. 3. - Le coips est ohlong; pubescent; les segmens dorsaux sont pourvus de points petits, piliferes; le deruier segment du corps est convexe. Habite la même localité que l'espèce précédente. 
5. zephirotia pumctata.

Gr.Rv., Annales des Sciences naturelles, t. VII, ann. 1837, p. 43. - Spharotherilim Punctatum, Bкаndт, Prodrom., Bulletin de la Soc. impér. des natur. de Moseou, t. VI, p. 199, 11. 4. - Le corps est suborale-oblong. glabre; les segmens dorsaux sont environnés tle points assez grands, enfoncès, non facilement visibles à l'œeil nu. - La patrie de cette espèce est inconnue.

\section{ZEPIRONIA ELONGATA.}

Gerv., Anuales des Sciences naturelles, t. V1I ann. 1837 , p. 43. - Sphtrotherium Elongatum, BraxdT. Prodrom., Bulletin de la Soc. impér. des natur. de Mosco", t. VI, p. 199 . n. 3. - Le corps est oblong, glabre; les segmens dorsaux marqués de points petits, plus rares, à peine visibles à l'œil nu. - Trouvé au cap de Bonne-Espérance.

7. zephroxia javaniCa. (Pl. 1. fig. 2,2 A.) Guér., Iconog. du Rég. anim. de Cuv., Ins., pl. 1. fig. 2, 2, a. - Gerv.. Annales des Sciences naturelles, t. VII, ann. 1837, p. 43. - Le corps de celte espèce est long de cinq à six lignes, finement ponctué, vu à la loupe, et d'un jaune pâle. - Cette espèce a été trouvée à Java.

\section{ZEPROXIA TESTACEA.}

Gery., Annules des Sciences naturelles, t. VII, ann. 1837, p. 43. - lulus Testa- ceus, Ourv. Encyclopédie Méthodique', t. VII , p. 414, n. 2. - Long. 1 pouc. $\frac{1}{2}$. Larg. 10 lig. - Tout le corps (l'animal desséché ) est d'une couleur testacée pâle ; les pattes ont une coulcur verdâtre. - Se trouve a Madagascar, dans les lieux ombragés, humides.

\section{ZEPHRONIA HERCULES.}

Gerv., Anna'es des Sciences naturelles, t. VII, ann. 1837, p. 43. - Sphcropeus Hercules, Brand, Prodiom., Bulletin de la Socićté impériale des naturalistes de Moscon, t. VI, p. 200 , n. 1. - Aucunes lignes saillantes sur le limbe supérieur du premier segment dorsal, terminant l'impression falciforme ou le sillon arque occupant la partie inférieure des pattes latirales. - La patrie de cette espèce est inconnue.

\section{ZEPIIRONIA INSIGNIS.}

Gerv., Amules des Sciences naturelles, t. VII, ann. 837 , p. $43 .-$ Sphoropeus Insignis, Brande, Predrom., Bulletit, de la Société impériale des naturatistes de Moscou, t. VI, p. 200 , n. 2. - Lignes saillantes au noinbre de neuf sur le limbe sujérieur du premier segment dorsal, ter. minant en dessus l'impression falciforme ou le sillon arqué occupant la partie inférieure des pattes latérales. - Cetie espèce a été trouvée à Java.

\section{TROISIEิHE FAMILL.}

\section{U I, I T E S,}

\section{NoBIs.}

Caractéres. Les animaux qui composent cette famille ont, de même que ceux de la précédente, le corps crustacé el dépourvu d'appendices pénicilliformes, mais il a une forme linéaire; de plus, ces animaux se roulent en spirale, et n'offrent point sur les côtẻs inferieurs d'écailles; le nombre des anneanx et des paltes est d'ailleurs trèsconsidérable, et augmente avec l'âge.

Genres : Polydesmus, Blaniulus, Iulus, Craspedosoma. Platyutus, Cambala.

\section{POLYDESMUS, LATR.; \\ Iulus, Linn., Fabi.., Oliv.; \\ Scolopendia, Geoefr., Scopol.}

Le corps, de forme variable, est plus ou moins carèné latèralement. - Les organes de la manducation ct les antennes sont semblables à ceux des Iules. - Les segmens sont au nombre de vingt (pour le corps, sans comprendre la tête). - Les pattes sont au nombre de trente et une paires chez toutes les espéces, ou au moins chez la majeure partie d'entre elles: la sixième paire est modifiée en forcipules chez les mâles. - Les yeux sont le plus souvent nuls.

Ces animaux se trouvent sous les pierres, et le plus souvent dans les lieux humides. M. Gervais, dans un travail ayant pour titre : Etades pour servi" a l'Histoire na. turelle des Myriapodes, a partagé les espèces qui composent ce genre en trois groupes.

PREMIER GROUPE.

(Polydesmes Glomédćriformes. Gerv.) 
1. POLYDESMUS SCARER.

Pentr, Delect. Anim. Ariculat. per Brasil., Spix et Martius, colleger., p. 210 , fob. 40, fig. 8. - Gerv.. Annales des Siciences naturelles, t. VII, ann. 1837 , 1) 43. - Le corps, en dessus et en lessous. est cendıé; le dessus est rude, granulé de blanc; les segmens en arviere sont un peu pointus, tridenlés on quadridentés sur le bord latéral ; le dessous avec les pieds sont d'un gris testace; les segmens, exceplé ceux qui forment la partie anale, sont au nombre de vingt-deux. Cette espèce a été trouvée dans les montagues de la province des Mines.

\section{POIYDESMUS ZEBRATUS.}

Genv., Ann. de la Soc. Entom. de France, ᄂ. V, p. 379 ; id., Aunales des Sciences naturelles, I. V II. ann. 1837, p. 43. - Long. 1 pouc. -- Couleur d'un jaune clair, avec une bande élroite de cuuleur vineuse au bord postérieur des an. neaux, et une ligne de mème teinte sur le bord des carènes latérales; l'angle postéyicur de celle - ci est assez aigu; le dessous des anneaux est blanchâtre, avec un limbe postérieur étroit et roux à quelques-uns ; les pattes sont jaunâtres, épaisses; le corps est trapu, glomédériforme. - Trouvé an Brésil.

\section{POLYDESMUS VIRGINiENSIS. (Pl. 1,} tig. 3,3 A.)

Palrsot de Beauvols, Ins. d'Afr. et d'Amér., Aptéres, p. 156, pl. 4, fig. 5. - Polydesmus Virginiensis, Gervars, Annales des Sciences naturelles, t. T11, ann. 4837 , p. 43. - Iulus Virginiensis, Drury, 11, 393.- Iulus Bidentatus, Fabr., Ent. Syst., t. II, p. 393. - Fontaria Virginiensis, T.-E. Gray, Anim. Lingd., Ins., pl. 135, fig. 1. - Le corps est d'un gris-pâle; les segmens sont convexes ; le second asticle des pieds est très aigu. Trouvé aux Etats-Unis d'Amérique.

\section{POLYDERRIS granulosus.}

Palisot de Brauvois, Insectes d'Afr. ct d'smér., p. 156, pl. 4, fig. 4. Gerv., Annales des Sciences naturelles, t. VII, ann. 1837, p. 44. - 11 est d'un rouge pâle et sale; le corps est presque déprimé; Jes segmens sont couverts de petits points granuleux; le sccond article est presque mutique. - Cette espece a été irouvee dans le royaume d'Oware.

\section{DEUXIEME GROUPB.}

\section{(Polydesmes proprement dits, Genv.)}

\section{5. polydesmes mexicanus. Nobis.}

Long. 3 pouc. 3 lig. - La couleur générale de cette espece est un noir-brun, avec des taches d'un cend é clair ot des points blanchâtres; la lète est d'un cendré concé, finement granulce, offrant au sommet deux tubercules sail'ans. de conleur noire; de plus elle présente dans son milieu une dépression longitudinale assez profondément marquèe qui se continue jusqu'au sommet, mais qui n'est plus visible à la partie où sont siluées les antennes; sur les côlés latéraux, derriere les anlennes et dans une concavité assez profo:de, on remarque un petit point en forme de disque, d'un jaune sale foncé; les antennes; d'un noir-brunâtie, sonț allongées, mais ne clépassent pas en longueur le troisieme segment; les divers articles qui les composent sont robustes et hérissés de poils pen allongés, peu scrrés entre eux, d'un jaune clair , le premier segment est entiérement d'un noir-brun, se terminant en pointe allongée de chaque côté, avec sa base offiant une séric transversale de petits inhercules brillans, saillans, sa partie médiane conrexe. lisse, sa parlie postétienre el les côtès laté. raux finement granulés et son bord latéro. antérieur finement spinulé; les segmens suivans sont très-larges. lenr partie médiane, convexe, lisse est d'un noir-brun, finement granulée poslérieurement, arcc une tache d'un cendré clair de chaque côté. leur partie dilatée ou leur carène d'un noir-brun, et quadridentée sur les côtés antéıieurement; on apercoit de chaque côtć un point blane de forme arrondie; lorsque ces anneaux sont rapprocliés, ces taches de diverses couleurs semblent former cinq bandes longitudinales dont la médiane entiérement d'un noir-brun; les latérales d'une couleur cendrée clair, et enfin les deux auires également latérales, formées par les points blan.' châtres; en dessous les segmens sont d'un roux foncé; les paltes sont robusles, d'un roussâtre foncé, parsemées de poils d'une couleur jaune claire, peu allongés et peu serrés entre eux. - Celte espéce a le Mexique pour patrie.

\section{POITDESMUS BILINEATUS. NORIS.}

Long. 2 pouc. 4 lig. - La conleur générale est un roux foncé, avec le bord des segmens d'un jaune pâle et dcux lignes longitudinales blanchâtues sur chaque seğ- 
ment dans leur partie médiane; la tête est d'un roussâtre foncé, arec une dépression longitudinale dans sa partie médiane, elle est finement granulée, avec deux petites saillies á son sommet ; les antennes sont de même couleur que la têle, peu allongées, cur elles ne dépassent pas en longueur le troisième segment, hèrissées cà el là de petits poils courts peu serrés entre cux, d'une couleur jaune; le premier segment est d'un roussâtre foncé, convexe, finement granulé, avec les bords latéraux terminés en pointe arrondie, et trés-finement tuberculés; dans sa partie médiane et de cha. que côté, on apercoit deux raies blanches, convexes du côlé externe, et qui semblent se réunir antérieuremen! ; les segmeus suivans, peu convexes, sont beaucoup plus larges que le premier, mais de unème couleur; ils sont finement granulés et présentent postérieurement une série transversale de petits tubercules assez saillans; dans leur partie médiane on apercoit de chaque côlé une raie blanche qui, lorsque les segmens sont réunis et se louchent, forment deux bandes longitudinales; leurs carènes sont furement denticulées et entourées d'une raie d'un jaune sale; en dessous ils sont de même couleur qu'en dessus; les pattes, de mêıne couleur que les segmens, ne sont pas très-robustes, elles sont hérissẻes de poils jaunes peu serrés entre eux et courts. Cette espèce a été trourée au Mexique.

\section{POLYESMUS COMPIATAUS. ( Pl. 1 ,} fig. 4.)

LATr., Gener. Crust. et Ins., 1. 1, p. 176 ; jd. . Nouveau Diotionnaire d'Histoive naturelle, i. p. - - T. F. GFaY, Anim. Kingd., Ins., pl. 1. fig. 5.- Gerv., Ann. des Sc. nat., t. VII, ann. 1837, p. 44. - Leacr, Zool. Miscell.. t. III, p. 371, 1ab. 135. - Inlus ( omplanatus, LiNs., Syst. Nat., t. I, , p. 1065, n. 4. - Scolopendre a 60 pattes. Geofrn., Hist. abrégée des lns. des env. de Paris, t. 2, p. 675 , 11. 2.-Iulus Complinatus, Degéer, Mém. poul servil a l'Hist. nat. des lus.. 1. VII, p. 386 , pl. 36 , fig. 23,26 . - Long. 6 lig. - Noirâtre en dessus; d'un blanc cendré en dessous; les pattes sont noirâtres; les segmens sont chagrinés. - Se trouve sous les pierres aux environs de Paris.

\section{POLYDESMUS DIADENA.}

Gerv., Annales de la Sociélé Entom. cle France, t. VII, Bullet.; id., Annales des Sciences naturelles, t. VII, ann. 1837, ๒. 4\%.-Long. $16 \mathrm{lig}$ - - La teinte générale est couleur terre de Sienne peu foncée; la têle est de cetle dernière couleur, parse. mée de petils points d'un brun foncé; les auneaux sont forte ment carénés, saillans dans leur partie médiane, qui est entièrement cle même couleur que la tête, mais dont les bords antérieurs et postérieurs sont d'une coulcur plus foncéc; près des carènes on apercoit de chaque côlé une ligne d'un brun foncé, qui, reproduite chez tous les segneus (l'anal excepté), forme deux bandes lougiludinales; les antennes et les pattes sont de même couleur que la tète, mais non parsemées de petits points. Cétte espèce a été trouvée par M. Rambur ¿ Gibraltar. (Cetle description a été fajte sur une figne qui nous a été communiquée par M. P. Gervais.)

\section{PoLYDESHUS DENTATUS.}

Genv., Amules des Siciences naturelles, t. III, ann. 1837, p. 44.-Iulus Dentalus, OLrv., Encyclopédie Mélhodique, t. VII, p. 417 . no 90. - Long. 18 lig. Le corps est quelquefois grisâtre, et plus souvent d'un brun fer:ugineux; les anneaux ont cle chaque côté plusieurs dentelures d'inégale grosseur, une ligne transversale au milieu de leur partie supérieure et une ou deur rangées de petits tubercules vers le borl postéricur; les pattes sont au nombre de trente et une paires. - Se trouve dans l'Amérique Septentrionale, à Cayenne.

\section{POIVDESMUS RUBESERS.}

Gerv., Aun. de la Soc. Ent. de France, t. V, p. 379; jd., Aun. des $S c$. nat., t. VII, ann. 1837, p. 44 . - Long. 1 pouc. $8 \mathrm{lig}$. Conleur générale d'un ronge vineux sur le dessus du corps, les côtés de l'abdomen et les pattes; la base de celles-ci d'un jaunâtre sale; antennes subvilleuses, de la couleur du corps, excepté sur le dernier et l'avant. deruier article, qui sont jaunâtres; anneaux du corps aplatis, régulièrement flexueux, mais non bombès; carènes très-développées, les deux dernières et les premières élant les seules qui se touchent; corps grêle. - Cietle espèce a été trouvée au Brésil.

11. POLYDESMUS BUAINVIIU, AEI.

EYd, et Gerv, Amm. de la Suc. Ent., t. $\mathrm{V}$, p. 379. - Genv., Alli, des Sc. nat., t. VII, ann. 4837, p. 44 ; id., Dict. d'Histoire raturelle, pl. 399, fig. 4. Long. 14 lig. - Couleur générale d'un roux ferrugineux; pattes au nombre de trente et une paires; antennes grêles, carénécs, ๙ssez saillantes; anncaux légére. 
ment bombés en dessus, lisses, d'un roux ferrugineux, marginés sur les carènes et marqués en dessus de points assez grands, ordinairement au nombre de trois, et qui sont d'un roux-maryon assez vif; yeux nuls. Le mâle est plus gros que la femelle. - Cette espece a élé trouvée sur la côte de Barbarie et en Egypte.

\section{POLY DESMUS GLABRATUS.}

Penty, Delect. Allim. Alticul., de MII. Spix et Mart., p. 210, pl. $40, \mathrm{fig} .7 .-$ Genv., Ann. des Sc. nut., t. V11, amn. 18:37, p. 44. - La couleur du corps varie; elle est lantôt roussâtre, tantôt d'un gris blanchâtre; le corps est composé de vingl-deux segmens, sans compler les deux anals, qui sont apodes; les segmens en dessus sont glabres, subarrondis sur les côtés, avec le bord recourbé. - Trouvé au Brésil.

43. POLYDESMUS CONSPEASS.

Perty, Delect. Anim. Aliticul., de MH. Spixel Hart., p. 210, pl. 40 , fig. 8 Gerv., dum. des Sc.nat., t. V [1. aun. 1837 , p. 44. - Le corps est entièrement d'un rouge pâle, glabre; les segmens sont au nombre de vingt-deux sans comptei les anals, qui sont apodes; ils sont finement granulés et couveris de taches et de points d'un fauve-roıgeâlre, ayant le bord latéral traticliant, calleux; tous les angles, $\mathrm{ex}$. cepté les poslérieurs, très-pointus; les intervalles sont lisses, sans taches; les pieds sont roussâtres, - Cette cspèce a été trouvée au Brésil, dans les montagnes de la provinces des Mines.

\section{POLYDESMUS MARGARATIERUS.}

Eyd, et Gerv. Annales de la Société Entomologique, t. V, ก. 379 ; id., Annales des Sciences natuelles, I. VII, ann. 1837. p. 44.- Long. 3 pouc.--Teinte genérale d'un brun jaunâtre, avec Jes carenes des anneaux d'un farve clair; anneaux fortement carénés, bombés en dessus et tuberculeux; les tubercules sont d'une antre couleur que le corps; ils sont d'un fauve clair et apparaissent comme autant de petites perles régulièıemeut dispersées: ces tubercules sont en lignes transiersales; il n'y en a qu'une seule rangée bien distincle aux anneaux antérieurs, laquelle est à leur bord postérieur ; mais aux autres il y en a qui sont peu ou moins évidentes; ce premier anneau, ou la cuirasse, est régulièrement bordé dans tout son poustour d'une rangée de ces petites aspérités; le dernier anneau avec une avance tres-élárgie, spatuliforme et demi-circu- lairc. Femelle. - Celle espèce a été trozvée à l'île de Luçon (Manille).

\section{TRDISILYE GROUPE.}

(Polydesmes Iuloides, Genv.)

15. POLYDESMUS PALLIPES. (P1.1, fig. 5.) Gerv., Mag. de Zool., 1835, t. VIII, no 135, p. 11 ; id., Ann. des Sc. nat., t. VII, ann. 1837, p. 44.-Guér., Icon. dı Règ, anim. de Cuv., Ins., pl. 1, fig. 4.-Iulus Pallipes, Olıv., Enc. méth., t. VIII, p. $414, n^{\circ} 12$. - Les amneaux du corps of frent une saillie latérale peu marquée; de plus ils sont peu arondis et variés, ferrugineux, avec deux points jaunâtres; les pieds sont d'une teinte plus pâle que le corps. Se trouve aux environs de Paris (Meudon, étang du Plessis-Piquet).

16. POLYDESMUS GERTASII. NoBIS.

Long. 1 pouc. - Teinte générale d'un brun foncé, avec la partie médiane les segmens de même couleur; ces derniers sonl a peine carénés, et les bords de ces carènes sont lachés de fauve clair; les côtés latéaux des segmens sont tachés de brun foncé, le reste est d'un fauve clair ; celte couleur commence depuis. Je premier segment et se continue jusqu'au dernier, ou elle devient de plas en plus apparente; enlin cette couleur faure claire est partagée dans son milien par une raie d'un brun foncé; tous les segmens sont canaliculés transiersalement; la lète est d'un brun foncé; les antennes sont de même couleur, mais beaucoup plus claires, et hérissées de poils d'un jaune sale ; le dessous du corps est. d'un brun clair, avec les pattes de même conleur, mais beancoup plus claire, surtout les premiers articles. - Cette espèce a été trouvée a la Nourelle-Hollande.

\section{POIYDESMUS GURTINII.}

Gerv., Alum. de la Suc. Ent., t. V, p. 686 : id., Ann. des $S_{c}$. nat., t. VII, ann. 1837, p. 44. - Long. 10 lig. - Le corps, Jes pieds el les antennes sont de même couleur, c'est-à-dire d'un jaune sale isabelle; les scgmeus sont cylindriques, a peine carénés sur les cités; le segment préanal est en forme de rosire. - Cette espèce a été trouvée à Madère.

\section{POLYDESHUS STIGMATOSUS.}

Genvars, Auntes des Sciences naturelles, t. VII, ann. 1837, p. 44. - Iutıs Stigmatosus, Eicmw., Zool. spec.. t. II , p. 124.-Strongylosoma Iuloides, Brand. Bulletin de la Soc. impér. des natur. de 
31oscou, 1. VI, P. 205. - Le corps est roussâtre, abondamment taché de chaque còté, avec les segments cylindriques et très lisses, ofliranı des stigmates placés postérieurement sur des pelites eminences et marqués d'un pelit sillon transversal. Celte espece se treuve communèment en I.ithuanie et en Volhynie.

\section{POLYDESMUS CYIINDRACEUS.}

Gerv., Ann. de la Soc. Ent.. t. VII, Bulletin; irl., Annales des Sciences naturelles, I. VII, ann. 1837, p. 44.- Le corps, les patles et les antenses sont de même conleur, c'est-à-dire d'un jame isa. belle foncé ; les segmens sont cylindriques, non carénés sur les côtés; le segment préanal est légérement terminé en pointe. Cielte esprece a été trouvée en Barbarie. (Sa description a été faite sur une ligure qui nous a été communiquée par M. P. Gervais.)

\section{POIYDESMUS DEPRESSU.}

Geniais, Amuales des Sciences naturelles, t. V11, ann. 1837 , p. 44. - Iulus Depressus, Faвr., Eut. Syst., t. 2. p. 393. -- Les segmens du corps sont rugueux, gris, hauts, filisaut saillie de chaque côté; la tête est noirâtre ; les pieds sont au nombre de treute de chaque côté. - Habite les Indes-Orientales.

\section{POIY DESHUS STIGMA.}

Genvais, dimales des Sciences naturelles, t. TII, ann. 1837, p. 44.-Iulus Stigma, Faвk., Eut. Syst., t. 2, p. 394. - Du double plus grand que le précédent; le corps est noir, avec lesanténnes de même couleur; les segmens marqués successivement de chaque côte d'un stigmatc calleux, èlevé, blanc; le dernier segment est pointu et blanc; les pieds sont au nombre de irente de chaque côté. - Cette espèce a été trouvée à Tranquebar.

\section{POLYDESMUS RUGUTOSUS.}

Esci., Mém. de la Soc. imp. des nat. de Mosc., ᄂ. VI, p. 112, n०3.-Gerv., Ann. des Si. nat., t. VII, ann. 1837, p. 44.-Le corps est brun, avec les antennes et les pieds fauves; la lête et les trois segmeris antérieurs sont lisses, trés-finement bordés latèralement; le bord postérieur est bisinué, avec l'angle postérieur pointu, un peu prolongé en arrière; les segmens pédigères sont un peu convexes en dessus dans leur milieu, rugueux, avec le dessous ponctuḱ ; le bord latéral subrecourbé, épais, lisse ct profondément ponctue; les angles posté. zieurs des segmens antérieurs sorat droits, pius pointus que les segmens postéricurs, en sorte que ces derniers sont vus avec leurs angles épineux en arrière; le dernier segment est convexe, bordé, beaucoup plus étroit que les autres, armé à sa base d'une pointe large, obtuse et courbée; les pieds sont au nombre de trente de chaque côtés. - Se trouve au Brésil.

\section{POLYDLSMUS IATERALIS.}

Esch., Mém. de la Soc. imp. des nat. de Mosc., t. VI, p. 112, n० 4. - Gerv., Aun。 des Sc.nat., t. V II, ann. 1837, p. 44.- La tèle est convexe, brune, asec la bouche ferrugineuse; les antennes sont brunes, grisâtres à la base, pubescentes; tous les segmens en dessus sont bruns, jaunes sur les côtés, d'un brun violacé et brillant en dessous, pâles dans le milieu; le premier segment est plus large que tous les autres, arrondi antérieurement, tronqué à la base, convexe et trés-lisse en dessus, peu recourbé sur les côtés; les trois segmens suivaus sont très-ètroits, arec les angles pos* térieurs épineax en arrière; les quatorze autres segmens ayant dans leur milicu une ligne transverse bisinuée; le pẻnultième est lisse (sans aucune ligne); le dernier est lisse, inerme sur les côtés, armé d'une épine jaune, épaisse dans le milieu, ayant le sommet tronqué et pourvu de deux petites dents; les pieds sont pâles, avec le clessus un peu noirûtre. - Cette espèce a été trouvée à l'île Gruam.

\section{POHYDESHUS GRANULATUS.}

$\mathrm{Sax}$, Journ. Acad. des Scicnc. Mat. de Phil., t. 2, part. 1, p. 107; id., OEuv. Ent, édil. Lequien, t. I, p. 20. - Geŕv., Inn. des $S$ c. nat., t. VI I, ann. 1837, p. 44. - Le corps, garni de poils courts, est pâle et teinté de rouge en dessous; les pieds sont plus pâles; la tête est d'une coulcur obscure, garnie de poils courts et épais; Ie labre est błanchâtre; les segmens sont un peu convexes, granulés; ces granulations sont arrondies et longitud:nalement oblon grues, ovales, élevées, obtuses, rapprochées les unes des autres, disposées tronsversalement environ en quatre séries presque régulières; le segment antéricur est transyersalement ovale, plus étroit que la tête; les stigmates sont élerés. - Se trouve en Pensylvanie.

\section{Pot YDESHUS SERRATUS.}

S.sy, Journ. Acad. des Scienc, nat. de Philadel., t. 2 part. 1, p. 106 ; id., OEuv. Ent., edit. LEQ.. t. I, p. 19.-Gerv., Ant. des Sc, nat., 1. VII, ann, 1837, p. 44. 
- Les segmens sont déprimés en dessus, avec quatre petites denlelures de chaque côté ; le premier segment est transversalement ovale-oblong, un peu angulaire de chaque côté postéricurement; les second, troisième et quatrième segmens n'ayant que trois dentelures; Je premier un peu plus long que le second, et n'ayant qu'une seule denielure obsoléte pres de l'angle postérieur; chaque segment présente une double série transverse de douze divisions squamiformes, légérement élevées; le segment antéricur n'ayant qu'une seule série ; la tète est glabre, ayant sur le vertex une impression linéaire Iongitudinale; les antennes, les pieds et le segment terminal sont poilus; la couleur est d'un brun-rougeâtre en dessus et d'un blanc-jaunâtre en dessous.-- Cielte espèce a été turouvée dans l'Amerique Bortale.

Pour les autres espèces, consultez Gray, Anim. Kingdom, où sont figurées les espéces suivantes, mais non accompagnées de description : P'olydesmus elegans, Ğ $\mathbf{n}$, op. cil.. pl. 135 , fig. 6 ; Polydesmus Leachii, op. cit., pl. 135, fig. 3.

\section{BLANIULUS, Gerv.; Iulus, Bosc., Latr., Leach.}

Corps et pieds des Iules. - Les yenx, mème dans l'âge adulic, ne se font pas remarquer.

Bhaniugs guttulatus: (PI. 1, fig. 6.) Gerv., Bull. de la Soc. Phil., ann. 1836, p. 72 ; id., Ant. des Sc. nal., t. VII, ann. 1837, p. 4/.-Iulus Guttulatus, Bosc, Bull. de la Suc. Philom., 1792, p. 10.Fabr., Ent. Syst., suppl., p. 289. - Iulus Pulchellus, Lеach, Tians. Linn., t. XI, p. 379 ; ibid., Zool. Miscell., t. III, p. 35 . -lulus Fragarius, LaM., Hist. des Anim. sans vert., t. V, p. 36. - Long. $7 \mathrm{lig}$. - Le corps est d'un blanc-jaunâtre trèspâle; les pieds sont au nombre de trentesept paires de chaque côté; les segmens du corps sont marqués de cliaque côlé d'un point rouge formant une ligne; les segmens intérieurs et postéricurs sont dépourvus de ces points. - Se trouve à Paris el dans ses cnvirons; M. Leach l'a aussi trouvé en Angleterre.

\section{IULUS, LinN., Fabr., Lata.}

Les segmens composant le corps dans ce genre sont nombreux (au nombre de quarante et même davantage), cylindriques, non carénés latéralenent. - Les pieds sont trés-nombreux. - Les ycux sont distincts.

Ces animaux fuient la lumicre; ils se re. tirent dans les lieux obscurs et en même temps humides; on les trouve principalement daus les bois, sous la mousse qui recouvre $l_{t}$ pied des arbres et sous les amas de feuilles mortes. Ils sont également assez communs dans le voisinage des eaux; quel. ques-uns vivent dans les lieux sablonneux, et il en est qui se retirent sous les pierres ou les petites molles de terre. D'autres enfin vivent dans des plaines plus ou moins découvertes.

Degéer a étudié les mœurs des Iules (Iulus Sabulosus). M. Savi ensuile a éludié celles d'un autre espèce (Iulus Communis), et ses observations ne s'accordent pas du tout avec ce!les de Degéer.

Ce dernier conserva un de ces animaux dans un vase parliculier; il obtint qu'il y pondît des œufs. "Celui (le Iule) dont je viens de donner la descriplion; dit Degéer ( t. VII, p. 582), était une femelle, car clle pondit un grand nombre d'œufs d'un blanc sale, dans la terre. près du fond du poudrier, ou elle les avoit placés en un tas les uns aupres des autres; ils sont très-petits et de fignte arrondie. Je n'espérois jas voir des petits sortir de ces oufs, car il étoit incertain si la mére avoit été fécondée ou non.

"Cependant après quelques jours, c'étoit le $1^{\text {er }}$ du mois d'août 1746 , de chargue ouf sortit un petit Iule blanc, qui n'avoit pas une ligne de longueur; j'examinai d'abord au microscope les coques d'œufs vides, et je vis qu'elles s'étoient fendnes en deux portions égales, mais qui tenoient pourtant ensemble vers le bas. Ces jeunes Iules nouvellement éclos me firent voir une chose à laquelle je ne m'attendois nullement. Je sarois que les insectes de ce genre ne subissent point de métamorphose, qu'il ne deviennent jamais des insectes ailés aussi j'étois comme assuré que les jeunes devoient être semblables en tigure, à la grandeur près, à leur inère, et par conséquent je croyois qu'ils étoient pourvus d'autant de paires de pattes qu'elle, mais je vis tout autre chose : chacun d'eux n'avoit en tout que six patles qui composoit trois paires, ou dont il y avoit trois de chaque côté du corps, elc. $\left.{ }^{1}\right)$. D

(1) Ce mène auleur avoit encore constaté que les Pollyxènes ont de mème moins d'anneaux et de paires de palles dans le jeune âge que dans l'âge adulte. "les Inles de la troisième grandeur (Pollyxenus Lagurus) éloient encore plus petits 
M. Paul Savi, comme nous l'arons déjà dit plus hant, s'est occupé aussi du dévelopjement des lules; il nomme Communis l'espèce qu'il a observée, et il la regarde comme distircte de toutes celles qu'on avoit décrites avant lui. Ce que M. Savi dit de plus remarquables sur ces animaux est en opposition complete avec les observations de Degéer. En ellet, d'après lui, Jes lules sont complètement apodes et non pourvus de six pattes lorsqu'ils viennent au monde. M. Savi a-t il bien observé? nous n'en voulons pas douter, mais nous ne croyons pas, dit M. P. Gervais auquel nous empruntons ce passage, qu'on puisse encore conclure de ces observations, que Degéer ait été dans l'erreur; le récit de ce dernier est trop circonstancié pour qu'il soit permis de le taxer d'inexactitude. Nous n'avons pu malheureusement réussir à voir pondre et éclore des Iules que j'ai fréquemment recueillis; mais en étudiant ces animaux dans leur jeune âge, rous avous constaté, comme Degér l'a fait observer, que le nombre des anneaux du corps, celui des pattes et celui des articles des antennes augmentent à mesure que se fait le développement, et c'est en arriere qu'apparoissent les nouvelles pattes; mais jusqu'au complet développement, il reste encore dans celle partie plusieurs anneaux apodes en avant de celui que presente l'anus. Mais un fait plas remarquable, et dont ni Degéer ni M. Savi ne font mention, c'est que les variations portent non-seulement sur les organes que nous venons de signaler, mais encore sur les yeux, qui sont eux-mèmes bien moins nombreux chez les jeunes que chez les adultes.

Dans les Iules parfaitement développés de l'espèce que nous avons le plus étudiée sous ce rapport, continue M. P. Gervais, le Iulus Lucifugus, les yeux yui apparoissur chaque côté de la tète comme une tache triangulaire d'un noir profond, sont comjosés de petits ocelles disposés eux-mêmes en lignes parfaitement régulières, et d'une manière tout-à-faitgéométrique. Le nombre

que ceux à six paires de pattes; iis sont trèscourts, et le dessus du corps est divisé en trois anmeaus; chaque anneau a quatre brosses, ainsi le corps de l'insecte est garni en tout de doure brosses; les ninceaux de la queue sont encore plus déliés que ceux des Iules de la grandeur moyenrie, et le nombre de leurs palles est pruportionné à leur grandeur; ils n'en ont que érois paires. DegéBR, MIém., t. VII, p. 577 , pl. $26,6 \mathrm{fg} .8$. des ocelles ehez un jeune Iule qui n'avoit encore que quelques anneaux au corps, et sept paires de pattes , étoil de six seulement; ils étoient sur trois lignes et déja disposés en un triangle équilatéral, la première ligne ne présentoit qu'un seul ocelle, la seconde en avoit deux et la suivante trois; chez un individu un peu plus âgé, une nouvelle rangée de quatre s'étoit déja mon. trée. Les vèritables itısectes, c'esi-à dire les Hexapodes n'offrent aucun exemple de ces modifications; les yeux des Iules, qui varient comme nous venons de le dire, sont donc beaucoup moins fixes et sans doute moins parfaits que ceux de ces animaux. IRappelons que parmi les Myriapodes, il est des animaux fort voisins des lules, qui ne présentent aucune, Irace d'yeux neême dans l'élat adulıe, tels sont les Blaniulıs, et les Polydesmus. Chez d'autres ces organes affectent des dispositions plus ou moins régulières; groupés en amas chez les Pollyxenes, où ils n'avoient pas été observés jusqu'á ces dernicrs temps, ils ont une forme à peu prés semblanle cliez les Zéplronies, tand s que chez les vrais Glomeris, ils sont disposés en une séi ie linéaire sur chaque côté de la tête. Cihez certains Iules ils sout assez ramassés et même assez confus.

11. Gervais, dans son ouvrage ci-dessus cité, a partagé ce genre en deux groupes.

\section{PREMIER GROUPE.}

Segmens plus ou moins striés longitudinalement; le dernier segment presque pas terminé en pointe.

\section{IUIUS DEGAISNEUS.}

Gervars, Alunules des Sciences naturelles, t. TII, année 1837 , p. 45 . Long. 6 à 7 lig. - Celle espece ressemble beaucoup an Blaninlus Grittulatus, mais elle est plus grêle, d'une conleur un peu plus brunâtre, avec les taches laterales de ses anneaux arrondies ou punctiformes, et d'une teinte purpurine légerement violacée; les yeux sont circulaires, distincts et de coulenr noire; les anneaux sont très. finement striés longitudinalensent; les antennes sont moins allongées. - Elle a été trouvée dans les serres du Muséum d'Histoire naturelle de Paris; nous l'avons aussi trouvée dans un jardin à Paris, sous des pots de fleurs.

2. IUtus Iucirugus. (Pl. 2. fig. 1, 1 A.)

Gerv., Annales de la Soc. Entom. de France, t. V, Bulletin. p. 66; id., Annales des Sc. natur., t. VII ann. 1837, p. 45 ; id., Dictionn. Kist. d'Hist. nat., 


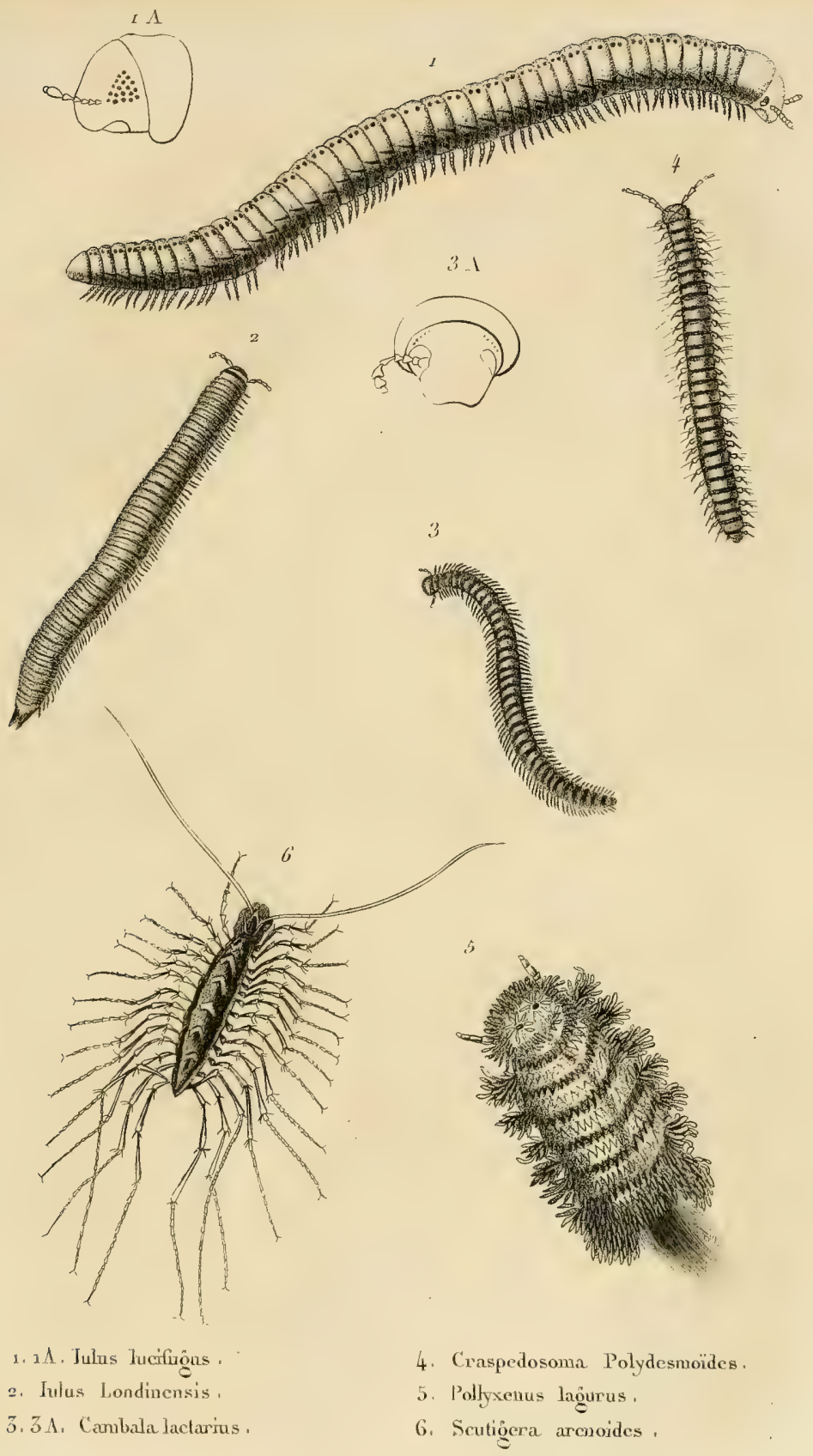



pl. 69 , fig. 39. - Long. 8 lig. - Le corps est épais, surlout antérieurement; la couleur est blanchâtre; le vaisseau dorsal est apparent; les côtés de chaque anneau presentent une tache virguliforme rougeâtre, dans laquelle s'ouvre le port sécrèteur; les yeux sont noirs, très-apparens; le crochet du segment pié-anal est obtus et ne dépasse pas l'anus. Chez cette espèce, les pores latéraux sécrètent une liqueur roussâtre très-odorante et qui sent parfaitement l'acide nitreux. M. Gervais a cherché à s'assurer de la nature de cette sécrétion, et il a reconnu qu'clle n'est ni alcaline, ni acide, comme on pourrait Je croire d'après son odeur. Cette matière est, en effet, sans action sur le papier rouge, ainsi que sur le papier bleu de tournesol. Cette espece, qui se trouve dans le tan, fuit constamment la lumière, et ce n'est qu'après la nuit close qu'elle commence à s'agiter et à se montrer à la surface. Un trouve très-communément cette esièce dans les serres du Muséum d'Histoire naturelle de Paris.

\section{IUนUS INDUS.}

Linn., Syst. nat., p. 1065, $\mathrm{n}^{\circ} 6$; id., Mus. Ulr., p. 462; id.. Mus., A D. Frid., 1, 90. - Farr., Syst. Ent., p. 428, $0^{\circ} 9$; id., Spec. Ins., t. 1, p. $530, \mathrm{n}^{\circ} 10$; id., Mantiss. Ins., t. I, p. $3 \leftrightarrows 0, n^{\circ} 10$.-Degéer. Mém. pour servir a l'Hist. nat. des Ins., t. VII, p. 588, pl. 43, fig. 7, 9. - Ourv., Eni. méth., t. VII, p.416, n 17.-Gesv., Ann. des Sc. nat, t. V] I, ann. 1837, p. 45. -Le corps est d'un brun-marron, très-lisse, avecles pattes et les antennes de coulenr rousse; les pattes sont au nombre de cent dix paires de chaque côté. - Cette espèce a été trouvée aux Indes.

\section{IUIUS вотTA.}

Gervars, Annales des Sciences naturelles, t. VII, ann. 1837 , p. 45. Long. 2 pouces $\frac{x}{2}$. - Voisin de l'espèce suivante, mais plus petite; elle a de même que celte dernière les anneaux fine. ment striés dans leur partie postérieure, sans lignes circulaires à la partie antérieure; la couleur est brunâtre, marginée en arrière de violacé sur chaque anneau, et on voit de cliaque côté du corps une séric de petits points noirâtres, arrondis ; tous les anneaux, excepté l'anal, qui est pour ainsi dire brunâtre, comme cliez les autres espèces de ce genre et de celles qui J'avoisinent, présentent deux paiı es de pattes; le premier des anneaux du corps, ou

$\Lambda$ s.. le bouclier, est aussi privé de pattes ; cellesci sont jaunâtres, velues, et sont au nombre de cent dix paires environ de chaque côté. - Trouvé dans l'Asie Septentrionale, en Egypte et en Abyssinie. (Cet1e description nous a été communiquée par M. P. Gervais.)

\section{IUIUS BOVEATUS.}

Grovars, Annales des Sciences naturelles, t. VII, ann. 4837 , p. $46 .-$ Long. 4 pouc. - Les stries longitudinales des anneaux sont très-fines, mais visibles cependant à la loupe; la mojtié antérieure des anneaux est finement marquée de lignes circulaires; le corps est allongé, de la grosseur d'une penne de cygne; les pattes, au nombre de cent vingt-cinq de chaque côté, existent à tous les anneaux, exceplé au bouclier du premier segment, qui est coupé obtusement à ses angles, et présente à son bord inféricur des stries courbes qui ne se voient point chez l'espéce précédente; la couleur (d'après deux individus desséchés) est jaunâtre sur Ia parlie des anneaux qui est striée circulairement; brun-verdâtre sur la moitié sillonnée longitudinalemont; les pattes sont rougeâtres, subvilleuses; le premier segment anal est glabre ainsi que tous les autres. - Se trouve en Egypte. (Cette description nous a èté communiquée par M. P. Gervais.)

\section{IULUS SEYCnTLARLSI.}

Drsu., Ann. de la Soc. Ent. de France, t. IV, p. 171; id., Proceedings Zool. Soc. Lond., 1835, p. 206. - Gervass, Anrales des Sciences naturelles, t. VII, ann. 4837 , p. 46 . - Long. 9 pouc. Larg. 8 lig. - Couleur d'un brun foncé tirant un peu sur le roux; les segmens, noirâtres à la partie postéricure, sont jaunâtres à la partie antérieure; les antennes sont:roussâtres; la tête est arrondie, échancrée vers la base; il existe, dans toute l'étendue du corps, une rangée de points noirâtres que l'on aperçoit facilement de chaque côté, chacun des segmens en offrant deux; les yeux, formés extérieurement par une masse de petites granulations noirâtres, représentent chacun un pelit triangle sphérique, rectangle, ou un petit ovale réniforme; les pattes sont au nombre de cent quarantetrois de chaque côté. - Cette espèce a élé trouvée dans l'île aux frégates.

\section{DEUXIEME GROUPE.}

Segmens striés longitudinalement; le dernier presque en pointe. 


\section{IULUS TERRESTRIS.}

LINN., Syst. nat., édil. 10, p. 635, spec. 3 ; id., Faun. Suec., $11^{\circ} 2066 .-$ IAвR., Eut. Syst., p. 427, no 3 ; id., Spec.Ins., t. I, p. 529, $\mathrm{n}^{\circ} 4$; id., Mantiss. Ins., t. 1, p. $340, n^{\circ} 4$. - Iule a deux cents pattes, Geoff., Hist. des Ins. des env. de Paris, 11, p. 679, 1.-DEgéer. Mém.pour servir a l'Hist. nat. des Ins., t. VII, p. 578, n० 2, pl. 36, fig. 9 et 10. - Iulus Teriestris, Aldorov., Ins., tab. 636 et 637 , fig. 4. - Scop., Eut. Carn., no 1152. Scni., Enum. Ins. Austr., no 1126.Rossi, Faun. Etrus., t. II, p. 120, n 950. - Vill., Entom., t. IV, p. 195, n². Fourci., Ent., part. 2, t. 11, p. 544, no 1. - Oliv., Encycl. méth., t. VII, p. 445. spec. 10. - Risso, Histoire de l'Europe Méridionale, t. V, p. 14́9. - Genvais, Annales des Sciences naturelles, t. VII, ann. 1837, p. 46. - LEAcH, Zool. Miscell., t. III, p. 34.-Long. 1 pouc.-Le corps est obscur, lisse, avec deux raies Jongitudinales, plus pâles lout le long du dos; les pattes sont blanchâtres, au nombre de cent de cha. que côté; le dernier segment est terminé en pointe plus forte et plus allongée que dans l'espèce suivante.-Se trouve en Europe. dans les chemins, sous les pierres, dans la terre et sur les arbres; commun aux environs de Paris.

\section{IULUS SABULOSUS.}

Livw., Syst. nat., édit. X, p. 640, 5 ; id., Faun. Suec., no 2069. - Fubr., Syst. Ent.. p. 428, no6; id., Spec. Ins., t. I, p. $530, n^{\circ} 7$; id., Mantiss. Ins., 1. I, p. 340, n* 7.- Iule à deux cent quarante paltes, Grorf., Hist. des Ins. des environs de Paris, t. 11 , p. $679, \mathrm{n}^{\circ} 2$, pl. 22 , fig. 5. - Iulus Fascialus, Degéen, Mém. pou. servi, al'Hist, nal. des Ins., t. VII, p. 578 , pl. 78, fig. 6, 15, adult.-Iulus Sabulosus, VILL. Entom., t. IV, p. 197, n० 4. Fourcr., Entom., part. 2, p. 544, n०2. Iule des sables, Latr., Hist. nat. des Crust. et des Ins., t. VII, p. 74. - Id. . Gener. Crust. et Ins., t. I, p. 76.-LEAci, Zool. Miscell., t. III, p. 33. - Risso, Hist. de l'Europ. Mérid., t. V, p. 149.Gerv., Ann. des Sc.nat. i. V I I, ann. 1837, p. 46.-Ourv., Enc. méth., t. VII, p. 415, no 11 . - Long. 1 pouce $\frac{1}{4}$. - Le corps est brun, lisse, avec une double raic rougeâtre sur le dos; les palles sont au nombre dé cent vingt de chaque côté, elles sont petiles et blanchâtres. - Se troure dans toute l'Europe, sur les arbres et quelquefois sur le sable; on la Irouve assez fréquemment aux environs de Paris.

9. IULUS LONDINENSIS. ('’l. 2, fig. 2.)

Leach, Trans. Linn. Soc., t. II, p. 378 ; id., Zool. Miscell., t. $11 \mathrm{I}$, p. 33, tab. 133. Gerv., Ann. des Sc. nat., i. V1I, ann. 1837 , p. 46. - Long. 1 pouce $5 \mathrm{lig}$. - Le dernier segment est d'un brun-noirảtre, légéremeut terminé en pointe; les pieds sont roussâtres, avec les articles pâles; le corps cst marqué longitudinalement par des lignes très-foibles. - Celte espèce se trours dans les bois, parmi les mousses, aux environs de Londres.

\section{IULUS NIGER.}

Leaci, Trans. Linn. Soc., t. II, p. 378; id., Zool. Misc., t. III, p. 134. - Genv.,

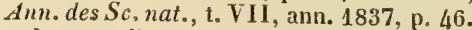
-Long. 1 lig. $\frac{1}{2}$.-Le dernier segment est terminé e! pointe, avec les pieds d'un pâle roussâtre; le corps est fortement marqué de petites lignes, lesquelles sont inégales. - Se trouve sous les pierres, aux.environs d'Edinbourg.

\section{IULUS ARBOreUs.}

Latr., Hist. nat, des Crust. et des Ins., t. VII, p. 75.-- Gerv., Ann. des Sc. nat., t. VII, ann. 1837, p. 46.-Cette esnece est très-petite, d'un brun clair, annelé de brun foncé ou de noirâtre; la partie anale a une saillie arrondie à son extrémité. - Cette espece se trouve dans toute la France sous les écorces.

\section{IULUS PUNCTATUS.}

LeacI, Trans. Linn. Soc. 1. II, p. 379 ; id., Zool. Misc., t. III. p. 34. - Gerv., Ann. des $S c$. nat., t. VII, ann. 1837, p. 46. - Long. 10 lig. - Le dernier segment est terminé en pointe; le corps, légérement pellicide, est de couleur de chair, avec Ja partie postérieure des segmens ponctuée de noir sur les côtés; le dessus et les côtés sont d'une couleur de chair pâle, marqués par de foibles lignes longitudinales; sur chaque côté on apercoit une jigne de points noirs; le corps en dessous est pâle, avec les pieds jaunâtre et les yeux noirs. - Se trouve en Angleterre.

\section{IULUS PUSILIUS.}

Leach, Trans. Linn. Soc. t. II, p, 379 ; ibid., Zool. Misc., 1. III, p. 35. -Genv., Anu. des Sc. nat.; t. VII, ann. 4837, p. 46. -Long. 5 a 6 lig.-Le dernier segment est légérement terminé en pointe; le corps est d'une couleur de chair noirâtre ou d'un brun-noirâtre, arec deux ligues roussâtres; 
quelquefois le cornns est roussâtre, avec les côtés d'un brun noirâtre, et unc ligne longitudinale en dessus de même couleur; le dessus est marqué de lignes plus fortes, $d$ stantes, droites, inégales; les antennes sont noirâtres, avec les articles d'une conleur plus claire; les pieds sont jaunâtres.-Cetle espèce a été trouvée sous les pierres, aux environs d'Edinbourg.

\section{IULUS AIMATOPODUS.}

Risso, Hist. de l'Europe Mérid., t. V, p. 149.-Gerv., Ann. des S c.nat., t. VII, ann. 1837 , p. 46. - Long. 1 pouc. 5 lig. Le corps est d'un noir-bleuâtre, sculpté par de petites lignes longitudinales; le dessous est orné d'une étroite bande d'azur, ainsi que les côtẻs, qui sont accompagnés de deux lignes noires ponctuées; les segmens en dessous de la ligne lalérale sont bleuâtres; les tentacules sont couleur de chair; les pieds sont d'un incarnat pâle, le troisième plus foncé. - $\mathrm{S}_{\mathrm{r}}$ trouve aux environs de Nice, sous les pierres.

\section{IULUS ANNUIATUS.}

Risso, Hist. de l'Europe Mérid., t. V, p. 149.-Gerv., Ann. des Sic.nat., t. Vil, ann. 1837 , p. 46. - Long. 1 pouc. 6 lig.-Le corps est teinté d'une légère couleur pourpre, sculpté par de petites lignes longitudinales, à segmens postérieurs jaunes; les pieds sont violâtres, - Se trouve sous les cailloux, aux environs de Nice.

\section{IULUS MODESTUS.}

Risso, Hist. de l'Europe Mérid., t. V, p. 150.-Genv., Ann. des Sc. nat., t. VII, ann. 1837, p. 46.-Long. 7 lig. $\frac{1}{2}$. - Chez celte espèce, le corps est hyalin, av ec le dessus teintè de pourpre, et les deux segmens antérieurs au pénultième de couleur grise, sculptés par de fines lignes longitudinales droites, et trois un peu plus larges, formées de points noirs, l'une située en dessus, et les deux autres latérales, placées sur un fond gris; la tête est glauque; les yeux sont noirs; les antennes violâtres et annelées de gris. -- Se trouve sous les pierres, aux environs de Nice.

\section{IUUES PICEUS.}

Risso, Hist. de l'Europ. Mérid., t. V, p. 150. - Geriv., Ann. des Sc. nat.. t. VII, ann. 1837, p. 46. - Long. 1 pouc. 9 lig. - Le corps est noirâtre, trés-lisse et fort luisant, sculpté par de très-petiles stries longitudinales, à dernier segment très-aigu; les tentacules sont noirâtres ; les ongles de couleur brunc. - Se trouve sous les pierres.

Les quatre espèces que nons venons de décrire d'après M.- Risso n'appartiennent peut-être pas à cette section, cet auteur n'ayant indiqué dans ses descriptions aucuns caractères qui puissent permettre de les placer a vec certitude dans telle ou telle section.

\section{IruUs COMMUNis.}

Sav., Opusc. scient., 1, 321; id., Mim. Sc., déc. 1, p. 44, pl. 2, fig. 1 à 11. -Gerv., Ann. des Sc.nat., t. V II, ann. 1837, p. 46. -Bull.des Sc.nat., 1823, t. IV, p. 330.Les segmens sont noirs en dessus, blanchâtres en dessous; les pieds antérieurs sont de la même couleur; les antennes sont d'un blanc cendré, avec l'anus obtus et le dernier segment obtusément terminé en pointe. - Cette espèce se trouve en Italie.

19. IULUS FORTIDISSIMUS.

Sav.,Op. scient., 1, 321 : id., Hém. Sc., déc. 1, p. 83, pl. 2, fig. 24 à 32. - GERv., Ann. des Sc. nat., t. VII. ann. 1837, p. 46. - Cette espèce est d'un pâle ferrugineux, avec le cou étroit; les antennes sont grêles, légérement claviformes; le corps est atténué postérieurement, avec les segmens sillonnés; ces sillons sont un peu grands, triangulaires; le dernier segment est obtus; les pieds sont allongés, pâles. - Cette espèce, qui a été trouvée en Italie, est peut-être le genre Callipus de M. Risso.

\section{IULUS PLIGATUS.}

Guér., Icon. du. Règ. anim. de Cuu., Ins., pl 4, fig. 3. - Long. 2 pouces. Cette espèce est d'un brun foncé, quelque. fois roussâtre; ses pattes sont pâles ; chaque segment du corps est muni d'un grand nombre de petites côtes élevées et longitudinales; l'anus est formé par deux vulves ovalaires. - Cette espèce a été trouvée en Egypte.

\section{IUIUS AMERICANUS.}

Pairsot de Beauv., Ins. d'Afr. et d'dmée"., p. 155, Apt., pl. 6, fig. 3.-GErv, Ann. des $S_{c}$. nat., t. VI I, ann. 1837, p. 4\%. - Cette espèce est cendrée, les segmens sont au nombre de quarante-neuf. - Elie a été trouvée aux Etats-Unis d'Amérique.

\section{IUIUS BEAUVOISII.}

Gervars, Annales des Scielices naiurelles, t. VII, ann. 1837, p. 47. - Iulus Indis, Palisot de Beauv., Ins. d'afi. ct d'Amér., p. 154, pl, 6, fig. 2. - Elle est cendrée; son corps est composé de cin- 
quante-cing scgmens, munis chacun d'un rebord coloré, d'un point brun et d'une double paire de pieds de chaque côté. Cette espèce a été trouvée à St.-Domingue.

\section{IULUS FESTIVUS.}

Perty . Delect. Anim. articulat., de MII. Spix et Martius, p. 211, pl. 40 , fig. 10. - Gerv., Annales des Sciences naturelles, t. VII, ann. 1837. p. 47. Long. lig. - Tout le corps es! glabre, un peu brillanl, ferrugineux, avec une série de chaque côté de points latéraux et deux bandesnoires parcourant tout le dessus; les aistennes sont couleur de châtaigne à la base, les autres articles sont noirâtres; les yeux sont noirs; les picds, au nombre de quatrevingt-seize paires, sont couleur châtaigne testacée.-Cetle espèce a été trouvée dans les montagnes de la province des Mines.

\section{IULUS VARIUS.}

FABR., Eut. Syst., t. II, p. 394; id., Spec. Ins., 1. I, p. 128, n०2; id., Mantiss. Ins., t. I, p. 3! $0, \mathrm{n}^{\circ}$ 2. - Oliv., Enc. méth., t. VII, p. 414, no 8. - Gerv., Anll. des $S c$. nat. t. VII, ann. 1837, p. 47.-La tête est noire, avec une bande blanche au milieu; les anneaux du corps sont blanchâtres, avec la base noire et le bord légére. ment ferrugineux; les pattes sont noires et au nombre de soixante-dix-huit paires de chaque côté. - Ciette espèce a été trouvée en Italie.

\section{IUTUS CRASSUS.}

Linn., Syst. nat., p. $1065, n^{\circ} 2$; id., Aman. Acad., t. 1V, p. 253, $\mathrm{n}^{\circ} 35$.Faвr., Ent. Syst., t. II, p. 427, n० 2 ; id., Spec. Ins., t. I, p. 529, no 3; id., Mantiss. Ins., t. I, p. $343, \mathrm{n}^{\circ} 3 .-$ OLIv., Enc. méth., t. VII, p. 415, n० 9. - Latr., Hist. nat. des Crust. et des Ins., 1. VII, p. 76. - Genv., Ann. des Sc. nit., t.VI I, arn. 1837, p. 47.- Le corps est pâle, avec une rangée de petits points noirs de chaque côté; le dernier anneau est terminé en poinle. - Se trouve en Asie.

\section{MULUS CARNIFEX.}

Fabr., Ent. Syst., t. II, p. 498, n $^{\circ} 8$; id., Spec. Ins., t. I, p. 530 , n० 8 ; id., Mantiss. Ins., t. I, p. $340, n^{\circ} 8$ - - OLIv., Encycl. méth., t. VII, p. 416, n०15.Latr., Hist. nat. des Crust. et des Ins., t. VII, p. 76. - Genv., Ann. des Sc. nat., 1. VII, ann. 1837 , p. 47. - La tête, le dernier segment, les pattes et une ligne longi. tudinale sur le dos, sont d'un rouge san- guin; le dernier segment est terminé en pointe. - Se trouve à Tranquebar.

\section{IULUS FUSCUS.}

Linn., Syst. nat., p. $1065, \mathrm{n}^{\circ} 5$; id., Aman. Acud., t. IV, p. 253, no 34. FABr., Ent. Syst., p. $428, n^{\circ} 10$; id., Spec. Ins., t. 1, p. 551, n 12; id., Mantiss. Ins., t. I, p. 310, $n^{\circ}$ 11. - OLIV., Enc. méth., t. VII, p. 4i6, no 28.-Latr., Hist. nat. des Crust. et des Ins., t. V11, p.76.-Gerv., Ann. des Sc. nat., t. VII, ann. 1837, p. 47. - Le corps est composé de soixante-quatre anneaux livides, bordés d'obscur ; les pattes sont pâles. - Elle a été trouvée aux Indes-Orientales.

\section{IULUS MAXIMUS.}

FABR, Ent. Syst., t. 11, p. 396 ; id., Spec. Ins., t. 1, p. 531, $\mathrm{n}^{\circ} 12$; id., Mantiss. Ins., t. 1, p. 240, n०12. - Olrv., Enc. méth., t. VII, p. 416, no 18.-Latr., Hist. riat. des Crust. et des Ins., t. V II, p. 76.-Genv., Amn. des Sc. nat., t. VII, ann. $1837, \mathrm{p} .47$. - Le corps est d'une coltleur jaune livide, un peu obscurc, il est composé de soixante-sept anneaux et muni de cen trente-sept paires de paltes. - So trouve dans l'A mérique Méridionale.

\section{IULUS RUPESTRIS.}

Gullenstedt, Hinn., t. I, p. 295 *

M. Brandt, dans le 1. 6, da Bulletin de la Soc. Imperr. des Nat. de Moscou, doit donner incessamment la description et les figures des espéces suivantes.

Spirobolus Olfersii, Brandt, Bull. de la Soc. Impér. des Nat. de Moscou, t. VI, P. 202, $n^{\circ}$ 1.- Cetle espèce habite le Brésil. Spirobolıs Bungii, Brandt; ibid., no 2. - Celte espèce a été trouvée en Chine. Spirotreptus Sebce, Brand , ibid., no 1 , p. 203. - Sева, Thes., tab. 87, fig. 5. Spirotreptus Audouinii, Brand, op. cit., p. 203, n $^{\circ}$ 2. Spir opceus Fischeri, BRandt, op. cit., p. 203, no 1. Spirocyclistus $A c u$ langulus, Brandt, op. cit., p. $204, \mathrm{n}^{\circ} 1$. - La patric de ces quatre espè ces nous est incongue.

\section{CALLIPUS, Risso.}

Le corps est allongé, cylindrique, avec le dernier article entier, obtus. - Les pieds sont très-longs. - Les yeux sont distincts, lentiformes, réliculés. - Les antennes sont de sept articles : le premier est large, très-

'Les espèces, depuis le n. 21 jusqu'a 29, ne nous sont connues que par la description des auleurs. 
petit; les quatre suivans graduellement élevés, souvent égaux; le sixième est en massue conique, tronqué au sommet; le septième est très-petit el conique.

\section{CALIIPUS RISSONIUS.}

Leach, Callipus Longipes, Rrsso, Hist. de l'Europe Méridionale, t. V, p. 151. Le corps est très-lisse, brillant, d'un légère teinte incarnate passant au ferrugineux inférieurement, sculpté par de fines stries obliques, qui s'élèvent graduellement vers la partie pos!érieure : les antennes sont brunes; les yeux sont d'un rouge ferrugineux intense; les pieds sont d'un gris-brun; les appendices du mâle sont très-lisses, unis, d'un noir ocracé. - Se trouve sous les pierres, anx environs de Nice ${ }^{1 .}$

\section{CRASPEDOSOMA, LEACH. Iulus, MoNr.}

Le corps est allongé , linéaire, déprimé, à segmens marginés et comprimés latéralement. - Les pieds sont trés-nombreux.Les yeux sont distincts, Jentiformes, agrẻgés. - Les antennes sont insérées sur la partie antérieure de la tête. - Le second article est plus court que le troisième.

\section{CRASPEDOSORA RatVinsir.}

Leach., Encycl. Brit. Suppl., 1, p. 430, pl. 22 ; id., Linn., Trans., t. II, p. 380 ; id., Zool. Miscell., t. III, p. 36, pl. 134, fig. 1 à 5. - Gerv. . Ann. des Sc.nat., t. VII, ann. 1837, p. 47.-Long. 7 lig.-Le dessus est d'un brun-noirâtre, avec quatre lignes de points blancs; le dessous et les pieds sont roussâtres. - Cette espẻce a èté trouvée très-communément aux environs d'Edinbourg, parmi les mousses et sous les pierres.

\section{CRASPEDOSOMA POLYDRSHOIDES. (PI. 2,} fig. 4.)

Lеaсн, Edinb. Encycl., 8, 407 à 435 ; id., Trans. Linn. Soc., t. II, p. 380; id., Enc. Brit. , t. 1, suppl. 1. p. 430 , pl. 22; id., Zool. Miscel., t. III, p. 36, pl. 134, fig. 6, 9. - Iulus Polydesmoides, Monr., Miscell. - Risso, Hist. de l'Europe Mérid., t. V, p. 151 - Gerv.,

(1) Lorsque l'espèce sur laquelle ce genre a été établi sera mieux connue, peul-être celte nouvelle coupe générique ne sera pas adoptée.
Annales des Sciences naturelles, t. VII, ann. 4837 , p. 47 . - Long. 6 lig. $\frac{x}{2}$. - Le corps est d'un gris-roux, avec les pieds plus pâles; le dessus est marqué d'une ligne longitudinale; les segmens ont leurs côtés très proéminens, avec les angles antérieurs arrondis, les postérieurs prolongés en arrière, sétigères; les soies sont coniques, blanches; l'aspect est d'un gris-roux foncé ; les yeux sont noirs; les antennes sont d'un gris-roux, légérement velues; en dessous, le corps est pâle, blanchâtre; les pieds sont roussâtres, pâles à leur base. Cette espèce se trouve en Angleterre, sous les pierres, rarement aur environs de Londres.

\section{CRASPEDosoma Richi.}

Cette espèce a été figurée par M. T. Gray, dans A nim. Kingdom. Ins., pl. 135, fig. 4; l'auteur n'en a pas donné la description. La patrie nous est inconnue.

\section{PLATyUlus, Gerv.}

Les pieds sont comme dans les Iulus.Les segmens sont nombreux et déprimés. -Les ycux sont sur une petite éminence, non agrégés, au nombre de dix seulement, mais se voient difficilement.

\section{PIATYULUS AUDOUINLANUS.}

Gerv., Soc. Philom., décembre 1836, et Journ. de l'Institut, 1836, p. 435; id., Ann. des Sc. nat., t. VII, ann. 1837, p. 47. - Celte espèce est jaunâtre, avec les antennes, les pattes et le dessous de même couleur, mais cependant un peu plus claire. - Elle a été trouvée sous les mousses, dans les bois de Meudon.

\section{CAMBALA, Gray.}

Ce genre élabli par M. T. Gray, dans Anim. Kingdom, parait devoir se placer, d'après la figure de cet auteur, près du genre précédent. La seule espèce connue est le :

Cambala lactamius. (Pl, 3, fig. 3,3 A.) Gray, Anim. Kingdom, Ins., pl. 135, fig. 2. - M. Gray n'en a pas donné de description; la patrie de cette espece rous est inconnue. 
DEUXILME ORDRE.

\section{I I}

LATREILLE.

Il comprend le genre $\boldsymbol{S}$ colopendira des auteurs. Chez ces animaux le corps est toujours linéaire, déprimé, membraneux, composé d'une série nombreuse d'anneaux, recouverts d'un plaque coriace et cartilagineuse, ne portant, dans le plus grand nombre, qu'une paire de pieds, insérés sur leurs côtés, et dont la dernière est ordinairement prolongée en arrière sous la forme de queue. - Les antennes, toujours plus grêles vers l'extrémité; ou sétacées, sont composées de quatorze article au moins. - La bouche présente $: 1^{\circ}$ un labre fort court; $2^{\circ}$ deux mandibules écailleuses, munies d'un petit appendice on forme de palpe, comme divisé en deux par l'apparence d'une suture transverse et terminées en manière de cuilleron dentelé sur ses bords $; 3^{\circ}$ une langue quadrifide, dont Ies deux divisions latérales plus grandes, ar. quees, annelées trausversalement, semblables aux pattes membraneuses des chenilles, et dont les deux internes en forme d'appendices maxilliformes, triangulaires; $4^{\circ}$ deux palpes ou petiıs pieds insêrés à leur base et terminés par un petit crochet. Quelques. uns ont des yeux à facettes; mais ceux du plus grand nombre ne se composent que de quatre à cinq yeux lisses, situés sur les bords latéraux de la tête; quel quefois les organes de la vue sont entièrement nuls. - Le premier segment du corps porte en dessous deux paires de pieds, les deux antéricurs sont horizontaux, avancès, réunis inférieurement au moyen d'un article commun, formant une plaque presque triangulaire, avec l'extrémité supérieure comprimée, tronquée et dentelée; ils sont terminés par un fort crochet écailleux, percé sous son extrémitẻ d'un trou pour la sortie d'uneliqueur venimeuse; les dcux autres pieds ressemblent aux suivans, et sont séparés par un petit segment ventral. - Les stigmales sont ordinaire. ment situés sur les côtés du corps et alternent par segmens; ceux des autres sont dorsaux; les trachées sont en totalité tubulaires; les organes de la génération sont placés à l'extrémité postérieure du corps et cachés. - Leurs organes internes ont été étudiés par divers naturalistes, tels que
MIM. Dufour, Marcelle de Serres, Gaëde, Treviranus, qui nous ont dévoilé l'organisation intérieure de quelques types; les recherches des deux premiers ont eu pour objet les espèces du genre Scutigera, et celles des autres les $S$ colopendra propres. Ici les stigmates sont latéraux et conduisent à un faisceau de fortes trachées, s'écartant en tous sens; etfournissant des anastomoses par arcades, avec les trachées des stigmates voisins. Les vaisseaux de Malpighi, au nombre de deux, sont situés sur les côtés du tube digestif, et occupent plus des deux tiers de la longueur du corps; on ne peut leur attribuer d'autre usage que celui d'organes sécréteurs; l'ovaire et l'oviducte de la femelle sont impairs; l'organe sexuel masculin paroît se composer d'un canal impair, terminé par ur paquet d'autres petits conduits longs et droits, el deux glandes accessoires. Muller observe que les yeux lisses diflèrent de ceux des Araignées et des Scorpions, en ce qu'iln'y a pas, comme dans ceux-ci, de corps vitré entre le cristallin et la choroìde. Sur les.quatre à cinq yeux com. posant chaque groupe oculaire, trois de ces cristallins sont circulaires, et l'autre est elliptique; les uns et les autres sont très-durs, transparents, très-convexes et de couleur d'ambre; leurs convexités internes correspondent à des enfoncemens, ayant la forme de calices et contenant lesparties internes de l'œil ; toute la cavité est tapissée par la choroïde, sous la forme d'une rétine entièrement blanche. Le professeur Gaëde a dècrit le canal digestif. le vaisseau dorsal et le système nerveux; la Scutigère aranéoïde, ou l'espèce de notre pays, a offert à M. L. Dufour deux glandes salivaires ayant la forme d'une grappe ovale, granuleuse, composée d'utricules, et quatre vaisseaux hépatiques d'inégale grosseur, plus courts que ceux des autres Myriapodes. Les organes mâles de la génération consistent en deux articles qui confluent en une anse courte, recevant le conduit des deux vésicules séminales et formant la partie la plus apparente de ces organes. Ceux de la femelle se composent d'un ovaire et de deux glandes séparées; la vulve est armée des cleux côtés d'une 
pièce mobile, qui doit jouer un rôle dans l'acte de la copulation; sous les plaques dorsales sont des glandes ou des sachets adipeux, d'où s'écoule une humeur d'un violet-rougeâtre; au-dessus des viscères sont deslobules adipcux blancs et disposés quel. quefois en mosaīque. M. Marcelle de Serres a observé sous chacune de ces plaques deux poches pneumatiques et trachées tubulaires, recevant l'air et communiquant arec les trachées latérales et inférieures. Ces Myriapodes courent très-vite, sont carnassiers, nocturnes, et se logent sous les pierres, les vieilles poutres, les écorces des arbres; dans la terre, le fumier, eic. Diverses espèces exotiques et de grande taille sont généralement redoutées, à raison de leur morsure. Cet ordre a été partagé en deux familles, les Scutigérites et le Scolopendriles.

\section{S C U T I G E R I T ES,}

Nobis.

Caractères. Le corps, proportionnellement plus court que celui des autres Chilopodes, est recouvert de huit plaques en forme d'écisson, sous lesquelles sont les nuvertures de la respiration conduisant à des poches pneumatiques qui communiquent avec d'autres trachées, mais latérales et inférieures.-Le dessous est divisé en quinze demi-anneaux, portant chacun une paire de pattes terminées par un tarse fort long, grêle et multi-articulé; les dernières sont plus grosses. - Les yeux sont grands, et leur cornée est réticulée ou à facettes.-Les antennes sont grêles et longues. - Les palpes sont saillans et garnis de petites épines.

Ces animaux se tiennent dans les maisons, s'y cachent entre les poutres ou les solives des charpentes, courent avec une vélocité extraordinaire, et perdent plusieurs de leurs pattes lorsqu'on les saisit.

Genre: Scutigera.

SCUTIGERA, LAMARCK, LATR.;

Scolopendra, Linn., Geoff., Fabr.;

Iulus, Pallas; Cermatia, Illig.

Le corps est presque cylindrique, large, moins déprimé que celui des Scolopendres, un peu rétréci en pointe à son extrémité postérieure et un peu plus large au bout opposé, le diamètre transversal de la tête étant un peu plus grand.-Celte partie est presque carrée, avec les angles postérieurs obtus, et son extrémité antéricure un peu avancée ct arrondie. - Les yeux sont un peu élevés, presque orbiculaires et à facettes très-nombreuses. - Les antennes, insćrées au-devant d'eux, sont rétrécies, pres- que aussi longues que le corps, et composées d'une multitude de petits articles. Les palpes maxillaires sont saillans, filiformes et épineux. - Les pieds-mâchoires extérieurs, ou crochets, sont, suivant M. Latreille, proportionnellement plus longs et plus courbés que ceux des Scolopendres.Les deux divisions de la fausse lèvre, comprise entre eux, ont leur bord supérieur entier et garni d'épines. Vu en dessous, le corps présente, dans sa ligne médiane, une série de quinze petites lames, ou demi-segmeus, presque carrées, un peu plus étroiins au bord antéricur, qui est arrondi à ses angles et foiblement échancré dans son milieu ; de chaque côté de chacune de ces la mes, sous leurs bords latéraux, est insérée une patte; ainsi, chaque demi-seginent en porte une paire, de sorte que le nombre total de ces organes du mouvement est de trente. - Le dessus du corps est recouvert longitudinalement par une suite de huit autres plaques, plus épaisses, formant autant de petits houcliers ou écussons presque carrés, un peu carénés dans le milieu de leur longueur, avec le bord postérieur arrondi aux angles, échancré au milieu, et offrant, dans le sinus, une petite fissure élevée sur ses bords, en manière de lèvre, représentant une espèce de stigmate; ces fissures sont en effet destinées au passage du fluide nécessaire à la respiration; celle de la dernière plaque, ainsi que son échancrure, est moins sensible; cette plaque est la plus petite de toules; la quatrième est presque une fois plus longue que les autres, ct a été désignée par Linné sous le nom d'élytre. Comme il la distingue ainsj des autres, le nombre des plaques n'est, 
cans sa supputation, que de sept; l'étendue de la dernière correspondant exactement à la cinquième plaque ventrale, cet anneau du corps n'est censé n'avoir qu'une paire de pattes, tandis que les précédentes en porient une de plus. Un segment anal, venant immédiatement à la suite des précédens, termine le corps; il est composé de deux petiles valvules formant, par leur courbure et leur réunion, un tube très-court qui renferme cinq appendices, dont les trois supérieurs très-petits, peu saillans, simples, presque triangulaires, et dont les deux autres inférieurs beaucoup plus longs, saillans, un peu relevés et contigus parallèlement dans leur portion inféricure; i]s sont composés de trois articles, dont les deux derniers beaucoup plus grêles que le rădical; le troisieme ou le terminal finit en pointe et présente l'apparence d'une épine. Les plaques du corps, tant supérieures qu'inférieures, et les segmens de la tête sont d'une consistance un peu coriace et qui garantit les parties plus foibles. Les pattes diffèrent essentiellement par leur composition; les coudes qu'elles forment et Jeur longucur, de celles des Scolopendres, se rapprochent à cet égard des Faucheurs. Elles tiennent au corps par deux articles correspondans à la hanche, et dont le second très-court; riennent ensuite deux autres articles plas gros que les suivans (le premier surtout), allongés, formant un angle à leur point de réunion, et qui représentent la cuisse. Une quatrième pièce, plus allongée que la précédente, mais plus menue, sera dès lors la jambe, ou du moins son second article, dans la supposition que l'article précédent, dont la forme est également plus cylindrique que celle du troisième, en fasse partic. Enfin, ces pattes sont terminées par un tarse plus grêle que la jambe, beaucoup plus long, testacé, composé d'un trẻs-grand nombre d'articles, susceptible de se contourner un peu en spirale, finissant insensiblement en pointe, arec un angle petit et simple au bout. Ce tarse est garni de petits poils qui, vus à son extrémité inférieure, sont réunis en très-petils faisceaux; le premier article est le plus long de tous, et les deux derniers sont très-courts, ceux de la cuisse et de la jambe sont généralement cylindriques, mais un peu comprimés, avec des arêtes longitudinales et des piquans assez forts à leur extrémité; les six dernières paires de pattes, et surtout les deux postérieures, sont brusquement plus longues que les précédentes: ces organes sont très-caducs, et rarement saisit-on l'animal sans qu'il en perde un certain nombre. A ces caractères, assignés par $\mathbf{M}$. Latreille au genre Scutigera, nous en ajouterons d'autres qui ont été indiqués par M. L. Dufour dans le t. II des Ann. des Sc. nat. Les yeux, loin d'êlre presque orbiculaires, comme le dit M. Latreille, circons. crivent un triangle dont la base est antérieure et arrondie. Les pieds-mandibules s'insèrent sur un demi-anneau fort étroit, placé derrière le bord occipital de la tête et caché sous le premier segment dorsal. Ils sont composés de quatre articles dont le dernier est un crochet brun, moảérément arqué. Les antennes offrent, vers le quart environ de leur longueur, à partir du point d'insertion, un article trois ou quatre fois plus long que ceux qui le précèdentel le suivent. Ainsi, dans l'animal vivant, M. L. Dufour a souvent remarqué en cet endroit un léger coude. Il y aurait donc, dans les antennes de cette Scutigère, un vestige de la division en deux pièces principales. Celte même réflexion est même applicable aux tarses de ce Chilopode. Ces tarses, a l'exception de ceux de la dernière paire de pattes sont, comme on sait, composés de deux ordres d'articles qui semblent constituer deux pièces distinctes l'une de l'autre par le nombre, la grandeur, la texture des articles, et sans doute aussi par leurs usages. Les huit ou dix premiers articles du tarse sont beaucoup plus longs que les suivans, et garnis en dessous d'un duvet fin et spongieux. L'autre pièce, qui se termine par un seul ongle, et qui est susceptible de rouler un peu à son extrémité comme les tarses des Phalangium, est composée d'une multitude innombrable de très-petits articles hérissés en dessous de poils courts et mobiles, qui servent très-efficacement à l'animal pour grimper et courir sur les surfaces les plus verticales, les plus lisses. Les pattes se désarticulent ou moindre contact, et conservent pendant plusieurs minutes, après a voir été séparées du corps, une contractilité irrégulière presque convulsive. M. L. Dufour a cru remarqner que celte contractilitẻ se conserroit d'autant plus long-temps que les pattes étoient plus postérieures. La somme de vilalité de celles.ci seroit donc plus considérable. Indépendemment des segmens dorsaux pédigères . l'extrémité postérieure du corps (Scutigera Araneoides 9 ) offre deux plaques rétractiles arrondies, dépourvues de soies. Au-dessous de ces plaques, M. L. Dufour a obserré 
d'abord deux crochets bruns, acérés, à peine arqués, bi-articulés, puis deux pièces ovalaires hérissées comme des brosses.

\section{SCutigeia ananeoides. (PI. 2,} fig. 6.)

Latr., Hist. nat. des Crust. et des Ins., t. VII , p. 88 ; id., Gener. Crust. et Ins., t. I, p. 77; id., Règ. anim. de Cuv., t. IV,

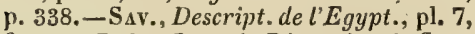
fig. 1,--GuÉn., Icon. du Règ. anim. de Cuv., Ins., pl. 7, fig. 1. - Gerv., Ann. des Sc. nat., t. VII, ann. 1837, p. 48.-Scutigera Lineata, L. Dur., Ann. des Sc. nat. . t. II, p. 92. - Cermatia Lineala, Illig. - Cermatia Variegata, Risso, Hist. de l'Europe Mérid., t. V, p. 153. - Cermatia Livida, LEACH, Zool. Misc., t. III, p. 38, tab. 136. - Scutigera Livida, Gray, Anim. Kingd., pl. 1, fig. 2. - Scolopendra Coleoptrala, LiNn., Syst. nat., édit, 13, t. I, pars 2, p. 1062.-F'Bв., Ent. Syst., 1. 2, p. 389. -Iulus Airaneoides, Pallas, Sp. Zool., fasc. 9, tab. 4, fig. 16. - La Scolopendre à vingt.huit pattes, GeorF., Hist.des Ins, des environs de Paris, t. II, p. 676. - Long. 1 pouc. $\frac{T}{2}$. - Elle est d'un jaune - roussâtre ou couleur de cire, avec trois lignes d'un noir-bleuâtre sur le dessus du corps, dont une au milieu, et les deux autres latérales; les pattes ont aussi des bandes transverses de cette couleur. - Se trouve en Europe et en Afrique.

M. L. Dufour, dans le t. II des Ann. des Sc.nat., a donné une description anatomique très-détaillée de cette espèce, et que nous rapporterons ici.

Ainsi que dans le Lithobius Forcipatus, les organes de la digestion se composent des glandes salivaires, du tube alimentaire et des vaisseaux hépatiques.

Des glandes salivaires. Il y en a une de chaque côté de l'œsophage moins grande que celles du Lithobie ; elles consistent chacune en une grappe ovale, blanchâtre, granuleuse, composée d'utricules ovalesoblongues, assez serrées entre elles, et traversée, suivant sa longueur, par une rainure médiane.

Quoique j'aie vu, dit M. L. Dufour, auqquel nous empruntons ces intéressantes observations, ces glandes bien circonscrites, bien isolées, cependant le conduit qui verse la salive dans la bouche a éludé jusqu'à ce jour mes investigations.

Du tube alimentaire. 11 a la plus grande analogie, pour sa longueur et sa conformation générale, avec celui du Lithobie. L'œ- sophage est d'une extrême briévelé; il faut ouvrir la tête pour le mettre en évidence; il se continue hors de celle-ci ou en un tube court du même diamètre que lui, ou en une légère dilatation qui mérite le nom de jabot, et qui se distingue du ventricule chylifique, soit par une contraction annulaire peu sensible, soit surtout par une différence tranchée de texture. Le ventricule chylifique est cylindroïde et occupe environ les trois quarts de la longueur du corps. Il a une capacité assez vaste; ses parois sont assez épaisses et d'une texture remarquable. Examinées à la loupe, elles paroissent couvertes de cryptes glanduleux ronds ou ovales, excessivement nombreux, qui donnent à cette surface un aspect pointillé et conme réticulé. Ces cryptes s'effacent à l'œil par une macération, même peu prolongée. Cet organe est brusquement séparé de l'intestin par un bourrelet annulaire où s'insèrent les vaisseaux biliaires. L'intestin parôit plus musculeux que le ventricule chylifique. Dans l'individu dont j'offre le dessin (Ann. des Scienc. nat., t. II, mai 1834 , pl. 5 , fig. 4), il étoít assez renflé à son origine, puis contracté, sans aucune apparence de valvule, et avant de se terminer par le rectum, il présentoit une dilatation, une sorte de cœcum renfermant des crottes grisâtres; les parois de ce cœcum étoient marquées de plissures longitudinales.

Des vaisseaux hépatiques. Dans le Li.. thobie et la Scolopendre, il n'y a que deux de ces tubes biliaires, tandis qu'on en obsorve quatre dans la Scutigère. Ils sont proportionnellement plus courts que dans les autres Myriapodes. L'une des paires, sensiblement plus grosse que l'autre, correspond à celle du Lithobic et a le même mode d'insertion que dans ce dernier, c'està-dire de chaque côté du bourrelet ventriculaire ; l'autre paire, d'une ténuité capiJaire, s'implante en dessus et en dessous de l'extrémité du ventricule. Au lieu de se diriger vers la tête, comme dans le Lithobie, ils se portent, au contraire, vers la partie postérieure du corps, où leurs bouts flottans s'enfoncent dans le tissu adipeux splanchnique.

Organes mâles de la génération. Je dois prévenir, dit M. L. Dufour, que je n'ai encore ell qu'une seule fois l'occasion de voir cet appareil; et, malgré tout le soin que. j'ai mis dans la dissection et le déploiemeut de ces organes délicats, malgré que je n'aie rien dessiné que ce que j'ai vu, il est très- 
2) ssible que des dissections ultérieures viennent modifier ma description.

Des testicules. Je considère comme tels, continue MI. L. Dufour, deux corps oblongs uont le bord externe est lègérement boursoufflé et festonné, et qui sont en lignes presque adhérentes par leur bord interne. Ces deux corps, semblables entre eux et bien distincts, sont représentés séparés dans la figure, afin de faire reconnoitre leurs formes et leurs connexions. Amincis à leur bout antérieur, ils confluent aussitôt en une anse courte qui recoit le conduit commun des vésicules séminales. Par leur extrémité postérieure, ils dégénèrent chacun en un canal déférent filiforme, qui bientôt offre un renflement aussi considérable que le testicule lui-même; puis il se rétrécit de nouveau en un conduit tubuleux pour se porter, isolé de son congénère, dans l'appareil copulateur.

Des vésicules séminales. Fllles forment la partie la plus apparente de l'appareil générateur; elles débutent par deux utricules ovoïdes placées à peu près vers le milieu de la cavité abdominale, et munies chacune d'un conduit capillaire. Ces conduits repliés, trèsfluxueux, sont d'abord contigus, adhérens entre eux; puis ils confluent en un seul tube fort délié dont les sinuosités élégantes et rapprochées rampent sur la paroi supérieure du ventricule chylifique dont elles ne sont séparées que par une toile adipeuse légère. Ce tube ou conduit commun des vésicules séminales est plus long que tout le corps de la Scuti. gère; il s'insinue entre les deux testicules et va s'aboucher dans l'anse où confluent les extrémités antérieures de ces organes sécréteurs du sperme.

Organes femelles de la génération. Ovaires. Il est simple et ressemble parfaitement à celui du Lithobie; c'est un sac allongé dont l'extrémité arrondie atteint Ie milieu environ du ventricule chylifique, et dont le pourtour est garni de graines ovigères uniloculaires, sphéroïdes, plus ou moins saillantes, et contractées à l'endroit de leur insertion au sac. Les œufs qu'il reaferme sont globuleux, blancs , assez petits.

Glandes sébacées de l'oviducte. De chaque côté de la partie postérieure de l'ovaire on aperçoit un disque arrondi, lenticulaire, semi-diaphane ou opaloĩde, se terminant par un gros pédicule. En déchirant celui-ci, on reconnoît dans son intérieur uu tube capillaire, un vẻritable conduit cxcréteur.

Appendice. En-enlevant les plaques dorsales pour mettre à découvert les viscères, on crève souvent des glandes ou des sachets adipeux, d'où s'écoule une humeur d'un violet-rougeâtre. Indépendamment de cela, il y a, surtout au-dessous des viscères, des Jobules adipeux, blancs et disposés parfois en mosaïques.

\section{SCUTIGERA LONGICORHIS.}

Latr., Nouv. Dict. d'Hist. nat, , t. XXX. p. 446. - Gerv., Annales des Sciences naturelles, t. VII, ann. 1837, p. 48. - Scolopendra Longicornis, FaBr., Ent. Syst., t. II, p. 390 , n ${ }^{\circ}$ 3. - Les antennes sont jaunes, du double plus longues que le corps ; ce dernier est couvert de sept écailles oblongues; les pattes sont allongées, variées de bleu pâle; le dessus est brun, avec une ligne dorsale ferrugineuse; le dessous est jaunâtre. - Se trouve á Tranquebar.

\section{SCUTIGERA VIRESCENS.}

LAtr., Nouv. Dict.d'Hist. nat., t. XXX, p. 447.-Gerv., Ann. des Sc. nat., t. VII, ann. 1837, p. 49. - Très-voisine de la précédente; son corps est d'un verdâtre obscur, avec les pieds plus sales. - Cette espèce a élé trouvée à l'Ile-de-France.

\section{SCUTIGERA LESUEURII.}

M. Latreille, dans le tome XXX du Nouveau Dictionnaire d'Histoire naturelle, p. 447. dit; Péron et M. Lesueur ont rapporté de leur voyage aux Terres-Australes une autre Scutigère dont le corps est cntierement brun. M. Latreille ne lui a pas donné de nom spécifique, nous le désignerons sous celui de Scutigera Lesueurii, en lui donnant pour caractères spécifiques la phrase suivante:

Elle est brune, avec une raie de même couleur, mais plus claire, sur chaque segment, ce qui forme de chaque côté une ligne longitudinale; les pattes sont d'un jaune sale; avec les antennes de même couleur; le dessous est d'un jaune-grisâtre. - Trou. vé á la Nouvelle-Hollande. 


\section{S GOLOPENDRITES,}

\section{Nomis.}

Caractères. Le corps est partagé, sur deux faces, en un pareil nombre de segmens, portant chacun une paire de nieds. - Les stigmates sont latéraux. - Les yeux, lorsqu'ils sont visibles, se composent d'un assez grand nombre d'yeux lisses. - Les pattes, à l'exception au plus des deux dernières paires, sont presque égales, et de six arlicles. - Les antennes sont peu allongées, comparativement au corps. - Les irachées artérielles, ou celles qui reçoivent directement l'air, sont latérales, ainsi que les ouvertures par lesquelles il pénètre, ou les stigmates.

Lue développement des espèces de la famille des Scolopendrites n'avait jamais ẻtẻ, avant M. P. Gervais, observé par personne, aussi empruntons-nous à ce naturaliste les détails suivans. Envisagé dans leur état complet de développement, les Lithobies ont quinze paires de patles; de là le nom de Scolopendres à quinze paires de pattes que leur impose Geoffroy ; elles ont les antennes grenues et composées de quarante articles cnviron; enfin leur yeux sont fort nombreux, disposés et groupés sur les côtés de leur tête. Un jeune Lithobie que je recueillis, dit II. P. Gervais, le 29 mai 1836, n'avait encore que sept paires de pattes, dix anneaux pour tout le corps, deux yeux seulement de chaque côté et huit articles aux antennes. liemarquons d'abord qu'un seul de ces anneaux, l'anal, était privé de pieds, ce quí établit de suite une différence entre les jeunes Lithobies et les jeunes Iules, auxquels nous avons toujours vu à l'arrière du corps plusieurs segmens apodes. Cette même larve, car je crois que ce nom peut lui être appliqué, montrait déjả, le 8 juin suivant, quatorze articles aux antennes et huit paires de pattes; il y avoit encore un anneau apode pour l'anus, mais on comptait en tout onze segmens.

La figure que je donne (Etudes, pour servir a l'Hist, nat. des Myriap., Ann. des $S_{c}$. nat., t. VII, pl. 4) représente une autre Lithobie à peu près du même âge, mais qui a déjà trois yeux, et une de celles q̨ue j'ai encore étudiées avoit six paires de paltes, dont les deux postérieures rudi- mentaires et á peine formées; la même planche donne la figure d'une Lithobie dont les pattes sont toutes développées, mais qui n'a pas encore tous ses yeux, chaque côtés n'en présentant encore que huit. Les Lithobies subissent donc comme les Iules des variations dans le nombre des anneaux de leur corps, de leurs paires de pattes, ainsi que dans celui des articles de leurs antennes; elles nous présentent un second exemple d'animaux chez lesquels les yeus varient avec l'âge, particulurité bien remarquable et que je ne crois pas avoir encore été signalée. Les yeux des Myriapodrs paroissent tout-à-fait comparables aux yeux lisses ou stemmates des Entomozoaires Hexapodes, mais ils offrent d'un genre à l'autre des variations remarquables; les Scolopendres n'en ont que quatre paires, et chez les Iules, où ils sont nombreux et rapprochés, ils se groupent de différentes façons, et leur disposition peut, dans cer. tains cas, offrir de véritables caractères pour la distinction des espéces et même pour celle des genres. Quelques Myriapodes cependant manquent d'œufs à toutes les époques de leur vie.

11 me reste maintenant à examiner com ment se développent les pattes et les anneaux du corps à mesure que chaque jeune Lithobie avance en âge. Etudiés en dessous chez un individu adulte, les segmens pédigères des Lithobies sont à peu près égaux entre eux; maisen dessus, où ils sont comme imbriqués, quelques-uns apparoissent plus grands et d'autres plus petits; les plus grands de ces arceaux pédigères sont les premier, deuxième, troisième, cinquiẻme, septième, huitième, dixième, douzième. treizième el quatorzième; ces trois derniers correspondent à quatre demi-arceaux inférieurs et par suite à quatre paires de pattes; les deuxième, quatrième, sixième, neuvième et onzième sont plus petits; j'aj constaté que les pattes existent déjà aux arceaux les moins grands, avant que la partie supérieure de ceux-ci ne se soit montrée, et je ferai observer que ce qui est permanent pour un des segmens postérieurs qui n'a en dessus qu'un écus- 
son, existe alors vers les deux scgmens postérieurs; ils n'ont en dessus qu'un seul ćcusson, le plus pelit des deux écussons n'ayant pas encore apparu; ce fait mérite d'être signalé, car si l'on suppose ce même phénomène permanent pour tous les anneaux de la Scutigère qui n'out point de carapace supérieure, on s'expliquera comment à tous les âges cette dernière a moins de segmens visibles en dessus qu'elle n'a de paires de pattes. Chez les Géophiles, la clisposition est tout autre, et c'est une nouvelle preuve des nombreuses différences que les divers genres de la classe présentent entre eux; mais comme M. P. Gervais n'a pu encore se procurer qu'en très-petit nombre de Géophiles, il n'en parlera qu'après en avoir étudié un plus grand nombre.

Les animaux qui composent cette famille se trouvent toujours dans les lieux humides, dans la terre, sous les pierres, sous les écorces des arbres, dans le vieux bois, etc.

Genres: Lithobius, Scolopcndra, Cryp. tops, Geophilus.

\section{LITHOBIUS, Leacu; \\ Scolopendra, Linn.}

Les segmens du corps dans l'âge adulte sont au nombre de dix-sept, imbriqués en dessus, inégaux. - Les pieds sont au nom. bre de quinze paires seulement de chaque côté; les postérieurs sont les plus allongés. - Les antemnes, variant suivant l'âge, coniques, ont de trente à quarante articles, sétacés; ces derniers décroissant du premier au deruier, le premier et le second étant beaucoup plus grands que tous les autres. - Les yeux sont granuleux, distribués en deux groupes de chaque côté, et varient aussi, comme les antennes, suivant l’âge.

ITHobius forcipatus. (Pl. 3 , fig. 1, 1 A.) Gervars, Annales des Sc. naturelles, t. VII, ann. 1837 , p. 49 . - GuÉri., Iconographie du liègne animal de Cuvier, Ins., pl. 1, fig. 6. - Trevinanus, Zeitschrififür Physiol., t. II, p. 18, pl. 4 à 6. - Scolopendra Forcipata, Line. Syst. nat., édit. 13, t. I, pars 2 , p. 1062 ; jd., Faun. Suec., édit. 2, n०2064. - Scolopendre a trente patle's, Geofrr., Ins. des env. de Pavis. 1. II. pl. 22, fir. 3. - Siolopendie furchue. DEgéen, Mćm. ponr ser. vir a l'Hist.nat. des Ins., t. Y II, pl. 35 , fig. 42 a I6. - Scolopendra Forficata, IABR. Ent. Syst., t. 1I, p. 290. - Latr.,
Gener. Crust. et Ins., t. I, p. 78 ; id., Iist. nat. des Crust. et des Ins., t. V II, 1. 93. - Lithobius Forficatus, LEACH, Zool. Hiscell., t. III, p. 39, pl. 137; id., Edinb. Encycl., t. VII, p. 408 ; id., Trans. Limn. Soc., t. II, p. 481 ; id., Enc. Brit., suppl. 1, p. 431, pl. 22. - L. Dur., Ann. des Sc. nat., t. II, mai 1824, pl. 15, fig. 1.-Risso, Hist. de l'Eul. Mérid., t. V, pl. 154. - Long. 1 pouc. Cette espece est lisse, d'un roux ferrugineux ou bien noirâtre, quelquefois d'un brun de poix, ou tantôt d'un roux qui tire sur l'ambre; ses antennes sont longues, velues, ct les segmens de son corps, sauf le quatrième et le cinquième, sont alternativement plus grands et plus petits; les antennes ont quarante et quelques articles; dans le jeune âge, cette espèce est de cosıleur blanchâtre et comme étiolée, parce qu'elle vit dans les lieux obscurs; ce n'est que quelques jours après avoir pris toutes ses pattes qu'elle commence à devenir rousse; elle se trouve dans toute l'Europe; on l'a signalée en France, en Italie, en Allemague, en Belgique et en Angleterre. On la rencontre ordinairement sous les pierres, les écorces, dans les lieux humides. M. L. Dufour cn a donné une bonne anatomie dans le tome II des Annales des Sciences naturelles, pl. 5 , fig. 1 a 3, et que nous rapporterons ici.

Organes de la digestion. Des glandes salivaires. Elles s'observent à l'issue de la tête sous la forme de deux grappes assez grandes, pcu distinctes l'une de l'autre, plus ou moins contiguës etadhérentes entre elles, déprimées, et le plus souvent concaves, parce qu'elles enveloppent l'origine du tube alimentaire. Leur suructure, trèsdifficile à démêler, sémble n'offrir à l'ceil nu qu'une masse gélatineuse sons organisation apparente, remarquable par une couleur d'un bieu améthiste souvent très-foncé. Mais, avec le secours du microscope on y reconnaît des granulations ovalaires, dis persées par grappes confusément aggolomérées. Observons que la couleur bleue-améthiste dont nous venons de parler n'est pas exclusivement propre aux glandes salivaires; elle s'étend fréquemment, mais avec une foible nuance, sur toute la couche musculaire qui revêt l'intérieur du corps. Aucun des antenrs qui ont traité de lanatomie du Lithobie n'a fait mention de l'existence d'un appareil salivaire. Ces grappes glanduleuses n'ont cependani pas échappé à la perspicacité de Trevirauus, 

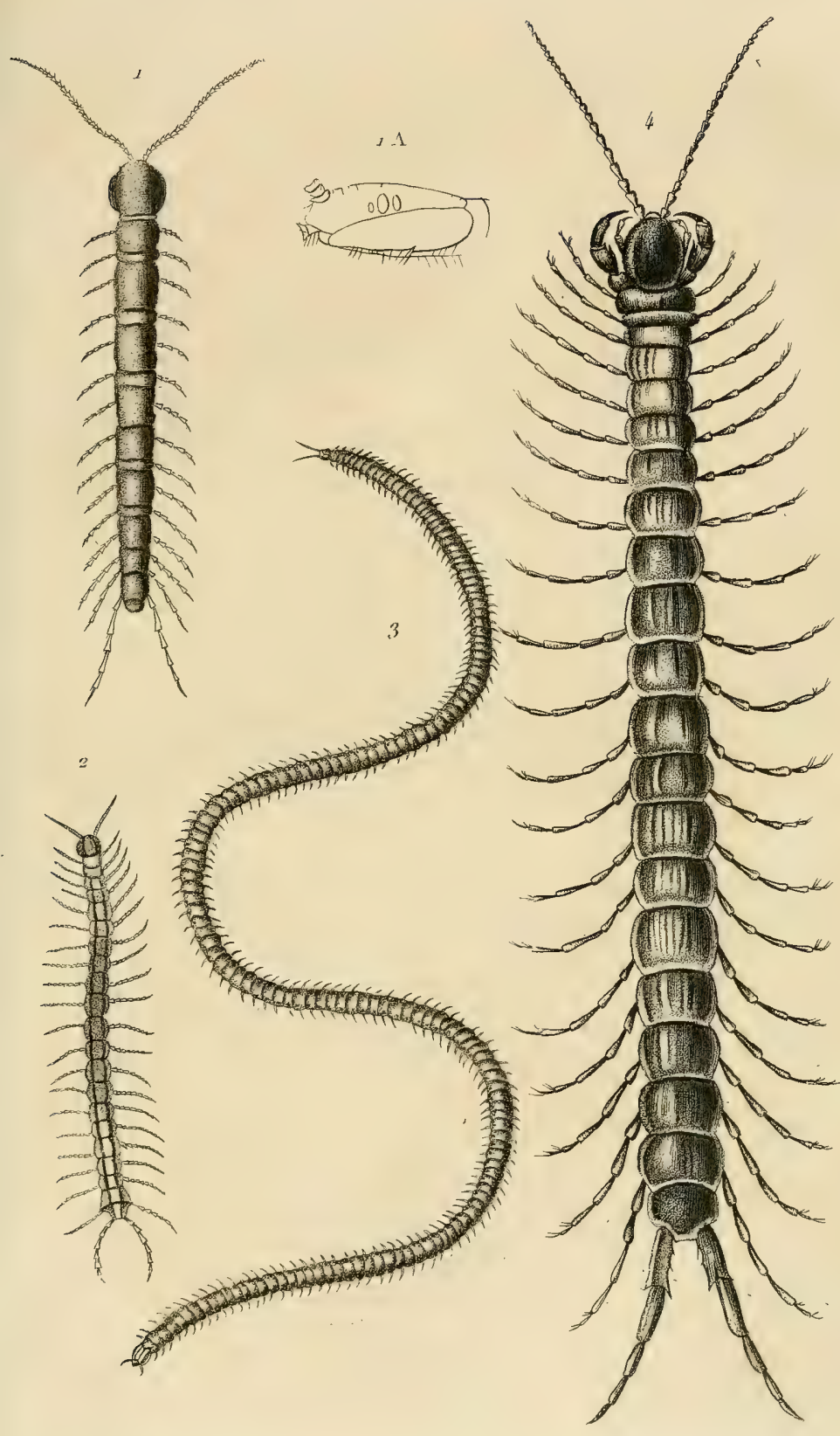
1. 1A. Lithobius forcipatas
2. Cryptops Savignya ,

3. Geophilus Walc Ecnaerii,

4. Scolopendra morsicans. 

qui en indique la situation précise et qui en a fidèlement représenté la forme générale (op. cit., p. 25 , tab. V, fig. $4, q, q$ ). Mias ce savant anatomiste, trompe par des apparences, et peut-être par des idées prèconçues sur les connexions qu'il dit exister constamment entre le tissu adipeux et les extrémités des vaisseaux biliaires, se contente de les désigner sous le nom de masses graisseuses. M. Marcelle de Serres, dans J'exposition des traités analogues de ce même myriapode, ne dit pas un mot de cet organe (Observ. sur les usages des vaiss. dors., etc., p. 166).

Du tube alimentaire. Il est tout-à-fait droit, et par conséquent sa longueur ne dépasse point celle du corps du Lithobie. Dans les individus nombreux soumis à mon scalpel, dit M. L. Dufour, l'œsophage et le jabot (si ce dernier cxiste) ne formoient qu'un mème tube, d'un diamètre uniforine, cylindrique, enveloppé dans sa situation naturelle par les grappes salivaires et atteignant à peine la seconde plaque doisale. Trériranus et M. Marcelle de Serres n'admettent point le jabnt; mais l'analogie me fait présumer que celte première poche gastrique doit exister; et, si elle n'es! pas prononcée, c'est que les alimens n'y séjournant que quelque temps et en petile quantité, n'y déterminent pas de dilatation sensible. L'existence d'un léger bourrelet a l'origine du ventricule chylifique, bour' . relé qui me semble l'indice d'une valvule annulairc, vient prêter un grand poids a l'induction par analogie. Cette valvule prouve que les alimens ne doivent pénétrer dans la poche qu'elle précède qu'après avoir subi une élaboration préliminaire dans le jabot en question. Le ventricule chylifique forme a lui seul les trois quarts de la longueur de tout le tube digestif. Il est allongé, plus ou moins déprimé, d'une texture inusculo-membraneuse, et se termine en arrière par un bourrelet peu saillant, siege d'une valvule interne, où vienacnt s'aboucher les vaisseaux hépatiques. Les dilatations irrégulières qui s'observent parfois à ces organes sont purement accidentelles. Dans les portions plus contractées, on reconnoît une disposition annulaire dans les fibres de la tunique musculaire. Tréviranus a très-bien représenté les rubans longitudinaux qui coupeut, à des intervalles réguliers, les fibres annulaires. La cavité du ventricule chylifique renferme un palpe alimentaire homogene d'un gris. roussâtre. L'intestin, bien moins large que le précédent et cylindrique, paroît courbé suivant sa longueur, lorsqu'il est vide et contracté sur lui-même. $\Lambda$ vant de se terminer à l'anus, il offre un coecum à peine sensible.

Des vaisseaux hépatiques. Il n'y en a qu'une paire, ils s'insèrent un de chaque côté, et par un bout légérement renflé, au bourrelet valvuleux, que nous avons dit terminer en arrière le ventricule chylifique; ils sont bien distincts, flexueux, diaphanes et constamment dirigés vers la tête, où leurs extrémités sont maintenues par un ligament suspenseur d'une ténuité presque imperceptible. Le mode de connexion a échappé à Tréviranus, qui, imbu de l'idée que les extrémités des vaisseaux biliaires sont constamment enveloppées du tissu adipeux, a donné á ceux du Lithobie cette même disposition, comme je l'ai dejà fait pressentir' plus haut : c'est peut-être celte idée première qui a détourné cet anatomiste d'un examen plus attentif des glandes salivaires, considérées par lui comme une masse simplement graisseuse. M. Marcelle de Serres, en avançant que le duodenum reçoit vers sa partie moyenne un grand nombre de vaisseaux hépatiques grêles, blanchâtres et assez allongés, nous prouve clairement qu'il n'a point reconnu de conduits biliaires du Lithobie.

Organes mâles de la génération. On y distingue des testicules, des vésicules séminales, une verge.

Des testicules. Ils consistent, pour chaque côté, en une paire de glandes allongées, pointues, comme lancéolées, blan. châtres, inégales en longueur, et parcourues par une rainure médiane; aussi on pourroit croire que le Lithobie a quatre testicules; à l'œil nu ou à la loupe ordinaire, ils offrent l'aspect d'une grappe granuleuse; mais, étudiés plus attentivement avec les secours du microscope, ils m'ont paru plutôt ressembler à des sacs conoïdes hérissés, et comme guillochés en dehors par des petites bourses inégales et polymorphes, que j'ai distinctement vues remplies de sperme. Chacune de ces glandes a un canal déférent tubuleux et capillaire. Je n'ai pı constater parl'observation directe le mode de connexion de ces deux canaux entre eux, ni celui qu'ils ont, soit avec les vésicules séminales, soit avec les testicules du côté opposé pour la formation du conduit éjaculateur. La petitesse et la texture délicate de toutes ces parties se sont jusqu'ici opposées à ce que je pusse les mettre en 
évidence. Croiroit-on que ces testicules aient été pris par Tréviranus pour des masses graisseuses? c'est cependant sous cette dernière dénomination qu'il les a signalés et représentés. Cette méprise est d'autant plus singulière dans un anatomiste aussi exercé que lui à triompher des plus grandes difficultés, qu'il a reconnu et très. bien figuré les canaux eflèrens de ces prétendues masses graịseuses. Une simple réflexion sur ce dernier fait eût dû lui faire présumer que ces canaux devoient nécessairement appartenir ou à ces organes sécréteurs, ou au réservoir d'une glande. Quant à M. Marcelle de Serres, je ne sais sur quel fondement il avance, dans l'ouvrage précité, que les organes reproducteurs mâ: les du Lithobie sont composés de deux testicules arrondis.

Des vésicules séminales. Il y en trois, dont deux latérales et une intermédiaire. Elles sont bien apparentes, fort développées comparativement aux autres parties de l'appareil générateur, et presque aussi longues que tout le corps quand elles sont déroulées; c'est surtout dans leur élat de turgescence spermatique que leur dissection est moins difficile. Les vésicules latérales sont semblables entre elles, filiformes, renflées en bouton a leur extrémité flottante, et leurs replis sont quelquefois si adhérens qu'il est presque impossible d'en opérer le dépluiement complet sans les rom. pre; elles confluent en arrière en une anse assez ouverte, au centre de laquelle s'insère la vésicule intermédiaire, et d'où partent postérieurement deux conduils grêles qui vont recevoir les canaux déférens des testicules. Cetle vésicule séminale intermédiaire est sensiblement plus grosse que les latérales, et je l'ai souvent trouvée mouchetée par l'ellet desflocons intérieurs du sperme. Quand elle ne contient pas le liquide séminal, elle, est grêle, diaphane, terminée en pointe, et difficile à mettre en évidence. Dans le cas contraire, elle a une texture un peu roide, el son bout renflé a une sorte de bec. Les vésicules séminales du Eithobie paroissent avoir èté prises par Tréviranus pour les organes principaux de la préparation du sperme; il désigne l'intermédiaire sous le nom de vaisseau séminal du centre, et les autres sous celui de réservoirs latéraux.

De la verge. M. L. Dufour n'a pas observé cet organe, mais Trériranus parle d'une vésicule dans laquelle se rendent tous les vaisseaux ou conduits spermatiques, et qui s'curre dans un pelit corps charnu, conoìde, qu'il appelle verge, placé sous le segment dorsal du corps du Lithobie.

Organes femelles de la génération. IIs se composent d'un ovaire et des glandes sébacées de l'oviducte. Il consiste en 1 m seul sac allongé, atteignant a peu près le milieu de la capacité du corps. et maintenu en place par quelques trachées lâches et capillaires. Il contient des cufs globıleux et blancs ; ses parois pároissent granuleuses, à cause des gaines ovigères qui se présentent sous la forme de pelites bourscs uniloculaires, brièvement pédicellées, ro:?des comme ies œufs qu'elles renferment. Je ne serois pas surpris que l'ovaire du Lithobie fût divisé intérieurement en deux loges par un diaphragme longitudinal, J'ai cru reconnoître la trace de celui-ci; mais je sens le besoin de nouvelles dissections pour m'éclairer sur ce point douleux. Je n'ai pas non plus vérifié la manière dout l'ovaire se comporte en approchant de la vulve; mais d'apres les observations et les figures de Trériranus, il se términeroit par un oviducte simple, assez long, dilaté à son extrémité postérieure. Que conclure de l'assertion de M. Marcelle de Serres, qui attribue au Lithobie un oviductè commun divisé en huit branches principales ou en huit ovaires, et des conjectures auxquelles il se livre à ce sujet? c'est qu'il n'a pas vu, dit M. L. Dufour, ces organes du même ail que T'éviranus et moi.

Des glandes sébacées de l'oviducte. De chaque côté de la partie postérieure de l'ovaire, on observe deux grappes allongées, diaphanes, formées chacune de deux rangées d'utricules granuleuses quelquefois bien distinctes, séparées par une rainure médiane qui loge une trachée des plıs fines. Chaque grappe se termine en arrière par un conduit eflérent flexueux, semi-diaphane; les deux conduits s'abouchent conjointement au bout extérieur d'un réservoir ovaleoblong rempli d'une humeur bianche coagulable, et qui paroît formé de deux tuniques; ce réservoir se lermine en arrière par un canal excréleui qui s'enfonce sous l'inteslin, et va se degorger dans l'oviducte. Cet organe, exclusivement propre à la femelle, revêt tous les caraclères d'une glande spéciale; on y trouve des parties propres à la sécrétion, à la conservation et à l'excrétion de l'humeur. Tréviranus a décrit et figuré cet appareil, mais il a entièrement méconnu sa structure, ses fonclions; et il est encore tombé ici dans la 
même méprise qu'à l'occasion des glandès salivaires et des testicules. Les grappes sécrétoires ne sout pour lui que des masses adipeuses, et il a mal saiši le mode de connexion de leurs effẻrens. Il avance que ceux-ci se rendent au vagin, tandis qu'ils s'insèrent évidemment, comme je l'ai dit, au bout antérieur du réservoir. 11 appelle ce dernier une vésicule oblongue, et, ainsi que moi, il l'a trouvé formé de deux membranes. Mais il a mal vu son mode de dégénèration en un conduit excréteur. La vulve du Lithobie est flanquée á droite et à gauche par une pièce crochue, biarliculée, terminée par une pointe bifide, et armée de deux dents courtes; cette pièce crochue est mobile et joue un rôle dans l'acte de la copulation.

\section{HITHOBIUS VARIEGatUS.}

Leach, Edinb. Enc., 7, 409; id., Trans. Linn. Soc., 11, 382; id., Zocl. Miscell., t. III, p. 40.- Gerv., Aun. des Sc. nat., t. VII, ann. 1837, p. 49.- Long. 9 lig. Le corps est un peu plus large que la tête, avec les pieds d'un jaune testacé pâle, tachés de brun; les secondes cuisses présentent des points légérement enfoncés et une expansion lamelliforme : cetle pspèce diffère de la précédente par sa tête, qui est un peu étroite, par ses secondes cuisses, qui sont moins ponctuées, et par ses pieds, qui sont de même couleur. - Se trouve en Angleterre.

\section{LTTHORIUS VULGaris.}

Leacir, Zool. Misc., t. III, p. 40 ; id., Edinb. Enc, 7,409; id., Trans. Linn. Soc., 11, 382.-Gerv., Ann. des Sc. nat., t. VII, ann. 1837, p. 49.-Long. 1 pouc. --La tête est de la largeur du corps, avec lespieds d'un jaune testacé; les secondes cuisses offrent une expansion lamelli orme, très-glabre et luisante antérieurement, et très-obscurément ponctuée; les autennes sont légérement poilues; les seconds pieds ont leurs tarses très-noirs et leur sommet brun; les cuisses sont arrondies, avéc leurs bords antérieurs découpés par une expansion lamelliforme, denticulée, ferrugineuse, d'un brun-noir à leur somme1. - Cetle espèce a été trouvée dans la Grande-Bretagne.

\section{IITHOBIUS IONGICORNIS.}

Risso, Hist. de l'Europ. Mérid., t. V, p. 154.-Gerv., Ann. des Sc. nat., t. VII, ann. 1837, p. 49.- - Long. 10 lig.--Suivant M. Risso, cette espèce a la tête, les antennes, le dos, le ventre et les pieds d'un jaunc safran; les mandibules sont ferrugineuses, noires au sommet, et les antennes presque toujours aussi longues que le corps. Se trouve sous les pierres.

Nous ne connoissons que par les descrip. tions des auteurs les espèces $2,3,4$ et 6 .

\section{LITHORIUS NUDICORNIS.}

Gervais, Annales des Sciences naturelles, t. VII, ann. 1837 , p. $49 .-$ Cette espèce diffère du $L$. Forcipatus par sa couleur d'un brun plus mat et ses antennes de quarante-deux articles environ, mais non velues et a articles serrés; le dernier et le pénultième plus longs que ceux qui précèdent. - Cette espèce a été trouvée on Suède.

\section{LITHOBIUS SPINIPES.}

$\mathrm{S}_{\boldsymbol{A Y}}$, Journ. de l'Acad., des Sc. de Philadelp., t. II, p. 108; id., OEuvr. Entom., édit. Lequien, t. I, p. 21 . - Long. 1 pouc. - Le corps est d'un brun noisette, lisse, non ponctué, avec des poils courts, épars; les segmess ont leurs bords latéraux réfléchis; le premier est le plus court, transverse; le deuxième est carré, à angles arrondis; les cinq ou six derniers sont rétrécis postérieurement et émarginés sur le bord postérieur; les angles postérieurs de ceux qui sont près du segment anal sont plus aigus; le segment anal est tronqué, conicocylindrique; les antennes sont pâles, testacées, avec des poils roides, serrés, courts ; l'article terminal est aussi long que les deux précédens ensemble; les pattes sort pâles, testacées; les articles sont épincux à l'extrémité, et on aperçoit une épine a.jlongée à l'extrémité de chacun en dessous: la paire antérieure est la plus courte; ja postérieure est la plus longue et la plus robuste'; la levve longitudinalement est échancrée, non ponctuée; les dents de l'extrémité sont noires; les antennes sont composées de trente articles. - Cette espèce se trouve communément sous les pier. res dans l'Amérique Boréale.

\section{SCOLOPENDRA, I InN., FABr., Latr.}

Les segmens du corps sont comprimés, au nombre de ringt-trois, la tête comprise. - Les yeux sont au nombre de quatre de chaque côté, stemmatiformes - Les forcipules ou les pieds maxillaires sont robustes.

- Les pieds sont au nombre de vingt et un de chaque côté ; les postérieurs étant les plus longs, avec le premier article épineux. - Les antennes sont sétacées, au nombre de dix sept à vingt articles. 


\section{SCOLOPENDRA VIOLACEA.}

Fabr., Ent. Syst., t. II, p. 289. GuÉR., Iconographie du Règne animal de Cuv., Ins., pl. 1, fig. 7. - Gerv., Ann. des Sciences naturelles, I. V1I, ann. 1837, p. 50. - Long. lig. - La tête, les mâchoires et les anneaux des mâchoires sont d'un rouge cerise, ainsi que les derniers anneaux de l'abdomen; les suivants sont d'un brun d'airain brillant; il y a une double ligne longitudinale sur ies anneaux, elle est assez rapprochée de la ligne médiane, et placées toutes deux dans la mème direction, au lieu d'être obliques comme cela a lieu chez quelques espèces; le dessous présente une double ligne semblable; sur le premier anneau en dessus, la double ligne n'est point encore comme en dessus, et en arrière, c'est-à-dire sur le dernier, elle ne se voit plus, seulement on remarque un petit enfoncement médian; le dessous du dernier anneau n'est point sillonné; les pattes sont d'une couleur brune d'airain; Jes antennes sont de même couleur, ce qui iranche assez bien avec la couleur rouge de la tête; le dessous du corps est un peu plus clair que le dessus. - Cette espèce se trouve au cap de Bonne-Espérance. (C'ette description nous a été communiquée par M. P. Gervais.)

\section{SCOLOPENDRA FULVA.}

Gervais, Annales des Sciences naturelles, t. VII, ann. 1837 , p. 50. - Long. 13 lig. - Le dessus de la tête ainsi que le corps et les pattes sont d'une couleur fauve uniforme; les ongles sont bruns; le dernier et l'avant-dernier article des pattes sont pourvus d'un petit crochet; les paltes postérieures sont planes en dessus, et ont au bord interne de cette partie du premier segment, quatre èpines dont la dernière composée est elle-même subdivisée en quatre autres faciles à voir à la loupe ; la face inférieure du même segment présente deux épines armées de quatre autres épines; les anneaux du corps sont bisillonnés comme chez toutes les autres espèces, carrés et marginés en dessus. - Elle a été trouvée en Sicile. (Cette description nous a été communiquée par M. P. Gervais.)

\section{SGOLOPETDRA MORSIGANS. (Pl. 3,} fig. 4.)

Livn., Syst. nat. - WiLL., Ent., 4, 11, 17, 18.-S $\mathrm{AV}$, , Descript. de l'Egypte, pl. 1, fig. 1.-Gerv., Ann. des Sc. nat., t. V1I, ann. 1837, p. 50.-Scolopendra Alternans,
Leaci, Zool. Misc., t. III, p. 40, tab. 130. - Scolopenidra Complanata, Latr., Nouv. Dict.d'Hist. nat., t. XXX, p. 393.-Sco. lopendra Cingutata, id., lièg. anim. de Cit., t. IV, p. 339.-Long. 2 pouc. 8 lig. - Cette espèce est teintée d'une couleur ferrugineuse verdâtre, avec les segments aplatis, carrés; les articles composant les antennes sont au nombre de dix-huit à vingt; les pieds postérieurs sont épais; le premier arlicle de ces derniers présente à sa face interne près de la supérieure cinq épines et deux à sa face inférieure. - Cette espèce se trouve dans la France méridionale, daus l'Afrique septentrionale et dans l'Asie occi. dentale.

\section{SCOLOPENDRA AUDAT.}

Gervais, Annales des Sciences naturelles, t. VII, ann. 1837 , p. 50 . Long: 5 pouc. $\stackrel{1}{-}$ - Cette espèce diffère de la précédente, par son corps qui est d'un bleu-verdâtre, á peine déprimé, avec les articles plus étroits; les pieds sont aplatis en dessous, marginés et comme annelés; les tubercules répandus sur le bord interne de la face supérieure elde la face inférieure sont au nombre de seize; les postérieurs sont plus longs, à peine déprimés, avec le premier article portant trois épines en dedans et deux intérieurement; les ongles sont noirs; les articles qui composent les antennes sont au nombre de dix-huit, grêles, décroissans. - La patrie de cette espèce est i nconnue.

\section{SCOLOPENDRA SUBSPINIPES.}

Leach, Linn. Trans., t. XI, p. 385 ; id., Zool. Misc., t. 1II, p. 41 ; id., Enc: Brit., p. 430.- Genv., Ann, des Sc.nat., t. VII, ann. 1837, p. 50 . - Long. 5 pouc. $\frac{1}{2}$._- Les arlicles qui composent les antennes sont au nombre de dix-huit; les anneaux sont quadrilatères; le bord antérieur est un peu moins large que le postérieur; les bords latéraux sont marginés; les pattes postérieures sont marginées, aplaties, porlant trois ou quatre crochets supérieurement et deux inférieurement; la couleur générale est un roux foncé. - Palrie inconnue.

\section{SCOLOPEYDRA BRAYDTIANA.}

Gervars, Annales des Sciences naturelles, t. VII, ann. 1837 , p. 50 . - Long. 4 pouc. - Dix-huit articles composent les antennes de cette espèce; les segmeus du corps sont roussâtres, avec les postérieurs marginés latéralement en dessus, et marqués à celte partic ainsi qu'en des- 
sous de sillons doubles, analogues à ceux des autres espèces, le dernier segment ne présente pas de sillons; les pieds sont de la couleur du corps, et ceux de la dernière paire ont leurs premier, second et troisième articles aplatis en dessus, marginés principalement en dehors, avec douze ou seize épines au premier article; la dernière de ces épines est complexe. - Patrie inconnue. (La description de cette espèce nous a été communiquée par M. P. Gervais.)

\section{SCOLORENDRA EYDOUXIAVA.}

Gervais, Annales des Sciences nattlrelles, t. V1I, ann. 1837 , p. 50. Long. 3 pouc. 3 lig. - La tête est entièrement noire; vingt articles composent les antennes, dont les quatre premiers, beaucoup plus gros que les autres, sont d'un beau vert foncé; les suivants, qui vont en décroissant, sont d'un roussâtre clair; les mandibules sont robustes, annelées de roux et de vert; les segmens sont roussâtres, avec leur bord postérieur et leurs côtés latéraux teintės de verdâtre, les second, troisième et qualrième segmens sont beau. coup plus étroits que les autres; les pattes, qui sont au nombre de vingt et une paires, sont d'un beau vert clair, excepté cependant la dernière paire, qui est d'un vert plus foncé, avec les côtés externe eủ interne bruis; les pattes vont en augmentant de longueur et de grosseur depuis la seconde jusqu'à la dernière paire, laquelle présente à son côté interne trois épines, et à son bord inférieur six épines; en dessous, on aperçoit deux pièces longitudinales terminèes en pointe, et qui sont d'une belle couleur orange, pointillées de brun. - Cette espèce a été trouvée par M. Eydoux, au Sénégal. (Cette description a été faite sur une fort belle figure, que nous a communiquée M. P. Gervais, qui doit la publier incessamment.)

\section{SCOLOPENDRA SAGREA.}

Gervais, Annales des Sciences naturelles, I. VII, ann. 1837 , p. 50.Guér., Voy. à Cuba de M. de la Sagra, Ent. Misc. - Scolopendra Morsitans, Sndw., Natur. Miscell., t. I, pl. 9? Long. 5 pouc. 4 lig. - Les segmens sont marginés latéralement, excepté les deux premiers; ils sont striés et sillonnés, surtout en dessous : ces sillons n'égalent pas les segmens; les mandibules sont robustes; dix-sept articles composent les antennes; le segment supportant les mâchoires est ANN. large, marqué d'une raie transversale courbe; les pieds postérieurs sont cylindriques; le premier article présente à sa partie interne et inférieurement de nom. breuses épines, vingt à vingt-cinq environ; la couleur générale est ferrugineuse, variée de vert, avec les pieds en dessous d'une couleur plus claire.-Cette espèce a lîle de Cuba pour patrie. (Sa description nousa été communiquée par M. P. Gervais.)

\section{SCOLOPENDRA TRIGONOPODA.}

LEACH, Zool. Miscell., t. III, p. 41. - Gervais, Annales des Sciences naturelles, t. VII, ann. 1837 , p. 51.Les pieds postérienrs sont triangulaires, avec le premier article spinifère intérieurement. - La patrie de cette espece est incounue.

\section{SCOLOPENDRA GIGAS.}

Leach., Trans. Linn. Soc., t. II, p. 385; id., Encycl. Britan., Surpl., p. 431; id., Zool. Miscell., t. III, p. 42. Gervass, Annales des Sciences naturelles, t. VII, ann. 1837, p. 51. - Les segmens sont carrés transversalement, avec les angles arrondis, d'un brun ferrugineux et d'un jaune clair postérieurement; les antennes et les pieds sont testacés; les seconds pieds sont ferrugineux, avec les ongles noirs; le corps est légérement ponctué. - Patrie inconnue.

\section{SCOLOPENDRA VIRIDIPES.}

L. Dur., Ann. génér. des Sc. phys., t. IV, p. 317. - Gervais, Annales des Sciences naturelles, t. VII, ann. 1837, p. 51. - Long. 18 lig. - Les segmens du corps sont á peu près carrés et égaux entre eux, à l'exceplion des deux premiers et du dernier; la tête est petite et ovale; tout le corps a une couleur livide marquée; les pattes et les antennes sont verdâtres; celles ci se terminent en pointe sétacée, et ont bien plus de quinze articles; les paties ont une longueur croissante de la tête a la partic anale; les palpes se terminent par un article dilaté et rond. Cette espèce a été trouvée par M. L. Dufour, sous les pierres dans les montagnes du royaume de Valence.

\section{SCOLOPENDRA ITALICA.}

Koci, Deutsch. Crust. Myriap., fasc. 9, tab. 1. - Gervais, Annales des Sciences naturelles, tom. VII, année 1837 , p. 51. - D'un jaune brillant, avec le pre' mier article dorsal des pieds postérieurs 
plan, armé de quatre dents intérieurement, noires; les suivantes eylindriques; les antennes sont composées de dix-neuf articles.

13. SCOLOPENDA MARGIVATA.

SAY, Journ. Ac. nat. Sc. de Philad., t. II, p. 1, p. 100 ; id., OEuvr. Ent., éd. Lequien, t. I, p. 22. - Gervais, Annales des Sciences naturelles, t. VII, année 1837, p. 51 . - Long. 2 pouc. $\frac{1}{2}$. - Le corps est d'un vert-olivâtre obscur; le dessous est blanchâtre ou fauve; les seg. mens sont non ponctués, bordés de chaque côté et postérieurement de vert-noir; les premier, troisième et quatrième sont les plus courts, les cinq ou six derniers sont plus distinctement bordés; la tête est couleur de châtaigne; les antennes sont vertes; les pattes sont pâles, d'un vert-bleuâtre au sommet; les ongles sont noirâtres; les pattes postérieures sont à peine plus longues que les trois derniers segmens du corps réunis; la longueur des articles à peine égale au double de leur largeur; le premier est épineux en dessous ou en dedans, armé à son sommet d'un angle aigu, fort et saillant. - Cette espèce est assez commune en Géorgie et dans le Floride orientale.

\section{SCOLOBERDRA VIRIDIS.}

SAy, Journ. Acad. nat. Sc. de Phil., t. II, p. 110; id., OEuvr. Ent., édit. Lequien, t. 11, p. 23:- Gervats, Annales des $S$ ciences naturelles, t. VII, ann: 1837 , p. 51. - Long. 2 pouc. 4 lig. - Le dessus du corps est d'un vert-bleuâtre, immaculé; les segmens postérieurs sont bordés de jaunâtre pâle ; les mandibules sont d'un blanc-jaunâtre; les pattes sont blanchâtres à la base; les derniers articles d'un vert-bleuâtre pâle; la paire postérieure est d'un jaune pâle. - Cette espèce habite la Géorgie et la Floride orientale.

S. Gigantea, Linv., Syst. nat., éd. 2, p. 1063 , pl. 4. - Brown., JaMr, tab. 42 , fig. 4. - Amérique.

S. Ferruginea, Degérr, Mém. pour servir a l'Hist. nat, des Ins., t. VII, p. 568, tab. 43 , fig. 6. - Afrique.

S. Dorsalis, Fabr., Ent. Syst., t. II, p. 391. - Tranquebar.

S. Clypeata, Fabr., Ent. Syst., t. II, p. 393. - Tranquebar.

Ces espèces dont nous donnons seulement les citations ont été irop brièvement décrites pour pouvoir être rapportées avec certitude au vrai genre $S$ colopendra.
L'espèce qui a élé figurée par M. Savigny, dans le grand ouvrage d'Egypte, pl. 1, fig. 2, pourroit servir de type à une nouvelie coupe générique, si les anneaux qui sont au nombre de dix-huit étoient constants; en attendant nous la désignerons sous le nom de Scolopendra Savignyana, Nobis.

\section{CRYPTOPS, LEACH. ; Scolopendra, Косн.}

Antennes composées de dix-sept articles. - Les pieds sont au nombre de vingt de chaque côté; les postérieurs étant les plus longs et ne présentant pas d'épines. - Les yeux ne sont pas apparens.

\section{CRYPTOPS nORTEXSIS.}

Leacu, Edinb. Enc., t. VII, p, 408; id., Tranis. Linn. Soc., t. II, p. 384; id., Enc. Brit. Suppl., 1, p. 432, pl. 22 ; id., Zool. Misc., t. III, p. 42, pl. 139, fig. 1.-Genv., Ann. des Sc. nat., t. VII, arn. 1837 , p. 51 . - Long. 11 lig. - D'un testacé ferrugineux, avec la partie dorsale plus foncée et les pieds poilus. - Se trouve en Angleterre et en France.

2. cRyptons savignyir. (PI. 3, fig. 2.) LeacH, Zool. Mise., t. III, p. 42, fig. 2 à 4. - Gervais, Annules des Sciences naturelles, t. VII, ann. 1837. p. 51. - Scolopendra Germanica, Косн, Deutsch, Ciust. MIyriap., fasc. $9, \mathrm{n}^{\circ} 2$. - Long. 20 lig. - D'un jaune testacé, avec la tête d'un ferrugineux pâle, et les pieds postérieurs surtout épineux. Se trouve en Angleterre, en Allemegne et en France.

\section{CRYPTOPS HYALINUS.}

S.x, Journ. de Phil., t. II, p. 11; id., OEuvr. Ent., édit. Lequien, t. I, p. 23. - Gervais, Annales des Sciences naturelles, t. VII, ann. 1837, p. 51. - Long. 7 lig. - La téte est d'un brunrougeâtre, lisse, non ponctuée, avec des poils épars, sans ligne enfoncée sur le chaperon; les antennes sont d'un brun-rougeâtre, velues; les articles sont sessiles, cylindriques, les derniers arrondis; le corps est blanc, lisse, avec deux lignes noires, internes et quelquefois éparses; il n'est pas ponctué; les pattes ayant quelques poils; les pattes postérieures sont d'un brun-rougeâtre; le premier article moins long que cleux fois sa largeur et armé, ainsi que le deuxième, de nombreuses soies roides, 
courtes, avec une ligne échancrée en dessous; le troisième article présente quatre ou cinq dents en dedans; le quatrième en a deux environ. - Cette espèce a été trouvée en assez grande quantité sous l'écorce d'un vieux quercus virens, sur la rivière Saint-Jean, dans la Floride orientalc.

\section{CRYPTOPS SEX-SPINOSUS.}

SAY, Journ. de Phil., t II, p. 112; id., OEuvr. Entomolog., édit. Leçuien, t. 1, p. 34. - Gerviss. Anrales des Sciences naturelles, t. VII, ann. 1837, p. 54. - Le corps est d'un ferrugineux rougeâtre, pointu; le deuxiẻme segment est le plus courl, ensuite le quatrième et le sixième; le dernier est échancré au sommet, et armé en dessous d'une double épine proéminente, robuste; les antennes sont hérissées de poils trẻs-courts, serrés; les articles sont ovales, séparés par un pédoncule très-court; les pattes ont deux épines courtes, mobiles, an sommet externe du quatriéme article; le cinquième en a une au-dela du milieu, et une autre a l'extrémité; les pattes postérieures ont sous la base une épine subtriangulaire, bien marquèe, élevẻe, comprimée, aiguë, et une autre plus petite sur le côté interne en dessus, plus près du milieu. - Se trouve communément dans le bois pourri.

\section{CRYPTOPS pOSTICUS.}

$\mathrm{S}_{\mathrm{AY}}$, Journ. de Phil., t. 11, p. 112; id., OEuvr. Ent., édit. Lequien, t. I, p. 24. - Gerv., Airn. des Sc. nat., t. VII, ann. 1837 , p. 51.-Le corps est roux, plus pâle en dessous, ponctué ; les segmens présentent deux lignes Iongitudinales enfoncées en dessus, et une autre profondément enfoncée en dessous; le dernier segment est plus long que les deux précédens ensemble, et l'on aperçoit deux lignes obsolèies, imprimées, abrégées à la base, et une autre intermédiaire plus distincte, coniinue; les pattes postérieures sont très-robustes, ả peine plus longues que le dernier segment; l'ongle est très-fort; aussi long que les deux précédens articles pris ensemble. - Cette espèce est remarquable, elle se distingue des précédentes par sa paire postérieure de pattes très-épaisses et courtes, dont les ongles se croisent.l'un sur l'autre, et servent souvent à l'animal pour se défendre. Elle habite la Géorgie et la Floride orientale.

GEOPHILUS, LEACH ;

'icolopend'a, Linn., Faer., Degéer.

- Le corps, de grandeur variable, est tou- jours très-long proportionnellement à sa largeur, et composé d'un très-grand nom. bre d'articles ou anneaux; tous ces anneaux ne portent pas de pattes, mais l'antérieur ou céphalique et le postérieur ou anal sont les seuls qui en soient dépourvus; les petits appendices ou antennules que présente celui-ci ne sont pas de véritables pattes, ils sont sans ongles, et ne dépassent pas les véritables pattes en longueur; tous les autres anneaux portent chacun une paire de pattes, ils sont simples en dessous et comme doubles en dessus; leur forme offre quelques variations, et l'on aperçoit des impressions qui se dessinent á leur surface; les pattes, toujours courtes, varient en nombre selon les espèces; elles paraissent offrir quelques différences, suivant l'âge; mais néanmoins dans l'état adulte, ces individus d'une même espèce en ont toujours un nombre fixe. Ces animaux sont privés d'yeux, et leurs antennes sont composées d'articles variables pour la forme et la longueur, mais toujours au nombre de quatorze. L'organisation des Géophiles, leurs mœurs et les modifications jue la succession des àges leur fait éprouver, ont été peu étudiées. Tréviranus a donné, dans les Vermischte Schriflon, pl. 7, l'anatomic de leur systeme nerveux, et il a reconnu qu'il existe chez eux autant de ganglions que d'anneaux au corps, c'esta-à-dire un pour chaque paire de pattes; le canal digestif paraît résulter d'un long tube presque droit, auquel se font remarquer quelques rétrécissemens et dilatations circonscrivant un osophage ou estomac, etc. Ce canal ne présente qu'un seul repli trèspeu étendu, et situé vers le dixième tiers de la longueur totale: c'est à ce repli qu'aboutit le rectum. Les organes de la génération, le mode d'accouplement et les phases du développement des petits sont encore peu connus.

Lies Géophiles vivent ordinairement sous terre, et leur nom générique indique parfaitement cette habitude. Ils recherchent les endroit humides, le bord des ruisseaux, les bosquets, le pieds des arbres et les mousses; on les trouve aussi sous les pierres, dans les trous des vieux murs, sous le fumier et jusque dans les habitations, sous les boiseries et les décombres; l'Europe n'est pas la seule partie du monde qui les possède, on en trouve en Afrique, ainsi qu'en Amérique, et probablement aussi dans l'A sie. Les espèces décrites sont peu nombreuses, cc qui ne veut pas dire qu'il 
n'en existe que peu dans la nature, mais plutôt qu'on les a peu recherchées', et qu'elles ont rarement excité l'attention des naturalistes.

Quoique ces animaur atteignent souvent une longueur assez considérable, ils ne sont nullement à craindre; cependant ils sont susceptibles, s'il faut en croire quelques médecins et le vulgaire, de s'introcluire dans les narines et d'y causer des maladies des plus cruelles: plusieurs faits de ce genre ont été consignés, mais toutefois la question ne paroit pas encore bien rẻsolue. Un des plus intéressans et des micux recueillis, c'est certainement celui que rapporie le compte rendu de l'Acadénie médicale des Sciences de Metz (1830). Đepuis plusieurs mois, une fermière des environs de Metz, âgée de vingt-huit ans, ressentait dans les narines un fourmillement très-incommode, accompagné d'une sćcrétion abondante du mucus nasal; lorsque vers la fin de 1827, de frég̨uens maux de tête vinrent s'ajouter à ces symptômes; lesdouleurs, supportables dans les premiers momens, prirent bientôt de l'intensité et se renourelèrent par accès. Ces accès, à la vétité, n'avoient rien de régulier dans lcur retour ni dans leur série; ils débutoient ordinairement par des douleurs lancinantes plus ou moins aiguës, occupant la racine du nez et la partie moyenne du front, ou par une douleur gravative, qui s'ètendoit de la région frontale droite à la tempe et à l'oreille du même côté, puis à toute la tête. L'abondance des mucosités nasales forçoit la malade à se moucher continuellement. Ces mucosités fréquemment mêlées desang avoient une odeur fétide; à cet état s'ajoutoit souvent un larmoicment involon. taire. des nausées et des vomissemens. Quelquefois les douleurs étoient tellement atroces, que la malade croyoit être frappée d'un coup de marteau, ou qu'on lui perforoit le crâne; alors les traits de la face se décomposoient, les mâchoires se contractoient, les arteres temporales battoient avec force, les sensde l'ouĩe et de la vue étoient dans un tel élat d'excitation, que la lumière et le moindre bruit devenoient insupporables; d'autres fois la malade éprouvoit un véritable délire, se prenoit la tête dans les mains et fuyoit sa maison, ne sachant ou trourer un refuge. Ces crises se renouve. loient cinq ou six fois dars la nuit et autant dans la journce ; une d'clles dura quinze jours presque sans interruption. Aucun traitement méthodique ne fut emplloyé: enfin, après une année de souffrances, celte maladie extraordinaire fut subite. ment terminée par l'expulsion d'un insecto qui, jelé sur le plancher, s'agitoit avec rapidité et se rouloit en spirale; placé dans un peu d'eau, il y vécut plusieurs jours, et ne périt que lorsqu'il fut mis dans l'alcool. Les savans du pays reconnurent que cet insecte étoit une Scolopendre électrique (Geophilus Curpophagus, Lescr). Un fait semblable a été communiqué à la Soc. Ent. de France, par M. Alexandre Lefebrre.

Quelques Géophiles jouissent des propriétés phosphorescentes et répandent une lueur assez brillante pendant la nuit; c'est principalement en automne qu'ils sont plus remarquables sous ce rapport; tous recherchent, comme nous l'avons déjà dit plus haut, les lieux humides, et ils peuvent vivre quelque temps dans l'eau sans périr. M. Gervais, dans son mémoire déjà ci-dessus cité, a partagé les espèces qui composent ce genre en trois groupes principaux.

\section{PREMIER GROUPE.}

\section{Les Maxillaires, Gerv.}

Mandibules robustes. - Tête étroitc, allongée, non cachée. - Antennes moniliformes, poilues, un peu allongées.

\section{GEOPHILUS MAXILLARIS.}

Gervais, Armales des Sciences naturelles, t. VII , ann. 1837 , p. $52 .-$ Long. 3 pouc. - Les antennes, surtout les mâchioires très-derveloppées de cette espèce, ainsi que la lête étroite et allongée, se rap. prochent de la suivante, mais elle a le corps plus large que cette derniere, et d'ailleurs sa tête et ses antennes sont seules de couleur. ferrugineuse, tout le reste étant d'un jaunâtre clair, comme chez l'espéce désignée sous le nom de G. Electricus. Chez beaucoup d'individus le vaisseau dorsal est assez apparent et sa couleur est bruue. - Elle se troure communément dans les serres du Muséum d'IIistoire naturelle de Paris; on se la procure facilement en soulevant les pots à fleurs enfoncés dans la terre; elle se tient ordinairement dans les cavités qu'on à pra. tiquées pour ces derniers, et elle y vit avec les Cryptops et les Iulus Lucifugus.

\section{GEOPHILUS FERREGINEUS.}

Kосн, Deutsch Crust. Myriapod. and Arachn., fase. 3, tab. 1, fig. 2. - GerVaIs, Annales des Sciences naturelles, t. VII, ann. 1837, p. 52. - Long. 
18 lig. - Fusiforme, d'un brun-ferrugineux, avec une ligne dorsale plus obscure; les mandibules sont plus longues que la tête.

\section{DEUXIEME GROUPE.}

\section{Les Longicornes, Gerv.}

Mandibules moins robustes. - Tête plus large. - Antennes variables.

\section{GEOPHILUS ELECTRICUS.}

Gervars, Annales des Sciences naturelles, t. VII, ann. 1837 , p. 52 ; id., Dict. pilt. d'Histoire naturelle, pl. 399 , fig. 13,13 A. - Kocr, Deutsch. Crust. Myriapod. and Arachn., fasc. $3, n^{\circ} 9$. - Geophilus Crassipes, id., op. cit., n० 5. - Geophilus Longicornis, LEACH, Trans. Linn. Soc., t. XI, p. 386 ; id., Zool. Miscell., t. III, p. 45 , pl. 440 , fig. 3 à 6 ; id., Encycl. Brit., Suppl., 1 , 431, pl. 22. - Scolopendra Electrica, Linn. - Scolopendia Fulva, Degéer, Mlém. pour servir a l'Hist. nat. des Ins., t. VII, p. 361 . pl. 35 , fig. 17. - Scolopendra Fulva, Trév., Vermischt Schrift, t. II, p. 33 , tab. 7 , fig. 3 à 5 . - Le corps est jaune, avec la tète ferrugineuse et les antennes plus longues. - Se troure sous les pierres, aux environs de Londres et d'E. dimbourg.

\section{GEOPHILUS SIMPLEX.}

Gerv., Mlagas. de Zool., cl. $9, \mathrm{n}^{\circ} 133$, p. 9, et pl. 37, fig. 1, 1835 ; id., Annales des Sciences naturelles, t. VII, année 1837 , p. $52 .-$ Geophilus Linearis, Kocr, Deutsch. Crust. Myriapod. and Arachn., fasc. 4, $\mathrm{n}^{\circ}$ 1. - Long. 2 pouc. 10 lig. - La couleur est généralement d'un jaune pâle sur tout le corps; les antennes, deux fois aussi longues que la tête, sont moniliformes, mais a articles serrés, courts, égaux entre eux, si ce n'est le dernier, qui est deux fois au moins aussi long que ceux qui le précèdent; les impressions des anneaux sont peu marquées, ce sont en dessus deux petites traits obliques manquant quelquefois, et en dessous une impression stigmatiforme à peine visible; les pattes sont au nombre de quatrevingts paires. - Cette espèce se trouve communément à Meudon et sur les bords de la Jivière de Bièvre.

\section{GEORIIH US RURENS.}

Say, Journ. Acad. nat. des Sc. de Philadclphic, 1. II ; id., OEnv1. Entom., édil.
Leq., t. I, p. 25. - Genvars, Annoles des Sciences naturelles, t. VII, ann. 1837, p. 52. - Le corps a toute sa largeur au milicu, non ponctué, rouge, avec des poils courts, plus nombreux sur les antennes et les pattes; les segmens ont deux lignes longitudinales enfoncees et une autre aiguë, transrerse, près de la base de chacun; le dernier est un peu plus long que le précédent, rétréci ct arrondi au sommet; la tête a en dessous une tache noirâtre de cha. que côté à la base des mandibules, et une autre à la base de l'article terminal; la lèvre présente une profonde fissure, non dentelée; les antennes ont l'article terminal plus long que les précédens, d'un diamètre égal, non atténué; les pattes sont presque égales. - Cette espèce so trouve très-communément dans le bois pourri, sous les pierres.

\section{GEOPHILUS CARPOPHAGUS.}

Leacu, Trans. Lim. Soc., t. 9, p. 384; id., Zool. Miscell., t. III, p. 43; id., Elcycl. Brit., Suppl., t. 1, p. 431.Gerv,, Magas. de Zool., cl. $9, n^{\circ} 133$. - Id., Annales des Sciences naturelles, t. VII, ann. 1837 , p. 52. - Long. 2 pouc. $\frac{1}{2}$. - Cette espèce est marquee sur le dos d'une ligne d'un brun-violet, bordée de jaunâtre, avec la tête et la partie anale de cette dernière couleur; les antennes ont leurs articles tous arrondis, bien distincts et égaux entre eux. - Se troure. en France et en Angleterre.

\section{GEOPHILUS SUBTERRANEUS.}

Leaci, Trans. Linn. SOC , t. II, p. 385 ; id., Encycl. Brit., Suppl., t. I, p. 431 ; id., Zuol. Miscell., t. III, p. 44. - GERyars, Annales des Sciences naturelles, t. VII ann. 1837, p. 52. - Scolopendra Subierranea, Sнaw, Trans.Linn. Soc., t. II, p. 7. - Long. 3 pouc. $\frac{1}{2}$. - Le corps est jaune, avec la tête ferrugineuse ; les segmens en dessus font saillie latéralement, et on aperçoit deux lignes longitudinales raccourcies; les pieds ont leurs articles ferrugineux, avec les ongles noirâtres. Gette espèce se troure dans les jardins , en Angleterre.

\section{GEOPHIUS ACUMivatUS,}

Leach, Trans. Linn. Soc., t. 11, p. 431 ; id., Enc. Bril., Suppl., t. I, p. 431; id., Zool. Miscell., t. III, p. 45. Genv., Ann. des Sc. nat., t. VII, ann. 1837, p. 52.-Косн, Deutsch.Crust., fasc, $9, \mathrm{n}^{\circ} 6$. 
- Long. 1 pouc. $\frac{1}{2}$. - Corpsentièrement ferrugineux, plus étroit peu à peu antérieurement; la tête antérieurement et les pieds plus pâles. - Se trouve parmi les mousses, dans la Grande:Bretagne.

\section{GEOPHILUS MARITIMUS.}

Leach, Zool. MIiscell., t. III, p. 44, tab. 140 , fig. 1 à 2. - Genvais, $A n$ nales des Sciences naturelles, t. VII, ann. 1837, p. 53 . - Long. 1 pouc. $\frac{1}{2}$. Linéaire, d'un brun ferrugineux; les antennes et la tête sont ferrugineuses; les pieds sont d'un brun-jaunâtre.-Se trouve communẻment dans la Grande-Bretagne, cntre les rochers qui bordent le rivage.

\section{GEOPHILUS GABIILLS.}

Gervais, Annales des Sciences naturelles, to VII ann. 1837: p. 53. Scolopendra Gabrielis, Linv., Syst. nat. - Fabr, Ent. Syst., t. 11, p. 392. Scolopendra Semipedalis, L. Durour, Ann. génér. des Sc. phys., t. VI, p. 317, pl. 96 , fig. 8. - Long. 6 à 7 pouc. - Cette espèce est mince, d'un couleur rousse ; les antennes sont moniliformes; les appendices postérieurs sont filiformes, de six articles; les pattes sont au nombre de cent quarante de chaque côté lorsqu'on saisit cette espèce avec la main, outre qu'elle s'accroche avec force par les pattes, elle se colle désagréablement par une viscosité toute particulière qui transsude par des pores placés à l'origine des pattes. - Elle se trouve en Espagne sous les pierres.

\section{Geophilus walckevaeni. (Pl. 3,} fig. 3.)

Gerv., Magas. de Zool., cl.9, p. 133, fig.1, p. 8 ; id., Ann. des Sc. nat., t. VII, année 1837, p. 53.-Long. 7 pouc. 9 lig. -Les pattes sont au nombre de cent soixante-trois paires; les antennes, deux fois aussi longues que la tête et en chapelet ou monilicornes, ont leurs articles foiblement décroissant vers l'extrémité; les anneaux du corps sont extrêmement nombreux, on en compte antant que de paires de pattes, et de plus un céphalique et un autre anal; ils sont plus larges au milieu qu'en avant et en arrière, le diamètre des plus grands est à peu près de deux lignes: chacun d'eux présente à sa face supérieure deux petites impressions longitudinales, obliques, et intérieuremen $\hat{\imath}$ une impression médiane, circulaire et enfoncée; sur les bords des externes de la même face on voit aussi une ligne longitu- dinale enfoncée. Les couleurs offrent suivant les indiridus quelques légères variations, mais elles sont toujours plus foncẻes sur les deux tiers postérieurs du corps que sur le tiers antérieur, celui-ci, ainsi que la tête, est d'un jaunâtre pâle, le reste est brun ferrugineux, à l'exception cependant de l'anneau postérieur, qui est de la couleur de la tête; sur toute la longueur des points stigmatiformes on voit souvent une trainée de couleur sanguinolente, dont il existe quelquefois l'analogue sur le dos; les pattes sont un peu moins foncées que la partie postérieure du corps, et ont leurs ongles ou articles terminaux de couleur noirâtre. Celte espèce a été trouvée dans un jardin de l'intérieur de Paris, sous le fumier, sous les pierres et dans la terre. On la trouve aussi dans les appartemeus et surtout chez les ébénistes, qui l'appellent le roi des Scolopendres.

\section{TROISIÈME GROUPE.}

\section{Les Acuticornes, Gerv.}

Antennes à articles inégaux, décroissans,

\section{GEOPHIUS MIEVIGATUS.}

Gervais, Amales des Sciences naturelles, to VII, ann. 1837 , p. 53 ; id., Magas. de Zool., cl. 9, pl. 187, fig. 2. - Cryptops Lavigatus, Brulté, Expéd. scient. de Morée, Ins., p. 62, pl. 28, fig. 14. - Long. lig. - Antennes de quatorze articles, presque cylindriques, moins aplaties que dans le $G$. Gabriclis, diminuant d'épaisseur jusqu'à l'extrémité ; le corps est entièrement d'un fauve pâle, et présente en dessus un léger sillon longitudinal étendu d'un bout à l'autre; tout le reste des segmens est lisse ;-ces même segmens en dessous sont surmontés à leur milieu d'une carène longitudinale; les pattes sont plus courtes que dans l'espèce précédente, et au nombre de cent paires environ. - Gette espèce a été trouvée en Morée; M. Gervais pense qu'elle habite aussi le Portugal.

\section{GEOPHIUS SULCATUS.}

Gervais, Annales des Sciences naturelles, iom. VII, annẻe 1837 , p. 53. - Cryptops Sulcatus, Brulé, Expéd. scient. de Morée, p. 62, pl. 28, fig. 2.Long. lig. - Les articles des antennes, au nombre de quatorze, comme dans les Scolopendres, sont plus aplatis et diminuent sculement de largeur jusqun'à l'ex- 
trémité ; tout l'animal est d'un jaune pâle, avec le bout des pattes noir ; il est parcouru en dessous dans toute sa longueur par un sillon longitudinal; chaque segment en dessus est marqué à son milieu de plusieurs stries longitudinales rapprochées, formant une longue bande impressionnée sur toute la longueur du corps; les pattes sont au nombre de cent quarante paires environ. - Il a été trouvé en Morée.

\section{GEOPHILUS Barbaricus.}

Gerv., Magas. de Zool., cl. 9, pl. 133, fig. 3, p. 10. - Id., Annales des Sciences naturelles, t. V1I, ann, 1837, p. 53. - Long. 4 pouc. 6 lig. - Cette espèce diffère du G. Walckenaerii par les antennes, ainsi que par la forme des anneaux de son corps, qui sont plus larges et plus longs; la face supérieure de chacun de ceux-ci présente une ligne médiane, saillante et parallèle à l'axe du corps, ainsi que deux petites impressions latérales peu apparentes et légérement enfoncées; la face inférieure manque de points stigmatiformes, on peut dire qu'elle est tout-à-fait lisse; les antennes sont à peu près deux fois aussi longues que la tête et comme déprimées, leur couleur, ainsi que celle de tout le reste de l'animal, est d'un roux ferrugineux, qui paroît uniforme; les anneaux du corps sont au nombre de cent vingt, il existe un nombre égal de paires de pattes. - Cette espèce a été trouvée à Bone (côtes de Barbarie).

\section{GEOPHLUS SAVIGNYANUS.}

Gervats, Annales des Sciences naturelles, t. VII, ann. 1837 , p. 53. Scolopendra...... S S Avig., Description de l'Egypte, Myriap., pl. 1, fig. 4. - Long. 3 pouc. - Cette espéce présente deux cent dix paires de pattes; les segmens vont en augmentant jusqu'au cent unième et diminuent ensuite, il en est de même pour les pattes; les antennes sont hérissées de poils peu serrẻs entre eux. - Celte espèce a été trouvé en Egypte.

16. GEOPHIUS LEFEBVRAI.

Guér. . Icon. dı lièg. anim. de Cuv., Ins., pl. 1, fig. 10. - Long. 6 pouc. 5 lig. Cette espèce diffère du $G$. Savignyanus par sa taille et par la forme de sa tête: sa couleur dans l'alcool est un brun-jaunâtıe assez foncé, mais elle doit avoir été plus pâle dans son état de vie; sa tête est à peu près aussi longue que large, un peu avancée âu bord antérieur; les antennes sont épaisses, aplaties, un peu plus de deux fois plus longues que la tête; à sa suite on compte plus de cent cinquante-neuf segmens, portant chacun une paire de pattes; chacun de ces segmens présente, en dessus, deux impressions longitudinales et parallèles, et le milieu est un peu déprimé, ou foiblement canalicuié; les pattes du dernier segment sont portées sur deux grosses pièces en forme de hanches, fort larges et se touchant presque sur la ligne médiane en dessous, rugueuses des deux côtés, séparées en dessus par trois segmens diminuant de largeur, rugueux, dépourvus d'appendices, et que l'on pourroit considérer comme constituant une sorte de queue; l'anus se voit en dessous, placé à la base du dernier segment pédigère, dans un espace médian laissé libre entre la base des deux grosses hanches rugueuses dont nous avons parlé plus haut. - Cette espèce a été trouvée en Egypte, près des pyramides de Gizé, par M. A. Lefebvre.

Les espèces désignées sous les noms qui suivent ont été décrites trop brièvement pour qu'on puisse les placer avec certilude dans les groupes qui ont été établis dans ce genre.

G. Phosphorescens, Lrnn., GMex., Syst. nat., 2, p. 1064, sp. 4. - Asie.

G. Occidentalis, Scolop. Occid., LINN. Syst. Nat., sp. 10. - Amérique.

G. Angustatus, Escri., Mém de lu Soc. Impér des nat. de Moscou. t. VI, p. 112; id.. Bull. des Sc. nat., t. VII. p. 267. lle Guam.

G. Longissimus, Risso, Hist. de l'Europe Merid., t. V, p. 155. - France Méridionale.

G. Attenuatus, Say, Journ. de Philadelphie, t. II , p. 143, sp. 3; id., OEuvr. Ent., édit. Lequien, t. I, p. 26. - Amérique Septentrionale. 



\section{MONOMORPHES.}

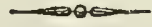

M. Latreille avait donné à ces insectes le nom de Thysanoure, M. de Laporte ensuite leur a imposé celui de Monomorphe. Ces insectes sont peu nombreux en especes, ne subissent point de métamorphoses, sont aptères, et reconnoissables entre tous par les organes particuliers de mouvement qu'ils portent à l'extrémité de l'abdomen, ct qui leur permettent d'exécuter des sauts plus ou moins considérables; ils varient du reste beaucoup sous le rapport de la forme générale et de la composition de chaque organe en particulier; chez les uns le corps est allongé, piriforme, convexe en dessus, et se compose, non compris la tête, de treize segmens, dont trois pour le thorax et dix pour l'abdomen; les parties de la bouche sont les mêmes que dans les insectes broyeurs, c'est-à-dire, consistant en un labre, des mandibules, des mâchoires, une lèvre inférieure et des palpes. - Les antennes sont longues, sétacées, compo. sćes d'une multitude de petits articles. Les yeux sont plus ou moins grands, et formés par la réunion d'un nombre variable de petits yeux lisses. - Le thorax offre distinctement trois anneaux: le prothorax, le mésothorax et le métathorax. - L'abdomen est terminé dans les deux sexes par trois filets servant à sauter et par une tarvière dans les femelles; les neuf premiers segmens portent chacun une paire d'appendices lamelliformes attachés aux arceaux ventraux par un pédicule articulé et dont les derniers sont les plus Iongs. - Les pattes sont grêles, à hanches très-grandes, et les quatre postérieures de celles-ci sont munies d'appendices pareils à ceux du ventre; enfin tout le corps est couvert d'écailles s'élevant au moindre conlact.

Chez les autres le corps est simplement poilu et garni de petites écailles peu serrées et quelquefois glabres; sa forme est allongée sans être piriforme et assez souvent globuleuse; l'abdomen offre au plus cinq segmens, et se confond quelquefois avec le prothorax de manière a ne pouvoir en être distingué ; son extrémité, dépourvue defilets, porte en dessous un appendice tantôt fourchu, tantôt simple, qui prend nais- sance sous le pénultiẻme arceau ventral et se loge dans une gouttière au repos. En se débandant comme un ressort, cet appen. dice envoie l'animal en l'air à une plus ou moins grande hauteur; la bouche n'offre plus que des rudimens de mandibules et de mâchoires; les antennes ne sont composées que de quatre articles, dont le dernier paroît divisẻ en un grand nombre de petites articulations; enfin les yeux sont formés également par la réunion de petits yeux lisses, mais seulement au nombre de six pour chacun.

M. Guérin a observé les segmens abdominaux des Machilis, et il a vu sous ces segmens, de petits sacs membraneux semblables aux organes respiratoires de certains Crustacés. Les six segmens abdominaux, poursuit M. Guérin, sont un peu repliés en dessous, avec les bords arrondis; chacun d'eux, à l'exception du dernier, porte en desous une grande lame (arceau inférieur); celle du premier, échancrée au milieu, offre de chaque côté une petite vésicule blanche; mais elle n'a pas de filet articulé ou fausse patte; le segment inférieur, semblable au premier pour la forme, offre de chaque côté deux vésicules blanches, et extérieurement un petit appendice articulé ; les troisième, quatrième et cinquième présenteut absolument la même disposition; le sixième, dans l'individa qui a servi à la dissection, offre deux vésicules à droite, et une seulement à gauche; la plus extérieure de droite est au moins double de l'autre ; les septième et huitième segmensn'offrent de chaque côtẻ qu'une seule vésicule piriforme, assez gros: se; les trois derniers segmens n'ont plus de ces vésicules; les vésicules dont je viens d'indiquer la position, dit M. Guérin, me paroissent être des organes de respiration analogues à ceux qu'on trouve sous l'abdomen de beaucoup de Crustacés, et qui sont placés à la base des fausses pattes abdominales. M. Guérin, dans son Icon. du Règ. anim. de Cur., pl. 2, fig. 1, a très-bien représenté ce mode de respiration.

Ces insectes, par l'absence de métamorphoses et les apyendices latéraux imitant de fausses pattes, dont les côtés de l'abdomen 
sont garnis dans quelques-uns d'entre eux, semblent faire le.passage des Myriapodes aux vérilables insectes et pourroient former une classe distincte. Tous sont aptères, très-agiles, et échappent, soit par une fuite prompte, soit en sautant, à la main qui veut les saisir. Les uns vivent dans I'intérieur des maisons; les autres se trouvent sous les pierres, sur le bois pourri, les matières végétalesen décomposition, les feuilles, l'eau et même la neige; la plupart n'ont acquis toute leur grandeur qu'à la fin de l'été ou en automne. Cet ordre a été partagé en deux familles, les Lépismènes et les Podurelles.

\section{PREMIẼRE FAMILLE.}

\section{E P I S M N E S,}

\section{LATREILLE.}

Caractères. La bouche est composée d'un labre, de deux mandibules submenbraneuses, de deux mâchoires bilobées et d'une lèvre quadrifide. — Les palpes maxillaires sont longs, composés de cinq à sept articles; Ies palpes labiaux sont plus courts, quadriarticulés. - Les antennes sont longues, sétacées, multi articulées. - Les yeux sont formés de petits yeux lisses, conglomérés, de nombre variable. - Le corps est en ellipse allongé ou ovolaire, avec le thorax gibbeux. - L'abdomen est allongé et rétréci à son extrémité postérieure; celui-ci est composé de dix segmens, portanten dessous neuf paires d'appendices la melliformes attachés aux arceaux ventraux par un pédicule articulé, et dont les derniers sontles plus longs. - La tarrière des femelle est comprimée et formée de deux valves conniventes. Ces insectes, entièrement couverts d'écailles brillantes, se tiennent ca chés dans les lieux où la lumière du jour ne pénètre pas; ils sont connus vuigairement sous le nom de Boissons Argentẻs.

Cette famille renferme trois genres: $M a$ chilis, Petrobius, Lepisma.

\section{MACHILIS, LATr.; \\ Lepisma, Lrnn., Fabr.; \\ Forbicine, Geoff., Leacr.}

Le corps des Machiles, composé, outre la tête, de treize segmens, dont trois thoraciques et dix abdominaux, est cblong ; plus étroit et presque cylindrique en devant, puis subitement élargi et élevé en bosse, abaissé après, et finissant en maniẻre de cône allonge, avec le bout tronqué, et portant trois filets sétacés, pluri-articulés, dont l'intermédiaire est supérieur aux autres plus long et plus épais. - Ces insectes sautent avec une telle promptitude, qu'il n'est pas facile d'observer la manière dont ils s'y prennent pour exécuter ces mouvemens; mais il est probable que l'abdomen y joue, avec les appendices, le rôle principal, sautant itérativement à d'assez grandes distances, et avec beaucoup de vivacité; lorsqu'on les met à découvert, il est nécessaire, si on veut s'en emparer sans altérer leurs couleurs formées par les écailles qui lesrecouvrent entièrement, d'employer une pince garnie de réseau, de la tenir ouverte, lorsqu'on lève les pierres sous lesquelles ces animaux se tiennent cachés, et de la placer de manière qu'on puisse la saisir dans l'instant du saut; autrement on les perdroil aussitôt de vue. La portion antérieure et rétrécie du corps se compose de la tête et du premier segment thoracique. Au-devant et immédiatement au-dessous des yeux s'avancent les antennes, et dans les entre-deux, les palpes maxillaires, qui, par leur grandeur et leur saillie, ont de la ressemblance avec elles, ou avec des pieds se portant aussi d'abordenavant, et courbés ensuite; le second segment thoracique est le plus volumineux de tous et très-voûté, et forme avec le suivant la portion élargie et bossue du corps. - L'abdomen compose ensuite celle de figure conique qui le termine, et dont la longueur égale environ celle de la tête et du thorax. On peut se faire uneidée de la forme générale du corps, d'après celle d'une espèce de sauterelle, très-commune en automne, aux environs de Paris et dans les départemens méridionaux, celle que Fabricius nomme ephippiger, ou porte-selle. Cette similitude est encore plus frappante, si la comparaison s'applique à des individus femelles, puisqu'ils sont pourvus d'une tarrière saillante, con- 
rormée presque de même. - La tête est triangulaire, grande et enfoncée verticalement jusqu'aux yeux, dans une large et profonde échancrure du premier segment du thorax; elle s'allonge et se réirécit inférieurement en manière de museau, et le chaperon, avec le labre, forment une voûte sous laquelle se logent les mandibules, dont la longueur nécessitoit une telle disposition. - Les yeux, élevés et occupant presque tout le front, sont orbiculaires, contigus au bord jnterne, et offrent une cornée qui, cxaminée avec une loupe composée de la réunion de deux fortes lentilles, m'a paru, dit M. Latreille, auquel nous empruntons ces observations très-finement et très-régulièrement chagrinée, ou composée d'une multitude prodigieuse de petits grains arrondis, égaux, luisans, très-rapprochés, et disposés, en quinconce, par séries ou allées très-nombreuses ; étant dépourvu de bon microscope, je n'ai pu comparer cette cornée avec celle des yeux à facettes des autres insectes. Au-dessous de ces organes, sont insérés, sur une ligne transverse, les deux antennes; elles sont sétacées, presque aussi Iongues au moins que le corps, avancées, garnies de petites écailles et de petits poils, et composées d'une infinité de petits articles, à l'exception du radical, ou le pédoncuJaire, qui est assez grand et presque cylindrique. - Le chaperon ou épistome est triangulaire, plus élevé et caréné longitudinalement dans son milieu, avec une échancrure à son extrémité, recevant la portion basilaire du labre. Cette pièce, taillée en carré long et plus étroit en devant, est brusquement et triangulairement déprimée dans son milieu, et paroît ainsi comme encadrẻe ou rebordée latéralement; le bout est échancré. - Les mandibules, par leur couleur généralement blanchâtre, semblent à l'égard de la nature de leur substance, avoir plus de rapports avec celles des Crustacés qu'avec celles des insectes; les dents ou les portions dures de leur extrémité, qui en font l'office, sont seules de coulenr brune et cornées. Leur forme est très-diffé. rente de celle des mandibules des Lépismes. Elles sont en majeure partie, presque cylindriques, longues, étroites, un peu courbes, offrent près de leur extrémité l'apparence d'une suture transverse, et se bifurquent immédiatement après. - Le côté interne se dilate ou se prolonge presque perpendiculairement à l'axe, en une sorte de dent cylindrique, tubulaire, épaisse, courte et tronquée obliquement à son ex- trémilé ; l'autre branche, formée par le pro. longement terminal et direct du corps de la mandibule, est presque conique, ou lancéolée, avec l'extrémité obtuse, divisée longitudinalement par quelques stries fines el très-courtes, qui la font paroître quadri. dentée. - Les palpes maxillaires, proportionnellement plus gros que les antennes et insérés sur le dos des mâchoires, sont environ de la longueur de la moitié du corps, hérissés de poils et de petites épines, trèsrapprochés, d'abord avancés et filiformes, puis courbés, en formant deux coudes, et amincis insensiblement, et finissant en pointe; ils sont composés de sept articles, tous cylindriques, à l'exception du dernier, dont la forme est celle d'un cône allongé; le radical est plus court, et remarquable par un petit appendice cylindrico-conique et inarticulé, inséré sur son dos; le second est un peu courbe, et le cinquième le plus long de tous; le sixième et le septième semblent, au premier coup-d'œil, n'en former qu'un, celui-ci est plus court, et diffère un pen, selon les sexes. Il est plus pointu dans les femelles; les petites épines, au nombre de trois, dont son extrémité est arméc, sont plus saillantes que dans les mâles, et paraissent composer une espèce d'onglet. - Les mâchoires, très-courtes comparativement à la longueur de leurs palpes, se terminent par deux pièces, l'une extérieure ou dorsale, membraneuse représentant la galette des Orthoptères, des Termés; et l'autre interne et analogue encore à la division interne et mandibuliforme, qui, dans les mêmes insectes, est recourerte par la précédente; la pièce extérieure, plus Iongue et tubulaire à sa base, largement échancrée, ou évasée vers le haut, rétrécie ensuite, se termine en une sorte de languette, dont l'extrémité semble former un petit article dentelé au bout; on peut comparer cette piece au spathe de certaines fleurs, telles que celles des arums; l'interne est celle qui sert le plus à la manducation; elle se compose d'une tige membraveuse, en carré long ou cylindracée, s'articulant à son extrémité avec une petite pièce transverse, et qui nous a paru formée de deux dents réunies, l'une terminale, bien distincte, recourbée à sa pointe, et l'autre antérieure et supérieure, et presque carrée. Souvent lorsqu'on dissèque la bouche, cette division interne ne s'isole point et demeuse appliquée à la face interne de la galette, où elle se présente sous l'aspect d'une petite pièce carrée el brunc. - La 
lèvres est membraneuse el pariagée à son exitrémité en quatre lobes arrondis, susceptibles de se gonfler et de se plier longitudinalement en deux, dans la contraction ou zprès la dessiccation; les dents intermédiaires sont plus petites; ses palpes, insérés supérieurement sur ses côtés, se divisent en quatre articles, dont le premier ou basilaire plus court, est en forme de hacbe ou de cône renversé, tronqué obliquement, plus membraneux et dilatable au côté interne; le précédent est cylindrique ; l'intérieur de la bouche offre, comme les $\mathrm{Or}_{\mathrm{r}}$ thoptères, les Termès, etc., une sorte de langue vésiculeuse et échancrée. - Le thorax est, comme dans tous les insectes, formé de trois segmens, mais dont nous ne décrirons, suivant l'usage ordinaire, que la région dorsale, ou les demi-anneaux supérieurs; l'antérieur est presque tubulaire, court, comprimé látéralement, élevé brusquement le long du milieu du dos en une carène écrasée ou aplatie, fortement échancrée au bord antérieur, et même aussi, mais moins et en sens contraire, à l'opposé; les angles latéraux sont arrondis, et les deux antérieurs se prolongent on forme de lobe; le milieu du bord antérieur s'avance un peu en pointe; le segment suivant, le plus grand de tous et s'élargissant de devant en arrière, est très-élevé ou bossu, voûté au milieu, échancré aux deux bouts, avec les angles des côtés arrondis ou obtus; le troisième et dernier segment, parallèlement arrondi à chaque extrémité latérale, est transversal, semi-annulaire, le plus court de tous, mais un peu plus étendu en largeur que le précédent, le débordant de chaque côté. - Les pattes sont de longueur moyenne, mais assez épaisses et robustes, comprimées et recouvertes, ainsi que les autres parties du corps, de petites écailles et de petits poils; les deux dernières, ainsi que d'ordinaire, sont plus longues. La hanche est ètroite, allongée et d'un seul article. La cuisse est divisée en deux, à peu de distance de sa naissance, par une suture transverse et oblique. Le tarse présente aussi à sa base une division analogue, de sorte $q u^{\prime}$ on pourroit le considèrer comme biarticulé; il est armé au côté interne de petites épines et se termine de même que dans les Lépismes, par deux crochets très-foibles, en forme de triangle allongé, pointus au bout, et sans pelotte intermédiaire. Les cuisses exceptées, dont la forme est ovalaire, les pièces composant ces organes sont lineaires, mais elles offrent un caractère que je n'ai observé dans aucun autre insecte, pas même dans les Lépismes. Ainsi que le premier article des palpes maxillaires, les quatre hancbes postérieures, et qui correspondent, ainsi que les deux autres, à cet article, portent sur leur face dorsale un petit appendice cylindrico-conique, velu, mais arliculé et semblable à ceux que nous offrira le ventre. J'ai aperçu une ou deux fois au-dessous de la dernière paire de pattes et de chaque côté, une fente transverse, avec deux valvules; n'ayant poins réitéré cette observation, il me reste des doutes sur sa réalité ; s'il n'y a pas eu de d'illusion, il serait naturel de présumer que ces ouver. tures sont des oscules aériens ou des stigmates. - L'abdomen, en forme de cône allongê, comprimé sur les côtés, un peu arqué et relevé postérieurement, est concave ou creusé en gouttière en dessous; il se compose de dix anneaux, formés chacun de deux demi-segmens, dont les supérieurs transversaux, repliés inférieurement sur les côtés, et recouvrant ainsi les extrémités des inférieurs ou de ceux du ventre; le dernier ou l'anal est échancré postérieurement, et donne naissance à trois longs filets sétacés, iubulaires, droits, dirigés en arrière peu divergens, composés d'une infinité de petits articles, et garnis d'écailles et de petits poils; l'intermédiaire, plus gros et plus long, part du milieu de l'échancrure, et les deux autres sont insérés plus bas, sur ses côtés. Le ventre offre deux rangées longitudinales de neuf paires (une par chaque demi-segment) de lames ou de feuillets membraneux, appliqués sur sa surface, la recouvrant entièrement, et revêtues extérieurement, ainsi que les autres parties, de petites écailles presque carrées, anguleuses et sinuées au bord postérieur, moins cependant aux lames antérieures, plus avancées et en manière de dents à son angie interne, conniventes et contiguës au bord interne; dans une échancrure latérale du bord postérieur de chaque lame, les deux premières exceptées, est inséré un appendice mobile, articulé, cylindrico-conique, velu, terminé en une pointe formée de petites soies et de petites épines, et parfaitement analogue à celui des quatre hanches postérieures. Ceux des sept premières paires sont plus petits, presque membraneux en apparence, dirigès transversalement ou obliquement, et se courbent en dessous. Les deux postérieurs semblent généralement se rapprocher davantage, par leur grandeur, leur forme plus conique ou plus sétacée, leur direction, 
leurs écailles et leurs couleurs, des filets de la queue. Les deux lames de l'èchancrure postérieure desquelles ils sortent. sont pareillement plus allongées, presque en forme de parallélogramme avecles deux angles de leu $\mathbf{r}$ extrémité, et séparés par cette échancrure, prolongés chacun en manière de dent, dont l'interne plus forte. Files servent dans les femelles de gaine à l'oviducte extérieur ou la tarrière. J'ai observé dans l'entre-deux de celles des six premiers demi-segmens, une petite piece triangulaire, en forme d'écaille, dont la grandeur diminue graduellement, de manière que cette pièce finit par disparoittre. Le premier article des palpes maxillaires et les quatre hanches postéricures étant pourvus d'un semblable appendice, celles des Lépismes ayant des rapports, par leur forme foliacée, avec ces lames ventrales des Machiles; nous sommes tentés d'assimiler ces dernières pièces, dont le nombre est de dix-huit, et portant toutes, à l'exception des deux antérieures, un tel appendice, à des hanches, et ne différant des pattes membraneuses de certains Entomostracés, que parce qu'elles ne sont point suivies des autres articles qui les composent. Ainsi les Machiles seroient des Thysanoures, munies de douze paires de pattes, dont trois thoraciques et complètes, et neuf ventrales, mais rudimentaires. Ces insectes doivent donc, dans une série naturelle, venir immédiatement après les $\mathbf{M y -}$ riapodes.

La tarrière, logée dans la commissure des deux lames ou valvules postérieures du ventre, est formée comme dans les Tenthrédines, les Sauterelles, étc., de deux pièces étroites, allongées, très-comprimées, pointues au bout, appliquées l'une contre l'autre par leur face interne, demi-transparentes et garnies de petits poils, particulièrement sur le rebord de leur contour. Leur còté extérieur présente deux crêtes longitudinales, avec les intervalles coupés, vers le bout au moins, par des stries ou petits traits transversaux, plus transparens; l'extrémité est armée sur ses bords, de petites épines ou de dentelures courbées. Dans l'espèce, l'Annulicorne, qui a été plus spécialement le sujet de mes recherches, cette tarrière, d'environ un tiers plus court que les deux derniers appendices, et proportionnellement plus large que celle des autres espèces, est rétrécie vers son origine, et se termine en forme de spatule étroite et allongée; l'intervalle compris entre les deux arêtes est plus grand que ceux qui s'é. tendent entre elles et le rebord latéral, qui est noirâtre. Dans les autres espèces, de même que dans les Lépismes, elle est presque linéaire ou d'égale largeur partout. Celle des Lépismes est moins à découvert, ses valvules la renferment en grande partie. Dans la figure du Petrobius Maritimus, donnée par M. Leach (Zool. Misc., t. III, p. 145), elle est très-bien exprimée, et l'on voit qu'elle se prolonge beaucoup audelà des deux derniers appendices; mais il n'en parle pas dans le texte; l'absence de cet oviducte caractérise extẻrieurement les individus de l'autre sexe. Je n'ai pu découvrir, au moyen de la dissection, quelquesuns de ces organes copulateurs que l'on observe dans les mâles de la plupart des autres animaux de cette classe.

C'est à la fin de l'été et en automne que les Machiles ont acquis toute leur grandeur et sont propres à la gènération. On en trouve bien quelques individus du même âge au printemps, mais en très-petit nombre. Les jeunes sont à cette époque très. abondans : non-seulement ils se distinguent des précédens par leur taille, leur couleur d'un gris cendré plus clair et bien nettement coupé par deux rangées longitudinales de taches noires, mais encore par les filets latéraux de leur extrémité postérieure, qui sont très-courts, et seulement un peu plus gros que les denx derniers appendices du ventre, de sorte qu'on pourroit les considérer eux-mêmes comme des parties analogues; ces appendices sont, ainsi que les précédens, pâles et membraneux. Je n'ai point été témoin de l'accouplement de ces Thysanoures. Les œufs que j'ai retirés du ventre des femelles m'ont paru assez gros et d'un jaune-roussâtre.

\section{MACHILIS CYLTNDRICA.}

L.1cons, et Boisd., Faun. Ent. des env. de Paris, t. 1, p.114.-Forbicine Cylindrique, Geofr., Ins. des env. de Paris, t. Il, p. 614. - Lepisma Saccharina, Will., Eint. Linn., t. IV, pl. 11, fig. 1. - M.Annuticorne, LAтr., Org. des Thys., Nouv. Ann. du Mus., t. I, p. 177. - Long. 4 à 5 lig. - Cette espèce est d'un cendré mélangé de brun luisant; on apercoit en dessus deux rangs de taches noirâtres, triangulaires, plus ou moins prononcées; les antennes et les filets caudaux sont annelés de blanc, les premières sont plus longues que le corps, la tarrière est spatuliforme. Elle se trouve assez communément aux ensirons de Paris. 


\section{MACHLLTS BREVICORNIS.}

Latr., Org. des Thys., Nouv. Ann. du Mus., t. I; p. 179. - Lacond. et BoIsd., Faun. Ent. des env. de Paris, t. I, p. 111. - Lepisma Polypoda; Livn., Syst. nat., t. II, p. 1012; GuéR., Iconogr, du Régn. anim. de Cuv., Ins., pl. 2, fig. 1. - Lepisma Thezerna? Fabr., Sup. Ent. Syst., p. 199. - Long. 3 lig. $\frac{3}{4}$. - D'un cendré noirâtre, avec une tache dorsale grande, obscure; les antennes sont plus courtes que le corps, tachetées de gris, ainsí que les filets caudaux; la tarrière est linéaire, jaunâtre.-Cette espèce, qui est assez rare, a été trouvée à Fontainebleau, sous les pierres.

\section{MACHILIS VARIABIIIS:}

$\mathrm{S}_{\Delta \mathrm{Y}}$, Journ. des $S_{i}$. de l'Acad. de Phil., t. II, p. 11; id., OE $t v r$. Ent., édit. Lequien, t. I, p. 12.-Le corps est cendré en dessous, un peu irisé, mélangé de noir; la partie gibbeuse du corps est đ̣e la même couleur; on aperçoit une bande blanchâtre plus ou moins régulière; les fausses pattes sont blanches, velues, sétacées au sommet; le filet supéricur de la queue est deux fois plus long que les intérieurs. Celle espèce présente plusieurs variétés.

Var. A. Corps en dessus unicolor, sans bande dorsale blanche.

Var. B. Corps ferrugineux, avec des taches latérales sombres.

Var. C. Corps ayant de chaque côté plusieurs taches d'un blanc de neige.

Cette espèce est commune dans beaucoup d'endroits humides, probablement dans toutes les parties tempérées de l'Amé. rique du Nord. Elle varie ordinairement beaucoup.

\section{PETROBIUS, LEACH ; Machilis, Latr.}

Les antennes sont plus longues que le corps; le pénultième article du corps est muni de deux appendices biarticulés; le deuxième article est sétacé.

\section{PETROBIUS MantTIUUS.}

LeACH, Zool. Misc., t. III, p. 62 , tab. 145. - Machilis Maritimus, Latk., Organisation des Thys., Annales du Mu. séım d'Histoire, t. I, p. 178. - Long. 11 lig. - La tarrière est très - saillante, grêle et linéaire; le corps est noirâtre, arec des ćcailles dorẻes; les pieds sont jaunâ. tres, et les filets de la queue, et non les antenues, sont entrecoupés d'anneaux blancs. - Cette espèce habite la Grande. Bretagne, sur les rochers qui bordent le rivage.

\section{LEPISMA, Linx., Fabr., Latr.; Setoura, Brown, : Forbicina, Geofr.}

Les insectes renfermés dans ce genre ont le corps ovalaire, rétréci postérieurement, déprimé, mais un peu et insensiblement élevé vers le milieu du dos; avec la tête horizontale, soit en forme de carré transversal et arrondi aux angles postérieurs, soit presque demi-circulaire. - Le premier segment du thorax est grand, presque semi-circulaire, embrassant dans une échancrure antérieure la base de la tête, échancrée aussi, mais en sens opposẻ au bord postérieur; les deux autres segmens sont transversaux, presque égaux et échancrés postérieurement. - L'abdomen est en forme de triangle fort allongé, avec les neuf premiers demi-segmens supérieurs transversaux; le dernier, ou la plaque anale, est un peu plus long que large, et de son dessous nartent, au même niveau, trois filets sètacés, pluri-articulés, égaux et divergens. - Les antennes, insérées entre les yeux, mais un peu avant de l'espace qui les sépare, sont sétacées, pluri-articulées et généralement longues. - Les yeux sont latéraux, très-écartés, souvent cachés par les extrémités antérieures des côtés du premier segment thoracique, et formés chacun de douze ocelles ou petits yeux lisses, sous la forme de petits grains jaunâtres, disposés, du moins dans l'espèce commune (Saccharina), sur quatre rangées transrerses, deux, trois, quatre, trois. - La tête, immédiatement après le bord antérieur de sa plaque supérieure, tombe brusquement, et présente un chaperon en carré transversal, terminé par un labre pareillement transversal, mais plus court et presque linéaire, inembraneux et entier. - Les mandibules sont presque en forme de triangle allongé, dont la base formant l'exirémité, un peu courbes et épaissies vers le milieu de leur longueur, et comprimées ensuite; le bord interne de l'extrémité est dentelé, comme divisé en deux, au moyen d'un vide ou d'une incision; la portion supérieure offre trois dentelures, toutes ou doni deux au moins aiguës; la portion inférieure est moins 
avancée et n'a qu'une seule dent bien perceptible, celle de l'angle supéricur; on découvre au côté inférieur, et près de ce bout, un petit appendice composé d'un petit faisceau de soie. - La division supérieure du bord apical pourroit correspondre à la portion conique, dentelée et terminale des mandibules des Macbiles, et la division supéricure á l'avancement du rameau interne de celles-ci. - Les palpes maxillaires de ces insectes sont conformés de même que ceux du genre précédent, ou d'abord filiformes et amincis après graduellement pour se terminer en pointe; mais ils sont beaucoup plus petits et composés seulement de cinq articles, dont le premier beaucoup plus court, sans appendice, les trois suivans presque égaux et cylindracés, et le dernier plus long, cylindrico-conique; cependant suivant Mi. Latreille ce dernier article lui a paru divisé en deux dans quelques individus, ce qui porteroit le nombre de ces articles à six au lieu de cinq; les labiaux, plus courts que les maxillaires, ainsi que ceux des Nachiles, en offrent quatre, dont le radical fort court, et les deux derniers appliqués l'un sur l'autre, et composant une massue très-grande, comprimée et triangulaire. - La lèvre est pareillement quadrilobée à son sommet. - La galette est aplatie, en forme de feuillet, tronquéc obliquement et légérement ciliée au bout. - La division interne de la mâchoire est petite, comprimée, triangulaire, terminée par deux dents aiguës, de couleur brune ou noirâtre, de même que celles des mandibules, el ciliẻe au bord interne. - Les pattes sont très-comprimées et remarquables surtout par leurs hanches et leurs cuisses, qui sont fort grandes et en forme de lames et de feuillets ovalaires; les hanches' sont plus grandes et plus rondes; les cuisses sont divisées en deux, ainsi que celles des Machiles. - Les jambes et les tarses sont étroits, allongés et presque linéaires, dont le premier beaucoup plus long, et dont le dernier, un peu moins court que l'intermédiaire, se termine par deux petits crochets aigus. Quelques épines d'inégale grandeur couronnent l'extrémité des jambes.-Le ventre, non canaliculé, est plus convexe dans son milieu, n'a que deux paires d'appendices, et qui sont insérés, l'antérieur ou supérieur sur le huitième demisegment, et l'inférieur sur le suivant; ces appendices, dont les deux postérieurs un peu plus grands, sont lancéolés ou cylindrico-coniques et comprimés, articulés, velus, et un peu diaphanes, ou presque membianeux en apparence. - Le hord postérieur des six premiers demi-segmens est droit; mais celui des deux suivans est échancré dans son milien, et même quadrilobé au huitième, à raison des échancrures où prennent naissance les deux appendices supéricurs; le neuvième segment, et qui semble être le dernier du ventre, est beancoup plus allongé que les précédens, el composé de deux lames triangulaires, se joignant au bord interne par une ligne droite, profondément échancrées sur les côtés, aux points d'insertion des deux appendices postérieurs, avec deux dents à chaque, l'une terminale, et l'autre formée par le prolongement de l'angle inférieur et marginal de l'échancrure; ces lames valvulaires servent aussi d'étuis à la tarrière. - Les côtés du ventre offrent chacun en dessus des appendices, et dans la même ligne cinq petites aigrettes de soie. Quelques espèces en ont aussi d'autres, plus rapprochés des bords du ventre.

Les Lépismes sont des petits animaux qu'Aldrovande et Geoffroy avoient nommés Forbicines et que l'on compare à de petits poissons, à raison de la manière dont ils se glissent en courant et des couleurs brillantes de quelques especes; ils se cachent ordinairement dans les boiseries, les fentes des châssis qu'on n'ouvre que rarement, ou sous les planches un peu humides, etc.; d'autres se tiennent sous les pierres. Ces petits animaux courent très-vite, et il est difficile de les saisir sans enlever des écailles dont leur corps est couvert; ils paroissent fuir la lumiere. La mollesse des organes masticateurs de ces.insectes annonce qu'ils ne peuvent ronger des matières dures; cependant Linné et Fabricius ont dit que l'espèce commune se nourrit de sucre et de bois pourri : suivant le premier elle ronge les livres et les habits de laine; Geoffroy pense qu'elle mange des individus du Psoque pulsateur, connu sous le nom de Pou de bois.

Ce genre se compose de très-peu d'espèces; nous les diviserons ainsi :

A. Espèces dont le prothorax, le mésothorax et le métathorax sont étroits, et dont les antennes surpassent ordinairement en longueur le corps. - Les soies caudales sont ordinairement allongées.

1. LEPISHA EGYPTIACA, Nobis. SAv., Descript. de l'Egypt., Ins., pl. 1, 
fig. 7.- Long. 4 lig. $\frac{7}{2}$ - Le corps étroit, avec les antennes beaucoup plus longues que lui, hérissées de petits poils; la tête antérieurement présente près des antennes quelques poils assez allongés; les palpes sont longs, grêles, hérissés de poils; les pattes sont également liérissées de poils, mais seulement à leur bord inférieur; l'abdomen est couvert de petites écailles et offre en dessus et sur les côtés latéraux des petites touffes de poils assez allongés; les soies qui terminent l'abdomen sont trèsgrandes, surtout la médiane; les latérales sont plus courtes : ces soies sont ciliées. Se trouve en Egyple.

\section{Lepisma pilifera, Nobis.}

SAv., Descript.de l'Egypt., Ins., pl. 1, fig. 8. - Long. 3 lig. - Elle est plus large que la précédente; la tête antérieurement est hérissée de longs poils, ainsi que les bords antérieurs et les côtés latéraux du prothorax, du mésothorax et du métathorax; les antennes sont beaucoup plus longues que'le corps, ciliées; les palpes sont grêles, allongés, également ciliés; les pattes sont ciliees à leurs bords supérieur et inférieur; les anneaux de l'abdomen présentent en dessus et latéralement des petits faisceaux de poils très-allongés; les soies qui terminent l'abdomen sont trèsallongées, surtout la médiane; celles qui sont sur les côtés latéraux le sont beaucoup moins, toutes sont ciliées et présentent de distance en distance des poils beaucoup plus allongés. - Se trouve en Egypte.

3. LEPISMa sacchariva. (Pl. 1, fig. 3.) Linn., Syst. nat., t. II, p. 1012; id., Faun. Suec., edit. 2, no 1925. - F'ABr., Ent. Syst., t. II , p. 63. - Lépisme du sucre, Latr., Hist. nat. des Crust. et des Ins., t. VIII, p. 62. - La Forbicine plate, GeofF., Ins. des enw. de Paris, t. II, p. 613, pl. 20 , fig. 3 ; la Forbicine demi-cylindrique, Degéer, Mém. sur les Ins., t. VII, p. 44; Schozff., Elem. d'Entom., tab. 75; Lacond. et Borsd., Faun. Entom des env. de Paris, t. I, p. 3.-Latr., Gener. Crust. et Ins., t. I, p. 164; id., Regn. de Cuv., t. IV, p. 342. - Guér., Iconogr. du Régn., anim. de Cuv., Ins., pl. 2, fig. 2. - Long.4à 5 lig.-D'un blanc entièrement argenié sans tache, plus brillant en dessous qu'en dessus; antennes et filets caudaux légérement ta. chetés de ferrugineux. - Trés-commune dans les maisons, où elle habite de préférence les lieux humides et renfermćs; se nourrit de sucre, de substances végétales, et probablement aussi de très-petits insec. tes. - Cette espèce, suivant M. Latreille, est originaire d'Amérique.

\section{LEPisma giliata.}

L. Duf., Annales des Sciences natu. relles, t. XXII, p. 240 , pl. 13 , fig. 2.Le corps est allongé, avec le corselet à peine un peu plus large que l'abdomen; le bord antérieur de la tête a une barbe roussâtre; les antennes sont glabres et d'un roux pâle, ainsi que les palpes; les maxillaires de ceux-ci sont assez saillans, et composés de cisq articles allongẻs, presque égaux entre eux, à l'exception du premier, qui est fort court; les bords du corseletet de l'abdomen sont hérissés de poils fasciculés; on voit sur la région dorsale de celui-ci des points noirâtres, disposés en série, et dont chacun offre a la loupe un double fas. cicule de poils, l'un couché, étalé en étoile, l'autre redressé ; les soies qui terminent l'abdomen sont à peu près égales entre elles, et de la longueur de celui.ci. -Cette espèce a été trouvée sous les pierres, aux environs de Murviedro et de Moxente, dans le royaume de Valence. C'étoit une femelle, dit M. L. Dufour, entourée de ses petits qui étoient attroupés comme ceux du cloporie, el qui lui ressembioient à la grandeur près.

\section{LEPISMA VITTATA.}

Fabr., Suppl. Ent. Syst., p. 299. Latr., Règ. anim., t. IV, p. $342 .-\mathrm{LA}_{\text {. }}$ COrd. et Borsd., Faune Entomologique des environs de Paris, t. I, p. 112. - Long. 4 lig. - D'un cendré entièrement demimat, pointillé de noirâtre; l'abdomen présente en dessus quatre raies de cette dernière couleur. - Aussi commune que la Saccharina et se trouve dans les mèmes lieux.

\section{LEPISMA ANNULISETA.}

Guér., Iconogr. du Règn, anim. de Cuv., p. 9.-Cette espèce est presque le double plus grande que le Lepisma Saccharina, elle est argentée; sa tête n'est pas tronquéc en avant comme dans la précédente, elle se termine en pointe peu saillante; Jes antennes sont un peu moins longues que le corps; les soies caudales sont plus longues que dans la Saccharina, jaunâtres, annelées de brun. - Elle a été trouvée aux environs de Paris.

\section{LEPISMA SUBVITTATA.}

Gứr., Iconog. du Règn. anim. de Cuv., 
p. 10.-Les antennes sont presque de moitié plus longues que le corps, pâles; les filets latéraux de la queue sont plus courts que les antennes, l'intermédiaire est à peine plus long que les latéraux, el tous les trois sont annelés de brun; la couleur du corps d'un inciividu desséché est d'un jaunâtre métallique, avec les côtés du thorax piguetés de noir; l'abdomen offre six raies longitudiuales de gros points noirs. Elle a étè trouvée aux environs de P'aris.

\section{LEPISMA PETITI.}

Guér., Iconogr. du Règn. anim. de Cuv., p. 10. - Le thorax est épais, avec l'abdomen rétréci brusquement en arrière; les antennes sont de la longueur du corps, pâles, ainsi que les pattes; les filets caudaux sont aussi de même lungueur, pâles, annelés de brun; le corps est noir, avec le bord postérieur de chaque segment argenté. Gette espéce a èté trouvée dans une boîte d'insectes qui arrivoil du Sénégal.

B. Espèces dont le prothorax, le mésothorax et le métathorax sont très-larges, et dont les antennes ne surpassent pas en longueur le corps. Les soies caudales sont ordinairement tress-courtes.

\section{Lepisma savignyi, Nobis.}

Sav., Descript.de l'Egypt., Ins., pl. 1, fig. 10. - Long. 2 lig. $\frac{1}{2}$. Larg. 1 lig. $\frac{1}{4}$. Cette espèce est remarquable par la longueur de sou prothorax, de son mésotho. rax et de son métathorax; les antennes, qui sont finement ciliées, grêles, ne dépassent pas le corps par leur longueur; les palpes sont grêles; les pattes sont peu allongées, couvertes de Jongs poils; la tête est large, arrondie, avec son bord antérieur couvert de poils; le prothorax est très-large, non écailleux, avec son bord antérieur concave dans sa partie médiane, arrondi et hérissé de poils sur les côtés latéraux; le mésothorax est un peu moins large, il en est de même du métathorax, tous deux sont non écailleux, avec leurs bords latéraux arrondis et ciliés; les segmens de l'abdomen sont lisses et diminuent de largeur jusqu'à la partie postérieure; les premier, second, troisieme et quatrième offrent à leur bord postérieur de chaque côté, près du côté latéral, deux petıtes lignes finement ciliées; les cinquième, sixième et septieme sont lisses seulement, leur bord latéral, ainsi que celui des précédens, présente une épine qui est beaucoup allongée au cinquième et au Ans. sixième; ce dernier en dessous est trèséchancré et présente deux autres épines. très fortes et légérement courbées à leur côté interne : toutes ces épines sont finement ciliées ainsi que les bords posterieurs des segmens en dessous; le dernier segment est lisse, allongé et protége les soies caudales, lesquelles sont insérées en dessous; la médiane est un peu plus allongéc que les latérales, et toutes sont finement ciliées.-Se trouve en Egypte.

\section{F-10. 10. Lepisma Audouivit, Nobis.}

Sav., Descript. de l'Egypt., Ins., pl. 1, fig. 9. -Long. 2 lig. Larg. 1 lig. $~_{+}^{t}$ - L La tête est tout-à-fait cachée par le prothorax, seulement on aperçoit en dessus les longs cils dont elle est hérissée ; les antennes sont longues, ne dépassent pas cependant le corps; elles sont un peu plus fortes que dans l'especce précćdente et non ciliées; les palpes maxillaires sont assez robustes, ciliés et composés de cinq articles, dont le second est beaucoup plus fort que tous les autres; le premier est très-court, lisse; le second est un peu plus allongé, cilié et large à sa base; le troisième est très-large et très convexe au côté interne; le quatrième est allongé, terminé en pointe, arrondi à sa base, trèslarge dans sa partie médiane, avec son bord extérieur trés-convexe; tous ces articles sont ciliés, non-seulement en dessus, mais encore sur les bords externe et interne; le prothorax est très-large, arrondi antérieurement et sur les côtés, et couvert de petiles écailles en dessus; le mésothorax et le métathorax sont étroits et également hérissés comme le prothorax de petites écailles; les segmens de l'abdomen sont écailleux et présentent en dessus, près du bord latéral (le dernier excepté), une épine assez. allongée; leurs côtés latéraux sont égale ment épincux; le dernier segment est beaucoup plus allongé que les autres it présente, à peu près à la naissance de chaque côté, une épine beaucoup plus forte que les autres; les soies caudales sont excessivement courtes, avec la médiane plus allongéee que les latérales: elles sont toutes pourvues de longs cils; les pattes sont assez allongées, robustes, et présentent çà et là des cils forts, allongés. - Elle habite la même localité que l'espèce précédente.

\section{LEPISMA AUREA.}

Duf., Ann. des Sc.nat., t. XXII, p.419, pl. 13, fig. 1. - D'un jaune paille doré uniforme; les segmens du corselet sont remar- 
quablespar une largcurbien plus grande que toutes les autres espèces; le dernier segment de l'abdomen est deux fois plus long que le prècédent, et tronqué à son extrémité; les suies de la queue sont glabres et du double plus courtes que l'abdomen; les appendices inférieurs sont ciliés, ainsi que les bords des plaques ventrales. Se trouve dans di- verses contrées de l'Espagne, notamment dans la Navarre, la Catalogne et le royaume de Valence. - Elle habile en sociétés assez nombreuses sous les pierres, el se retire dans des conduits souterrains. M. L. Dufour dit l'avoir souvent rencontrée en compagnie des fourmis, avec lesquelles elle paroît vivre en bonne intel'igence.

\section{DEUXIL̀ME FAMILLF.}

\section{P O D U R E L L E S,}

\section{LATREILLE.}

Caractires. La bouche présente, pour toutes parties visibles, deux petiles lames longitudinales, parallèles, portant à leur extrémité trois ou quatre divisions sétacẻes, et deux petites pieces réliformes légérement crochues. - Les yeux sont conglomérés, composés chacun de six petits yeux lisses. - Les antennes sont composées de quatre ou cinq articles dans le plus grand nombre. - L'abdomen est dépourvu d'appendices latéraux, et est composé de cinq segmens, logeant dans une gouttière en dessous un appendice plus on moins fourchu ou simple, prenant naissance sous le pénultième arceau ventral, et susceptible de se débander comme un ressort; les organes sexuels sont situés entre les deux pattes postérieures. - Ces insectes sont généralement d'une très-petite taille, mous, couverts d'écailles peu serrées, quelquefois paroissant glabres. Ils forment assez souvent, par l'immense quantité de leurs individụs, ces espaces noirâtres semblables à de la poudre à canon fine qu'on observe sur les eaux stagnantes, les plantes aquatiques, lestroncs d'arbres, les chemins ; d'autres fréquentent de préfèrence les feuilles de divers végétaux. Cette famille renferme quatre genres.

Genres: Orchesetla, Podura, Achorutes, Smynthurus.

\section{ORCHESELLA, Teuplet.}

Antennes de six ou sept articles, presque aussi longues que le corps, filiformes.

orcitesella Fuliconits.

Templ, Trans. de la Soc. Ent. de Lord., t. I, p. 63, pl. 11, fig. 2. - Long. 6 millim. - La lête est globuleuse, un peu aplatie sur les côtés, avec une bande brune en arrière, sur le vertex et vers le cou; les quatre premiers articles des antennes sont noirs à la base et blancs à leur extrẻmité; les autres articles sont pâles, longs, sub-égaux et garnis de poils; les anneaux thoraciques sont très-poilus ou épinetx, particulièrement vers le cou, renfermant entre leur centre vert-brun et leurs bords noirs des taches irrégulières blancltes; les anneaux abdominaux ne sont pas aussi poilus que les précédens, le premier est d'un verdâtre - pâle postérieurement, avec les bords noires et des lignes parallèles de même couleur aux angles antérieurs; le second est noir, excepté sur les bords, avec une ligne élroite, pâle en arrière; le troisième est pâle, avec une grande tache carrée, noire, marquee de deux points blancs; le quatrième est noir, avec un espace triangulaire de même couleur postérieurement; enfin, le dernier anneau est vert; les jambes sont d'un verdâtre pâle, annelées de noir. Les individus encore jeunes ont des taches brunes souvent interrompues. - Cetie espèce se trouve très-communément à Cranmore.

2. ORGHeSELla civcta. (PI. 1, fig. 1.) Templ., Trans. de la Soc. Ent. de Lond., t. I, p. 93, pl. 11, fig. 3.-Long. 5 millim. - La tète est globulcusa, proportionnelle. ment plus grande que dans l'espèce précédente; les premier, deuxième et troisième articles des antennes d'un brun foncé à la base, blancs à l'extrémité; le quatriéme est très-noir, avec les autres articles d'un brun-rougeâtre à la base et blancs à leur extrémité; les anneaux thoraciques sont très-noirs, et présentent de chaque côté une tache irrégulière, longitudinale, d'un verdâtre pâle à la base; le premier an neau abdominal est verdâtre à la base, blanc au sommet, et pas aussi dilaté que 

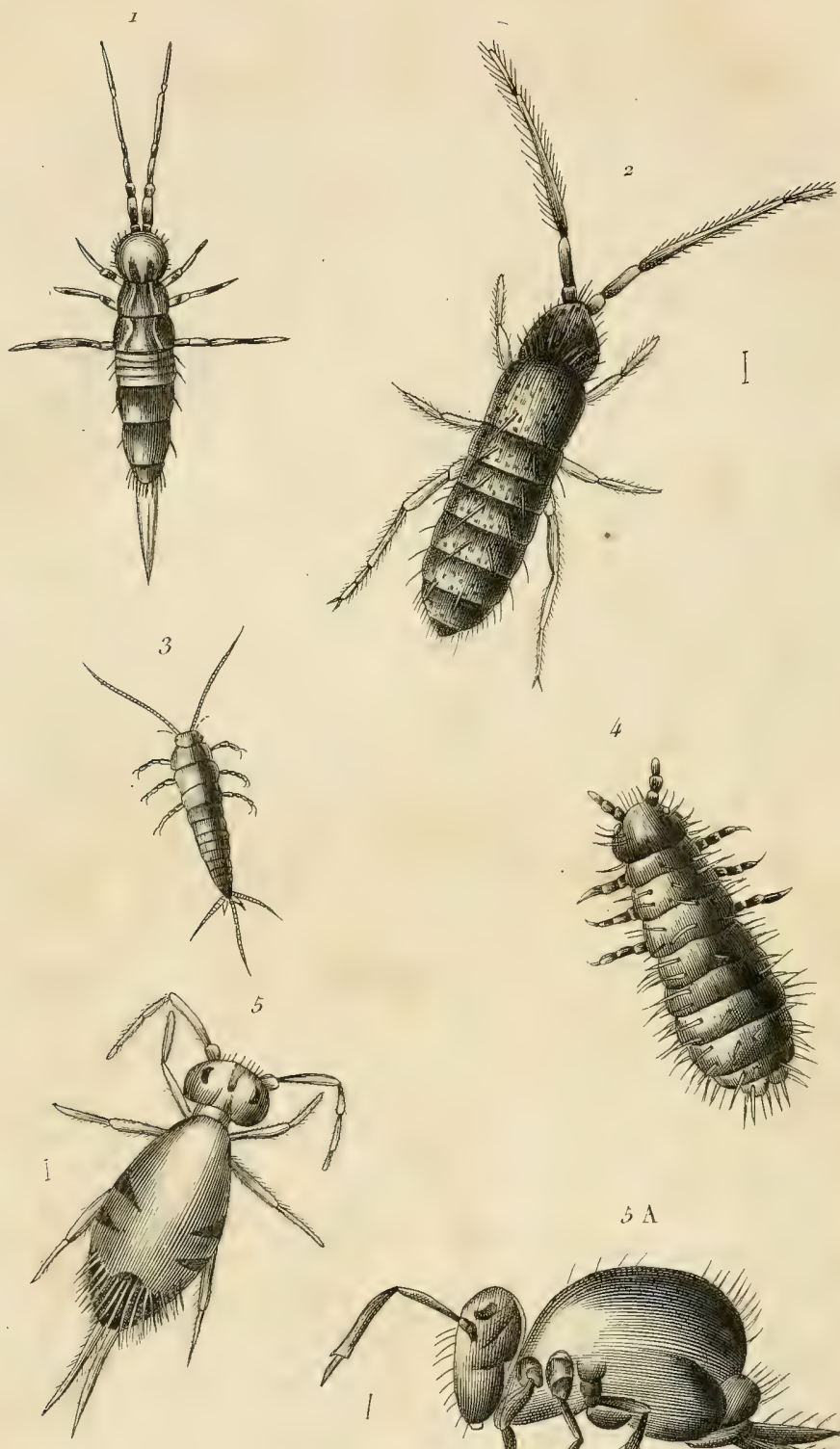

51

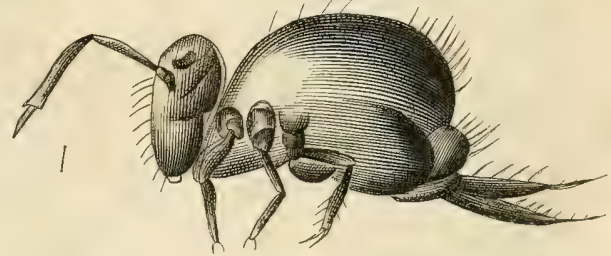

I. Orchesella cincta,

3. Lepisma saccharina.

2. Podura plumbea.

4. Achorutes muscorum.

5. $5 \Lambda$. Smynthurus signatus. 

dans l'espèce précédente; le sccond anneau et ceux qui suivent sont d'un noir fonce brillant; les filets de la queue sont blancs. - Cette espéce se trouve dans la mème localité que l'espèce précédente.

\section{ORCHESELLA SUCCINCTA.}

Gúe., Exp. des pl. de l'Icon. du Règ. anim. de Cuv., p. 10..-Podura Succinctre, id.; Icon. du Rég. anim. de Cuv., Ins., pl. 2, fig. 3. - Cette espèce est d'un noir vif; les antennes ont la base noire, marquée de blanc au premier segment, et le reste de leur longueur est jaunâtre; les pattes sont brunes, avec la base des cuisses et des jambes jaunes; le corps est velu ; il y a deux petites houppes de poils blancs sur le second segment du thorax; le premier anneau de l'abdomen offre en arriere une large bande jaune, enfin l'avant-dernier est bordé de poils blancs. - Se trouve aux environs de Paris.

\section{PODURA, Linn., Fabr., LATr.}

Absence de la tarrière, propre aux femelles des Machiles et des Lépismes; une tête entièrement dégagée et sans palpes saillans; des antennes de quatre articles allongés, insérés sur une ligne transverse entre les yeux; des yeux composés, ainsi que ceux des Lépismes, d'un groupe latéral d'yeux lisses, mais seulement au nombre de six par chaque ; un abdomen n'offrant en dessus que cinq segmens au plus, et logeant dans un canal inférieur, un appendice mou, flexible, susceptible d'ètre rejeté brusquement en arrière, ou de se débander et de servir au saut, prenant naissance sous le pénultième demi-segment ventral, composé d'une tige ou support presque linéaire, mais formé de trois plans, l'un superieur et canaliculé, et les deux autres infèrieurs, produisant à leur point de réu. nion une carène, et terminés par deux branches en forme de lanières linéaires, allant en pointes et velues, pouvant s'écarter, se rapprocher et se croiser; des pattes cylindracées, à tarses d'un seul article, paroissant même se confondre avec la jambe, et terminć par un crochet unique, et quelques dentelures en dessous, sur une série longitudinale, dont la plus inférieure sem. ble représenter l'autre crochet ordinaire du bout; enfin, des organes sexuels, placés loin de l'anus, entre les deux dernières pattes : tels sont les caractères qui signalent, par leur ensemble, le genre Podura.

Cies insectes sont tous très-petits, fort mous, d'une conservation difficile, se desséchant presque aussitôt qu'ils sont morts, et se tiennent dans les lieux humides, sous les pierres, les poutres, les écorces des ar. bres; ou bien, tels que ceux du genre Smynthure, sur les feuilles de divers végétaux; plusieurs sont couverts de petites écailles; mais il en est d'autres dont le corps est presque entièrement nu, et simplement hérissé de petits poils, dont quelques-uns au moins, observés au microscope, sont obtus à leur extrémité.

L'instrument avec lequel ils sautent semble d'abord constituer un organe anomal; mais d'après l'exposition que nous avons faite des deux dernières lames ventrales des Lepismènes, on peut aisément découvrir l'origine et l'analogie de cet appendice fourchu. On voit, en effet, qu'il est formé sur le même type; car les deux branches de la fourche peuvent être considérées comme les analogues d'autant d'appendices styliformes de ces lames ventiales, et la tige ou le support de la fourche représentera dès lors l'une d'elles. La gouttière ventrale, où se loge l'organe du saut, gouttière luisante et comme vernissée, m'a offert, vers sa partie supérieure, une petite piéce saillante, se dirigeant en arrière, en forme de carré long et bidentée à son extrémité, que l'on pourroit encore assimiler à une autre lame ventrale des Machiles.

Par des examens réitérés et la vue même de la sortie des dèjections excrémentielles, je me suis assúré que l'anus était situé à l'extrémilé postérieure de l'abdomen, au bout du cinquième anneau, autant que j'ai pu compler, et dont les bords sont découpés ou lobés. Cetle portion du ventre, relevée et divisée par une fente, que Degéer a observée dans les Podures, étant éloignée de l'ouverture anale, devra, par analogie avec les Arachnides, faire partic des organes sexuels ou de l'un d'eux. J'ai aperçu aussi, dans l'entre-deux des patles postèrieures ou à la base du ventre, une protubérance cylindrique, courte, épaisse, rebordée ou relevée tout autour de son sommet, avec deux ou trois mamelons au milieu.

L'extrémitẻ anterieure de la tête se termine par une sorte de museau très-court, offrant un espace circonscrit, en manière d'ovale transversal et occupé par la bouche, la lèvre inférieure se compose de deux petites lames longitudinales, parallèles, avec trois ou quatre divisions sétacées, au 
bord supérieur de chaque, et dont l'une est peut être un palpe. Quelques autres pièces, et qui à en juger par la couleur brune ou tirant sur celle de la corne, de leur extrémité, sont probablement les mandibules et les mâchoires, remplissent les côtés. J'ai aperçu à chacun d'eux un petit corps arrondi portant une soie, et que je présume être un palpe maxillaire. Le centre de la bouche est mou, vésiculeux et cintré supérieurement par le labre. J'ai souvent examiné avec une grande attention la bouche de ces insectes etant encore en vie; je n'en ai vu saillir aucune partie, il m'a été impossible d'en déterminer, avec certitude, l'organisation. J'ai consulté anciennement sur cet objet mon ami Savigny, et je me rappelle qu'il me répondit qu'il n'avait pas éte plus leurcux que moi. Je suis donc porté à croire que la description des organes cibaires, donnée par Fabricius dans son Genera Insectorum, est absolument fictive. J'ai dit plus haut que les antennes étaient composées de quatre piéces ou articles; $j$ 'en ai cependant compté une de plus, ou cinq dans une espèce. La troisieme, dans une autre, et la plus grande de celle que j'ai rencontrées, formoit un long filet sétacé el susceptible de se contourner à la façon d'une vrille oa d'un cirrhe. Ce filet, mais moins long, étoit divisé en deux dans une autrc. Eufin, ces organes sont sujets à des monstruosilés, puisque je possède un individn où l'une des antennes a trois articles et l'autre deux. Je les ai examinérs, l'animal était vivant, et je n'ai aperçu aucune trace de mulilation. Ges variations, ainsi que les anomalics rclatives a nombre des yeux lisses, semblent indiquer que la nature tâtonne ici, en quel. que sorte, et qu'il ne faut pas dès lors attacher une grande importance a ces caractères numériques.

\section{PODURA ARBOREA.}

Lins., Syst. nat., t. 11, p. 1014. Fabro, Ent. Syst., t. II, p. 66. - LA. cono. et Borsp., Faune Entomologique des environs de Paris, t. I, p. 113. - La Podure porte anneau, Geofr, Ins. des env. de Paris, t. II, p.609. - Long. 1 lig. $\frac{3}{4}$. Cette espece, qui est peat-ètre la plus grande du genre, est d'un noir lisse et bril. lant, avec la base des antennes et du thorax jaune; les pattes et les appendices sal. tałoires sont blanchâtres. - Elle se trouve communément sur les troncs vermoulus dans les bois.

\section{PODURA VIATICA.}

Linv., Faun. Suec., no 1179. - LA. Cord. et Borsd., Faune Entomologique des environs de Paris, t. 1, p. 113. - La Po. dure noire terrestre, Geoff., Ins. des env. de Paris, t. II, p. 610.-Long. 1 lig. $\frac{1}{5} .-$ De forme cylindrique; sa couleur est un noir mat ; ses antennes sont assez grosses, de la longueur de la moitié du corps. Cette espèce vit en rassemblement nombreux sur les chemins.

\section{PODURA plumbea. (Pl. 1, fig. 2.)}

LINN., Syst. nat., t. II, p. 1013. - DEGÉEn, Mém. sur les Ins., t. V1I, p. 31, pl. 3, nig. 1. - Lacond. et Borsd., Faume Entomologique des environs de P'aris, t. I, p. 113. - Templ., Trans. de la Soc. Ent. de Lond., t. 1, p. 93, pl. 11, fig. 4.La Podure grise commune, Geoff., Ins. des env. de Paris, t. II, p. 610. - Fabr., Ent. Syst., t. II, p. 67.-Long. 2 lig. Le corius est allongé, cylindroĩde, couvert d'écailles épaisses d'un bleu-pourpre, qui, lorsqu'elles sont détacliées, laissent voir leur surface, qui est d'un jaune doré ; la têle est sub-triangulaire; le premier article des antennes est noirâtre, avec l'extrémité jaune, les deux deiniers sont pâles, fortement garnis de petits poils blanchâ. tres; un rang épais de poils blanchâtres, ro. bustes, dirigés en avant, entoure le cou; il y en a d'autres qui se trouvent serrés irrégulièrement sur les anneaux thoraciques et abdominaux; le dessous est d'un brun pâle; les paltes sont jaunes, avec les tarses fâles, transparens; ceux de la dernièrc paire d'un rouge-pourpre. - Cette espéce est tris-commune.

Cette description, que nous avons empruntée à M. 'Templeton, diffère beaucoup de celle des anciens auteurs. Suivant MI. Lacordaire et Boisduval, Faun. Ent. des env. de Paris, t. 1, p. 113, cette espèce seroit d'un gris luisant et sans taches, produit par des petiles écailles dont tout le corps est couvert. D'aprẻs cette description, nous sommes portés à croire que l'individu décrit par M. Templeton constitueroit peutêtre une espèce nouvelle.

\section{PODURA VILLOSA.}

LINN., Syst. nat., t. II, p. 1014. Fabr., Ent. Syst., t. II, p. 66. - LAcond. et Boisd., Faune Entomolngique des environs de Paris, t. I, p. $143 .-\mathrm{LaPo-}$ dure commune velue, GeFF., Ins. des env. de Paris, t. II, p. 607, pl. 20, fig. 2. - 
Long. 2 lig. - Cette espèce est oblongue, d'un brun-rougeâtre, entrecoupé de taches et de raies noires; la tête et le thorax son velus; l'abdomen est presque glabie. Se trouve communément sous les pierres.

\section{5. podura aNivulata.}

FABr., Ent. Syst., t. II, p. 67. -- LA. cond. et Borsp., Faune Entomologique des environs de Paris, t. I, p. 114. - La Podure janne a anneaux noirs, Georr., Ins. des env. de Paris, t. II, p. 606. Long. $\frac{2}{3}$ lig. - Elle est d'un brun livide, pâle; l'abdomen est annelé de noir; les articulations des pattes sont noirâtres. - Se trouve assez communément sous les picrrcs, et vit en société avez la précédente.

\section{6. podua aovatica.}

Lins., Syst.nat. . t. II , p. 1014. Degéer, Mém. pour servir a l'Itist. nat. des Ins., t. VII, p. 33, pl. 2. fig. 14 à 15. - Fabr., Ent. Syst., t. II, p. 67. - LAcond. et Borsd., Faune Entomologique des environs de Paris, t. I, ค. 114. - La Podure noire aquatique, Geofr., Ins. des env. de Paris, t. II, p. 610. - L Long. $\frac{1}{2}$ lig. - Elle est cylindrique, d'un noir mat; les antennes sont presque de la longneur du corps. - Cette espece vit en rasscmblement nombreux, sur les feuilles des plantes aquatiques et l'eau starnante des mares.

\section{7. ponura navalis.}

Linn., Syst, ual., t. II, p. 1013. - LAcond. et Borsd., Frune Entumologique des environs de Paris, t. I, p. 114. - Podura Arborea, DEgÉER, Mém. pour sertir a l'Hist. nat. des Ins., t. VII, p. 21, pl. 2, fig. 8.-FABR., Ent. Syst., t. 11, p. 66.Long. $\frac{7}{2}$ lig. - Elle est oblongue, d'un grisnoirâtre, avec quelques taches noires. Elle vit en rassemblement nombreux sur la neige, les troncs d'arbres pendant l'hiver.

\section{PODURA CINCTA.}

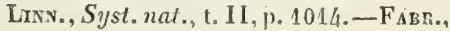
Filt. Syst., t. II, p. 67. - Licond. et BoIsd., Faune Entomologique des environs de Paris, t. I, p. 114. - Long. $\frac{1}{2}$ lig. Elle est cylindrique, avec un anneau noir et blanc à la partic antéricure de l'abdomen.-Se trouve dans les bois, sur les feuilles et les trones d'arbres.

\section{PODURA HIGNORUM.}

Fatr., Ent. Syst., t. I1, p. 67. Lacond., Faun. Ent. des env. de Paris, 1. I, p. 114. - Elle est petite; la tête est pâle, avec la bouche et les antennes noires; le thorax est pâle, sans tache ; l'abdomen est d'un gris-plombé, avec l'appendice saltatoire blanc. - Se trouve dans les bois, sur les vieux troncs.

\section{PODLRA PUSIIIAA.}

Line., Syst. nat., t. II, p. 1014. FABr., Ent. Syst., t. II, p. 67. - LACono. et Borsp., Faune Entomologique des environs de Paris, t. I, p. 114. - Tlle est petite, cylindrique; sa couleur est d'un brun-bronzé - noirâtre; l'appendice saltatoire est blanc. - Se trouve dans les bois, sur les feuilles et les troncs d'arbres.

\section{PODURA VAGA.}

Livv., Syst. nat., t. II, p. 1013.-Fabr., Ent. Syst., t. 11, p. 66. - LAzorid, et Borsd.. Fane Entomotugique des environs de Paris, t. 1, p. 114. - Elle est oblongue, d'une couleur noire, avec l'abdomen et une tache sur les antennes blancs. - Se trouve dans les bois.

\section{PODURA AMBUI AYS.}

Lins., Syst. nat., t. I1, p. 1014. Degéer, Mém. pour servil a l'llist. nat. des Ins.. 1. TII, p. 33, pl. 3, fig. 5. Faвr., Ent. Syst., t. II, p. 68. - Lacord. et Borsd., Faune Entomologique des environs de Paris, t. I, p. 115. - Elle est blanche, avec l'appendice saltatoice non ramené sous le ventre, mais étendu en arricre en ligne droite. - Elle ne saute pas et se trouve dans les bois, sous les mousses ou à leur surface.

\section{PODURA MONUnA.}

Scirnank, Ent. Ins. Austr., p. 497. - Lacond., Fam. Entom. des env. de Paris, t. 1, p. 145. - Long. lig. - Elle est d'un hlanc légirement cendré, avec une ligne d'un brun clair, s'étendant de la tèle à l'extrémité de l'ablomen; l'appendice saltatoire est tri-articulé, simple é conique.-Cette espere saute avec bien moins de vivacilé que ses congenères. Elle se trouve dans les mêmes licux que l'espècc précédente, mais plus rarement.

\section{PODURA FIYETAZIA.}

Livi, , Syst. nat., t. II , p. 1014. Fabro. Enl. Syst., t. II, p. 67.- Schrank, Eint. Ins, dustr., p. 497. - LaCond, et Borsd., Fanne Entomologique des environs de Paris, t. I, p. 115. - Long. $\frac{5}{4}$ ìg. Eile est d'un blanc d'ivoire éclitant; l'appendice saltatoire est nul. - Habile dans les terres grasses, les jardins, sous les pots à fleurs et autres licux analogues. 
15. POdURA NITDA.

Templet., Trans, de la Soc. Ent, de Lond., t. I, p. 94, pl. 11, fig. 6.-Long. 4 lig. - Le corps est presque ovale, lisse, brillant; la tête est globuleuse, un peu avancée en avant; les yeux sont d'un brunrougeâtre; les anneaux thoraciques et abdominaux sont pâles et présentent de nom. breuses stries et taches d'un brun-rougeâtre, particulièrement à la base, et deux ou trois gros poils au milieu, un collier de poils semblables entoure le cou, et on en apercoit d'autres beaucoup plus petits sur le corps; les antennes et les pattes sont pellucides. - Se trouve communémentà Cranmore, sur la terre.

\section{PODURA Nigro-MHacUlata.}

Trmplet., Trans. de la Soc. Ent. de Londres, t. I, p. 94, pl. 11, fig. 6.Long. 2 lig. $\frac{1}{2}$. - Le corps est sub-ovale, verdâtre ou d'un jaune pâle; la tête est petite, subtriangulaire, avec une bande blanche antérieurement entourant les yeux; les anneaux thoraciques postérieurs sont un peu bigarrés sur les côtés; les premier et deuxième anneaux de l'abdomen sont grands, larges, et présentent de chaque côté une tache triangulaire noire, s'élevant vers le sommet et dirigée en avant; le quatrième anneau présente les angles noirs; les derniers anneaux sont petits, sans taches; les pattes et les antennes sont pellucides, couvertes de poils. - Se trouve très-communément dans les jardins, à Cranmore.

\section{7. podura albo-cincta.}

Templet., T'rans. de la Soc. Ent. de Londres, t. I, p. 95 , pl. 12, fig. 1. Long. $\frac{3}{2}$ lig. - Le corps est ovale, noir, couvert de longs poils; la tête est sub. globulcuse, large, blanchâtre, un peu obscurcie en avant; le second anneau thoracique a la moitié de son sommet d'une couleur blanche; le troisième anneau abdominal a la moitiẻ de sa base blanche; les antennes et les pattes sont pellucides. - Cette espèce se trouve à Cranmore, mais elle y est rare.

\section{8. podura cinguLa.}

Teuplet., T'rans. de la Soc. Ent. de Londres, t. I, p. 95 , pl. 12, fig. 2. Long. 1 lig. $\frac{1}{2}$. - Le corps est cylindrique, verdâtre, brun sur les côtés; la tête est subglobuleuse, tronquée, brune postérieurement; les yeux sont noirs; le second anneau abdominal est noir à la base, avec sa partie antéricure blanche, brillante; les pattes et les antennes sont d'un pâle-brun. - Elle a été trouvée à Cranmore, sous une brique.

\section{9. podura ruligrvosa.}

Templet., Trans. de la Soc. Ent. de Londres, t. I, p. 95 , pl. 12 , fig. 3.Long. 2 lig. - Le corps est subcylindrique, d'un noir verdâtre ; la tête est subtriangulaire; les antennes ne sont pas beaucoup plus longues que la tête; le premier anneau thoracique est beaucoup plus large que le suivant; Ic troisième est aussi fort large et on aperçoit sur le milieu du dos une ligne de couleur noire; les pattes, d'un verdâtre pâle, sont courtes et diminuent de grosseur jusqu'à leur extrémité. Trouvée sous les écorces, à Cranmore.

\section{Podura Fasciata.}

$\mathrm{SAY}$, Journ. Acad. des Sc. de Phil., t. II , p. $15, \mathbf{n}^{\circ} 1$; id., OEuvr. Ent., édit. Lequien, $n^{\circ} 1$, t. I, p. $13 .-$ Long. $\frac{1}{2}$ lig. - Le corps est blanc-jaunâtre, avec quatre bandes noires distantes; la queue est noire; les bandes sont plus pâles en dessous; le ressort est blanc; les antennes sont noirâtres; les yeux sont noirs. Cetle espèce se troure en grand nombre sous l'écorce des vieux chênes, en Georgie et dans la Floride Orientale.

\section{PODURA BICOLOR.}

SAY, Journ. Acad.des Sc. de Phil., t. II, p. $12, n^{\circ} 1$; id., OEuvr. Ent., éd. Lequien, t. I, p. $13, \mathrm{n}^{\circ} 2$. - Long. 1 lig. $\frac{1}{2}$. - Le corps est conleur de plomb; les pattes offrent des poils qui sont un peu plus pâles à la base; les ongles sont petits, aigus; le ressort est long, blanc; les yeux sont d'un noir foncé. - Cette espèce se trouve très-communément sous les pierres dans l'Amérique Boréale.

\section{PODURA InICOLOR.}

SAY, Journ. Acad.des Sc. de Phil., to II, p. $13, \mathrm{n}^{0} 3$; id., OEuvr. Ent., édit. Lequien, t. II, p. $13, \mathrm{n}^{\circ} 3$. - Long. 2 lig. $\frac{1}{2}$. - Le corps est noirâtre, irisé ; le corselet présente de longs poils antérieurement; l'abdomen est poilu au sommet; les pattes sont poilues, blanchâtres; le dessous de la tête et les antennes sont poilus. - Elle se trouve communément en Pensylvanie.

\section{ACHOR UTES, TEMplet. ; Podira, Linx.}

Les antennes sont de quatre articles, plus 
courtes que la tête. - La queue est obsolète.

\section{ACHonutes Duhes.}

Templet., Tians. de la Soc. Ent. de Londres, t. I, p. 96, pl. 12, fig. 5.Long. 1 lig. - Le corps est subcylindrique, d'un noir pourpre ; les côtés sont tuberculés, parsemés d'épines; la tête est large, subtriangulaire, tronquée antérieurement; les yeux sont placés à la base sous le premier article des antennes, celles-ci ayant les deux premiers articles très-courts; les suivans sont longs et peu contractés; l'extrémité de l'abdomen se termine d'une manière obtnse. - Peut-être le jeune du Podura Aquatica, de Linné. - Se trouve à Cranmore, sur l'eau.

2. ACHondtes musconUm. (PI. 1, fig. 4.) Teuplet., Trans. de ta Soc. Ent. de Londres, t. I, p. 97, pl. 12, fig. 6. Long. 1 lig. - Le corps est subcylindrique, arrondi postérieurement, et se termine par deux petits mamelons d'une couleur pourpre foncé ; la tête est courte, triangulaire; les yeux ne naissent pas de la base des antennes; celles-ci sont très-courtes et ont le premier article très-grand; les suivants diminuent successivement de lon. gueur; le dernier est pointu ; les pattes sont d'un bleu pâle; les anneaux offrent des poils très-forts ou épines disposés par rang le long du dos; ces poils ordinairement sont dressés par paires; la démarche de celte espèce est très-lente.

\section{ACHORUTES MaRITIMUS.}

Guér. Exp. des pl. de l'Icon. du Rég. anim. de Cuv., p. 11. - Long. 2 lig. - Cette petite espèce est entièrement noirc. - Elle a été trouvée au Tréport, en Normandie, près de l'embouchure d'une petite rivière, dans la partie couverte par les eaux à chaque marée.

\section{SMYNTHURUS, LATR.; Podura, Linn., Farr.}

Le corps est globuleex ou ovalaire. Le thorax et i'abdomen sont confondus en une seule masse. - Les antennes sont sétiformes à leur extrémité, géniculées; le premier article paroissant multiarticulé.

1. SAYNTHURUS SIGNaTUS.(Pl.1, fig. 5,5 А.)

Fabr., Ent. Syst., t. II, p. 65, - Lacond. et Borsd., Faune Entomologique des cnvirons de Paris, t. I, p. 115. - Smyn- thurus Signata, Trarpet., Trans. de la Soc. Ent. de Londres, t. 1, p. 97, pl. 12, fig. 8. - La Podure noiratre a taches fauves sur le ventre, Gxorfr., Ins. des Env. de Paris, t. II, p. 667. - Long. $\frac{1}{2}$ lig. Cette espèce est globuleuse; les antennes sont presque de la longueur du corps; elle est d'un brun-noirâtre un peu luisant, avec trois ou quatre taches fauves de chaque côté du corps; l'appendice saltatoire est d'un brun clair. - Se trouve sous les pierres humides. Elle a été aussi rencontrée sous les feuilles humides, à Cranmore, par M. Templeton.

\section{SHYNTHURUS VIRIDIS.}

Georf., Hist. des Ins. des Env. de Paris, t. II, p. 607. - FABr., Ent. Syst., t. II, p. 605. - Lacord. et Borsd., Fanne Entomologique des environs de Paris, t. I, p.115. - Templet., Trans. de la Soc. Ent. de Londres, t. I, p. 97, pl. 12, fig. 7. - Long. $\frac{1}{4}$ de lig. - Elle est globuleuse; l'abdomen est renflé à son extré. mité, avec un angle rentrant de chaque côté; elle est d'un vert clair mat, avec la tête flavescente et les yeux noirs; les antennes sont de la longueur du corps. - Se trouve sur les écorces. Ele a été aussi rencontrée à Cranmore.

\section{SMYNTHURUS POLYPODUS.}

Lrino, Syst. Nat., t. II, p. 1013.Farr., Ent. Syst., t. II, p. 65. - LACORD. et Borsd., Faune Ento molugique des environs de Paris, t. I, p. 116. - Sub. globuleuse; sa couleur est d'un noir profond; les antennes sont de la longueur du corps, avec l'extrémité blanche. - Se trouve sur les plantes.

\section{SMINTIURES ATER.}

Linn., Syst. Nat., t. II, p. 1013. DegéER, Mém. pour servir à l'Hist. nat. des Ins., t. VII, p. 35, pl. 3, fig. 7, 8. Smynthurus Atra, FABR., Ent. Syst. t. II, p. 65. - Lacond. et Borsd., Faun. Entom. des env. de Paris, t. I, p. 116.- - TeMplet., Trans. de la Soc. Ent, de Londies, t. I, p. 97. - Globuleuse, d'un brun Juisant; les antenues sont longues, - Se trouve sur les plantes el à terre.

\section{SMYNTHURUS FESCUS.}

Lacord, et Borsd., Faun. Ent. des env. de Paris, t. I, p. 116. - La Podure brune enfumée, Geoffr., Ins. des env. de Paris, t. II, p. 608. - Cette espèce, qui est globuleuse et couleur de suie, se trouve sur les plantes au printemps. 
6. SMYNTHURes gUtTatus.

$\mathrm{S}_{\mathrm{AY}}$, Journ. Acad. des Sc. de Phil., t. II, p. 13 ; id., OEuvr. Ent., édit. Lequien, 1. I, p. 13. - Long. $\frac{3}{4}$ lig. - Le corps est blanc, jaunâtre; les taches sont nombreuses, d'un brun-rougeâtre, irrégulières , disposées par bandes; les poils sont nombreux, épars, blancs, et on aperçoit deux tubercules de chaque côté du milieu, tronqués au sommet; le dessous est blanc; les antennes sont d'un brun-rougeâtre, poilues; la face est maculée, avec une ligne de taches irrégulières derrière les yeux; ces derniers sont noirs; le ressort est couleur de chair. - Cette espèce a été trouvée sous l'écorce du pin à longues feuilles (pinus palustris), en Georgie. 


\section{ANOPLOURES.}

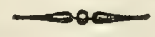

M. Latreille arait primitivement rangé dans les Parasites Ies animaux qui composent cet ordre; mais $M$. Leach a formé avec ces insectes un autre ordre qu'il a désigné sous le nom d'Anoploure, et qui a été adopté par MM. Lacordaire et Boisduval dans leur Faune Entomolog. des environs de Paris, et M. Nitzch enfin a donné aux animaux qui composent maintenant cet ordre, le nom d'Orthoptera ou de Mallophaga.

Caractères. Ces animaux sont tous aptères; leur forme est très-variable et quelquefois bizarre, surtout celle de la tête, qui est souvent très-developpèe. - Leur bouche offre, comme dans les insectes broyeurs, un labre, des mandibules, des mâchoires et une lévre inférieure. - Les palpes seuls. sont sujets à disparoître complétement; le tout est plus ou moins distinct, et a au premier coup d'œil l'apparence d'un bec recourbé et robuste.-Le thorax est souvent bi-parti, c'est-à-dire composé sculement de deux anneaux. - Le prothorax et le mésothorax; le troisième ou le mé. tathorax se confondant avec l'abdomen, de maniere à ne pouvoir s'en distinguer.-Ce dernier, composé de neuf à dix segmens, est, en général, dépourvu d'appendices, tcls que stylets, filets caudaux; des soies seules plus ou moins nombreuses le revêtent dans un grand nombre d'espèces. Les paltes sont courtes, robustes, et leurs tarses sont terminés par un onglet très-fort ou par deux crochets faisant l'office de pince. -Les antennes, qui sont également courtes et généralement composées de trois à cinq articles, sont elles-mêmes quelquefois chéliformes. - Les espèces qui composent cet ordre sont très-nombreuses, et toutes, sans exception, épizoïques; elles vivent aux dépens des Mammifères et des oiseaux, rongeant l'épiderme, ainsi que les poils des premiers et les parties les plus délicates des jlumes des seconds. L'homme seul en est exempt. Chaque animal en nourrit habiiuellement plusieurs espéces, et l'on en connoît qui en ont jusqu'à cinq. Les espèces d'Anoploures sont généralement peu connues, cependant la science est redevable d'un très-bon travail qui a été fait sur ces animaux par M. le professeur Nitzch.
Genres : Philopterus, Trichollectes, Liotheum, Gyropus.

\author{
PHILOPTERUS, Nitzch ; \\ pediculus, Linn., Fabr., Scop.; \\ Ricinus, Degéer; Nirmus, Herm.
}

La tête est déprimée, scutiforme et horizontale. - La bouche est placée à la partie inférieure. - Les mandibules sont courtes, dures, munies d'une dent à leur partie moyenne interne, bidentées à leur sommet; il y a des mâchoires. - Le labre, dilaté à sa base, est souvent renflé en dessus et légérement échancré. - La lèvre est moins dilatée, subéchancrée, et laisse une ouverture lorsqu'elle s'applique contre le labre. - 'Les palpes labiaux sont trèscourts, biarticulés. - Le troisième article des antennes envoie souvent dans les mâles un rameau qui, se recourbant sur le premier article, forme une sorte de pince. - Les yeux sont latéraux, quelquefois subglobuleux, ailleurs invisibles ou nuls. - Le thorax est bi-parti, avec le prothorax plus étroit que la tête. - L'abdomen est composé de neuf segmens. - Les tarses sont recourbés, biarticulés, armés de deux crochets parallèles, connivens, cro. chus et formant une pince avec l'extré. mité de la jambe, qui est armée de deux éperons. Ces insectes vivent sur les oiseaux. Ce genre renferme quatre sous-genres : Docophorus, Nirmus, Lipeurus et Goniodes.

\section{SURGENUS I.}

\section{Docophorus, Nrтzcr.}

Le corps est large. - La tête est très. grande, arrondie en arrière. - Les antennes sont semblables dans les deux sexes. - Le dernier segment de l'abdomen des mâles est arrondi et entier.

\section{1. philopterus ocellatus.}

Scop., Ent. Carn., 382. - Lacord. et Borsd., Faune Entomologique des environs de Paris, t. I, p. 119. - Le Pou du corbeau, Geofr., Ins. des env. de Paris, t. 1I, p. 600.-Pediculus Cornicis, FABR., Syst. Eut., 344. - Le Pou du corbeas, 
LrONNET, OEuvr. posth., p. 38, pl. 5, fig. 3. - Pediculus Corvi, Redr, Explic., p1. 16. - Long. 1 lig. - Cette espèce est d'un blanc-grisâtre livide; les yeux sont noirs, grands; il y a des taches noires, transversales, coniques, et marquées chacune d'un point pâle sur les côtés de l'abdomee, qui offre en outre en dessus, à son extrémité, une bande transverse, lancéolée, rougeâtre, marquée de deux points. - Se trouve sur le corbeau et la corneille mantelée, principalement sur la tête. Elle pond des cufs en cercle autour des yeux de ces oiseaux.

\section{Philopterus hamatopus.}

Scop., Ent. Carn., p. 381. - Lacord. et Borsd., Faune Entomologique des environs de Paris, t. I, p. 119. - Pediculus Strigis, Fabr., Syst. Ent., p. 343. - Pou de l'épervier? LYONNET, OEuvr. posth., p. 38, pl. 5, fig. 4. - Philopterus Platyrhynchus, Niтzcu, Ins. Epiz. Mag. de Germ.. t. III, p. 290. - Long. 1 lig. La tête, d'un jaune de paille brillant, est subcordiforme, obtuse, déclive antérieurement; l'abdomen est ovale, blanc, avec une bande marginale rouge et une ligne dorsale noire; les pattes sont rouges. - Se trouve sur les faucons et sur la chouette hulotte.

\section{3. philopterus garruli.}

Lacond. et Borsd., Faun. Ent. des env. de Paris, t. I, p. 120. - Pou du geai, LyONNET, OEuvr. posth., p. 38 , pl. 5 , fig. 6. - Long. 1 lig. - Elle est d'un grisjaunâtre; la tête est grande; les yeux sont gros et saillans; l'abdomen est large, ovale, avec sept taches lancéolées, marquées d'un gros point blanchâtre, sur chacun des côtés et ayant une raie noirâtre transversale à son extrémité. - Cette espèce se trouve sur lc geai.

Sont placées dans ce sous-genre les espèces qui suivent :

Philopterus Atratus, Communis, Leontodon, Excisus, Pertusus, Icterodes, Melanocephalus, Auratus, Latifrons, Tricolor, Incompletus.

\section{SUBGENUS II.}

\section{Nirmus, Niтzch.}

Le corps est allongé. - La tête est de moyenne grandeur, - Les antennes sont scmblables dans les deux sexes quelquefois, mais rarement, un peu plus grosses dans les mâles: - Le dernier segment de l'abdomen est arrondi.

\section{4. philopterus attendatus.}

Niтzcr, Ins. Epiz. Mag. de Germ., t. II , p. 291. - Lacord. et Borsd., Faune Entomologique des environs de $\mathrm{Pa}_{\mathrm{a}}$ ris, t. I, p.120. -Pediculus Ortygometra? Schranck, Ent. Ins. Austr., p. 503. Long. $\frac{3}{4}$ lig.-Elle est blanchâtre, avec des taches noires très-grandes sur les côtés de l'abdomen; la tête est cordiforme, plus étroite à sa partie antérieure; le thorax est étroit, allongé, un peu élargi postérieurement; l'abdomen est oblong. - Cette espéce vit sur le râle du genêt.

Les Philopterus Discocephalus, Leuco. pleurus, Cameratus, Fenestratus, Uncino. sus, Argulus, Gracilis, Decipiens, Piceus, Fissus, Punctatus, Eugrammicus, Minutus font partie du sous.genre Nirmus.

\section{SUBGENUS III.}

\section{Lipeurus, Niтzcr.}

Le corps est allongé. - La lête est de moyenne grandeur, étroite. - Le premier article des antennes est gros et allongé dans les mâles; le troisième est prolongé en ra. meau. - Le dernier segment de l'abdomen est échancré ou sessile dans le même sexe.

\section{PHILOPTERUS SOUALIDUS.}

Niтzсн, Ins. Epiz. Mag. de Germ.; t. III, p. 292.-Lacond. et Borsd., Faune Entomologique des environs de Paris, t. I, p. 120. - Pediculus Anatis, FaBr., Ent. Syst., p. 345. - Elle est allongée; la tête est d'un jaunc luisant; l'abdomen est blanchâtre, avec deux bandes latérales noires. - Se trouve sur le canard domestique.

\section{Philopterdus bacdues.}

Nitzch, Ins. Epiz. Mag. de Germ., t. III , p. 293. - Lacond. et Borsd., Faune Entomologique des environs de $\mathrm{Pa}$ ris, t. 1, p. 121.-ReDr, Exp., pl. 2.-Pe. diculus Columber, Panz., Faun. Ins. Germ., p. 51, pl. 22. - Pou de la tourterelle, LYONNET, OEuvr. posth., p. 41, pl. 51, fig. 10. - Le Pou du pigeon, Geoff., Ins. des env. de Paris, t. II, p. 599. - Long. 1 lig. $\frac{3}{4}$ - Elle est trèsallongée et aplatie; la tête est presque carrée et arrondie antérieurement; le thorax est carré; l'abdomen s'èlargit un peu de 



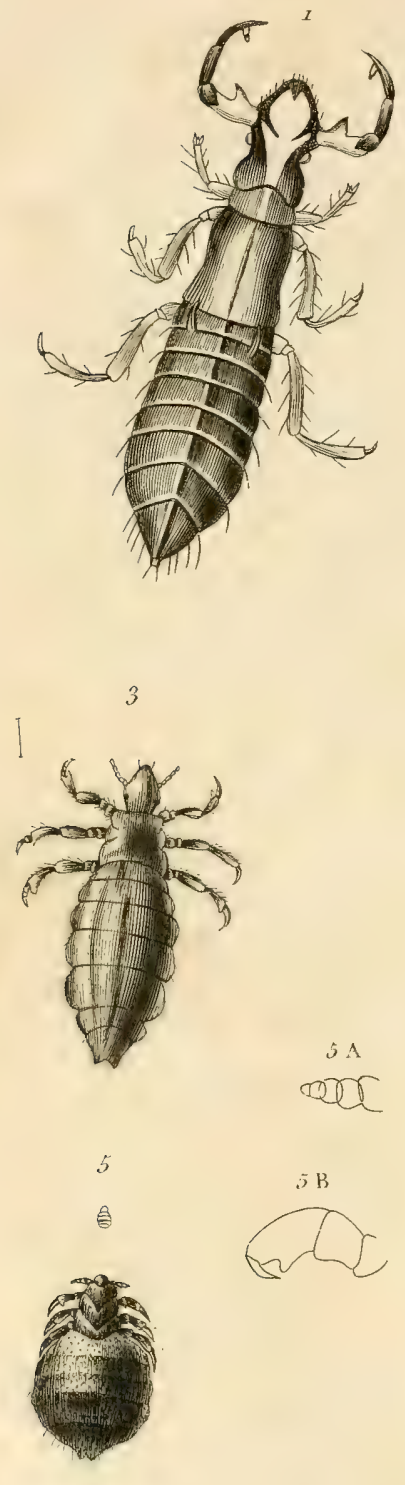

1. Philopterus diomedece, mẩe.

I A . . id . . . . id . . . femelle.

2. Phthirus pubis.
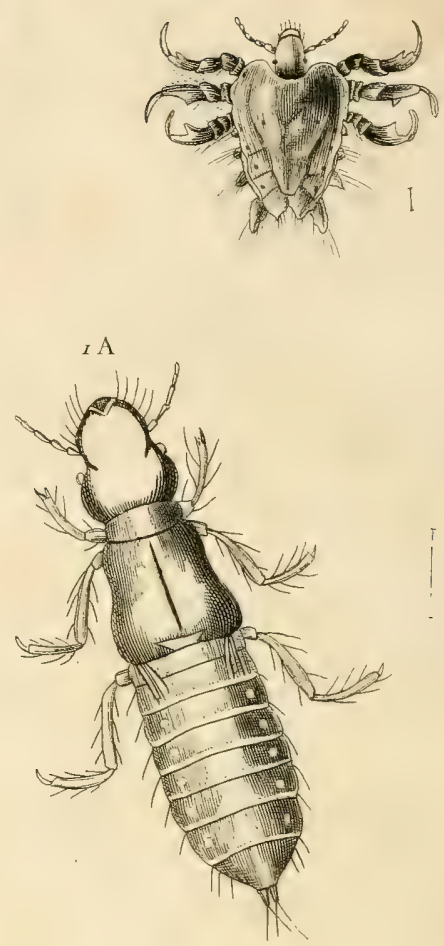

4

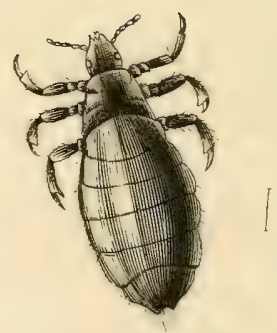

3. Pediculus cervicalis .

4. Pediculus vestimenti.

5. 5A, 513. Pediculus phoce, 
la base au sommet, de couleur brune, avec une grande tache en losange couleur de feuille morte sur chaque segment abdomi$\mathrm{nal}$; ces taches se touchent et forment une bande non interrompue. - Gette espéce vit sur les tourterelles et sur les pigeons.

Les Philopterus Versicolor, Luridus, Temporalis, Jejunus, Polytrapezius, $V a$ riabilis, Heterographus, Ebrceus, Quadripustulatus appartiennent au sous-genre $L i$. peurus.

\section{SUBGENUS IV.}

\section{Goniodes, Niтzcr.}

Le corps est large, rarement étroit. La tête est à angles temporaux proéminens et bifides. - Les antennes sont tantôt semblables dans les deux sexes, tantôt rameuses et chẻiformes dans les mâles.

7. PHILOpterus FaLCicornis.

Nitzcr, Ins, Epiz. Mag. de Germ., Ł. III, p. 293.-- Lacond, et Borsd., Faune Entomologique des environs de Paris, t. I, p. 121. - Pediculus Pavonis, Fabr., Syst. Antl., p. 347. - Redr, Explic., pl. 1, fig. 2. - Panz., Faun. Germ., fasc. 51, no 19. - Le Pou du dindon, Georf., Ins, des env. de Paris, t. II, p. 600 . - La tête est arrondie antérieurement, arec les angles temporaux trèsgrands; le thorax est cordiforme, anguleux postérieurement; l'abdomen est court, rétréci à sa base et élargi à son sommet; il est d'un gris sale, avec une bande longitu. dinale sur l'abdomen. - Se trouve sur le paon.

\section{PHIOPTERES STYLIFER.}

Nitzch, Ins. Epiz. Mag. de Germ., t. $11 \mathrm{I}$, p. 294. - Lacord. et Borsd., Faune Entomologique des environs de $\mathrm{Pa}$ ris, t. I, p. 151. - Pediculus Meleagridis, Schrank, Ent. Ins. Aust., p. 504. - La tête est arrondie antérieurement, avec ses angles temporaux prolongés en pointeaiguë, et munis de deux autres èpines plus petites à leur bord postérieur; le thorax est étranglé antérieurement et rhomboïdal, cordi. forme postérieurement et s'avancant sur l'abdomen; le dernier anneau de celui-ci est profondément bilobé, avec un stylet à chaque, d'un gris sale, avec une tache brune, oblongue, transversale, et une rangée de points sur les six segmens intermédiaires. - Se trouve sur le Mleleagris gallo-pazo.
9. PHILOPHERUS DIOMEDEE. (Pl. 1 , fig. $1 \delta^{x}, 1$ A $q$.)

L. Dufour, Anin. de la Soc. Ent. de France, t. IV, p. 674 , pl. 21, fig. $1 \sigma^{\top}$, 2 o.-Pediculus Diomedex, Faвr., Ent. Sys., t. IV, p. 421. - Long. 3 à 4 lig. La forme de cette espèce est allongée, d'une couleur châtain - noirâtre, luisant quand elle est bien adulte. Elle est glabre, mais la loupe fait apercevoir ça et là quelques poils isolés, soit au contour antérieur de la tète, soit sur les bords de l'abdomen, soit aux pattes. La tête est ovalaire, plus longue et plus fortement échancrée en arrière dans le mâle, blanche dans la femelle, avec les bords châtains plus ou moins foncés, marquée dans le mâle d'un ruban longitudinal blanchâtre. Les antennes de la femelle sont blanchâtres, moins longues que la tête, à peu près droites, composées de cinq articles cylindroïdes, dont le second est le plus court; celles du mâle ressemblent plutôt à des mandibules ou à des pieds-mâchoires qu'à des antennes, et c'est leur insertion ainsi que leur composition qui les rattachent à ce genre d'organes. L'antenne du mâle du $P$. Diomedeœ, qui surpasse en développement et én force les pattes, est coudée en forme de bras ou de pied-pince; elle se compose, comme l'antenne de la femelle, de cinq articles; le premier de ceux-ci très-grand, robuste, couroé et blanchâtre dans sa moitié inférieure, est armé à la base interne el inférieure d'une apophyse épineuse renflée à son orjgine; le deuxieme et le troisjème, châtains et à peine arqués, forment un coude avec le premier, le quatrième et le cinquième, qui ont la forme et la structure de ceux de la femelle, sont appendus un peu en arrière du bout du troisième; ils ne semblent que rudimentaires quand on les compare aux précédens; ces articles terminaux doirent cependant être considérés, suivant M. L. Dufour, comme la partie essentiellement fonctionnelle de l'antenne; leur structure les rend propres à toucher, à palper, à être un organe des sens, tandis que les articles précédens con. stituent plutôt un appareil de préhension, un membre, une sorte de bras destiné à accrocher, à soumettre la femelle dans l'acte du coït. Les yeux latéraux sont assez saillans, hémisphériques. Les mandibules sont oblongues, cornèes, roussâtres, bifides a leur pointe, situécs en arrière d'un vaste espace arrondi, occupant la face inférieure de la tête et faisant l'office de ventouse 
pour le sucoir. Le thorax est plus long que la tête, composé de deux pièces visibles, le prothoraxet le métathorax. Le mésothorax est nul en dessus, soudé en dessous avec le mélathorax; ce dernier est du double plus long que le prothorax et quadrilatere; dans ]e mâle, sa surface inférieure et divisée en trois plaques oblongues, longitudinales, dont la médiane est plus courte que les latérales. Le thorax est parcouru sur le dos par une ligne blanche plus étroite dans le mâle. Le métathorax est marqué d'une ligne dorsale enfoncée, et munie dans les ceux sexes, au còté interne de ses angles postérieurs, d'un pinceau allongé et dirigé en arrière de quelques poils roussâtres, sétiformes. L'abdomen est un peu plus large que la têle et le thorax pris ensemble; il est composé de huit segmens ou anneaux non compris, il est fort petit, souvent peu apparent, et qui difere suivant les sexes; ce dernier formant dans le mâle une petite saillie tronquée, profondément bifide dans la femelle, avec deux soies terminales a chaque lanière. Le bord postéricur des segmens abdominaux ayant une fine bordure blanchâtre, et en outre dans la femelle une soie blanche fort large dans les individus non encore adultes. Les pattes sont courtes, surtout les antérieures; la hanche est formée de deux articles, dont le basilaire est bien plus grand; la cuisse cst grande et robuse; la jambe est un peu moins longue et moins grosse qu'elle; le tarse, proprement dit, est nul ou simplement vestigiaire. On aperçoit deux ongles cornès, forts, modérement arqués, qui sont tellement adossés et contigus l'un à l'autre qu'il faut une exploration répétée et soutenue, à une forte lentille du microscope, pour s'assurer qu'ils ne consistent pas en un crochet unique. Ces ongles gẻminés offrent à leur base interne un talon arrondi, hémisphérique, une sorle de peaume qui n'est qu'un tarse rudimentaire et qui est surtout bien marqué aux pattes antérieures. Dans ces derniers l'angle interne du bout du tibia se termine en une spinule aiguë, et l'on voit une pointe cornèe un peu moins saillante, insérée vers la base du talon; celle structure permet aux pattes antéricures, que leur brièvetẻ rend et plus robustes et plus rapprochées de la bouche, de saisir, d'accrocher, de serrer, de grimper; les pattes intermédiaires ainsi que les postérieures, semblent plus spécialement ambn. atoires; les six pattes sont mélangécs de blanchâtre et de châtain, mais il y a piu de blane dans la femelle que dans le mâle. - Cette espèce se trouve sur l'albatros.

\section{PHilopteris pederifonuis.}

L. Duf., Ann.dela Soc. Ent. de France, t. IV, p. 676, pl. 21, fig. 4. - Long. 1 lig. $\frac{3}{y^{\circ}}$ - La tête, ovale arrondie, subquadrîlatère, est á peine échancrée en arrière, largement en arc de cercle au bord antérieur, qui est cilié; les antennes de la femelle sont filiformes, proportionnellement un peu plus longues que dans l'espèce précédente, de cinq articles cylindriques : le premier article des antennes du mâle est un peu ventru, le plus grand de tous et inerme; le troisième est assez court, plus mince que les précédens, comme tronqué, donnant insertion vers le milieu de son bord, aux derniers articles qui ont la forme ordinaire; le prolongement du troisième arlicle au delà de cette insertion peut en imposer à des yeux peu sévères, pour une bifurcation de l'antenne; le thorax est plus long que la tête; le prothorax est bien plus court et un peu plus étroit que le métathorax ; celui-ci est subquadrilatère, cblong, arec une ligne enfoncée, médiane et un léger étranglement vers le tiers antérieur du bord externe; il y a un petit pinceau de quelques poils assez longs de cha. que côté de son bord postérieur près de' l'angle de celni-ci, comme dans l'espèce précédente; l'abdomen est oblong; les seg. mens dorsaux sont finement bordès de blanchàtre et munis d'un poil sétiforme oux angles postérieurs; le dernier de ces segmens est entier, arrondi dans la femelle, échancré dans le mâle; les pattes sont courtes et fortes; la jambe des antérieures est analogue à celle du Philopt. Diomedecr, et munie entre celle-ci et Ies ongles, d'une panme convexe, qu'accompagne anssi une spinule; les jambes des pattes intermédiaires el postẻrieures sont armées en dessous près de leur extrémité, de quelques piquans roides; les cuisses de ces mêmes pattes ont au côté interne ou inférieur, un étranglement abrupte qui y forme un col. - Celte espèce a èté trouvée au milieu du duvet de l'albatros.

\section{PHilopterus nOUBare.}

Ricinus Houbur $\propto$, Bartuélem., Ann. de la Soc. Ent. de France, 1. V, p. 689 , pl. 20 , fig. B.-Long. 1 lig. - Il est allongé, pres. que parallèle, et sa couleur est d'un jaune testacé : chacun de ses segmens présente 
tne maculation, mais ces maculations n'offrent pas une forme identique; la tache du premier segment en occupe toute la surface; celle du second présente un carré long; elle est divisée par une petite ligne blanche; les troisième et quatrième figurent des cônes tronqués, dont la base s'appuie sur les parties latérales de l'insecte; la ligne divi'soire est plus large que la précédente; la ligne supérieure de la cinquiène tache est horizontale, et la ligne inférieure est oblique, de manière à former un triangle irrégulier; la sixieme est semblable aux troisième el quatrième; la septième est comme Ja deuxième; la huitième forme un carré long, présentant moins de surface que la figure $\mathrm{n}^{\circ} 2$; la neuvième est en forme de croissant, elle occupe tout le segment, sauf un petit espace qui est de la même couleur que le corps; l'espace compris entre les maculations, de chaque cêté du corps, va s'èlargissant à partir du deuxième segment jusqu'au huitieme, el figure ainsi une suite de triangles jaunâtres à côtés inégaux, dont deux supérieurs ont la base dirigée vers la tète de J'insecte, et dont trois inférieurs, aussi à faces inégales, séparés des premiers par une croix, ayant ses branches latérales plus étendues que les branches ascendante et descendante, ont leur base dirigée vers l'extrémité abdominale; la tête est grosse, ovale, encadrée par un léger filet noir; elle peut diviser le corps tout entier en trois parties à peu près égales; les yeux, au nombre de deux, sont placés latéralement; ils sont lisses et noirs; on apercoit vers le milieu de la longueur de la tête un sinus ou éctancrure; c'est là que sont insérëes les antennes, composées de cinq articles; ces articles sont armés les uns et les autres de quelques poils ou cils disposés irrégulièrement, et variables en nombre; le dernier article, le plus long de tous, est conique et terminé par un cil assez long; les pieds sont courts; les tarses sont très-distincts, articulés et terminés par deux crochets égaux; les individus jeunes ne présentent aucune maculation sur les segmens; ils sont entièrement d'un blanejaunâtre. - Cette espèce a été trouvée sur une outarde houbara vivante, venant de Sfax.

\section{Philopterus hrevis.}

L. Dufour, Ann. des Sc.nat., t. IV, p. 675 , pl. 21, fig. 3.-Long. 2 lig.-Couleur génèrale, brun-châtain : la tète est largement triangulaire, sans diffẻrence no- table de configuration et de grandeur dans les deux sexes; son bord occipital est sinueux, avec ses angles postérieurs détachés, arrondis, hérissés de quelques poils divergens, et son milieu en lobe médiocrement convexe; son bord antérieur est en forme de museau tronqué, ayant un espace circonscrit comme un chaperon d'une teinte plus claire, séparé du reste du segment par un trait blanchâtre; les bords lateraux présentent, dans les deux sexes, vis-à-vis l'insertion des antennes, une apophyse épineuse fort petite, dirigée en arriére ; les antennes des femelles sont droites, de cing articles cylindrico-conoüdes ; celles du mâle sont tout-à-fait de forme différente, proportionnellement moins développées, moins robustes que dans le Philopterus Diomedea; leur premier article plus court que le deuxième, cylindroïde, est dépourvu d'épine; le deuxième est allongé; le troisième est moins long que le précédent, obliquement tronqué à son extrémilé; les deux derniers sont de forme ordinaire, insérés vers le milieu de cette troncature; le thorax est marqué d'une ligne médiane longitudinale enfoncée; le prothorax, bien distinct du métathorax, est moins largeque lui; l'abdomen, plus large que la tête, présente sonvent une ligne médiane blanchâtre, parfois en partic effacée; son cxtrémité est pointue dans la femelle et échancrée dans le mâle. Dans un individu. de ce sexe, M. L. Dufour a rencontré en saillie dans celte échancrure anale wne pièce noire, cornée, terminée en arrière par un lobe en fer de flèche, séparée de sa base par un col étroit; celte pièce fait sans doute partic de l'armure copulatisce; les pattes sont courtes et grosses; les jambes intermédiaires et postérieures sont sensiblement plus renflées que les antérieures, garnies en dessous d'une série de sept à huit pinceaux de soies grisâtres, courbées en arrière vers leur extrémité. - Cetıe espèce se trouve communément sur l'Albatros.

Les Philopterus Chelicornis, Dissimilis, Dispar, P'aradoxus, Hologaster, Compar, Microthorax, Rectangulutus, font partic du sous-genre Goniodes.

\section{TRICHODECTES, Nitzci ; Pediculus, Linn., Fabr.; Ricinus, Degéer.}

La tête est déprimée, scutiforme, horizontale, avec le prothoras plus large. - 
La bouche est placée à la partle inférieure. - Les mandibules sont bidentées à leur extrémité. - Il y a des mâchoires. - Le labre est dilaté à sa base et souvent renflé cn dessus et légérement échancré. - La lèvre est moins dilatée, subéchancrée, et laisse une ouverture lorsqu'elle s'applique contre le labre. - Les palpes maxillaires sont nuls ou à peine sensibles; les palpes labiaux sont très-courts, biarticulés.-Les antennes sont filiformes, biarticulées, plus épaisses et presque chèliformes dans les mâles. - Le thorax est biparti. - Les yeux, placés vers le bord latéral de la tête, près des antennes, sont à peine visibles. - L'abdomen est composé de neuf segmens. - Les tarses sont recourbés, biarticulés, n'ont qu'un seul crochet robuste, formant une pince, avec l'extrémité de la jambe.-Les espèces qui composent ce genre vivent sur les Mammifères.

\section{TRICHODEGTES CRASSUS.}

Nrtzcir, Ins. Epiz. Mag. de Germ., t. III , p. 295. - Lacorid. et BorsD., Faune Eutomologique des environs de Pa. ris, t. I. p. 122.-Pediculus Melis, Fabr., Syst. Antl., p. 341. - Cette espèce est tres-petite; son corps est ovale, aplati, avec les bords foliacés et entiers; le thorax est brun; l'abdomen est d'un gris-blanchâtre. - Se trouve sur le blaireau.

\section{TRICIODECTES SPIIEROCEPHAIUS.}

Niтzci, Ins. Epiz. Mag. de Germ., t. III, p. 296. - LAGokD. et BoIsD., Faune Entomologique des environs de Paris, t. 1, p. 122. -Pediculus Ovis, FaBr., Syst. Antl., p. 341.-REDr, Exp., pl. 22, fig. 1. - Schranck, Ent. Ins. Aust., p. 502 , pl. 1, fig. $8,9$. - Cette espéce est blanchâtre, sétigère, avec une tache médiane, et deux raies longitudinales, obscures, sur la tête, et neuf bandes transverses de même couleur sur l'abdomen; la tête est orbiculaire; les yeux latéraux sont trespetits et noirs; le thorax est étranglé dans son milieu; le premier segment est très-petit, subconique, le second plus court et plus large; l'abdomen est ovale, garni lateraiement d'un faisceau de poils sur chaque segment; les crochets des tarses sont très-grands. - Se trouve sur les moutons.

Les autres espèces que ce genre renferme, sont: Trichodectes Latus, Subrostratus, Retusus, Exilis, Climax, Scalazis, Longicornis.
LIOTHEUM, NITZCH.;

$$
\begin{gathered}
\text { Pediculus, Linn., Fabr.; } \\
\text { Ricinus, Degerr, Latr.; } \\
\text { Nirmus, Herm., Leach. }
\end{gathered}
$$

La tête est déprimẻe, scutiforme et hori. zontale. - La bouche est inférieure, mais plus approchée du front que dans les deux genres précédens. - Les mandibules sont bidentees, dures et courtes. - Le labre est légérement échancré. - Les palpes maxillaires sont longs, filiformes, quadriarticulés. - La lèvre inférieure est légérement échancréc. - Les antennes sont quadri-articulées, insérées sous le re!bord de la tête, souvent cachées dans une cavité, et alor's invisibles; leur dernier article, ovale ou glo. buleux, est uni au précédent par un pédicule et forme avec lui une massue. - Les yeux sont situés vers un rebord de la tête, près des antennes. - Le thorax est biparti ou miparti ; le mésothorax est petit, quelquefois indistinct. - L'abdomen est formé de dix segmens. - Les tarses sont droits, propres à la marche, biarticulés, munis de deux crochets distincts, écartés, droils à leur base et crochus à leur sommet. Ces espèces vivent sur les oiseaux, quelquefois en société avec les Philopterus.

Ce genre renferme trois sous-genres: Colpocephalum, Mlenopon, Lemobothrion.

SUBGENUS I.

\section{(Colpocephalum, Niтzcr.)}

La tête est large et offre de chaque côté une incision profonde qui sépare les tempes des joues et du front. - Les antennes sont visibles, à massue sub globuleuse ou ovale. - Le prothorax est peu distant.

\section{LIOTHEUM SUBAOUALE.}

Nrtzch, Ins. Epiz. Mag. de Germ., t. III, p. 299. - Lacord, et Borsd., Faune Entomologique des environs de $\mathrm{Pa}$ ris, t. I, p. 123. - Pou du corbeau, Lyonn., OEuv. posth, p. 34, pl. 4, fig. 5. - Long. 1 lig. - La tête est arrondie antéricurerement, munie sur chacun des lobes postérieurs de trois soies aussi longues que le corps; le prothorax est en forme de trèfle; le mésothorax est triangulaire, à angles postėrieures saillants; l'abdomen est ovale. un peu rétréci à sa base, d'un blanc sale, avec les côtés du thorax, huit bandes transversales sur l'abdomen et l'extrémité de ce- 
lui-ci d'un beau noir. - Se trouve sur le corbeau, Corvus Corax et le freux, Corvus Frugilegus.

\section{LIOTHEUM 10.FASCIATUM.}

Lacond, et Borsd, Faun. Ent. des criv. de Paris, t. I, p. 123. - Pou du héron. LYONN., OEuvr. posth., p. 33, pl.4, fig. 4. — Long. 1 lig. - La tête est arrondie à sa partie antérieure, à lobes postérieurs très-saillans et arrondis; Ie premier segment thoracique, ovale et transversal, est rétréci antérieurement et dilaté à sa base; l'abdomen est ovale, d'un gris sale, avec des taches sur la tête, deux bandes transversales sur le thorax, et huit sur l'abdomen de couleur noire. - Se trouve sur le hèron.

Les Liotheum Zebra, Flavesens, Ochra. ceum, appartiennent à ce sous-genre.

\section{SUBGENUS II.}

\section{(Menopon, Niтzсн.)}

Le corps est large, semi-lunaire ou trapézoïdal. - La lête est sans incisions latérales. - Les antennes sont sonvent cachées sous une cavité de celte dernière. - Le mésothoras est très-petit.

\section{LIOTHEUM PHANEROSTIGMATON.}

Niтzci, Ins. Epiz. Mag. de Germ., t. $11 \mathrm{I}$, p. 300. - Lacond, et BoIsD., Faune Entomologique des environs de $\mathrm{Pa}$ vis, t. I, p. 124. - Pediculus Fasciatus, Scop., Ent. Carn., p. 383. - Moins d'une ligne de long. - Le corps est déprimé; la tête est cordiforme, d'un gris-jaunâtre brillant, ainsi que le thorax; l'abdomen est blanchâtre, avec des bandes brunes transversales. - Se trouve sur le coucou.

Les Liotheum Pallidum, Stramusenm, Cucullare, Meralencum, Minutum, font partie de ce sous-genre.

\section{SUBGENUS III.}

\section{(Lamobothrion, Niтzch.)}

La tête est oblongue, non bilobée postérieurement; les antennes sont toujours cachées. - Le mésothorax est distinct; le métathorax est rebordé, ainsi que l'abdo. men.

\section{4. hiotheUM Giganteum.}

Nirzc日, Ins. Epiz. Mag. de Germ., t. III , p. 301. - Lacond. et Borsd., Faune Entomologique des environs de $\mathrm{Pa}$ ris t. I, p. 124. - Pediculus Maximus,
Scop., Ent. Carn., p. 382. - Pou du busard, Grorf., Ins. des env. de Paris, I. II, p. 598, pl. 20, fig. 1.-Pediculus Buteonis, Faвr., Syst. Antl., p. 343. - Long. 4 lig. - Cette espèce est 1rès-grande, d'un brun clair, avec deux points noirâtres antérieurs et une tache ferrugineuse discoĭdale sur la tête; le thorax est lisse, avec trois lignes brunes longitudinales, dont l'inter. médiaire plus courte; l'abdomen est lamellé, d'une couleur plus claire que le reste du corps, avec deux raies latérales et deux points marginaux sur chaque segment brurs. - Se trouve sur le Busard, Fulco Buteo.

\section{LIOTHEUM DOLICOCEPHALUM.}

Scop., Ent. Carn., p. 382. - Lacond. et Boisd., Faune Entomologique des environs de Paris, t. 1, p. 125. - Liotheum Sulphureum, Nrтzс., Ins. Epiz. Mag. de Germ., t. III, p. 302. - Long. 2 lig. La tête est allongée; les pattes antérieures sont courtes, glabres et entières, blanchâtres, avec une ligne longitudinale brune sur l'abdomen. - Se trouve sur le loriot.

\section{GYROPUS, Nıtzch ; \\ Pediculus, Linn., Fabr., Schranck.}

La tête est déprimée, scutiforme, horizontale, à partie postérieure séparée du front par des incisions marginales. - La bouche est antérieure. - Les mandibules sont unidentées. - Le labre est avancé, trapézoide, entier. - Les palpes maxillaires sont avancés, rigides, conico-cylindriques, quadriarticulés. - La lèvre est avancée, entière. -- Les antennes sont quadriarticulées; le dernier article est uni au précédent par un pédicule, et forme avec lui la massue. - Les yeux sont invisibles ou nuls. - Le thorax est biparti. L'abdomen est composé de dix segmens. - Les tarses sont biarticulés, recourbés et presque droits; il y a un seul crochet arqué à ceux des dernières paires de pattes, formant en s'appliquant entre la jambe une pince presque circulaire.-Les espèces qui composent ce genre vivent sur les mammifères.

\section{GYROPUS GRACILIS.}

Nrтzc日, Ins. Epiz Mlag. de Germ., t. III. p. 304. - Lacond. et Boisd., Faune Entomologique des environs de $P_{a}$. ris, t. I, p. 125. - Pediculus Porcelli, Schraxck, Ent. Ins. Aust., p. 500, pl. 1, 


\section{6}

ìg, 1. -Cette espèce est d'un gris livide, à demi transparent; la tête est ovale; le sernier article des antennes est très-grand; le thorax est allongé, filiforme ou pentaèdre irrégulier; l'abdomen est presque cylindrique, oblong, diaphane, avec les deux

\section{GYROPUS.}

premiers segmens plus obscurs et le dernier terminé par deux stylets courts; les crochets des tarses sont courts et presque droits. - Se trouve sur le cochon d'Inde. Savia Cobaye. 


\section{PARASITES.}

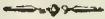

Caracteres. Les insectes qui composent cet ordre sont aptères et ne subissent aucune métamorphose; ils vivent uniquement sur les mammifères, l'homme lıi-même n'en est pas exempt el en nourrit plusieurs espèces. Ils ont les plus grauds rapports de conformations avec les Anoploures, mais en different essentiellement en ce qu'ils sont suceurs au lieu d'être broycurs; ils vivent du sang des animaux, tandis que les autres, munis de mandibules, rongent les poils et l'épiderme de ces derniers. La tête des Parasites est petite et un peu allongée ; a sa partie anterieure on apercoit une fente dans laquelle est un siphoncule droit, très-court et très-grèle, reçu à sa base dans une gaîne molle, susceptible de rentrer en elle-mème, comme les tentacules oculaires des limacons, et muni antérieurement de pelits crochets qui servent à fixer l'insecte à l'animal aux dépens duquel il vit. Cetle gaine et ce séphoncule qu'elle supporte rentrent complétement au besoin dans Ja tête. - Les antennes sont filiformes et composées de cing articles. - Les yeux, sétacés sur les bords latéraux de la tête près des antennes, sont pe. tits et indistincts dans plusieurs espèces. Le thorax ne forme qu'une massue conique, ou l'on distingue cependant les traces d'une division en tross parties. - Les segmens de l'abdomen sont générilement au nombre de neuf. - Les pattes sont de grandeur médiocre, robustes, monodactyles ou didactyles, et terminées par un crochet conique, recourbé, susceptible de se replicr entre la jambe, et formant alors avec l'extrémité de cette dernière une pince au moyen de laquelle il s'accroche, comme les Anoploures, au corps sur lesquels il se trouve. Ces insctes pullulent avec une rapidite effrayante chez les personnes qui négligent les soins de la propreté; ils sont ovipares; leurs oufs, qui sont connus sous le nom de lentes, sont déposés sur les cheveux ou sur les vêtemens; les petits en sortent au bout de cinq à six jours, aprés plusicurs mues, et au bout d'environ dix-huit jours ils sont en état de se reproduire. Ils mul. tiplient beaucoup; les expériences ont prou.

AnN. véqu'en six jours un pou peu faire cinquante œufs, et il en reste encore dans le ventre. On calcule que deux femelles peuvent avoir dix-huit mille petits en deux mois. Lorsque certaines causes qui nous sont inconnues favorisent extraordinairement leur multiplication, ces animaux donnent naissance a l'une de ces maladies les plus horibles dont l'homme puisse être alteint, la phthiriasis. La proprelé la plus grande ne suffit plus alors pour les expulser, et le malade succombe apres de longues douleurs. La teigne des enfansest presque toujours accompagnèe d'une multiplication semblable de ces insectes.Cét ordre renferme deux genres: Pediculus, Phthirus.

\section{pEDicUluU, Linn., Fabro, Latr. Hicmalopinus, LEACH.}

Le thorax est distinct, médiocre. - Les segmens abdominaux sont fortement bilobes sur leurs bords.

1. pedicules cervicalis. (PI. 1, fig. 3.)

Leach., Zool. Miscell., 1. III, 1. 67.Lacond, et Borsd, Faune Entomologique des enviruns de Paris, t. I, p. 127. - Pediculus IIumanus, Lis,, Syst. nat., t. II, p. 1016. - FABr., Syst. Aust., p. 340. - Guéli., Iconographie du Rígne animal de Cuvier, Iıs., pl. 2, fig. 6. - Le Pou ordinaire, Geoff., Ins. des env. de Paris, t. II, p. 597. - Le Pou humain de la téte, DegéEn, Mém. pou. servir à l'Hist. nat. des Ins.. t. T 1I, p. 67. - Long. 1 lig. -11 est ovale oblong; le thorax est de la largeur de l'abdomen; ce dernier est linéaire, à lobes arrondis, la couleur est un cendré-grisâtre, avec une rangée de taches obscures, petites de chaque côté du corps. - Se tronve sur la têle de l'homme et particulièrement des enfans.

2. Pediculus vestimenti. (PI. 1, fig. 4.) Nitzci, Ins. Epiz. Mag. de Germ., t. III, p. 305.-Lacond. et Boisd., Faune Entom. des env. de Paris, 1. I, p. 128.-. Pediculus Humanus, Livn., System. Nat., p. 1046.-FABR., Entom. System., p. 340. - Leaci, Zool. Miscell., i. 111, p.67. - 
Georf., Abrégé ds l'lifist. nal. des Ins. des environs de Paris, t. 11, p. 597. Guér., Iconographie du Règne animal de Cuvier, Ins., pl. 2 fig. 5. - Le P(u humain du corps, DEgéE, Mém. pour servir à l'Hist. nat. des Ins., t. V $1 \mathrm{I}$, p. 67. - Long. $\frac{1}{+}$ de lig. - Il est oblong ; le thorax est comme dans l'espéce précédente; les lobes de l'abdomen sont moins saillans; la conleur est un blanc sale, sans taches ni raies. Se trouve sur le corps de l'homme, dans les vêtements. C'est cette espèce qui, en se multipliant outre mesure, cause cette affreuse maladie désignée sous le nom de phthiriasis.

\section{PEDICULUS URIUS.}

Nrtzch, Ins. Epiz. Mag. de Germ., t. III, p. 305.-Laconde et Bossd., Faune Entomolog. des environs de Paris, t. I, p. 128. - Pediculus Suis, Linn., Syst. uat., t. II, p. 1017. - Faвr., Syst. Antl., p. 342. - Hamatopinus Suis, LEACH, Zool. Miscel., t. III, p. 66, tab. 147. - Le thorax est très-petit; l'abdomen est élargi subitement, très large, à lobes légérement saillans; la tête, les antennes et le thorax sont jaunâtres, avec des taches brunes; la poitrine et l'abdomen sont d'un blanc cendré, avec deux raies latérales sur ce dernier, et deux points sur le dernicr segment de couleur noir.- Vit sur le cochon domestique et le sanglier.

\section{PEDICULUS BOVIS.}

LivN., Syst. nat., t. II, p. 1017. Lacond. et Borsd., Faune Entomologique des environs de Paris, t. I, p. 128. Fabr., Syst, Antl., p. 342.-Le Pou du bauf chargé de huit bandes transversales, Groff., Ins. des env. de Paris, t. II, p. 598. - Cette espèce est très-petite; la tête est jaunâtre; les pattes sont fauves et à extrémilé blanche; l'abdomen est moins large que dans le précédent, blanc, avec huit bandes transversales en dessus, cinq en dessous rouges, et huit points brums de chaque côté de l'extrémité des bandes. Se trouve sur le bœuf.

\section{PEDigulus eUrysterves.}

Nitzcy, Ins. Epiz. Mag. de Germ., t. 111 , p. 305. - Lacord. et Borsd., Faune Entomologique des environs de $P$ aris, t. I, p. 128.-Pediculus Vituli, LINN., Syst. nat., t. II, p. 1018. - FABr., Syst. Antl., p. 342. - Le Pou du bouf, à ventre de couleur nlombé, Geoff., Ins. des env. de Paris, t. II, p. 598.-Il est plis grand que l'espèce précédente; les pattes sont courtes, grosses, grises, ainsi que la tête et le thorax; l'abdornen est gros, terminé en pointe, d'un gris plombé bleuâtre. - Se trouve sur les veaux et plus rarement sur les bøufs.

6. PEDICUIUS PIIOC.E. (PI. 5, fig. 5 A, B, C.) Lucas, Mag. de Zuol., t. cl.1, pl.121. - Long. 1 lig. - La tête est ronde, terminée en pointe à sa partie antérieure, et couverle de tubercules rougeâtres; clle supporte deux antennes dont les premiers articles sont gros et globuleux, le dernier est très-petit et terminé en pointe à sa base; le thorax est court, tuberculé et recouvert en grande partie par l'abdomen; les pattes sont robustes, d'un rouge foncé, surtout les premiers articles; la première paire est la plus courte, la seconde est un peu plus longue que la troisième; ces pattes sont toutes munies d'un fort onglet, épais à sa partie antérieure et très-acéré à son extrémité; l'abdomen est bombé en dessus, de forme arrondie, composé de liuit à neu segmens distincts, dont les trois premier sont très petits, tronqués à leur partie antérieure, surtout le premier segment, qu est recouvert par des poils bruns placés sur des tubercules rougeâtres; les suivans, jusqu'à l'avant-dernier segment, sonl à peu près de même grandeur que les autres; ils diflèrent tous du premier, d'abord parce qu'ils sont plus giands, et ensuite parce que les bords de ces segmens sont hérissćs de poils bruns très-forts, semblables a des épines; le dernier segment est sensible. ment plus petit que les autres, et les borcis latéraux sont hérissés de poils un peu plus longs; le dessus de l'abdomen est hérissé de poils dorés. - Se trouve sur le phoque.

\section{PHTHIRIUS, LEACH; \\ Pediculus, Linn., Fabr., Latr.}

Le thorax est très court et se confond presque avec l'abdomen. - Celui-ci s'élargil subitement. - Les segmens sont fortement bilobés.

PItmirius inguivalis. (Pl. 1, fig. 2.)

Redi, Exp., pl. 19, fig. 1. - Lacord. et Borsb., Faune Entomologique des environs de Paris, t. I, p. 129.-Pediculus Pt/* bis, Fabr., Syst. Antl., 341.-Guén., Icon. du Règn, anim. de Cuv., Ins., pl. 2, fig. 7.Le Morpion, Grofs.. Ins. des env. de Paris 
8. 11 , p. 897. - Leacr, Zoul. Miscell., :. III, p. 65. - Long. 1 lig. - Cette espéce est beaucoup plus large et plus arrondie que le Pediculus Cervicalis; les quatre pattes postéricures sont très-robustes; le second segment de l'abclomen est plus fortement bilobè que dans les autres; elle est d'un blanc-grisâtre, sans tache. - Elle vit dans le poil du pubis, des aisselles et des sourcils de l'homme, très-rarement ailleurs. Sa piqûre est beaucoup plus vive que celle des espèces précédentes, et elle s'attache beaucoup plus fortement à la peau. 



\title{
TABLE DES MATIÈRES
}

\author{
CONTENUES
}

DANS GE VOLUME.

Acanthodon Petitii, A. de Petit. $\quad 467$ Acanthonyx (genre), Acanthonyce.

- Lunulatus, A. Junulé.

- Petiverii, A. de Petiver. Acarides (famille). Acarus (genre).

- Dimidiatus, A. mi-parti.

- Domesticus, A. domestique.

- Fanarius, A. usurier.

- Plumiger, A. à plumes. Aceles (genre), Acete.

- Indicus, A. indien.

Achreus (genre), Achée.

- Cranchii, A. de Cranch. Achorutes (genre), Achorute.

- Dubius, A. douteux.

- Maritimus, A. maritime.

- Muscorum, A. des mousses. Actinopus (genre), Actinope.

- Audorinii, A. d'Audouin.

- Nigripes, A. à pattes noires.

- Rufipes, A. à pattes rousses.

- Tarsalii, A. de Tarsal. Ega (genre), Ega.

- Emarginata, E, échancrée.

- Tridens, Æ. à trois dents.

Eglea (genre), Eglée.

- Lavis, A. lisse.

Athra (genre), Ethre.

- Scruposa, $\mathbb{E}$ rude.

Agelcna (genre), Agelène.

- Labyrinthica, A. labyrinthe. Aglaura (genre), Aglaure.

- Fulgida, A. èclatante. Agnostus (genre), Agnoste.

-Pisiformis, A. forme de pois. Albione (genre), Albione.

- Areolata, A. aréolée.

- Indica, A. indienne.

- Lavis, A. lisse. id.

$i d$.

478

489

id.

$i d$.

$i d$.

id.

199

$i d$.

147

148

560

567

id.

id.

344

344

345

344

345

249

id.

id.

172

id.

111

id.

417

418

15

id.

313

id.

38

39

id.

40
- Muricata, A. rocheuse.

Pages.

- Piscium, A. des poissons.

- Squalorum, A. des squales.

- Vittata, A. à bandes.

Albionites (groupe).

Albunea (genre), Albunée.

- Symnista, A. symniste.

Alciopa (genre), Alciope.

- Reynaudii, A. de Reynaud.

Alima (genre), Alime.

- Hyalina, A. transparent.

Amathia (genre), Amathie.

- Rissoana, A. de Risso.

Alpheites (groupe).

Amphinoma (renre) Amphinome 10

- Alcyonia, A. aleyon.

- Aolides, A. aolide.

- Carunculata, A. Caronculée.

- Complanata, A. aplatie.

- Tetraedra, A. tétraèdre.

- Vagans. A, errante.

AMPHinomites (groupe).

A MPHIPODES (ordre).

39

id.

id.

id.

37

157

id.

18

id.

208

id.

147

$i d$.

182

10

11 .

$i d$.

id.

id.

10

10

224

218

$\begin{array}{cc}\text { - Reynaudii, A. de Reynaud. } & 249 \\ \text { Ammothea (genre), Ammothée. } & 443\end{array}$

- Carolinensis, A. de la Caroline. id.

Amphithoe (genre), Amphithoe. 229

- Costata, A。à côte. $i d$.

- Jurinei, A. de Jurine. id.

- Pausilipo, A. de Pausilipe. id.

- Serrata, A. à scie. id.

Anchylomera (genre). 238

- Blossevillii, A, de Blosseville. id.

Anceus (genre). Ancée. 243 .

- Forficularis, А. perce-oreille. id. Androctonus (genre). Androctone. 224 .

- Leptochelys, A. à jambes grêles. id.

- Quinque striatus, A. à cinq stries. id.

- Scaber, A. rude. 
- Variegatus, A. varié.

Anilocra (genre), Anilocere.

- Capensis, A. du Cap de Bonne. Espérance.

- Cuvieri, A. de Cuvier.

- Mediterranea, A. de la Méditerranée.

Annelides (classe).

Annelides (ordre).

Annelides Terricoles (ordre).

Annelides Tubicoles (ordre).

ANNELIDES SUCEUSES ET HÉkUdINES(ordre). 37

Anomaux (section).

A Noploures (famille).

Anthosoma (genre), Anthosome.

- Smithii, A. de Smith.

Anthura (genre), Anthure,

- Grocilis, A. grêle.

Aonis (genre), Aonide.

- Foliosa, A. foliacée.

Aphrodita (genre), Aphrodite.

- Aculeata, A. aiguillonnée.

- Audouini, A. d'Audouin.

- Aurata, A. dorée.

- Hystrix, A. porc-épic.

- Sericea, A. soyeuse.

A purodites (groupe).

A porobranches (ordre).

Apseudes (genre). Apseude.

- Ligioides; A. Ligie.

- Talpa, A. taupe.

Apus (genre), Ape.

Cancriformis, A. Crabriforme.

Arachines.

Aranéides (famille).

Arenicolites. (groupe).

Arcania (genre), Arcanie.

- Erinaceus, A. hérisson.

Arcturus (genre), Arcture.

cturus (genre), Arcture. $\quad 258$

Arenicola (genre), Arénicole.

- Abildgaardti, A. d'Abildgaardt.

- Branchialis, A. branchiale.

- Carbonaria, A. charbonnière.

- Clavata, A. en massue.

- Marina, A. marine.

Argas (genre), Argas.

- Persicus, A. de Perse.

- Pipistrella, $\Lambda$. de la chauve-sou.

ris de pipistrelle.

- Replexus, A. réfléchi.

Arovés (LEs) (tribu).

Argulus (genre), Argule.

- Foliaceus, A. foliacé.

Argyroneta (genre), Argyronète.

- Aquatica, A. aquatique.

A ricites (groupe).

Aricia (genre). Aricie.
324

250

id.

id.

id.

4

5

33

23

37
241

569

298

id.

256

$i d$.

21

id.

6

7

id.

id.

id.

id.

6

441

242

243

id.

286

287

315

328

31

123

id.

259

32

id.

$i d$.

id.

id.

id.

483

484

483

id.

79

294

295

440

id.

20

20
- Cuvieri, A. de Cuvier.

- Latreillei, A. de Latreille.

- Sertulata, A. sertule.

Aristenia (genre), Aristénie.

Arkys (genre), Arkyde.

- Lancearius, A. lancier.

Armadillo (genre), Armadille.

- Officinalis, A. officinale.

- Pustulatus, A. pustulé.

- Vulgaris, A. commun.

Arenurus (genre).

-Caudatus, A. à queue.

- Pustulalor, $\Lambda$. à pustule.

- Rubiginosus.

- Tricuspidator, A. à trois pointes.

- Viridis, A. vert.

Artemia (genre), Artémie.

- Salina, $\Lambda$. des marais salans. id.

Asaphus (genre), Asaphe.

- Caudatus, A. à queue.

- Cornigerus, A. porte-corne. 310

- Debuchii, A. de Debuch. id.

- Hausmanni, A, de Hausmann. 311

- Laticauda, A. à large queue. id.

Asellotes (famille).

Asellus (genre), Aselle.

- Aquaticus, A. aquatique.

Aspidiphores (famille).

Astacus (genre), Ecrevisse.

- Fluviatilis, A. des rivi ères.

Atax (genre).

- Albidus, A. blanchâtre.

- Crassipes, A. à paites épaisses.

- Confluens, A. confluent.

- Diaphanus, A. iransparent.

- Elegars, A. élégant.

- Falcatus, A. en faux.

- Fastuosus, A. fastueux.

- Figuralis, A. figural.

- Freniger, A. porte frein.

- Histrionicus, A. histrion.

- Hyalinus, A. hyalin.

- Limosus, A. du limon.

- Lobatus, A. lobé.

- Lutescens, A. jaunâtre.

- Minimus, A. très-petit.

- Pictus, A. peint.

- Punicus, A. ponceau.

- Truncatus, A. tronqué.

- Vernatis, A. du printemps.

Atelecyclus (genre), Atélécycle.

259

id.

id.

286

179

180

497

499

id.

id.

id.

498

id.

id.

id.

499

497

499

498

499

498

499

id.

498

499

498

- Cruentatus, A. ensanglanté. 94

- Heterodon, A. à dents dissemblables.

Athanas (genre).

id.

- Nitescens, A brillant. 186

Autonomea (genre). Autonomée. 184

- Olivi, $\Lambda$, Olivi.

d.

.

d.

12

82

5

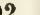

.

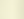

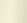

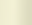

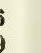


TAULE.

Pages.

- Fusca, E. brune.

- Bos, A. bœuf.

- Maculatus, A. tacheté.

- Morsitans, A. mordant.

- Peregrinus, A. étranger.

- Phrinoides, A. faucheur.

- Protervus, A. insolent.

- Urvillei, A. d'Urville.

- Variegatus, A. variẻ.

\section{- Dentata, B. denté.}

Branchejllonites (groupe). Branchellion (genre), Branchellion.

-Pumatum, B.

- Torpedinis, B. engourdie. lis ichrores (famille).

Branchipus (genre).

P'iges.

- Stagnalis, B. des étangs.

Buthus (genre).

- Afer, B. africain. id.

- Americanus, B. américain. $\quad 323$

-Bahiensis, B. de Bahia. id.

- Gracilis, B. grêle. : id.

- Junceus, B. jonc. id.

- Longicauda, B. à longue queue. id.

-Occitanus. B. du Languedoc. $\quad 322$

- Punctatus, B. ponctue. 323

- Testaceus, B. lestacé. 322

Calıppa (genre) Calappa. ‥ 109

- Cristata, C. à crête. $\quad 110$

- Ciallis. C. coq. id.

- Granulata, C. granulée. id.

-Tuberculosa, G. tuberculée. id.

Calapeites 'groupe). $\quad \ldots \quad 109$

Caligus (genre), Calige. $\quad 296$

- Mulleri. C. de Muller. _ $\quad 297$

- Piscinus, C. des poissons. id.

Callianidea (genre), Callianidée. $\quad 177$

- Typa, C. type. ir.

Callianassa (genre), Callianasse. $\quad 176$

- Subterranea, C. souterraine. id.

Callianisea (genre), Callianesée. 177

- Elongata, C. allongée. 178

Callipus (genre), Callipe. $\quad 532$

- Rissonius, C. de Risso. 533

Calommata (genre), Calommate. \$35

- Fulvipes, C. pattes fauves. $\quad 346$

Calymene (genre). $\quad 309$

-Blumenbachii, C. de Blumen-

bach. $i d$.

- Macrophthalma, C. yeux longs. 310

- Tristani, C. de Tristan. 309

- Variolaris, C. variolée. $\quad 340$

Campecopea (genre), Campecope. 254

- Cranchii, C. de Grauch. id.

- Hirsuta, C. hérissé.

Campiscia (genre), Camposcie. 131

- Retusa. C. émoussé. id.

Cancellus'genre), Cancelle. $\quad \mathbf{1 6 4}$

- Typus, C. type. id.

Cancerites (groupe. 79

Cancer (genre), Crabe. $\quad 79$

- Acanthus, C. épine. 82

- Calculosis, C. pierreux. id.

- Integerrimus, C. très-entier. $\quad 80$

- Limbalus, C. limbé. $\quad 81$

- Lobatus, C. lobé. $\quad i d$.

- Mamillatus, C. mamelonné. $\quad 81$

- Marginatus, C. bordé. $\quad 80$

- Ocyroe, C. ocyroe. 81

- Roseus, C. rose. $\quad 80$

- Savignyi, C. de Savigny. _ $\quad 81$

- Siutptus, C. sculpté. - id.

- Spinimanus, G. mains épineuses. 82 
pages.

Cambala (genre), Cambale. - Lactarius, C. laiteux.

Canolira (genre), Canolire. - Rissoniana, C. de Itisso.

533

id.

250

id.

Caphyra (genre), Caphyre. - Rouxii, C. de Roux.

Caprella (genre), Caprelle.

- Acuminifera, C. en pointe.

- Acutifrons, C. front aigu.

- Linearis, C. linéaire.

Carcinites (groupe).

Carcinus (genre), Carcin.

- Manas, C. manade.

Cardisoma Carnifex (genre), C. bour. reau.

Caridina (genre), Caridine.

- Longirostris, C. à long bec.

Caridioides (famille).

Carpilius (genre), Carpilie.

- Convexus, C. convexe.

- Corallinus, C. coralline.

- Maculatus, C. tacheté.

-Venosus, C. veiné.

Caculus (genre), Cocule.

- Echinipes, C. pattes de hérisson.

Cecrops (genre), Cecrope.

- Latreillei, C. de Latreille.

Cenobita (genre), Cénobite.

- Clypeata, C. à bouclier.

- Rugosa, C. rugueuse.

Cerapus (genre), Cérape.

- Tubularis, C. tubulaire.

Ceratophthalmes (famille).

Cetochylus (genre), Cetochylus.

- Australis, C. austral.

Cilicaa (genre), Cilicœé.

- Latreillei, C. de Latreille.

Cirolana (genre), Cirolane.

- Cranchii, C. de Cranch.

Cirrhatulus (genre), Cirrhatule.

- Cirratus, C. bouclé.

- Lamarckii, C. de Lamarck.

Chelifer (genre), Chelifer ou portepince.

- Cancroides, C. crabroìde.

- Geoffroyi, C. de Geofroy.

-Hermannii, G, de Hermann.

- Latreillei, C. de Latreille.

- Muscorum, C. des mousses.

- Nepoides, C. nèpe.

- Olfersii, C. d'Olfers.

- Scorpioides, C. scorpion.

Chetopterus (groupe), Chetoptère.

- Pargamentaceus, C. pargamen. tacé.

Cunlognathes (ordre).

Cullopodes (ordre).

Chlaia (genre), chloie.

185

201

82

83

\section{2}

8.3

$i d$.

465

$i d$.

299

id.

163

id.

164

231

id.

287

253

id.

254

id.

252

id.

21

id.

id.
- Capillata, C. chevelue. - Rupestris, C. des rochers.

Payes.

Chlorodius (genre), Chlorodie. $\quad 88$

- Areolatus, C. aréolé. $\quad 89$

- Eudorus, C. eudore.

- Exaralus, C. séché.

- Longimanus, C. longues mains.

- Niger, C. noir.

- Sanguineus, C. rouge de sang.

- Ungulatus, C. ungulé.

Chorinus (genre), Chorine.

- Aculeatus, C. aiguillonnẻ.

- Dumerilii, C. de Dumeril.

- Heros, C. héros.

Cladoceras (famille).

Clastes (genre), Clastes.

451

id.

452

id.

id.

453

452

id.

451

22

$i d$.

517

534

10
- Freycinetii. C. de Freycinet.

Cleistoma (genrel Cleistome.

- Leachii. C. de Leach. id.

Clotho (genre), Clotho. 408

- Durandii, C. de Durand. $\quad 409$

- Longipes, C. à longues pattes. $\quad 410$

- Nitida, C. brillante.

Cloportides (famille).

Clubiona (genre), Clubione.

- Accentuata, $\mathrm{G}$. accentuéc.

- Atrox. C. atroce.

- Epimelas, C. épimelas.

- Fallax, C. Irompeuse.

- Ferox, C. féroce.

- Holosericea, C. soyeuse.

- Lapidicolens, C. des pierres. $\quad 402$

- Necator, C. assassine. id.

- Nutrix. C. nourrice. $\quad$ \03

- Rupicola, C. des roches. 401

Clymene (genre), Clymene. 31

- Amphistoma, C. Amphistome. id.

- Lumbricolis, C. Jumbric. id.

Clymenites (groupe). id.

Condylura (genre), Condylure. $\quad 267$

- Orbignyi, C. d'Orbigny. $\quad 268$

Conilera (genre), Conilère. 249

- Montagui, C. de Montague. id.

Corophium (genre), Corophie. 232

- Longicorne, C. à longues antennes.

Coronis (genre), Coronide.

id.

- Scolopendra, C. scolcuendre.

Cosmetus (genre), Cosmele. 457

- Andreae, C. de Saint-André, id.

- Bipunctatus, C. à deux points, id.

- Conspersus, C. arrosé. id.

- Lagenarius, C. bouteille. id.

- Marginalis, C. bordé. $\quad 458$

- Pictus. C. peint. 457

- Flavus, C. jaune. 458

- Patius, C. varić. id. 
TABLE.

Pages.

- Dentalus, C. denté.

Conystites (groupe).

Crape. Voy. Cancer et Carcinus.

Crangonites (groupe).

Crangon (genre).

- Fasciatus, à bandes.

- Vulgaris, commun.

Craspedosoma(genre). Craspédosome. 533

- Polydesmoides, C. forme de po.

lydesme.

-Rawlinsii, C. de Pawlins.

- Richii, C. de Hiche.

Crevette (genre). Voyez Palamon.

Crevettines (famille).

Criocarcinus (genre), Criocarcin.

- Superciliosus, C. à sourcils.

Crustacés (classe).

Grustacés édentés.

Cryptopodites (groupe).

Cryptopodia (genre), Cryptopodie.

- Fornicata, voûtée.

Cryptops (genre), Cryptop่s.

- Hortensis, C. des jardins.

- Hyalinus, G. transparent

- Posticus, C. postérieur.

- Savignyi, C. de Savigny.

-Sex-spinosus, C. à six épines. $\quad 547$

Cryptostemma (genre).

- Westermannii, C. de Westermann.

Cryptopus (genre), Cryptope.

- Defrancii, C. de Defrance.

Ctenus (genre), Ctène.

- Fimbriatus, C. frangé.

- Oudinoti, C. d'Oudinot.

- Rufibarbis, C. barbe rousse.

- Rufus, C. roux.

Sanguinolentus, C. ensanglan

. ensanglanté. 365

Cuma (genre), Cume. 268

- Audouinii, C. d'Audouin.

Cumrres (groupe).

Cyamus (genre), Cyame.

- Erraticus, C. errant.

- Gracilis, C. grêle.

- Ovalis, C. ovale.

Cyclops (genre), Cyclope.

- Castor, C. castor.

- Staphylinus, C. staphylin.

- Vulgaris, C. commun.

Cyclograpsus (genre), Cyclograpse.

- Integer, C. entier.

- Latreillei, G. de Latreille.

- Octodentatus, $\mathrm{G}_{\text {。 á huit dents. }}$

- Punctatus, C. ponctué.

- Sexdentatus, C. à six dents.

('ymodocea (genre).

- Bifida, C. bifide.

- Emarginata, C. échancrée.
184

id.

181

id.

id.

id.

id.

id.

225

140

id.

47

290

111

111

112

546

id.

id.

547

546

466

id.

199

$i d$.

365

id.

366

266

\section{id.}

267

221

$2 \div 3$

id.

id.

271

272

id.

id.

70

71

id.

id.

id.

i.l.

255

id.

i.l.
- Lamarchii, C de Lamarck.

Pages.

- Truncata, C. tronquee.

Cymopolia (genre), Cymopolée.

255

- Caronii, C. de Caron.

Cysothoades (famille).

id.

114

id.

247

Cymothoa (genre), Cymothoe. $\quad 248$

- Bivittata, C. à deux bandes. id.

- Gibbosa, C. gibbeuse. id.

-Mathoi, C. de Mathieu. id.

- Navicularia. C. naviculaire. id.

- OEstrum,C. œstre. $\quad 249$

- Ricinoides, C. Ricin. 249

- Rosucea, G. de rose. 248

- Triangularis, C. triangulaire. id.

Cynthia (genre), Cynthie. 204

- Aimata, C. armée. id.

Cypris (genre), Cypris. 280

- Aurantia, C. orangée. 281

- Candida, C. candide. 282

- Conchacea, C. coquille. 281

- Fusca, C. brune. id.

- Fuscata, C. brunâtre. $\quad 282$

- Marginata, C. bordée. 281

- Monacha, C. moine. ill.

- Ophthalmica, C. ophthalmique. 282

- Ornata, C. ornée. 281

- Ovata, C. ovale. id.

-Ovum, C. æuf. 283

- Picta, G. peint. 282

- Pubera, C. poilue. 281

- Punctata, C. ponctuée. 282

- Rubra, C. rouge. 281.

- Striata, C. strièe. 282

- Strigata, C. ridée. id.

-Unifasciata, C. à une seule bande transversale.

- Vidua, C. veuve.

- Villosa, C. velue.

- Virens, C. verte.

Cythere (genre) id.

- Flavida, C. jaunâtre.

- Gibba, C. bossue. id.

- Gibbera. C. gibbeuse. 280

- Lutea, G. jaune. $\quad 279$

- Viridis, G. verte. id.

Dactylocera (genre). Dactylocère. 238

- Niciensis, D. de Nice. $i d$.

Daira (genre), Daire. 235

-Gabertii, D. de Gabert. id.

Daphnia (genre), Daphnie. 273

- Brachiata, D. à bras. $\quad 276$

- Clathrata, D. treillagée. 277

- Cornuta, D. cornue. id.

- Longicollis, D. à long con. $\quad 276$

- Longispina, D. à épine longue. id.

- Magna, D. grande. iil.

- Mucronala, D. à pointe. id.

- Nasuta, D. à long nez. il. 
- Pulex, D. puce.

- Rectirostris, D. à bec droil.

- Sieticulata, D. réticulée.

- Sima, D. camus.

Decapones (ordre).

Decempedes (famille).

Delena (genre), Delene.

- Cancerides, D. crabre.

- Crabroides, D. crabroìde.

- Hastifera, D. porte-lance.

- Peronianus, D. de Péron.

- Plagusia, D. plagusie.

Dermanyssus (genre), Dermanysse.

- Avium, D. des oiseaux.

- Convolvuli. D. du liseron.

- Murinus, D. grisâtre.

- Musculi, D. rat.

- Oribatis, D. oribates.

Desis (genre), Dese.

- Dysderoides, D. dysdère.

Deto (genre), Deto.

- Echinata, D. hérisson.

Dichelesthium (genre), Dichelesthie.

- Sturonis, D. de l'esturgeon.

Diclapodes (ordre).

Dinemoura (genre). Dinemoure.

- Producta, D. prolongée.

Dipnedmones (tribu).

Diopatra (genre).

- Cuprea, D. cuivreuse.

- Amboinensis, D. d'Amboine.

- Italica, D. italienne.

Discosoma (genre).

- Cinctum, D. ceint.

Doclea (genre), D. Doclée.

- Hybrida, D. hybride.

- MIuricala, D. rocher.

- Ovis, D. brebis.

Dolichoscelis (genre), Dolichoscèle.

- Haworthii, D. de Haworth.

Dolomedes (genre), Dolomede.

- Atalanta, D. Atalante.

- Fimbriatus, D. frangé.

- Hippomene, D. hippomene.

- Mirabilis, D. admirable.

Dolophones (genre), Dolophone.

- Notacantha, D. à dos épineux.

Dorippa (genre), Dorippe.

- Astuta, D. rusée.

- Lanata, D. laineuse.

- Quadridentata, D. à quatre dents. id.

Donippites (groupe).

Drassus (genre), Drasse.

- Ater, D. noir.

- Fulgens, D. éclatant.

- Lucifugus. D. lucifuge.

- Nocturnus, D. nocturne.

- Rubens, D. rougeâtre.
Pagei.

275

276

277

276

5 ?

243

380

id.

381

$i d$.

id.

380

478

id.

479

id.

480

$i d$.

405

$i d$.

261

id.

301

302

266

298

id.

350

14

$i d$.

id.

id.

458

id.

143

444

id.

id.

457

id.

362

363

id.

id.

364

368

id.

115

116

id.

114

405

406

407

405

406

id.
- Trucidator, D. égorgeur.

Pages.

- Viridissimus, 408

Dromia (genre), Dromie. $\quad 112$

- Caput mortuum. D. tête de mort. 113

- Communis, D. coinmune. 112

- Hirtissima, D. trés hérissée. 113

- Rumphii, D.de Rusnphius. id.

Dromites (groupe).

Dyction (genre), Dyction.

- Caudatum, D. à queue.

Dynamene (genre), Dynamene.

- Lesueleri, D. de Lesueur. $\quad 256$

- Montagui, D. de Montague. 255

- Rubra, D. rouge. . id.

- Viridis, D. verte.

Dysdera (genre), Dysdère.

- Erylhrina, D. rongeâtre. $\quad 348$

- Hombergii, D. de Homberg. $\quad 349$

- Insidiatrix, D. traître. id.

- Lata, D. Large. $\quad 348$

- Solers, D. ingénieuse. $\quad 349$

Doto (genre).

-Sulcatus, D. sillonné. id.

Ebalia (genre). Ebalie. 121

- Bayerii, E. de Bayer. 122

- Cranchii. E. de Cranch. id.

- Pennantii, E. de Pennant. 121

Ecrevisse (genre). Voyez Astacus.

Egeria (genre), Egerie.

144

-Arachnoides, E.à forme d'araignée. 145

Elamena (genre), Elamène. - 150

- Mathai, E. de Mathieu. ' id.

Epeira (genre), Epeire. 419

- Aculypha, E. acalyphe. $\quad 425$

- Adianta, E. adiante. id.

- Agalena, E. agalene. - $\quad 424$

- Alsine, E. Alsine. $\quad 423$

- Angulata, E. anguleuse. $\quad 422$

- Antriada, E. Antriade. $\quad 427$

- Apoclisa, E. apoclise. $\quad 426$

- Alrantia, E. orangée. 421

- Bicorris, E. bicorne. 422

- Calophylla. E. à belles feuilles. 427

- Ceropegia, E. céropégie. 425

- Chrysogaster, E. à ventre doré. 419

- Circulata, E. circulaire. 428

- Clavipes, E. à pattes en massue. 419

- Conica, E. conique. 420

- Cornuta, E. cornue. $\quad 422$

- Cratera. E. cratère. $\quad 424$

- Cruciata, E. à croix. $\quad 423$

- Cucurbitina, E. citrouille. $\quad 428$

- Diadema, E. diadème. $\quad 423$

- Diodia, E. Diodée. 425

- Drypta, E. Drypte. $\quad 424$

- Fasciata, Eo a bandes transver-

sales.

- Fastuosa, E. fastueuse. 
TABLE.

- Fusca, E. brune.

Puges.

- Gibbosa, E. bossue.

- Inclinata, E. penchée.

- Latreillana, E. de Ialreilie.

- Latro, E. voleuse.

- Mammata, E. m melonnée.

- Marmorea. E. marbrée.

- Mellittagria, E. mellitiagric.

- Myabura, E. mange-inouches.

- Myagria, E. myagrie.

- Oculita, E. oculee.

- Opuntice, E. de l'opuntia.

- Pullida L. palle.

- Plumipes, E. à paltes plumées.

- Quadrata, E. carree.

- Scalaris, E. à échelous.

- Sericea, E. soyeuse.

- Triguttata, E. à trois gou tes.

- Tuberculata, E. tuberculèe.

- Tubulosa, E. tubuleuse.

- Umbraticola, E. des lieux ombragés.

Epialtus (genre), Epialte.

- Bi-tuberculalus, $\mathbf{E}$. à deus tuber cules.

- Oculatus, E. oculé.

Ephyra (genre), Ephyre.

- Pelagica, E. des rivages.

- Punctata, E. ponctuée.

Episinus (genre), Episine.

- Truncatus. E, tronqué.

Epicorides (famille).

Erichtites (groupe)

Eresus (genre), Lrese.

- Acantophilus, E. ami des épines.

- Cinaberinus, E. cinabre.

- Dufourii, E. de Dufour.

- Frontatis, E. frontal.

Erichtonius (genre), Erichtonie. - Difformis, E. difforme.

Ericthus (genre), Ericthe.

-Vitreus, E. vitré.

Erigone (genre).

- Vagans, E, errante.

Eriphia (genre), Eriphie.

- Gonagra, E. gonagre.

- Lavimana, E. mains lisses.

- Spinifrons, E. front épineux.

Eripus (genre), Eripé.

- Eterogaster, E. hétérogastre.

Eriodon (genre), Eriodon.

- Occatorius, E, hersant.

Erythraus (genre).

- Cornigerus, E. cornu.

- Flavas, E. jaune.

- Ignipes, E. à pattes defeu.

- Kuricola, E. campagnard.

Eryon (gesre), Frynn.
428

422

427

420

421

id

426

423

424

423

429

id.

424

419

425

424

421

424

423

427

426

132

id.

$i d$.

196

id.

197

4:4

435

245

206

370

371

370

372

371

231

id.

$2 \cup 7$

208

$4: 99$

440

78

79

id.

$i d$.

388

389

346

347

475

477

476

id.

475

178
- Curieri, E. de Cuvier.

Pages.

Ethusa (genre), Ethuse.

176

117

- Mascarone, E. mascarone. id.

Elisus (genre), Elise. 92

- Anaglypius, E. sculpté. $\quad$ id.

- Dentalus, E. denté. $i d$.

Eulimene (genre). 289

- Albida, E. blanchâtre. $\quad 290$

Eumedon (genre), Eumedun. 127

- Niger, E. noir.

Eumolphe (genre).

- Fragilis, E. frêle.

Eunice (genre), Eunice.

- Antennata, E. à antennes.

- Aphroditais, E. aphrudite.

- Bellii, E. de Bell.

- Gallica, E. française.

- Gigantea, E. géante.

- Harassii, E. de Harass.

- Hispanica, E. d'Espagne.

- Norwegica, F. de Norwège.

- Paretti, E. de Paretti.

- Pinnata, E. à bouquet.

- Sanguinea, E id.

Eunicites (groupe).

Euphema (genre), Euphème. $\quad 196$

- Armata, E. armée.

Euphrosyna (genre), Euphrosyne.

- Foliosa, E. foliacée. id.

- Laureata. E. laurier. id.

- Myrtosa, E. myrte. id.

Eurydice (genre).

- Pulchra, E. belle.

Eurynome (genre), Eurynome.

- Aspera, E. rude.

251

id.

127

id.

146

- Latreillei, E. de Latreille. $\quad 147$

Eusarcus (genre).

455

id.

tras, armé.

- Grandis, E. grand.

- Muticus, E. sans arme.

- Pumilio, E. nain.

id.

id.

id.

Eylais (genre).

- Chrysis, E. doré.

- Exiendens, E. étendant.

503

504

503

445

347

iil.

- Bicolor F bicolore

223

480

481

482

Brevis, G. conrt.

- Coleoptratorum, G. des Coléo-

ptères.

480

- Crassipes, G. à pattes épaisses, 481

- Giganteus, G. géant.

- Lagenaire, G. bonteille.

id.

id.

- Intrinitis, C.bude. 480 
- Monachus, G. moine. 482

- Rotundatus, G. arrondi.

- Testudinarius, G. tortue.

- Tetragonoides, G. quadrangu. laire.

Gammarus (genre), Gammarus.

- Fluviatilis, G. des rivières.

- Locusta, G. sauterelle.

- Marinus, G. marin,

-Olivii, G. d'Olivier.

- Ornatus, G. orné.

- Roselii, G. de Hæsel.

Galatines (tribu).

Galathea (genre), Galathée.

- Squammifera, G. écailleuse.

- Strigosa, G. striée.

- Rugosa, G. rugueuse.

Galeodes (genre), Galéode.

- Araneoides, G. araignée.

- Cubar, G. de Cuba.

- Dorsalis, G. dorsale.

- Limbata, G. bordée.

- Melanus, G. noire.

Gatigites (famille).

Gasteracantha (genre).

- Audouinii, G. d'Audouin.

- Cancriformis, G. crabriforme.

- Clypeata, G. à bouclier.

- Curvicauda, G. à queue courte. 430

- Fasciata, G. à bande transver-

sale.

- Geminata, G. géminée.

431

- Gracilis, G. grêle.

- Lepelletierii G de Lepeletier.

Linetleteri, G. de Lepeletier. 431

- Lineata, G. a lignes.

- Rhomboidea, G. rhomboïde. 431

- Rubrospinis, $\mathrm{G}$. à épines rouges. id.

- Theisii, G. de Theis. id.

Gebia (genre), Gebie.

- Littoralis, G. des rivages.

- Stellata, G. étoilée.

Gecarcinites (groupe).

Gecarcinus (genre), Gecarcin.

- Ruricola, G. campagnard.

Gelasimus (genre), Gelasime.

- Maracoani, G. de Maracoan.

- Marionis, G. de marion.

- Pugilator, G. combattant.

- Tangerii, G. de Tanger.

175

id.

id.

\section{2}

62

\section{3}

58

59

60

59

id.

- Tetragonon, G. quadriangulaire. 60

- Vocans, G. appelant.

Geophilus (genre), Geophile.

- Acuminatus, G. en pointe.

- Barbaricus, G. de Barbarie.

- Carpophagus, G. mangeur de fruits. 549

- Electricus, G. électrique. id.

- Ferrugineus, G. ferrugineux. 548

- Gabriclis, G. de Gabriel.
- Lavigatus, G. lisse.

- Lefebvrai, G. de Lefebvre.

Pages.

- Maritimus, G. maritime.

- Maxillaris, G. à mâchoire.

- Rubeus, G. rougeâtre.

- Savignyanus, G. de Savigny.

- Simplex, G. simple.

- Sulcatus, G. sillonne. 549

- Subterraneus, G. souterrain 550

-Walckenaerii, G. de Walckenaer. 550

Glaucothoe (genre), Glaucothoe. $\quad 174$

- Peronii, G. de Peron. 175

Glomeris (genre).

- Annulata, G. annelée.

- Castanea, G. marron.

- Guttata, G. à gouttes.

520

521

id.

- Hexasticha, G. à six pointes. 520

- Klugii, G. de Klug. id.

- Lepida, G. jolie. id.

- Limbata, G.limbée. $\quad 521$

- Marginata, G. bordéc. $\quad 520$

- Marmorea, G. marbrée. $\quad 521$

- Plumbea, G. plombee. id.

- Pustulata, G. pustulee. $\quad 520$

- Quadripunclata, G. à quatre points.

- Tetrasticha G. id.

Glomerites (famille). à quatre pointes.

Glossiphonia (genre), Glossiphonie. $\quad 40$

- Bioculata, G. bioculée. id.

- Circulans, G. en cercle. $\quad \mathbf{4 1}$

- Complanata, G. aplatie. $\quad 40$

- Heteroclyta, G. hétéroclyte. 41

-Paludosa, G. des marais. $\quad 40$

- Tricolor, G. tricolore. 41

-Trioculata, G. trioculée. $\quad 40$

Glycera (genre), Glycère. 20

-Mecketii, G. de Meckel. id.

- Rouxï, G. de Roux. id.

- Unicornis, G. unicorne. id.

Ginatophyllum(genre), Gnatophylle. 186

- Elegans, G. élégante. id.

Goniada (genre), Goniade. 19

- Emerita, G. émérite. id.

Gonodactylus (genre), Gonodactyle. 212

- Chiragra, G. à mains goutteuses. id.

Gonoplax (genre), Gonoplace. $\quad 73$

- Bispinosa, G. à deux épines. id.

- Rhomboidatis, G. rhomboïdal. id.

Gonoplacites (groupe). , $\quad 72$

Gonosioma (genre), Gonosiome. $\quad \mathbf{4 5 6}$

- Conspersum, G. parsemé. id.

- Ferragineum. G. ferrugineux. id.

- Junceum, G. de jonc. 457

-Modestum, G. modeste. $\quad \mathbf{4 5 6}$

- Obscurum, G. obscur. $\quad 457$

- Patruele, G. oncle. 456 .

- lioridum, G. arrusé. 'id. 
- Sulphureum, G. soufré.

- Squalidum, G. sale.

- Varium. G. varié.

-Versicolor, G. versicolor.

Gonyleptes (genre).

- Aculeatus, G. aiguillonné.

- Armatus, G. armé.

- Asper, G. rude.

- Curvispina, G. à épine recourbée. id.

- Elegans, G. élégant.

- Horridus, G. horrible.

- Scaber, G. rugueux.

- Spinipes, G. pattes épineuses.

Grapsortes (groupe).

Grapsus (genre), Grapse.

- Cruentatus, G. ensanglanté.

- Messor, G. moissonneur.

- Pictus, G. peint.

- Strigosus, G. ridé.

- Varius, G. varié.

Grimothea (genre), Grimothée.

- Gregaria, G. brebis.

Gyropus (genre), Gyrope. -Gracilis, G. grêle.

Guaia (genre), Guaia.

-Punctata, G. ponctuée.

Hamopis (genre), Hæmopis.

- Lacertina, II. lézard.

- Luctuosa, H. en Jueil.

- Nigra, H. noir.

- Sanguisuga, H. succ-sang.

Jlatimus (genre), Halime.

- Aries, H. bélier.

Halpheus (genre), Halphe.

- Dentipes, H. pattes dentelćes.

- Ruber, H. rouge.

Hépatites (groupe).

Hepatus (genre), Hèpate.

- Fasciatus, H. à bandes transversales.

Herbstia (genre), Herbstie.

- Condyliata, $\mathbf{H}$. noueuse.

Hermella (genre), Ilermelle.

- Arenosa, H. des sables.

- Chrysocephala, H. à tête dorée.

Hermellites (groupe).

Hersilia (genre), Hersilie.

- Caudata, H. à queue.

- Indica, H. indienne.

HéTÉROCHÈLEs (section).

HÉTÉRopodes (famille).

Hesione (genre).

- Festiva, H. agréable.

- Pantherina, H. panthère.

- Splendida, H. splendide.

Hieracony $x$ (genre).

- Abbreviatus. II raccourci.

Hippa (genre), Hippe.
Pages.

458

id.

id.

id.

453

id.

454

id.

\section{id.}

453

454

id.

66

67

68

69

68

id.

69

172

id.

575

id.

121

id.

41

42

id.

id.

41

142

id.

182

183

id.

108

108

id.

143

id.

27

id.

$i d$.

id.

366

$i d$.

id.

117

241

18

id.

id.

id.

237

id.

157
- Emerita, H. émèrite.

Pages.

Hippides (tribu).

Hippolyte (genre).

157

156

187

-Aculeatus, H. aiguillonne. 188

- Desmarestii, H. de Desmarest. id.

- Prideauxiana, II. de Prideaux. 187

- Varians, H. variant.

- Viridis, H. vert.

id.

id.

Hipponoa (genre), Hippone. 11

- Gaudichaudi, H. de Gaudichaud, id.

Hirudo (genre), Sangsue. $\quad 42$

- Egyptiaca, S. égyptienne. - 43

- Granulosa, S. granuleuse. id.

- Interrupta, S. interrompue. id.

-Japonica, S. du Japon. $\quad 44$

- Medicinalis, S. médicinale. 43

- Obscura, S. obscure. id.

- Oficinalis, S. officinale. 42

- Swampina, S. swampine. $\quad 44$

- Troctina, S. truite. , 43

- Verbana, S. verveine. id.

- Zeylanica, S. zeylanique. $\quad i d$.

Hohakdiens (iribu). 178

Homarus (genre), Homard. $\quad 180$

- Vulgaris, H. commun. id.

HоMоснеLes (section).

Homola (genre), Homole. 151

- Cuvieri, H. de Cuvier. id.

- Spinifrons, H. front épineux. 152

Номоцiтes (groupe). 151

Hyas (genre), Hyas. 141

- Aranea, H. araignée. id.

- Coarctata, H. étranglée. il.

Hydrachna (genre). 505

- Geographica, H. géographique. 509

- Globosa, H. globuleuse. 505

HydRAchNelLES (groupe). 497

Hymenocera (genre), Hyménocère. 182

Hrmenopodes (́tribu). 298

Iymenosoma (genre), Hymenosome. 150

- Orbiculare, H. orbiculaire. id.

Hyaenosomites (groupe). 150

Hyperia (genre), Hyperie. 233

- Latreillei, H. de Latreille. id.

- Pelagica, H. des rivages. 234

Hyperines (famille). 233

Hypogeon (genre). 34

- Hirtum, $\mathbf{H}$. hérissé. $\quad 35$

Hypopht TALMES (tribu). $\quad 151$

Hypopus (genre). $\quad 484$

- Spinitarsus, à tarses épineux. id.

Ibacus (genre), Ibaque. $\quad 167$

- Peronii, I. de Péron. iil.

Idotea (genre), Idotée. 256

- Acuminata, I. acuminée. 258

- Basteri, I, de Baster. ill.

- Entomon, J. insecte. 257

- OEstrum, 1. cstre. 258 
TABI.E.

Pages.

- Pelagica, 1. des rivages. $\quad 258$

- Peloponesiana, I. de Péloponèse. id.

- Tricuspidala, I. à trois pointes. 257

- Variegata, I. variee. 258

I dotoldes (famille).

256

Ilia (genre), llie.

- Nucleus, I, noir.

- Rugulosa, I. rugueuse.

120

id.

id.

Inachus (genre).

- Dorynchus, I. dorynque.

145

- Leptorynchus, I. a bec uince. id.

- Scorpio, I. scorpion.

- Thoracicus, I. thoracique.

Ione (genre), Ione.

145

146

246

- Thoracicus, I. thoracique.

Iphionea (genre), Iphionee.

- Muricata, I. rocailleuse.

id.

9

id.

Iphis (genre), Iphis.

124

- Septemspinosa, I. à sept épines. id.

Isopodes (ordre).

240

Iulus (genre), lule.

- Aimatopodus, I. à pattes ensan. glantées.

-Americanus, I. américain.

- Annulatus, I. annelé.

- Arborcus, 1. des arbres.

id.

$i d$.

- Beauvoisii, I. de Beauvois.

530

- Botta, 1. de Botta.

531

- Boveanus, 1. de Bové.

- Carnifex, I. bourreau.

-Communis, I. commun.

- Crassus, I. épais.

- Decaisneus, I. de Decaisne.

529

id.

532

$5: 1$

532

- Festivus, I. joli.

528

532

- Fetidissimus, I. très-puant. 531

- Fuscus, I. brun.

- Indus. I. indien.

532

529

528

- Lucifugus, 1. lucifuge.

-Maximus, I. très-grand.

532

531

- Modestus, I. modeste.

- Niger, I. noir.

530

531

- Plicatus, I. plissé.

- Punctatus, l. ponctué.

- Pusillus, I. très-petit.

- Rupestris, I. des rochers.

- Sabulosus, 1. des sables.

- Seychellarum, I. des Seychelles. 529

- Terrestris, 1. terrestre.

- Varius, 1. varié.

id.

530

id.

532

530

xa (genre). Ise.

- Canaliculata, I. canaliculée.

Ixodes (genre), I y de.

530

532

123

- Camelizius. I. du chameau.

- Egyptius, I. d'Egypte.

- Erinacei, I. du hérisson.

- Iispanus, I. d'Espagne. .

- Nigua, I. tigre.

id.

493

497

496

493

496

id

- Plımbeus, 1.plombé.

Pages.

- Reduvius, 1 . reduve.

495

- Reticulatus, 1. rèticulé.

493

- Rhinoceris, I. de rhinocéros. 496

- Sylvaticus, I. des forêts. 497

- Trabeatus, I. Ja robe royale. $\quad 494$

Janira (genre), Janire. $\quad 260$

- Maculosa, J. tachetee... id.

Joera 'genre), Joere. 260

- Albifrons, J. front blanc. id.

Lachesis (genre), Lachesis. $\quad 417$

- Perversa, L. perrers. id.

Lambrus (genre), Lambre. $\quad 126$

-Angulifrons, L. front anguleux. id.

- Longimanus, L. longues mains. id.

- Massena, L. de Massena.

id.

- Mediterraneus, L. de la Méditer-

ranée.

127

Lambricites (groupe).

33

LAMEdrpodes (ordre). 219

Langoustines (tribu). $\quad 167$

Lagostoma (genre), Lagostome. $\quad 84$

- Perlata, L. perlee. id.

Latreillia (genre), Latreillie. $\quad 149$

-Elegans, L. élégant. id.

Latrodectus (genre), Latrodecte. 410

- Argus, L. argus. $\quad 411$

- Formidabilis, L. formidable. 419

- Malmignathus, L. M Imignathe, 41:

Lepidurus (genre), Lepidure. 287

- Productus, L. prolongé. id.

Lepisma (genre), Lepisme. 558

— Egyptiaca, L. d'Egypte. _. . 559

- Arnuliseta, L. à soies annelées. 560

- Audouinii, L. d'Audouin. 561

- Aurea, L. dorée. id.

- Ciliata, L. ciliée. $\quad 560$

- Petitii, L. de Pelit. _ 561

- Pilifera, L. poilue. $\quad \mathbf{5 6 0}$

- Saccharina, L. di suce. . id.

- Savignyi, L. de Savigny. 561

- Subvittata, L. à bandes faibles. 560

- Vittata, L. a bandes longitudi-

nales.

Lefismenes (famille).

id.

Leptomera (genre), Leptomère. 223

- Ventricosa, L. ventrue. id.

Leptopodia (genre), Leptopodie. $\quad 149$

- Sagittaria, L. sagitlaire. . - id.

Leptus (genre). $\quad \mathbf{5 1 0}$

- Autumnatis, L. de l'automne. id.

Lernanthropus'genre), Lernanthrope, 307

- Musca, L. mousse. id.

Lernacantha (genre). 306

- Delarochinna, L. de Delaroche. id.

Lernca (genre), Lernæe. 304

- Basleri, L. de Baster. id.

- Clavata, L. en massue. id. 
Pages.

- Cyclophora, L. porte-cercle.

Lerncomizon (genre).

- Elongata, L. allongée.

- Pernettiana, L. de Pernetty.

- Pinnarum, L. des Pinnes.

- Pyriformis, L. pyriforme.

- Uncinata, L. ongulće.

Lernentoma (genre).

- Asellina, L. des aselles.

- Corrula, L. cornue.

- Dufresnii, L. de Dufresne.

- Gobina, L. du goujon.

- Nodosa, L. noueuse.

- Radiala, L, rayonnée.

- Trigla, L. du irigle.

Lerneocera (genre), Lernéocère.

- Branchialis, L. branchiale.

- Cyclopterina. du Cycloptère.

- Cyprinacea, L. du Cyprinus.

- Surrirensis.

Lerneupenna (genre).

- Bocconica, L. de Boccone.

- Holteni, L. de Holten.

- Sagitta, L. flèche.

Lerneopoda (genre), Lerneope.

- Brongniurtii, L. de Brongniart.

- Salmonea, L. du saumon.

- Stellata, L. étoilée.

Lennoefformes (famille).

Lestrigon (genre).

- Fabrei, L. de Fabre.

LeUctFerites (groupe).

Leucifer (genre).

- Lieynaudi, L. de Reynaud.

Leucosia (genre), Leucosie.

- Craniolaris, L. Craniolaire.

- Urania, L. uranie.

Leucostrus (groupe).

Leucipa (genre), Leucipe.

- Pentagona, L. à cinq angles.

Leucotho (genre), Leucothœ.

- Furina L. voleuse.

Libinia (genre), Libinie.

- Canrticulata, L. canaliculée.

- Spinosa, L. épineuse.

Lygia(genre), Lygie.

- Exotica, L. exotique.

- Hypnorum, L. des mousses.

- Italica, L. italienne.

- Ocearica, L. Océanique.

Limnadia (genre), Limnadie.

- Hermannii, L. de Hermann.

- Mauritiana, L. de la M.

- Tetracera, L. à quatre cornes.

Limnatis (genre).

- Nilutica, L. du Nil.

Limnochares (genre), Limnocharc.

- Aqualicus, L, aquatique.
304

304

305

id.

id.

id.

304

305

id.

306

id.

305

id.

id.

306

303

$i d$.

id.

id.

id.

303

304

id.

id.

306

id.

307

id.

299

235

id.

205

205

206

120

121

id.

119

132

id.

230

id.

142

$i d$.

143

261

263

id.

262

id.

284

285

id.

id.

44

id.

504

id.
Limnoria (genre), Limnorie.

Pages.

- Terebrans, L. vibrante. id.

Limulıs (genre), Limule. ․ 291

- Latreillei, L. de Latreille. $\quad 293$

- Macleaii, L. de Mac-Leai. id.

- Moluccanus, L. des Moluques. 292

- Polyphemus, L. polyphème. id.

- Rotundicauda, L. a queue arron-

die.

- Sowerbii, L. de Sowerbi. id.

-Virescens, L, verdâtre. 293

Liotheum (genre), Liothée. $\quad 574$

- Dolichocephalum, L. 575

- Fasciatum, L. a bandes transversales.

- Giganteum, L. géant.

- Phanerostigmaton, L. à stigmates apparents.

- Subcequale, L. presque égal. $\quad 574$

Lissa (genre), Lisse. 138

- Chiragra, L. à mains goutteuses. id.

Lithobius (genre), Lithobie. $\quad 540$

- Forcipatus, L. à pince. id.

- Longicornis, L. à longues antennes.

543

- Nudicornis, L. à antennes nues. id.

- Spinipes, L. à pattes épineuses. id.

-Variegatus, L. varié. id.

-Vulgaris, L. commun. id.

Lithodes (genre), Lithode. 152

- Arctica, L. arctique. $\quad 158$

Linyphia (genre), Linyphie. $\quad 434$

- Montana, L. des montagnes. id.

- Triangularis, L. triangulaire. id.

Livoneca (genre); Livonece: 251

- Desmarestii, L. de Desmarest. id.

- Rafineskii, L. de Rafinesque. id.

- Redmanii, L. de Redmann. . id.

Lomis (genre), Lome. 153

- llirta, L. hirta. id.

Lophy Ropes (ordre). $\quad 270$

Lumbricjtes (groupe). 33

Lumbricus (genre), Lumbric (ver de terre).

- Gordioides, L. gordius. $\quad 34$

- Iagenbachii, L. de Hagenbach, id.

- Terrestris, L. terrestre. id.

Lumbrineris (genre), Lumbrinère. 14

- Latreillei, L. de Latreille. 5

- Orbignyi, L. d'Urbigny. id.

Lupa (genre), Lupée. 100

- Cribraria, L. criblée. 102

- Dicantha, L. à deux épines. 101

- Forceps, L. pince. 103

- Granulata, L. granuleuse. $\quad 102$

- Hastata, L. armée d'une pointe. 103

- Lobifrons, L. front lobé. $\quad 102$

- Pelagica, L. des rivages. 
Pages.

102

-Rubra, L. rouge.

401

- Seba, L. de Seba, 102

- Spinimana, L. mains épineuses. id.

- Tranquebarica, L. de Tranquebar.

Lycastis (genre), Lycaste.

- Armillaris, L. annelée.

id.

- Brevicornis, L. à antennes courtes.

Lycosa (genre), Lycose.

- Agilis, L. agile. id. 359

360

- Albimana, L. à mains blanches. 362

- Allodroma, L. coureuse.

- Audax, L. hardie.

- Captans, L. saisissante.

- Erythrognata, E. à mâchoires rouges.

- Liguriensis, L. de Liguric.

- Nautica, L. nautique.

- Narbonensis, L. de Narbonne.

- Piratica, L. pirate.

- Saccata, L. à sucre.

- Tarentula, L. tarentule.

- Vorax, L. vorace.

\section{0}

361

359

361

359

362

359

362

360

356

360

Lysmata (genre), Lysmate.

- Seticauda, L. à queue soyeuse. 190

Lyncieus (genre).

277

- Aduncus, L. courbé.

id.

- Laticornis, L. à larges antennes. id.

- Roseus, L. rosé.

- Sphcericus, L. sphérique.

- Striatus, L. striè.

Lysiainassa (genre), Lysianasse.

- Costa, L. de Costa.

Lysidice (genre), Lysidice.

- Galathina, L. Galathine,

- Niscetta, L. niscette.

- Olimpia, L. olimpe.

- Valentina, L. Valentine.

Machilis (genre), Machile.

- Brevicornis, M. à antennes cour-

tes.

- Cylindrica, M. cylindrique.

-Variabilis, M. variable.

Macropodites (groupe).

Macrophthalmus (genre), Macroph. thalme.

- Dentipes, M. à pieds dentés.

\section{id.}

278

id.

226

227

14

id.

id.

id.

id.

554

- Parvimanus, M. à petites mains.

- Rouxii, M. de Roux.

Macrodres (famille).

Maia (genre).

- Squinada, M. squinade.

- Verrucosa, M. verruqueuse.

Maĩtes (groupe).

Matula (genre), Matule.

- Lunaris, M. lunaire.

133

id.

134

128

106

id.
- Victor, M. vainqueur.

Megalops (genre), Megalope.

- Montagui, M. de Montague.

- Mutica, M. mutique.

Megamerus (genre).

- Castaneus, M. marron.

- Celer, M. prompt.

- Fallax, M. trompeur.

- Inflatus, M. enflé.

- Longipes. M. à pattes longues.

- Roseus, M. rosé.

Melia (genre), Melie.

- Tesselata, M. marquetée.

Mencthius (genre), Menœthic.

- Monoceros. M. unicorne.

Micippa (genre), Micippe.

- Cristata, M. à crête.

- l'hylira, M. phylise.

Miclyris (genre).

- iongicarpus, M. longicarpe.

Microphturifs (famille).

Mitilordes (famille).

Mithrax (geure).

- Dama, M. daim.

- Dicatomus, M. bifide.

- Hispidus, M. hérissé.

- Sculptus, M. sculpté.

- Spinosissimus, M. très-épineux.

-- Verrucosus, M. verruqueus.

Monolepis (genre), Monolepe.

- Inermis, M. sans arme.

Pagres.

107

173

id.

$i d$.

471

472

$i d$.

$i d$.

471

id.

472

$7 \dot{4}$

id.

130

131

139

440

id.

60

61

510

284

128

129

128

129

id.

id.

id.

173

174

553

108

Mursia (genre), Mursie.

- Cristata, M. à crête.

Mygale (genre).

$i d$.

334

338

337

355

337

338

339

335

- Cancerides, M. crabe.

- Fasciata, M. à bandes transver-

sales.

334

339

337

- Funebra M. funèbre.

- Hirsuta, M. hérissée.

id.

336

338

335

336

337

335

- Notasiana, M. de la Notasie.

- Ovicularia, M. oviculaire.

- Valenciana. M. de Valence.

-Wersicolor, M. versicolore.

- Zebra, M. zébrée. $\quad 336$

Myra (zenre), Myre.

122

- Fugax, fuyante.

Myriana (genre), Myriane.

$i d$.

18 
Pages.

Iี YTTATिODES.

Myrmecia (genre), Myrmecie.

- Fulva, M. fauve.

- Vertebrata, M. vertébrée.

RIYsites (groupe).

Mysis (genre), Myse.

- Frontalis, M. fronj̧al.

- Longicornis, M. a longues antennes.

- Spinosulus, AI. épineux.

NaGeUrs (tribu).

Nais (genre), Naĩde.

- Digitala, N. digitée.

- Proboscidea, N. à trompe.

- Serpentina, N. serpentine.

- Vermicularis, N. vermiculée.

Nattes (groupe).

Naupredia (genre), Nauprédie.

Nautilocorystes(genre), Nautilocoryste.119 - Ocellatus, N. ocellé.

511

569

id.

id.

201

201

203

Nautilograpsus (genre), Nautilograpse. 71

- Minutus, N. petit.

Naxia (genre), Naxie.

- Serpulifera, N. porte serpules.

Nebalia (genre), Nebalie.

Geoffroyi, N. de Geoffroy.

Nebazites (groupe).

Nelocira (genre), Nelocire.

- Swaisonii, de Swaison.

Nemesis (genre), Néméside.

- Carchariarum, N. des Carcha.

rias.

- Lamna, N. du Lamna.

Nephelis (genre), Nephelide.

- Atomaria, N. à atômes.

- Cinerea, N. cendrée.

- Gigas, N. géante.

- Rutila, N. éclatante.

- Testacea, N. jaunâtre.

-Vulgaris, N. commune.

Nephrops (genre), Nephrope.

- Norwegicus, N. de Norwège.

Nephtys (genre), Nephtyde.

- Hombergii, N. de Homberg.

Nereidites (les) (groupe).

Nercis (genre), Nereide.

- Fucata, N. colorée.

- Marionii, N. de Marion.

- Podophylla N à pattes foliace id.

Nerocila (genre), Nerocilc.

- Blainvillii, N. de Blainville.

Nescea (genre), Nesée.

- Bidentata, N. à deux dents.

Nicothoe (genre), Nicothoe.

- Astaci, N. de l'Ecrevisse.

Nika (genre), Nike.

- Edulis. N. comestible.

Nogaus (genre), Nogaude.

AXN. I.
- Latreillei, N. de Lalreilie. $\quad 268$

Notopodes (les) (tribu). 112

Normaux (section). $\quad 247$

Notopténygiens (tribu). 154

Nursia (genre), Nursie. : $\$ 24$

- Hardwichii, M. de Ilardwick. id.

Nympinonides (famille). $\quad 442$

Nymphon (genre). $4 / 2$

- Femoratum. N. fémoral. 443

- Grossipes, N. à grosses palles. 442

Nyssus (genre), Nysse. 418

Obisium (genre), Ubisie. $\quad 449$

- Carcinoz̈des, O. Crabroides. $\quad 450$

- Ischnocheles, O. à jambes grîles. 449

- Maritimum, O. maritime. $\quad 450$

- Muscorum, O. des mousses. $\quad 449$

- Orthodactylum, O. à doigts droits.

450

- Walkenaerii, O. de Walkenac̈r. id.

Ocypoda (genre), Ocypode. $\quad 56$

- Albicans, 0 . blanchâtre. $\quad 58$

- Arenaria, 0 des sables. 58

- Ceratophthalma, O. yeux pédiculés.

57

- Cordimana, 0, à mains en cœur. 58

- Fabricii, (. de Fabricius. $\quad 57$

- Ippeus, $\mathbf{0}$. chevalier. id.

- Macrocera, O. à longues antennes.

- Rhombea, O. Rhombe.

rvillei, O. d'Urville. 57

Ocrpodites (groupe). $\quad 56$

Ocypete ((genre), Ocypète. $\quad 510$

- Rubra, O. rouge. id.

Ogygia (genre), Ogygie. 311

- Desmaresti, O. de Desmarest. 312

- Guettardi, O. de Guettard. id.

OEnone (genre), OEnone. 15

- Lucida, OE. brillante. 16

Olencirs (genre), Olencire. 251

- Lamarckii, O. de Lamarck. id.

Olios (genre), Oliode. $\quad 394$

- Castaneus, O. marron. $\quad \$ 96$

- Columbianus, O. de Colombie. 395

- Grapsus, O. grapse. $\quad 394$

- Lencosius, O. Leucosic. \$95

- Longipes, O. à pattes longues. 396

- Pinnotheres, O. pinnothère. $\quad 394$

- Taprobanius, O. Taprobain. $\quad 395$

Oniscus (genre), Cloporte. 263

- Asellus, C. anon. 264

Onuphis (genre), Onuphide. 13

- Eremila, O. ermite. id.

- Tubicola, O. tubicole. 14

Ophelia, (genre). Ophelie. 21

- Bicorris, O. à deux cornes. id.

Oplophorus (genre), Oplophore. $\quad 137$

- Typus, 0. type.

id. 
Oraicularaes (iribu).

$1: 8$

5612

Orchesella (genre), Orcheselle.

- Cincta, 0. ceinte.

- Filicornis, O. à antennes filiformes.

- Succincta, 0. entourée.

Orchestia (genre), Orchestie.

- Fischerii, 0 . de Fischer.

- Litioralis, O.des rivages.

Oreophorus (genre), Oreophore.

- Horridus, 0 . horrible.

Oribates (genre), Oribate.

- Calcaratus, O. aiguillonné.

- Casianeus, O. marron.

- Clavipes, 0 . pattes en massue.

- Dasypus, O. a pattes velues.

- Orbicularis, 0 . orbiculaire.

- Ovalis, 0 , ovale.

Orithya (genre), Orithye.

-Mamillaris, 0. mamillaire.

Onithytes (groupe).

Ostracidium (genre), Ostracidion.

- Fuscam, O. brun.

- Succineum, O. d'ambre.

Ostrapodes (ordre).

Ovales (famille).

Oxycophalus (genre), Oxycéphale.

- Oceanicus, O. de l'Ócéan.

Ozius (genre), Ozie.

- Frontalis, O. frontal.

- Guttatus, O. à gouttes.

- Truncatus, 0. tronqué.

- Tuberculosus, O. tuberculé.

Pachygnatus (genre), Pachygnathe.

- Villosus, P. velu.

Pactolites (groupe).

Pactolus (genre), Pactole.

- Boscii, de Bosc.

Paguriens (tribu).

Pagurus (genre), Pagure.

- Angulatus, P. anguleux.

- Callidus, P. rusé.

- Maculatus, P. tacheté.

- Medilerraneus, P. de la Méditer. rance.

- Misanthropus, P. misanthrope. 162

- Ornatus, P. ornè.

- Prideauxii, P. de Prideaux.

- Pugilator, P. combattant.

- Striatus, P. strié.

- Timidus, P. timide.

Palénonites (groupe).

Palemon (genre), Crevelte.

- Serratus, C. à scie.

- Squilla, G. squille.

- Tritianus, G. trition.

Palinurus (genre), Langouste.

- Guttalus, E. à gouttes.

163

161

id.

186

190

192

id.

id.

168

169
- Ricordii, P. de Iicord.

-Vulgaris, P. commune.

2.l. Palmyra (genre), Palmyre.

- Aurifera, P. porte or.

Palpimanus (genre), Palpimane 10

- Gibbulus, P. bossue.

Pandalus (genre), Pandale.

- Annulicornis, P. à antennes an. nelées.

- Narwal, P. Narval.

Pandarus (genre), Pandare.

-Bicolor, P. bicolor.

- Boscii, P. de Bosc.

- Carcharia, P. du requin.

- Cranchii, P. de Cranch.

Panopeus (genre), Panopée.

-Herbstii, P. de Herbst.

- Limosus, P. bourbeux.

Paradoxides (genre), l'aradoxide.

- Gibbosus, P. bossu. 312

- Laciniatus, P. déchiré.

- Scaraboides, P. scaraboïde.

- Spinulosus, P. épineux.

- Tessini, P. de Tessin.

Paramicippa (genre), Haramicippe. 140

- Tuberculosa, P. tuberculeuse. 141

Paramithrax (genre), Paramithrace. 1311

- Peronii, P'. de Péron.

Parasites (ordre).

Parthenopites (groupe).

Parthenope (genre), Parthenope.

- Horrida, P. berrible.

Pasijhaca (genre), Yasiphée.

- Sivado, P. Sivade.

Pectinaria (genre), Pectinaire.

- Egyptia, P. égyptienne.

- Chrysodon, P.dent dorée.

- Granulata, P. granuleuse.

Pediculus (genre), Pou.

- Bovis, P. da bœuf.

- Cervicalis, P. de la tête.

- Eurysternus, P. a large poitrine.

- Phoca, P. du phoque.

- Urius, P. urie.

- Vestimenti, P. des vêtemens.

$i d$.

577

125

$i d$.

id.

197

198

29

30

$i d$.

id.

577

578

577

Pedipalpes (famille).

Pencus (genre), Pence.

- Caramate, P. caramate.

id.

$i d$.

577

318

195
- Membranaceus, P.membianeax. 196

- Monoceros, P. unicorne. 195

Peneites (groupe). $\quad 193$

Pericera (genre), Pericere. 134

- Bicorna, P. à deux cornes. $\quad 135$

- Cornuta, P. cornue.

- Trispinosa, P. à trois épines.

Deripatites (genre), Peripatiles.

id.

id.

22

- Peripatus, P. Peripate.

id. 
- Iuliformis, P. Iulifurme.

124 id.

- Latreillei, P. de Latreille.

- Lichtenstenii, P. de Lichtensteu. id. Phalangiens (famille).

Phalangium (genre), Faucheur.

453

458

463

461

462

- Annulatum, F. annelé.

- Bicolor, F. bicolor.

- Bimaculatum. F. à deux taches. 461

- Crassum, F。 épais.

462

- Cristatum, P. à crête. 460

- Fasciatum, F. à bandes Iransversales.

463

- Grossipes, F. à grosses pattes.

-Helwigii, F. de Helwig.

-Hispidum, E. rude.

- Histrix, F. hérisson.

- Lineola, F. à une ligne.

- Longipes, F. à pattes longues.

- Monacantha, F. à une épine.

- Muscorum, F. des mousses.

- Palliatum, F. mantelé.

- Palpinale, F. à palpes.

- Rotundum, F. arrondi.

-Spinosum, F. épineux.

- Spinosum, F. épineux.

- Triangulare, F, triangulaire.

-Tricuspidatum, F. à trois pointes. 462

Philoscia(genre), Philoscie.

- Muscorum, P. des mousses.

Philodromus (genre), Philodrome.

- Aureolus, P.àuréolè.

- Dispar, P. différent.

- Jejunas, P. stérile.

- Oblongus, $\mathbf{P}$. oblong.

- Pallidus, P. pâle.

$i d$.

462

463

460

462

463

id.

461

id.

464

461

460

464

id.

263

id.

390

393

392

391

393

392

- Rhombiferens, P. porte-rhombe. 394

- Rufus, P. roux.

- Tigrinus, $\mathbf{H}$. tigré.

392

391

Paillopodes (ordre).

Philopterus (genre), Philoptère.

284

569

- Attenuatus, P. atténué.

570

id.

573

- Brevis, P. court.

571

- Diomedece P. de 1.Albatros.

- Falcicornis, P. à antennes en faulx.

id.

- Garruli, P. du Geai.

570

- Homatopus, P. à pattes ensanglantées.

- Houbarce, P. de l'outarde hou. bara.

- Ocellatus, P. ocellé.

- Pederiformis, P. forme de pédère.

- Squalidus, P. sale.

570
- Stylifer, P. porte-style.

pages.

Phlias (genre), Phliade.

- Serratus, P. à scie.

Phorcus (genre), Phorque.

- Reynaudi, P. de Reynaud.

Pholcus (genre), Pholque.

- Caudatus, P. à queue.

- Phalangioides, P. fauchenr. id.

Phoxychilus (genre), Phoxychile. 443

- Phalangioides, p. faucheur. id.

Phrynus (genre), Phryne. 327

- Lunatus. P. luné. id.

- Reniformis, P. réniforme. id.

- Variegatus, P. varié.

Phronima (genre), Phronime - 38

- Sedentaria, P. sédentaire. id.

Phthirius (genre), IIorpion, 578

- Inguinalis, M. de l'aine. id.

Phylira (genre); Phylire. 122

- Porcellana, P. porcellane. 123

- Scabriuscula, P. raboteux. id.

Phyllodoce (genre), Phyllodoce. 18

- Clavigera, P. porte-massue. $\quad 19$

- Flava, P. jaune. id.

- Geoffroyi, P. de Geoffroy. id.

- Gervillii, P. de Gerville. id.

- Laminosa, P. à lamelles. id.

- Longa, P. longue. id.

- Maculata, P. tachetée. jú.

-Viridis, P. verte. id;

Phyllosoma (genre), Phyllosome. 213

- Affinis, P. voisin. 215

-Brevicornis, P. à antennes courtes. 210

- Clavicurnis, P. à antennes en mas sue.

215

- Communis, P. commun. id.

- Duperreyi, P. de Duperrey. 217

- Freycinetii, P. de Freycinet. 216

- Mediterranea, P. de la Méditer. ranée.

- Punctata, P. ponctué. 216

Pilubinites (groupe). $\quad 76$

Pilumnus (genre), Pilamne. $\quad 76$

- Aculeatus, $\mathrm{P}$. aiguillonné. $\quad 78$

- Forskalii, P. de Forskal. id.

- Hirtellus. P. hérissé. 77

- Peronii, P. de Péron. id.

- Quoyi, l'. de Quoy. id.

- Spinifer, P. porte épines. 78

- Tomentosus. P. colonneux. 77

- Vespertilio, P. chauve-souris. id.

Pinnodactyles (tribu). 204

Pinnotherites (groupe). ' 65

Pinnotheres (genre). Pinnothère. id.

- Montagui, de Montagui. 66

- Pisum, P. pois. id.

- Veterum, P. des anciens. id.

- Villosulus, P. velu. is. 
Pirimela (genre), Pirimèle.

Pages.

- Denliculata, P. denticulée.

Pisa (genre), Pise,

113

368

- Sirmala, P. armée.

- Corallina, P. coralline.

137

id.

- Gibsii, P. de Gibbs.

- Styx, P. Styx.

- Tetriodon, P. quatre dents.

138

137

Piscicola (genre), Piscicole.

- Geometra, P. géomètre.

- Marginata, P. bordée.

- Tessellata, P. marquetée.

38

id.

id.

idl.

Plagusia (genre). Plagusie.

-Clavimana, P. à mains en massue. id.

- Depressa, P. déprimée.

- Squamosa, P. écaileuse.

- Tomentosa, P. cotonneuse.

'latycarcinus (genre), Platycarcin.

- Irroratus, P. arrosé.

- Pagurus, P. tourteau.

Platymera (genre), Platymère.

- Gaudichaudii, P de Gaudichaudo

Platyonichus (anre) Platyonique.

- Bipustulatus, P. à deux taches.

- Latipes, P. à pattes larges.

- Nasutus, P. à grand nez.

- Ocellatus, P. ocellé.

Platyulus (genre), Platyule.

- Audouinianus, P.d'Audouin.

P'ODOCERides (famille).

Podocerus (genre), Podocère,

- Cylindricus, P. cylindrique.

- Pulchellus, P. joli.

Podophthalmus (genre), Podophthalme.

- Vigil, P. vigilant.

Bodura (genre), Podure.

- Albo-cincta, P. entourée de blanc.

- Ambulans, P. ambulante.

- Annulata, P. annelée.

- Aquatica, P. aquatique.

- Arborea, P. des árbres.

- Bicolor, P. bicolore.

- Cincta, P. entouree.

- Cingula, P. ceinture.

- Fasciata, P. à bandes transvergales.

- Fimetaria, P. du fumier.

id.

id.

id.

id.

109

96

97

id.

$i d$.

$i d$.

533

id.

234

232

id.

id.

- Fuliginosa, P. couleur de suie.

- Iricolor, P. à couleurs irisées.

- Lignorum. P. du bois.

- Monura, P. à une queue.

- Navalis, P. navale.

- Nigro-maculata, P. tachetée de noir.

- Nitida, P. brillante.

- Plumbea, P. plombée.
566

565

id.

id.

464

566

565

566

id.

565

566

id.

565

id.

$i d$.

c66

id.

564
- Pusilla, P. très-pelíte.

- Vaga, P. errante.

- Viratica, P. des chemins.

- Villosa, P. velue.

Podurelles (famille).

Polybius (genre), Polybie.

- Ilenslowii, P. de Henslow.

Polydectus (genre), Polydecte.

- Cupulifera, P. cupulifère.

Polydesmus (genre), Polydesme.

- Bilineatus, P. à deux lignes.

- Blainvillari, P. de Blainville.

- Complanatus, P. aplati.

- Consperus, P. parsemé.

- Cylindraceus, P. cylindrique.

- Ventutus, P. denté.

-Depressus, P. déprimé.

- Diadema, P. diadème.

- Gervaisii, P. de Gervais.

- Glabratus, P. glabre.

- Granulatus, P. granulé.

- Granulosus, P. granuleux.

- Guerinii, P. de Guérin.

- Lateralis, P. latéral.

Pages.

565

id.

564

id.

562

97

id.

95

96

522

523

524

$i d$.

525

526

524

526

524

525

id.

526

523

525

526

- Margaratiferus, P. porte-perles. 525

- Mexicanus, P. du Mexique. 52.3

- Pallipes, P. à pieds pâles. 525

- Rubescens, P. rougeâtre. $\quad 524$

- Rugulosus. P. rugueux. 526

- Scaber, P. raboteux. 523

- Serratus, P. en scie. $\quad 526$

- Stigma, P. à tache.

- Stigmatosus, P. tacheté.

id.

- Virginiensis, P. de la Virginie 593

- Zebratus, $\mathrm{P}$ zèbre.

Polyodontes (genre), Polyodonte.

Polyna (genre), Polynoe.

- Blainvillii, P. de Blainville.

- Cirrata, P. bouclée.

- Floccosa, P. Flocconeuse.

- Imbricata, P. imbriquée.

- Levis, P. lisse.

- Longa, P. Iongue.

- Longissima, P. très-longue.

- Minuta, P. petite.

- Punctata, P. ponctuée.

- Scolopendrina, P. scolopendre. id.

-Setosissima, P. très-soyeuse.

Polyphemus (genre), Polyphème. 273

- Stagnorum, P. des etangs. id.

Pollyxenites (famille).

Pollyxenus (genre), Pollyxène.

518

518

- Fasciculatus, P. à pinceau. $\quad 519$

- Lagurus, P. à queue de lièvre. $i d$.

Pontia (genre), Pontie.

- Savignyi, H. de Savigny.

pontonia (gence), Pontonie.

268

183

- Armala, P. armée. id.

9

8

id.

id.

9

8

9

S

8

(n)

9

iे 
TABLE.

Pages.

- Thyrrhena, P. de la mer de 'l'y. rhène.

184

Porcellana (genre), Porcellane.

170

- Longicornis, $\mathrm{P}$. à longues antennes. id.

- Platycheles, P. à larges jambes, id.

- Punctata, P. ponctuée.

Porcellio (genre), Porcellion.

171

- Lavis, P. lisse.

- Scaber. P. rude.

264

id.

id.

Pontunites (groupe).

Portunus (genre), Portune.

- Corrugatus, P. ridé.

\section{6}

98

99

- Holsatus, P. holsate.

$i d$.

-Integrifrons, P. front entier. $\quad 100$

- Longipes, P. à pattes longues. 99

- Marmoreus, P. marbré.

-Plicatus, P. plisse.

- Puber, P. jeune.

- Pusillus, P. très-petit.

- Rondeleti P. de hondelet.

- Tuberculatus, P. tuberculé.

Pou, voyez Pediculus.

Praniza (geure), Pranize.

- Fuscata, P. brunåtre.

- Maculata, P. tachetée.

- Marina, P. marine.

Primno (genre), Primne.

- Macropa, P. à lodgues pattes.

Pronoe (genre).

- Capito, P. a grosse tête.

Prosopistoma (genre).

- Punctifrons, P. front ponctué.

- Variegatum, 1. varié.

Pseudocarcinus (menre) Pseudocarcin id

- Bellangerii, P. de Bellanger. id.

- Gigas, P. géant.

- Ocellatus, P. ocellé.

- Rumphii, P. de Rumphius.

$i d$.

Pseudocorystes'genre), Pseudocoryste. 119 - Armatus, $\mathrm{P}$. armé.

Pseudograpsus (genre), Pseudograpse. 71 - Penicilliger, P. porte pinceau. id. Pseudorhombila (genre), Pseudorhom. bile.

-Quadridentata, P. quadridentée. 73

Pterelas (genre), Ptelerade. $\quad 249$

- Webbii, P. de Webb.

Pteroptus (genre), Pteropte.

- Abdominalis, P. abdominal.

- Acuminatus, P. acuminé. 250 483

-Vespertilionis, P. de la chauvesouris.

Pycnogonides (famille).

Pycnogonon (genre), Pycnogonon.

- Balcenarum, P. des Baleines.

Quadrilatères (tribu).

lianilia (genre), Ranilie.

arericata, $\mathrm{R}$. rocheuse.
Ranina (genre), Ranine.

Pages

Raninoides (genre), Raninoide.

- Levis, R. lisse. id.

Raphignathus (genre). $\quad 470$

- Ruberrimus, R. très-rouge. id.

Remipes (genre), Remipède. 158

- T'cstudinarius, R. tortue. id.

Rhynchocinetes(genr.), Rhynchocinete.188

- Typus, R. type. id.

lihyncolophus (genre). $\quad 472$

- Cinereus, R. cendré. $\quad 473$

- Degcerii, R. de Degéer. 472

- Nemorum, R. des bois. $\quad 474$

- Rubescens, R, rougeâtre. 479

- Trimaculatus, $\mathrm{R}$. à trois taches. id.

Rocinela (genre), Hocinèle. 249

- Danmoniensis, R. danmoniense. id.

Rhoea (genre), Rhée. 241

- Latreillei, R. de Latreille. $\quad 242$

Ruppellia (genre), Ruppellie. $\quad 78$

- Annulipes, R. pattes annelées. $\quad i d$.

- Tenax, R. tenace. id.

Sabella (genre), Sabelle. $\quad 25$

- Fabricia, S. de Fabricius. $\quad 26$

- Flabellata, S. flabellée. id.

- Infundibula, S. en entonnoir. id.

-Judica, S. juive. id:

-Magnifica, S. magnifiģue. id.

- Pennicillus, S. à pinceau. id.

- Reniformis, S. réniforme. id.

- Spallanzanii, S. de Spalanzani. id.

- Vesiculosa, S. vésiculeuse. id.

Salicolues (tribu). 180

Sangsue, voyez Hirudo.

Sanguisugites (groupe). $\quad 40$

Sarcoptes (genre), Sarcopte. 485

- Equi, S. du cheval. 487

- Hominis, S, de la galle humàine. 468

-Musculinus, S. du rat: $\quad 487$

- Palumbinus, S. du pigeon. id.

Scirus (genre), Scire. $\quad 491$

- Elaphus, S. elaphe. $\quad 492$

Scolopendra (genre), Scolopendre. 543.

- Audax, S. hardie. 544

- Brandtiana, S. de Brandt. id.

-Eydouxiana, S. d'Eydoux. $\quad 545$

- Fulva, S. fauve. $\quad 544$

- Gigas, S. géante. ' 545

- Italica, S. italienne. id.

- Marginata, S. bordée. $\quad 546$

- Morsilans, S. mordante, 544

- Sagraa, S. de Sagra. $\quad 545$

- Subspinipes, S. à pattes épineuses. 544

-Trigoropoda, S. à pattes trigones. 545.

- Violacea, S. violeite. 544

-Viridis, S. verte. 546.

- Viridipes, S. à pattes vertes. 545 
Scolopeadartes (famille).

SCORPIONIDES.

Scorpio (genre), Scorpion.

-Europaus, S. d'Europe.

Scutigera (genre), Scutigère.

- Araneoides, S. forme d'araignce. 537

- Lesueurii, S. de Lesueur. 538

- Longicornis, S. à longues anten. nes.

- Vireseens, S. verdâtre.

Scutigerites (famille).

Scytudes (genre), Scytode.

- Paradoxa, Paradoxe.

- Rufescens, S. roussâtre.

- Rufipes, S. à pattes rousses.

- Thoracica, S. thoracique.

Scyllarides (tribu).

Scyllarus (genre), Scyllare.

- Equinoxialis, S. équinoxial.

- Arctus, S. ours.

- Latus, S. large.

Sergestes (genre), Sergeste.

- Atlanticus, S. de l'Océan allantique.

Segestria (genre), Segestrie.

- Perfida, S. perfide.

- liuficeps, S. à tête rousse.

- Sava, S. cruelle.

- Senoculata, S. à six taches ocellees.

Sclenops (genre), Selenope.

- Aissus, S. aisse.

- Fugitivas, S. fugitif.

- Omalosoma, S. corps plat.

- Spixii, S. de Spix.

Scrpula (genre), Serpule.

- Contortuplicata S, à plis confus

- Gigantea, S. géante.

- Porrecta, S. prolongée.

- Spirorbis, S. à spirale en cercle.

- Vermicularis, S. vermiculée. id.

Senpultites (groupe).

Servlis (genre), Serole.

- Fabricii, S. de Fabricius.

Sesarma (genre), Sesarme.

- Africana, S. africaine.

- Impressa, S. imprimée.

- Pisoni, S. de Pison.

- Quadrata, S. carrée.

Seticenes (famille).

Sicyonia (genre), Scyonie.

- Carinata, S. carénée.

- Sculpta, S. sculptée.

Siyalion (genre), Sigalion.

- Hermionce, S. d'Hermione.

- Mathilda, S. de Mathilde.

Smaridia (genre), Smaride.

- Papillosa, S. à papilles.
Pages.

539

318

323

324

535

538

id.

id.

354

355

$i d$.

354

$i d$.

165

165

160

165

166

198

350

iil.

353

354

353

З๖ 9

390

id.

389

390

23

id.

id.

213

247

id.

69

70

id.

id.

$i d$.

270

193

194

id.

9

id.

id.

491

id.
- Villosa, S. velue.

Pages.

491

SipноNostomes (ordre). $\quad 294$

Sipunculites (groupe) $\quad 36$

Sipunculus (genre), Sipuncule. $\quad 36$

-Balanaphorus, S. porte tubercule. 37

Smynthurus (genre), Smynthure. $\quad 567$

- Ater, S. noir.

- Fuscus, S. brun.

id.

-Guttatus, S.à gouttes.

$i d$.

568

-Polypodus, P. à pieds nombreux. 567

- Signatus, S. marqué.

- Viridis, S. vert.

Sparassus (genre), Sparasse.

- Argelasius, S. d'Argelas.

- Fuscus, S. brun.

- Smaragdulus,

s. émeraude $\quad 397$

367

- Alexandrinus, S. d'Alexandre. 368

-Heterophthalmus, S. aux yeux différens.

- Indicus, S. indien.

- Italicus, S. d'Jtalie.

- Lineatus, S. à lignes.

Spheromides (famille).

Sphoroma (genre), Sphœrome,

- Curtum, S. court.

367

id.

id.

id.

252

252

253

- Dumerilii, S. de Duméril.

- Gigas, S. géant.

- Hookeri, S. de Hooker.

$i d$.

$i d$.

$i d$.

- Prideauxianum, S. de Prideaux, il.

- Rugicauda, S. à queue ridée. id.

- Serratum, S. en scie.

- Trigona, S. trigone.

- Tristense, S. tristan.

Squilla (genre), Squille.

- Cerisyi, S. de Cerisy.

- Desmareti, S. de Desmarest.

- Ferrussaci, S. de Ferrussac.

- Mantis, S. mante.

- Stylifera, S. porte-style.

SQuillites (groupe).

Squillericthus (genre), Squillericthe, 206

- Typus, S. Iype.

Stenocionops (genre), Stenocionope. 130

- Cervicornis, S. cornes de cerf. id.

Stenopus (genre), Sténopé. 193

- Hispidus, S. hérissé.

id.

Stenorhynchus (genre), Stenorhynque. 148

- Egyptius, \$. égyptien. id.

- Longirostris, S. à long bec. $\quad 149$

- Phalangium, S. faucheur. $\quad 148$

Stenasoma (genre), Stenosome. $\quad 259$

- Hecticum, S. étique. id.

- Lineare, S. linéaire. id.

Stomapodes (ordre).

Slorena (geare), Storene.

- Cyanea, S. bleue.

Stygnus (genre), Stygne.
200

364

id.

455 
- Armatus, S. armé.

Syllis (genre), Syllide.

- Fulgurans, S. étincelante.

-Monillaris. S. à Bracelet.

Tachypleus (genre), Tachyplée.

-Heterodactylus, $\mathbf{T}$. à dents dissemblables.

Talitrus (genre), Talitre.

- Saltator, T. sauteur.

Tanais (genre), Tanaide.

Tarentules (tribu).

Tegenaria (genre), Tegenaire, ou Araignée proprement dite.

- Agrestia, T. des champs.

- Civilis, T. civile.

- Domestica, T. domestique.

Terebella (genre), Terebelle.

- Cincinnata, T. frisée.

- Cirrata, T. bouclée.

- Conchilega, T. coquillière.

- Constricta, T. étranglée.

- Cristata, T. à crête.

- Gigantea, T. geante.

- Medusa, T. méduse.

- Nebulosa, T. nébuleuse.

-Scylla, T. Scylla.

-Ventricosa, T. ventrue.

- Venustata, T. jolie.

TEReBer.Litrs (groupe).

Tetrugnatha (genre), Tetragnathe.

- Extensa, T. étendue.

Tetrapneumones (tribu),

Tetranychus (genre).

- Caudatus, T. à queue.

- Cristatus, T. à crête.

- Lintearius, T. voilé。

- Major, T. grand.

456

17

id.

id.

290

id.

226

id.

241

325

413

416

415

413

?8

id.

28

id.

29

$i d$.

id.

id.

433

id.

334

467

469

id.

467

469

- Prunicolor, T. couleur de prune. 468

- Termipes, T. patte de termes. 469

- Trombidinus, ' $\Gamma$. trombidion. $\quad 470$

- Ulmi, T. de l'orme.

- Urtica, T. de l'ortie.

Thalamila (genre), Thalamite.

- Admeti, T. admete.

- Annulata, T. annelée.

- Callianassa, T. callianasse.

- Chaptalii, T. de Chaptal.

- Crenata, T. crénelée.

- Crucifera, T. porté croix.

- Erythrodactyla, T. à doigt rouges.

- Sima, T. sima.

-Truncata, T. tronquéc.

Thalassema (genre), Thalassème.

- Echiurus, à queue de serpent.

Thalassina (genre), Thalassine.

- Scorpionoides, T. furme scorpion.
Thalassinides (tribu).

Pages.

Thelpheusa (

- Berardii, T. de Bérard. 76

- Fluviatilis, T. fluviale. $\quad 75$

- Indica, V. indienne. $\quad 76$

Theipheusites (groupe).

Thelyphonus (genre). $\quad 326$

- Angustus, T. étroit. 326

- Caudatus, T. à queue. id.

- Giganteus, T. gigantesque. id.

- Rufipes, T. pattes rousses. id.

Themisto (genre), Themiste. 235

- Gaudichaudii, T. de Gaudichaud, id.

Thenus (genre), Thene. 167

- Orientalis, T. oriental. id.

Theridion (genre), Theridion. $\quad 435$

- Aphane, T. aphane. $\quad 394$

- Benignum, T. bon. id.

- Carolinum, T. de la Caroline. 437

- Crypticolens, T.des lieux cachés. id.

- Denticulatum, T. dentelé. id.

- Lepidum, T. agréable. id.

- Lineatum, T. à lignes. $\quad 436$

- Lugubre, T. lugubre. $\quad 438$

- Nervosum, T. à nervures. $\quad 437$

- Obscurum, T. obscur. $\quad 439$

- Ovatum, T. ovale. 437

- Paykullianum, T. de Paykull. 436

-Pulchellum, T. genti. 437

- Punctatum, T. ponctué. $\quad 436$

- Quadripunctatum, T. à 4 points. 438

- Redimitum, T. orné. 435

- Signatum, T. marqué. $\quad 439$

- Sysiphum, T. sysiphe. $\quad 436$

- Tinctum, T. teint. 437

- Triangulifer, T. porte triangle. id.

- Urtica, T. de l'ortie. $\quad 438$

Thia (genre), Thie. 94

- Polita, T. polie. $\quad 95$

Thomisus (genre), Thomise. $\quad 382$

- Abbreviatus, T. raccourci. $\quad 386$

- Atomarius, T. à atômes. $\quad 387$

- Citreus, T. citron. id.

- Cristatus, T. à crête. $\quad \$ 36$

- Diana, T. Diane. 387

- Floricolens, T. des fleurs. id.

- Fucatus, T. coloré. $\quad 383$

- Hirtus, T. hérissé. id.

- Malacostraceus, T. malacosiracé.

- Marginata, T. brodé. $\quad 384$

- Maugi, T, de Mauge. 383

- Onustus, T. chargé. $\quad 386$

-Piger, T. paresseux. $\quad 387$

- Rotundatus, T. arrondi. $\quad 382$

- Rugosus, T. rugueux. 383

- Stelloides, T. en ítoile. 385

- Truncalus, T. tronqué. 385 
Pages.

- Tillosus, T. velu.

388

Thysanopoda (genre), Thysanopode. 204

- Tricuspida, T. a trois pointes. 205

Traciéennes (ordre).

Trapezoites (groupe).

444

74

Trapezia (genre), Trapezic.

- Dentifrons, T. front dentalé.

- Ferruginea, T. ferrugineuse.

Trichodactylus (genre), Trichodactyle. 76

- Quadratu, M. carré. . id.

Triangulaires (tribu). $\quad \mathbf{1 2 4}$

Trichodectes (genre), Trichodecte. $\quad 573$

-. Crassus, T. épais.

- Spharocephalus, T. à tête ronde. $i d$.

Trilobites (ordre).

307

Trogulus (genre), Trogule.

464

- Nepœiformis, T. forme de nèpe. 405

Trombrdites (famille).

467

Trombidium (genre), Trombidion. 474

- Cordatum, T. en cour.

- Elongatum, T. allongé.

475

- Fascialım, T. à bandes transversales.

474

- Glabrum, T. glabre.

- Holosoriceum, T. soyeux.

- Phalangii, T. des Faucheurs.

- Puniceum, T. rouge.

- Svlvaticum, T. des forêts.

- Trigonum, T. trigone.

Typhis (genre), Typhide.

- Ferox, T. farouche.

475

id.

id.

474

475

id.

id.

239

id.

Tylos (genre), Tylode.

260

261

- Armadillo, T. armadille.

64

id.

- Una, U. une.

423

Uloborms (genre), Ul bore.

- Walckenacrius, U.de Walckenaer. 434

Unciola (genre). Unciole.

- Irrorata, U. arrosée.

Unicuirassés (famille).

231

Uptiotes (genre), Uptiotes.

- Schreberii, U. de Schreber.

Uropoda (genre), Uropode.

- Opaca, U. opaque.

- Nitida, U. brillant,

- Vegetans, U. végélant.

Varuna (genre), Varune.

- Litterata, V. lettré.

Pibilia (genre), 1 jbilie.
- Peronii, V. de Péron.

Pages.

ง.3

84

85

87

86

- Crenalus, X. crénelé.

- Floridus, X. fleuri.

- Gaudichaudi, X. de Gaudichaud. 87

- Hiripes, X. pattes hérissées. id.

- Hirtissimus, X. très-hérissé. $\quad 85$

- Impressus, X.imprim. $\quad 89$

-Incisus, X.fendu. $\quad 88$

-Lamarckii, X. de Lamarck. $\quad 85$

- Lividus, X. livide. $\quad 86$

-Octodentatus. X. à huit dents, $\quad 88$

- Parvulus, X. petit. $\quad 87$

- Peronii, X. de Péron. $\quad-86$

- Planus, $\mathbf{X}$. plan. $\quad 88$

- Punctatus, X. ponctue. $\quad 87$

- Radiatus, X. rayonnè. $\quad 88$

- Reynandii, X. de Reynaud. $\quad 86$

- Rivulosus, X. des ruisseaux. - 87

- Rotundifrons, X. front arrondi. 88

- Rufopunctatus, X. ponctué de roux.

- Scaber, X. raboteux.

- Setiger, X. soyeux.

- Vermiculatus X rermiculé

Xyphosunes (ordre).

Zcphronia (genre), Zephronie. $\quad 521$

- Compressa, Z. comprimée. id.

- Elongata, Z. altongée. 522

- Hercules, Z. hercule.

- Insignis, Z. remarquable. id.

- Javanica, Z. de Java. ' id́.

- Lichtensteinii, Z. de Lichtenstein. 521

- Ovalis, Z. ovale. id.

- Punctala, Z. ponctuée. $\quad 522$

-Rotundata, Z, arrondie. $\quad 521$

- Testacea, Z. jaunâtre. $\quad 522$

Zother (genre), Zothée. 12

- Meridionalis, Z. méridionale. id.

Zozymas (genre), Zozyme. 83

- Ancus, Z. bronzée. $\quad 84$

- Latissimus, Z, très-large. $\quad 83$

-Pubescens, Z, velu. . . id.

- Rugatus, Z. ridée. … 84

- Tomentosus, Z. cotonneux. $\quad 38$

Zuzara (genre), Zuzure. 254

- Diadoma, Z. diadème. $\quad t d$.

-Semi-punctata, Z. demi-ponctuée. id. 






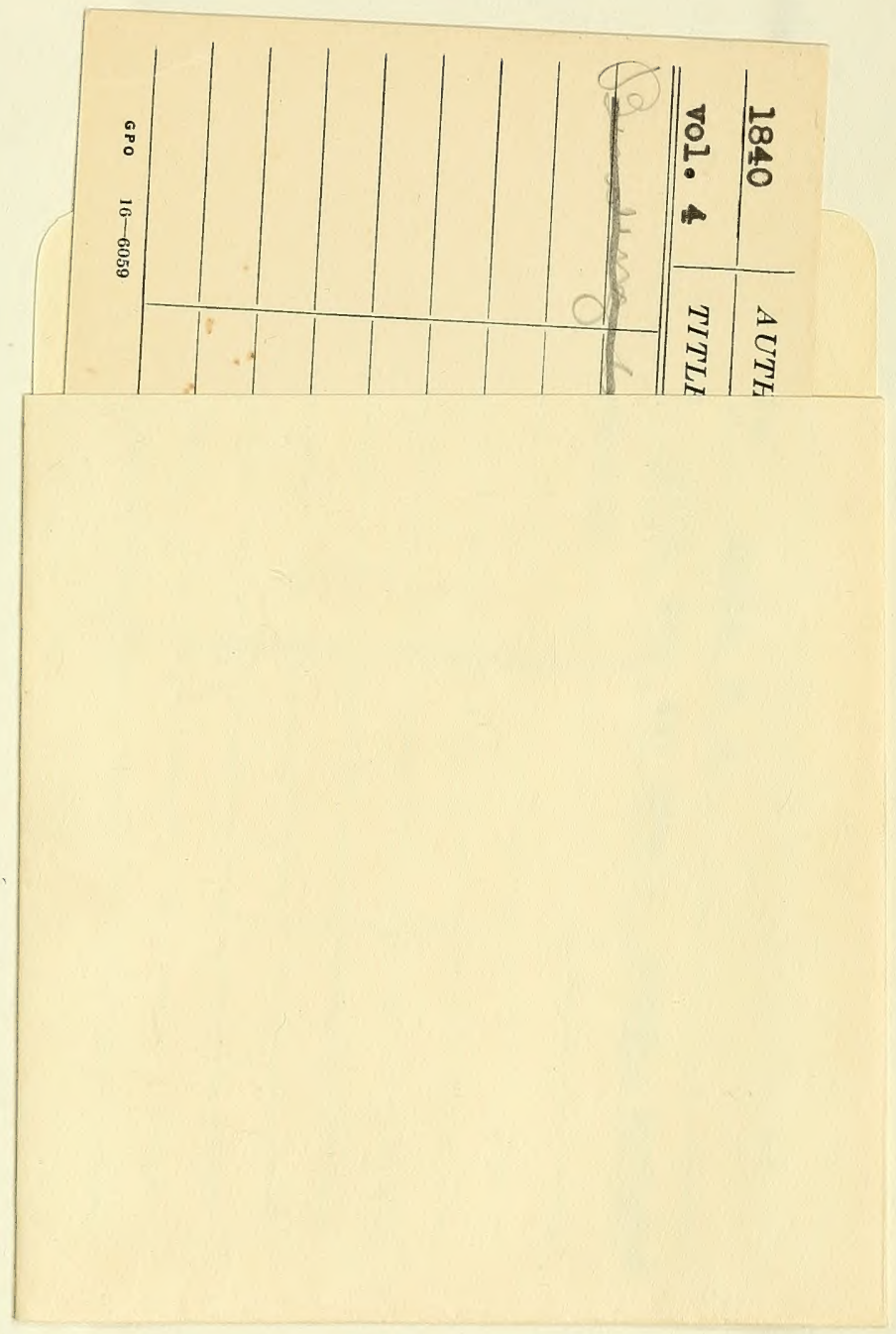


SMITHSONIAN INSTITUTION LIBRARIES

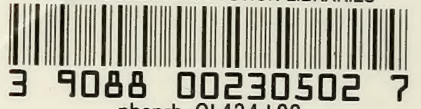

nhenrb 01434.193

Histoire naturelle des crustac:es, 